\title{
Modern Trends in Research on Steel, Aluminium and Composite Structures
}

\section{Edited by}

Marian A. Giżejowski, Aleksander Kozłowski, Marcin Chybiński, Katarzyna Rzeszut, Robert Studziński \& Maciej Szumigała 
MODERN TRENDS IN RESEARCH ON STEEL, ALUMINIUM AND COMPOSITE STRUCTURES 


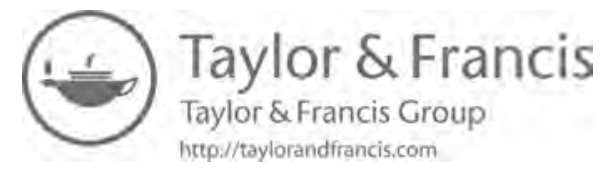




\section{Modern Trends in Research on Steel, Aluminium and Composite Structures}

\section{Editors}

Marian A. Giżejowski

Department of Concrete and Metal Structures, Warsaw University of Technology, Poland

Aleksander Kozłowski

Department of Building Structures, Rzeszów University of Technology, Poland

Marcin Chybiński

Institute of Building Engineering, Poznan University of Technology, Poland

Katarzyna Rzeszut

Institute of Building Engineering, Poznan University of Technology, Poland

Robert Studziński

Institute of Building Engineering, Poznan University of Technology, Poland

Maciej Szumigała

Institute of Building Engineering, Poznan University of Technology, Poland 
Routledge is an imprint of the Taylor \& Francis Group, an informa business

(C) 2021 selection and editorial matter, the Editors; individual chapters, the contributors

Typeset by Integra Software Services Pvt. Ltd., Pondicherry, India

The right of M.A. Giżejowski, A. Kozłowski, M. Chybiński, K. Rzeszut, R. Studziński, \& M. Szumigała to be identified as the authors of the editorial material, and of the authors for their individual chapters, has been asserted in accordance with sections 77 and 78 of the Copyright, Designs and Patents Act 1988.

The Open Access version of this book, available at www.taylorfrancis.com, has been made available under a Creative Commons Attribution-Non Commercial-No Derivatives 4.0 license.

Although all care is taken to ensure integrity and the quality of this publication and the information herein, no responsibility is assumed by the publishers nor the author for any damage to the property or persons as a result of operation or use of this publication and/ or the information contained herein.

\section{Library of Congress Cataloging-in-Publication Data}

A catalog record has been requested for this book

Published by: Routledge

Schipholweg 107C, 2316 XC Leiden, The Netherlands

e-mail: enquiries@taylorandfrancis.com

www.routledge.com - www.taylorandfrancis.com

ISBN: 978-0-367-67637-7 (hbk)

ISBN: 978-0-367-67638-4 (pbk)

ISBN: 978-1-003-13213-4 (ebk)

DOI: $10.1201 / 9781003132134$ 


\section{Table of contents}

Preface

xiii

Acknowledgements

$\mathrm{xV}$

Organisation and committees

xvii

Keynote papers

Research developments on glass structures under extreme loads

C. Bedon

Design of beam-to-column steel-concrete composite joints: From Eurocodes and beyond

J.-F. Demonceau

Stainless steel structures - research, codification and practice

L. Gardner \& F. Walport

Testing, modelling and design of bolted joints - effect of size, structural properties, integrity and robustness

A. Kozlowski, P. Kawecki, D. Kukla \& K. Ostrowski

Design of hybrid beam-to-column joints between RHS tubular columns and I-section beams

L.S.D. Silva \& Y. Harada

Selected aspects of designing the cold-formed steel structures

66

L. Sokót \& K. Rzeszut

Advanced analysis and direct methods of design

Experimental investigation of angle length effect - angles in tension connected by one leg

W. Barcewicz, S. Wierzbicki, M.A. Giżejowski, S. Labocha \& R. Czyż

On elastic lateral-torsional buckling analysis of simply supported I-shape beams using Timoshenko's energy method

A.M. Barszcz, M.A. Giżejowski \& Z. Stachura

Numerical evaluation of dynamic response of an experimentally tested base-isolated and fixed-base steel structure model

T. Falborski, T. Jaroszewski \& R. Jankowski

Research on the interface elements in soil-steel structures based on the in situ test 
Reliability analysis of tensegrity towers in a system approach

W. Mochocki \& P. Obara

The generalized constitutive law in nonlinear structural analysis of steel frames

D. Mrówczyński, T. Gajewski \& T. Garbowski

Impact of the self-stress state on the static properties of double-layered tensegrity grids

J. Tomasik \& P. Obara

Calculation of a crimping point shear resistance for steel sheet piles based on a calibrated numerical model

J.V. Voorde, P.E. Boueiz, A. Glorieux \& J. Martins

Influence of bimoment restraints on load-bearing capacity of steel I-beams

K. Wierzbicki \& M. Szumigata

Simplified approach to assess the dynamic response of a container ship subjected to bow slamming load

K. Woloszyk \& M. Bogdaniuk

\section{Cold-formed elements and structures}

Cold-formed perforated uprights: Experimental evaluation of M-N domains

N. Baldassino, M. Bernardi \& R. Zandonini

Design of semi-compact Z-shaped steel sheet pile walls

A. Enders \& U. Kuhlmann

Elastic buckling of thin-walled beam-columns based on a refined energy formulation

M.A. Giżejowski, A.M. Barszcz \& J. Uziak

Buckling analysis of thin-walled sigma beams with respect to different numerical descriptions

K. Rzeszut, I. Szewczak, P. Różyło \& M.J. Guminiak

Generalized nonlinear constitutive law applied to steel trapezoidal sheet plates

N. Staszak, T. Gajewski \& T. Garbowski

Experimental tests of second generation trapezoidal sheets

T. Szumigała

\section{Composite structures}

Resistance of a new type of flat shear connectors dedicated to composite columns

M.P. Chrzanowski, C. Odenbreit, R. Obiala, T. Bogdan \& H. Degée

Influence of type and orientation of thin-walled beams on the interaction effectiveness with sandwich panels

K. Ciesielczyk \& R. Studziński

Experimental tests of sheeting made of sandwich panels acting as a diaphragm

M. Górski 
Testing the core of sandwich panels with square shear specimen

S. Grimm \& J. Lange

Numerical study on the revised rules for minimum degree of shear connection in propped and unpropped steel-concrete composite beams

C. Odenbreit \& V. Vigneri

Numerical analysis of proposed tubular perfobond shear connector

K.L.B. Souza, A.T. Silva, P.C.G.S. Vellasco, M.C. Rodrigues \& J. Henriques

Strengthening of steel-concrete composite beams in experimental study

P. Szewczyk \& M. Szumigała

Composite beams with aluminium girders - a review

M. Szumigała, M. Chybiński \& E. Polus

Analysis of puzzle shaped continuous shear connector

P. Vaňová, R. Kanishchev \& V. Kvočák

\section{Engineering structures}

Buckling of externally pressured cylinders with different degrees of ring-stiffening

E. Azizi \& N. Stranghöner

On steel mast dynamic analysis including some environmental uncertainties

R. Bredow \& M. Kamiński

Shape-finding and behavior of the prestressed hybrid cable-stayed string steel bridge

P. Dabrila \& A. Juozapaitis

Fatigue design of tubular bracings in steel and composite bridges

L. Gölz \& U. Kuhlmann

Masonry infilled frames - contemporary structural concepts

I. Radić, T. Dokšanović, D. Markulak \& B. Pervan

Steel telecommunication towers subjected to fire - case studies

J. Szafran \& K. Juszczyk-Andraszyk

\section{Joints and connections}

Failure modes of steel angles connected by one leg

E. Bernatowska \& L. Ślęczka

Effective resistance of demountable shear connectors

A. Kozma, J. Yang \& C. Odenbreit

Analysis of steel bolted end-plate joints under accidental situation

D. Kukla \& A. Kozlowski

3D numerical models of steel joints with hollo-bolts - a comparison with experimental results

A.B. Mesquita, L.S.D. Silva \& S. Jordão 
Effective weld lengths of RHS overlapped K connections with the transverse gusset plates

P. Milewski \& M. Broniewicz

The bearing capacity of hybrid bolted and riveted joints in steel bridge structures

K. Pawlowski

Modelling of the ferritic stainless steel grade 430 bolted connections with damage implementation

K.P. Sobrinho, A.T. Silva, M.C. Rodrigues, P.C.G.S. Vellasco, L.R.O. Lima \& J. Henriques

Research on AM non welded N RHS truss joints - resistance criteria

J.K. Szlendak \& A. Szpyrka

Load capacity of anchors embedded into concrete and multi-layer façade slabs

J.K. Szlendak \& D. Tomaszewicz

Innovative bolted end-plate connections for high web I-beams

P. Tucki \& E. Hotala

Advanced analysis of members with gusset plate joints

M. Vild, V. Chalupa, L. Šabatka \& F. Wald

\section{Structural stability and integrity}

Effectiveness of butterfly-shaped links on structural behavior of slotted steel shear panels

H.M. Ahmadi \& G.D. Matteis

Full scale field testing of trapezoidal core sandwich panels subjected to adjacent and contact detonations

H. Al-Rifaie, R. Studziński, T. Gajewski, M. Malendowski, P. Peksa, W. Sumelka \& P.W. Sielicki

Torsional, flexural and torsional-flexural buckling of angle section members - an analytical approach

A. Beyer, A. Bureau, J-P. Jaspart, J.F. Demonceau \& M-Z. Bezas

Resistance assessments of steel columns of variable cross sections

P. Blażejewski, S. Kołodziej, J. Marcinowski \& V. Sakharov

The elastic local buckling behaviour and strength of the simply supported I-beam utilising the energy equilibrium method

S.M. Fujak, Y. Kimura \& A. Suzuki

Critical load of unbraced steel frames with classical and semi-rigid joints

P. Krystosik

Lateral torsional buckling of tapered steel I-beams with stiffener ribs

J. Kuś \& T. Maleska

Experimental testing of the critical loading for flexural-torsional buckling of steel two-chord columns laced in a single plane

P. Lorkowski \& B. Gosowski

Axial capacity of steel built-up battened columns

P. Pieczka \& P. Iwicki 
Major axis in-plane buckling resistance of I-section beam-columns under moment gradient

Z. Stachura, M.A. Giżejowski, R.B. Szczerba \& M.D. Gajewski

Robust optimisation of a single-layer lattice dome

P. Zabojszcza, U. Radoń \& P. Tauzowski

\section{Structural steel, metallurgy, durability and behaviour in fire}

Numerical investigation on cyclic behavior of steel shear panels endowed with innovative perforation patterns

H.M. Ahmadi \& G.D. Matteis

Fatigue life estimation of treated welded attachments via high frequency mechanical impact treatment (HFMI-treatment)

H. Al-Karawi, M. Al-Emrani \& R. Haghani

Fire design proposal for cold-formed steel lipped channel beam-columns

F. Arrais, N. Lopes \& P.V. Real

Fire resistance of stainless steel slender cross-sections under bending and axial compression

F. Arrais, N. Lopes \& P.V. Real

Lifetime estimation for hollow-section joints under variable amplitude loading

A. Dürr \& J. Roth

A new approach for the design of plates with trapezoidal longitudinal stiffeners

M.Z. Haffar, S. Ádány \& B. Kövesdi

Fire resistance evaluation of simple steel hall carried out by using various computational models

M. Maślak, M. Pazdanowski, M. Suchodoła \& P. Woźniczka

Investigations of the relationship between the Brinell hardness and strength parameters of structural steels $\mathrm{S} 235$ and S355

P. Organek, B. Gosowski \& M. Redecki

Yield strength of structural steel

P.J. Wolert \& A.S. Nowak

Design of experiments approach for ultimate strength assessment of corroded stiffened plates

K. Wołoszyk \& Y. Garbatov

MAG welding process for S700MC steel

B. Szczucka-Lasota, T. Węrrzyn, B. Lazarz, T. Szymczak, A. Jurek, K.I. Wilczyński \&

P. Cybulko

Author index 


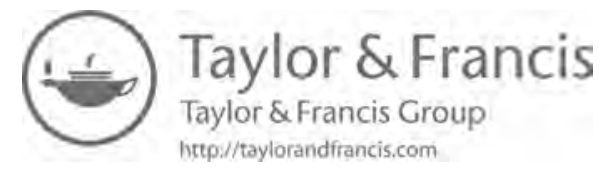




\section{Foreword}

Poznan University of Technology involvement in the organisation of the 14th International Conference of Metal Structures is perceived by me as a distinction, but also as a proof of trust in the University. This activity fits perfectly the University mission to educate at all levels of higher education and in lifelong learning programs in close connection with scientific and research development. Nowadays, Poznan University of Technology offers education at 9 faculties, covering a total of 33 fields of study. Nearly 16,000 students study here and over 1,300 academic teachers cater to their education. The didactic offer of Poznan University of Technology covers the most important fields related to modern technology with a recently launched program in Artificial Intelligence; it is also well adapted to the requirements of both domestic and foreign employers. High-quality scientific research is an integral element of Poznan University of Technology strategy, characterized by scientific achievements of its employees who published more than 2,000 scientific contributions: highly ranked articles, monographs, textbooks and other publications. The total number of PUT Library collections is over 450,000 volumes. Among numerous achievements, the University is proud of the H2020 Marie Sklodowska-Curie Global Fellowships and ERC grants. Furthermore, our scientists are among the authorities of the Polish Academy of Sciences ( 9 representatives) and are also members of numerous international scientific societies. According to Shanghai Ranking 2020 edition in disciplines, PUT was classified among the best 400 universities in the world in Mechanical Engineering. Also, we are ranked by students as the most popular university in Poland according to the Ministry of Science and Higher Education in the 2020/2021 academic year.

Owing to EU funding, recent years have introduced the development of research infrastructure at the Warta university campus. In 2020 our University also became a leader of European University EUNICE - a project funded by the European Commission with a budget of more than 6 million EUR. Our university consortium partners originate from Belgium, Germany, France, Finland, Italy and Spain. EUNICE's main goal is to build a common European University of the future, and prepare its structure and management design within 3 years. EUNICE is aspiring to provide a high-quality digital learning, offering flexible and multidisciplinary studies, as well as opportunities for students and staff for international exchange and networking. EUNICE will develop modern and innovative pedagogical methods and provide enhanced student services, in terms of enrolment, recognition, student counselling and guidance aimed at boosting the employability of all students. Just recently, PUT was also granted by the European Commission a follow-up scientific project REUNICE. This H2020 strategic project for the European University Alliance EUNICE aims at aligning its education, research and innovation strategies through an ambitious and transformative agenda.

Therefore, I am convinced that Poznan University of Technology is an excellent environment for the organisation of the 14th International Conference of Metal Structures. It should be emphasized that this conference is a broad forum for discussion and exchange of experiences on the latest achievements in the broadly understood area of metal structures. The main topics refer to issues closely related to the interest of many research groups especially in civil and mechanical engineering such as: advanced analysis and direct methods of design, safety and reliability assessment, structural stability and integrity, plated, cable, membrane, shell and 
composite structures, robustness and resistance to progressive collapse as well as structural health monitoring, refurbishment and repair.

Finally, I would like to express my gratitude for assigning me, the Rector of Poznan University of Technology, as the honorary patron of the Conference, and I accept it as a token of appreciation for the University, but above all as a commitment. I am sure that the meeting will take place in a friendly atmosphere, rich in fruitful discussion and in the most comfortable conditions possible.

Professor Teofil Jesionowski, Ph.D., D.Sc.

Rector of Poznan University of Technology 


\section{Preface}

The $14^{\text {th }}$ International Conference on Metal Structures 2021 (ICMS 2021) continued the series of conferences initiated in 1958. The previous three conferences were organised in Rzeszów (2006), Wrocław (2011) and Zielona Góra (2016) and they provided an ideal opportunity for the exchange of professional experience between researchers, designers and engineers. In 2021, the Conference was hosted by the Poznan University of Technology. Due to the global pandemic, it was delivered online from June 16 to June 18, 2021. As in previous years, the aim of the $14^{\text {th }}$ ICMS was to provide a forum for the presentation and discussion of new ideas related to the behaviour, design, fabrication, and execution of steel, aluminium and composite structures. The $14^{\text {th }}$ ICMS summarised a few years' theoretical, numerical and experimental research on these structures, and presented new concepts.

Seven plenary lectures were prepared for presentation at the Conference plenary sessions, including "Research developments on glass structures under extreme loads", Parhp3D - The parallel MPI/openMPI implementation of the 3D hp-adaptive FE code", "Design of beam-tocolumn steel-concrete composite joints: from Eurocodes and beyond", "Stainless steel structures - research, codification and practice", "Testing, modelling and design of bolted joints effect of size, structural properties, integrity and robustness", "Design of hybrid beam-tocolumn joints between RHS tubular columns and I-section beams" and "Selected aspects of designing the cold-formed steel structures".

This book contains six plenary lectures and all the individual papers presented during the Conference, sorted according to seven theme sessions:

1. Advanced analysis and direct methods of design,

2. Cold-formed elements and structures,

3. Composite structures,

4. Engineering structures,

5. Joints and connections,

6. Structural stability and integrity,

7. Structural steel, metallurgy, durability and behaviour in fire.

The editors wish to thank the authors of the plenary lectures and individual papers for the effort related to preparing their contributions. They also extend their thanks to the Scientific Committee for reviewing the submissions. Moreover, the editors' gratitude goes to the sponsors for their support. Last but not least, the editors would like to thank the members of the Organising Committee for preparing the Conference.

M.A. Giżejowski, A. Kozłowski, M. Chybiński, K. Rzeszut, R. Studziński, \& M. Szumigała

Editors 


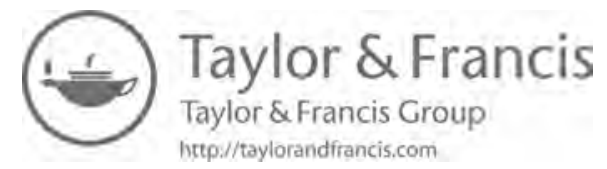




\section{Acknowledgements}

Due to the COVID pandemic, the organisation of the Conference was a big challenge. Profound gratitude goes to those who made this event possible.

A special thanks goes to the Rector of Poznan University of Technology, the Voivode of the Wielkopolska Region, the Marshal of the Wielkopolska Region, the Mayor of the City of Poznań, the Head of the Institute of Building Engineering, and the ICMS 2021 National Honorary Committee for their support.

We are grateful to "Nowoczesne Hale", "Builder", "Konstrukcje Stalowe" periodicals and "Buduj ze stali" for their help with promoting the Conference.

Our gratitude goes to the International Association for Bridge and Structural Engineering and the European Convention for Constructional Steelwork for their support.

Thanks are expressed to the Sponsors of the $14^{\text {th }}$ ICMS:

- Fronius Polska Sp. z o.o.

- GammaCAD Sp. z o.o.

- Nord-Lock Poland Sp. z o.o.

- PAP24 Sp. z o.o.

- Polska Izba Konstrukcji Stalowych

- Ruukki Polska Sp. z o.o.

- STRENCO Adam Machowiak

- Technika Spawalnicza Sp. z o.o.

- Zwick Roell Polska Sp. z o.o. Sp. k. 


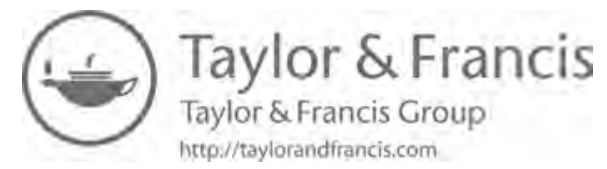




\section{Organisation and Committees}

\section{ORGANISED BY}

The Committee for Civil Engineering of the Polish Academy of Sciences, Section of Metal Structures

Poznan University of Technology, Institute of Building Engineering

\section{UNDER THE AUSPICES OF}

ECCS

IABSE

\section{UNDER THE HONORARY AUSPICES OF}

Rector of Poznan University of Technology

Voivode of the Wielkopolska Region

Marshal of the Wielkopolska Region

Mayor of the City of Poznań

\section{ADVISORY COMMITTEE}

Jerzy Ziółko, Honorable Chairman

Aleksander Kozłowski, Chairman

Marian Giżejowski, Vice chairman

Maciej Szumigała, Vice chairman

\section{NATIONAL HONORARY COMMITTEE}

President of the Committee for Civil Engineering of Polish Academy of Sciences

President of the Polish Chamber of Steelworks

President of the Polish Chamber of Civil Engineers

President of the Polish Association of Civil Engineers and Technicians

President of the Polish Corrosion Society

Rector of Poznan University of Technology

and

Zbigniew Barłóg, Tadeusz Biliński, Jan Bródka, Andrzej Garstecki, Roman Jankowiak, Mirosław Kosiorek, Zbigniew Kowal, Agnieszka Królikowska, Witold Kucharczuk, Ernest Kubica, Zdzisław Kurzawa, Stanisław Kuś, Andrzej Machowski, Antoni Matysiak, Zbigniew Mendera, Janusz Murzewski, Adam Reichhart, Kazimierz Rykaluk, Bernard Wichtowski, Wojciech Włodarczyk, Walter Wuwer. 


\begin{tabular}{|c|c|c|c|}
\hline Pradipta Banerji & India & Czesław Machelski & Poland \\
\hline Charalampos C. Baniotopoulos & UK & Arkadiusz Madaj & Poland \\
\hline Eduardo Bayo & Spain & Jakub Marcinowski & Poland \\
\hline Chiara Bedon & Italy & Damir Markulak & Croatia \\
\hline Antoni Biegus & Poland & Mariusz Maślak & Poland \\
\hline Jan Bień & Poland & Federico M. Mazzolani & Italy \\
\hline Frans Bijlaard & Netherlands & Andrzej S. Nowak & USA \\
\hline Reidar Bjorhovde & USA & Christoph Odenbreit & Luxemburg \\
\hline Mark Bradford & Australia & Szymon Pałkowski & Poland \\
\hline Luis Braganca & Portugal & Hartmut Pasternak & Germany \\
\hline Mirosław Broniewicz & Poland & Marek Piekarczyk & Poland \\
\hline Dinar Camotim & Portugal & Zbigniew Pozorski & Poland \\
\hline Siu-lai Chan & Hong Kong & Katarzyna Rzeszut & Poland \\
\hline Maël Couchaux & France & Alexandr Shimanovsky & Ukraine \\
\hline Gianfranco de Matteis & Italy & Shigeru Shimizu & Japan \\
\hline Jean-Francois Demonceau & Belgium & Wojciech Siekierski & Poland \\
\hline Dan Dubina & Romania & Luis S. da Silva & Portugal \\
\hline Laszlo Dunai & Hungary & Tomasz Siwowski & Poland \\
\hline Charis Gantes & Greece & Wojciech Skowroński & Poland \\
\hline Tomasz Garbowski & Poland & Bert Snijder & Netherlands \\
\hline Leroy Gardner & UK & Leopold Sokół & France \\
\hline Adam Glema & Poland & Natalie Stranhoener & Germany \\
\hline Jerzy Goczek & Poland & Wojciech Sumelka & Poland \\
\hline Bronisław Gosowski & Poland & Jerzy K. Szlendak & Poland \\
\hline Daniel Grecea & Romania & Elżbieta Szmigiera & Poland \\
\hline Werner Guggenberger & Austria & Andrzej Szychowski & Poland \\
\hline Marian Gwóźdź & Poland & Lucjan Ślęczka & Poland \\
\hline Eugeniusz Hotała & Poland & Thomas Ummenhoffer & Germany \\
\hline Piotr Iwicki & Poland & Elżbieta Urbańska-Galewska & Poland \\
\hline Joanna Jankowska-Sandberg & Poland & Ivan I. Vedjakov & Russia \\
\hline Robert Jankowski & Poland & Milan Veljkovic & Netherlands \\
\hline Karoly Jarmai & Hungary & Pedro Vellasco & Brazil \\
\hline Jean-Pierre Jaspart & Belgium & Paulo M.M. Vila Real & Portugal \\
\hline Janusz Kawecki & Poland & Frantisek Wald & Czech Rep. \\
\hline Paweł Kossakowski & Poland & Zhao Xianzhong & China \\
\hline Mieczysław Kuczma & Poland & Yeong-Bin Yang & China \\
\hline Ulrike Kuhlmann & Germany & Nesrin Yardimci & Turkey \\
\hline Vincent Kvocak & Slovakia & Jan Zamorowski & Poland \\
\hline Dennis Lam & UK & Riccardo Zandonini & Italy \\
\hline Raffaele Landolfo & Italy & Alphose Zingoni & South Africa \\
\hline Jörg Lange & Germany & Henryk Zobel & Poland \\
\hline Richard Liew Jat Yuen & Singapore & Małgorzata Zubielewicz & Poland \\
\hline Wojciech Lorenc & Poland & Krzysztof Żółtowski & Poland \\
\hline Mladen Lukic & France & & \\
\hline
\end{tabular}




\section{ORGANISING COMMITTEE}

Maciej Szumigała, Chairman

Katarzyna Rzeszut, Vice chairman

Marcin Chybiński, Vice chairman

Robert Studziński, Secretary

Katarzyna Ciesielczyk, Secretary Office

Luksz Polus, Secretary Office

Tomasz Szumigała, Secretary Office 


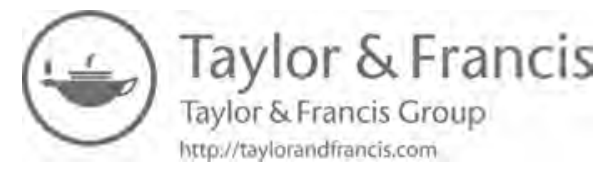


Keynote papers 


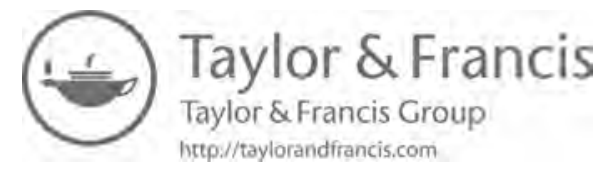




\title{
Research developments on glass structures under extreme loads
}

\author{
C. Bedon \\ University of Trieste, Trieste, Italy
}

\begin{abstract}
The increasingly use of glass in buildings certainly represents a new challenge for designers and researchers. On one side, the continuous development and innovation supports the development of novel solutions. At the same time, research studies and efforts are still required to optimize the safety levels and structural performances of this unconventional constructional material. Finally, a special care must be necessarily spent for the protection of glass structural elements and systems from the effects of potentially extreme design loads that may occur during their life-time (such as impact or explosive events, but also earthquakes, fire accidents and even excessive vibrations). In most of the cases, the major challenge comes from the mechanical (and even thermal) interaction of primary glass components with other constructional materials, like metal fasteners, and others. This paper gives evidence of some research developments and ongoing challenges.
\end{abstract}

\section{INTRODUCTION}

\subsection{Glass structures}

The industrialized use of glass in buildings as an effective load-bearing material for constructions is a relatively recent solution, compared to traditional and consolidated alternatives such as timber, steel, concrete and composites or masonry. On one hand, positive arguments in support of the large use in claddings and envelopes is related to the thermal, energy, light and aesthetic performance of glass. The same architectural trend that evolves towards the design and construction of geometrically complex solutions is another intrinsic support to further glass developments. Finally, the technological innovation in the building sector is also favorable to the use of transparent load-bearing components (Figure 1).

Besides, major challenges that are related to the use of glass in buildings are still associated to its basic mechanical properties, that make the design approach more challenging than other constructional materials. The relatively low tensile strength and tensile brittle behavior of glass as a material in load-bearing applications requires dedicated resistance verifications (especially in presence of holes or a long series of affecting parameters (Haldimann et al., 2008; CNR-DT 210/2013)). At the same time, the use of relatively small glass thicknesses to cover large surfaces in windows and facades make severe the need of serviceability deflection verifications, so as to ensure appropriate operational performances for glass members and structures.

The combination of the above aspects makes thus glass material itself the first potential responsible of high vulnerability for the occupants (Figure 2), given that both in the form of partition member or load-bearing component it is required to sustain loads, satisfy rigid performance metrics and optimally behave under mechanical or even climatic and thermomechanical loads. The designer is thus demanded to account for unfavorable basic material features and maximize the ensured safety levels. Even in presence of refined calculation 
a)

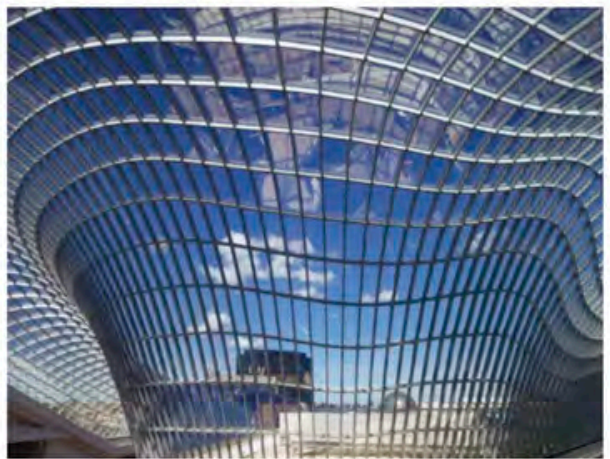

c)

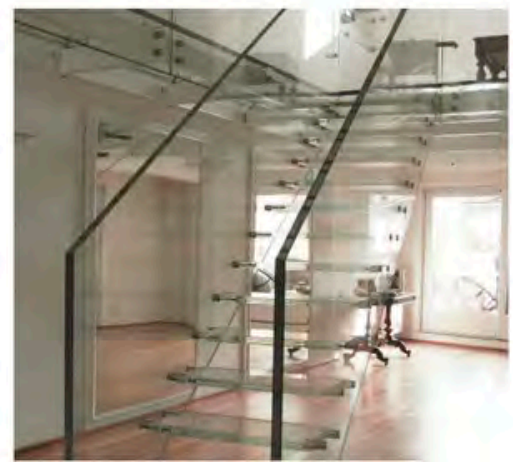

b)

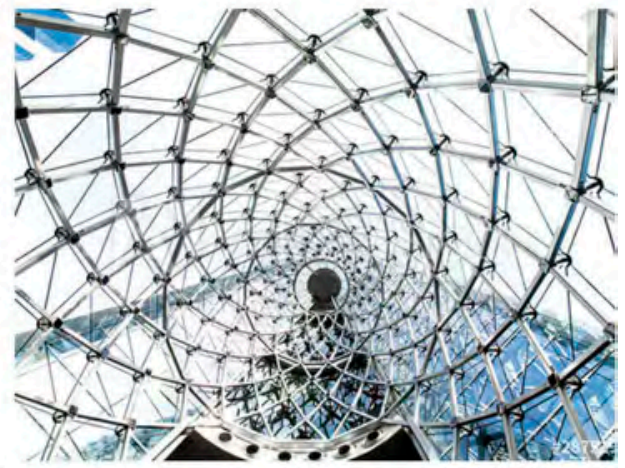

d)

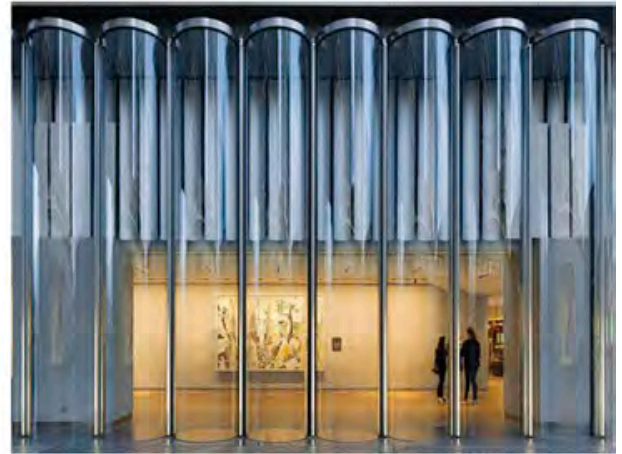

Figure 1. Structural glass applications in buildings: a) - b) roofs, c) stairs or d) facades.

a)

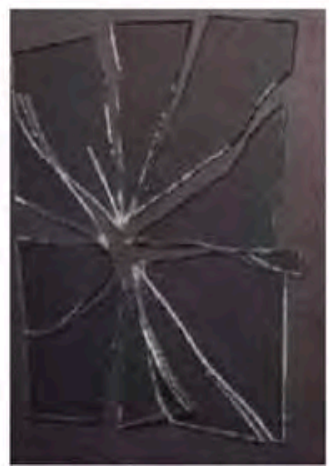

b)

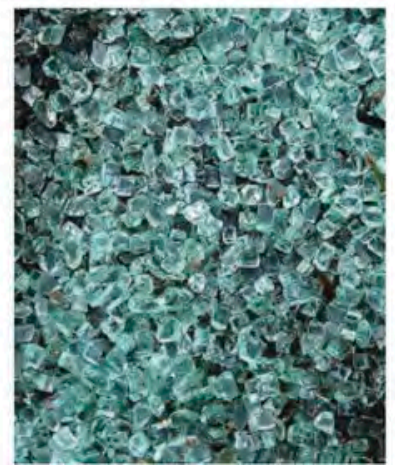

c)

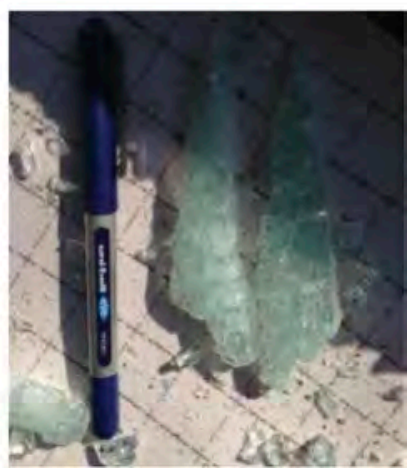

Figure 2. Selected examples of fractured glass: a) float glass; b) tempered glass and c) glass shatters due to explosion (figures reproduced from (Bedon et al., 2018)).

approaches and methods that can be based on the use of Finite Element (FE) or Computational Fluid Dynamics (CFD) numerical simulations, glass structures are often representative of a critical component in buildings and constructed facilities. This is true especially when extreme loading conditions are expected at the design stage, or could even occur over the lifetime of a given structural system. Glass windows and envelopes, in this regard, are required to act as the physical line of separation of indoor and outdoor spaces. Horizontal systems like roofs, floors, stairs are further required to offer even larger safety levels to the occupants. This 
is also the case of glass balustrades, when a potential risk of failure may occur. As a general rule, multidisciplinary approaches and specific fail-safe design criteria are necessarily required both under operational design loads and even more under critical conditions that may occur in a given life-time.

In this regard, design standards and technical documents are in continuous evolution and refinement (see for example the $\mathrm{prCEN} / \mathrm{TS} \mathrm{xxxx}-1$ and $\mathrm{prCEN} / \mathrm{TS} \mathrm{xxxx}-2$ documents) to support all the fundamental design and maintenance stages.

Besides, further research efforts are still required to optimize the existing design procedures, extend the available methods to general loading and boundary conditions of technical interest, or even adapt the existing methods to ongoing progress and innovation in the building sector.

\subsection{Extreme design loads for glass in buildings}

Even more than other constructional materials, glass members and systems should be properly designed with the maximization goal of safety, robustness, redundancy (CNR-DT 210/2013; $\mathrm{prCEN} / \mathrm{TS} \mathrm{xxxx}-1$; prCEN/TS $\mathrm{xxxx}-2$ ). The satisfaction of this requirements is a strategic task for the design and construction of attractive glass structures that can take advantage of human perceptions and emotions based on the material transparency (Figure 3a-b). Besides, major challenges are represented by extreme accidental events that can take the form of impacts (Kalamar et al., 2016; Zhang et al., 2020); explosive events (Figure 3c and (Bedon et al., 2018)); fire accidents (Figure 3d and (Bedon, 2017)) or vibrations (Section 2) and earthquakes (Section 3).

The two main requirements associated to structural safety of individual elements composed of glass include the Ultimate Limit State (ULS) and the Serviceability Limit State (SLS). The

a)

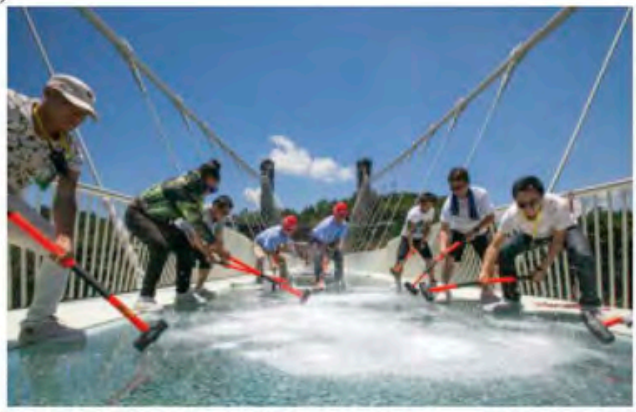

c)

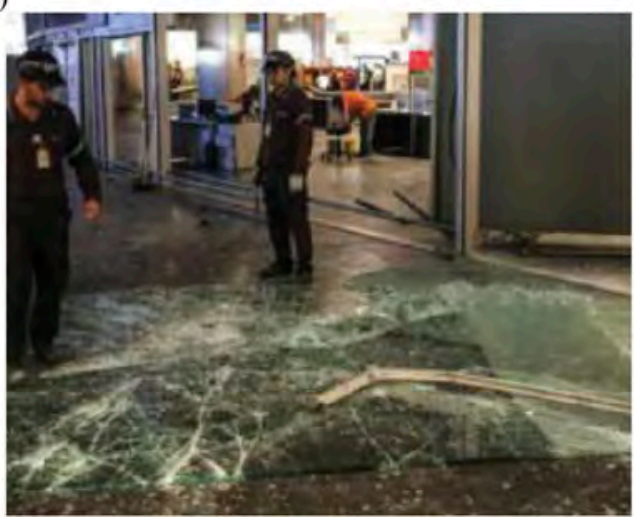

b)

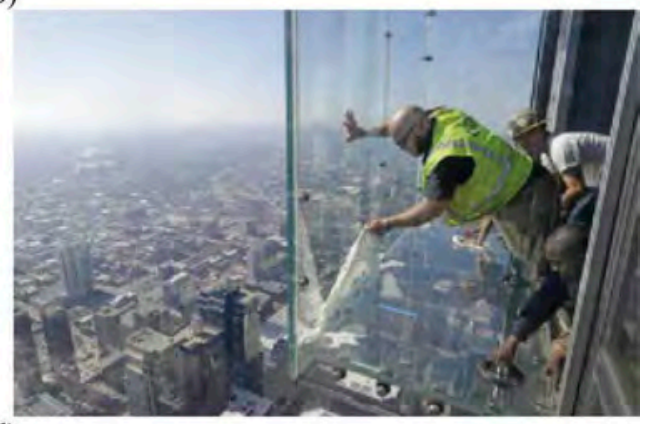

d)

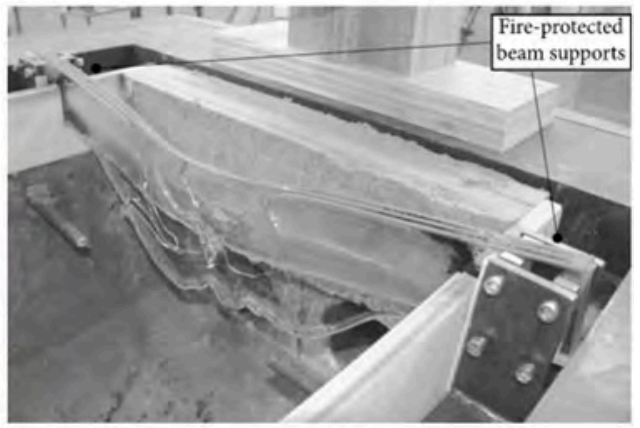

Figure 3. Structural glass applications in buildings: a) bridge; b) balcony; c) envelope collapse due to blast and d) laminated glass beam in fire testing (reproduced from (Bedon, 2017) under the terms and conditions of the Creative Commons Attribution (CC BY) license). 
first one ensures that structural elements have adequate strength to withstand the anticipated actions without fracture or stability loss, whereas the SLS requirements usually focus on deflections and vibrations, which might affect aesthetics, comfort of users or cause damage to other structural elements. The so-called Collapse Limit State (CLS) adopted by the Italian technical document CNR-DT 210/2013 represents a third level of analysis.

According to the fail-safe approach, it follows the need to account that an imponderable event can cause some glass components to fragment partially or completely. As such, it is required to ensure that even in this limit condition the glass element to verify can maintain enough load bearing capacity to carry permanent loads, and also a part of the variable loads that is consistent with the working conditions, thus preventing dangerous falls of material.

Accidental or man-made explosions are a critical condition for glass, given that they are typically characterized by a rapid and sudden release of energy in the form of shock wave, light, heat and sound. These shock waves consist of highly compressed air traveling at supersonic velocity.

When the shock waves hit the front surface of a structure or building, they are then reflected and amplified. Given an explosive event, the magnitude of the overall incident blast pressure is usually defined as a function of the equivalent charge weight of TNT, the geometry and stand-off distance from the centre of the charge to the wave front. The peak pressure of the compressed wave decays very rapidly, typically in times of the order of milliseconds. The initial compressive shock wave is followed by a vacuum as a result of gas and material being expelled rapidly from the point of detonation. For buildings and structural systems which are not designed to resist against blast, explosive events waves generally impinge on the external envelope, leading to the failure of glass windows and facades with the propagation of dangerous shards (Figures 2 and 3c). The use of laminated glass resisting sections can ensure a major absorption of input energy and protect people from severe shatters. The use of triple insulated glass units can be efficient (Sielicki et al., 2020). However, special benefit can be taken from the blast-resistant design of glass as well as by some available techniques for the mitigation of glass components (Zhang \& Bedon, 2017; Förch, 2020). Support can be taken from FE numerical analysis, once the design load features and the mechanical components are properly characterized (Larcher et al., 2016).

Fire accidents, as well as explosions, can severely affect the mechanical performance of a given glass member to verify (Figure 3d). The first issue, in this regard, arises from the progressive modification of glass state and material properties with the increase of imposed temperatures (Bedon, 2017). This result in a complex thermo-mechanical response in which first the stress peaks in glass migrate towards the cold regions, and the load-bearing members is still able for a while to sustain the imposed mechanical loads. Suddenly, as far as the temperature further increases, the glass member itself is not able to offer any kind of residual stiffness, thus leading to the final collapse/melting. Premature thermal shock can also occur in glass, thus experimental support should be preferred for the development of general numerical studies (Kozlowski et al., 2018; Sjöström et al., 2020). While special fire-resistant glass solutions are already distributed and used in practical design, these applications are limited to selected configurations (partition walls, barriers, doors) and the use of ordinary, soda-lime silica glass still prevails in constructed facilities.

As a general rule, special methods of analysis are required when for highly dynamic loads and/or temperature/humidity scenarios that may result in variations in the mechanical properties of materials in use. This is the case of glass but also of the viscoelastic bonding layers that are used for laminates, as well as secondary components in joints, etc. Selected examples reported in Figure 4 give evidence of current effects due to strain rate on the tensile and compressive strength of glass (Figures 4a-b), as well as of the vibration frequency effect on the shear rigidity of common interlayers (Figure 4c). Finally (Figure 4d). it is also important to analyze the local effect and the global performances due to soft layers that are typically interposed to glass and the restraining systems (especially metal frame members or point-fixings). 
a)

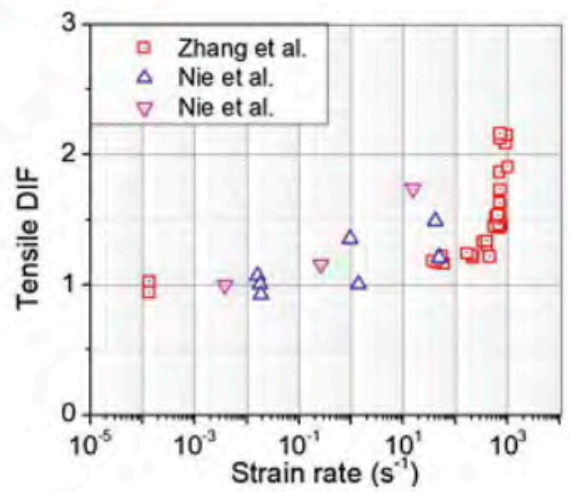

c)

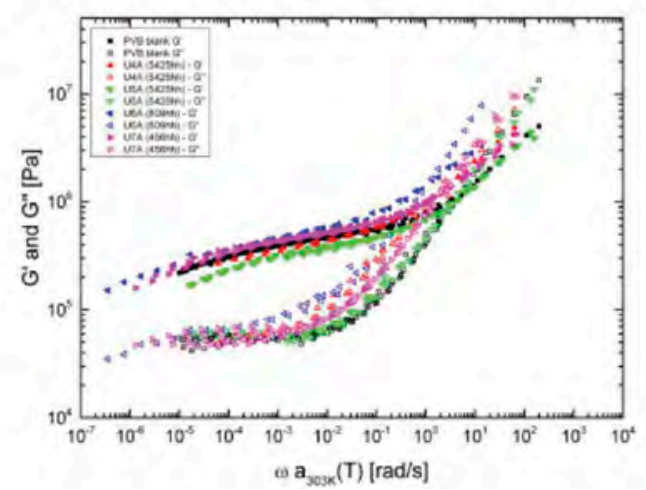

b)

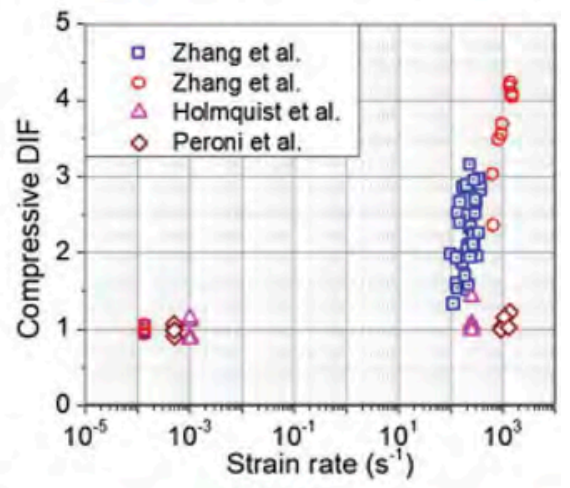

d)

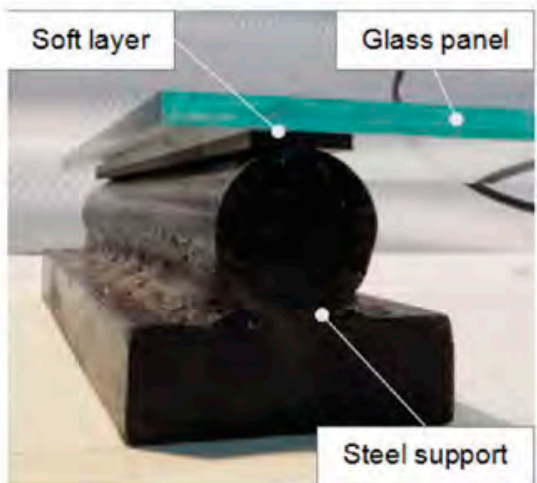

Figure 4. Examples of modification of material properties: a) tensile and b) compressive glass strength (dynamic increase) as a function of the imposed strain rate (figures reproduced from Bedon et al., 2018); c) shear stiffness modification in viscoelastic interlayers, as a function of the imposed vibration frequency (reproduced from (Bedon \& Fasan, 2019) under the terms and conditions of the Creative Commons Attribution (CC BY) license); d) local analysis of soft layer effects on the restraint and vibration response of glass members (reproduced from (Bedon et al., 2019) under the terms and conditions of the Creative Commons Attribution (CC BY) license).

\subsection{Fasteners for glass structures}

Under the effects of extreme design loads, the role of fasteners and restraints is even more strategic than under ordinary operational conditions. Any kind of energy dissipation, mitigation and protection of glass edges from premature stress peaks can take large benefit (or even severe magnification) from the connection detailing. This is especially the case of glass members and systems that are required to suffer for large/repeated displacements, as it is under seismic events.

Most of the existing studies and research projects of literature are in fact focused on the seismic assessment of specific constructional systems. This is the case of ordinary glass curtain walls, where glass panels are fully braced by continuous framing members, and merely intended as infill components. Several efforts have been also spent in the past for the design and analysis of glass structures with bolted connections, but only few research investigations are available for point-supported facades in earthquake-prone regions, with a focus on the intrinsic flexibility under in-plane seismic loads. The dissipation capacity of ordinary curtain walls under seismic events was partly assessed also in with the support of experiments, while an efficient, dissipative timber-glass composite shear wall was proposed in for earthquake resistant buildings.

In (Bedon \& Amadio, 2018), for example, it was demonstrated that even ordinary glass curtain walls can be efficiently involved in the dynamic response of multi-storey buildings under seismic events, as well as multi-hazards in general. Based on special dissipative connectors, the 
feasibility of a "distributed-Tuned Mass Damper (TMD)" concept was numerically explored, giving evidence of certain potential benefits for both the primary building and also for the glass facade components. The same research study highlighted, however, the need of a detailed design of the involved connectors, to avoid inconsistent stress/displacement demands under seismic loads.

Certainly, the design of fasteners and anchoring systems represent a key challenge for glass structures in seismic regions. The primary goal of design is in fact to prevent stress peaks in glass, due to the seismic deformations of the main structure they belong to, and large deformation capacity.

\section{SEISMIC EVENTS}

Among others, seismic events still represent for glass structures a critical operational condition that should be properly addressed at the design stage. Induced accelerations and vibrations can in fact be responsible of severe stress peaks that the glass components should be able to withstand. At the same time, both for stand-alone glass assemblies or for interventions in existing primary buildings that are made of other constructional typologies/materials, the glass members should be able to accommodate the required displacement demand. Such a request must be fulfilled for glass components but also for the restraints in use. This is highly demanding for a material that is characterized by a well-known tensile brittle behaviour, as well as by a high sensitivity to local effects that progressively reduce the expected design tensile strength (Section 1).

Some criticalities may further derive from the presence of point-fixings and holes in glass that require the local analysis of stress concentrations, or to the design of (even secondary) glass systems that are expected to take place in strategic buildings. The study reported in (Bedon et al., 2019), in this regard, points out such a condition.

The case study example is also summarized in Figure 5, and consists of a glass partition assembly composed of double laminated glass (LG) walls with metal point-fixings. The partition assembly was designed in the early 2018, to take place in an historical building in Trieste (Italy), and to protect one of its entrances from wind and rain exposure (Figure 5). The building, known as "Ferdinandeo Palace" is one of the most prestigious monuments of the city (erected in 1858 in honor of the Emperor Ferdinand I of Habsburg), and since 1999 hosts the MIB School of Management.

The 3D glazed assembly in Figure 5 covers up to $\approx 50$ square meters. The resisting section of each LG panel is composed of two, $6 \mathrm{~mm}$ thick fully tempered layers and a $1.52 \mathrm{~mm}$ thick, Poly-

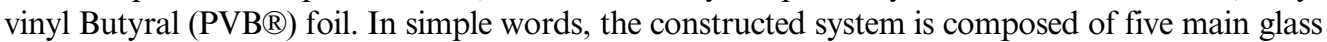
walls, with a nominal span in the range from $1.68 \mathrm{~m}$ to $2.65 \mathrm{~m}$. For these walls, the top height (in the range $4.3-4.65 \mathrm{~m}$ ) is obtained by means of two glass panels in the elevation of the structure.

The main feature of the design concept is represented by the minimization of metal fasteners and restraints to brace the system. A set of metal connectors was in fact chosen to erect the partition walls and provide an appropriate restraint in the elevation of the system. Several types of point-fixings were used, all of them composed of AISI 304 (EN 1.4301) and AISI 316 (EN 1.4436) steel types (Figures 5c and 5d).

Some of the steel point-fixings in use were realized in the form of bespoke joints able to fix the LG panels to the columns of the Palace. These bespoke joints-agreeing with and adapted from DP-44-100 devices from Metalglas ${ }^{\circledR}$ - consisted of a central M12 bolt and a steel solid section (with $42 \mathrm{~mm}$ the nominal diameter) for the main body and head. The total length of these devices (up to $180 \mathrm{~mm}$ ) was properly defined for each one of them, in order to accommodate the actual distance between the partition walls and the columns of the building.

Most importantly, a series of holes (with a diameter of $22 \mathrm{~mm}$ ) was also realized in the resisting section of the LG panels, to facilitate the installation of the partition system but also to ensure the presence of an appropriate gap with the M12 bolts. Under in-plane lateral forces due to seismic actions (or even wind), the case-study structural concept takes advantage of the "box-behaviour" and mechanical interaction of adjacent/orthogonal walls. As such, the 
a)

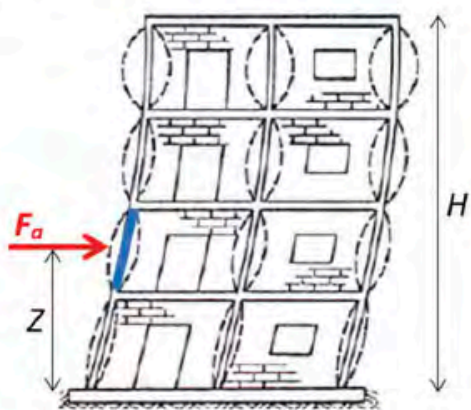

c)

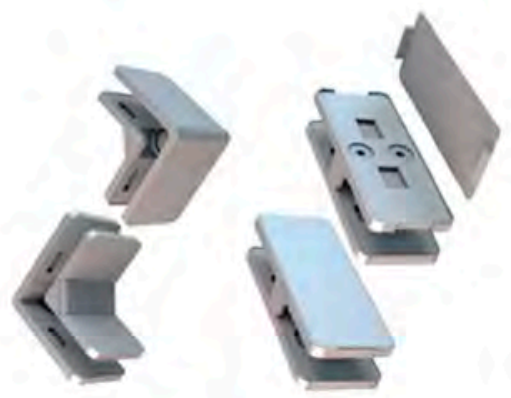

b)

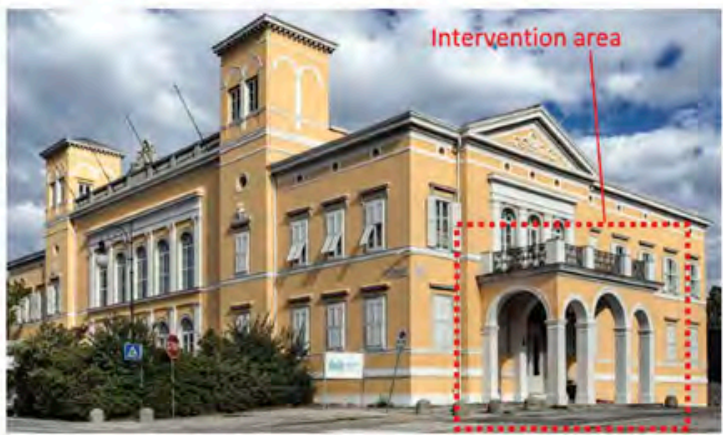

d)

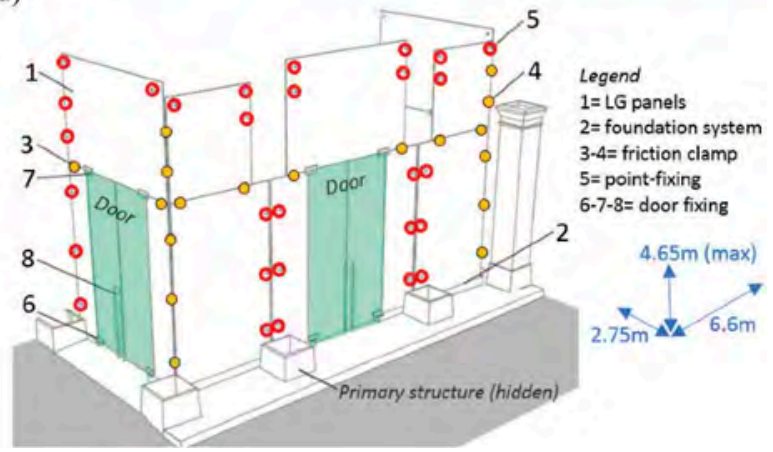

Figure 5. Seismic design of a secondary frameless glass system: a) local seismic force calculation; b) case-study intervention; c) examples of metal restraints in use and d) schematic representation of the final setup with evidence of the fastener type/position (figures reproduced from (Bedon et al., 2019) under the terms and conditions of the Creative Commons Attribution (CC BY) license).

analysis and verification of single glass walls (i.e., Figure 6a) requires appropriate considerations for the calculation of reaction forces transferred from one wall to the other. Lastly, the presence of glass holes needs the analysis of local stress peaks that are magnified due both to primary bending effects (Figure 6b) but also in-plane design loads/reaction forces.

\section{VIBRATIONS}

The vibration serviceability assessment of a given load-bearing system is known to represent a strategic step of design (EN 1990; ISO 10137). Besides the positive resistance and deflection verifications, a given system could be still weak in terms of comfort for the occupants, or even damage issues due to induced vibrations.

In the specific case of pedestrian systems composed of glass, the design challenge is even more complex rather than for slabs that are composed of traditional constructional materials. The structural mass, damping and stiffness are in fact key input parameters of the structure that are required to interact with a given moving load due to pedestrians (Figure 7).

While validated calculation methods are available since long in several technical documents and standards for the vibration serviceability analysis and assessment of concrete, steel, composite or timber slabs, this is not the case of structural glass solutions (Bedon \& Fasan, 2019). Literature approaches are in fact intrinsically verified and calibrated for the analysis of horizontal load-bearing members in which the mass is expected to be typically higher than the occupants (depending on the final destination of the system). Further, the typical range of vibrations for concrete, steel or timber slabs is also well defined and can be predicted with the support of simple mechanical models. 
a)

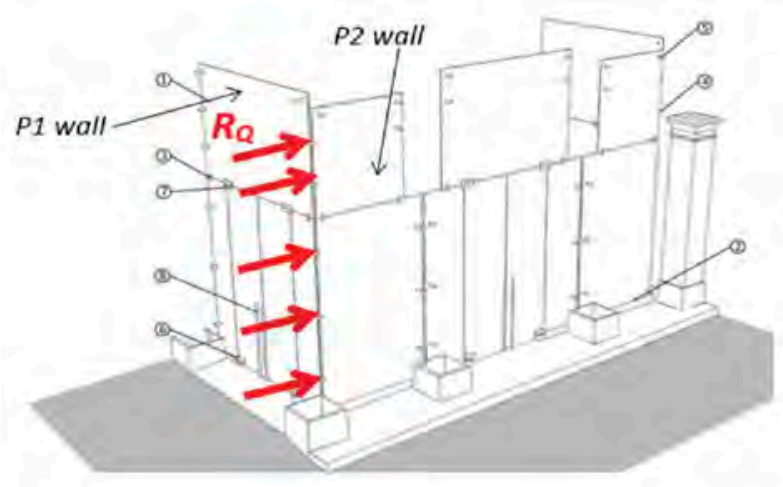

b)

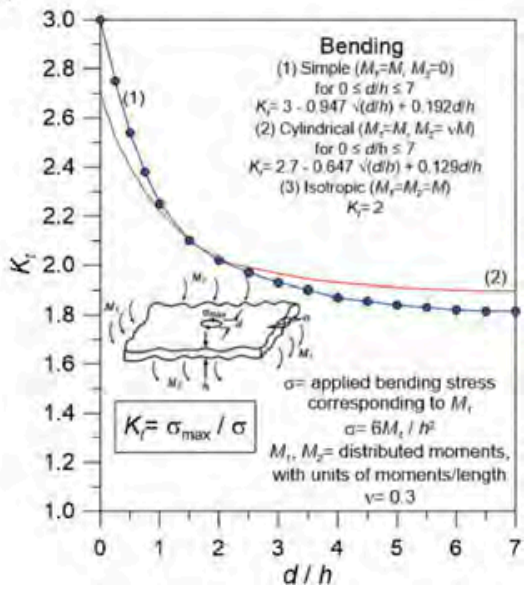

Figure 6. Seismic analysis of stress peaks in the region of holes: a) typical redistribution of seismic forces in the glass walls and b) stress correction factor for bending (figures reproduced from (Bedon et al., 2019) under the terms and conditions of the Creative Commons Attribution (CC BY) license).

a)

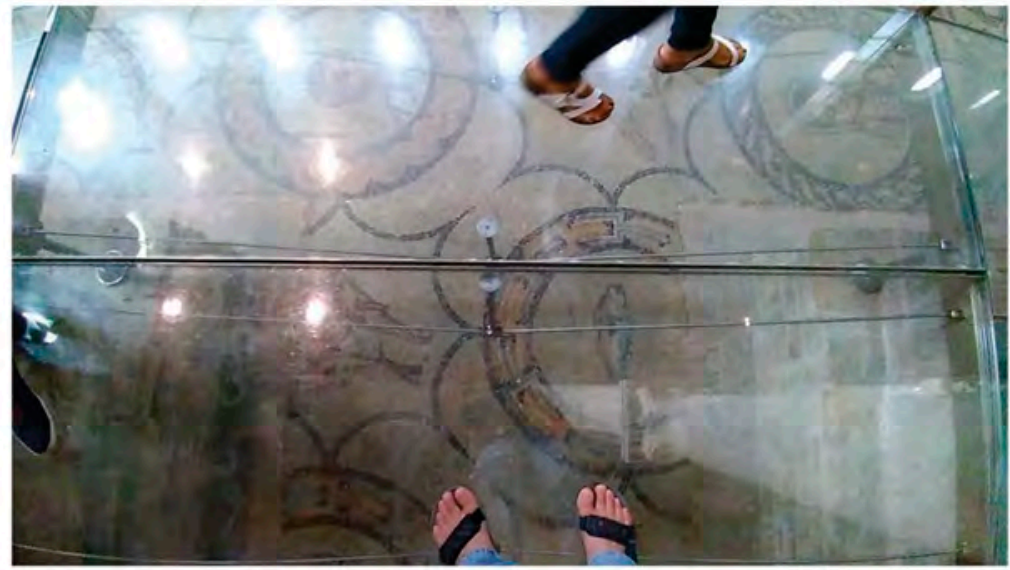

b)

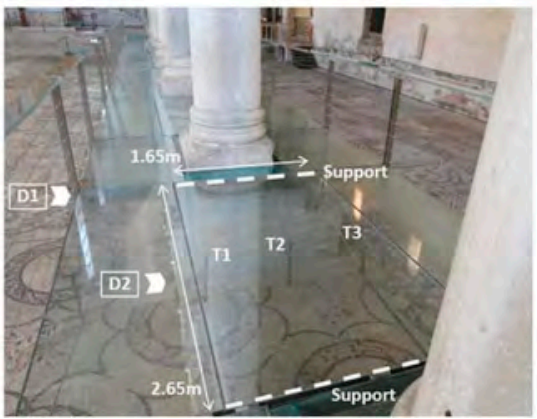

c)

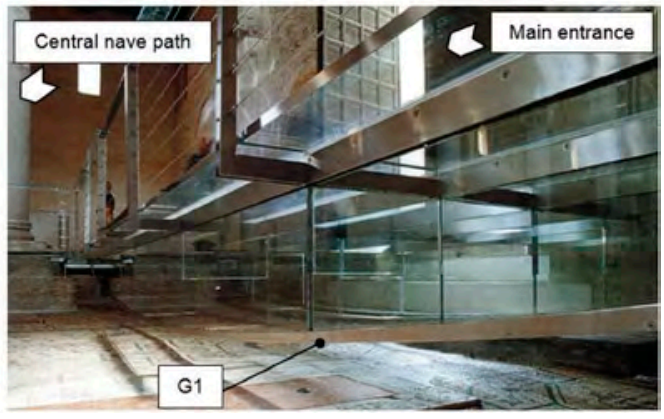

Figure 7. Vibration analysis of an existing in-service glass walkway: a) visual inspection and b) - c) details of the structural system. Figures reproduced from (Bedon \& Fasan, 2019) under the terms and conditions of the Creative Commons Attribution (CC BY) license). 
The vibration analysis in structural glass slabs and roofs includes on the other side some additional uncertainties and difficulties for reliable calculations. First, the structural mass is often lower than the mass of the occupants. Such a primary effect involves a severe modification of the overall structural dynamic response of the system, with consequent variations in the conventional human-structure interaction phenomena. The fundamental vibrations of glass structures are consequently even more sensitive to the presence of standing or moving occupants. Finally, the vibration response of these systems is also affected by time and ambient conditions, given that the interlayers in use to bond the glass panels are subjected to a progressive degradation of stiffness that combines with a further stiffness modification in the same layers (as a direct effect of their viscoelastic nature and response to external induced vibration frequencies).

Recent studies can be found in (Bedon, 2019a; Bedon, 2020), where a case-study system has been investigated with the support of Operational Modal Analysis techniques, Finite Element numerical models, and analytical models of literature that have been properly adapted to the examined boundaries.

The same case-study system was successively explored with a focus on point-fixed glass handrails that are shown in Figure 8 and investigated in (Bedon, 2019b). The vibration analysis of in-service load-bearing members can find further uncertainties and complexities when the actual mechanical properties (i.e., shear rigidity of interlayers) is difficult to quantify due to long-term and high-humidity phenomena (see for example the details in Figure 8a), but also the real restraint effect of fasteners cannot be easily characterized (Figures $8 b-8 c$ ). In this sense, the use of experimental on-site techniques that are typical of the Operational Modal Analysis approaches can offer further support for diagnostics and assessment purposes.

a)
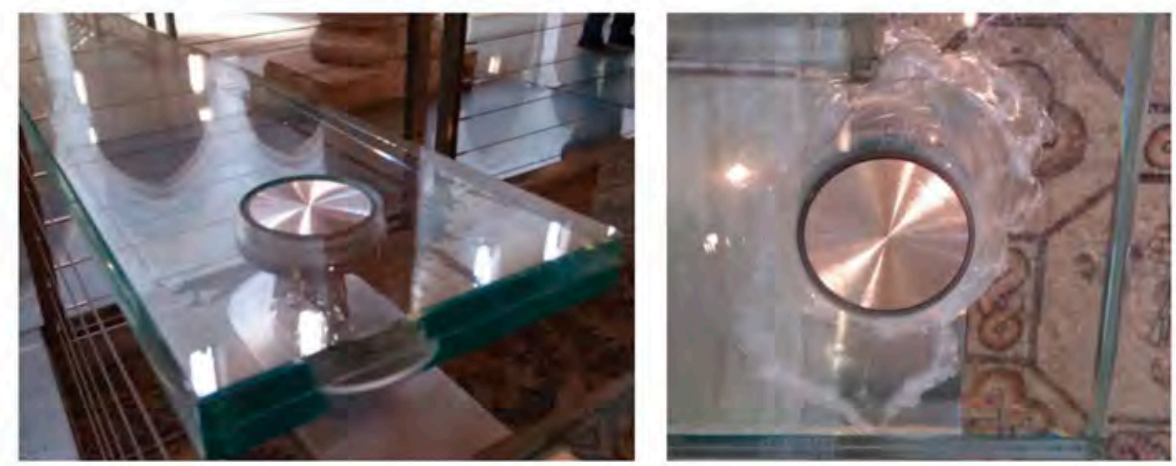

b)

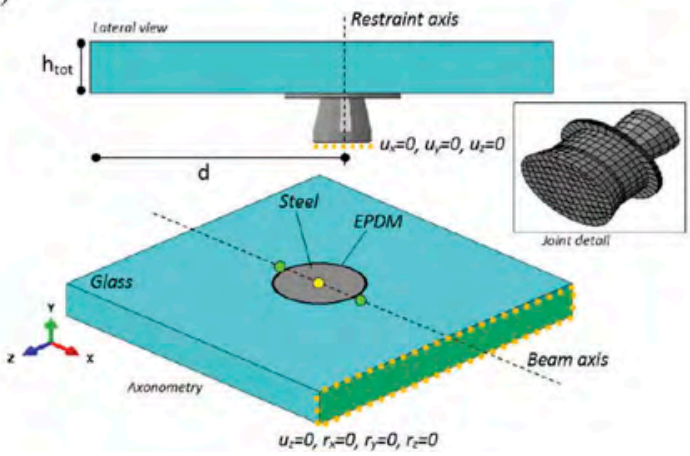

c)

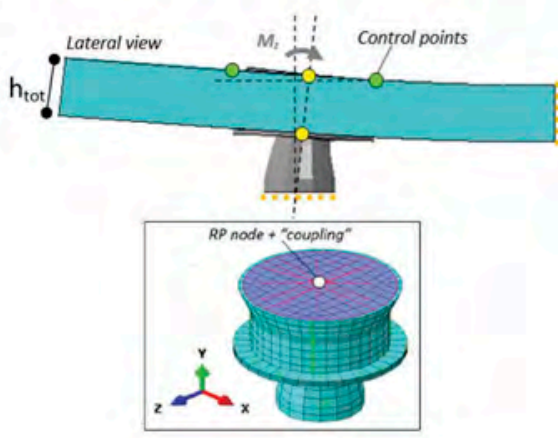

Figure 8. Vibration analysis of point-fixed glass handrails for an existing in-service glass walkway: a) restraint detail, with evidence of delamination and b) - c) selected detail views for the FE numerical analysis (ABAQUS). Figures reproduced from (Bedon, 2019b) under the terms and conditions of the Creative Commons Attribution (CC BY) license). 


\section{CONCLUSIONS}

The use of structural glass member and components in buildings showed a fast increase in the last decades. To this aim, harmonized technical documents and guidelines have been developed (and are still in progress) to support designers and provide fail-safe recommendations of practical use. Besides, the verification and design under extreme design loads and accidental events like impacts and explosions, earthquakes, fire accidents, or even extreme vibrations, still represent an open issue that requires specific calculation and analysis methods. In most of the cases, major challenges are represented by the intrinsic properties of glass and related materials, first of all the viscoelastic interlayers that are used to bond multiple panels together, but also all the secondary components that take place in the region of joints and connections. Furthermore, a glass member itself is required to interact (even with interposed soft layers) with metal frame members of point-fixings and fasteners that could represent a critical region for the prevention of premature stress peaks. As a further important aspect that needs to be properly addressed, is the progressive modification of material properties with variations in the imposed strain rate, vibration frequency, but also time loading, temperature, humidity.

\section{REFERENCES}

Bedon, C., Amadio, C. 2018. Numerical assessment of vibration control systems for multi-hazard design and mitigation of glass curtain walls. Journal of Building Engineering, 15: 1-13.

Bedon, C., Amadio, C., Noé, S. 2019. Safety Issues in the Seismic Design of Secondary Frameless Glass Structures, Safety, 5(4), 80; https://doi.org/10.3390/safety5040080.

Bedon, C., Fasan, M. 2019. Reliability of Field Experiments, Analytical Methods and Pedestrian's Perception Scales for the Vibration Serviceability Assessment of an In-Service Glass Walkway. Applied Sciences, 9(9), 1936; https://doi.org/10.3390/app9091936.

Bedon, C., Fasan, M., Amadio, C. 2019. Vibration Analysis and Dynamic Characterization of Structural Glass Elements with Different Restraints Based on Operational Modal Analysis. Buildings, 9 (1): 13; https://doi.org/10.3390/buildings9010013.

Bedon, C., Zhang, X., Santos, F., Honfi, D., Kozłowski, M., Arrigoni, M., Figuli, L., Lange, D. 2018. Performance of structural glass facades under extreme loads - Design methods, existing research, current issues and trends. Construction and Building Materials, 163: 921-937.

Bedon, C. 2019a. Diagnostic analysis and dynamic identification of a glass suspension footbridge via on-site vibration experiments and FE numerical modelling. Composite Structures, 216: 366-378.

Bedon, C. 2019b. Issues on the Vibration Analysis of In-Service Laminated Glass Structures: Analytical, Experimental and Numerical Investigations on Delaminated Beams. Applied Sciences, 9(18): 3928; https://doi.org/10.3390/app9183928.

Bedon, C. 2020. Experimental investigation on vibration sensitivity of an indoor glass footbridge to walking conditions. Journal of Building Engineering, 29: 101195.

CEN/TC 250. 2019s. prCEN/TS xxxx-1: 2019-In-Plane Loaded Glass Components; CEN-European Committee for Standardization: Brussels, Belgium.

CEN/TC 250. 2019b. prCEN/TS xxxx-2: 2019-Out of-Plane Loaded Glass Components; CEN-European Committee for Standardization: Brussels, Belgium.

CNR-DT 210. 2013. Istruzioni per la Progettazione, L'esecuzione ed il Controllo di Costruzioni con Elementi Strutturali di vetro [Guide for the Design, Construction and Control of Buildings with Structural Glass Elements]; National Research Council of Italy (CNR): Roma, Italy, 2013; available online: www.cnr.it/it/node/2630.

EN 1990. 2005. Eurocode 0 - Basis of Structural Design - Annex A2: Application for Bridges; CEN: Brussels, Belgium.

Förch, M. 2020. Time-Temperature Dependency of Laminated Glass Subjected to Blast Load A Numerical Study. International Journal of Structural Glass and Advanced Materials Research, 4(1): 69-81, https://doi.org/10.3844/sgamrsp.2020.69.81.

Kalamar, K., Bedon, C., Eliášová, M. 2016. Experimental investigation for the structural performance assessment of square hollow glass columns. Engineering Structures, 113 (4), 1-15.

Kozlowski, M., Bedon, C., Honfi, D. 2018. Numerical Analysis and 1D/2D Sensitivity Study for Monolithic and Laminated Structural Glass Elements under Thermal Exposure. Materials, 11(8): 1447, https://doi.org/10.3390/ma11081447. 
Haldimann, M., Luible, A., Overend, M. 2008. Structural Use of Glass; IABSE: Zurich, Switzerland, ISBN 978-3-85748-119-2.

ISO 10137. 2007. Bases for Design of Structures - Serviceability of Buildings and Walkways Against Vibrations; International Organization for Standardization (ISO): Geneva, Switzerland.

Larcher, M., Arrigoni, M., Bedon, C., van Doormaal, A., Haberacker, C., Hüsken, G., Millon, O., Saarenheimo, A., Solomos, G., Thamie, L., Valsamos, G., Williams, A., Stolz, A. 2016. Design of blast-loaded glazing windows and facades: a review of essential requirements towards standardization. Advances in Civil Engineering, https://doi.org/10.1155/2016/2604232.

Sielicki, P.W., Bedon, C., Zhang, X. 2020. Performance of TGU Windows under Explosive Loading. In: Hofreiter L., Berezutskyi V., Figuli L., Zvaková Z. (eds) Soft Target Protection. NATO Science for Peace and Security Series C: Environmental Security, pp. 49-59. Springer, Dordrecht. https://doi.org/ 10.1007/978-94-024-1755-5_4.

Sjöström, J., Kozlowski, M., Honfi, D., Lange, D., Albrektsson, J., Lenk, P., Eriksson, J. 2020. Fire Resistance Testing of a Timber-Glass Composite Beam. International Journal of Structural Glass and Advanced Materials Research, 4(1): 24 40, https://doi.org/10.3844/sgamrsp.2020.24.40.

Zhang, X., Bedon, C. 2017. Vulnerability and Protection of Glass Windows and Facades under Blast: Experiments, Methods and Current Trends. International Journal of Structural Glass and Advanced Materials Research, 1(2), 10-23. https://doi.org/10.3844/sgamrsp.2017.10.23.

Zhang, X., Meng, Q., Bedon, C., Sielicki, P.W. 2020. Strengthening of Laminated Glass Windows against Windborne Debris Impact. International Journal of Structural Glass and Advanced Materials Research, 4(1): 209-224, https://doi.org/10.3844/sgamrsp.2020.209.224. 


\title{
Design of beam-to-column steel-concrete composite joints: From Eurocodes and beyond
}

\author{
J-F. Demonceau \\ University of Liège, Liège, Belgium
}

\begin{abstract}
The design of beam-to-column structural joints and, in particular, of steelconcrete composite joints is covered in the Eurocodes through the application of the wellknown component method which is nowadays recognized as one of the most appropriate analytical method for the characterization of joints. However, even if the concept behind the component method allows the covering of a wide range of joint configurations and of loading situations, the detailed application rules as presently provided in the Eurocodes allow to only cover specific loading situations. It is particularly the case for composite joints for which their characterization is only possible for hogging moments. In the present paper, it is proposed to provide a global overview of recent researches which aimed at overcoming this limitation and at proposing new application rules for new loading conditions met in actual design projects.
\end{abstract}

\section{INTRODUCTION}

Nowadays, the component method is recognized as a reference analytical approach able to predict accurately the main mechanical characteristics of structural joints. In particular, this method is behind the design recommendations reported in the Eurocodes and, in particular, in Eurocode 3, Part 1-8 (EN 1993-1-8 2010) dedicated to steel joints and in Eurocode 4, Part 1-1 (EN 1994-1-1 2004) which provides additional rules to allow the characterization of steelconcrete composite joints.

The application of the component method requires three main steps (J.-P. Jaspart and Weynand 2016):

1. the identification of the joint components activated under the considered loading condition;

2. the characterization of the so-identified individual basic components in terms of stiffness and/or resistance and;

3. the assembly of all the individual basic components to determine the stiffness and/or the resistance of the whole joint.

The component method can be seen as an application of the finite element approach at a macro scale in which the activated basic components are represented by springs as illustrated in

Figure 1 and through which the mechanical properties of the whole joint are obtained by applying the principles of the static and cinematic theorems.

As mentioned above, the application of the component method requires rules for the characterization of the basic components; the ones covered in Eurocode 3, Part 1-8 and in Eurocode 4, Part 1-1 are listed in Table 1. In addition, Eurocode 4, Part 1-1 also provides rules for components for which their mechanical properties are affected by the possible presence of concrete, i.e. the column web panel in shear and the column web in compression. 

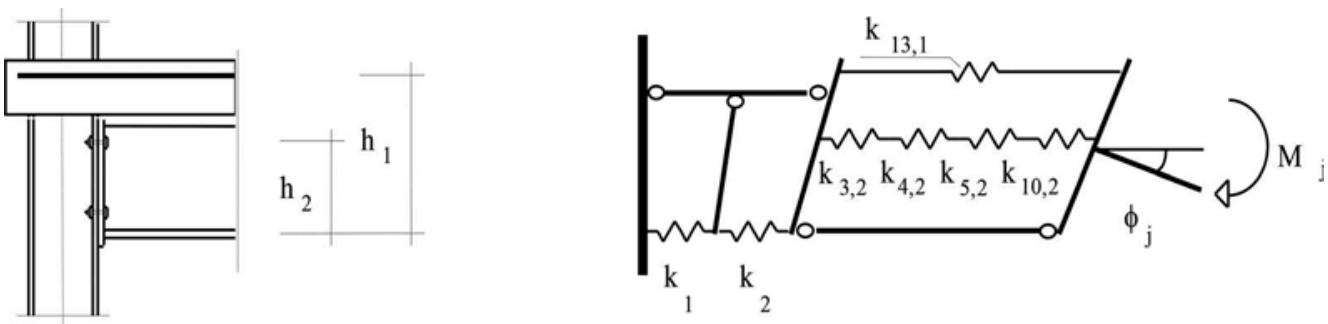

Figure 1. Example of a spring model for a composite flush end-plate connection subjected to hogging moments (Anderson 1999).

Table 1. Joint components covered by Eurocode 3, Part 1-8 (components 1 to 12) and Eurocode 4, Part 1-1 (components 13 and 14).

\begin{tabular}{llll}
\hline $\mathrm{N}^{\circ}$ & Joint components & $\mathrm{N}^{\circ}$ & Joint components \\
\hline 1 & Column web panel in shear & 8 & Flange cleat in bending \\
2 & Column web in compression & 9 & Bolts in tension \\
3 & Beam flange and web in compression & 10 & Bolts in shear \\
4 & Column flange in bending & 11 & Bolts in bearing \\
5 & Column web in tension & 12 & Plate in tension or compression \\
6 & End-plate in bending & 13 & Longitudinal steel rebars in tension \\
7 & Beam web in tension & 14 & Steel contact plate in compression \\
\hline
\end{tabular}

With the so-available joint components, it is possible to characterize a wide range of structural joint configurations and to predict their main mechanical properties, i.e. their stiffness, their resistance in bending and their resistance in shear. Also, the Eurocodes allows estimating their ability to exhibit a sufficient ductility for the realization of a plastic analysis (with plastic hinges forming at the level of the joints) even if an explicit computation of the joint ductility or rotation capacity is not possible.

But, looking closer to the rules provided in the Eurocodes regarding composite joints, it can be observed that rules are only provided to predict the resistance of composite joints under shear forces and hogging moments.

However, the design of composite structures considering actions such as earthquake, fire... or the request for robustness in case of exceptional event requires to be able to characterize composite joints under other loading conditions, i.e. under sagging bending, under cyclic loading, under combined moment and axial force (M-N), under elevated temperature or under dynamic loading.

Within the present paper, it is proposed to give a global overview of some recent researches conducted in the field of composite joints; in particular, it will be demonstrated how the component method can be easily adapted to cover new loading conditions.

Section 2 first addresses the behavior of composite joints under sagging moment. Then, Section 3 deals with the behavior of composite joints under M-N and Section 4 with the behavior of composite joints at elevated temperature. Section 6 presents recent investigations on the behavior of joints subjected to dynamic loading and finally, Section 7 reports on a method allowing predicting the ductility of joints and, in particular, of composite joints.

\section{COMPOSITE JOINTS UNDER SAGGING MOMENT}

Under usual loading conditions, composite beam-to-column joints are mainly subjected to shear forces and hogging moments. However, for some specific loading conditions such as moment resisting frames subjected to significant horizontal forces (for instance associated to 
an earthquake) or composite frames subjected to a column loss scenario, sagging moments may occur at the level of the joints.

Looking to the global concept behind the component method as presented in the previous section, the latter is applicable whatever are the loading conditions if the designer is able (i) to characterize the activated basic components and (ii) to proceed with the assembly of the basic components. For composite joints under sagging moment, the assembly procedure as proposed in the Eurocodes can be extended in a straightforward way to cover this specific loading condition. But the characterization of composite joints under sagging moments requires the characterization of a new component which is not reported in Table 1 and so not yet covered in the Eurocodes: the concrete slab in compression. Indeed, when a sagging moment is applied at the level of a composite joint, the bottom part of the connection is subjected to tension while the upper part which is mainly composed of the slab connected to the beam is subjected to compression (Figure 2).

In the last decades, the behavior of composite joints under sagging moments have been studied through different researches ((Liew, Teo, and Shanmugam 2004; Ferrario 2004; J.-F. Demonceau 2008; J.-F. Demonceau et al. 2008; Braconi, Elamary, and Salvatore 2010; Piluso, Rizzano, and Tolone 2012) amongst other). In particular, in (J.-F. Demonceau 2008), it is proposed to characterize the "concrete slab in compression" through the definition of an equivalent cross-section with an effective width as proposed in (Ferrario 2004) and with a height defined as proposed in (Liew, Teo, and Shanmugam 2004):

- The effective width is taken as equal to $b_{\text {eff,conn }}=b_{c}+0.7 h_{c} \leq b_{\text {eff }}$ where $b_{c}$ is the width of the column profile flange, $h_{c}$ the height of the column profile cross section and $b_{\text {eff }}$, the effective width of the concrete/composite slab to be considered for the beam in the vicinity of the joint; $b_{c}$ represents the contribution of the concrete in contact with the column flange while $0.7 h_{c}$ is the contribution of the developed concrete rods in the "strut-and-tie" behavior (Figure 3);

- The height of the equivalent cross-section is computed expressing the equilibrium between the compression developing in the concrete slab and the components activated in tension assuming a rectangular stress distribution in the concrete (equal to $f_{c d}$ $=0.85 f_{c k} / \gamma_{c}$ in a design as recommended in Eurocode 4, Part 1-1 - see Figure 2):

$$
z=\frac{\sum_{i} F_{R d, i}}{b_{\text {eff }, \text { conn }}\left(0,85 \cdot f_{c k} / \gamma_{c}\right)} \leq h_{\text {concrete }}
$$

where $h_{\text {concrete }}$ is the total height of the concrete slab (in case of a composite slab, $h_{\text {concrete }}$ is equal to the concrete above the ribs), $f_{c k}$ is the characteristic strength of the concrete, $\gamma_{c}$ is the safety coefficient for the concrete material and $F_{R d, i}$ is the tensile resistance of bolt row $i$.

The resistance of the "concrete slab in compression" can be obtained using the following formula, assuming that the latter is located at mid-height of the contributing part of the slab (z):

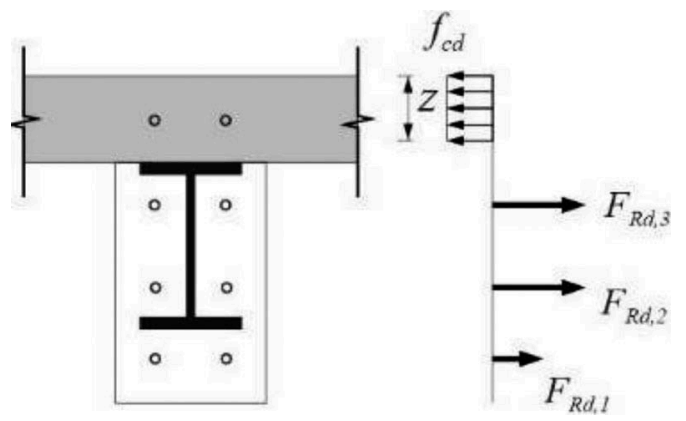

Figure 2. Composite joint subjected to sagging moment (J.-P. Jaspart and Weynand 2016). 


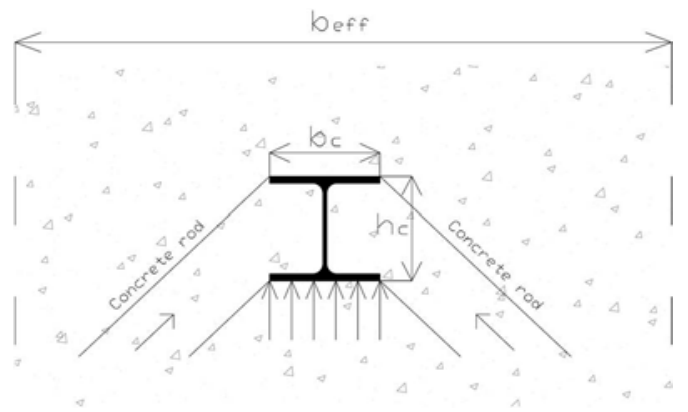

Figure 3. Development of a strut-and-tie behavior in the vicinity of the joint - Definition of an equivalent effective width (J.-F. Demonceau et al. 2008).

$$
F_{R d, \mathrm{CSC}}=b_{e f f, c o n n} \cdot z \cdot f_{c d}
$$

In (J.-F. Demonceau et al. 2008), a proposal for the characterization of this component in terms of stiffness is also made and is funded on an approach which is proposed in (Weynand 1999) for the characterization of a concrete block against a rigid plate, configuration which can be met in column bases:

$$
k_{\mathrm{csc}}=\frac{E_{c m} \cdot \sqrt{b_{e f f, c o n n} \cdot z}}{1,275 \cdot E_{a}}
$$

where $E_{c m}$ is the secant Young modulus for the concrete, $E_{a}$, the elastic Young modulus for the steel and $k_{c s c}$, the stiffness of the component "concrete slab in compression" to be used in the component method.

The so-proposed model for the characterization of the new component "concrete slab in compression" has been validated in (J.-F. Demonceau 2008) though comparisons to experimental tests results performed in the framework of RFCS European projects (Bitar et al. 2006; Bursi et al. 2008). Such an example of validation is presented in Figure 4 where the prediction obtained through the proposed analytical model is compared to experimental tests performed in Trento (Bursi et al. 2008) on single sided composite joints in isolation. It can be observed on this figure that two experimental curves are reported; the two reported tests differ from the configuration of the slab: TEST 2 joint is made of a composite slab while TEST 3 joint is made of a concrete slab. From the comparison, it can be seen that a very good agreement is reached between the analytically predicted curve and the experimental ones, at least

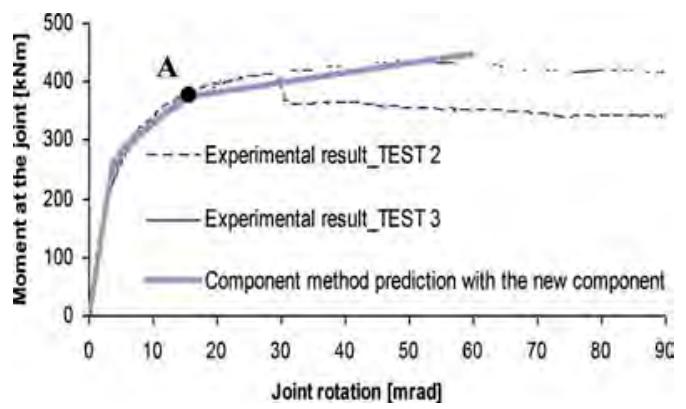

Figure 4. Composite joint under sagging moment - comparison of the analytical prediction to experimental results (J. Demonceau and Ciutina 2019). 
up to point A, i.e. up to the plastic resistance of the studied joint which corresponds to the targeted value with the component method as presently proposed in the Eurocodes. How to obtain analytically the rest of the curve, i.e. the part of the curve after point A, will be discussed in Section 6. This demonstrate how the component method can be easily adapted to new loading conditions.

\section{COMPOSITE JOINTS UNDER M-N INTERACTION}

When a structure is subjected to a column loss scenario, the joints which are initially subjected to shear forces and bending moments are progressively subjected to axial forces while the membrane forces are developing in the structure (J.-F. Demonceau and Jaspart 2010). In particular, if partial strength joints are met at the extremities of the beams, this transition from a pure bending mode to a bending plus axial force mode takes place when the joints are already yielded in bending; accordingly, this transition can only occur if a sufficient ductility is available at the level of the yielded joints. The mastering of this process requires to be able to accurately predict the response of joints under $\mathrm{M}-\mathrm{N}$ interaction.

If reference is made to the Eurocodes, the characterization of joints under $\mathrm{M}-\mathrm{N}$ is covered through a simplified approach proposed in Eurocode 3, Part 1-8, for steel joints. In this approach, it is assumed that the influence of $\mathrm{M}-\mathrm{N}$ interaction can be disregarded as long as the axial force $\mathrm{N}_{\mathrm{Ed}}$ applied to the joint is smaller than $5 \%$ of the axial design plastic resistance of the connected beam cross-section $\mathrm{N}_{\mathrm{pl}, \mathrm{Rd}}$ Above this limitation, a linear interaction between $\mathrm{M}$ and $\mathrm{N}$ is assumed. The so-defined criterion is illustrated in Figure 5.

However, it has been demonstrated in (Cerfontaine 2003) that this criterion does not allow to accurately predict the actual resistant curve of steel joints under $\mathrm{M}-\mathrm{N}$ and can even provide an unsafe prediction of the joint resistance. Also, this procedure is proposed for steel joints but nothing is proposed for composite ones; this mainly comes from the " $5 \%$ " criterion for which no scientific background is provided and which is quite questionable.

For all these reasons, the behavior of joint under $\mathrm{M}-\mathrm{N}$ has been the topic of different researches in the past decades ((Simões Da Silva and Girão Coelho 2001; Kuhlmann et al. 2008; Rodrigues et al. 2010; Gao et al. 2019) amongst other).

In particular, a new analytical model has been recently developed at the University of Liège and is presented in (Jean-François Demonceau, Cerfontaine, and Jaspart 2019). The proposed model is in full agreement with the component method philosophy (and so with the Eurocode philosophy) and is funded on a new assembly approach to account for the combined

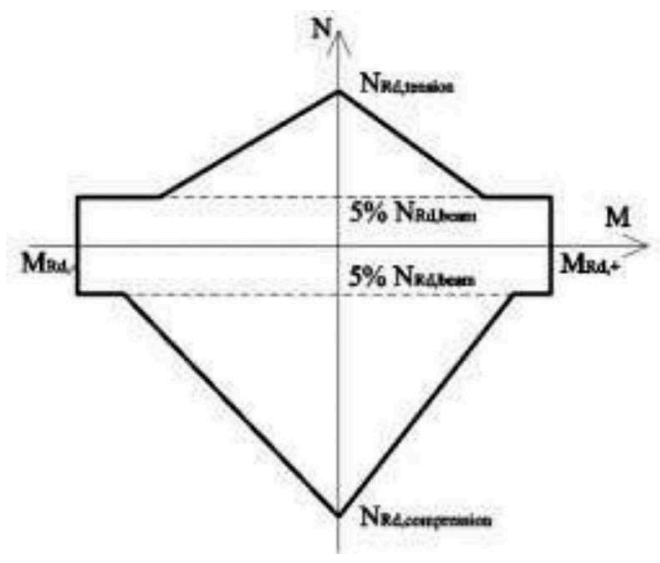

Figure 5. M-N resistant interaction curve proposed in Eurocode 3, Part 1-8 (Jean-François Demonceau, Cerfontaine, and Jaspart 2019). 
application of axial forces and moments on the joints. The applicability of the proposed model to steel and steel-concrete composite joints has been checked comparing the analytical predictions obtained with the model to experimental test results.

The validation of the model through comparisons to experimental test results obtained at the University of Stuttgart in the framework of a RFCS project (Kuhlmann et al. 2008) is illustrated in

Figure 6 . The five reported tests relate to a single joint configuration but have been realized so as to cover the "M-N" interaction domain, including sagging and hogging moments, but also axial tension forces.

On Figure 6, two analytically predicted curves are given:

- one named "plastic resistance curve" obtained using the actual elastic strengths of the materials and;

- one named "ultimate resistance curve" computed using the actual ultimate strengths of the materials.

Through this comparison, it can be seen that the analytical curves are in very good agreement with the experimental ones. Indeed, it appears that the experimental curves are between the plastic analytical resistance curves and the ultimate analytical resistance curves; this corresponds to the loading sequence followed during the tests.

On Figure 6, the curves which would have been obtained using the Eurocode 3 criterion reported in Figure 5 are also provided. It can be observed that the latter does not allow to accurately predict the experimental results; this confirms the inadequacy of the criterion presently proposed in the Eurocodes.

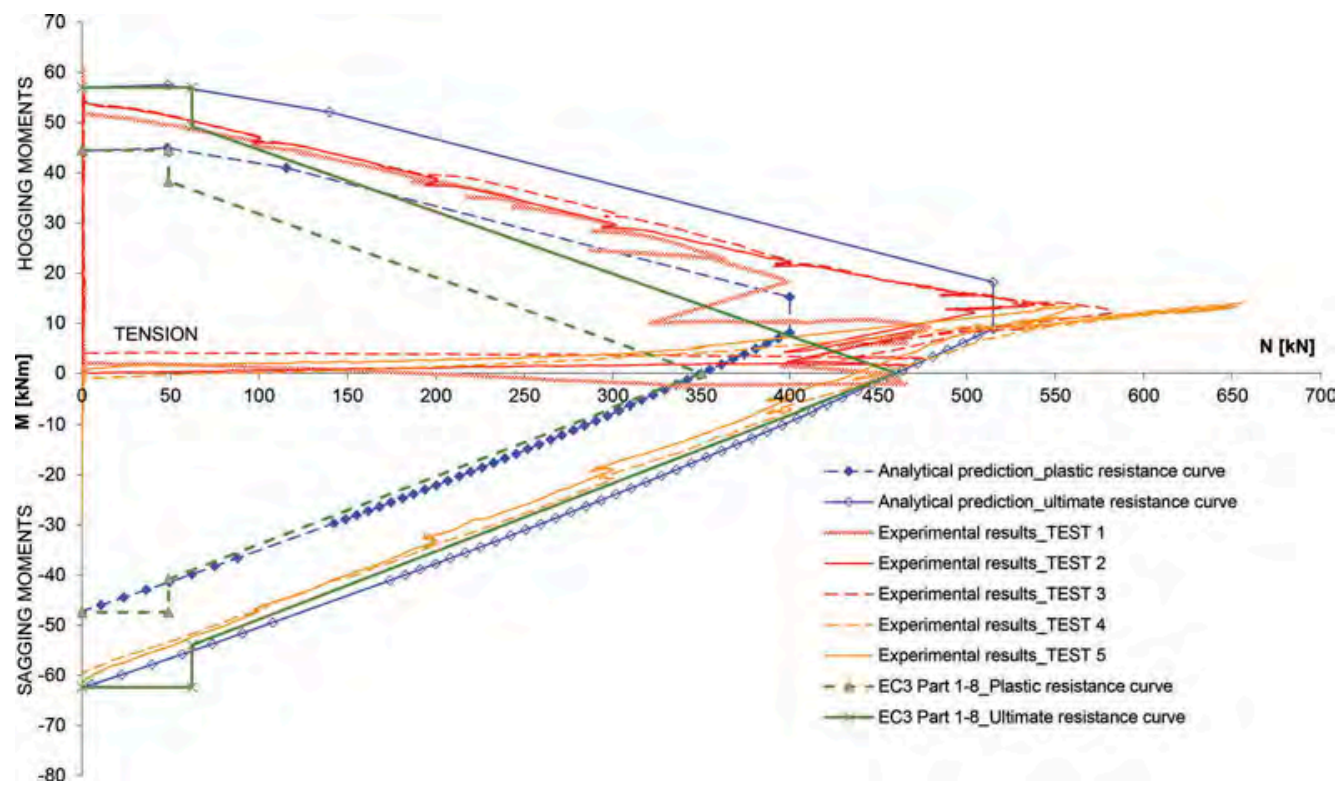

Figure 6. Comparison between the predicted analytical curves and the experimental ones (J. F. Demonceau, Cerfontaine, and Jaspart 2019). 


\section{COMPOSITE JOINTS AT ELEVATED TEMPERATURES}

In case of fire, joints can also be subjected to M-N interactions:

- bending and compression due to the dilatation of the members at the beginning of the fire and;

- bending and tension due to the development of membrane forces at the end of the fire when significant deformations and displacements are appearing.

But, in addition to these combined loadings, the joints are also subjected to elevated temperatures which affect their properties.

The characterization of composite joints under $\mathrm{M}-\mathrm{N}$ and at elevated temperature has been investigated in the framework of a European RFCS project called ROBUSTFIRE (J. Demonceau et al. 2012) dedicated to the investigation of the response of car parks subjected to a localized fire leading to a column loss. In particular, experimental tests on joints subjected to $\mathrm{M}-\mathrm{N}$ combinations and to elevated temperatures were conducted at the University of Coimbra. With the so-obtained test results, it was then possible to validate the adaptation of the model mentioned in the previous section to accurately predict the response of joints at elevated temperature (Haremza et al. 2016). This adaptation requires to predict first the temperatures of the different activated components and then to account for the effects of these temperatures on the component properties.

An example of comparisons between the analytical prediction and experimental results obtained for a composite joint subjected to a temperature of $700^{\circ} \mathrm{C}$ is provided in Figure 7 . The accuracy of the proposed model prediction can be observed.

\section{BEHAVIOUR OF COMPOSITE JOINTS UNDER CYCLIC LOADING}

According to Eurocode 8, Part 1 (EN 1998-1 2004), the seismic design of composite structures is based on the concept of dissipative structures, in which specific zones of the structures are identified and designed to develop plastic deformations in order to dissipate the seismic energy. In moment resisting frames, the beam extremities are generally used as dissipative zones, and the beam-to-column joints are designed in order to resist to the internal forces associated to the development of plastic hinges at the beam extremities. However, such an approach may lead to quite expensive joint solutions, mainly due to the fact that the possible overstrength and strain hardening effects developing in the dissipative zones have to be taken

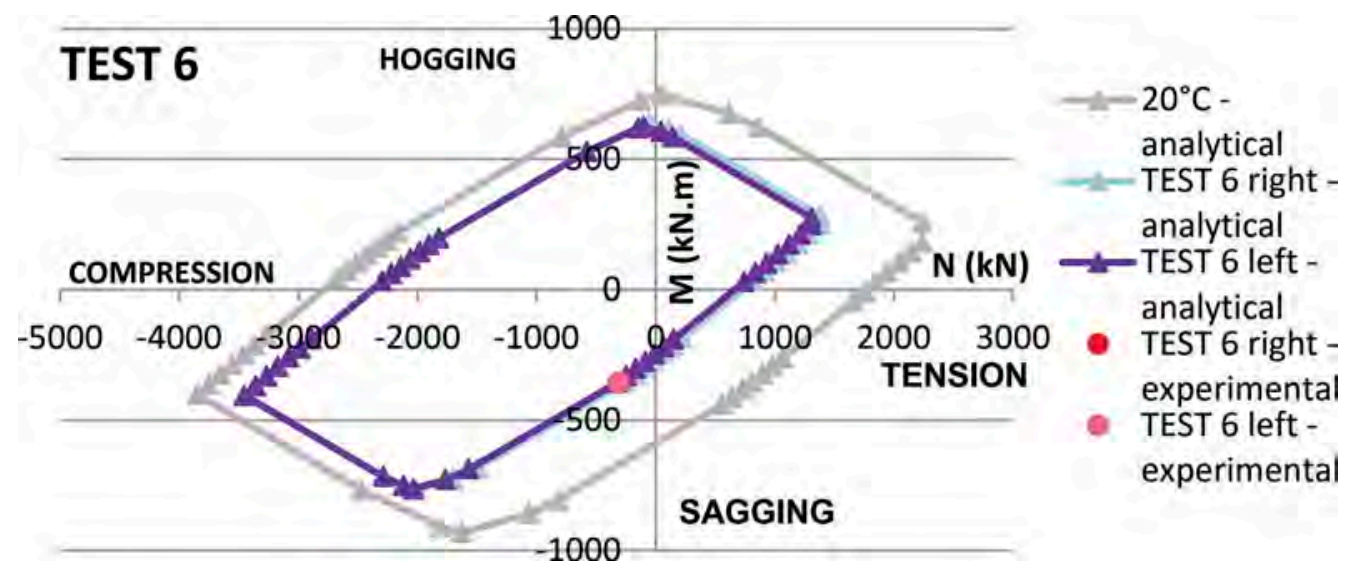

Figure 7. Double-sided composite joint at $700^{\circ} \mathrm{C}$ - Analytical prediction vs. experimental results (Haremza et al. 2016). 
into account when designing the non-dissipative zones. EN 1998-1 allows the use of partialstrength joints as dissipative zones but, in this case, the ductility and the dissipation capacity of the joints should be demonstrated by means of experimental tests, which is not realistic for practical projects.

Through different recent researches, the ability of composite joints in dissipating the seismic energy through an appropriate level of ductility has been investigated, mainly through experimental investigations ((Braconi, Elamary, and Salvatore 2010; Ciutina, Aribert, and Lachal 2004; Lee and Lu 1989; Dubina, Ciutina, and Stratan 2002; Ferrario 2004) amongst other). Through these investigations, it has been demonstrated that it is possible to reach the level of rotation capacity under cyclic loading as required in Eurocode 8, Part 1, to dissipate sufficient energy at the joint level, i.e. $35 \mathrm{mRad}$ for high seismic zone. This requires to ensure the activation of ductile joint components at yielding such as the end-plate in bending or the column flange in bending but also the rebars in tension using Class $\mathrm{C}$ rebars.

For steel joints, a step further has already been achieved through the outcome of the EQUALJOINTS RFCS project which aimed at prequalifying steel joints for seismic actions (Landolfo et al. 2018a, 2018b). Through this project, different beam-to-column steel joint configurations have been prequalified and sophisticated and simplified design procedures have been provided and will be proposed for codification in the European standards. Such a procedure could also be contemplated for the prequalification of composite joints in the future.

\section{BEHAVIOUR OF COMPOSITE JOINTS UNDER DYNAMIC LOADING}

The design for robustness of a structure may also include the consideration of dynamic actions such as impact or explosion. These dynamic actions can induce dynamic effects within the structure and, in particular, at the level of the joints. The behavior of joints under impact has been the topic of recent researches ((Barata et al. 2016; D'Antimo et al. 2018; Santos et al. 2020; Ribeiro et al. 2015; Keller 2019; Jean-François Demonceau et al. 2017) amongst other). In particular, the dynamic response of composite joints subjected to dynamically applied combined axial forces and bending moments was experimentally investigated in (Keller 2019).

Through these researches, it has been demonstrated that significant strain rate effects can develop at the level of some joint components and can significantly influence the joint properties in terms of resistance and ductility. In particular, the resistance exhibited by the joint appears to be improved under dynamic loading when compared to its static response while the ductility appears to be more limited.

The component method could be adapted to predict the joint properties under dynamic loading if the strain rates is appropriately accounted for as demonstrated in (Santos et al. 2020). But the main encountered difficulty is the prediction of the strain rates developing in the different basic components, strain rates which is different for each of them. The prediction of the strain rates can be performed through the development of sophisticated FEM models as illustrated, for instance, in (Santos et al. 2020; D'Antimo 2020) but the use of such tools is of course not appropriate for the daily practice of design engineers. So, there is still a need for developing simplified approaches allowing predicting with a sufficient accuracy the strain rates developing within a joint subjected to a dynamic loading. This is a topic of investigation which is still ongoing in different institutions.

\section{DUCTILITY OF COMPOSITE JOINTS}

For steel and composite joints, very few information is provided in the Eurocodes which would enable the designer to check whether enough plastic rotational capacity is locally available. However, the estimation of this property is crucial when partial strength joints are used, in particular when it is intended to activate the yielding of the joints to allow plastic redistributions within the structure or to dissipate energy in case of seismic actions. 
In (J. P. Jaspart, Corman, and Demonceau 2019), a procedure to estimate the rotation capacity of joints is presented using the component method approach. The application of this procedure requires, first, the estimation of the ultimate resistance of the joint $M_{R u}$ and, second, the estimation of the post-yielding stiffness $S_{j, s t}$. With these two properties, it is possible to predict the post-yielding behaviour of the joint and so to predict the rotation capacity defined here as the rotation corresponding to the ultimate resistance $\mathrm{M}_{\mathrm{Ru}}$. The application of this procedure is illustrated in Figure 4 to predict the part of the analytical curve after point A. In this figure, it can be observed that a good prediction of the ultimate resistance and of the post-yielding stiffness of the joint is obtained for TEST 3 while it is not the case for TEST 2. The difference observed for TEST 2 is due to a premature failure of the component "concrete slab in compression" due to a lack of ductility occurring for a joint rotation of $29 \mathrm{mRad}$. This highlight the fact that the application of the proposed procedure required the mastering of the ductility of the basic component which is not yet the case for the newly identified "concrete slab in compression" component.

An alternative to the accurate prediction of the rotation capacity is the proposal of design criteria to ensure a sufficient joint ductility for specific requirements. As previously mentioned, it is the strategy which is adopted in the Eurocodes which are proposing such criteria to allow for plastic analyses with plastic hinges forming at the level of partial strength joints. Such criteria have also been derived in (Rölle and Kuhlmann 2014) to ensure a sufficient ductility at the level of partial strength joint in case of column loss scenario. However, such criteria are not yet available to cover the different joint configurations and loading conditions that a designer could met in practice.

The ductility of joints and, in particular, of composite joints is still a topic of investigations and studies are still progressing with the objective (i) to provide a good prediction of the ductility of at a local level, i.e. at the level of the component and (ii) to provide an appropriate assembly procedure to predict the global joint ductility and that for different loading conditions (quasi-static, cyclic, dynamic...).

\section{CONCLUSIONS}

Even if the scope of the present draft of the Eurocodes and, in particular, of Eurocode 4, Part $1-1$, is limited to beam-to-column composite joints subjected to hogging moments, it has been demonstrated through the global overview proposed in this paper that recent research outcomes allow to go far beyond this limitation and to cover a lot of other loading conditions that the practitioners have to account for in their design approach, considering the request in terms of seismic performance, of fire design or of design for robustness. This offers very interesting perspectives for possible improvement and development of the future draft of the Eurocodes!

\section{REFERENCES}

Anderson, D. 1999. "Composite Steel-Concrete Joints in Frames for Buildings: Design Provisions." COST C1 - Semi-Rigid Behaviour of Civil Engineering Structural Connections.

Barata, Pedro, Aldina Santiago, João P.C. Rodrigues, and Constança Rigueiro. 2016. "Development of an Experimental System to Apply High Rates of Loading." International Journal of Structural Integrity 7 (2): 291-304.

Bitar, D., S. Caramelli, W. Salvatore, F. Taucer, J.-P. Jaspart, J.-F. Demonceau, M. Haller, et al. 2006. Applicability of Composite Structures to Sway Frames. Edited by Office for Official Publications of the European Communities.

Braconi, Aurelio, Ahmed Elamary, and Walter Salvatore. 2010. "Seismic Behaviour of Beam-to-Column Partial-Strength Joints for Steel-Concrete Composite Frames." Journal of Constructional Steel Research 66 (12): 1431-44.

Bursi, O., F. Ferrario, M. Haller, T. Lennon, L. Bianco, R. Mallardo, J.-F. Demonceau, et al. 2008. Prefabricated Composite Beam-to-Concrete Filled Tube or Partially Reinforced-Concrete-Encased Column Connections for Severe Seismic and Fire Loadings. Edited by European commission. 
Cerfontaine, Fréderic. 2003. "Etude de l'interaction Entre Moment de Flexion et Effort Normal Dans Les Assemblages Boulonnés." University of Liège.

Ciutina, A., J.M. Aribert, and A. Lachal. 2004. "Expérimentation et Modélisation Numérique Du Comportement d'assemblages Boulonnés Métalliques et Mixtes Acier-Béton Sous Sollicitations Cycliques de Type Sismique." Construction Métallique Journal, 3-34.

D’Antimo, M., M. Latour, G. Rizzano, J.-F. Demonceau, and J.-P. Jaspart. 2018. "Preliminary Study on Beam-to-Column Joints under Impact Loading." Open Construction and Building Technology Journal 12. https://doi.org/10.2174/1874836801812010112.

D’Antimo, Marina. 2020. "Impact Characterization of Innovative Seismically Designed Connections for Robustness Application." PhD Thesis Presented at the University of Liège.

Demonceau, J.-F. 2008. "Steel and Composite Building Frames: Sway Response under Conventional Loading and Development of Membrane Effects in Beams Further to an Exceptional Action." https:// orbi.uliege.be/handle/2268/2740.

Demonceau, J.-F., and J.-P. Jaspart. 2010. "Experimental Test Simulating a Column Loss in a Composite Frame." Advanced Steel Construction 6 (3).

Demonceau, J.-F., J.-P. Jaspart, R. Klinkhammer, K. Weynand, F. Labory, and L.-G. Cajot. 2008. "Recent Developments on Composite Connections." Steel Construction 1: 71-76.

Demonceau, Jean-François, Fréderic Cerfontaine, and Jean-Pierre Jaspart. 2019. "Resistance of Steel and Composite Connections under Combined Axial Force and Bending Including Group Effects: Analytical Procedures and Comparison with Laboratory Tests." Journal of Constructional Steel Research 160: 320-31. https://doi.org/10.1016/j.jcsr.2019.05.030.

Demonceau, Jean-François, Hélène Vanvinckenroye, Marina D'Antimo, Vincent Denoel, and Jean-Pierre Jaspart. 2017. "Beam-to-Column Joints, Column Bases and Joint Components under Impact Loading." Proceedings of the Eurosteel 2017 Conference 1 (2-3): 3890-99. https://doi.org/10.1002/cepa.445.

Demonceau, Jean-François, and Adrian Ciutina. 2019. "Characterisation of Beam-to-Column Steel-Concrete Composite Joints Beyond Current Eurocode Provisions.” Structures 21 (max 10): 167-75. https://doi.org/10.1016/j.istruc.2019.01.014.

Demonceau, Jean-François, Clara Huvelle, Ludivine Comeliau, Long Van Hoang, Jean-Pierre Jaspart, Cheng Fang, Bassam Izzuddin, et al. 2012. Robustness of Car Parks against Localised Fire. European Commission.

Dubina, Dan, Adrian Liviu Ciutina, and Aurel Stratan. 2002. "Cyclic Tests on Bolted Steel and Composite Double-Sided Beam-to-Column Joints." Steel and Composite Structures 2 (2): 147-60. https://doi. org/10.12989/scs.2002.2.2.147.

EN 1993-1-8. 2010. Design of Steel Structures. Part 1.8: Design of Joints. Edited by CEN. Brussels, Belgium.

EN 1994-1-1. 2004. Eurocode 4: Design for Composite Steel and Concrete Structures - Part 1-1: General Rules and Rules for Buildings. Edited by CEN. Brussels, Belgium.

EN 1998-1. 2004. Eurocode 8: Design of Structures for Earthquake Resistance - Part 1: General Rules, Seismic Actions and Rules for Buildings. Edited by CEN.

Ferrario, Fabio. 2004. "Analysis and Modelling of the Seismic Behaviour of High Ductility SteelConcrete Composite Structures." University of Trento.

Gao, Shan, Man Xu, Feng Fu, and Lanhui Guo. 2019. "Performance of Bolted Steel-Beam to CFST-Column Joints Using Stiffened Angles in Column-Removal Scenario." Journal of Constructional Steel Research 159: 459-75. https://doi.org/10.1016/j.jcsr.2019.05.011.

Haremza, C., A. Santiago, J.-F. Demonceau, J.-P. Jaspart, and L.S. Da Silva. 2016. "Composite Joints under M-N at Elevated Temperatures." Journal of Constructional Steel Research 124. https://doi.org/ 10.1016/j.jcsr.2016.05.012.

Jaspart, J.-P., and K. Weynand. 2016. Design of Joints in Steel and Composite Structures. Edited by ECCS Eurocode Design Manual. Wiley, Ern.

Jaspart, J. P., A. Corman, and J. F. Demonceau. 2019. "Ductility Assessment of Structural Steel and Composite Joints." Stability and Ductility of Steel Structures - Proceedings of the International Colloquia on Stability and Ductility of Steel Structures, 2019, 564-69.

Keller, Nadine. 2019. "Robustheit von Stahl- Und Verbundrahmen Durch Gezielte Knotenausbildung." University of Stuttgart.

Kuhlmann, U., L. Rölle, J.-P. Jaspart, J.-F. Demonceau, O. Vassart, K. Weynand, C. Ziller, et al. 2008. Robust Structures by Joint Ductility. Edited by European Commission.

Landolfo, Raffaele, Roberto Tartaglia, Silvia Costanzo, Jean-Pierre Jaspart, Aurel Stratan, Dominiq Jaka, Dan Dubina, Ahmed Elghazouli \& Dan Bompa. 2018a. EQUALJOINTS+: Volume with Pre-normative Design Recommendations for Seismically Qualified Steel Joints. Edited by ECCS European Convention for Constructional Steelwork. ECCS. ECCS - European Convention for 
Constructional Steelwork. https://www.steelconstruct.com/wp-content/uploads/DWP2-3_EJplus_FI NAL_v2-compressed.pdf.

Landolfo, R., D’Aniello, M., Tartaglia, R., Costanzo, S., Demonceau, J.-F., Jaspart, J.-P., Stratan, A., Jaka, D., Dubina, D., Elghazouli, A. \& Bompa D. 2018b. EQUALJOINTS+: Volume with Pre-normative Design Recommendations for Seismically Qualified Steel Joints. ECCS - European Convention for Constructional Steelwork. https://www.steelconstruct.com/wp-content/uploads/DWP2-3_EJplus_FI NAL_v2-compressed.pdf.

Lee, Seung Joon, and Le Wu Lu. 1989. "Cyclic Tests of Full-Scale Composite Joint Subassemblages." Journal of Structural Engineering (United States) 115 (8): 1977-98. https://doi.org/10.1061/(ASCE) 0733-9445(1989)115:8(1977).

Liew, R.J.Y., T.H. Teo, and N.E. Shanmugam. 2004. "Composite Joints Subject to Reversal of Loading Part 2: Analytical Assessments.” Journal of Constructional Steel Research, 247-68.

Piluso, Vincenzo, Gianvittorio Rizzano, and Immacolata Tolone. 2012. "An Advanced Mechanical Model for Composite Connections under Hogging/Sagging Moments." Journal of Constructional Steel Research 72: 35-50. https://doi.org/10.1016/j.jcsr.2011.10.001.

Ribeiro, João, Aldina Santiago, Constança Rigueiro, and Luís Simões Da Silva. 2015. "Analytical Model for the Response of T-Stub Joint Component under Impact Loading." Journal of Constructional Steel Research 106: 23-34.

Rodrigues, M.C., L.R.O. De Lima, S.A.L. De Andrade, P.C.G. da S. Vellasco, and J.G.S. Da Silva. 2010. "Numerical Analysis of Endplate Beam-to-Column Joints under Bending and Axial Force." Proceedings of the 4th Internation Conference on Steel \& Composite Structures.

Rölle, Lars, and Ulrike Kuhlmann. 2014. "Vereinfachtes Bemessungsverfahren Geschraubter Teiltragfähiger Stahl- Und Verbundknoten.” Stahlbau 83 (9): 614-25. https://doi.org/10.1002/stab.201410197.

Santos, Ana Francisca, Aldina Santiago, Massimo Latour, Gianvittorio Rizzano, and Luís Simões da Silva. 2020. "Response of Friction Joints under Different Velocity Rates." Journal of Constructional Steel Research 168. https://doi.org/10.1016/j.jcsr.2020.106004.

Simões Da Silva, L., and A. M. Girão Coelho. 2001. "Analytical Evaluation of the Response of Steel Joints under Bending and Axial Force." Computers and Structures 79 (8): 873-81. https://doi.org/ 10.1016/S0045-7949(00)00179-6.

Weynand, Klaus. 1999. "Frames, Column Bases in Steel BuildingNo Title." COST C1 - Semi-Rigid Behaviour of Civil Engineering Structural Connections. 


\title{
Stainless steel structures - research, codification and practice
}

\author{
L. Gardner \& F. Walport \\ Imperial College London, London, UK
}

\begin{abstract}
This paper provides a summary of recent developments in research, codification and design practice surrounding the structural use of stainless steel, with an emphasis on structural stability. Stainless steel has a nonlinear material response and this directly influences the structural behaviour. Guidance on material nonlinearities in international design standards largely relates to the occurrence of traditional idealised plastic hinges, as seen in carbon steel structures. However, such hinges do not form in stainless steel structures. Design codes provide the design framework that structural engineers use to demonstrate structural safety. With stainless steel being a high value material, its efficient use is paramount, and this is a particular incentive to embrace the opportunities offered by advanced system-level analysis and design. The most accurate representation of the behaviour of a structure is achieved by directly allowing for instability, plasticity, residual stresses and initial geometric imperfections in a second order inelastic analysis. This paper presents an overview of recent developments in the stability design of stainless steel structures, due to be included in upcoming revisions of prEN 1993-1-4, AISC 370 and ASCE-8; inclusion of these new provisions for advanced analysis in these codes represents a huge opportunity for enabling more widespread application of stainless steel in structural applications. Recent applications of stainless steel in practice are also presented herein and, with a view to the future, opportunities for the application of advanced design and construction methods to stainless steel structures are explored.
\end{abstract}

\section{INTRODUCTION}

Stainless steel is a high-performance construction material that is synonymous with modern, resilient and sustainable construction. There is a wide variety of grades to suit a range of applications and demands. The initial cost of stainless steel is relatively high compared to carbon steel (typically 3-5 times); it is therefore particularly important that design codes make efficient use of the material properties based on a comprehensive understanding of the structural response and embrace advanced design methods that may deviate from traditional approaches. Increased availability and sophistication of advanced computational tools is transforming the landscape of structural design. Advanced analysis allows for more efficient, more accurate and safer design as well as the potential for more optimised design solutions.

Stainless steel has a nonlinear material response and this directly influences the structural behaviour. It is important that this is reflected in design methodologies to enable the safe and efficient assessment and design of stainless steel structures. Design codes provide the design framework that structural engineers use to demonstrate structural safety. As structural systems become more complex, the shortcomings of the current design standards become more marked, requiring an increased level of idealisation and design assumptions. Eurocode 3 is currently under revision and a new version of each part, including EN 1993-1-4 (prEN 1993$1-4,2020)$ for the design of stainless steel structures, is due for publication in about 2023. Work is also currently ongoing on the preparation of the first American design standard for 
hot-rolled and welded stainless steel construction, AISC 370 (AISC, 2020). These codes closely mirror their carbon steel counterparts (AISC, 2016; prEN 1993-1-1, 2020), but deviate where necessary to account for the differences in material behaviour between stainless steel and carbon steel and the resulting influence on structural behaviour (SCI, 2020; Baddoo \& Francis, 2014; SCI, 2017). Additionally, new codified provisions for the design of steel and stainless steel structures by finite element (FE) analysis are in preparation for the upcoming prEN 1993-1-14 (prEN 1993-1-14, 2019); this will include detailed rules for FE analysis, material models, including a two-stage Ramberg-Osgood material model (Arrayago, Real \& Gardner, 2015) for stainless steel and cold-formed steel (Gardner \& Yun, 2018), equivalent bow imperfections for inelastic analysis (Walport, Gardner \& Nethercot, 2020b) and CSM strain limits, enabling design by second order inelastic analysis to be carried out. The current absence of appropriate guidance on system-based design is a barrier to the optimal use of stainless steel in construction. These new international design provisions will enable the more accurate and sophisticated design of stainless steel structures, promoting their wider use in practice.

In this paper, the material stress-strain response of stainless steel is first discussed as this is fundamental to developing an understanding of the structural response at the cross-section, member and frame levels. With an emphasis on frame level design, Sections 3 and 4 provide an overview of the key developments introduced above for the stability design of stainless steel structures in prEN 1993-1-4 and AISC 370, respectively. In Section 5, recent applications of stainless steel in practice are presented and, with a view to the future, opportunities for the application of advanced design and construction methods to stainless steel structures are explored. Finally conclusions are drawn in Section 6.

\section{MATERIAL NONLINEARITY}

An accurate description of the material behaviour is crucial for the reliable assessment of a structural system. If material nonlinearity is considered in the global analysis of a frame, greater deflections ensue due to the loss of material stiffness (Walport et al., 2019; Walport, Gardner \& Nethercot, 2019; Gardner, 2019) and, neglecting the effects of material nonlinearity can result in over-predictions of system strength (Walport, Gardner \& Nethercot, 2020b).

Stainless steel differs significantly from carbon steel in that its stress-strain curve is characterised by a rounded response with no sharply defined yield point. A number of material models have been developed to describe this nonlinear stress-strain behaviour, with the most widely used based on the basic Ramberg-Osgood formulation, as modified by Hill (Ramberg \& Osgood, 1943; Hill, 1944). While this formulation provides an accurate representation for the degree of nonlinearity in certain regions of the stress-strain curve, depending on the choice of the strain hardening exponent, it does not, in general, provide an accurate representation of the full curve. This has led to the development of some two-stage Ramberg-Osgood models, notably by (Mirambell \& Real, 2000; Rasmussen, 2003; Gardner \& Nethercot, 2004; Gardner \& Ashraf, 2006; Arrayago, Real \& Gardner, 2015).

The modified Ramberg-Osgood model, given in Equations (1) and (2), where $\varepsilon$ and $\sigma$ are the strain and stress respectively, $f_{\mathrm{y}}$ is the yield $(0.2 \%$ proof $)$ stress, $E$ is the Young's modulus, $f_{\mathrm{u}}$ is the ultimate stress, $E_{\mathrm{y}}$ is the tangent modulus at the yield $(0.2 \%$ proof $)$ stress, defined by Equation (3), $\varepsilon_{\mathrm{u}}$ is the ultimate strain, and $n$ and $m$ are the strain hardening exponents, is currently provided in EN 1993-1-4 (EN 1993-1-4:2006 + A1:, 2015) and the Fourth Edition of the Design Manual for Structural Stainless Steel (SCI, 2017).

$$
\begin{gathered}
\varepsilon=\frac{\sigma}{E}+0.002\left(\frac{\sigma}{f_{y}}\right)^{n} \text { for } \sigma \leq f_{y} \\
\varepsilon=0.002+\frac{f_{y}}{E}+\frac{\sigma-f_{y}}{E_{y}}+\varepsilon_{u}\left(\frac{\sigma-f_{y}}{f_{u}-f_{y}}\right)^{m} \text { for } f_{y}<\sigma \leq f_{u}
\end{gathered}
$$




$$
E_{y}=\frac{E}{1+0.002 n \frac{E}{f_{y}}}
$$

An alternative form of the second stage is given by Equation (4), where $\varepsilon_{0.2}$ is the total strain at the $0.2 \%$ proof stress, equal to $0.002+f_{\mathrm{y}} / E$, which provides increased accuracy in the region of the ultimate stress, particularly for less ductile materials e.g. ferritic stainless steels; this is the model due to be included in the upcoming prEN 1993-1-14 (prEN 1993-1-14, 2019).

$$
\varepsilon=\varepsilon_{0.2}+\frac{\sigma-f_{y}}{E_{y}}+\left(\varepsilon_{u}-\varepsilon_{0.2}-\frac{f_{u}-f_{y}}{E_{y}}\right)\left(\frac{\sigma-f_{y}}{f_{u}-f_{y}}\right)^{m} \quad \text { for } \quad f_{y}<\sigma \leq f_{u}
$$

The two-stage Ramberg-Osgood expression has also been applied to the modelling of stainless steel material behaviour at elevated temperature (Gardner et al., 2010), where the second strain hardening exponent $m$ (denoted $m_{\theta}$ at elevated temperature) can be defined explicitly with reference to the strength at $2 \%$ strain $\sigma_{2, \theta}$, the value of which is provided in structural fire design standards including EN 1993-1-2 (EN 1993-1-2, 2005). The elevated temperature stressstrain curve is forced to pass through $\sigma_{2, \theta}$ at $2 \%$ strain by defining $m$ in the following manner (Liang et al., 2019), where symbols are as previously defined with $\theta$ denoting elevated temperature:

$$
m_{\theta}=\frac{\ln \left(\frac{\varepsilon_{u, \theta}}{0.02-\varepsilon_{0.2, \theta}-\frac{\sigma_{2, \theta^{-}} \sigma_{0,2, \theta}}{E_{0.2, \theta}}}\right)}{\ln \left(\frac{\sigma_{u, \theta}-\sigma_{0.2, \theta}}{\sigma_{2, \theta}-\sigma_{0.2, \theta}}\right)}
$$

\section{STABILITY DESIGN OF STAINLESS STEEL STRUCTURES IN EUROCODE 3}

EN 1993-1-4 gives supplementary guidance for the design of stainless steel structures that complements the design rules given for carbon steel in EN 1993-1-1. The supplementary rules for stainless steel currently give no additional information for the global analysis of stainless steel structures. The guidance on material nonlinearities in EN 1993-1-1 largely relates to the occurrence of traditional idealised plastic hinges, as seen in carbon steel structures. However, such hinges do not form in stainless steel structures; instead zones of plasticity with gradually reducing stiffness, but often with peak capacities well in excess of the traditional plastic moment are exhibited (Theofanous et al., 2014). Eurocode 3 is currently under revision; this section summarises the key changes to the codified provisions for the stability design of stainless steel structures due to be included in prEN 1993-1-4 (prEN 1993-1-4, 2020).

\subsection{Material nonlinearity at frame level}

Degradation of stiffness significantly affects the behaviour of a structural system and consequently, the distribution of internal forces and moments (Walport, Gardner \& Nethercot, 2019). Figure 1 shows the ratio of moments from first order and second order plastic zone analyses using the two-stage Ramberg Osgood material model of an austenitic stainless steel portal frame plotted against the ratio of the secant modulus $E_{\mathrm{s}}$ to elastic modulus $E$ of the most heavily stressed point of the frame for increasing load levels (Walport et al., 2021). Depending on the location in the frame, ignoring material nonlinearity can result in both over-estimations and under-estimations of internal forces and moments. When the ratio of $E_{\mathrm{s}} / E$ is less than 0.2 , these errors approach $10 \%$; therefore, Equation 6 , where $E_{\mathrm{s}}$ is the secant modulus as calculated using Equation 7, is proposed to define the limit beyond which members in the frame are deemed to remain predominantly elastic. 


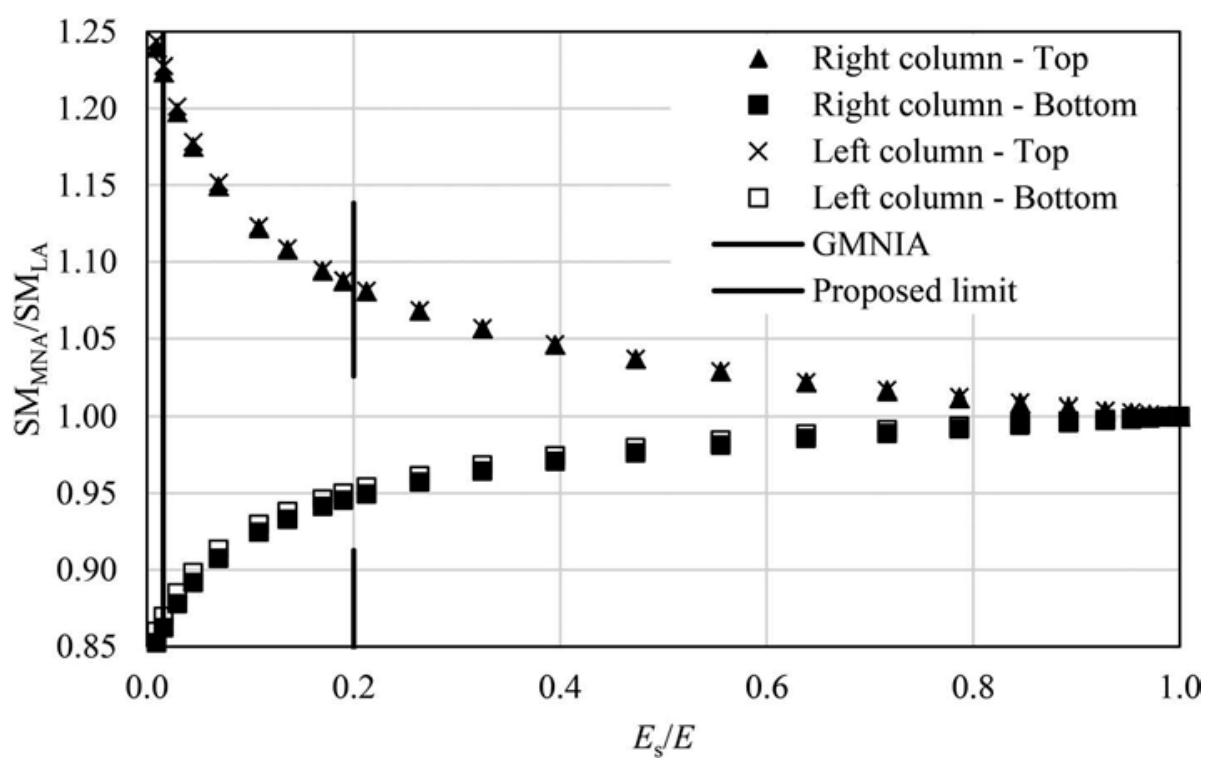

Figure 1. Ratio of internal moments from a plastic $\left(\mathrm{SM}_{\mathrm{MNA}}\right)$ and elastic $\left(\mathrm{SM}_{\mathrm{LA}}\right)$ analysis around the frame for an example $5 \times 10 \mathrm{~m}$ austenitic stainless steel portal frame plotted against the ratio of secant modulus $E_{\mathrm{s}}$ to elastic modulus $E$ at the most heavily stressed point in the frame.

$$
\begin{gathered}
\frac{E_{s}}{E}>0.2 \text { for elastic analysis } \\
E_{s}=\frac{E}{1+0.002 \frac{E}{\sigma}\left(\frac{\sigma}{f_{y}}\right)^{n}}
\end{gathered}
$$

Considering geometric nonlinearities at the frame level, EN 1993-1-1 (prEN 1993-1-1, 2020) and other international steel design standards state that second order effects may be neglected provided $\alpha_{\mathrm{cr}, \mathrm{sw}}$ is greater than or equal to 10 when an elastic analysis is employed, with $\alpha_{\mathrm{cr}, \mathrm{sw}}$ being the factor by which the design loading on a frame has to be increased to cause overall buckling in a global sway mode. The nonlinear stress-strain behaviour of stainless steel results in greater deformations as the material loses its stiffness and, therefore, a greater susceptibility to second order effects (Walport et al., 2019); a stricter requirement is therefore needed for plastic analysis. The influence of material nonlinearity on the sway stiffness of frames may be

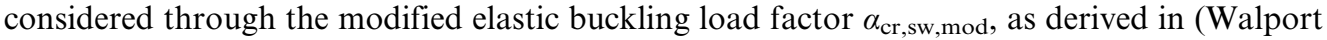
et al., 2019; Walport, Gardner \& Nethercot, 2019; Walport et al., 2021), and given by Equation 8 , where $K_{\mathrm{s}} / K$ is the ratio of the secant lateral stiffness of the frame $K_{\mathrm{s}}$ at the design value of the load to the initial lateral stiffness $K$ due to the influence of plasticity (i.e. as obtained from a first order plastic zone analysis) and $\mathrm{Y}$ is a factor that approximates the further loss of stiffness due to second order effects, taken from Table 1 (Walport et al., 2021).

$$
\alpha_{c r, s w, \bmod }=\frac{K_{s}}{K} Y \alpha_{c r, s w}
$$

The method provides a consistent treatment of second order effects between elastic and plastic global analysis i.e. a limit of 10 on both $\alpha_{\mathrm{cr}}$ and $\alpha_{\mathrm{cr} \text {,mod }}$, deeming second order effects sufficiently small to be ignored if the amplification of the internal forces is no more than $10 \%$ of the original internal forces determined according to first order theory. 


\begin{tabular}{lll}
\hline & $\begin{array}{l}\text { For single storey } \\
\text { portal frames }\end{array}$ & $\begin{array}{l}\text { For all } \\
\text { other frames }\end{array}$ \\
\hline Austenitic stainless steel & 0.80 & 0.55 \\
Duplex stainless steel & 0.85 & 0.60 \\
Ferritic stainless steel & 0.90 & 0.65 \\
\hline
\end{tabular}

\subsection{Design by inelastic analysis}

The most accurate representation of the behaviour of a structure is achieved through directly allowing for instability, plasticity, residual stresses and initial geometric imperfections through the use of second order (advanced) inelastic analysis with imperfections (i.e. GMNIA). The combined influence of residual stresses and geometric imperfections can be accounted for through the use of equivalent bow imperfections, as discussed in Section 3.2.1. Advanced analysis is commonly carried out using beam finite elements for ease of use and computational efficiency but these elements cannot capture local cross-section deformations. While shell finite elements are able to capture cross-section local buckling behaviour, they are computationally expensive. A practical solution is to use beam elements, with strain limits applied to simulate local buckling and control the level of plastic deformation and hence the capacity of the cross-section and ultimately the structure. In this approach (Fieber, Gardner \& Macorini, 2020, 2019; Walport, Gardner \& Nethercot, 2020a), the influence of material nonlinearity on the structural response is directly modelled through the definition of the full stress-strain curve of the material, while the strain limits, as defined by Equations (9) and (10), are taken from the continuous strength method (CSM), as further detailed in Section 3.2.2. Failure of the member/system is defined as the point at which either (1) the CSM strain limit is reached at any point in the system or (2) the peak load is attained during the analysis, whichever occurs first (Walport et al., 2019).

$$
\begin{gathered}
\frac{\varepsilon_{c s m}}{\varepsilon_{y}}=\frac{0.25}{\bar{\lambda}_{p}^{3.6}}+\frac{0.002}{\varepsilon_{y}} \quad \text { but } \leq \Omega \quad \text { for } \quad \bar{\lambda}_{p} \leq 0.68 \\
\frac{\varepsilon_{c s m}}{\varepsilon_{y}}=\left(1-\frac{0.222}{\bar{\lambda}_{p}^{1.05}}\right) \frac{1}{\bar{\lambda}_{p}^{1.05}}+\frac{0.002\left(\sigma / f_{y}\right)^{n}}{\varepsilon_{y}} \text { for } \quad 0.68<\bar{\lambda}_{p} \leq 1.0
\end{gathered}
$$

where $\bar{\lambda}_{p}=\sqrt{f_{y} / \sigma_{c r, c s}}$ is the local slenderness of the full cross-section, where $f_{\mathrm{y}}$ is the yield (or $0.2 \%$ proof) stress and $\sigma_{\text {cr,cs }}$ is the elastic local buckling stress of the full cross-section (Gardner, Fieber \& Macorini, 2019), $\varepsilon_{\mathrm{y}}$ is the yield strain, $\varepsilon_{\mathrm{u}}$ is the ultimate strain, $\sigma$ is the maximum compressive stress at the considered cross-section, $n$ is the strain hardening exponent and $\Omega$ is a project specific design parameter defining the permissible level of plastic deformation, with a recommended value of 15 to prevent excessive deformation (Fieber, Gardner \& Macorini, 2019).

The design approach enables consistent and accurate exploitation of cross-section slenderness dependent levels of spread of plasticity, moment redistribution and strain hardening. Additionally, the continuous nature of the approach allows all cross-sections (i.e. those of all cross-section classes) to be designed in the same way. Design by inelastic analysis with strain limits allows for safe and reliable assessment of structures while maintaining computational efficiency and practicality for widespread use in industry. 


\subsubsection{Equivalent bow imperfections}

Direct modelling of residual stresses in an analysis can present challenges to the designer and is not possible in many software packages; EN 1993-1-1 therefore provides 'equivalent' bow imperfections that implicitly account for the combined effects of geometric and material (i.e. residual stresses) imperfections. The equivalent bow imperfections given in prEN 1993-1-1 are for use with second order elastic analysis. These tabulated equivalent imperfections apply equally to second order elastic analysis of stainless steel members, provided the appropriate value of $\alpha$ is employed, though, due to the limiting slenderness in the stainless steel buckling curves not being a constant value, a revised equation, replacing the constant 0.2 with $\bar{\lambda}_{0}$, for back calculating the equivalent bow imperfection is needed, as given by Equation 11 (Walport, Gardner \& Nethercot, 2020b), where $\alpha$ is the imperfection factor, $\bar{\lambda}$ is the relative slenderness of the member, $\bar{\lambda}_{0}$ is the limiting relative slenderness and $M_{\mathrm{Rk}}$ and $N_{\mathrm{Rk}}$ are the characteristic value of the moment and axial resistance, respectively.

$$
e_{0}=\alpha\left(\bar{\lambda}-\bar{\lambda}_{0}\right) \frac{M_{R k}}{N_{R k}}
$$

It is generally not appropriate to use equivalent bow imperfections developed for elastic analysis in inelastic analyses, because the effects of plasticity can be double-counted and overpredictions (i.e. unconservative results) or under-predictions (i.e. conservative results) of buckling resistances can arise, depending on the form of the adopted material stress-strain curve (Walport, Gardner \& Nethercot, 2020b). For design by second order inelastic analysis, equivalent bow imperfection magnitudes may be calculated using Equation 12, where $L$ is the member length.

$$
\frac{e_{0}}{L}=\alpha \beta=\frac{\alpha}{150} \quad \text { but } \quad \frac{e_{0}}{L} \geq \frac{1}{1000}
$$

\subsubsection{The continuous strength method}

An elastic perfectly-plastic material model and the associated concept of cross-section classification underpin current metallic structural design codes. To overcome the shortcomings for application to materials that exhibit a high degree of nonlinearity and strain hardening, the continuous strength method was developed as a more rational alternative to cross-section classification (Gardner, 2008). The implications of the rounded stressstrain curve of stainless steel are that Class 4 cross-sections experience inelastic local buckling below the $0.2 \%$ proof stress while Class $1-3$ cross-sections can benefit from the substantial strain hardening exhibited by stainless steel beyond the $0.2 \%$ proof stress. Depending on the type and proportions of the structural element or system, the nonlinear material response can lead to either a reduced or enhanced capacity relative to an equivalent component featuring an elastic, perfectly plastic material response (Gardner, 2019; Walport, Gardner \& Nethercot, 2020b). In general, in strength governed scenarios, such as the in-plane bending resistance of stocky beams, the substantial strain hardening of stainless steel gives rise to capacity benefits, while in stability governed scenarios, the early onset of stiffness degradation results in reduced capacity.

The continuous strength method (CSM) is a deformation based design approach (Gardner, 2008; Gardner, Wang \& Liew, 2011; Afshan \& Gardner, 2013; Liew \& Gardner, 2015; Buchanan, Real \& Gardner, 2018; Zhao, Afshan \& Gardner, 2017) that enables a rational exploitation of the spread of plasticity, strain hardening and element interaction in the design of stainless steel cross-sections. The benefit of considering element interaction is greatest for cross-sections where the slenderness of the flange and web differ most, while the capacity increase from strain hardening is of most benefit for more compact cross-sections and for the materials exhibiting the highest level of hardening i.e. the austenitic grades. The strain limits also control the level of moment redistribution, the benefit of which depends on the 
proportions, loading and degree of indeterminacy in the structure. The magnitude of all these benefits will vary between structures but can be very significant and often up to $30 \%$.

\section{STABILITY DESIGN OF STAINLESS STEEL STRUCTURES IN AISC 370}

The new AISC 370 Specification (AISC, 2020) will encompass the design, fabrication and erection of hot-rolled and welded austenitic and duplex stainless steel structures. The provisions closely mirror AISC 360 (AISC, 2016), but deviate where necessary to account for the differences in material behaviour between stainless steel and carbon steel and the resulting influence on structural behaviour (Baddoo \& Francis, 2014; SCI, 2013). In AISC 370 (AISC, 2020), the influence of material nonlinearity and residual stresses can be accounted for in stability design by either (1) performing an elastic analysis but with reduced stiffness in the members or (2) performing an inelastic analysis. In the former case, the relative simplicity of elastic analysis is retained, while in the latter case, more accurate results are achieved.

\subsection{Second order elastic analysis with stiffness reduction}

Design by elastic analysis with stiffness reduction has been developed and widely used for carbon steel structures (Deierlein, 2003; Surovek-Maleck \& White, 2004a, 2004b). More recently, this method of design has been extended to the design of stainless steel structures (Walport, Kucukler \& Gardner, 2021) and is due to be incorporated into the upcoming AISC 370 (AISC, 2020) and ASCE-8 (ASCE, 2020) Specifications.

For design by second order elastic analysis, two stiffness reduction factors are defined: (1) $\tau_{\mathrm{b}}$, to account for the reduction in stiffness of members in compression due to the effects of yielding and residual stresses, and (2) $\tau_{\mathrm{g}}$, to account for the additional reduction in member stiffness due to combined compression plus bending. Additionally, for slender members, the $\tau_{\mathrm{g}}$ factor results in a system design strength equal to $\tau_{\mathrm{g}}$ times the elastic stability limit, which is equivalent to the margin of safety provided by the column buckling curves (Deierlein, 2003).

The proposed stiffness reduction factor $\tau_{\mathrm{b}}$ for stainless steel, accounting for the combined effects of material nonlinearity and residual stresses, was derived directly from the RambergOsgood expression, given by Equation 1. The stiffness reduction factor $\tau_{\mathrm{b}}$ was taken as the ratio of the tangent modulus $E_{\mathrm{t}}$ to the elastic modulus $E$, where $E_{\mathrm{t}}=d \sigma / d \varepsilon$ and $\sigma=P_{\mathrm{r}} / A$, where $P_{\mathrm{r}}$ is the axial compression and $A$ is the cross-sectional area. To allow for the influence of residual stresses, the strain hardening exponent $n$ was modified to an effective strain hardening exponent $n_{\text {eff }}$ through calibration against FE results for the tangent flexural stiffness obtained from a W8 $\times 31$ cross-section divided into 1440 monitoring areas, subjected to pure axial compression. The resulting stiffness reduction factor to account for the reduction in stiffness of stainless steel members in compression due to the effects of yielding and residual stresses is given by Equation 13, where $P_{\mathrm{r}}$ is the applied axial load, $P_{\mathrm{ns}}$ is the yield load and $f_{\mathrm{y}}$ is the yield stress, while the values of the effective strain hardening exponents $n_{\text {eff }}$ are presented in Table 2.

$$
\tau_{b}=\frac{1}{1+0.002 n_{e f f} \frac{E}{f_{y}}\left(\frac{P_{r}}{P_{n s}}\right)^{n_{e f f}-1}}
$$

Since $n_{\text {eff }}$ is a function of $n$, the varying degrees of roundedness of the stress-strain behaviour, as shown in Figure 2 for the typical grades of stainless steel (austenitic grade 301, duplex grade S32101 and ferritic grade 410S) is reflected in $\tau_{\mathrm{b}}$. The greatest reduction at low to moderate axial load levels occurs for austenitic stainless steel, mirroring the low limit of proportionality and the low value of the strain hardening exponent $n$.

Walport, Kucukler \& Gardner (2021), calibrated $\tau_{\mathrm{g}}$ against benchmark results from nonlinear finite element analysis of pin-ended stainless steel columns, beams and beam-columns, 
Table 2. Stiffness reduction factors $\tau$ for second order elastic analysis of stainless steel structures.

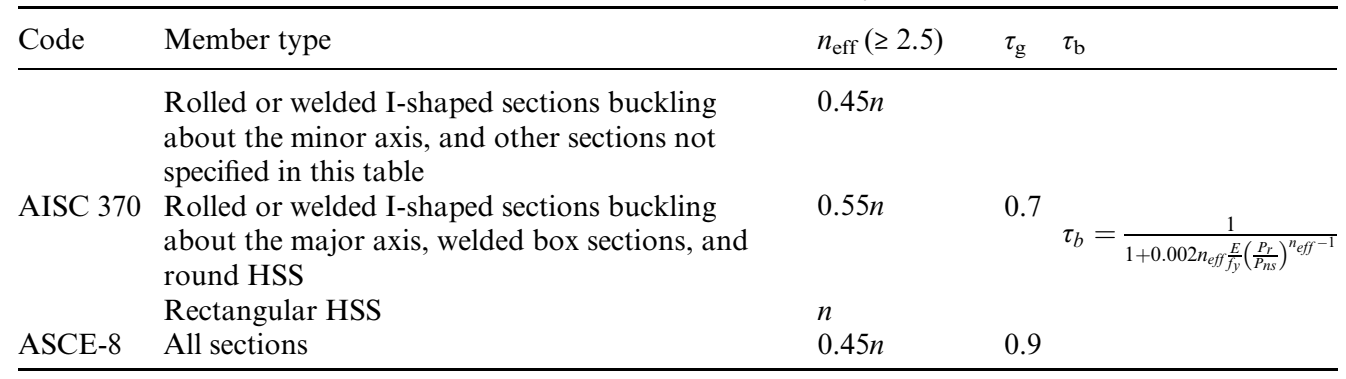

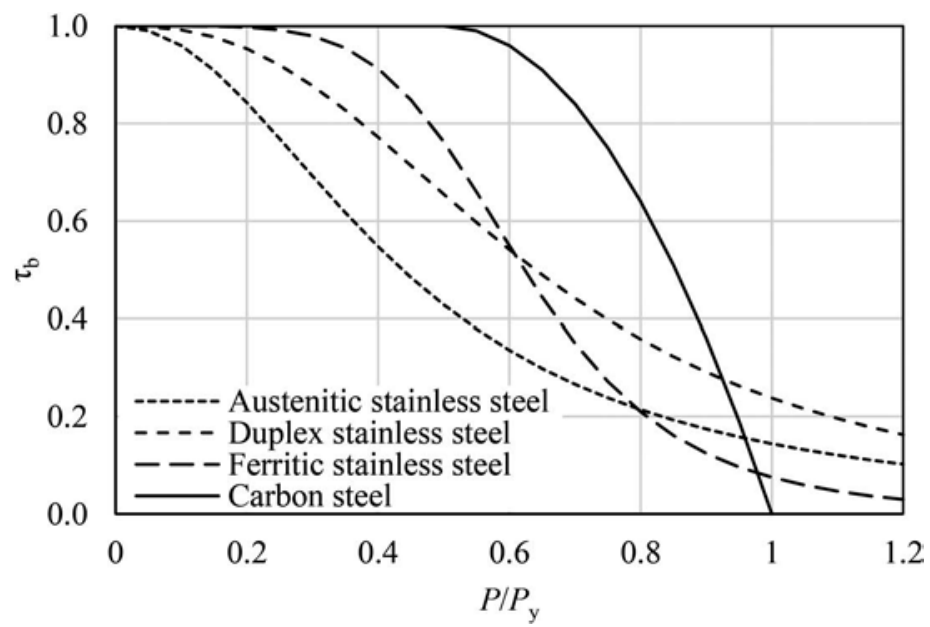

Figure 2. Stiffness reduction factor $\tau_{\mathrm{b}}$ for typical austenitic, duplex and ferritic grades of stainless steel for I-shaped sections buckling about the minor axis in AISC 370 and for all sections in ASCE-8.

as well as sample frames. For AISC 370 and ASCE-8, values of 0.7 and 0.9 are required to sufficiently account for the influence of plasticity, respectively. The difference between the proposed value of $\tau_{\mathrm{g}}$ for AISC 370 and ASCE- 8 reflects the different cross-section forcemoment interaction equation, the different column buckling curves and the different moment capacities between the two codes.

\subsection{Second order inelastic analysis}

As in prEN 1993-1-4, the most accurate representation of the behaviour of a structure is achieved through directly allowing for instability, plasticity, residual stresses and initial geometric imperfections through the use of second order (advanced) inelastic analysis with imperfections - see Section 3.2.

\section{PRACTICE}

With the growing need for sustainable and resilient structures, the use of high performance materials such as stainless steel, with its excellent durability characteristics, could help meet these future demands. Stainless steel has been used in construction since the 1920s; the earlier applications were predominantly chosen based on architectural appeal, for example in the cladding of the Chrysler Building in New York, while more contemporary applications take 
a)

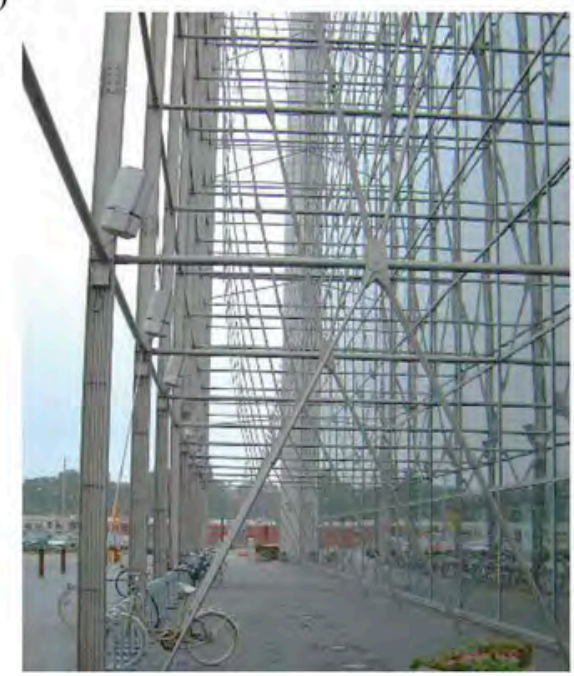

b)

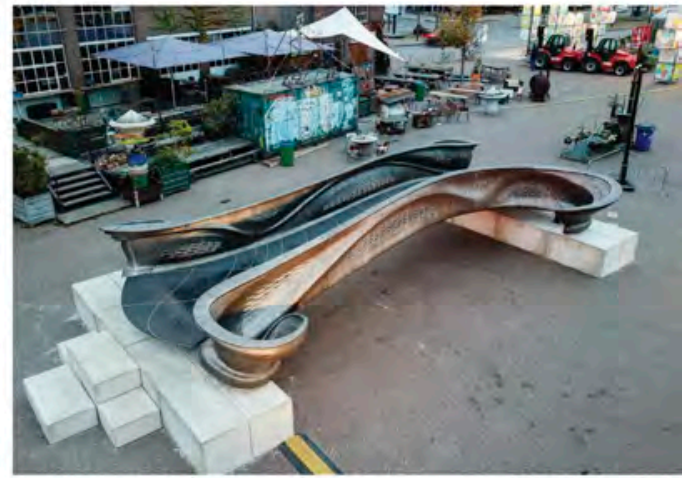

Figure 3. Recent examples of the use of structural stainless steel in practice. a) Sanomatalo Building, Helsinki; b) MX3D bridge at Dutch Design Week. 2018.

advantage of the desirable durability and structural properties, two examples of which are shown in Figure 3, including the Sanomatalo Building in Helsinki, in which stainless steel was used to form an exterior bracing system (Figure 3a).With a drive for more sustainable construction, the opportunities for the increased use of stainless steel is clear and this is reflected in the annual consumption of stainless steel increasing at a compound growth rate far in excess of other materials (Baddoo, 2008). Further information of the use of stainless steel in construction and more examples of practical structural applications may be found in (Baddoo, 2008; Gardner, 2005; SCI, 2020).

Another emerging innovation in construction is metal 3D printing, also known as additive manufacturing (Gardner, 2019; Buchanan \& Gardner, 2019). Additive manufacturing allows for highly optimised structures and engineered materials unlike those that can be achieved using traditional fabrication methods. Early research into the behaviour of metal 3D printed structural elements has been reported in (Kyvelou et al., 2020) (Buchanan et al., 2017), while a review of the methods, research, applications, opportunities and challenges for this technology has been presented in (Buchanan \& Gardner, 2019). Wire and arc additive manufacturing (WAAM) has been used to create the world's first metal 3D printed bridge constructed by the Dutch company MX3D, as shown in Figure 3b (Gardner et al., 2020). Additive manufacturing offers many opportunities for the construction sector, but there will also be fresh challenges and demands. The verification of the MX3D bridge has involved a significant amount of material, cross-section and structural testing, alongside advanced finite element simulations. This is a pioneering example of the potential of additive manufacturing and a offers a new way of thinking for the design and verification of such structures.

Embracing the digital age will be fundamental for increased sustainability within the structural engineering industry and this will rely on greater emphasis on the use of advanced analysis, as well as inspection and load testing. Structural design is significantly dictated by the current state of design guidance; the current sparsity of appropriate guidance on system-based design and advanced analysis is a barrier to its use in achieving optimal design. It is essential to ensure that working in the digital world is comparable to the traditional well-established and widely accepted approaches in terms of accessibility, flexibility, complexity and productivity. This requires the novel system-level advanced analysis approaches to be embedded in the design environment through clear guidance. International codes of practice and design guides 
form the core of that design guidance; inclusion of these new methods in the upcoming design codes presents a step-change for the future direction of structural design.

\section{CONCLUSIONS}

The nonlinear material stress-strain curve of stainless steel has a direct bearing on the structural response of stainless steel cross-sections, members and frames. With stainless steel being a high value material, its efficient use is paramount, and this is a particular incentive to embrace the opportunities offered by advanced system-level analysis and design. The most accurate representation of the behaviour of a structure is achieved by directly allowing for instability, plasticity, residual stresses and initial geometric imperfections in a second order inelastic analysis, but there is limited guidance to enable design on this basis in practice. As described in the present paper, the new provisions for design by advanced analysis in the upcoming second generation of the Eurocodes and the new American design standards will address this shortcoming, representing a huge opportunity for enabling more efficient and more widespread application of stainless steel in structural applications.

\section{REFERENCES}

Afshan, S. \& Gardner, L. (2013) Experimental study of cold-formed ferritic stainless steel hollow sections. Journal of Structural Engineering ASCE. 139 (5), 717-728.

AISC (2016) AISC 360. Specification for Structural Steel Buildings. AISC.

AISC (2020) AISC 370. Specification for Structural Stainless Steel Buildings. Draft. AISC.

Arrayago, I., Real, E. \& Gardner, L. (2015) Description of stress-strain curves for stainless steel alloys. Materials and Design. 87, 540-552.

ASCE (2020) ASCE-8-20: Specification for the Design of Cold-Formed Stainless Steel Structural Members. ASCE.

Baddoo, N. \& Francis, P. (2014) Development of design rules in the AISC Design Guide for structural stainless steel. Thin-Walled Structures. 83, 200-208.

Baddoo, N.R. (2008) Stainless steel in construction: A review of research, applications, challenges and opportunities. Journal of Constructional Steel Research. 64 (11), 1199-1206.

Buchanan, C. \& Gardner, L. (2019) Metal 3D printing in construction: A review of methods, research, applications, opportunities and challenges. Engineering Structures. 180, 332-348.

Buchanan, C., Matilainen, V.P., Salminen, A. \& Gardner, L. (2017) Structural performance of additive manufactured metallic material and cross-sections. Journal of Constructional Steel Research. 136, 35-48.

Buchanan, C., Real, E. \& Gardner, L. (2018) Testing, simulation and design of cold-formed stainless steel CHS columns. Thin-Walled Structures. 130 (May), 297-312.

Deierlein, G. (2003) Background and Illustrative Examples on Proposed Direct Analysis Method for Stability Design of Moment Frames. Report on behalf of AISC TC 10. 1-17.

EN 1993-1-2 (2005) Eurocode 3: Design of steel structures - Part 1-2: General rules - Structural fire design. CEN.

EN 1993-1-4:2006 + A1: (2015) Eurocode 3 - Design of steel structures - Part 1-4: General rules - Supplementary rules for stainless steels. Brussels, CEN.

Fieber, A., Gardner, L. \& Macorini, L. (2019) Design of structural steel members by advanced inelastic analysis with strain limits. Engineering Structures. 199, 109624.

Fieber, A., Gardner, L. \& Macorini, L. (2020) Structural steel design using second-order inelastic analysis with strain limits. Journal of Constructional Steel Research. 168, 105980.

Gardner, L. (2019) Stability and design of stainless steel structures - Review and outlook. Thin-Walled Structures. 141, 208-216.

Gardner, L. (2008) The continuous strength method. Proceedings of the Institution of Civil Engineers Structures and Buildings. 161 (3), 127-133.

Gardner, L. (2005) The use of stainless steel in structures. Progress in Structural Engineering and Materials. 7 (2), 45-55.

Gardner, L. \& Ashraf, M. (2006) Structural design for non-linear metallic materials. Engineering Structures. 28 (6), 926-934. 
Gardner, L., Fieber, A. \& Macorini, L. (2019) Formulae for calculating elastic local buckling stresses of full structural cross-sections. Structures. 17, 2-20.

Gardner, L., Insausti, A., Ng, K.T. \& Ashraf, M. (2010) Elevated temperature material properties of stainless steel alloys. Journal of Constructional Steel Research. 66 (5), 634-647.

Gardner, L., Kyvelou, P., Herbert, G. \& Buchanan, C. (2020) Testing and initial verification of the world's first metal 3D printed bridge. Journal of Constructional Steel Research. 172, 106233.

Gardner, L. \& Nethercot, D.A. (2004) Experiments on stainless steel hollow sections — Part 1: Material and cross-sectional behaviour. Journal of Constructional Steel Research. 60 (9), 1291-1318.

Gardner, L., Wang, F. \& Liew, A. (2011) Influence of strain hardening on the behavior and design of steel structures. International Journal of Structural Stability and Dynamics. 11 (5), 855-875.

Gardner, L. \& Yun, X. (2018) Description of stress-strain curves for cold-formed steels. Construction and Building Materials. 189, 527-538.

Hill, H.N. (1944) Determination of Stress-Strain Relations from 'Offset' Yield Strength Values. Technical Note No.927, National Advisory Committee for Aeronautics.

Kyvelou, P., Slack, H., Daskalaki Mountanou, D., Wadee, M.A., et al. (2020) Mechanical and microstructural testing of wire and arc additively manufactured sheet material. Materials and Design. 192, 108675.

Liang, Y., Manninen, T., Zhao, O., Walport, F., et al. (2019) Elevated temperature material properties of a new high-chromium austenitic stainless steel. Journal of Constructional Steel Research. $152,261-273$.

Liew, A. \& Gardner, L. (2015) Ultimate capacity of structural steel cross-sections under compression, bending and combined loading. Structures. 1, 2-11.

Mirambell, E. \& Real, E. (2000) On the calculation of deflections in structural stainless steel beams: an experimental and numerical investigation. Journal of Constructional Steel Research. 54 (1), 109-133.

prEN 1993-1-1 (2020) Eurocode 3 - Design of steel structures - Part 1-1: General rules and rules for buildings. CEN. Final Draft.

prEN 1993-1-14 (2019) Eurocode 3 - Design of steel structures - Part 1-14: Design by FE analysis. CEN. Draft 1.

prEN 1993-1-4 (2020) Eurocode 3 - Design of steel structures - Part 1-4: General rules - Supplementary rules for stainless steels. CEN. Draft 2.

Ramberg, W. \& Osgood, W. (1943) Description of stress-strain curves by three parameters. Technical Note No. 902, National Advisory Committee For Aeronautics. http://hdl.handle.net/2060/19930081614.

Rasmussen, K.J.R. (2003) Full-range stress-strain curves for stainless steel alloys. Journal of Constructional Steel Research. 59 (1), 47-61.

SCI (2017) Design Manual for Structural Stainless Steel Design. Fourth Edition. SCI Publication No. P413. UK, The Steel Construction Institute.

SCI (2020) prDG27. Draft 2.

SCI (2013) Structural Stainless Steel - AISC DG27. AISC. 159.

Surovek-Maleck, A.E. \& White, D.W. (2004a) Alternative Approaches for Elastic Analysis and Design of Steel Frames. I: Overview. Journal of Structural Engineering ASCE. 130 (8), 1186-1196.

Surovek-Maleck, A.E. \& White, D.W. (2004b) Alternative approaches for elastic analysis and design of steel frames. II: Verification studies. Journal of Structural Engineering ASCE. 130 (8), 1197-1205.

Theofanous, M., Saliba, N., Zhao, O. \& Gardner, L. (2014) Thin-Walled Structures Ultimate response of stainless steel continuous beams. Thin Walled Structures. 83, 115-127.

Walport, F., Arrayago, I., Gardner, L. \& Nethercot, D.A. (2021) Assessment and treatment of second order effects in plastically-design stainless steel frames. Journal of Constructional Steel Research. (In preparation).

Walport, F., Gardner, L. \& Nethercot, D.A. (2019) A method for the treatment of second order effects in plastically-designed steel frames. Engineering Structures. 200, 109516.

Walport, F., Gardner, L. \& Nethercot, D.A. (2020a) Design of structural stainless steel members by second order inelastic analysis with CSM strain limits. Thin-Walled Structures. in press, 107267.

Walport, F., Gardner, L. \& Nethercot, D.A. (2020b) Equivalent bow imperfections for use in design by second order inelastic analysis. Structures. 26, 670-685.

Walport, F., Gardner, L., Real, E., Arrayago, I., et al. (2019) Effects of material nonlinearity on the global analysis and stability of stainless steel frames. Journal of Constructional Steel Research. 152, 173-182.

Walport, F., Kucukler, M. \& Gardner, L. (2021) Stability design of stainless steel structures. Journal of Structural Engineering ASCE. Submitted for publication.

Zhao, O., Afshan, S. \& Gardner, L. (2017) Structural response and continuous strength method design of slender stainless steel cross-sections. Engineering Structures. 140, 14-25. 


\title{
Testing, modelling and design of bolted joints - effect of size, structural properties, integrity and robustness
}

\author{
A. Kozlowski \\ Rzeszow University of Technology, Rzeszow, Poland \\ P. Kawecki \\ Civil Engineering Office Mostostal Co., Warsaw, Poland \\ D. Kukla \\ Inzynieria Rzeszow SA, Rzeszow, Poland \\ K. Ostrowski \\ MTA Engineering, Rzeszow, Poland
}

\begin{abstract}
Research activities aiming at understanding selected items of steel joints behavior in the persistent and accidental situation has been conducted at Rzeszow University of Technology. The following subjects were considered: the behavior of beam splices of beams in large size steel industrial structures and especially the assessment of safety to use the component method of EN 1993-1-8 to design such joints; the role of joints in assurance survival of steel-framed structures subjected to accidental loading, especially influence of joints geometrical and material properties on their behavior in column loss scenario; estimation of actual values of available rotation capacity of selected steel joints, to be used in robustness analysis of steel frames. An investigation was provided by experimental tests of bolted end-plate joints, advanced FEA with the use of validated models, and wide parametric studies. Results of the above-mentioned researches can find application in design practice.
\end{abstract}

\section{INTRODUCTION}

Joints, in the same range as members, have a decisive influence on steel structures' safety and economy. Proper shaping, design calculation, and appropriate details arrangement in technical drawings play an essential role in providing competitiveness, long-time exploitation, failure-free solution. During the last decade's very large experimental, theoretical, and fine element modeling researches were conducted to provide modern design tools to practitioners. Many of these findings were incorporated to design codes, as (EN 1993-1-8 2005). Despite this, still exist few gaps in regulation provisions. A few of them, which are the subject of research projects and doctoral dissertation conducted at Rzeszow University of Technology, are presented below. The following subjects will be described:

- behavior of joints in large-scale steel structures, i.e. influence of the size of the joints designed according to (EN 1993-1-8 2005) on the structure safety,

- behavior of steel-framed structures under exceptional loading condition (robustness) and the role of joint in counteraction against the progressive collapse of the structure,

- quantitative assessment of rotation capacity of joints, while in (EN 1993-1-8 2005) only qualitative rules are available. 


\section{BEHAVIOUR OF JOINTS IN LARGE-SCALE STEEL STRUCTURES}

The component method used in the standard (EN 1993-1-8 2005) has been developed for joints in framed building structures, where usually bolted end-plate connections are used, with two-three rows of bolts located in the vicinity of the tensioned flange of the beam (Figure 1a). The members of such frames were made of IPE sections with a height of not more than 400$450 \mathrm{~mm}$, very often of class 1 or 2 . Numerous experimental tests of such joints confirm the adequacy of the component method for such frame joints. In the case of higher beams, especially those with a plate welded girder cross-section $\left(h_{b}=1000-2000 \mathrm{~mm}\right)$, connected by endplate splices with many bolt rows (Figure 1b), the standard (EN 1993-1-8 2005) methods fail, especially with regard to the distribution of internal forces in individual bolt rows, when assessing the resistance (see 6.2.7.2 (EN 1993-1-8 2005)).

Calculations of the design moment resistance of joints with several bolt rows are performed according to the component method using the formula:

$$
M_{j, R d}=\sum h_{r} \cdot F_{t r, R d}
$$

where: $F_{t r, R d}$ - the effective design tension resistance of bolt row $r, h_{r}$ - the distance from bolt row $r$ to the center of compression, $r$ - the bolt row number.

Only limitation to including in formula (1) all bolt rows with their full resistance, is:

- $\mathrm{T}<\mathrm{C}$ and/or $\mathrm{S}$; the resistance of the tension zone must be smaller than the resistance of compression and/or shear zone, and

- linear reduction of bolt row resistance acc. to (2) when the effective design tension resistance $F_{t x, R d}$ of one of the previous bolt rows $x$ is greater than $1.9 F_{t, R d}$ :

$$
F_{t r, R d} \leq F_{t x, R d} h_{r} / h_{x}
$$

where $h_{x}$ - the distance from bolt row $x$ to the center of compression, $x_{i}$ - the bolt row farthest from the center of compression that has a design tension resistance greater than $1.9 F_{t, R d}$.

This calculation method has not been changed in the current update of the standard (EN 1993-1-8 2005).

Comparison of sizes of bolted end-plate joints used for hot-rolled member section, typical for building structures and, welded I girders used in industrial structures is shown in Figure 1.

Many doubts and questions, coming from designers, were raised, if component method as in code (EN 1993-1-8 2005) is appropriate (safe) for large-size structure joints? In the opinion of professional engineers and few researchers, the answer for this question is not, because:

- the component method presented in (EN 1993-1-8 2005) in relation to joints of high beams is not confirmed by an experimental test of such joints - only a few tests of large size joints $\left(h_{b}>1000 \mathrm{~mm}\right.$ ) were conducted (Morrison et al. 1985), (Borgsmiller et al.1995), (Ryan 1999), (Sumner 2003), (Katula 2009), (Jain 2015) but most of them with only 2 - 3 bolt rows below tension flange,

- steel beams of large height are designed as composed welded girders, very often of class 4 section for web, where the transmission of forces down from tensioned beam flange through the very thin web is very doubtful,

- distribution of forces in particular bolt rows along beam height is not in conformity with stress distribution in the beam section.

Research project (Kawecki 2021) has been conducted in Rzeszow University of Technology, as follows:

- experimental tests of four beam splices of beam $1000 \mathrm{~mm}$ and $1500 \mathrm{~mm}$ high (Kawecki \& Kozlowski 2020),

- creation of fine element method joint models, hierarchically validated, 


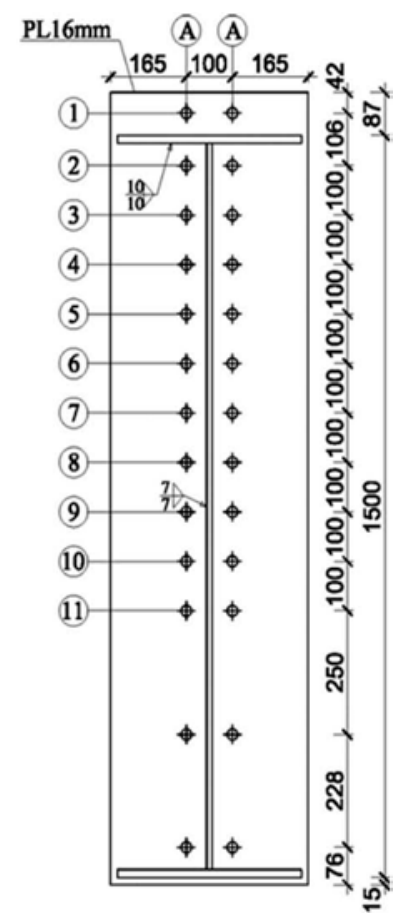

Figure 1. Comparison of size of end-plate bolted joints, for a) rolled sections, b) welded section.

- parametric study to investigate the influence of other factors, e.g. end-plate thickness, steel grade, stiffening of the joints,

- verification of component method (EN 1993-1-8 2005) by comparison its results to experimental tests and parametric study results,

- proposal to improve component method procedures to be safe for large size beam joints.

Experimental tests were conducted for the following joints, shown in Figure 2.

Tests were performed in the Laboratory of Building Structures at Rzeszow University of Technology. View and picture of test stand were presented in Figure 3.

The following quantities were measured during tests: the strains along the bolt axis, the strains in the tension flange of the beam and in the web near the bolts, the strain in the compression flange, the separation of the end plates, the mid-span deflection of the beam and under the jacks. More details of test results can be found in (Kawecki \& Kozlowski 2020). Only selected of them are presented below. The distribution of forces in each bolt, obtained during experiments on the basis of measurement of bolt strains by strain gauges are shown in Figure 4. From Figure 4 it is seen that the distribution of forces in the particular bolt rows is not equal on the beam height. Also the moment resistance of the joint $M_{j, R k}$ determined by the component method is much bigger than reached during experimental tests.

Table 1 presents the values of actual forces in each bolt row, obtained on the basis of measurements of strains in bolts during tests, obtained from FEA analysis with the use of validated FEM models and values calculated using the component method from code (EN 1993-1-8 2005).

Figure 5 shows the distribution of forces in individual bolt rows $F_{t, R k, i}$, calculated according to the component method (EN 1993-1-8 2005), experimental tests $F_{t, i}$, FEM calculation $F_{t, i, m e s}$ for connection W2-1, and for comparison FEM results taking into account end-plate of $14 \mathrm{~mm}$ thickness.

Results presented in Figure 5 and Table 1 for joint W2-1 (end-plate thickness $16 \mathrm{~mm}$ ) confirm the conclusion that the distribution of bolt forces calculated acc. to code (EN 1993-1-8 2005 ) is very far away from obtaining in experiment and FEA, especially in lower bolt rows. 
W2-1

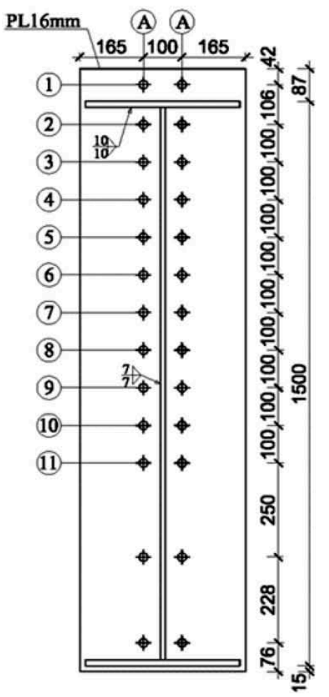

W1-1

PL16mm (C)B(A) (A) B) 45
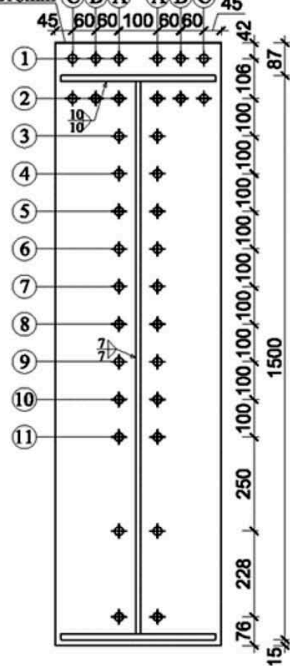

W3-1

PL20mm (B) (A) B

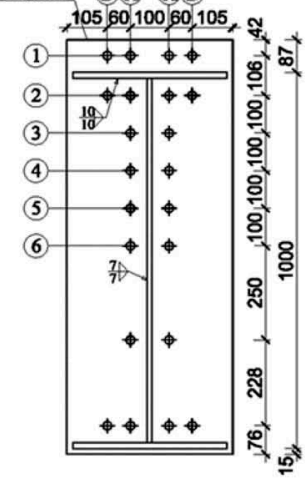

W3-2

PL16mm (B) A (A)

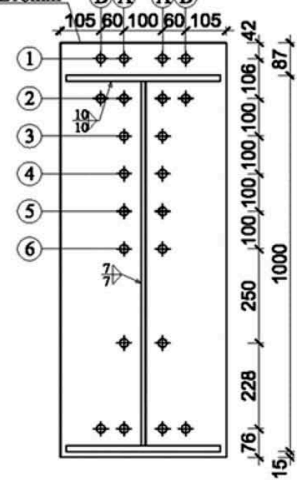

Figure 2. Experimentally tested joints.

Table 1. Comparison of actual bolt forces distribution obtained in tests and from FEA with values calculated acc. to the component method (EN 1993-1-8 2005).

\begin{tabular}{lllll}
\hline & & \multicolumn{2}{c}{$\mathrm{W} 2-1$} \\
\cline { 3 - 5 } & & $\mathrm{EXP}$ & $\mathrm{FEA}$ & $\mathrm{EC} 3$ \\
\cline { 3 - 5 } Bolt row number & $h_{i}[\mathrm{~m}]$ & $\mathrm{F}_{\mathrm{T}, \mathrm{i}}$ & $F_{T, i \text { mes }}$ & $\mathrm{F}_{\mathrm{T}, \mathrm{Rk}, \mathrm{i}}$ \\
\hline 1 & 1.537 & 362.8 & 417.2 & 380.1 \\
2 & 1.431 & 499.6 & 499.4 & 470.5 \\
3 & 1.331 & 281.2 & 246.6 & 344.4 \\
4 & 1.231 & 199.3 & 211.6 & 344.4 \\
5 & 1.131 & 174.1 & 176.8 & 344.4 \\
6 & 1.031 & 148.8 & 145.6 & 344.4 \\
7 & 0.931 & 104.6 & 117.2 & 344.4 \\
8 & 0.831 & 73.6 & 91.6 & 344.4 \\
9 & 0.731 & 67.1 & 68.6 & 0 \\
10 & 0.631 & 49.3 & 50 & $M_{j, R k}=3795$ \\
\hline 1 & 0.531 & 35.9 & 42.8 & 1.82 \\
\hline Moment resistance $[\mathrm{kNm}]$ & \multicolumn{5}{c}{$M_{B, k}=2090$} & $M_{B, k, m e s}=2124.5$ & 1.79 \\
\hline$M_{j, R k} / M_{B, k}$ & & & &
\end{tabular}

The same joint with the end-plate thickness $14 \mathrm{~mm}$ shows behavior much closer to test and FEA results. This is because T-stubs in joint with end-plate $14 \mathrm{~mm}$ show failure mode 1 while joints with end-plate $16 \mathrm{~mm}$ failure mode 2. That means that the component method as in code (EN 1993-1-8 2005) can be used for high beam splice only when T-stubs in all bolt rows show failure mode 1 . 
a)

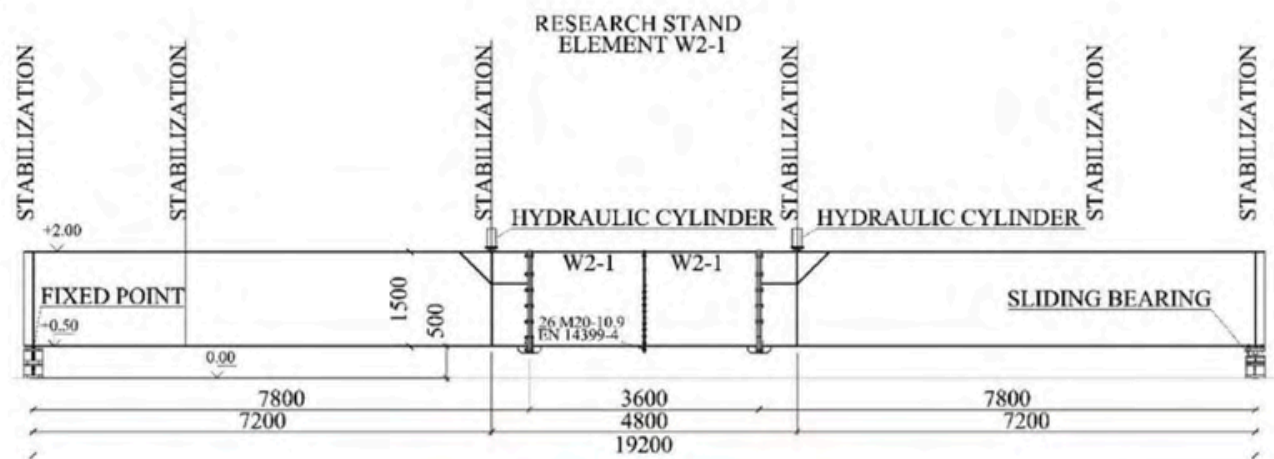

b)

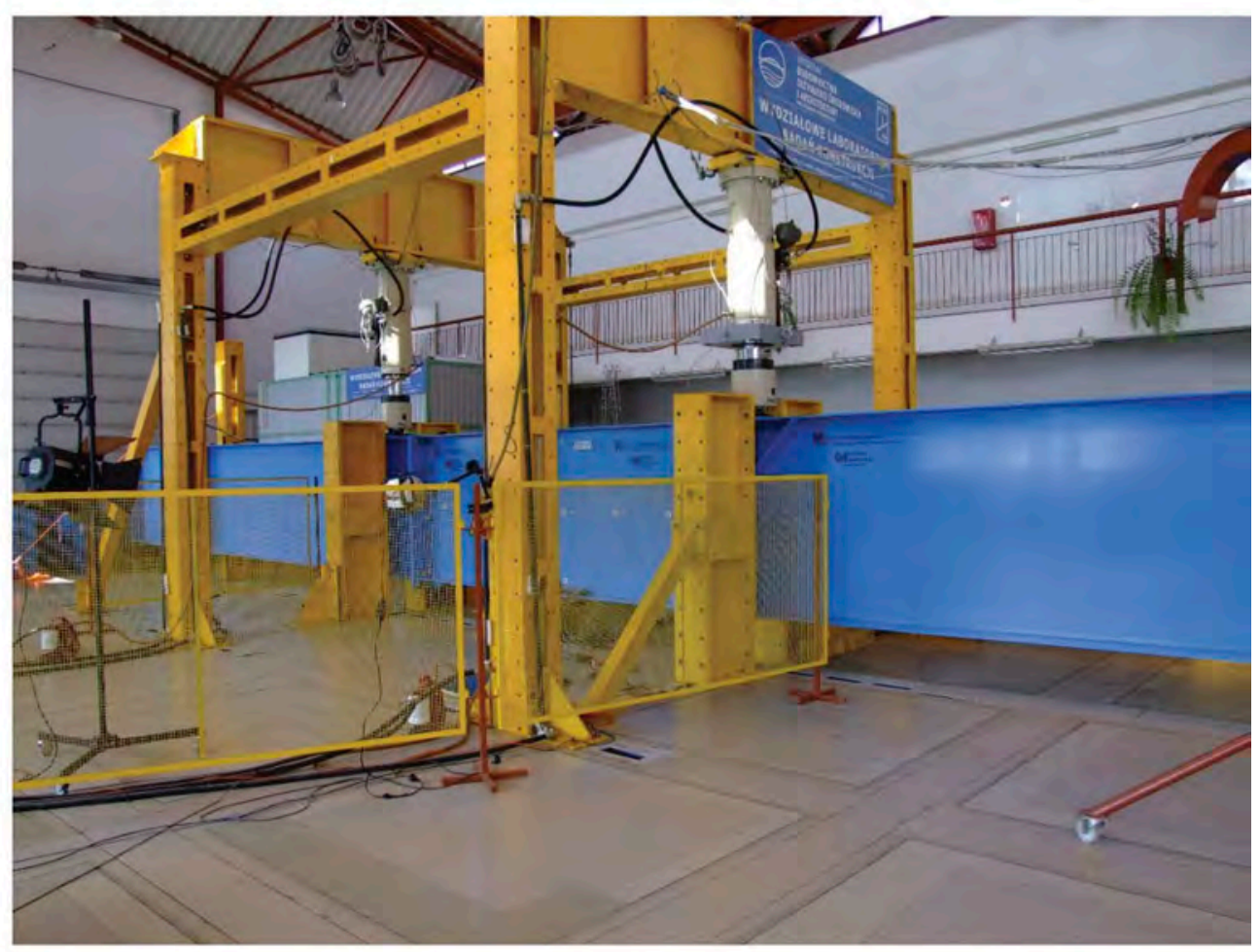

c)

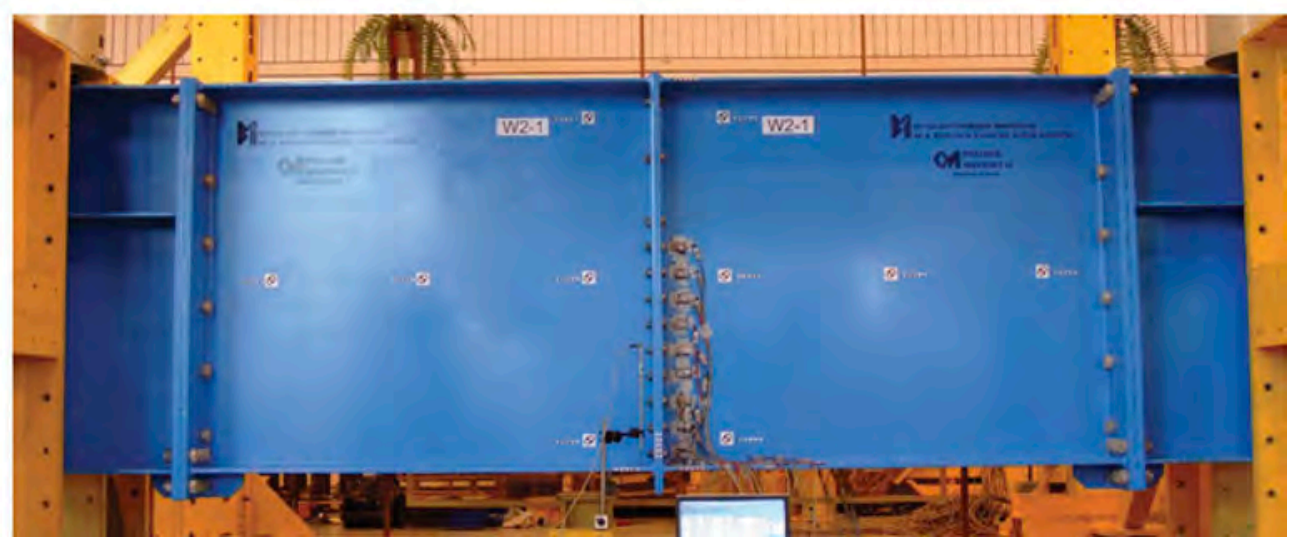

Figure 3. The test stand, a) scheme, b) general view, c) investigated specimen. 


\section{W2-1 Bolt Forces}

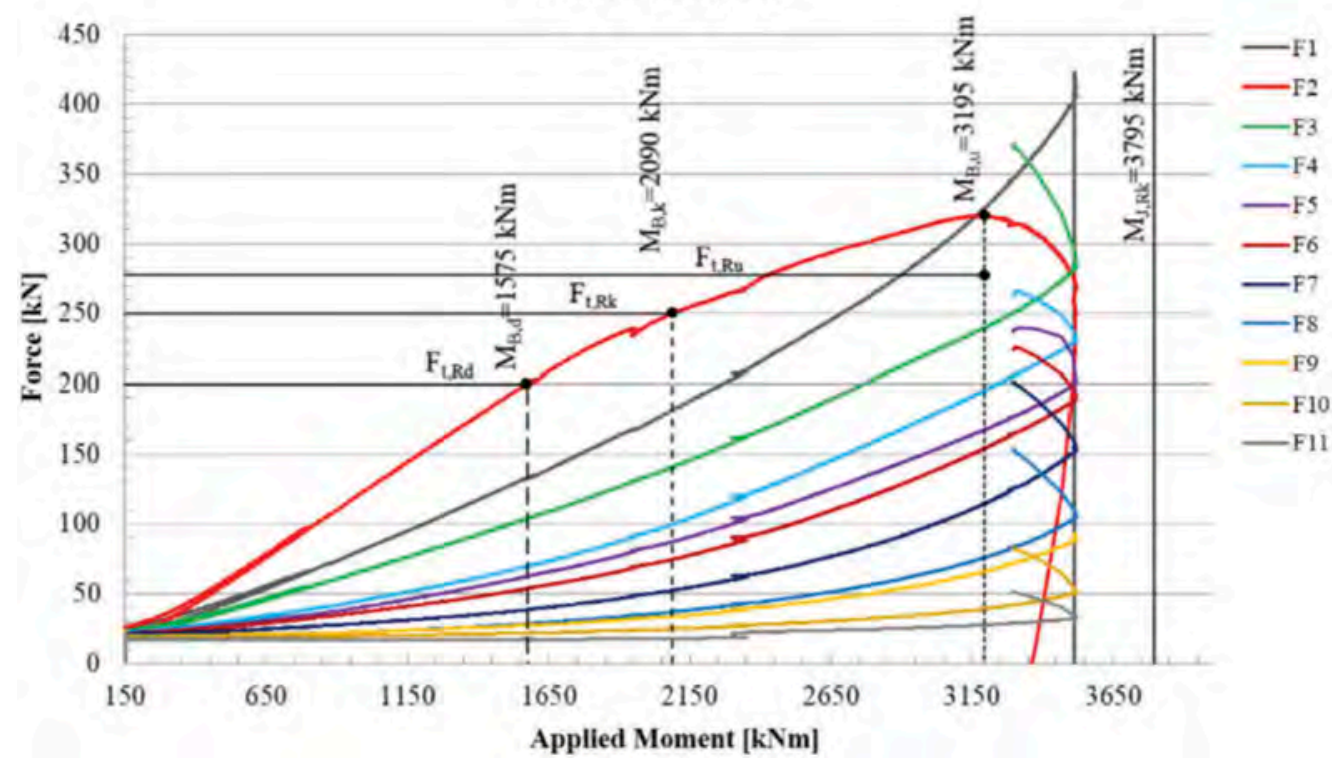

Figure 4. Moment vs. bolt-force distribution of specimen W2-1; $F_{i}$ forces in bolt row $i$, obtained from tests; notation of moments: $M_{B, d}$ when the design resistance of the bolt was reached; $M_{B, k}$ when the characteristic ultimate resistance of the bolt was reached; $M_{B, \mathrm{u}}$ when the ultimate resistance of the bolt was reached; $M_{j, R k}$ characteristic moment resistance obtained by component method (EN 1993-1-8 2005).
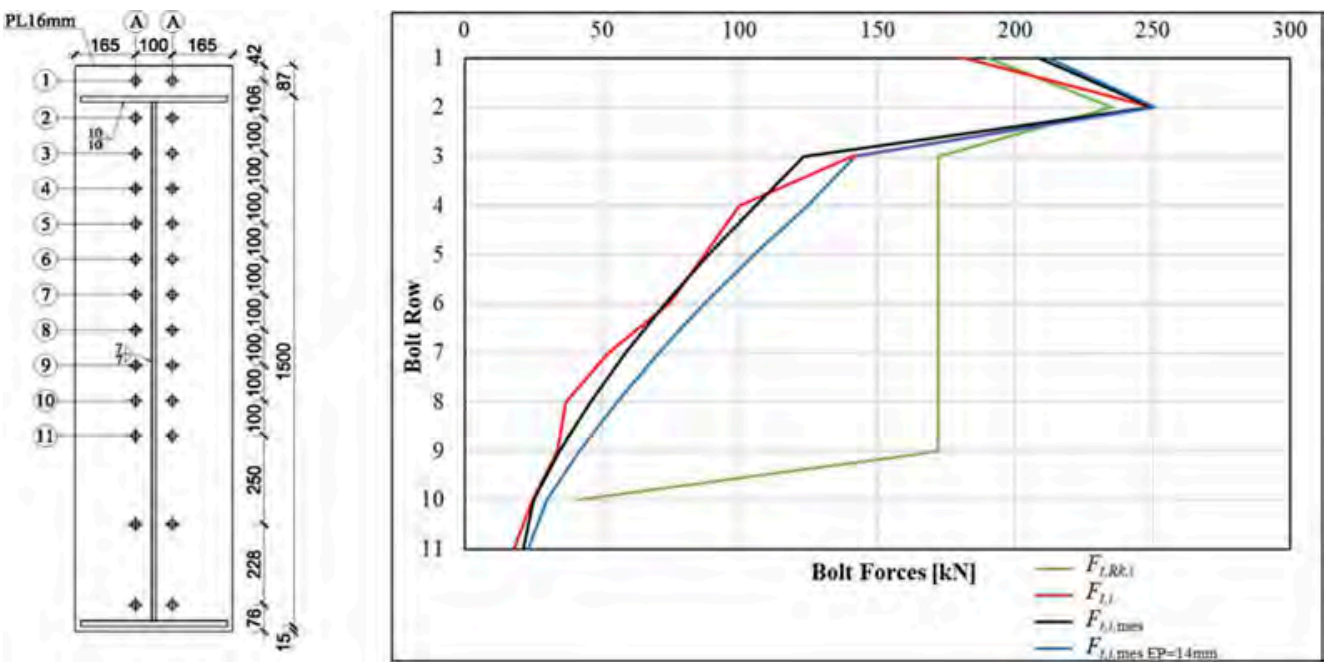

Figure 5. Distribution of forces in individual bolt rows according to component method (EN 1993-1-8 2005) $\left(F_{t, R k, i}\right)$, experimental tests $\left(F_{t, i}\right)$, FEM calculation $\left(F_{t, i, m e s}\right)$ for connection W2-1 and for comparison FEM results for end-plate of $14 \mathrm{~mm}$ thickness.

In Figure 6 results of FEM analysis with the use of validated joint model conducted for connection W2-1 (11 bolt rows) and in series, with 10, 9, 8, 7, 6, 5, 4, and 3 bolt rows were 


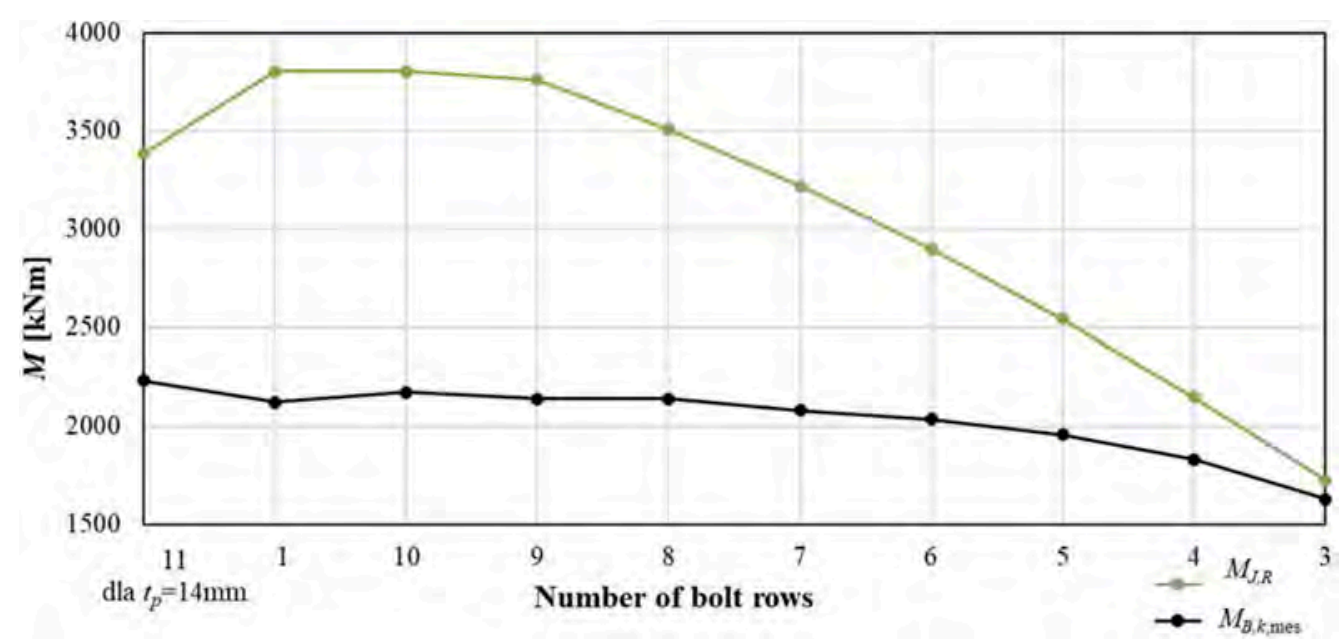

Figure 6. Characteristic moment capacity $M_{j, R k}$ according to EN 1993-1-8 (EN 1993-1-8 2005) and $M_{B \text {, }}$ $k$,mes of the W2-1 connection depending on the number of bolt rows.

presented. For each of these cases, moment resistance was calculated also using the component method (EN 1993-1-8 2005).

It is seen that only connections with one or two bolt rows below beam tensioned flange can be calculated by code (EN 1993-1-8 2005) without essential errors. It has been shown that the component method according to code (EN 1993-1-8 2005) does not provide a safe assessment of the load capacity of joints with a failure mode of 2 or 3 , with the number of internal bolt rows greater than 2 .

Two methods are proposed to improve the component method.

Modified Component Method (MCM) introduces a numerical correction of the design resistance of the T-stubs in bolt rows 1 and 3, determined according to (EN 1993-1-8 2005) by formula (3), and a linear reduction of forces in further rows.

$$
F_{T, i}=\omega_{i} F_{T, i, R d}
$$

where: $F_{T, i, R d}$ - design resistance of T-stub in bolt row $i$, according to EN 1993-1-8/8.3.4, $\omega_{i}-$ coefficient reducing the bearing capacity of the T-stub in bolt row $i$, depending on the failure model 2 or 3 , according to Table 2 .

The load capacity of bolt rows $i>3$, is linearly reduced, in relation to the reduced load capacity of bolt row 3 , according to the formula (4):

$$
F_{T, i>3}=F_{T, 3 A} \frac{h_{i}-\beta h_{0}}{h_{3}-\beta h_{0}}
$$

where $\beta=0,5$ - for failure mode 3 , when $\max h_{i}>0.5 h_{0}, \beta=1 / 3$ - in other cases, $h_{0}$ - the height of the beam.

The second proposal is the Stiffness and Rotation Method (SRM), which assumes the distribution of internal forces in the bolts depending on the stiffness of the seating and the distance from the axis of the compression chord, in relation to the design resistance of the most loaded bolt rows determined according to (EN 1993-1-8). The capacities of individual bolt rows at the level of a given row are determined depending on the position in relation to the tension flange and the direction of force distribution. 
Table 2. Reduction coefficient $\omega_{i}$.

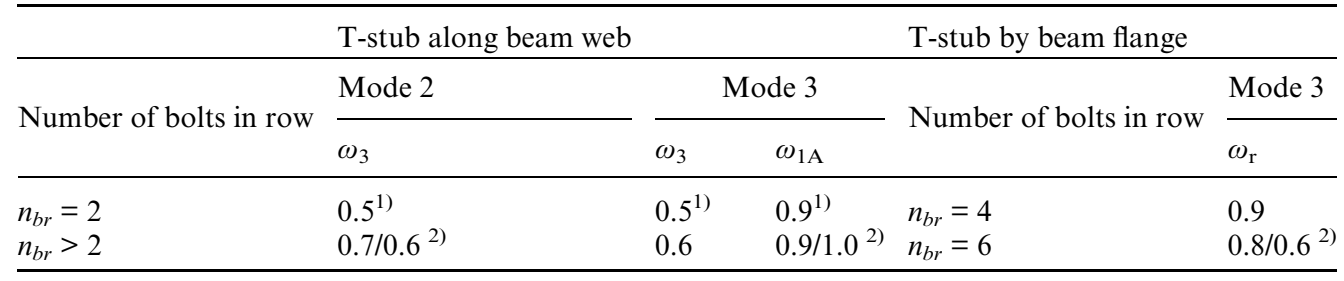

1) not applied when number of internal bolt rows $<3$

2) extended/flush end-plate

\section{ROBUSTNESS OF STEEL FRAMED STRUCTURES BY JOINTS DUCTILITY}

Each framed structures should be designed in two design situation: persistent, typical for the exploitation phase of structure life, and accidental, when the structure is subjected to unexpected loading, not included in everyday design. In a persistent situation (Figure 7a) loading acting on the frame is transferred through the entire system of appropriately connected columns and beam, while in accidental situations (Figure 7b), the column removal scenario may take place as a result of an explosion in the building, fire or impact of the vehicle. The accidental actions that should be taken into account are collected in (EN 1991-1-7 2006). Redistribution of forces in the internal connection took place: in the persistent situation (Figure 8a), the column is mainly subjected to the axial compression force; beams and joints are subjected to bending moment and shear forces. In an accidental situation (Figure 8b), when the column ceases to be support for the beams, large axial forces appear in the beams, and a sign of moment acting on joints change. The ability of a structure to withstand these events without being damaged to an extent disproportionate to the original cause is called robustness.

One of the strategies proposed by codes and regulations e.g. (DSA 2003), (DoD 2005), (EN 1991-1-7 2006), research projects (Robust structures by joint ductility 2009) is incorporating sufficient redundancy in the structure to facilitate the transfer of actions to alternative load paths following an accidental event. The main goal in the robustness design is shaping structures in such a way as to be able to create a secondary mechanism, i.e. catenary action in the scenario of column loss. The essential role of joints in providing catenary action and structural robustness is undisputed. Joints should possess not only essential load capacity to moments having a changeable sign but also very large rotation capacity to enable load redistribution.

a)

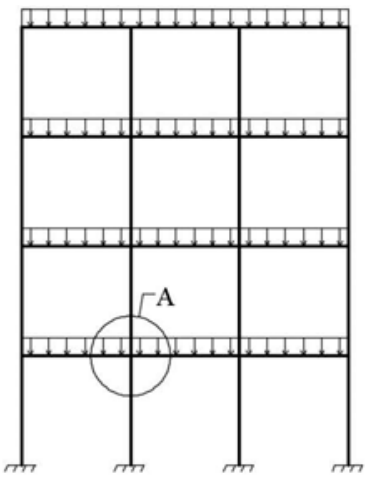

b)

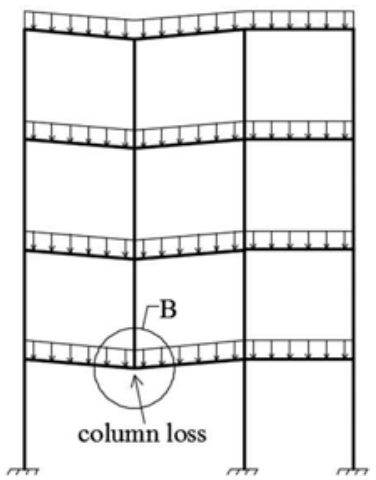

Figure 7. Design situations of frame structures: a) persistent situation, b) accidental situacion. 
The aim of the research project conducted in Rzeszow University of Technology was to:

- check the ability of very often used bolted end-plate joints for development of the catenary action, Flush and expended joints were considered,

- estimation of available rotation capacity of investigated joints, by experimental tests (Kukla \& Kozlowski 2019), and advanced FEA conducted on validated models of joints,

- recognizing failure modes of joints and find the way to change them to ductile mode, by the proposal of modification of joints,

- finding values of tie forces that appear in the structure during an accidental situation.

The project was conducted in the following stages:

a) Experimental tests of selected flush and extended bolted end-plate joints, conducted for isolated joints. Tests were conducted in cruciform set-up, for joints collected in Table 3.

Test stand of P-6 specimen and column web deflection are shown in Figure 9.

The set of obtained $M-\varnothing$ curves is presented in Figure 10 .

Based on the conducted tests, it can be concluded that:

- amongst the end-plate bolted connections with flush end-plate and extended end-plate, the highest bending resistance was obtained in connection with plate $15 \mathrm{~mm}$ (specimen P-5),

a)

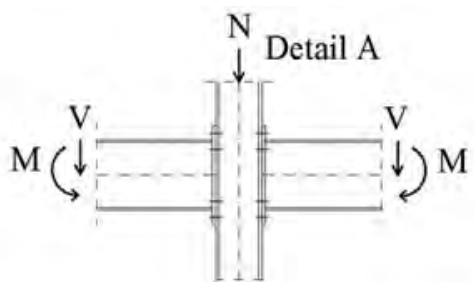

b)

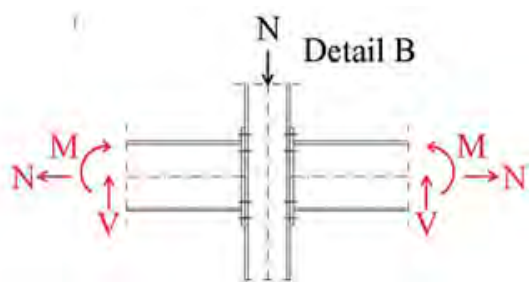

Figure 8. Configuration of force in connection: a) at the persistent situation, b) at the accidental situation of column loss.

a)

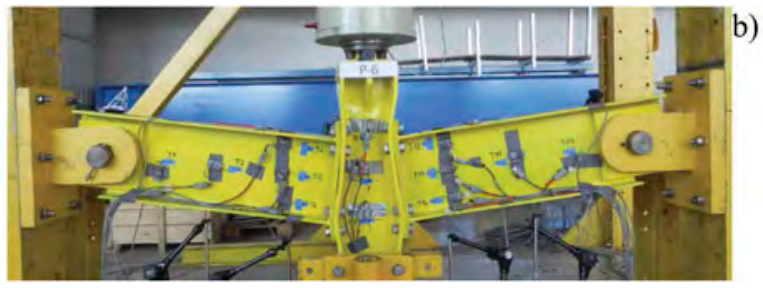

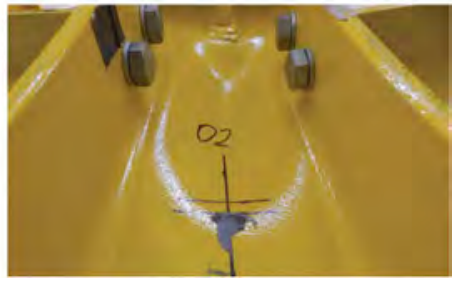

Figure 9. Sample P-6: a) view of test set-up, b) deflection of column web.

Table 3. Geometric parameters of tested specimens.

\begin{tabular}{lllllll}
\hline Specimen & Beam section & Column section & End plate & Platethickness [mm] & Bolt size & Bolt rows \\
\hline P-1 & IPE 300 & HEB 200 & Flush & 10 & M20 & 2 \\
P-2 & IPE 300 & HEB 200 & Flush & 15 & M20 & 2 \\
P-3 & IPE 300 & HEB 200 & Flush & 20 & M20 & 2 \\
P-4 & IPE 300 & HEB 200 & Extended & 10 & M20 & 4 \\
P-5 & IPE 300 & HEB 200 & Extended & 15 & M20 & 4 \\
P-6 & IPE 300 & HEB 200 & Extended & 20 & M20 & 4 \\
\hline
\end{tabular}


- end-plate joints with an extended plate (EP) show a greater capacity to develop catenary action than connections with flush plate - stronger tensile zone (4 tension bolts) was the main reason,

- the use of thicker endplates increases the bending capacity and the development of catenary action for unstiffened columns,

- the lack of stiffeners of the column web allows large deformations of the flanges and the web of the column, contributing to the increase in the rotation of connections significantly,

- results of connection tests were also used to validate numerical models of connections (Figure 11).

b) Recognizing behavior of joints tested in substructure, by advanced FEA of previously tested subframe (Kozlowski et al. 2011).Subframe analysis results are presented in details in (Kukla \& Kozlowski 2021).

c) Numerical parametric study of flush and extended end-plate steel joints in the case of column loss were conducted using validated FEM models. The effects of geometrical and mechanical features such as bolt size and grade, number of bolt rows, and end-plate thickness on joint behavior were examined.

The following conclusions can be drawn from the parametric study:

- the application of thin end plates (i.e., $6 \mathrm{~mm}$ and $8 \mathrm{~mm}$ ) decreases the deformability of the joint, and as a result, the rotational capacity,

- thick end plates are recommended in the case of an unstiffened column. A higher ultimate rotation and a developed catenary action are observed,

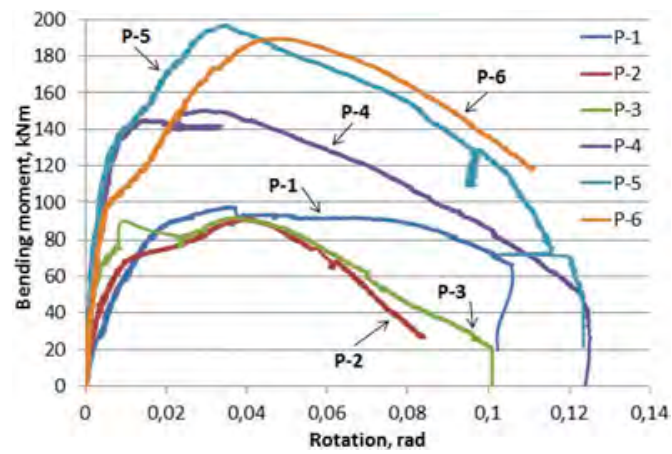

Figure 10. Comparison of the behavior of tested joints.

a)

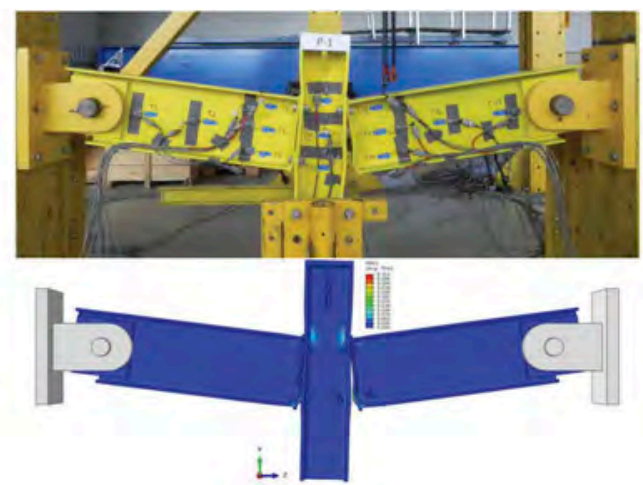

b)

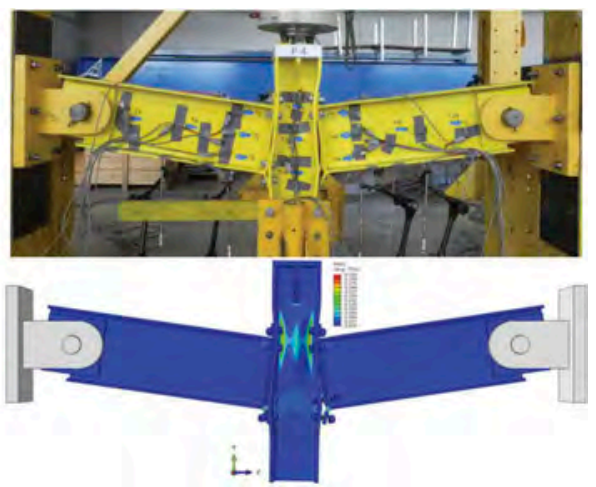

Figure 11. Comparison of experimental and numerical test of joint: a) $10 \mathrm{~mm}$ flush end plate, b) $10 \mathrm{~mm}$ extended end plate. 
- the higher bolt grade, i.e., class 12.9, and application of a larger bolt diameter has a positive influence on the ultimate joint behavior - leads to a significant increase in ultimate capacity and leads to avoiding the brittle failure mode of the joint. Therefore, the use of the M24 (or M27) bolt size is recommended.

a) Proposals of end-plate joint modifications.

Three innovative modifications of extended end-plate joints: additional channels, additional saddles, and additional rings were suggested to reach a significant raise in load and rotational capacities (Figure 12). Results of their numerical analysis and comparison of behavior are presented in Figure 13.

It is seen that proposed innovative modifications of extended end-plate joints lead to achieving a significant increase in stiffness, as well as load and rotational capacities. Additional elements used to improve the joints allow avoiding brittle damage to the bolts and create a ductile mechanism with significant development of catenary action.

a) Frame dynamic analysis in a sudden column loss scenario.

These analyses were conducted to estimate:

- required rotation capacity of joints to be able to achieve catenary action,

- behavior and failure modes of joint in destroyed frames.

a)

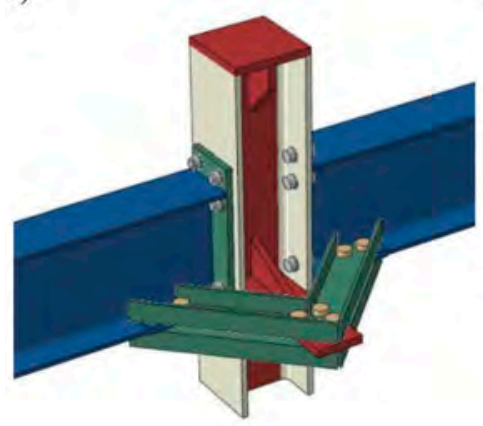

b)

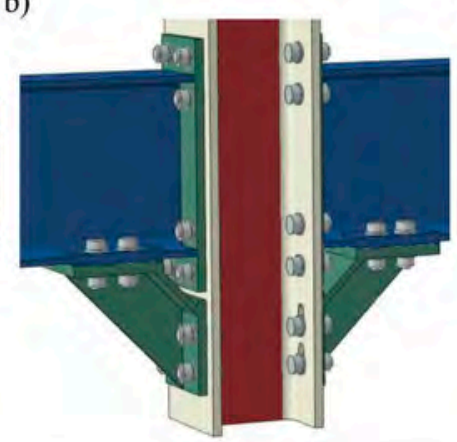

c)

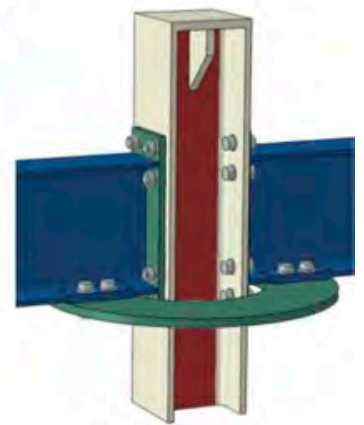

Figure 12. Proposal of joint modification by additional a) channel (AC), b) saddle (AS), c) ring (AR).

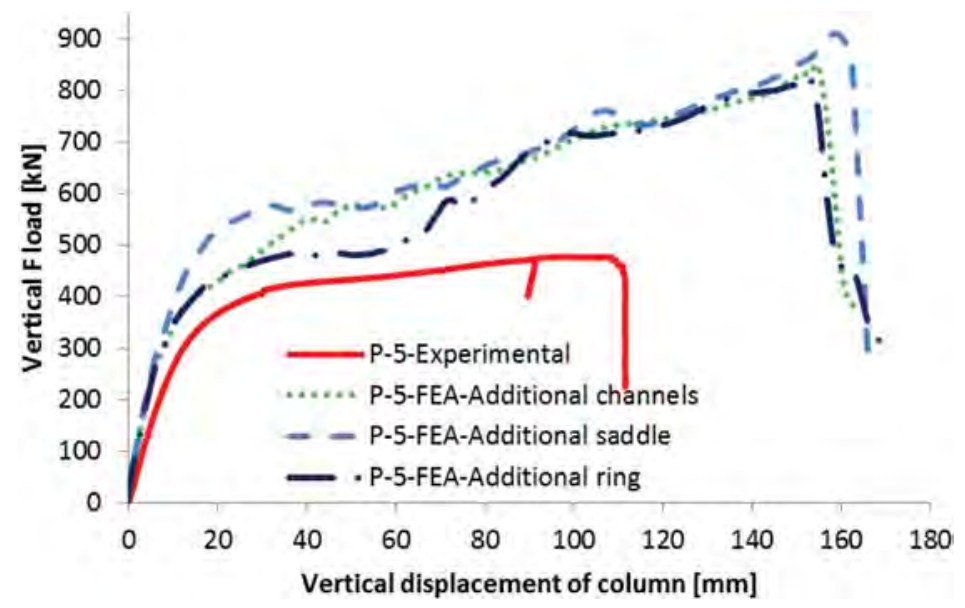

Figure 13. Effect of the modifications of joint with extended end plate. 
Few plane frames configuration were analyzed. Selected results for one of the analyzed frames (Figure 14) were presented below.

The full advanced MES models with solid elements for joints parts and shell elements for beams and columns were created and dynamically analyzed. End-plate joints as a connection of beam-to-column were applied to the whole frame. Two different cases of column loss in the analysis were adopted i.e. sudden, as for impact and/or blast, and gradual as in case of fire. Removal of a column was simulated as the loss of restraint in the support, for the central column at the "0" level (Figure 14).

The behavior of the frame under the sudden column loss scenario was presented in Figure 15. Bolted end-plate joints with $10 \mathrm{~mm}$ flush end-plate (Figure 15a) and $10 \mathrm{~mm}$ extended end-plate were used (Figure 15b). The extended end-plate joints allow for higher redistribution of load on beam length, which is visible by bent beams near the central column.

In Figure 16a the external W7 joint is shown at the end of the structure loading stage. A significant deflection of the column and endplate, as well as significant strains at column web at joint zone, can be observed. The W8 joint (Figure 16b) was destroyed by the fracture of all bolts of the lower rows.

Based on the obtained first results, the following remarks can be drawn:

- the application of end-plate bolted joint in frame structure leads to obtain a significant load capacity, rotational capacity, and large deformation of the joint and whole structure,

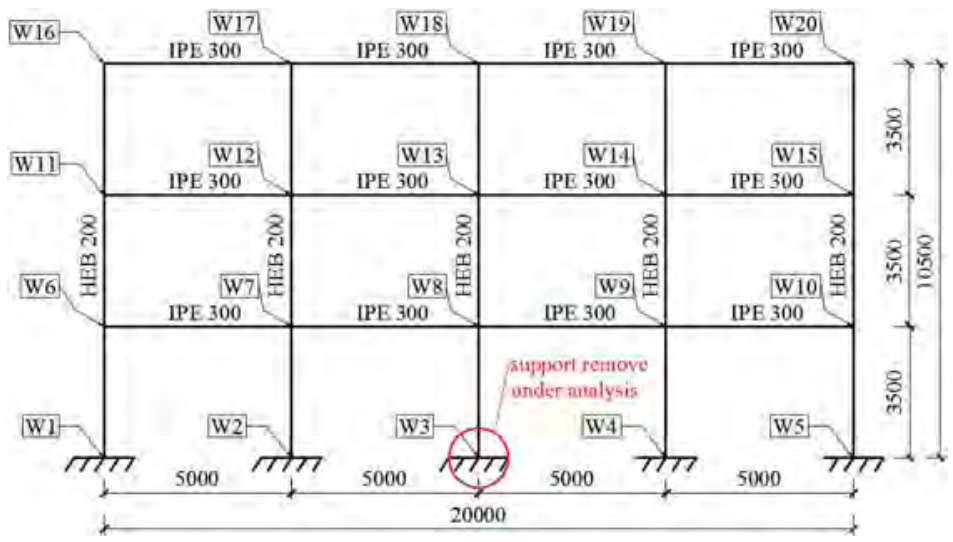

Figure 14. Static diagram of the analyzed frame.

a)

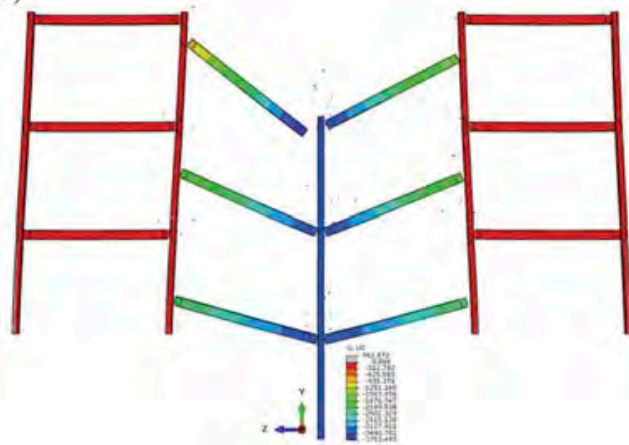

b)

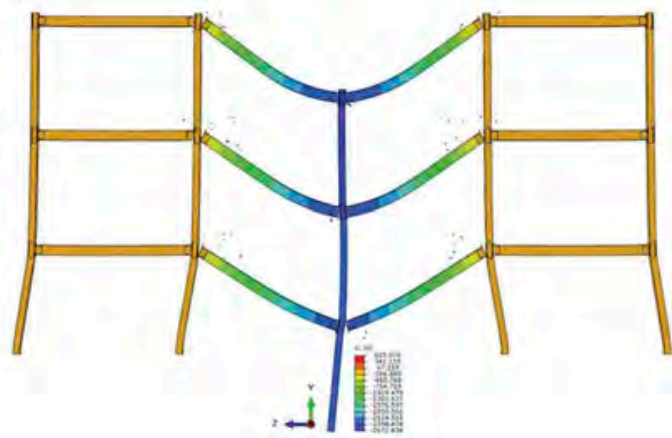

Figure 15. Map of vertical displacement of the frame under sudden column loss with a) $10 \mathrm{~mm}$ flush end plate joints, b) $10 \mathrm{~mm}$ extended end-plate joints. 
a)

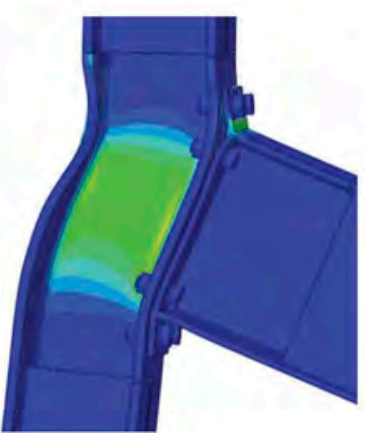

b)

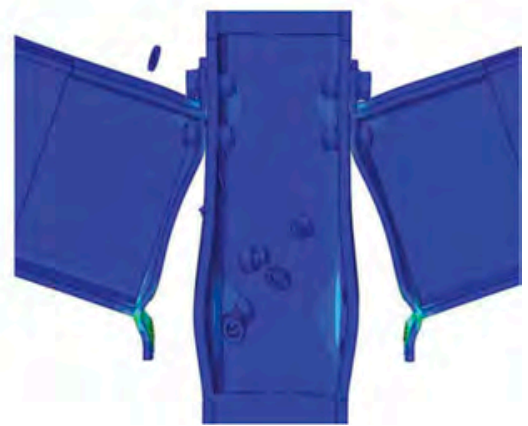

Figure 16. The failure mode of joint with $10 \mathrm{~mm}$ extended end-plate: a) external $\mathrm{W} 7, \mathrm{~b}$ ) internal W8.

- extended end plate joints has a higher load and rotational capacity, which is necessary for the development of catenary action in frame,

- the advanced model allows to observe all joint components behavior under time analysis, point out the weakest components and failure modes of joint and structure.

\section{ROTATION CAPACITY OF JOINTS}

Rotation capacity plays a very important role in an advanced analysis of steel frames, especially in the plastic design of structures and also in robustness analysis of steel frames. The previous analysis of rotation capacity was carried out with the use of the component method (Kuhlmann \& Fürch 1997), (da Silva \& Girao 2001), (Beg et al. 2004) probabilistic analysis (Beg \& Zupancic 2004), (da Silva 2004) and finite element method (Ostrowski 2014) but without practical guidelines how to use them in the design. The design procedures given in (EN 1993-1-8 2005) allow to estimate the main flexibility characteristics, as moment resistance $M_{j, R d}$ and initial stiffness $S_{j, \text { ini }}$ of the bolted and welded joints (Figure 17). As for rotation capacity, there is not enough information on how to calculate $\varnothing_{c u}$. There are only qualitative descriptions of the rotation capacity of selected connection types.

Rotation capacity is influenced by many variables, as the grade of steel, type and geometry of the joints(configuration, bolts arrangement, methods of joint stiffening), the section of beams and columns, joint placement (external or internal joint).

A large number of factors influencing rotation capacity forced researchers to find a simple, alternative to the component method, design procedure. One of them is based on the theory of experimental design and fine element analysis.

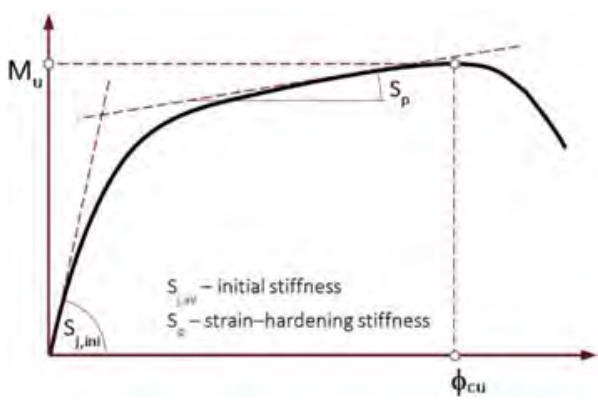

Figure 17. Graphical representation of rotation capacity. 


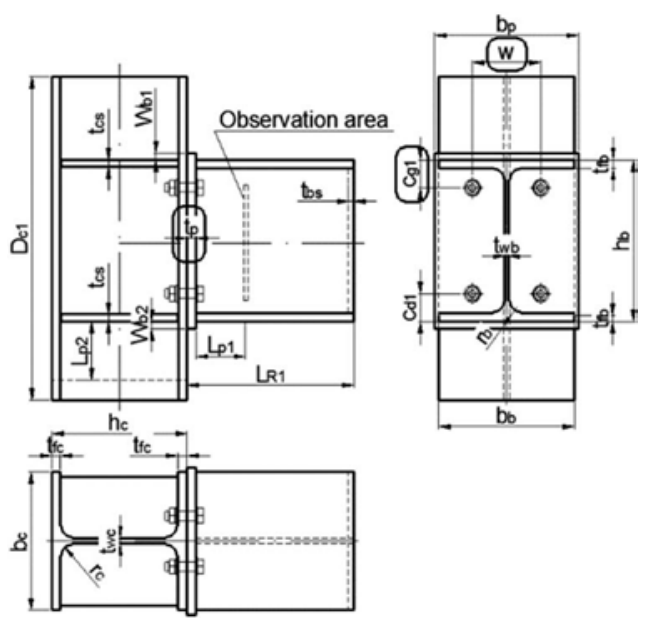

Figure 18. View of investigated join and designation of variable factors: , $t_{p},,, c_{g l}$, and ,w”.

Theory of experimental design (Polanski 1984), (Kozlowski \& Ostrowski 2019) gives researchers a very effective and efficient tool to analyses multi-factors processes in technology and science. It allows to a remarkable reduction of needed experiments and/or numerical simulations, which must be conducted to obtain an analytical model of the investigated object.

Theory of experimental design was adopted to the numerical simulation by FEM and used to obtain rotation capacity of selected, e.g. stiffened flush end-plate steel joint shown in Figure 18.

The following procedure was used to obtain the rotation capacity:

- hierarchical validation of FEM models (Figure 19) was performed by comparing the results obtained from the experimental tests with the results of FEM models (Ostrowski \& Kozlowski 2015),

- after parametric study the factor showing the strongest influence on the rotation of the joint were selected, i.e. thickness of the end-plate $t_{p}$, horizontal bolt spacing $w$, distance from the bolt axis to the upper edge $c_{g l}$ (Figure 18),

- on the basis of the substantive analysis of the most frequently used in practice solutions, the range of variability of the tested factors was determined as:

$t_{p}=10 \div 20 \mathrm{~mm}, w=120 \div 180 \mathrm{~mm}, c_{g 1}=50 \div 90 \mathrm{~mm}$,

- constant factors have been established as beam section HEA 360, column section HEB 300, S235 steel grade, M20 bolts, class 10.9,

- in order to determine the function of the maximum rotation angle of the joint, the theory of experimental design [9] adapted to numerical simulations was used. Hartley's PS/S, PS/DSP: Ha3 (Table 4), based on the hyper sphere (hK) with 11 variable factor systems was chosen,

- using a validated FEM model, calculations of joints with dimensions resulting from the experiment plan were made, in order to obtain a rotation angle $\varnothing_{c u}$ (Figure 17).

Solving all configurations of the experiment's plan allowed elaborating the response surface of the rotation angle. Results of this analysis are presented in Figure 20.

The function of rotation capacity angle was assumed as a polynomial function as below:

$$
\varphi_{c u}=t_{p}^{\alpha} \cdot c_{g 1}^{\beta} \cdot w^{\gamma}-A
$$

where: $a, b, g$ - are the coefficients of polynomial, A - is the constant of the polynomial.

The coefficients of polynomial described by the equation (5) were calculated by the program Statistica 12, with the use of the nonlinear regression analysis. The following function of available rotation capacity of joint was obtained: 
a)

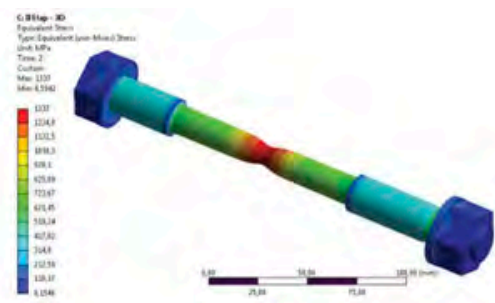

c)

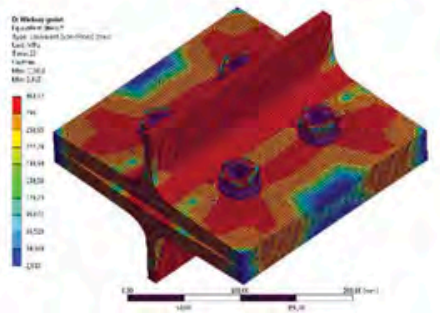

b)

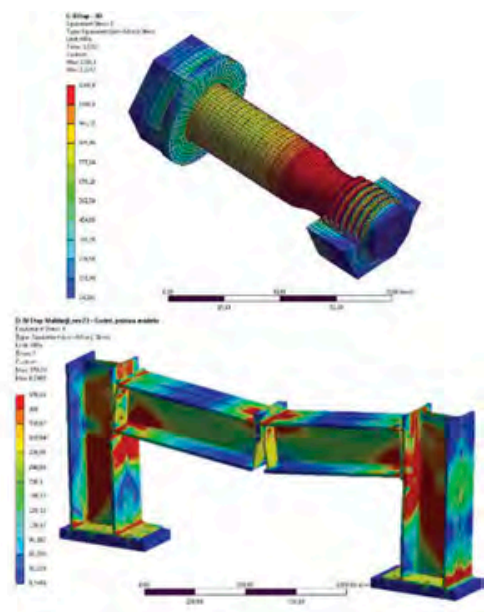

Figure 19. Stages of hierarchical validation: a) Stage I - tension test of a steel sample, b) Stage II - tension of a bolt in a bolt-washer-nut set, c) Stage III - tension of T-stubs, d) Stage IV - bending of the beam-to-column joint in the subframe.

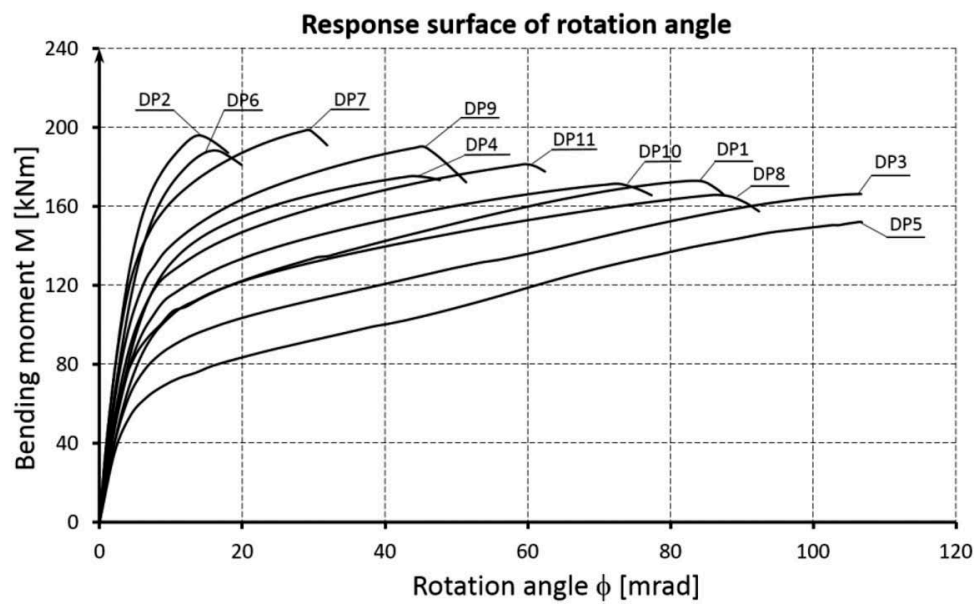

Figure 20. Moment-rotation of joints analyzed in experiment plan.

$$
\varphi_{c u}=t_{p}^{-1,267} \cdot c_{g 1}^{1,044} \cdot w^{0,714}-42,48
$$

Such procedures can be used to analyze other joint configurations. Finally, a catalog of joints with values of available rotation capacity will be created and can be used in the design.

\section{CONCLUSIONS}

Unique experimental tests of four beam splices of beam $1000 \mathrm{~mm}$ and $1500 \mathrm{~mm}$ high were performed. Results of tests, especially values of forces in particular bolt rows and also results of the parametric study conducted by FEA using validated models of high beam splices lead to conclusions that: 
Table 4. Experimental plan Hartley's PS/S.

\begin{tabular}{llllllll}
\hline & \multicolumn{1}{c}{$\mathrm{x}_{\mathrm{k}}$} & \multicolumn{2}{c}{$x_{k}$} & Rotation [mrad] \\
\cline { 2 - 7 } & $\mathrm{x}_{1}$ & $\mathrm{x}_{1}$ & $\mathrm{x}_{2}$ & $\mathrm{t}_{\mathrm{p}}$ & $\mathrm{c}_{\mathrm{g} 1}$ & $\mathrm{w}$ & $\emptyset_{\mathrm{cu}}$ \\
\hline 1 & -1 & -1 & 1 & 12.11 & 58.45 & 167.32 & 83.07 \\
2 & 1 & -1 & -1 & 17.89 & 58.45 & 132.68 & 13.98 \\
3 & -1 & 1 & -1 & 12.11 & 81.55 & 132.68 & 106.69 \\
4 & 1 & 1 & 1 & 17.89 & 81.55 & 167.32 & 43.75 \\
5 & -1.732 & 0 & 0 & 10.00 & 70.00 & 150.00 & 106.84 \\
6 & 1.732 & 0 & 0 & 20.00 & 70.00 & 150.00 & 15.85 \\
7 & 0 & -1.732 & 0 & 15.00 & 50.00 & 150.00 & 29.38 \\
8 & 0 & 1.732 & 0 & 15.00 & 90.00 & 150.00 & 86.58 \\
9 & 0 & 0 & -1.732 & 15.00 & 70.00 & 120.00 & 45.37 \\
10 & 0 & 0 & 1.732 & 15.00 & 70.00 & 180.00 & 72.59 \\
11 & 0 & 0 & 0 & 15.00 & 70.00 & 150.00 & 59.81 \\
\hline
\end{tabular}

- distribution of forces in the particular bolt rows is not equal on the beam height. Also the moment resistance of the joint $M_{j, R k}$ determined by component method acc. to code (EN 1993-1-8 2005) is much bigger than reached during experimental tests,

- only connections with one or two bolt rows below tension beam flange can be calculated by code (EN 1993-1-8 2005) without essential errors,

- the component method does not provide a safe assessment of the load capacity of joints with a failure mode 2 or 3 , with the number of internal bolt rows greater than 2 .

Two methods are proposed to improve the component method to be safe also for joints applied in very high beams with multi bolt rows.

Experimental tests of joints advanced FEA of isolated joints, the subframe and whole steel frames, as well as wide parametric study, lead to the conclusion that:

- application of end-plate bolted joint in frame structure leads to obtain a significant load capacity, stiffness, and large deformation of the joint and whole structure,

- use of thin end plates (i.e., $6 \mathrm{~mm}$ and $8 \mathrm{~mm}$ ) decreases the deformability of the joint, and as a result, the rotational capacity,

- extended end plate joints, compared to flush, has a higher load and rotational capacity, which is necessary for the development of catenary action in frame,

- application of a larger bolt diameter has a positive influence on the ultimate joint behavior - leads to a significant increase in ultimate capacity and leads to avoiding the brittle failure mode of the joint. Therefore, the use of the M24 or M27 bolt size is recommended.

Three innovative modifications of extended end-plate joints: additional channels, additional saddles, and additional rings were suggested to reach a significant raise in load and rotational capacities.

The theory of experimental design was adopted for numerical simulation by FEM and used to obtain the available rotation capacity of the exemplary joint. i.e. stiffened flush end-plate. By application of the proposed procedure, a catalogue of most often used in practice joints, with values of available rotation capacity can be created and be used as a design tool in steel frame design.

\section{REFERENCES}

Beg, D. \& Zupancic, E. 2004. Statistical evaluation of rotation capacity of moment connections. Connections in Steel Structures $V$. Amsterdam.

Beg, D. \& Zupancic, E. \& Vayas, I. 2004. On the rotation capacity of moment connections. Journal of Constructional Steel Research 60:601-620.

Borgsmiller, J. \& Sumner, E. \& Murray, T. 1995. Tests of Extended Moment End-Plate Connections Having Large Inner Pitch Distances, in Research Report CE/VPI-ST-95/01. Department of Civil Engineering. Virginia Polytechnic Institute and State University. Blacksburg VA. 
Department of Defence (DoD), Unified facilities criteria (UFC): Design of structures to resist progressive collapse, Washington, 2005.

EN 1991-1-7: Actions on structures - Part 1-7: General actions - Accidental actions. CEN. 2006.

EN 1993-1-8: 2005. Design of steel structures. Part 1-8 Design of joints. CEN. 2005.

General Services Administration (GSA). 2003. Progressive collapse analysis and design guidelines for a new federal office buildings and major modernization project.

Jain, N. 2015. Developing and validating new bolted end-plate moment connection configurations. Virginia Tech.

Katula, L. 2007. Bolted end-plate joints for crane brackets and beam-to-beam connections, in PhD. Dissertation. University of Technology and Economics Budapest.

Kawecki, P. \& Kozlowski, A. 2020. Experimental investigation of end-plate splices multiple bolt rows of large girders. Journal of Constructional Steel Research, Volume 167:1-19.

Kawecki, P. 2020. Ultimate limit states of multi bolts end-plate splices of the welded I girders. PhD Dissertation. Rzeszow University of Technology.

Kozlowski, A. \& Gizejowski, M. \& Sleczka, L. \& Pisarek, Z. \& Saleh, B. 2011. Experimental investigation of the joints behaviour-Robustness assessment of steel and steel concrete composite frames. Proceeding of the 6th European Conference on Steel and Composite Structures: 339-344. Budapest.

Kozłowski, A. \& Ostrowski, K. 2019. Application of theory of experimental design and FEA to assessment of rotation capacity of steel joints. Advances in Resource-saving Technologies and materials in Civil and Environmental Engineering. Cham:Springer:188-194.

Kuhlmann, U. \& Fürch, A. 1997. Rotation Capacity of Steel Joints. COST Project C1 Meeting.

Kukla, D. \& Kozlowski, A. 2021. Parametric study of steel flush and extended end-plate joints under column loss scenario. Engineering Structures 2021 (Paper under review).

Kozlowski, A. \& Kukla, D. 2019. Experimental tests of steel unstiffened double side joints with flush and extended end plate. Archives of Civil Engineering. vol. LXV. ISSUE 4:127-154.

Kukla, D. \& Kozlowski, A. 2021. Analysis of steel bolted end-plate joints under accidental situation. ICMS 2021. Poznan, 2021. (Paper under review).

Morrison, S. \& Astaneh-Asl, A. \& Murray, T. 1986. Analytical and Experimental Investigation of the Multiple Row Extended Moment End-Plate Connection with Eight Bolts at the Beam Tension Flange. University of Oklahoma Norman OK Research Report FSEL/MBMA 84-04 Fears Structural Engineering Laboratory.

Ostrowski, K. 2014. Finite element analysis of the rotation capacity of beam-to-column end-plate bolted joints. Eurosteel 2014. September 10-12. Naples.

Ostrowski, K. \& Kozlowski, A. 2015. Hierarchical validation of FEM models. XIV International Scientific Conference Rzeszow - Lwow - Koszyce. Rzeszow.

Polanski, Z. 1984. Experimental design in technique. (In Polish). PWN. Warsaw.

Robust structures by joint ductility. 2019. Research Found of Coal and Steel.

Ryan, J.1999. Evaluation of Extended End-Plate Moment Connections Under Seismic Loading. Master of Science Civil Engineering Thesis. Virginia Polytechnic Institute.

Silva, S. \& Borges, L. \& Garvasio, H. 2004. A probabilistic evaluation of the rotation capacity of endplate beam-to-column steel joints. Connections in Steel Structures V. Amsterdam.

Silva, S. \& Girao, A. 2001. A ductility model for steel connections. Journal of Constructional Steel Research 57: 45-70.

Sumner, E. 2003. Unified design of extended end-plate moment connections subject to cyclic loading. Dissertation submitted to the Faculty of the Virginia Polytechnic Institute. 


\title{
Design of hybrid beam-to-column joints between RHS tubular columns and I-section beams
}

\author{
L. Simões da Silva \\ ISISE, Civil Engineering Department, University of Coimbra, Coimbra, Portugal \\ Y. Harada \\ Department of Architecture, Faculty of Engineering, Chiba University, Chiba, Japan
}

\begin{abstract}
This paper presents the proposal of a framework and operational proposal for the inclusion of hybrid joints between tubular columns and open section beams in EC3$1-8$, providing a design specification for the most common types of joint typologies and allowing for the evaluation of their stiffness and resistance. The code conform specification further characterizes the equivalent cross-section component model for the tube zone that contributes to the joint behaviour, including the out-of-plane deformation of the column faces.
\end{abstract}

\section{INTRODUCTION}

Tubular steel columns provide efficient structural solutions because they combine several advantages when compared to open cross-section alternatives:

- Appealing aesthetics

The use of tubes usually leads to pleasant visual results, being the undisputed option whenever the structure is exposed as it is the case of stadia, airports, large halls and sports arenas.

- Balanced mechanical performance

Structures with tubular profiles present a very high strength-to-weight ratio because the various failure modes are well balanced with respect to tension, major and minor axis bending, compression and torsion, minimizing the needs for bracing and also providing easy ways of obtaining increased resistance by composite action with e.g. concrete filling.

- Better fire performance

Structures with tubular profiles present a better fire performance because of the reduced exposed area.

- Easier fabrication and erection

The production process of tubes leads to smooth surfaces and no sharp corners, therefore improving corrosion resistance. Additionally, because of the balanced resistance of the tubes, erection is simpler, with less temporary bracing and supports.

- More economic life-cycle costs

Tubular structures present life-cycle cost savings due to smaller fire protection and painting costs (smaller surface area), facilitating maintenance operations and leading to a longer service life.

Additionally, on a more global note, steel structures are more environmentally friendly because steel is infinitely recyclable without loss of characteristics and steel solutions are easily reusable (Simões da Silva et al, 2021a). Furthermore, recent advances in steel production with 
coal-free Hydrogen-based reduction - HYBRIT (LKAB, 2021) will further reduce the carbon footprint of steel production.

However, concerning connections, tubular profiles present the disadvantage of not allowing easy access to the inside of the tube. This leads to difficulties in using traditional bolted solutions. These difficulties are further amplified by the usual small thickness of the tubes that leads to the possibility of additional critical and complex failure modes.

Hybrid bolted beam-to-column joints connecting tubular columns to open I-section beams are still nowadays not specified in Eurocode 3, part 1-8 (2005) or the revised version that is currently in its final stages of approval (2021), henceforth denoted prEC3-1-8, despite their widespread use. Invariably, such joints are semi-rigid and partial strength and highly susceptible to the deformability of the column faces, which is still the missing component in the prEC3-1-8 specification. It is the objective of this paper to present efficient solutions for the connection of tubular columns to open I-section profiles, to discuss the specific aspects of the behavior of these joints and to provide a design proposal in code format that complies with the EC3-1-8 methodology for the design of joints.

\section{CONNECTION SYSTEMS FOR HOLLOW SECTION TUBES}

\subsection{Conceptualization}

There are four groups of solution strategies to connect open sections to tubes given the difficulties described above:

- Welded joints: welded beam-to-column joints require in-situ welding; hence, they are not interesting solutions, both from an economic point of view as well as from safety and technical criteria and will not be further addressed in this paper.

- Bolted joints using special fasteners: solutions whereby the beam is directly attached to the column face using end plates and special fasteners that can be installed and tightened from the outside.

- Bolted joints whereby the beam is bolted to plates or channels welded to the column face: these solutions allow the use of standard bolts with access to tighten them from both sides.

- "Through-diaphragm" joints: joints whereby continuity plates (diaphragms) are inserted into the column tube; however, although providing rigid connections, these joints are very expensive to manufacture.

\subsection{Special fasteners}

In order to overcome the difficulty of accessing the inside of a tube, several types of solutions were developed, including special fasteners in order to allow positioning and tightening only from one side. The following three types of solutions are described in the following paragraphs:

- Welded studs (Figure 1): this type of solution presents the drawback that the bolts may be damaged during transport and erection; furthermore, it is very difficult to position the beams and to achieve continuous contact between the endplate and the column face because of the welds around the bolts. The performance of this type of solution is reasonable assuming that welding is performed adequately.

- Threaded holes (Figure 2): This type of solution consists of the execution of threaded holes that can be used with standard bolts (e.g. Flowdrill system). The system is adequate for thicknesses varying from $5 \mathrm{~mm}$ to $12.5 \mathrm{~mm}$ and bolts M-16 to M-20 but the main disadvantage of the system relates to the fact that it does not allow for tolerances.

- Special fasteners (Figure 3): they allow the use of standard holes with normal or oversize tolerances and they rely on the expansion of the blind end of the bolt that is mechanically connected to the parts that will be joined. These systems are normally proprietary systems from various manufacturers such as Huck International Inc, Lindapter International, 


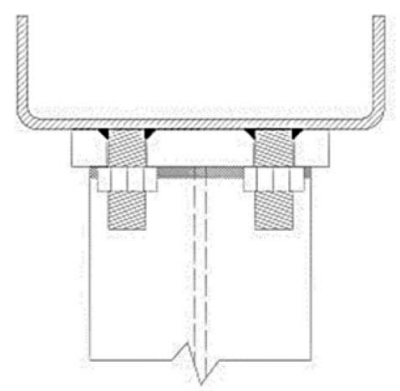

Figure 1. Welded studs.

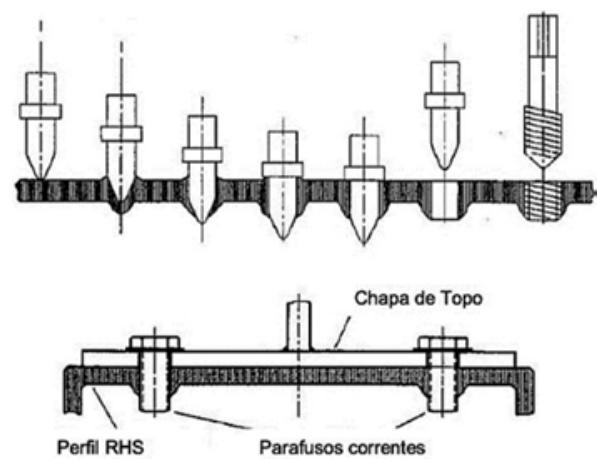

Figure 2. Threaded holes: Flowdrill system.

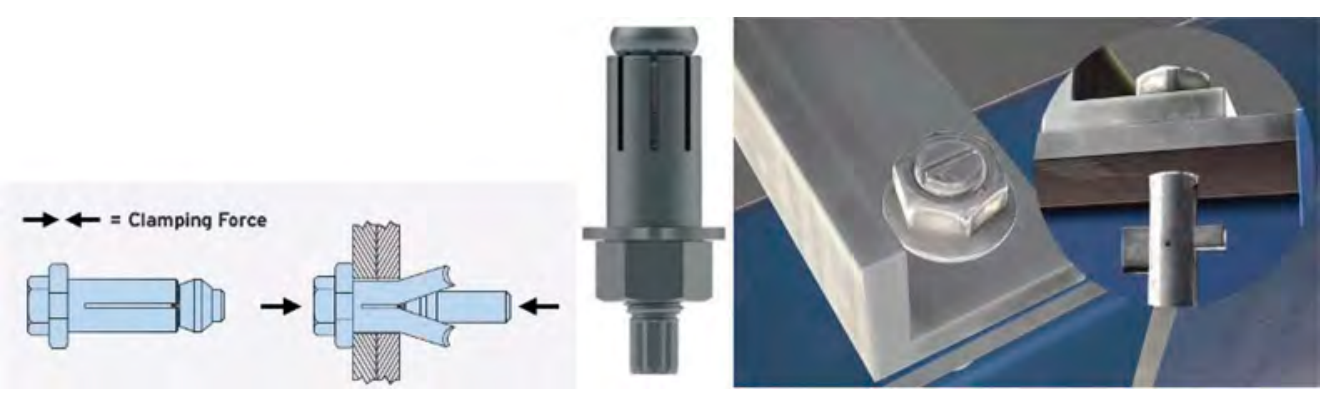

Figure 3. Special fasteners.

AJAX Pty, BlindBolt Ltd and TCB Ltd. The various systems have been extensively studied by several authors (Yeomans, 1998; France et al, 1999; Tizani and Ridley-Ellis, 2003; Tizani et al, 2013; Oktavianus, 2018).

\subsection{Joint typologies}

Depending on the desired performance of the joint, several joint typologies are usually adopted to connect tubular columns to open section beams. Whenever only shear force transfer is desired, a fin plate connection, illustrated in Figure 4, is the usually preferred solution because of its ease of fabrication, easy erection due to the straightforward positioning of the beam and good tolerances. 
From a design point of view, some degree of fixity at the beam ends has a very favorable impact on the design of the beam and the control of deflections. In this case, solutions that provide partial moment resistance are preferred. The first group consists of full or partial depth end-plate joints directly attached to the column face using special fasteners (Figure 5a), while the second group corresponds to bolted reverse channel joints (Figure 5b).

Finally, if rigid joints that satisfy the overstrength criteria are required, then complex and expensive through-diaphragm joints are necessary.

\section{BEHAVIOUR OF THE RHS CONNECTION ZONE}

\subsection{Introduction}

The behavior of the joint typologies listed in sub-section 2.3 may be established by combining the behavior of two distinct zones, illustrated in Figure 6: (i) ZONE A: the section of the tube that is mobilized by the connection; and (ii) ZONE B: the connection zone.

The behavior of the connection zone is independent from the type of column cross-section: it follows the specifications of clause 8 of prEC3-1-8 (2021). The exception relates to the reverse channel joint, whereby the above statement is only applicable for the sub-zone B.2, because the components that are active in zone B.1 are currently not specified in prEC3-1-8. This specific case will be addressed later in this paper.

The behavior of the tube zone is complex because of the couplings between the column faces. To simplify the problem, firstly, it is necessary to understand the nonlinear out-of-plane behavior of the isolated column face (Harada and da Silva, 2019a). Secondly, the interactive

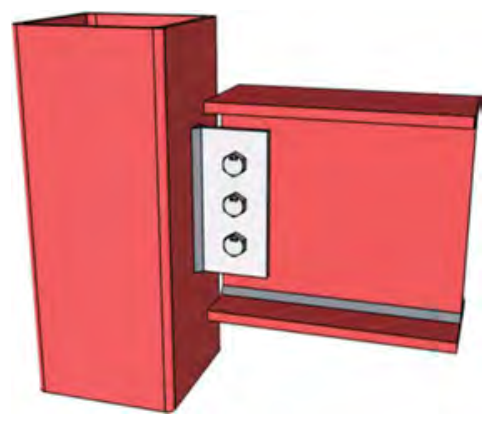

Figure 4. Fin plate joint.

a)

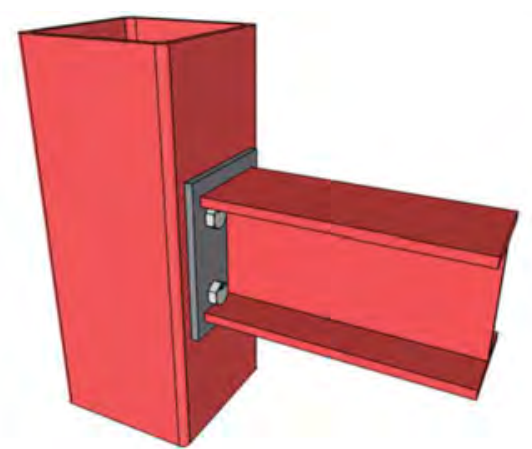

b)

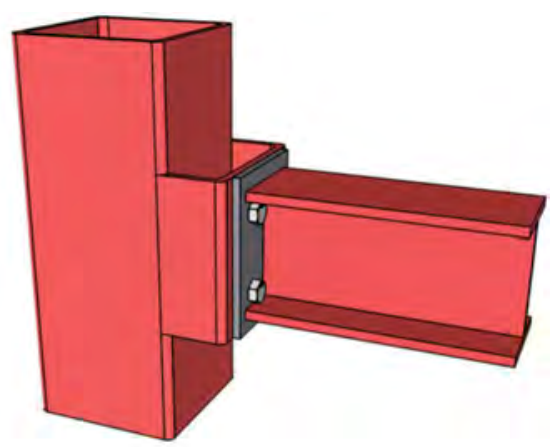

Figure 5. Partial strength semi-rigid bolted joints. a) end-plate joints with blind bolts b) reverse channel joints. 


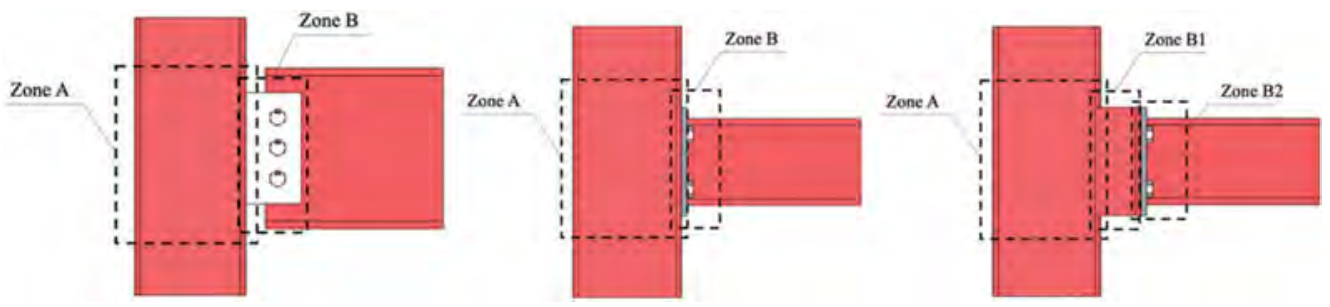

Figure 6. Definition of the zones of each joint typology.

behavior of the multiple column faces is treated in the form of a novel joint component, the "equivalent cross-section" component model (Harada and da Silva, 2019b). Both aspects are addressed in detail in the next sub-sections.

\subsection{Out-of-plane behavior of an isolated column face}

The out-of-plane behavior of a loaded isolated column face depends on various factors:

- Shape and orientation of the connecting element (annular, corresponding to a bolt head, rectangular or built-up shape, longitudinal or transverse with respect to the column axis).

- Type of action transferred by the connecting element (inwards or outwards force, bending moment or shear force), evaluated at the mid-plane of the column face.

- Position of the connecting element with respect to the column face centerline (centric or eccentric).

The multiple failure modes associated to yielding of the column face may be a consequence of a pure bending mechanism, a punching shear mechanism or a mixed mechanism, involving both shear and bending. For high width-to-thickness ratios of the column face, the membrane forces will decisively contribute to the ultimate resistance and second-order effects play a major role. The deformability of the column face is also significant and needs to be assessed to establish the stiffness of the joint.

\subsubsection{Plastic resistance}

Several authors have addressed the evaluation of the plastic resistance of a column face loaded out-of-plane. Yield-line theory is invariably used to derive design expressions. For longitudinal rectangular plates welded to the column face, Kosteski et al (2003) have proposed a design expression that is adopted in EC3-1-8. This equation was recently adopted (Simões da Silva et al, 2021) for a reverse channel welded to the column face, symmetrically placed with respect to the centerline of the column. For transverse rectangular plates welded to the column face or bolts attached to the column face through an endplate, several models are available: Wardenier et al (2007) that is adopted in EC3-1-8, the improved and more accurate proposal by Gomes et al (1996), the simplified expressions by Yeomans (1998) and SCI (2005) that is adjusted to deal with special fasteners such as Hollobolts and the recent proposal by Wang and Wang (2016) that was experimentally calibrated to a set of 14 test results.

\subsubsection{Stiffness}

Concerning stiffness, for end-plate joints directly attached to the column face, Simões da Silva et al (2003) have proposed an equivalent strip model that allows the calculation of the initial stiffness and the membrane stiffness of the column face. This model was recently extended to cyclic out-of-plane behavior by Harada and Simões da Silva (2019a). For single or double longitudinal rectangular plates welded to the column face, Simões da Silva et al (2021b) proposed design expressions for this component that allow the calculation of the initial stiffness of fin plate or reverse channel configurations. 


\subsection{Equivalent cross-section tube model}

The "equivalent cross-section" component model allows to consider the local deformation of the cross-section of the RHS column tube. In relation to this approach, the "ring" model is well established in the field of tubular structures: to estimate the local behavior of a circular tube (CHS), its cross-section is modeled as a planar framework with the cross-section's shape (Togo, 1967). For RHS tubes, the deformable tubular column section can be modeled as a planar framework with four equal beam members with the same length $L$, which corresponds to the plate width of the column plate, and the flexural rigidity EI. This cross-section component is supported by four pin supports at their four corners, as shown in Figure 7.

According to Harada \& Simões da Silva (2019b), the relation between the force and the deformation vectors (eq. (6)), which have four elements corresponding to the four column plates in the cross-section component is the stiffness equation of the cross-section component. Eq. (6) can be regarded as a description of the interaction between the behaviors of the four column plates. The flexural rigidity is determined so that the deflection of the side beam coincides with the out-of-plane deformation of the column plate, obtained as described in subsection 3.2.2. The nonlinear behavior of the single column plate is assumed to be decomposed into two contributions, i.e., elastic-plastic and membrane contributions: the elastic-plastic contribution is modeled by plastic hinges on the side beams, and the membrane contribution by uniaxial membrane springs at the middle of the side beams. This modeling approach assumes that the elastic-plastic behaviors of the four column plates can interact while the membrane behaviors of the four plates are independent.

\section{COMPONENT MODEL}

The design of the 3 joint typologies between I-section beams and RHS tubular columns is based on the component method. It requires the calculation of the applied internal forces acting on the joint and the identification of the active components. Following prEC3-1-8, the safety of each joint is established, as appropriate, by satisfying equations (1) to (3):

$$
\begin{gathered}
N_{i, E d} \leq N_{i, R d} \\
V_{i, E d} \leq V_{i, R d} \\
M_{i p, i, E d} \leq M_{i p, i, R d} M_{o p, i, E d} \leq M_{o p, i, R d}
\end{gathered}
$$

where $N_{i, E d}$ is the applied axial force, $V_{i, E d}$ is the applied shear force, $M_{i p, i, E d}$ is the applied bending moment in the plane of the joint, $M_{o p, i, E d}$ is the applied out-of-plane bending moment, $N_{i, R d}$ is the axial force resistance, $V_{i, R d}$ is the shear force resistance, $M_{i p, i, R d}$ is the bending moment resistance in the plane of the joint and $M_{o p, i, R d}$ is the out-of-plane bending moment resistance.
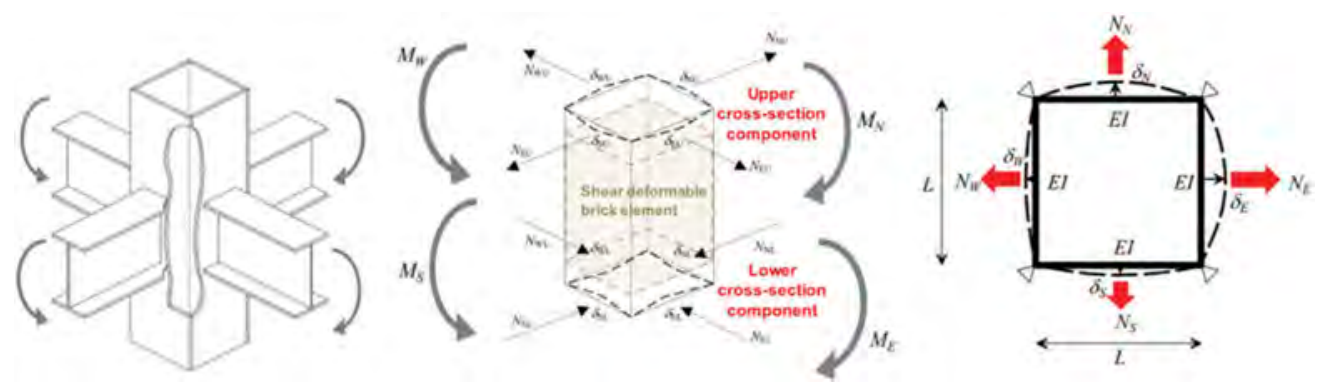

Figure 7. Outline of the equivalent cross-section component model (reproduced from Harada \& Simões da Silva, 2019b). 

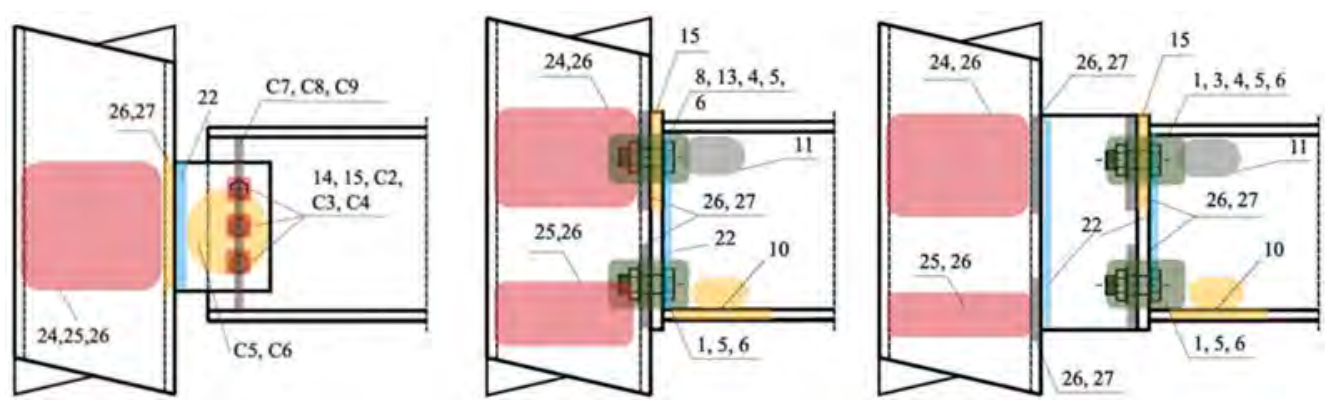

Figure 8. Active components.

Figure 8 identifies the active components for each of the 3 joint typologies. The fin plate joint follows most of Annex C of prEC3-1-8 (Jones and Wang, 2011) except for Zone A, related to the local deformation of the cross-section of the RHS tube. For the endplate joints, Zone B also follows the specifications in Annex B of prEC3-1-8, but it must be combined with the equivalent cross-section component model to tackle the behavior of the tube zone. Several subtypes exist that have been widely studied, namely the connection to concrete filled tubes (Wang et al, 2009; Wang \& Zhang, 2017; Li et al, 2019; Fan et al, 2021) or solutions with through-thickness long bolts (Van Long et al, 2015; Zhou et al, 2019). Finally, the reverse channel joint (Lopes et al, 2013) combines the standard behavior of end-plate joints (Zone B.2) with the equivalent cross-section component model (Zone A) and the specific behavior of the reverse channel (Zone B.1) that shares several features with the column face (Heistemann et al, 2015; Lopes et al, 2015).

\section{CODE SPECIFICATION}

\subsection{Framework and proposed implementation}

prEC3-1-8 follows a component methodology for the evaluation of the structural properties (resistance, stiffness and deformation capacity) of the various joint typologies. Clause 9, Hollow section joints, constitutes the exception, although a Technical Specification (CEN, 2021) is currently being prepared based on Weynand et al (2015) that specifies the design of hollow section joints in a component method format.

Clause 8 of prEC3-1-8 deals with joints between open section members while clause 9 deals with hollow section joints, following Wardenier et al (2010). Hence, a new clause 10 is proposed that addresses hybrid joints, meaning joints between hollow sections and open sections. Also, according to the new structure of prEC3-1-8, the new components that are currently not specified in prEC3-1-8 are added to Annex A and a new annex corresponding to the specific joint typologies addressed in this paper is specified: Annex E - I or H-section beam-to-tubular column joint configurations.

The following sub-sections briefly summarize the proposed implementation, in code format.

\subsection{Clause 10}

\subsubsection{1 - General}

(1) The design methods in Clause 10 should be used to determine the structural properties of joints connecting hollow section members and open cross-section members in framed structures. To apply these methods, joints should be modelled as an assembly of basic components. 
(2) The basic components identified in Table 10.1 (Table 1) should be used. Their properties should be determined in accordance with the provisions given in Annex A. Other basic components may be used provided their properties are based on tests, or analytical and numerical methods supported by tests, see Annex D of EN 1990 (2003).

(3) The design methods for basic joint components given in this Standard are of general application and may also be applied to similar components in other type of joint configurations. However, the specific design methods for determining the design moment resistance, rotational stiffness and rotation capacity of a joint are based on an assumed distribution of internal forces for the joint configurations indicated in Annex E. For other joint configurations, design methods for determining these properties should be based on appropriate assumptions for the distribution of internal forces.

\subsubsection{2 - Structural properties}

(1) The structural properties of joints should be based on the properties of its relevant components, which should be chosen among those in Table 10.1 (Table 1).

(2) The relationships between the properties of the basic components of a joint obtained from Annex A and the structural properties of the joint should be in accordance with Annex E for I or H-section beam-to-tubular column joint configurations.

\subsubsection{3 - Equivalent cross-section component model for RHS tubular members}

\subsection{1 - Application}

(1) The equivalent cross section component model, see Figure 10.1 (Figure 9), may be used to model the design resistance and the stiffness of the following basic components in joints connecting beams or trusses to a tubular RHS or SHS columns:

- RHS column face in out-of-plane bending.

- RHS column face in punching shear.

(2) The equivalent cross-section component model is applicable to the joint typologies illustrated in Figures 3 to 5.

\subsection{2 - Modes of failure}

(1) The possible modes of failure of the faces of the equivalent cross-section component model may be assumed to be similar to those expected to occur in the basic component that it represents.

\subsection{3 - Total effective length}

(1) The total effective length $\Sigma l_{\text {eff }}$ of each face of the equivalent cross-section component model should be such that the design resistance of each face is equivalent to that of the basic joint component that it represents.

NOTE The effective length of the equivalent cross section is a notional length and does not necessarily correspond to the physical length of the basic joint component that it represents.

10.3.4 - Design out-of-plane bending resistance

(1) The design out-of-plane bending resistance of a face should be determined from:

Table 1. Table 10.1 - Basic joint components.

\begin{tabular}{lll}
\hline Component name & Designation & Ref. to appl. rules \\
\hline RHS side wall in tension & $\mathrm{t}, \mathrm{tcsw}$ & A.24 \\
RHS side wall in compression & $\mathrm{c}, \mathrm{tcsw}$ & A.25 \\
RHS face in out-of-plane bending & $\mathrm{f}, \mathrm{tcf}$ & A.26 \\
RHS face in punching shear & ps,tcf & A.27 \\
RHS side wall in shear & tcsw & A.28 \\
RHS side wall in punching shear & tcps & A.29 \\
\hline
\end{tabular}



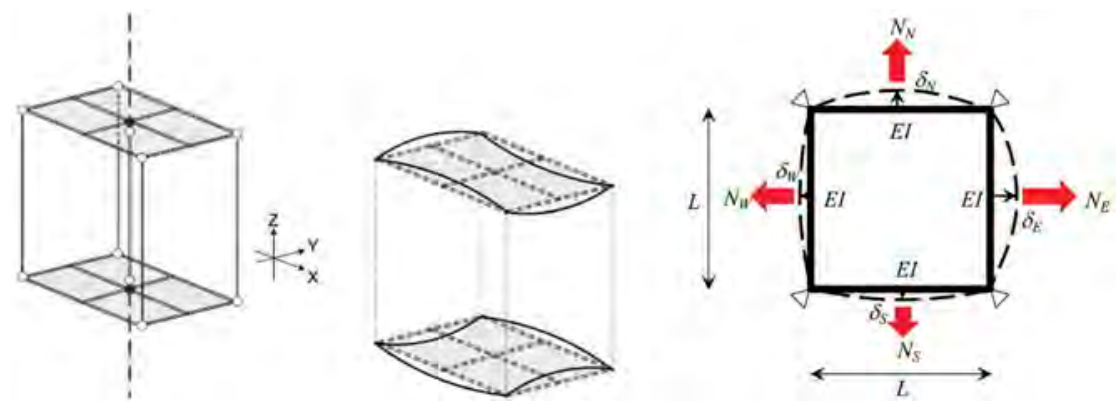

Figure 9. Figure 10.1 - Equivalent cross-section component model.
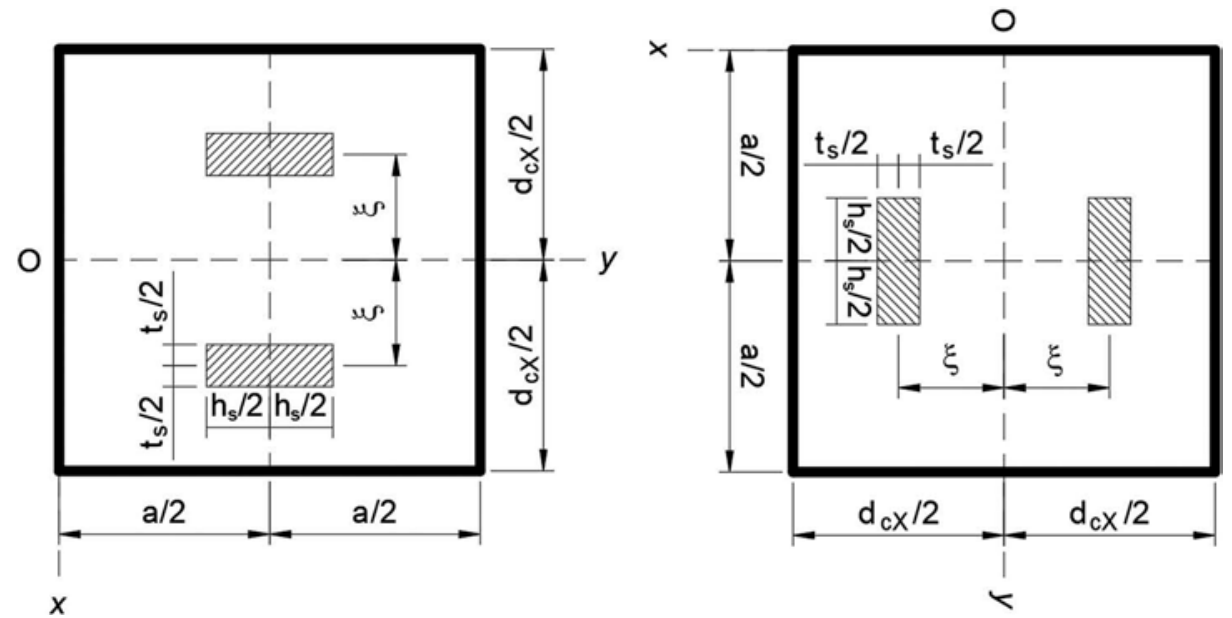

Figure 10. Figure A.16 - Types of loading on the face of the tube (reproduced from Simões da Silva et al, 2021b).

$$
F_{t, t c f, R d}=Q m_{p l} \sum l_{e f f}
$$

where $Q$ is a factor and $\Sigma l_{\text {eff }}$ is the total effective length, both given in Annex A, with

$$
m_{\mathrm{pl}}=\frac{t^{2} f_{y}}{4 \gamma_{M 0}}
$$

where $t$ is the thickness, $f_{y}$ is the yield stress and $\gamma_{M 0}$ is the partial factor.

\subsection{5 - Design out-of-plane bending stiffness}

(1) The 3D interaction between the flexibility of the column faces of RHS tubular members must be accounted for in the determination of its initial stiffness.

(2) The 3D interaction between the flexibility of the column faces of different plug-and-play connections may be accounted for using the equivalent cross-section component model defined in Figure 10.1 with 


$$
\left[\begin{array}{l}
P_{1} \\
P_{3} \\
P_{2} \\
P_{4}
\end{array}\right]=[K]\left[\begin{array}{c}
\delta_{1} \\
\delta_{3} \\
\delta_{2} \\
\delta_{4}
\end{array}\right]=\left[\begin{array}{llll}
k_{b 1} & k_{b 3} & k_{h 2} & k_{h 2} \\
k_{b 3} & k_{b 1} & k_{h 2} & k_{h 2} \\
k_{b 2} & k_{b 2} & k_{h 1} & k_{h 3} \\
k_{b 2} & k_{b 2} & k_{h 3} & k_{h 1}
\end{array}\right]\left[\begin{array}{c}
\delta_{1} \\
\delta_{3} \\
\delta_{2} \\
\delta_{4}
\end{array}\right]
$$

where $k_{b i}, k_{h i}$ are the initial stiffness coefficients to be determined according to A.26, $P_{i}$ is the load at cross section face $\mathrm{i}$ and $\delta_{i}$ is the deformation of the section face $i$.

\subsection{Structural properties of basic components}

\subsubsection{A.26-RHS face in out-of-plane bending}

\section{A.26.1 - Field of application}

(1) This clause applies to the two cases defined in Figure A.16 (Figure 10): the face may be loaded by:

- Face loaded by two transverse strips: two transverse rectangular loaded areas, approximately corresponding the flanges of an open section or a row of bolts of an end plate

- Face loaded by two longitudinal symmetrical strips: two vertical rectangular loaded areas, corresponding to a socket or a reverse channel welded to the column face.

(2) For both cases, a single plate is a valid limiting case, corresponding to a vertical or a horizontal fin plate.

(3) The two strips may be loaded with same sign forces (both tension or both compression), corresponding to a tensile or compressive joint or forces with a different sign (one tension and the other compression), corresponding to a bending moment.

\section{A.26.2 - Design resistance}

(1) The design resistance of a RHS wall face in out-of-plane bending is given by an appropriate yield line model and should be determined as follows:

$$
F_{t, c b}=\min _{i} F_{t, c b, i}=\min _{i} \frac{Q_{u, i} Q_{f} f_{y 0} t_{0}^{2}}{\gamma_{M 0}}
$$

with:

- $Q_{f}$ chord stress factor.

- $Q_{u, i}$ mechanism factor, that depends on the appropriate yield line model and the following geometrical parameters:

$-\beta$ ratio of the plate width $b_{s}$ to the column width $b_{0}$;

- $\eta$ ratio of the plate depth $h_{s}$ to the column width $b_{0}$.

\section{A.26.3 - Stiffness coefficient}

(1) The stiffness coefficients, $k_{b i}, k_{h i}$, of the face in out-of-plane bending are obtained from Harada \& Simões da Silva $(2019 \mathrm{a}, \mathrm{b})$ for a face loaded by two transverse strips or Simões da Silva et al (2021b) for a face loaded by two longitudinal symmetrical strips.

\subsubsection{A.27 - RHS face in punching shear}

\section{A.27.1 - Field of application}

(1) This clause applies to the two cases defined in Figure A.16 (Figure 10): the face may be loaded by:

- Face loaded by two transverse strips: two transverse rectangular loaded areas, approximately corresponding the flanges of an open section or a row of bolts of an end plate

- Face loaded by two longitudinal symmetrical strips: two vertical rectangular loaded areas, corresponding to a socket or a reverse channel welded to the column face. 


\section{A.27.2 - Design resistance}

(1) The design resistance of a RHS wall face in punching shear is given by an appropriate yield line model and should be determined as follows:

$$
F_{t, c p s}=\frac{f_{y 0}}{\sqrt{3} \gamma_{M 0}} t_{0} l_{p, e f f}
$$

where $l_{p, e f f}$ is the effective length of the face in punching shear that depends on the appropriate yield line model.

A.27.2 - Stiffness coefficient

(1) The stiffness coefficient of the face in punching shear is taken as infinity.

$$
k_{p s, t c f}=\infty
$$

\subsection{Annex E-I or H-section beam-to-tubular column joint configurations}

5.4.1 E.1 - Scope

(1) This Annex applies to bolted joints between RHS tubular columns and I-section beams according to Figures 3 to 5.

5.4.2 E.2 - Design resistance

(1) Joints should be designed to resist the bending moments, axial forces, and shear forces applied to the joints by the connected members.

(2) The stresses due to internal forces and moments in a member may be assumed not to affect the design resistances of the basic components of a joint.

\subsubsection{E.3 - Rotational stiffness}

(1) The rotational stiffness of a joint should be determined from the flexibilities of its basic components, each represented by an elastic stiffness coefficient $k_{i}$ obtained from Annex A.

(2) For bolted end plate joints with more than one row of bolts in tension, the stiffness coefficients $k_{i}$ for the related basic components should be combined.

\section{CONCLUDING REMARKS}

This paper presented the proposal of a framework and operational proposal for the inclusion of hybrid joints between tubular columns and open section beams in EC3-1-8, providing a design specification for the most common types of joint typologies and allowing for the evaluation of their stiffness and resistance. The equivalent cross-section component model for the tube zone is able to capture the 3D interactions between the column faces of RHS tubes and thus allow to efficiently assess the contribution of the column faces towards the momentrotation response of these joints.

\section{REFERENCES}

LKAB. 2021. HYBRIT - Towards Fossil-Free Steel. https://www.lkab.com/en/about-lkab/technologicaland-process-development/research-collaborations/hybrit-for-fossil-free-steel/accessed 2021/03/13.

CEN. 2005. EN 1993-1-8: Eurocode 3 - Design of steel structures - Part 1-8: Design of joints. 2005 (+AC:2005 +AC:2009)

CEN. 2021. prEN1993-1-8: Eurocode 3 - Design of steel structures - Part 1-8: Design of joints (March 2021). 
CEN. 2003. EN 1990: Eurocode - Basis of structural design. 2003

CEN. 2021. TS 1993-1-801: Hollow section joint design according to the component method. First draft.

Fan, J., Zhao, J. \& Gao, W. 2021. Moment-rotation model of endplate blind bolted joints with CFST column. Journal of Constructional Steel Research 176: 106446.

France, J.E., Davison, J.B. \& Kirby, P.A. 1999. Strength and Rotational Response of Moment Connections to Tubular Columns using Flowdrill Connectors. Journal of Constructional Steel Research 50: 1-14.

Gomes, F.T., Jaspart, J-P. \& Maquoi, R. 1996. Moment capacity of beam-to-column minor axis joints. In: Proceedings of IABSE international colloquium on semi-rigid structural connections, Istambul, Turkey. IABSE: 319-326.

Harada, Y. \& Simões da Silva, L. 2019. Three-dimensional macro-modelling of rectangular steel hollow section beam-to-column joints under cyclic loading - Part 1: Cyclic out-of-plane behaviour of single isolated column plate, Journal of Constructional Steel Research 162: 105713.

Harada, Y. and Simões da Silva, L. 2019. Three-dimensional macro-modelling of rectangular steel hollow section beam-to-column joints under cyclic loading - Part 2: Modelling by an extended component-based approach. Journal of Constructional Steel Research 162: 105714.

Heistermann, C., Koltsakis, E., Veljkovic, M., Lopes, F., Santiago, A. \& Simões da Silva, L. 2015. Initial stiffness evaluation of reverse channel connections in tension and compression. Journal of Constructional Steel Research, 114: 119-128.

Jones, M.H. \& Wang, Y.C. 2011. Shear and bending behaviour of fin plate connection to concrete filled rectangular steel tubular column - Development of a simplified calculation method. Journal of Constructional Steel Research 67: 348-352.

Li, B., Wang, J., Lu, Y., Zhang, Z. \& Wang, J. 2019. Seismic response tests and analytical assessment of blind bolted assembly T CFST frames with beam-connected SPSWs. Engineering Structures 178: 343-360.

Lopes, F.C., Santiago, A., Simões da Silva, L., Heistermann, T., Veljkovic, M. \& da Silva, J.G. 2013. Experimental behaviour of the reverse channel joint component at elevated temperatures. International Journal of Steel Structures, 13(3): 1-14.

Lopes, F., Santiago, A., Simões da Silva, L., Iqbal, N., Veljkovic, M. \& da Silva, J.G.S. 2015. Subframes with reverse channel connections to CFT composite columns - experimental evaluation. Advanced Steel Construction, 11(1): 110-125.

Oktavianus, Y., Goldsworthy, H. \& Gad, E. 2018. A blind bolted moment connection with an RBRF for composite moment resisting frames. $13^{\text {th }}$ International Conference on Steel, Space and Composite Structures 31 January - 2 February 2018, Perth, Australia.

SCI/BCSA. 2005. Joints in steel construction: simple connections. The Steel Construction Institute (SCI) \& The British Constructional Steelwork Association (BCSA).

Simões da Silva, L., Neves, L.C. \& Gomes, F.T. 2003. Rotational stiffness of RHS joints. Journal of Structural Engineering 129(4): 487-494.

Simões da Silva, L., Silva, L.C., Tankova, T., Craveiro, H., Simões, R., Costa, R., D’Aniello, M., Landolfo, R. 2021a. Performance of modular hybrid cold-formed/tubular structural system. Structures 30: 1006-1019.

Simões da Silva, L., Craveiro, H., Costa, R., Gervásio, H., Simões, R., Tankova, T., Iglesias, G., Agorostiza, A., Bureau, A., Nguyen, T.M., Veljkovic, M., Yan, R., Frade, H., Faria, R., Marques, B., Landolfo, R., D'Aniello, M., Poursadrullah, A. 2021b. INNO3DJOINTS - INNOvative 3D JOINTS for robust and economic hybrid tubular construction. Research Fund for Coal and Steel: Final Report, EU, Brussels.

Tizani, W. \& Ridley-Ellis, D.J. 2003. The performance of a new blind-bolt for moment-resisting connections. In: Jaurietta, M.A., Alonso, A., Chica, J.A. (eds.), Tubular Structures X, Proceedings of the $10^{\text {th }}$ international symposium on tubular structures, Madrid, Spain, 18-20 September 2003. Rotterdam: Balkema, 395-400.

Tizani, W., Al-Mughairi, A., Owen, J.S. \& Pitrakkos, T. 2013. Rotational stiffness of a blind-bolted connection to concrete-filled tubes using modified Hollo-bolt. Journal of Constructional Steel Research 80: 317-331.

Togo, T. 1967. Experimental study on mechanical behaviour of tubular joints, Doctoral Thesis, Osaka University (in Japanese).

Van-Long, H., Jaspart, J-P. \& Demonceau, J-F. 2015. Extended end-plate to concrete-filled rectangular column joint using long bolts. Journal of Constructional Steel Research 113: 156-168.

Wang, J. \& Zhang N. 2017. Performance of circular CFST column to steel beam joints with blind bolts. Journal of Constructional Steel Research 130: 36-52.

Wang, J-F., Han, L-H. \& Uy, B. 2009. Behaviour of flush end plate joints to concrete-filled steel tubular columns. Journal of Constructional Steel Research 65: 925-939. 
Wang, Z-Y. \& Wang Q-Y. 2016. Yield and ultimate strengths determination of a blind bolted endplate connection to square hollow section column. Engineering Structures 111: 345-369.

Wardenier, J., van der Vegte, G.J. \& Liu, D.K. 2007. Chord stress function for rectangular hollow section $\mathrm{X}$ and $\mathrm{T}$ joints In: Proceedings of the $17^{\text {th }}$ International Offshore and Polar Engineering Conference, Lisboa, Portugal, 2007. 3363-3370.

Wardenier J., Packer J.A., Zhao X.-L., Ven der Vegte A. 2010. Hollow section in structural applications. CIDECT, $2^{\text {nd }}$ edition.

Weynand K., Jaspart J.-P., Demonceau J.-F., Zhang L. 2015. Component method for tubular joints. CIDECT Report $16 \mathrm{~F}-3 / 15$.

Yeomans, N.F. 1998. Rectangular hollow section column connections using the Lindapter HolloBolt. In: Choo, Y.S., van der Vegte, G.J. (eds.), Tubular Structures VIII, Proceedings of the $8^{\text {th }}$ international symposium on tubular structures, Singapore, 1998. Rotterdam: Balkema, 559-566.

Zhou, G., An Y., Li, D. \& Ou J. 2019. Analytical model of moment-rotation relation for steel beam to CFST column T connections with bidirectional bolts. Engineering Structures 196: 109374. 


\title{
Selected aspects of designing the cold-formed steel structures
}

\author{
L. Sokół \\ Indépendant, Centre des Hautes Etudes de la Construction, Arcueil, France \\ K. Rzeszut \\ Institute of Building Engineering, Poznan University of Technology, Poznań, Poland
}

\begin{abstract}
This paper addresses the selected issues of designing the cold-formed steel structures in the form of shells and bars such as facades, purlins, wall rails and main bearing capacity members. In first part of the study particular consideration is paid on stability of steel structures with a reference to the theoretical background of global, local and distortional buckling. To study the most typical stability response of structures with imperfections using nonlinear algebraic equilibrium equations which strictly describe pre- and post-buckling behaviour of structures a basic bar model is analysed. The second part of the article presents the transition from the von Kàrmàn scientific theory to the first semi-empirical approach known as "Winter formulas" and the formulas adopted in EN 1993-1-3 and EN 1993-1-5, to be currently used in structural engineer practice. Then, the particularities in the verification of the resistance and different modes of buckling of the cold formed profiles with stiffened or unstiffened walls are discussed, through theoretical calculations and test-assisted calculations. Finally, the typical applications of cold formed products are presented.
\end{abstract}

\section{INTRODUCTION}

Research on the development of theories and methods of designing thin-walled cold-formed steel structures is currently carried out in many centres and covers a very wide range of problems. The use of cold formed steel sections is very advantageous from an economic point of view, however, the design of this type of structure presents many difficulties due to their high sensitivity to initial geometric imperfections and their tendency to local instability. The commonly used beam theory proposed by Timoshenko (1961) and developed by Vlasov (1963) does not allow taking into account local effects. In turn, it is possible using the shell theory in FEM and the interactive buckling analysis, which may take the form of local buckling, distortional, flexural, torsional or flexural-torsional. Although FEM analysis allows for a comprehensive analysis of the entire structural system, it is still a very time-consuming process. In Chou \& Rhodes (1997) reviewed the work on plate buckling with particular emphasis on experimental work on thin-walled plates and beams. Some of the experimental results were selected comprehensively and exhaustively, and then developed to form a database for use by future researchers. The current state of knowledge on the rational design of steel structures made of cold-formed sections, both in relation to calculation models and to construction issues, is presented in Bródka et all. (2006). It includes the latest results of experimental tests of bent sheet structures and discusses a number of complex calculation models for thin-walled structures proposed in European standards. A thorough analysis of the works carried out in the last few years in the field of designing thin-walled steel structures was also carried out by Schafer (2011). He put particular emphasis on the review of currently used calculation 
methods together with the analysis of their effectiveness. In addition, he presented the progress in the application of individual analysis and design methods and indicated future directions for the development of cold-formed steel structures, at the forefront of which are issues related to geometric imperfections. In the case of cold formed steel members, the initial geometric imperfections have a significant influence on the stability response of the structure. There are many works that present the different types of geometric imperfections characteristic of cold-formed structures and the ways of introducing them into the numerical model. One of the most common methods of accounting for initial geometric imperfections, dominant in design standards, is the use of an appropriate equivalent load or initial deflection Kozłowski (2008), Murzewski (1996) This approach is based on a second-order analysis in which the effects of residual stresses and initial geometric imperfections in individual elements are taken into account in the global analysis. In Barszcz \& Gizejowski (2007) the authors proposed an alternative method of imperfection modelling, based on the concept of equivalent bar stiffness. In this method, the bar is treated as a hypothetically simple element, and its stiffness is determined at each load level. This approach does not require explicit modelling of equivalent geometric imperfections or equivalent forces. The methods presented above work only in the case of global imperfections, while in the case of local imperfections it is necessary to use the shell models. Then it is possible to introduce to the initial configuration of the bar deformed geometry obtained on the basis of measurements of actual imperfections or standard tolerances. However, this method is very laborious, especially when the bar is FEM-modelled with shell elements. Moreover, due to the large randomness of imperfections, the obtained results are not always reliable. The problem of the plausibility of the results of numerical analyses concerning the stability of the structure was undertaken in Schafer \& Peköz (1998) examining the accuracy of the computational models taking into account the initial geometric imperfections and residual stresses and comparing the obtained results with the results of experimental tests. In the works Dubina \& Ungureanu (2001) the influence of local geometric imperfections of thin-walled sections on the stability of columns and short beams was analysed. Particular attention was paid to the characterization and classification of imperfections in order to develop convenient methods of their introduction into nonlinear FEM models. Since the most dangerous imperfections are those whose shape corresponds to the buckling modes, a very effective method of considering them can be the method of generating the shape of the deformed geometry of the initial nonlinear analysis tasks as a linear superposition of the buckling modes obtained from solving the linear eigenvalue problem Rzeszut et all. (2004). In this method, the amplitudes of the buckling modes are scaled with proportionality coefficients determined from actual imperfections measurements using the Galerkin-based error minimization. The studies by Garstecki \& Rzeszut (2009) describe the effectiveness of the above method in terms of the number of measurement points and the manner of their distribution along the bar length, minimizing the approximation error. It is worth noting that the amplitude and shape of the imperfections strongly affect the stability of the structure. Therefore, the correct modelling of the imperfection corresponding to the actual measured geometrical imperfections plays a key role in the stability analysis and design of thin-walled members. This problem is related to another dangerous phenomenon, interactive buckling. The interaction of the global ultimate load capacity and the local critical load capacity was investigated by (Kowal 2001). He pointed out that in the case of an ideal column, the loss of local and global stability may occur separately, which corresponds to the assumption of uncoupled equations. However, in real structures, burdened with imperfections, there is a mutual influence of local and global stability. The author criticized the commonly applicable criterion of the initial column bending as a condition for technical acceptance of the structure and proposed the introduction of a new constraint, which is taking into account the influence of interactive buckling. The interaction of global and local stability loss occurs when the critical loads corresponding to local and global buckling are equal or slightly different. This phenomenon may lead to a reduction in the value of the critical load and to the unstable post-critical behaviour of the structure. Due to the high sensitivity of the structure to initial imperfections, the stability analysis should be carried out with appropriate consideration of the initial geometric imperfections, both local and global. 


\section{MECHANICS OF THIN-WALLED, COLD-FORMED MEMBERS IN STABILITY PROBLEMS}

The main mechanism causing the failure of thin-walled steel structures is the loss of stability. The broadly understood stability of a structure is defined as a phenomenon in which a slight disturbance causes a very large change. Depending on the effect of the disturbance, the condition of the structure can be defined as stable or unstable. Lapunov, who investigated the stability of differential equations using two separate methods, direct and indirect, is considered to be the creator of this definition. The indirect method is based on the assumption that the explicit form of the solution of the differential equation is known. On the other hand, the more general direct method does not require knowledge of an explicit solution. The works of Lapunov were developed by Bogusz (1972), who formulated the concept of technical stability.

Another approach to the analysis of the equilibrium states of the structure is the energy approach, consisting in the analysis of the potential energy, which is the basis for determining the equilibrium state of the structure. The structure is in equilibrium when the potential energy reaches a minimum. The necessary condition for the occurrence of the minimum potential energy is the disappearance of its first variation. This condition can be written as:

$$
\delta \Pi=0
$$

where $\Pi$ is the potential energy of the system.

The nature of the equilibrium path is determined by the higher order variations of potential energy. The type of bifurcation point can be determined based on the analysis of the second variation of the potential energy according to:

$$
\delta^{2} \Pi\left\{\begin{array}{cc}
>0 & \text { stable } \\
=0 & \text { neutral } \\
<0 & \text { unstable }
\end{array}\right.
$$

In the classical theory of stability, the type of equilibrium path can be illustrated by a ball moving on a differently shaped surface. Figure 1a shows the stable equilibrium. After any position disturbance, the ball always returns to its initial position, which corresponds to the minimum of potential energy. Unstable state of equilibrium is illustrated in Figure 1b: the initial position of the ball corresponds to the maximum of potential energy, and a small impulse changing the position of the ball causes an imbalance until the minimum potential energy is reached. Figure 1c shows the state of neutral equilibrium in which the ball changes its position by rolling on a horizontal plane without changing the potential energy. In the problems with many degrees of freedom, there are also other cases, e.g. the metastable point (Figure 1d, e). It is a point on a curve or surface characterized by local minimum of potential energy, that in any of its surroundings, the ball may follow the stable or unstable path of equilibrium. This surface is generally referred to as a hypersurface.

In stability studies, the primary task is to identify bifurcation points or limit points, since it is at these points that the structure is lost. The bifurcation point can be determined on the basis of solving the eigenvalue problem, as a result of the critical load value and a normalized

a)

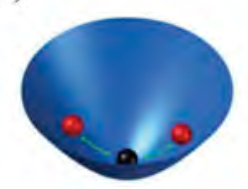

b)

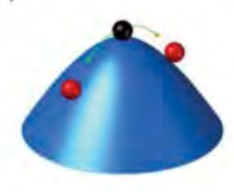

c)

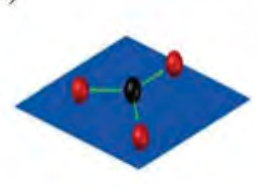

d)

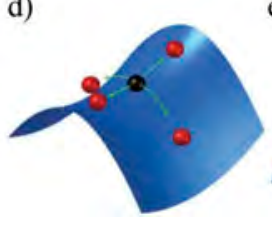

e)

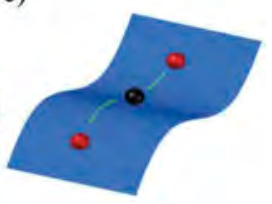

Figure 1. States of equilibrium: a) stable, b) unstable, c) neutral, d), e) metastable. 
eigenvector are obtained. Based on the critical load value, only multidirectional equilibrium path is determined, but no information is obtained about the post-critical behaviour of the structure. Therefore, it is extremely important to define the nature of the bifurcation point. For this purpose, an analysis of post buckling should be performed by determining the higherorder variation of potential energy. Hence, a stable and symmetrical bifurcation point can be distinguished when the following conditions are met:

$$
\delta^{2} \Pi=0, \quad \delta^{3} \Pi=0, \quad \delta^{4} \Pi>0
$$

and an unstable bifurcation point when:

$$
\delta^{2} \Pi=0, \quad \delta^{3} \Pi=0, \quad \delta^{4} \Pi<0 .
$$

Moreover, when:

$$
\delta^{2} \Pi=0, \quad \delta^{3} \Pi>0, \quad \delta^{4} \Pi<0,
$$

the bifurcation point is asymmetric. It is worth noting that reaching the bifurcation point should not always be associated with the failure mechanism of structure. Equilibrium paths can take a more complex form when there is more than one minimum of potential energy. Usually it is associated with so called snap-through phenomenon based on transition from the local to the global minimum of potential energy. Commonly it is associated with the release of internal energy due to a sufficiently large impulse and the transition of the structure to a lower energy level. In thin-walled steel structures, this phenomenon is accompanied by a loud sound effect. The impulse to snap-through phenomenon is usually caused by the specific configuration of initial geometric imperfections, difficult to predict and define. Therefore, snapthrough analysis presents a challenging engineering issue and creates a lot of design problems (Zhao et. all 2008). In the case of variable loads, a multiple snap-through may cause material fatigue and, consequently, its brittle failure. An excellent illustration of this behaviour can be found in the example of the Mises truss of small height (Figures 2a), in which the bars are elastic, and the deformations are symmetrical. When imposing ever-greater deflections $u$, the value of the force $P$ can be calculated using the equilibrium equation. Hence $P$ is a function of $u$. Note that the part of the curve (1-2) represents the unstable equilibrium path. In the case of the gravitational action of force $P$, the snap-through takes place from point 1 to point 1 'located on the stable equilibrium path 1'-4. In the unloading process, the structure follows the equilibrium path from point 4 through point 1 'to point 3 , for which the force $P=0$ is related to the displacement $u=2 f$. This is an example of an irreversible process. Full non-linear equilibrium paths for Mises's truss were presented by Kwaśniewski (2009). As a result of experimental studies on slender steel girders Rzeszut et al. (2009) it was shown that the snap through can be a fully reversible process (Figure 2c).

The above considerations concern the global stability of bars. Thin-walled bars, depending on the ratio of their width to thickness, may additionally lose their local stability under the influence of compressive or shear stresses. When considering the general stability, the Vlasov theory is used, in which a model of a bar with an open cross-section is assumed, which meets the conditions of the rigid contour hypothesis taking into account warping. When considering local stability, it is assumed that the member axis remains undeformed, while the contour is distorted. Thus, the rigid contour hypothesis is rejected here. In addition to the local loss of stability, distortion instability is observed. The analysis of the local loss of stability is carried out on the basis of the theory of plates and shells, the foundations of which were formulated by, inter alia, Timoshenko, Bleich and Brzoska. Numerical analysis of thin-walled bars is carried out using the shell model in Finite Element Method (FEM) or in the Finite Strip Method (MPS). Figure 3 illustrates the phenomena related to the stability of thin-walled elements. It presents the critical stresses of an axially compressed thin-walled bar determined with the use 
a)

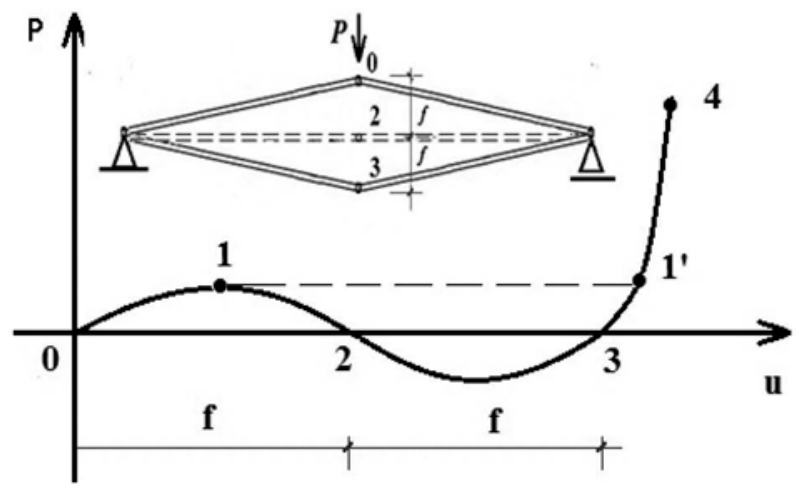

b)

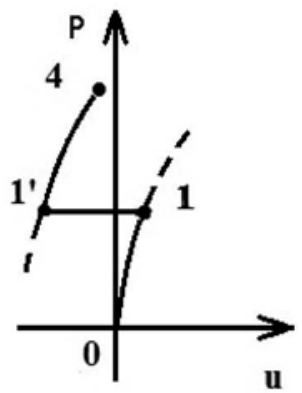

Figure 2. Snap through phenomenon; a) model of a structure and equilibrium paths for Mises truss Rzeszut (2015), b) results of experimental tests Rzeszut et al. (2009).

of FEM beam and shell elements and the Vlasov theory. In the case of very slender bars, characterized by the global loss of stability, all results obtained by FEM are in great agreement with the Vlasov beam theory.

However, in the case of bars, where first buckling mode is local, the application of Vlasov theory leads to very large errors. Therefore, in the case of thin-walled steel members, an individual numerical analysis based on the shell models is necessary. However, despite the everfaster developing numerical technologies and despite the increase in computing power of computers, the analysis of the entire real structure using the shell models is still too timeconsuming and impractical. In engineering applications, torsion and plate stability are analysed separately. This approach can be dangerous when assessing the bearing capacity of real thin-walled, cold-formed steel structures. Therefore, when assessing the load bearing capacity of elements according to Vlasov theory, the influence of loss of cross-sectional walls stability should be additionally investigated in accordance with the plate theory. The local loss of

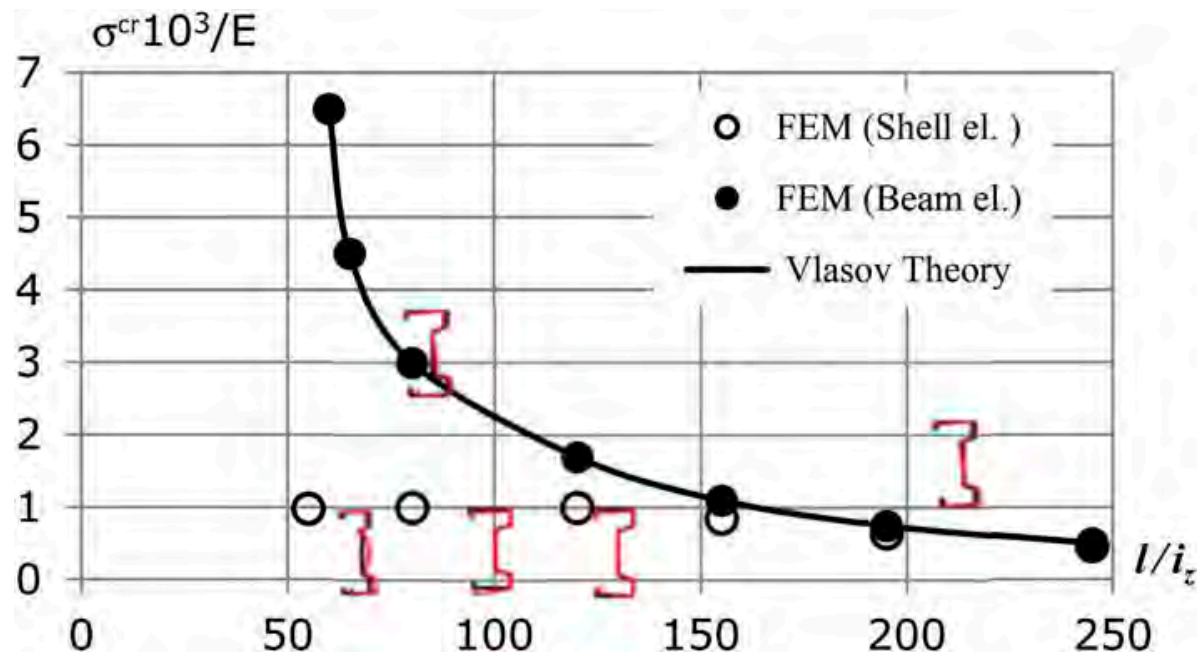

Figure 3. Critical stresses of an axially compressed thin-walled bar determined with the use of FEM beam and shell elements and the Vlasov theory, Rzeszut (2015). 
stability is also related to the post-critical load bearing capacity, which is the ability of the cross-sectional walls to continue load bearing capacity in the safe range after reaching a critical state. The condition for such behaviour of the wall is that at least one longitudinal edge is stable. It needs to be highlighted that multimodal post-critical analysis of thin-walled bars allows for the determination of interactive buckling, which may lead to a reduction in the critical load value, to unstable post-critical behaviour and to a high sensitivity to imperfections.

\section{NUMERICAL EXAMPELS}

\subsection{Model structures}

In order to analyse the complex cases of initial imperfection interactions, a model structure was developed consisting of four perfectly rigid bars connected by linear elastic hinges with the rotational stiffness $k_{n}$ where $n=1,2,3$ (Figure 4).

It allows for derivation of close form formulas accounting for large displacements in a form of a set of three nonlinear equations of equilibrium:

$$
\left\{\begin{array}{l}
k_{1}\left[a s \frac{u_{1}}{L}-a s \frac{u_{2}-u_{1}}{L}\right]=P u_{1} \\
k_{2}\left[a s \frac{u_{2}-u_{1}}{L}-a s \frac{u_{3}-u_{2}}{L}\right]=P u_{2} . \\
k_{3}\left[a s \frac{u_{3}-u_{2}}{L}-a s \frac{u_{3}}{L}\right]=P u_{3}
\end{array}\right.
$$

The above equations represent a non-linear eigenvalue problem in which the displacement of nodes $u_{n}$ is unknown. The initial geometrical imperfections are introduced into the model in the form of initial displacement $v_{n}{ }^{i}$ and do not induce any stress. Thus the total displacements take the form:

$$
u_{n}=u_{n}^{i}+u_{n}^{e}
$$

The terms with superscript $e$ represent elastic part of displacements and with superscript $i$ initial geometrical imperfections. Numerical examples are solved for various amplitudes of initial imperfections (Eq. 8) introduced as a linear combination of eigenvectors $u_{m}{ }^{\mathrm{cr}}$ obtained from the linear eigenvalue problem scaled by mode participation factor $a_{m}$ :

$$
u_{n}^{i}=\alpha_{m} \cdot u_{m}^{c r}
$$

From among many special cases studied by the authors, let us consider the example shown in Figure 5.

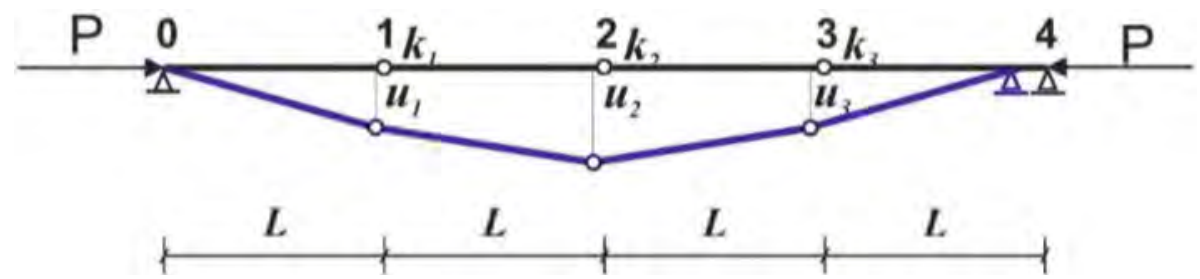

Figure 4. Geometry of model structure, Rzeszut (2015). 
a)

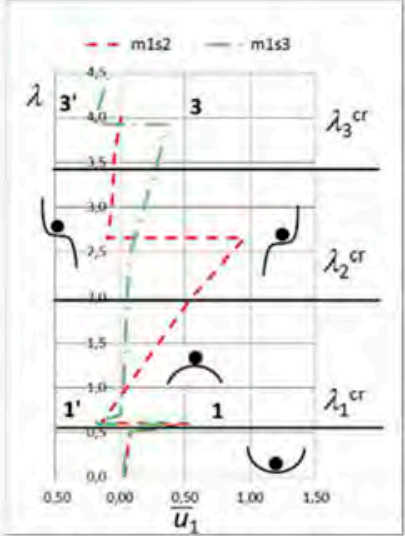

b)

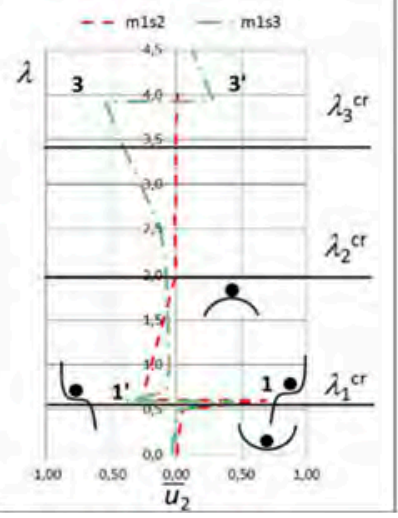

c)

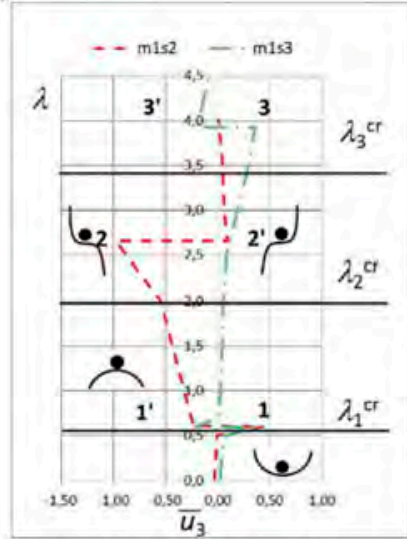

Figure 5. Equilibrium paths obtained for initial geometric imperfections developed as superposition of: low amplitude of the first and medium amplitude of the second or third buckling mode (m1s 2 or $\mathrm{m} 1 \mathrm{~s} 3$ ); displacement of the node: a) No. 1, b) No. 2, c) No. 3, Rzeszut (2015).

This example shows the equilibrium paths $\lambda \quad \overline{u_{i}}$, where $\overline{u_{i}}$ is normalized displacement of $i^{t h}$ node with respect to bar length and $\lambda$ is buckling load multiplier obtained for small amplitudes of geometric imperfections developed according the shape of the first buckling mode (m1) and medium amplitude of second buckling mode (s2) or third one (s3). The presented paths describe the equilibrium paths in node 1, 2 and 3 respectively. It is worth to notice that in all three cases stable, unstable and metastable equilibrium states are observed. Moreover two snap-through and thus two bifurcation points are observed: the first is related to the first and the second is related to the second or third buckling mode.

The analysis of displacements before and after the snap-through shows that the initial imperfection, being a superposition of two different buckling modes, strongly influences the shape of the displacement vector. In Figure 6 pre- and post- snap-through displacement configuration for case $\mathrm{m} 1 \mathrm{~s} 2$ is presented. It can be seen that at the first bifurcation point (snapthrough from point 1 to point $1^{\prime}$ ) the decisive factor is the first buckling mode, and at the second bifurcation point (snap-through from point 2 to point $2^{\prime}$ ) shape of displacement corresponds to the second buckling mode.

On the other hand in Figure 7 pre- and post- snap-through displacement configuration for case $\mathrm{m} 1 \mathrm{~s} 3$ is presented. As it was shown in the previous case the first bifurcation point (snapthrough from point 1 to point $1^{\prime}$ ) the decisive factor is the first buckling mode, but at the second bifurcation point (snap-through from point 3 to point $3^{\prime}$ ) shape of displacement

a)

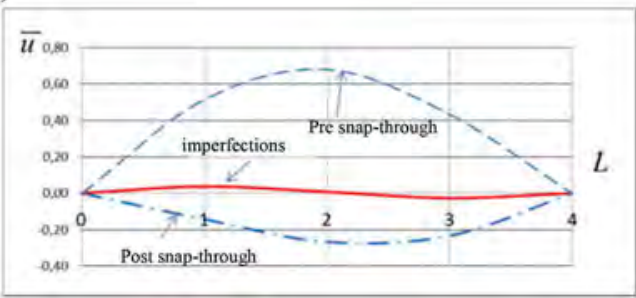

b)

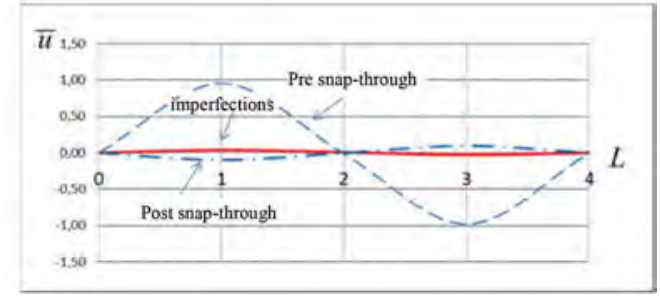

Figure 6. Pre- and post- snap-through displacement configuration for case m1s2, Rzeszut (2015). a) snap-through from point 1 to point $1^{\prime}$, b) snap-through from point 2 to point $2^{\prime}$. 
a)

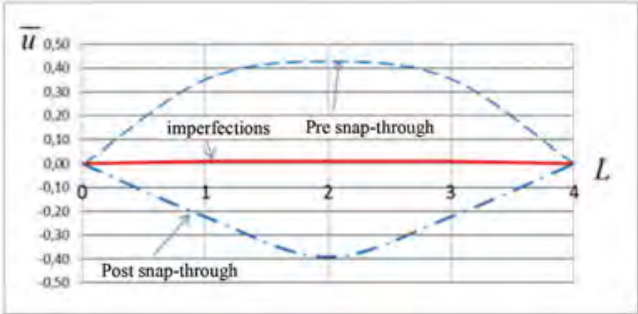

b)

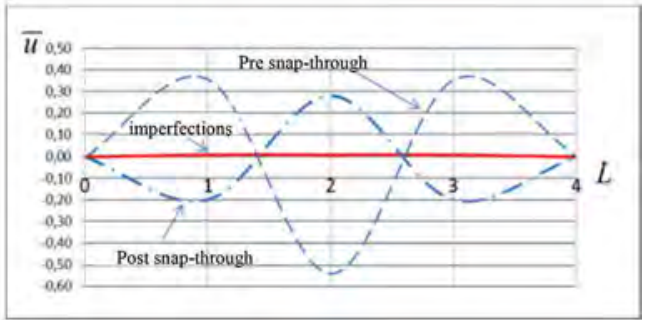

Figure 7. Pre- and post- snap-through displacement configuration for case m1s3, Rzeszut (2015). a) snap-through from point 1 to point 1', b) snap-through from point 3 to point $3^{\prime}$.

corresponds to the third buckling mode. Thus, the type of initial geometric imperfection strongly influences the nature of the equilibrium path.

\section{BASIS OF EFFECTIVE WITDH OF COMPRESSED PLATE CALCULATION}

\subsection{Theoretical basis}

The following differential equation for buckling of a plate was introduced by von Kàrmàn:

$$
\frac{\partial^{4} w}{\partial x^{4}}+2 \frac{\partial^{4} w}{\partial^{2} x \partial^{2} y}+\frac{\partial^{4} w}{\partial y^{4}}=\frac{1}{D}\left(N_{x} \frac{\partial^{2} w}{\partial x^{2}}+2 N_{x y} \frac{\partial^{2} w}{\partial x \partial y}+N_{y} \frac{\partial^{2} w}{\partial y^{2}}\right)
$$

where: $D=\frac{E t^{3}}{12\left(1-\nu^{2}\right)}, N_{x}, N_{y}$ and $N_{x y}$ are forces applied uniformly to the edges of the plate. In the case where the plate is subjected to a load $N_{x}$ uniformly distributed on edge a, the deflected shape is shown in the Figure 8.

The minimum potential energy method, with the series:

$$
w=\sum_{m=1}^{\infty} \sum_{n=1}^{\infty} a_{m n}\left(\sin \frac{\pi m x}{a} \sin \frac{\pi n y}{b}\right)
$$

gives the following solution:

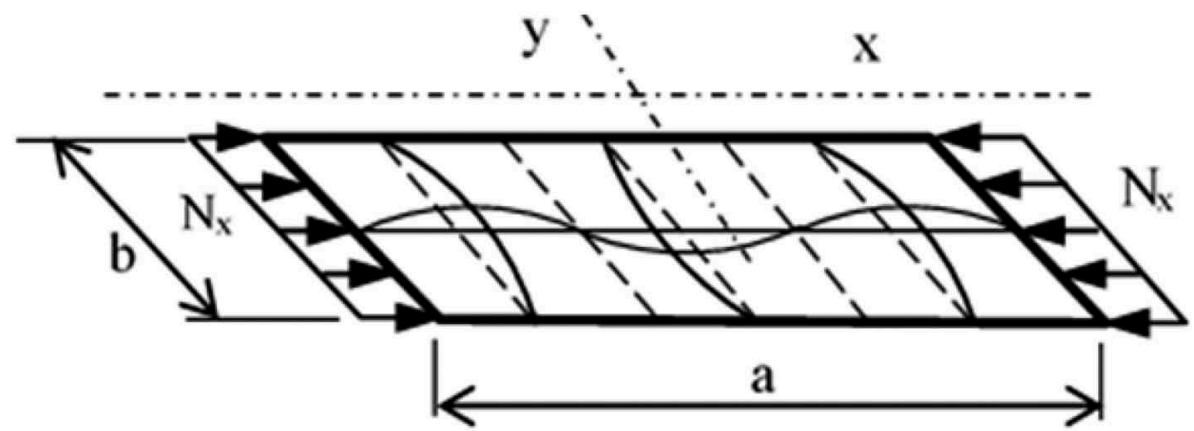

Figure 8. Rectangular plate subjected to compression stress. 


$$
N_{c r}=\frac{\pi^{2} a^{2} D}{m^{2}}\left(\frac{m^{2}}{a^{2}}+\frac{n^{2}}{b^{2}}\right)^{2} .
$$

When the $\mathrm{b}$ dimension is relatively large, the minimum value of the critical force $N_{x}$ is obtained with $n=1$ and $b=a$, which leads to the formula:

$$
\sigma_{c r}=\frac{N_{c r}}{t}=E\left(C \frac{t}{b}\right)^{2}
$$

where:

$$
C=\frac{\pi}{\sqrt{3\left(1-\nu^{2}\right)}}=1.90
$$

The distribution of the stresses over the width of the plate is not uniform, because the interior part undergoes a local buckling. The more the pressure applied to the plate increases, the more the stress in the middle of the wall decreases:

a)

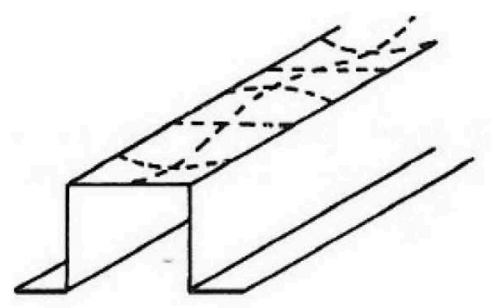

b)

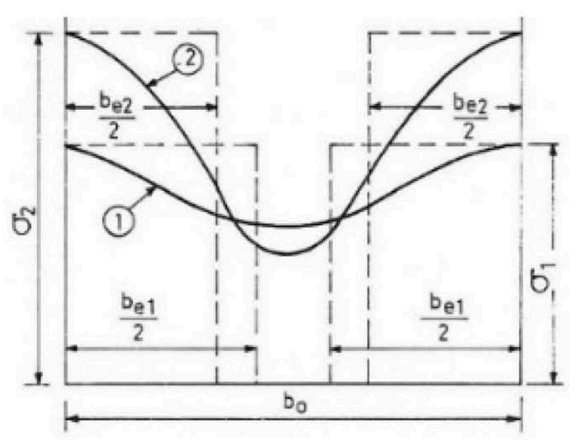

Figure 9. Local buckling in a compressed wall.

This observation led von Kàrmàn in 1932 to the concept of "effective width", where:

- the central part of the wall under buckling is neglected,

- the total load is carried by the external parties.

In this approach, it is assumed that on the edges the yield stress $f_{y}$ is reached and that it is constant over the fictitious effective width derived from (12) by replacing $\sigma_{c r}$ by $f_{y}$ and $b$ by $b_{e}$ :

$$
b_{e}=C t \sqrt{\frac{E}{f_{y}}} .
$$

From equations (12) and (14) the following relation can be obtained:

$$
\rho=\frac{b_{e}}{b}=\sqrt{\frac{\sigma_{c r}}{f_{y}}} .
$$




\subsection{Particularities to consider in order to adapt von Kàrmàn theory to cold formed sections}

Von Kàrmàn theory is based, in particular, on the following explicit or implicit assumptions:

(1) The section is composed of flat walls with sharp corners,

(2) The thickness of each wall is constant over whole its width,

(3) The yield stress is constant over whole section,

(4) There are no residual stresses in the section,

(5) The edge stress of all walls of the section is constant and equal to the yield stress,

(6) There are no geometric imperfections in the section.

In the case of cold formed sections, the above assumptions are not satisfied, namely:

- the corners are rounded and (2) the thickness is reduced in rounded corners (Figure 10);

- (3) the yield stress is higher and (4) the residual stress exists in the rounded corners (Figure 11);

- (5) the edge stress is not constant in the webs (Figure 12);

- (6) in real structures, imperfections always exist.

\subsection{Empirical improvement of von Kàrmàn theory}

Typical example of testing of trapezoidal sheeting behaviour, in order to investigate on the behaviour of sheeting where the upper flanges work in uniform compression and the webs work under stress gradient, is shown in the Figure 12. A typical example of experimental investigation on trapezoidal sheets, in order to verify their behaviour under a bending moment, where the upper flanges work in uniform compression and the webs work under stress gradient, is illustrated in Figure 13.

Based on large experimental and theoretical investigation, Winter (1947) found that Eq. (16) is applicable when the edge stress of the wall is $\sigma<f_{y}$ :

$$
b_{e}=C t \sqrt{\frac{E}{\sigma}}
$$

Subsequently, he demonstrated that there is a linear relation between $C$ and $t / b_{p} \sqrt{E \sigma}$ and consequently he proposed the following value for the term $C$ :

$$
C=1.9\left(1-0.475 \frac{t}{b_{f}} \sqrt{\frac{\sigma_{c r}}{f_{y}}}\right)
$$

where $b_{f}$ is explained in the Figure 10.

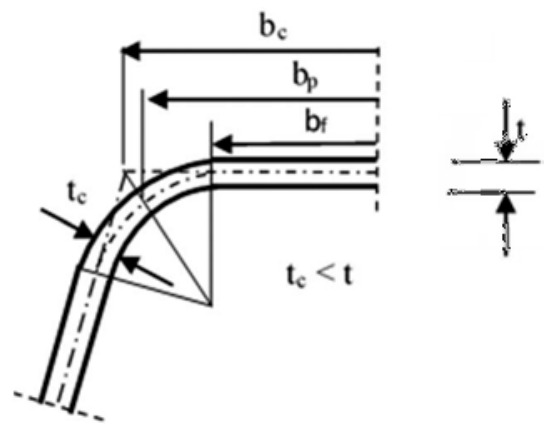

Figure 10. Rounded corner between two adjacent walls. 

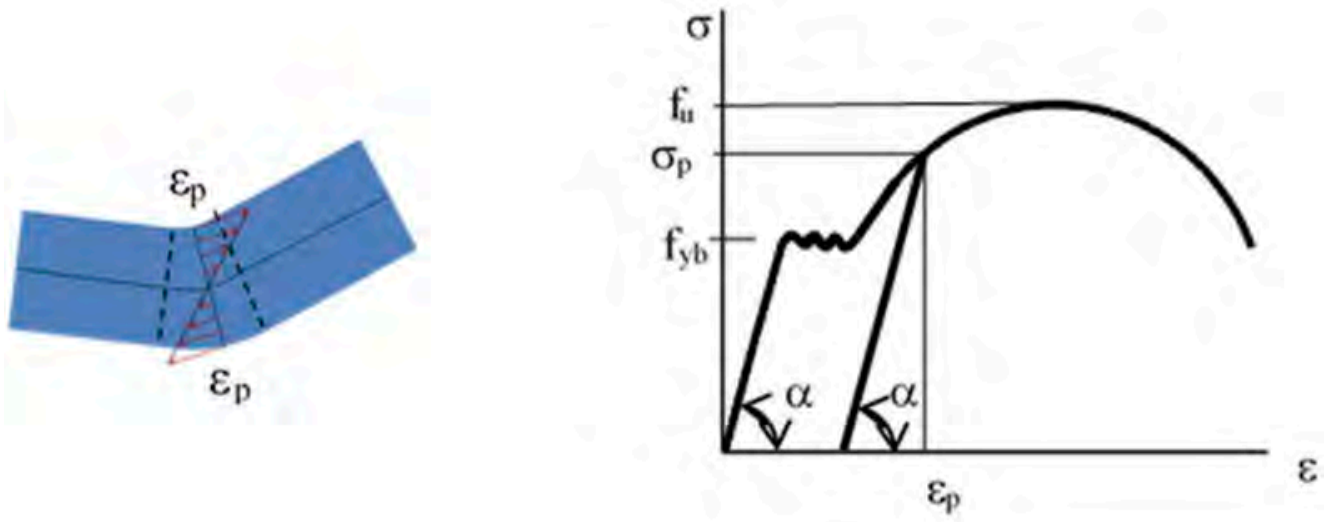

Figure 11. Effect of strain hardening in the cold worked corner.

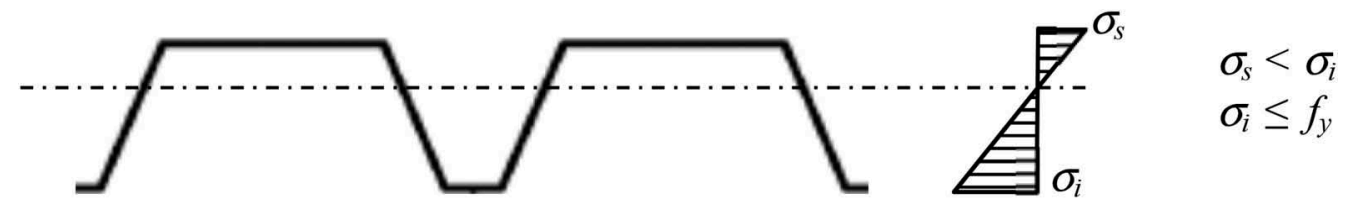

Figure 12. Distribution of stresses in asymmetric sheets.
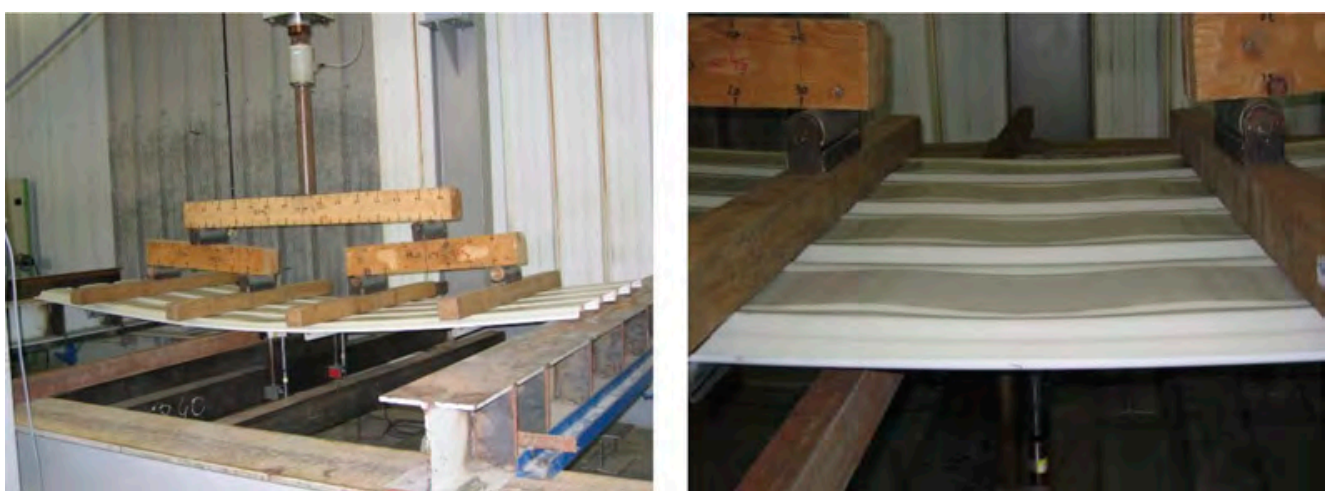

Figure 13. Example of testing of trapezoidal sheeting under bending moment.

Therefore, the equation (16) takes the form:

$$
b_{e}=1.9 t \sqrt{\frac{E}{\sigma}}\left(1-0.475 \frac{t}{b_{f}} \sqrt{\frac{E}{\sigma}}\right)
$$

so, the equation (16) may be written as a function of ratio $\sigma_{c r} / \sigma=\rho$ as follows: 


$$
\rho=\sqrt{\frac{\sigma_{c r}}{\sigma}}\left(1-0.25 \sqrt{\frac{\sigma_{c r}}{\sigma}}\right)
$$

After a long-accumulated experience, the equation (19) was refined as follows:

$$
\rho=\sqrt{\frac{\sigma_{c r}}{\sigma}}\left(1-0.22 \sqrt{\frac{\sigma_{c r}}{\sigma}}\right)
$$

The equation (18) can also be presented as:

$$
b_{e}=\rho b_{f}
$$

where:

$$
\begin{gathered}
\rho=\frac{1-0.22 / \lambda}{\lambda}, \\
\lambda=\frac{1.052 b_{p}}{t} \sqrt{\frac{\sigma}{E k}} .
\end{gathered}
$$

The formulae (21) to (23) are used in AISI Specification and in North American Specification. A similar formulation, although more universal, is adopted in EN 1993-1-5:

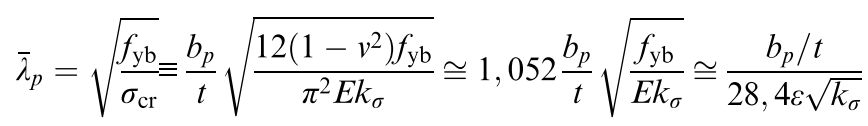

where: $b_{p}$ is explained in the Figure 10, $k_{\sigma}$ is the buckling factor corresponding to the stress ratio $\psi=\sigma_{2} / \sigma_{1}, \sigma_{1}$ and $\sigma_{2}$ are the edge stress of the wall, $\sigma_{2} \leq \sigma_{1}, \varepsilon=\sqrt{\frac{235}{f_{y}}}$.

When $\sigma_{c o m, E d}<f_{y b} / \gamma_{M 0}$ the coefficient $\rho$ is defined as follows:

$$
\begin{gathered}
\bar{\lambda}_{\mathrm{p}, \text { red }}=\bar{\lambda}_{p} \sqrt{\frac{\sigma_{\mathrm{com}, \mathrm{Ed}}}{f_{\mathrm{yb}} / \gamma_{\mathrm{M} 1}}} \\
\rho=\frac{1-0,055(3+\psi) / \bar{\lambda}_{\mathrm{p}, \text { red }}}{\bar{\lambda}_{\mathrm{p}, \text { red }}}+0,18 \frac{\left(\bar{\lambda}_{p}-\bar{\lambda}_{\mathrm{p}, \text { red }}\right)}{\left(\bar{\lambda}_{p}-0,6\right)} \text { but } \rho \leq 1
\end{gathered}
$$

\subsection{Taking into account of distortional buckling}

\subsubsection{Distortional buckling of plane walls with stiffeners}

The examples of distortional buckling and the calculation model for elements with intermediate and edge stiffeners are shown in the Figure 14.

According to this model the elastic critical buckling stress in the stiffener is defined as for an infinite long beam on elastic foundation under constant compression: 


$$
\sigma_{c r, s}=\frac{2 \sqrt{K E I_{s}}}{A_{s}}
$$

where: $A_{s}$ and $I_{s}$ are respectively area and second moment of area of the stiffener.

The buckling coefficient is determined in function of the relative slenderness $\overline{\bar{\lambda}}_{d}$

$$
\bar{\lambda}_{d}=\sqrt{f_{y b} / \sigma_{c r, s}}
$$

\subsubsection{Distortional buckling of section}

The examples of distortional buckling of sections are shown in the Figure 15.

A particular case of distortional buckling and the calculation model for beams under bending, with one flange held as shown in the Figure 16, was studied by Sokol (1979, 1988, 1995, 2000) and the results obtained have been incorporated into EN 1993-1-3.

Unlike the case of buckling of the stiffener, in this case is taken into account the variation of the compression in the member, depending on the bending moment distribution, as shown in the Figure 17.

The solution is found by expressing the total potential energy:

$$
E=\frac{L}{0}\left\{\frac{E I\left(y^{\prime \prime}\right)^{2}}{2}+\frac{\beta y^{2}}{2}+\frac{\delta_{1} q_{1}}{2}\left[(\eta-1) \frac{x^{2}}{2 L}-\eta x+\frac{L}{2}(1+\eta)\right]\left(y^{\prime}\right)^{2}+\frac{1}{2} \delta_{p} P\left(y^{\prime}\right)^{2}\right\} d x
$$

in form of functional $J[u]=F\left(\xi, u, u^{\prime}, u^{\prime \prime}\right) d \xi$ that reaches the minimum when its first variation is zero, expressed by the so-called Euler-Poisson relation:

$$
F_{y}-\frac{d}{d x} F y^{\prime}+\frac{d^{2}}{d x} F y^{\prime \prime}=0
$$

resulting in the following differential equation of equilibrium:

$$
\alpha\left(\frac{d^{4} y}{d \xi^{4}}+\pi^{4} K y\right)-\pi^{2} \delta_{1}\left[(\eta-1) \xi^{2}-2 \eta \xi+\eta+\delta_{P} \delta_{1} \psi+1\right] \frac{d^{2} y}{d \xi^{2}}--2 \pi^{2} \delta_{1}[(\eta-1) \xi-\eta] \frac{d y}{d \xi}=0
$$

a)
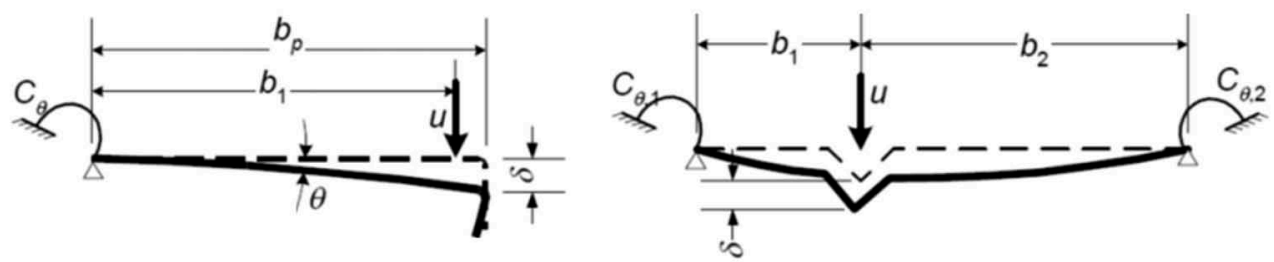

b)
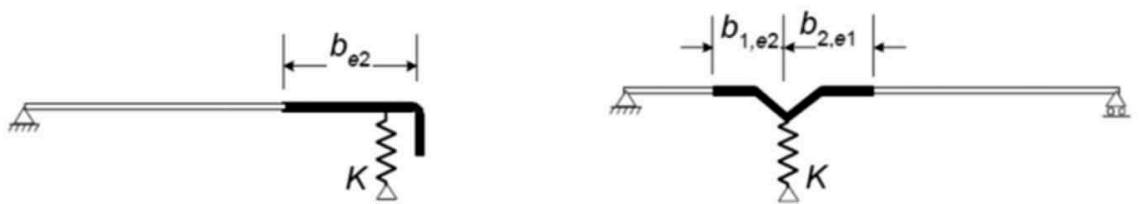

Figure 14. Examples of distortional buckling modes and determination of spring stiffness for edge and intermediate stiffeners of the plate wall. a) Actual system, b) Equivalent system. 

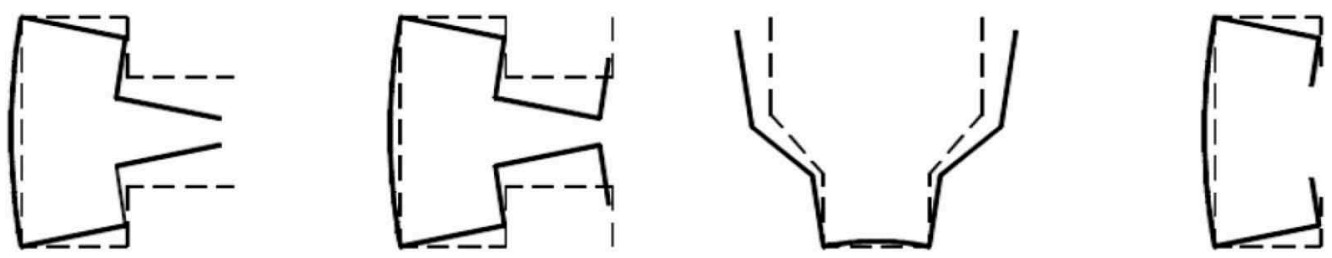

Figure 15. Examples of distortional buckling shapes.

a)

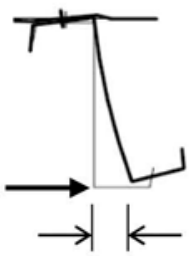

b)

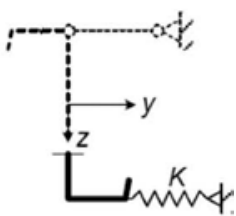

$\mathrm{K}=\mathrm{u} / \delta$

Figure 16. Calculation model for the distortion buckling of the beam with one flange fully supported laterally and partially maintained in rotation. a) Actual system, b) Equivalent system.

a)

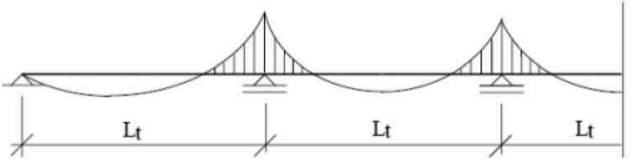

b)

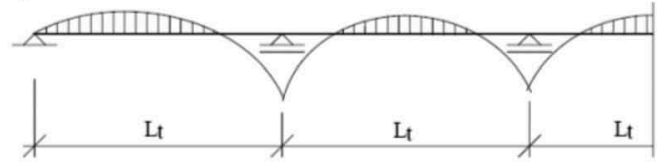

Figure 17. Variation of compression in the free flange depending on bending moment. a) Under down load, b) Under up-lift load.

Using the direct Galerkin method, with the functional basis $\Phi_{i}=\sin \pi i \xi$, the following system of $n$ equations is obtained:

$$
\left[\alpha+\delta_{1} \frac{2 \pi^{2}\left(2+\eta+3 \delta_{1} \delta_{p} \psi\right) j^{2}-3(1-\eta)}{6 \pi^{2}\left(j^{4}+K\right)}\right] a_{j}+\frac{4 \delta_{1}}{\pi^{2}\left(j^{4}+K\right)} \sum_{\substack{i \neq j \\ i \neq j}}^{n} \frac{i j\left(i^{2}+j^{2}\right)}{\left(i^{2}-j^{2}\right)}\left[\eta-(-1)^{i+j}\right] a_{j}=0
$$

where: $i=1, n ; j=1, n$.

The maximum eigenvalue $\alpha_{c r}$ of the matrix corresponding to the equation system (32) defines the critical buckling length $L_{f}$ :

$$
L_{f}=L \sqrt{\alpha_{c r}} \text {. }
$$

Finally, several numerical calculations with a series of different parameters led to the following empirical formula:

$$
L_{f}=\eta_{1} L_{a}\left(1+\eta_{2} R^{\eta_{3}}\right)^{\eta_{4}}
$$

where: $L_{a}$ is the distance between anti-sag bars, or if none are present, the span $L$ of the beam $\eta_{1}$ to $\eta_{1}$ are the coefficients depending on the number of anti-sag bars, the situation of the 
span (simple, end or intermediate) and direction of the load (down or uplift), given in Table 10.2 of EN 1993-1-3.

The buckling coefficient $\chi$ is defined using the buckling length $L_{f}$ from formula (34).

\section{CONCLUDING REMARKS}

In the paper selected aspects of designing of the cold-rolled steel structures were discussed. In the first part of the study special attention was paid on pre- and post-buckling behaviour of structures with various combinations of geometrical imperfections developed in accordance with three consecutive buckling nodes. It was found that small amplitudes of geometrical imperfections developed in form of first, second or third buckling mode are accompanied by bifurcation points corresponding to the stable, unstable or metastable equilibrium paths. Moreover at the bifurcation point it is possible snap through related to the transition of the structure from a higher to a lower level of potential energy. Introduction of the imperfections, developed as a linear superposition of two buckling modes, results in the appearance of two bifurcation points corresponding to the solution obtained for the perfect structure.

In the second part of the paper, first the transition from the von Kàrmàn scientific theory to the first semi-empirical approach known as "Winter formulas" and ending with the formulas adopted in EN 1993-1-3 and EN 1993-1-5 were presented. Then, the particularities to be considered in the verification of the resistance and different modes of buckling of the cold formed profiles with stiffened or unstiffened walls are discussed, through theoretical calculations and test-assisted calculations.

\section{REFERENCES}

American Iron and Steel Institute. 2016. North American Specification for the Design of Cold-Formed Steel Structural Members, AISI S100-2016, Washington.

Barszcz A.M. \&, Giżejowski M.A. 2007. An equivalent stiffness approach for modelling the behaviour of compression members according to Eurocode 3. Journal of Constructional Steel Research 63(1): 55-70.

Bogusz W. 1972. Stateczność techniczna. Warszawa: WNT.

Bródka J., Broniewicz M., Giżejowski M. 2006. Ksztaltowniki gięte, Poradnik projektanta, wyd. 1, Rzeszów, Polskie Wydawnictwo Techniczne.

Chou S.M. \& Rhodes J. 1997. Review and compilation of experimental results on thin-walled structures. Computers and Structures 65(1): 47-67.

Dubina D., Ungureanu V., Szabo I. 2001. Codification of imperfections for advanced finite analysis of cold-formed steel members. Proceedings of the 3rd ICTWS: 79-186.

Kowal Z. 2001. Interaction of global limit bearing capacity and local critical bearing capacity of columns. X Konf. Konstr. Met. Gdańsk: 397-404.

Kozłowski A. 2008. Imperfekcje oraz efekty II rzędu w projektowaniu ram stalowych według PN-EN 1993-1-1. Konferencja NKILiW PAN i Komitetu Nauki PZITB: 311-318.

Kwasniewski L. 2009. Complete equilibrium paths for Mises trusses. Int. J. of Non-Linear Mechanics 44: $19-26$.

Murzewski J. 1996. Imperfections and P-Delta effects in multistorey steel frames. Archives of Civil Engineering 38(3): 191-203.

Rzeszut K. \& Garstecki A. 2009. Modeling of initial geometrical imperfections in stability analysis of thin-walled structures. Journal of Theoretical and Applied Mechanics 47(3): 667-684.

Rzeszut K. 2015. Stability of thin-walled metal structures with clearances and imperfections (in Polish), Wyd. Politechniki Poznańskiej, ISBN 978-83-7775-371-2.

Rzeszut K., Chybiński M., Garstecki A. 2009. Nonlinear stability analysis of steel welded girders with diagonal rib configuration. Computer Methods in Mechanics, Zielona Góra, Poland: 149-150.

Rzeszut K., Garstecki A., Kąkol W. 2004. Local-sectional imperfections in coupled instabilities problems of steel thin-walled cold formed $\Sigma$ members. Proceedings of Fourth International Conference on Coupled Instabilities in Metal Structures: 21-30.

Schafer B.W. \& Peköz T. 1998. Computational modeling of cold-formed steel: characterizing geometric imperfections and residual stresses. Journal of Constructional Steel Research 47: 193-210.

Schafer B.W. 2011. Cold-formed steel structures around the world. Steel Construction 4 (3): 141-149. 
Sokol L. 2015. Wymiarowanie konstrukcji z profili giętych na zimno. Wybrane zagadnienia: teoria, badania, praktyka. Konferencja KB PAN, Kraków.

Sokol L. 1979. Calcul des pannes en section Z. Construction Métallique 1.

Sokol L. 1988. Specific Aspects of Design of Purlins in Z-sections. Der Metallbau im KonstructivenIngenieurbau. Karlsruhe.

Sokol L. 1995. Stability of Cold Formed Purlins Braced by Steel Sheeting. Proceedings of the Third International Conference on Steel and Aluminium Structures, Istanbul.

Sokol L. 2000. Lateral Buckling of Prismatic Members About an Imposed Axis of Rotation. Fifteenth International Specialty Conference on Cold-Formed Steel Structures. St. Louis, Missouri U.S.A.

Timoshenko S.P. \& Gere J.M. 1961. Theory of elastic stability. New York, McGraw-Hill Book Co.

Vlasov V.Z. 1963. Thin-walled elastic rods (in Russian). Moscow, Izd. Akad. Nauk SSSR.

Von Karman, T., Sechler E. E., Donnell L. H. 1932. The Strength of Thin Plates in Compression. Transactions ASME 54: 54-5.

Winter, G. 1947. Strength of Thin Steel Compression Flanges (with Appendix). Bulletin 35/3, Cornell University Engineering Experiment Station, Ithaca, $N Y$.

Zhao J., Jia J., He X., Wang H. 2008. Post-buckling and snap-through behavior of Inclined Slender Beams. Journal of Applied Mechanics 75 (4): 7. 


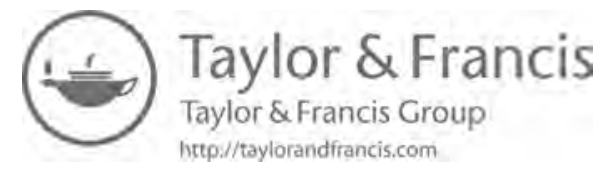


Advanced analysis and direct methods of design 


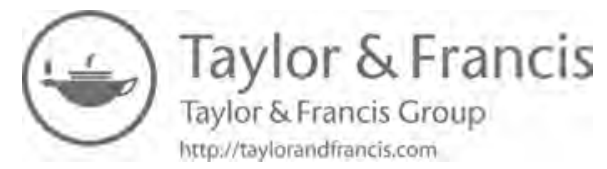




\title{
Experimental investigation of angle length effect - angles in tension connected by one leg
}

\author{
W. Barcewicz, S. Wierzbicki \& M.A. Giżejowski \\ Warsaw University of Technology, Warsaw, Poland \\ S. Labocha \\ University of Technology in Katowice, Katowice, Poland \\ R. Czyż \\ ENPROM Ltd., Warsaw, Poland
}

\begin{abstract}
In the present paper, the results of experimental tests of angle specimens subjected to tension and connected by one leg are presented. Structural members of such a form are commonly applied to the steel lattice supports of overhead electrical lines. The bolted connections of angles connected by one leg to gusset plates are under tension and additional bending moment that results from the eccentricity of the bolt group. Majority of available existing experimental and numerical investigations regarding the bolted connections of steel angles in tension have been conducted using mostly short specimens. Within this paper, the influence of the specimen length on the behaviour of angles connected by one leg in tension is shown on the basis of the comparison of the results from the experimental tests of shorter and loger specimens of the same size of angle section.
\end{abstract}

\section{INTRODUCTION}

\subsection{General information}

Investigations presented in this paper are the part of the research works conducted by ENPROM Ltd. within the framework of the project No. POIR.01.01.01-00-0789/17 entitled „Elaboration of the new series of types of $400 \mathrm{kV}$ transmission towers and foundations suitable for them, including foundations to the use on grounds about particularly disadvantageous geotechnical parameters", co-financed by The National Centre for Research and Development in Poland.

Within the framework of the project, new types of transmission towers and innovative shallow foundations (prefabricated with special overlay plates, hybrid monolithic-prefabricated and special strengthened footings with anchoring micropiles) with the increased pull-off capacity have been elaborated. Besides of the unique full scale (1:1) experimental tests of the steel lattice transmission towers and different types of footing foundations, the essential part of the research work within the ENPROM project are complementary laboratory tests of tension connections of hot-rolled steel angles connected by one leg, typically used in the transmission towers of overhead high voltage electric lines.

The project was led in cooperation with the Faculty of Civil Engineering, Warsaw University of Technology. Research works in the field of steel structures are foreseen to the direct 
application at the construction of the latest overhead high voltage transmission lines in Poland and Europe.

\subsection{Aim and scope of the presented research}

The purpose of this paper is to present the experimental destructive tests of eighteen angle specimens connected by one leg to the gusset plates on both ends by means of bolted connections and subjected to tension, as well as to discuss the influence of the specimen length on their behaviour.

Motivation to study such an effect was the observations of the authors of this paper from the earlier tests of total ninety specimens consisted of different angle sections but of the same length, conducted in the laboratory of the Faculty of Civil Engineering, WUT within the ENPROM project introduced above. The bolted connections of angles connected by one leg, theoretically under axial tension, are in fact also subjected to bending moment that results from the eccentricities of the bolt group. It was observed that the smaller specimen length to its leg width ratio, the deformation of the angle specimen due to bending stresses was more and more visible. The majority of available existing experimental and numerical investigations regarding the bolted connections of steel angles in tension have been conducted using mostly short specimens, generally in the range of around 500 to $600 \mathrm{~mm}$ (e.g. Agrawal \& Gupta 2018, Bernatowska \& Ślęczka 2018, 2019, Geethu et al. 2014, Gupta \& Gupta 2004). Within this paper, the influence of the specimen length on the behaviour of angles connected by one leg in tension is shown on the basis of the comparison of the results from the experimental tests of shorter and longer specimens of the same size of angle section.

\section{EXPERIMENTAL TESTS}

\subsection{Description of the specimens and the test rig}

Specimens considered in the experimental tests described herein consist of angle section connected by one leg to the gusset plates on both ends. For the purpose of this publication two series of equal-leg angles are taken into account, namely L120 $\times 120 \times 8$ and L90 $\times 90 \times 6$. The experimental tests of the selected specimens were performed in two stages. Firstly, the set of short specimens of the length equal to $600 \mathrm{~mm}$ were tested. In the second stage, the tests of the longer specimens of $1500 \mathrm{~mm}$ long were performed. The summary of the specimens considered in the present paper is given in Table 1. Exemplary specimens from two length groups are presented in Figures 1 and 2.

All angle members are connected to steel gusset plates by means of lap bolted connections, using 3 bolts M20 cl. 8.8 at each end. The bolts were fastened with the controlled tightening

Table 1. Summary of the tested specimens.

\begin{tabular}{|c|c|c|c|c|}
\hline \multirow{2}{*}{$\frac{\text { Type of specimens }}{\text { Hot-rolled sections }}$} & \multicolumn{2}{|c|}{ Short specimens $(\mathrm{L}=600 \mathrm{~mm})$} & \multicolumn{2}{|c|}{ Long specimens $(\mathrm{L}=1500 \mathrm{~mm})$} \\
\hline & $\mathrm{L} 90 \times 90 \times 6$ & $\mathrm{~L} 120 \times 120 \times 8$ & $\mathrm{~L} 90 \times 90 \times 6$ & $\mathrm{~L} 120 \times 120 \times 8$ \\
\hline \multirow[t]{5}{*}{ Specimen names } & L90/6/3M20-1 & L120/8/3M20-1 & L90/6/3M20-6 & L120/8/3M20-6 \\
\hline & L90/6/3M20-2 & L120/8/3M20-2 & L90/6/3M20-7 & L120/8/3M20-7 \\
\hline & L90/6/3M20-3 & L120/8/3M20-3 & L90/6/3M20-8 & L120/8/3M $20-8$ \\
\hline & L90/6/3M20-4 & L120/8/3M20-4 & L90/6/3M20-9 & \\
\hline & $\mathrm{L} 90 / 6 / 3 \mathrm{M} 20-5$ & $\mathrm{~L} 120 / 8 / 3 \mathrm{M} 20-5$ & $\mathrm{~L} 90 / 6 / 3 \mathrm{M} 20-10$ & \\
\hline
\end{tabular}




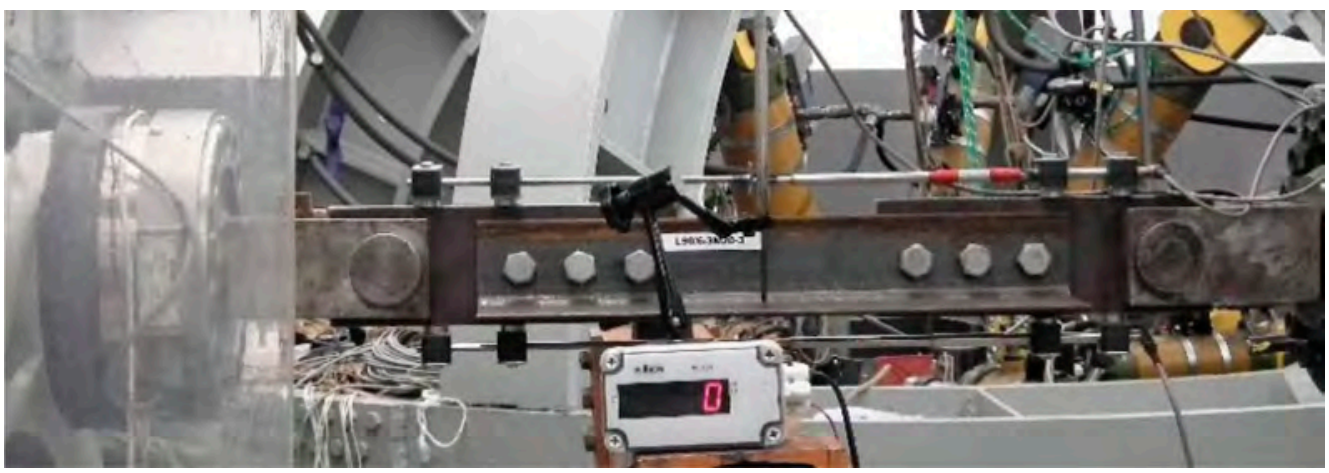

Figure 1. Exemplary short specimen.

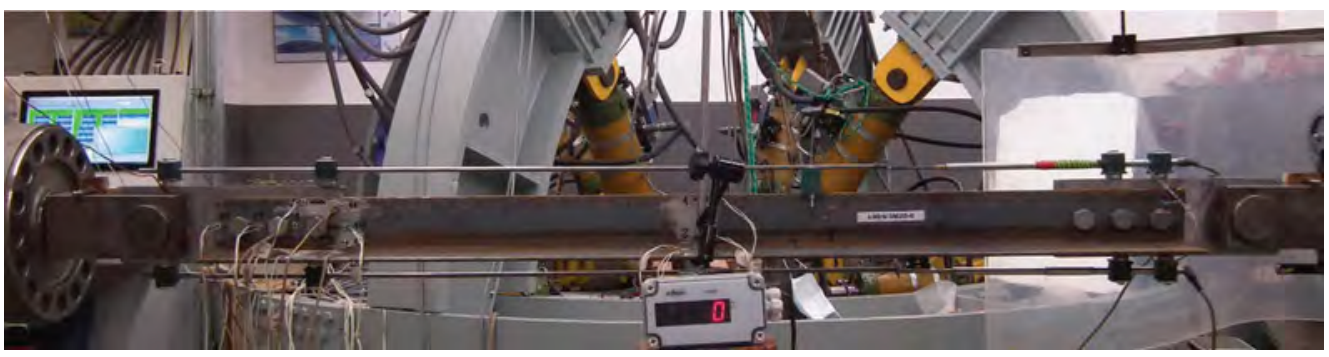

Figure 2. Exemplary long specimen.

moment equal to $246 \mathrm{Nm}$. End and edge distances $\left(e_{1}=40 \mathrm{~mm}, e_{2}=60 \mathrm{~mm}\right.$ for L120 $\times 120 \times 8$ and $45 \mathrm{~mm}$ for L $90 \times 90 \times 6)$, as well as the spacing between bolts $\left(p_{1}=65 \mathrm{~mm}\right.$ for L120 $\times 120 \times 8$ and $60 \mathrm{~mm}$ for L90×90×6), met the requirements of EN 1993-1-8 (CEN 2005). Dimensions of the gusset plates were properly fitted to the angle sections in order to avoid undesirable failure modes in the gusset plates and were equal to $28 \times 120 \times 360 \mathrm{~mm}$ and $15 \times 120 \times 350 \mathrm{~mm}$, respectively for L $120 \times 120 \times 8$ and L $90 \times 90 \times 6$. Both the hot-rolled sections as well as the gusset plates are made of steel grade $\mathrm{S} 355 \mathrm{~J} 2$.

The experimental tests were conducted using $1000 \mathrm{kN}$ universal testing machine, in which the specimens were placed horizontally. The gusset plates at both ends of the specimens were connected by pins to the grips of the testing machine.

\subsection{Description of the testing procedure}

The specimens were subjected to a monotonic tensile force, which was applied to horizontal steel grips that were fixed to the testing machine, as shown in Figures 1 and 2. The tests were carried out under displacement control at a possibly slowest steady speed up to a failure of the specimens.

Two linear variable displacement transducers (LVDTs) were attached to the gusset plates on the top and the bottom side of the plates. Their function was a measurement of specimen 
elongations. Moreover, two additional LVDTs were applied in order to measure out-ofplane displacement, one in the vertical direction and the other in the horizontal direction perpendicular to the longitudinal axis of a specimen. Selected specimens (two representatives from each series with $\mathrm{L} 90 \times 90 \times 6$ ) were also equipped in the set of strain gauges located close to one bolted connection at one end of the specimen and also in the middle of the specimen length.

Load and displacement data were collected by a data acquisition system and exported to Excel.

\subsection{Material properties of structural steel}

Additionally to the experimental tests of the specimens with bolted connections, tests of material properties were also conducted. From each angle type considered herein, three coupons were cut off and tested according to the requirements of EN ISO 6892-1 (CEN 2016).

Summary of the mechanical properties of the steel used for fabrication of the specimens is shown in Table 2, distinguishing sizes of an angle section as the original material for cutting the tensile coupons as well as the average values of the yield strength $f_{\mathrm{y}}$, the ultimate strength $f_{\mathrm{u}}$ and their standard deviations ( $s_{\mathrm{fy}}$ and $s_{\mathrm{fu}}$, respectively).

\subsection{Failure modes of the specimens}

The failure mode for the whole series of the short L $120 \times 120 \times 8$ angle specimens is presented in Figure 3a. It was the same for each specimen from this series and based on the angle net cross-section rupture with accompanying significant plastic deformations due to bending of the angle sections. The place of the net cross-section failure every time passes by the external bolt hole located closer to the midspan of the specimen. The series of short L90 $\times 90 \times 6$ angle specimen was destroyed in a similar manner as the described above (see Figure $3 \mathrm{~b}$ ), except specimen L90/6/3M20-4, in which the acting force immediately dropped down due to bending, before reaching damage of the net cross-section of the angle. The deformations due to bending were also observed but their range was smaller than in the group of short L120 $\times 120 \times 8$ angles.

In the case of both groups of the longer specimens, the deformations due to bending are not so visible, what is shown in Figure $3 \mathrm{c}$, d. The tests of the long L90 $\times 90 \times 6$ angle specimens were terminated due to net cross-section rupture (Figure 3d). While failure modes of the long L $120 \times 120 \times 8$ angles were more varied (Figure 3c). It can be distinguished three types: bolts shear with visible deformations of one angle end and ovalisation of bolt holes due to bearing of bolts (in L120/8/3M20-6), rupture of angle net cross-section (in L120/8/3M20-8) and simultaneous interaction of the bolts shear (two bolts were sheared) and tearing of the edge of angle section in the vicinity of the outer bolt (in L120/8/3M20-7).

Table 2. Summary of steel mechanical properties.

\begin{tabular}{|c|c|c|c|c|}
\hline $\begin{array}{l}\text { Angle section- length } \\
\text { (series type) }\end{array}$ & $\frac{f_{\mathrm{y}}}{\mathrm{MPa}}$ & $\frac{s_{\mathrm{fy}}}{\mathrm{MPa}}$ & $\frac{f_{\mathrm{u}}}{\mathrm{MPa}}$ & $\frac{s_{\mathrm{fu}}}{\mathrm{MPa}}$ \\
\hline $\begin{array}{l}\mathrm{L} 120 \times 120 \times 8-600 \mathrm{~mm} \\
\mathrm{~L} 120 \times 120 \times 8-1500 \mathrm{~mm}\end{array}$ & $\begin{array}{l}427 \\
427\end{array}$ & $\begin{array}{l}4.9 \\
4.1\end{array}$ & $\begin{array}{l}521 \\
524\end{array}$ & $\begin{array}{l}5.3 \\
4.8\end{array}$ \\
\hline $\begin{array}{l}\mathrm{L} 90 \times 90 \times 6-600 \mathrm{~mm} \\
\mathrm{~L} 90 \times 90 \times 6-1500 \mathrm{~mm}\end{array}$ & $\begin{array}{l}409 \\
428\end{array}$ & $\begin{array}{l}5.6 \\
1.8\end{array}$ & $\begin{array}{l}597 \\
579\end{array}$ & $\begin{array}{l}5.3 \\
8.9\end{array}$ \\
\hline
\end{tabular}


a)

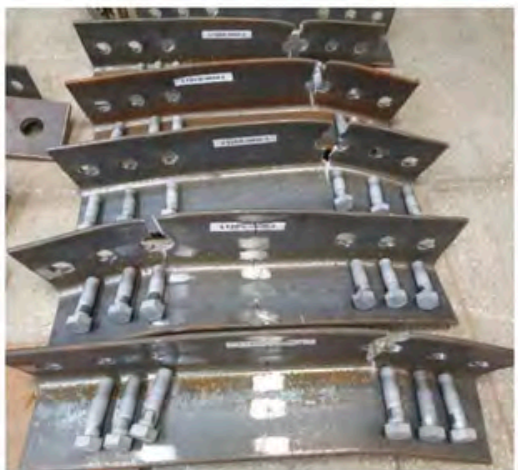

b)

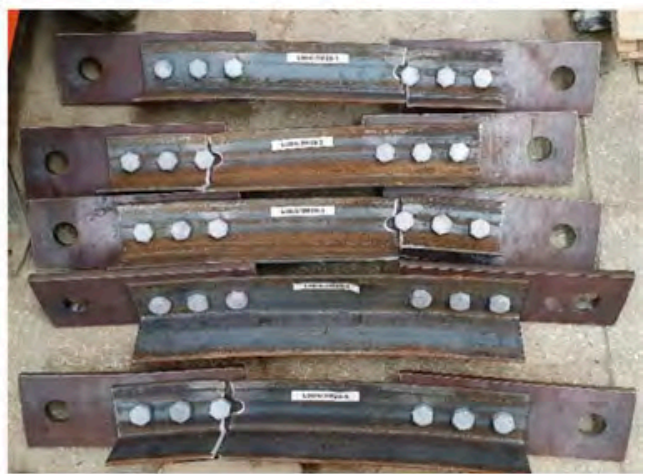

c)

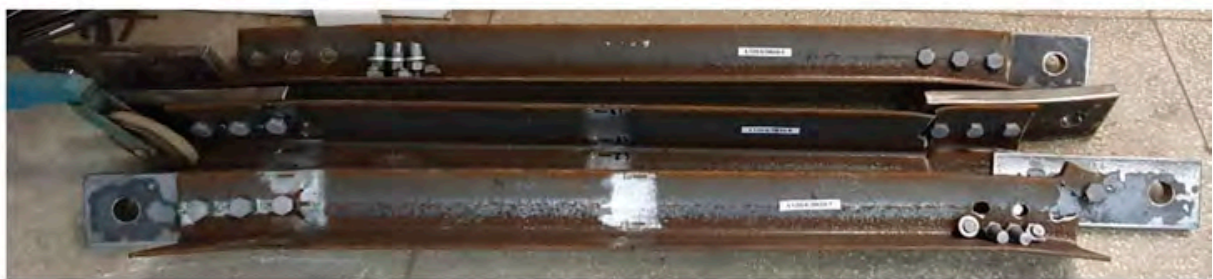

d)

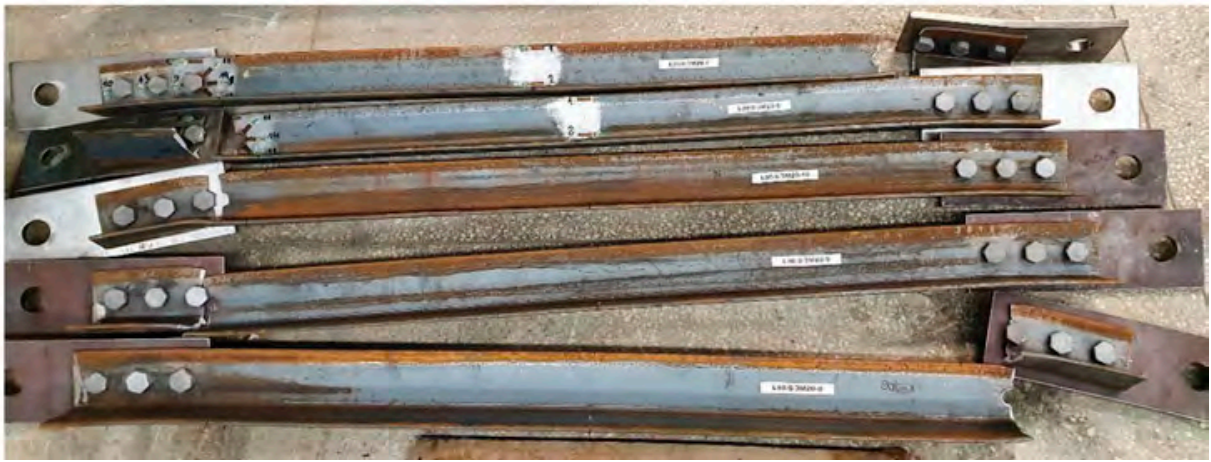

Figure 3. Overview of the specimen failure modes. a) Short L120 $\times 120 \times 8$ specimens after tests, b) Short

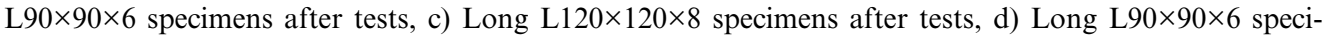
mens after tests.

\section{COMPARISON OF THE EXPERIMENTAL RESULTS}

The summary of the test results for all specimens considered herein is shown in Table 3 . The values of maximum forces are presented as well as accompanying deformations in the form of elongations of the angles, measured at the top and the bottom of the specimens and deflections in the midsection of the angles. In Table 3, their average values are also calculated. Moreover, graphical representation of the test results is shown, in the form of force-displacement curves for the selected specimens (continuous lines for short specimens, dashed lines for long specimens).

\section{CONCLUSIONS}

Within this paper, the influence of the specimen length on the behaviour of angles connected by one leg in tension is shown on the basis of the comparison of the results from the experimental tests of shorter and longer specimens of the sections L $120 \times 120 \times 8$ and L $90 \times 90 \times 6$. The 
Table 3. Summary of test results.

\begin{tabular}{|c|c|c|c|c|c|c|}
\hline \multirow[b]{3}{*}{ Series } & \multirow[b]{3}{*}{ Specimen } & \multirow[b]{2}{*}{$F_{\max }$} & \multicolumn{2}{|c|}{ Displacement at $F_{\max }$} & \multicolumn{2}{|c|}{ Deflection at $F_{\max }$} \\
\hline & & & $\begin{array}{l}\text { Top } \\
\text { LVDT }\end{array}$ & $\begin{array}{l}\text { Bottom } \\
\text { LVDT }\end{array}$ & $\begin{array}{l}\text { Horizontal } \\
\text { LVDT }\end{array}$ & $\begin{array}{l}\text { Vertical } \\
\text { LVDT }\end{array}$ \\
\hline & & $\mathrm{kN}$ & $\mathrm{mm}$ & $\mathrm{mm}$ & $\mathrm{mm}$ & $\mathrm{mm}$ \\
\hline \multirow{6}{*}{ L120×120×8 } & L120/8/3M20-1 & 540.62 & 38.85 & 27.88 & 14.36 & 9.66 \\
\hline & L120/8/3M20-2 & 529.91 & 41.35 & 31.56 & 18.88 & 12.90 \\
\hline & L120/8/3M20-3 & 541.50 & 42.77 & 31.93 & 15.19 & 10.54 \\
\hline & L120/8/3M20-4 & 533.73 & 35.56 & 26.37 & 12.95 & 17.35 \\
\hline & L120/8/3M20-5 & 549.36 & 45.28 & 40.61 & 13.11 & 15.69 \\
\hline & Average values & 539.02 & 40.76 & 31.67 & 14.90 & 13.23 \\
\hline \multirow{4}{*}{$\begin{array}{l}\text { Long } \\
\text { L120 } \times 120 \times 8\end{array}$} & L120/8/3M20-6 & 574.80 & 44.39 & 32.51 & 20.79 & 18.12 \\
\hline & L120/8/3M20-7 & 566.20 & 55.37 & 30.48 & 19.20 & 19.25 \\
\hline & L120/8/3M20-8 & 567.65 & 42.30 & 27.66 & 19.94 & 19.75 \\
\hline & Average values & 569.55 & 47.35 & 30.22 & 19.98 & 19.04 \\
\hline \multirow{6}{*}{ Short L90×90×6 } & L90/6/3M20-1 & 328.52 & 23.92 & 12.67 & 12.27 & 10.32 \\
\hline & L90/6/3M20-2 & 346.78 & 23.07 & 12.74 & 9.99 & 14.19 \\
\hline & L90/6/3M20-3 & 325.48 & 22.98 & 14.65 & 11.91 & 6.24 \\
\hline & L90/6/3M20-4 & 362.12 & 23.35 & 11.29 & 11.88 & 13.59 \\
\hline & L90/6/3M20-5 & 364.64 & 26.14 & 12.10 & 10.93 & 17.30 \\
\hline & Average values & 345.50 & 23.89 & 12.69 & 11.40 & 12.33 \\
\hline \multirow[t]{6}{*}{ Long L90×90×6 } & L90/6/3M20-6 & 351.05 & 28.62 & 19.68 & 17.72 & 12.50 \\
\hline & L90/6/3M20-7 & 357.29 & 33.87 & 20.26 & 18.90 & 15.04 \\
\hline & L90/6/3M20-8 & 350.50 & 28.99 & 16.75 & 19.53 & 13.12 \\
\hline & L90/6/3M20-9 & 354.82 & 65.77 & 34.23 & 18.65 & 10.52 \\
\hline & L90/6/3M20-10 & 350.40 & 30.34 & 29.70 & 17.30 & 11.27 \\
\hline & Average values & 352.81 & 37.52 & 24.12 & 18.42 & 12.49 \\
\hline
\end{tabular}

a)

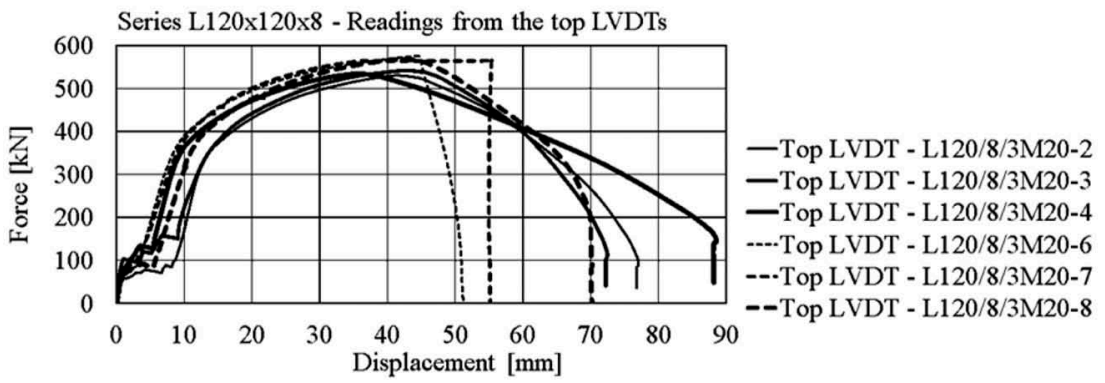

b)

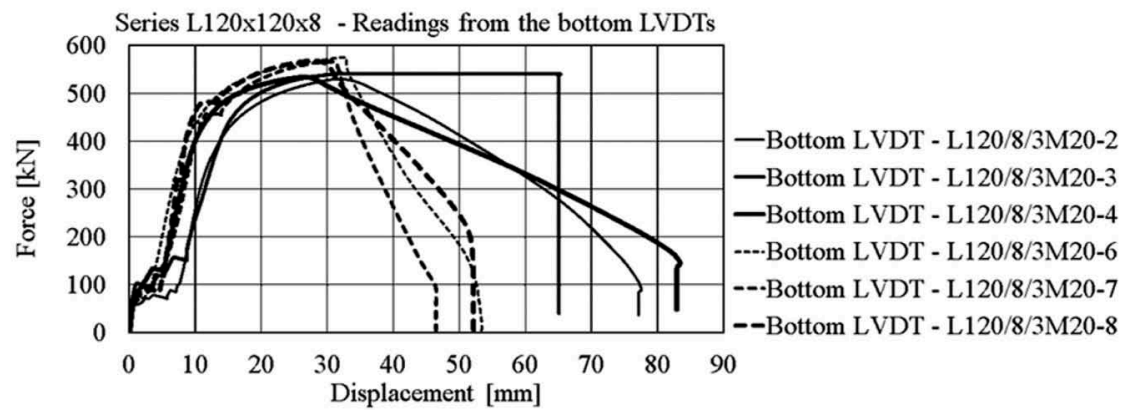

Figure 4. Load - displacement relationships for the selected specimens made of section L120×120×8 
a)

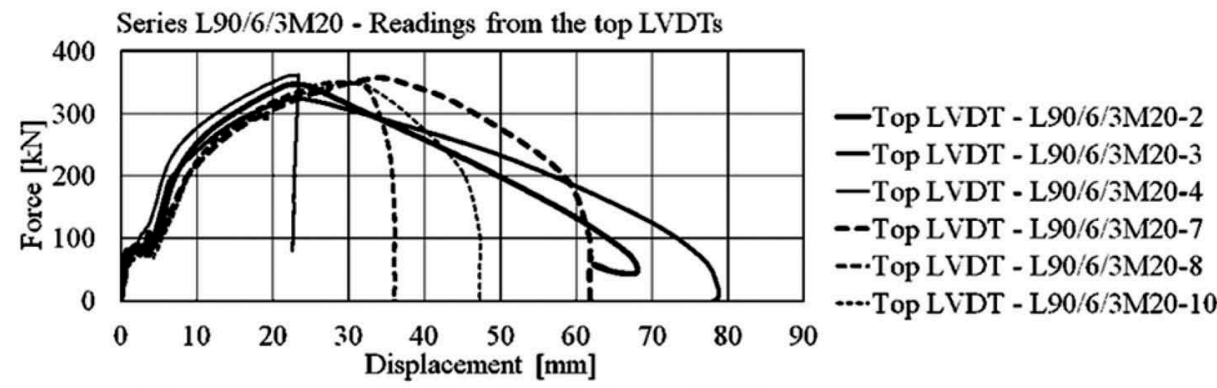

b)

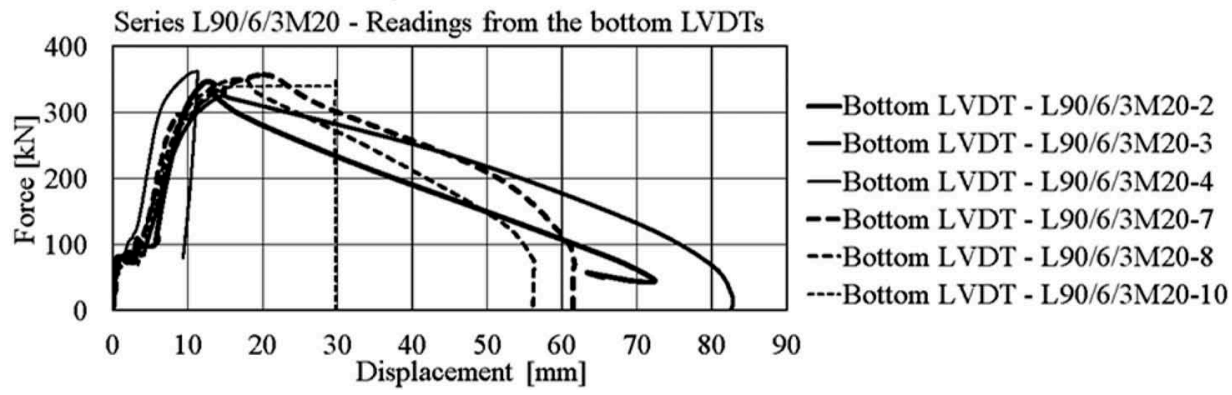

Figure 5. Load - displacement relationships for the selected specimens made of section L $90 \times 90 \times 6$.

higher influence of the specimen length is more visible in the series made of L120 $120 \times 8$. On this stage of research, it was clearly visible that the longer specimens reached a higher ultimate force of more than $5 \%$ in comparison to the shorter counterparts. The ultimate forces of shorter angle specimens, commonly tested by researchers, might be slightly underestimated due to a length effect with extra bending along the specimen length, not present in the real behaviour of slender tensile members.

\section{REFERENCES}

Agrawal, D. \& Gupta, M.K. 2018. Analysis of hot-rolled steel angles under tension. International Research Journal of Engineering and Technology 5(08): 1071-1074.

Bernatowska, E. \& Ślęczka, L. 2018. Stress and Strain concentrations in steel angle tension members connected by one leg. Journal of Civil Engineering, Environment and Architecture 65(2/18): 5-16.

Bernatowska, E. \& Ślęczka, L. 2019. Net section fracture assessment of steel bolted joints with shear lab effect. MATEC Web of Conferences 262, 09002 (2019): 1-8.

CEN. 2005. EN 1993- 1-8.Eurocode 3: Design of steel structures - Part 1-8: Design of joints. Brussels: CEN.

CEN. 2016. EN ISO 6892-1:2016. Metallic materials: Tensile testing - Part 1: Method of test at room temperature. (ISO 6892-1:2016). Brussels: CEN.

Geethu C.V., Unni Kartha G. \& Usha S. 2014. Effect of connection eccentricity in the behaviour of steel tension members. International Journal of Civil Engineering and Technology 5(12): 56-65.

Gupta M. \& Gupta L.M. 2004. Evaluation of stress distribution in bolted steel angles under tension. Electronic Journal of Structural Engineering 4: 17-27. 


\title{
On elastic lateral-torsional buckling analysis of simply supported I-shape beams using Timoshenko's energy method
}

\author{
A.M. Barszcz, M.A. Giżejowski \& Z. Stachura \\ Department of Concrete and Metal Structures, Warsaw University of Technology, Warsaw, Poland
}

\begin{abstract}
The classical energy formulation dedicated to the lateral-torsional buckling of I-section steel members is based on the so-called linear buckling approach (LBA) and inclusion the prebuckling stress resultants in the energy equation. As a result, the buckling analysis may be converted to the linear eigenproblem analysis (LEA). The "exact" closed-form solution of the differential equilibrium equation is obtained only for uniform bending. Moment gradient cases need approximate analytical or numerical methods to be used. Investigations presented in this paper deal with the energy formulation in which the classical energy equation is modified in the way proposed by Timoshenko, so that such an energy approach is named the Timoshenko's energy method. It leads to the nonlinear eigenproblem analysis (NEA). Using this method, practical approximate solutions may be obtained for any asymmetric transverse loading conditions that produce a moment gradient. The stability criterion in this paper is formulated for a general case of transverse loading, the solution of which is obtained by treating the general loading patterns and corresponding moment diagrams as a superposition of symmetric and antisymmetric components. The results are presented in a table format for considered simple loading cases. For combined loading cases, results are presented in the form of nomograms. Solutions obtained for selected combined loading cases are verified with use of LTBeam software.
\end{abstract}

\section{INTRODUCTION}

\subsection{Overview}

The Classical Energy Method (CEM) for the evaluation of elastic beam lateral-torsional buckling problems belongs to the stability theory of thin-walled members. The general formulation of torsion and bending of thin-walled members was developed by Vlasov and summarized in Vlasov (1961). Many monograph publications have then been devoted to stability problems related to torsional or flexural-torsional modes of buckling governed by Vlasov theory, e.g. Březina (1966), Roik et al. (1972), Chen \& Atsuta (1976), Roik (1978), Weiss \& Giżejowski (1991), Trahair (1993), Rykaluk (2012). Energy based methods and differential equilibrium equations were used in the formulation of stability criteria. The energy formulation of the lateral-torsional buckling of beams was studied by many authors, the summary of which has been given by Pi et al. (1992). A way for the improvement of CEM was firstly shown in the monograph of Timoshenko and Gere (1961). In case of LTB problems, energy based solutions may be improved by making use of the minor axis bending differential equilibrium equation. Trahair (1993) refers this method to TEM (Timoshenko's Energy Method) and this terminology is used hereafter. This method was used by many authors to solve different lateraltorsional buckling (LTB) problems of I-shape section beams, e.g. Mohri et al. (2003), Bijak (2015). This study discusses different issues related to the formulation of TEM for the elastic LTB problem of beams in simple and combined loading cases.

DOI: $10.1201 / 9781003132134-8$ 


\subsection{Statement}

Giżejowski et al. (2021) used the classical energy approach to solve the elastic flexuraltorsional buckling problems of beam-columns subjected to a general loading pattern dependent upon a single load parameter $\psi_{i}$ (where $i=M, q, Q$ ), enabling to represent the case of unequal end moments and span loads being different on both half-lengths of the member. When the axial compressive force is equated to zero, the presented there solutions are valid for the lateral-torsional buckling of beams. This paper constitutes research being a continuation of that previously conducted. LTB problems are dealt with showing an improvement of TEM results over those obtained from CEM. In the improved energy method presented in this paper for solving the critical load multiplier of beams, the minor axis secondorder equilibrium equation is used for the evaluation of the second derivative of the minor axis field displacements in order to replacing the classical energy term dependent upon the product of multiplication of $\phi$ (the angle of mean twist rotation that for the present study is equal to the twist rotation $\theta_{x}$ ) and $v^{\prime \prime}$ (second derivative of the minor axis displacement) of the out-of-plane deformation state by the term dependent upon the field twist rotation $\phi$.

\section{LTB OF I-SECTION BEAMS SUBJECTED TO NON-UNIFORM BENDING}

\subsection{Formulation of basic TEM energy equation}

Let us consider a case of the elastic lateral-torsional buckling of simply supported bisymmetric I-section beam of length $L$ subjected to the linear moment gradient being the action effect of unequal end moments and the nonlinear moment gradient being the action effect of span loads $Q_{z, j}$ and $q_{z, i}$ (Figure 1). The classical energy equation is adopted for the linear buckling analysis (LBA) in order to solve the bifurcation load on the elastic primary equilibrium path by using eigenproblem analysis. The Cartesian coordinate system, general loading arrangement and deformation states considered hereafter are shown in Figure 1.

The classical energy equation used in LEA takes the well-known form, e.g. Roik (1978), Trahair (1993):

$$
\begin{array}{r}
\frac{1}{2} \int_{0}^{L}\left\{E I_{z} \delta\left[\left(v^{\prime \prime}\right)^{2}\right]+E I_{w} \delta\left[\left(\phi^{\prime \prime}\right)^{2}\right]+G I_{T} \delta\left[\left(\phi^{\prime}\right)^{2}\right]+2 M_{y} \delta\left(v^{\prime \prime} \phi\right)\right\} d x \\
+\frac{1}{2} \sum_{i} \int_{x_{q 1, i}}^{x_{q 2, i}} q_{z, i} z_{q, i} \delta\left(\phi^{2}\right) d x+\frac{1}{2} \sum_{j} Q_{z, j} z_{Q, j} \delta\left(\phi^{2}\right)=0
\end{array}
$$

where $v=x$-coordinate dependent minor axis displacement; $\phi=x$-coordinate dependent angle of twist rotation; and $I_{z}=$ minor axis moment of inertia; $I_{T}=$ torsion constant; $I_{w}=$

a)

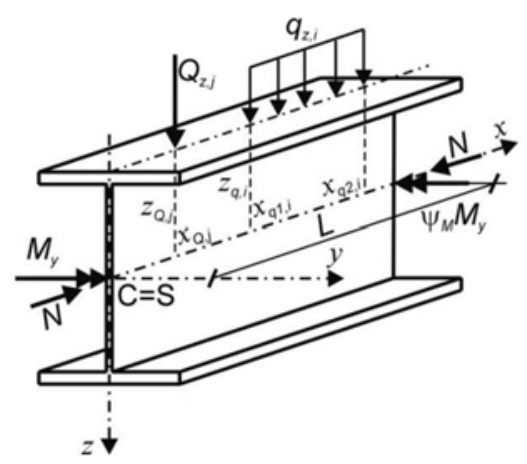

b)

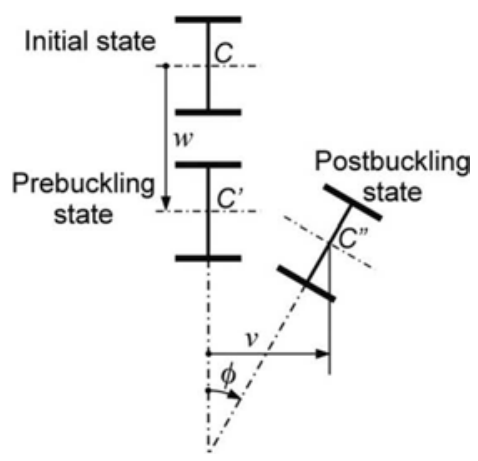

Figure 1. I-section beam: a) considered actions and coordinate system, b) deformation states. 
warping constant; $M_{y}=x$-coordinate dependent major axis moment equation; $E=$ Young's modulus; $G=$ Kirchhoff's modulus; $q_{z, i}=$ component ' $i$ ' of uniformly distributed loads (UDLs); $Q_{z, j}=$ component ' $j$ ' of concentrated loads (CLs), $z_{q, i}, z_{Q, j}=$ section coordinate $z$ of applied UDL and CL.

The minor axis beam differential equilibrium equation corresponding to the minor axis bending and torsion is of the well-known form:

$$
E I_{z} v^{\prime \prime}=-M_{y} \phi
$$

where the section warping free and bending rotation allowed boundary conditions at the member end sections are applied.

Solving Equation (2) for $v^{\prime \prime}$ and substituting to the first and fourth terms of the first integral in Equation (1), a refined form of the energy equation is obtained in which all the terms are dependent upon the angle of twist rotation of the buckling mode and its derivatives. The sum of the first integral terms of Equation (1) involving $v^{\prime \prime}$ and the product of $\phi$ and $v^{\prime \prime}$ becomes:

$$
\frac{1}{2} \int_{0}^{L}\left\{E I_{z} \delta\left[\left(v^{\prime \prime}\right)^{2}\right]+2 M_{y} \delta\left(v^{\prime \prime} \phi\right)\right\} d x=-\frac{1}{2} \int_{0}^{L} \frac{M_{y}^{2}}{E I_{z}} \delta\left(\phi^{2}\right) d x
$$

As a result, the accuracy of the energy solution is uplifted since the approximation of twist rotation is more accurate than that of the product of twist rotation and a guessed curvature of the minor axis deflected shape. Finally, the energy Equation (1) becomes:

$$
\begin{array}{r}
\frac{1}{2} \int_{0}^{L}\left\{E I_{w} \delta\left[\left(\phi^{\prime \prime}\right)^{2}\right]+G I_{T} \delta\left[\left(\phi^{\prime}\right)^{2}\right]-M_{y, \max }^{2} \frac{\left(M_{y} / M_{y, \max }\right)^{2}}{E I_{z}} \delta\left(\phi^{2}\right)\right\} d x \\
+\frac{1}{2} \sum_{i} \int_{x_{q 1, i}}^{x_{q 2, i}} q_{z, i} z_{q, i} \delta\left(\phi^{2}\right) d x+\frac{1}{2} \sum_{j} Q_{z, j} z_{Q, j} \delta\left(\phi^{2}\right)=0
\end{array}
$$

where $M_{y, \max }=$ maximum moment.

For any loading case, the general solution of Equation (4) may be converted to a typical ultimate state criterion used for the codification purposes in the elastic design:

$$
\frac{M_{y, \max }}{M_{c r}}= \pm 1
$$

where $M_{c r}=M_{c r, 0} C_{b c}$ is the critical moment for any major axis moment gradient; $M_{c r, 0}=i_{0} \sqrt{N_{z} N_{T}}$ is the critical moment in the case of uniform major axis bending; $i_{0}=$ polar radius of gyration; $C_{b c}=$ equivalent moment conversion factor for representing the critical moment of any moment gradient case by its uniform moment counterpart.

The following approximations of buckling shape functions were usually adopted for solving CEM buckling problems based on Equation (1):

$$
\begin{gathered}
v=a_{1} \sin (\pi \xi)+a_{2} \sin (2 \pi \xi) \\
\phi=a_{3} \sin (\pi \xi)
\end{gathered}
$$

where $\xi=$ dimensionless coordinate equal to $x / L ; a_{1}, a_{2}$ and $a_{3}=$ unknown buckled shape constants.

Hereafter, Eq. (7) is used and substituted to Eq. (4) in which the terms associated with $q_{z, i}$ and $Q_{z, j}$ are omitted (span loads at the shear centre line). As a result, the stability criterion becomes: 


$$
\delta a_{3} K_{L T} a_{3}=0 \rightarrow K_{L T}=0
$$

in which:

$$
K_{L T}=i_{0}^{2} N_{T}-\frac{M_{y, \max }^{2}}{N_{z}}\left[\left(\frac{M_{y, s, \max }}{M_{y, \max }}\right)^{2} \frac{1}{C_{b s}}+\left(\frac{M_{y, a, \max }}{M_{y, \max }}\right)^{2} \frac{1}{C_{b a}}\right]
$$

where $M_{y, s, \max }=$ maximum moment for the BMD symmetric component; $M_{y, a, \max }=$ maximum moment for the BMD antisymmetric component; $C_{b s}, C_{b a}=$ elemental conversion factors squared for the symmetric and antisymmetric BMDs, the inversions of which are the doubled integrals of the respective products of dimensionless field moment squared and twist rotation shape function squared:

$$
\begin{aligned}
& \frac{1}{C_{b s}}=2 \int_{0}^{1}\left[\frac{M_{y, s}(\xi)}{M_{y, \mathrm{~s}, \max }}\right]^{2} \sin ^{2}(\pi \xi) d \xi \\
& \frac{1}{C_{b a}}=2 \int_{0}^{1}\left[\frac{M_{y, a}(\xi)}{M_{y, a, \max }}\right]^{2} \sin ^{2}(\pi \xi) d \xi
\end{aligned}
$$

Using Equations (8) - (10), the moment conversion factor $C_{b c}$, being denoted by $C_{b c, T E M}$ in the TEM solution, takes the form:

$$
C_{b c, T E M}=\left[\left(\frac{M_{y, s, \max }}{M_{y, \max }}\right)^{2} \frac{1}{C_{b s}}+\left(\frac{M_{y, a, \max }}{M_{y, \max }}\right)^{2} \frac{1}{C_{b a}}\right]^{-\frac{1}{2}}
$$

\subsection{Solutions for simple cases of unequal end moments or unequal half-span loads}

The loading cases considered hereafter are given in Figure 2, namely: unequal end moments (EMs), uniformly distributed loads being unequal in half-lengths (UDLs) and concentrated loads being unequal in half-lengths (CLs).

End moments of different values generate asymmetric non-uniform bending. Let us introduce the moment gradient ratio $\psi_{M}=M_{y M \text {, min }} / M_{y M \text {, max }}$ being a ratio of the minimum end moment divided by the maximum moment (including the sign, cf. Figure 2a). For the case of unequal end moments $C_{b s}=1.00$ and $C_{b a}=7.65$, Equation (11) leads to the following conversion factor:

$$
C_{b c, T E M}=\frac{1}{\sqrt{\left[0.5\left(1+\psi_{M}\right)\right]^{2}+0.1307\left[0.5\left(1-\psi_{M}\right)\right]^{2}}}
$$

a)

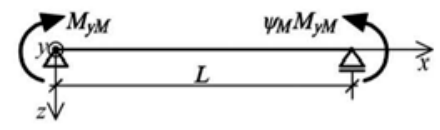

b)

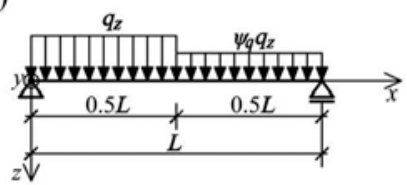

c)

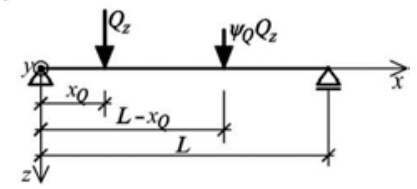

Figure 2. Considered simple loading cases: a) EMs, b) UDLs, c) CLs. 
The solution based on the classical energy method, cf. Equation (1), has been presented first by Trahair (1993) and confirmed by Giżejowski et al. (2021). Recalling $C_{b s}=1.00$ and $C_{b a}=7.71$ from Giżejowski et al (2021), Equation (11) becomes:

$$
C_{b c, C E M}=\frac{1}{\sqrt{\left[0.5\left(1+\psi_{M}\right)\right]^{2}+0.1298\left[0.5\left(1-\psi_{M}\right)\right]^{2}}}
$$

Comparing both solutions one can notice that TEM and CEM lead to the same structure of $C_{b c}$ factor but with different values of $C_{b a}$. The first square root term in the dominator of Equations (12) \& (13) refers to uniform bending while the second one - to antisymmetric bending. It is obvious that the solutions are the same for uniform bending $\left(\psi_{M}=1\right)$ while there is a slight difference for moment gradient cases $\left(-1 \leq \psi_{M}<1\right)$. The TEM solution gives the lesser value of the critical moment. In the case of antisymmetric bending $\left(\psi_{M}=-1\right)$ the difference reaches its maximum value of less than $0.35 \%$ in the critical moment prediction.

The TEM solutions for $C_{b c, T E M}$ concerned with other simple load cases of span uniformly distributed loads in the half-lengths $q_{z, 1}$ and $q_{z, 2} \leq q_{z, 1}$ or concentrated loads $Q_{z, 1}$ and $Q_{z, 2} \leq Q_{z, 1}$ may also be obtained using Equation (11). Factors $C_{b c, T E M}$ for symmetric $\operatorname{BMD}\left(\psi_{i}=1\right)$ and antisymmetric $\operatorname{BMD}\left(\psi_{i}=-1\right)$ are summarized in Table 1 . The results from present study are compared with $C_{b c, C E M}$ obtained by Giżejowski et al. (2021). $\psi_{i}=-1$ means an antisymmetric bending moment diagram $(i=q, Q)$.

Load cases presented in Table 1 generate non-uniform bending. To the best authors' knowledge, the results referred to $C_{b c, T E M}$ for $\psi_{i}=-1$ have not been reported in earlier studies. TEM and CEM solutions for the symmetric load cases coincide with those reported earlier in the literature, $\mathrm{cf}$. references cited at the end of this paper.

\subsection{Solutions for span loads in combination with unequal end moments}

A more important difference between the elastic LTB solutions using classical and refined energy equations may arise for beams under combined loading. The case of combined unequal end moments and UDL is considered hereafter (superposition of loads given in Figure 2a and $2 \mathrm{~b}$ with $\psi_{q}=1$ ). The maximum moment $M_{y \text {, max }}$ within the beam length under unequal end moments and UDL depends upon the moment $M_{y M \text {, } \max }$ - greater of end moments, and $M_{y q \text {, } \max }=0.125 q_{z} L^{2}-$ mid-span moment when the distributed load is acting alone, and upon the moment gradient ratio $\psi_{M}$. Therefore, an additional load effect parameter is introduced $\mu=M_{y q, \text { max }} / M_{y M \text {, max }}$ in order to cover all the load combination cases of unequal end moments and UDL.

Establishing dimensionless moment in Equations (10) and carried out the integration, the coefficients $1 / C_{b s}$ and $1 / C_{b a}$ are obtained, and then by substituting to Equation (11) it allows for the evaluation of the $C_{b c}$ conversion factor related to the combined case of unequal end moments and UDL. The results obtained for different $\mu$ are graphically presented in Figure 3

Table 1. Comparison of TEM and CEM coefficients: $C_{b c, T E M}$ and $C_{b c, C E M}$.

\begin{tabular}{|c|c|c|c|c|c|}
\hline \multirow[b]{3}{*}{ Load type } & \multicolumn{2}{|l|}{ CEM } & \multicolumn{2}{|l|}{ TEM } & \\
\hline & \multicolumn{2}{|c|}{$C_{b c, C E M}{ }^{*}$} & \multicolumn{3}{|c|}{$C_{b c, T E M} *$} \\
\hline & & $\psi_{i}=1$ & $\psi_{i}=-1$ & $\psi_{i}=1$ & $\psi_{i}=-1$ \\
\hline$q_{z}$ & 1.15 & 1.43 & 1.13 & 1.37 & \\
\hline$Q_{z}\left(x_{Q}=L / 2\right)$ & 1.38 & 0.00 & 1.37 & 0.00 & \\
\hline$Q_{z}\left(x_{Q}=L / 3\right)$ & 1.12 & 1.74 & 1.10 & 1.56 & \\
\hline$Q_{z}\left(x_{Q}=L / 4\right)$ & 1.05 & 1.81 & 1.04 & 1.73 & \\
\hline
\end{tabular}


a)

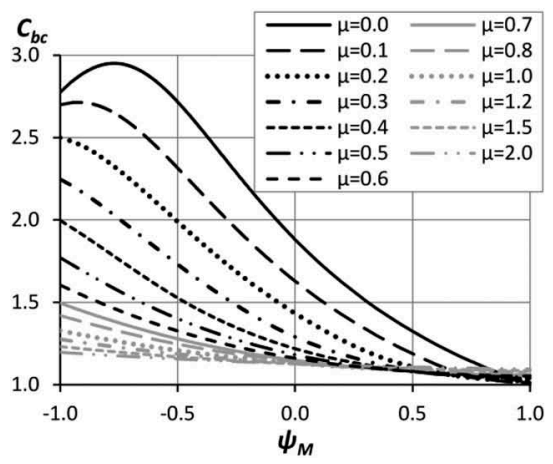

b)

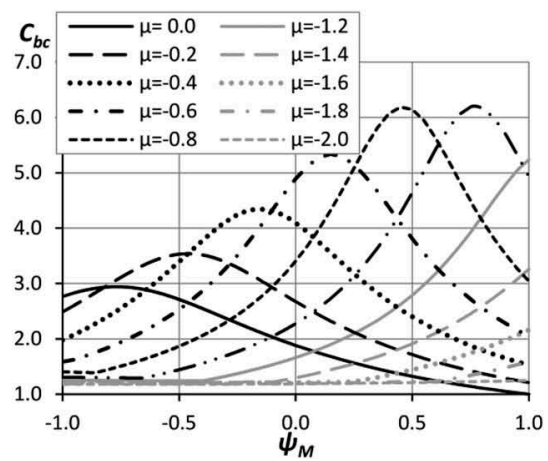

Figure 3. $C_{b c}$ conversion factor for different $\mu$ and $\psi_{M}$ parameters; a) $\mu>0$, b) $\mu<0$.

as a function of $\psi_{M}$. The $C_{b c}$ conversion factor is presented in Figure $3 a$ for $\mu>0$ and in Figure $3 \mathrm{~b}$ for $\mu<0$ in the form of multiple curves dependent upon $\mu$. Nomograms similar to those presented in Figure 3 are included in Annex B of the ECCS Eurocode Design Manual authored by Simoes da Silva et al. (2016).

For positive values of $\mu$, the $C_{b c}$ curves are not continuous since the maximum moment upon the combined loading cases changes its location along the member length as well as because there is a continuous change of the moment diagram shape. For a narrow range of small positive values of $\mu$, the curves go up when $\psi_{M}$ travels from negative towards positive values, reaching the maximum value greater than those for $\psi_{M}=-1$, then they decrease. For larger positive values of $\mu$, the curves decrease from the maximum value reached for $\psi_{M}=-1$.

For negative values of $\mu$, the $C_{b c}$ curves are also not continuous. The curves go up when $\psi_{M}$ travels from negative towards positive values, reaching the maximum value being greater and above those for $\psi_{M}=-1$. The maximum value is slightly above 6 for $\mu$ between -0.6 and -0.8 .

\section{VERIFICATION OF DEVELOPED SOLUTIONS FOR COMBINED LOADING CASES}

Comparing the TEM curves obtained in this study with those of Giżejowski et al. (2021), one may conclude that in some regions of $\mu$ and $\psi_{M}$ the curves presented in Figures $3 \mathrm{a}, \mathrm{b}$ of this paper are importantly different from those yielding from CEM investigations. Generally, the curves from TEM presented in this study are placed lower than those from CEM, especially for high values of $C_{b c}$ appearing in the range of negative $\mu$.

Differences in $C_{b c}$ values for combined loading cases, referred mainly to the range of negative $\mu$ values, need to be verified by finite element numerical simulations and other analytical solutions, especially dedicated for practical applications. In the comparison presented hereafter, the CEM results of Giżejowski et al. (2021) and TEM of present study are verified with use of the finite element simulations made by the LTBeam software available in the public domain. For calculations, IPE300 section is considered for the beam of $6 \mathrm{~m}$ in length, simply supported with regard to bending about both axes and free to warp. The following combined loading cases with unequal end moments are dealt with using $\mu=-1.2$ and shear centre span loads: case 1 of UDL $-\psi_{q}=1$; case 2 of CL at the beam mid-length $-\psi_{Q}=0$. The results of verification are presented in Table 2. Results under a) are from CEM, under b) from TEM and under c) from LTBeam. 
Table 2. Verification of $C_{b c}$.

\begin{tabular}{|c|c|c|c|c|c|c|c|c|}
\hline For $\psi_{M} *$ & & -1.0 & -0.7 & -0.4 & 0 & 0.4 & 0.7 & 1.0 \\
\hline \multirow[t]{3}{*}{ Case 1} & a) & 1.276 & 1.271 & 1.277 & 1.747 & 2.779 & 4.985 & 23.16 \\
\hline & b) & 1.258 & 1.247 & 1.242 & 1.661 & 2.468 & 3.655 & 5.238 \\
\hline & c) & 1.236 & 1.228 & 1.225 & 1.644 & 2.454 & 3.644 & 5.140 \\
\hline \multirow[t]{3}{*}{ Case 2} & a) & 1.309 & 1.386 & 1.670 & 2.580 & 5.575 & 18.36 & 6.376 \\
\hline & b) & 1.263 & 1.317 & 1.543 & 2.175 & 3.277 & 3.957 & 3.421 \\
\hline & c) & 1.244 & 1.300 & 1.528 & 2.165 & 3.250 & 3.834 & 3.309 \\
\hline
\end{tabular}

* Same $\psi_{M}$ values for both combined loading cases considered.

\section{CONCLUSIONS}

The modified energy approach, referred herein to TEM, is discussed in this paper in relation to elastic LTB problems. It is shown that for beam simple load cases CEM and TEM solutions are close to each other while for combined loading cases there might be a noticeable difference. NEA conversion factors $C_{b c, T E M}$ are of smaller values than their LEA counterparts $C_{b c, C E M}$.

Verification of TEM results presented in Table 2 for selected combined loading cases showed that the results obtained in this study are closer to the results from the computer code LTBeam than those yielding from CEM, especially in the range of $\psi_{M}$ between 0.5 and 1.0 (see values being bolded in Table 2).

\section{REFERENCES}

Vlasov, V.Z. 1961. Thin Walled Elastic Beams. Second ed., Jeruzalem: Israel Program for Scientific Translations.

Březina, V. 1966. Stability of metal structures members. Warszawa: Arkady [Polish translation].

Roik, K., Carl, J., Lindner, J. 1972. Biegetorsionsprobleme gerader dünnwandiger Stäbe. Berlin: Wilhelm Ernst \& Sohn.

Roik, K. 1978. Vorlesungen über Stahlbau. Grundlagen. Berlin: Verlag von Wilhelm Ernst \& Sohn.

Chen, W.F. \& Atsuta, T. 1976. Theory of Beam-Columns, vol. 2: Space Behavior and Design, New York: McGraw-Hill.

Weiss, S. \& Giżejowski, M.A. 1991. Stability of metal structures. Rod structures. Warszawa: Arkady [in Polish].

Trahair, N.S. 1993. Flexural-Torsional Buckling of Structures. Boca Raton: CRC Press.

Rykaluk, K. 2012. Stability problems of metal structures, Wrocław: Dolnośląskie Wydawnictwo Edukacyjne [in Polish].

Pi, Y-L, Trahair, N.S. \& Rajasekaran, S. 1992. Energy equation for beam lateral buckling. Journal of Structural Engineering 118(6):1462-1479.

Timoshenko, S.P. \& Gere, J.M. 1991. Theory of Elastic Stability, 2nd edition. New York: McGraw-Hill.

Mohri, F., Brouki, A. \& Roth, J.C. 2003. Theoretical and numerical stability analyses of unrestrained, mono-symmetric thin-walled beams. Journal of Contructional Steel Research 59:63-90.

Bijak, R. 2015. The lateral buckling of simply supported unrestrained bisymetric I-shape beams. Archives of Civil Engineering 61(4): 127-140.

Giżejowski, M.A., Barszcz, A.M. \& Stachura, Z. 2021. Elastic flexural-torsional buckling of steel I-section members unrestrained between end supports. Archives of Civil Engineering 67 (1)[in print].

Simoes da Silva, L., Simoes, R., Gervasio, H. 2016. Design of Steel Structures (2nd Edition). ECCS Mem Matrins: Multicomp Lda. 


\title{
Numerical evaluation of dynamic response of an experimentally tested base-isolated and fixed-base steel structure model
}

\author{
T. Falborski, T. Jaroszewski \& R. Jankowski \\ Faculty of Civil and Environmental Engineering, Gdańsk University of Technology, Gdańsk, Poland
}

\begin{abstract}
Seismic isolation is recognized as one of the most popular and effective methods of protecting structures during earthquake. The present paper is focused on the comparison between the dynamic responses of buildings with fixed and isolated bases exposed to seismic excitations. The aim of the study is to investigate the effectiveness of a simplified base isolation numerical modelling technique using the linear springs. One-storey steel structure model has been considered using ETABS software, which was previously tested during the shaking table tests. The comparison of the structural response has been performed between the numerical and experimental results. High compatibility of the results for the fixed-base steel model between the numerical and experimental analyses has been obtained which proves the effectiveness of the modelling techniques used in the ETABS software. It has also been found that the isolation system is effective in improving the response of the steel structure during earthquake. However, modelling the isolation system using the linear springs is not an accurate technique due to the large differences in the structural responses obtained between the numerical and experimental analyses.
\end{abstract}

\section{INTRODUCTION}

Earthquake is considered as one of the most dangerous phenomenon caused by nature as it led to catastrophic damages in many previous seismic events. Scientists have worked extensively to develop new techniques to decrease the level of damages of buildings exposed to earthquakes or eliminate the damages at all (see, for example, Sołtysik, Falborski \& Jankowski, 2016; Sołtysik, Falborski \& Jankowski, 2017; Miari, Choong \& Jankowski, 2019; Naderpour, Naji, Burkacki \& Jankowski, 2019; Miari, Choong \& Jankowski, 2020). One of the modern techniques to resist the effects of earthquakes is the use of isolation systems (see, for example, Robinson \& Greenbank, 1976; Robinson, 1982; Buckle \& Mayes, 1990; Kelly, 1990; Kelly, 1993; Skinner, Robinson \& McVerry, 1993; Robinson, 1998; Buckle, 2000). Base isolators, such as Lead Rubber Bearings, High Damping Rubber Bearings, and Friction Pendulum Bearings, are widely used in practice in many earthquake-prone regions to mitigate structural vibrations, and consequently minimize the loss of life and property damage during seismic events (see, for example, Nagarajaiah \& Xiaohong, 1996; Nagarajaiah \& Xiaohong, 2000). These systems decrease the damages in buildings during earthquakes by controlling the accelerations and displacements of the vibrating structures through inducing flexibility to their bases. The use of this technique prevents the resonance between the structure and the dominant frequency of the ground motion (see, for example, Booth \& Key, 2006; Chopra, 2012).

In order to get an insight into the mechanical behaviour of base isolation devices, quasistatic or dynamic tests are usually performed. One of the most common procedures for experimentally testing buildings subjected to earthquakes is to test them on a seismic shaking table

DOI: $10.1201 / 9781003132134-9$ 
(see, for example, Falborski \& Jankowski, 2017a). Also, the dynamic behaviour of a structure is often modelled numerically using commercial software (see, for example, Falborski \& Jankowski, 2017b; Falborski, Sołtysik \& Jankowski, 2018; Lasowicz, Falborski \& Jankowski, 2018; Falborski \& Lasowicz, 2019). This facilities the consideration of highly complex problems with less difficulties and budget. In the numerical analysis of buildings, several factors are important, such as the modelling approach and the ground conditions. The ground conditions have a large impact on the response of the structure under a seismic load (see, for example, Lasowicz \& Falborski, 2018; Falborski, 2020, Falborski, 2020, Elwardany, Seleemah, Jankowski \& El-khoriby, 2019).

The aim of this study is to investigate the effectiveness of a simplified base isolation modelling technique using the linear springs since the advanced mathematical models are often difficult to be applied in commercial programs. One-storey steel structure model has been considered using ETABS software, which was previously tested during a seismic table test (see, for example, Falborski \& Jankowski, 2018). The response of the numerical model of the one-storey building has been compared with that of the experimental model intending to validate the numerical model. The steel structure model has been studied with two types of bases, i.e. fixed and isolated bases. Comparison has been performed between these models (with different types of bases) to investigate the effect of the use of isolation system on the response of buildings exposed to earthquake excitations.

\section{EXPERIMENTAL MODEL AND SHAKING TABLE INVESTIGATION}

The experimental study has been conducted for a single-storey steel structure model. This model, consisting of a steel frame and two concrete slabs, is of $1.20 \mathrm{~m}$ height and weights $95.12 \mathrm{~kg}$ (see Figure 1). Rectangular elements made of hollow section elements (RHS $15 \times 15 \times 1.5 \mathrm{~mm}$ ) form a welded steel frame, and the columns have been set on a rectangular plan with a spacing of $0.556 \mathrm{~m}$ in the transverse direction (x-direction) and $0.465 \mathrm{~m}$ in the longitudinal direction (y-direction). Diagonal bracings have also been used in the planes of the sidewalls, which are responsible for counteracting transverse and torsional vibrations. The simulation of the weight of the floor and foundation slabs is presented through two concrete plates $(50 \times 50 \times 7 \mathrm{~cm})$.
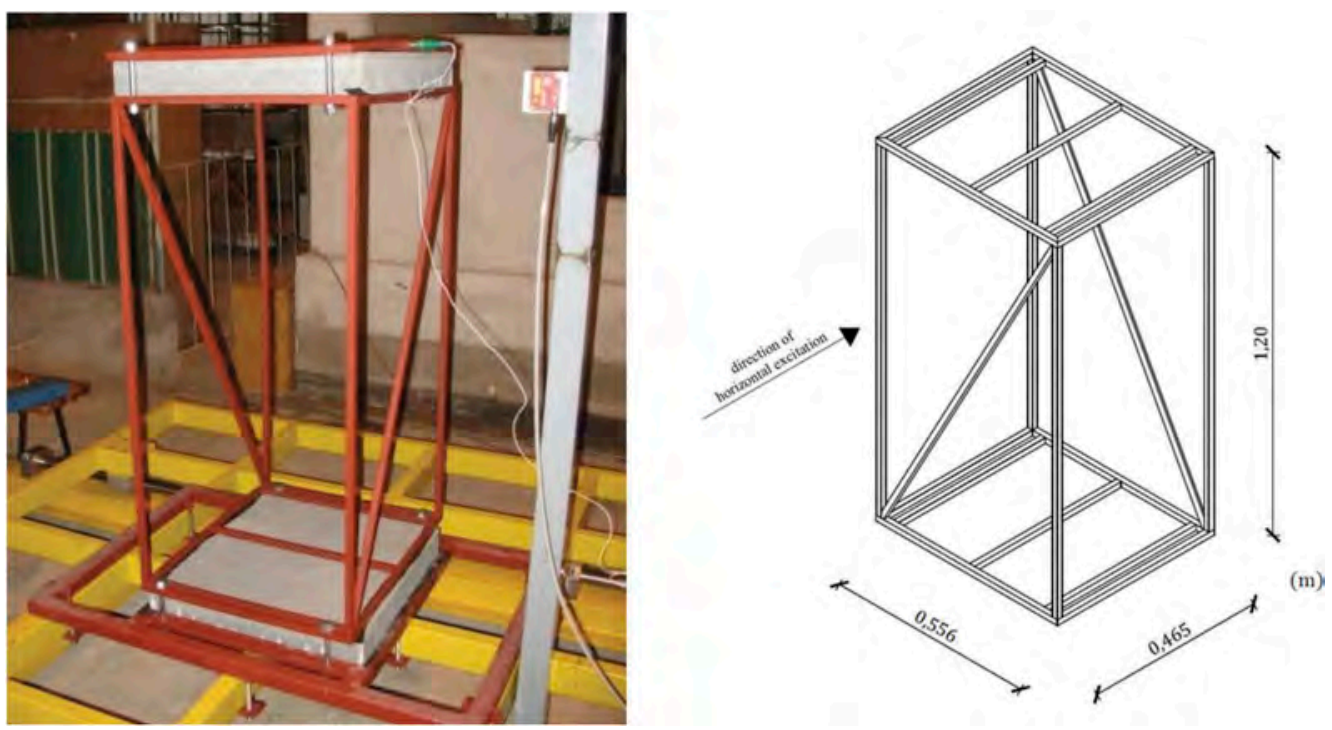

Figure 1. Single-storey steel structure model mounted on the shaking table. 
The dynamic characteristics of the experimental model were previously determined by conducting free vibration tests (see Falborski \& Jankowski, 2017a). The fundamental frequency of the experimental model was calculated to be $3.31 \mathrm{~Hz}$, whereas the damping ratio $0.53 \%$. A middle-sized shaking table located at Gdańsk University of Technology, Poland, was used to investigate the seismic response of the experimental model to a series of earthquake ground motions. All the experimental tests for steel structure models were carried out for a time step size of $0.002 \mathrm{~s}$.

\section{NUMERICAL MODEL}

In this study, single-storey building has been modelled in ETABS software using the Finite Element (FE) method. The slabs have been modelled using shell elements and the beams and columns applying frame elements. The numerical model has been studied first with fixed bases. Then, the same model has been studied with the isolated bases. A simple mathematical model in the form of springs has been introduced in ETABS software. The FE models of both building (with fixed and isolated bases) are shown in Figure 2.

To determine the lateral stiffness $K$ of the springs used, the hysteresis loop at excitation of 2 $\mathrm{Hz}$ has been utilized (see Figure 3). By using this method, the value of the lateral stiffness has been found to be $45 \mathrm{kN} / \mathrm{m}$.

a)

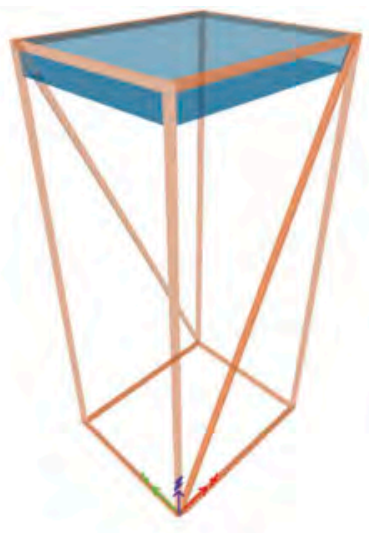

b)

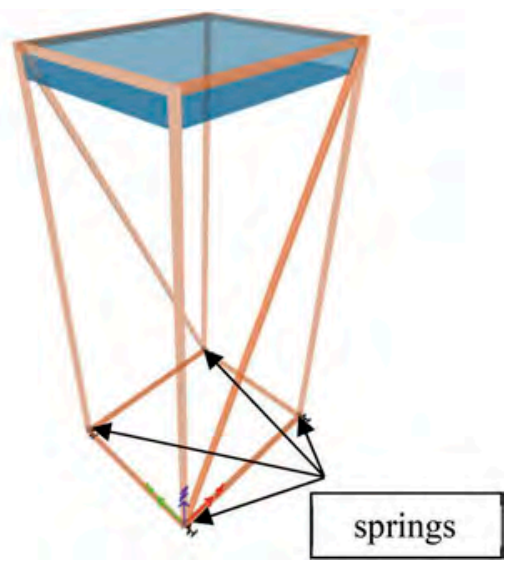

Figure 2. Numerical models of fixed-base building a) and base-isolated building b).

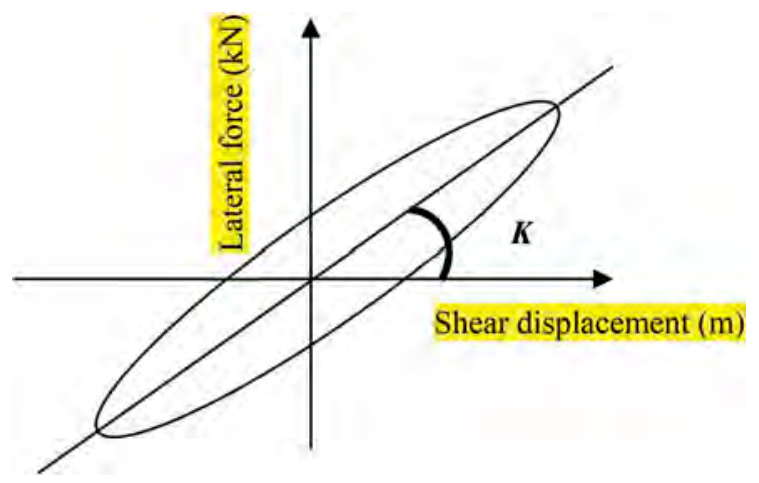

Figure 3. Schematic diagram of a hysteresis loop. 
Table 1. Ground motions used in this study.

\begin{tabular}{llll}
\hline Earthquake & PGA $\left[\mathrm{m} / \mathrm{s}^{2}\right]$ & Station & Year \\
\hline El Centro & 3.070 & Array 9 & 1940 \\
San Fernando & 5.688 & Paicoma Dam & 1971 \\
\hline
\end{tabular}

The detailed numerical analyses have been performed for the described model under two ground motions with different Peak Ground Accelerations (PGA) (see Table 1 for details). The response has been obtained using the linear direct integration method which is based on the Hilbert-Hughes-Taylor method, where the leading parameters are $\gamma=0.5, \beta=0.25$ and $\alpha=0$. The time step size used for the El Centro and San Fernando ground motions has been set at $0.01 \mathrm{~s}$. All the mentioned earthquakes have been properly scaled in the ETABS software to obtain comprehensive comparative analysis.

\section{VALIDATION OF THE NUMERICAL MODEL}

The acceleration time histories computed for the fixed-base model and base-isolated model under various seismic excitations are presented in Figures 4-5. The comparison of the results obtained from the numerical analysis and the shaking table investigation are briefly reported in Table 2 and Table 3. The comparison between the numerical and experimental models for the fixed-base buildings reveals that there is a good agreement between the responses. The difference of the peak acceleration between the numerical and experimental models of the fixedbase building ranges between $4 \%$ and $11 \%$ (see Figure 4 and Table 2). This means that the numerical model is capable of representing the response of the fixed-base building quite accurately. However, the comparison between the acceleration time histories of the numerical and experimental models for the base-isolated buildings reveals that the response is not close and there is no good agreement between them. The difference of the peak acceleration between the

a)

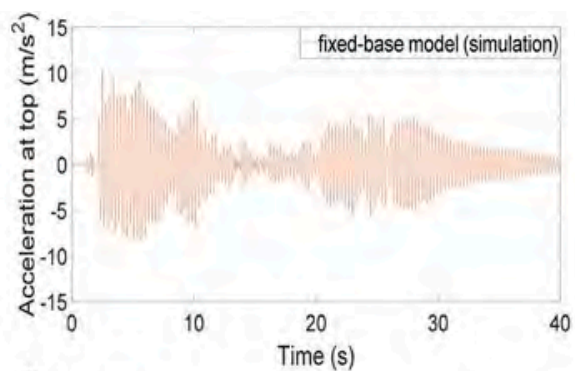

c)

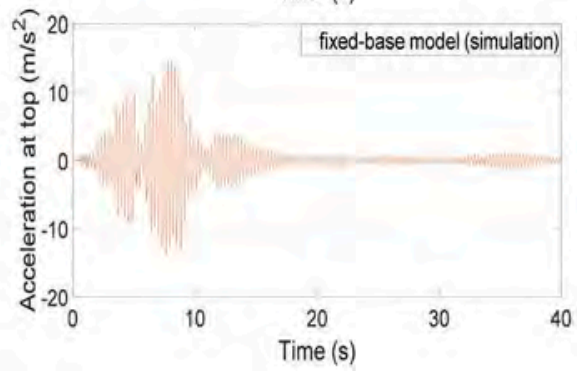

b)

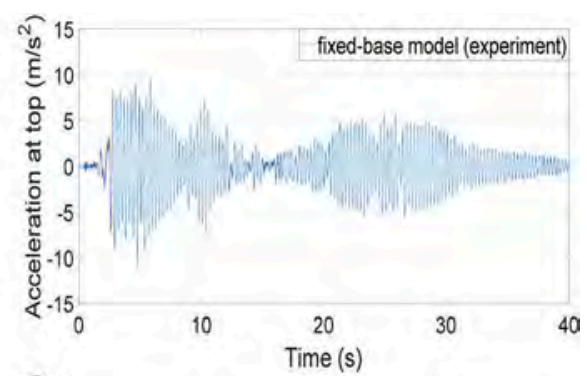

d)

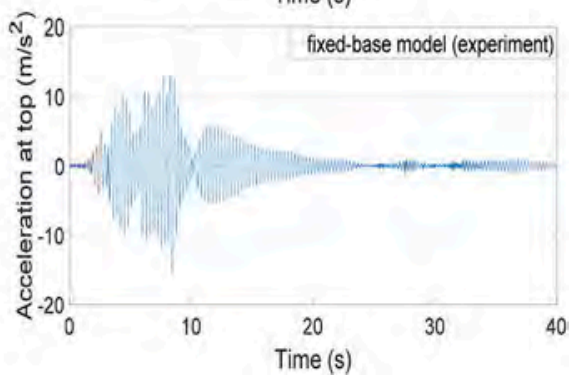

Figure 4. Numerically obtained (left) and experimentally determined (right) time-acceleration history plots for the fixed-base one-storey model during different ground motions: a, b) the 1940 El Centro earthquake and c, d) the 1971 San Fernando earthquake. 
a)

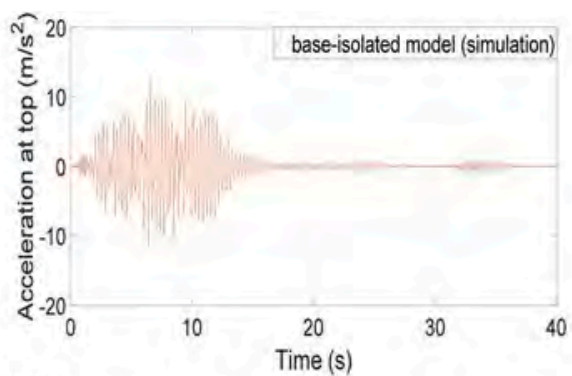

c)

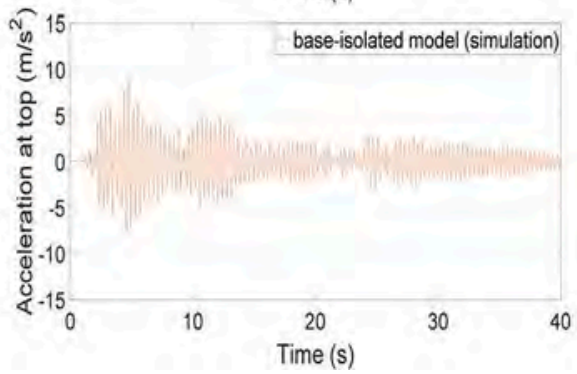

b)

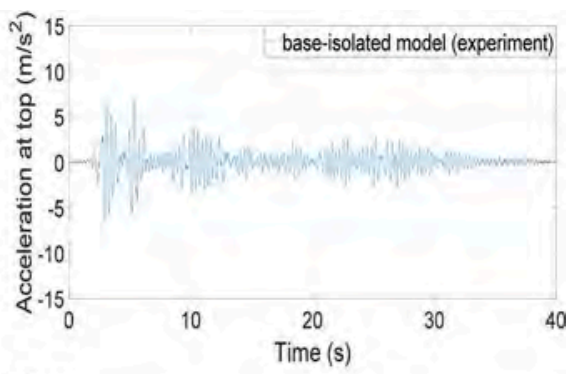

d)

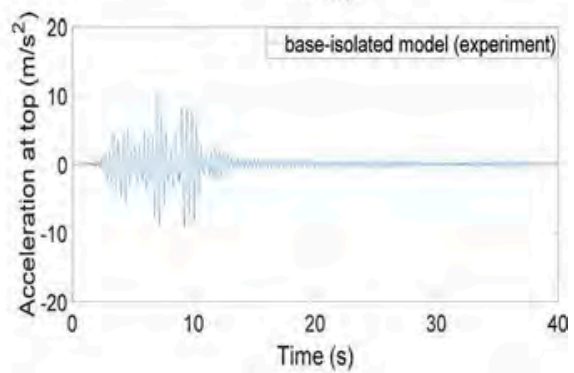

Figure 5. Numerically obtained (left) and experimentally determined (right) time-acceleration history plots for the base-isolated one-storey model during different ground motions: a, b) the 1940 El Centro earthquake and c, d) the 1971 San Fernando earthquake.

Table 2. Results obtained from numerical and experimental investigation for fixed-base model.

\begin{tabular}{llll}
\hline & \multicolumn{2}{l}{$\begin{array}{l}\text { Peak acceleration at the top of the } \\
\text { single-storey steel structure model }\left[\mathrm{m} / \mathrm{s}^{2}\right]\end{array}$} & \\
\cline { 2 - 3 } Dynamic excitation & $\begin{array}{l}\text { Numerical analysis } \\
\text { using ETABS }\end{array}$ & $\begin{array}{l}\text { Shaking table } \\
\text { investigation }\end{array}$ & $\begin{array}{l}\text { Percentage } \\
\text { difference [\%] }\end{array}$ \\
\hline El Centro earthquake & 10.21 & 11.39 & 10.36 \\
San Fernando earthquake & 14.96 & 15.59 & 4.04 \\
\hline
\end{tabular}

Table 3. Results obtained from numerical and experimental investigation for base-isolated model.

\begin{tabular}{lccc}
\hline & \multicolumn{2}{l}{$\begin{array}{l}\text { Peak acceleration at the top of the } \\
\text { single-storey steel structure model }\left[\mathrm{m} / \mathrm{s}^{2}\right]\end{array}$} & \\
\cline { 2 - 3 } Dynamic excitation & $\begin{array}{l}\text { Numerical analysis } \\
\text { using ETABS }\end{array}$ & $\begin{array}{l}\text { Shaking table } \\
\text { investigation }\end{array}$ & $\begin{array}{l}\text { Percentage } \\
\text { difference [\%] }\end{array}$ \\
\hline El Centro earthquake & 9.06 & 6.98 & 22.96 \\
San Fernando earthquake & 12.89 & 10.47 & 18.77 \\
\hline
\end{tabular}

numerical and experimental models of the base-isolated building ranges between $19 \%$ and $23 \%$ (see Figure 5 and Table 3). This means that the numerical model is not capable of representing the response of the base-isolated building. This is referred to the mathematical simplification of the spring model. For more accurate results, more advanced bearing model should be used. 


\section{CONLUSIONS}

This paper has been focused on comparison between the dynamic responses of buildings with fixed and isolated bases exposed to earthquake excitations. One-storey steel structure model has been considered using ETABS software, which was previously tested during the shaking table tests. The main conclusions of this study are:

- High compatibility of the results for the fixed-base steel structure model between the numerical and experimental analyses has been obtained which proves the effectiveness of the modelling techniques used in the ETABS software.

- The use of isolated system is an effective method in improving the response of building exposed to earthquake excitations, as concluded from the results of both experimental and numerical analyses.

- Modelling the isolated system by using the simplified method with linear springs is not an accurate technique due to the large differences in the structural responses found between the numerical and experimental analyses. Therefore, more advanced mathematical models should be used to simulate the behaviour of isolation systems during earthquakes.

\section{REFERENCES}

Booth, E. \& Key, D. 2006. Earthquake Design Practice for Buildings. London: ICE Publishing.

Buckle, I.G. \& Mayes, R.L. 1990. Seismic isolation: History, application, and performance: A world view. Earthquake Spectra 6: 161-201.

Buckle, I.G. 2000. Passive control of structures for seismic loads, Proceedings of the 12th World Conference on Earthquake Engineering 2825: 1-8.

Chopra, A.K. 2012. Dynamics of Structures: Theory and Applications to Earthquake Engineering. New York: Prentice Hall.

Elwardany, H., Seleemah, A., Jankowski, R. \& El-khoriby, S. 2019. Influence of soil-structure interaction on seismic pounding between steel frame buildings considering the effect of infill panels, Bulletin of Earthquake Engineering 17(11): 6165-6202.

Falborski, T. \& Jankowski, R. 2017a. Experimental study on effectiveness of a prototype seismic isolation system made of polymeric bearings. Applied Sciences 7 (8): 808.

Falborski, T. \& Jankowski, R. 2017b. Numerical evaluation of dynamic response of a steel structure model under various seismic excitations. Procedia Engineering 172: 277-283.

Falborski, T. \& Jankowski, R. 2018. Advanced hysteretic model of a prototype seismic isolation system made of polymeric bearings. Applied Sciences 8 (3): 400.

Falborski, T. \& Lasowicz, N. 2019. Numerical investigation on dynamic response of a steel lattice tower under various seismic events, 13th International Conference: Modern Building Materials, Structures and Techniques., 16-18 May 2017.

Falborski, T. 2020. Evaluation of foundation input motions based on kinematic interaction models. In: Köber D., De Stefano M., Zembaty Z. (eds), Seismic Behaviour and Design of Irregular and Complex Civil Structures III. Geotechnical, Geological and Earthquake Engineering, Vol 48. Cham: Springer.

Falborski, T. 2020. Numerical study on seismic response of a high-rise RC irregular residential building considering soil-structure interaction. In: Köber, D., De Stefano, M., Zembaty, Z. (eds), Seismic Behaviour and Design of Irregular and Complex Civil Structures III. Geotechnical, Geological and Earthquake Engineering, Vol 48. Cham: Springer.

Falborski, T., Sołtysik, B. \& Jankowski, R. 2018. Numerical investigation on dynamic performance of a multi-storey steel structure model and comparison with experimental results. Dynamical Systems in Applications, Springer Proceedings in Mathematics and Statistics 249: 105-113.

Kelly J.M., 1993. Earthquake-Resistant Design with Rubber. New York: Springer-Verlag.

Kelly, J.M. 1990. Base isolation: Linear theory and design. Earthquake Spectra 6: 223-244.

Lasowicz, N. \& Falborski, T. 2018. Soil-structure interaction effects on modal parameters of office buildings with different number of stories. MATEC Web of Conferences 219 (8): 03001.

Lasowicz, N., Falborski, T. \& Jankowski, R. 2018. Analysis of temporary steel grandstand with different bracing systems exposed to crowd load. Journal of Measurements in Engineering 6 (4): 256-262. 
Miari, M., Choong, K. K. \& Jankowski, R. 2019. Seismic pounding between adjacent buildings: Identification of parameters, soil interaction issues and mitigation measures. Soil Dynamics and Earthquake Engineering 121: 135-150.

Miari, M., Choong, K.K. \& Jankowski, R. 2020. Seismic pounding between bridge segments: a state-ofthe-art review. Archives of Computational Methods in Engineering DOI: 10.1007/s11831-019-09389-x (published online 13. 01.2020).

Naderpour, H., Naji, N., Burkacki, D. \& Jankowski, R. 2019. Seismic response of high-rise buildings equipped with base isolation and non-traditional tuned mass dampers. Applied Sciences 9(6): 1201.

Nagarajaiah, S. \& Xiaohong, S. 1996. Seismic performance of base-isolated buildings in the 1994 Northridge earthquake. In Proceedings of the 11thWorld Conference on Earthquake Engineering, Acapulco, Mexico, 23-28 June 1996.

Nagarajaiah, S. \& Xiaohong, S. 2000. Response of base-isolated USC hospital building in Northridge earthquake. Journal of Structural Engineering 126: 1177-1188.

Robinson, W.H. \& Greenbank, L.R. 1976. An extrusion energy absorber suitable for the protection of structures during an earthquake. Earthquake Engineering \& Structural Dynamics 4: 251-259.

Robinson, W.H. 1982. Lead-rubber hysteretic bearings suitable for protecting structures during earthquakes. Earthquake Engineering and Structural Dynamics, 10: 593-604.

Robinson, W.H. 1998. Passive control of structures, The New Zealand experience. Journal of Earthquake Technology 35: 63-75.

Skinner, R.I., Robinson, W.H. \& McVerry, G.H. 1993. An Introduction to Seismic Isolation. New York: Wiley.

Sołtysik, B., Falborski, T. \& Jankowski, R. 2016. Investigation on damage-involved structural response of colliding steel structures during ground motions. Key Engineering Materials 713: 26-29.

Sołtysik, B., Falborski, T. \& Jankowski, R. 2017. Preventing of earthquake-induced pounding between steel structures by using polymer elements - experimental study. Procedia Engineering 199: 278-283. 


\title{
Research on the interface elements in soil-steel structures based on the in situ test
}

\author{
Cz. Machelski \\ Wroclaw University of Technology, Wroctaw, Poland \\ P. Tomala \& M. Mońka \\ ViaCon Polska Sp. z o.o., Rydzyna, Poland
}

\begin{abstract}
One of the characteristic features of steel-soil structures in comparison to classical bridges is the impact of the surrounding soil and the road superstructure for its bearing capacity. In this paper based on the in-situ test it is proved that the results of analysis are sensitive of the direction of live load vehicle. For this purpose, the methodology, where the vehicles change their positions was used. Both in the test and the analysis, the full load cycle was carried out, including the drive of the vehicle in two directions, i.e. from the starting position to the turning point and back. A special feature is structure tendency to reaching the primary readings after full cycle of loading. This proves an elastic behavior of soil-steel structure, which is especially important where the one of the basic structural material is the soil (in the classical arch bridges treated as a non-structural).
\end{abstract}

\section{SOIL-STEEL STRUCTURE TESTING}

As one of the examples of performance of tests involving strain gauge measurements, the paper presents those performed on the test structure built in Rydzyna (Poland), shown in (Figure 1). The geometrical parameters of the perimeter zone of the shell are as follows: span $L=$ $17.594 \mathrm{~m}$ rise $H=5.459$ and top radius $R=13.735 \mathrm{~m}$. The geometry of the corrugated steel plate is described by its technical designations SC $380 \times 140 \times 7$ - SuperCor type with the dimensions: $a=380 \mathrm{~mm}$ - corrugation pitch, $f=140 \mathrm{~mm}$ - its depth, $g=7 \mathrm{~mm}$ plate thickness.

The test results presented in this paper apply to a structure in 8 years after completion of the construction but without its service. Therefore, this is an example of the structure behavior taking into account the occurring processes of soil backfill consolidation. Our load consists of a loader as shown in (Figure 1), without diggings in the bucket. Axle-loads of the loader on both axles were similar: $P_{1}=114.3 \mathrm{kN}$ (reference axle) and $P_{2}=104.7 \mathrm{kN}$. Axle base (measured along the structure) was $3.4 \mathrm{~m}$. Location of the vehicle is determined on the figures with regard to the crown point of the soil-steel structure using the $x_{\mathrm{p}}$ coordinate. The loader travelled along the longitudinal axis of the bridge in a steeping way with $\Delta x_{p}=1.5 \mathrm{~m}$. The vehicle wheels were located symmetrically along the structure axis.

\section{HYBRID MODEL OF THE STRUCTURE}

In the case of a hybrid model, as shown in (Figure 2), the structure is divided into two subsystems: the upper part comprising the soil backfill and road surface, and the lower one made of corrugated steel plate. A specifically modelled interface elements are used in the soil-steel 


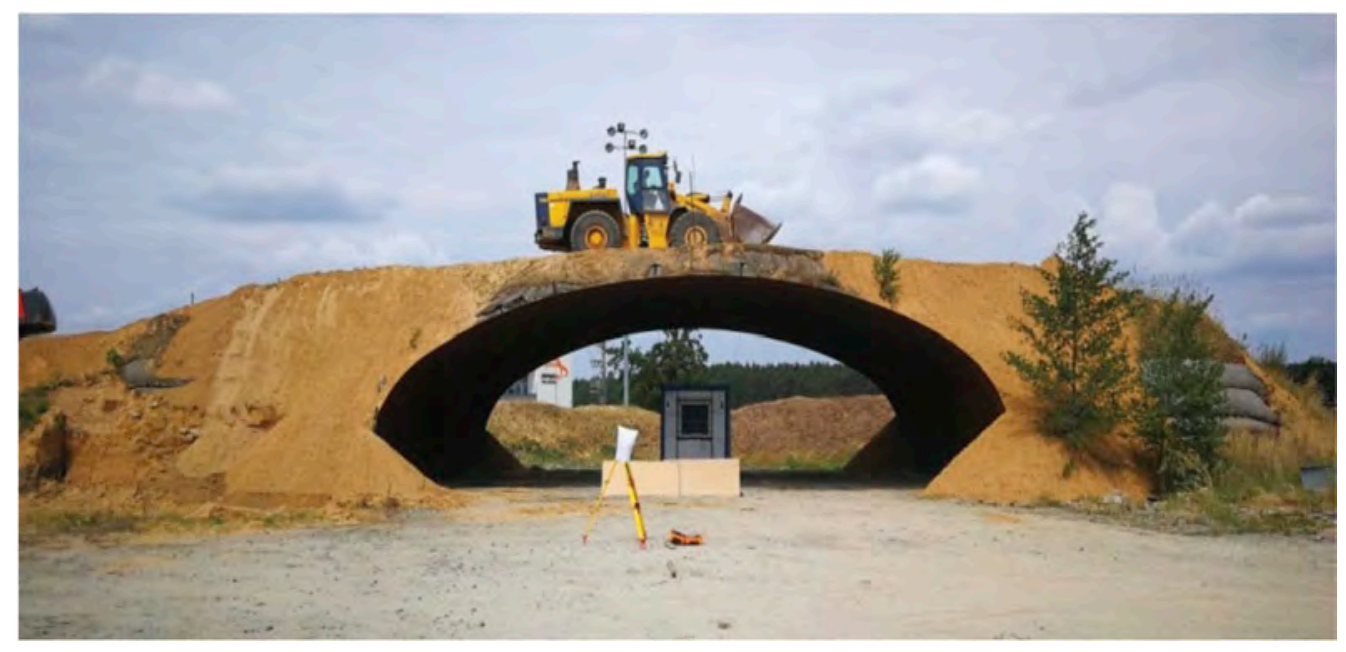

Figure 1. View of the loaded structure.

a)

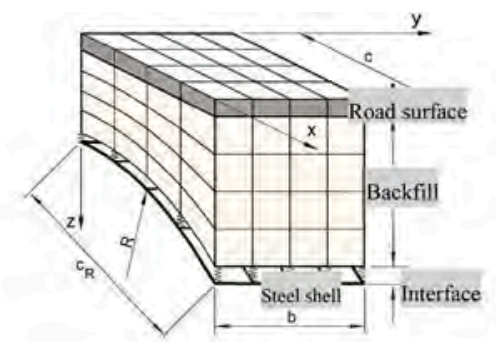

c)

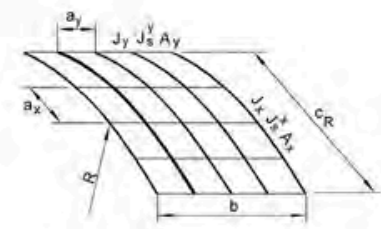

b)

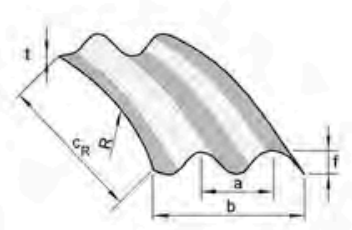

d)

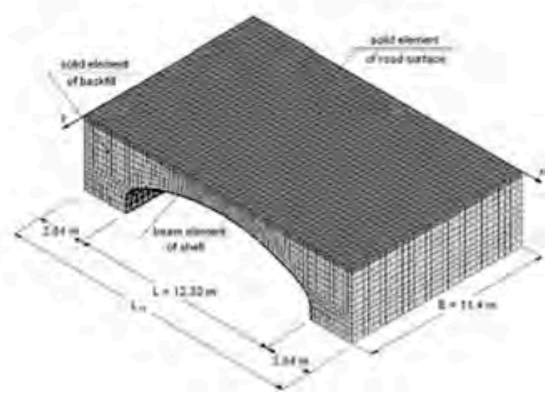

Figure 2. Example of a soil-steel composite bridge.

structures between mentioned above sub-systems. Steel structure was modelled as a orthogonal isotropic grillage as shown in (Figure 2c). In comparison to the conventional bridges, a characteristic feature consists in taking the backfill, the basic material of the structure, as a structural element. For this model, mapping of the interface layer between the soil backfill and the steel structure is of particular importance. Mutual interactions in the layer in question are the basis for the analysis presented in this paper.

\section{INTERNAL FORCES}

In this paper the internal forces are taken directly from the strain gauge measurements. Electrical resistance strain gauges were fixed to the surface of the corrugated steel plates 
(accessible from the inside) within the structure periphery. In every measurement section, the gauges were applied in pairs, in the crest and valley of the corrugation, around the structure periphery as shown in (Figure 3b). This layout of gauges and assumption of flat cross-sections makes it possible to determine the normal force according to the following formula:

$$
N=E A \cdot \varepsilon=E A \frac{\varepsilon_{D}(f-g)+\varepsilon_{g}(f+g)}{2 f}
$$

The formula (1) includes the geometry of the corrugated steel plate as shown in (Figure 3b). In order to determine the curvature change $\kappa$ and the structure radius $\rho$, geometrical relations of the steel plate can be used with $\varepsilon_{D}$ and $\varepsilon_{g}$, and then the bending moment can be calculated according to the formula:

$$
M=E I \cdot \kappa=E I \frac{\varepsilon_{g}-\varepsilon_{D}}{f}
$$

Both formulas include the stiffness of the cross-section $E A$ and $E I$.

Figure $3 \mathrm{a}$ presents the distribution of interactions $p(\mathrm{~s})$ and $t(\mathrm{~s})$ along the length of the analysed structure periphery. The pressure $p(\mathrm{~s})$ is applied radially, i.e. in accordance with the radius $R$. The functions of internal forces $N(\mathrm{~s})$ and $M(\mathrm{~s})$ directly give the normal interactions:

$$
p(s)=\frac{d^{2} M}{d s^{2}}+\frac{N}{R}
$$

and the tangential interactions, distributed along the structure periphery:

$$
t(s)=\frac{d N}{d s}+\frac{d M}{d s} \frac{1}{R}
$$

When using a differential approach to determine the normal interaction forces $p(\mathrm{~s})$, the following formula (3) can be used:

$$
p_{j}=\frac{1}{c^{2}}\left(M_{j-1}-2 \cdot M_{j}+M_{j+1}\right)+\frac{N_{j}}{R}
$$

a)

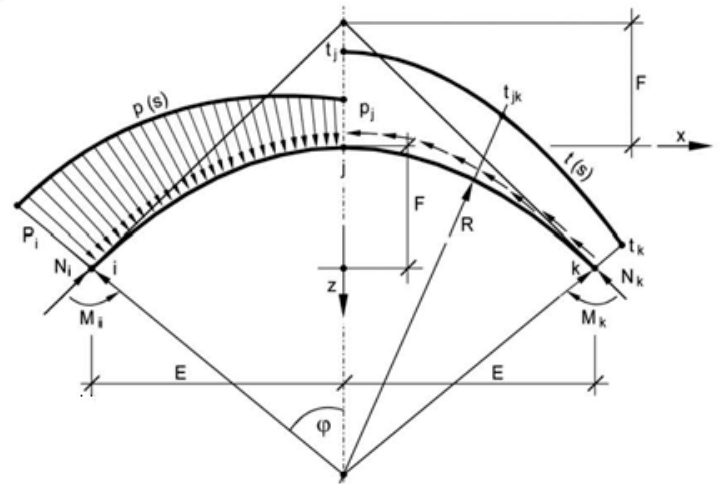

b)

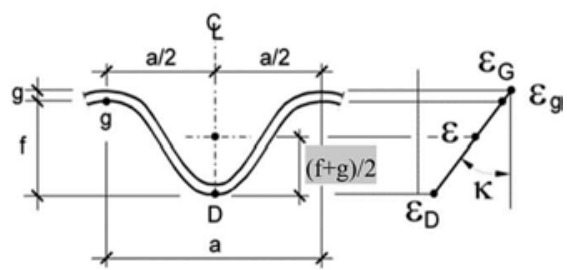

Figure 3. Distribution of contact forces between two adjacent subsystems (steel structure and surrounding soil). 

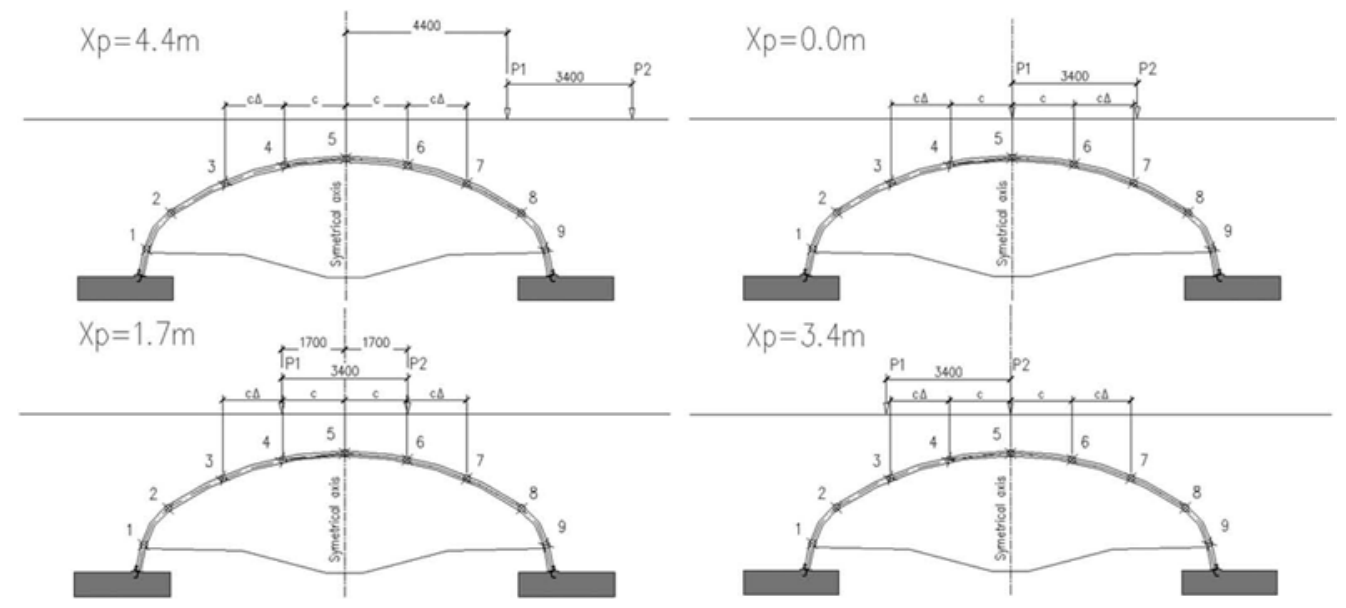

Figure 4. Layout of measurement points of the shell's periphery. Individual stages of loading.

Tangential interactions calculated according to the formula (4) are included in the equation:

$$
t_{i j}=\frac{1}{c}\left[\left(N_{i}-N_{j}\right)+\frac{1}{R}\left(M_{i}-M_{j}\right)\right]
$$

Due to the calculation method, this is a mean value between the measurement points around the periphery. In both formulas, $c$ is the distance between the measurement points.

\section{MEASURING BASE}

The strain gauge layout along the periphery of the shell is presented in (Figure 4). Therefore, the measuring system is not regular but symmetrical in relation to the crown point. The distances between the points located near-crown are $c=1.202 \mathrm{~m}$. When the point layout is irregular and the length of the preceding section is $c \cdot \Delta=1.202 \cdot 2.88=3.462 \mathrm{~m}$, then the derivative of the bending moment is calculated according to the formula (5) in the differential approach is included in the following equation:

$$
\frac{d^{2} M}{d s^{2}}=\frac{2}{c^{2}(1+\Delta) \Delta}\left[\Delta \cdot M_{i-1}-(1+\Delta) M_{i}+M_{i+1}\right]
$$

where $\Delta=3.462 / 1.202=2.88$. The section with the length $c \cdot \Delta$ is located from the $i+1$ point, where length of the opposite section (i-1) is c.

\section{CONTACT INTERACTIONS}

Figures 5 and 6 present the changes in contact interaction components: normal $p$ and tangential $t$. The horizontal axis of the diagrams specifies the value of $x_{\mathrm{p}}$ as the distance of loader axle as the force $P_{1}$ from the structure crown point. The legend to the diagrams marks the curves plotted from the loader back (W) and forth pass (P). In both passes, the location of the vehicle is exactly the same in each position marked with $x_{\mathrm{p}}$. The measurements started and had been finished at $x_{\mathrm{p}}=21 \mathrm{~m}$. At $x_{\mathrm{p}}=-9 \mathrm{~m}$ the passing direction was changed. Characteristic vehicle locations are: 
a)

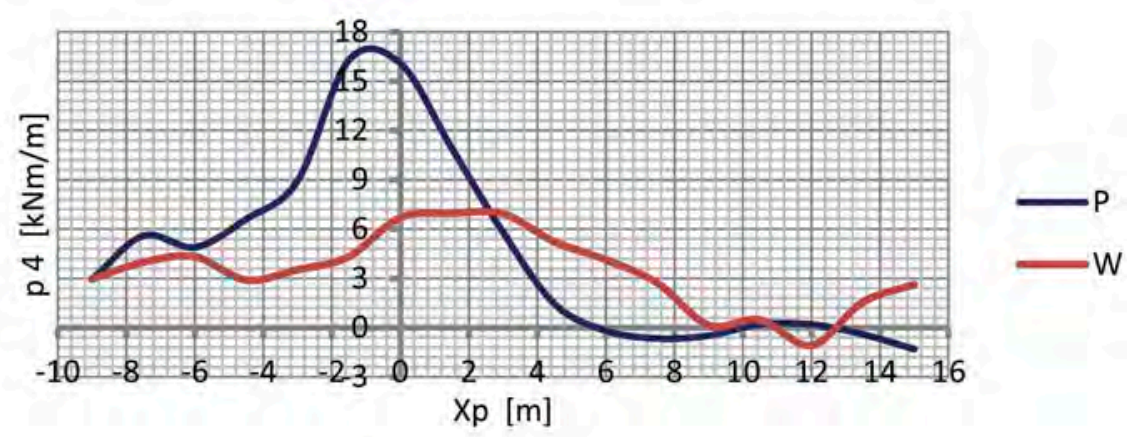

b)

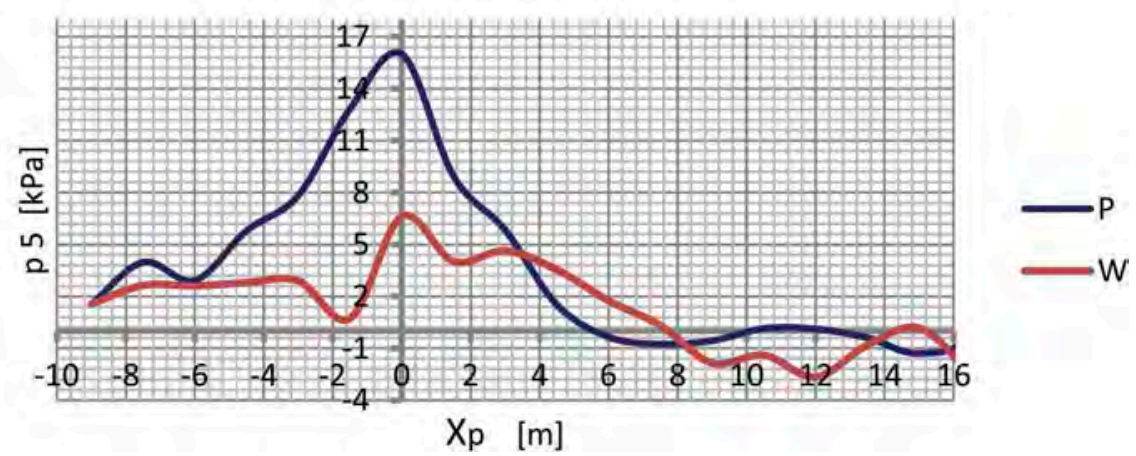

Figure 5. Normal interactions in the structure crown point area. a) intermediate point 4 , b) structure crown, point 5.

$-x_{\mathrm{p}}<L / 4=4.4 \mathrm{~m}$, where contact interactions increase;

$-x_{\mathrm{p}}=0$, where the loader axle $P_{1}$ is above the structure crown point;

$-x_{\mathrm{p}}=-1.7 \mathrm{~m}$, where the vehicle axles $P_{1}$ and $P_{2}$ are equally distanced from the structure crown point;

$-x_{\mathrm{p}}=-3.4$, where the loader axle $P_{2}$ is above the structure crown point.

In order to determine the analysed shell measurement points in Figures 5 and 6 , we used the marking of the location of the measurement points $x_{4}=1.2 \mathrm{~m} x_{5}=0$ (crown point) $x_{6}=-1.2 \mathrm{~m}$.

The curves in Figure 5 are very similar in terms of their shape but show significant differences between the values during the back (W) and forth $(\mathrm{P})$ passes. The similar maximum values $p$ in the points 4, 5 mean that there is similar pressure from the loader wheels load in the crown point area. During the forth pass $(\mathrm{P})$, there is no second wave with the peak value, where the second axle $P_{2}$ of the loader is just above the analysed point. Such peaks can be seen for the back pass (W). From the results of the analysis, we draw a conclusion of a significant reduction of the interaction $p$ when the vehicle returns to its starting point. Therefore, there is a hysteresis loop for the earth pressure.

The sense of the tangential forces $t_{45}$ is matching the direction specified in (Figure 3 ). The main feature of the functions $p\left(\mathrm{x}_{\mathrm{p}}\right)$ and $t\left(\mathrm{x}_{\mathrm{p}}\right)$ is that they are similar during the back and forth drive of the loader. High values of the force $t$, created when the vehicle returns to the starting point, are very significant. The same curves were obtained also for points located further from the crown point but on the opposite side of the symmetry axis of the shell. Therefore, there is no hysteresis loop for tangential forces.

Very high values of $t(\mathrm{~s})$ in comparison with $p(\mathrm{~s})$ are not here an error of the calculation algorithm (and of measurements). The relation $t / p$ - assumed not to exceed the friction coefficient values specified in the paper - does not include the effects of interactions from the self 
a)

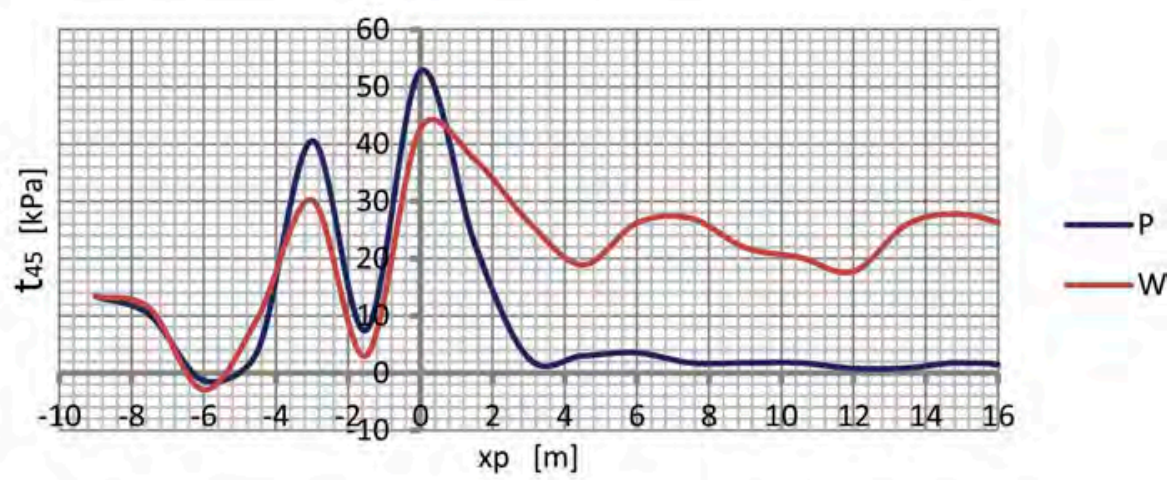

b)

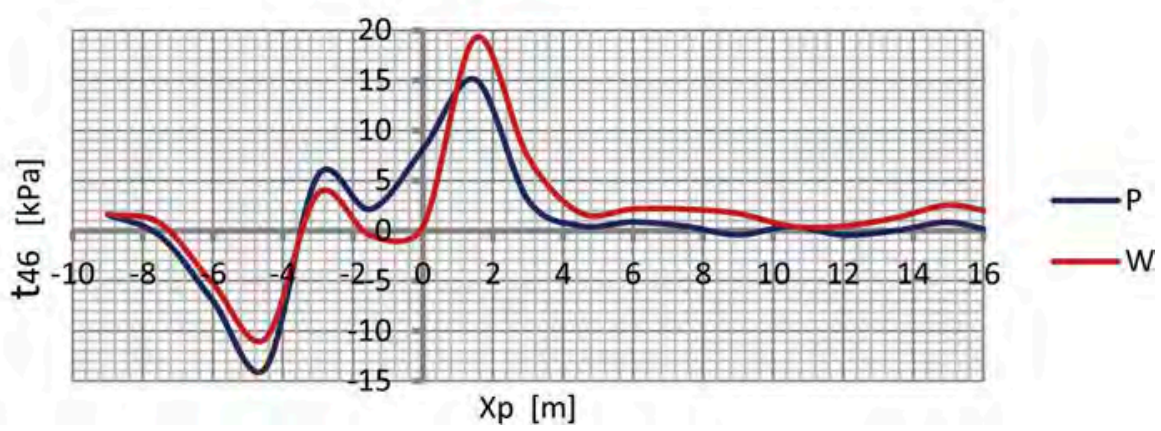

Figure 6. Tangential interactions in the structure crown point area. a) from the ramp side, b) in the crown point.

weight of the soil (occurring during the backfilling). In the analysed example of a structure, the maximum strain in the corrugated steel plate reached the value of:

$$
\sigma=E \cdot \varepsilon=205000 \cdot 184 \cdot 10^{-6}=37,7 \mathrm{MPa}
$$

\section{CONCLUSIONS}

For a hybrid structure model, it is important to determine the principle of contact interactions between the adjacent subsystems. The paper presents the results of the algorithm for determining the soil interactions onto the shell as the normal $p$ and tangential $t$ components based on the strain gauge measurements. The hybrid model uses the condition of consistence of contact interactions between the soil and the shell. The principle of displacement conformity is not included, i.e. slip at the interface of the two adjacent materials is allowed. This is an important advantage of the algorithm.

A characteristic feature of the soil-steel composite bridges is a significant difference of displacement, internal forces and contact interactions (as in work) between the back and forth passes of the live load vehicle. When the analysed values, after the vehicle full passage (back and forth), return to the initial, a characteristic hysteresis loop is achieved. This phenomenon in bridge structures is poorly known and concerns moving loads, i.e. ones which change their position. The outcomes of the test data evaluation presented in this study are to be used in the ongoing research for a validation of the numerical finite element hybrid model proposed by Authors in section 2. 


\section{REFERENCES}

Machelski C., Effects of surrounding earth on shell during construction of flexible bridge structure. Studia Geotechnica et Mechanica, No 22019 p. 67-73.

Machelski C., Tomala P.: Investigation of displacements functions in soil-steel bridge structure based on tensometric measurements. International Conference on Arch Bridges, Porto 2-4 October 2019

Pettersson L.: Full Scale Tests and Structural Evaluation of Soil Steel Flexible Culverts with low High of Cover. Doctoral Thesis in Civil and Architectural Engineering Stockholm, 2007.

Sobótka M. Numerical simulation of hysteretic live load effect in soil-steel bridge. Studia Geotechnika et Mechanica. (2014) 36.1. 103-109.

Vaslestad J.: Soil structure interaction of buried culverts, Institutt for Geoteknikk, Norges Tekniske Hogskole, Universitetet I Trondheim,1990. 


\title{
Reliability analysis of tensegrity towers in a system approach
}

\author{
W. Mochocki \& P. Obara \\ Kielce University of Technology, Kielce, Poland
}

\begin{abstract}
In this paper, a reliability analysis of tensegrity towers is presented. The towers built with Simplex modules are considered. The analysis of tensegrity structures consists of three stages. The first stage leads to the identification of the existing mechanisms and self-stress states in the structure. The second stage focuses on the determination of reliability models, whereas third - contains determination the influence of the level of self-stress state on static parameters and consequently on the reliability index.
\end{abstract}

\section{INTRODUCTION}

Tensegrities are the structures composed of only compressed (struts) and tensioned elements (cables). A characteristic feature of tensegrity structures is system of internal forces holds the structural components in stable equilibrium. This is called the self-stress state. The changes of the level of self-stress state influences on behaviour of structures, whereas the absence causes that structures are geometrically variable (infinitesimal mechanism occurs). Initially, the idea of tensegrity construction was associated primarily art. Currently, the use of such structures is increasing in civil engineering and tensegrity concept is used among others in towers (Schlaich 2004, Snelson 2013, Obara 2019).

The paper develops the considerations of tensegrity towers presented in (Obara 2019). A new problem concerning on reliability analysis of such structures has been studied. The towers built with Simplex modules (Fuller 1962, Emmerich 1964, Snelson 1965) are considered. The reliability assessment consists in comparing the reliability index of the structure with the required value of the reliability index. The required value of the reliability index was chosen for the RC2 reliability class (50 years reference period). In accordance with the standard (PN-EN 1990:2004), "Three reliability classes $(\mathrm{RC} 1, \mathrm{RC} 2$, and $\mathrm{RC} 3$ ) may be associated with the three consequence classes CC1, CC2, and CC3". The tower's construction was classified as a structure with the consequence class $\mathrm{CC} 2$. This means that "Medium consequence for loss of human life and economic, social, or environmental consequences are considerable". The required value for the reliability class $\mathrm{RC} 2$ is $\beta=3.8$. In this paper the towers built with Simplex modules are considered. The influence of the level of self-stress state on static parameters and the reliability index is analysed. The static analysis is carried assuming the hypothesis of large displacements. In turn to assessing the reliability of a structure the system approach is used wherein the reliability index is calculated according to the assumption of serial connections.

\section{MATHEMATICAL DESCRIPTION}

Reliability analysis of tensegrity structures is a three-stage process. The first stage (the qualitative analysis) includes the identification of self-stress states and infinitesimal mechanisms. The second stage focuses on the determination of reliability models, whereas third - contains 
determination the reliability index in order to the self-stress state. The last two stages are the quantitative analysis.

The first stage is carried out based using singular value decomposition of the compatibility matrix (Pellegrino 1993, Gilewski et al. 2015, 2019, Obara 2019, Obara \& Tomasik 2020). The compatibility matrix for structures is determined using the finite element formalism (Zienkiewicz 2000, Obara \& Tomasik 2020). Tensegrity towers aren-element space trusses $(e=1,2, \ldots, n)$ described by the elasticity matrix $\mathbf{E}\left(\in \mathbb{R}^{n \times n}\right)$ with $m$-degrees of freedom $\mathbf{q}\left(\in \mathbb{R}^{m \times 1}\right)$. The singular value decomposition of matrix $\mathbf{B}\left(\in \mathbb{R}^{n}\right)$ is a factorization in the form:

$$
\mathbf{B}=\mathbf{Y} \mathbf{N X}^{T},
$$

where $\mathbf{Y}\left(\in \mathbb{R}^{n \times n}\right)=\left[\begin{array}{llll}\mathbf{y}_{1} & \mathbf{y}_{2} & \ldots & \mathbf{y}_{n}\end{array}\right]$ and $\mathbf{X}\left(\in \mathbb{R}^{m \times m}\right)=\left[\begin{array}{llll}\mathbf{x}_{1} & \mathbf{x}_{2} & \ldots & \mathbf{x}_{m}\end{array}\right]$ are orthogonal matrices and $\mathbf{N}\left(\in \mathbb{R}^{n \times m}\right)$ is a rectangular diagonal matrix. The orthogonal matrices $\mathbf{Y}$ and $\mathbf{X}$ as well as matrix $\mathbf{N}$ are related to eigenvectors and eigenvalues of the following problems:

$$
\left(\mathbf{B B}^{T}-\mu \mathbf{I}\right) \mathbf{y}=\mathbf{0},\left(\mathbf{B}^{T} \mathbf{B}-\lambda \mathbf{I}\right) \mathbf{x}=\mathbf{0},
$$

where $\mu$ and $\lambda$ are eigenvalues of the respective matrix. If any $\mu$ value is equal to zero, a selfstress state exists. If any $\lambda$ value is equal to zero, a mechanism exists. In order to identify whether the mechanism is infinitesimal or finite, nonlinear analysis of the stiffness matrix with the use of geometric stiffness matrix $\mathbf{K}_{G}(S)$, which takes into account the self-stress state $S$, should be applied. If all eigenvalues of the matrix $\left(\mathbf{B}^{T} \mathbf{E B}+\mathbf{K}_{G}(S)\right)$ are positive, the identified mechanism is infinitesimal and the structure is stable.

In the second stage a reliability model must be defined. Due to all analysed towers are tensegrities, which are characterized by mechanisms occurs, a reliability model is a serial system. Reliability of the system $R$ is calculated from the formula:

$$
R=\prod_{i=1}^{n} R_{i}
$$

where $R_{i}$ is reliability of a single element. The procedure that leads to the determination of the reliability of element $R_{i}$ was presented, among others, in papers (Mochocki et al. 2018, 2019, 2020). To do this, the static analysis must be performed. It is necessary to determine random variables of the effect of action $E_{i}$, and of capacity $N_{i}$. Random variables are described by means of the normal distribution with the parameters expected value $\mu$ and standard deviation $\sigma$. With respect to standard deviation for effect of actions $E_{i}$, the variation coefficient is assumed at the level of $6 \%$, whereas with standard deviation for capacity $N_{i}$, it is at the level of $10 \%$. A subsequent step is determining the safety margin $Z_{i}$, which is also a random variable described by means of the normal distribution. The parameters of this system are the expected value of the safety margin $\mu_{Z i}=\mu_{N i}-\mu_{E i}$ and standard deviation of the safety margin $\sigma_{Z i}=\left(\sigma_{E i}^{2}+\sigma_{N i}^{2}\right)^{0.5}$. Next, the reliability index for a single element is computed $\beta_{i}=\mu_{Z i} / \sigma_{Z i}$. On its basis, the probability of the element failure can be estimated $P_{f i}=\Phi\left(-\beta_{i}\right)$, where $\Phi$ is the Laplace function. The final step involves the computation of the reliability of a single element $R_{i}=1-P_{f i}$ and at the end - the reliability of the system $R(3)$.

In the last, third stage, the reliability index is calculated:

$$
\beta=-\Phi^{-1}(1-R) .
$$

It must be added, in the case of tensegrity structures the static parameters depend on the level of self-stress state. It means, the self-stress state consequently influences on the reliability index (4). 
In order to fully understand the behaviour of such structures, in the first the static analysis was carried out. The influence of the level of self-stress state on the normal forces $N$, the loadbearing capacity ratio $W_{\max }=N / N_{R d}$ and the stiffness were calculated. The static analysis was carried out assuming the hypothesis of large displacements:

$$
\mathbf{K}_{S} \mathbf{q}=\mathbf{P} ; \mathbf{K}_{S}=\left[\mathbf{B}^{T} \mathbf{E B}+\mathbf{K}_{G}(N+S)+\mathbf{K}_{N, N L}(\mathbf{q})\right],
$$

where $\mathbf{P}$ is the load vector, $\mathbf{K}_{G}(N+S)$ is the geometric stiffness matrix, which takes into account the self-stress state $S$ and the normal force $N$ and $\mathbf{K}_{N, N L}(\mathbf{q})$ is the initial strain matrix. The change in rigidity was measured using the so-called global stiffness parameter (GPS) (Obara 2019). The GPS parameter expresses the ratio of two strain energies, measured at the minimum and at the $i$-th level of self-stress:

$$
G P S=\frac{\left[\mathbf{q}\left(S_{\min }\right)\right]^{T} \mathbf{K}_{S}\left(S_{\min }\right) \mathbf{q}\left(S_{\min }\right)}{\left[\mathbf{q}\left(S_{i}\right)\right]^{T} \mathbf{K}_{S}\left(S_{i}\right) \mathbf{q}\left(S_{i}\right)},
$$

where $\mathbf{K}_{S}\left(S_{\text {min }}\right)$ and $\mathbf{q}\left(S_{\text {min }}\right)$ are a secant stiffness matrix and a design displacement vector with a minimum level of self-stress state, and $\mathbf{K}_{S}\left(S_{i}\right)$ and $\mathbf{q}\left(S_{i}\right)$ - at $i$-th level of self-stress state.

\section{EXAMPLES}

In this paper, the reliability analysis of tensegrity towers is performed. As the first, qualitative analysis leads to classification towers to tensegrity groups are carried out. Next, the calculations of the influence of self-stress state on the normal forces, the load-bearing capacity ratio, the stiffness and, at the end, on the reliability index are performed. The structures built with Simplex modules are taken into account. The single module is considered as the first and then towers build with two and six modules are analysed. The design solution of the Halfen DETAN Rod System is adopted and the following characteristics are assumed:

- Young modulus: $E=210 \mathrm{GPa}$ and density: $\rho=7860 \mathrm{~kg} / \mathrm{m}^{3}$

- cables: made of rods, steel S460N, diameter $\phi=20 \mathrm{~mm}$, moment of inertia: $I=7.85 \cdot 10^{9} \mathrm{~m}^{4}$, cross-sectional area: $A=3.14 \cdot 10^{4} \mathrm{~m}^{2}$, load-bearing capacity: $N_{R d}=110.2 \mathrm{kN}$,

- struts: made of hot-finished circular hollow section, steel: S355J2, diameter: $\phi=76.1 \mathrm{~mm}$, thickness: $t=2.9 \mathrm{~mm}$, moment of inertia: $I=4.47 \cdot 10^{7} \mathrm{~m}^{4}$, cross-sectional area: $A=6.88 \cdot 10^{4} \mathrm{~m}^{2}$, load-bearing capacity: $N_{R d}=203.5 \mathrm{kN}$.

Normalized self-stress state forces were multiplied by the level of self-stress state $S$ and applied to the structure. The minimum applied level of the self-stress state $S_{\min }$ provides proper identification of the elements (i.e. struts are compressed and cables are tensed). The maximum level of the self-stress state $S_{\max }$ does not cause the exceedance of the load-bearing capacity of the elements. These levels are equal respectively: $S_{\min }=1 \mathrm{kN}$ and $S_{\max }=110 \mathrm{kN}$. The models was loaded with a vertical force $P=-10 \mathrm{kN}$ and $P=-20 \mathrm{kN}$ applied to one top node. For calculation, a procedure in the "Mathematica" environment was created.

\subsection{Qualitative analysis}

The first considered structure is the single Simplex module (model S1) (Figure 1a), which consists of twenty elements $(n=12)$, i.e. three struts and nine cables, and six nodes. The coordinates of the nodes are shown in Table 1 . The analysis was performed for the module with twelve degrees of freedom $(m=12)$ (the blocked displacements are $\left.q_{1}, q_{3}, q_{5}, q_{6}, q_{7}, q_{9}\right)$ thus the number of elements and the number of degrees of freedom are equal $(n=m=12)$. The 
a)

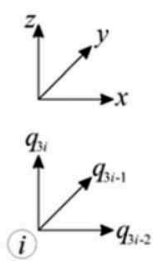

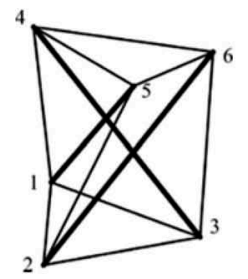

b) struts:

$-1.0000$

top and bottom cables:

0.3853

middle cables:

0.6966 c)

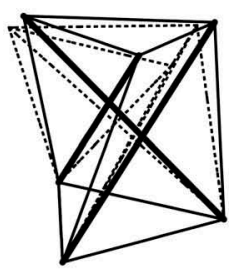

Figure 1. Simplex module: a) geometry, b) normalised self-stress state, c) infinitesimal mechanism.

Table 1. Coordinates of the nodes [m] of the single Simplex module.

\begin{tabular}{lllllll}
\hline No. of node $(i)$ & 1 & 2 & 3 & 4 & 5 & 6 \\
\hline$x$ & -0.500 & 0.000 & 0.289 & -0.577 & 0.289 & 0.289 \\
$y$ & 0.289 & -0.577 & 0.289 & 0.000 & -0.500 & 0.500 \\
$z$ & 0.000 & 0.000 & 0.000 & 1.000 & 1.000 & 1.000 \\
\hline
\end{tabular}

compatibility matrix $\mathbf{B}\left(€ \mathbb{R}^{12 \times 12}\right.$ is square, therefore the matrices $\mathbf{B B}^{T}$ and $\mathbf{B}^{T} \mathbf{B}$ are equal too. There is one zero eigenvalue in both matrices, thus one self-stress state (Figure 1b) and one mechanism is identified (Figure 1c) - summarised results of performed qualitative analyses are shown in Table 2. All eigenvalues of the matrix $\left[\mathbf{B}^{T} \mathbf{E B}+\mathbf{K}_{G}(\mathbf{S})\right]$ are positive thus the identified mechanism is infinitesimal and the stability of the structure is ensured. The model S1 meets all tensegrity features, it means that it can be classified as the ideal tensegrity.

Next, tensegrity towers built with Simplex module are analysed. Modules are linear connected in a strut-strut system. The models consisting with two modules - model S2 and six modules model S6 are considered (Kłosowska et al. 2018). The structures are supported as a model S1. For both models self-stress states $(S)$ and mechanisms $(M)$ are identified. The number of them is equal number of modules (Table 2). None of the self-stress states identifies correctly struts and cables so for the quantitative analysis superposed and normalized self-stress state for the single modified Simplex module is taken into account. All eigenvalues of the stiffness matrix $\left[\mathbf{B}^{T} \mathbf{E B}+\mathbf{K}_{G}(\mathbf{S})\right]$ are positive so towers are stable. Other than mentioned above characteristic features $S$ and $M$, the structure satisfies requirements of characteristics $T$ (it is a truss) and $C$ (tensile elements are cables and have no rigidity in compression). The analysed tensegrity towers can be classified as the structures with tensegrity features of class 1 (Obara 2019).

\subsection{Quantitative analysis}

The influence of the level of self-stress state on the normal forces (Figure 2) are analysed as the first. Next, changes in the load-bearing capacity ratio $W_{\max }$ for cables (Figure 3a) and for struts (Figure 3b), the stiffness parameter GPS (Figure 4a) and the reliability index $\beta$ (Figure $4 \mathrm{~b}$ ) are presented. The external load $P$ prestresses the structure - additional tensile and compressive forces are generated respectively in the cables and struts. After introducing the self-stress state, normal forces from the external load successively decrease. For example,

Table 2. Results of the qualitative analysis of the towers built with the Simplex modules.

\begin{tabular}{lllllll}
\hline $\begin{array}{l}\text { No. of single } \\
\text { modules }\end{array}$ & $\begin{array}{l}\text { No. } \\
\text { of } \\
\text { nodes }\end{array}$ & $\begin{array}{l}\text { No. } \\
\text { of elements }\end{array}$ & $\begin{array}{l}\text { Degrees of } \\
\text { freedom }\end{array}$ & $\begin{array}{l}\text { No. } \\
\text { of mechan- } \\
\text { isms }\end{array}$ & $\begin{array}{l}\text { No. of } \\
\text { self-stress } \\
\text { states }\end{array}$ & Classification \\
\hline 1 & 6 & 12 & 12 & 1 & 1 & ideal tensegrity \\
\hline 2 & 9 & 21 & 21 & 2 & 2 & structures with tensegrity \\
6 & 21 & 56 & 56 & 6 & 6 & features of class 1 \\
\hline
\end{tabular}


in Figure 2 presented a change in the value of normal forces arising from loads $N(P)$ and normal forces generated in total by the load and prestress forces $N(P+S)$. The analyses performed showed that the effect of the self-stress state is greater at lower load and that the impact of the load is most significant at low values of initial prestress forces.

The initial prestress forces affect normal forces $N$, hence on effort of structure. In Figure 3 the load-bearing capacity ratio $W_{\max }$ are presented. For the minimum level of self-stress state

a)

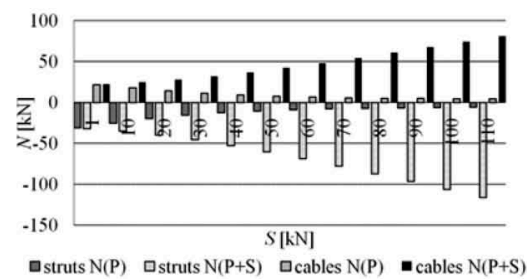

c)

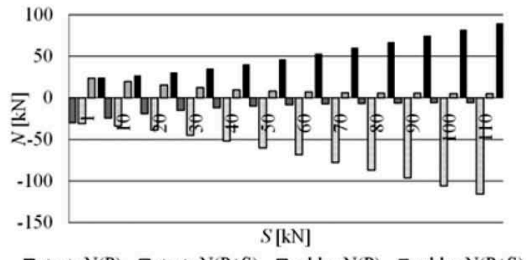

e)

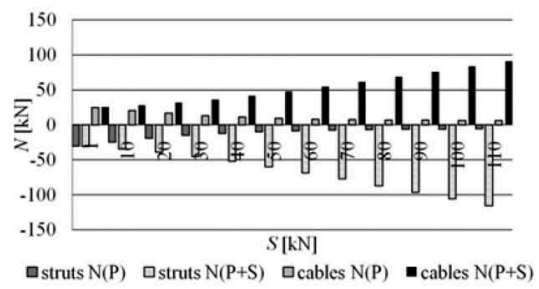

b)

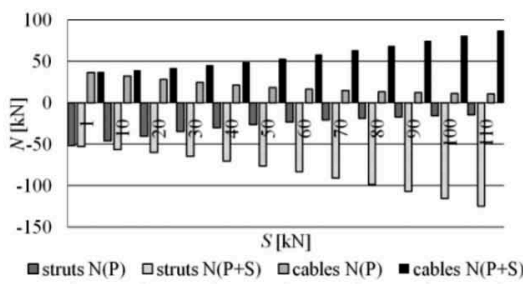

d)

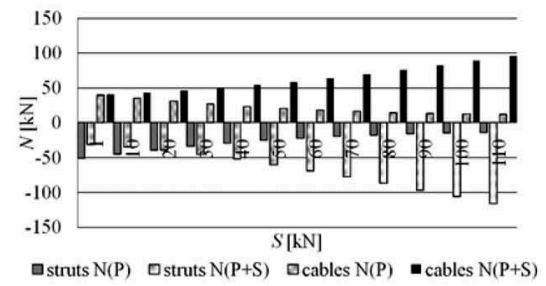

f)

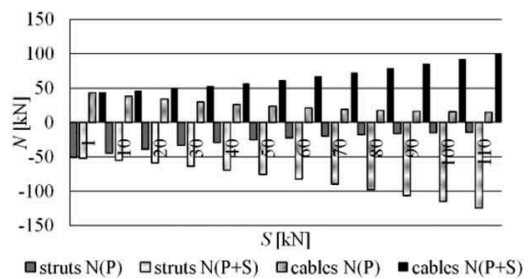

Figure 2. Influence of the self-stress state on the normal forces: a) $P=-10 \mathrm{kN}$ for model $\mathrm{S} 1, \mathrm{~b}$ ) $P=-20 \mathrm{kN}$ for model S1, c) $P=-10 \mathrm{kN}$ for model S2, d) $P=-20 \mathrm{kN}$ for model S2, e) $P=-10 \mathrm{kN}$ for model S6, f) $P=-20 \mathrm{kN}$ for model S6.

a)

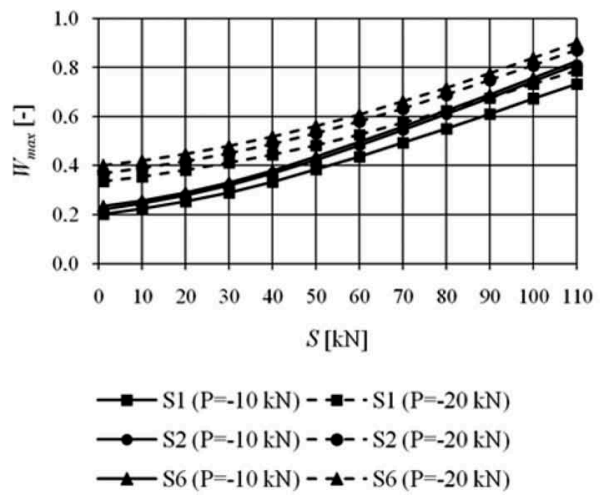

b)

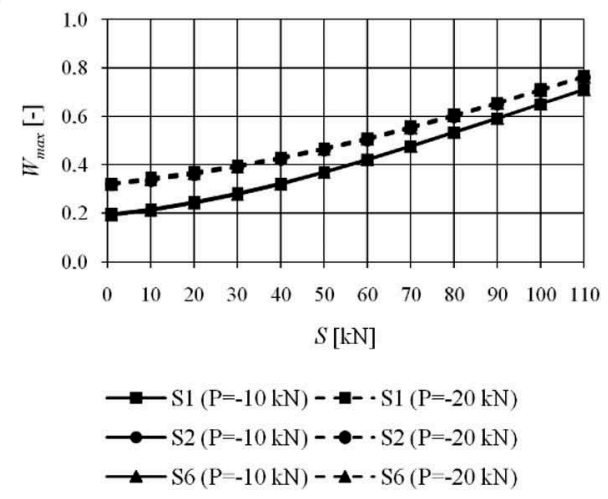

Figure 3. Influence of the self-stress state on load-bearing capacity ratio $W_{\max }$ : a) for cables, b) for struts. 
a)

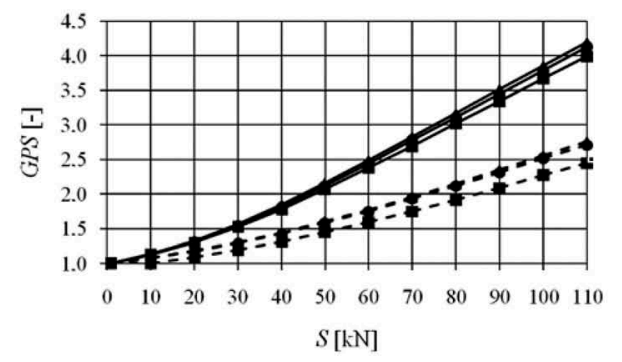

b)

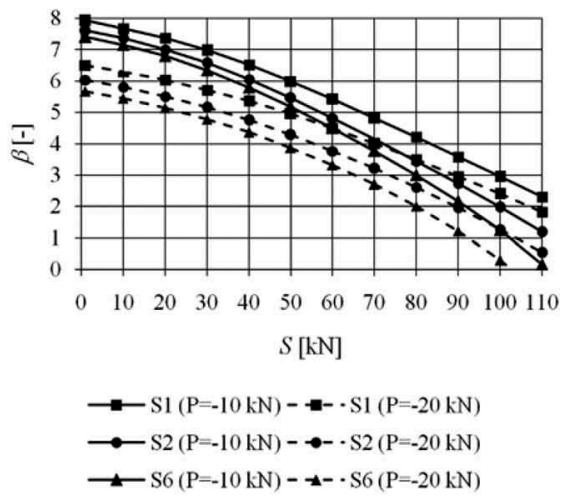

Figure 4. Influence of the self-stress state on: a) global parameter of stiffness GPS, b) reliability index $\beta$.

the increase of the applied force by $10 \mathrm{kN}$ causes the reduce of the maximum load-bearing capacity ratio by the over 60 percentage points. The impact of the load, like previous, decreasing with increasing the level of self-stress state - the same change in the level of the applied force causes the reduce of the maximum load-bearing capacity ratio by the 7-9 percentage points. In addition the effort of structure, the stiffness was monitored too. The global stiffness parameter GPS is calculated. The nature of changes in theGPS parameter is presented in Figure 4a. At maximum of the self-stress state in case $P=-10 \mathrm{kN} G P S$ is 1.51 .6 times as high as that for $P=-20 \mathrm{kN}$. This confirms the earlier conclusions that the influence of selfstress state decreases with increasing load. The initial prestress forces causes increasing the stiffness of structures, but significantly influence on decreasing the reliability index (Figure 4b) Despite to the maximum level of self-stress state does not cause the exceedance of the load-bearing capacity of the elements, the required standard level of reliability $\beta=3.8$ is exceeded.

\section{CONCLUSIONS}

In this paper, the qualitative and quantitative analyses of the towers built with the Simplex modules were performed. Analysed structures were classified as an ideal tensegrity or as a structure with tensegrity features of class 1 . In both cases, the self-stress states and infinitesimal mechanisms were identified. The stiffness of these structures depends not only on the geometry and material properties, but also on the prestress level (which stabilizes the infinitesimal mechanisms that occur) and the level of external load. External load induces additional stress in the system, and the impact of the load is most significant for the low values of the initial prestress forces. As the level of prestress increases, the effect of the external load decreases. Moreover, the initial prestress forces have a greater influence on the total stiffness of the structure with smaller external loads. Similarly, like for stiffness of tensegrity structures, in the case of effort, the influence of self-stress state decreases with increasing loads. The effort of cables is higher than that of struts and the difference between them increases with the increment of the prestress level.

Generally, with increasing the initial prestress forces the stiffness of structures increase. Unfortunately, the self-stress state significantly influence on decreasing the reliability index. Despite to the maximum level of self-stress state does not cause the exceedance of the load-bearing capacity of the elements, the required standard level of is exceeded. Therefore, in the case of tensegrity structures checking only the load-bearing capacity ratio is insufficient. 


\section{REFERENCES}

Emmerich, D.G. Construction de Reseaux Autotendants. French Patent 1,377,290, 28 September 1964.

Fuller, R.B. Tensile-integrity structures. U S Patent No 3.063.521, 1962.

Gilewski, W. et al. 2015. Application of singular value decomposition for qualitative analysis of truss and tensegrity structures. Acta Sci. Pol. Hortorum Cultus 14 (3): 14.

Gilewski, W. et al. 2019. Parametric analysis of some tensegrity structures. In Proceedings of MATEC Web of Conferences: 262, 10003.

Kłosowska, J. et al. 2018. Self-stress control of real civil engineering tensegrity structures. In AIP Conference Proceedings: 1922 (1), 150004.

Mochocki, W et al. 2018. Influence of Truss Topology on Reliability Index. IOP Conference Series: Materials Science and Engineering, 471.

Mochocki, W et al. 2019. Analysis of basic failure scenarios of a truss tower in a probabilistic approach. Applied Sciences-Basel 9 (13), 2662.

Mochocki, W et al. 2020. Impact of the wind load probability distribution and connection types on the reliability index of truss towers. Journal of Theoretical and Applied Mechanics 58 (2): 403-414.

Obara, P. 2019. Dynamic and dynamic stability of tensegrity structures (in Polish). Kielce: Wydawnictwo Politechniki Świętokrzyskiej.

Obara, P. \& Tomasik, J. 2020. Parametric analysis of tensegrity plate-like structures: Part 1 - qualitative analysis. Applied Sciences 10: 7042.

Pellegrino, S. 1993. Structural computations with the singular value decomposition of the equilibrium matrix. International Journal of Solids and Structures 30 (21): 3025-3035.

PN-EN 1990:2004. Eurocode: Basis of Structural Design; PKN: Warszawa, Poland, 2004.

Schlaich, M. 2004. The Messeturm in Rostock. A Tensegrity Tower. Journal of the International Association for Shell and Spatial Structures IASS 45 (2), 145: 93-98.

Snelson, K. Continuous tension, discontinuous compression structures. U S Patent No 3,169,611, 1965.

Snelson, K. 2013. Art and Ideas. NY: Kenneth Snelson In Association With Marlborough Gallery.

Zienkiewicz, O.C. \& Taylor, R.L. 2000. The Finite Element Method. Vol. 1. The Basis. London: Elsevier Butterworth-Heinemann. 


\title{
The generalized constitutive law in nonlinear structural analysis of steel frames
}

\author{
D. Mrówczyński \\ R\&D Department, FEMat sp. z o.o., Poznań, Poland
}

\author{
T. Gajewski \\ Institute of Structural Analysis, Poznan University of Technology, Poznań, Poland \\ T. Garbowski \\ Department of Biosystems Engineering, Poznan University of Life Sciences, Poznań, Poland
}

\begin{abstract}
The article presents a modified finite element (FE) based algorithm for nonlinear analysis of 2D beam structures, which takes into account the influence of the shear forces. The method proposed enables using complex materials with nonlinearities without the need of implementing advanced constitutive models in FE routines. It can be directly integrated with commonly available FE software for linear analysis of beam structures, so its functionality can be easily extended also with material nonlinearities. The presented approach adopts the generalized constitutive law algorithm to iteratively modify the stiffness of beam element. To address an influence of a shear stiffness, a Timoshenko beam element was used. The methodology was implemented and its performance was verified on several numerical examples. For validation, the displacements and the ultimate loads were compared with the values from a commercial FE software. The results shown a good correlation between the reference model and the method proposed.
\end{abstract}

\section{INTRODUCTION}

For decades an advanced engineering problems are effectively modelled by finite element (FE) method, which is very popular due to its versatility and accuracy. The FE models are often implemented in various modern engineering tools, in comparison to the analytical ones they have wider applicability and universality. Most civil structures can be analysed using simple 2D beam or frame structures without sacrificing the accuracy of the results obtained with simplified models. Thus, majority of commercial software for FE analyses of civil structures use the beam, truss or frame finite elements only. Nowadays, the developers of engineering software often provide their users a functions extending its capabilities with new features. For instance, the users may include new material or element subroutines, which are tailored for their particular needs; this trend may be observed in many top engineering softwares. In such cases, a numerical and material mechanics expertise is required, in order to extend the mechanical models with nonlinear (material or geometric) features through user subroutines. An attractive alternative may be the use of classic beams and frames finite element method (FEM) with linear solver extended with a generalized nonlinear constitutive law (GNCL) algorithm, which is simple and easy to implement. 
This idea appeared in the 70s of the 20th century. One of the first papers which introduced the idea of dividing a cross-section into layers was the analysis of the behaviour of bending composite beams by Rotter \& Ansourian presented in 1978. The theoretical values were compared with the experimental results, a good correlation was obtained. In 1982, Lodygowski applied the method of the generalized nonlinear constitutive law (GNCL) to the geometric and physical nonlinear analysis of beams and plane frames. Later, Lodygowski \& Szumigała applied the division into layers in a two-stage bending analysis of composite beams. In the first stage of the method, the cross-section is discretized, and the constitutive law is formulated as the bending moment-curvature relationship. In the second stage, the constitutive law is adopted in the nonlinear finite element code. The two-stage approach was also used by Szumigała in 2007 to analyse composite steel-concrete frame structures. The constitutive law was formulated in the form of the bending stiffness-curvature relationship. In 2019, Grzeszykowski \& Szmigiera used the GNCL method to compute the nonlinear longitudinal shear distribution in composite steel-concrete beams. The GNCL algorithm was described in more detail by Mrówczyński et al. in 2021, where its performance in steel and composite beam structures was presented.

From a practical point of view, the method is a promising alternative to be used by the structural engineers. The method proposed here extends its original version by including a shear effect. It is easy to use, if one would like to consider in modelling not only complex material/geometrical nonlinearities, but also the shear effect, thus, it may be utilized, instead of building a complex FEM models.

\section{METHODS AND MATERIALS}

\subsection{Normal and shear strains}

The classical framework of FE analysis was used to embed the method proposed. In the small strains and deformations framework, the beam and frame FE was implemented; it may be loaded with an external forces and/or displacements. The nodal displacements are computed in iterations, since the method presented iteratively changes the flexural and shear element stiffness.

The global stiffness matrix is assembled in the classical way by including the stiffness matrices of all elements. In the method proposed, due to deformations the element stiffness is iteratively decreased in the loop. Deformations, namely, $\varepsilon_{0}$ - normal strains, $\gamma$ - shear strains and $\kappa$-curvature, are computed from the nodal displacements $d$. Normal strain, $\varepsilon_{0}$ is taken in the following form:

$$
\varepsilon_{0}=\frac{\Delta l}{l}=\frac{u_{2}-u_{1}}{l}
$$

where $l$ is the beam length, $\Delta l$ is its elongation and $u_{1}, u_{2}$ are the nodal displacements along the beam axis.

Shear strains, $\gamma$, are taken as the difference between the nodal rotation $\varphi$ and the first derivative of vertical deflection, $v$, according to Timoshenko theory:

$$
\gamma=\varphi-\frac{\mathrm{d} v}{\mathrm{~d} x}
$$

Bernoulli theory is also considered in the paper, in order to compare its results with the one including Timoshenko theory. According to Bernoulli's hypothesis the crosssection is perpendicular to the axis of the deformed beam. As the consequence, the shear strains, $\gamma$, equals zero. 
The curvature, $\kappa$, in small displacements, is calculated as the second derivative of a deflection in a vertical direction:

$$
\kappa=\frac{\mathrm{d}^{2} v}{\mathrm{~d} x^{2}}
$$

\subsection{Stiffness reduction}

Element deformations, namely $\varepsilon_{0}, \gamma$, and $\kappa$ - shown in the previous subsection, serves to calculate the element stiffness reduction. For each layer, a location, height, width and crosssectional area of individual material are determined. The procedure is repeated for materials and layers obtained from a cross-section division.

Further, the reduced (effective) strains, $\varepsilon_{r e d}$, are calculated by utilizing the normal and shear strains. Next, in each layer the reduced stress, $\sigma_{\text {red }}$, is derived from the reduced strain by using $\sigma_{r e d}$ vs. $\varepsilon_{r e d}$ plot, which is determined for each material used, if multi-material cross-section is analysed.

Later, from the stresses and strains the Young's modulus, $E$, is calculated. The shear modulus for isotropic materials, $G$, may be classically taken as:

$$
G=\frac{E}{2(1+\nu)}
$$

where $\nu$ is Poisson's ratio. Young's and shear modulus allows to compute the tensile and shear stiffnesses, $B_{N}$ and $B_{V}$, respectively:

$$
B_{N}=\sum_{j=1}^{m} \sum_{i=1}^{n} E_{i}^{j} A_{i}^{j}, B_{V}=\sum_{j=1}^{m}\left(\sum_{i=1}^{n} G_{i}^{j} A_{i}^{j}\right) / k^{j},
$$

where $i$ and $j$ are the layers in the cross section and materials, respectively; $n$ and $m$ are the total number of layers and number of materials, respectively. $A_{i}{ }^{j}$ is area of a cross-section of $i$-th layer and $j$-th material, and $k^{j}$ is a shear correction factor for $j$-th material.

A position of neutral axis $y_{g}$ is computed from:

$$
y_{g}=\frac{\sum_{j=1}^{m} \sum_{i=1}^{n} E_{l}^{j} A_{i}^{j} y_{i}}{E A} .
$$

From the position of the neutral axis, a moment of inertia of $i$-th layer, $I_{i}^{j}$, may be determined; then a bending stiffness, $B_{M}$, may be computed according to the formula:

$$
B_{M}=\sum_{j=1}^{m} \sum_{i=1}^{n} E_{i}^{j} I_{i}^{j}
$$

In the original method, the computations for cross-section are performed before the main algorithm. The law $B_{M} \quad \kappa$ is only computed for the normal forces assumed. The element stiffness values is determined by interpolation of in-between values, thus, the accuracy depends on a prior mesh density assumed. Due to this feature of the original method, an additional 
Table 1. Material parameters of steel used in the study.

\begin{tabular}{|c|c|c|c|c|}
\hline & $E$ & $G$ & $\nu$ & $f_{y}$ \\
\hline Material & [GPa] & [GPa] & {$[-]$} & [MPa] \\
\hline steel & 210.0 & 81.0 & 0.3 & 235.0 \\
\hline
\end{tabular}

modification was proposed in this paper. In the method proposed, the cross-section was analysed during computations (within each iteration loop). This allowed to eliminate the interpolation error due to the usage of exact values for the cross-section analysed. The updated GNCL method was implemented in the MATLAB in-house code.

\subsection{Materials}

The proposed method allows to use a nonlinear constitutive law of any material. In the examples, the nonlinear law of steel were used. In Table 1, the engineering parameters of steel used in the study are presented, where $E$ is a Young's modulus, $G$ is a shear modulus, $\nu$ is a Poisson's ratio and $f_{y}$ is a yield strength of steel.

In the examples analysed here, the steel was described by an elastic perfectly-plastic model:

$$
\sigma_{\text {red }}=\left\{E \varepsilon_{\text {red }}, \quad \text { for } \quad \varepsilon_{\text {red }}<\frac{f_{y}}{E}, \quad f_{y} \text { for } \quad \varepsilon_{\text {red }} \geq \frac{f_{y}}{E}\right\} .
$$

\section{EXAMPLES}

\subsection{Example 1}

In order to verify the proposed method, the simply supported beams of IPE300 steel member and lengths of $1.5 \mathrm{~m}$ and $2.4 \mathrm{~m}$ (beams of two lengths to obtain two different values of slenderness ratio) were modelled. The beams with a vertical displacement in the center of the span were loaded. The displacement control was used. The obtained forces from the GNCL method were compared with the reference model results. The beams in FE commercial software were divided into $5 \mathrm{~mm}$ long elements, thus 300 and 480 2-node linear beam elements were obtained for $1.5 \mathrm{~m}$ and $2.4 \mathrm{~m}$, respectively. In Figure 1, the static equilibrium paths for two beam lengths were shown.

In the beginning, the force increases linearly - the material is in the elastic phase. Later, the cross-section begins to plasticize as shown by the nonlinear shape of the plot. For beam of length of $1.5 \mathrm{~m}$, the difference between the proposed model and the reference model is $6.2 \%$, and for a length of $2.4 \mathrm{~m}$ it is $2.1 \%$.

The influence of the shear force on the load capacity of the cross-section was also analysed. For this purpose, the Bernoulli and Timoshenko theory were applied, and the proposed method was used. In Figure 2, the obtained static equilibrium paths are presented.

In Figure 2, the force obtained for the Bernoulli theory is greater than the force obtained for the Timoshenko theory. This is due to the fact that taking into account the shear strains causes a greater stiffness reduction, and thus the possibility of transferring a smaller force. The shorter the beam, the greater the influence of the shear force on the behaviour of the structure. In the analysed case, for the slenderness ratio of 5 (beam length $1.5 \mathrm{~m}$ ) the difference in load capacity is $6.5 \%$, and for the slenderness ratio of 8 (beam length $2.4 \mathrm{~m}$ ) it is only $2.2 \%$. 
a)

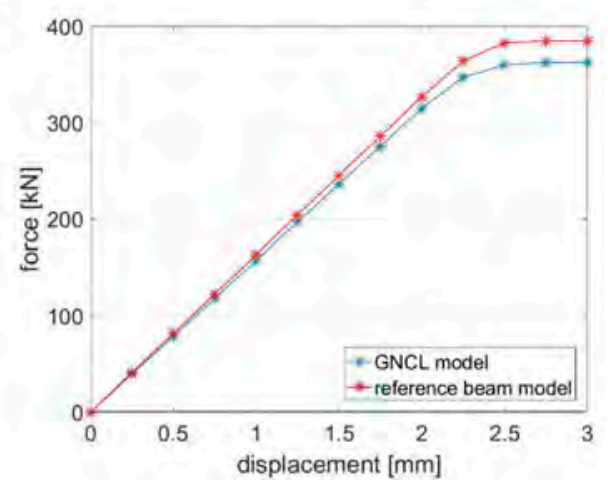

b)

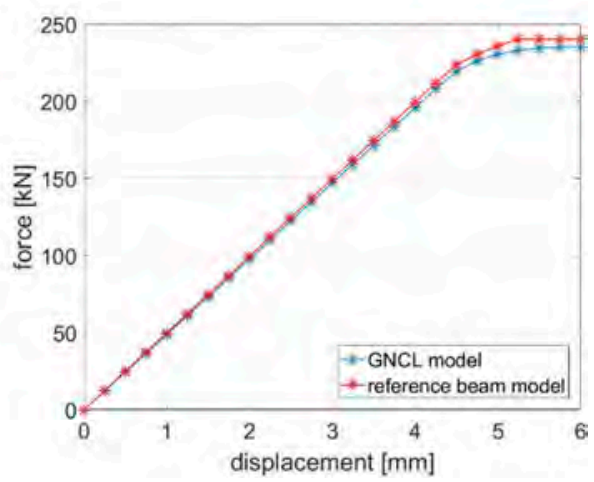

Figure 1. Force vs. displacement plots due to enforcing displacements in the middle of the IPE300 beams for their lengths of a) $1.5 \mathrm{~m}$ and b) $2.4 \mathrm{~m}$.

a)

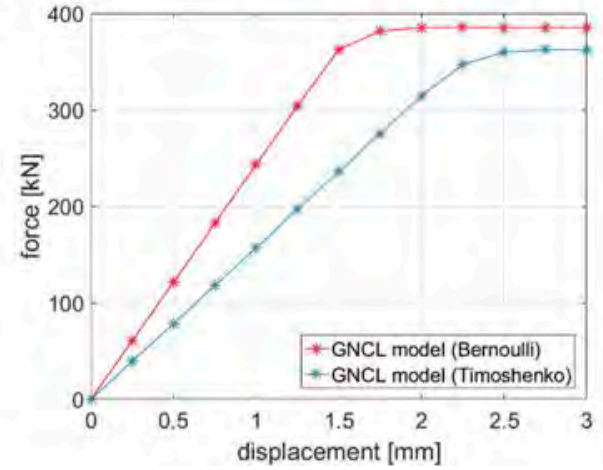

b)

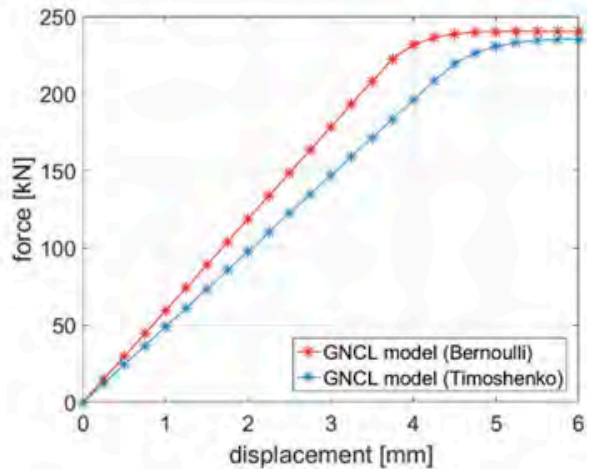

Figure 2. Force vs. displacement plots obtained for the Bernoulli and Timoshenko theories of the IPE300 beams for their lengths of a) $1.5 \mathrm{~m}$ and b) $2.4 \mathrm{~m}$.

\subsection{Example 2}

The influence of the material plasticization and shear force was also shown on the example of a single-nave frame with overhangs (cantilevers) loaded with a uniformly distributed load $Q=70.0 \mathrm{kN} / \mathrm{m}$ on the beam and concentrated forces $P=70 \mathrm{kN}$ on the ends of the cantilevers. The static scheme of the frame is shown in Figure 3. The stiffness reduction of the beam and cantilevers caused by plasticization of the material was computed according to GNCL method for Bernoulli theory and Timoshenko theory and was shown in Figure 4a and Figure 4b, respectively.

Comparing Figure $4 \mathrm{a}$ and Figure $4 \mathrm{~b}$ shows that taking into account the effect of the shear force causes a greater stiffness decrease. This is associated with an displacement increase. The maximum deflections in the middle of the horizontal element (point $\mathrm{C}$ ) and cantilever end (point A) for the Bernoulli theory are $4.29 \mathrm{~cm}$ and $1.07 \mathrm{~cm}$, respectively, and for the Timoshenko theory $9.75 \mathrm{~cm}$ and $1.23 \mathrm{~cm}$. Taking into account the influence of the shear force, the deflections in the middle of the horizontal element and at the cantilever end increased by $127.3 \%$ and $15.0 \%$, respectively. 


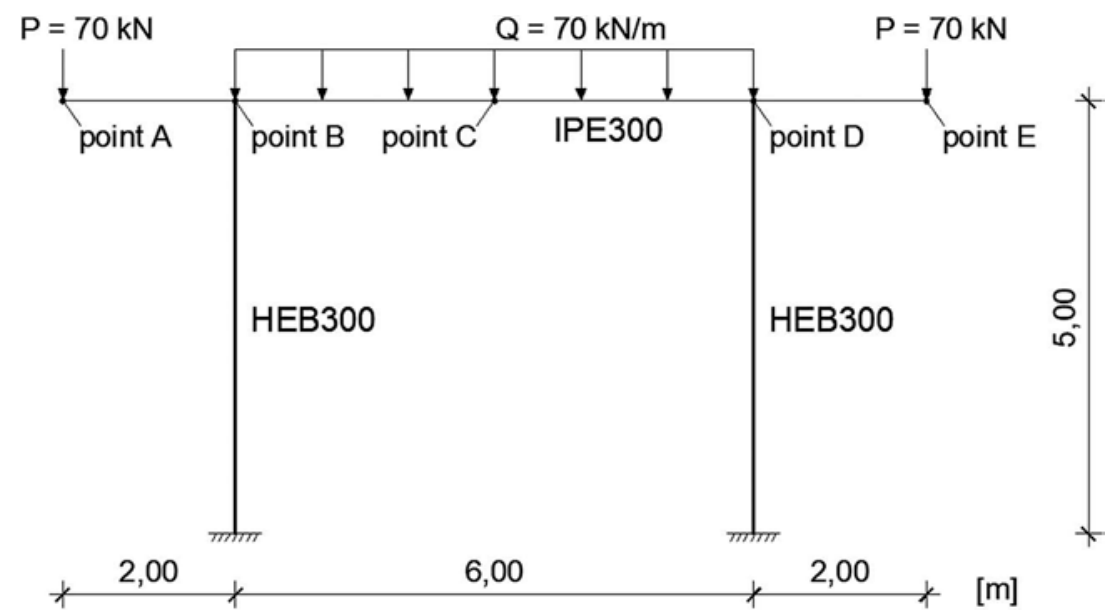

Figure 3. Static scheme of the Example 2.

a)

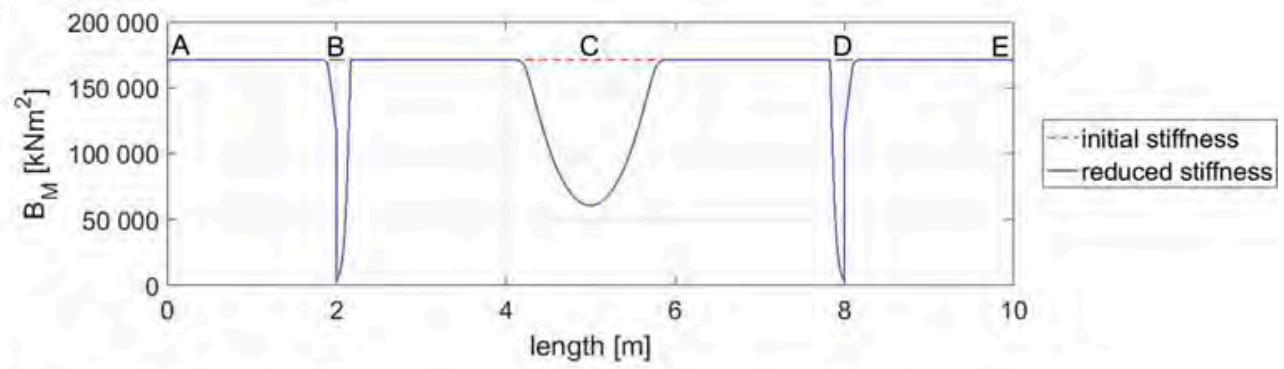

b)

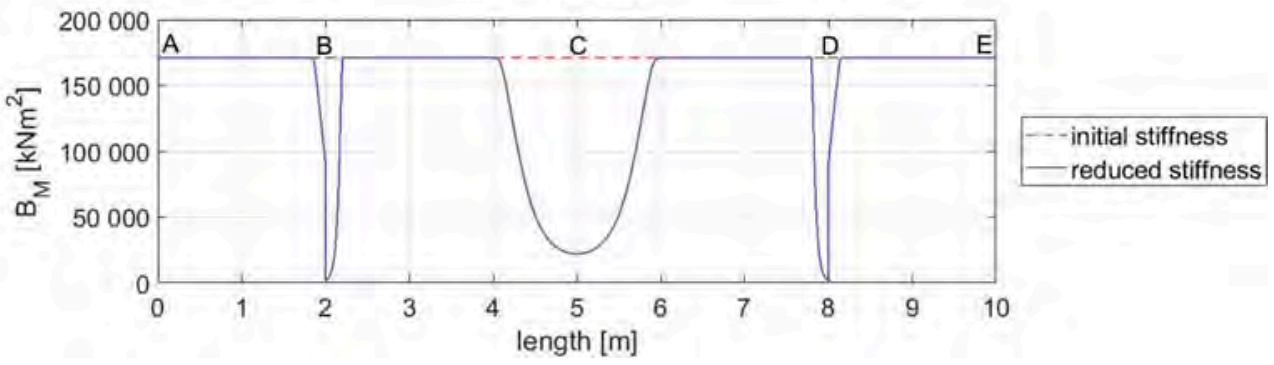

Figure 4. Reduction of bending stiffness $B_{M}$ of beam and cantilevers according to a) Bernoulli theory and b) Timoshenko theory.

\section{CONCLUSIONS}

The method of generalized nonlinear constitutive law presented in the paper extends the classical finite element method approach and seems to be promising tool for fast and accurate simulations of complex structures. Especially in cases, in which the cross-section is multi-material, compound of many subsections and the nonlinear properties of material should be included. Here, the classical GNCL method was extended with Timoshenko theory in order to apply the method in a less slender structures. This utility is not available in the classical finite element method softwares for structure engineers. In this paper, the method was described and shown on numerical examples. The results were compared with 
the commercial software for simply supported beam, with a good agreement of the displacements. Also, the Bernoulli vs. Timoshenko theory was confronted in the example of single-nave frame with overhangs, in which including a shear effect had a big influence on the displacement obtained.

\section{REFERENCES}

Grzeszykowski, B. \& Szmigiera, E. 2019. Nonlinear longitudinal shear distribution in steel-concrete composite beams. Archives of Civil Engineering 65(1): 65-82.

Łodygowski, T. 1982. Geometrycznie nieliniowa analiza sztywno-plastycznych i sprężysto-plastycznych belek i ram płaskich. Warsaw.

Łodygowski, T. \& Szumigała, M. 1992. Engineering models for numerical analysis of composite bending members. Mechanics of Structures and Machines 20: 363-380.

Mrówczyński, D., Gajewski, T. \& Garbowski, T. 2021. Application of the generalized nonlinear constitutive law in 2D shear flexible beam structures. Archives of Civil Engineering (accepted for publication).

Rotter, J. \& Ansourian, P. 1978. Cross-section behaviour and ductility in composite beams.

Szumigała, M. 2007. Zespolone stalowo-betonowe konstrukcje szkieletowe pod obciążeniem doraźnym. Wydawnictwo Politechniki Poznańskiej. Poland. 


\title{
Impact of the self-stress state on the static properties of double-layered tensegrity grids
}

\author{
J. Tomasik \& P. Obara \\ Kielce University of Technology, Kielce, Poland
}

\begin{abstract}
In this paper, a static parametric analysis of double-layered tensegrity grids is presented. The grids built with modified Simplex modules are considered. Starting from a single-module structure, more complex cases were sequentially analysed. The analysis of tensegrity structures consists of two steps. The first step (qualitative analysis) leads to the identification of the existing mechanisms and self-stress states in the structure. The second step (quantitative analysis) focuses on the behaviour of tensegrities under external loads. To carry out the qualitative assessment, the spectral analysis of the truss matrices and the singular value decomposition of the compatibility matrix are used. The qualitative analysis is performed using the second and third order theories. The influence of the level of self-stress state on the static parameters like displacements and the maximum load-bearing capacity ratio is considered.
\end{abstract}

\section{INTRODUCTION}

Tensegrity is a term derived from English language as a contraction of two words: "tension" stretching and "integrity" - stability. It relates to the structures composed only of compressed (struts) and tensed elements (cables). Tensegrity systems are featured by the presence of selfstress states and mechanisms what distinguishes them from conventional structures. The selfstress state can be defined as a system of self-equilibrated normal forces that satisfy homogeneous equations of equilibrium. The absence of those forces makes tensegrity structures unstable, i.e. geometrically variable. To ensure the stabilisation, initial stresses must be introduced to the structure. Modifying the level of self-stress state, it is possible to the control the static parameters of the structure.

In this paper, the influence of the level of self-stress state on the static behaviour of doublelayered tensegrity grids is considered. The analysis contains in two steps. Firstly, self-stress states and infinitesimal mechanisms are identified (qualitative analysis). At the second step, the impact of the level of self-stress state on displacements and the load-bearing capacity ratio is investigated (quantitative analysis). Due to their unique features, tensegrity structures stiffen under external load, and that stage of the analysis can require the assumption of the hypothesis of large displacements (third order theory). On the other hand, for some cases of tensegrity structures, the effect of stiffening is less relevant, the influence of the geometrical nonlinearity is insignificant and a quasi-linear setting (second order theory) is sufficient for the quantitative analysis. This work develops the considerations of double-layered tensegrity grids presented in (Obara 2019a, b, c, Obara \& Tomasik 2020), where structures built with modified Quartex module was taken into account, and shows results of the analysis of the structures built with modified Simplex module. 


\section{MATHEMATICAL DESCRIPTION}

As stated above, the complete analysis of tensegrity structures consists of two stages: the qualitative analysis and the quantitative analysis.

The qualitative analysis is provided for $n$-element space truss $(e=1,2, \ldots, n)$ described by the elasticity matrix $\mathbf{E}\left(\in \mathbb{R}^{n \times n}\right)$ with $m$-degrees of freedom $\mathbf{q}\left(\in \mathbb{R}^{m \times 1}\right)$. This analysis can be done through the singular value decomposition of the compatibility matrix B (Pellegrino 1993, Rahami et al. 2013, Gilewski et al. 2015, 2016, 2017, Obara 2019a, b, c, Obara \& Tomasik 2020). The compatibility matrix $\mathbf{B}\left(\in \mathbb{R}^{n \times m}\right)$ for tensegrity structures is determined using the finite element formalism (Bathe 1996, Zienkiewicz 2000, Gilewski \& Kasprzak 2012, Obara \& Tomasik 2020). The singular value decomposition of matrix $\mathbf{B}$ is a factorization in the form:

$$
\mathbf{B}=\mathbf{Y} \mathbf{N X}^{T},
$$

where $\mathbf{Y}\left(\in \mathbb{R}^{n \times n}\right)=\left[\begin{array}{llll}\boldsymbol{y}_{1} & \boldsymbol{y}_{2} & \ldots & \boldsymbol{y}_{\boldsymbol{n}}\end{array}\right]$ and $\mathbf{X}\left(\in \mathbb{R}^{m \times m}\right)=\left[\begin{array}{llll}\mathbf{x}_{1} & \mathbf{x}_{2} & \ldots & \mathbf{x}_{m}\end{array}\right]$ are orthogonal matrices and $\mathbf{N}\left(\in \mathbb{R}^{n \times m}\right)$ is a rectangular diagonal matrix. The orthogonal matrices $\mathbf{Y}$ and $\mathbf{X}$ as well as matrix $\mathbf{N}$ are related to eigenvectors and eigenvalues of the following problems:

$$
\left(\mathbf{B B}^{T}-\mu \mathbf{I}\right) \mathbf{y}=\mathbf{0}, \quad\left(\mathbf{B}^{T} \mathbf{B}-\lambda \mathbf{I}\right) \mathbf{x}=\mathbf{0} .
$$

where $\mu$ and $\lambda$ are eigenvalues of the respective matrix. If any $\mu$ value is equal to zero, a self-stress state exists. If any $\lambda$ value is equal to zero, a mechanism exists. In order to identify whether the mechanism is infinitesimal or finite, nonlinear analysis of the stiffness matrix with the use of geometric stiffness matrix $\mathbf{K}_{G}(\mathbf{S})$, which takes into account the self-stress state $\mathbf{S}$, should be applied. If all eigenvalues of the matrix $\left(\mathbf{K}_{L}+\mathbf{K}_{G}(\mathbf{S})\right)$ are positive, the identified mechanism is infinitesimal and the structure is stable. Zero eigenvalues are related to finite mechanisms, whereas a negative eigenvalue represents instability of the structure.

The quantitative analysis of the effect of self-stress state on the static behaviour of structures is performed using the quasi-linear theory (second order theory):

$$
\left[\mathbf{K}_{L}+\mathbf{K}_{G}(\mathbf{S})\right] \mathbf{q}=\mathbf{P} ; \mathbf{K}_{L}=\mathbf{B}^{T} \mathbf{E B}
$$

and the third order theory:

$$
\left[\mathbf{K}_{L}+\mathbf{K}_{G}(\mathbf{S})+\mathbf{K}_{N, N L}(\mathbf{q})\right]=\mathbf{P},
$$

where $\mathbf{P}$ is the load vector and $\mathbf{K}_{N, N L}(\mathbf{q})$ is the initial strain matrix.

\section{EXAMPLES}

In this paper, the parametric qualitative and quantitative analyses of tensegrity plate-like structures are performed. The structures built with modified Simplex modules are taken into account. The single module is considered as the first one and then four more complex cases are analysed. The models consisting of six, ten, fourteen and eighteen modules are taken into consideration.

The qualitative analyses lead to the classification of the structures to the one of two classes: ideal tensegrity or structures with tensegrity features of class 1 (Obara, 2019c, Obara \& Tomasik, 2020). Ideal tensegrities are featured by all tensegrity characteristics, i.e. they are trusses $(T)$ with at least one existing self-stress state $(S)$ and infinitesimal mechanism $(M)$, their elements form a discontinuous set of compressed elements $(D)$ which is contained within a continuous net of tensile elements $(I)$, tensile elements are cables with zero compression 
rigidity $(C)$. Structures with tensegrity features of class 1 are featured by characteristics $T, S$, $C$ and $M$.

The quantitative analyses contain calculations of the influence of the self-stress state on displacements and the load-bearing capacity ratio. The quasi-linear (II) and non-linear analyses (III) are carried out. For calculation, a procedure in the "Mathematica" environment was created.

The design solution of the Halfen DETAN Rod System is adopted and the following characteristics are assumed:

- Young modulus: $E=210 \mathrm{GPa}$ and density: $\rho=7860 \mathrm{~kg} / \mathrm{m}^{3}$,

- cables: made of rods, steel S460N, diameter $\phi=20 \mathrm{~mm}$, load-bearing capacity: $N_{R d}=110.2 \mathrm{kN}$,

- struts: made of hot-finished circular hollow section, steel: S355J2, diameter: $\phi=76.1 \mathrm{~mm}$, thickness: $t=2.9 \mathrm{~mm}$, moment of inertia: $I=4.47 \cdot 10^{7} \mathrm{~m}^{4}$, cross-sectional area: $A=6.88 \cdot 10{ }^{4} \mathrm{~m}^{2}$, load-bearing capacity: $N_{R d}=203.5 \mathrm{kN}$.

\subsection{Single modified Simplex module}

The first considered structure is the single modified Simplex module (Figure 1a). The module consists of twenty elements $(n=12)$, i.e, three struts and nine cables, and six nodes $(w=6)$. Its shape is based on a regular prism. The coordinates of the nodes are shown in Table 1 . The projection of the top surface of the modified Simplex module is inscribed into the bottom one, allowing easily connect single units into multi-module structures (Emmerich 1964, Kono \& Kunieda 1966, Kasprzak 2014, Al Sabouni-Zawadzka \& Gilewski 2018, Kłosowska et al. 2018, Gilewski 2019).

a)
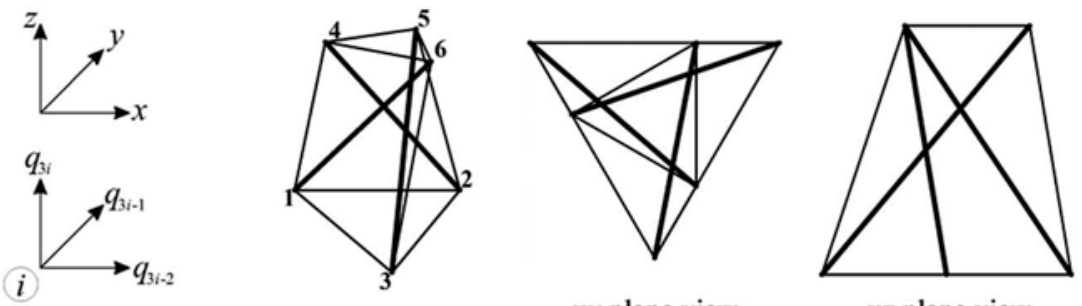

c)

b)
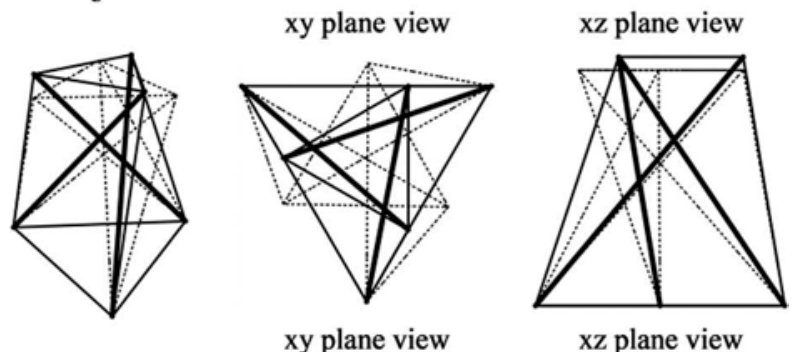

$\mathrm{xz}$ plane view

Figure 1. The single modified Simplex module: a) geometry, b) normalised self-stress state, c) infinitesimal mechanism.

Table 1. Coordinates of the nodes of the single modified Simplex module.

\begin{tabular}{lllllll}
\hline No. of node $(i)$ & 1 & 2 & 3 & 4 & 5 & 6 \\
\hline$x$ & -0.500 & 0.500 & 0.000 & -0.333 & 0.167 & 0.167 \\
$y$ & 0.866 & 0.866 & 0.577 & 0.000 & 0.866 & -0.866 \\
$z$ & 0.000 & 0.000 & 0.000 & 1.000 & 1.000 & 1.000 \\
\hline
\end{tabular}


The qualitative analysis was performed for the module with twelve degrees of freedom $(m=12)$ (the blocked displacements are $q_{1}, q_{3}, q_{5}, q_{6}, q_{7}, q_{9}$ ) thus the number of elements and the number of degrees of freedom are equal $(n=m=12)$. The compatibility matrix $\mathbf{B}\left(\in \mathbb{R}^{12 \times 12}\right)$ is square, therefore the matrices $\mathbf{B B}^{T}$ and $\mathbf{B}^{T} \mathbf{B}$ are equal. There is one zero eigenvalue in both matrices, thus one self-stress state (Figure 1b) and one mechanism is identified (Figure 1c) - summarised results of performed qualitative analyses are shown in Table 2. All eigenvalues of the matrix $\left[\mathbf{K}_{L}+\mathbf{K}_{G}(\mathbf{S})\right]$ are positive thus the identified mechanism is infinitesimal and the stability of the structure is ensured. The single modified Simplex module meets all tensegrity features; it means that it can be classified as the ideal tensegrity.

Next, the quantitative analysis was carried out. The module was loaded with a vertical force $P_{18}=-10 \mathrm{kN}, 20 \mathrm{kN}$ and $30 \mathrm{kN}$ applied to 6th node. The influence of the level of selfstress state $S$ on displacement $q_{18}$ (Figure 2a) and the maximum load-bearing capacity ratio $W_{\max }$ (Figure 2b) was considered:

$$
W_{\max }=N_{\max } / N_{R d}
$$

where $N_{\max }$ is the maximum normal force and $N_{R d}$ is the load-bearing capacity.

Normalized self-stress state forces were multiplied by the level of self-stress state $S$ and applied to the structure. The minimum applied level of self-stress state $S_{\min }$ provides proper identification of the elements (i.e. struts are compressed and cables are tensed). The maximum level of self-stress state $S_{\max }$ does not cause the exceedance of the load-bearing capacity of the elements. For the single modified Simplex module these levels are equal respectively: $S_{\min }=1$ $\mathrm{kN}$ and $S_{\max }=110 \mathrm{kN}$. There can be observed significant differences between the displacement $q_{18}$ calculated using second (II) and third (III) order theory for the lower level of self-stress state. The differences between the results obtained from both theories also increase with the

Table 2. Results of the qualitative analysis of the structures built with the modified Simplex modules.

\begin{tabular}{lllllll}
\hline $\begin{array}{l}\text { No. of single } \\
\text { modules }\end{array}$ & $\begin{array}{l}\text { No. of } \\
\text { nodes }\end{array}$ & $\begin{array}{l}\text { No. of } \\
\text { elements }\end{array}$ & $\begin{array}{l}\text { Degrees of } \\
\text { freedom }\end{array}$ & $\begin{array}{l}\text { No. of self- } \\
\text { stress states }\end{array}$ & $\begin{array}{l}\text { No. of } \\
\text { mechanisms }\end{array}$ & Classification \\
\hline 1 & 6 & 12 & 12 & 1 & 1 & ideal tensegrity \\
\hline 6 & 19 & 60 & 45 & 16 & 1 & \\
10 & 29 & 98 & 75 & 24 & 1 & structures with tensegrity \\
14 & 39 & 136 & 105 & 32 & 1 & features of class 1 \\
18 & 49 & 174 & 135 & 40 & 1 & \\
\hline
\end{tabular}

a)

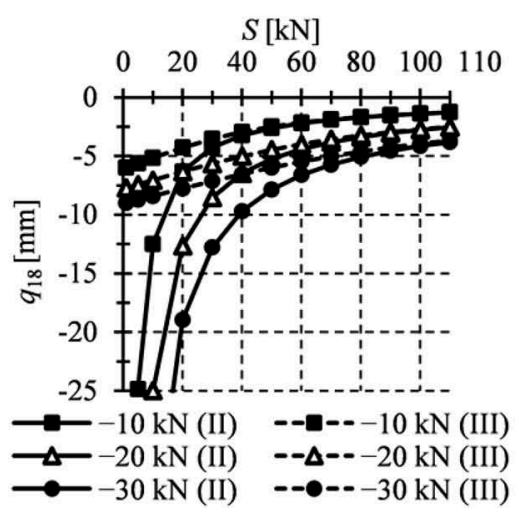

b)

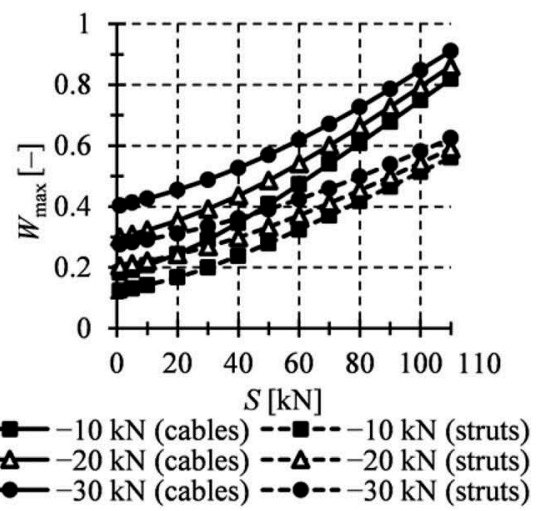

Figure 2. Influence of the level of the self-stress state $\mathrm{S}$ on the: a) displacement $q_{18}$, d) maximum load-bearing capacity ratio. 
increment of the external load. For $S_{\min }$, the relative error between displacements is equal to $1967 \%, 3102 \%, 4025 \%$ respectively for $P=-10 \mathrm{kN}, 20 \mathrm{kN}$ and $30 \mathrm{kN}$. In the case of the maximum load-bearing capacity ratio, differences obtained for the different levels of the load decreases with the rise of the level of self-stress state. For the minimum level of self-stress state, the increase of the applied force by $10 \mathrm{kN}$ causes the increase of the maximum loadbearing capacity ratio by 11 percentage points in cables and by 7.6 percentage points in struts. The same change in the level of the applied force but for the maximum level of self-stress state causes the increase of the maximum load-bearing capacity ratio by 5 percentage points in cables and by 3.2 percentage points in struts.

\subsection{Multi-module modified Simplex tensegrity plate-like structure}

Next, tensegrity plate-like structures built with modified Simplex module are analysed. The models consisting with six - the model P6 (Figure 3a), ten - the model P10 (Figure 3b), fourteen - the model P14 (Figure 3c) (Kasprzak 2014, Al Sabouni-Zawadzka \& Gilewski 2018), or eighteen - the model P18 (Figure 3d) are considered. The structures are supported on the four nodes of the bottom surface.

For each model one mechanism $(M)$ and a number of self-stress states $(S)$ exist (summarized results are shown in Table 2). None of the self-stress states identifies correctly the type of elements (that is, what is a strut and what is a cable) so for last part of the analysis superposed and normalized self-stress state for the single modified Simplex module is taken into account. Beside the above mentioned characteristic features $M$ and $S$, the structures satisfy requirements of the characteristics $T$ and $C$. The feature $D$ cannot be met because of the assumed way of connecting modules. All analysed tensegrity plates can be classified as the structures with tensegrity features of class 1 .

Then, all structures were loaded with the concentrated vertical forces $P=-1 \mathrm{kN}$ applied to all top nodes. For double-layered grids the minimum level of self-stress state increases with the number of modules used in given model and $S_{\min }$ is equal to $6 \mathrm{kN}$ for the model P6, $18 \mathrm{kN}$ for the model P10 and $40 \mathrm{kN}$ for the model P18. The maximum applied level of self-stress state $S_{\max }$ is equal to $60 \mathrm{kN}$ so the maximum load-bearing capacity ratio differentiate between $87 \%$ (P6) and 95\% (P18).

The maximum displacements of top nodes are shown in Figures $4 \mathrm{a}, 4 \mathrm{~b}, 4 \mathrm{c}$, and the maximum load-bearing ratio is shown in Figure $4 \mathrm{~d}$. The most significant difference between the displacements calculated using second (II) and third (III) order theory can be observed for the structure built with six modified Simplex modules. However, the difference decreases with the increase of the level of self-stress state - for the six-module structure the highest relative error between displacements is $28 \%$ (for $S_{\min }=6 \mathrm{kN}$ ) and the lowest error is $2.2 \%$ (for $S_{\max }=60 \mathrm{kN}$ ). The largest displacements are calculated for the structure built with 18 modules. Comparing the maximum load-bearing capacity ratios, there is no significance difference

a)

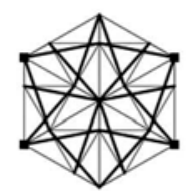

b)

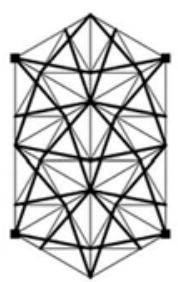

c)

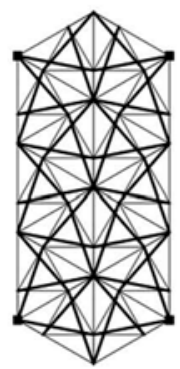

d)

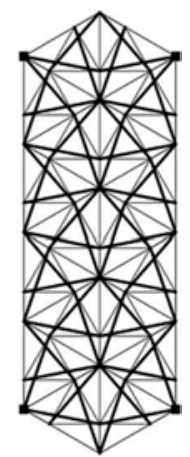

Figure 3. Top view of tensegrity plate-like structure models a) P6, b) P10, c) P14, d) P18. 
a)

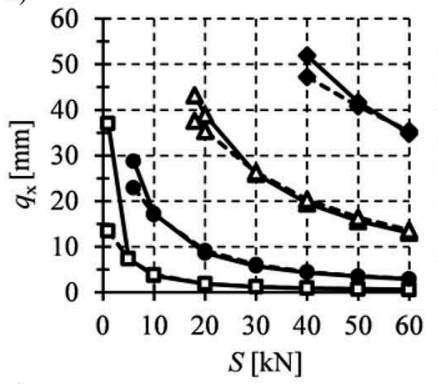

c)

\section{$S[\mathrm{kN}]$}
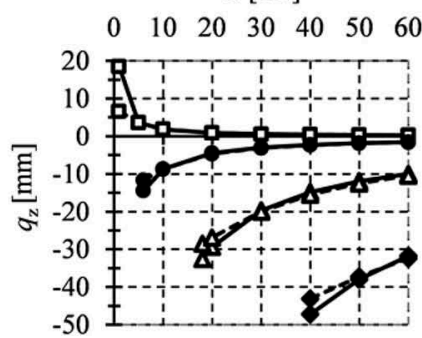

b)

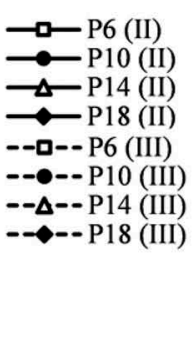

d)

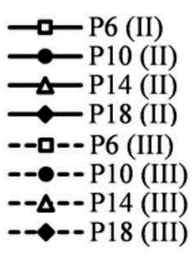

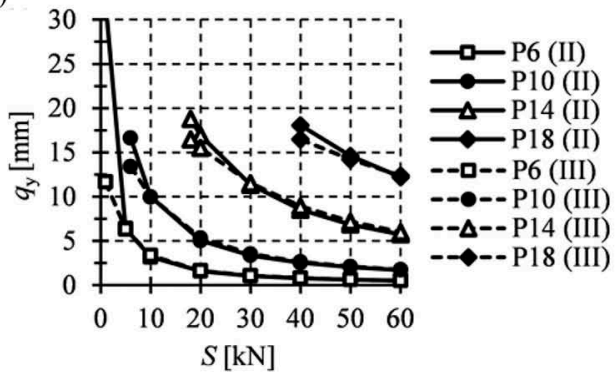

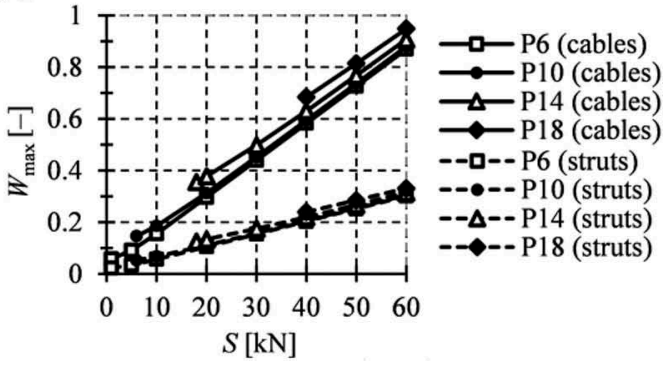

Figure 4. Influence of the self-stress state on: a) the maximum $x$ displacements, b) the maximum $y$ displacements, c) the maximum $z$ displacements, d) the maximum load-bearing capacity ratio.

for the models P6 and P10. For P14 and P18 this ratio slightly rises. Additionally, with the increase of the level of self-stress, the differences between the maximum ratios of struts and cables decrease.

\section{CONCLUSIONS}

In this paper, the qualitative and quantitative analyses of the structures built with modified Simplex modules were performed. The analysed structures were classified as ideal tensegrities or as structures with tensegrity features of class 1 . In both cases, the presence of self-stress states and infinitesimal mechanisms lets to control its static parameters. The rise of the level of self-stress provides the decline of the nodal displacements and the decrease of the impact of the geometrical nonlinearity. The influence of the nonlinearity is also affected by the minimal possible level of self-stress state. If it is almost equal to zero, the influence of the nonlinearity is significant and the third order theory needs to be applied. It can be observed in case of the single modified Simplex. If the minimum level of self-stress is higher, the influence of the nonlinearity decreases and the quasilinear approach (second order theory) is sufficient. It should be noted that the minimal level of self-stress state is higher for structures consisting of higher number of modules. It means that for the structures built with a large number of modified Simplex modules the second order theory analysis is sufficient.

\section{REFERENCES}

Al Sabouni-Zawadzka, A. \& Gilewski, W. 2018. Inherent Properties of Smart Tensegrity Structures. Applied Sciences 8: 787.

Bathe, K.J. Finite Element Procedures in Engineering Analysis; Prentice Hall: New York, NY, USA, 1996. 
Emmerich, D.G. Construction de Reseaux Autotendants. French Patent 1,377,290, 28 September 1964.

Gilewski, W. \& Kasprzak, A. 2012. Introduction to mechanics of tensegrity modules. In Theoretical Foundation of Civil Engineering. Mechanics of Structures and Materials: 83-94.

Gilewski, W. et al. 2015. Application of singular value decomposition for qualitative analysis of truss and tensegrity structures. Acta Sci. Pol.Hortorum Cultus 14 (3): 14.

Gilewski, W. et al. 2016. Verification of Tensegrity Properties of Kono Structure and Blur Building. In Proceedings of $X X V$ Polish - Russian - Slovak Seminar "Theoretical Foundation of Civil Engineering": $173-179$.

Gilewski, W. et al. 2017. The influence of self-stress on the behavior of tensegrity-like real structure. In Proceedings of MATEC Web of Conferences: 117, 00079.

Gilewski, W. et al. 2019. Parametric analysis of some tensegrity structures. In Proceedings of MATEC Web of Conferences: 262, 10003.

Kasprzak, A. 2014. Assessment of the possibility of using tensegrity in bridge structures (in Polish). PhD thesis, Warszawa.

Kłosowska, J. et al. 2018. Self-stress control of real civil engineering tensegrity structures. In AIP Conference Proceedings: 1922 (1), 150004.

Kono, Y. \& Kunieda, H. 1966. Tensegrity grids transformed from double-layer space grids. In Conceptual Design of Structures, Proceedings of the International Symposium: 293-300, Stuttgart, 7-11 October.

Obara, P. 2019a. Analysis of orthotropic tensegrity plate strips using a continuum two-dimensional model. In Proceedings of MATEC Web of Conferences: 262.

Obara, P. 2019b. Application of linear six-parameter shell theory to the analysis of orthotropic tensegrity plate-like structures. Journal of Theoretical and Applied Mechanics 57 (1): 167-178.

Obara, P. 2019c. Dynamic and dynamic stability of tensegrity structures (in Polish). Kielce: Wydawnictwo Politechniki Świętokrzyskiej.

Obara, P. \& Tomasik, J. 2020. Parametric Analysis of Tensegrity Plate-Like Structures: Part 1-Qualitative Analysis. Applied Sciences 10: 7042.

Pellegrino, S. 1993. Structural computations with the singular value decomposition of the equilibrium matrix. International Journal of Solids and Structures 30 (21): 3025-3035.

Rahami, H. et al. 2013. Analysis of near-regular structures with node irregularity using SVD of equilibrium matrix. International Journal of Civil Engineering 11: 226-239.

Zienkiewicz, O.C. \& Taylor, R.L. 2000. The Finite Element Method. Vol. 1. The Basis. London: Elsevier Butterworth-Heinemann. 


\title{
Calculation of a crimping point shear resistance for steel sheet piles based on a calibrated numerical model
}

\author{
J. Vande Voorde \\ ArcelorMittal R\&D Industry Gent, Zelzate, Belgium \\ P. El Boueiz \& A. Glorieux \\ ArcelorMittal Global $R \&$ D Belval \& Differdange, Esch-sur-Alzette, Luxembourg \\ J. Martins \\ ArcelorMittal Commercial RPS Sàrl, Esch-sur-Alzette, Luxembourg
}

\begin{abstract}
As the interlock of $U$ type ArcelorMittal steel sheet pile wall is located on the neutral axis, where the shear stress is maximum, it is very important that the connection is solid and strong enough to transfer the shear stress from one pile to the other. A solution is to crimp the interlock to guarantee the shear force transmission. Nowadays the shear resistance of the crimped sheet piles is limited by the power of the crimping press and the occurrence of cracks in the crimped areas. Furthermore, the value can only be obtained by mechanical testing, which should be performed for each sheet pile profile. ArcelorMittal R\&D developed a numerical model that simulates the crimping mechanism, as well as the shear (compression) test used to determine the shear resistance and stiffness. This Abaqus ${ }^{\circledR}$ model was calibrated and validated using a wide range of experimental data of crimping tests and compression tests performed at the mills in Belval (LU) and Dabrowa (PL). Based on numerous numerical results, correlations were developed and verified between the different influencing parameters and the effectiveness of the tool (crimping force, tool displacement, final depth of the crimped point, shear force, tool massiveness......). These formulas present a simplified method to calculate the shear resistance of each performed crimping point along the sheet pile length.
\end{abstract}

\section{INTRODUCTION}

U-type ArcelorMittal steel sheet piles are usually driven as double or triple piles (Figure 1). As the common Larssen interlock is on the neutral axis, it is important to ensure the shear stress transfer through the connection. The common interlock should then be solidarized, otherwise reduction factors according to the EN 1993-5 will be applied, implying a bending resistance reduction up to $50 \%$. The wall would also allow unwanted oblique bending.

The standard solution is to crimp the common interlock in such a way that it guarantees the transmission of the shear force through the interlock. In this way two single U piles act as one double pile. Thus, the mechanical properties of a sheet pile wall, built-up of double $U$ piles, generally come very close to the properties of the continuous wall. The crimping point should satisfy the stiffness and shear resistance level as defined in the German design recommendations EAU, determined by mechanical tests until now. The shear resistance at $5 \mathrm{~mm}$ of displacement should be at least $75 \mathrm{kN} /$ point, which implies a minimum required stiffness of 15 $\mathrm{kN} / \mathrm{mm} / \mathrm{pt}$. EN 1993-5 and prEN 10248 (Annex E) will allow a $10 \mathrm{~mm}$ displacement for the ultimate resistance of the crimps. 

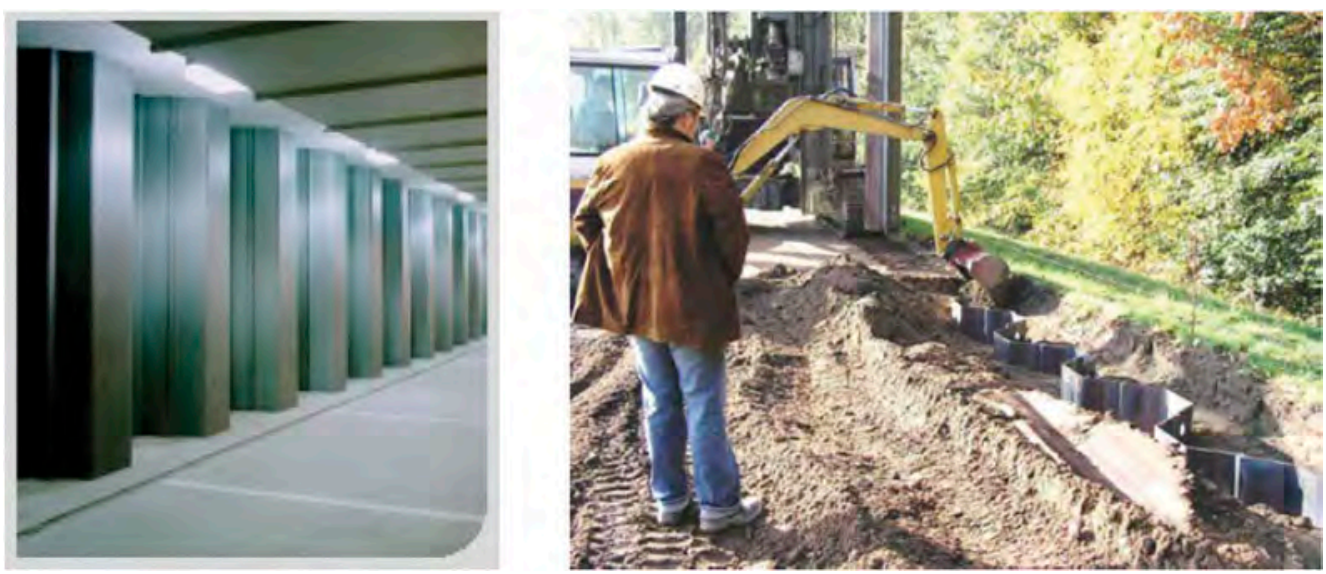

Figure 1. Examples of $\mathrm{U}$ sheet pile wall.

The following article details the development of an Abaqus ${ }^{\circledR}$ numerical model to simulate both the crimping mechanism and the compression test used for determination of shear resistance and stiffness. The numerical models were calibrated based on previous mechanical tests performed in ArcelorMittal Belval (LU) and Dabrowa (PL) mills. This will allow a theoretical definition of the crimping points characterization and of the role of the different parameters (including but not limited to the crimping force, the sheet pile material, the interlock geometry and the tool geometry).

Defining the crimping resistance theoretically avoids large tests campaign and provide savings in terms of cost and time. Having such correlations will allow to calculate a lot of crimping configurations considering a large amount of parameters. It becomes thus possible to optimise the crimping process knowing the limitations of the available crimping machine and tool geometry.

\section{ABAQUS $^{\circledR}$ FINITE ELEMENT MODELING DEVELOPMENT}

\subsection{Outlook}

The crimping is performed at ArcelorMittal production site with a press capable of driving a 3-headed tool into the interlocking part of two sheet piles with a force of up to 280 Tonnes. The result is a triple clinch-like forged deformation holding both sheet piles together. The connection has to withstand the shear forces occurring when the sheet piles are driven into position. A compression test is prescribed to test this shear resistance. The crimped interlock section is subjected to (shear) compression while the displacement and the compression force are logged (Figure 2). The by standard prescribed minimum strength is $75 \mathrm{kN}$ at $5 \mathrm{~mm}$ displacement per crimped point.

\subsection{Experimental data}

The logged data of crimping campaigns performed from 2008 until 2016 on a PU32 profile, was provided by ArcelorMittal Global R\&D. The data includes the position of the crimping cylinders and the forces they exercise as a function of time, as well as the final depth of the crimped points. The data covered additionally geometric measurements and material properties. 

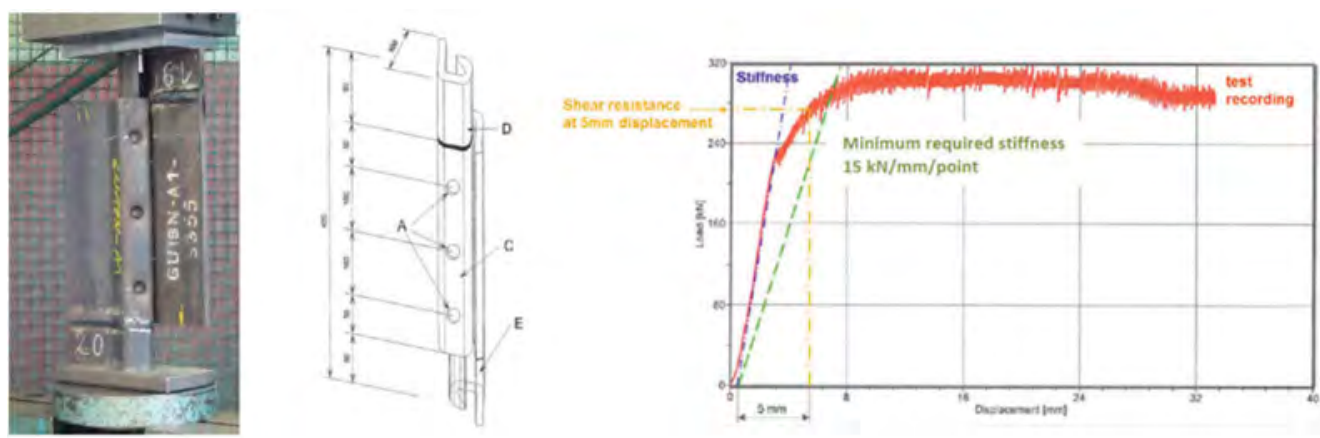

Figure 2. Shear compression test set-up with data log and minimum requirement (scheme of crimping point from prEN 10248).

\subsection{Numerical simulation}

In this section the methodology to perform simulations of the crimping process and the shear compression test is detailed. The output of the crimping simulation is used as input for the shear compression test to account for deformation and strengthening of the material. Therefore, this simulation is treated first.

The crimping is done by pressing a triple tool into the sheet pile interlocks. The sheet pile is supported by an anvil. Its position relative to the zero plane is named dYS. The displacement of the tools during the contact is called dYC. The final crimping depth after retreat of the tools (and spring back) is called FD and the maximum crimping force FC.

The area around the crimping points, is meshed with $3 \mathrm{D}$ elements. The rest of the sheet pile is meshed with shell elements which are connected to the local area model using shell-to-solid coupling. The material behavior is elasto-plastic with a steel grade S $430 \mathrm{GP}$, while the tools are modelled purely elastic. Boundary conditions are applied to the ends of the sheets: symmetry on one end and pinned on the other (Figure 3).

The normal contact definition is "hard" (meaning any overlap is countered by a penalty force) and a tangential friction coefficient is prescribed. The friction coefficient of 0.2 was used in the simulations. To ensure that this choice won't have influence on the model calibration, simulations with coefficients from 0.1 to 0.3 showed that this coefficient has a negligible effect on the result.

The full sheet pile model allows including the influence of gravity and the twisting of the sheet piles during the crimping process.

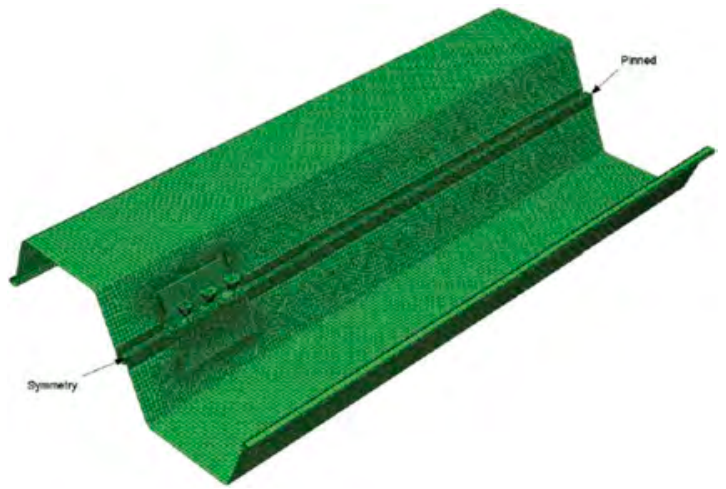

Figure 3. Full sheet pile model mesh with boundary conditions. 


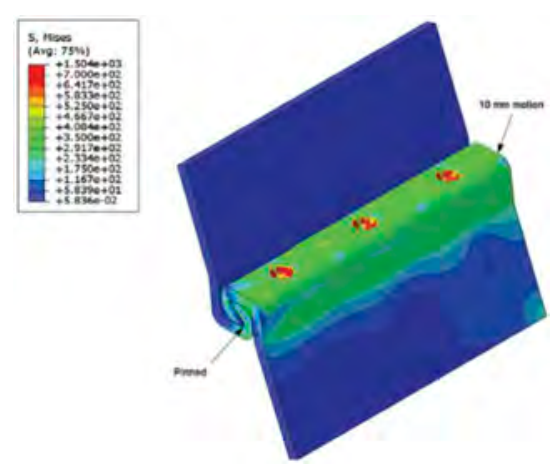

Figure 4. Initial conditions for the shear test simulation.

The shear compression test is modelled by taking the deformed local crimping area from the crimping simulation, including the residual stresses and the work hardening of the material, and subjecting it to a prescribed displacement of $10 \mathrm{~mm}$, as defined by the standard and illustrated in Figure 2 in section 2.1. The deformation, hardening and residual stresses of the crimping operation are included at the start of the simulation (Figure 4). The front of the bottom sheet is pinned, while a translation of $10 \mathrm{~mm}$ is prescribed at the end of the top sheet.

\section{RESULTS AND MODEL CALIBRATION}

In this section the simulation methodology is validated against experimental data from 2016 testing campaign, by referring to an average chosen point. The true interlock geometry as well as the material data derived from the tensile test was used to numerically reproduce the test result.

The simulation crimping curve is compared to the experimental value (Figure 5). The calculated final depth of $13.67 \mathrm{~mm}$ is almost identical to the experimental value of $13.37 \mathrm{~mm}$. In addition, the sheet pile behaviour is similar in terms of stiffness to the test result. This model can therefore be considered fully, qualitatively and quantitively, validated for the crimping simulation.

In Figure 6 below, a few simulation results are compared to the experimental data in the form of compression curves (only one full compression curve was provided). It is clear that the shearphnomenon is captured well, both qualitatively and quantitatively.

\section{CORRELATIONS WITH CRIMPING PARAMETERS}

Results of the crimping operation and compression shear test depend on several input parameters (for instance adherence to geometric tolerances). In this section, the simulations results are used to correlate the maximum crimping force FC, the final crimping depth FD and the shear force at $5 \mathrm{~mm}$ compression $\mathrm{F} \_5 \mathrm{~mm}$ or $\mathrm{F} 5$ to various parameters. These correlations can then be used for fine-tuning of the real process.

\subsection{Design of experiments}

The effect of the following parameters will be studied:

a) Crimping tool displacement dYC: Depth of the crimping, ranged from 13 to $18 \mathrm{~mm}$

b) Position of the support anvil dYS: Amount of the lifting, ranged from -4 to $4 \mathrm{~mm}$ 


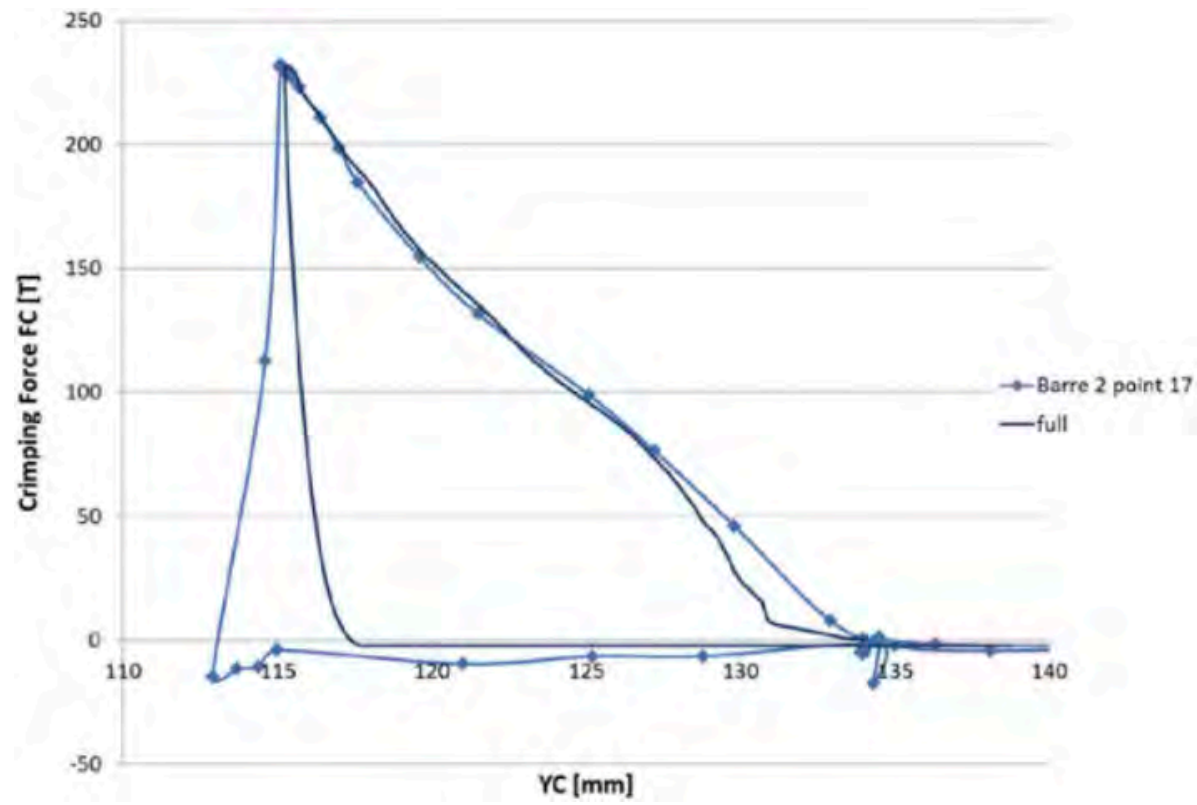

Figure 5. Crimping curves: comparison of full sheet model results to experimental data.

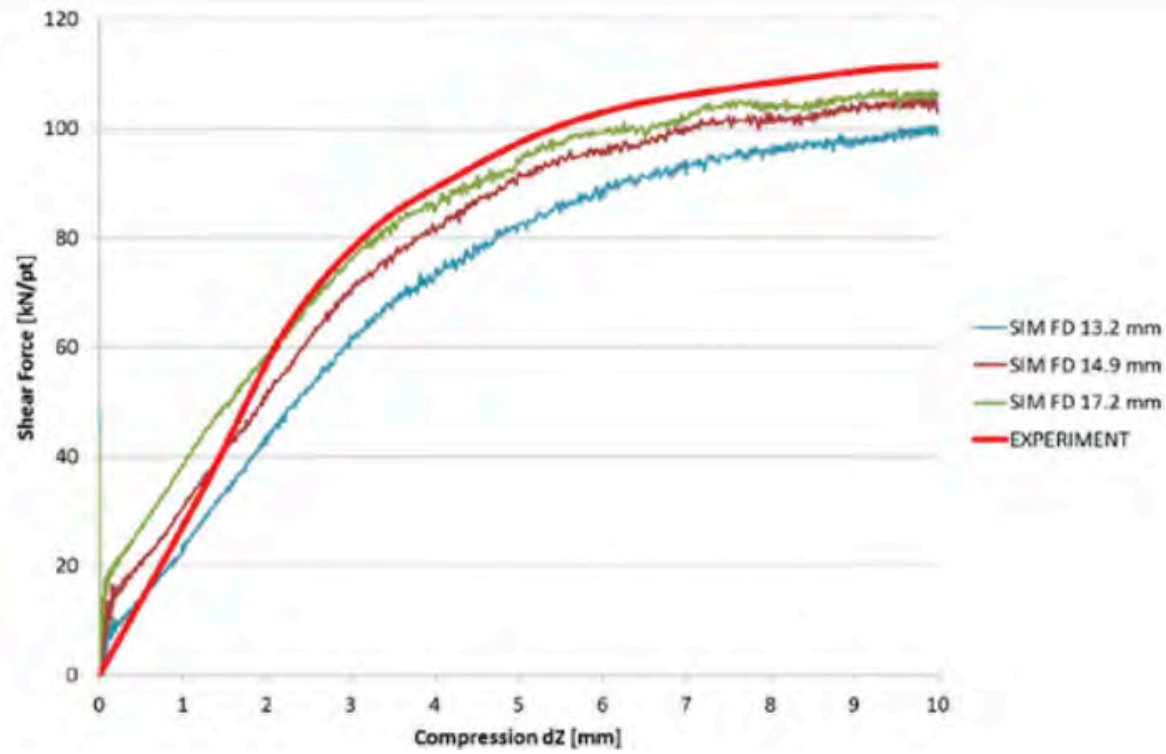

Figure 6. Comparison of simulated shear force curves to experimental data (heavy line).

c) Material properties: yield point Re and strengthening capacity $n$ : Definition of a straight tensile curve by defining stress at yield $(\mathrm{Re})$ and at $100 \%$ strain $(\mathrm{Re}+\mathrm{n})$, ranged from 400 to $600 \mathrm{MPa}$ for Re and from 500 to $2500 \mathrm{MPA}$ for $\mathrm{n}$.

d) Geometry of the sheet pile interlocks: SheetFullness, ranged from 0.9 to 1.0 of the nominal dimensions.

e) Massiveness of the tool: scale. This parameter depends on the tool shape. Ranged from 0.5 (slender) to 2.0 (massive). A value of 1.0 corresponds to the current tool. 


\subsection{Correlations}

In the following section, only the most important conclusions are treated.

The final depth FD is correlated very strongly to the tool displacement dYC (Figure 7). The position of the support anvil dYS and the material are the only other parameters who have a minor influence on the final depth. For the maximum crimping force FC and the shear force F_5mm such strong singly determined correlations don't exist. The strongest correlations are FC(FD) and F5(FC). Both parameters are linearly correlated with both the final depth FD and the sheetFullness.

The position of the support anvil has a complicated, but significant influence on FC and F_5mm and even on FD (as a rare parameter apart from dYC). The results relate linearly to dYS for negative values, but strongly non-linearly for positive values.

Understandably the strength of the material has an influence on the crimping force FC and the shear force F_5mm. Due to springback it also a non-linear has an influence on the final depth FD.

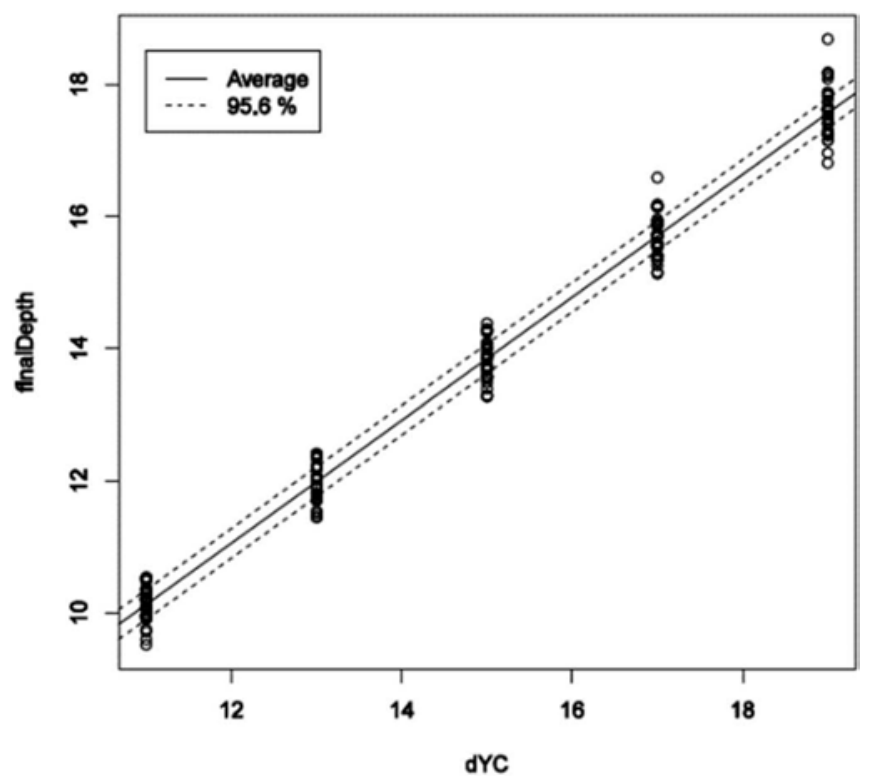

Figure 7. Correlation of finalDepth with dYC.

The derived correlations are summarized in the Table 1 below.

Table 1. Summary of the derived correlations.

\begin{tabular}{ll}
\hline Parameter & Correlation \\
\hline & $F D=-0.1085+0.93 \times d Y C$ \\
& $F D=1.332+0.758 \times d Y C-0.223 \times \mathrm{dYS}-0.022 \times d Y C \times$ \\
& $\mathrm{d} Y \mathrm{~S}+0.0056 \times d Y C^{2}+0.0086 \times d Y C^{2}+0.0097 \times d Y S^{2} \times$ \\
& $d Y C+0.00056 \times d Y C^{2} \times d Y C-0.00035 \times d Y C^{2} \times d Y S^{2}$ \\
& $F D=0.314+0.961 \times d Y C-3.4 \times 10^{-4} \times R e-2.648 \times 10^{-4} \times$ \\
& $n+5.426 \times 10^{-8} \times n^{2}-4.103 \times 10^{-6} \times d Y C \times R e-2.068 \times$ \\
& $10^{-5} \times d Y C \times n+1.297 \times 10^{-7} \times R e \times n$ \\
&
\end{tabular}


Table 1. (Continued)

\begin{tabular}{|c|c|c|}
\hline Parameter & Correlation & \\
\hline \multirow{3}{*}{$\mathrm{FC}$} & $\begin{array}{l}F C=-9.552 \times F D+31.641 \times F D \times \text { sheetFullness }+31.778 \\
\times \text { sheetFullness }-88.086\end{array}$ & (4) \\
\hline & $\begin{array}{l}F C=10.55+11.69 \times d Y C+16.23 \times d Y S-2.63 \times d Y C \times \\
d Y S+0.291 \times d Y C^{2}+0.203 \times d Y S^{2}+0.199 \times d Y S^{2} \times \\
d Y C+0.0688 \times d Y C^{2} \times d Y S-0.0137 \times d Y C^{2} \times d Y S^{2}\end{array}$ & (5) \\
\hline & $\begin{array}{l}F C=-9.58+1.434 \times d Y C+1.38 \times 10^{-2} \times R e-2.889 \times 10^{-} \\
2 \times n+3.991 \times 10^{-2} \times n^{2}+1.837 \times 10^{-2} \times d Y C \times R e+6.239 \\
\times 10^{-2} \times d Y C \times n+8.431 \times 10^{-2} \times \operatorname{Re} \times n\end{array}$ & (6) \\
\hline \multirow{3}{*}{$\mathrm{FC}$} & $\begin{array}{l}F \quad 5 m m=22.046 \times F D-8.942 \times F D \times \text { sheetFullness }+ \\
384.518 \times \text { sheetFullness }-460.676\end{array}$ & (7) \\
\hline & $\begin{array}{l}F 5=-56.14+9.35 \times d Y C+4.25 \times d Y S-0.346 \times d Y C \times \\
d Y S+0.0401 \times d Y C^{2}+7.7 \times d Y S^{2}-1.06 \times d Y S^{2} \times d Y C+ \\
0.00152 \times d Y C^{2} \times d Y S+0.0358 \times d Y C^{2} \times d Y S^{2}\end{array}$ & (8) \\
\hline & $\begin{array}{l}F-5 m m=-22.3+3.5 \times d Y C-0.0913 \times R e+0.00264 \times n- \\
3.63 \times 10^{-6} \times n^{2}+0.0125 \times d Y C \times R e+0.00144 \times d Y C \times \\
n-3.12 \times 10^{\wedge-7} \times \operatorname{Re} \times n\end{array}$ & (9) \\
\hline
\end{tabular}

Where:

FD: $\quad$ Final crimping depth

FC: $\quad$ Crimping force

F_5mm: Compression shear force @ $5 \mathrm{~mm}$ displacement

dYC: $\quad$ Crimping displacement

dYS: $\quad$ Position of the lower anvil vs zero plane

Re: $\quad$ Yield point of the sheet pile material

$\mathrm{N}$ : $\quad$ Strengthening of the material

sheetFullness: Factor describing the sheet pile interlock thickness

\section{CONCLUSIONS}

In this paper, a sheet pile crimping simulation methodology, as performed in ArcelorMittal Belval plant, and the subsequent compression shear test is presented. The model was validated against experimental data provided by AM Global R\&D. This model was used to set up correlations between the crimping performance (such as the required crimping force and the shear resistance in the compression force) and various parameters of the crimping process. These correlations can now be used in the factory line to perform the current crimping under optimum circumstances, as well as to calculate numerically the crimping point characteristics, that is nowadays only possible with mechanical tests. Moreover, the study highlighted the most influencing parameters of the crimping process on the crimping resistance, allowing to target precisely the optimization.

\section{REFERENCES}

EAU (2012): Recommendations of the Committee for Waterfront Structures Harbours and Waterways EAU 2012, Ernst \& Sohn.

EN 1993-5, Eurocode 3: Design of steel structures - Part 5: Piling, Feb 2007.

prEN 10248-1: Hot-rolled steel sheet piling - Part 1: Technical delivery conditions, March 2006. 


\title{
Influence of bimoment restraints on load-bearing capacity of steel I-beams
}

\author{
K. Wierzbicki \\ Faculty of Civil and Environmental Engineering, West Pomeranian University of Technology, Szczecin, \\ Poland \\ M. Szumigała \\ Faculty of Civil and Transport Engineering, Poznan University of Technology, Poznańn, Poland
}

\begin{abstract}
The study presents the results of steel I-beams' numerical analysis performed using Finite Element Method implemented in ABAQUS software. An influence of bimoments restraints on critical moment of bending and load-bearing capacity of steel I-beams were investigated. Studied beams were bisymmetric I-section, single span and fork-supported at both ends. An external load was applied as a concentrated force in the middle of the span. Geometrically and materially nonlinear analysis with imperfections (GMNIA) was applied. The initial curvature was obtained from the first mode of Lateral-Torsional Buckling in LBA in ABAQUS software. The amplitude of initial imperfection was calculated accordingly to new LTB design rules and their derivation (the Snijder's approach). Results were compared to Eurocode's "General Formula" and LTBeamN software. Bimoment restraints were defined as steel plates connected to both flanges in a plane parallel to the element's web. The side plates working as a bimoment restraints were added to the computational model for different values of initial external load, which allowed to estimate its strengthening effect in existing I-beams.
\end{abstract}

\section{INTRODUCTION}

The steel I-beams are widely applied as bending members in building structures. In case of lack of additional lateral support the load-bearing capacity is often determined by lateraltorsional buckling of the element. The phenomenon is related i.e. with the buckling of the compressed flange of an I-beam and causes rotation along the longitudinal axis of the element. This initiates the warping effect which imposes rotation between two flanges caused by bimoments.

There are many parameters and physical characteristics that affect the lateral-torsional buckling. The most important are geometrical properties of beam's cross section (visible in the moments of the area) and its length. What is more, it is crucial to properly represent existing support in calculations. This requires to include warping degree of freedom and possibility of lateral bending at supports. Calculating load-bearing capacity of hot-rolled elements is similar to thin-walled members, where for a beam structure scheme 3 translational and 3 rotational degrees of freedom (DOF) are not sufficient to evaluate load-bearing capacity.

The slenderness is a parameter correlated to the length and cross-section of an element as well as type of its supports. The bigger the slenderness the more vulnerable the element is to lateral-torsional buckling. 


$$
\begin{aligned}
& \mathrm{M}_{\mathrm{cr}}=\mathrm{C}_{1} \frac{\pi^{2} \cdot \mathrm{E} \cdot \mathrm{I}_{\mathrm{z}}}{\left(\mathrm{k}_{\mathrm{z}} \cdot \mathrm{L}\right)^{2}}\left(\sqrt{\left(\frac{\mathrm{k}_{\mathrm{z}}}{\mathrm{k}_{\mathrm{w}}}\right)}{ }^{2} \frac{\mathrm{I}_{\omega}}{\mathrm{I}_{\mathrm{z}}}+\frac{\left(\mathrm{k}_{\mathrm{z}} \cdot \mathrm{L}\right)^{2} \cdot \mathrm{G} \cdot \mathrm{I}_{\mathrm{T}}}{\pi^{2} \cdot \mathrm{E} \cdot \mathrm{I}_{\mathrm{z}}}+\left(\mathrm{C}_{2} \cdot \mathrm{z}_{\mathrm{g}}-\mathrm{C}_{3} \cdot \mathrm{z}_{\mathrm{j}}\right)^{2}-\right. \\
& \left.-\mathrm{C}_{2} \cdot \mathrm{z}_{\mathrm{g}}-\mathrm{C}_{3} \cdot \mathrm{z}_{\mathrm{j}}\right)
\end{aligned}
$$

The next group of factors that influences the loss of stability are the parameters correlated to the type of load and its location in respect to the shear centre of the an I-beam.

The value of the maximum bending moment for an ideally-shaped element (without any imperfections) is called the critical moment ( $\left.\mathrm{M}_{\mathrm{cr}}\right)$. The new edition of the Eurocode 3 (CEN, 2006) does not provide any method of calculating it. However, a method can be found in the older versions of European Standard 3 (CEN, 1992) or other codes under the name of "General Formula".

Additional non-dimensional factors such as $\mathrm{C}_{1}, \mathrm{C}_{2}, \mathrm{C}_{3}$ or $\mathrm{k}_{\mathrm{z}}$ and $\mathrm{k}_{\mathrm{w}}$, are introduced as there is no simple calculation of critical moment for simply supported beam with non-fork support or non-centre alignment of the load. The general differential equation can be solved using trial and error method (Galambos, Surovek, 2008) or be approximated using e.g. Laplace transformation (Bosowski, 2015).

Factor $\mathrm{k}_{\mathrm{z}}$ and $\mathrm{k}_{\mathrm{w}}$ take values from 0.5 to 1.0 (where 0.5 means full fixity on both support and 1.0 means full pinned support).

In the research (Wierzbicki, 2018), the influence of endplates on the increase of the loadbearing capacity of an I-beam was examined. To achieve a significant impact it was necessary to strengthen the I-beam (type IS-300/150/S355JR L=5.0 m) with $40 \mathrm{~mm}$ thick endplates. For thickness of $80 \mathrm{~mm}$ the increase in the load-bearing capacity was almost unnoticeable. It is highly unusual to apply plates thicker than $40 \mathrm{~mm}$ in elements such as IPE160 - IPE400 or HEA equivalents, which are the most popular hot-rolled I-beams. It is hard to fix those plates using welding, because due to a big difference in thickness the thicker element requires preheating as to not influence the temperature of the welded joint.

To achieve significant increase of the load-bearing capacity of an I-beam under bending with lateral-torsional buckling it is possible to strengthen the cross-section with additional elements. Use of elements that connect top and bottom flanges in a plane of bending, allows to increase the value of Saint Venant's stiffness needed to reduce the warping effect. The examples of this solution are transverse ribs along the length of the beam, the X-shaped spacer, diagonal or orthogonal ribs (Chybiński, Garstecki, 2016 \& Chybiński, 2008) closed steel diaphragms or bimoment restraints (Kurzawa, 2006). This study focuses on the latter solution. The reduction of the $\chi_{\mathrm{LT}}$ coefficient required in some cases is sometimes impossible to achieve due to already existing loads or limited space for enlarging the compressed flange (generally the top one) which can be fixed with other elements such as concrete slabs, trapezoidal sheet or sandwich panels. Increasing the load-bearing capacity of an I-beam using bimoments restraints requires only a small amount of additional steel and simple welding in comparison to other methods of strengthening which require extensive works.

This paper is an extension of previous studies (Wierzbicki, 2020) which investigated the effect of restraint on load-bearing capacity of an I-beam.

\section{MATERIALS AND METHODS}

\subsection{Geometrical and material properties of the beam}

A hot-rolled, steel I-beams IPE200 with three lengths of $2.5 \mathrm{~m}, 5.0 \mathrm{~m}$ and $7.5 \mathrm{~m}$ were taken into consideration. They are simply and fork supported at the ends. The load is applied as a concentrated force in the middle of the span, located at the top flange in the plane of the web. The I-beams were modelled using bilinear stress-strain model of S355JR steel. To enhance the load-bearing capacity of bending, four longitudinal stiffeners were rigidly connected to inner sides of the flanges. Dimensions of each plate are $183 \mathrm{~mm} \times 183 \mathrm{~mm}$ with $20 \mathrm{~mm}$ thickness. Due to fork and pinned support at both ends the maximum warping occurs 
there. Due to this additional plates were fixes at supports. That location proved to be the most efficient (Piotrowski, Szychowski, 2015 \& Iwicki, 2010).

\subsection{Methods}

Calculations were conducted in ABAQUS CAE environment. The beams were modelled using $25 \mathrm{~mm}$ S4R shell elements. First of all, for each beam the shape was determined for a normal mode and the geometry was assumed based on this result. Similar approach can be seen e.g. in (Giżejowski, 2016 \& 2017). The next step of the analysis was to apply a load and in some cases additional longitudinal stiffeners for different load values. Then, non-linear analysis (using the Riks method) was carried out to calculate the maximum value of load that can be applied to model. To simplify the calculations and due to the fact, that at supports the value of bending stress in I-beam is rather insignificant, the influence of welding was omitted. Authors will consider this phenomenon in further studies.

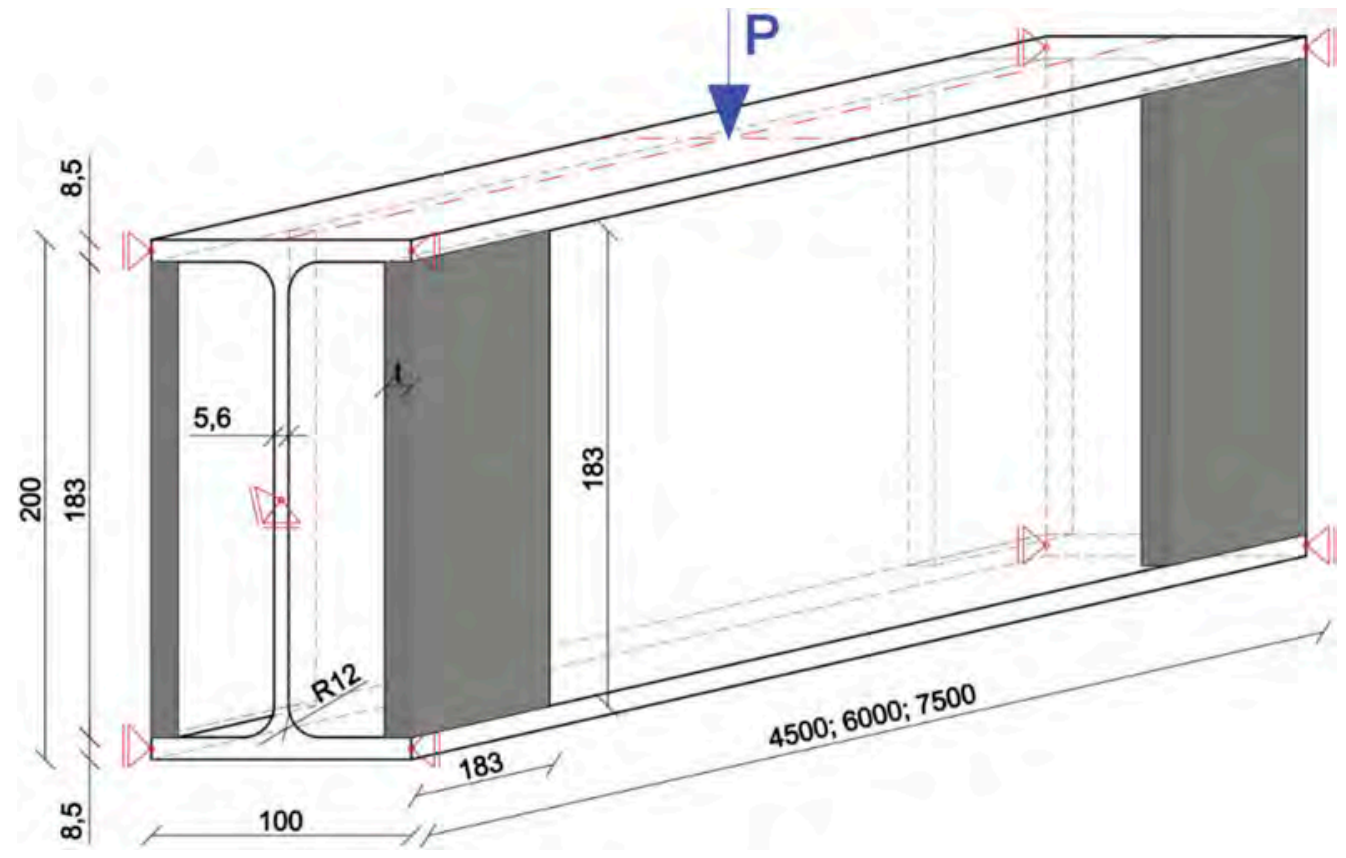

Figure 1. Geometrical characteristics of I-beams with bimoment restraints, similar to (Wierzbicki, 2020).

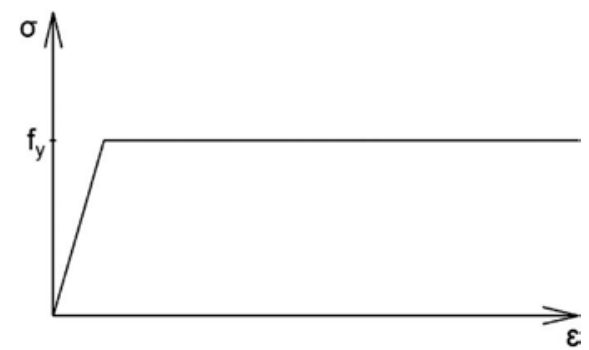

Figure 2. Stress-strain relation included in the calculations, as in (Wierzbicki, 2020).

To show the influence of added restraints at certain load levels the outcomes were presented as a relation of the load and lateral displacement of a node in the middle of the span. 
This analysis includes non-linear geometrical and material imperfections (GMNIA). The value of geometrical imperfection's amplitude was calculated based on (Rykaluk, 2012 \& Snijder, 2018):

$$
\mathrm{e}_{0, \mathrm{~d}}=\alpha_{\mathrm{LT}}\left(\bar{\lambda}_{\mathrm{LT}}-0.2\right) \frac{\mathrm{M}_{\mathrm{Rk}}}{\mathrm{N}_{\mathrm{Rk}}}
$$

where $\alpha_{L T}-$ imperfection factor, for $\mathrm{h} / \mathrm{b}>1.2$ :

$$
\alpha_{\mathrm{LT}}=0.12 \sqrt{\mathrm{W}_{\mathrm{el}, \mathrm{y}} / \mathrm{W}_{\mathrm{el}, \mathrm{z}}} \leq 0.34
$$

\section{RESULTS AND DISCUSSION}

\subsection{Results for a beam with $L=2.5 \mathrm{~m}$}

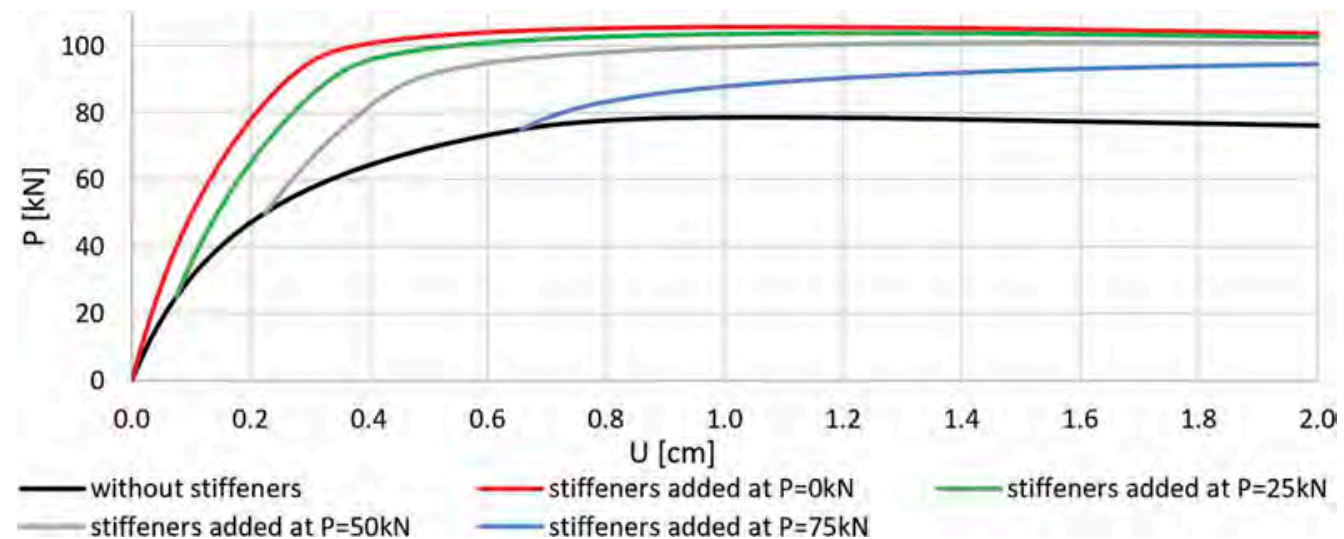

Figure 3. Correlation between load and lateral displacement for $2.5 \mathrm{~m}$ I-beam.

\subsection{Results for a beam with $L=5.0 \mathrm{~m}$}

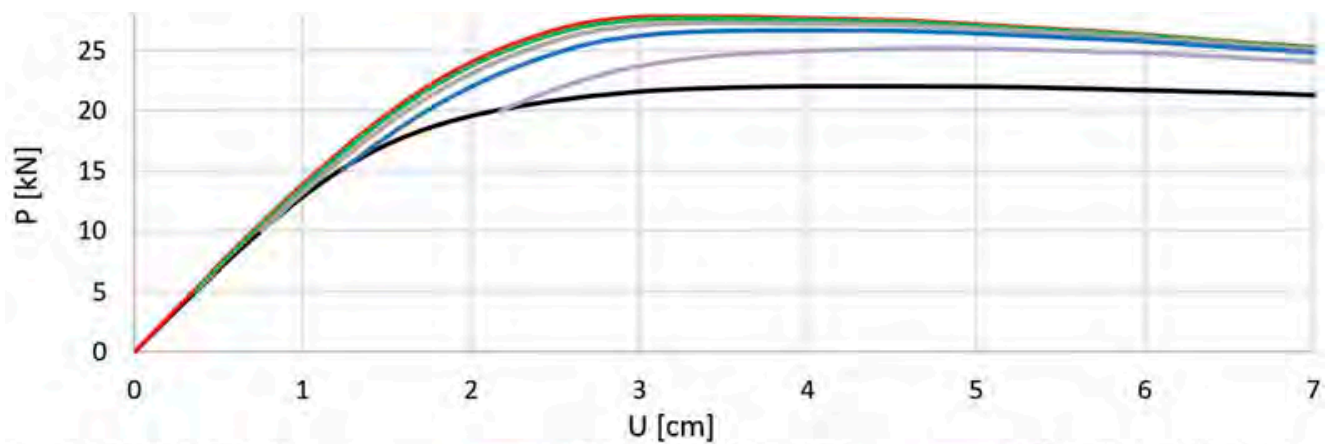

\section{- without stiffeners \\ stiffeners added at $\mathrm{P}=10 \mathrm{kN}$}

- stiffeners added at $\mathrm{P}=0 \mathrm{kN}$

- stiffeners added at $\mathrm{P}=5 \mathrm{kN}$

stiffeners added at $P=15 \mathrm{kN}$ stiffeners added at $P=20 \mathrm{kN}$

Figure 4. Load versus lateral displacement of node from the top flange in the middle span for $5.0 \mathrm{~m}$ I-beam. 


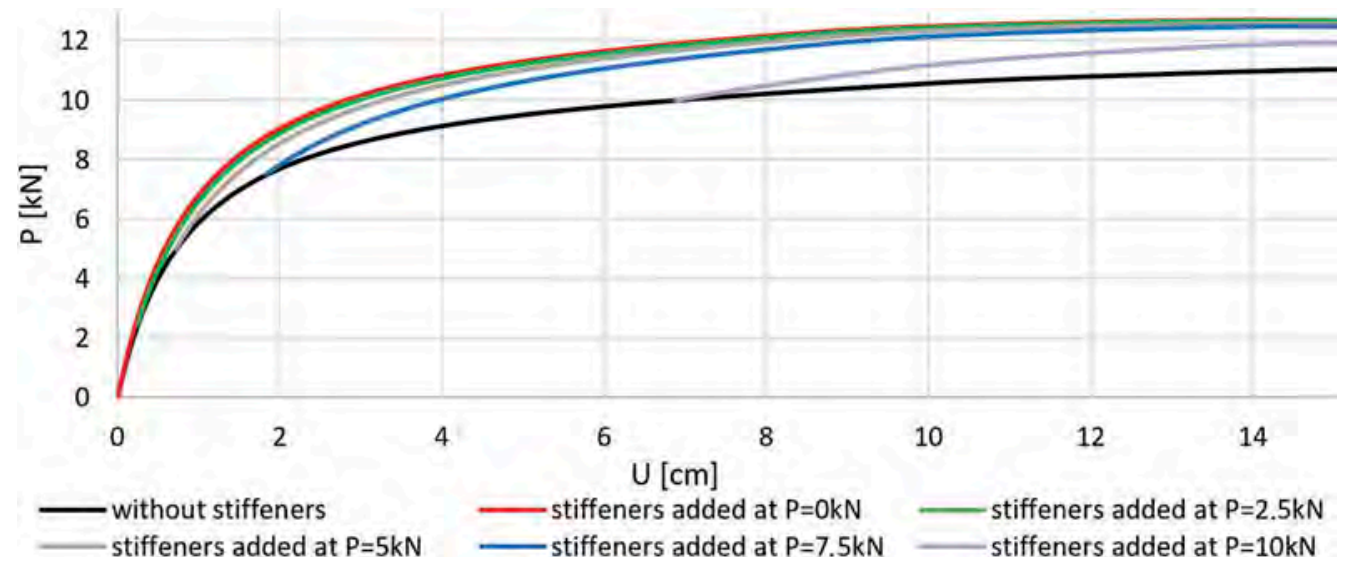

Figure 5. Load versus lateral displacement of node from the top flange in the middle span for $7.5 \mathrm{~m}$ I-beam.

\subsection{Comparison and discussion}

The shorter the beam, the bigger differences between load bearing capacity after strengthening. It can be seen that addition of restraint at the location of rapidly growing lateral displacement can strengthen the beam significantly. Nevertheless, adding the restraints to the beam which is almost at its load bearing capacity limit should be done using special safety measures, because during welding of the restraints there is always a danger of weakening the construction due to post welding stress and reduction of yield strength due to growth of temperature. The less loaded the construction is during strengthening with bimoment restraints the bigger load bearing capacity will be reached in the end.

The values of elastic critical moment of bending without any stiffeners were calculated in three ways (Table 1). First of all, the same model as described in paragraph 2.1 was taken into consideration. Secondly, the same geometrical parameters of beams, supports and load were modelled in LTBeam software. Then, calculation were conducted according to the General Formula. The biggest differences can be spotted for the shortest beam. The $2.5 \mathrm{~m}$ IPE200 is too short to be analyzed properly (without significant differences to more complex models) using beam object (as in LTBeam) or without taking into consideration shell structure in a membrane state $(\mathrm{L} / \mathrm{h}=12.5<20)$.

Table 2 shows a comparison between elastic critical moment values for models with longitudinal restraints $183 \times 183 \times 20 \mathrm{~mm}$ (as described in paragraph 2.1) and model with rigid, nondeformable plates. It can be seen that the solution gives similar results as a full rigid support for warping. Results from LTBeam and ABQAUS model are almost the same (with the biggest deviation between them for the shortest beam).

Table 1. Values of the elastic critical moment for beams without imperfections and longitudinal stiffeners - buckle modes.

\begin{tabular}{llll}
\hline Length $[\mathrm{m}]$ & $\begin{array}{l}\text { ABAQUS } \\
\text { shell S4R }\end{array}$ & LTBeam & $\begin{array}{l}\text { General } \\
\text { Formula eq. (1) }\end{array}$ \\
\hline 2.5 & 60.61 & 63.54 & 64.19 \\
5.0 & 29.39 & 29.90 & 30.33 \\
7.5 & 20.03 & 20.32 & 20.65 \\
\hline
\end{tabular}


Table 2. Values of the elastic critical moment for beams without imperfections and with longitudinal stiffeners - buckle modes.

\begin{tabular}{llll}
\hline Length $[\mathrm{m}]$ & $\begin{array}{l}\text { ABAQUS shell S4R } \\
\text { stiffeners 183x183x20 mm }\end{array}$ & $\begin{array}{l}\text { ABAQUS shell } \\
\text { S4R rigid stiffeners }\end{array}$ & $\begin{array}{l}\text { LTBeam rigid } \\
\text { stiffeners }\end{array}$ \\
\hline 2.5 & 109.20 & 113.28 & 115.49 \\
5.0 & 39.74 & 39.85 & 40.22 \\
7.5 & 24.02 & 24.09 & 24.29 \\
\hline
\end{tabular}

\section{CONCLUSIONS}

Strengthening the steel I-beam by adding bimoment restraints at the ends of a simply and fork supported beam causes a significant increase in the critical moment of bending and - as a consequence - the load bearing capacity of an element. The use of typical $10-20 \mathrm{~mm}$ plates is sufficient to limit the warping of the element. There is no need to increase the thickness of the plates.

The increase of load-bearing capacity after strengthening a loaded beam is correlated to its slenderness. The more slender the beam the lower the strengthening effect will occur when the load is applied (except for stocky beams, where load-bearing capacity of element is defined by plastic resistance in major axis bending). The more load is applied to the beam during strengthening the lower influence on stability can be obtained. The bigger the load before adding restraints the smaller the increase of load bearing capacity at bending. It is important to strengthen the beam before reaching the plastic operation, because then the strengthening effect is the most significant. For the purpose of this study an assumption was made, that welding the bimoment restraints at the ends of a beams can be omitted in modelling due to negligible values of stresses there. However, it will be taken into consideration during further studies. That problem require more complex analysis.

\section{REFERENCES}

Chybiński, M. \& Farkas, J. \& Garstecki, A. \& Jarmai, K. \& Rzeszut, K. 2008. Optimization of Steel Beams and Columns for Variable Rib Configuration: International Conference Proceedings 2008, Miskolc, Hungary, April 24-26, 2008: 113-118.

Chybiński, M. \& Garstecki, A. 2016. Diagonal versus orthogonal ribs in stability of steel I beams: Procedia Engineering 172 (2017): 172-177.

EN 1993-1-1.2006.Eurocode 3: Design of steel structures - Part 1-1: General rules and rules for buildings: CEN.

prEN 1993-1-1. 1992. Eurocode 3: Design of steel structures - Part 1-1: General rules and rules for buildings: CEN.

EN 1999-1-1. 2006. Eurocode 9: Design of aluminium structures - Part 1-1: General structural rules: CEN.

Galambos, T.V. \& Surovek, A. E. 2008. Structural Stability of Steel: Concepts and Applications for Structural Engineers: John Wiley \& Sons, Inc: 236-289.

Giżejowski, M. \& Szczerba, R. \& Gajewski, M. 2017. Influence of imperfections on LTB resistance of steel rolled and welded beams: JCEAA, t. XXXIV, z.64 (3/I/17): 447-460 (in Polish).

Giżejowski, M. \& Szczerba, R. \& Gajewski, M. 2016. FEM models and simulation methods in lateraltorsional buckling analysis of steel elements: JCEAA, t. XXXIII, z.63 (1/I/16), 339-346, 2016 (in Polish).

Gosowski B. 2015. Bending and torsion of thin walled metal structures: Oficyna Wydawnicza Politechniki Wrocławskiej (in Polish).

Iwicki, P. 2010. Sensivity analysis of buckling loads of bisymetric I-section columns with bracing elements: Archives of Civil Engineering, Vol. LVI, Issue 1: 69-88.

Kurzawa, Z. \& Rzeszut, K. \& Szumigała, M. \& Chybiński M. 2006. Influence of endplates on the Critical Moment of of I-beams: Inżynieria i Budownictwo Nr 3/2006: 163-166 (in Polish).

Piotrowski, R., Szychowski, A. 2015. Lateral-torsional buckling of beams elastically restrained against warping at supports: Archives of Civil Engineering, Vol. LXI, Issue 4: 155-174. 
Rykaluk, K. 2012. Stability issues of metal structures: Dolnośląskie Wydawnictwo Edukacyjne: 176-201 (in Polish).

Snijder, H.H. \& van der Aa, R.P. \& van Hove, B.W.E.M. 2018. Lateral torsional buckling design imperfections for use in non-linear FEA: Steel Construction: Design and Research, 11(1): 49-56.

Wierzbicki, K. 2018. Influence of endplates on the value of critical moment 2018: International Interdisciplinary PhD Workshop (IIPhDW): 142-146.

Wierzbicki, K. 2020. Influence of bimoment restraints on the load-bearing capacity of a steel I-beam: CEER 2020;30 (4): 33-47. 


\title{
Simplified approach to assess the dynamic response of a container ship subjected to bow slamming load
}

\author{
K. Wołoszyk \& M. Bogdaniuk \\ Polish Register of Shipping, Gdańsk, Poland \\ Faculty of Ocean Engineering and Ship Technology, Gdansk University of Technology, Gdańsk, Poland
}

\begin{abstract}
Simplified approach to assess the dynamic response of a container ship subjected to the bow slamming load, resulting in a transient vibratory response, typically called a 'whipping', is presented. The accurate numerical modelling is very complex and involves coupling of the hydrodynamic and structural solution at every time step, leading to huge computational and workload cost. Thus, the one-way coupling methodology is adopted, and hydrodynamic loads are derived using linear strip theory in the first step and applied to the FE beam model. Structural response is obtained in the time domain using an explicit dynamic solver. Extreme bending moment is derived and compared with the normative values of the wave-induced bending moment. Comparing to more accurate methods, the presented approach seems to overestimate the bending moment and leads to a conservative design. Thus, it may be used in the early stages of the design, where fast and reliable methods are essential.
\end{abstract}

\section{INTRODUCTION}

During heavy sea conditions, the ship's bow oscillates vertically, resulting in impulsive highpressure values, called slamming. This results in transient vibrations of the ship. The occurrence of whipping could be visible in Figure 1, where stress measurements at the weather deck during a full-scale sea trial of the frigate are presented (Tuitman 2010). The response seems to be non-impulsive in general; however, after around 1355 seconds, the ship starts to whip. The stresses are notably increased concerning quasi-static response. The slamming loading increases not only global response, but local pressure loads are increased as well. The transient vibratory response could be critical not only for ships but for inland structures too, e.g. bridges (Wang et al. 1992) or railway tracks (Costa et al. 2010).

The whipping response is well known for many ship types (Aalberts and Nieuwenhuijs 2006). Due to the rapid growth of container ships size, whipping becomes a more important effect influencing ship structural response. Container ships have relatively low stiffness in comparison to their length. In recent years, the problem was analysed in the experimental and numerical domain. In the experiments, both model tests (Storhaug et al. 2010) and full-scale measurements (Gaidai et al. 2016, Mao et al. 2015) were carried out. In model testing, the tests are usually quite expensive, and only a limited number of cases could be investigated. It is very hard to simulate the flexibility of the real ship. The results of such experiments are also subjected to high uncertainties. In numerical calculations, many authors explored different modelling techniques (Barhoumi and Storhaug 2014, Malenica and Derbanne 2014).

The numerical modelling of whipping is very complex and involves coupling of the hydrodynamic and structural solution at every time step. The whipping simulation tool must consist of hydrodynamic (seakeeping and slamming), structural and coupling part. In each of these parts, different modelling method could be adopted. Even separate modelling of nonlinear 


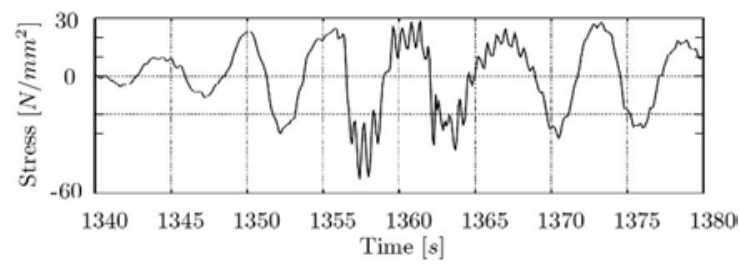

Figure 1. Measured stress during full-scale trials of the frigate (Tuitman 2010).

hydrodynamic part is very challenging. The procedure used for hydroelastic analysis utilises the potential flow theory for the hydrodynamic part, and 3D FE or beam model for the structural part. Nowadays, seakeeping models based on complex CFD calculations were developed. However, there are very sensitive to different numerical parameters and require huge CPU requirements.

Although the two-way coupled approach gives the most accurate results regarding whipping contribution, the one-way coupled approach could be adopted for the first estimation. This type of approach could be adopted in the initial design stage to avoid very complicated calculations. In the presented analysis, the hydrodynamic loading and structural response are assumed to be independent.

\section{SHIP MOTIONS ANALYSIS}

In the final strength assessment case, the three-dimensional seakeeping calculations are to be performed to obtain the ship motions. However, for the first estimation, the simplified ship motion closed-form expressions presented by Jensen et al. 2004 could be utilised, where the ship hull is considered non-deformable.

The frequency response functions for a box-shaped vessel can be derived analytically by the linear strip theory (Gerritsma and Beukelman 1964). The equations of motions (heave and pitch) for a given wave amplitude $a$ are equal to (Jensen 2001):

$$
\frac{2 k T}{\omega^{2}} \ddot{w}+\frac{A^{2}}{k B \alpha^{3} \omega} \dot{w}+w=a F \cos \left(\omega_{e} t\right) ; \frac{2 k T}{\omega^{2}} \ddot{\theta}+\frac{A^{2}}{k B \alpha^{3} \omega} \dot{\theta}+\theta=a G \sin \left(\omega_{e} t\right)
$$

where $k$ is the wave number, $\omega$ is the wave frequency, $B$ and $T$ are the breadth and draft of the box. The encounter frequency $\omega_{e}$ is equal to $\omega_{e}=\omega-k V \cos \beta=\alpha \omega$, where $V$ is the ships forward speed, $\beta$ is the heading angle (180 degrees for head sea), $\alpha=1-\left(\frac{k V}{\omega}\right) \cos \beta$.

The sectional hydrodynamic damping is modelled as a ratio between incoming and diffracted wave amplitude: $A=2 \sin \left(0.5 k B \alpha^{2}\right) \exp \left(-k T \alpha^{2}\right)$, the forcing functions $F$ and $G$ are then equal to:

$$
F=\kappa f \frac{2}{k_{e} L} \sin \left(\frac{k_{e} L}{2}\right) ; G=\kappa f \frac{24}{\left(k_{e} L\right)^{2} L}\left[\sin \left(\frac{k_{e} L}{2}\right)-\frac{k_{e} L}{2} \cos \left(\frac{k_{e} L}{2}\right)\right]
$$

where $k_{e}=|k \cos \beta|$ is the effective wave number and $f=\sqrt{(1-k T)^{2}+\left(\frac{A^{2}}{k B \alpha^{3}}\right)^{2}}$. The Smith correction factor $\kappa$ is taken approximately as $\kappa=\exp \left(-k_{e} T\right)$.

Solutions of Equations 1 result in frequency response functions: $\phi_{w}=\eta F ; \phi_{\theta}=\eta G$, where $\eta=\left(\left(1-2 k T \alpha^{2}\right)^{2}+\left(\frac{A^{2}}{k B \alpha^{2}}\right)^{2}\right)^{-\frac{1}{2}}$.

The resulting frequency response functions for the vertical motion $u=w \quad x \theta$ and the velocity $v=\omega_{e}(w-x \theta)$ in a longitudinal position, $x$ from the centre of gravity are equal to:

$$
\phi_{u}=\sqrt{\phi_{w}^{2}+x^{2} \phi_{\theta}^{2}} ; \phi_{v}=\omega_{e} \phi_{u}
$$


However, to evaluate the slamming load, one needs the relative vertical motion $r(x, t)$ concerning the wave elevation $h(x, t): r(x, t)=w(t) \quad x \theta(t) \quad h(x, t)$. The relative motion in a position $x$ is equal to:

$$
\phi_{r}=\sqrt{\left(\phi_{w}-\cos \zeta(x)\right)^{2}+\left(x \phi_{\theta}+\sin \zeta(x)\right)^{2}}
$$

where $\zeta(x)=\varepsilon_{e}+\varepsilon_{r}+k_{e} x$, and $\varepsilon_{e}$ and $\varepsilon_{r}$ need to satisfy the following terms:

$$
\cos \varepsilon_{e}=1-\frac{k T}{f} ; \sin \varepsilon_{e}=\frac{A^{2}}{k B \alpha^{3} f} ; \cos \varepsilon_{r}=\left(1-2 k T \alpha^{2}\right) \eta ; \sin \varepsilon_{r}=-\frac{A^{2}}{k B \alpha^{2}} \eta
$$

The presented equations are derived for the box-shaped floating object. To evaluate the ship motions, the breadth $B$ is replaced by the $B C_{b}$.

\section{BOW FLARE SLAMMING LOAD}

To estimate the slamming load acting on a bow of a containership, the simplified equations shown by Zhao and Faltinsen 1993 could be used. The bow hull geometry is treated as a wedge (see Figure 2a).

The impact force per unit length due to slamming in a particular moment can be approximated as:

$$
q(t)=3 C_{p} \rho v^{3} t_{s}
$$

where $C_{p}=\frac{\pi^{2}}{4 \tan ^{2} \alpha}$, is the dynamic pressure coefficient, $\rho$ is the water density, $\alpha$ is the deadrise angle of wedge section and $t_{s}$ is the time accounting for the water rise-up at maximum immersion, equal to:

$$
t_{s}=\frac{2 B_{l} \tan \alpha}{6 v}
$$

where $B_{l}$ is the local breadth, which could be calculated equal to $B_{l}=\frac{\Delta H}{\tan \alpha}$, and $\Delta H=0.75$ (Depth Draft) in $\mathrm{m}$.

The section which represents the slamming section could be taken at the location $x=0.95 \mathrm{~L}$. The deadrise angle $\alpha$ is a mean from the four points as presented in Figure $2 \mathrm{~b}$.

\section{NUMERICAL EXAMPLE}

\subsection{Analysed ship}

As a reference model for the whipping analysis, the 14500 TEU container ship has been chosen. The ship dimensions are: length between perpendiculars of $347 \mathrm{~m}$, breadth of $48.2 \mathrm{~m}$, depth of $29.85 \mathrm{~m}$ and the general arrangement of the ship is presented in Figure 3 .

a)

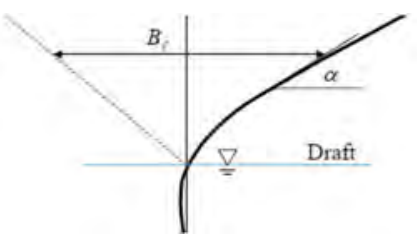

b)

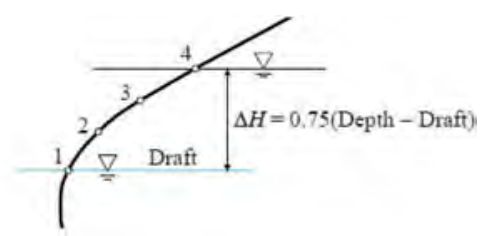

Figure 2. Deadrise angle and local breadth of wedge section a) and calculation procedure b) (American Bureau of Shipping 2014). 


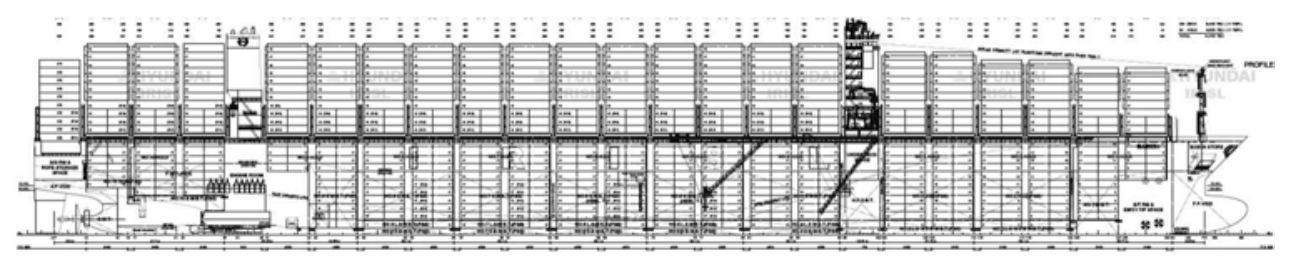

Figure 3. The general arrangement of the container ship.

\subsection{Slamming force}

The 25-year significant wave height is considered as presented in IACS Recommendation 34 (International Association of Classification Societies 2001), considering regular wave. The slamming force is calculated for all wave periods, and the wave height, which maximises the slamming force, is chosen. Figure 4 presents the dependency between the wave period and the slamming force.

The maximum slamming force is for a wave height of $15.3 \mathrm{~m}$ and a period of 11.5 seconds. For that wave height, one can consider the $0.25 \mathrm{~V}$ as a ship speed. The service speed for the considered ship is equal to 22 knots, so 5.5 knots is the velocity for a particular wave height.

The wave length can be estimated equal to:

$$
\lambda=\frac{2 \pi g}{\omega^{2}}=\frac{2 \pi 9.81}{0.5236^{2}}=224.8 \mathrm{~m}
$$

The encounter frequency for a considered case is equal to $0.5236 \mathrm{rad} / \mathrm{sec}$. The coefficient of sectional hydrodynamic damping $A$ is calculated equal to 0.3541 . The forcing functions $F$ and $G$ are equal to 0.38592 and 0.005624 , respectively. The resulting ship motions are as follows: bow motion $-10.355 \mathrm{~m}$, bow velocity $-5.973 \mathrm{~m} / \mathrm{s}$, relative bow motion $-17.638 \mathrm{~m}$, relative bow velocity $-10.175 \mathrm{~m} / \mathrm{s}$. The latter value is used to calculate the slamming load.

The slamming section's local breadth is equal to $11.3 \mathrm{~m}$, and the deadrise angle is equal to 45.6 degrees. The maximum slamming force is equal to:

$$
F_{S L}=0.01 L \frac{\pi^{2}}{\tan ^{2} \alpha} \rho v^{2} \Delta H=0.01 \cdot 347 \frac{\pi^{2}}{\tan ^{2} 45.6} 1.025 \cdot 10.175^{2} \cdot 11.51=40.23[M N]
$$

\subsection{FE model}

Based on the information about weight distribution and the longitudinal variation of the cross-sectional moment of inertia, the beam model employing CBEAM elements and

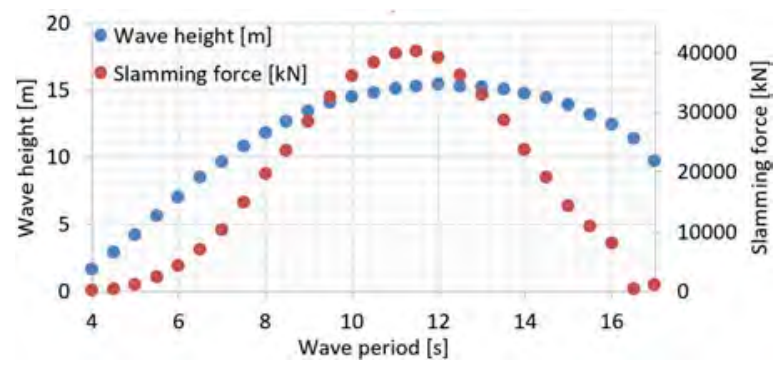

Figure 4. Slamming force in the function of wave period. 


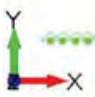

Figure 5. FE model of the container ship with the applied load.

commercial software FEMAP has been prepared. The assessment of dynamic transient response is done with the assumption that the bending moments generated by the slamming load could be superimposed with the still water and wave-induced bending moments. Nevertheless, one needs to consider missing boundary conditions. It is well known that the ship hull can be considered as a beam with spring supports. Each node is supported by the spring element having two characteristics: stiffness and damping. The sectional stiffness can be calculated from the buoyancy force:

$$
k_{i}=\rho g B_{i} l_{i}
$$

where $B_{i}$ is the ship breadth on the waterline in the longitudinal position of the considered node and $l_{i}$ is the mean length of the adjacent elements.

Furtherly, the sectional hydrodynamic damping can be calculated as follows:

$$
b_{i}=2 A \sqrt{k_{i} m_{i}}
$$

where $A$ is the hydrodynamic sectional damping, $k_{i}$ is the hydrodynamic sectional stiffness calculated from Eq. 10 and $m_{i}$ is the total mass of the considered section.

Lastly, it needs to be pointed that during ship vibrations, not only the hull mass is oscillating, but hull induces the acceleration of some amount of fluid mass. This effect is needed to be included as additional inertia to the system, and it is well-known as a so-called 'added mass'. The added mass of the section is assumed as a mass of displaced water. The added mass is incorporated in the FE model by adding non-structural mass to the beam elements.

The slamming time-history is modelled as a linear function starting from a zero value at the moment that bow is hitting the wave up to the maximum value within the time $t_{s}$ as calculated by Eq. 7, and then drops to 0 value again. The total duration of the simulation is taken 5 seconds, as a multiplication of a couple of vibration periods of the lowest natural mode, which was obtained by solving an eigenvalue problem. Furtherly, the time step has been derived as a fraction of one of the highest natural modes. The beam FE model with the applied slamming load as a nodal force is presented in Figure 5.

\section{RESULTS AND DISCUSSION}

The bending moment time-histories for each section are derived. In Figure 6, the bending moment charts for sections in $1 / 4$, half and $3 / 4$ of the ship length are presented. Notable, in the midship section, the bending moment is dominated by 2-node vibrations. In the case of sections in $0.25 \mathrm{~L}$ and $0.75 \mathrm{~L}$, the bending moment results from the superposition of 2-node and 3-node vibrations. Apart from these major contributors, the influence of other vibration modes is visible too. The bending moment is in the range between -2000 MNm up to $2000 \mathrm{MNm}$.

Nevertheless, the maximum bending moment is obtained for the section located in $0.4 \mathrm{~L}$. The value of the maximum bending moment is equal to $2509 \mathrm{MNm}$ in hogging condition. In the case of the sagging condition, the maximum bending moment is equal to $2304 \mathrm{MNm}$.

To see the influence of whipping-induced bending moment, the maximum value from Section 6 is compared with the wave-induced bending moments calculated in accordance with IACS UR S11A (International Association of Classification Societies 2015). 


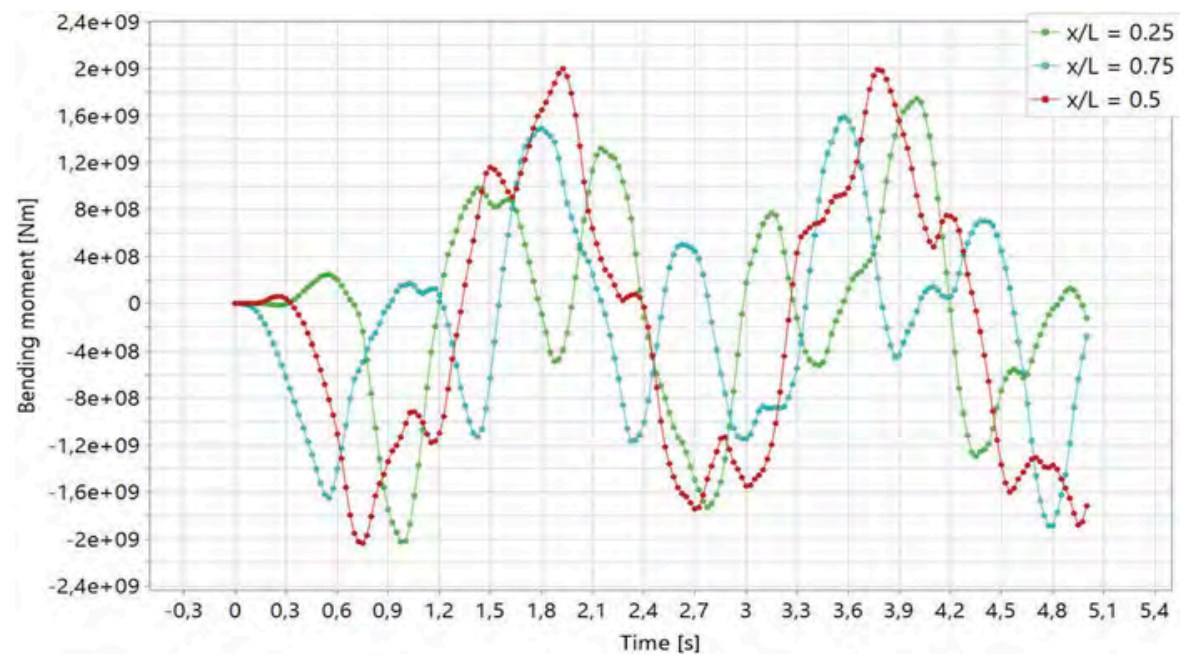

Figure 6. The bending moment $[\mathrm{Nm}]$ time-history for cross-sections $\mathrm{x}=0.25 \mathrm{~L}, \mathrm{x}=0.5 \mathrm{~L}$ and $\mathrm{x}=0.75 \mathrm{~L}$.

Table 1. Influence of whipping moment in the total dynamic bending moment.

\begin{tabular}{|c|c|c|c|c|}
\hline & $\begin{array}{l}\text { Wave-induced } \\
\text { moment } M_{w}\end{array}$ & $\begin{array}{l}\text { Whipping bending } \\
\text { moment } M_{\text {whip }}\end{array}$ & $M_{w h i p} / M_{w}$ & $\begin{array}{l}\text { Total bending } \\
\text { moment }\end{array}$ \\
\hline & [MNm] (UR S11A) & {$[\mathrm{MNm}]$} & {$[\%]$} & {$[\mathrm{MNm}]$} \\
\hline Hogging & 8462 & 2509 & 29.7 & 10971 \\
\hline Sagging & 9233 & 2304 & 25.0 & 11537 \\
\hline
\end{tabular}

The comparison of whipping contribution for both sagging and hogging condition is presented in Table 1.

It could be concluded that whipping phenomena significantly impact the total dynamic bending moment and need to be considered from the beginning of the analysis of the strength of container ships. Nevertheless, when compared with the fully coupled analysis (Tuitman 2010, Malenica and Derbanne 2014), the whipping influence could be possibly overestimated.

\section{CONCLUSIONS}

The presented work investigated the whipping influence on the container ship's longitudinal strength, using a simplified approach. Compared to the more advanced techniques, the proposed method was swift and practical, especially when considering initial design stages. The calculated influence of whipping bending moment into the wave-induced bending moment reached the level of $30 \%$, which seems to be overestimated value when compared to the fully coupled analysis, which could lead to the conservative design. The maximum bending moment has been achieved in the section lying on the 0.4 lengths of the ship and not in the middle. The 2-node vibrations were the main component influencing the bending moment in the midship cross-section, whereas, in the case of sections located in the $1 / 4$ and $3 / 4$ of the ship's length, both 2 -node, as well as 3 -node vibration modes, contributed to the bending moment value. 


\section{REFERENCES}

Aalberts P.J., and Nieuwenhuijs M. 2006. Full scale wave and whipping induced hull girder loads. In 4th. Int. Conf. on Hydroelasticity. Wuxi, China.

American Bureau of Shipping. 2014. Guidance notes on whipping assessment for container carriers.

Barhoumi, M., and Storhaug, G. 2014. Assessment of whipping and springing on a large container vessel. International Journal of Naval Architecture and Ocean Engineering. 6(2): 442-458.

Bian, X., Cheng, C., Jiang, J., Chen, R., Chen., Y. 2016. Numerical analysis of soil vibrations due to trains moving at critical speed. Acta Geotechnica, 11: 281-294.

Gaidai, O., Storhaug, G., and Naess, A. 2016. Extreme large cargo ship panel stresses by bivariate ACER method. Ocean Engineering, 123: 432-439.

Gerritsma, J., and Beukelman, W. 1964. The distribution of the hydrodynamic forces on a heaving andpitched shipmodel in still water. International Shipbuilding Progress. 11(123): 506-522.

International Association of Classification Societies. 2001. Recommendations. 34. Standard Wave Data.

International Association of Classification Societies. 2015. Unified Requirements. S11A. Longitudinal Strength Standard for Container Ships.

Jensen, J. J. 2001. Load and global response of ships. Elsevier.

Jensen, J. J., Mansour, A. E., \& Olsen, A. S. 2004. Estimation of ship motions using closed-form expressions. Ocean Engineering. 31(1): 61-85.

Malenica, S., and Derbanne, Q. 2014. Hydro-structural issues in the design of ultra large container ships. International Journal of Naval Architecture and Ocean Engineering. 6(4): 983-999.

Mao, W., Li, Z., Ogeman, V., \& Ringsberg, J. W. 2015. A regression and beam theory based approach for fatigue assessment of containership structures including bending and torsion contributions. Marine Structures. 41: 244-266.

Storhaug, G., Malenica, S., Choi, B. K., Zhu, S., \& Hermundstad, O. A. 2010. Consequence of whipping and springing on fatigue and extreme loading for a 13000TEU container vessel based on model tests. In 11th International Symposium on practical design of ships and other floating structures. Rio de Janeiro, Brazil (pp. 19-24).

Tuitman, J. T. 2010. Hydro-elastic response of ship structures to slamming induced whipping (Doctoral dissertation, Dissertation of Delft University of Technology).

Wang, T. L., Huang, D., Shahawy, M. 1992. Dynamic response of multigirder bridges. Journal of Structural Engineering. 118(8): 2222-2238.

Zhao, R., and Faltinsen, O. 1993. Water entry of two-dimensional bodies. Journal of Fluid Mechanics. 246: 593-612. 
Cold-formed elements and structures 


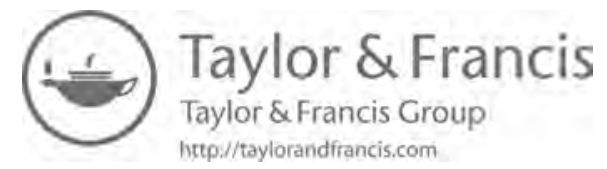




\title{
Cold-formed perforated uprights: Experimental evaluation of M-N domains
}

\author{
N. Baldassino, M. Bernardi \& R. Zandonini \\ Università di Trento, Trento, Italy
}

\begin{abstract}
Adjustable pallet rack systems are framed structures made of cold-formed steel profiles. The columns of these systems usually are open mono-symmetric perforated profiles. Their design ask for a mixed approach, which combines experimental and analytical evaluations. In service conditions, uprights are mainly subjected to a combination of axial force and bending moments. The main features of these profiles and their variability in terms of sections geometry and layout of perforations stress the need of ad hoc investigations. The study presented in this paper focuses on a typical commercial rack upright, which was experimentally investigated under 'pure compression' and under a combination of axial load and bending moment, assigned by applying eccentric compression loads. Specimens with a length of 1 meter were studied and a total of 9 eccentricities were considered. Results allowed drawing the normalized $\mathrm{M}-\mathrm{N}$ domains, pointing out the remarkable interaction between axial load and bending moment.
\end{abstract}

\section{INTRODUCTION}

The research presented in this paper focuses on the cold-formed steel profiles commonly adopted as columns in steel storage pallet rack systems. These profiles (commonly known as uprights) are characterized by a 'C'-like stiffened open section and, to allow the connection of the beams, are provided by a regular pattern of perforations along their length (Moen 2008). The cold-forming process locally modifies the steel mechanical properties (Dubina et al. 2013) and results in geometrical imperfections that affect the performance of the profiles. The slenderness of the uprights make them highly sensitive to different types of buckling, i.e. local, distortional, and global buckling singularly or in combination (Dinis et al. 2014). The open sections, generally characterized by a single axis of symmetry and by a shear centre not coincident with the centroid, make these profiles sensitive as well to torsional instability phenomena. The main Standards for the design of cold-formed profiles provide rules for the uprights' safety checks, but their accuracy is limited to unperforated elements with non-complex sections that respect fixed limits in terms of width-to-thickness ratios (EN 1993-1-3:2005). When these requirements are not met, the 'design by testing' approach is suggested by the Standards (Baldassino \& Zandonini 2011). Following this procedure, tests allow calculating members and sub-assemblies performances to be adopted in design. As to the rack uprights, being the profiles perforated, the reference standard EN 15512:2009 suggests a mixed analyticalexperimental approach. Bending and compression tests are required to evaluate the effective sections properties, i.e. effective section moduli and effective area. In case of compression tests, a key issue is the identification of the centroidal axis of the member. In fact, the presence of complex patterns of perforations along the length of the elements results in different resistance sections with different geometrical properties. Therefore, it is not possible to define a unique centroid for the profile (Baldassino \& Zandonini 2011). Buckling phenomena add

DOI: $10.1201 / 9781003132134-17$ 
complexity to the problem, since inducing additional changes of the effective resistance of the cross-section. To solve this problem, EN 15512:2009 suggests to select the load application point as the one associated to the maximum collapse axial force. Furthermore, to evaluate the sensitivity of the members to the different buckling modes compression tests on specimens of different lengths are also required to define the buckling curves.

The experimental evaluation of the profile's performance under pure compression or pure bending does not allow taking into account the combination between them. Nevertheless, it should be stressed that uprights are usually subjected to combined axial and bending moments. The limited number of studies performed on this topic, although clearly pointed out the importance of the bending-compression interaction, are related to a narrow range of uprights sections (Bonada et al. 2016, Bertocci et al. 2017, Baldassino et al. 2020). As a consequence, the outcomes of these studies cannot be generalized to all the typical available sections and, at this purpose, further analyses are required.

This paper presents the main features and results of an experimental study performed on a typical cold-formed perforated open upright section. Specimens with a length of 1 meter were tested under 'pure compression' and under a combination of compression and bending, assigned by applying eccentric compression loads. At this aim, nine load eccentricities were considered. The tests outcomes allowed defining the $\mathrm{M}-\mathrm{N}$ resisting domains.

\section{THE EXPERIMENTAL PROGRAMME}

\subsection{The specimens}

The specimens were a typical cold-formed rack upright profile with a mono-symmetric perforated open section. Figure 1 shows a simplified drawing of the section (Figure 1a) and of the perforation system of the profile (Figure 1b). The nominal steel grade was S350GD (EN 19931-3:2005) and the thickness was of $1.45 \mathrm{~mm}$. For sake of confidentiality, the geometrical and mechanical properties of the specimens are not explicitly reported in this paper.

Specimens had a length of 1 meter, selected according to the typical height of the bracing panels in the cross-aisle direction, i.e. the transversal direction, of racks. Both ends of the specimens were welded to a square steel plate with a side of $220 \mathrm{~mm}$ and a thickness of $5 \mathrm{~mm}$, to allow connection with the testing set-up and the application of the load. To consider the interaction between axial force and bending moment, tests were carried out under eccentric loading conditions. At this aim, different relative positions between the centroid of the plates and the centroid of the upright gross section were selected in the $y-y$ and $z-z$ directions (Figure 1). In the $\mathrm{z}-\mathrm{z}$ direction, due to the symmetry of the section, only positive eccentricities with nominal values $\left(e_{n, z-z}\right)$ of $+15 \mathrm{~mm},+30 \mathrm{~mm}$ and $+42 \mathrm{~mm}$ were assigned (Figure 2). Nominal eccentricities $\left(e_{n, y-y}\right)$ of $-10 \mathrm{~mm},-20 \mathrm{~mm},-30 \mathrm{~mm},-40 \mathrm{~mm},+10 \mathrm{~mm}$ and $+20 \mathrm{~mm}$ were adopted in $y$-y direction (Figure 2). The values of the eccentricities were selected to apply the axial load within the sectional perimeter and taking into account the dimensional limits of the steel

a)

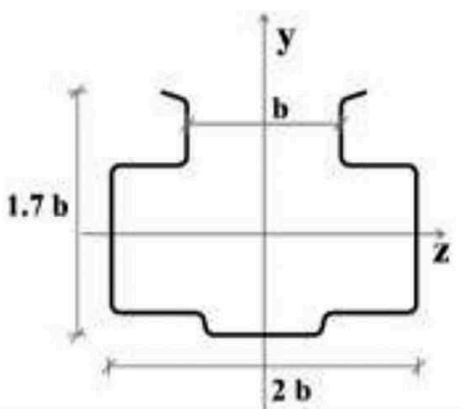

b)

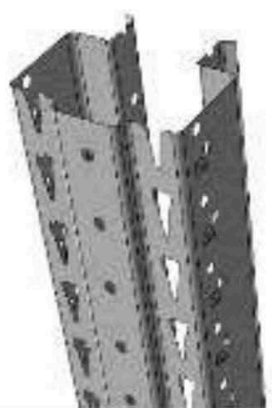

Figure 1. Uprights section and perforation system. 


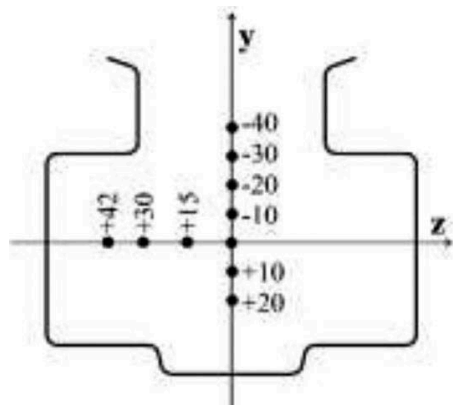

Figure 2. Eccentricities considered in the tests (dots represent the load application points).

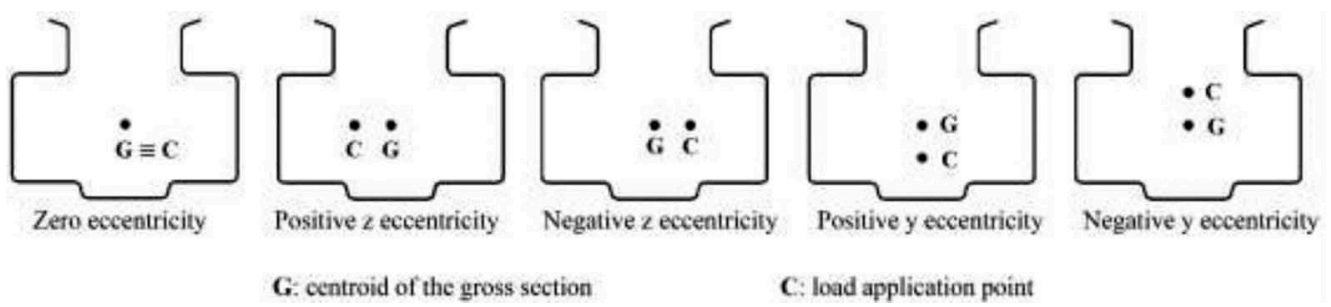

Figure 3. Convention adopted for positive and negative eccentricities.

plates welded at the ends of the specimens. For comparison purposes, the case of zero nominal eccentricity was also considered. Zero eccentricity means that the centroid of the plates was coincident with the centroid of the gross section of the column to allow the application of 'pure compression'. Figure 3 shows the convention adopted for the definition of positive and negative eccentricities.

\subsection{The experimental set-up and the testing procedure}

Figure 4 presents the experimental set-up adopted in the tests. The specimen was hinged and warping prevented at both the ends. During the test the applied load was measured by using a loading cell with a maximum capacity of $600 \mathrm{kN}$ in class 0.5 according to EN ISO 376. In addition, the vertical displacement of the top end of the specimen was measured by means of two $50 \mathrm{~mm}$ displacement transducers with a linearity of $0.1 \%$ (Figure 4 ). Before the test, all the specimens were measured to evaluate the assigned eccentricity, which had a mean deviation respect to its nominal value was less than $1.50 \%$.

The testing procedure consisted of two phases: an initial loading and unloading cycle up to $10 \%$ of the expected failure load and a subsequent load increasing up to the collapse of the specimen. The expected failure load was evaluated by a preliminary test. A total number of 50 tests were performed: five for each load case.

\subsection{Main results}

Independently on the load eccentricity, distortional instability activated the collapse of the specimens, as shown in Figure 5, which presents a collapsed specimen for the case of load eccentricity of $-40 \mathrm{~mm}$ in $y-y$ direction. Tests results are presented in Figures 6 and 7, which refer to $z-z$ and $y-y$ direction of eccentricity, respectively. In the figures, for each eccentricity, the mean value of the adimensionalised collapse loads (n) is reported. 


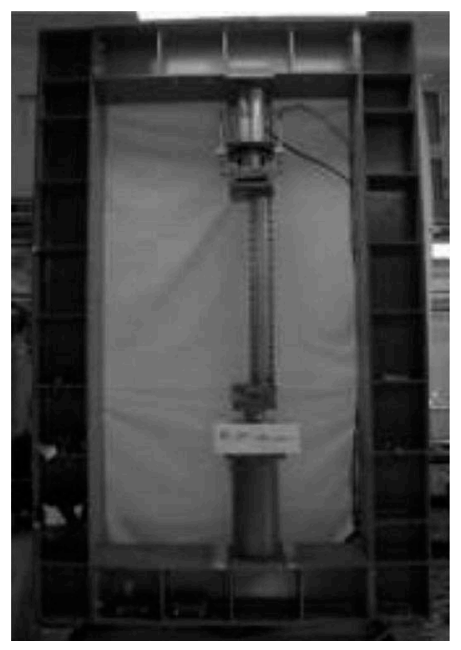

Figure 4. Experimental set-up.
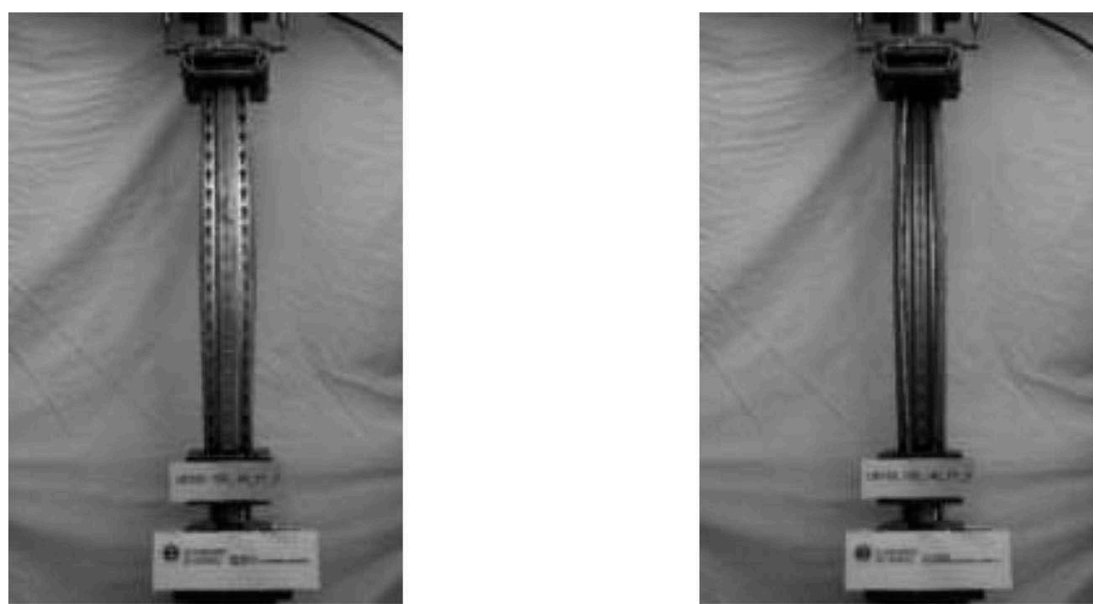

Figure 5. Distortional collapse of a specimen.

The collapse loads were normalised with respect to the nominal sectional load carrying capacity, i.e. $A_{g} f_{y}$, where $A_{g}$ is the gross area of the upright section and $f_{y}$ is the nominal yielding steel strength. Independently on the eccentricity direction, a quite limited scatter of the experimental results was observed, with a maximum value of standard deviation equal to 0.013 . To underline the influence of the eccentricity on the collapse loads for each eccentricity, the percentage variation respect to the 'pure compression' case is reported in the figures, pointing out the significant influence of the eccentricity, i.e. of the bending moment. By increasing the eccentricity, an approximately linear decrease of the collapse loads can be observed. In $\mathrm{z}-\mathrm{z}$ direction, negative eccentricities, moving the load application point towards the rear flanges, affect to a greater extent the bearing capacity than positive eccentricities.

Results allowed evaluating the bending moment - axial force adimensionalised domains $(\mathrm{m}-\mathrm{n})$ that are presented in Figures 8 and 9. 


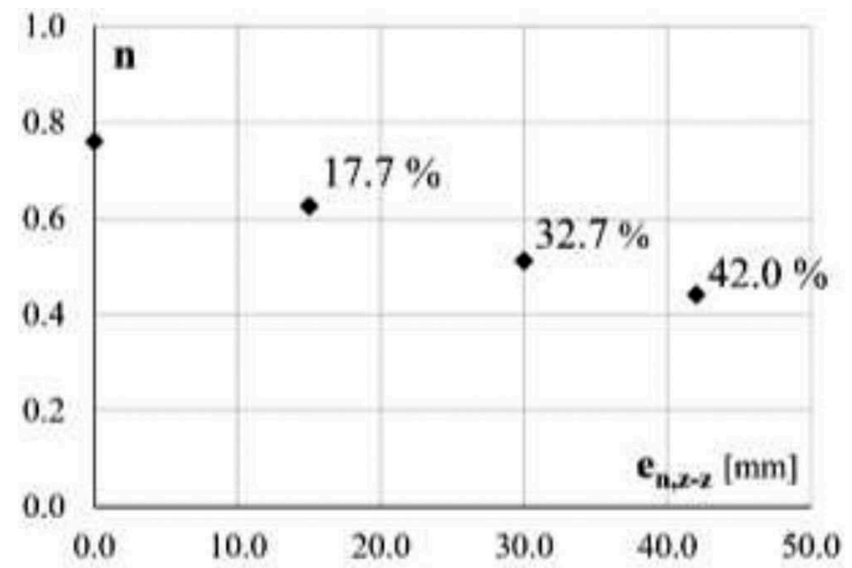

Figure 6. Collapse load vs. z-z eccentricity.

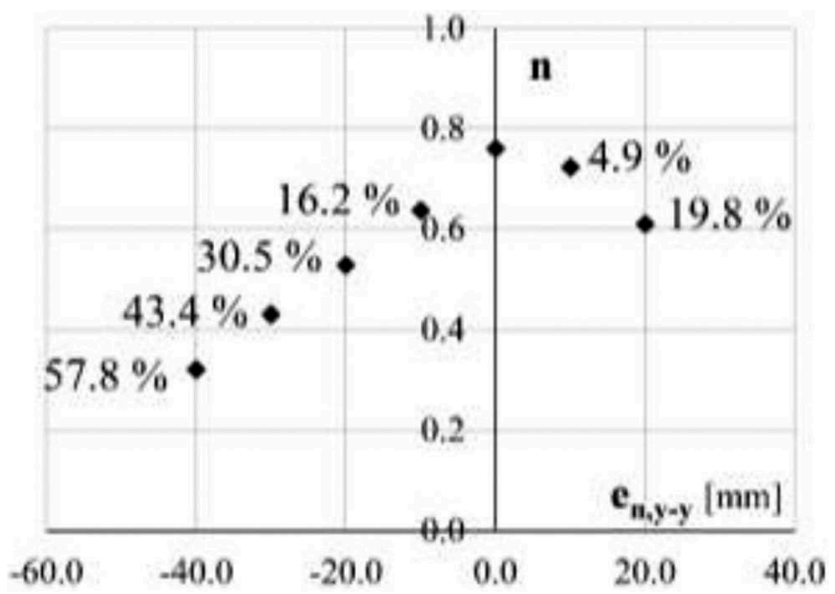

Figure 7. Collapse load vs. y-y eccentricity.

Figure 8 refers to the $z-z$ eccentricities while Figure 9 to the $y-y$ direction. As previously reported, the axial load is normalized with respect to the nominal load carrying capacity of the gross cross-section. In a similar manner, the bending moment is normalized with respect to the relevant bending capacity of the cross-section, i.e. $\mathrm{W}_{\mathrm{g}} \mathrm{f}_{\mathrm{y}}$, where $\mathrm{W}_{\mathrm{g}}$ is the section modulus of the gross section and $\mathrm{f}_{\mathrm{y}}$ is the nominal yielding steel strength. For the $y$-y direction, the minimum section modulus was considered. In the case of $z-z$ direction (Figure 8), due to the symmetry of the section, to obtain the domain for the negative eccentricities, the domain for positive eccentricities was mirrored with respect to the $\mathrm{n}$ axis. The figures clearly point out the non-negligible interaction between axial force and bending moment, which appears more evident for the $y$-y direction. In this case, negative eccentricities (i.e. the load application point moves away from the web of the section) are more penalizing than positive ones. In particular, the eccentricity of $-30 \mathrm{~mm}$ identifies a sort of 'limit', beyond which an increase of resisting bending moment is not possible. Eccentricities greater than $-30 \mathrm{~mm}$ correspond in fact to load application points in the area of the rear flanges, outside the ' $\mathrm{C}$ '-section perimeter (Figure 2). 


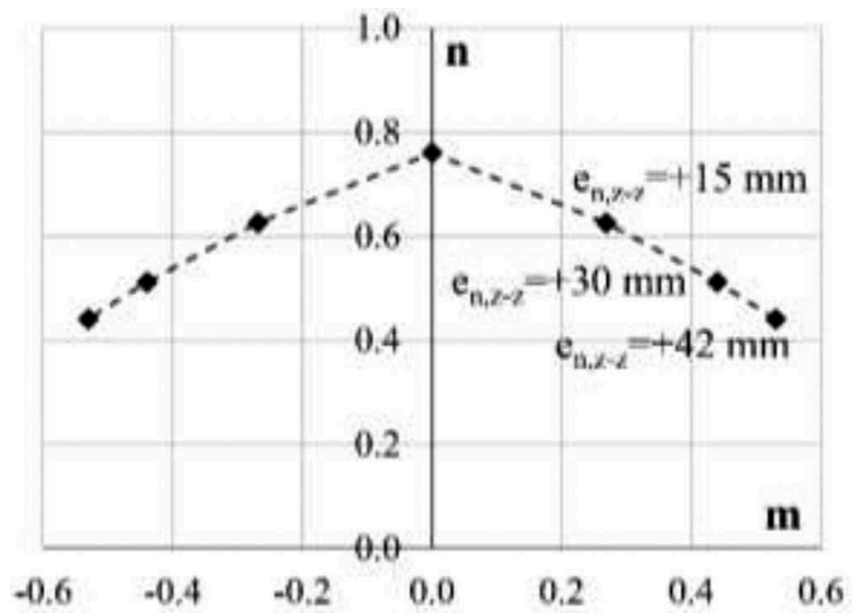

Figure 8. Adimensionalised M-N domain (m-n) for $z-z$ direction.

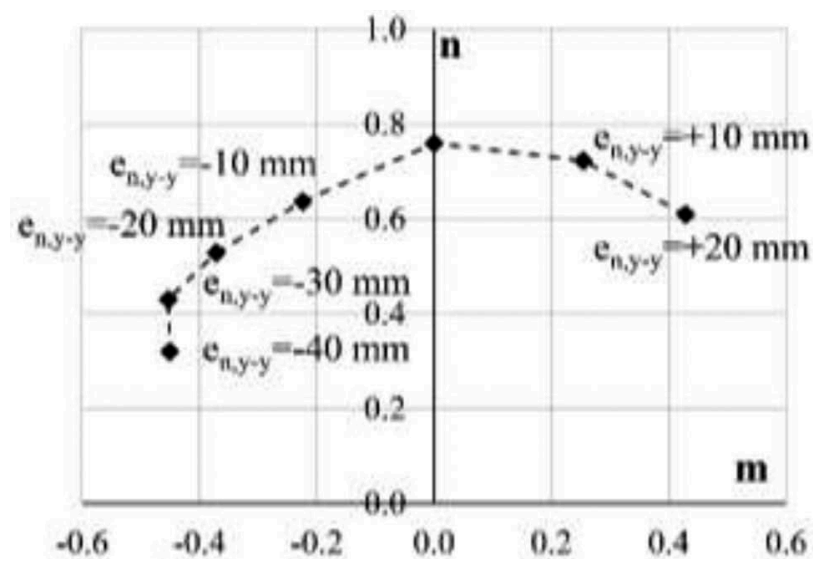

Figure 9. Adimensionalised M-N domain (m-n) for $y-y$ direction.

\section{CONCLUDING REMARKS}

This paper presents an experimental study of the response of a commercial rack perforated upright under compression forces. The purpose of the study was the evaluation of the interaction between axial force and bending moment. At this aim, the experimental programme comprised tests on specimens with a length of 1 meter subjected to 'pure compression' and eccentric compression. The 'pure compression' cases had the load application point coincident with the centroid of the gross cross-section. Eccentric tests were obtained by moving the load application point along the principal axes of the section. A total of 9 eccentricities were considered. In all cases, distortional buckling triggered the collapse of the specimens. Experimental results pointed out a non-negligible influence of the eccentricities on the collapse load. By assuming the 'pure compression' case as a reference, a maximum reduction of the collapse load equal to $42.0 \%$ and $57.8 \%$ were observed for eccentricities along the non-symmetry and symmetry section axes, respectively. Results allowed drawing the adimensionalised M-N domains, pointing out the significant interaction between axial load and bending moment. 


\section{ACKNOWLEDGEMENTS}

The Authors gratefully acknowledge the work by the laboratory technicians of the University of Trento Stefano Girardi and Marco Graziadei and the contribution of the company Metalsistem S.p.A. that provided the upright specimens.

\section{REFERENCES}

Baldassino, N., Bernardi, M., Bernuzzi, C. \& Simoncelli, M., 2020. Perforated TWCF steel beam-columns: European design alternatives. Steel and composite structures 35(5): 701-715. http://dx. doi.org/10.12989/scs.2020.35.5.701.

Baldassino, N. \& Zandonini, R., 2011. Design by testing of industrial racks, Advanced Steel Construction 7(1): 27-47. https://doi.org/10.18057/IJASC.2011.7.1.3.

Bertocci, L., Comparini, D., Lavacchini, G., Orlando, M., Salvatori, L. \& Spinelli, P., 2017. Experimental, numerical, and regulatory $\mathrm{P}-\mathrm{M}_{\mathrm{x}}-\mathrm{M}_{\mathrm{y}}$ domains for cold-formed perforated steel uprights of pallet-racks. Thin-Walled Structures 119: 151-165. https://doi.org/10.1016/j.tws.2017.06.001

Bonada, J., Pastor, M.M., Roure, F. \& Casafont, M. 2016. Distortional influence of pallet rack uprights subject to combined compression and bending. Structures 8: 275-285. https://doi.org/10.1016/j. istruc.2016.05.007.

Dinis, P.B., Young, B. \& Camotin, D. 2014. Local-distortional interaction in cold-formed steel rack-section column, Thin-Walled Structures 81: 185-195. https://doi.org/10.1016/j.tws.2013.09.010.

Dubina, D., Ungureanu, V. \& Landolfo, R., 2013. Design of Cold-Formed Steel Structures. Eurocode 3: Design of Steel Structures-Part 1-3 Design of Cold-Formed Steel Structures, Brussels, Belgium: ECCS European Convention for Structural Steelworks and Berlin, Germany: Wilhelm Ernst \& Sohn.

EN1993-1-3:2005. Eurocode 3 - Design of steel structures - Part1-3: General rules: supplementary rules for cold-formed members and sheeting. Brussels, Belgium: European committee for Standardization.

EN15512:2009. Steel storage systems - Adjustable pallet racking systems - Principle for structural design. Brussels, Belgium: European committee for Standardization.

Moen, C.D. 2008. Direct Strength design of cold-formed steel members with perforations. Ph.D. Dissertation, Johns Hopkins University, Baltimore, Maryland.

UNI EN ISO 376:2011. Materiali metallici - Taratura degli strumenti di misurazione della forza utilizzati per la verifica delle machine di prova uniassiali. Milano, Italy: Ente Italiano di Normazione UNI. 


\title{
Design of semi-compact Z-shaped steel sheet pile walls
}

\author{
A. Enders \& U. Kuhlmann \\ Institute of Structural Design, University of Stuttgart, Stuttgart, Germany
}

\begin{abstract}
To benefit from the potentials in the bending moment capacity of semicompact Z-shaped steel sheet piles forming the infills of combined walls, four-point bending tests were carried out by the Institute of Structural Design at the Materials Testing Institute in Stuttgart in 2019. A FE-model was validated by back-calculating the tests followed by an extensive parametric study with different Z-piles. Among others the different geometries, which lead to different b/t-ratios and the steel grade were varied leading to a different compression flange slenderness. In addition, the lock state was varied to investigate the impact on the bending moment capacity as: Free lock rotation, crimped interlocks with different crimping densities and fully welded over the entire length. Three resistance models were investigated and evaluated for further development of Eurocode 3 Part 5.
\end{abstract}

\section{MOTIVATION}

Steel sheet piles are often used as infill of combined walls with H-piles as primary elements for quay walls in harbour constructions or as excavation support in civil engineering. The piles are connected with interlocks and are driven besides each other into the soil, so that they are forming a continuous wall. Among U-steel sheet piles also Z-shaped piles with free interlocks or crimped interlocks are widely used for these constructions. The sections of steel Z/U-piles and interlocks are schematically shown in Table 1.

The pressure of costs and efficiency and the competition with concrete solutions lead to necessary developments in the design of steel sheet pile walls for further economic steel solutions. New developments due to the bending moment resistance of semi-compact cross-section are included in the draft of EC-3 Part 1-1 (2020), considering elastic-plastic section modulus for the resistance of steel cross-section in buildings which are classified between cross-section class 2 and 3. To ensure consistency between the new drafts of Eurocode 3 Part 1-1 and Part 5 and to provide economical elastic-plastic resistance for Z-piles, experimental and numerical investigations were executed within the FOSTA project P1327.

\section{FOUR-POINT BENDING TESTS (4-PBT) AT THE UNIVERSITY OF STUTTGART}

The 4-PBT aimed to investigate the bending moment capacity of Z-shaped piles and the influence of crimped interlocks. In addition, a FE-Model should be validated for further numerical investigations. The test specimens were planned approximately between the $\mathrm{b} /(\mathrm{t} \cdot \varepsilon)$-ratios 45 and 66 , which are the current limits for class $2 \& 3$ and class $3 \& 4 \mathrm{Z}$-shaped cross-sections according to Eurocode 3 part 5 (2007). In sum, six 4-PBT were executed, where four double piles were with free interlocks and two were crimped. At least the double Z-piles of Test No. (3) to (6) can be defined as 'compact' and the piles of Test No. (1) and (2) are 'semi-compact'. Table 2 shows the actual elastic and plastic bending moments, which 
Table 1. U- and Z-shaped steel sheet pile sections as a single- and double-pile with interlock detail, cf. Eurocode 3 Part 5 (2007) and EN 10248 (2006).

Single Pile $\quad$ Double Pile $\quad$ Single Pile

Table 2. Tensile test results, actual resistance values in bending and cross-section classification.

\begin{tabular}{lllll}
\hline & & $\begin{array}{l}\text { actual plastic and elastic } \\
\text { bending moment in } \mathrm{kNm} \\
\mathrm{M}_{\text {act,pl }} \mid \mathrm{M}_{\text {act,el }}\end{array}$ & $\mathrm{b} /(\mathrm{t} \cdot \varepsilon)$ ratio & $\begin{array}{l}\text { class according } \\
\text { EC 3-5 }\end{array}$ \\
\hline$(1)$ & 514.8 & $1092 \mid 895$ & 56 & 3 \\
$(2)$ & 522.4 & $1247 \mid 1038$ & 49 & 3 \\
$(3)$ & 472.7 & $2830 \mid 2409$ & 40 & 2 \\
$(4)$ & 473.5 & $2830 \mid 2409$ & 40 & 2 \\
$(5)$ & 455.4 & $3510 \mid 2984$ & 33 & 2 \\
$(6)$ & 455.4 & $3450 \mid 2910$ & 33 & 2 \\
\hline
\end{tabular}

were determined with the actual geometry and yield strength, the corresponding $b /(t \cdot \varepsilon)$-ratio and the material properties. The material properties were determined with small-sample tensile tests according to ISO 6892-1 (2017). The geometry of the small tensile samples corresponded with DIN 50125-1 (2016), where the location within the section was in accordance with EN 10248 (2006).

Similar 4-PBT with industry partners were executed by Kuhlmann \& Just (2017a) with slender sheet profiles. The test setup proved to be reliable and positive experience was available, thus the general test setup was not changed. An overview of the test setup and the static system is shown in Figure 1. The test setup consisted of a frame construction made of steel (1), which was anchored in the strong floor. Two hydraulic cylinders (2) were suspended in vertical direction and attached on the horizontal beam of the frame (1). The load was introduced centered in vertical direction by the hydraulic cylinders (2) and was transferred over the distributing steel plates (4) and the H-beams (5) into the supports (6. A spherical bearing (3) was located between the hydraulic cylinder and the distributing steel plate (4) to allow rotation and avoid restraints.

The support units (9) were anchored in the strong floor. Between the support units and the test specimen (7) a sliding bearing was placed, which consisted of two Teflon layers (8) and a roller bearing. This setup allowed an almost friction-free support and a free rotation of the end plates. The distance of the supports (6) was chosen with $1.0 \mathrm{~m}$ in longitudinal direction and the distance between the support units (9) was $8.0 \mathrm{~m}$. Inclinometers $\mathbb{A}$ and displacement transducers (1) were used for the measurements between axis (B) and (C). While loading linear strain gauges recorded the strains in longitudinal direction and provided data of the stress distribution in the section. In total, 16 strain gauges per test were used, where 4 gauges were glued on the top and bottom flange and the rest of the gauges were equally distributed over the web. Rotations were measured at the endplates of the test specimen in axis (A) and (D) as well as in the middle of the double Z-pile in axis (B) and (C). The results of the experiments are shown in $\mathrm{M}-\varphi$-diagrams, see Figure 2.

The semi-compact Z-piles from the tests (1) and (2) - which are classified as class 3 sections reached bending moments, which are higher than the actual elastic bending moments. The difference between the crimped and free interlock profiles in the bending moment capacity was 


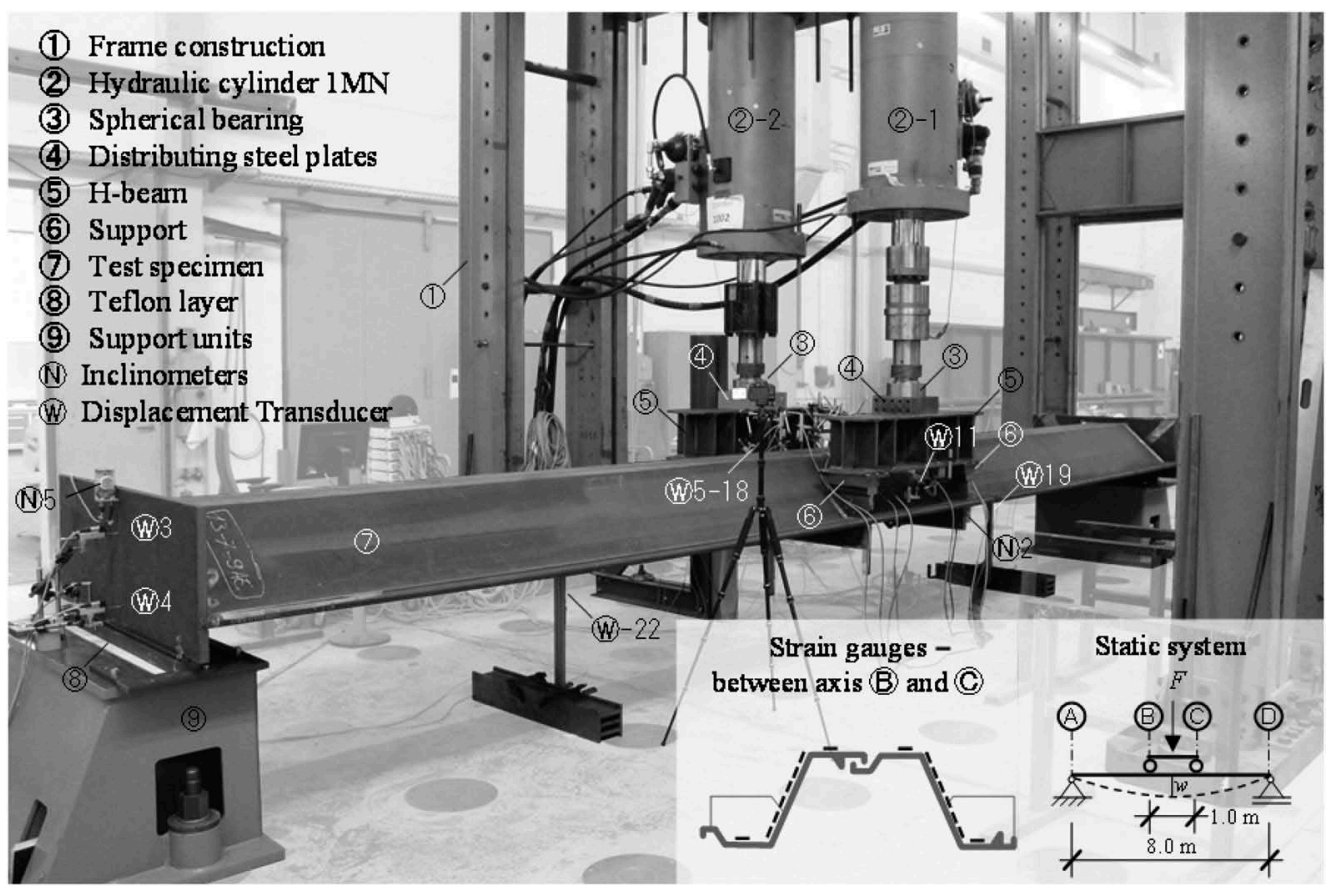

Figure 1. Test setup of the 4-PBT at the University of Stuttgart.

low, because the distance of the three crimping point repetition, which was chosen with $700 \mathrm{~mm}$, was large, cf. Figure 2 tests (3) with (4) and (5) with (6). The bending moment capacity of the tests (3) and (4) was lower than the actual plastic bending moment, though the b/ $(t \cdot \varepsilon)$-ratio was lower than 45. Similar observations were made by Kuhlmann et al. (2017a) who also confirmed that due to a movement of the locks at the compression flange downwards their contribution to the plastic moment resistance was reduced.

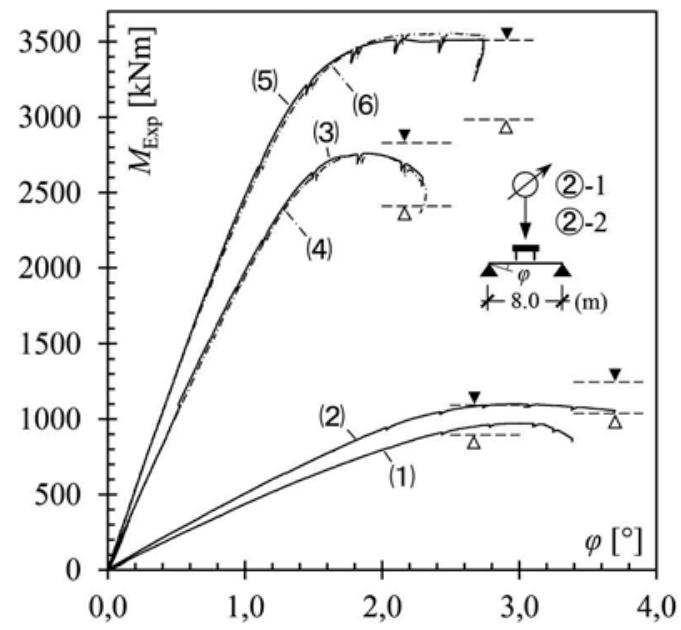

Explanations:

$$
\begin{aligned}
& M_{\text {act,pl }}-\mathbf{\Xi}_{-} \text {. } \\
& M_{\text {act,el }}{ }^{-} \mathrm{\Delta}^{-} \\
& F_{\text {exp }}=\frac{F_{(2)-1}+F_{(2)-2}}{2} \\
& M_{\exp }=F_{\exp } \cdot 3,5 \mathrm{~m}
\end{aligned}
$$

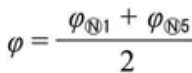

Figure 2. Results of 4-PBT: M- $\varphi$-diagram and maximum bending moment.
No. $M_{\text {exp, } \max }$ in $\mathrm{kNm}$

(1)

971

(2)

1099

2760

(4)

3516

(6)

3555 


\section{BACK-CALCULATION OF THE EXPERIMENTS}

A validated FE-model was developed by Kuhlmann et al. (2017b) for an industry project. The model represents half of the test setup, as the tests were quasi-symmetric. However, this model is too time consuming for an extensive parametrical study. Thus, the existing model was improved by reducing the whole test setup to a $1.0 \mathrm{~m}$ short beam and modelling the crimping points according to Kuhlmann et al. (2021) and ArcelorMittal (2019). The FE-geometry corresponds with the measured actual geometry of the test specimen. The real stress-strain curves for the flange and web were derived from the actual stress-strain curves, which were recorded during the small sample tensile tests. The FE-model, which was built up in ANSYS is shown in Figure 3a. On the front surface, a symmetry plane in X-direction was defined. The bending moment was applied by a rotation of the stiff endplate. Solid elements were used for the Z-piles and shell elements for the stiff endplate. The contact formulation was adopted from Kuhlmann et al. (2017c) and Kuhlmann \& Enders (2019) at the interlocks. They were defined with the pure penalty method. However, a small penetration was necessary to avoid convergence issues. The calculations and experiments showed that class 2 sections in the transition zone between class 2 and 3 do not reach the plastic moment. The section is not fully plastified when the moment capacity is reached. This is a result of a shape rotation, because the locks are still not fully in contact and allow a rotation of the flange downwards. This phenomenon was also observed by Kuhlmann et al. (2017b), Just (2020) (see Figure 3b). The failure is characterised by a plastic indentation in the middle of the beam, which also happened at the experiments. The FE-results are shown in Table 3.

The mean ratio between the FE-results and the experiments is 0.99 , where minimum ratio occurred for (1) 0.97 and the maximum for (3) with a value of 1.03 . The coefficient of variation $(\mathrm{COV})$ of the ratio was $2.6 \%$. In addition, the tests were also back-calculated with the model according to Kuhlmann et al. (2017b). This led to similar results, being only slightly better: The mean ratio was 1.0 and the COV was $2.4 \%$. The reliability of the new simplified FE-model regarding the bending moment capacity is good, thus the simplified model was used for the parametric study.

a)

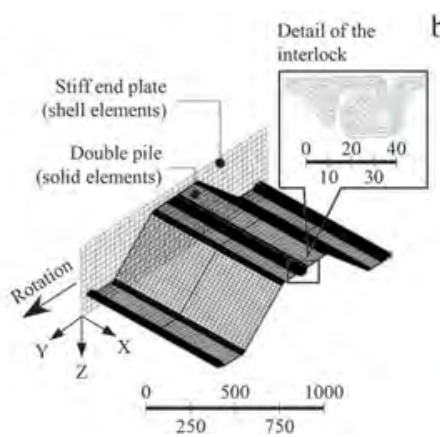

b)

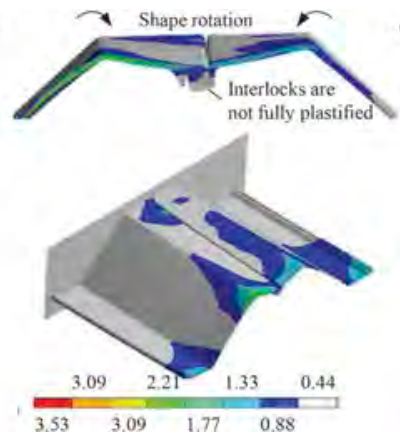

c)

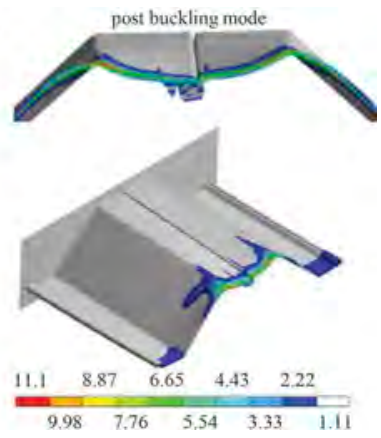

Figure 3. FE-Model exemplarily shown for test (1): a) FE-Mesh, b) strains in \% at the maximum value for the bending moment, c) strains in $\%$ at the post buckling-mode.

Table 3. Results of the test back-calculations, FE Results and Ratio between FE and Experiment.

\begin{tabular}{llllllll}
\hline Test No. & $M_{E x p, \max }$ & $M_{F E, \max }$ & Ratio & Test No. & $M_{E x p, \max }$ & $M_{F E, \max }$ & Ratio \\
\hline$(1)$ & $971 \mathrm{kNm}$ & $997 \mathrm{kNm}$ & 0.97 & $(4)$ & $2759 \mathrm{kNm}$ & $2769 \mathrm{kNm}$ & 1.00 \\
$(2)$ & $1099 \mathrm{kNm}$ & $1150 \mathrm{kNm}$ & 0.96 & $(5)$ & $3516 \mathrm{kNm}$ & $3590 \mathrm{kNm}$ & 0.98 \\
$(3)$ & $2760 \mathrm{kNm}$ & $2689 \mathrm{kNm}$ & 1.03 & $(6)$ & $3555 \mathrm{kNm}$ & $3552 \mathrm{kNm}$ & 1.01 \\
\hline
\end{tabular}


a)

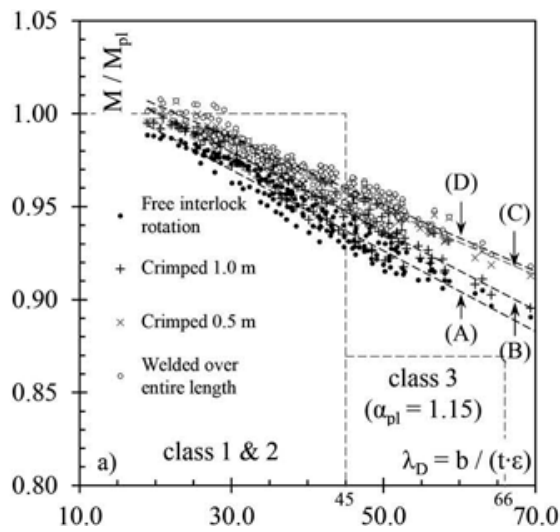

b)

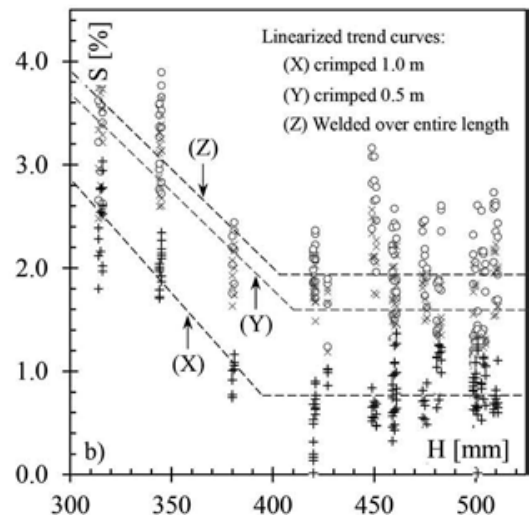

Figure 4. A) Results of the parametric study regarding the moment capacity of: Free interlocks, crimped $(0.5 \mathrm{~m})$, crimped $(1.0 \mathrm{~m})$ and welded interlocks dependent on the $\mathrm{b} /(\mathrm{t} \cdot \varepsilon)$-ratio including the trend lines (A), (B), (C), (D) for the different lock states; b) Increase S of bending moment capacity in comparison to the bending moment for free interlocks dependent on the lock state and profile height $\mathrm{H}$.

\section{PARAMETRIC STUDY}

A parametric study was carried out with the improved model to investigate the influence of the $\mathrm{b} /(\mathrm{t} \cdot \varepsilon)$-ratios and different lock states on the bending moment capacity. The lock states resulted in a different lock stiffness and were as follows: Free interlock rotation, crimped with a distance of $0.5 \mathrm{~m}$, crimped with a distance of $1.0 \mathrm{~m}$ and fully welded over the entire length. The welding seam was considered as a geometrical $6 \mathrm{~mm}$ thick one-sided fillet weld between the Z-piles. In total, 42 different profiles with nominal geometry and the steel grades S240GP, S355GP, S430GP and S460 were considered in the study. Considering all parameters 672 FE calculations were executed (Figure 4a). The experiments and the parametric study shows that Z-piles are not capable to reach the plastic moment in the transition zone at $b /(t \cdot \varepsilon)$-ratios from 30 to 45 . The crimping points with a distance of $1.0 \mathrm{~m}$ have no significant influence on the bending moment capacity, cf. Figure 4a trend curves (A) and (B). This corresponds with the tests where the distance was $0.7 \mathrm{~m}$. A crimping point distance of $0.5 \mathrm{~m}$ and the fully welded interlocks showed higher moment capacities compared to the free interlocks (Figure 4a (C) and (D)). The increase of the bending moment for crimped piles is overall low. However, for Z-piles with a height lower than $350 \mathrm{~mm}$ and a web angle lower than $43^{\circ}$, the moment increase may be of some relevance (Figure $4 \mathrm{~b}$ ).

\section{EVALUATION OF THE RESISTANCE MODELS (RM)}

The current resistance model for the bending moment capacity of Z-piles is given in Eurocode 3 Part 5 (2007). The cross-sections of Z-piles may be classified in class 1, 2 and 3. For b/(t·e)ratios up to 45 the full plastic moment may be used as the decisive value. Between the defined limits of 45 and 66, the elastic moment may be used. Following the planned procedure in the draft EC-3 Part 1-1 (2020), Annex B in sum 3 resistance models were investigated for the further development of the draft of EC-3 Part 5 (2020). It is rational to assume a linear interpolation between the defined limits, which lead to the first modified RM 'EC 3-5 (mod.)'. Hartmann-Linden (1997) suggested to use a b/(t-e)-ratio limit value of 40 between class 2 and 3 sections, which is here defined as RM 'H.-L'. Just (2020) also adopted a value 40 and modified the resistance function with a reduction factor $c$ of 0.965 for the plastic moment to consider that the plastic moment cannot be reached in the transition zone. All presented RM can 


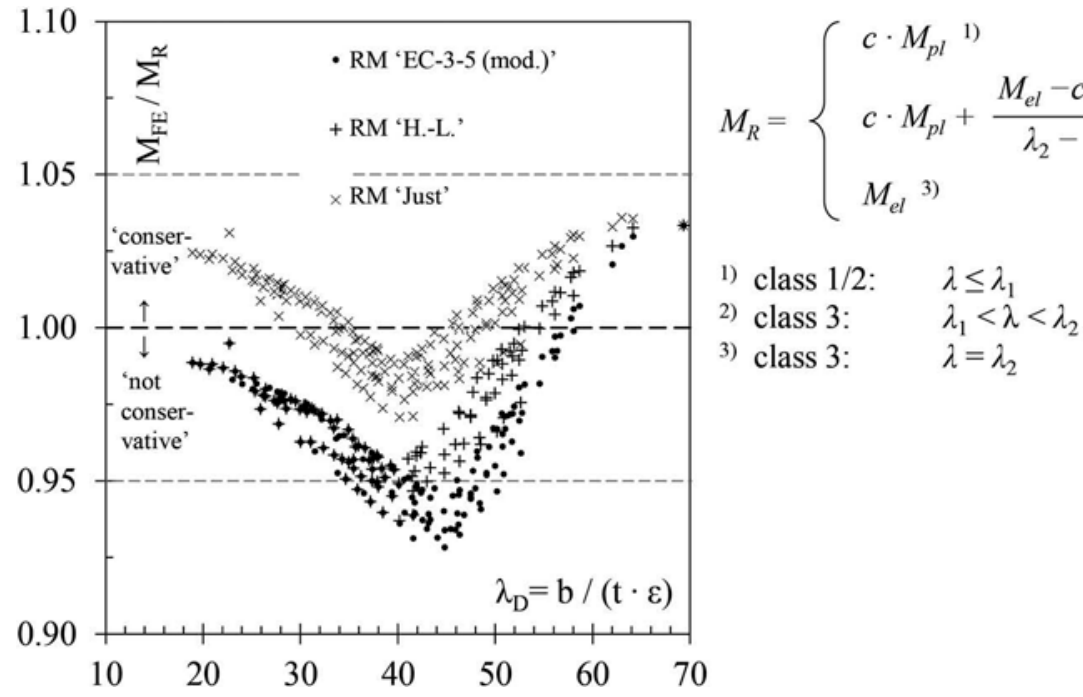

Figure 5. $\mathrm{M}_{\mathrm{FE}} / \mathrm{M}_{\mathrm{R}}$-ratios depending on the $\mathrm{RM}$ and the $\mathrm{b} /(\mathrm{t} \cdot \varepsilon)$-ratio (Kuhlmann et al (2021)).

be described with the following resistance function, shown in Eq. (1). The Factor $c$ in Eq. (1) is a constant factor, which reduces the plastic bending moment; $\lambda_{1}$ is the limit between class 2 and 3 sections; $\lambda_{2}$ is the limit between class 3 and 4 and $\lambda$ is defined as the $\mathrm{b} /(\mathrm{t} \cdot \varepsilon)$-ratio, where $\varepsilon$ is a material-dependent value and is defined by $\left(235 / f_{\mathrm{y}}\right)^{0.5}$ (see Eurocode 3 Part $5(2007)$ ). The bending moment capacity of the parametric study with the validated model was compared with the resistance models (see Figure 5). $\mathrm{M}_{\mathrm{FE}} / \mathrm{M}_{\mathrm{R}}$-ratios above 1.0 indicate a 'conservative' and ratios below a 'not conservative' resistance model. In addition, the resistance models were evaluated within the FOSTA Project P1327 following the standardized procedure in Eurocode 0 (2010) Annex D to derive partial factors.

\section{CONCLUSION}

Four-point bending tests were carried out with Z-shaped steel sheet piles to investigate the bending moment capacity. A FE-model was developed to execute an extensive parametric study with different nominal geometries, steel grades and interlock states. The crimping of Z-piles may be considered for profiles with a height lower than $350 \mathrm{~mm}$ and a web angle lower than $43^{\circ}$. Then, three resistance models for semi-compact sections following the draft of EC-3 Part 1-1 (2020) and in respect of Just (2020) and Hartmann-Linden (1997) were tested and evaluated according to Eurocode 0 (2010) Annex D. The results serve for a further discussion in the working group TC250/SC3/WG 18 and a further development of the draft of EC-3 Part 5 (2020) regarding the consideration of semi-compact cross-section in bending of Z-shaped steel sheet piles.

\section{ACKNOWLEDGMENTS}

The work presented has been carried out as part of the FOSTA research project P1327 financed by $\mathrm{AiF}$, within the development program for industrial community research and development IGF from the Federal Ministry of Economic Affairs and Energy based on a decision of the German Bundestag. Special thanks to ArcelorMittal S.A. Luxembourg for their support by materials and fabrication of the test specimens. We would also like to thank the industrial committee accompanying the project for technical and practical support and 
our project partners Prof. Dr. J. Grabe and J. Beuße, M.Sc. from Technical University of Hamburg-Harburg for their good cooperation.

\section{REFERENCES}

ArcelorMittal. 2019. Behaviour of AZ crimping. Background document. Unpublished.

DIN 50125. 2016. DIN 50125: 2016-12:Testing of metallic materials - Tensile test pieces. In German.

EN 10248. 2006. EN 10248-1: 2006-05:Hot-rolled steel sheet piling, Part 1: Technical delivery conditions.

Eurocode 0. 2002. EN 1990: 2010-12: Eurocode: Basis of structural design.

Eurocode 3 Part 5. 2007. EN 1993-5:2007: Eurocode 3: Design of steel structures - Part 5: Piling.

Hartmann-Linden. 1997. Tragfähigkeit von Stahlspundwänden. Dissertation, University of Aachen, Institute of Steel Construction.

ISO 6892-1. 2017. EN ISO 6892-1: 2017-02: Metallic materials - Tensile testing - Part 1: Method of test at room temperature.

Just A. 2020. Zum Tragverhalten von Stahlspundwänden mit breiten Zwischenbohlen. Dissertation, University of Stuttgart, Institute of Structural Design.

Kuhlmann, U.; Enders A. 2019. Investigations on combined sheet pile walls (HZ/AZ System) under water pressure loading, Experimental investigations with five AZ | HZ combinations in reverse setup position (b), 4th Addition to the Experimental Report 2010-24X. Experimental Report, University of Stuttgart, Institute of Structural Design, No. 2019-8X. Unpublished.

Kuhlmann, U.; Grabe, J.; Beuße, J.; Enders, A. 2021. Optimized Design of Combined Steel Walls for the Installation Phase and the Final State. Final Report of the AiF-FOSTA-Project P 1327 (IGF No. 19937 N), Düsseldorf. In progress.

Kuhlmann, U.; Just A. 2017a. Test Report AZXL: 800 mm wide AZ sheet piles, Phase 3: Three and FourPoint Bending Tests. Technical report, University of Stuttgart, Institute of Structural Design, No. 2017-2X. Unpublished.

Kuhlmann, U.; Just A. 2017b. Expert Statement AZXL: $800 \mathrm{~mm}$ wide AZ sheet piles, Phases 2 and 3 Load-Deformation Behavior: Bending and Waling. Final Report, No. 2017-64X, University of Stuttgart, Institute of Structural Design, 2017. Unpublished.

Kuhlmann, U.; Just A. 2017c. Combined HZ-MIAZ Pile Walls Loaded with Water Pressure, Evaluation of Additional Tests and Statistical Re-evaluation of the Characteristic Resistance Values. Final Report, Expert Statement, No. 2017-56X, University of Stuttgart, Institute of Structural Design. Unpublished.

Draft EC-3 Part 1-1. 2020. prEN 1993-1-1:2020: Eurocode 3 - Design of steel structures - Part 1-1: General rules and rules for buildings, document TC250/SC3/N3159.

Draft EC-3 Part 5. 2020. prEN 1993-5:2020: Eurocode 3: Design of steel structures - Part 5: Piling, document TC250/SC3/N3200. 


\title{
Elastic buckling of thin-walled beam-columns based on a refined energy formulation
}

\author{
M.A. Giżejowski \& A.M. Barszcz \\ Department of Concrete and Metal Structures, Warsaw University of Technology, Warsaw, Poland \\ J. Uziak \\ Faculty of Engineering and Technology, University of Botswana, Gaborone, Botswana
}

\begin{abstract}
The paper discusses the effects of both in-plane displacements and second order $P-\delta$ bending on the elastic flexural-torsional buckling of beam-columns. An energy based solution of the elastic flexural-torsional buckling limit curves under arbitrary proportion between the major axis bending moment and the axial force is presented. The novelty of the approach is related to the development of an improved closed-form solution, in which the equivalent uniform moment modification factor should vary not only with the minor axis buckling force utilization ratio $N / N_{z}$ but also with that of major axis buckling $N / N_{y}$ represented by the factored ratio $N / N_{z}\left(1-k_{1}\right)$. Investigations include the effect of in-plane displacements resulting from an arbitrary moment gradient on the elastic flexural-torsional buckling of thin-walled narrow flange and wide flange double-tee section members. The obtained solution is illustrated by elastic flexural-torsional buckling curves for different values of the factor $k_{1}$ of a beam-column subjected to unequal end moments.
\end{abstract}

\section{INTRODUCTION}

The elastic flexural-torsional instability of bisymmetric open section members belongs to the classical buckling problem investigated with the use of the Vlasov theory of thin-walled members. Many analytical closed-form and approximate solutions have been obtained for unrestrained beam-columns under major axis bending and presented in scientific papers published worldwide and summarized in the textbooks, e.g. Trahair (1993). The investigations expose a strong interaction between the column buckling and the beam lateral buckling, in which the buckling mode is the combination of flexural or torsional ones in relation to compression and lateral-torsional mode with respect to the major axis bending. The classical stability theory of thin-walled members based on the Vlasov theory uses the assumption of small, in-plane, bending displacements allowing to ignore the effect of prebuckling deflections on the flexural-torsional critical state.

It has to be noted that the Linear Eigenvalue Analysis (LEA) equations are quite conservative for wide flange sections, leading to uneconomical design of beams and beam-columns made of wide flange rolled steel or equivalent welded $\mathrm{H}$-sections. Conservatism is more pronounced for double-tee sections, in which case the minor axis moment of inertia is closer to that of the major axis. For rather imaginary situation, when the moments of inertia are equal, the flexural-torsional mode of buckling is proved to not affect the ultimate state of beam and beam-column members. This fact has been well accepted in the literature for a couple of decades, when the closed-form solution, for the case of double-tee bisymmetric beams under uniform moment of $M_{y}$, by including the second order prebuckling effects on the lateral-torsional buckling was presented. The buckling state of fork-supported beam-columns of such a section, for uniform bending, was presented by Trahair et al. (2008):

DOI: $10.1201 / 9781003132134-19$ 


$$
\left(\frac{\sqrt{k_{1} k_{2}} M_{y, \max }}{M_{c r, 0}}\right)^{2}=\left(1-\frac{N}{N_{y}}\right)\left(1-\frac{N}{N_{z}}\right)\left(1-\frac{N}{N_{T}}\right)
$$

where, the correction factors to be applied for the classical LEA solution are as follows:

- correction factor representing the second order effect of minor axis flexure:

$$
k_{1}=1-\frac{I_{z}}{I_{y}}=1-\frac{N_{z}}{N_{y}}=1-\frac{N_{z a}}{N_{y a}}
$$

- correction factor representing the second order effect of torsion:

$$
k_{2}=1-\frac{1}{2} \frac{G I_{T}}{E I_{y}}\left[1+\frac{E I_{w}}{G I_{T}}\left(\frac{\pi}{L}\right)^{2}\right]=1-\frac{1}{2}\left(\frac{\pi i_{0}}{L}\right)^{2} \frac{N_{T}}{N_{y}}
$$

where, $M_{c r, 0}=$ critical moment in uniform bending $M_{y, \text { max }} ; N_{y}, N_{y a}=$ major axis flexural buckling lowest and the second lowest bifurcation forces; $N_{z}, N_{z a}=$ minor axis flexural buckling lowest and the second lowest bifurcation forces; $N_{T}=$ torsional buckling lowest bifurcation force; $E=$ Young modulus; $G=$ Kirchhoff modulus; $I_{y}=$ major axis moment of inertia; $I_{z}=$ minor axis moment of inertia; $I_{w}=$ section warping constant; $I_{T}=$ section torsion constant; $i_{0}=$ polar radius of gyration.

Investigations for more accurate solutions have been carried out in the last decades for the critical state predictions of wide flange double-tee section thin-walled members. The mode of flexural-torsional buckling was extensively studied by Mohri et al. (2008) in relation to the bisymmetric double-tee sections. Because of existing coupling between the minor axis displacement and twist rotation, as well as their derivatives, the derivation of strain components for stability analysis needs to be thoroughly investigated in order to account for all the important factors affecting the buckling state formulation based on the thin-walled member theory. The classical energy equation is no longer valid when the effect of prebuckling displacements has an important effect on the buckling state.

To facilitate the formulation presented in this paper, a certain level of approximation, aligned with the development of energy equation, is maintained, so that the refined classical energy formulation from this study yields a required level of accuracy in combination with the simplicity of energy equation. This means that in the proposed refined energy equation only the effect described by $k_{1}$ factor in Eq. (1) is maintained while that concerned with $k_{2}$ factor is neglected.

In this paper, a derivation of the non-classical energy equation in relation to bisymmetric I-sections is discussed first, then its application for the development of a general closed-form solution for the flexural-torsional buckling of fork supported beam-columns under an arbitrary loading condition is presented. The formulation developed proved that the energy based solution of present study allows for sufficiently accurate predictions of the critical state of wide flange double-tee section beam-columns. It is shown that the moment modification factor is a function of not only $N / N_{\mathrm{z}}$, like in LEA formulation, but also of $N / N_{\mathrm{y}}$. To the authors' best knowledge, this is the first study that shows, in a general form, the effect of combined flexural in-plane and out-of-plane critical force utilization ratios on the equivalent uniform moment modification factor of the flexural-torsional buckling state.

\section{FIELD DISPLACEMENTS}

The accurate rotation matrix $\boldsymbol{R}$ was studied by Pi \& Trahair (1994) and then by Pi \& Bradford 2001). Two parallel Cartesian coordinate systems $(x, y, z)$ are chosen, one fixed in space and the other attached to the deformed elemental length $\Delta x$ of the member. The basis vectors in 
the initial state of the axis system are $\left(p_{x}, p_{y}, p_{z}\right)$ while these vectors become $\left(q_{x}, q_{y}, q_{z}\right)$ in the deformed state. The rotation $\theta$ is a compound rotation from the basis vectors $\left(p_{x}, p_{y}, p_{z}\right)$ to the basis vectors $\left(q_{x}, q_{y}, q_{z}\right)$, and represented by a rotation matrix $\boldsymbol{R}$.

In Pi \& Bradford investigations, the vector algebra was used to obtain the rotation matrix $\boldsymbol{R}$. The expressions for the components of the rotation matrix $\boldsymbol{R}$ are related to the choice of the technique for representing the sequence of rotations, so that the resultant rotation matrix components may not be easy interpreted in view of the explicit form of the displacement field components in the deformed state in reference to the initial state.

In the present study, the starting point is to formulate the rotation matrix for the deflected configuration, assuming small rotations in that configuration. This allows to write a general matrix relationship for the displacement field in the deflected configuration as:

$$
\left[\begin{array}{c}
u(x, y, z) \\
v(x, y, z) \\
w(x, y, z)
\end{array}\right]=\boldsymbol{R}\left[\begin{array}{c}
d x \\
y \\
z
\end{array}\right]-\left[\begin{array}{c}
d x+\omega \kappa_{x}(x) \\
y \\
z
\end{array}\right]
$$

where, $\omega=$ sectional warping coordinate; $\kappa_{x}(x)=$ twist along the axis indicated by the subscript symbol; $u, v, w=$ displacements along the axes $x, y, z ; f(\ldots)=$ variable $f$ being a function of selected arguments listed in the round bracket that indicate the coordinates of adopted Cartesian system (in the following, the arguments are dropped for the convenience of notation), and:

$$
\kappa_{x}=\phi_{x}^{\prime}
$$

where, the symbol $f^{\prime}=\frac{d f}{d x}$ and the coordinate system is the same as used in Barszcz et al. (2021).

The rotation matrix $\boldsymbol{R}$ defined in the member deflected configuration with regard to the fixed Cartesian coordinate system of the initial configuration takes the form:

$$
\boldsymbol{R}=\left[\begin{array}{ccc}
\sqrt{1+2 e} & -\phi_{z} & \phi_{y} \\
\phi_{z} & 1-\frac{1}{2}\left(\phi_{x}\right)^{2} & -\phi_{x} \\
-\phi_{y} & \phi_{x} & 1-\frac{1}{2}\left(\phi_{x}\right)^{2}
\end{array}\right]
$$

where, $\phi_{i}(i=x, y, z)=$ angles of rotation in the deflected configuration with reference to the initial configuration; $\sqrt{1+2 e} d x \approx(1+e) d x$ is the fiber length measured along the $x$-axis in the deflected configuration; $e=u_{0}^{\prime}+\frac{1}{2} \phi^{2}$ is the normal strain measure of the section fiber including the bowing effect of $\phi=\sqrt{\left(\frac{\partial v}{\partial x}\right)^{2}+\left(\frac{\partial w}{\partial x}\right)^{2}} ; u_{0}=$ displacement along the member axis.

The vector of rotation angles in the deflected configuration may be related to those in the initial configuration through the cosines direction matrix $\boldsymbol{T}_{R \boldsymbol{\theta}}$ as follows:

$$
\left[\begin{array}{c}
\phi_{x} \\
\phi_{z} \\
\phi_{y}
\end{array}\right]=\left[\begin{array}{c}
\theta_{x} \\
0 \\
0
\end{array}\right]+\boldsymbol{T}_{\boldsymbol{R} \boldsymbol{\theta}}\left[\begin{array}{c}
\theta_{z} \\
\theta_{y}
\end{array}\right]
$$

where, the direction cosines matrix:

$$
\boldsymbol{T}_{\boldsymbol{R} \boldsymbol{\theta}}=\left[\begin{array}{cc}
-\frac{1}{2} \theta_{y} & \frac{1}{2} \theta_{z} \\
\cos \phi_{x} & -\sin \phi_{x} \\
\sin \phi_{x} & \cos \phi_{x}
\end{array}\right]
$$

The angle $\theta_{x}$ is the twist rotation and the flexural rotations $\theta_{y}, \theta_{z}$, are given by: 


$$
\theta_{z}=\operatorname{acr} \tan \frac{v_{0}^{\prime}}{1+u_{0}^{\prime}}, \ldots \theta_{y}=\operatorname{acr} \tan \left(\frac{-w_{0}^{\prime}}{1+u_{0}}\right)
$$

where, $v_{0}, w_{0}=$ displacements of the member axis along $y$ and $z$ coordinates, respectively.

After decomposing the square rotation matrix in Eq. (6) into two components, namely into the vector corresponding to $d x$ and the rectangular rotation matrix component $\boldsymbol{R}_{\boldsymbol{y} z}$ corresponding to the section coordinates $(y, z)$, the displacement field may be expressed as follows:

$$
\left[\begin{array}{c}
u \\
v \\
w
\end{array}\right]=\left[\begin{array}{c}
u_{0}^{\prime}+\frac{1}{2} \theta^{2}-\omega \kappa_{x}^{\prime} \\
\theta_{z} \cos \phi_{x}-\theta_{y} \cos \phi_{x} \\
-\left(\theta_{y}+\theta_{z}\right)
\end{array}\right] d x+R_{y z}\left[\begin{array}{c}
y \\
z
\end{array}\right]
$$

in which, the framed variables are the terms of direction cosines matrix.

The rotation submatrix $\boldsymbol{R}_{\boldsymbol{y} z}$ takes the form:

$$
R_{y z}=\left[\begin{array}{cc}
-\left(\theta_{z} \cos \phi_{x}-\theta_{y} \sin \phi_{x}\right) & \left(\theta_{y} \cos \phi_{x}+\theta_{z} \sin \phi_{x}\right) \\
-\frac{1}{2}\left[\theta_{x}+\frac{1}{2}\left(\theta_{y}-\theta_{z}\right)\right]^{2} & -\left[\theta_{x}+\frac{1}{2}\left(\theta_{y}-\theta_{z}\right)\right] \\
{\left[\theta_{x}+\frac{1}{2}\left(\theta_{y}-\theta_{z}\right)\right]} & -\frac{1}{2}\left[\theta_{x}+\frac{1}{2}\left(\theta_{y}-\theta_{z}\right)\right]^{2}
\end{array}\right]
$$

\section{VARIATION OF THE TOTAL POTENTIAL ENERGY AT THE BUCKLING STATE}

The strain components depend upon the gradient of the displacement field vector given by:

$$
\frac{\partial}{\partial x}\left[\begin{array}{c}
u \\
v \\
w
\end{array}\right]=\left[\begin{array}{c}
u_{0}^{\prime}+\frac{1}{2} \theta^{2}-\omega \kappa_{x}^{\prime} \\
\theta_{z} \cos \phi_{x}+\theta_{y} \sin \phi_{x} \\
-\left(\theta_{y} \cos \phi_{x}+\theta_{z} \sin \phi_{x}\right)
\end{array}\right]+\left(\frac{d}{d x} R_{y z}\right)\left[\begin{array}{c}
y \\
z
\end{array}\right]
$$

in which:

$$
\left(\frac{d}{d x} \boldsymbol{R}_{y z}\right)\left[\begin{array}{l}
y \\
z
\end{array}\right]=\left(\left[\begin{array}{cc}
-\kappa_{z} & \kappa_{y} \\
0 & -\kappa_{x} \\
\kappa_{x} & 0
\end{array}\right]+\left[\begin{array}{cc}
\theta_{y} \kappa_{x} & \theta_{z} \kappa_{x} \\
0 & 0 \\
0 & 0
\end{array}\right]\right)\left[\begin{array}{l}
y \\
z
\end{array}\right]
$$

and the curvatures in the deflected configuration:

$$
\left[\begin{array}{c}
\kappa_{x} \\
\kappa_{z} \\
\kappa_{y}
\end{array}\right]=\frac{d}{d x}\left[\begin{array}{c}
\phi_{x} \\
\phi_{z} \\
\phi_{y}
\end{array}\right]=\theta x+\boldsymbol{T}_{\boldsymbol{R} \theta} \frac{d}{d x}\left[\begin{array}{c}
\theta_{z} \\
\theta_{y}
\end{array}\right]=\left[\begin{array}{c}
\theta^{\prime} \\
0 \\
0
\end{array}\right]+\boldsymbol{T}_{\boldsymbol{R} \boldsymbol{\theta}}\left[\begin{array}{c}
v_{0}\left(1+u_{0}^{\prime}\right)-v_{0}^{\prime} u^{\prime \prime}{ }_{0} \\
-w^{\prime \prime}{ }_{0}\left(1+u_{0}^{\prime}\right)-w_{0}^{\prime} u_{0}^{\prime \prime}
\end{array}\right]
$$

Let us acknowledge that the second order in-plane moment $M_{y}$ is the sum of the following symmetric and antisymmetric components of the transverse loading system:

$$
M_{y s}=\frac{M_{y s}^{I}}{1-\frac{N}{N_{y}}} \text { and } M_{y a}=\frac{M_{y a}^{I}}{1-\frac{N}{N_{y a}}}
$$


By defining the nonzero linear normal strain component $\varepsilon_{x x}=\frac{\partial u}{\partial x}$ and shear strain components $\varepsilon_{x y}=\frac{\partial u}{\partial y}+\frac{\partial v}{\partial x}$ and $\varepsilon_{x z}=\frac{\partial u}{\partial z}+\frac{\partial w}{\partial x}$ in the deflected configuration, the strain energy may be evaluated. Considering the strain energy terms belonging to the out-of-plane bifurcation problem, neglecting the terms of higher order than two and including the potential energy of the loading system measured from the untwist and laterally unbent configuration, the variation of the total potential energy at the buckling state becomes:

$$
\begin{aligned}
& \frac{1}{2} L\left\{E I_{z} \delta\left[\left(v^{\prime \prime}\right)^{2}\right]+E I_{w} \delta\left[\left(\phi^{\prime \prime}\right)^{2}\right]+G I_{T} \delta\left[\left(\phi^{\prime}\right)^{2}\right]\right\} d x+ \\
& \frac{1}{2} k_{1}{ }_{0}^{L} M_{y}^{I I}\left[2 \delta\left(v^{\prime \prime} \phi\right)-\frac{M_{z}^{I I}}{E I_{z}} \delta\left(\phi^{2}\right)\right] d x-\frac{1}{2} N{ }_{0}^{L}\left\{\delta\left[\left(v^{\prime}\right)^{2}\right]+i_{0}^{2} \delta\left[\left(\phi^{\prime}\right)^{2}\right]\right\} d x+ \\
& \frac{1}{2} \sum_{i}^{x_{q i, 2}} q_{z i i} z_{q i} \delta\left(\phi^{2}\right) d x+\frac{1}{2} \sum_{j} Q_{z j} z_{Q j} \delta\left\{\left[\phi\left(x_{q j}\right)\right]^{2}\right\}
\end{aligned}
$$

where, $k_{1}=$ according to Eq. (2); $\phi=$ angle of twist rotation $\phi_{x}$ (subscript $x$ is dropped hereafter for notation convenience); $M_{y}^{I I}$ is the $x$-coordinate dependent prebuckling major axis second order moment; $M_{z}^{I I}=-\left(M_{y}^{I} \phi+N v\right)$ is the $x$-coordinate dependent buckling minor axis second order moment; $q_{z i}=$ uniformly distributed load component (UDL); $Q_{z j}=$ point load component (PL), $z_{q}=$ section coordinate of applied UDL; $z_{Q}=$ section coordinate of applied PL.

\section{BUCKLING SOLUTION}

In the following, beam-columns being simply supported and free warped at the end sections are taken into consideration. Refining the linear initial stress term $M_{y} \delta\left(v^{\prime \prime} \phi\right)$ in Eq. (16), $v^{\prime \prime}$ is calculated from the following second order differential equilibrium equation:

$$
E I_{z} v^{\prime \prime}+N v=-M_{y}^{I} \phi
$$

and the minor axis displacements are approximated by:

$$
v=v_{s}+v_{a}=\frac{M_{y s}^{I} \phi}{N_{z}\left(1-\frac{N}{N_{z}}\right)}+\frac{M_{y a}^{I} \phi}{N_{z a}\left(1-\frac{N}{N_{z a}}\right)}
$$

where, $v_{s}, v_{a}$ - minor axis displacements corresponding to symmetric and antisymmetric components; $M_{y s}^{I}, M_{y a}^{I}$ - first order moment equations corresponding to symmetric and antisymmetric components.

Substituting the results to Eq. (16), the energy equation may be approximated by:

$$
\begin{aligned}
& \int_{0}^{L}\left\{\delta \phi^{\prime \prime} E I_{w} \phi^{\prime \prime}+\delta \phi^{\prime} G I_{T} \phi^{\prime}-\delta \phi \frac{k_{1}}{E I_{z}}\right. \\
& \left.\left[\frac{\left(M_{y s}^{I}\right)^{2}}{1-\frac{N}{N_{y}}}+\frac{N}{N_{z}} \frac{\left(M_{y s}^{I}\right)^{2}}{\left(1-\frac{N}{N_{y}}\right)\left(1-\frac{N}{N_{z}}\right)}+\frac{\left(M_{y a}^{I}\right)^{2}}{1-\frac{N}{N_{y a}}}+\frac{N}{N_{z a}} \frac{\left(M_{y a}^{I}\right)^{2}}{\left(1-\frac{N}{N_{y a}}\right)\left(1-\frac{N}{N_{z a}}\right)}\right] \phi-\delta \phi^{\prime}\left(i_{0}^{2} N\right) \phi^{\prime}\right\} d x+ \\
& \sum_{i} \int_{x_{q i, 1}}^{x_{q i, 2}} \delta \phi\left(q_{z i} z_{q i}\right) \phi d x+\sum_{j} \phi\left(x_{q j}\right)\left(Q_{z j} z_{Q j}\right) \phi\left(x_{q j}\right)+\int_{0}^{L}\left(\delta v^{\prime \prime} E I_{z} v^{\prime \prime}-\delta v^{\prime} N v^{\prime}\right) d x
\end{aligned}
$$




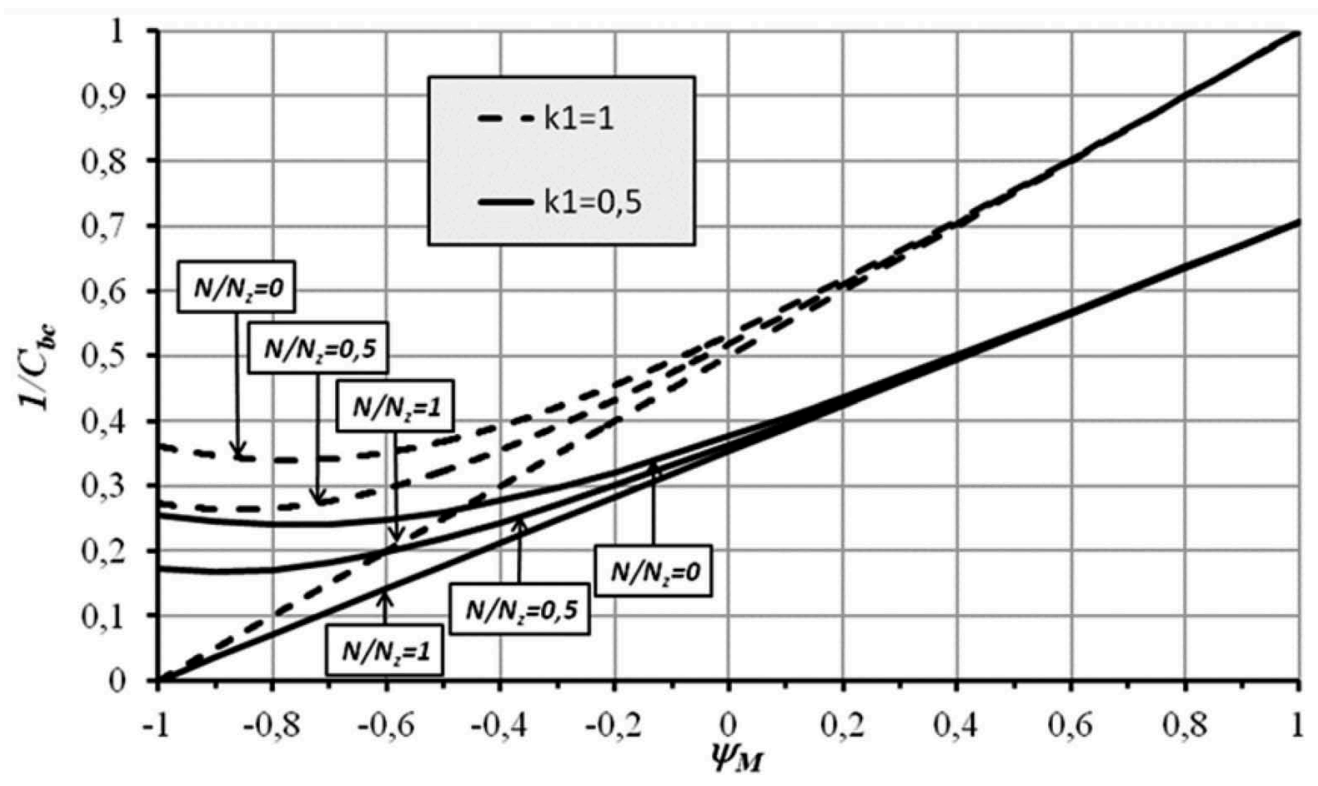

Figure 1. Comparison of the moment conversion factor $\frac{1}{C_{b c}}$ for unequal end moments.

The last integral in Eq. (19) is concerned with bifurcation modes under the axial force without any bending action effect about the major axis. By equating the relationship given by Eq. (19) to zero, then approximating the buckling modes by conventional trigonometric functions (combination of sinus half wave and wave functions for the minor axis displacement and sinus half wave for the angle of twist rotation), the following solution governs:

$$
\left(\frac{M_{y, \max }}{C_{b c} M_{c r, 0}}\right)^{2}=\left(1-\frac{N}{N_{y}}\right)\left(1-\frac{N}{N_{z}}\right)\left(1-\frac{N}{N_{T}}\right)
$$

where, $C_{b c}=$ equivalent uniform moment factor $\left(M_{c r}=C_{b c} M_{c r, 0}\right.$ where $M_{c r, 0}$ is the critical moment in uniform bending):

$$
\frac{1}{C_{b c}}=\sqrt{k_{1}\left\{\frac{1}{C_{b s, \text { rem }}}\left(\frac{M_{y s, \text { max }}}{M_{y, \text { max }}}\right)^{2}+\frac{\left[1-\left(1-k_{1}\right) \frac{N}{N_{z}}\right]\left(1-\frac{N}{N_{z}}\right)}{\left[1-\left(1-k_{1}\right) \frac{N}{N_{z a}}\right]\left(1-\frac{N}{N_{z a}}\right)} \frac{1}{C_{b a, \text { rem }}}\left(\frac{M_{y a, \text { max }}}{M_{y, \text { max }}}\right)^{2}\right\}}
$$

The moment distribution dependent parameters are given by:

$$
\frac{1}{C_{b s, r e m}}=\frac{2}{L} \int_{0}^{L}\left(m_{y s}^{I}\right)^{2} \sin ^{2} \frac{\pi x}{L} d x, \frac{1}{C_{b a, r e m}}=\frac{2}{L} \int_{0}^{L}\left(m_{y a}^{I}\right)^{2} \sin ^{2} \frac{\pi x}{L} d x
$$

where, $m_{y s}^{I}, m_{y a}^{I}=$ dimensionless bending moment functions corresponding to symmetric and antisymmetric load effect components, obtained by dividing the moment functions by $M_{y s, \max }$ and $M_{y a, \max }$, respectively. 
One has to notice that for the narrow flange I-section beam-columns that are laterally and torsionally unrestrained between supports, both in-plane effects may be ignored, i.e. assuming in Eqs. (20) and (21) the following: $k_{1}=1, \frac{N}{N_{z}}\left(\begin{array}{ll}1 & k_{1}\end{array}\right)=0$ and $\frac{N}{N_{z a}}\left(\begin{array}{ll}1 & k_{1}\end{array}\right)=0$.

In Figure 1, the inversion of the equivalent uniform moment conversion factor $C_{b c}$ of present study is compared for beam-columns subjected to unequal end moments. This asymmetric loading system is described by the moment gradient parameter $\psi_{M}=M_{y, \min } / M_{y, \max }$ so that the following relationships hold:

$$
\frac{M_{y s}}{M_{y, \max }}=\frac{1+\psi_{M}}{2}, \frac{M_{y a, \max }}{M_{y, \max }}=\frac{1-\psi_{M}}{2}
$$

and the factors given by Eqs. (22) are the same as those obtained for bending without compression, cf. Barszcz et al. (2021).

\section{CONCLUDING REMARKS}

The paper discusses issues related to the consistent formulation of the energy equation for beam-column flexural-torsional buckling. Equation (19) obtained in the paper differs from the classical one for which the nonlinear moment term in square bracket under the second integral of Eq. (16) must be replaced by its linear counterpart $\left[2 M_{y}^{I} \delta\left(v^{\prime \prime} \phi\right)\right]$.

It has been shown that the equivalent uniform moment modification factor should vary not only with the minor axis buckling force utilization ratio $N / N_{z}$ but also with that of major axis buckling $N / N_{y}$ represented by the factored ratio $N / N_{z}\left(1-k_{1}\right)$. The obtained solution, for the uniform bending, appears to be the same as that of the closed form solution, cf. Eq. (1) for $k_{2}=1$ and Mohri et al. (2008). When $k_{1}=1$, the obtained solution appears to be that obtained with the assumption of disregarding the effect of prebuckling displacements on the critical state. Contrary, when $k_{1}=0$, the LHS of Eq. (20) becomes zero (the critical moment becomes infinity) and the buckling state is entirely controlled by the compressive axial force, with no effect of the bending moment on the buckling state. Moreover, when either $N / N_{z}=1$ or $N / N_{T}=1$, the RHS of Eq. (20) becomes zero (the critical moment becomes zero).

\section{REFERENCES}

Trahair, N.S. 1993. Flexural-Torsional Buckling of Structures. Boca Raton: CRC Press.

Trahair, N.S., Bradford, M.A., Nethercot, D.A. \& Gardner, L. 2008. The behaviour and design of steel structures to EC3 (4th Edition). London-New York: Taylor and Francis.

Mohri, F., Bouzerira, Ch. \& Potier-Ferry, M. 2008. Lateral buckling of thin-walled beam-column elements under combined axial and bending loads. Thin-Walled Structures 46(3): 290-302.

Pi Y-L. \& Trahair N.S. 1994. Nonlinear inelastic analysis of steel beam-columns. Journal of Structural Engineering, Part I: Theory 120(7):2041-2061, Part II: Applications. 120(7):2967-2985.

Pi, Y.L., Bradford, M.A. 2001. Effects of approximations in analyses of beams of open thin-walled cross-section. International Journal for Numerical Methods in Engineering, Part I: Flexural-torsional stability 51: 757-72,Part II: 3D non-linear behaviour 51: 773-790.

Barszcz, A.M., Giżejowski, M.A. \& Stachura, Z. 2021. On elastic lateral-torsional buckling analysis of simply supported I-shape beams using Timoshenko's energy method. Proc. $14^{\text {th }}$ International Conference on Metal Structures [submitted]. 


\title{
Buckling analysis of thin-walled sigma beams with respect to different numerical descriptions
}

\author{
K. Rzeszut \\ Institute of Building Engineering, Poznan University of Technology, Poznań, Poland \\ I. Szewczak \\ Faculty of Civil Engineering and Architecture, Lublin University of Technology, Lublin, Poland \\ P. Różyło \\ Faculty of Mechanical Engineering, Lublin University of Technology, Lublin, Poland
}

M.J. Guminiak

Institute of Structural Analysis, Poznan University of Technology, Poznań, Poland

\begin{abstract}
The main aim of the study is buckling analysis of steel beams made of thinwalled cold-formed sigma profile with respect different numerical descriptions. The analyses are carried out on sigma profile with a height of $140 \mathrm{~mm}$ and a span of $2.20 \mathrm{~m}$. The numerical models of the Finite Element Method (FEM), developed in the Abaqus program, include modelling of the so-called boundary conditions of the forks with use of displacement limitations. The beams are modelled using S4R shell finite element with linear or square shape function. Local and global instability behaviour is investigated using linear buckling analysis and are verified by the comparisons with theoretical critical bending moment obtained from analytical close form formulas based on so called Vlasow beam theory dedicated to the thinwalled elements. In addition, the engineering analysis of buckling is carried out for a simple shell (plate) model of the separated cross-section part in form of flange wall using Boundary Element Method (BEM). The discussion concerning geometric simplification in sigma crosssection according theoretical assumptions is performed too. It is worth noting that the value of the critical bending moment calculated on the basis of the Vlasov beam theory does not take into account the loss of local stability or contour deformation. On the other numerical shell FEM models enable multimodal buckling analysis taking into account interactive buckling. In the paper eigenvalue and shape of buckling modes for selected numerical models are calculated for three first buckling modes but the values of critical bending moments are identified basing on the eigenvalue obtained for the first buckling mode.
\end{abstract}

\section{INTRODUCTION}

The history of research on the stability of structures is almost 250 years old and it was started in 1759 by Euler, who published a work on buckling in compression columns. Euler's work was continued by, inter alia, Timoshenko and Vlasov, who formulated a general theory of calculating thin-walled bars in a complex state of stress and elastic loss of stability. The theoretical and experimental studies on the stability of thin-walled elements have shown the shortcomings of classical linear theories and revealed the need for more advanced analyses. It became possible thanks to the development of computer methods and the formulation of a geometric matrix and

DOI: $10.1201 / 9781003132134-20$ 
incremental equations, and later the use of the Finite Element method has been comprehensively described by Zienkiewicz (1977). Loss of stability is the most important phenomenon that causes the load capacity of thin-walled metal structures to be exceeded. For this reason, stability conditions are the subject of a large part of design standards and have been introduced into the curriculum in engineering, master's and doctoral programs. In engineering practice two classes of stability problems of cold-formed members, have been distinguished. The first of them, the global stability is analysed according to Vlasov's theory, which takes into account torsion of the bar, assuming a non-deformable contour. The second class concerns the theory of post-critical load capacity taking into account the local stability of walls. When assessing the bearing capacity of building structures, it may be dangerous to consider these two classes of problems separately. Therefore, when assessing the load-bearing capacity of the elements according to Vlasov's theory, the influence of wall stability should be additionally investigated in accordance with the plate theory so called effective length concept proposed by Karman (1932). Many software for computer aided design of metal structures contain ready-made procedures for taking into account the influence of instability problems on the structure capacity. However, the phenomenon of stability is so complex that a routine approach to the design of thin-walled structures, as proposed by professional computer programs, can be dangerous or can lead to uneconomical projects. More over the problem becomes more complicated when there is a need to define the critical moment for symmetrical sections, where the axis of symmetry is the weaker one, e.g. channels or sigma sections Rzeszut (2018). The Polish standard PN-90/B-03200 provides a simplified method of checking the bearing capacity and torsion of beams made of C-section. In the case of no interaction of the bending moment and the sheer force, it allowed to determine the approximate share of torsion in the stress state of the channel section at approx. 15\%. On the other hand, the PN-EN 1993-1-1 Standard does not provide any method of determining the critical moment for symmetrical sections, where the axis of symmetry is the weaker axis, and refers the designer to basic knowledge on the strength of materials. This work involved the reliability assessment of the results of calculations of critical moments of cold-rolled sigma cross-section using analytical formulas based on the Vlasov beam theory, contained in AISI (1996), Bródka (2006) and Szczerba (2013) and Finite Element Method (FEM) using the Abaqus program and solid or shell finite elements. In addition, the paper attempts to analyse stability using Boundary Element Method (BEM) for the separate wall of profile.

\section{NUMERICAL ANALYSIS}

\subsection{Analytical formulas}

The critical bending moment can be determined based on the analytical procedures contained in standards such as PN-90/B-03200 or PN-EN 1993-1-1 but as it was mentioned above, in case of sections with only one weaker axis of symmetry the critical moment can be calculated using formula contained in AISI (1996):

$$
\mathrm{M}_{\mathrm{cr}}=\frac{C_{b} \pi^{2} E I_{y}}{l_{e}^{2}} \sqrt{\frac{I_{\omega}}{I_{y}}}
$$

where: $l_{e}$ - o lateral-torsional buckling length, $I_{y}$ - second moment of area with respect to the main axis of the section, perpendicular to the bending direction, $I_{\omega}-$ warping constant, $C_{b}-$ coefficient corresponding to bending moment variation along the bar length.

\subsection{Finite element method}

The problem of finding a solution to the eigenvalue equation, i.e. Eigenvalue problem often appears in linear buckling issue (also called as Eigenvalue buckling). This analysis predicts the theoretical buckling strength of an ideal elastic structure in form of critical load. In FEM 
analysis the eigenvectors $U$ have been computed by solving the linear eigenvalue problem which can be described as follow:

$$
\left(\mathbf{K}^{\mathrm{o}}+\lambda \mathbf{K}^{\mathrm{G}}\right) \mathbf{U}=0
$$

where $\lambda$ is the load multiplier and eigenvector $\mathbf{U}$ represents the buckling mode shapes, $\mathbf{K}^{\mathrm{O}}$ is the linear stiffness matrix, $\mathbf{K}^{\mathrm{G}}$ is the initial geometric matrix. In Eq. (2) the proportional loading and linearization of the pre-buckling state was assumed. The critical buckling loads are $\lambda_{i}{ }_{i} \mathbf{P}$, where $\mathbf{P}$ is the reference load (the base state).

\subsection{Boundary element method}

The initial stability problem of the plate structures can also be solved in an engineering manner using the Boundary Element Method (BEM). The complex steel profile can be divided into simple elements - plates, fixed at the edges. It is also assumed, that the considered plate is subjected to in-plane loading, which can have the constant or linear character along single plate edge.

The thin plate bending is described by the differential equation:

$$
D \nabla^{4} w=-\bar{p}
$$

where $D=E h^{3} /\left(12\left(1-v^{2}\right)\right)$ is the plate stiffness and

$$
\bar{p}=N_{x} \frac{\partial^{2} w}{\partial x^{2}}+2 N_{x y} \frac{\partial^{2} w}{\partial x \partial y}+N_{y} \frac{\partial^{2} w}{\partial y^{2}}
$$

is the substitute loading.

The solution of the equation (3) can be expressed as the integral representation in which the appropriate boundary values take place: the shear force, the bending moment, deflection, the angle of rotation in normal direction and the angle of rotation in tangent direction which is not independent and is calculated using a plate boundary deflection. Presented approach proposed by Guminiak (e.g. 2014, 2016) avoids Kirchhoff forces at the plate corner and equivalent shear forces at a plate boundary wherein two unknown variables are still considered at the boundary element node. The set of internal collocation points is introduced to establish a plate curvatures (Guminiak 2014, 2016). Alternatively the governing integral equations are derived using Betti's theorem. The solution of differential equation (4) in form of integral representation has the form of boundary-domain integral equations. Finally, after elimination of boundary variables the standard eigenvalue problem can be obtained (Guminiak 2014, 2016). The number of boundary elements is 160 and the number of internal collocation points is 320 .

\section{NUMERICAL EXCAMPLES}

The numerical analysis were carried out on sigma thin-walled beam made by "Blachy Pruszyński". The dimensions of cross-section of sigma profile was as follow: height $-140 \mathrm{~mm}$, the flange width $-70 \mathrm{~mm}$ and a wall thickness $-2.5 \mathrm{~mm}$. All tested beams were simply supported elements with the span of $2.20 \mathrm{~m}$ and loaded by uniformly distributed actions. A detailed description of laboratory tests and laboratory stand scheme are described in the paper (Rzeszut 2017, 2018). Beams were made of S350 GD steel grade, characterized by Young modulus E=201.8 $\mathrm{GPa}$, Poisson ratio $v=0.282$ and Yield stresses $\mathrm{f}_{\mathrm{y}}=418.5 \mathrm{MPa}$ determined on the basis of own material coupon test. The developed numerical models were different in terms of boundary conditions and, the type of finite element (FE). Two different types of finite elements were used, namely S4R type with a linear shape function (four-node type with reduced integration) (FEM- 
shell-1), and a shell element of S8R type with a square shape function was used (FEM-shell-s). The size of finite elements is $7.5 \mathrm{~mm}$. The supports were modelled in order to reflect so-called fork support. The supports were modelled using the displacement constraints imposed on partition plane of the beam in supports zone in distance of $0.4 \mathrm{~m}$ from the beam end in form of constrained horizontal displacements $\mathrm{Ux}$ at the web and edge stiffener, and in form of constrained vertical displacements Uy on the bottom flange. At all points located on this partition plane rotation was free (Figure 1). In order to meet Vlasov theory assumptions, among the others, that the resultant load should pass through the shear centre of the cross-section several numerical models were developed (see Figure 2). Various methods of external load modelling are marked with symbols V1, V2, V3. In the case of the V1 and V2, the uniformly distributed load was applied to the theoretical line located at the level of the upper flange of the cross-section and located directly above the shear centre of the cross-section. In the case V1, a reference point has been assigned to a non-deformable "WIRE line" (as part of 3D/Discrete Rigid modelling), which in turn determines the boundary conditions with the load as the unit force. Throughout the analysis, the line was a non-deformable part and was directly coupled to the entire cross-section of the Sigma type member. In the case V2, a non-deformable line of the WIRE type was assigned a reference point, in which the boundary conditions with the load being the unit force were determined. Throughout the analysis, the line was a non-deformable part and was directly coupled to the separated area (a line of a length adequate to the distance between the supports) located in the middle of the cross-section height of the Sigma type structure. In the case V3, uniformly distributed unit load was applied over the entire width of the upper flange and along the length equal to the spacing of supports. The methods of applying the external load in each case are shown in Figure 2.

a)

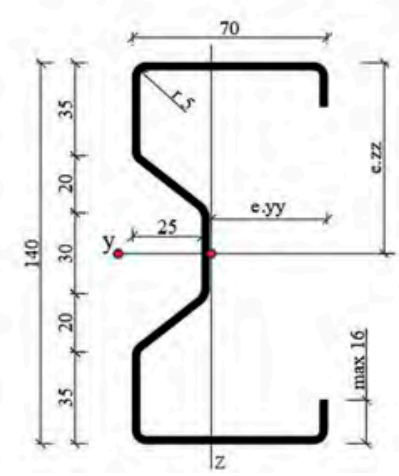

b)

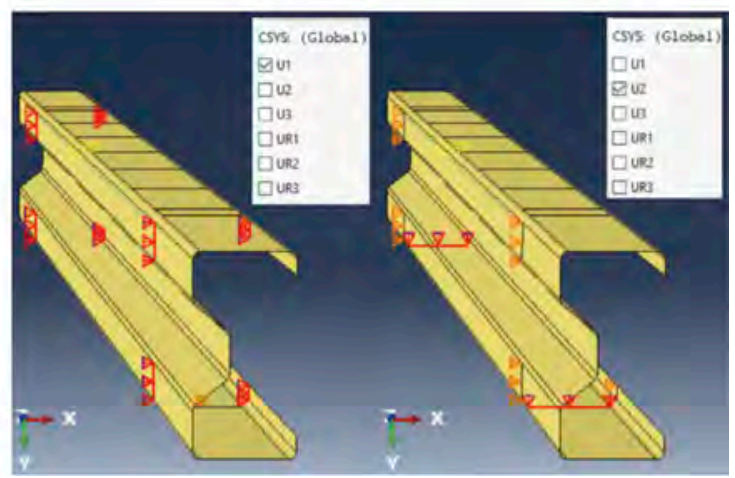

Figure 1. Numerical model. a) cross-section geometry $\Sigma 140 \times 70 \times 2.5$, b) support - displacement constraints.

a)

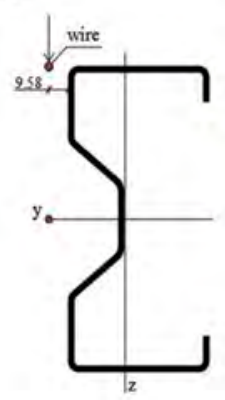

b)

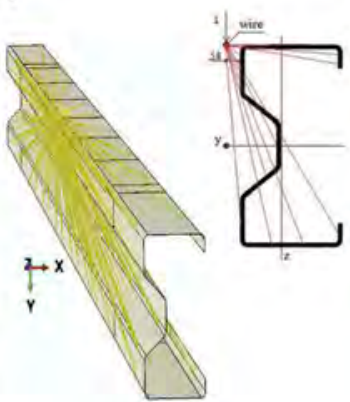

c)

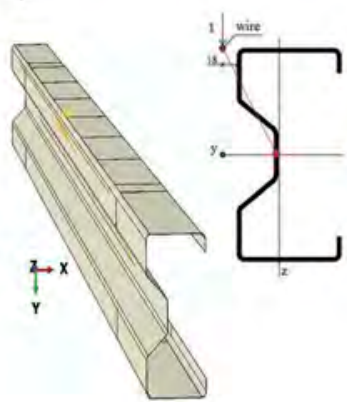

d)

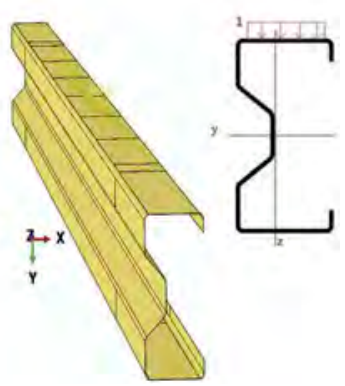

Figure 2. Load application in numerical model. a) WIRE line location, case: b) V1, c) V2, d) V3. 


\section{RESULTS OF NUMERICAL EXAMPLE}

Using Eq. 1 for simply supported, subjected to uniformly distributed load beam with the span of $2.20 \mathrm{~m}$ and made of $\Sigma 140 \times 2.5$ profile the critical moment was determined and it was at a value of $3272 \mathrm{kN} \mathrm{cm}$. The calculations were carried out for simplification of the sigma cross-section geometry in terms of omitting rounding. It is worth noting that the value of the critical bending moment calculated on the basis of the Vlasov beam theory does not take into account the loss of local stability or contour deformation. While, these phenomena can be analysed in the FEM shell model. For all developed FEM numerical models, a multimodal buckling analysis in Abaqus program was carried out. Eigenvalues and shape of three buckling modes are presented in Table 1.

Table 1. Shape of buckling mode and eigenvalue for three buckling mode.

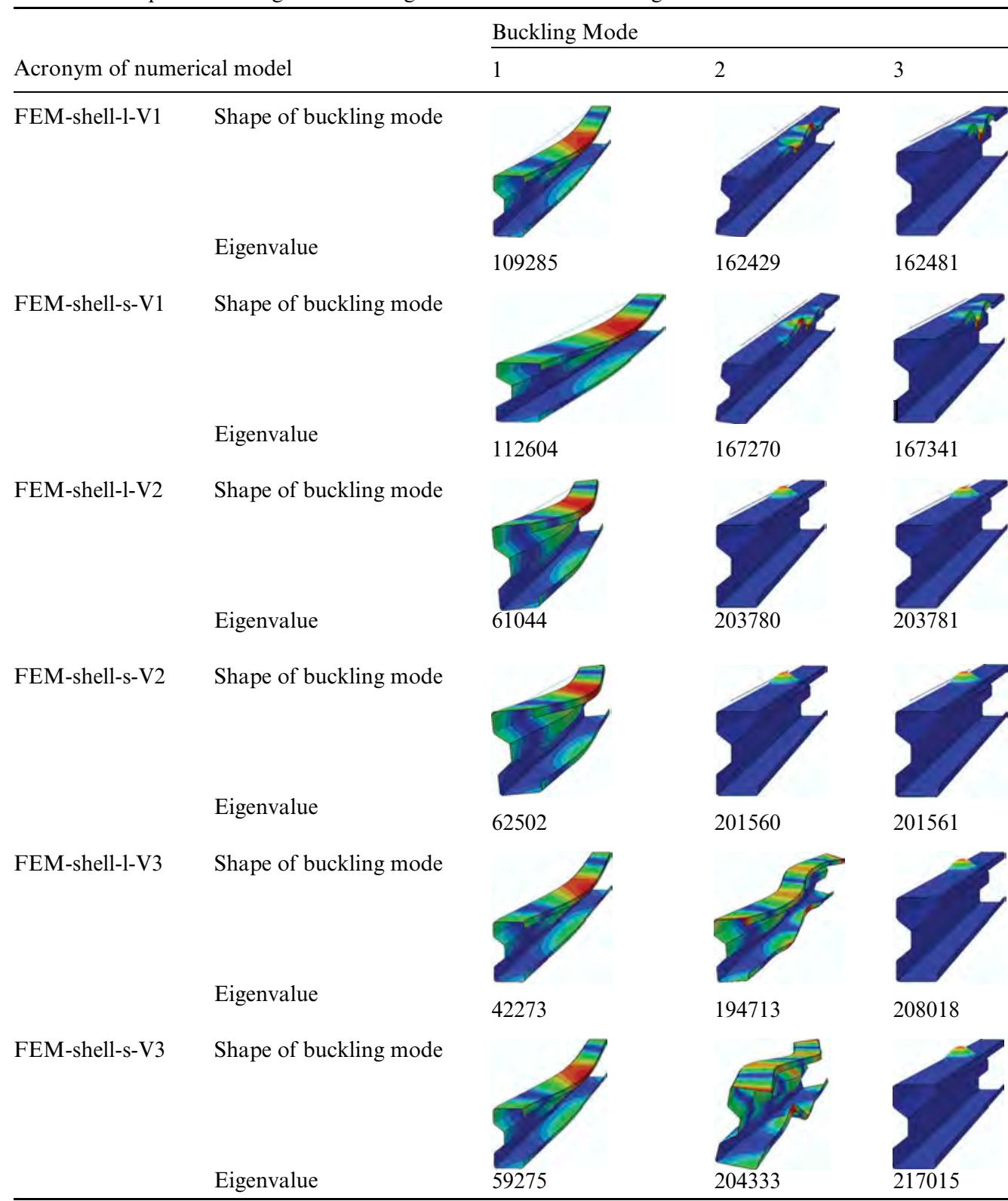


Table 2. Critical moment and critical stress for different numerical descriptions.

\begin{tabular}{lll}
\hline & Critical Moment $M_{c \mathrm{r}}$ & Critical stress $\sigma_{c r}$ \\
\cline { 2 - 3 } Acronym of numerical model & $\mathrm{kNcm}$ & $\mathrm{kN} / \mathrm{cm}^{2}$ \\
\hline FEM-shell-1-V1 & 3005 & 87.57 \\
FEM-shell-s-V1 & 3097 & 90.25 \\
FEM-shell-1-V2 & 1679 & 48.93 \\
FEM-shell-s-V2 & 1719 & 50.09 \\
FEM-shell-l-V3 & 1162 & 33.86 \\
FEM-shell-s-V3 & 1630 & 47.50 \\
Vlasov theory & 3272 & 95.35 \\
BEM-out & - & 28.92 \\
BEM-int & - & 97.62 \\
\hline
\end{tabular}

It can be clearly stated that the type of FE strongly influences on critical bending moment. The analysis of the buckling mode shape leads also to the conclusion that in all the analysed cases and for all buckling modes, the decisive instability type is local buckling of compressed flange. Therefore, it was considered justified to determine the critical stresses for the separated plate corresponding to the compressed flange using the Boundary Element Method (Eq. 4). Due to a number of simplifications related to BEM, the stability of the upper flange was analysed assuming two types of boundary condition, specifically cantilever, thus the flange was analysed as outstand compression walls (BEM-out) and simply supported where the flange was consider as internal compression (BEM-int). In order to performed comparison between analytical and FEM or BEM solution critical stresses were calculated for all considered numerical descriptions (Table 2). One can notice that the lowest values of the critical stresses are obtained for the BEM-out model, which gives the most restrictive values and, according to it, the loss of stability occurred the fastest. At the same time, the highest values of critical stresses are obtained for the BEM-int model, which means that designing the structure using this model may be dangerous. The same is the case of the critical stresses calculated on the basis of the Vlasov theory and in the case of FEM-shell-1-V1 and FEM-shell-s-V1 models. Therefore, these models should be regarded as overestimate and unreliable.

\section{CONCLUDING REMARKS}

On the basis of the conducted analyses, it is possible to formulate a number of interesting conclusions concerning the stability analysis of cold-formed steel elements.

First of all, it is clear that the type of application of the description of the calculation model strongly influences the value of critical stresses. Buckling analysis in FEM showed that the analysed element undergoes both local and global instability, and in many cases the decisive form of buckling is the local stability loss of compression flange. Unfortunately, as is known, theoretical critical bending moment obtained from analytical close form formulas based on so called Vlasov beam theory dedicated to the thin-walled elements does not take local buckling into account. Therefore, it can be seen that the load value obtained from Vlasow theory is much higher than that obtained from the FEM shell model. This means that Vlasow theory should not be directly applied in the analyzed case. It was also demonstrated that for local buckling, it is sufficient to analyse the single wall of the cross-section with the greatest plate slenderness. In this work, due to some BEM method simplification the compressed flange was consider only as outstand or internal wall, while in reality in fact there are semi-rigid support condition. That's why only the upper and lower estimates of the critical stresses were obtained. two such an analysis was performed for a compressed flange treated as a cantilever wall using BEM. On the other hand it should be emphasized that numerical FEM-shell-1-V3 and 
FEM-shell-s-V3 models which reflect the real engineering conditions of external load application simultaneously enable multimodal buckling analysis taking into account local and global buckling as well and provide reasonable values of critical stresses and thus should be regarded as the most suitable.

\section{ACKNOWLEDGEMENT}

This paper was financially supported by Lublin University of Technology: FN15/ILT/2020 and Poznan University of Technology: 0412/SBAD/0044.

\section{REFERENCES}

American Iron and Steel Institute. 1996. Specification for the Design of Cold-Formed Steel Structural.

Bródka J., Broniewicz M., Giżejowski M. 2006. Cold-formed profiles. Designer handbook. PWT, (in Polish).

Guminiak, M. 2014. An Alternative Approach of Initial Stability Analysis of Kirchhoff Plates by the Boundary Element Method. Engineering Transactions 62(1): 33-59.

Guminiak, M. 2016. The boundary element method in analysis of plates (in Polish). Poznan: Poznan Uni-versity of Technology Publishing House.

Karman T., Sechler E.E., Donnel L. H. 1932. Strength of thin plates in compression, Trans. ASME, 54.

Members. Publication CF 96-1. Washington D.C.

PN-90/B-03200: Steel structures - static calculations and design, (in Polish).

Rzeszut K., Folta W., Garstecki A. 2018. Reliability of Engineering Methods of Assessment the Critical Buckling Load of Steel Beams, [w]: Proceedings of the 22nd International Conference on Computer Methods in Mechanics, AIP Publishing, s. 150003-1-150003-7.

Rzeszut K., Szewczak I. 2017. Experimental Studies of Sigma Thin-Walled Beams Strengthen by CFRP Tapes. International Journal of Civil, Environmental, Structural, Construction and Architectural Engineering, Vol.11/2017, No.7, p.888-895. ISNI: 0000000091950263

Rzeszut K., Szewczak I., Różyło P. 2018. Issues of thin-walled sigma beams strengthened by CFRP tape in context of experimental and numerical study. Engineering Transaction, vol. 66, no. 1, 79-91.

Szczerba R. 2013. Load capacity and stability of steel C-section beams, Budownictwo i Architektura 12 (2) 283-290. (in Polish).

Zienkiewicz O.C. 1977. The finite element method in engineering science. London. McGraw Hill. 


\title{
Generalized nonlinear constitutive law applied to steel trapezoidal sheet plates
}

\author{
N. Staszak \\ $R \&$ D Department, FEMat sp. z o.o., Poznań, Poland \\ T. Gajewski \\ Institute of Structural Analysis, Poznan University of Technology, Poznań, Poland \\ T. Garbowski \\ Department of Biosystems Engineering, Poznan University of Life Sciences, Poznań, Poland
}

\begin{abstract}
In the paper, a modified nonlinear finite element method for analysis of trapezoidal plates geometrically reduced to shallow-shell Reissner-Mindlin formulation is presented. Due to the method proposed the complex plate cross-section and nonlinear materials may be modelled and no implementation of advanced constitutive law via user subroutines is needed. The generalized nonlinear constitutive law is used to update the stiffness of the plate element. The method enables modeling of complicated cross-sections, such as steel trapezoidal sheets, metal facing sandwich panels or reinforced concrete. Additionally, for those geometrically complex sections an advanced nonlinear material may be adopted. To verify the proposed method, a selected trapezoidal sheets were modeled in a commercial software as full 3D shell structures. By comparing displacements and forces, it was shown that both models behave almost identically, however, the simplified model has about 300-400 times less degrees of freedom, thus it is much more efficient.
\end{abstract}

\section{INTRODUCTION}

Steel trapezoidal plates are common structures used in civil engineering to cover roofs of industrial buildings. Such structures are easy to produce, transport and install at the building site. Due to its specific structure, they are light and have a very high ratio of load capacity to its mass. They are cheap, both as the material itself and in installation, and especially profitable, if there is a large plain roof area to cover. Its main disadvantage is low acoustic insulation, however, this is usually not the problem for industrial buildings such as warehouses or production halls.

Typical designing of such structures is easy due to detailed technical catalogues with load capacity tables included and released by its producers. However, for deeper strength analysis of the whole system of roofing, namely, steel trapezoidal sheets, bearing beams, roof windows, inspection holes, etc., such a simplified approach seems to be useless. Also, the formulas according to international standards, such as PN-EN 1993-1-3: 2008 - Eurocode 3 are pointless to apply. Moreover, if one would like to take into account a nonlinear aspect of steel or any other material in the system, only the detailed numerical model, for example utilizing a finite element method may give the reliable answer.

On the other hand, simulating the full geometry of the trapezoidal sheets may lead to a computationally very expensive models. In the recent 2020 paper of Zakhimi et al., one may find differentiation on three generations of sheeting, namely, unstiffened (see Figure 1a), 
a)

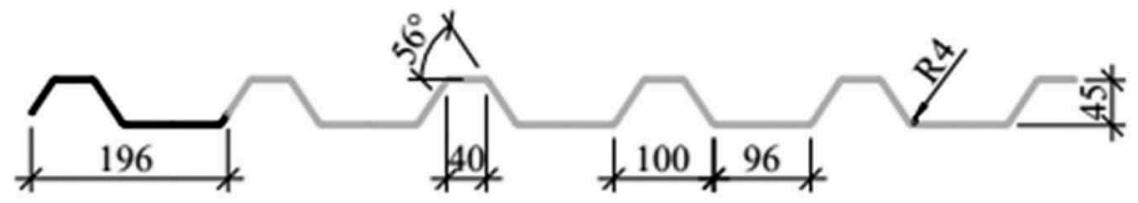

b)

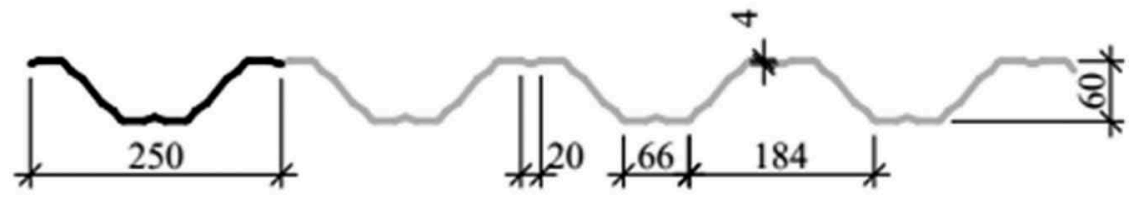

c)

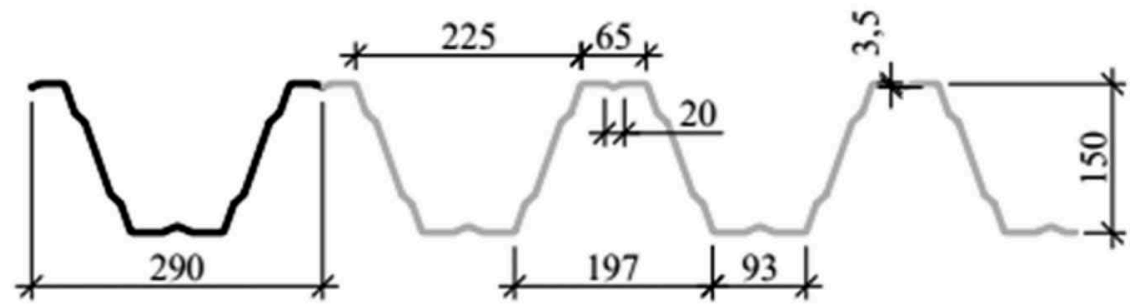

Figure 1. Examples of cross-sections of steel trapezoidal sheets used in civil engineering: a) T45 $(\mathrm{h}=$ $45 \mathrm{~mm}), \mathrm{b}) \mathrm{T} 60(\mathrm{~h}=60 \mathrm{~mm})$ and c) $\mathrm{T} 150(\mathrm{~h}=150 \mathrm{~mm})$.

longitudinally stiffened (see Figure 1b-c), and longitudinally and transversely stiffened. Stiffening is obtained by embossing the sheets. Steel sheets have not only simple idealized trapezoidal shapes, like in Figure 1a, but also more challenging shapes with embossing in two directions to model, see Figure 1b-c. Those profiling sheets due to its additional longitudinal and transverse stiffness are also in common use. The examples of detailed modelling of trapezoidal sheets are for instance available in the papers of Franco \& Batista (2017) or Flodr et al. (2014). Franco \& Batista analyzed what should be the outlines for longitudinal stiffeners called also intermediate stiffeners, in order to maximize the strength and economical objectives. Flodr et al. (2014) considered several numerical models with progressive complexity of modeling. In the paper, in each case the full geometry of trapezoidal sheets was used. As shown, this leads to computationally expensive models. The analytic approach, like the one shown by Mohammadi et al. (2015), is an alternative way to model steel trapezoidal sheets; this approach is not as versatile as the computational approach.

The objective of this paper is to introduce the computational approach to simplify the modelling of the full geometry of trapezoidal sheets in order to obtain a faster and comparably accurate model of finite element method. Finite element method is currently the leading method used for strength analysis of structures. Thus, the proposed modification may be easily implemented in common engineering softwares, without the need of advanced knowledge of finite element special techniques or nonlinear material modelling. The approach utilized in this paper is called the generalized nonlinear constitutive law (GNCL). In the literature, for instance, it was applied to model beams and frame structures as an attractive alternative of modelling full 3D geometries and nonlinear complex constitutive laws of steel or concrete in composite structures, see Łodygowski (1982), Łodygowski \& Szumigała (1992) and Szumigała (2007). In the paper of Mrówczyński et al. (2021), among others, the method was updated with the possibility of including shear effects (Timoshenko theory). The aim of this paper is to apply the GNCL method to model plate structures, in particular to effectively model steel trapezoidal sheets. The concept is original and was not applied before for plate structures. Otherwise the method is easy to use, if one would like to take into consideration in a simple plate modelling not only a complex geometry, but also material nonlinearities of steel instead of building an advanced and computationally expensive FEM model. 


\section{METHODS AND MATERIALS}

In Figure 2a, the overall algorithm of the proposed method is presented. After defining the input data (i.e. node coordinates, boundary conditions and cross-sections), the node displacements and internal forces are computed by using the finite element method. Based on the nodal displacements, the strains (normal strains $\boldsymbol{\varepsilon}_{0}$, shear strains $\boldsymbol{\gamma}$ and curvature $\boldsymbol{\kappa}$ ) are computed, which makes it possible to determine the reduced stiffness of each element. For new stiffnesses, the displacements are computed and subsequent iterations are carried out until the increment of structure displacements is smaller than the assumed tolerance.

In Figure 2b, the stiffness reduction function begins with the division of the cross-section into smaller layers for which the areas and position are determined. Based on the strains determined in the main part of the algorithm, the reduced strains in each layer are determined, and then the reduced stresses, element stiffnesses and the position of the neutral axis are computed. Successive iterations are performed until the change of the position of the neutral axis is smaller than the assumed tolerance. The mathematical formulation of the method proposed may be found in Mrówczyński et al. (2021).

Reissner-Mindlin plate is considered in this paper. Assuming the $x y z$ coordinate system, the displacement field for plates reads:

$$
\begin{gathered}
u(x, y, z)=z \theta_{x}(x, y), \\
v(x, y, z)=z \theta_{y}(x, y), \\
w(x, y, z)=w_{0}(x, y),
\end{gathered}
$$

a)

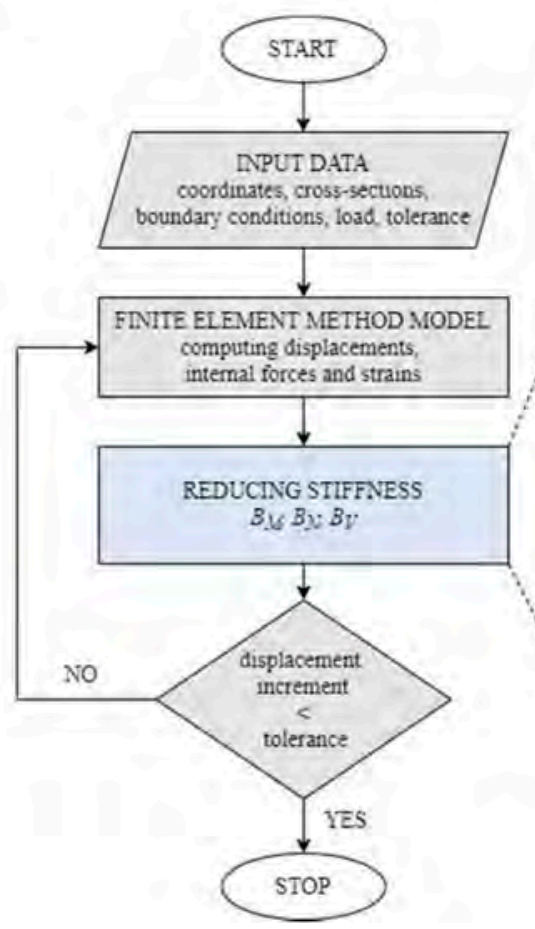

b)

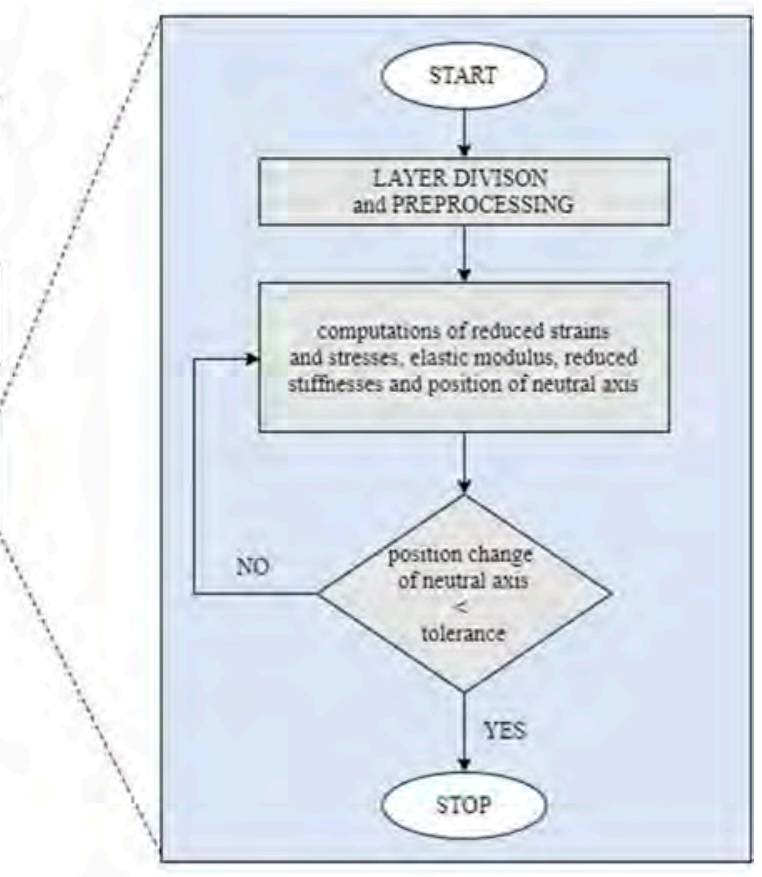

Figure 2. The GNCL algorithm: a) the overall scheme and b) the stiffness reduction function (where $B_{M}$ is bending stiffness. $B_{N}$ is tensile stiffness and $B_{V}$ is shear stiffness). 
where $u, v$ are two in-plane mid-surface displacements, while $w$ is out of plane mid-surface displacement of the plate; $\theta_{x}$ and $\theta_{y}$ are two rotations of the normal on the plane $x z$ and $y z$ :

$$
\theta_{x}=\partial w / \partial x+\phi_{x} ; \theta_{y}=\partial w / \partial y+\phi_{y}
$$

noting that $\gamma_{x}=-\phi_{x}$ and $\gamma_{y}=-\phi_{y}$.

In both the $x z$ and $y z$ vertical planes, the normal rotation was obtained as the sum of two rotations: (i) the corresponding slope of the middle plane of the plate and (ii) the additional rotation $\phi$, which results from the lack of orthogonality of the normal to the middle plane after deformation. Therefore, the rotations $\theta_{x}$ and $\theta_{y}$ cannot be calculated from the deflection only and become independent variables. This is the fundamental difference between ReissnerMindlin and Kirchhoff-Love plate theories. Relationships between strains (membrane $-\boldsymbol{\varepsilon}$, bending $-\boldsymbol{\kappa}$ and shear $-\boldsymbol{\gamma}$ ) and displacements are:

$$
\begin{gathered}
\epsilon=\boldsymbol{\varepsilon}+z \mathbf{\kappa}, \\
\boldsymbol{\varepsilon}=\left[\begin{array}{c}
\varepsilon_{x} \\
\varepsilon_{y} \\
\gamma_{x y}
\end{array}\right]=\left[\begin{array}{c}
\partial u / \partial x \\
\partial v / \partial y \\
\partial u / \partial y+\partial v / \partial x
\end{array}\right]=-z\left[\begin{array}{c}
\partial \theta_{x} / \partial x \\
\partial \theta_{y} / \partial y \\
\partial \theta_{x} / \partial y+\partial \theta_{y} / \partial x
\end{array}\right], \\
\mathbf{\kappa}=\left[\begin{array}{c}
\kappa_{x} \\
\kappa_{y} \\
\kappa_{x y}
\end{array}\right]=-\left[\begin{array}{c}
\partial \theta_{x} / \partial x \\
\partial \theta_{y} / \partial y \\
\partial \theta_{x} / \partial y+\partial \theta_{y} / \partial x
\end{array}\right]=-\left[\begin{array}{c}
\partial^{2} w / \partial x^{2} \\
\partial^{2} w / \partial y^{2} \\
\partial^{2} w / \partial x \partial y
\end{array}\right], \\
\boldsymbol{\gamma}=\left[\begin{array}{c}
\gamma_{x z} \\
\gamma_{x y}
\end{array}\right]=\left[\begin{array}{c}
\partial w / \partial x+\partial u / \partial z \\
\partial w / \partial y+\partial v / \partial z
\end{array}\right]=\left[\begin{array}{c}
\partial w / \partial x-\theta_{x} \\
\partial w / \partial y-\theta_{y}
\end{array}\right]=\left[\begin{array}{c}
-\phi_{x} \\
-\phi_{y}
\end{array}\right] .
\end{gathered}
$$

The stress-strain relations in local coordinates are given by:

$$
\begin{aligned}
& {\left[\begin{array}{c}
\sigma_{x} \\
\sigma_{y} \\
\sigma_{x y}
\end{array}\right]=\frac{E}{1-\nu^{2}}\left[\begin{array}{ccc}
1 & \nu & 0 \\
\nu & 1 & 0 \\
0 & 0 & \frac{1-v}{2}
\end{array}\right]\left[\begin{array}{c}
\varepsilon_{x} \\
\varepsilon_{y} \\
\gamma_{x y}
\end{array}\right],} \\
& \left\{\begin{array}{l}
\sigma_{x z} \\
\sigma_{y z}
\end{array}\right\}=\frac{k E}{2(1+\nu)}\left[\begin{array}{ll}
1 & 0 \\
0 & 1
\end{array}\right]\left\{\begin{array}{l}
\gamma_{x z} \\
\gamma_{y z}
\end{array}\right\},
\end{aligned}
$$

where $k$ is a shear correction factor, or in the compact form

$$
\boldsymbol{\sigma}=\mathbf{C} \in, \boldsymbol{\tau}=\mathbf{C}_{s} \boldsymbol{\gamma}
$$

The strain energy, $U$, reads

$$
U=\frac{1}{2} \int_{A}\left(\in^{T} \boldsymbol{D}^{*} \in+\boldsymbol{\gamma}^{T} \boldsymbol{D}_{s}^{*} \boldsymbol{\gamma}\right) d A
$$

where

$$
\boldsymbol{D}^{*}=\left[\begin{array}{ll}
\boldsymbol{A} & \boldsymbol{B} \\
\boldsymbol{B} & \boldsymbol{D}
\end{array}\right], \boldsymbol{D}_{s}^{*}=\boldsymbol{D}_{s}
$$

and $\mathbf{A}, \mathbf{B}, \mathbf{D}$ and $\mathbf{D}_{s}$ are stiffnesses of the plates given by: 
Table 1. Cross-section characteristics of trapezoidal sheets in $x-z$ plane.

\begin{tabular}{lllll}
\hline \multirow{2}{*}{ Cross-section } & Area & Inertia moment & Sheet thickness & Neutral axis position \\
\cline { 2 - 5 } & {$\left[\mathrm{cm}^{2}\right]$} & {$\left[\mathrm{cm}^{4}\right]$} & {$[\mathrm{mm}]$} & {$[\mathrm{cm}]$} \\
\hline T45 & 1.214 & 3.365 & 0.50 & 2.798 \\
T60 & 1.516 & 8.285 & 0.50 & 3.029 \\
T150 & 4.884 & 144.397 & 1.00 & 7.927 \\
\hline
\end{tabular}

$$
\begin{aligned}
(\mathbf{A}, \mathbf{B}, \mathbf{D}) & =\frac{1}{P} \iint \mathbf{C}\left(1, z, z^{2}\right) d x d z, \\
\mathbf{D}_{s} & =\frac{1}{P} \iint \mathbf{C}_{s} d x d z
\end{aligned}
$$

where $P$ is a wavelength period. For the sake of simplicity, the same stiffness in the $y$ direction was used, which is obviously a false assumption, but does not disturb the solution of the considered here a problem of a unidirectional bending of the plate.

If the matrix $\mathbf{B}$ becomes $\mathbf{0}$ then the membrane and bending effects are uncoupled and the neutral plane coincided with the plane $x y$. This means that the bending moments did not cause any membrane strains and the normal forces did not cause any curvature.

\section{COMPUTATIONAL EXAMPLES}

Here, three examples of a trapezoidal sheet with the cross-sections presented in Figure 1 are considered. The material parameters used in the reference model were selected in accordance with the specifications provided by the manufacturer. The initial sheet stiffnesses were calculated on the basis of equations (14) and (15), the characteristics used to compute $\mathbf{A}, \mathbf{B}, \mathbf{D}$ and $\mathbf{D}_{s}$ matrices are presented in Table 1.

The reference models were built and calculated in Abaqus using S4 shell elements with 4 nodes and 6 degrees of freedom at each node. The number of finite elements used in each model was selected to accurately reproduce the cross-sectional geometry of the trapezoidal sheet and was equal to $15,678,23,450,22,244$ for T45, T60 and T150, respectively. A static nonlinear displacement control analysis was used to generate force-displacement curves for later comparison with the curves obtained from the proposed algorithm described in Section 2, using simple shallow plate elements and GNCL.

\section{COMPUTATIONAL RESULTS}

In Figure 3, the deformed geometry of three trapezoidal sheets are presented, which were obtained from the full geometry reference models. The GNCL algorithm ensures the correct mapping of displacements, the stresses are calculated separately to reduce the equivalent stiffness. Later, only the section forces and moments are available.

Figure 4 shows a comparison of the force-displacement curves obtained from the reference models and from the simplified approach based on a simple shallow plate finite element (50 elements) and the GNCL algorithm described in Section 2. It should be noted that the number of elements used in the simplified (GNCL) models was about 300-400 times smaller than the number of elements used in the reference models.

Figures 3 and 4 show that the simplified methods presented here give results that both qualitatively and quantitatively do not differ from the results obtained from the reference 
a)

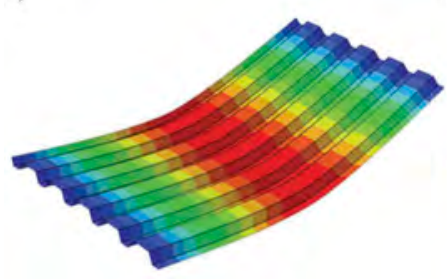

b)

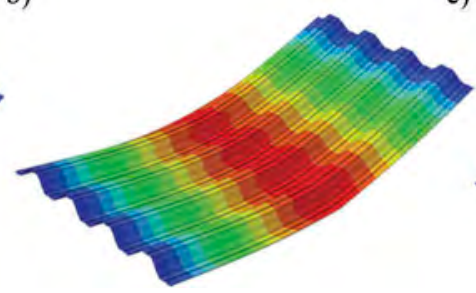

c)

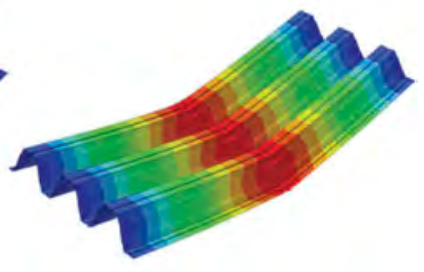

Figure 3. Displacement fields of finite element reference models for a) T45 (15678 elements), b) T60 (23450 elements) and c) T150 (22244 elements).

a)

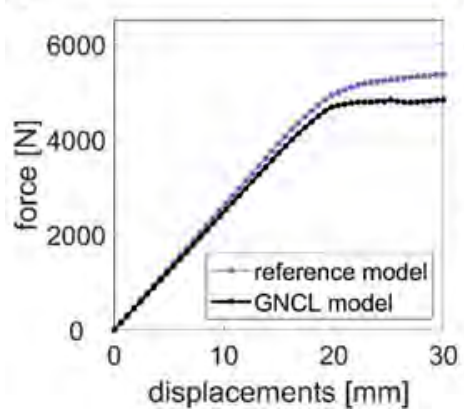

b)

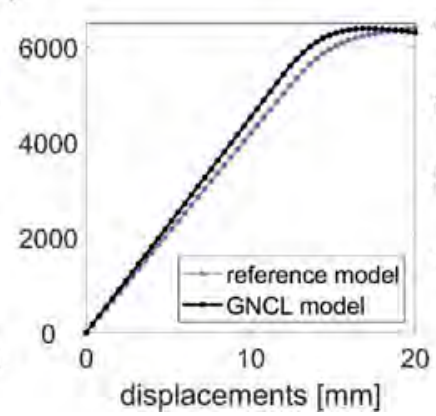

c)

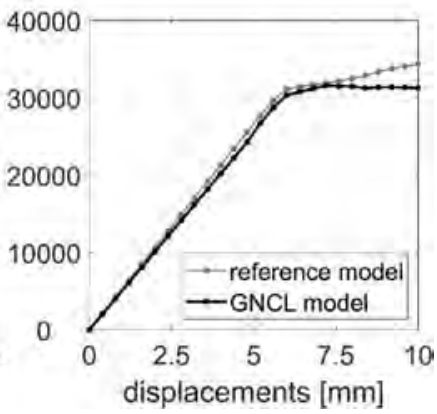

Figure 4. Force vs. displacement plots for trapezoidal sheet of a) T45, b) T60 and c) T150.

models. The difference between the maximal values of force is not greater than $10 \%$, what is acceptable in civil structures, in which the safety factors are much greater. This shows that the approach proposed here can be successfully applied to such calculations.

\section{CONCLUSIONS}

In the paper, the generalized nonlinear constitutive law was applied to steel trapezoidal sheet plates. The comparison between the modelling of full geometry of trapezoidal sheets and simplified approach of GNCL algorithm was presented for three trapezoidal sheets commonly used by designers of such structures. As shown, using the full geometry leads to computationally expensive models. On the contrary, the GNCL method not only, enables faster and similar accurate computations, but also enables, utilizing the material nonlinearities.

\section{REFERENCES}

Flodr J., Krejsa M., Mikolasek D., Sucharda O. \& Zidek L. 2014. Mathematical Modelling of Thin-Walled Cold-Rolled Cross-Section. Applied Mechanics and Materials 617: 171-174.

Juarez Moara Santos Franco \& Eduardo de Miranda Batista 2017. Buckling behavior and strength of thin-walled stiffened trapezoidal CFS under flexural bending. Thin-Walled Structures 117: $268-281$.

Łodygowski, T. 1982. Geometrycznie nieliniowa analiza sztywno-plastycznych i sprężysto-plastycznych belek i ram płaskich. Warsaw.

Łodygowski, T. \& Szumigała, M. 1992. Engineering models for numerical analysis of composite bending members. Mechanics of Structures and Machines 20: 363-380. 
Mohammadi H., Ziaei-Rad S. \& Dayyani I., 2015. An equivalent model for trapezoidal corrugated cores based on homogenization method. Composite Structures 131: 160-170.

Mrówczyński D., Gajewski T. \& Garbowski T., 2021, Application of the generalized nonlinear constitutive law in 2D shear flexible Beam Structures, Archive of Civil Engineering (accepted for publication).

PN-EN 1993-1-3: 2008 - Eurocode 3: Design of steel structures - Part 1-3: General rules - Supplementary rules for cold-formed members and sheeting, 2008.

Szumigała, M. 2007. Zespolone stalowo-betonowe konstrukcje szkieletowe pod obciążeniem doraźnym. Wydawnictwo Politechniki Poznańskiej. Poland.

Trapezoidal tables for sheets T45/196, T60/250 and T150/290. Technical catalogue for designers. Blachy Pruszyński. [https://pruszynski.com.pl/catalogue.php, online access: 5/11/2020].

Zakhimi H., Hofmeyer H., Snijder H.H, \& Mahendran M. 2020. Explicit and interaction direct strength methods for combined web crippling and bending moment failure of first-generation trapezoidal steel sheeting. Thin-Walled Structures 157. 


\title{
Experimental tests of second generation trapezoidal sheets
}

\author{
T. Szumigała \\ Institute of Building Engineering, Poznan University of Technology, Poznań, Poland
}

\begin{abstract}
This paper presents results of experimental tests of second generation trapezoidal sheets of various heights and thicknesses. The presented research program and test stand were prepared in order to meet the assumptions of the calculation model and to eliminate additional unfavourable factors influencing the ultimate bearing capacity. A series of tests of trapezoidal sheets of various heights $(135$ and $153 \mathrm{~mm})$ and of various thicknesses - 3 thicknesses for each type of sheet, was carried out. In total, 12 sheets were tested - 2 samples of each thickness. The results of the experimental tests were used to verify the numerical FEM model, which in turn will be used to carry out a dozen of parametric analyses necessary for the process of optimizing the geometry of the troughed sheet as the final task. The conclusions turned out to be promising and therefore the created model can be used in planned parametric analyses.
\end{abstract}

\section{INTRODUCTION}

Advanced manufacturing technologies and anti-corrosion protections made cold-formed, thinwalled steel profiles widely used in modern building structures. Use of thin sheets brings considerable benefits, such as lower material consumption, although it also can cause some difficulties. This type of structure is sensitive to initial geometrical imperfections and has tendency to local instability, especially in conjunction with global loss of stability. Therefore, the issue of local stability of cold-formed, thin-walled profiles has become the subject of scientific and technical research. Trapezoidal sheets are currently the most popular material used for light cladding of walls and roofs of halls and are used in many applications in general and industrial construction, as well as road and bridge construction. They are widely used as permanent formwork in the composite steel-concrete ceilings (GRISPE PLUS, 2018) and as a part of steel-soil composite structures in road culverts. Troughed sheets can function as self-supporting hall structures (Piekarczuk 2013). They can also stabilize structural elements (Rzeszut \& Chwiałkowska 2014), (Sokó 1996). The demand for this type of product in industry is therefore considerable. On the other hand, the manufacturers try to optimize production costs and cross-section geometry (steel consumption) in fierce competition. Various shapes and sizes of trapezoidal steel sheeting are available, their thickness usually varies from $0.5 \mathrm{~mm}$ to $1.5 \mathrm{~mm}$. However, the producers are still searching for new solutions in order to improve their products. Hence, the optimization problem is still valid and that is the reason for interest in that issue. The authors of this paper already made some initial analyses to determine the optimal cross-section of the above discussed element. Those works brought some conclusions which will be useful in more complex analyses and gave some general idea how modification of the particular walls of the cross-section affects its efficiency (Rzeszut \& Szumigała 2019). The research has been continued by preparing advanced numerical model and conducting physical experiment. The results of the test were used to verify both Eurocode methods (Pięciorak \& Piekarczyk 2012) and numerical analyses. Subsequently, the FEM model will be used for parametric analyses, essential for geometry optimisation of the trapezoidal sheet, which is the main objective. 


\section{DESCRIPTION OF TEST STAND AND PROGRAM}

Carrying out physical experiments for each of the postulated trapezoidal sheet geometry is too expensive and practically difficult to implement. The optimization of the cross-section is often associated with the minimization of the thickness of the sheet what causes that the load capacity is usually determined by the local loss of stability. Local buckling is a random phenomenon and strongly depends on initial geometrical imperfections. In order to obtain the real load-bearing capacity of such sheets by means of a physical experiment, many tests must be carried out and the results statistically analysed. It is not possible. The solution of this problem is to conduct a series of numerical and parametric analyses instead of laboratory tests. However, the numerical model used for these analyses should be experimentally verified. The presented experimental studies serve this purpose. It was decided to verify the numerical model only for the simple case of pure bending, neglecting the transverse forces that may affect the bearing capacity of the compressed (crippled) webs on the supports and at the point of the load application. The examination of the conventional case of "pure bending" was difficult to implement in practice, therefore the classic case of four-point bending, i.e. two concentrated forces in the span, spaced at 1/3 of the span length, was used. The stand available in the laboratory allowed to test elements with typical spans and such a length of sheets was assumed, namely $6 \mathrm{~m}$. The width of the element was equal to the standard width of the given type of sheet, e.g. $882 \mathrm{~mm}$. The scheme of the stand is shown in Figure 1.

The introduction of the external load in the form of two concentrated forces required the use of an additional intermediate structure to convert one force from the piston actuator into two forces transferred to the tested trapezoidal sheet. Initially, it was a wide-flange beam (H-section), which failed the first test. After the pilot tests of the first sheet, it was found that the existing test stand is unsuitable due to the highly dynamic nature of the failure mode. The testing process could turn out to be dangerous both for the valuable measuring apparatus and for the laboratory staff. Also, the uniformity of the linear load distribution was questionable due to the high flexibility of the plates and the low stiffness of the linear element transferring the load.

The stiffness of this element together with the timber blocks was insufficient and it was difficult to regard the load as linear and uniformly distributed. Therefore, another method of imposing almost uniform load was searched for. It was decided to replace single H-section with a special horizontal frame made of rectangular hollow sections. This element should be quite light and simultaneously rigid so that the initial loading of the sheet with auxiliary elements is not too significant in relation to the load capacity. A solution was chosen as it is shown in Figure 2 and after carrying out computational analyses taking into account the compliance of the sheet, it turned out that the load distribution is linear and uniform.

Linear loads should be applied to the tested sheet in such a way as not to cause local crippling of the webs and thus distorting the bending resistance. Similar situation occurred at the supports zone. It was decided to suspend the sheet at the supports, which means, support it only in the upper flanges in each fold and the load apply only in the lower flange (GRISPE 2015). For this purpose, special timber blocks adapted to the dimensions of the sheets were prepared. Those elements located on the supports are based on a special movable, hinge
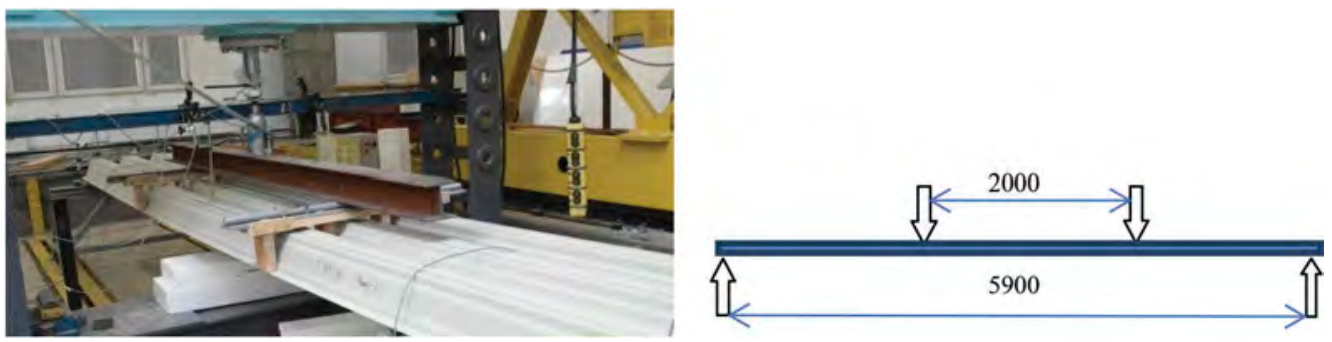

Figure 1. The experimental stand and scheme. 

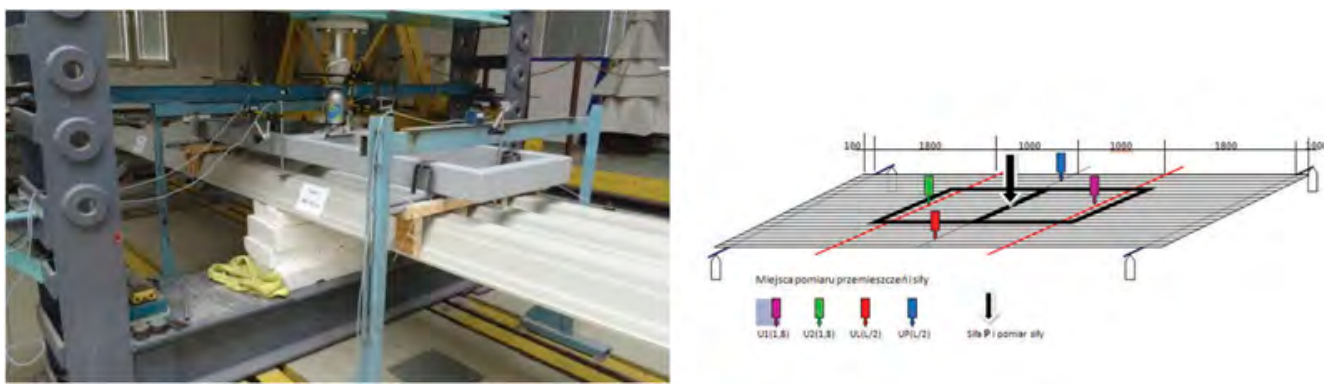

Figure 2. Modified laboratory stand.

support structure. On the elements located in the place of the applied load, special flat bars with welded round bars are placed in order to precisely locate the load. On the flat bars the above-mentioned frame transferring the load from the actuator is set. Due to the dynamic nature of the experiment, all elements were connected, as shown in Figure 3. A single trapezoidal sheet has a tendency to deformation of the cross-section (distortional deformation), which does not occur in real constructions, as the adjacent plates block this possibility. Hence, there was a need to ensure similar conditions and fasten the plates from below both at the supports and at the place of load application, as shown in Figure 4.

The performed numerical analyses showed that the experiment should introduce displacement control in order to observe the maximum value on the static equilibrium path, i.e. the load capacity of the element. Therefore, in the physical experiment, the force was introduced by creating a displacement. The view of the research stand with the tested element is shown in Figure 4. The tests were carried out until the slab was destroyed. The mode of failure is presented Figure 5.

During the test cycle, an automatic and continuous reading of the force and displacement was performed ("Catman" system) at selected points (Figure 2). The displacements were measured with inductive sensors (Figures 3,5) positioned in the centre of the span and at the point of direct application of the forces. A professional dynamometer was used to measure the force exerted by the hydraulic cylinder.
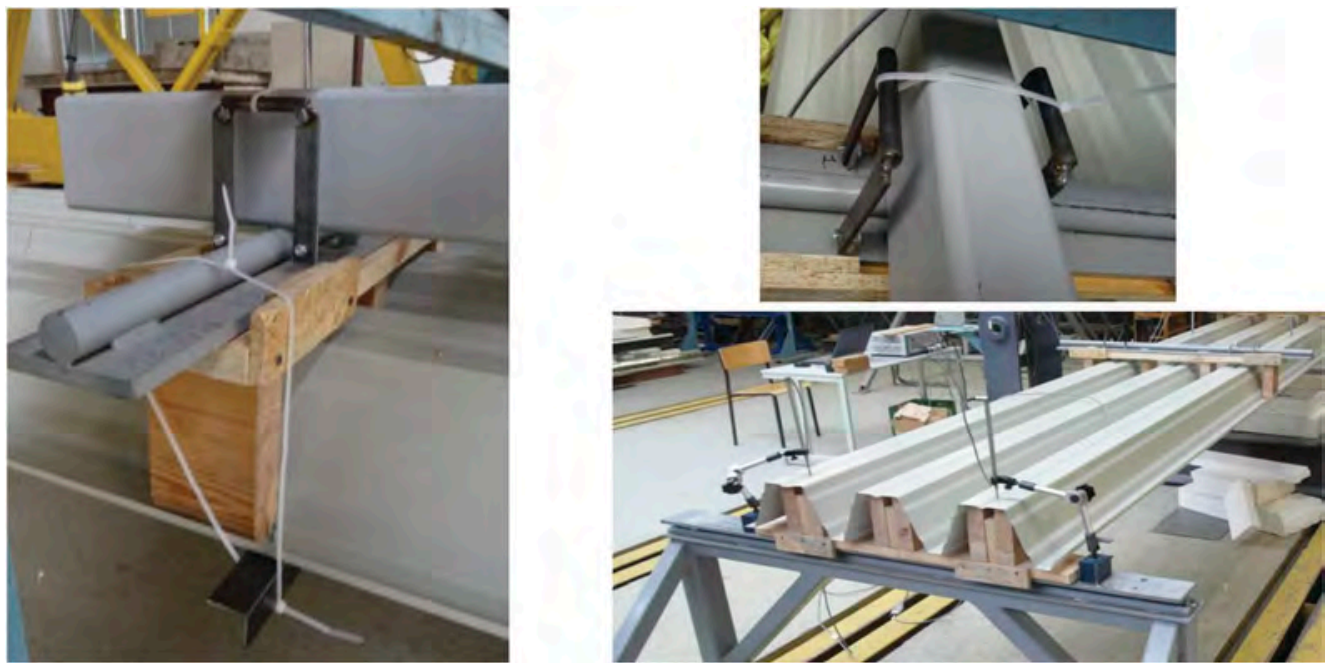

Figure 3. The supporting elements. 

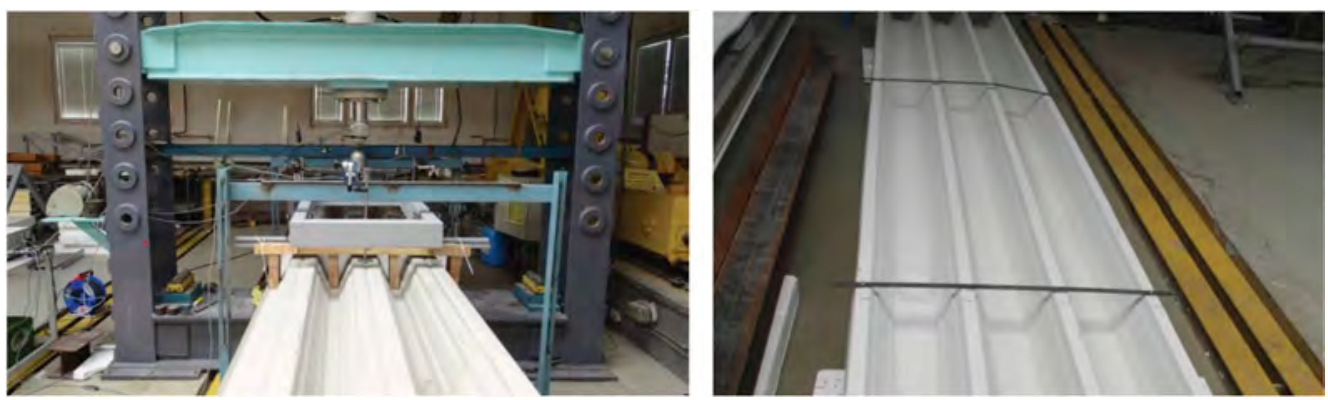

Figure 4. View of the test stand and transverse ties (stabilizing the sheet).
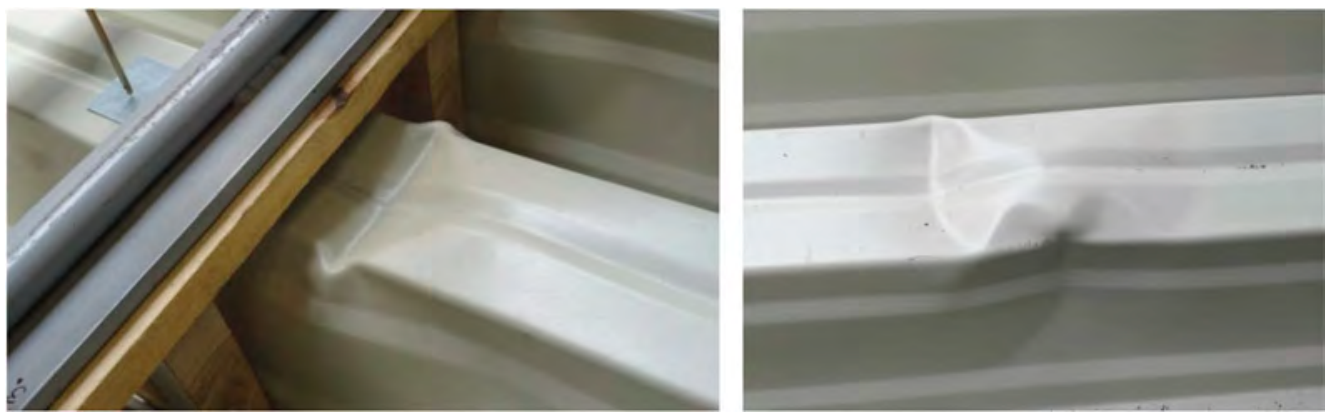

Figure 5. Failure modes.

\section{RESULTS OF THE PHYSICAL EXPERIMENT}

Information concerning the parameters of the material of the sheet was necessary to enable verification of the numerical model by the results of the physical experiment. For this purpose, material coupon tests were also carried out. Samples for the standard steel tensile test were prepared (cut using a stream of water) - Figure 6.

The samples were cut from different places of the cross-section of the sheet (flanges and webs). In order to avoid distortions of the results caused by the mechanical cutting process (overheating), it was decided to cut samples from the metal sheets with a water stream under high pressure. Before the test, the samples were carefully inventoried in terms of dimensions and it turned out that the declared thicknesses of the sheets are only a standard designation, and the actual thickness of the sheets is smaller according to the acceptable deviation. It was a very important observation from the point of view of the accuracy of geometrical data entered into numerical analyses. The samples were placed in the jaws of an "Instron" testing machine (Figure 6), an extensometer was mounted and the tests were carried out in accordance with the procedures, and the results obtained during the examination with the "Catman" software are presented in Figure 7.

\section{COMPARISON OF THE RESULTS OF THE PHYSICAL AND NUMERICAL EXPERIMENT}

A numerical model was prepared in the Abaqus system. The trapezoidal sheet was modelled with shell elements. The load was assumed in accordance with the experimental model, i.e. it was located in the lower part of the fold as a vertical extortion. The model includes also transverse ties (bracing elements). The support conditions were applied to the top of the folds as it 


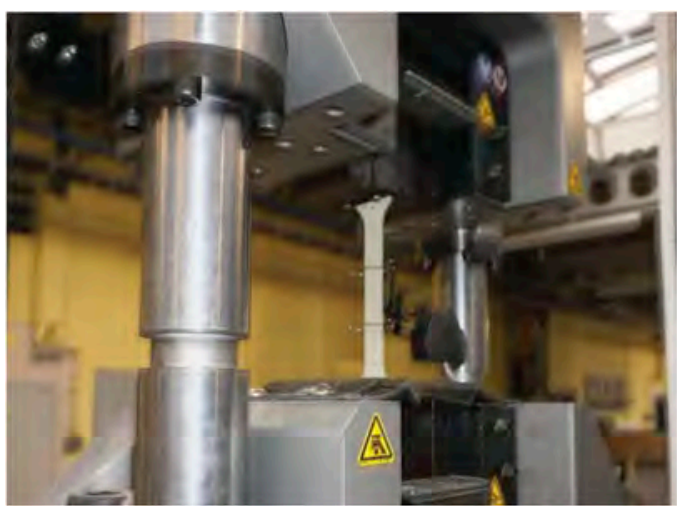

Sample $110 \mathrm{pc}$. (to be made of the elements $\mathrm{A} 1, \mathrm{~A} 2, \mathrm{~B} 1, \mathrm{~B} 2, \mathrm{C1}, \mathrm{C2}, \mathrm{D} 1, \mathrm{D} 2$ )

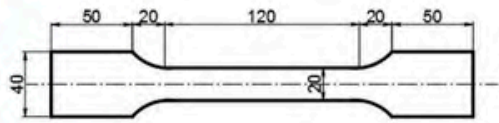

Sample $110 \mathrm{pc}$. (to be made of the elements $\mathrm{A}, \mathrm{B}, \mathrm{C}, \mathrm{D}$ )

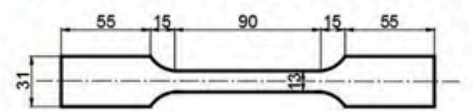

Figure 6. Standard tensile test of steel and samples.

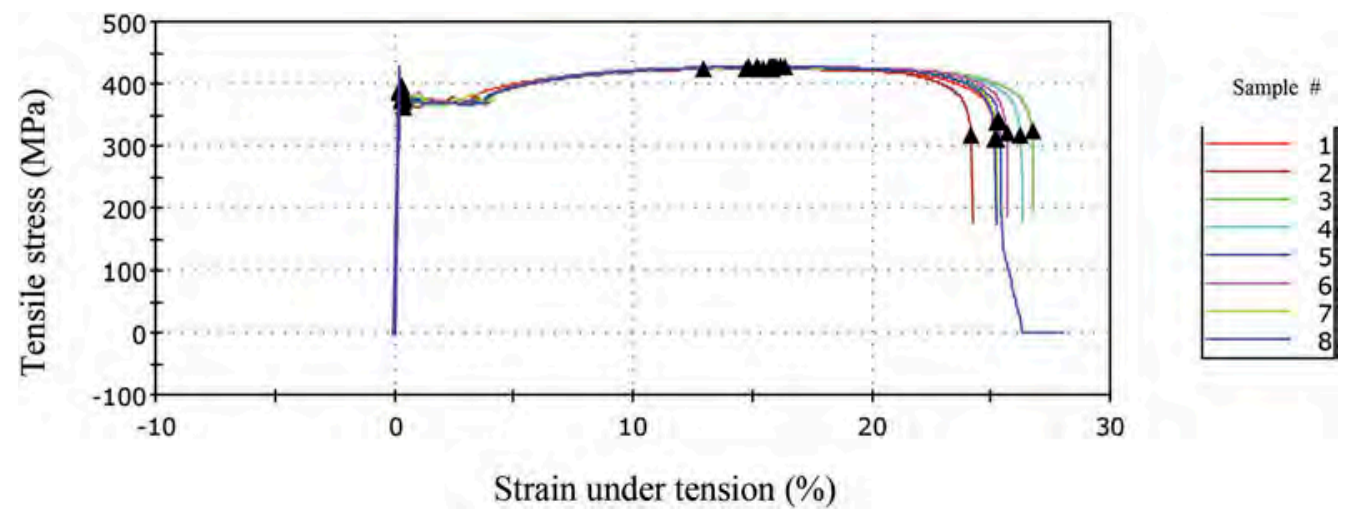

Figure 7. Stress-strain graph for steel sheets based on the experiment.

was in the tested model. The calculations were initially carried out in the Standard procedure using the Newton-Raphson incremental method. In the calculations using this method, it was not possible to unequivocally observe the maximum for the load-displacement static equilibrium path, despite the use of nonlinear procedures. Therefore, it was decided to use a different computational approach consisting of explicit integration method to solve equations of motion and the Explicit procedure to model the dynamic phenomenon (such was the nature of the failure of the sheet). The advantage of this method is that there is no need to look for convergence what is important for large deformations.

After numerous attempts, a numerical model was built. The actual sheet geometry and the measured mechanical properties of the steel were introduced, the parameters of the procedure were selected so that finally the results obtained were sufficiently consistent in terms of stiffness with the results of the experiment (Figure 8).

The AbaquslExplicit procedure for explicit integration of the kinematic equations of motion does not require the search for convergence in each iteration step and allows to better describe the behaviour of the plates (cross-sectional walls) in the experiment, and even to obtain similar forms of deformation at failure (Figure 9). 


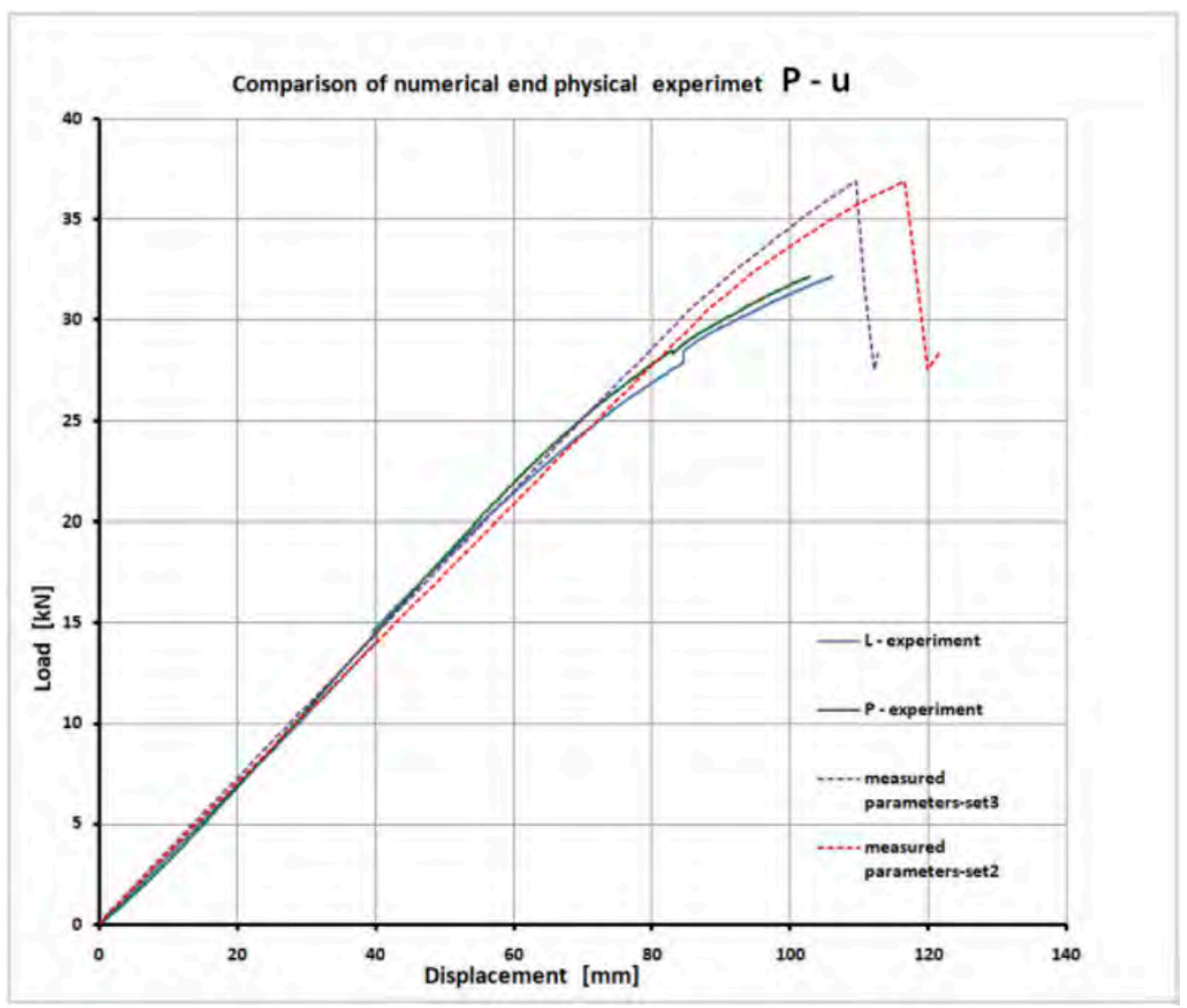

Figure 8. Comparison of results of experiment and numerical analyses.

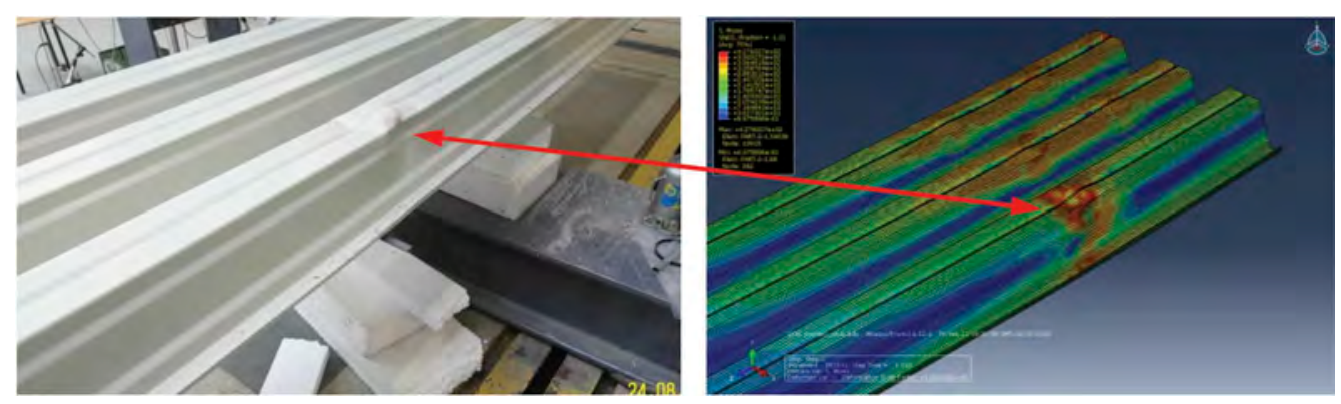

Figure 9. Similar failure modes in numerical analysis and physical experiment.

\section{CONCLUSIONS}

Based on the physical experiment of trapezoidal sheets, it can be concluded that the prepared numerical FEM model using the Explicit procedure is effective and it can be considered that it has been sufficiently verified in order to conduct further parametric analyses, which are necessary in the next part of the work consisting of conducting optimization analyses of the geometry of trapezoidal sheets (Rzeszut \& Szumigała 2019). Due to appropriately selected 
boundary conditions, both in the physical and numerical model, it was possible to eliminate additional effects consisting of the crippling of the webs, which could have had an impact on the results. Another problem to solve is establishing a parameter that measures the quality of optimization.

\section{ACKNOWLEDGEMENT}

This paper was financially supported by Poznan University of Technology: 0412/SBAD/0044.

\section{REFERENCES}

GRISPE PLUS Valorisation of knowledge for specific profiled steel sheets, WP $\mathrm{N}^{\circ}: 3$, WP Title: eLectures: Interactive electronic lectures, Deliverable $N^{\circ}$ : D3.1, Deliverable Title: Steel decks with embossments, Deliverable Date: 31st of March 2018.

GRISPE Test report of steel trapezoidal sheeting with and without embossments and outward stiffeners, Annex, 31.10.2014, Deliverable D 1.3 (Rev03. 29. June 2015).

Pięciorak E, Piekarczyk M., Wyznaczanie efektywnego przekroju zginanej blachy trapezowej w ujęciu normy PN-EN 1993-1-3, Czasopismo Techniczne, zeszyt 20, rok 109, Politechnika Krakowska 2012.

Piekarczuk A., Nowoczesne rozwiązania konstrukcyjne hal łukowych dla budownictwa rolniczego, Budownictwo i Architektura 12(2) (2013) 259-266 Politechnika Lubelska.

Rzeszut K., Chwiałkowska K., Nieliniowa analiza numeryczna stalowych belek pełnościennych stężonych przeciwskrętnie blachą trapezową, ZK2014 - Metal Structures 2-4 July 2014, KielceSuchedniów, Poland.

Rzeszut K., Szumigała T., Optimal design methods of trapezoidal steel sheets, AIP Conference Proceedings, Vol. 2060 (2019), DOI: 10.1063/1.5086142

Sokół L., Stability of cold formed purlins braced by steel sheeting. Thin - Walled Structures, 1996, $25,247-268$. 
Composite structures 


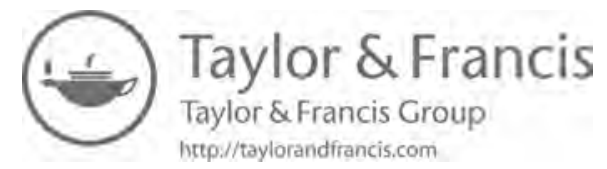




\title{
Resistance of a new type of flat shear connectors dedicated to composite columns
}

\author{
M.P. Chrzanowski \\ Arcelor Mittal Steligence ${ }^{\circledR}$, Warsaw, Poland \\ C. Odenbreit \\ AMCSC, FSTM, RUES, University of Luxembourg, Luxembourg \\ R. Obiala \& T. Bogdan \\ Global R\&D, ArcelorMittal, Esch-sur-Alzette, Luxembourg \\ H. Degée \\ FET, CERG, Hasselt University, Hasselt, Belgium
}

\begin{abstract}
The current practice to assure composite action foresees the usage of headed studs. This type of mechanical shear connectors was developed for composite beams and only adopted for the column's usage. Application in composite columns could lead to a reduced economy, especially for heavy composite columns used in high-rise buildings. A new type of flat shear connectors was developed and characterized that allows for fully automatic application process. This secures an increased safety of the whole structure, improved performance, optimized cross-section, reduced manufacturing time and costs. The presented paper gives a short description about the development process and focuses on the proposed analytical model describing the resistance of flat shear connectors. The developed analytical model comprises the complex stress state, which is present in the highly confined concrete directly under the connectors. The assumptions and theoretical models were confirmed in complex nonlinear FE simulations performed in the Abaqus software.
\end{abstract}

\section{INTRODUCTION AND MOTIVATION}

Heavy composite columns with multiple encased steel profiles can be found in the structural systems of high-rise buildings, like for example IFC Tower 2 in Hong Kong. A clear trend that cities are build more vertical can be observed in the work of Al-Kodmany (2012). Modern high-rise buildings moved beyond the scopes of applicability of current design codes, like EN1994-1-1 (2004). Typical structural solutions became no more attractive. In the case of composite columns, normally shear connection at the steel-concrete interface is secured by the application of shear studs. There exist other types of connectors, like for example welded stiffeners SmartCoCo (2016), bar connectors Roik (1984), channel sections Johnson (2004), T-sections Roik (1980), burls Roik (1984), perfobond solution Vianna (2009) or bearing plates Roik (1988) \& Hanswille (2004). In some cases, this solutions bring a problematic application process, where the construction safety, economy and erection are hardly meet. An example of shear studs and their application is shown in Figure 1. A replacement of the commonly used shear connectors with a new and more efficient solution dedicated to columns would be highly beneficial. 
a)

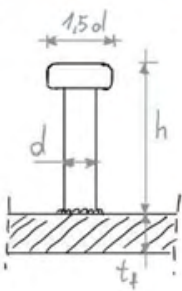

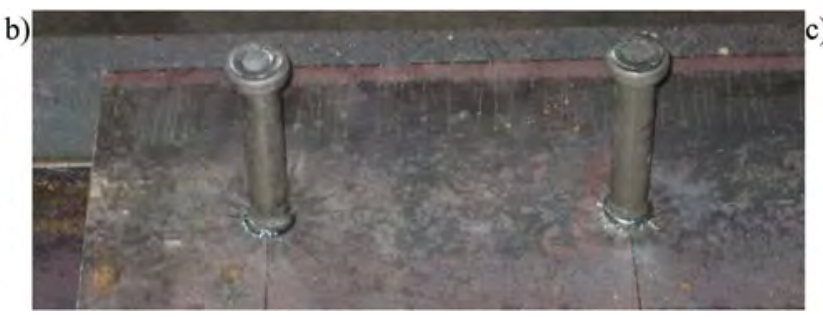

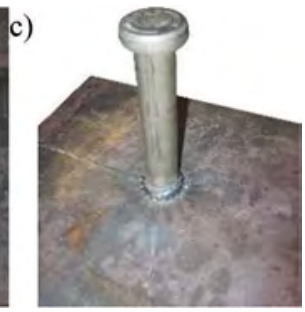

Figure 1. Shear studs: a) scheme, b) welding and c) detail (Source: DISCCO (2016)).

a)

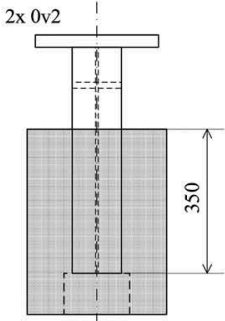

b)

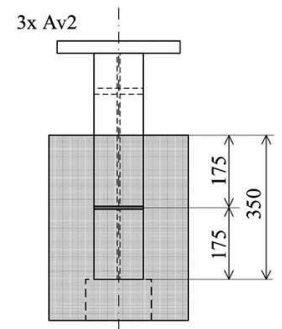

c)

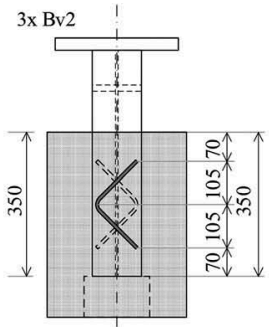

d)

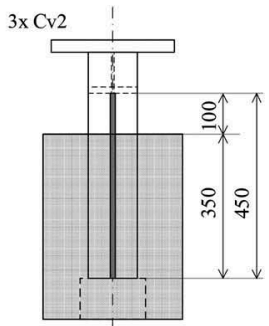

Figure 2. Layout of flat shear connectors: a) reference, b) transversal, c) V-shaped and d) longitudinal.

The developed new flat shear connectors dedicated to composite columns are made from regular reinforcement bars welded to the flanges of embedded steel profiles in a specific arrangement, as shown in Figure 2. Analysis of all variants, including distinction on mechanical bearing and bond phenomena, gave full understanding of the behaviour of flat shear connectors. Moreover, each variant can be subjected to the fully automatized application process. This directly improves the economy of the composite solution and help the entire construction process.

\section{TEST CAMPAIGN ON NOVEL SHEAR CONNECTORS}

To characterise the developed novel flat shear connectors, 11 column push-out tests were performed, where three variants of connectors - transversal, longitudinal and angled were tested, see Table 1. Two reference tests without mechanical shear connectors were included. All specimens had nominally identical geometry as shown in Figure 3. Detailed information about the test campaign can be found in Chrzanowski (2019).

The performed tests revealed the load-slip behaviour of flat shear connectors (Figure 4), where not only the load capacity was of importance, but also the stiffness and ductility. Failure patterns of tested connectors were studied in detail after opening of the specimens. Based on the taken observations and measurements, it can be observed that the best performance is indicated by the connector type Bv2, where all force transferring phenomena are combined. The occurred failure planes were noticed and respective strut-and-tie models were built. In order to investigate the load flux and precisely identify the failure sequence, numerical simulations in the 3D Finite Element (FE) software were crucial and supported the test campaign. The entire procedure, as well as the developed theoretical and numerical models are described in Chrzanowski (2019). 
a)
RB500B
(1) - longitudinal Ø10
(2) - stimups Ø12
(3) - U-links Ø12

Reinforcement bars

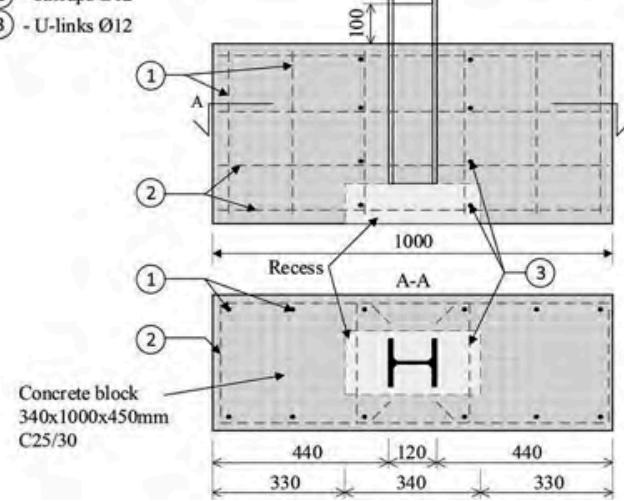

b)

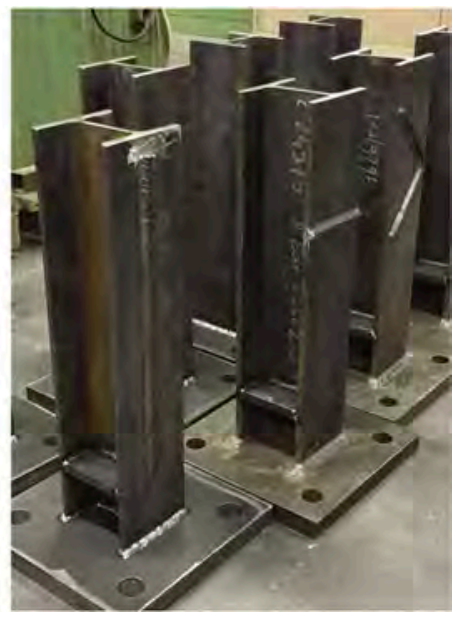

Figure 3. Geometry of push-out test specimens: a) scheme and b) view on welded flat shear connectors.

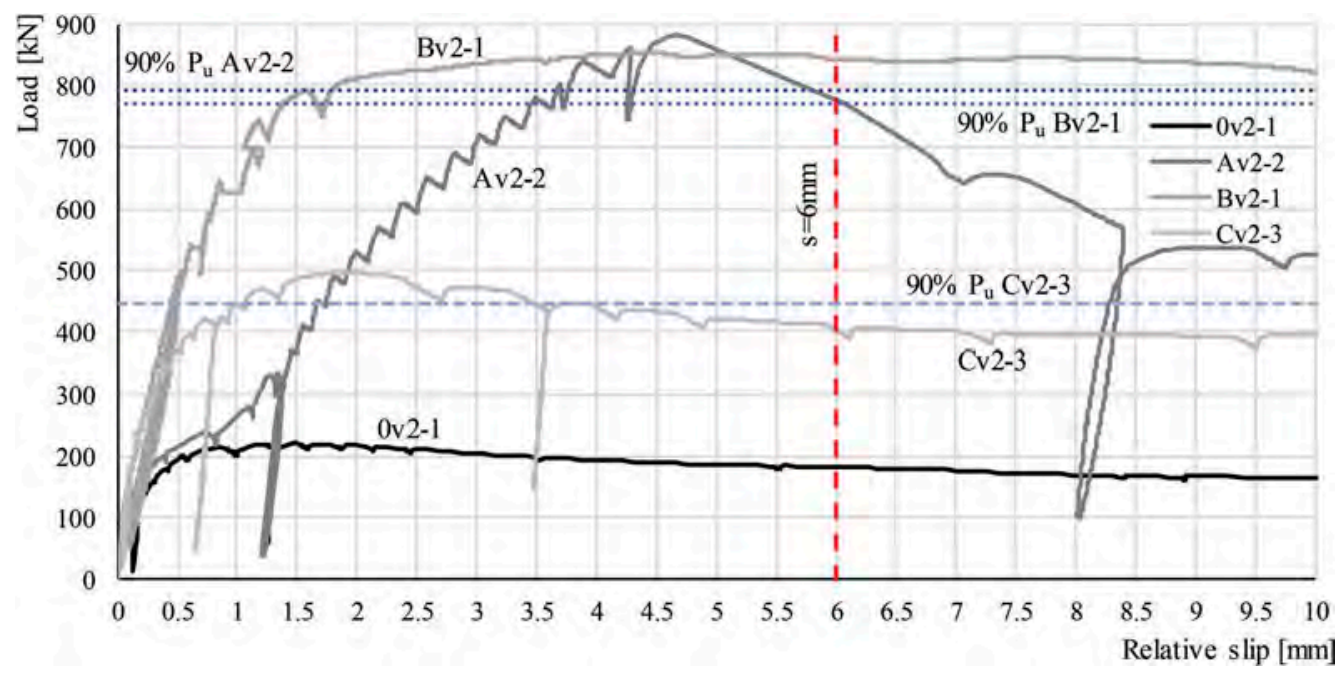

Figure 4. Load-slip behaviour of representative specimens for each type of flat shear connectors.

Table 1. Overview of the push-out test specimens.

\section{No of}

Series specimens Shear connection

0v2 2

Av2 3

Bv2 3

Cv2 3
Reference tests: no connectors (Figure 2a)

Flat shear connector, transversal

(Figure 2b)

Flat shear connector, angled, V-shaped

(Figure 2c)

Flat shear connector, longitudinal (Figure

2d)
Surface treatment

Cleaning: No

Coating: Release agent - demoulding oil 


\section{NUMERICAL SIMULATIONS OF THE PERFORMED PUSH-OUT TESTS}

Numerical simulations were performed in the FE code Abaqus (2017). Created models reflected the experimental campaign. In the developed models (i) the concrete confinement according to fib ModelCode 2010 (2000), (ii) the steel profile-concrete bond and (iii) connector-concrete bond were represented. All details about modelling are described in Chrzanowski (2019). Performed numerical study consisted of 267 simulations. A good coherence between the test and numerical results was obtained, as it can be observed in Figure 5.

\section{ANALYTICAL MODEL FOR THE RESISTANCE OF FLAT SHEAR CONNECTORS}

Based on the obtained load-slip curves (Figure 4), developed failure and strut-and-time models and insight to the load flux and failure sequences from FE simulations (Figure 5), the development of an analytical model describing the resistance of discussed novel flat connectors was possible. It is strictly referring to the test campaign and the following fundamental assumptions were used: (i) materials are homogenous, (ii) theory of elasticity covers the behaviour, (iii) stirrups are not undergoing deformation, (iv) long-term effects were disregarded and (v) no safety concept was used. The detailed derivation process can be found in Chrzanowski (2019).

The contribution of steel-concrete bond was assessed based on the reference specimens by employing an equation for the definition of stresses and removing the Coulomb frictional forces.

From the specimens with the longitudinal connector, the connector-concrete bond strength can be assessed. Considering only the contribution of the connector, all other contributing resistances should be removed, see Equation 1. Combining the relation for the definition of stresses and model from the fib ModelCode 2010 (2000) for the reinforcement bar-concrete anchorage strength $\tau_{b \max }=2.5 \sqrt{f_{c m}}$, where $f_{c m}$ is the mean concrete compression strength, the resistance of longitudinally oriented flat shear connector can be described by Equation 2.

$$
\begin{gathered}
F_{\text {connector }}=\left(F_{\text {test }}-F_{\text {bond steel prof }}-F_{\text {friction }}\right) / 2 \\
P_{R, b, C v 2}=2.5 \cdot \pi \cdot \lambda_{u} \cdot d \cdot L_{\text {emb }} \cdot \sqrt{f_{c m}}
\end{gathered}
$$

where $2=$ number of applied connectors, $\lambda_{u}=$ connector perimeter utilization factor, $d=$ connector diameter, $L_{e m b}=$ embedded length of the connector.

The transversal and longitudinal variants of flat shear connectors are specific cases of the angled variant, when the connector arm inclination angle is set to $90^{\circ}$ and $0^{\circ}$ respectively. In the angled variant, the vertical shearing of concrete should be considered in addition, as

a)

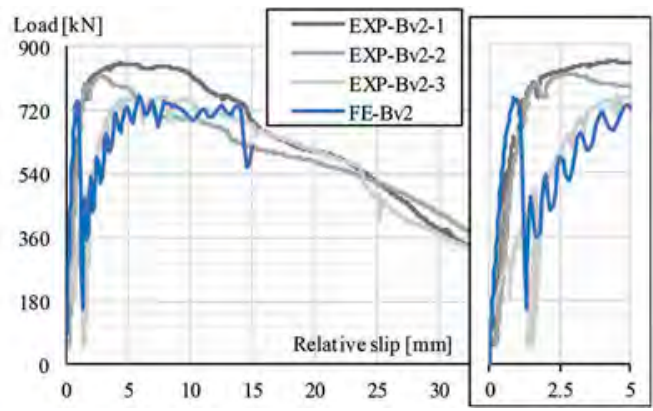

b)
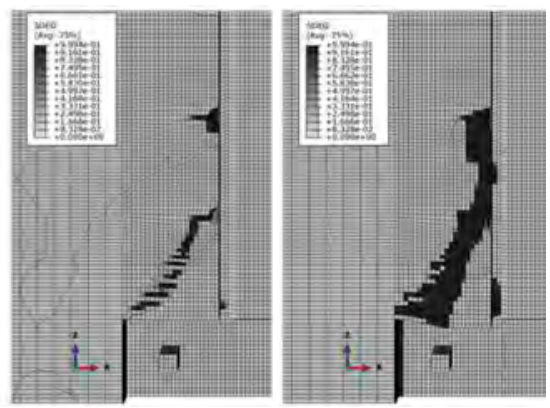

Figure 5. Results from the simulation of push-out specimen Bv2: a) load-slip and b) concrete damage. 
shown in Figure 6. The connector-concrete bond strength denoted as $P_{R, b}$, can be calculated according to Equation 2. The reaction forces can be split on each arm and projected into the pair of forces acting perpendicularly (Eq. 3) and tangentially (Eq. 4) on the connector surfaces.

$$
\begin{aligned}
& F_{n}=\frac{F_{R}}{n_{a}} \cdot \sqrt{\sin ^{2} \alpha_{c} \cdot \tan ^{2} \theta+\left(\sin \alpha_{c}+\cos \alpha_{c}\right)^{2}} \cdot \sin \beta \\
& F_{t}=\frac{F_{R}}{n_{a}} \cdot \sqrt{\sin ^{2} \alpha_{c} \cdot \tan ^{2} \theta+\left(\sin \alpha_{c}+\cos \alpha_{c}\right)^{2}} \cdot \cos \beta
\end{aligned}
$$

where $F_{R}=$ force acting on one connector, $n_{a}=$ number of connector arms, $\alpha_{c}=$ connector arm inclination angle, $\theta=$ angle of the concrete compression strut and $\beta=$ angle between the connector contact surface and the resultant acting force.

To evaluate resultant stresses in concrete, differential equations were needed to be solved and an assumption of full confinement was implemented. It was taken that in plane strain state, stresses in one direction are equal to stresses in another direction multiplied by the Poisson's ratio. The material law of concrete was based on the modified Mohr-Coulomb material law proposed by Nielsen \& Hoang (2011). Finally, the resistance of flat connectors, related to the concrete strength, can be described by three conditions: (i) maximum compression (Eqs. 5-6), (ii) maximum shear (Eqs. 7-8) and (iii) between-arm shearing (Eqs. 9-10). In addition, in Equation 11, a condition was given that checks if in principal direction tensile stresses can occur. When this condition is met, the confinement effect is vanished, and factors are set to $\omega_{c c}=1$ and $k_{s}=0$.

$$
\begin{gathered}
\sigma_{p 1}<f_{c m, c, c u b e} \\
P_{R, c}+P_{R, b}=\frac{n_{a} \cdot \lambda_{d} \cdot d \cdot L_{a r m} \cdot \omega_{c c} \cdot f_{c m, c u b e}}{\left(k_{s}+1\right) \cdot \psi_{B}-0.5 \cdot\left(k_{s}-1\right) \cdot \kappa_{1} \cdot(1+\nu)}+P_{R, b} \\
\tau_{\max }<\sigma_{s} \cdot \tan \varphi+c \\
P_{R, s 1}+P_{R, b}=\frac{n_{a} \cdot \lambda_{p} \cdot \nu_{s} \cdot d \cdot L_{a r m} \cdot f_{c m, c u b e}}{2 \sqrt{k_{s}} \cdot\left(\psi_{B}-0.5 \cdot \kappa_{1} \cdot(1+\nu) \cdot \mu\right) \cdot \sin \left(\alpha_{s 1}\right)}+P_{R, b} \\
\tau_{x 1 y 1}<\sigma_{x 1} \cdot \tan \varphi+c \\
P_{R, s 2}+P_{R, b}=\frac{n_{a} \cdot \lambda_{A} \cdot \nu_{s} \cdot \sin 2 \alpha_{c} \cdot L_{a r m}{ }^{2} \cdot f_{c m, c u b e}}{4 \sqrt{k_{s}} \cdot\left(\psi_{B, s 2,1}-\psi_{B, s 2,2} \cdot \mu\right)}+P_{R, b}
\end{gathered}
$$
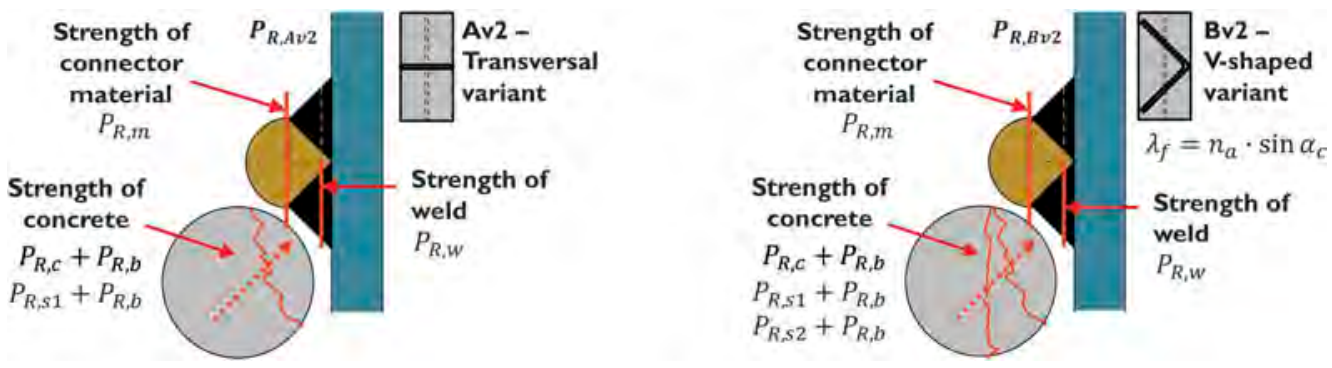

Figure 6. Failure modes of flat shear connectors, where $\lambda_{f}=$ force orientation factor, $P_{R, c}=$ resistance due to the maximum compression strength of concrete, $P_{R, s 1}=$ resistance due to the maximum shear strength of concrete, $P_{R, s 2}=$ resistance due to the between-arm shear strength of concrete, $P_{R, w}=$ resistance of weld and $P_{R, m}=$ resistance of connector material. 


$$
\frac{\kappa_{1} \cdot(1+\nu)}{2 \cdot \psi_{B}}<1
$$

where all used parameters are explained in Chrzanowski (2019), $f_{c m, c, c u b e}=$ confined strength of concrete, $\lambda_{d}=$ effective contact area factor, $L_{\text {arm }}=$ length of the arm of connector, $\omega_{c c}=$ transformation factor between confined Coulomb's material to the unconfined concrete strength, $f_{c m, c u b e}=$ mean compression strength of concrete, $k_{s}=$ inclination parameter for the Coulomb material, $\psi_{B}=$ simplification factor, $\kappa_{1}=$ load transformation factor, $\nu=$ Poisson's ratio of concrete, $\sigma_{s}=$ stress state in the normal direction corresponding to the maximum shear stress state, $\varphi=$ internal friction angle of concrete, $c=$ cohesion of concrete material, $\lambda_{p}=$ projection factor, $\nu_{s}=$ concrete cohesion reduction factor due to microcracking, $\mu=\tan -$ gent of internal friction angle of concrete, $\alpha_{s 1}=$ angle between the resulting shear plane and direction of flange of steel profile, $\tau_{x 1 y 1}=$ shear stresses in the between-arm shearing direction, $\sigma_{x 1}=$ normal stresses corresponding to the between-arm shearing stress state, $\lambda_{A}=$ shearing area correction factor, $\psi_{B, s 2,1}$ and $\psi_{B, s 2,2}=$ simplification factors.

The strengths of steel parts complete the resistance model. The weld resistance was evaluated based on the directional method of EN 1993-1-8 (2005), see Equation 12. The resistance of connector material is related to the plastic shear resistance and is given in Equation 14.

$$
\begin{gathered}
P_{R, w}=\frac{\lambda_{f} \cdot f_{u}}{\beta_{w} \cdot \psi_{w, e l} / p l} \\
\psi_{w, e l}=\sqrt{\frac{e_{w}{ }^{2} \cdot z^{2}}{I_{w}{ }^{2}}+3 \cdot \frac{1}{A_{w}{ }^{2}}} \psi_{w, p l}=\sqrt{\frac{e_{w}{ }^{2}}{d^{2} \cdot A_{w, t}{ }^{2}}+3 \cdot \frac{1}{A_{w}{ }^{2}}} \\
P_{R, m}=\frac{\lambda_{f} \cdot d \cdot L_{c o n} \cdot f_{y}}{\sqrt{3}}
\end{gathered}
$$

where $f_{u}=$ tensile strength of welded material, $\beta_{w}=$ weld parameter from EN1993-1-8, $e_{w}=$ force eccentricity acting on welded connection, $z=$ distance between weld centre of gravity and most external fibre in tension, $I_{w}=$ moment of inertia of welded connection, $A_{w}=$ area of welded connection, $A_{w, t}=$ area of weld subjected to tension, $f_{y}=$ yielding strength of connector. Areas of welds are according to the vertical weld centroid plane indicated in Figure 6.

\section{SUMMARY AND CONCLUSIONS}

In the presented paper, a comprehensive summary on the characterisation process of the developed flat shear connectors dedicated to composite columns and following innovative analytical model describing their resistance was given. Based on the conducted research, it can be observed that the angled, V-shaped variant of flat shear connector shows the best performance from the tested flat connectors. Moreover, the developed analytical model for this variant of connector creates one coherent model, which comprises all force transferring phenomena and failure modes of tested connectors. All details can be found in Chrzanowski (2019).

The presented analytical model was derived to strictly describe the load bearing resistance of the tested shear connectors and also to reflect the observed and possible failure modes. To increase the accuracy with test results, calibration factors were needed to artificially increase the strength of concrete - the compression strength (Equation 5) and shear strength (Equation 9) in the confined concrete state. Unfactored ratio of analytically calculated resistance to the experimentally obtained resistance for $\mathrm{V}$-shaped variant of connector varied from 0.65 for concrete crushing to 0.84 for concrete shearing. An exact match with the test results was achieved after putting 
in front of the resistance part in Equations $5 \& 9$ a factor 2.2 and 1.3 for the concrete compression and shear strengths, respectively. A conclusion can be drafted is that the currently available concrete confinement models, Nielsen (2011) \& fib ModelCode2010 (2000), are not precisely dealing with the heavy local 3D confinement of the concrete, which occurred in the zone beneath the flat shear connectors. The developed model consists of limitations due to the scope of performed test campaign and taken assumptions. Further studies are needed to investigate the calibration aspect and to extrapolate the proposed model.

\section{REFERENCES}

Al-Kodmany, K.: The Logic of Vertical Density: Tall Buildings in the 21st Century City, International Journal of High-Rise Buildings, CTBUH Korea, Vol. 1, No. 2, 131-148, 2012.

Chrzanowski, M.: Shear Transfer in Heavy Steel-Concrete Composite Columns with Multiple Encased Steel Profiles, PhD Thesis, University of Luxembourg, 2019. DOI: http://hdl.handle.net/10993/40011.

DISCCO, Development of improved shear connection rules in composite beams, European Commission, Research Programme of the Research Funds for Coal and Steel, TGS 8, RFSR-CT-2012-00030, 2016.

EN 1993-1-8, Eurocode 3: Design of steel structures - Part 1-8: Design of joints, European Standard, European Committee for Standardization, Brussels, 05. 2005.

EN 1994-1-1, Eurocode 4: Design of composite steel and concrete structures - Part 1-1: General rules and rules for buildings, European Standard, European Committee for Standardization, Brussels, 12.2004

fib Model Code for Concrete Structures 2010, Special Activity Group 5, International Federation for Structural Concrete (fib), Ernst\&Sohn, 2000. ISBN 978-3-433-03061-5.

Hanswille, G.; Porsch, M.: Lasteinleitung bei ausbetonierten Hohlprofil-Verbundstützen, Stahlbau, Ernst\&Sohn, Vol. 73, No. 9, 2004.

Houston, W.; Houston, I.: How to properly specify weld studs for use with the drawn arc stud welding process in structural applications, Modern Steel Construction, Solid Bond, steelwise, June 2015.

Johnson, R.P.: Composite Structures of Steel and Concrete. Beams, Slabs, Columns and Frames for Buildings, Third Edition, Blackwell Publishing, 2004. ISBN 1-4051-0035-4.

Nielsen, M.P.; Hoang, L.C.: Limit Analysis and Concrete Plasticity, Third Edition, CRC Press, Taylor \& Francis Group, 2011. ISBN 978-1-4398-0396-7.

Roik, K.; Bode, H.; Breit, M.: Momentfreie Anschlüsse an einbetonierte Stahlprofilstützen, Projekt 53, Studiengesellschaft für Anwendungstechnik von Eisen und Stahl e.V., 1980.

Roik, K.; Breit, M.; Schwalbenhofer, K.: Untersuchung der Verbundwirkung zwischen Stahlprofil und Beton bei Stützenkonstruktionen, Projekt 51, Studiengesellschaft für Anwendungstechnik von Eisen und Stahl e.V., 1984.

Roik, K.; Schwalbenhofer, K: Experimentelle Untersuchungen zum plastischen Verhalten von Verbundstützen, Projekt 125, Studiengesellschaft für Anwendungstechnik von Eisen und Stahl e.V., 1988.

SIMULIA User Assistance 2017, Abaqus, Dassault Systèmes Simulia Corp., Providence, RI, USA.

SmartCoCo, Smart Composite Components - Concrete Structures Reinforced by Steel Profiles, Technical Report, European Commission, Research Programme of the Research Funds for Coal and Steel, TGS8, RFSR-CT-2012-00031, 2016.

Vianna, J. da C.; Costa-Neves, L.F.; Vellasco, P.C.G. da S.; de Andrade, S.A.L.: Experimental assessment of Perfobond and T-Perfobond shear connector' structural response, Journal of Constructional Steel Research, Elsevier, 65, 408-421, 2009. 


\title{
Influence of type and orientation of thin-walled beams on the interaction effectiveness with sandwich panels
}

\author{
K. Ciesielczyk \& R. Studziński \\ Institute of Building Engineering, Poznan University of Technology, Poznań, Poland
}

\begin{abstract}
In the paper, the problem of the interaction between thin-walled beams with sandwich panels has been presented. The sandwich panels consist of steel external facings and the polyurethane foam core. The $\mathrm{Z}$ and $\mathrm{C}$ cross-section shapes and their various mutual orientations have been considered. The stabilization effect provided by the sandwich panels was investigated in a full-scale laboratory experiment and then compared with the numerical model. The full-scale test allowed for validation of the numerical model created in the Abaqus/CEA environment. The Newton-Raphson procedure with geometrical and material nonlinearity was implemented in order to perform the numerical computations.
\end{abstract}

\section{MOTIVATION}

In recent times, thin-walled beams are more and more frequently used as elements of a steel hall system (purlins, wall beams, construction of casings and eaves beams). The main advantage of designing structures with thin-walled elements is a favorable mass to bearing capacity ratio and mass to stiffness ratio. On the other hand, structures with thin-walled elements also have a negative effect due to the large slenderness of its walls - thin-walled cross sections are susceptible to the local loss of stability. Both local loss of stability (local buckling) as well as distortional buckling and global buckling (flexural, torsional, lateral-torsional and flexurallateral) are the most common forms of the thin-walled beams instabilities.

The interaction between structural elements is an important topic. In this case, structural elements which are understood as a roof or a wall sheathing are interacting with a steel supporting framework. Trapezoidal sheets and sandwich panels are commonly used as a roof or wall sheathing in steel structures. These types of sheathings are characterized by a high bending stiffness (plate behavior) and a high shear stiffness (diaphragm behavior). Therefore they can provide lateral and torsional buckling restraint of steel elements. Taking into account the mechanical interaction between a steel supporting framework and an external sheathing provide possibility for computing the construction as three-dimensional plate-diaphragm-rod load-bearing structures. For example Lucas et al. 1997a, b introduced simplified model and a full model which defines the interaction between thin walled beams and the sandwich panels. The procedure which is capable of determination the value of critical buckling moment of the thin-walled beam restrained by trapezoidal sheeting was proposed by Ye et al. 2002, Li $2004 \& \mathrm{Chu}$ et al. 2004. It is worth to mention that taking into the consideration the described influence may result in the global weight of a structure reduction and consequently, lowering the total cost.

The subject matter of steel elements interacting with trapezoidal sheets is widely discussed in the literature and has been reflected in EN 1993-1-3 code guidelines. In recent years, sandwich panels are more often used as elements of hall casing because of their good mechanical and thermal properties. The increasing popularity in using this type of sheathing has 
prompted researchers to also analyze the interaction of steel construction and sandwich panels, which recently were not used in common for the stiffening the structural elements. Over the last decade, there have been carried out some laboratory and numerical researches by Dürr 2008, Dürr \& Misiek 2011 which confirm that not only the trapezoidal sheets but also sandwich panels can provide the lateral restrain of the thin-walled elements. This topic was also discussed in research projects, which resulted in developing methods defining the interaction between sandwich panels and thin-walled beams. Furthermore, these methods have been also included in the European recommendations.

\section{PROBLEM FORMULATION}

The analysis was carried out on cold-formed sections which were made of $1.5 \mathrm{~mm}$ thick and $220 \mathrm{~mm}$ width sheet metal with the total length equal to $3300 \mathrm{~mm}$. Two shapes of crosssections were formed from steel sheets: " $Z$ " and " $C$ " with dimensions given in Figure 1.

So far, the analyses of the interaction between thin-walled beams and sandwich panels have been conducted for classical orientation of the thin-walled elements, see ZZ-1 and CC-1 models depicted in Figure 2. In this paper, authors had decided to analyze different orientations of thin-walled beams. The aim of this research was the analysis of the influence of thinwalled beams orientation stabilized by the sandwich panels on the thin-walled element buckling form. Nine different beam orientations have been analyzed: three of the Z-beams (Figure 2a), three of the C-beams (Figure 2b) and three with mixed composition of C-and Z- beams (Figure 2c).
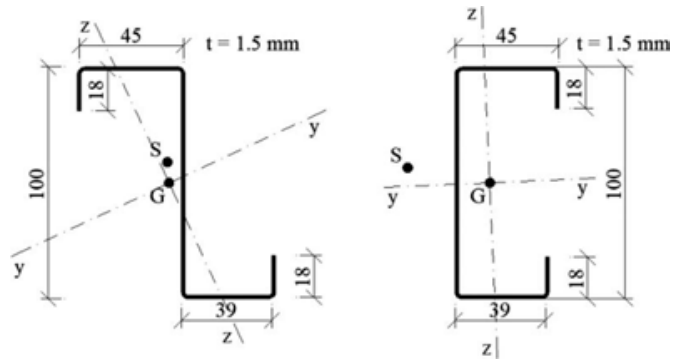

Figure 1. The dimensions of analyzed cross-sections, where $\mathrm{S}$ and $\mathrm{G}$ is location of the shear center and center of gravity, respectively.

a)

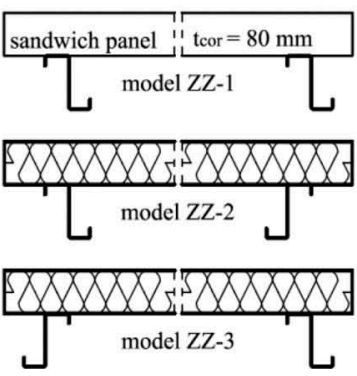

b)

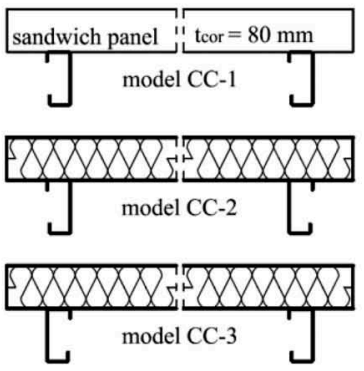

c)

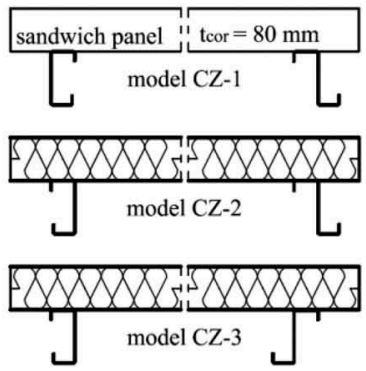

Figure 2. The relative orientation of the thin-walled elements - description in main text. 


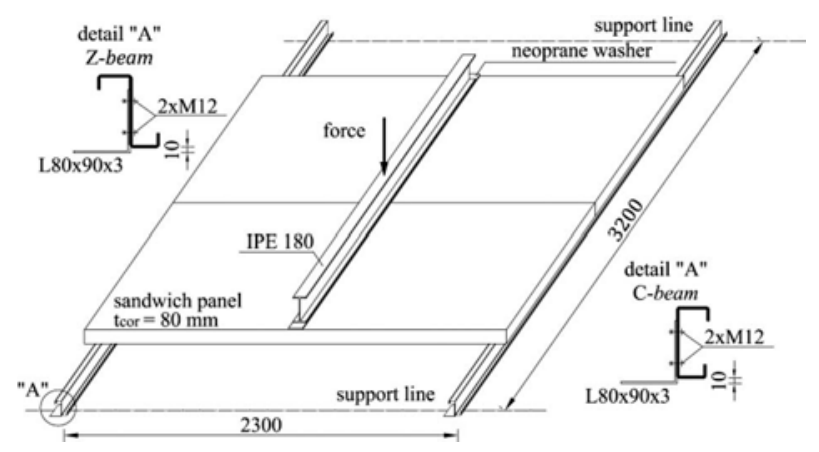

Figure 3. Scheme of the laboratory test-bed (Ciesielczyk \& Studziński, 2017).

\section{LABORATORY BACKGROUND}

Laboratory experiments cover full-scale experiments and material tests. Two thin-walled beams with the length equal to $3300 \mathrm{~mm}$ were stiffened by two sandwich panels with the width equal to $1100 \mathrm{~mm}$. The sandwich panel core of a thickness $100 \mathrm{~mm}$ was made of polyurethane foam. The scheme of the laboratory test-bed is presented in Figure 3. Two beam crosssections were taken under consideration: Z-beam and C-beam with dimensions given in Figure 1. Four angle cleats of a length $0.1 \mathrm{~m}$ were used in order to avoid the local compression of the thin-walled beam at the supports. During experimental tests two beam arrangements were investigated: ZZ-1 model (Ciesielczyk \& Studziński, 2017) and CC-1 model (Studziński \& Ciesielczyk, 2016). The sandwich panels which were used in the experiment consisted of two zinc-coated steel facings and thick and soft polyurethane core. The following geometrical dimensions of sandwich panel layers were measured: thickness of the core $d_{c}=80 \mathrm{~mm}$, thickness of the external $t_{F e}=0.594 \mathrm{~mm}$ and internal facings $t_{F i}=0.490 \mathrm{~mm}$. The aspect of the connection stiffness was considered in other paper (Studziński \& Ciesielczyk, 2019).

In order to determine the material properties, such as: Young's modulus, yield strength, ultimate tensile strength and stress-strain characteristic, the tensile tests have been carried out for the material samples of sandwich panel facings (12 samples) and thin-walled beams (6 samples). A tensile specimens had a shape of standardized cross-section sample and consisted of two shoulders and a gage between them. The dimensions of the prepared samples are presented in Figure 4a. Conducted tensile tests indicated that Young's modulus for the steel facing material and for the steel thin-walled beam material is equal to $190 \mathrm{GPa}$ and $198 \mathrm{GPa}$

a)

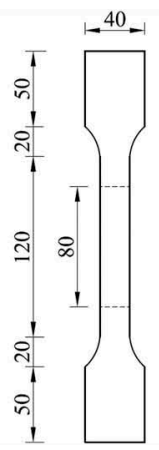

b)

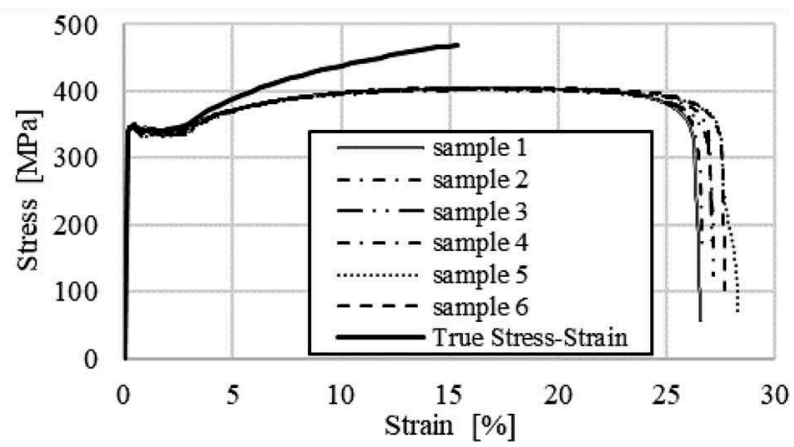

Figure 4. Tensile test: a) the steel sample dimensions, b) the stress-strain curve for steel from beam. 
respectively. The value of the Poisson's ratio for steel is equal to 0.3 . On the basis of the performed tests, the steel which was considered as element's materials was defined as mild steel with a plasticity effect (significant increase of strain without stress increase). The stress-strain curves obtained from the experiment for thin-walled beam steel ( 6 samples) are presented in Figure $4 \mathrm{~b}$. The average value of the upper yield strength determined by the experiment is equal to $348.87 \mathrm{MPa}$ while the value of ultimate tensile strength equals 402.72 MPa.

\section{LABORATORY BACKGROUND}

The numerical output model had been defined within the Abaqus/CEA environment (the model was also presented in Ciesielczyk \& Studziński, 2017). The numerical model had been verified and validated by the laboratory experiments described in the above subsection. The created numerical model reflected the laboratory experiment thus it consists of angle cleats, thin-walled beams with various shapes and orientations, sandwich panels, and an I-beam.

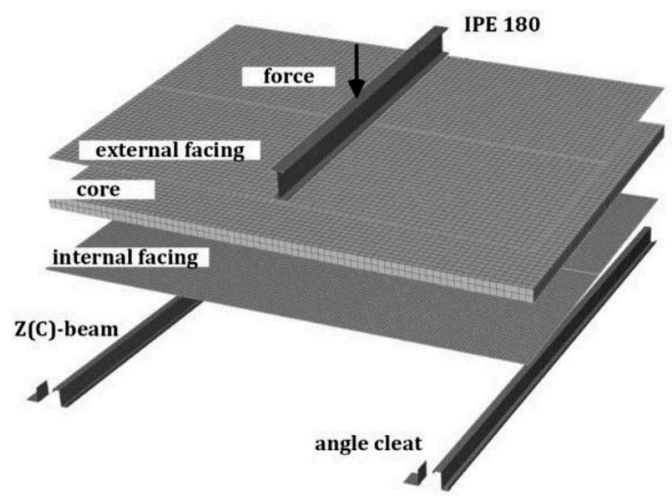

Figure 5. Scheme of the numerical model.

All steel properties used in the numerical model were determined by the laboratory experiments. The true stress-strain curve implemented into the numerical model has been presented in Figure $4 \mathrm{~b}$ by the continuous line. The true stress and strain were determined by the following formulas:

$$
\begin{gathered}
\sigma_{\text {true }}=\sigma_{\text {nom }}\left(1+\varepsilon_{\text {nom }}\right), \\
\varepsilon_{\text {true }}=\ln \left(1+\varepsilon_{\text {nom }}\right), \\
\varepsilon_{\text {true }}^{p l}=\left(\varepsilon_{\text {true }}-\sigma_{\text {true }}\right) / E,
\end{gathered}
$$

where: $\sigma_{\text {true }}$ represents true stress, $\sigma_{\text {nom }}$ represents nominal stress (engineering), $\varepsilon_{\text {nom }}$ represents nominal strain (engineering), $\varepsilon_{\text {true }}$ represents true strain, and $\varepsilon_{\text {true }}{ }^{p l}$ represents plastic true strain (required by Abaqus).

The properties of the sandwich panel core material such as: the shear modulus $\left(G_{C}=3.2\right.$ $\mathrm{MPa})$ and the Poisson ratio $\left(v_{C}=0.05\right)$ have been adopted from the previous work (Studziński, 2019). The non-linear stress-strain characteristic was used in the numerical model. The load in the numerical model consisted of: component's own weight and the concentrated force traversed into an uniformly distributed load by the I-beam. The boundary conditions have been applied to angle cleats in order to reflect the real connection with the support structure. Furthermore, in order to reduce the computation time the symmetry boundary conditions have been applied (the numerical model has been twice reduced). In order to obtain the nonlinear 
Table 1. Dimensions and type of the finite elements.

\begin{tabular}{llll}
\hline Model component & FE type & FE size in $[\mathrm{mm}]$ & number of FE \\
\hline IPE & C3D8R & $10 \times 10 \times 10$ & 5940 \\
External facing & S4R & $40 \times 40$ & 1998 \\
Core & C3D8R & $40 \times 40 \times 40$ & 4050 \\
Internal facing & S4R & $5 \times 5$ & 33110 \\
Thin-walled beam & S4R & $5 \times 5$ & 14190 \\
Angle cleat & S4R & $5 \times 5$ & 680 \\
\hline
\end{tabular}

static response, the Newton-Raphson procedure with Full Newton solution technique was adopted. All components of the model have been modeled by shell and solid finite elements. Their dimensions and types are presented in the Table 1, where according to the Abaqus documentation C3D8R is a 8-node linear brick finite element with reduced integration and hourglass control while S4R is a 4-node doubly curved thin or thick shell finite element with reduced integration, hourglass control, and finite membrane strains.

\section{DISCUSSION OF THE RESULTS}

From the assumed nine different beam orientations the following groups can be distinguished: the thin-walled beams with the upper flange directed in the same direction (ZZ-1, CC-1, CZ-2), the thin-walled beams with the upper flange directed "outside" (ZZ-2, CC-2, CZ-3), and the thin-walled beams with the upper flange directed "inside" (ZZ-3, CC-3, ZC1). The $C$ and $Z$ cross-sections have the same surface area and therefore the same self-weight per unit length, nevertheless the important differences between considered cross-sections refer to the geometrical characteristics influencing the size of the elastic critical bending moment, see Table 2.

According to data presented in Table 2, it can be noticed that the $\mathrm{Z}$ cross-section is characterized by higher warping properties than the $\mathrm{C}$ cross-section. The higher warping properties $\left(I_{t}, I_{z}, I_{\omega}\right)$, the higher magnitude of the elastic critical moment for lateral torsional buckling can be provided by the cross-section. Additionally, the position of the applied transverse load with regard to the shear center is significantly closer for $\mathrm{Z}$ than $\mathrm{C}$ cross-section. Therefore this parameter - which represent the point at the cross-section where the application of load does not cause its twisting - is favorable for $\mathrm{Z}$ cross-section. In other words, the torsional stresses, from the load of the same magnitude and way of application, are smaller for $Z$ than $C$ crosssection. On the other hand, principal central axes of both considered cross-sections do not coincide with the loading plane. This leads to biaxial bending nevertheless, in the case of $\mathrm{C}$ cross-section, the inclination angle of the principal central axes (from the loading plane) is 20 times smaller compared with $\mathrm{Z}$ cross-section. It means that the biaxial bending moment decomposition produces a larger bending moment against the weaker axis in the case of $\mathrm{Z}$ cross-section than in the case of $\mathrm{C}$ cross-section.

Table 2. Selected geometrical characteristic.

\begin{tabular}{lllll}
\hline No. & Geometrical characteristic & Z-section & C-section & Difference \\
\hline 1. & $I_{t}$ - torsion constant & $0.02 \mathrm{~cm}^{4}$ & $0.02 \mathrm{~cm}^{4}$ & $0.0 \%$ \\
2. & $I_{z}$ - second moment of area about the weak axis & $14.89 \mathrm{~cm}^{4}$ & $8.61 \mathrm{~cm}^{4}$ & $42.2 \%$ \\
3. & $I_{\omega}$ - warping constant & $259.00 \mathrm{~cm}^{6}$ & $209.00 \mathrm{~cm}^{6}$ & $19.3 \%$ \\
4. & $\alpha_{0}$ - inclination angle of the principal axes & $24.90^{\circ}$ & $2.50^{\circ}$ & $90.0 \%$ \\
5. & $y_{s}$ - distance of the shear center from the web & $2.41 \mathrm{~mm}$ & $-21.39 \mathrm{~mm}$ & $987.6 \%$ \\
\hline
\end{tabular}




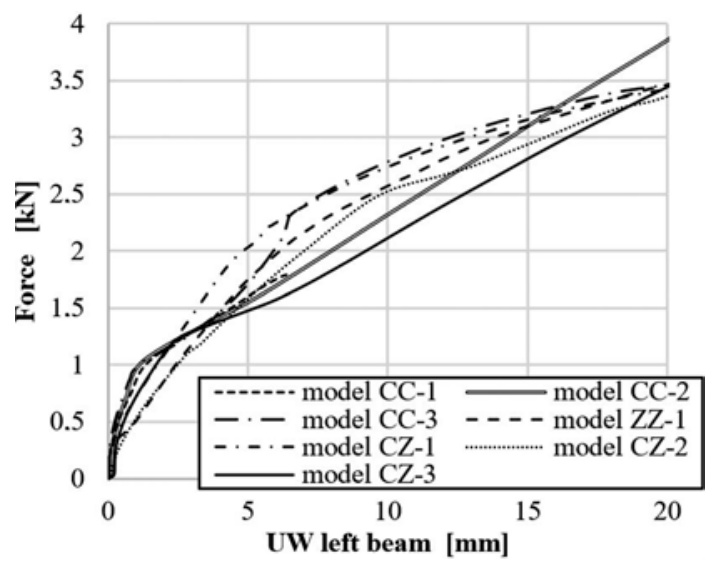

Figure 6. Load-displacement paths of the middle point of a bottom flange of the thin-walled beam.

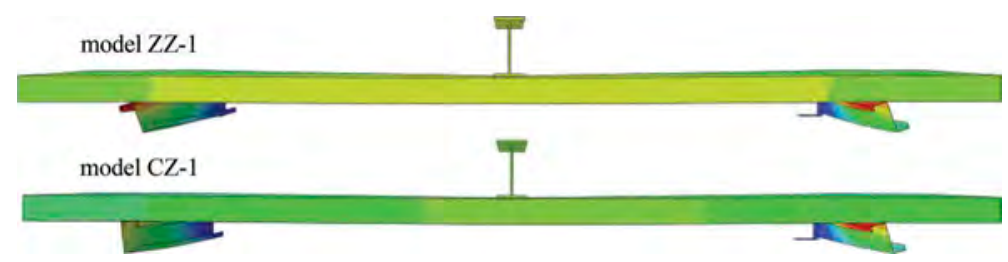

Figure 7. Maps of displacements for selected models - the cross section in the middle of the sandwich panel.

The resultant load-displacement paths of the middle point of the bottom flange of the left thin-walled beams is presented in Figure 6. The results of the ZZ-2 and ZZ-3 are not included due to the lack of convergence of the nonlinear FEA analysis. The deformation maps of three selected models are presented in Figure 7.

\section{CONCLUSIONS}

The following conclusion can be formulated. Firstly it was observed that the $\mathrm{Z}$ cross-sections are sensitive to the biaxial bending while the $\mathrm{C}$ cross-sections to twisting which leads to an initial greater stiffness of the system with C-beams than in the case of the system with Z-beams. This is due to:

- the initial in-plane bending of the C-beams because of small inclination angle of the principal axes with respect to the load plane, and

- the initial biaxial bending of the Z-beams because of large inclination angle of the principal axes with respect to the load plane.

Secondly the further increase of the loading (above "initial" i.e. in our cases above $1 \mathrm{kN}$ ) leads to:

- significant stiffness reduction of C-beams due to twisting (large distance between loading plane and the shear center), and

- gradual decrease of flexural stiffness of Z-beams (small distance between loading plane and the shear center). 


\section{ACKNOWLEDGEMENT}

This work was supported by the by Poznan University of Technology Grant no. 0412/SBAD/ 0046 .

\section{REFERENCES}

Lucas, R.M., Al-Bermani, F.G.A. \& Kitipornchai, S. 1997. Modeling of cold-formed purlins - sheeting systems - Part 1. Full model. Thin-Walled Structures, 27(3), pp. 223-243.

Lucas, R.M., Al-Bermani, F.G.A. \& Kitipornchai, S. 1997. Modeling of cold-formed purlins - sheeting systems - Part 2. Simplified model. Thin-Walled Structures, 27(4), pp. 263-286.

Ye, Z.M., Kettle, R., Li, L.Y. \& Schafer, B. 2002. Buckling behaviour of cold-formed zet-purlins partially restrained by steel sheeting. Thin-walled Structures, 40, pp. 853-864.

Li, L.Y. 2014. Lateral-torsional buckling of cold-formed zet purlins partial laterally restrained by metal sheeting. Thin-Walled Structures, 42, 7, pp. 995-1011.

Chu, X.T., Kettle, R. \& Li, L.Y. 2001. Lateral-torsional buckling analysis of partial laterally restrained thin-walled channel sections beams. Jour. of Constr. Steel Research, 60, 8, pp. 1159-1175.

EN 1993-1: Design of Steel Structures. Part 1-3: General rules - Supplementary rules for cold-formed members and sheeting, Brussels, 2001.

Dürr, M. 2008. Die Stabilisierung biegedrillknickgefährdeter Träger durch Sandwichelemente und Trapezbleche, $\mathrm{PhD}$ dissertation, Karlsruhe.

Dürr, M., Misiek, T. \& Saal H. 2011. The torsional resistant of sandwich panels to resist the lateral torsional buckling, Steel Construction, 4, pp. 251-258.

European Recommendations on the Stabilization of Steel Structures by Sandwich Panels, International Council for Research and Innovation in Building and Construction, 2013.

Ciesielczyk, K. \& Studziński, R. 2017. Experimental and numerical investigation of stabilization of thin-walled Z-beams by sandwich panels, Jour. of Constr. Steel Research, 133, pp. 77-83.

Studziński, R. \& Ciesielczyk, K. 2016. Experimental investigation of the stabilization of the C-section purlins by sandwich panels, Recent Progress in Steel and Composite Structures: Proceedings of the XIII International Conference on Metal Structures, pp. 101-106.

Studziński, R. \& Ciesielczyk, K. 2019. Connection stiffness between thin-walled beam and sandwich panel. Journal of Sandwich Structures \& Materials vol. 21, Issue 6, pp. 2042-2056.

Getting Started with Abaqus: Keyword Edition, 6.14, access online 2020.11.15 http://130.149.89.49:2080/ v6.14/books/gsk/default.htm

Studziński, R. 2019. Optimal design of sandwich panels with hybrid core, Journal of Sandwich Structures \& Materials, vol. 21, Issue 7, pp. 2181-2193. 


\title{
Experimental tests of sheeting made of sandwich panels acting as a diaphragm
}

\author{
M. Górski \\ Rzeszów University of Technology, Rzeszów, Poland
}

\begin{abstract}
Results of experimental tests of a part of sheeting made of sandwich panels are shown in this paper. In-plane stiffness and resistance of the sheeting have been determined and compared with the values achieved from formulas available in literature. The results show, that sheeting made of sandwich panels has noticeable in-plane parameters and is worth to be included in designing as an improvement of elements stability.
\end{abstract}

\section{INTRODUCTION}

The Eurocode EN 1993-1-3 specifies 3 structural classes differing from each other in the way of including the cooperation between structure and sheeting in design:

- Structural Class 1: Sheeting is included in the calculations of the overall strength and stability of a structure;

- Structural Class 2: Sheeting is included in the calculations of strength and stability of individual structural members;

- Structural Class 3: Sheeting is considered as an element that only transfers loads to the structure.

In the conventional designing of steel roofs, sandwich panels are considered as noncooperating sheeting due to rather thin steel plates used (ca. $0.5 \mathrm{~mm}$ ) and lack of seam fasteners between internal faces of each sandwich panels, which induces a low-effective way of transferring load in the sheeting plane, because each panel must act independently, as shown in Figure 1.

Nevertheless, some research is currently available, e.g. (Baehre \& Ladwein 1994, Dürr et al. 2007, Misiek et al. 2010, Dürr et al. 2011, Käpplein \& Misiek 2011, Georgescu \& Ungureanu 2012) showing noticeable stiffness of sheeting made of sandwich panels and the possibility of including them in the designing in Structural Class 2. Moreover even if the stiffness of sheeting is relatively small, it results in evident increasing of the purlin stability (Górski \& Kozłowski 2021).

This paper presents the results of own experimental tests of the part of sheeting made by sandwich panels in the context of cooperation with steel structure including designing in Structural Class 2.

\section{TEST STANDING}

The tested structure consist of a pair of girders with distance $5.4 \mathrm{~m}$ made of horizontalsituated hot-rolled channel UPN160, 3 purlins arranged at a distance of $2.9 \mathrm{~m}$, made of hot-rolled I-beam IPE160 and five sandwich panels Balextherm PU-PIR-W-ST 80.1100

DOI: $10.1201 / 9781003132134-25$ 


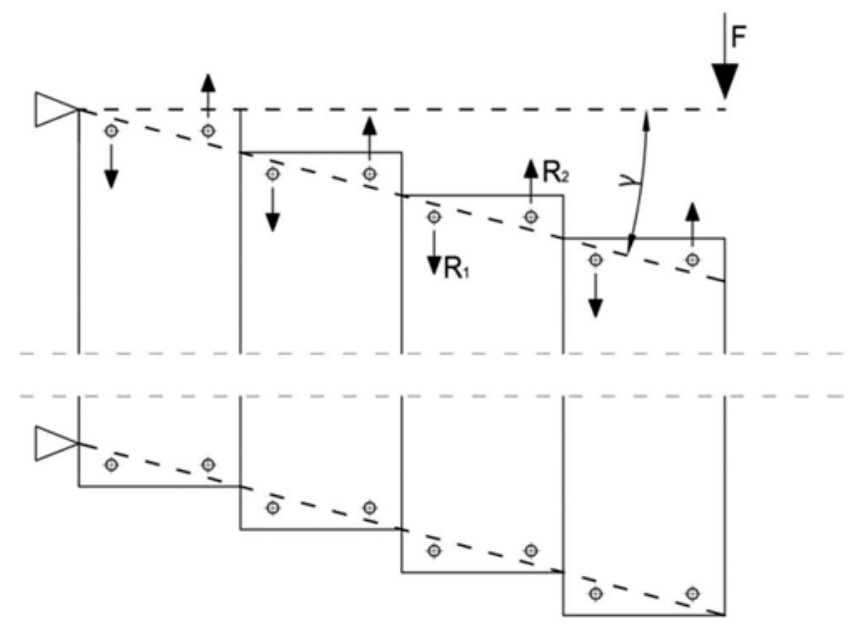

Figure 1. Assumption of transferring load $\mathrm{F}$ acting in sheeting plane by sandwich panels.

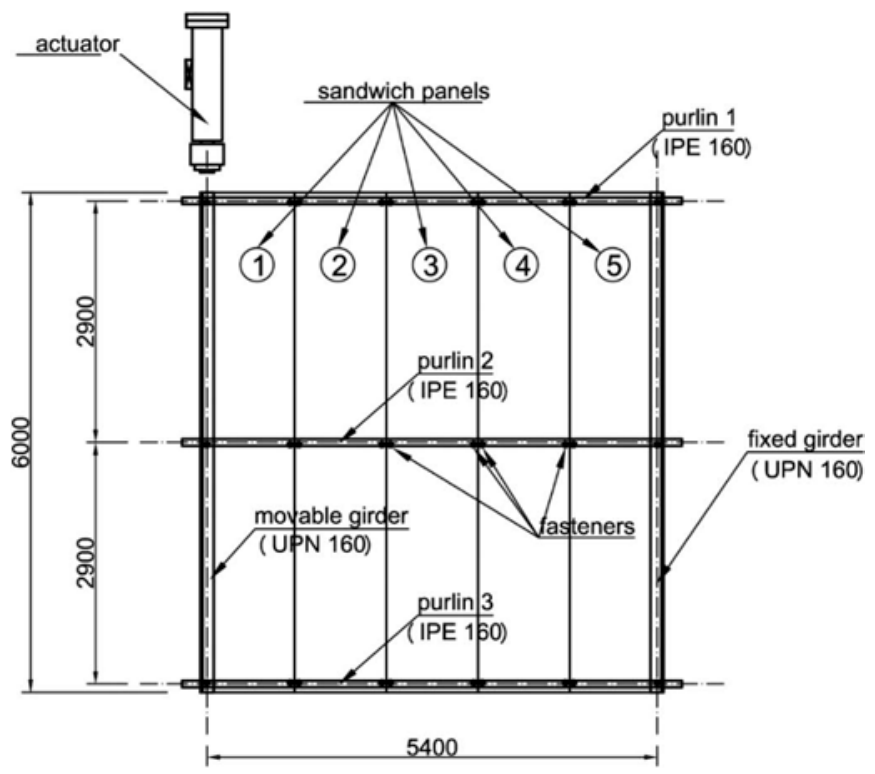

Figure 2. The schema of test standing.

with face sheets made of steel S320GD and thickness $0.5 \mathrm{~mm}$. The schema of test standing is shown in Figure 2.

The connections between purlin and girder were made of bended plates with thickness $6 \mathrm{~mm}$, additionally stiffened by welded diagonal ribs and bolted with structure by 2 pairs of bolts M12 (Figure 3). Each sandwich panel was connected with each purlin using 2 self-drilling screws $5.5 / 6.3 \mathrm{~mm}$ arranged in distance $50 \mathrm{~mm}$ from the panels edges (1000 $\mathrm{mm}$ from each other).

One of the girder was fully fixed. The second one has been placed on round rods to ensure free movement in the axis of girder. To prevent lateral movement of this girder, four vertical CHS profiles were used (Figure 4). 


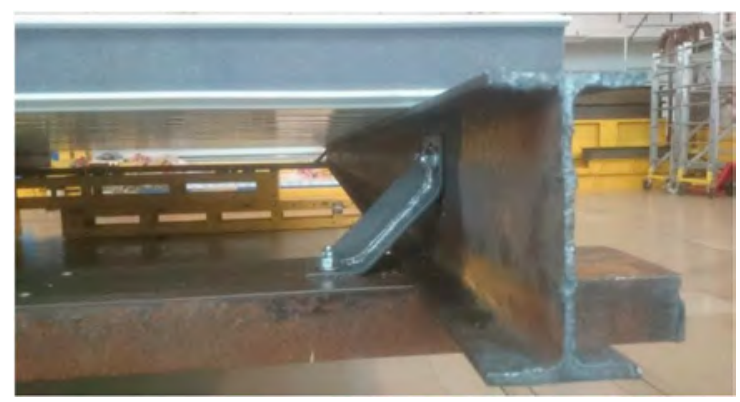

Figure 3. The view on connection between purlin and girder.

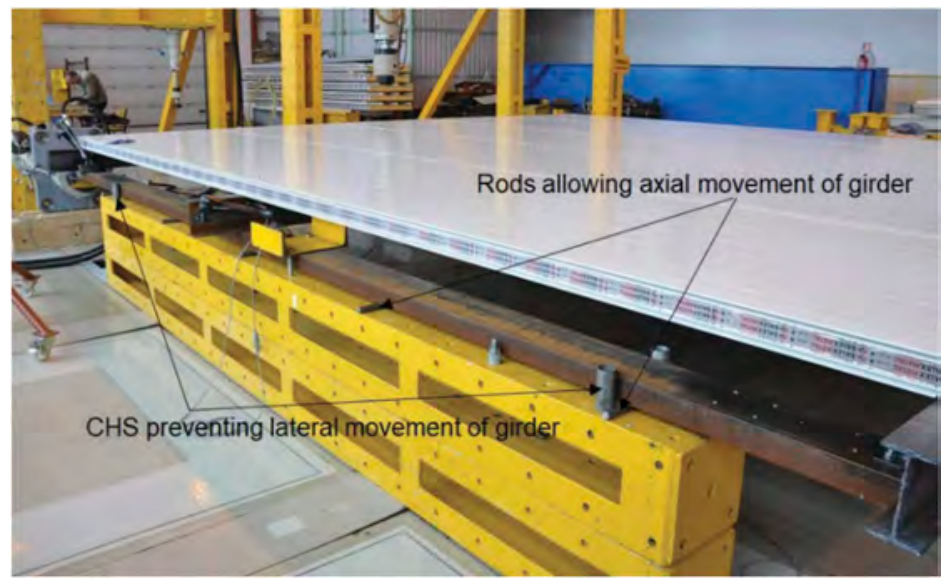

Figure 4. The schema of test standing.

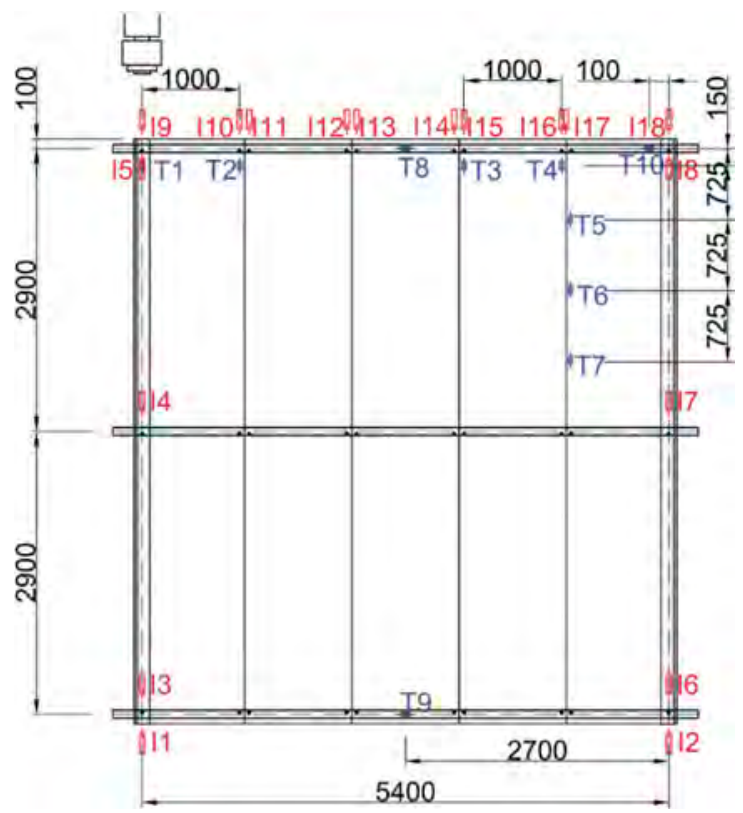

Figure 5. The arrangement of sensors and strain gauges during tests. 
The load was applied using horizontal-situated actuator Instron Schenck $630 \mathrm{kN}$ directly to the movable girder in 3 applications: $0-2.0 \mathrm{kN}, 0-4.0 \mathrm{kN}$ and $0-$ value of in-plane resistance.

The displacement of 18 selected points has been measured using inductive displacement sensors: movable girder relative to the floor (I1), fixed girder relative to the floor (I2), purlins in the place of connections with girders relative to the girders (I3 - I8) and each of sandwich panels in two points arranged at a distance $5 \mathrm{~cm}$ from their side edges relative to the purlin 1 (I9 - I18). In addition 10 foil strain gauges were used to measure the strains: on bottom face of sandwich panel number 1 and 4 in the distance $150 \mathrm{~mm}$ from the axis of the purlin $1(\mathrm{~T} 1-\mathrm{T} 4)$, on the bottom face of sandwich panel number 5 along its edge in contact with panel number 4 (T5 - T7), on the top flanges of side purlins in the middle of their spans (T8 and T9) and on the top flange of the purlin 1 in the distance $100 \mathrm{~mm}$ from the axis of the fixed girder (T10). The arrangement of the displacement sensors and strain gauges is shown in Figure 5.

\section{RESULTS}

The results of the test have been presented in two forms: of force - displacement relationship for data obtained from displacement sensors and of stress - force relationship for data obtained from strain gauges. Stress has been calculated by multiplying the values of strain and the Young modulus, which has been assumed as $210 \mathrm{GPa}$. Figure 6 shows the results from sensor I1 which are crucial to determine the global parameters of the sheeting. Figures $7-8$ shows the results from displacement sensors and Figures $9-10$ the results from strain gauges. The view of the deformed shape of sheeting is shown in Figure 11a and the hole elongation is presented in Figure 11b.

The results have proven the correctness of theoretical model shown in Figure 1. The forces in the connections located on the one side of the panels had opposite directions to the forces on the second side. The transverse edge of the sheeting, straight before test, became visibly serrated. The in-plane behavior of sheeting is nonlinear due to hole elongation in the connections. The sheeting resistance according to the shape of approximation curve equals $6.2 \mathrm{kN}$. The in-plane stiffness of sheeting can be calculated using formula (1). Table 1 shows the values of in-plane stiffness of tested sheeting obtained for various range of data.

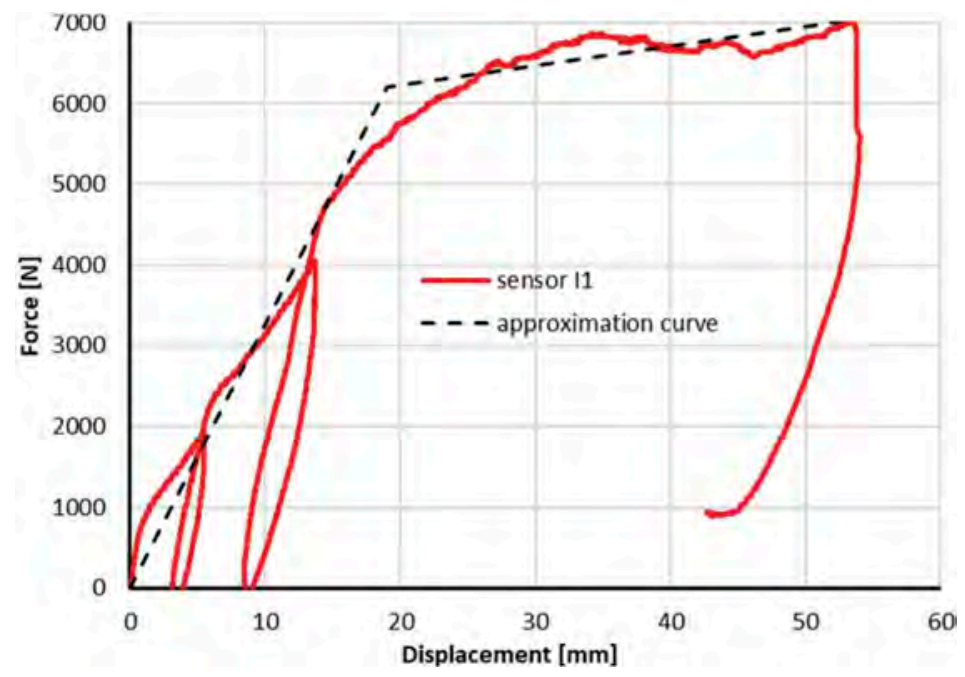

Figure 6. Dependence force - displacement for sensor I1. 
Sensors 13 - 18 (purlins supports)

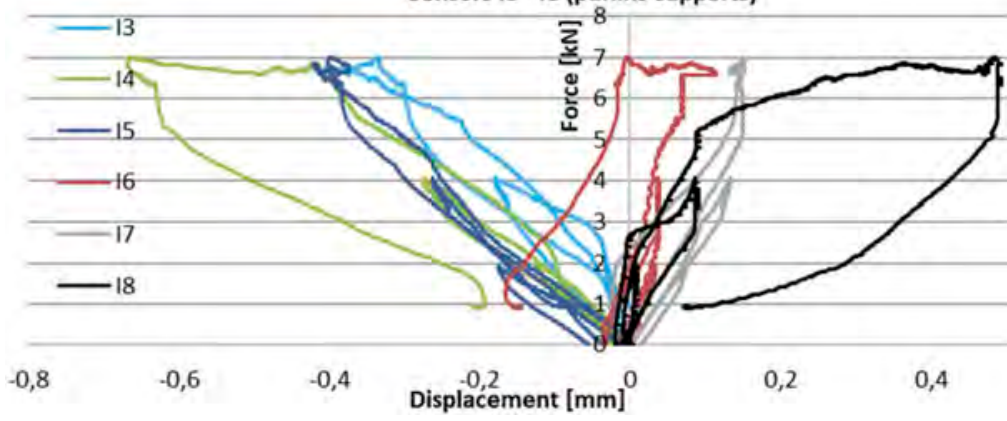

Figure 7. Dependence force - displacement for sensors I3 - I8.

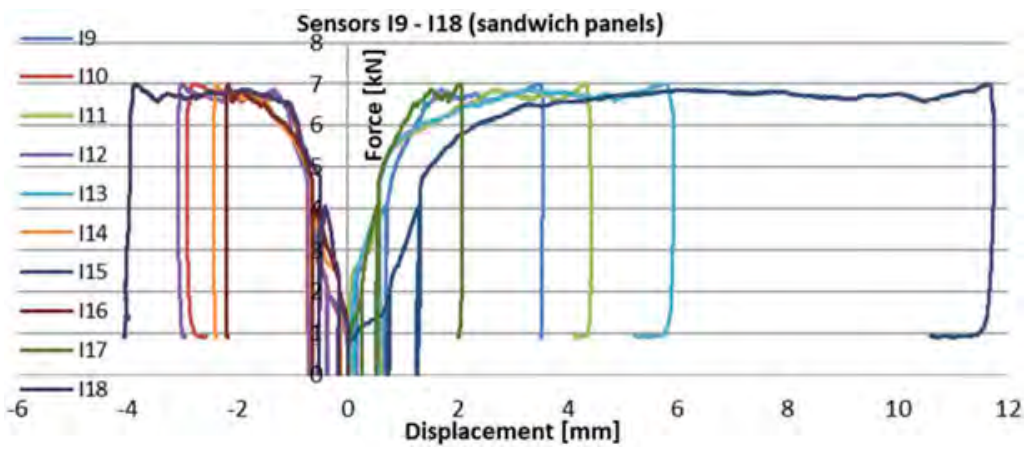

Figure 8. Dependence force - displacement for sensors I9 - I18.

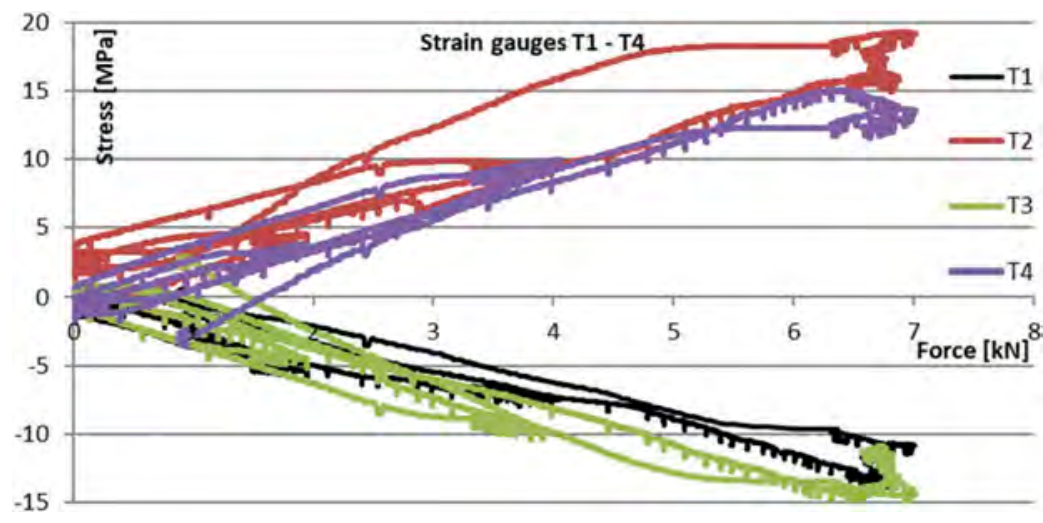

Figure 9. Dependence stress - force for strain gauges T1 - T4. 


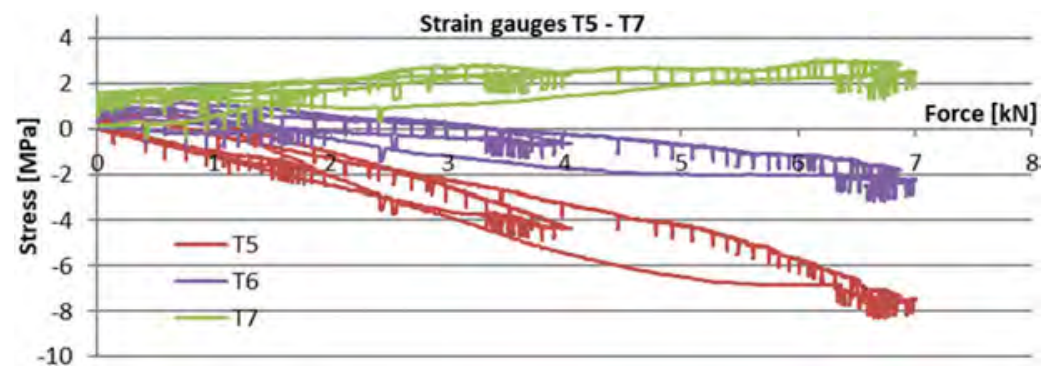

Figure 10. Dependence stress - force for strain gauges T5 - T7.

a)

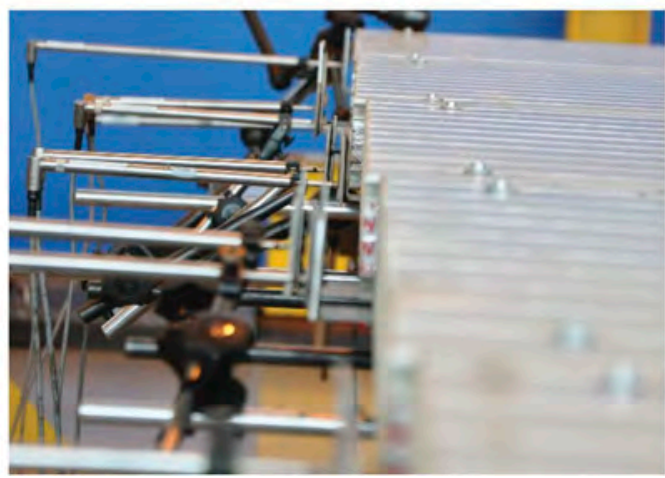

b)

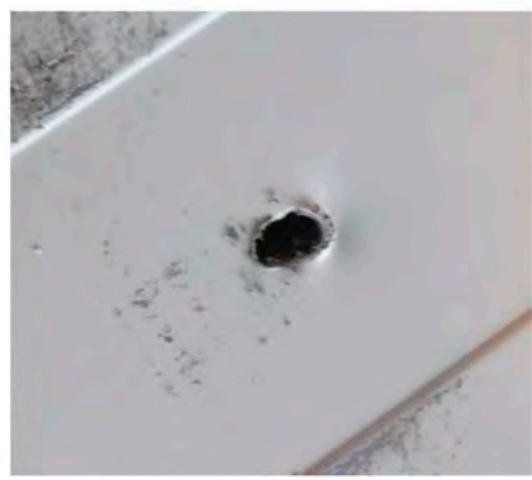

Figure 11. View of the structure after test: a) the transverse edge of the sheeting, b) the hole elongation after removing fastener.

Table 1. Values of in-plane stiffness of tested sheeting for various range of data.

\begin{tabular}{ll}
\hline & Stiffness per one purlin \\
\cline { 2 - 2 } Considered range of data & $\mathrm{kN} / \mathrm{m} / \mathrm{m}$ \\
\hline Beginning of the first force application $(0-0.8 \mathrm{kN})$ & 2052 \\
Beginning of the second force application $(0-2.0 \mathrm{kN})$ & 1494 \\
Beginning of the third force application $(0-4.5 \mathrm{kN})$ & 1368 \\
Approximation curve $(0-6.2 \mathrm{kN})$ & 587 \\
\hline
\end{tabular}

$$
S=\frac{F \cdot a}{\Delta \cdot n}
$$

where $F=$ applied force; $a=$ width of sheeting; $\Delta=$ displacement according to Figure 12 and $n=$ number of purlins.

According to formulas given in ECCS (2013), the in-plane stiffness of such sheeting made by sandwich panels equals $1200 \mathrm{kN} / \mathrm{m} / \mathrm{m}$. Although the initial stiffness of tested sheeting exceed this value, nonetheless the mean stiffness is noticeably smaller. 


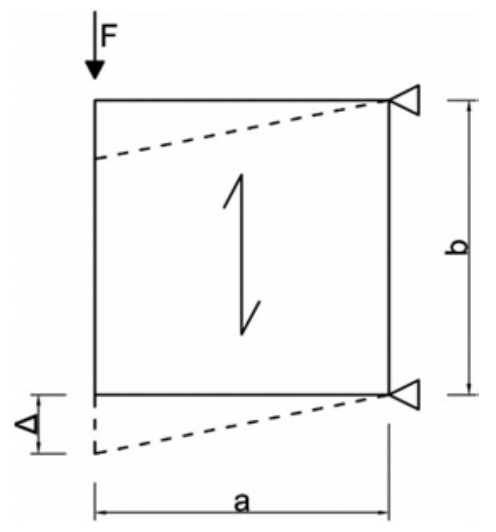

Figure 12. The model to calculation the in-plane stiffness of sheeting.

\section{CONCLUSIONS}

Performed tests proved that the sheeting made of sandwich panels has noticeable in-plane stiffness, despite a low-effective way of transferring loads. The sheeting may be included in designing of structure in Structural Class 2, results in improvement of elements stability. However, the carefulness must be made because of low values of the sheeting in-plane resistance, which can lead to holes elongation and decreasing the overall sheeting parameters.

\section{REFERENCES}

Baehre, R., Ladwein, Th. 1994. Diaphragm action of sandwich panels. Journal of Constructional Steel Research 31: 305-316.

Dürr, M., Misiek, Th., Saal, H. 2011. The torsional restraint of sandwich panels to resist the lateral torsional buckling of beams. Steel Construction - design and research 4: 251-258.

Dürr, M., Podleschny, R., Saal, H. 2007. Investigation of the torsional restraint of sandwich panels against lateral torsional buckling of beams) Stahlbau 76: 401-407.

ECCS 2013. European Recommendations On The Stabilization Of Steel Structures By Sandwich Panels.

EN 1993-1-3 (2006) Eurocode 3: Design of steel structures - Part 1-3: General rules - Supplementary rules for cold-formed members and sheeting.

Georgescu M., Ungureanu V. 2012. Stabilisation of continous Z-purlins by sandwich panels: Full scale experimental approach. The 6th International Conference on Coupled Instabilities in Metal Structures, Glasgow.

Górski M., Kozłowski A. 2021. Behaviour of hot-rolled purlins connected with sandwich panels. Archives of Civil Engineering 67/1 (in printing)

Käpplein, S., Misiek, Th. 2011. Stabilisation of beams by sandwich panels. EASIE report D3.3 - part 1,2 and 3.

Misiek, Th., Käpplein, S., Dürr, M., Saal, H. 2010. Stabilisation of purlins by sandwich panels - new regulations and recent research results., Proceedings of 18 th CIB World Congress Salford. 


\title{
Testing the core of sandwich panels with square shear specimen
}

\author{
S. Grimm \& J. Lange \\ Institute for Steel Construction and Materials Mechanics, Technical University of Darmstadt, Darmstadt, \\ Germany
}

\begin{abstract}
This paper presents the results of research on the determination of shear stiffness and strength of curved sandwich panel's core material. A new test setup was developed to determine the material parameters of the core. Furthermore, the material properties orthogonal to the longitudinal axis of linearly manufactured sandwich panels were examined. The findings are relevant for the three-dimensional modelling of shell structures made of curved sandwich panels. The new test setup can be used for the assessment of the global load-bearing behaviour of plane panels, which are loaded by torsion or shear stresses resulting from suspended facades, as well as the local load-bearing behaviour of sandwich panels with openings or point loads.
\end{abstract}

\section{INTRODUCTION}

Today lightweight sandwich panels are a common solution for roof and wall claddings. Due to their excellent weight to load ratio, their good heat insulation, their high load-bearing capacity as well as the economical manufacturing and erection process, sandwich panels are used frequently. Their load-bearing behaviour is usually analysed with beam models following their longitudinal axis, which also is the direction of production (x-axis) of linearly manufactured sandwich panels. Therefore, shear-test were developed for sandwich panels to determine the stiffness and strength of the core in the y-z-plane.

The linear manufacturing process of sandwich panels usually limits the possible building cubature to rectangular shapes. In an interdisciplinary project, architectural, civil engineering and mechanical engineering institutes of Technical University of Darmstadt developed a concept to build shell structures out of linearly manufactured uniaxial curved sandwich panels. The project shows that arched sandwich panels have a high potential regarding the load-bearing capacity.

This paper presents the results of a research project on the shear stiffness and strength of the core material of curved sandwich panels. A new test setup was developed to determine the material parameters of curved panels. Furthermore, it can be used to assess these properties in directions differing from the longitudinal axis of the panels. In this context, these material properties are needed to model the three-dimensional behaviour of sandwich shell structures. In a further study, the material properties differing from the longitudinal axis of linearly manufactured sandwich panels were examined. The material properties of the core deviating from the longitudinal axis are for instance relevant for the assessment of the global loadbearing behaviour of plane panels, which are loaded by torsion or shear stresses resulting from suspended facades, as well as the local load-bearing behaviour of sandwich panels with openings or point loads. 


\section{SQUARE SHEAR TESTS}

Square shear tests are for instance described by Jungbluth and Berner (1986) as well as Davies (2001). They were used as an alternative setup to the established four-pointbending shear test, which is described in EN 14509 annex A.3. Jungbluth and Berner (1986, Bild 7.23) compared the results of these different shear test, also taking into account three rail shear tests as well as dynamic three-point bending tests. Their results show that the shear stiffness and strength evaluated with the square shear tests most reasonably correspond to the values determined with the four-point-bending tests. Furthermore, square shear tests avoid an influence of indentations resulting from the support and loading of the specimen in the four-point-bending test. They have increasing importance since the depth of today's sandwich panels can easily reach up to $300 \mathrm{~mm}$. Nevertheless, studies during the development of the new test setup showed an important weakness of the existing square test setups.

\subsection{Assumptions of shear tests on square-shaped specimen}

A small specimen is cut from the panel, which has to be square-shaped in the plane of interest. On the four sides of the square stiff plates, either from steel (Jungbluth \& Berner 1986) or wood (Davies 2001) are attached. The specimen is loaded diagonally by tensile or compression forces. Shear stresses and strengths can be determined based on the measured load and displacement as well as the geometry of the specimen, pure shear stresses assumed.

The shear strain can be calculated as:

$$
\gamma=\frac{\sqrt{2} u}{l}
$$

where $u=$ is the displacement; $l=$ length of the square sides.

The shear stress can be calculated as:

$$
\tau=\frac{P}{\sqrt{2} A}
$$

where $P=$ is the load; $A=$ area resulting from the length of the square sides and the depth of the specimen.

\subsection{Assessment on the square shear test setup}

Due to the deviations of the shear strengths determined by using the square tests or the fourpoint bending tests, the load-bearing of the square test setup used by Jungbluth and Berner was studied in two-dimensional finite element models.
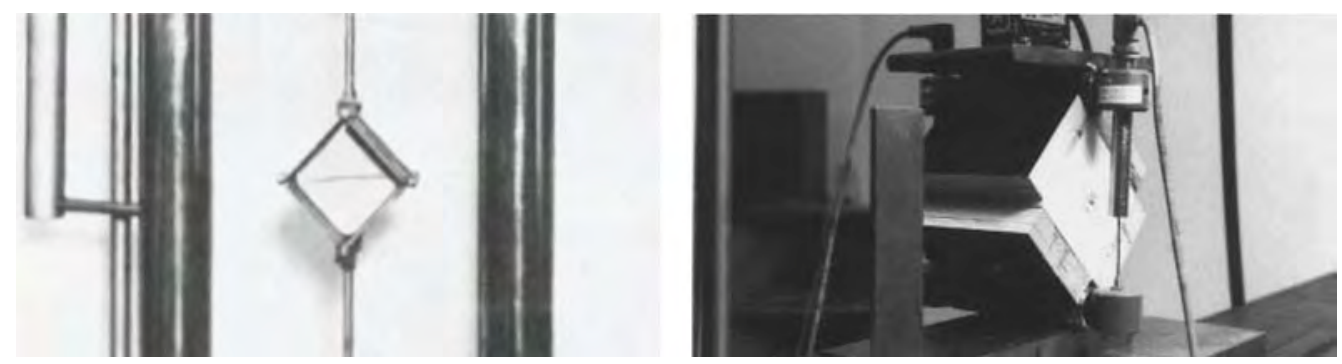

Figure 1. Square tests by Jungbluth \& Berner (1986, Bild 7.21) and Davies (2001, Fig. 13.4). 


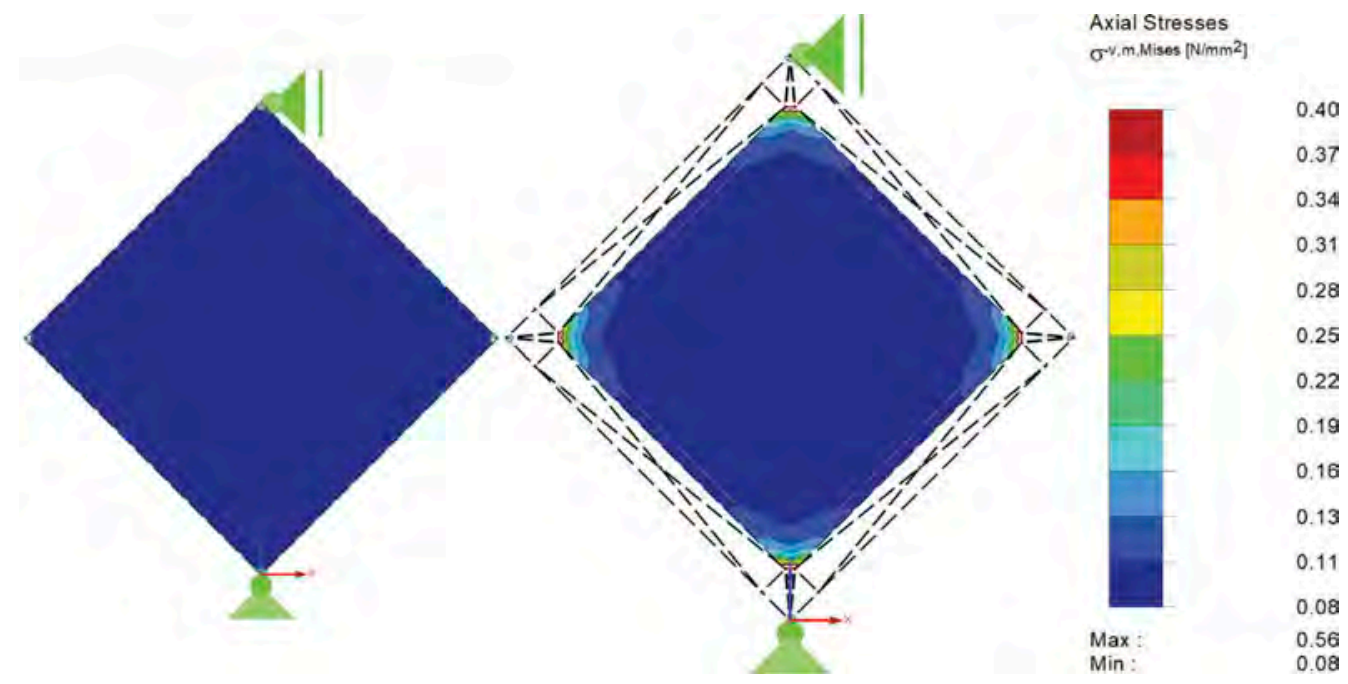

Figure 2. Results of the numerical models - plate thickness of $0 \mathrm{~mm}$ (left) and $20 \mathrm{~mm}$ (right).

The specimen with a length, height and thickness of $100 \mathrm{~mm}$ was modelled using shell elements. Only the core itself was modelled using an ideal-elastically orthotropic material law. Since the shear modulus was $3.0 \mathrm{~N} / \mathrm{mm}^{2}$ for all directions, the Poisson's ratio was set to 0.25 according to Kurpiela (2013). The Young's modulus for all directions was set to $3.0 \mathrm{~N} / \mathrm{mm}^{2}$ as well. The steel plates where modelled with a framework of rigid beams, which have a hinged connections in their edges (see Figure 2). In order to avoid numerical problems the edges of the specimen where rounded by a radius of $2 \mathrm{~mm}$.

The models were loaded by a diagonal tensile force of $1000 \mathrm{~N}$ and evaluated according to Equation (1) and (2). Figure 2 shows the resulting von-Mises stresses. On the left, the results of a dimensionless hinged bordering frame are shown. The specimen on the right is restrained by plates with a thickness of $20 \mathrm{~mm}$. The von-Mises stresses are given in Figure 2 since they take into account the shear stresses as well as the normal stresses. The results show that a pure shear stress state can only be assumed for a test setup with a frame without thickness but with infinite bending stiffness, like the rigid beams in the finite element model on the left. The eccentricity of the hinges causes additional normal stresses in the edges of the specimen that affect the results of the evaluation.

The evaluation of models with growing thickness or eccentricities of the hinges showed unrealistic high values for the shear modulus of the core material. Figure 3 shows the ratio of the evaluated and modelled shear modulus for different thicknesses of frame plates. The hinges were modelled in the centroid of the plates.

It can be seen that the dimensions of the restraining plates affect the validity of the assumptions on which the evaluation in Equation (1) and (2) are based. Technically, it is not possible to design a frame without any eccentricity of the hinges, which equally meets the requirement of a high bending stiffness compared to the core material. Therefore, a hinged frame, which is able to carry the expected loads, will lead to a shear modulus that is approximately 15 to 20 percent higher than the actual material parameter, based on the theoretical results. This also matches to results of the comparison of Jungbluth and Berner (1986, Bild 7.23).

\subsection{Development of the new shear test setup}

Based on the results of the numerical study a revised test setup was developed. The setup is intended to comply with the formulated restrictions of minimum thickness and high bending 


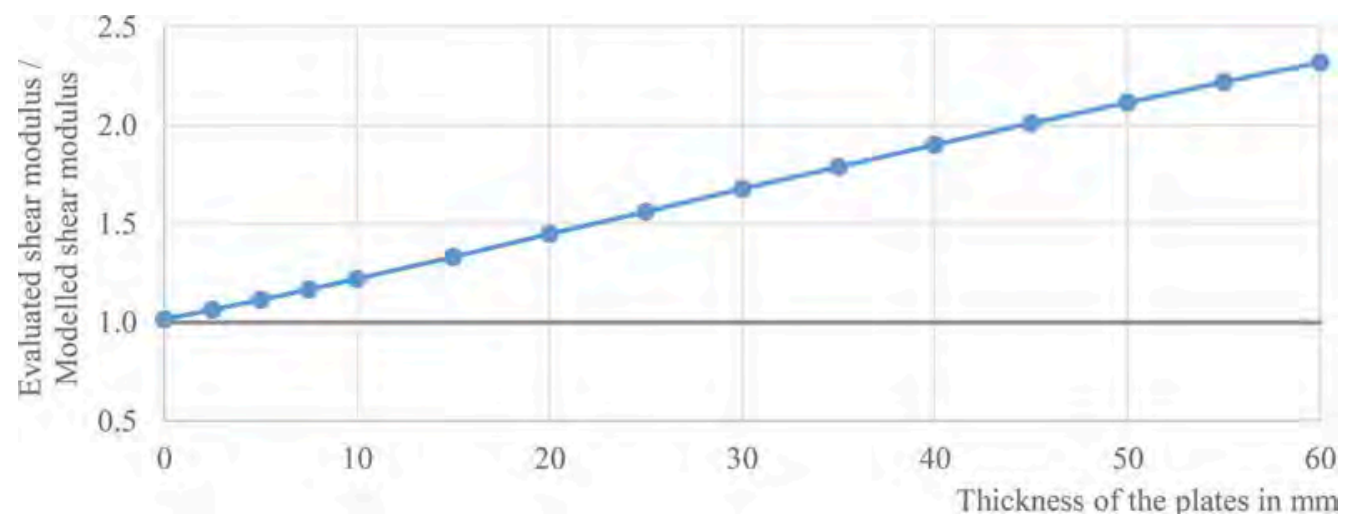

Figure 3. Error of the square tests.

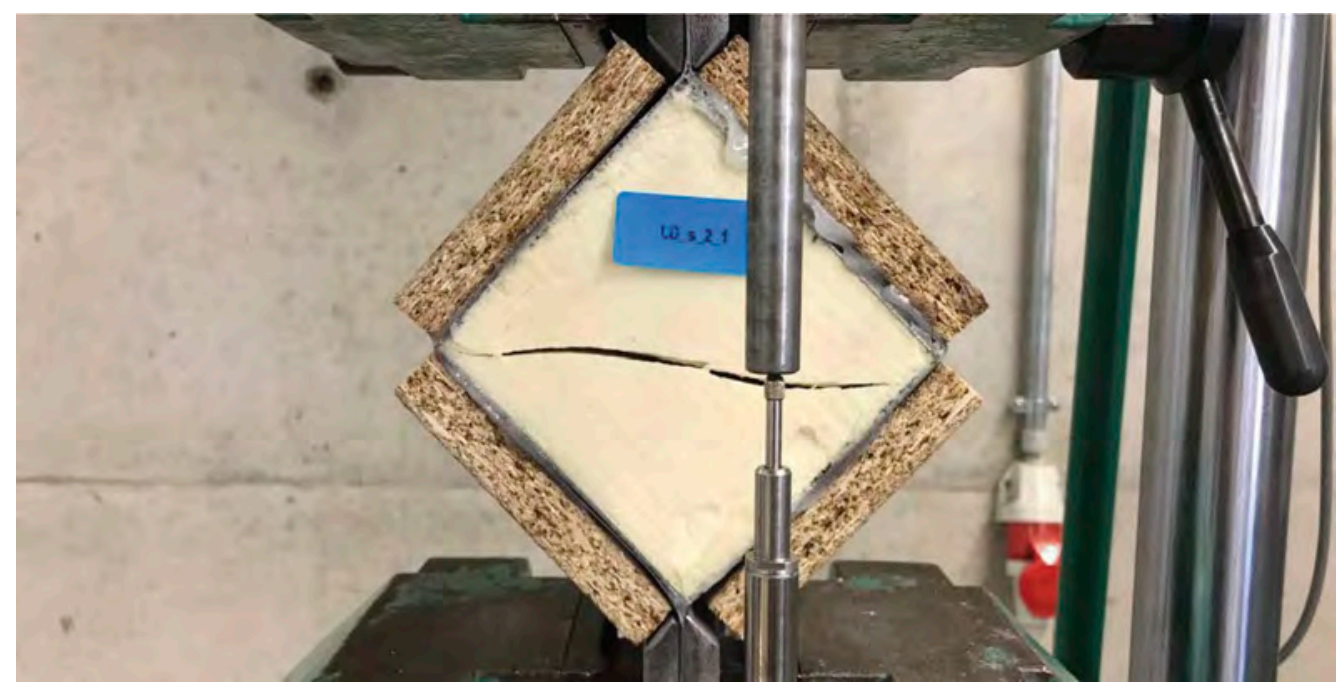

Figure 4. Plastic hinge square shear test - Shear fracture.

stiffness compared to the core material, as well as the face sheets of the specimen. The solution was found in the plastic hinge square shear test.

Instead of thick plates, metal sheets with a thickness of $0.5 \mathrm{~mm}$ are glued on the sides of the square shaped specimen. The frame is split into two cold formed steel sheets on the left and the right side of the specimen. The ends of these sheets are clamped by steel plates in the upper and lower edge of the specimen (Figure 4). To provide a high bending stiffness thick wooden plates are glued on the steel sheets afterwards. The different stiffness resulting from the Young's modulus of steel sheets and the wooden plates provide that the axial forces in the frame are acting in the plane of the steel sheets. So the setup provides that they are acting very close to the surface of the specimen, while the wooden plates prevent the sheets from bending.

After the bending-load capacity is reached plastic hinges develop in the edges of the frame. They prevent that the frame is carrying further loads and following only the specimen is stressed. Because of the thin sheets, the load-bearing capacity of the frame is small, but can still be calculated and taken into account in the test evaluation (Grimm et al. 2020). 
Since the testing principle is similar to the tests with a picture frame fixing according to ASTM D8067/D8067M, the plastic hinge square shear test provides the basis for further detailed research on sandwich-panels core material using digital image correlation measurement systems (DIC). Further studies will be carried out to validate the results of the new test setup. In a first step four-point-bending shear tests where modelled using the shear modulus determined by the plastic hinge square shear test. Deflections in the model show good accordance with the values measured during the associated tests.

\section{STUDIES WITH THE NEW PLASTIC HINGE SQUARE SHEAR TESTS}

The new plastic hinge square shear test was used for different studies. In a project on shell structures made of curved sandwich panels, their shear modulus was determined, as the panel's curvature has little effect on the results because of the small dimensions of the specimen. Furthermore, it was used to assess the shear stiffness and strength of the core of sandwich panels differing from their longitudinal axis.

\subsection{Shear testing of curved sandwich panels}

In the project on curved sandwich panels, a test-procedure for the determination of the material properties of the panel's core was needed. Since an effect of the panel's curvature on the results of the four-point-bending or two- or three-rail shear tests must be assumed, the square shear test seemed to be the most promising setup.

Because of the relatively small dimensions of the square-shaped specimen, its curvature can be neglected. Furthermore, the setup of the square shear test avoids the influence of normal stresses. These result from supporting or loading situations of a bending test or the free edges of two- and three-rail tests. Moreover, DIC measurement systems offer the ability of detailed investigation of the inhomogeneity of the core material. These might be affected by a new production process for curved sandwich panels.

\subsection{Shear testing of sandwich panels differing from the longitudinal axis}

Since the direction of the profiling of the panels face sheets does not affect the results of a square shear test, a preliminary study with tests deviating from the longitudinal axis was conducted. The specimens for this study were cut from sandwich panels with a PIR-core in five different angles including the longitudinal (x-axis or $0^{\circ}$ ) and transverse direction (y-axis or $90^{\circ}$ ). The vertical direction of all specimen was the z-axis. The loading rate was set according to EN 14509 annex A.3.4. Five or three specimen were tested for each direction at room temperature. The shear stresses and deformations were calculated according to Equation (1) und (2).

The shear modulus was determined as:

$$
G=\frac{\tau}{\gamma}
$$

with $\tau$ according to Equation (1) and $\gamma$ according to Equation (2).

The results in Figure 5 show that the shear modulus decreases with growing angle referred to the longitudinal axis of the panel. Only the result for the angle of $22.5^{\circ}$ does not fit into this trend. Deviating from the other orientations the specimen with the $22.5^{\circ}$ direction had a higher initial stiffness, which decreases beyond the distortion of $0.01 \mathrm{rad}$, which was the upper value of the evaluation field that was set the same for all directions. Furthermore, the divergence in the results for the $0^{\circ}$ direction is significantly higher than for the $22.5^{\circ}$ direction.

The results for the ultimate shear strength show a similar trend like the shear modulus. Different from the above, the result for the $22.5^{\circ}$ direction matches the trend. Summarizing, it 


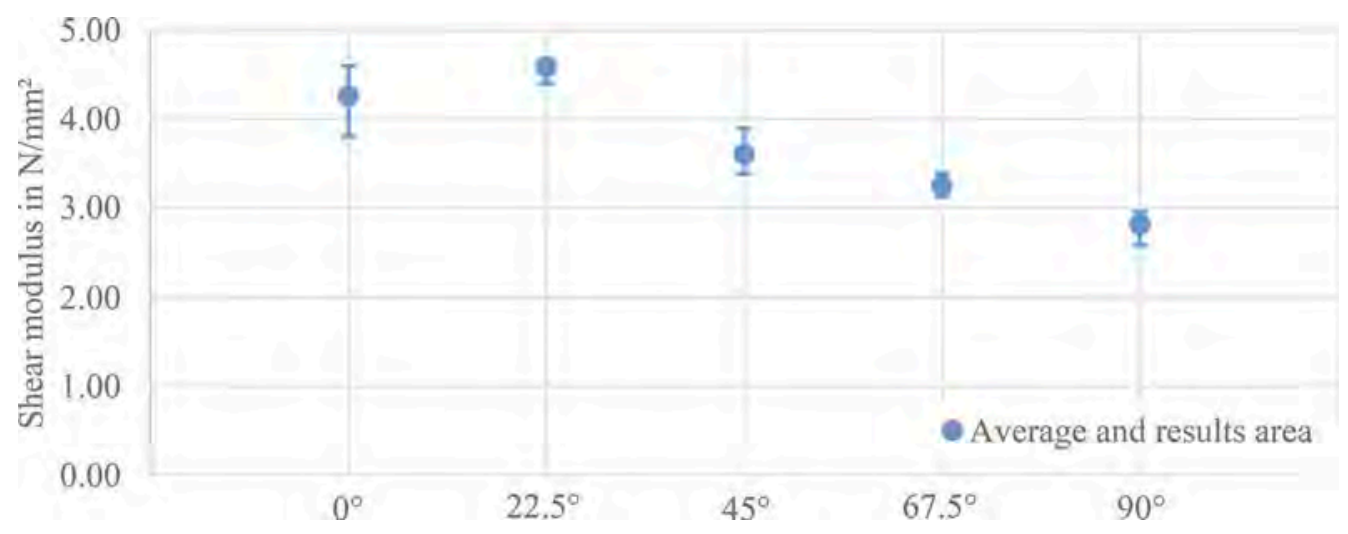

Figure 5. Shear modulus of the PIR-core in different directions.

can be assumed, that the shear stiffness and strength of the core of sandwich panels is optimized for their common use as a beam following their longitudinal axis. These findings might be due to their linear manufacturing process. Further research is planned to examine if these findings can be confirmed for a larger number of specimen and be transmitted to the core materials of other manufacturers as well.

\section{CONCLUSIONS AND OUTLOOK}

A new test setup was developed to investigate the shear stiffness and strength of the core of sandwich panels in all possible planes of interest, regardless from the panel's curvature, dimensions or the profiling of its face sheets. Furthermore, the new test setup offers the opportunity to investigate the inhomogeneity of the core material using digital image correlation measurement systems (DIC). The tests on the PIR sandwich core differing from the longitudinal axis suggests that sandwich panels are optimised for their usual application as a beam structure. In a preliminary study the shear stiffness and strength are reduced with a growing angle towards the longitudinal axis, in exception of the $22.5^{\circ}$ direction.

At the moment the four-point bending shear tests according to EN 14509 annex A.3 is examined similar to the numerical studies on the square shear tests, to validate the results of these tests on theoretical basis. Also further experimental studies are planned to investigate, whether there is a relation between the shear stiffness and strength of the core materials of different manufacturers and the tested angle of direction to reduce the number of tests for future test programs.

\section{REFERENCES}

ASTM D8067/D8067M:2017-01. Standard Test Method for In-Plane Shear Properties of Sandwich Panels Using a Picture Frame Fixture. West Conshohocken: ASTM International.

Grimm, S., Moneke, M., Reising, J., Lange, J., Groche, P., Schäfer, S. 2020. P 1234 Flächentragwerke aus gekrümmten Sandwichelementen. Düsseldorf: FOSTA - Forschungsvereinigung Stahlanwendung e. V.

Davies, J.M. (ed) 2001. Lightweight Sandwich Construction. Oxford et al: Blackwell Science.

EN 14509:2013-10. Self-supporting double skin metal faced insulating panels - Factory made products Specifications. Brussels: CEN European Committee for Standardization.

Jungbluth, O. \& Berner, K. 1986. Verbund- und Sandwichtragwerke: Tragverhalten, Feuerwiderstand, Bauphysik. Berlin: Springer.

Kurpiela, A. 2013. Optimierung von Sandwichwandbauteilen mit PUR-Kern und Stahldeckschichten. Darmstadt: Institut für Stahlbau und Werksto $\square$ mechanik der Technischen Universität Darmstadt. 


\title{
Numerical study on the revised rules for minimum degree of shear connection in propped and unpropped steel-concrete composite beams
}

\author{
C. Odenbreit \& V. Vigneri \\ University of Luxembourg, Luxembourg-Kirchberg, Luxembourg
}

\begin{abstract}
The work presents a numerical study that focuses on steel-concrete composite beams using ductile headed stud shear connectors. The objective is to check the suitability of the proposed revised EN 1994-1-1 rules for the minimum degree of shear connection. Therefore, a non-linear 3D finite element model of simply supported composite beams was developed and validated against the analytical values of the plastic bending design resistance. The parametric study consists of 10 configurations where the relative slip at slab-beam interface was carefully investigated at different degrees of shear connection and propping conditions. Specifically, the slip at the minimum degree of shear connection shall not exceed the limit of $6 \mathrm{~mm}$ defined as the characteristic slip of ductile connector according to EN 1994-1-1. The results showed that the revised rules for unpropped beams delivers conservative results whereas one case with propped conditions exhibit a maximum slip significantly higher than $6 \mathrm{~mm}$.
\end{abstract}

\section{INTRODUCTION}

According to current design rules of EN 1994-1-1 (British Standards Institution, 2004), ductile shear connectors (e.g. headed studs) in composite beams allow the use of partial shear connection in plastic design as confirmed by past experimental and numerical studies (Johnson \& Molenstra, 1991). However, to limit the occurring slip between the steel beam and the concrete slab within the characteristic slip capacity of the connector (at least $6 \mathrm{~mm}$ ) at ultimate and serviceability limit state (SLS and ULS), a minimum degree of shear connection shall be guaranteed. CEN/TC250/SC4.PT3 proposed a revised version of the design rules relative to the minimum degree of shear connection $\eta_{\min }$ accounting for the partial utilization of the beam and propping construction procedure. However, there are only few studies focused on the occurring slip in unpropped composite beams with symmetrical sections. Therefore, the authors performed a numerical study aiming to fill this gap and to justify the reduction factors proposed in the new design proposal for minimum degree of shear connection.

\section{PROPOSED EQUATION FOR MINIMUM DEGREE OF SHEAR CONNECTION}

Based on the design proposal of CEN/TC250/SC4.PT3 and further investigations, the following equations have been recently proposed for beams subjected to sagging bending moment, taking into account their partial utilization with the factor $\delta_{I}$.

For steel sections having equal flanges, propped construction and ductile shear connectors: 


$$
L_{e} \leq 25: \eta \geq\left[1-\underset{L_{e}>25}{\left.\left(\frac{355}{f_{y}}\right)\left(0.75-0.03 L_{e}\right)\right] \cdot \delta_{1}^{2} ; \eta \geq 0.4}\right.
$$

With:

$$
\delta_{1}=\frac{M_{E d}}{0.95 M_{p l, R d, \eta}} \geq 0.8
$$

Where $L_{e}$ is the distance in sagging bending between points of zero bending, $M_{E d}$ is the acting design bending moment and $M_{p l, R d, \eta}$ indicates the bending moment resistance depending on the degree of shear connection $\eta$.

In addition to the positive influence of the utilization of the beam, the required degree of shear connection for unpropped beams can be further reduced based on the self-weight to resistance ratio with the factor $k_{\text {unpr }}$, as follows:

$$
\begin{gathered}
L_{e} \leq 25: \eta \geq\left[1-\left(\frac{355}{f_{y}}\right)\left(0.75-0.03 L_{e}\right)\right] \delta_{1}^{2} \cdot k_{\text {unpr }} ; \eta \geq 0.3 \\
L_{e}>25: \eta \geq 1
\end{gathered}
$$

With:

$$
\begin{gathered}
k_{\text {unpr }}=\left\{\begin{array}{cl}
1.0 & \text { for } \frac{M_{E d}}{M_{P l, R d, \eta}} \geq 0.95 \\
\left(1-\delta_{2}\right) & \text { for } \frac{M_{E d}}{M_{P l, R d, \eta}}<0.95
\end{array}\right. \\
\delta_{2}=\frac{M_{s w, E d}}{M_{p l, R d}} \leq 0.15
\end{gathered}
$$

Where $M_{s w, E d}$ is the bending moment due to the self-weight of the composite beam and $M_{p l, R d}$ is the bending moment resistance for full shear connection (i.e. $\eta=1.0$ ). For the investigation of the slip displacement, a finite element (FE) model was developed and it is presented in section 3 .

\section{DESCRIPTION OF THE FINITE ELEMENT MODEL}

\subsection{General}

The FE model presented in this chapter bases on the experience gained over the past research studies where the behaviour of composite beams with partial shear connection was investigated. Among these, the recent RFCS research projects DISCCO (Lawson, et al., 2017) and REDUCE (European Commission: Directorate-General for Research and Innovation, 2020) as well as the work made by CEN/TC250/SC4.PT3 are mentioned. The software ABAQUS 2017 (Dassault Systèmes Simulia, 2014) was used to develop a finite element (FE) model able to simulate the mechanical behaviour of a composite beam. The structural system reproduced in the study was a simply supported beam under uniformly distributed load as shown in Figure 1. The FE model, consist of 3 main parts: (i) concrete slab, (ii) steel beam and (iii) a set of shear connectors that transfer the longitudinal shear force between them, as detailed in Table 1.

\subsection{Material properties}

In the FE modelling of composite beams using composite slabs with profiled steel sheeting, only the effective height of the concrete above the rib of the steel sheeting was considered. Notwithstanding that the material damage was not considered in this model, the "Concrete 

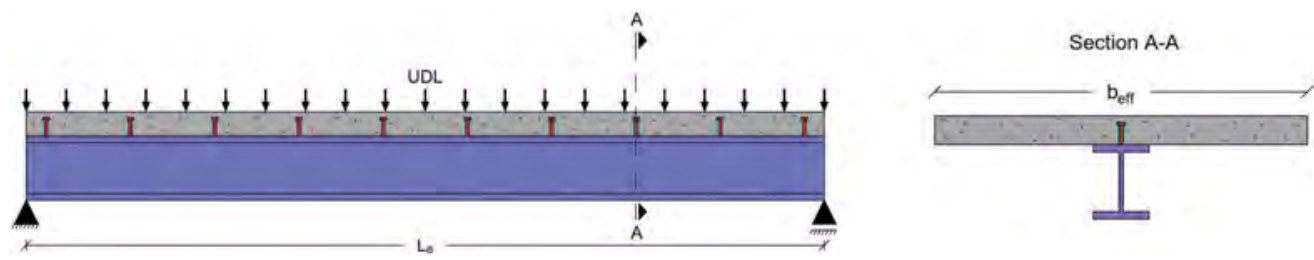

Figure 1. Structural system considered in the study.

Table 1. Instances and material of the FE model.

\begin{tabular}{llll}
\hline & Instance & Element type & Material \\
\hline (i) & Concrete slab & Solid (C3D8R) & Concrete Damaged Plasticity \\
(ii) & Steel beam & Solid (C3D8R) & 3D von Mises plasticity model \\
(iii) & Shear connectors & Fastener & Uniaxial non-linear law \\
\hline
\end{tabular}

Damaged Plasticity" (CDP) model available in ABAQUS was applied to the concrete. The main material parameter are given in Table 2 . They include: modulus of elasticity $E_{c m}$, Poisson's ratio $v$, dilation angle $\psi$, flow potential eccentricity $e$, ratio of compressive strength under biaxial loading to uniaxial compressive strength $f_{b o} / f_{c}$ and the ratio of the second stress invariant on the tensile meridian to that on the compressive meridian $K_{c}$. The values assigned to the CDP plasticity parameters are also given in Table 2 . The concrete behaviour under compression was modelled according to the design parabola-rectangle uniaxial law of EN 1992-1-1. As already done in a similar study (Aggelopoulos, et al., 2018), the tensile strength was taken as approximately $10 \%$ of the corresponding compressive strength of the concrete. Beyond this point, a full plastic plateau was assumed in the uniaxial stress-strain law. The steel beam was reproduced through solid continuum elements (C3D8R). To ease the mesh modelling procedure, the web-flange junctions were neglected. The beam material follows the Von Mises plasticity criterion with a bilinear stress-strain law with a very small hardening slope of less than $\mathrm{E}_{\mathrm{s}} / 200$. The modulus of elasticity was taken as $210000 \mathrm{MPa}$ while the Poisson's ratio was 0.3 .

Finally, the shear connectors were modelled through the ABAQUS feature *FASTENER which allows to connect two points with a directional spring law and to attach these points to the selected surfaces. First, the attachment points were created on the top flange of the steel beam along the longitudinal direction with a constant spacing of $250 \mathrm{~mm}$. Then, the corresponding attached points were created on the bottom surface of the "effective" concrete slab (projection along normal direction) and coupled with the respective attachment points on the top flange, see Figure 2.

To reproduce the behaviour of actual shear connectors in composite beams, only the relative displacement in the longitudinal direction of the coupled points was released using the type of mechanical constraint "Slot" and "Align" in *CONNECTOR SECTION.

The uniaxial load-slip curve along the longitudinal direction of each connector was defined through a bi-linear uniaxial load-slip curve. It was assumed that the ultimate design resistance

Table 2. Plasticity parameters of the CDP model (Dassault Systèmes Simulia, 2014).

\begin{tabular}{llllll}
\hline Property & $\begin{array}{l}\text { Dilation } \\
\text { angle } \psi\left[\left[^{\circ}\right]\right.\end{array}$ & $\begin{array}{l}\text { Eccentricity } \\
e[-]\end{array}$ & $\begin{array}{l}\text { Biaxial to axial } \\
\text { strength ratio } \\
f_{b 0} / f_{c}[-]\end{array}$ & Coefficient $K_{C}[-]$ & $\begin{array}{l}\text { Viscosity parameter } \\
\mu[-]\end{array}$ \\
\hline Value & 38 & 0.1 & 1.16 & 0.667 & $1 \times 10-5$ \\
\hline
\end{tabular}




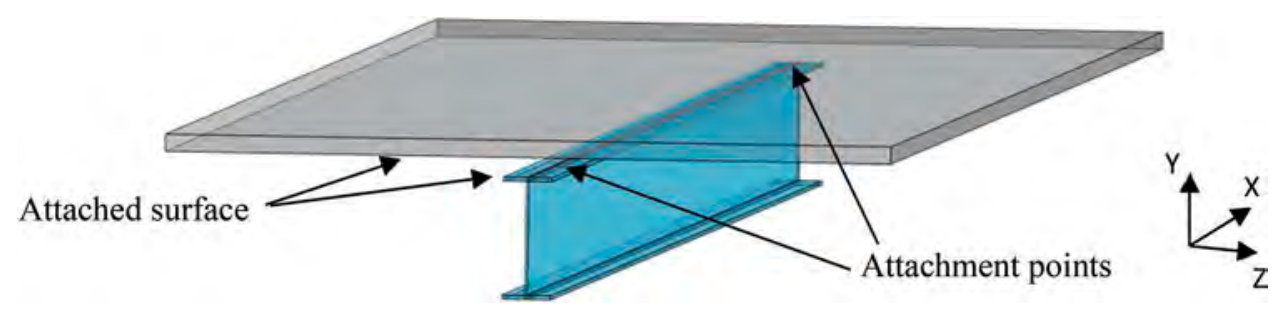

Figure 2. Attachment points of the FE model corresponding to the location of the shear connectors.

of the shear connectors $P_{R d}$ is achieved at a slip displacement of $1 \mathrm{~mm}$. Beyond this value, the connector has a full plastic behaviour. The resistance $P_{R d}$ was modified in each configuration to fit the needed degree of shear connection, as explained in Chapter 4.

\subsection{Mesh modelling, boundary conditions and load application}

The concrete slab and the steel beam were modelled with continuum solid elements with reduced integration (C3D8R). A sensitivity analysis was performed to check the most efficient mesh size. The average mesh size of the concrete slab was defined as $150 \mathrm{~mm}$ with 4 layers along the vertical direction. The mesh of the steel beam was approximately $50 \mathrm{~mm}$. It was also checked that a denser mesh does not improve the accuracy of the FE model. To reproduce the simply supported conditions given in Figure 1, one of the supports was restricted to translate in the three principal directions $(\mathrm{X}, \mathrm{Y}$ and $\mathrm{Z}$ ) whereas only the longitudinal displacement along $\mathrm{X}$ was allowed in the other support. In both cases, the rotation around the axis $\mathrm{Z}$ was released. These boundary conditions were implemented in ABAQUS by coupling reference points to the ends of the steel beam. Furthermore, to account for the effect of the contiguous slabs in the transversal direction, symmetric boundary conditions in the transversal direction were included along the lateral edges of the slab. In this way, any lateral displacement was prevented. Finally, the load was applied on a partitioned strip located on the surface of the top flange through the ABAQUS feature *SURFACE TRACTION. The load direction was defined through a vector to ensure that the load applies along the vertical direction throughout the whole simulation.

\subsection{Unpropped conditions}

To reproduce the loading stages of unpropped composite beams, two different sub-models were initially created: the first considers only the steel beam (before concreting) while the other includes the concrete slab as well as the shear connectors (after concreting). The former model was needed to compute the stress field of the steel beam after applying the load due to the self-weight of the beam and the slab. After that, this stress field was imported in the second model via the feature *PREDEFINED FIELD-STRESS available in Abaqus, in Step 1 . During the step 2, the additional "imposed" load was increasingly applied on the composite system until failure. Such procedure for modelling numerically the unpropped conditions were also used in several previous studies (Aggelopoulos, et al., 2018).

\section{PARAMETRIC STUDY}

Once the FE model was successfully validated for propped and unpropped beams against the analytically obtained values of the bending design resistance, several configurations were analysed within their typical range of application. The span length ranges between 10 and $21 \mathrm{~m}$ while the depth-to-span ratio of the steel profile vary around 25, typically considered for the design of composite beams. All the cases refer to composite slabs with $80 \mathrm{~mm}$ deep 
Table 3. Data of the configurations analysed.

\begin{tabular}{|c|c|c|c|c|c|c|c|c|c|}
\hline \multirow[b]{2}{*}{ N. } & \multirow[b]{2}{*}{ Case } & \multirow{2}{*}{$\frac{\text { Span }}{\mathrm{m}}$} & \multirow{2}{*}{$\begin{array}{l}\text { Steel } \\
\text { grade }\end{array}$} & \multirow{2}{*}{$\begin{array}{l}\text { Steel } \\
\text { section }\end{array}$} & \multirow{2}{*}{$\begin{array}{l}\text { Concrete } \\
\text { class }\end{array}$} & \multirow{2}{*}{$\begin{array}{l}\begin{array}{l}\text { Slab } \\
\text { width }\end{array} \\
\mathrm{mm}\end{array}$} & \multirow{2}{*}{$\begin{array}{l}\begin{array}{l}\text { Eff. slab } \\
\text { depth }\end{array} \\
\text { mm }\end{array}$} & \multirow{2}{*}{$\begin{array}{l}\text { Rib } \\
\text { height }\end{array}$} & \multirow{2}{*}{$\begin{array}{l}M_{s w} / M_{p l, R d} \\
-\end{array}$} \\
\hline & & & & & & & & & \\
\hline 1 & $10-300-\mathrm{A}$ & 10 & S355 & IPE 300 & C30/37 & 2500 & 70 & 80 & 0.16 \\
\hline 2 & $10-400-\mathrm{A}$ & 10 & S355 & IPE 400 & C30/37 & 2500 & 70 & 80 & 0.10 \\
\hline 3 & $12-400-\mathrm{A}$ & 12 & S355 & IPE 400 & C30/37 & 3000 & 70 & 80 & 0.16 \\
\hline 4 & $12-500-\mathrm{A}$ & 12 & S355 & IPE 500 & C30/37 & 3000 & 70 & 80 & 0.11 \\
\hline 5 & $16-450-\mathrm{A}-27$ & 16 & S355 & IPE 450 & C30/37 & 2700 & 70 & 80 & 0.29 \\
\hline 6 & 16-600-A & 16 & S355 & IPE 600 & C30/37 & 4000 & 70 & 80 & 0.17 \\
\hline 7 & $18-500-\mathrm{A}$ & 18 & S355 & IPE 500 & C30/37 & 4500 & 70 & 80 & 0.33 \\
\hline 8 & $18-600-\mathrm{A}$ & 18 & S355 & IPE 600 & C30/37 & 4500 & 70 & 80 & 0.23 \\
\hline 9 & 21-600-A & 21 & S355 & IPE 600 & C30/37 & 5250 & 70 & 80 & 0.35 \\
\hline 10 & 21-750-A & 21 & S355 & IPE 750 & C30/37 & 5250 & 70 & 80 & 0.27 \\
\hline
\end{tabular}

profiled sheeting (transverse to the beam) and a total slab depth of $150 \mathrm{~mm}$. Only the effective portion of the slab (i.e. $70 \mathrm{~mm}$ deep) was considered in the FE model. For all configurations listed in Table 3, the resistance of shear connectors was adjusted to achieve different degree of shear connection ranging from 0.2 to 1.0 according to:

$$
P_{R d}(\eta)=\frac{N_{c}}{n} \eta
$$

Where $N_{c}$ is the total compression force in the concrete slab and $n$ is the number of studs in the shear length of the beam. For each case, both propped and unpropped conditions were simulated.

\section{EVALUATION OF THE RESULTS FOR DUCTILE CONNECTORS}

\subsection{General}

To check the suitability of the design proposal for the minimum degree of shear connection, the values of the slip of the shear connections obtained in the parametric study was determined at an applied load level leading to a mid-span acting bending moment equal to $95 \%$ of the plastic bending design resistance $\left(M_{p l, R d, \eta}\right)$ of the beam. This value was analytically calculated in accordance with the plastic rigid theory of EN 1994-1-1 for partial shear connection using the design properties of the steel and concrete. Such procedure is consistent with the assumptions made in the original calibration of the shear connection rules of current EN 1994-1-1 (Aribert, 1997). Due to the different application of the load on unpropped beams, the cases with propped conditions exhibited higher slip values. Specifically, the slip reduction due to the unpropped construction is significant and it typically ranges between $15 \%$ and $50 \%$ depending on the load level.

\subsection{Evaluation of the slip values}

In order to check that the slip limit is not exceeded according to the proposed design equations in section 2, (a) each system was analysed (b) for different degrees of shear connection and (c) the output of the simulation were extracted at different utilization factor UF. Finally, (d) all the simulations were run for propped and unpropped conditions. The value of the end-slip s was plotted at different levels of $\mathrm{UF}=M_{E d} / M_{p l, R d, \eta}$ from each run. This procedure was repeated for different degree of shear connection $\eta$ until the $\eta-s$ curves were complete, see Figure 3. 


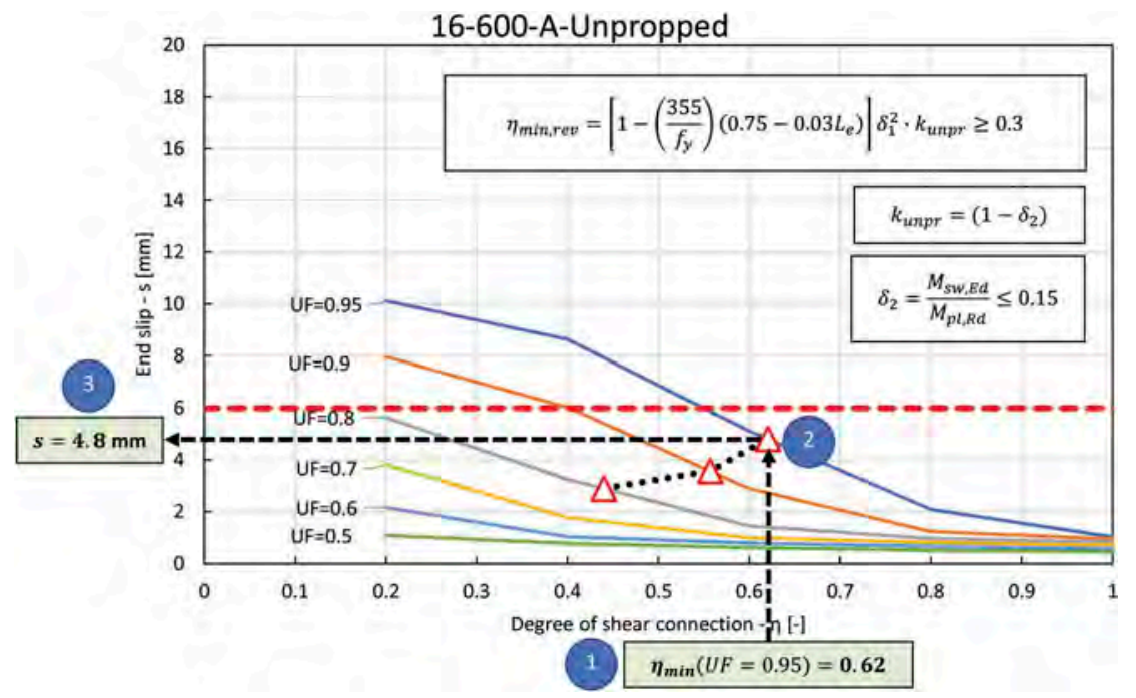

Figure 3. Example of slip - degree of shear connection curves showing the occurring slip at the design minimum degree of shear connection for ductile connectors at $\mathrm{UF}=0.95$.

(1) Once the curves are generated, the minimum degree of shear connection $\eta_{\min }$ was firstly calculated for a given value of UF according to the proposed design rules for ductile studs. In case of propped beams, Eq. (1) shall be used while Eq. (3) apply to unpropped beams.

(2) The intersection with the corresponding curve gives the value of the occurring slip at $\eta_{\min }$.

(3) After repeating the procedure for different load levels $(\mathrm{UF}=0.95,0.9,0.8 \ldots)$ the values of the occurring slip are displayed as red triangles in Figure 3.

If these values are lower than $6 \mathrm{~mm}$, the design rules can be safely applied to the configuration considered. The values of the slip at the minimum degree of shear connection were plotted for all cases considered in Figure $4 \mathrm{a}$ and Figure $4 \mathrm{~b}$, for propped and unpropped conditions at $\mathrm{UF}=0.9$ and $\mathrm{UF}=0.95$ respectively. According to these results, the revised rules for minimum degree of shear connection for unpropped beams can be safely applied whereas only one case of the propped configurations shows a maximum slip of ca. $8.6 \mathrm{~mm}$.

a)

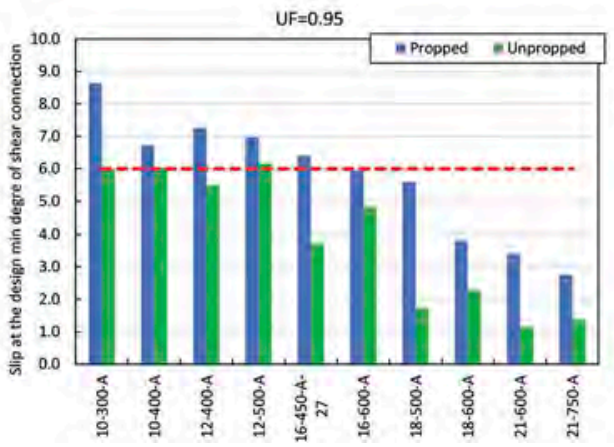

b)

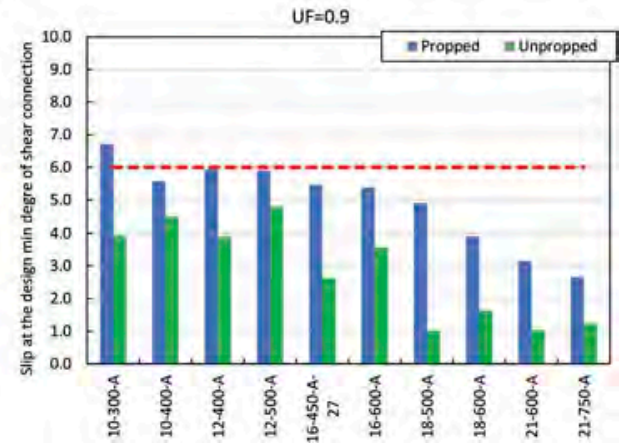

Figure 4. Occurring slip at the design minimum degree of shear connection for ductile connectors at: a) $\mathrm{UF}=0.95$ and $\mathrm{b}) \mathrm{UF}=0.9$. 


\section{CONCLUSIONS AND OUTLOOK}

A finite element model of propped and unpropped composite beam with symmetrical beams was presented and validated against analytical results. Then, a parametric study was performed to assess the maximum occurring slip at the minimum degree of shear connection according to the proposed revised rules that accounts for the positive effect of the unpropped conditions.

Based on the study presented, the slip at the minimum degree of shear connection according to revised rules for unpropped beams with ductile connectors is lower than $6 \mathrm{~mm}$. Therefore, this design solution can be safely applied to unpropped composite beams. On the other side, only one of the propped configurations shows a maximum slip noticeably higher than $6 \mathrm{~mm}$.

However, to provide a more reliable evidence of the suitability of the design rules, further simulations of composite beams using solid slabs are foreseen. Furthermore, the approach presented to assess the design rules for the minimum degree of shear connection may be extended to propped and unpropped composite beams with asymmetrical and/or cellular steel beam.

\section{REFERENCES}

Aggelopoulos, E., Couchman, G. \& Lawson, M., 2018. Minimum degree of shear connection in composite beams in buildings. Valencia, s.n.

Aggelopoulos, E., Hanus, F. \& Lawson, M., 2018. Shear connection requirements for composite cellular beams. Valencia, s.n.

Aribert, J. M., 1997. Analyse et formulation pratique de l'influence de la nuance de l'acier du profile sur le degre minimum de connexion partielle d'une poutre mixte. Construction Métallique, Volume 3, pp. $39-55$.

British Standards Institution, 2004. EN 1992-1-1: 2004 Eurocode 2 - Design of concrete structures Part 1-1: General rules and rules for buildings. London: s.n.

British Standards Institution, 2004. EN 1994-1-1: 2004 Eurocode 4 - Design of composite steel and concrete structures Part 1-1: General rules and rules for buildings. London: s.n.

CEN-TC250-SC4, 2018. CEN-TC250-SC4-N1893: 1.1 - SC4.T3_FIN_DOC_EN1994-1-1_6.6.1.1\& 6.6.1.2_eta, s.1.: s.n.

Dassault Systèmes Simulia, 2014. Abaqus Analysis User's Guide v6.14, s.1.: s.n.

European Commission: Directorate-General for Research and Innovation, 2020. Reuse and demountability using steel structures and the circular economy (REDUCE), Brussels: s.n.

Johnson, R. P. \& Molenstra, N., 1991. Partial shear connection in composite beams for buildings. Proceedings of the Institution of Civil Engineers, 91(4), pp. 679-704.

Lawson, M. et al., 2017. Development of improved shear connection rules in composite beams - Final Report, s.1.: s.n. 


\title{
Numerical analysis of proposed tubular perfobond shear connector
}

\author{
K.L.B. Souza, A.T. Silva, P.C.G.S. Vellasco \& M.C. Rodrigues \\ State University of Rio de Janeiro, Rio de Janeiro, Brazil \\ J. Henriques \\ Hasselt University, Hasselt, Belgium
}

\begin{abstract}
The most common means for connection between steel and concrete is mechanical, usually through shear connectors. Currently, numerous shear connectors are available to designers which have been subject of study in the past decades. Eurocode 4 prescribes a minimum characteristic slip capacity for the connector to be considered as ductile. Thus, this paper proposes an alternative tubular perfobond shear connector encompassing the resistance of the conventional Perfobond and providing the required ductility prescribed by the code. The study has been conducted using the finite element method through push-out tests to determine the connector resistance and slip capacity. The influences of the most relevant parameters and properties were determined. Due to the lack of results on the tubular perfobond connectors, the experimental results on Perfobond connectors available in the literature were previously used to validate the numerical model. The proposed connector has presented a satisfactory performance and could be considered viable.
\end{abstract}

\section{INTRODUCTION}

The composite structure is an innovative, efficient and economical structural solution that reveals the human capacity for technological innovation through the use of new materials and the conception of optimized structural systems. The connection between the materials, transfer of efforts and the shear strength along the steel-concrete contact surfaces can be achieved by mechanical means such as shear connectors. The shear connector confers the interaction between steel and concrete, transmitting forces from one material to the other, enabling them to work in a solid and monolithic way to resist the solicitations. Gu et al. (2019) consider shear connectors as the key element of the composite structure, where they make the composite behaviour happen, minimizing the slip between the materials.

Many shear connectors have been developed in the last decades, such as stud bolt, C-profiles, U-profiles, Crestbond, Perfobond, among others. The stud is standardized by Eurocode 4 (2005), and it is the most commonly used due to the practicality and quickness of its installation process. Its disadvantage is related to low resistance to fatigue and the need for electricity to installation. These disadvantages led to the necessity of developing alternative connectors, which can be produced at the construction site. According to Bezerra et al. (2018), these new connectors can encourage the popularization of composite construction. The U-profile connector was one of those that became widely used due to stud limitation. This connector is easy to manufacture and weld, but its web has a relatively small stiffness, allowing it to suffer great deformations.

Due to the limitations, new alternative connectors were created. In this process, the Perfobond connector was conceived. It has stood out from the others, and it is known to have 
greater rigidity and resistance than studs. However, it has low slip capacity, which often characterizes it as a non-ductile connector.

Therefore, there is a need for an alternative connector to Perfobond that can present excellent resistance, as well as Perfobond, and to achieve adequate slip capacity, as recommended by Eurocode 4 (2005). Thus, from this need, a tubular shear connector is proposed. It is expected that a tubular cross-section can optimize the connector performance, leading to satisfactory resistance and ductility. Therefore, to evaluate the proposed connector, some parameters are studied, and a brief numerical study is performed and presented.

\section{VALIDATION OF THE NUMERICAL SIMULATION OF PERFOBOND CONNECTORS}

\subsection{Reference push-out tests on Perfobond connectors}

There is no result of a connector similar to the tubular; thus, a validation of the numerical modelling will be carried out from the results of the Perfobond connectors of Vianna et al. (2009). Their research covered Perfobond and T-Perfobond connectors. For this validation, the Perfobond connector with two holes (EX-P-2H-120) was chosen. The dimensions and geometries of the specimen in question can be found in Vianna et al. (2009).

\subsection{Development of the numerical model}

The study was performed in Abaqus 6.14 (2010). The explicit solver was used in the nonlinear numerical analysis conducted, which encompasses complex contact interactions, the nonlinearity of materials and large deformations. Other authors such as Gu et al. (2019) have used this solver previously for similar numerical simulations. The loading process was quasi-static, and its ratio was monitored to avoid dynamic effects. During the analysis, the kinetic energy was kept between $5 \%$ and $10 \%$ of the internal energy to guarantee a quasi-static analysis.

\subsubsection{Geometry, loading and boundary conditions}

All components were modelled with solid elements and are shown in Figure 1. As in the experimental test, a loading was applied from the introduction of an axial displacement on the "I" profile section upper face. About the boundary conditions, displacement restrictions have been applied in the three directions of the global axes at the slabs bases. Both have been applied to the reference points belonging to the multi-point constraints (MPCs) (Figure 1c).

\subsubsection{Material modelling}

The modelling of the materials considered the properties used by Vianna et al. (2009). The steel employed were S355, S275 and S500 for the connector, the beam and the reinforcement,

a)

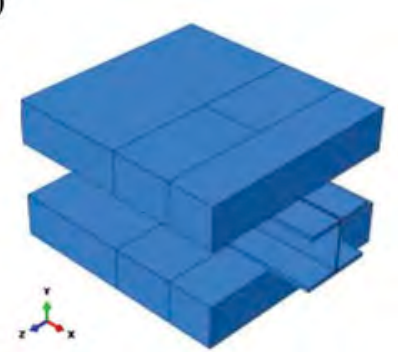

b)

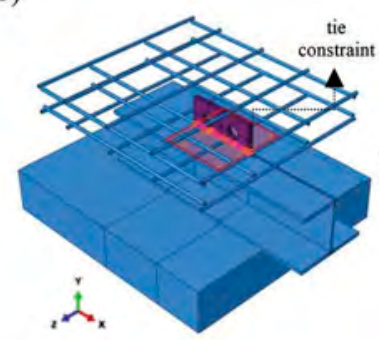

c)

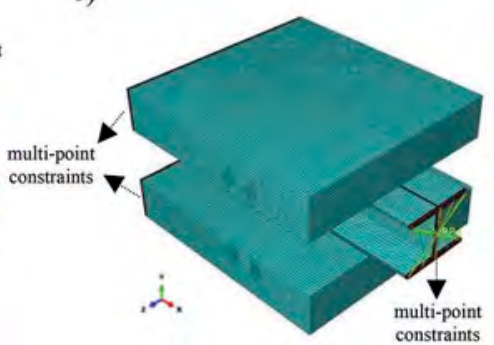

Figure 1. Geometry, load, boundary conditions, tie constraints and mesh of Perfobond numerical model. a) Push-out test model layout, b) Tie constraint, c) Mesh and details of load and boundary conditions at MPCs. 
respectively. For the modelling of the beam and reinforcement, an elastic perfectly plastic stress-strain model was chosen. Regarding the shear connector, it was modelled following the quadrilinear stress-strain law proposed by Yun and Gardner (2017).

The concrete has $f_{c m}$ equal to $28 \mathrm{MPa}$ and $52 \mathrm{MPa}$. A concrete damaged plasticity model (CDP) was chosen to characterize the concrete behaviour. To use this package, it is necessary to inform five plastic parameters and the behaviour under compression and tension. The parameters, dilation angle $(\psi)$, eccentricity $(\varepsilon)$, the ratio of biaxial to uniaxial compressive strength $\left(f_{b o} / f_{c o}\right)$, the ratio of the second stress invariant on the tension meridian to that on the compressive $(\mathrm{K})$ and a viscosity parameter $(\mu)$ are taken as $38,0.1,1.16,0.667$ e 0 , respectively.

The constitutive law proposed by Pavlovic (2013) was adopted to characterize the behaviour of concrete under compression in terms of a stress-strain ratio. About the damage model, Genikomsou and Polak (2015) consider that concrete under compression only loses stiffness after reaching its resistance, $f_{c m}$. All parameters necessary can be found in Pavlovic (2013) and Genikomsou and Polak (2015). The bilinear tensile behaviour recommended by CEB (2010) was used through the stress-crack opening relation. Similar to the compression behaviour, the authors also consider that concrete only cracks after reaching its resistance, $f_{\text {ctm }}$. More details about these formulations can be found in CEB (2010) and Genikomsou and Polak (2015).

\subsubsection{Constraints and contact interactions}

The interaction between the reinforcement bars and the concrete was applied through the embedded constraint. To simulate the weld between the shear connector and the steel beam, the tie constraint was applied in a manner that keeps the faces together during the entire numerical simulation (Figure 1b). Regarding the contact properties, the normal hard contact behaviour was applied to avoid overlapping between the parts during the simulation. A tangential behaviour was also assumed during the analysis with a coefficient of friction equal to 0.15 .

\subsubsection{Meshes}

A mesh (Figure 1c) was adopted with an overall size of $5 \mathrm{~mm}$ e $24 \mathrm{~mm}$ for the shear connector and reinforcement bars, respectively. The slab and the steel beam mesh adopted an $8 \mathrm{~mm}$ element size. All the components of the model were discretized with 3D elements of type C3D8R.

\subsection{Validation of the numerical model}

The shear connection capacity obtained from the experimental tests (EX-P-2H-120-28MPa and EX-P-2H-120-52MPa) and finite element analysis (NM-P-2H-120-28MPa and NM-P-2H-120$52 \mathrm{MPa}$ ), as well as the load-slip ratio of the specimens, are exhibited in Table 1 and Figure 2.

Analyzing the results, it can be seen that a satisfactory agreement was reached between the two results, mainly to the model with $28 \mathrm{MPa}$. It could be observed that the connector numerical model with $28 \mathrm{MPa}$ presented resistance $4 \%$ higher when compared to the experimental one. The $52 \mathrm{MPa}$ model was $10 \%$ more resistant than the experimental connector model. However, when comparing the slip capacity of the connector, the $52 \mathrm{MPa}$ numerical model was the most similar to the experimental one. This fact can also be proved when observing the post-peak behaviour of the load-slip ratio. NM-P-2H-120-28MPa presented initial stiffness similar to the experimental one. After reaching its resistance, the numerical model lost stiffness faster, which justifies the lower slip capacity. NM-P-2H-120-52MPa lost stiffness slower in the post-peak segment,

Table 1. Comparison from experimental and FEA results.

\begin{tabular}{|c|c|c|c|c|c|c|}
\hline & $P_{\mathrm{EXP}}$ & $P_{\mathrm{NUM}}$ & $P_{N U M}$ & $\delta u_{E X P}$ & $\delta u_{N U M}$ & $\delta_{N U M}$ \\
\hline Connector & $\mathrm{kN}$ & $\mathrm{kN}$ & $P_{E X P}$ & $\mathrm{~mm}$ & $\mathrm{~mm}$ & $\delta_{E X P}$ \\
\hline $\mathrm{P}-2 \mathrm{H}-120-28 \mathrm{MPa}$ & 329.75 & 342.94 & 1.04 & 7.77 & 4.35 & 0.56 \\
\hline $\mathrm{P}-2 \mathrm{H}-120-52 \mathrm{MPa}$ & 394.20 & 434.47 & 1.10 & 7.80 & 8.92 & 1.14 \\
\hline
\end{tabular}


a)

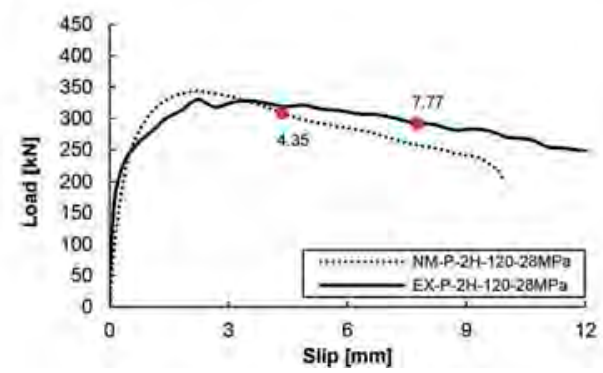

b)

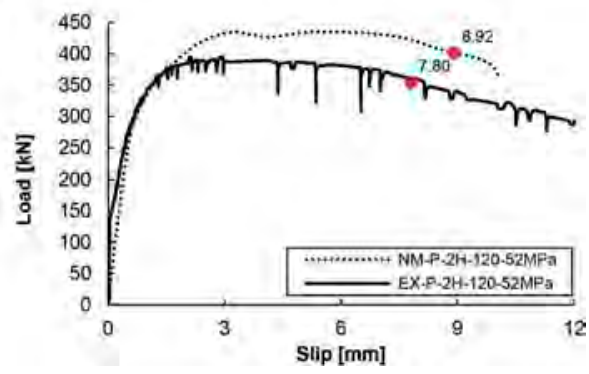

Figure 2. Comparison of experimental and FEA results. a) NM-P-2H-120-28MPa and EX-P-2H-120$28 \mathrm{MPa}, \mathrm{b}) \mathrm{NM}-\mathrm{P}-2 \mathrm{H}-120-52 \mathrm{MPa}$ and EX-P-2H-120-52MPa.

resembling the experimental despite the resistance difference. Therefore, the $28 \mathrm{MPa}$ model was validated in terms of peak load and the $52 \mathrm{MPa}$ in terms of post-peak behaviour.

\section{NUMERICAL ASSESSMENT OF THE POTENTIAL OF THE NEW TUBULAR PERFOBOND SHEAR CONNECTOR}

\subsection{Numerical modelling}

The numerical modelling previously presented was applied in the tubular connector study, including material properties, constraints, contacts, interfaces, boundary conditions, mesh, among others. The tubular connector has been studied as without holes, with two holes and with two holes and rebar (Figure 3a-c). To minimize computational cost, only a quarter model was modelled, using double symmetry restrictions. It is possible to observe in Figure $3 \mathrm{~d}$, the surface 1 (X-Z plan) was set as symmetrical in the $\mathrm{Y}$-axis with all nodes on this surface restricted from moving in the $\mathrm{Y}$ direction. Surface $2(\mathrm{X}-\mathrm{Y})$ has been imposed as symmetrical in the direction in the Y-axis, restricting its nodes to the movement in this direction. The width of Perfobond was maintained to a tubular connector to allow comparisons. Figure $3 e$ presents the tie constraint that links the surfaces between the tubular connector and the steel beam.

Concerning the nomenclature of the models, the TP index indicates tubular perfobond. The $\mathrm{S}$ indicates square section $70 \times 70 \times 3.6 \mathrm{~mm}$ while the $\mathrm{R}$ indicates rectangular section $70 \times 50 \times 3.6 \mathrm{~mm}$. NH denotes that the connector has no holes, $2 \mathrm{H}$ denotes that it has two holes and $2 \mathrm{H}-\mathrm{R}$ denotes that it has two holes and rebar. $28 \mathrm{MPa}$ and $52 \mathrm{MPa}$ indicate concrete resistance. For example, TP-S-2H-R-28MPa refers to a square section tubular connector model with two holes, rebar and concrete with $f_{c m} 28 \mathrm{MPa}$.

a)

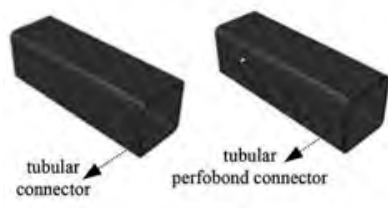

c)

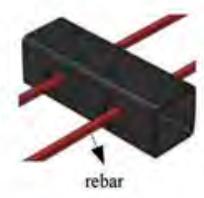

d)

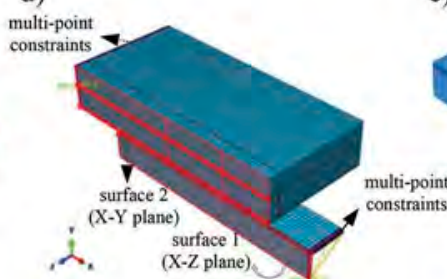

e)

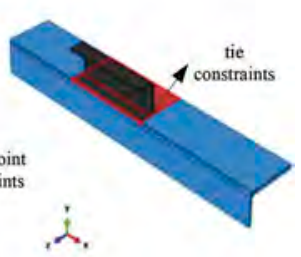

Figure 3. Tubular perfobond connector model. a) Without holes, b) With two holes, c) With two holes and rebar, d) Symmetric surfaces, multi-point constraints and mesh, e) Tie constraint. 


\subsection{Parametric study}

As presented, two concrete compressive strength $\left(f_{c m}\right)$ were studied to evaluate their influence on the connector performance. The influence of the hole and the rebar, as well as the connector cross-section, was also evaluated. Figure 4 and Figure 5 present the results in regards to the load-slip ratio and the parameters influence, respectively. Table 2 presents the results obtained in terms of maximum $(P)$ and characteristic resistance $\left(P_{r k}\right)$, shear rigidity $\left(K_{s}\right)$, slip capacity $\left(\delta_{u}\right.$ and $\left.\delta_{u k}\right)$, ductility rating and failure mode. Except for the shear rigidity and failure mode, all results were taken according to Eurocode 4 (2005). The rigidity was defined according to Chen et al (2011) and the failure mode was determined according to the evolution of the degradation.

Analyzing the models with both concrete strengths, it can be seen that the connector with the largest transversal area presents the greatest resistance for all the conditions studied. However, the increase in the cross-sectional area provided only slight increases in resistance, ranging from $3 \%$ to $5 \%$. The use of the hole and rebar conferred a resistance increase for the models with $28 \mathrm{MPa}$. For $52 \mathrm{MPa}$, it did not influence the resistance due to the excessive connector yield. For all models, it led to the connector peak load occur to higher slip values, contributing to ductility.

The increase in the concrete strength resulted in a significant improvement in the shear connector resistance for the different cases studied, ranging from $16 \%$ to $29 \%$. There was an expressive increase in the slip capacity of the tubular shear connector due to the rise in the $f_{\mathrm{cm}}$, ranging from $18 \%$ to $137 \%$. Briefly, the concrete strength influenced in a more significant way the square section connector concerning the shear strength and the rectangular section connector ductility. About ductility, Eurocode 4 (2005) defines the shear connector as ductile if its characteristic slip capacity is at least $6 \mathrm{~mm}$. Thus, only the TP-S-NH-28MPa and TP-R-NH$28 \mathrm{MPa}$ connectors were not ductile.

a)

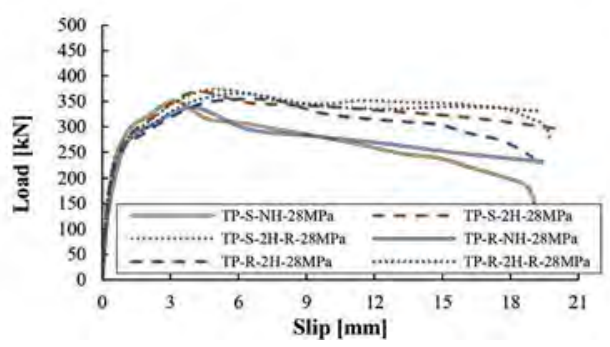

b)

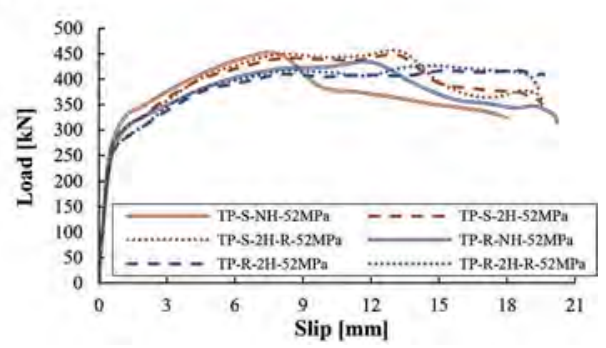

Figure 4. Load-slip curve for 28 and $52 \mathrm{MPa}$ models. a) TP-NH, TP-2H and TP-2H-R for $28 \mathrm{MPa}$, b) TP-NH, TP-2H and TP-2H-R for $52 \mathrm{MPa}$.

a)

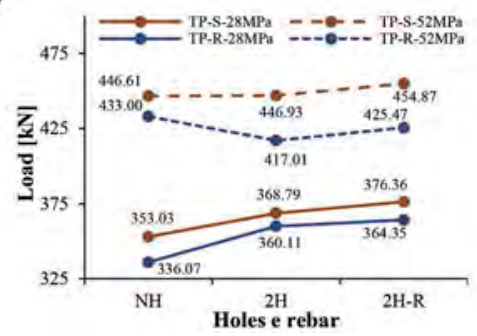

b)

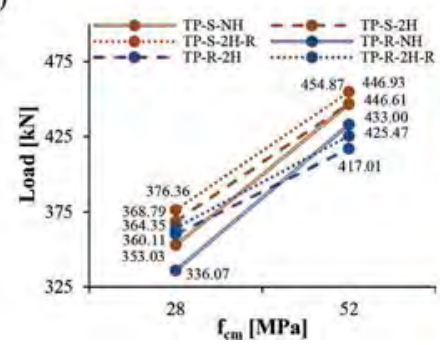

c)

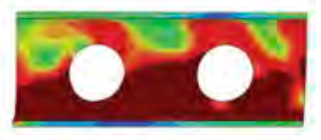

d)

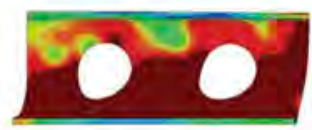

Figure 5. Influence of parameters and von mises stress distribution for TP-R-2H models. a) Influence of holes and rebar, b) Influence of concrete $f_{c m}$, c) TP-R-2H-28MPa, d) TP-R-2H-52MPa. 
Table 2. Push-out analyzes results.

\begin{tabular}{lllllllll}
\hline & $P$ & $P_{r k}$ & $K_{s}$ & $\delta_{u}$ & $\delta_{u k}$ & & & \\
\cline { 2 - 5 } Model & $\mathrm{kN}$ & $\mathrm{kN}$ & $\mathrm{kN} / \mathrm{mm}$ & $\mathrm{mm}$ & $\mathrm{mm}$ & Ductile? & Failure mode* \\
\hline TP-S-NH-28MPa & 353.03 & 317.72 & 572.20 & 4.55 & 4.10 & No & 3 \\
TP-S-NH-52MPa & 446.61 & 401.95 & 653,87 & 9.18 & 8.26 & Yes & 3 \\
TP-R-NH-28MPa & 336.07 & 302.46 & 534.15 & 5.88 & 5.29 & No & 3 \\
TP-R-NH-52MPa & 433.00 & 389.70 & 591.70 & 13.91 & 12.52 & Yes & 3 \\
TP-S-2H-28MPa & 368.79 & 331.91 & 646.23 & 12.35 & 11.12 & Yes & 1 \\
TP-S-2H-52MPa & 446.93 & 402.24 & 671.25 & 14.62 & 13.15 & Yes & 1 \\
TP-R-2H-28MPa & 360.11 & 324.10 & 595.81 & 11.03 & 9.93 & Yes & 3 \\
TP-R-2H-52MPa & 417.01 & 375.31 & 650.00 & $>20$ & $>20$ & Yes & 1 \\
TP-S-2H-R-28MPa & 376.36 & 338.73 & 616.24 & 17.83 & 16.05 & Yes & 1 \\
TP-S-2H-R-52MPa & 454.87 & 409.38 & 705.93 & 19.75 & 17.78 & Yes & 1 \\
TP-R-2H-R-28MPa & 364.35 & 327.92 & 604.10 & 9.64 & 8.68 & Yes & 3 \\
TP-R-2H-R-52MPa & 425.47 & 382.92 & 654.45 & 19.41 & 17.47 & Yes & 1 \\
\hline
\end{tabular}

* 1 -Failure of the connector. 2 - Local concrete crushing. 3 - Failure of the connectors associated with local concrete crushing.

All models with no holes (NH) had failure of the connectors associated with concrete crushing. All models with two holes $(2 \mathrm{H})$ and two holes and rebar $(2 \mathrm{H}-\mathrm{R})$ had failure of the shear connector with the exception of TP-R-2H-28MPa and TP-R-2H-R-28MPa which had similar failure mode to those with no holes. Figure $5 \mathrm{c}-\mathrm{d}$ shows the excessive yield of the TP-R-2H$28 \mathrm{MPa}$ and TP-R-2H-52MPa connectors.

\subsection{Tubular perfobond connector vs Perfobond connector}

The 70x70x3.6 mm square section was chosen for comparison with Perfobond connector due to its similar area. Comparing the tubular connector with the perfobond numeric connector model, it is evaluated that the tubular connector presents shear resistance $7.5 \%$ higher for the model with $f_{c m} 28 \mathrm{MPa}$, and $2.9 \%$ for $52 \mathrm{MPa}$. However, when compared to the experimental, the difference increases to $12 \%$ and $13 \%$ for $f_{c m} 28 \mathrm{MPa}$ and $52 \mathrm{MPa}$, respectively. Regarding slip capacity, the proposed connector presented $184 \%$ more than Perfobond when analyzed the numerical models of the Perfobond connector with $28 \mathrm{MPa}$ and $64 \%$ for $52 \mathrm{MPa}$ model.

The section chosen does not present such a superior resistant capacity when compared to Perfobond; however, it is important to mention that the peak load occurs for a higher level of slip and deformation, which is positive, considering that this is the proposal of this connector, being able to maintain the resistance while increasing its slip capacity, characterizing it as ductile.

\section{CONCLUSIONS}

The modelling validation indicated that numerical choices led to an adequate calibration in terms of ultimate load. The connector area variation led to a discrete increase in resistance. The presence of holes and rebar delayed the peak load, granting greater slip capacity to the connector. The increase of the concrete strength influenced the square section connector significantly in terms of increased shear resistance and the rectangular section connector ductility. Finally, the increase of the connector area, the use of the hole and the rebar and the increase of the concrete strength directly influenced the shear rigidity. When compared to Perfobond, the proposed connector presented a discretely superior resistance; however, it reached the desired ductility, presenting excellent post-peak slip capacity. Except for the two no holes connectors, all the proposed connectors could be considered ductile by Eurocode 4 (2005). Thus, it is important to enlarge the study considering other parameters and conditions, though this tubular connector proposal can be considered feasible. 


\section{ACKNOWLEDGEMENT}

The authors would like to thank CAPES (Finance code 001), CNPq (306042/2013-4; 305026/ 2017-8), FAPERJ and CERG for the financial support to this research program.

\section{REFERENCES}

Abaqus Documentation, Version 6.14, Dassault system, USA, 2010.

Bezerra, L. M.; Cavalcante, O. O.; Chater, L.; Bonilla, J. 2018. V-shaped shear connector for composite steel-concrete beam. Journal of Constructional Steel Research 150: 162-174.

CEB-FIP. 2010. Model code for concrete structures. International Federation for Structural Concrete (FIB), Switzerland.

Chen, Z.; Yuqing, L.; Shuangjie, Z.; Hino, S.; Yamaguchi, K. 2011. Experimental analysis of shear behavior of oval perfobond connector. International Conference on Tissue Engineering.

Eurocode 4, EN 1994- 1-1. 2005. Design of composite steel and concrete structures, Part. 1.1 general rules and rules for buildings. CEN, European Committee for Standardization.

Genikomsou, A. S.; Polak, M. A. 2015. Finite element analysis of punching shear of concrete slabs using damaged plasticity model in ABAQUS. Journal of Engineering Structures 98: 38-48.

Gu, J. C.; Liu, D.; Deng, W. Q.; Zhang, J. D. 2019. Experimental study on the shear resistance of a comb-type perfobond rib shear connector. Journal of Constructional Steel Research 158: 279-289.

Pavlovic, M. S. 2013. Resistance of bolted shear connectors in prefabricated steel-concrete composite decks. Doctoral Dissertation - Faculty of Civil Engineering, University of Belgrade, Belgrade.

Vianna, J. da C.; Costa-Neves, L. F.; Vellasco, P. C. G. da S.; de Andrade, S. A. L. 2009. Experimental assessment of Perfobond and T-Perfobond shear connectors' structural response. Journal of Constructional Steel Research 65: 408-421.

Yun, X.; Gardner, L. 2017. Stress-strain curves for hot-rolled steels. Journal of Constructional Steel Research 133: 36-46. 


\title{
Strengthening of steel-concrete composite beams in experimental study
}

\author{
P. Szewczyk \\ Faculty of Civil and Environmental Engineering, West Pomeranian University of Technology, Szczecin, \\ Poland \\ M. Szumigała \\ Faculty of Civil and Transport Engineering, Poznan University of Technology, Poznań, Poland
}

\begin{abstract}
The paper presents selected results of experimental research performed on steel - concrete composite beams. The study aimed at determining efficiency and technical feasibility of strengthening such structures. The main assumption was that strengthening was conducted under load, which is consistent with the factual state of the modernized structure. Beams were strengthened by welding sheet metal to increase the area of the steel section. The safe level of stress during welding and the appropriate order of joints were determined. The study focused on distortion caused by welding, cooling and shrinkage. Following the strengthening, the beams were overloaded, underwent plastic distortion and were ultimately damaged. The beams' increased stiffness and capacity due to strengthening was monitored.
\end{abstract}

\section{INTRODUCTION}

Structures must be strengthened for a variety of reasons; due to design errors, workmanship defects, wrong exploitation, vibration or lack of proper maintenance. On the other hand, the need to strengthen can be triggered by changes in the way a structure is used, by changes in technology or by a different purpose the structure is supposed to serve. In each of the above situations, attention should be paid that modernization is conducted on an already existing construction, i.e. one that carries at least its own constant weight and possibly service and technological load. It would be ideal to completely relieve a structure of any load to design the strengthening as one designs brand new objects. However, that would require to remove any elements that load the object. It would be expensive and time-consuming. Putting up shoring posts would be another way to deal with the problem. That would, however, take up space below. Sometimes, it is not possible to remove the service load. Compare an interesting object, discussed in the following papers (Paczkowski, Wróblewski \& Skibicki, 2020), (Wierzbicki et al., 2020). Therefore, in most cases it is fair to assume that a strengthened structure has a certain actual stress ratio, which sometimes can be significantly high.

Steel structures are suitable to be strengthened (Liu and Gannon, 2009), (Wang et al., 2015), (Ali, Kvočák \& Platko, 2017). Elements that are strengthened and strengthening parts can be welded and stress can be plastically redistributed. However, welding operations involve additional distortion and weld shrinkage. The magnitude of these effects depends on the sign and level of stress in the welded place,

The present study tried to take into account all the above factors. A steel-concrete composite beam was taken as the research model. Owing to the composite character of the beam's 
cross-section which involves both plastic, ductile steel and brittle concrete, its analysis poses significant challenges.

\section{EXPERIMENTAL RESEARCH}

\subsection{Research model}

A steel-concrete composite beam with a cross-section presented in Figure 1 was adopted as the research model. The beam's dimensions were chosen so that its neutral axis was close to the joint's area. The beam was analyzed in a simply supported system, with the spacing between supports of $5 \mathrm{~m}$. This static scheme provided a classic division between a compressed concrete and a stretched steel part. The flexible reinforced concrete (C25/30 concrete, Bst500 reinforcement) was connected to the steel (S235JR) with SD stud connectors. In all the tests, a 10x120 mm flat bar was welded to the bottom flange of IPE200 beam. Because the width of the flat bar was greater than the width of the flange by $20 \mathrm{~mm}$, the elements were welded in a preferable PB horizontal vertical position. The length of the sheet metal stiffener was smaller than the distance between the supports and it was 3,200 $\mathrm{mm}$. A comprehensive analysis of the optimal choice of strengthening plate can be found in (Szewczyk and Szumigała, 2016).

\subsection{Strengthening under load}

The first step was the introduction of preload to simulate the tension before reinforcement. The load was supposed to be reduced so that at each stage of reinforcement the ultimate limit state would be met. When a structure is welded, its cross-section is locally weakened. This weakening can be taken into account by the reduced cross-sectional area. The reduction of the area occurs in the place where the structure gets hot. Its range depends on the linear energy of electric arc $q_{l}$. The welding was done using 111 method: $140 \mathrm{~A}$ current, $28 \mathrm{~V}$ voltage, $3 \mathrm{~mm} / \mathrm{s}$ welding velocity. Owing to the type of steel used (S235JR), the area reduction was assumed to be $\Delta \mathrm{A}=220 \mathrm{~mm}^{2}$ (Augustyn \& Skotny, 1991). It was assumed that the effect of welding heat coming from two joints can occur simultaneously. That is why the reduction was applied on both sides of the flange, which is shown in Figure 2.

The beam was tested in a four-point bending scheme. The force spacing was $2000 \mathrm{~mm}$, which is presented in Figure 3a. The force of $60 \mathrm{kN}$ was adopted as preload. Together with its own weight, it caused $163 \mathrm{MPa}$ stress in the bottom flange. When stiffness reduction is taken into account, stress at this point increases to $228 \mathrm{MPa}$, which is $97 \%$ of allowable stress. This means that the assumed stress is at a high but safe level during welding. The introduced force was supposed to simulate the load on the structure. It was essential to maintain a constant level of the force through the total time of the test (several hours), also during welding.
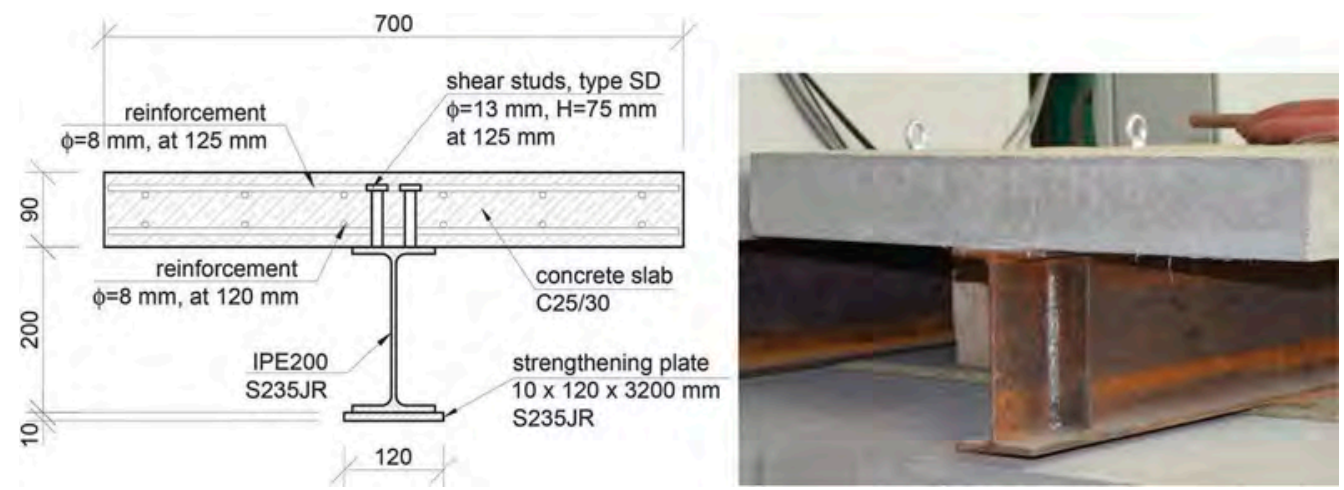

Figure 1. Cross-section of composite beam. 

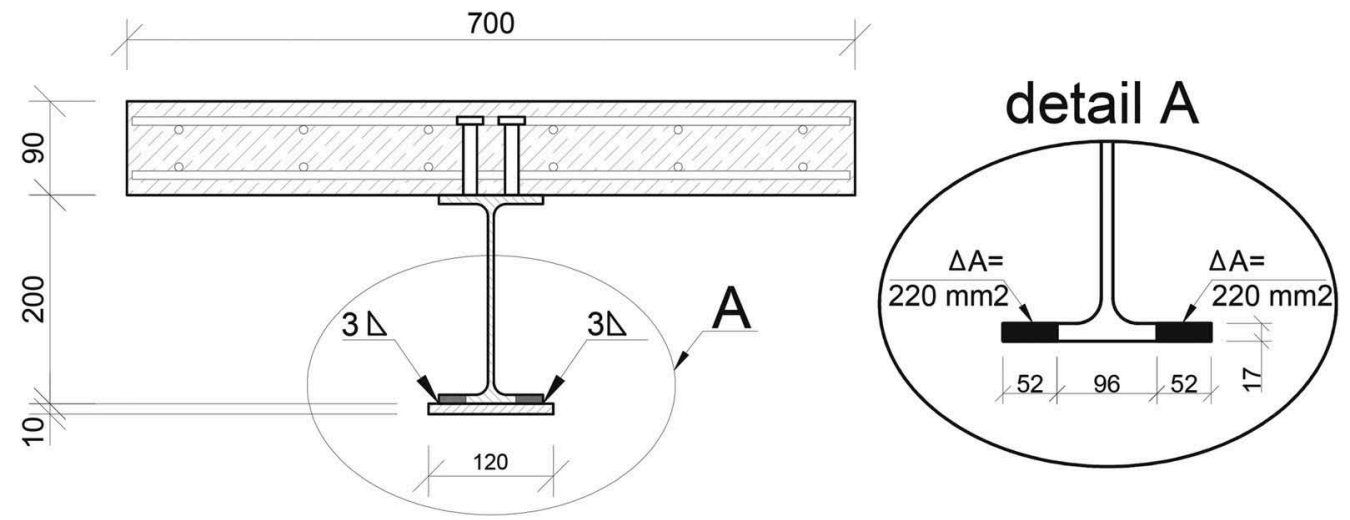

Figure 2. Localization of the cross-sectional area reduction $\Delta \mathrm{A}$.

a)

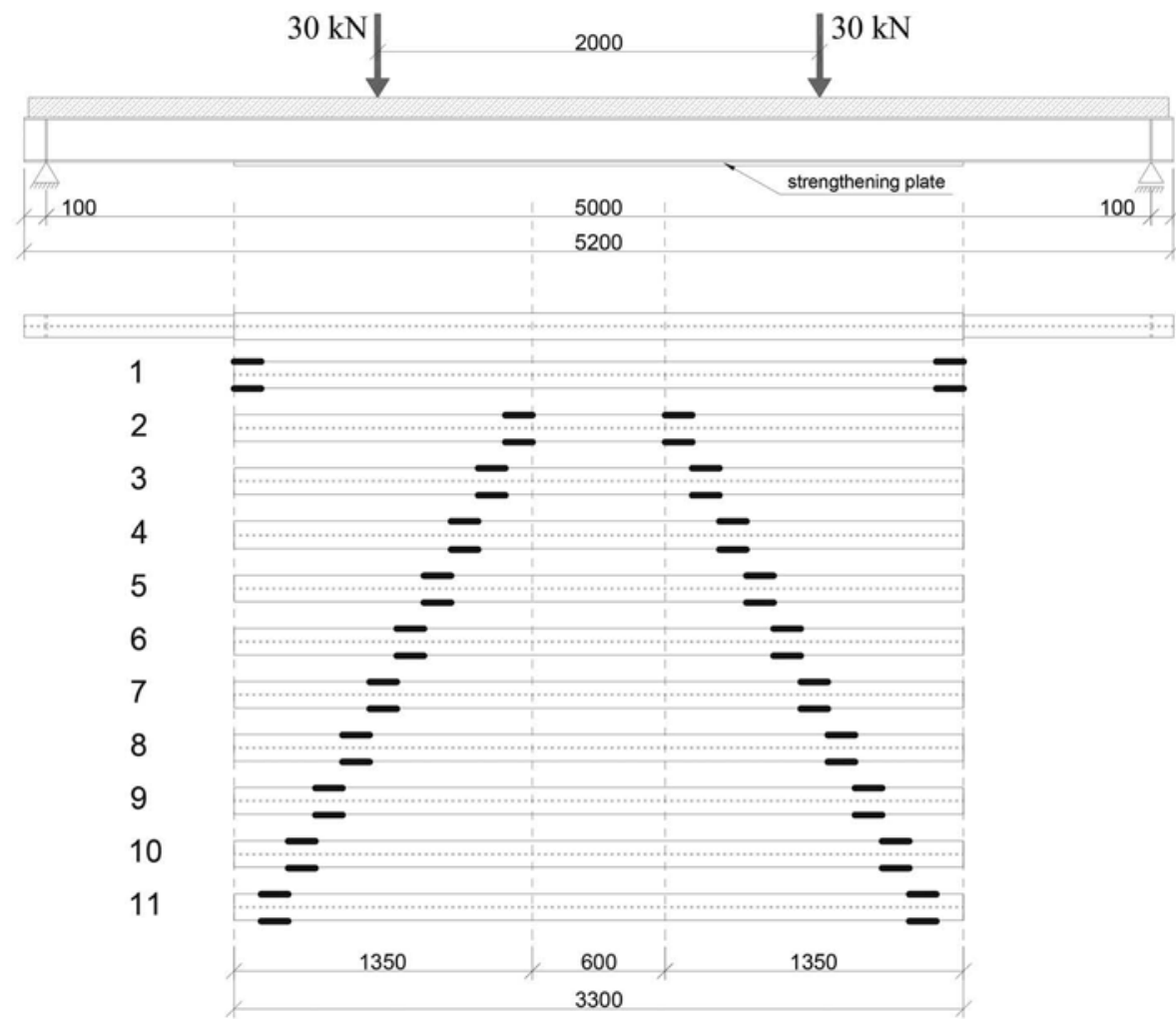

Figure 3. Welding plan, a) beam view, b) the order of making the welds.

Welding through heating up the bottom flange increased its bending. The weld shrinkage caused a reversed direction of deflection. At the same time, the piston had to change its position according to the deflection of the beam, while maintaining a constant, predefined load. The task was completed using a PID precisely preset hydraulic servomotor. Owing to that, force deviation during welding was only $10 \mathrm{~N}$. 


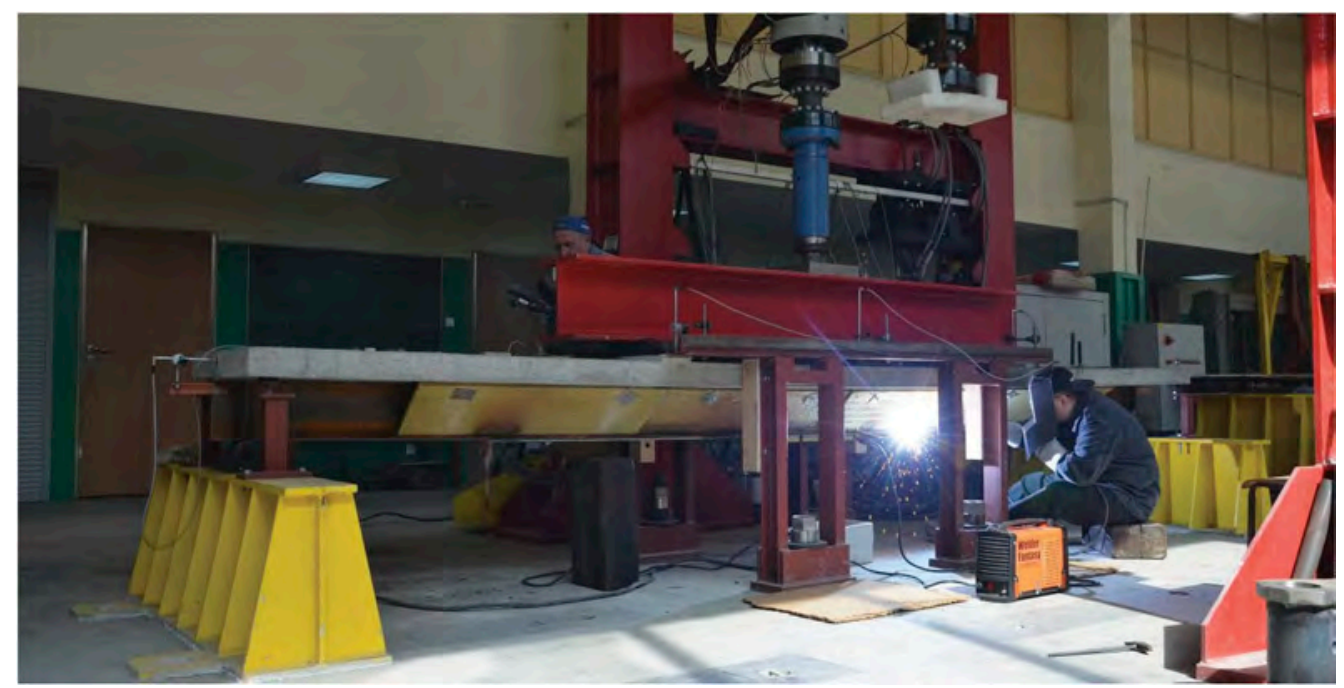

Figure 4. Welding of a strengthening plate.

\subsection{Welding under load}

After the beam completely cooled down and when displacements stabilized, the strengthening sheet metal was put in place. To make sure the sheet metal was close to the beam given its curvature under load, the sheet metal was connected to the bottom flange with steel ties. The welding order is presented in Figure 3b. In line with the guidelines (Augustyn \& Skotny, 1991), (Bródka, 1995), sheet metal ends were welded first. The next welds were done in the order from the middle of the beam towards its ends. Owing to high level of stress where welding was conducted, transverse welds were not done at the end of strengthening sheet metal. As shown, $300 \mathrm{~mm}$ in each direction, i.e. in the vicinity of the beam's middle section, no welds were done to protect strain gauges. The length of individual welds was equivalent to the length of electrodes and equaled approximately $120 \mathrm{~mm}$. Welds were not laid simultaneously but alternately, keeping the symmetry of laid lines. Since welds were done on both sides of the beam, two specialists separately equipped were conducting their welding operations. However, welds were never laid at the same time. Figure 4 shows the model during welding.

\section{RESEARCH RESULTS}

\subsection{Measurements during strengthening}

Vertical displacement in the middle cross-section of the beam was measured during all the test. Displacement values during strengthening are shown in Figure 5. Displacement observed prior to welding process was the effect of preload, defined in Section 2.2. The heating up of the bottom flange during welding increased its deflection. The highest displacement was observed in the first phases of welding when the beam was heated starting from the initial temperature. In the subsequent stages of welding the sheet metal was being connected to the beam and therefore its stiffness was increasing. Also, the first welds started to cool and contract which caused opposite displacement. Therefore, approximately in the middle of strengthening process the measured displacement did not increase so sharply and at the end of it deflection tended to decrease. The latter occurred despite subsequent welds being laid.

All the three graphs of welding show clearly the cycles of displacement increase and decrease caused by heating up and cooling during breaks in the welding process. The strengthening of the first model of the beam took $1.5 \mathrm{~h}$. Following the positive results of the first test, 


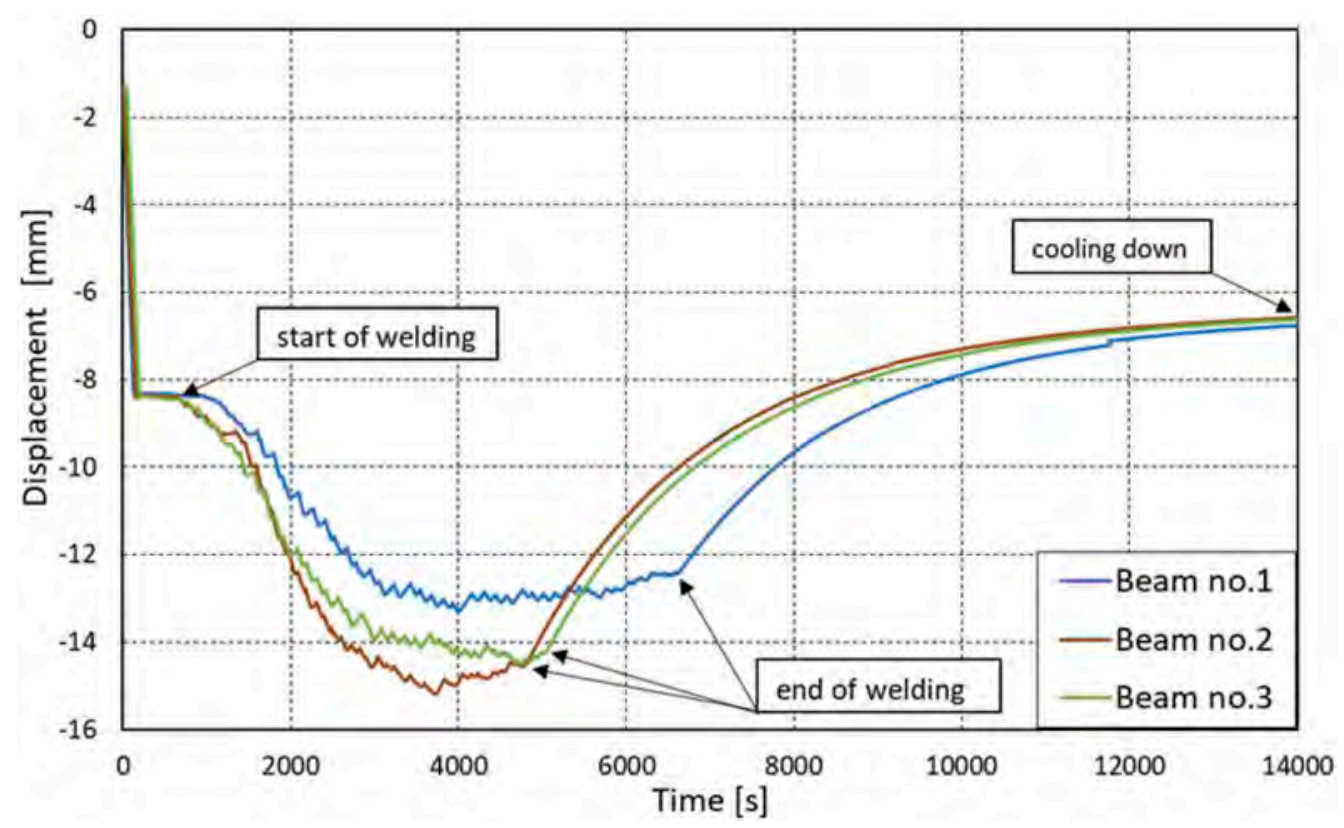

Figure 5. Beam displacement while welding.

the time between laying subsequent welds was shortened, which reduced the total welding time down to $1 \mathrm{~h}$. The Figure 5 shows that welding time, i.e. intensity of heating has clear effect on displacement during strengthening. After cooling, regardless of displacement during welding, deflection of all three beams stabilized at the same level, which is a very important conclusion from the test.

The above process is also presented in Figure 6. It shows displacement recorded for other cross -sections along the beam's axis. The colored dots represent measured values. The solid lines are averaged displacement values. Please note that measurements before and after the welding process are very consistent. Only displacement during welding have greater spread, which is due to different intensity of heating the beams during welding.

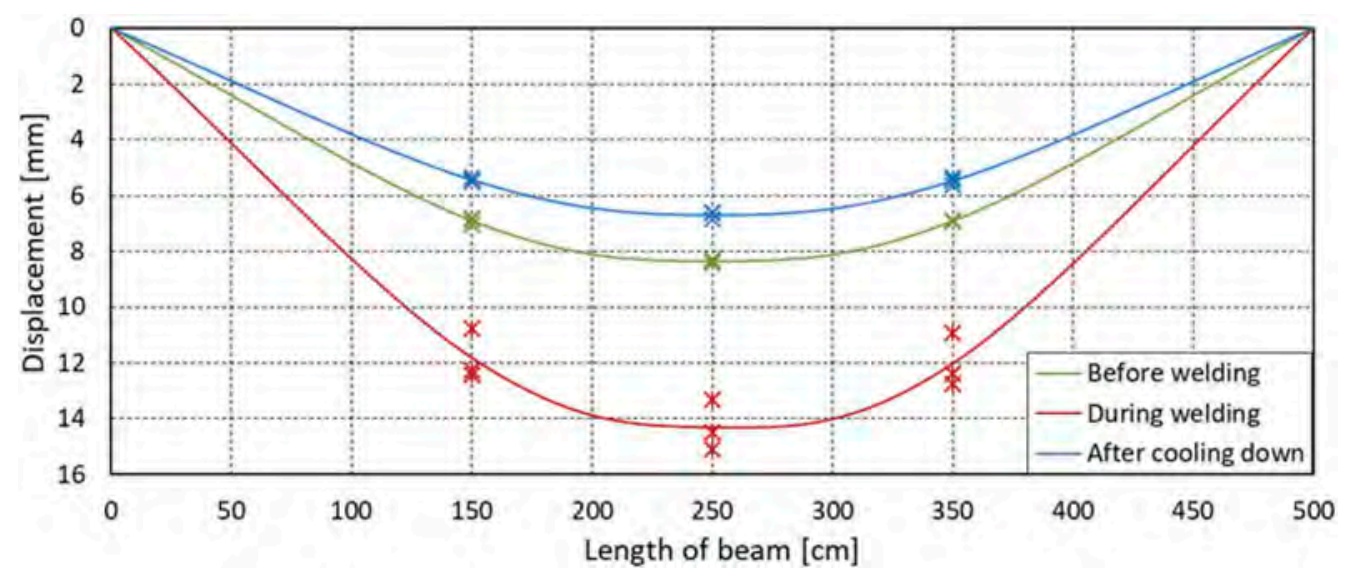

Figure 6. Beam deflection line before, during and after welding. 


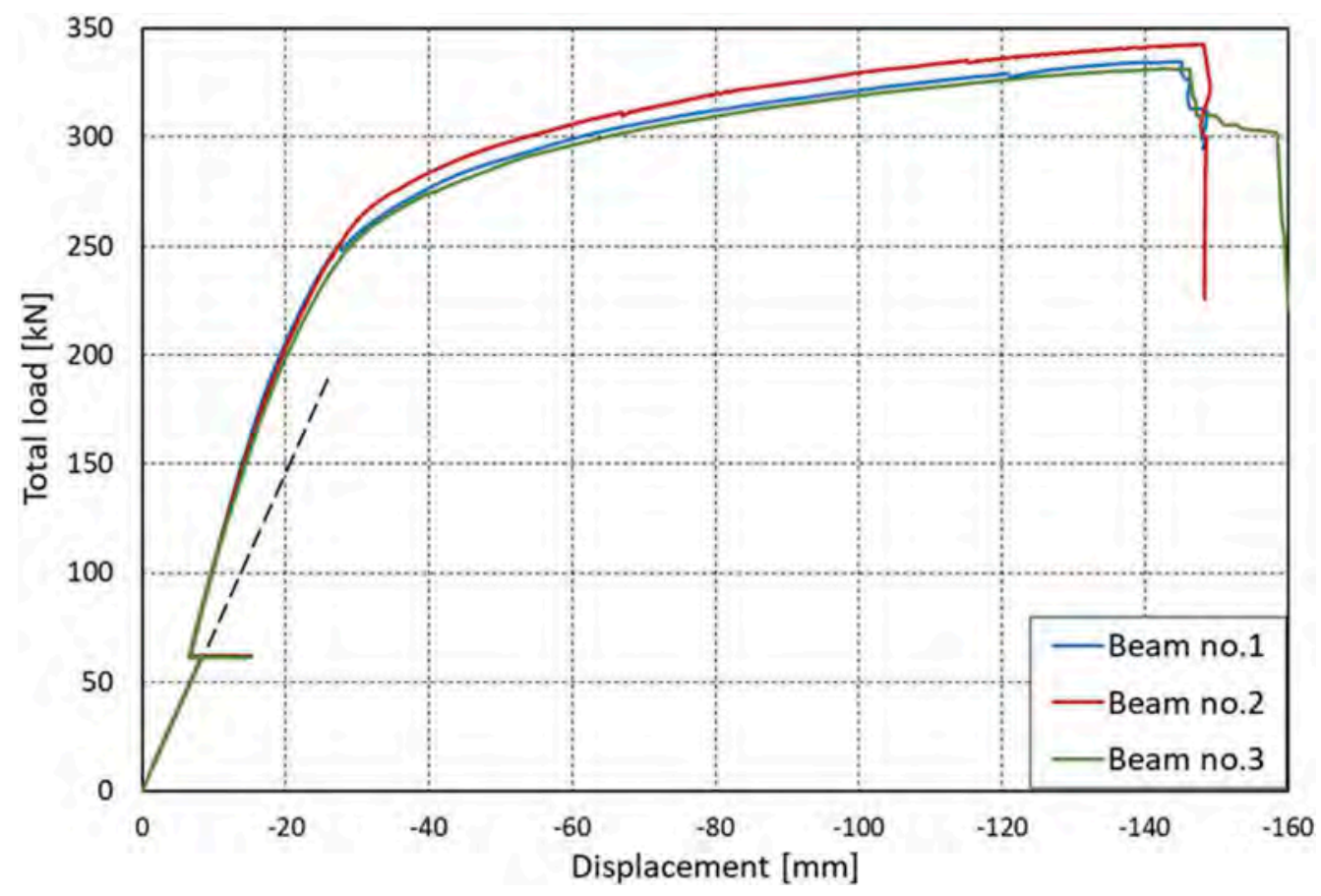

Figure 7. Static equilibrium paths of the strengthened beams.

\subsection{Load increase}

After complete cooling, the next phase of the test was to increase load up to the yield moment and damage of the element. Static equilibrium pathways are a very good tool to present how a structure behaves in all its stages of operation (Szewczyk \& Szumigała, 2019). Accordingly, Figure 7 shows static equilibrium pathways obtained for the analyzed beams. Those are loaddisplacement curves in the middle of the beam's span. For the load of $60 \mathrm{kN}$ (i.e. the load at which strengthening was completed), there are displacement changes at the constant force due to welding and cooling. Those are shown in more detail in Figures 5 and 6.

From then on, there is clear increase of capacity and stiffness, due to the increasing strengthening effect of sheet metal. The graph also shows a dotted line which is a continuation of the initial direction of static equilibrium pathway (without strengthening). Stiffness increase is seen as a change of the inclination angle before and after strengthening.

When the element left the elastic regime of its operation, further load increase led to yield moment, first observed in the outer, stretched steel fibers. It resulted in redistribution of stress in the strengthened and strengthening parts. The further operation in the plastic regime resulted in greater compressive strain in the reinforced concrete slab. Consequently, compressive strength was exceeded and concrete was crushed. It can be seen in the static equilibrium pathway curve as a sudden drop of the force. Shortly before the beam was damaged, high displacement was observed. It was over $140 \mathrm{~mm}$, i.e. 1/35 of the beam's length. Damage was predictable, occurred in a place of the constant bending moment.

\section{CONCLUSIONS}

The paper presents experimental research on a composite beam strengthened by extending the stretched steel part. In operations of this type attention should be paid that the strengthened structure is under load. The consequence of that is e.g. the effect of weld shrinkage which 
occurs during welding operations. In the analyzed case, owing to the location of welds well below the neutral axis, weld shrinkage decreased the beam's deflection, which was a positive effect.

The final displacement of all the welded beams were very similar. However, instantaneous dis-placement due to sudden heating of the structure during welding correlated very strongly with the ratio of welding time and breaks between laying subsequent welds. This is a significant conclusion as for operational or technological reasons the serviceability limit state can be exceeded even for a short time with negative or dangerous consequences.

The presented research is part of a larger project aiming at developing a numerical model of a composite beam strengthened under load.

\section{REFERENCES}

Ali, M. Al, Kvočák, V. \& Platko, P. (2017) Stress State of Steel Column Strengthened under Load, Procedia Engineering, 190, pp. 632-636. doi: 10.1016/j.proeng.2017.05.390.

Augustyn, J. \& Skotny, J. (1991) Tymczasowe wytyczne wzmacniania elementów konstrukcji stalowych przy pomocy spawania pod obciażenieme. Warszawa: Izba Projektowania Budowlanego.

Bródka, J. (1995) Przebudowa i utrzymanie konstrukcji stalowych. Łódź: Mostostal-Projekt, Politechnika Łódzka.

Liu, Y. \& Gannon, L. (2009) Experimental behavior and strength of steel beams strengthened while under load, Journal of Constructional Steel Research, 65(6), pp. 1346-1354. doi: 10.1016/j. jesr.2009.01.008.

Paczkowski, W., Wróblewski, T. \& Skibicki, S. (2020) Skanowanie laserowe stalowej konstrukcji elektrowni węglowej, Builder, 273(4), pp. 22-25. doi: 10.5604/01.3001.0013.8793.

Szewczyk, P. \& Szumigała, M. (2016) Numerical Modelling Of The Strengthening Process Of Steel-Concrete Composite Beams, Civil And Environmental Engineering Reports, 19(4), pp. 99-110. doi: 10.1515/ceer-2015-0056.

Szewczyk, P. \& Szumigała, M. (2019) Static Equilibrium Paths of Steel-Concrete Composite Beam Strengthened Under Load, Civil and Environmental Engineering Reports, 28(2), pp. 101-111. doi: 10.2478/ceer-2018-0022.

Wang, Y. Q. et al. (2015) Behavior of I-section steel beam welding reinforced while under load, Journal of Constructional Steel Research, 106, pp. 278-288. doi: 10.1016/j.jcsr.2014.12.020.

Wierzbicki, K. et al. (2020) Torsional stability assessment of columns using photometry and FEM, Buildings, 10(9). doi: 10.3390/BUILDINGS10090162. 


\title{
Composite beams with aluminium girders - a review
}

\author{
M. Szumigała, M. Chybiński \& Ł. Polus \\ Institute of Building Engineering, Poznan University of Technology, Poznań, Poland
}

\begin{abstract}
This paper summarises a few years' research on the structural behaviour of composite beams with aluminium girders, i.e., aluminium-concrete composite beams and aluminium-timber composite beams. In the discussed systems, aluminium girders are connected to concrete or LVL slabs using demountable shear connectors. In this paper, the authors present a review of their theoretical, experimental and numerical analyses of the composite beams with aluminium girders. They also summarise the current state of knowledge on this topic.
\end{abstract}

\section{INTRODUCTION}

Nowadays, aluminium alloy structural members are widely used in civil engineering (Mazzolani 2006). Thanks to their lightness and durability, they can be used in domes, roofing, silos, tanks, bridges, towers, off-shore structures, pipelines and elevations (Siwowski 2006a, 2009) (Gwóźdź 2007) (Szumigała \& Polus 2015) (Kossakowski et al. 2017) (Lacki \& Derlatka 2017) (Chybiński et al. 2019a). Aluminium alloys have been used in composite structures since 1958, when the Clive Road Bridge - the first aluminium-concrete composite bridge - was erected. However, the use of aluminium alloys in composite structures is not popular due to the lack of applicable design rules. For this reason, composite structures with aluminium alloys are still being investigated.

\section{ALUMINIUM-CONCRETE COMPOSITE BEAMS}

Aluminium members and concrete members can be used within one structure. For example, bars and sheets made of aluminium have recently been used to strengthen reinforced concrete beams (Yu et al. 2020) ( $\mathrm{Xu}$ et al. 2020). A truss made of $7005 \mathrm{~T} 53$ aluminium alloy has been used with a concrete slab in a military bridge (Szelka \& Kamyk 2013) (Hanus et al. 2008). Furthermore, a column can be made by filling an aluminium tube with concrete (Zhou \& Young 2009). The concrete core improves both the member capacity and the fire resistance of the column, and the aluminium tube acts as a stay-in-place formwork (Chen et al. 2017).

An aluminium girder can be combined with a concrete slab to create an aluminiumconcrete composite (ACC) beam. ACC beams have been the subject of several studies. Bond tests on aluminium rods embedded in concrete, push-out tests of aluminium shear connectors and static bending tests of ACC beams with channel shear connectors were conducted by (Stonehewer 1962). The failure mode of the composite beams was associated with the yielding of the aluminium beam and the cracking and crushing of the concrete slab. Stonehewer showed that for beams with complete interaction between the concrete slab and the aluminium beam, the transformed section theory may be used to determine the strains. Two ACC beams with solid slabs were tested by (Bruzzese et al. 1989). The beams had identical geometric configurations, except for the stirrup spacing $(6.5 \mathrm{~cm}$ or $13.0 \mathrm{~cm})$. The stirrup spacing had an 
impact of the failure modes of the beams. The failure mode of the beam with the higher number of stirrups was associated with the damage of the compressed and tensioned edges of the concrete slab in the mid-span. The failure mode of the beam with the lower number of stirrups was associated with longitudinal and transverse fractures. A continuous span aluminium girder concrete deck bridge was tested by the researchers from Iowa State University (Abendroth et al. 1996). The results of the experimental study revealed that the strength properties of aluminium were sufficient for bridge girders. The deflections and strains measured in the 1993 field tests were in close agreement with the results of the pre-calculated values. Flexural behaviour of aluminium-lightweight concrete composite beams was investigated by Siwowski (2006b). Most of the studies performed on ACC structures to date have focused on systems in which solid slabs and non-demountable shear connectors were used.

A novel ACC beam, in which a concrete slab is poured into steel sheeting and connected with an aluminium beam using demountable shear connectors was presented by Polus \& Szumigała (2019a) (see Figure 1a). The profiled sheeting resists tension and acts as a stay-in-place formwork. A notable benefit of using demountable shear connectors is that they make it possible to separate aluminium girders from a concrete slab once the design life of the structure is over. Aluminium girders may later be reused or recycled. Headed studs and composite dowels are commonly used connectors but they are not demountable or they require labour-intensive processes to separate the components of the composite beam (Lee \& Bradford 2013) (Nijgh et al. 2018) (Szewczyk \& Szumigała 2018) (Kożuch \& Lorenc 2019). Furthermore, when demountable shear connectors are used, composite action is achieved without welding, which reduces the strength parameters of aluminium alloys in heat-affected zones. However, the bending resistance of unprotected ACC beams decreases very fast in a fire, e.g., the bending resistance of the ACC beam studied by Chybiński \& Polus (2018) decreased by $99.4 \%$ after a 15-minute car fire. Fire resistance may be increased by concreting aluminium girders in a similar way to concreting steel elements (Szmigiera 2007).

The load-slip behaviour of the demountable shear connectors was characterised in laboratory push-out tests. The slip modulus of the connection was low $\left(k_{0.4}=5.9 \mathrm{kN} / \mathrm{mm}\right)$ because of the clearance between the bolt and the hole (Polus \& Szumigała 2016). However, the clearance made it easier to install demountable shear connectors through the holes in the aluminium beam flange. The behaviour of the ACC beams with profiled sheeting and of said shear connectors was investigated in the bending tests by Polus \& Szumigała (2019a). The tested ACC beams showed signs of rib-shearing failure. For this reason, the use of profiled sheeting with a greater rib width, and the use of the waveform reinforcement showed by Patrick (2000) is recommended to prevent such failure in the future. Furthermore, the calculation procedure for steel-concrete composite elements was used to calculate the load-carrying capacity of the ACC beams. The bending resistance of the ACC beam from the analytical estimations was 1.05 times higher than the bending resistance from the tests (Polus \& Szumigała 2019a). What is more, non-linear 3D finite element models of the ACC elements used in the bending test and

a)

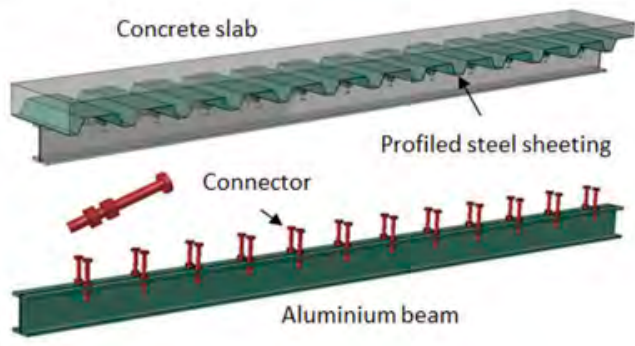

b)

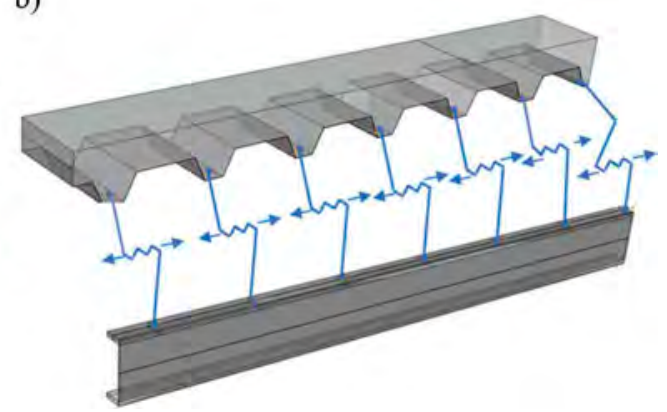

Figure 1. The aluminium-concrete composite beam tested by (Polus \& Szumigała 2019a): a) beam parts, b) a quarter of the beam with zero-length springs. 
in the push-out test were developed and verified against the experimental results. The shear connectors were modelled using zero-length springs (see Figure 1b). As a result, the slip between the aluminium beam and the concrete slab was taken into account (Polus \& Szumigała 2019a). Discrete springs were used to model connections by Hassanieh et al. (2016), Kyvelou et al. (2018), Studziński \& Ciesielczyk (2019), Polus \& Szumigała (2019b), Chybiński et al. (2019b) and by Abramowicz et al. (2020). They provided reasonable accuracy. The comparison of the numerical and experimental analyses demonstrated that the adopted numerical models captured the responses of the beams and their joints relatively well (Polus \& Szumigała 2019a).

\section{ALUMINIUM-TIMBER COMPOSITE BEAMS}

An aluminium girder can be combined with a timber slab to create an aluminium-timber composite (ATC) beam. ATC beams have been the subject of several studies. Bending tests on ATC beams with screws and plywood slabs were conducted by (Saleh \& Jasim 2014). Recently, the flexural behaviour of ATC beams with laminated veneer lumber (LVL) slabs has been investigated by (Szumigała et al. 2017, 2019) (Chybiński \& Polus 2019) (see Figure 2).

The advantages of using ATC beams instead of steel-concrete composite beams include reduced construction time, small self-weight and high durability of aluminium girders. Furthermore, LVL has fewer defects than solid wood (Komorowski 2017). However, the problem of stresses evoked by temperature change in ATC beams calls for more investigations (Marcinowski 2018). Aluminium beams may be combined with LVL slabs using screws or bolts.

The load-slip behaviour of the screw connections in ATC beams was characterised in laboratory push-out tests (Chybiński \& Polus 2019). The failure mode of the screw connection was associated with the crushing of the timber, the formation of one plastic hinge within the connector at the aluminium-timber interface and the hole ovalisation in the flange of the aluminium beam (see Figure 3). The behaviour of the ATC beams was studied in bending tests by Chybiński and Polus (2019) (see Figure 4). The failure mode of the ATC beams was associated with LVL damage. The veneers separated from each other in the tensioned parts of the LVL slabs and cambered in the compressed parts.

Furthermore, the calculation procedure for steel-concrete composite elements was used to calculate the load-carrying capacity of the ATC beams. The bending resistance of the ATC composite beam from the analytical estimations was 1.08 times lower than the bending resistance from the tests (Chybiński \& Polus 2019). What is more, the non-linear three-dimensional

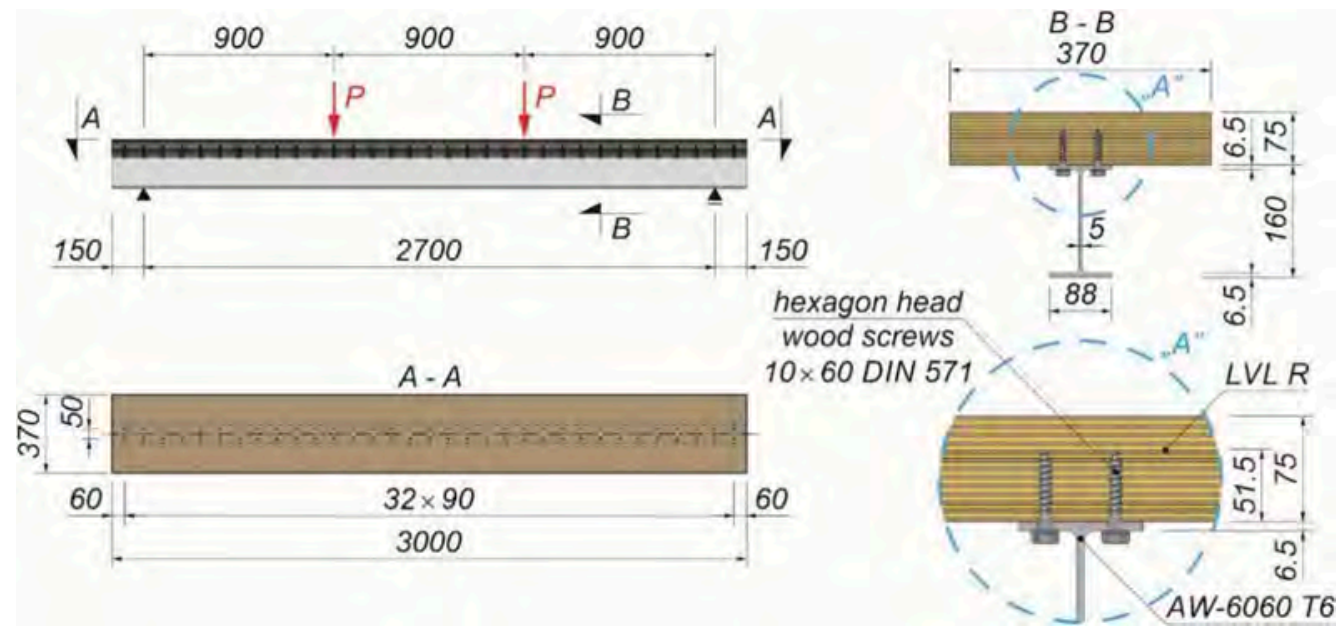

Figure 2. The aluminium-timber composite beam tested by (Chybiński \& Polus 2019). 

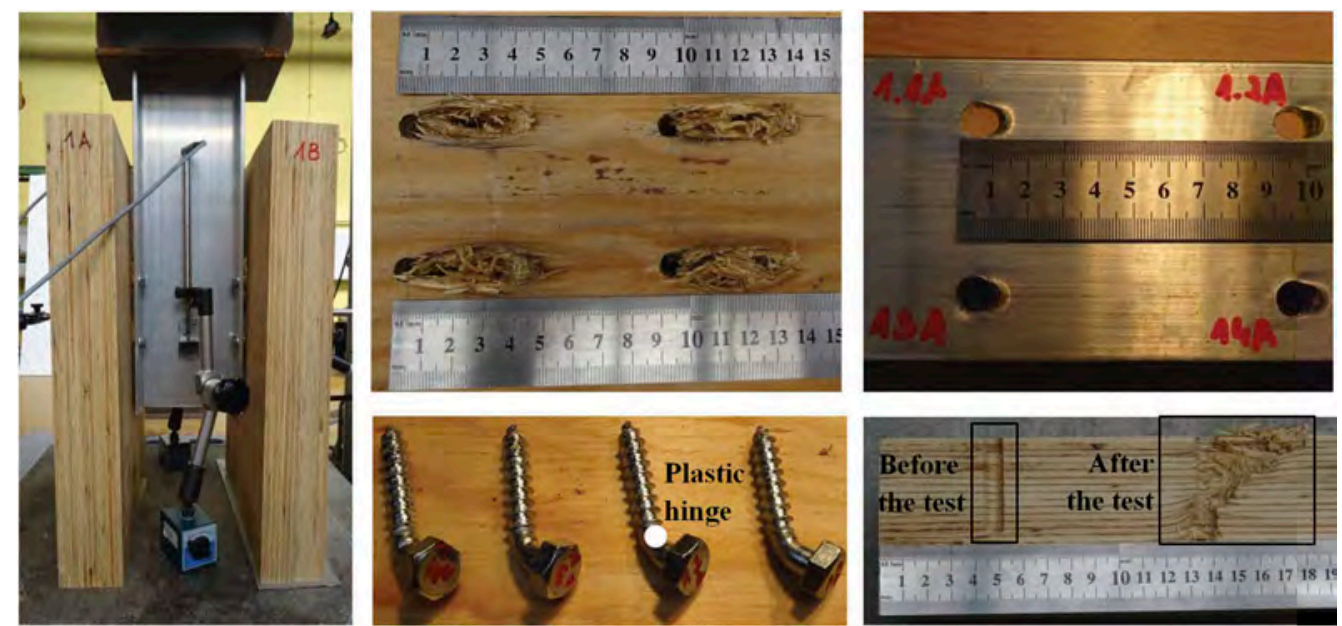

Figure 3. The push-out test specimen after the test (Chybiński \& Polus 2019).

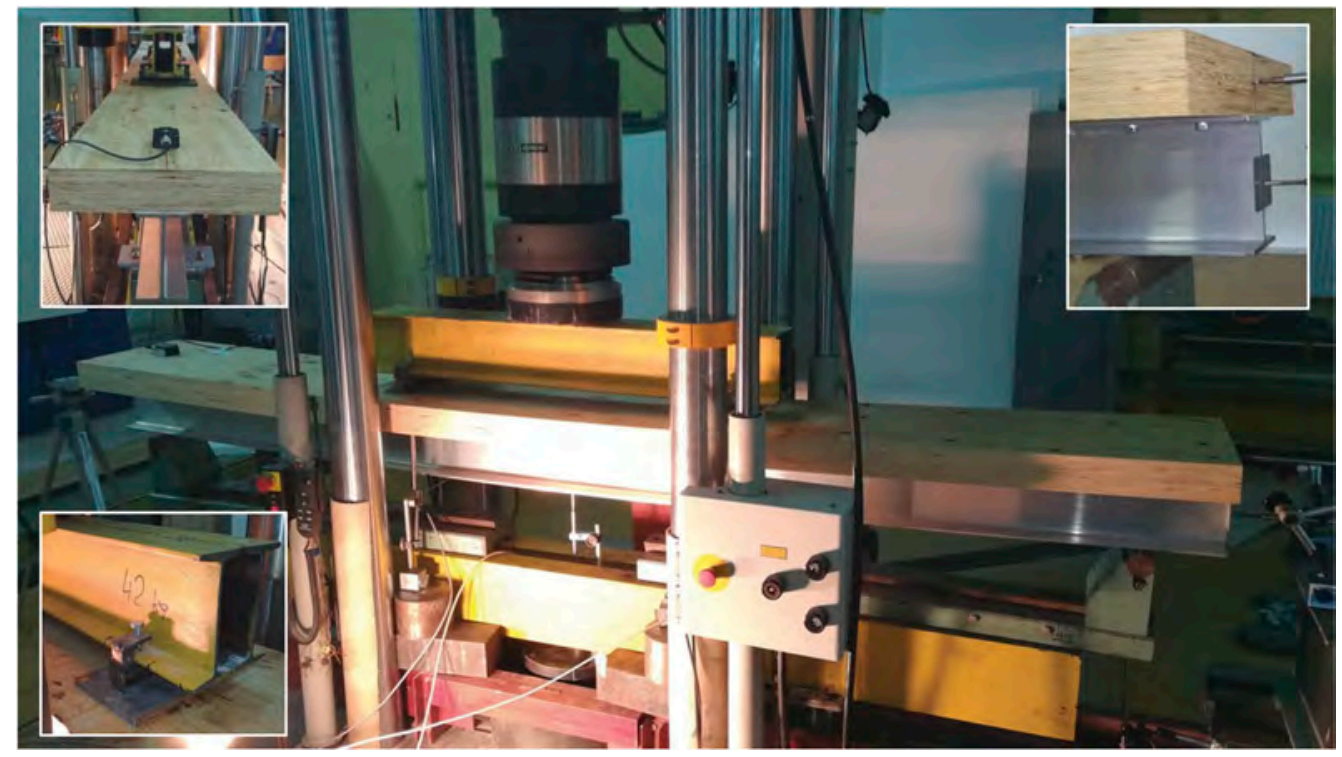

Figure 4. The aluminium-timber composite beam in the bending test (Chybiński \& Polus 2019).

finite element models of the ATC elements used in the bending test and in the push-out test were developed and verified against the experimental results. The shear connections were modelled using zero-length springs. The comparison of the experimental and numerical results demonstrated that the adopted numerical models were able to adequately capture the response of the ATC elements (Chybiński \& Polus 2019).

\section{CONCLUSIONS}

The ACC beams analysed by Polus and Szumigała (2019a) were beams with partial interaction, i.e., the degree of the shear connection was 0.79 , because the connectors could 
only be placed in the ribs of the profiled sheeting. The clearance between the bolt and the hole made it easier to install the shear connectors in the aluminium beam flange. However, it had a negative impact on the connection stiffness $\left(k_{0.4}=5.9 \mathrm{kN} / \mathrm{mm}\right)$. The stiffness of the connection can be increased by tightening the connectors with a higher torque (pre-tensioning) (Rehman et al. 2018) (Kozma et al. 2019) and/or by reducing the clearance (Suwaed 2017). The connections presented by Polus and Szumigała (2016, 2019a) showed brittle behaviour, which was caused by the rib-shear failure resulting from the small width of the profiled sheeting ribs. Furthermore, the analysed connections showed a lower level of slip capacity $(4.2 \mathrm{~mm})$. For this reason, the use of profiled sheeting with wider ribs and of the waveform reinforcement presented by Patrick (2000) to prevent the rib-shearing failure is recommended. The load bearing capacity of the aluminium beams analysed by Polus and Szumigała (2019a) $(22.3 \mathrm{kNm})$ increased 3.2 times (to $72.2 \mathrm{kNm}$ ) after they were joined with concrete slabs.

The ATC beams analysed by Chybiński and Polus (2019) were almost full-composite beams, i.e., the degree of the shear connection was 0.97 . Their flexible connections $\left(k_{0.4}=5.5\right.$ $\mathrm{kN} / \mathrm{mm}$ ) had an impact on the stiffness of the ATC beams. However, the connections were ductile, and the failure mode appeared in the middle of the ATC beam, where a sudden tensile fracture was observed. The load bearing capacity of the aluminium beams analysed by Chybiński and Polus (2019) $(18.3 \mathrm{kNm}$ ) increased 3.4 times (to $62.8 \mathrm{kNm}$ ) after they were joined with LVL slabs.

The bending resistance of the novel structural solutions presented in this paper was calculated using the method for steel-concrete composite elements with partial shear connection and compared with the experimental results. The proposed method of calculating the bending resistance of the composite beams with aluminium girders produced similar results to the bending tests. However, only four ACC beams and two ATC beams were tested. Therefore, it is advisable to perform complementary tests on ACC and ATC beams of different geometries and to verify the method against a greater number of experimental results.

When it comes to numerical modelling, the behaviour of shear connections can be modelled using zero-length springs, the load-slip behaviour of which is obtained in laboratory push-out tests.

It should be noted that the serviceability limit state criterion may be more difficult to satisfy than the ultimate limit state criterion when designing composite beams with aluminium girders because of the low value of the Young's modulus of aluminium.

\section{REFERENCES}

Abendroth, R.E., Sanders, W.W. \& Mahadevan, V. 1996. A continuous span aluminium girder concrete deck bridge, Final Report, Part I: Field Test Performance and Evaluation. Bridge Engineering Center, Iowa State University.

Abramowicz, M., Berczyński S. \& Wróblewski, T. 2020. Modelling and parameter identification of steel-concrete composite beams in 3D rigid finite element method. Archives of Civil and Mechanical Engineering 20, article 103, doi: 10.1007/s43452-020-00100-7.

Bruzzese, E., Cappelli, M. \& Mazzolani, F.M. 1989. Experimental investigation on aluminium-concrete beams. Construzioni Metalliche 5: 265-282.

Chen, Y., Feng, R. \& Xu, J. 2017. Flexural behaviour of CFRP strengthened concrete-filled aluminium alloy CHS tubes. Construction and Building Materials 142: 295-319.

Chybiński, M. \& Polus, Ł. 2018. Bending resistance of metal-concrete composite beams in a natural fire. Civil and Environmental Engineering Reports 4(28): 149-162.

Chybiński, M. \& Polus, Ł. 2019. Theoretical, experimental and numerical study of aluminium-timber composite beams with screwed connections. Construction and Building Materials 226: 317-330.

Chybiński, M., Polus, Ł., Ratajczak, M. \& Sielicki, P. 2019a. The evaluation of the fracture surface in the AW-6060 T6 aluminium alloy under a wide range of loads. Metals 9(3), article 9030324, doi: 10.3390/ met9030324.

Chybiński, M., Polus, Ł., Szwabiński, W. \& Niewiem, P. 2019b. FE Analysis of Steel-Timber Composite Beams. AIP Conference Proceedings, 2078, article 020061, doi: 10.1063/1.5092064. 
Gwóźdź, M. 2007. Project problems of contemporary aluminium structures. Czasopismo Techniczne 104 (z. 4-A): 281-286.

Hanus, J.P., Ray, J.C., Bank, L.C. \& Velazquez, G.I. 2008. Optimized design and testing of a prototype military bridge system for rapid in-theater construction. In J.A. Parmentola \& A.M. Rajendran (eds.), Proceedings of the 25th US Army Science Conference, Transformational Army Science and Technology Charting the future of $S \& T$ for the Soldier, Tech Science Press.

Hassanieh, A., Valipour, H.R. \& Bradford, M.A. 2016. Experimental and numerical study of steel-timber composite (STC) beams, Journal of Constructional Steel Research 122: 367-378.

Komorowski, M. 2017. Manual of design and build in the STEICO system, Basic information, Building physics, Guidelines. Warsaw: Forester Communication.

Kossakowski, P., Wcislik, W. \& Bakalarz, M. 2017. Selected aspects of application of aluminium alloys in building structures. Structure and Environment 9(4): 256-263.

Kozma, A., Odenbreit, C., Braun, M.V., Veljkovic, M. \& Nijgh, M.P. 2019. Push-out tests on demountable shear connectors of steel-concrete composite structures. Structures 21: 45-54, doi: 10.1016/j. istruc.2019.05.011.

Kożuch, M. \& Lorenc, W. 2019. Stress concentration factors of shear connection by composite dowels with MCL shape. Archives of Civil and Mechanical Engineering 19(1): 32-46.

Kyvelou, P., Gardner, L. \& Nethercot, D.A. 2018. Finite element modelling of composite cold-formed steel flooring systems. Engineering Structures 158: 28-42.

Lacki, P. \& Derlatka, A. 2017. Strength evaluation of beam made of the aluminum 6061-T6 and titanium grade 5 alloys sheets joined by RFSSW and RSW. Composite Structures 159: 491-497.

Lee, S.S.M. \& Bradford, M.A. 2013. Sustainable composite beam behaviour with deconstructable bolted shear connectors. In The World Congress on Advances in structural engineering and mechanics (ASEM13), Jeju, Korea, 8-12 September 2013: 3188-3199.

Marcinowski, J. 2018. Stresses in a layered, composite structure fabricated from materials of different thermal expansions. Materiaty Budowlane 4: 107-109.

Mazzolani, F.M. 2006. Structural applications of aluminium in civil engineering. Structural Engineering International 16(4): 280-85.

Nijgh, M., Gîrbacea, A. \& Veljković, M. 2018. Optimization of a composite (steel-concrete) floor system for fast execution and easy demolition. In 14th International Scientific Conference on Planning, Design, Construction and Building Renewal Conference, iNDiS, Novi Sad, 21-23 November 2018: 45-52.

Patrick, M. 2000. Experimental investigation and design of longitudinal shear reinforcement in composite edge beams. Progress in Structural Engineering and Materials 2: 196-217.

Polus, Ł. \& Szumigała, M. 2016. Tests of shear connectors used in aluminium-concrete composite structures. In: M. A. Giżejowski, J. Marcinowski, A. Kozłowski \& J. Ziółko (eds.), Recent Progress in Steel and Composite Structures: Proceedings of the XIII International Conference on Metal Structures (ICMS2016), Zielona Góra, Poland, 15-17 June 2016: 113-136. Boca Raton: CRC Press.

Polus, Ł. \& Szumigała, M. 2019a. An experimental and numerical study of aluminium-concrete joints and composite beams. Archives of Civil and Mechanical Engineering 19(2): 375-390.

Polus, Ł. \& Szumigała, M. 2019b. Theoretical and numerical analyses of an aluminium-concrete composite beam with channel shear connectors. Engineering Transactions 67(4): 535-556.

Rehman, N., Lam, D., Dai, X. \& Ashour, A. F. 2018. Testing of composite beam with demountable shear connectors. Proceedings of the Institution of Civil Engineers, Structures and Buildings 171(SB1): $3-16$.

Saleh, S.M. \& Jasim, N.A. 2014. Structural behavior of timber aluminum composite beams under static loads. International Journal of Research in Engineering and Technology 3(10): 1166-1173.

Siwowski, T. 2006a. Aluminium bridges - past, present and future. Structural Engineering International 16(4): 286-293.

Siwowski, T. 2006b. Prediction of the flexural behaviour of "aluminium-lightweight concrete composite girder”. In M. Giżejowski, A. Kozłowski, L. Ślęczka \& J. Ziółko (eds.), Progress in Steel, Composite and Aluminium Structures, Proceedings of the XI International Conference on Metal Structures (ICMS 2006), Rzeszow, Poland, 21-23 June 2006: 236-237. London: Taylor \& Francis Group.

Siwowski, T. 2009. Structural behaviour of aluminium bridge deck panels. Engineering Structures 31: $1349-1353$.

Stonehewer, J. 1962. A study of composite concrete-aluminum beams, Master of Engineering, Montreal: McGill University.

Studziński, R. \& Ciesielczyk, K. 2019. Connection stiffness between thin-walled beam and sandwich panel. Journal of Sandwich Structures \& Materials 21(6): 2042-2056.

Suwaed, A.S.H. 2017. Development of novel demountable shear connectors for precast steel-concrete composite bridges, $\mathrm{PhD}$, Warwick: University of Warwick. 
Szelka, J. \& Kamyk, Z. 2013. Kompozytowe mosty wojskowe. Budownictwo i Architektura 12(2): 63-70.

Szewczyk, P. \& Szumigała, M. 2018. Static equilibrium paths of steel-concrete composite beam strengthened under load. Civil and Environmental Engineering Reports 28(2): 101-111.

Szmigiera, E. 2007. Influence of concrete and fibre concrete on the load-carrying capacity and deformability of composite steel-concrete columns. Journal of Civil Engineering and Management 13(1): $55-61$.

Szumigała, M. \& Polus, Ł. 2015. Applications of aluminium and concrete composite structures. Procedia Engineering 108: 544-549.

Szumigała, M., Chybiński, M. \& Polus Ł. 2017. Preliminary analysis of the aluminium-timber composite beams. Civil and Environmental Engineering Reports 27(4): 131-141.

Szumigała, M., Chybiński, M. \& Polus Ł. 2019. Stiffness of composite beams with full shear connection. IOP Conference Series: Materials Science and Engineering 471, article 052083, doi: 10.1088/1757-899X/ $471 / 5 / 052083$.

Xu, Y., Wang, Q., Xie, M. \& Wei, Q. 2020. Shear behavior of reinforced concrete beams strengthened with aluminum alloy sheets. Huazhong Keji Daxue Xuebao (Ziran Kexue Ban)/Journal of Huazhong University of Science and Technology (Natural Science Edition) 48(2): 47-53.

Yu, X, Xing, G. \& Chang, Z. 2020. Flexural behavior of reinforced concrete beams strengthened with near-surface mounted 7075 aluminum alloy bars. Journal of Building Engineering 31, article 101393.

Zhou, F. \& Young, B. 2009. Concrete-filled aluminium circular hollow section column tests. Thin-Walled Structures 47: 1272-1280. 


\title{
Analysis of puzzle shaped continuous shear connector
}

\author{
P. Vaňová, R. Kanishchev \& V. Kvočák \\ Technical University of Košice, Košice, Slovakia
}

\begin{abstract}
Continuous shear connectors are a recent invention, from a bridge science point of view as the first one was patented in 1985 by W. Andrä after spare of general interest in this area after the end of World War II. Therefore their development is now still hugely a focus of many researchers. At Technical University of Košice, Faculty of Civil Engineering, new geometrical characteristics of puzzle shaped steel perforated strip were designed. The strip underwent several tests, in which it was closely observed and measured, specifically the push-out tests as well as the bending tests. Both materials, steel and concrete, also underwent testing to find out their exact material characteristics for precise analysis input data along with FEM analysis later in the research. The results were analysed and are presented in this paper together with the geometrical, material and testing process description.
\end{abstract}

\section{INTRODUCTION}

Several authors contributed to this area of study. Firstly, Oguejiofor and Hosain were amongst the first researchers to publish a study of FEM analysis of continuous shear connectors at the end of last century (Oguejiofor \& Hosain, 1993). From nowadays researches, Lorenc et al. did a comprehensive study of dowel shape (Lorenc, 2009, 2016); Classen and Hegger researched the pry-out failure of concrete in specimens with dowel connectors (Classen \& Hegger, 2017).

\section{SHAPE}

As the title suggests, the proposed perforated strip is of a puzzle shape. In the Figure 1, the dimensions of one tooth are shown. Its shape was carefully design to spread the stress with the geometrical advantage being a possibility to produce two identical shapes out of one I-beam by cutting it into two equal longitudinal halves.

Firstly, the cross-section of the composite beam was being considered and tested as a rectangle - the shear connectors being simply poured into a concrete block. However, this design consisted unnecessary parts, where tension in concrete was present. For this very reason, those parts were missed out of the following testing, to make even more effective design, which is still easy to prefabricate. The new design of the cross-section is shown in the Figure 2.

\section{MATERIALS}

The tested specimens were manufactured from two basic materials: steel and concrete. Material characteristics were established from series of testing the materials underwent. 


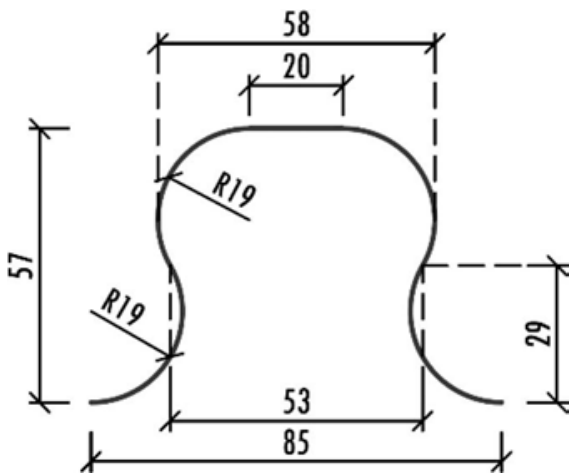

Figure 1. The exact shape of one puzzle tooth.

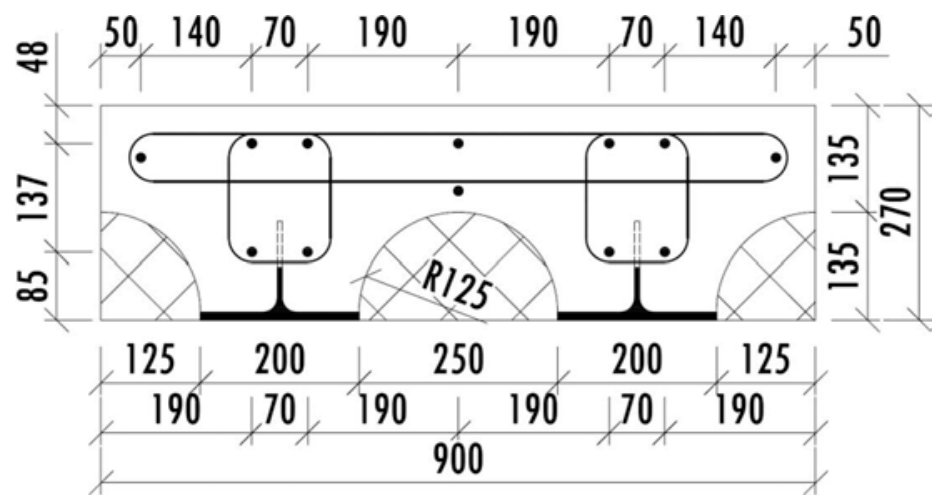

Figure 2. Dimensions of lightened beam in cross-section.

\subsection{Concrete}

European quality concrete C30/37 was used. The necessary tests performed on one year old specimens at Laboratory of Excellent Research:

- The compressive tests of cubes, beams and cylinders of standardized dimensions; measured with calliper beforehand;

- The four-point flexural tests onto beams;

- The Young's Modulus tests;

- The tensile tests.

Material characteristics included in FEM analysis are summarized in the following Table 1.

Table 1. Properties of concrete.

\begin{tabular}{lll}
\hline Characteristic & Measured value & Unit \\
\hline Mass density & $2.274 \mathrm{E}-09$ & tonnel $\mathrm{mm}^{3}$ \\
Young's Modulus & 33423.8 & $\mathrm{MPa}$ \\
Poisson's ratio & 0.2 & - \\
Tensile Strenght & 6.89 & $\mathrm{MPa}$ \\
Compressive Strenght & 66.31 & $\mathrm{MPa}$ \\
\hline
\end{tabular}




\subsection{Steel}

Steel used for the connector was tested by Faculty of Metallurgy. They performed tensile tests to determine Yield point of the material, results are visible in Figure 3. Other values were taken from normative characteristics, summarized in the Table 2.

\subsection{Reinforcement}

Reinforcement used in the experiments were not tested, therefore in any further numerical study the norm characteristics were considered. The bars were of $12 \mathrm{~mm}$ diameter, with european label B500.

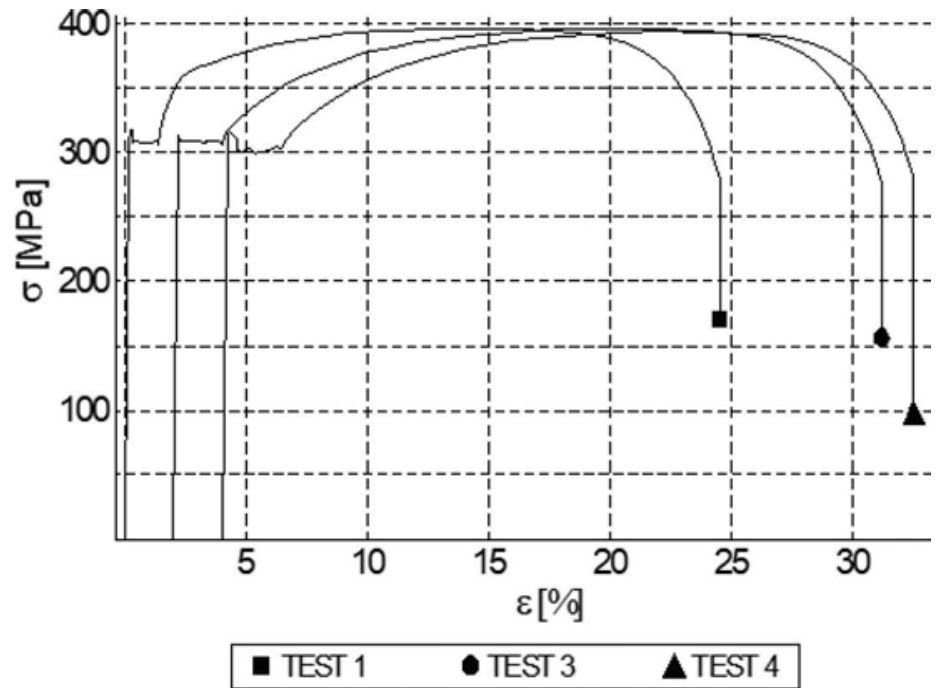

Figure 3. Diagrams of three steel samples tested.

Table 2. Properties of steel.

\begin{tabular}{lll}
\hline Characteristic & Measured value & Unit \\
\hline Mass density & $8.654 \mathrm{E}-09$ & tonnelmm \\
Young's Modulus & 210000 & $\mathrm{MPa}$ \\
Poisson's ratio & 0.3 & - \\
Yield point & 315.3 & $\mathrm{MPa}$ \\
\hline
\end{tabular}

Table 3. Properties of reinforcement.

\begin{tabular}{lll}
\hline Characteristic & Measured value & Unit \\
\hline Mass density & $8.65 \mathrm{E}-09$ & tonnelmm \\
Young's Modulus & 210000 & $M P a$ \\
Poisson's ratio & 0.3 & - \\
Yield point & 490 & $M P a$ \\
\hline
\end{tabular}




\section{EXPERIMENTAL PROGRAMME}

Two experiments were performed onto three specimens each, to determine the shear and bending resistance of the composite connection. They are described in the following sub-chapters.

\section{$4.1 \quad$ Push-out test}

Four specimens were made in order to find out the shear resistance of the puzzle shaped continuous shear connector via push-out tests. Two connectors connected with steel plate were poured into two $200 \times 600 \times 600 \mathrm{~mm}$ concrete blocks and put into hydraulic press, which loaded the specimens during 99 loading conditions. Slip was measured by inductive displacement sensors placed on both sides of the middle steel plate. The results recorded are presented in Fihure 4.

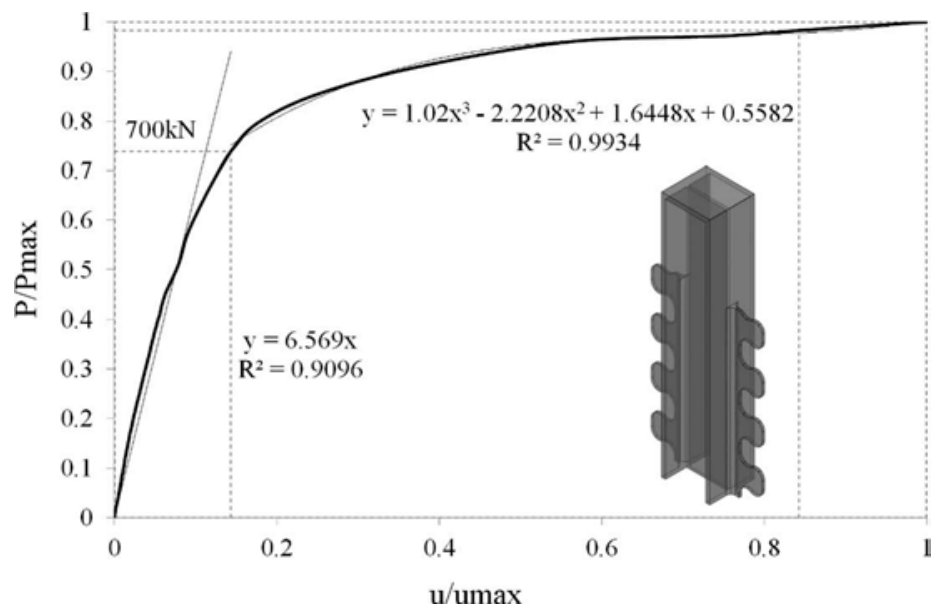

Figure 4. Diagram of the push-out tests results.

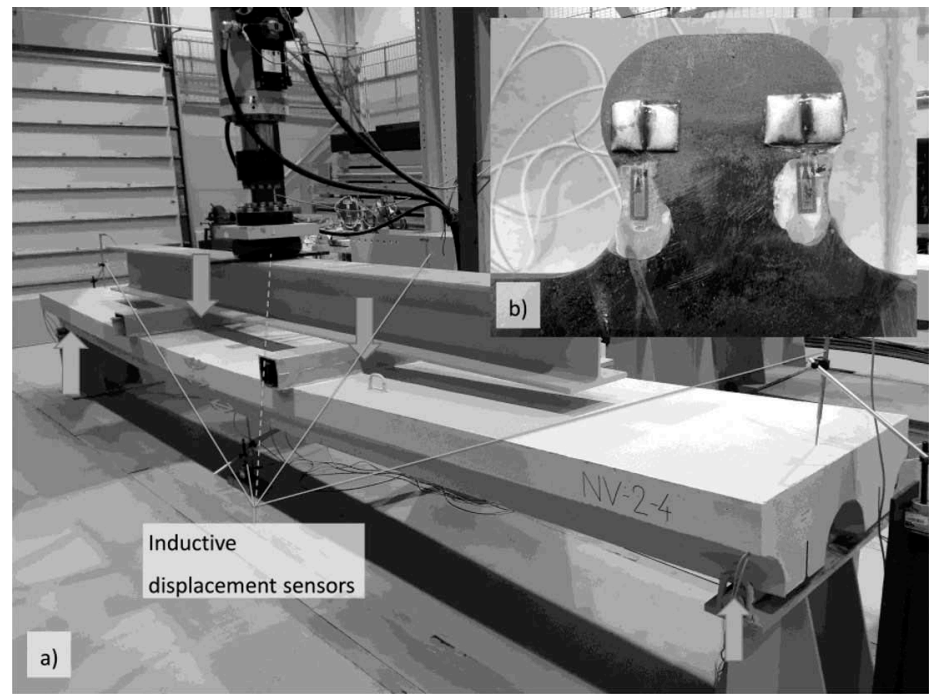

Figure 5. Four-point flexural test: a) the overall layout of the test; b) strain gauges application on the tooth of the strip. 


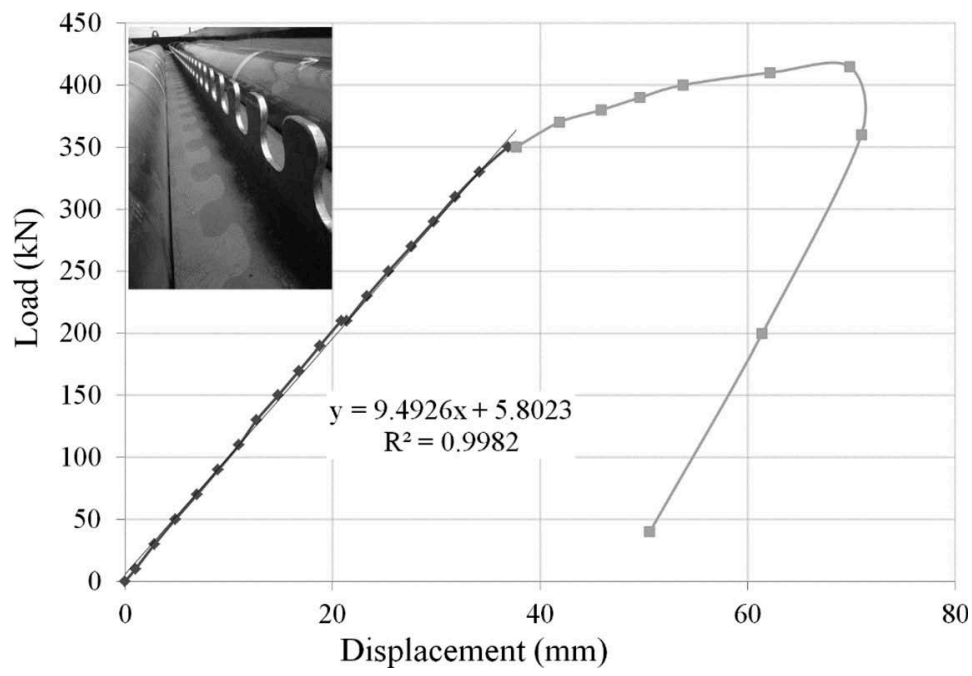

Figure 6. Diagram of the four-point flexural tests results.

The first part of the diagram shows linear behaviour of the specimens, at the end of which the shear resistance was determined. The loading condition was at the value of $700 \mathrm{kN}$ at that point. Afterwards, the specimens started to develop bigger slip, which is visible in the second, horizontal part of the graph. In the third part, the slip started growing uncontrollably, and the tests were stopped.

\subsection{Four-point flexural test}

Four-point flexural tests were performed on three $6 \mathrm{~m}$ long lightened beams that included two rows of connectors. Two support were located $100 \mathrm{~mm}$ from the beams ends and two loads forces were applicated approximately $900 \mathrm{~mm}$ from the center of the beam.

During the loading process, two loading cycles were done to prove the linear behaviour of the specimens.

In the Figure 6, the results are shown. The end of the linear part was determined to be at the point of $350 \mathrm{kN}$, which equals the bending resistance of the specimens.

\section{NUMERICAL PROGRAMME}

Finite element model was created to simulate the four-point flexural test. The analysis was developed in Abaqus/CAE software.

Dynamic, Implicit step was chosen for the analysis. General contact was included, with 0.93 coefficient of friction in-between the surfaces of steel dowel and concrete. Both loading cycles were also included. The loading conditions were the exact copy of the loading conditions set in experiments. The specimen was meshed by C3D4 element for concrete and steel, described as 4-node linear tetrahedrons (see Figure 7).

As visible in Figure 8, the first loading cycle acted as expected. The second one, on the other hand, presented with slightly bigger displacement changes, which might by caused by insufficiently accurate material properties of concrete.

The bending resistance from software was a little higher with ratio of 1.06 at $370 \mathrm{kN}$. However, the deviation was lower during every loading condition, except first and last, and the average deviation was $20.49 \%$. 


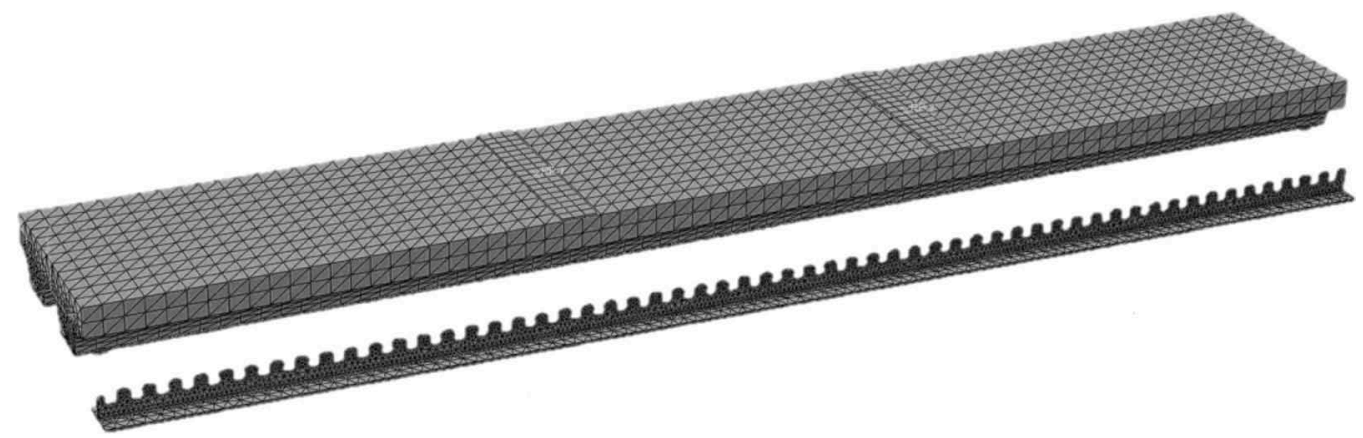

Figure 7. Mesh of the four-point flexural test modeled in Abaqus/CAE.

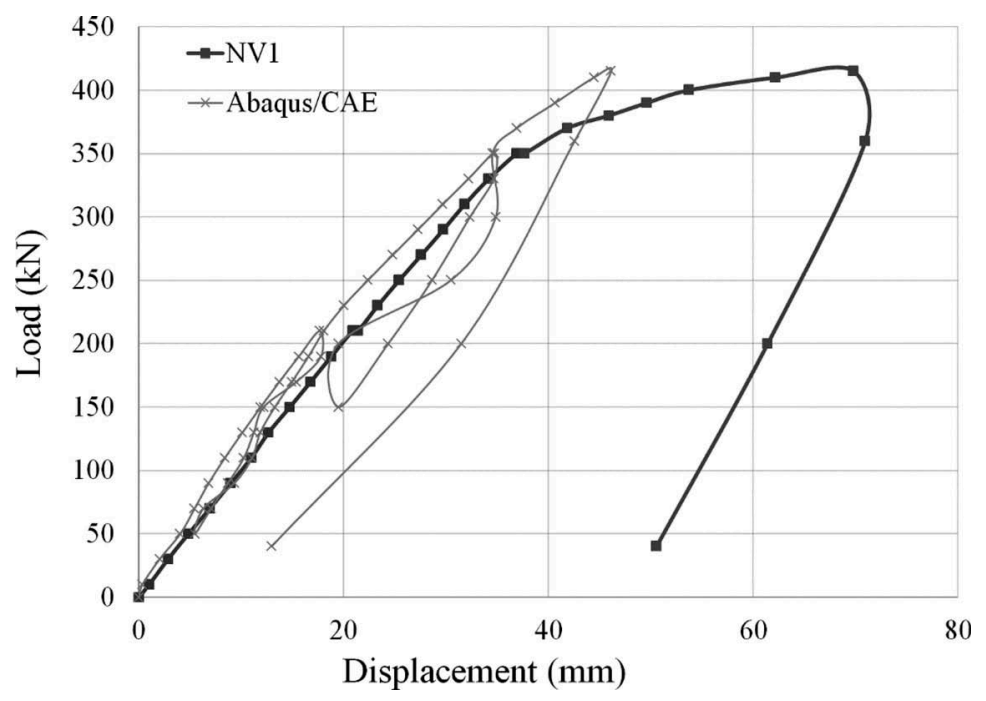

Figure 8. Results from Abaqus software compared with experimental results.

\section{CONCLUSION}

In conclusion, the experiments proved the eligibility of the puzzle shaped continuous shear connectors as well as of the lightened beams cross-section for the usage for short-span bridges in practice.

The FEM analysis was also successfully with deviation mentioned above, it is suitable for the further parametric study.

\section{REFERENCES}

Classen, M. and Hegger, J. 2017. Shear-slip behaviour and ductility of composite dowel connectors withpry-out failure. Engineering Structures 150: 428-437.

Lorenc, W. 2009. Boundary approach in shape study of composite dowel shear connector. Archives of Civil and Mechanical Engineering 9: 55-66.

Lorenc, W. 2016. The design concept for the steel part of a composite dowel shear connection. Steel Construction 9(2): 89-97.

Oguejiofor, E. C. and Hosain, M. U. 1997. Numerical analysis of push-out specimens with perfobond rib connectors. Computers and Structures 62: 617-624. 


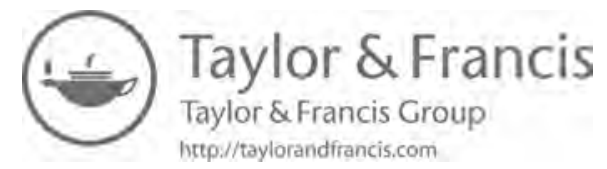


Engineering structures 


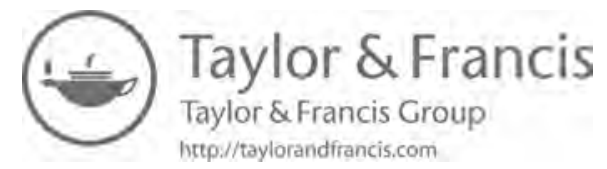




\title{
Buckling of externally pressured cylinders with different degrees of ring-stiffening
}

\author{
E. Azizi \& N. Stranghöner \\ Institute for Metal and Lightweight Structures, University of Duisburg-Essen, Essen, Germany
}

\begin{abstract}
Ring-stiffened cylindrical shells are extensively used in engineering applications such as tanks, silos, pressure vessels, submarine hulls, aircraft fuselages, and pipelines for conveying fluids or gases. The attachment of ring stiffeners on the shell wall allows increasing the buckling resistance or distributing the local loads in the circumferential direction. However, the generation of efficient and user-friendly design rules is not an easy task because of various possible failure modes of these shell structures: (i) local buckling in the shell wall between ring stiffeners, (ii) overall buckling of the whole shell structure, including ring stiffeners, and (iii) local failure of ring stiffeners. In the presented paper, theoretical and experimental results from literature are discussed, and new results from computational analyses are presented regarding the imperfection sensitivity of ring-stiffened cylindrical shells under uniform external pressure. Based on the results, the most detrimental imperfection pattern is identified for future numerical investigations.
\end{abstract}

\section{INTRODUCTION}

Ring stiffeners are widely attached to the shell wall of cylindrical shells to increase their buckling strength in the circumferential direction with a relatively low increase in construction weight. While material nonlinearity, boundary conditions, and both material and geometric imperfections play an important role on the buckling strength of unstiffened cylindrical shells, many further phenomena such as local buckling of the shell wall and instability of ring stiffeners must be taken into account for ring-stiffened cylindrical shells, see Azizi/Stranghöner (2020). These shell structures display a rather more complex buckling behaviour than those without stiffeners.

In the relevant design standard EN 1993-1-6 (2007) and the European Recommendation ECCS EDR5 (2013), only simple and partial efficient design rules are given for unstiffened shells for such cases where the buckling resistance is relatively independent on the shell length and where local stresses associated with the detailed geometry or loading condition do not exist. In the case that a direct dependence on the shell length exists or the stress distribution is locally constituted (e.g. due to the attachment of stiffeners), the buckling strength assessment gets much more complicated and EN 1993-1-6 as well as the design recommendations are either silent or they are providing ineffective rules. Therefore, several significant improvements to hand calculation rules have been established in the draft revision of pr EN 1993-1-6:2020.

Depending on the size of a stiffened shell structure, three different types of failures can occur: (i) local buckling in the shell wall between ring stiffeners, (ii) overall buckling of the whole shell structure, including ring stiffeners, and (iii) local failure of ring stiffeners. Shell structures used in tanks and the aerospace industry are usually thin-walled and closely spaced ring-stiffened cylindrical shells, which fail mainly due to overall buckling under elastic conditions, see Figure 1b. In contrast to this, cylindrical shells applied in vessels, offshore

DOI: $10.1201 / 9781003132134-32$ 
a)

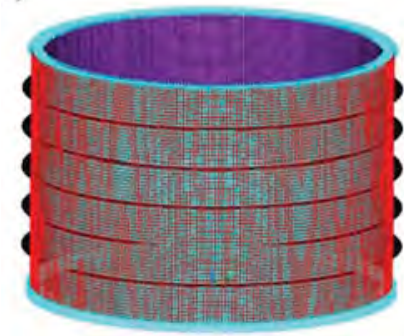

b)

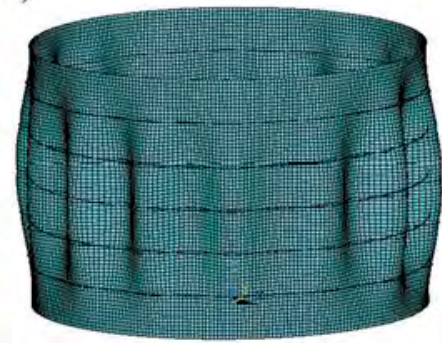

c)

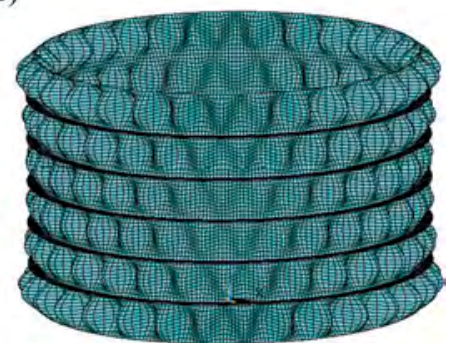

Figure 1. Types of instability or failure in ring-stiffened cylindrical shells subjected to external pressure. a) Ring-stiffened shell under uniform external pressure, b) Overall buckling of the whole shell system, c) Local buckling in the shell wall between stiffeners.

constructions, and the marine industry are always thick-walled shells with wide distanced ring-stiffeners, so that their failure is local buckling in the shell wall between the ring stiffeners under elastic-plastic or plastic conditions, see Figure 1c.

The buckling behaviour of unstiffened cylindrical shells under elastic conditions and uniform external pressure has been the subject of many previous research studies, and it is well established that their buckling resistance is dependent on their length $(l)$, radius-to-thickness ratio $(r / t)$, material properties (Young's modulus $E$, Poisson's ratio $v$ ), and end boundary conditions. These investigations were summarised by the authors in Azizi/Stranghöner (2021) as they are important for understanding of the buckling behaviour of ring-stiffened shells when the failure mode is local buckling of the shell wall between the stiffeners. In such a case, every single panel between two ring stiffeners can be considered as an unstiffened shell with their corresponding boundary conditions, as defined in the last draft version of prEN 1993-1-6:2020.

For ring-stiffened cylindrical shells subjected to uniform external pressure, Wunderlich et al. (1991) focused on the relationship between the elastic critical buckling pressure and the number of ring stiffeners using numerical analyses. As a result, they pointed out that the elastic buckling capacity increases with increasing the number of ring stiffeners until a particular level of bending stiffness is reached at which the elastic buckling strength cannot be affected anymore by the variation of the number of stiffeners. The importance of the end boundary conditions for the elastic critical buckling pressure was studied by Kaminsky (1954) and Ross (1965). The outcomes of these research studies have indicated that the critical buckling resistance of ring-stiffened shells with clamped end boundary conditions is significantly higher than those shells with simply supported boundaries at their ends.

Kendrick (1953) attempted to investigate the effect of the local panel length by varying the distance of ring stiffeners on the elastic critical buckling pressure. As expected, he found that the elastic buckling strength is reduced by increasing the distance between ring stiffeners. Singer and Haftka (1967) continued this work by exploring the relationship between the strength and the position of ring stiffeners by a linear discrete stiffener theory. They concluded that externally attached ring stiffeners have generally higher elastic buckling capacity compared to those attached internally. However, this conclusion was not confirmed by Düsing/ Schmidt (1996) as their investigations indicated that a general statement could not be made, and many different parameters (e.g. stiffness and shell geometry) have to be taken into account to answer the question whether internal or external stiffeners are more efficient.

Many other theoretical (Kendrick (1972; 1984)), numerical (Wunderlich et al. (1991)), and experimental (Düsing/Schmidt (1996)) investigations have been carried out to provide design recommendations, including the influence of imperfections, nonlinearity, and plasticity on the buckling strength of ring-stiffened cylindrical shells so that they can be applied to real shell constructions. One of these key works was carried out by Kendrick (1984), whose recommendations were adopted in the British Standard BS 5500 (1976) and the ECCS EDR4 (1998). These design rules were later modified and enhanced by Greiner (1987) so that they 
were incorporated into the German DASt-Guideline No. 17 (1992). To take into account the methodology and terminology of EN 1993-1-6 (2007), the design rules were again amended in a collaboration between Schmidt and Greiner, who prepared the improved design rules given in Chapter 17 of ECCS EDR5 (2013).

\section{IMPERFECTION SENSITIVITY OF RING-STIFFENED CYLINDRICAL SHELLS}

For unstiffened shell structures made of steel, initial imperfections cause mainly a mismatch between experimentally determined buckling strengths and those predicted by theoretical approaches (Yamaki (1984); Rotter/Schmidt (2013); Stranghöner/Azizi (2019)). However, it was found (Hutchinson/Amazigo (1967)) that the sensitivity of the buckling strength to the geometric imperfections is generally reduced by stiffening the shell. Furthermore, the impact of prominent imperfections on the buckling capacity of externally loaded cylinders is less than other loading cases (e.g. meridional compression). Despite the above aspects, it is vital to include the effects of geometric imperfections in the design process of ring-stiffened cylindrical shells. The reason is that geometric imperfections, e.g. deviations of the shell geometry from its perfect geometric shape, irregularities at and near welds, deviations from nominal wall thickness, and lack of evenness of supports, are unavoidable introduced during the fabrication and manufacturing process.

\subsection{Details of the computational model used in nonlinear bucking analyses}

The finite element program ANSYS APDL v20.1 has also been applied for the nonlinear buckling analyses. All computational simulations were performed using the arc-length method, which is a popular method in the stability analysis, and was already identified to be suitable for predicting the buckling resistance of shells (e.g. by Sadowski et al. (2017), Stranghöner et al. (2019)). Since a bifurcation point in the pre-buckling state can stay undetected in case of application of the arc-length method (Riks (1979)), the nonlinear equilibriums path near the failure load was automatically followed to ensure that no bifurcation point with a negative stiffness matrix remains undetected, see Azizi/Stranghöner (2021).

At the bottom and top edges of the investigated cylindrical shells, the boundary conditions were assumed to be radially restrained but free to rotate about the circumferential edge and to display in the meridional direction (BC2f acc. to EN 1993-1-6, corresponding to Yamaki's S3).

All numerical models have meshed with four-node Shell-181 elements, which has six degrees of freedom at each node, and its suitability has been checked by authors (e.g. Azizi/Stranghöner (2021)). For an optimal mesh resolution, a series of preliminary investigations were conducted on perfect cylindrical shells using a LBA and a geometrically nonlinear elastic analysis (GNA). Afterwards, the mesh refinement has been progressively applied to each geometry of perfect assumed cylinders until the computational results of each modelled geometry obtained convergence, and the size of the circumferential mesh allowed an accurate representation of the critical number of half-waves.

Four different types of analysis, known as GN(I)A and GMN(I)A acc. to EN 1993-1-6, were used for nonlinear FE analyses of this study. For the geometrically nonlinear elastic analyses on perfect and imperfect cylindrical shells (GNA or GNIA), an elastic material law was chosen. By contrast, a perfectly elastic-plastic material law without strain hardening was employed for all other nonlinear analyses, in which the impact of material nonlinearity (GMNA or GMNIA) was taken into account. For all nonlinear FE analyses, it was assumed that the applied material for the shell wall and the ring stiffeners is identical and exhibits $E=$ $200 \mathrm{GPa}, v=0.3$, and $\sigma_{y}=235 \mathrm{MPa}$.

\subsection{Relationship between the degree of ring stiffening and load-bearing behaviour of imperfect cylinders}

For understanding the load-bearing behaviour of shell structures, it is necessary to take into account the effect of geometric nonlinearities and imperfections on the buckling strength. 
These physical phenomena cause the main deviation between the classical linear eigenvalue buckling load and the buckling strength of real shells (experimental tests). To consider the impact of these both phenomena into the design process, EN 1993-1-6 (2017) provides an analytical formulation for the elastic buckling reduction factor $\left(\alpha=\alpha_{I} \alpha_{G} \# \mathrm{x} 03 \mathrm{~B} 1\right.$; based on a proposal of Rotter (2011)\#x03B1; which allows considering the influence of imperfections by $\alpha_{I}$ and geometric nonlinearity by $\alpha_{G}$.

Exemplary, Figure 2 illustrates the relationship between the degree of ring stiffening and the load-bearing capacity of a short cylinder $(l / r \approx 1)$ with a constant $r / t$-ratio of 1000 . The geometric nonlinear buckling analyses on imperfect cylinders were performed adopting an eigenmode-affine imperfection pattern with an initial amplitude to shell wall-thickness equal to $\delta_{0} / t=1$. One of the challenges after conducting such analyses for cylindrical shells under external pressure is the interpretation of the outcomes because the transition from pre- to post-buckling path occurs in many cases without bifurcation. Therefore, it is difficult to detect the failure load. To this end, the inflection point as an alternative criterion for evaluating the results of nonlinear buckling analyses was proposed by Yamaki (1984), included in EN 1993-1-6, and used by the previous numerical study of the authors (Azizi/Stranghöner (2021)).

Based on the results obtained from computational analyses, as shown in Figure 2, it can be summarised that the buckling resistance increases with increasing the degree of stiffening until a particular level of stiffening is reached. After this specific level, here at $\beta_{\theta, s t}=0.23\left(\beta_{\theta, s t}=E_{s t}\right.$ $I_{s t} /\left(0.092 E_{s h} t_{s h}^{3} l_{s t}\right)$ as defined in Azizi/Stranghöner (2020)), the buckling strength is not significantly affected by further increasing the degree of stiffening.

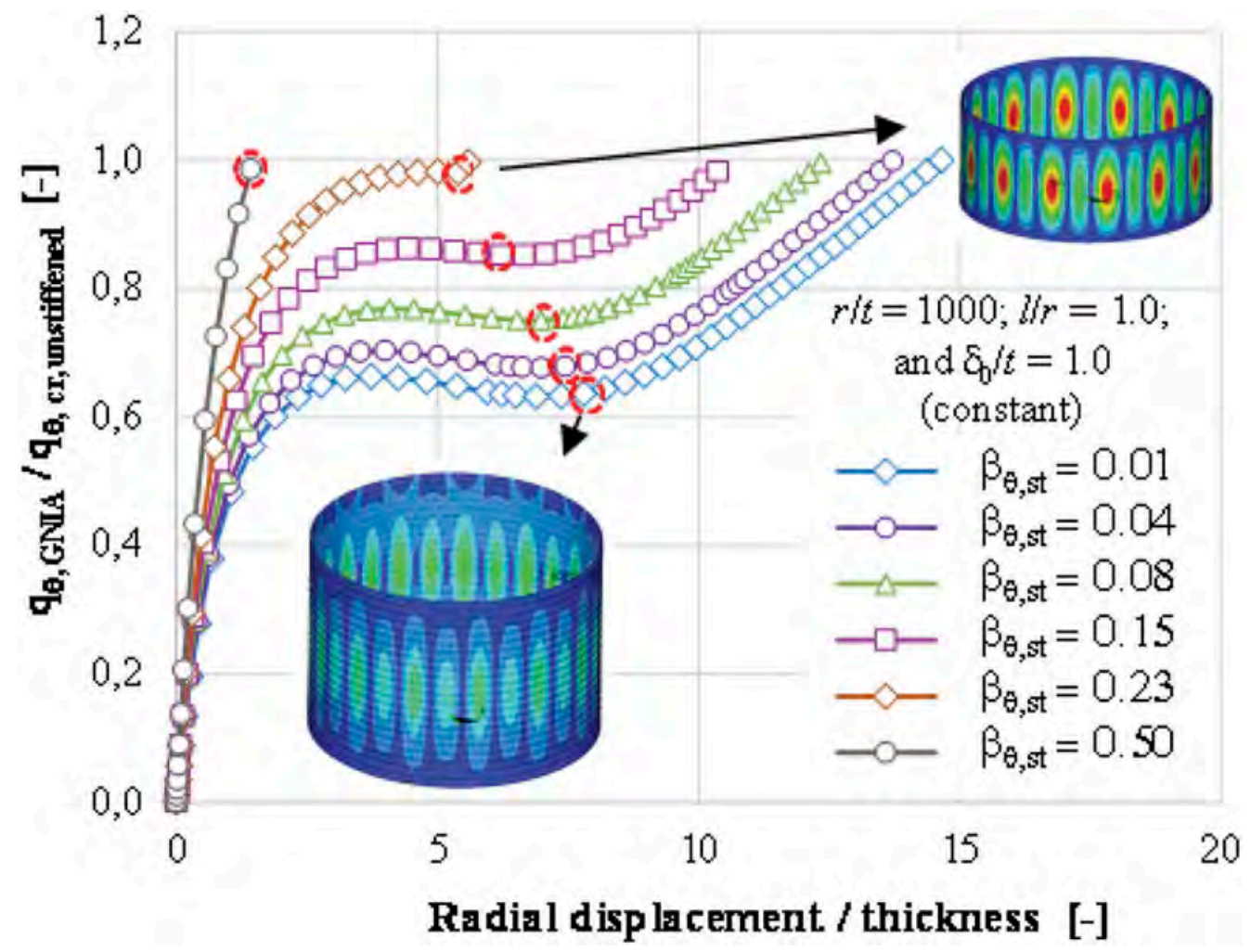

Figure 2. Effect of the degree of stiffening $\beta_{\theta, s t}$ on the load-carrying behaviour of ring-stiffened shells under uniform external pressure. 


\subsection{Impact of imperfections on the buckling capacity of ring-stiffened cylindrical shells}

In some loading conditions (e.g. meridian compression), the buckling behaviour can be significantly affected when a relatively small geometric imperfection is present (Stranghöner/Azizi (2019)). For thin-walled cylinders under uniform external pressure, however, initial imperfections may have less impact on the buckling resistance (Yamaki (1984); Azizi/Stranghöner (2021)). To obtain an overview on the effect of the amplitude of imperfections on the buckling behaviour of ring-stiffened shells under uniform external pressure, in the first step, nonlinear buckling analyses were conducted using eigenmode-affine imperfections obtained from LBAs.

Figure 3 shows the relative load-deformation curves derived from numerical investigations for a relatively short cylinder ( $l / r \approx 1)$ with a constant degree of stiffening $\left(\beta_{\theta \square s t}=\square \square \square \square\right)$ and a fixed $r / t$-ratio $(r / t=1000)$, where various imperfection amplitudes were adopted in the numerical models aiming to investigate the reduction of the buckling resistance due to geometric nonlinearity and imperfections. While the shape of the relative load-deflection cures changes with variation of the imperfection amplitudes, the inflection points of each curve remain quite in the same place. This implies that the buckling capacity of ring-stiffened cylindrical shells is not highly sensitive to geometric imperfections. After assuming large values for the imperfection amplitude (e.g. $\delta_{0} / t=5$ ), a smooth transition from the pre- to the postbuckling path can be observed without any inflection point. Therefore, it makes no sense to increase the amplitude of the imperfections because the deeper imperfection will not lead to an increase of the buckling strength, see Sadowski/Rotter (2011) and Rotter (2011).

In the second step, nonlinear buckling analyses were performed on imperfect ringstiffened cylindrical shells to investigate the relationship between the imperfection sensitivity and the degree of stiffening. For this purpose, the amplitude of imperfections was kept constant, and only the stiffing degree was assumed to be variable. As can be seen in

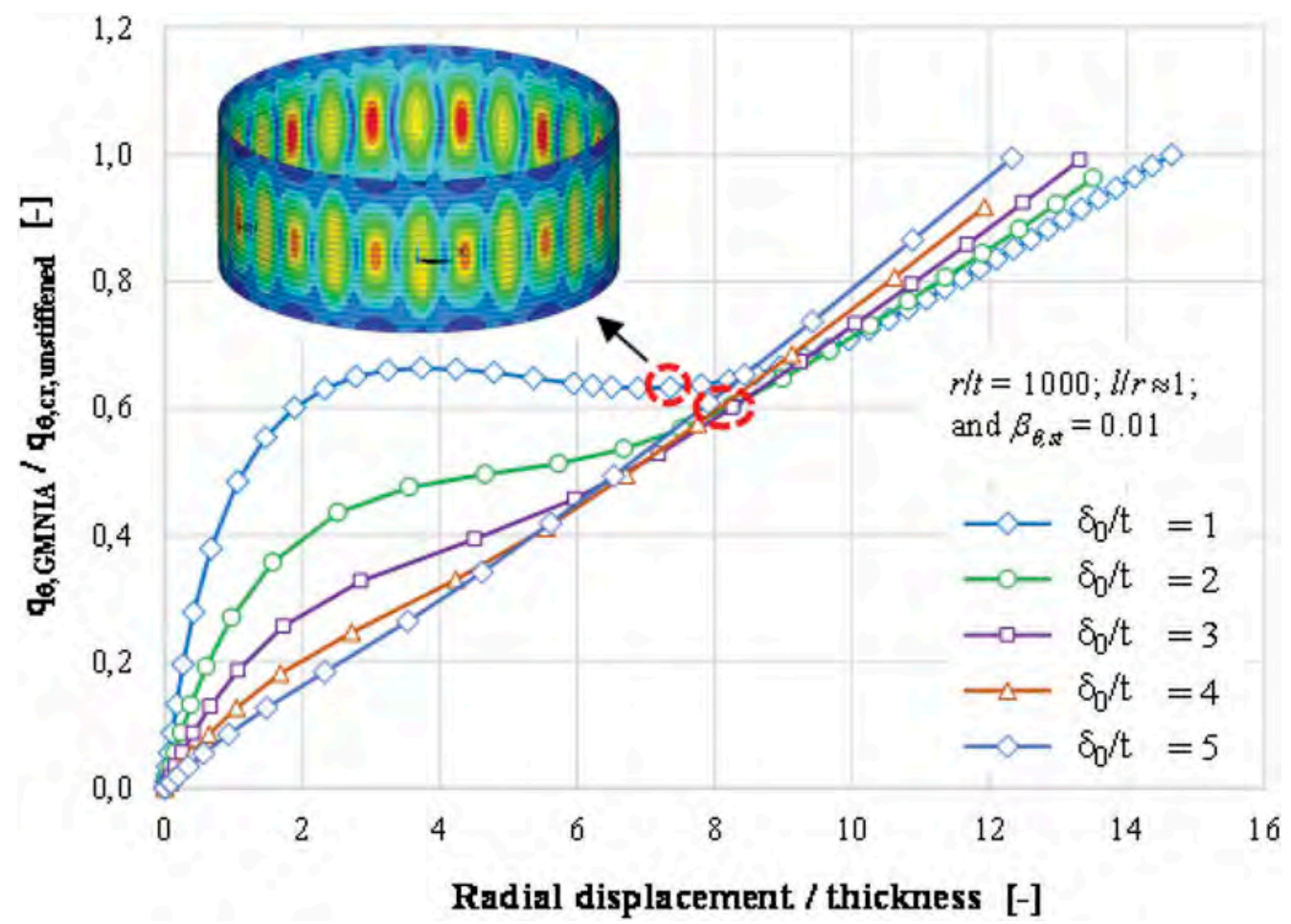

Figure 3. Relationship between the buckling capacity and the amplitude of imperfections for ring-stiffened shells under uniform external pressure. 
a)

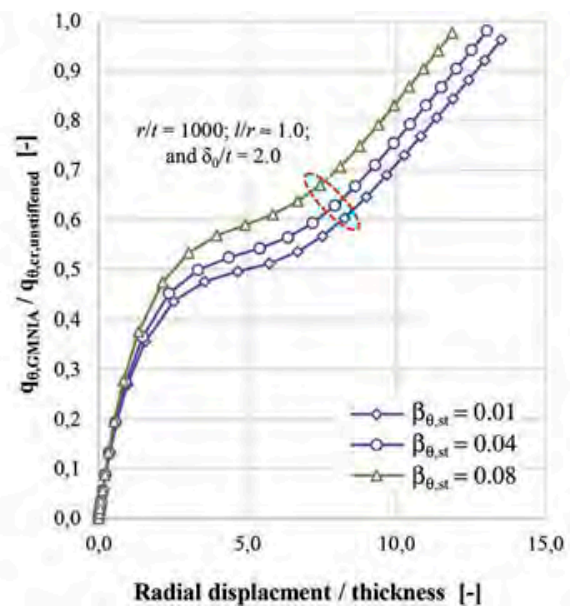

b)

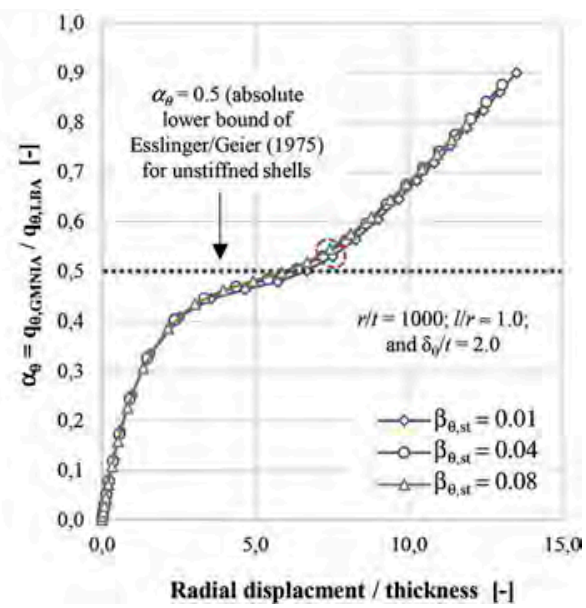

Figure 4. Relationship between the strength loss due to geometric nonlinearity and imperfections of ring-stiffened cylindrical shells subjected to uniform external pressure and degree of stiffening. a) Relative load-displacement curves, b) Elastic imperfection reduction factors.

Figure $4 \mathrm{a}$, higher resistances can be gained by increasing the degree of stiffening. By contrast, as shown in Figure 4b, the loss of buckling strength due to geometric nonlinearity and imperfections is relatively unaffected by the variation of the stiffening degree when all other geometric parameters are kept constant. However, a minor reduction in the imperfection sensitivity of light ring-stiffened shells can be estimated by increasing the degree of stiffening.

This paper deals only with a part of the problem in determining the imperfection sensitivity of light ring-stiffened shells with an overall buckling failure mode that occurs for thin-walled and in closely spaced stiffened shells. Further computational analyses are required regarding all potential failure modes.

\section{CONCLUSIONS}

The buckling behaviour of ring-stiffened cylindrical shells under uniform external pressure has been investigated in the presented study. To investigate the relationship between the buckling strength and the degree of stiffening, nonlinear buckling analyses (G(M)NIAs) were carried out on imperfect shells using an eigenmode-affine imperfection pattern. It has been shown that the buckling capacity increases with increasing the degree of stiffening until a particular level of stiffening is achieved in which the buckling strength is not sensitive anymore to changes of the stiffener geometry and distance. Finally, it has been pointed out that the imperfection sensitivity of ring-stiffened shells is slightly dependent on the degree of stiffening when light ring stiffeners are closely attached to the shell wall, and the failure mode is overall buckling.

\section{REFERENCES}

Azizi, E. \& Stranghöner, N. 2020. Beultragverhalten von ringversteiften Kreiszylinderschalen unter Umfangsbeanspruchung (buckling behaviour of ring-stiffened shells under external pressure). 22. DASt-Forschungskolloquium, Deutscher Ausschuß für Stahlbau: 21-24. Karlsruhe: Germany.

Azizi, E. \& Stranghöner, N. 2021. Imperfection sensitivity of unstiffened cylindrical shells under external pressure. In: Ernst \& Sohn, Proceedings of Eurosteel 2021 (accepted for publication). Sheffield: England. 
BS 5500 1976. Specifications for unfired fusion welded pressure vessels, Section 3.6. London: British Standards Institutions.

DASt-Richtlinie 017 Entwurf 1992. Beulsicherheitsnachweis für Schalen - spezielle Fälle. Deutscher Ausschuß für Stahlbau, Stahlbau-Verlagsgesellschaft.

Düsing, I. \& Schmidt, H. 1996. Beulversuche an Stählernen Kreiszylinderschalen mit angeschweißten Ringsteifen unter Außendruckbelastung. Forschungsbericht 40, FB Bauwesen d. Universität GH Essen.

ECCS EDR4 1988. European Recommendations for Steel Construction: Buckling of Shells. 4th edn. JConv. Constr. Steelwork. Brussels: Belgium.

EN 1993-1-6:2007 + AC:2009 + A1:2017, Eurocode 3: Design of steel structures - Part 1-6: Strength and stability of shell structures.

EN 1993-1-6:2007 + AC:2009, Eurocode 3: Design of steel structures - Part 1-6: Strength and stability of shell structures.

EN 1993-1-6:2020 (draft), Eurocode 3: Design of steel structures - Part 1-6: Strength and stability of shell structures, final draft, August, 2020.

Esslinger, M. \& Geier, B. 1975. Postbuckling behaviour of structures. Wien/New York, Springer.

Greiner, R. 1987. Ring-stiffened cylindrical shells under external pressure, an extended proposal for design of recommendations, Int. Coll. Stability of Plate and Shell Structures: 373-384. Ghent: Belgium (ECCS).

Hutchinson, J.W. \& Amazigo, J.C. 1967. Imperfection - sensitivity of eccentrically stiffened cylindrical shells. AIAA Journal 5(3): 392-401.

Kaminsky, E. 1954. General instability of ring-stiffened cylinders with clamped ends under external pressure by Kendrick's method. David Taylor Models Basin Rept. 855.

Kendrick, S. 1953. The buckling under external pressure of circular cylindrical shells with evenly spaced, equal strength, circular ring frames - Part IIII: NCRE Report R211.

Kendrick, S. 1972. Collapse of stiffened cylinders under external pressure. Proc. Inst, of Mech. Engrs Conf. on Vessels under Buckling Conditions: 33-42, paper C190/72. London, England.

Kendrick, S. 1984. The Technical Basis of the External Pressure Section of BS5500, J. of Pressure Vessel Technology 106(2): 143-149.

Riks, E. 1979. An incremental approach to the solution of snapping and buckling problems. In: International Journal of Solids and Structures 15: 529-551.

Ross, C.T.F. 1965. The collapse of ring-reinforced cylinders under uniform external pressure. Trans. Roy. Inst. Naval Arch., RINA 107: 375-394.

Rotter, J.M. \& Schmidt, H. 2013 (EDS.). Buckling of steel shells, European design recommendations. 5th Edition, Revised $2^{\text {nd }}$ impression. ECCS - European Convention for Constructional Steelwork.

Rotter, J.M. 2011. Shell buckling design and assessment and the LBA-MNA methodology. Stahlbau 80 (11): 791-803.

Sadowski, A.J. \& Fajuyitan, O. K. \& Wang J. 2017. A computational strategy to establish algebraic parameters for the Reference Resistance Design of metal shell structures. Advances in Engineering Software 109: 15-30.

Sadowski, A.J. \& Rotter, J.M. 2011. Buckling of very slender metal silos under eccentric discharge. Engineering Structures 33(4): 1187-1194.

Singer, J. \& Haftka, R. 1967. Buckling of Discretely Ring-Stiffened Cylindrical Shells. TAE Report 67.

Stranghöner, N. \& Azizi, E. \& Gorbachov, A. 2019. Influence of material nonlinearity on the buckling resistance of stainless steel shells. Journal of Constructional Steel Research 157: 386-396.

Stranghöner, N. \& Azizi, E. 2019. Stability of axially compressed cylindrical shells made of stainless steel for different imperfection patterns. The International Colloquium on Stability and Ductility of Steel Structures (SDSS), 11-13 September 2019: 1077-1085. Prague: Czech Republic.

Wunderlich, W. \& Lu, Z. \& Obrecht, H. 1991. Elastic and inelastic buckling of ring-stiffened circular cylindrical shells subjected to external pressure. In: Buckling of Shell Structures, on Land, in the Sea and in the Air. J.F. Jullien (ed.), Elsevier Applied Science: 233-241, London: England.

Yamaki, N. 1984. Elastic stability of circular cylindrical shells. Elsevier Applied Science Publishers. Amsterdam: North Holland. 


\title{
On steel mast dynamic analysis including some environmental uncertainties
}

\author{
R. Bredow \& M. Kamiński \\ Department of Structural Mechanics, Lodz University of Technology, Łódź, Poland
}

\begin{abstract}
The aim of this work is numerical study of stochastic time-invariant reliability of some steel mast subjected to dynamic fluctuations of the wind. This structure undoubtedly belongs to the highest reliability class RC3, so that its precise stochastic analysis should be available. Further motivation is stochastic analysis of skeletal steel structures subjected to large deformations, which may be problematic especially for the masts. This study has been performed using civil engineering oriented Finite Element Method package ROBOT, while stochastic calculus have been programmed in symbolic algebra system MAPLE, where dynamic responses of this structure have been visualized and processed also. Two different resulting dynamic spectra have been contrasted here - the one resulting from Newmark method and the second, resulting from application of the Hilber-Hughes-Taylor approach. Probabilistic analysis has been entirely carried out using higher order iterative generalized stochastic perturbation technique compared with the Monte-Carlo simulation and also with the semi-analytical method.
\end{abstract}

\section{AIM OF WORK}

The aim of this work is to analyse nonlinear structural response of some steel mast under dynamic fluctuations of the wind pressure assuming additional uncertainty in its guys temperatures. Two different methods of the equations of motion integration have been contrasted in this context and three various probabilistic approaches have been compared while determining stochastic response of this mast.

\section{OBJECT OF RESEARCH}

This case study concerns a steel mast having the height equal to $198.0 \mathrm{~m}$. Its shaft has been designed using S235J2 steel in form of three-walled lattice with side width $130.0 \mathrm{~cm}$. The leg members have been designed as round pipes of diameter equal to $168.3 \mathrm{~mm}$ and varying thicknesses; the mast face lacing has been designed using round pipes of diameter $63.5 \mathrm{~mm}$. Its guys have been attached to the shaft at following levels: $60.0 \mathrm{~m}, 120.0 \mathrm{~m}, 180.0 \mathrm{~m}$; they have been designed as spiral strand steel rope 1 x 37 with diameter of $26 \mathrm{~mm}$ having the strength of 1960 $\mathrm{MPa}$. Initial tension of the guys has been set by pre-shortening equal to $11.0 \mathrm{~cm}, 22.0 \mathrm{~cm}$ and $31.0 \mathrm{~cm}$, correspondingly. The environmental uncertainty (Eurocode 12010 ) has been represented by varying mast guys temperature. The temperature load taken into account has been described by a range varying from $-10^{\circ} \mathrm{C}$ up to $+40^{\circ} \mathrm{C}$ for the heated guys and also from $-50^{\circ}$ up to $+0^{\circ} \mathrm{C}$ - for the cooled guys. This temperature has been applied by equally subdivided steps $\left( \pm 5^{\circ} \mathrm{C}\right)$ resulting in 11 computational cases for both ranges. It has been assumed that all 9 guys have been virtually heated and cooled by equally distributed temperature along their

DOI: $10.1201 / 9781003132134-33$ 
length. Principal state variables have been established as normal stress in the main legs and also extreme horizontal displacements and rotations of this mast.

\section{NUMERICAL RESULTS IN THE ARSA SIMULATION}

\subsection{General procedure}

It is well known that Autodesk Robot Structural Analysis system does not calculate efficiently the stress tensor components in the thin-walled beam elements. Normal stresses have been investigated in order to check if it is necessary to calculate the reduced Huber-Mises stress in each time step manually in the main legs and in the face lacing elements. In order to pursue such an investigation, the reduced stresses have been calculated in structural elements exhibiting extreme normal or shear stresses calculated by the system ROBOT during the vibrations period. Computer FEM model has been completed with 894 2-noded linear beam finite elements and 9 cable finite elements; simple supports have been modelled at the ground level and the subsoil has been assumed as perfectly rigid. Numerical results show that the mast elements are dominantly subjected to the axial forces and to some bending moments, so that shear forces and torsional moments are accidental and are of about three orders of magnitude smaller than the normal forces. Normal stress has been calculated as a product of axial force and bending moments acting on a cross section of element. Total shear stress has been calculated as a product of vector aggregation performed on shear stress generated by shear forces and also by a torsional moment. Taking into account the aforementioned procedure, the reduced stress has been calculated for the main leg and for the face lacing truss. The extreme internal forces in the principal leg of the mast (RHS $168.3 \times 12 \mathrm{~mm}$ ) have been determined numerically as $\quad N_{E d}=-1089.19 \mathrm{kN}, \quad T_{E d}=-0.05 \mathrm{kNm}, \quad M_{y . E d}=4.84 \mathrm{kNm}, \quad M_{z . E d}=-3.88 \mathrm{kNm}$, $V_{y . E d}=0.97 \mathrm{kNm}, V_{z . E d}=-6.47 \mathrm{kN}$ and the resulting normal stress has been calculated respectively as:

$$
\sigma_{A}=\frac{-N_{E d}}{A}+\frac{M_{E d}}{J_{1}} \cdot \rho=-213.695 \mathrm{MPa}
$$

The shear stress has been calculated in a point corresponding to the largest normal stress and considering relatively small shear stress contribution, this selected point describes the greatest reduced stress as well.

$$
\sigma_{\text {red }}^{H A}=\sqrt{\left(\sigma^{A}\right)^{2}+3\left(\tau^{A}\right)^{2}}=213.702 M P a
$$

A comparison of a normal stress to effective stress shows that the influence of shear stress might be neglected. As a result, calculating effective stress every time step of calculations can be neglected and normal stress can be taken as a representative instead.

$$
\frac{\left|\sigma^{A}\right|}{\sigma_{\text {red }}{ }^{H A}}=\frac{213.695 \mathrm{MPa}}{213.702 \mathrm{MPa}}=0.99997=99.997 \%
$$

From a perspective of the conducted research it may be underlined that stress analysis of this mast would be analysed on the basis of normal stress and it will be free from any major computational error in further probabilistic analysis.

\subsection{Newmark and Hilber-Hughes-Taylor algorithms implemented into ARSA}

The governing equation of motion implemented in the Finite Element Method system ROBOT has been described as 


$$
\mathbf{M} \cdot a_{(t)}+\mathbf{C} \cdot v_{(t)}+\mathbf{K} \cdot d_{(t)}=F_{(t)},
$$

in which damping matrix is calculated as

$$
\mathbf{C}=\alpha \cdot \mathbf{M}+\beta \cdot \mathbf{K}
$$

where $\mathbf{M}$ denotes the mass matrix, $\mathbf{C}$ - damping matrix, $\mathbf{K}$ - stiffness matrix, $\mathbf{a}$ is acceleration vector, $\mathbf{v}$ - velocity vector, $\mathbf{d}$ - displacement vector; $\mathbf{F}$ is the vector of external forces, while $\alpha, \beta$ are the coefficients of Rayleigh damping. The Newmark method is uniquely determined by two parameters, namely $\beta$ and $\gamma$, and two most frequent combinations recommended in the literature are $\beta=\frac{1}{4}, \gamma=\frac{1}{2}$ and $\beta=\frac{1}{6}, \gamma=\frac{1}{2}$ (Newmark 1959). These specific combinations of input parameters correspond to the Average Acceleration Method and Linear Acceleration Method accordingly; the ARSA implementation of the Newmark method is the Average Acceleration Method. Let us recall that the Newmark algorithm of solving the governing equation of motion may be represented in the following way, where lower index represents the given time moment:

$$
\left\{\begin{array}{c}
x_{i+1}=x_{i}+\Delta t \cdot \dot{x}_{i}+\left[\left(\frac{1}{2}-\beta\right) \cdot \ddot{x}_{i}+\beta \cdot \ddot{x}_{i+1}\right] \cdot(\Delta t)^{2} \\
\dot{x}_{i+1}=\dot{x}_{i}+\left[(1-\gamma) \cdot \ddot{x}_{i}+\gamma \cdot \ddot{x}_{i+1}\right] \cdot \Delta t
\end{array}\right.
$$

Newmark solver implemented into the system ARSA can be modified by a substitution of the coefficients adequate to the Average Acceleration Method; there holds:

$$
\left\{\begin{array}{c}
x_{i+1}=x_{i}+\Delta t \cdot \dot{x}_{i}+\left[\frac{1}{4} \cdot \ddot{x}_{i}+\frac{1}{4} \cdot \ddot{x}_{i+1}\right] \cdot(\Delta t)^{2} \\
\dot{x}_{i+1}=\dot{x}_{i}+\left[\frac{1}{2} \cdot \ddot{x}_{i}+\frac{1}{2} \cdot \ddot{x}_{i+1}\right] \cdot \Delta t
\end{array}\right.
$$

The second technique of solving equation of motion available in ARSA for non-linear systems is Hilber-Hughes-Taylor algorithm called also $\alpha$-method, where the parameter $\alpha$ describes higher-order vibrations damping without any accuracy loss. This parameter $\alpha$ can be taken from the interval $[-0.3 ; 0.0]$ and the values closer to 0 represent smaller mechanical damping (Hilber, Hughes \& Taylor 1977). The remaining parameters $\beta$ and $\gamma$ can be described in terms of $\alpha$ in the following way:

$$
\beta=\frac{(1-\alpha)^{2}}{4}, \gamma=\frac{1-2 \alpha}{2}
$$

A substitution of the value $\alpha=0$ leads to the values of $\beta$ and $\gamma$ exactly the same as in the Average Acceleration Method in the Newmark scheme. The HHT method is based upon the following approximation of displacements and velocities:

$$
\left\{\begin{array}{c}
x_{i+1}=x_{i}+\Delta t \cdot \dot{x}_{i}+\left(\frac{1}{2}-\beta\right) \cdot(\Delta t)^{2} \cdot \ddot{x}_{i} \\
\dot{x}_{i+1}=\dot{x}_{i}+(1-\gamma) \cdot \Delta t \cdot \ddot{x}_{i}
\end{array}\right.
$$

As it is seen from a comparison of the additional equations, the Newmark scheme uses for these predictions $\ddot{x}_{i+1}$, which is not the case of the HHT algorithm. Another factor that affects the results obtained by these two methods in ARSA is that the Newmark algorithm in nonlinear cases uses the following proportionality for the damping matrix: $\mathbf{C}=a \cdot \mathbf{M}$, which is definitely not the case of the HHT method. Four different values of the input parameter $\alpha$ have been inserted in the HHT solver: $-0.30,-0.20,-0.10$ and 0.00 . Numerical results of these computations have been compared with each other and additionally with the Newmark solver results, where $\alpha$ always equals zero. The fact that damping matrix in the Newmark method is simplified may also cause some differences in comparison to the HHT scheme even with its input $\alpha=0$. 


\section{PROBABILISTIC ANALYSIS OF STATE VARIABLES}

The discrete values of the mast stresses and displacements have been saved for each second of the vibrations, and each step has been additionally subdivided into 10 time steps, so that $\Delta t=0.10 \mathrm{~s}$. This calculation procedure has been repeated for 11 series of temperature loads in the range from $-50{ }^{\circ} \mathrm{C}$ up to $+40{ }^{\circ} \mathrm{C}$ applied to all the guys. 600 discrete values of extreme stresses and displacements for 11 series of tests was the input for further Structural Response Function polynomial recovery. These polynomials have been fitted by the Least Squares Method and their accuracy has been adjusted by the mean square root error minimization criterion as well as maximization of the correlation factor. The SRFs have been created for each extreme state variable independently (leg stress, facing stress, horizontal displacement and rotation) at any time step for both solvers (HHT and Newmark) giving as a result 2.400 analytical SRFs, similarly to the research presented in (Bredow \& Kamiński 2020). These SRFs are the functions of the guys temperature and the polynomial order was the same for all series of the SRFs for the same state variable, i.e. horizontal displacements. This means that all 600 SRFs associated with horizontal displacement in subsequent save steps of the mast vibrations are described by polynomials of the same order. All these approximations have been provided using the computer algebra system MAPLE 2019. The differences in-between the results for the Newmark and for the Hilber-Hughes-Taylor solvers have been investigated first. Figure 1 presents time fluctuations of the extreme mast horizontal displacements and it contains two different values of the parameter $\alpha$ in the HHT method. General observation here is that neglecting of this parameter $(\alpha=0.00)$ results in larger deformations of the mast.

Two different numerical methods have been compared in Figure 2. It is seen that the Newmark method results form a similar pattern to the displacement history resulting from the HHT solver, when its parameter $\alpha$ vanishes. Generally, the results computed using these two methods return slightly different time fluctuations in the structural response. Deterministic dynamic responses of the mast have been recalculated for several realizations of the input random variable. In each time step these functions have been recovered as the polynomial of the given random variable and unknown coefficients using the Least Squares Method (Kamiński 2013). It has been assumed that supporting guys temperature is the input random variable having Gaussian distribution of constant expected value $\left(+30^{\circ} \mathrm{C}\right)$ and standard deviation equal to $10 \%$ of this expectation. Final estimation of the probabilistic characteristics of the mast response has been achieved with the aid of the iterative generalized stochastic perturbation technique abbreviated as SPT (Kamiński 2015) and also with the Monte Carlo simulations (MCS) and the semi-analytical method (SAM). Time fluctuations of the expected values (Figure 3), coefficients of variation (Figure 4), skewness (Figure 5) and kurtosis (Figure 6)have been numerically determined in each second of the mast vibrations. The expected values have been presented in $[\mathrm{MPa}]$, whereas all remaining parameters are nondimensional.

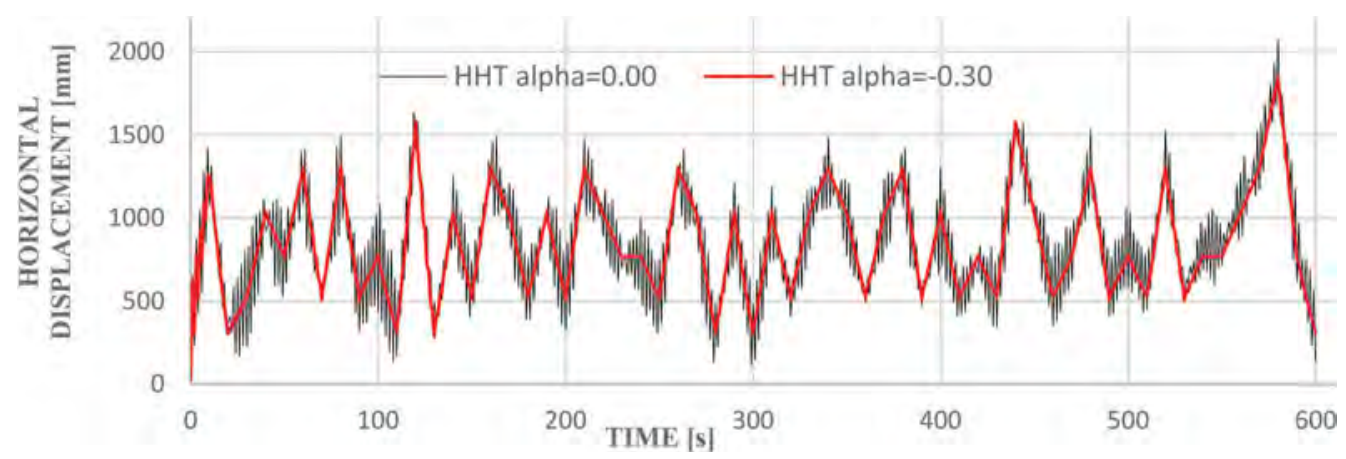

Figure 1. Extreme horizontal displacement spectrum of mast in the HHT method. 


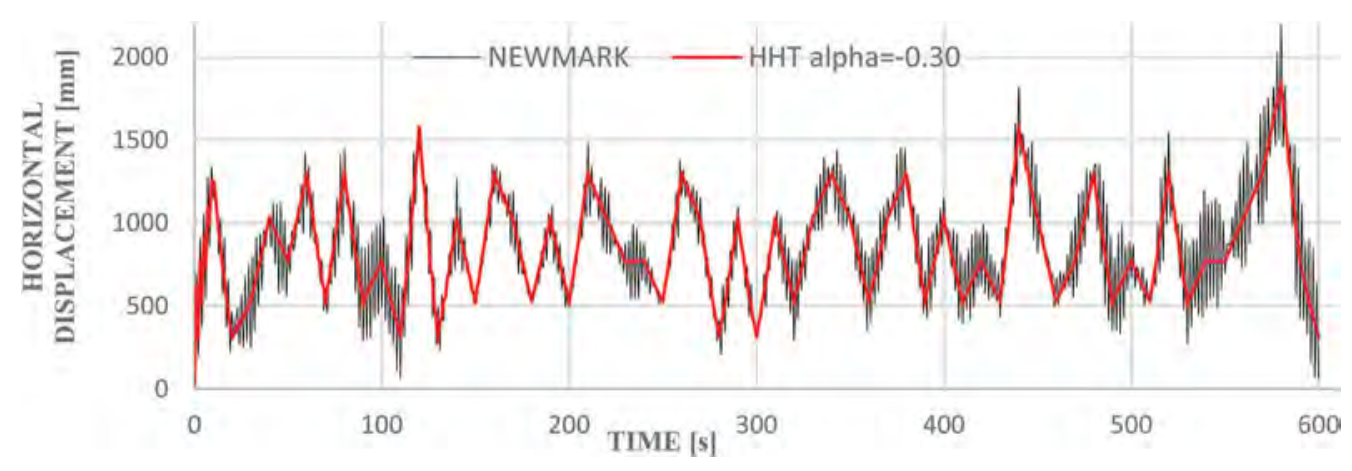

Figure 2. Extreme horizontal displacement spectrum of the steel mast in HHT and Newmark methods.
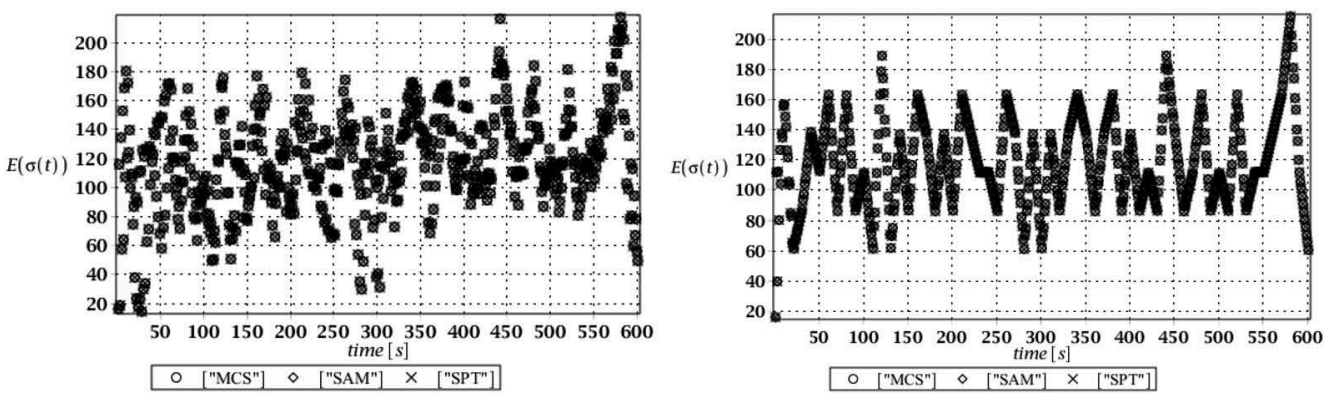

Figure 3. Expected value of normal stress in the main leg for Newmark \& HHT methods.
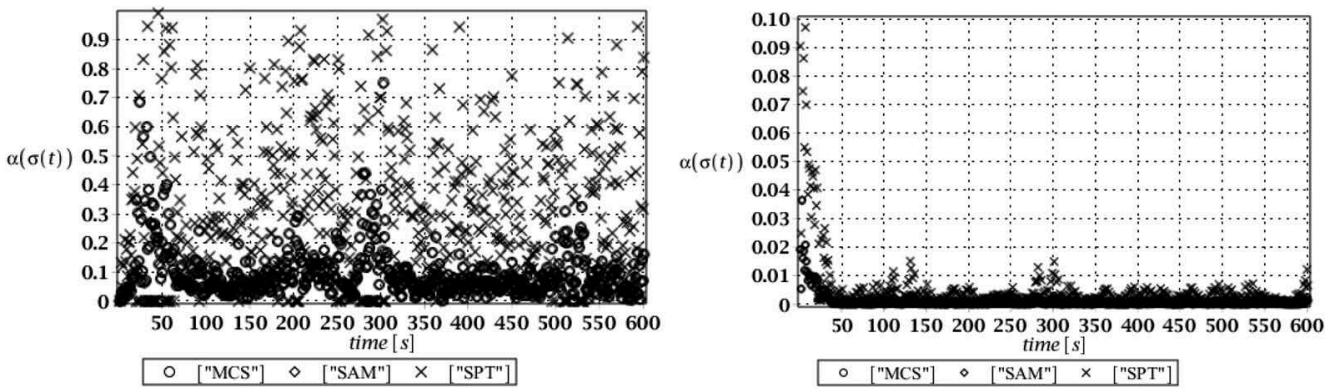

Figure 4. Coefficient of variation of normal stress in the main leg for Newmark \& HHT methods.
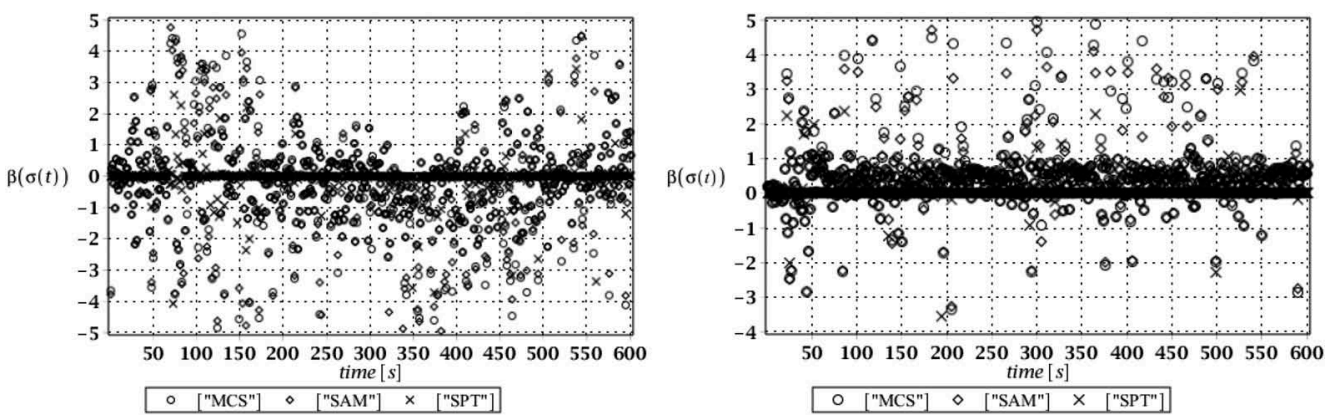

Figure 5. Skewness of normal stress in the main leg for Newmark \& HHT methods. 

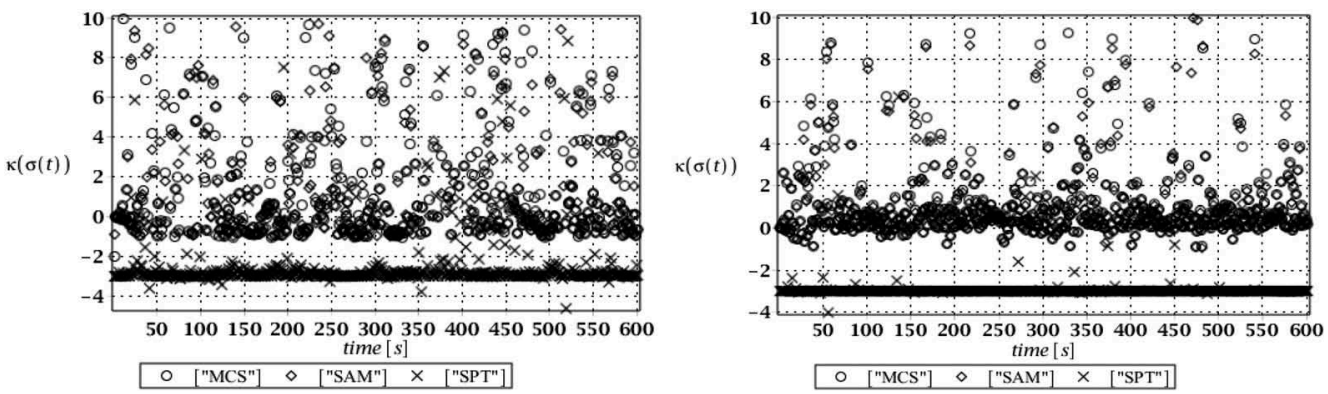

Figure 6. Kurtosis of normal stress in the main leg for Newmark \& HHT methods.

It is remarkable that the vertical ranges of all probabilistic moments and coefficients of extreme normal stresses for both numerical methods are almost the same. The only exception is in the coefficients of variation, where the Newmark method returns numerical values with ten times larger than the concurrent technique and it concerns the discrete values obtained with the SPT. Further, one can notice that all probabilistic characteristics computed on the basis of the Newmark structural responses exhibit larger scattering that these computed with the HHT approach. However, a coincidence of all three probabilistic computer methods is satisfactory in both cases, which essentially confirms applicability of the stochastic perturbation technique, and particularly SFEM analysis based on the HHT method, for analysis of stochastic vibrations of steel guyed structures. Higher order statistics definitely differ from 0 , so that the resulting stresses cannot have Gaussian distribution for sure. The incidentally larger $\mathrm{CoV}$ for the Newmark solution disables this approach in further reliability assessment (Eurocode 0 2005), so that the HHT approach is recommended for this analysis in conjunction with the perturbation-based SFEM analysis of the mast.

\section{FINAL REMARKS}

It has been demonstrated that probabilistic characteristics of time fluctuations of extreme normal stresses in the mast obtained using the Newmark method are more scattered in reference to the results computed with the Hilber-Hughes-Taylor approach. Proposed iterative generalized stochastic perturbation technique and its Stochastic Finite Element Method implementation present satisfactory coincidence with the Monte-Carlo simulation and semi-analytical probabilistic method. Therefore, this methodology can be further recommended in reliability index estimation for the steel masts and other cable structures under dynamic wind excitations.

\section{REFERENCES}

Bredow, R. \& Kamiński, M., Computer analysis of dynamic reliability of some concrete beam structure exhibiting random damping, International Journal of Applied Mechanics and Engineering (in press)

Eurocode 0: Basis of structural design. EN 1990:2002/A1 - European Committee for Standardization, Brussels, 2005.

Eurocode 1: Actions on structures - Part 1-4: General actions - Wind actions - European Committee for Standardization, Brussels, 2010.

Hilber, H.M, Hughes, T.J.R \& Taylor, R.L. (1977) Improved Numerical Dissipation for Time Integration Algorithms in Structural Dynamics, Earthquake Engineering \& Structural Dynamics, 5, 282-292.

Kamiński, M. (2013): The Stochastic Perturbation Method for Computational Mechanics - Chichester, Wiley.

Kamiński, M. (2015): On the dual iterative stochastic perturbation-based finite element method in solid mechanics with Gaussian uncertainties - International Journal for Numerical Methods in Engineering, 104(11),1038-1060.

Newmark, N.M. (1959): A method of computation for structural dynamics. Journal of the Engineering Mechanics Division, 85 (EM3): 67-94. 


\title{
Shape-finding and behavior of the prestressed hybrid cable-stayed string steel bridge
}

\author{
P. Dabrila \& A. Juozapaitis \\ Department of Steel and Composite Structures, Vilnius Gediminas Technical University, \\ Vilnius, Lithuania
}

\begin{abstract}
One of the main issues in the design of cable-stayed steel bridges is the way of stabilization of its initial form under symmetrical and asymmetrical loads. The main mass of the load-bearing structures is concentrated in the stiffening girder. The article presents a hybrid pre-stressed cable-stayed steel bridge structural system. The behavior of this new system of the intersecting stay cables and the flexible string under the effect of the permanent and the temporary loads are the issues under analysis. The efficiency of this proposed cablestayed steel bridge structure system was determined based of the performed numeric experiment.
\end{abstract}

\section{INTRODUCTION}

Due to efficiency and excellent architectural appearance cable-stayed bridges have a special place among other structural bridge systems (Gimsing and Georgakis, 2012; Walther, 1999). The bridges of this type of structure are covered with record-setting spans (Svensson, H., 2012; Reis and Oliveira Pedro, 2019). Moreover, cable-stayed systems are successfully used on smaller span steel pedestrian bridges (Schlaich, et al. 2005; Strasky, 2005). Nevertheless, these bridges also have several disadvantages: i.e. their deformability under asymmetrical or local loads and the relatively big mass of stiffening girder and the pylons (Evans, 2009; Malinowski et al., 2018). A successful way of stabilizing the initial form of the bridge could be the use of intersecting stay cables and additional pylons. They can assist in reducing the pylon height and at the same time they can successfully control the bridge displacements. Such cable-stayed pedestrian bridges were built in the United Kingdom: Royal Victoria Dock Bridge (Wells, 2002), in Dunkirk - Passerelle du Grand Large bridge (Robin, et. al. 2014) and the Forthside Footbridge (Brownlie et al., 2008). It is noteworthy that the cross-sections of the stiffening girders of these bridges are still relatively massive, as they take up not only the bending moments from the applied loads, but also the high compressive forces from the stressed intersecting stay cables.

The well-known stress ribbon bridges are extremely lightweight and graceful (Schlaich and Bleicher, 2007; Strasky, 2005). These types of load-bearing steel structures are characterized with some of the lowest cross-sectional heights and at the same time have the lowest mass. However, such bridges are also distinguished by not only high deformability (Juozapaitis and Norkus, 2007), but also by the necessary initial sag of a certain size (Schlaich, et al. 2005; Strasky, 2005). Different additional design measures have also been developed to reduce the kinematic-type displacements of such bridges (Juozapaitis et al. 2006; Bleicher et al. 2011; Sandovic et al. 2017). However, some of them are quite complicated. In addition, the curved initial shape of these bridges causes some operation problems (Goldack et al. 2016). 
To keep the straight structure (span) shape suitable for the bridge the suspended string structures are designed. A pre-stressed string functions as the main supporting element (Unitsky, 2019). This supporting element has no kinematic displacements, i.e. it is not sensitive to the effects of asymmetrical loads. Despite the high stresses in the string, their cross-sections are relatively small, especially with the use of the high strength materials (Beivydas, 2019; Unitsky, 2019). One of the disadvantages of these structures could be noted as well. They can cover only small-size spans.

This article deals with the hybrid cable-stayed string steel bridge system consisting of intersecting stay cables and additional intermediate pylons and a pre-stressed string that replaces a relatively massive common-type stiffness girder. A numeric experiment is used to analyze the behavior of this proposed structural system under symmetrical and asymmetrical loads. This article contains the evaluation of the efficiency of such cable-stayed steel bridge loadbearing structural system according to the mass criteria.

\section{THE BEHAVIOR ANALYSIS OF THE PRE-STRESSED HYBRID CABLE-STAYED STRING BRIDGE SYSTEM}

With the aim to improve the classical cable-stayed bridge with non-movable bearings, its massive stiffening girder is replaced with a tension element - a pre-tensioned flexible string. This method represents a new structural solution for this type of cable-stayed bridge. A prestressed string is selected in order to reduce not only the effect of kinematic displacements, but also to reduce the consumption of steel. The behavior integrates the different load-bearing elements of this system (the string, the stay cables and the pylons). It is necessary to acknowledge that the use of this proposed bridge structural system will significantly increase the horizontal bridge support reactions, which will likewise increase the mass of the anchored foundations for the stress ribbon bridges.

Regarding the static? behavior of this proposed structural system - it must be highlighted that this complicated pre-stressed system is clearly geometrically nonlinear behavior. The displacements of the direct load-bearing element (the string) have a significant impact not only on its own strains, but also on the stress strain behavior of the other elements. Consequently, the pre-stressing of the stay cables significantly changes the strains and displacements of the string.

Therefore, to research the behavior of the new hybrid structural system and to compare it with the classical bridge systems, a numerical modelling related to the system was performed under analogous initial conditions: the main span length was $100 \mathrm{~m}$ and $20 \mathrm{~m}$ for the side spans (see Figure 1). Selected loads are applied in the model: the temporary (traffic) load $12.5 \mathrm{kN} / \mathrm{m}$, the permanent load $-12.5 \mathrm{kN} / \mathrm{m}$. (see Figure 3). Possible solution for bridge deck cross-section is provided in Figure 2.

The main structures of this bridge (string and stay cables) are cable elements, while the pylons are beam elements. The cross sections of this hybrid cable-stayed string system are given in Table 1. The selected string cross-section is the same as the cross-section of the

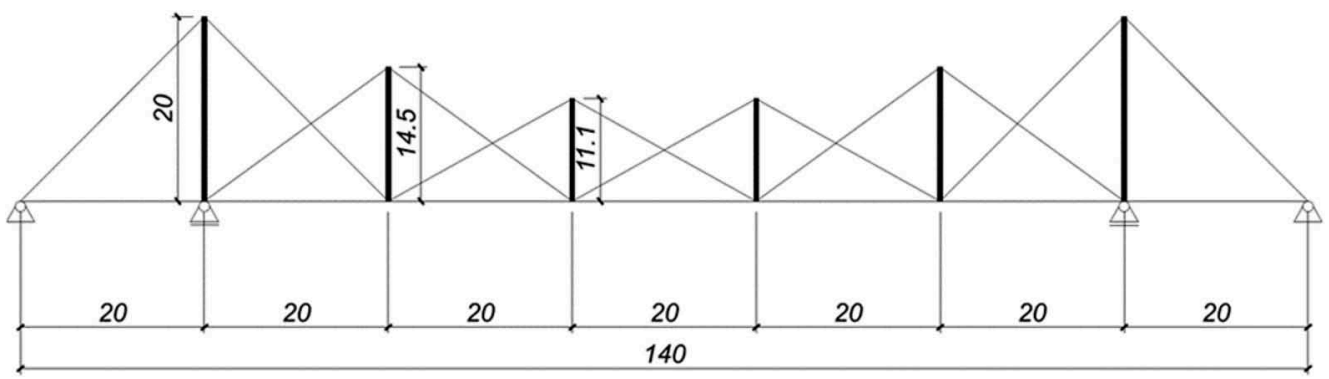

Figure 1. The hybrid cable-stayed string bridge scheme. 


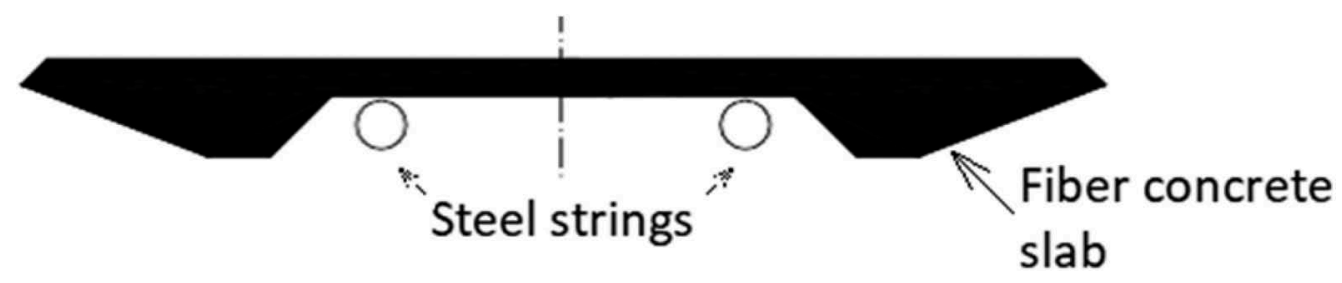

Figure 2. Fiber concrete slab supported by steel strings.

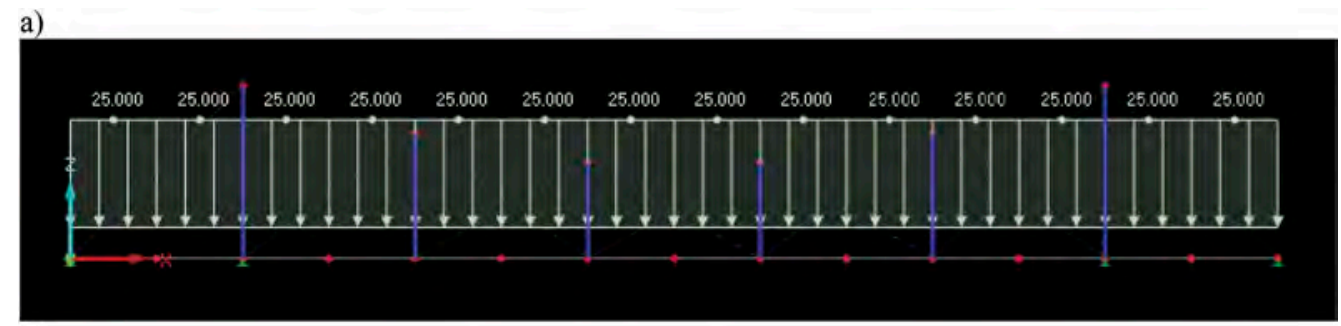

b)

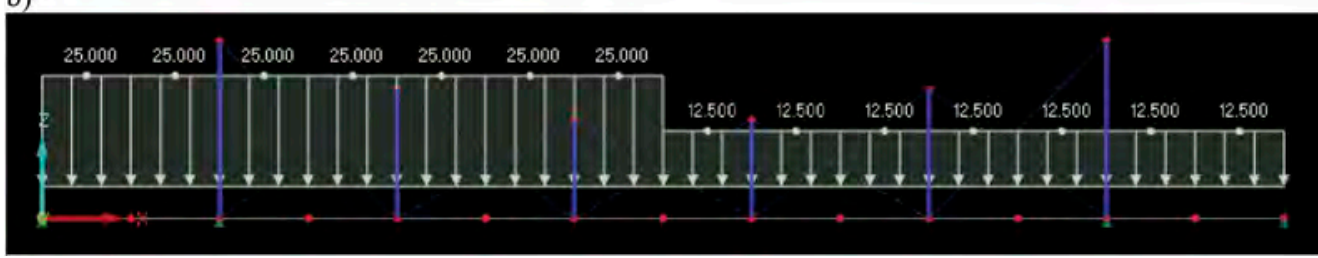

Figure 3. Hybrid cable-stayed string bridge's loading cases: a) symmetrical loading case, b) asymmetrical loding case.

Table 1. Cross sections of cable-stayed bridge structural elements.

\begin{tabular}{llll}
\hline Element & $\begin{array}{l}\text { Steel } \\
\text { class }\end{array}$ & $\begin{array}{l}\text { Cross-section } \\
\text { form }\end{array}$ & $\begin{array}{l}\text { Cross-section parameters } \\
\text { (dimensions) }\end{array}$ \\
\hline $\begin{array}{l}\text { The string and the stay cables of the side pylons } \\
\text { Side pylons }\end{array}$ & $\begin{array}{l}\text { S960 } \\
\text { Intermediate pylon }\end{array}$ & $\bullet$ & $\mathrm{d}=0.07 \mathrm{~m}$ \\
Middle pylon & $\mathrm{S} 355$ & $\mathrm{O}$ & $\mathrm{RO} 57 \times 30$ \\
Intermediate intersecting stay cables & $\mathrm{S} 355$ & $\mathrm{O}$ & $\mathrm{RO} 406 \times 12.5$ \\
$\mathrm{RO} 244.5 \times 20$ \\
$\mathrm{~d}=0.06 \mathrm{~m}$
\end{tabular}

backstay cables $(\mathrm{d}=0.07 \mathrm{~m})$. Both the string and the stay cables are designed from highstrength steel (S960) due to the resulting high stress values. The results of numerical modelling are in Figures 4 and 5 and Table 2.

This structural system is marked with an interaction between the cross-arranged cable stays and the string. In this case the horizontal components of the intersecting cable stays form strains opposite in sign compared with the tensile strain acting in the string. This force seems to apply pressure to the string and thus reduce the tensions in it. However, to reduce the bridge displacement values it is necessary to increase the pre-stress value of the string. Changing the string pre-stress values helps adjust not only the string stress-strain state, but also the stress-strain state of the entire bridge. 

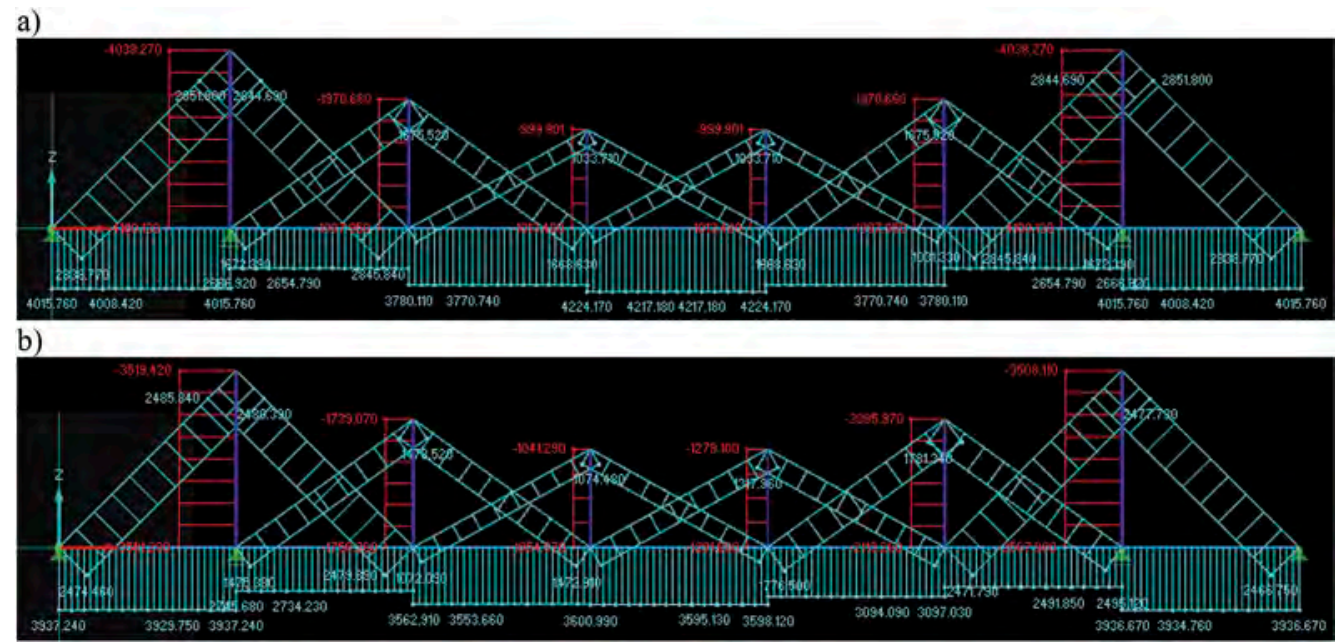

Figure 4. Axial forces of a hybrid cable-stayed string bridge [kN]: a) under symmetrical load, b) under asymmetrical load. Positive values - tension, negative - compression.

a)

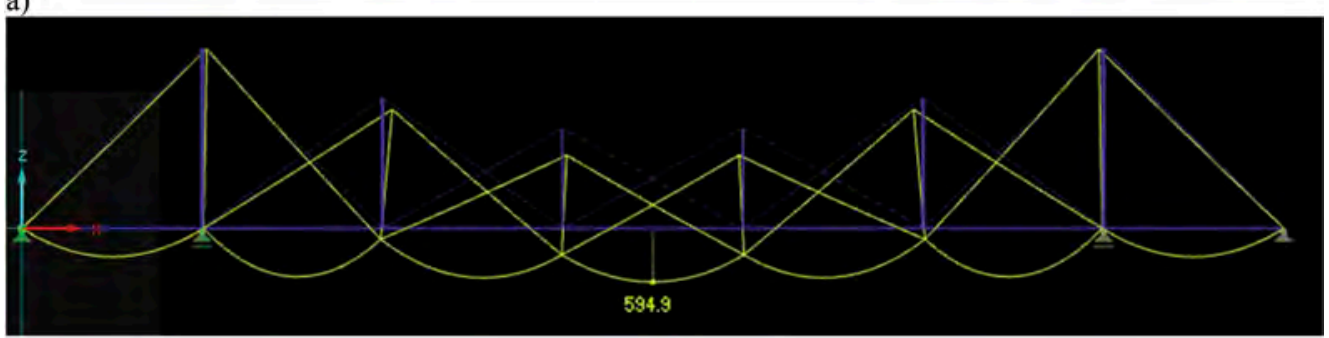

b)

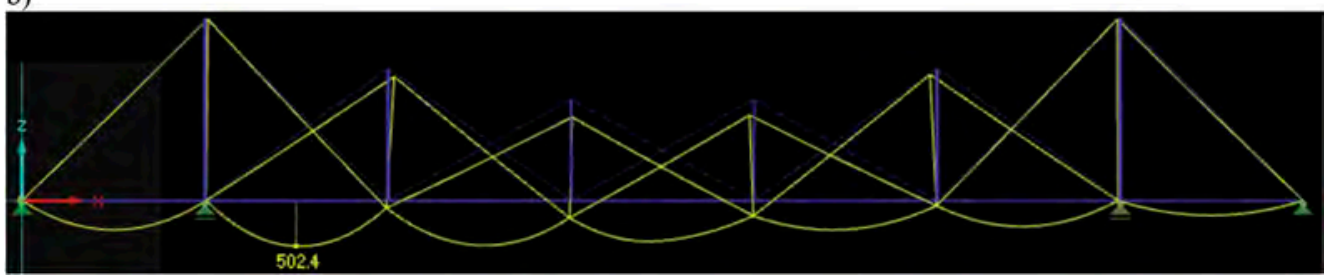

Figure 5. Displacements of a hybrid cable-stayed string bridge: a) under symmetrical load, b) under asymmetrical load.

Table 2. The hybrid cable-stayed string bridge strains and displacements.

\begin{tabular}{llllll}
\hline & $\begin{array}{l}\text { Axial force in } \\
\text { the string }\end{array}$ & $\begin{array}{l}\text { Stresses in the } \\
\text { string }\end{array}$ & $\begin{array}{l}\text { Axial force in } \\
\text { the pylon }\end{array}$ & $\begin{array}{l}\text { Stresses in the } \\
\text { pylon }\end{array}$ & Displacements \\
\cline { 2 - 6 } & {$[\mathrm{kN}]$} & {$[\mathrm{MPa}]$} & {$[\mathrm{kN}]$} & {$[\mathrm{MPa}]$} & {$[\mathrm{mm}]$} \\
\hline Symmetrical load & 3435.0 & 897.1 & 4038.0 & 129.3 & 743.0 \\
Asymmetrical load & 3076.0 & 803.4 & 3591.2 & 140.5 & 701.0 \\
\hline
\end{tabular}


It is crucial to note that the axial forces in the string under the asymmetrical load reach the maximum value not in the middle of the span, but also in the side nodes (see Figure 2). The difference between the values of these forces makes about 15 percent. The lowest tensile strain of the string is characteristic of the first node from the supporting pylon due to the effect of "unloading" (compressing) of the cable stays. For this very reason under the effect of the asymmetrical load large displacements of string occur in this node (see Figure 3).

The identified advantage of this structure system is that under symmetrical and asymmetrical loads the string strains are distributed almost evenly over the entire length of the bridge. The bridge displacements are larger in the case of symmetrical loads, but they can also appear not in the middle of the span. It is essential to note that the values of displacements caused by symmetrical and asymmetrical loads are only slightly different (approximately 5 percent). The analysis results are presented in Table 2.

In summary, it could be pointed out that to stabilize the initial form of the new structure, it is necessary to make a proper selection of the string and cable pre-stress values. Meanwhile, the latter depend not only on the intensity of the acting loads, but also on the ratio of temporary (traffic) to permanent loads. The maximum stresses in a balanced bridge structure system in both the string and the cable stays are quite high (approximately 700-800 MPa). The pylons of this hybrid bridge are distinguished by a significantly smaller change in stresses under different loads. The largest axial (compressive) forces can be noticed in the side pylons. The strains of the intermediate pylons decrease uniformly towards the middle of the span. Interestingly enough, in the case of asymmetrical loads, the strains of the intermediate pylons of the part non-loaded with the temporary load are higher than those of the pylons in the loaded part (see Figure 2).

The analysis of the behavior of the cable-stayed system with a stiffening girder and the cable-stayed string bridge system led to the preliminary comparative technical-economic efficiency evaluation of these versions. Three cable-stayed bridge systems were compared: (a) a classical system with two pylons and radially distributed cable stays; (b) the cable-stay system with intersecting cable stays and the stiffening girder; (c) the cable-stayed string system with intersecting cable stays. Two lengths of the analyzed bridges were selected: $140 \mathrm{~m}$ (main span of $100 \mathrm{~m}$ ) and $84 \mathrm{~m}$ (main span of $60 \mathrm{~m}$ ).

According to preliminary results, in case of the $140 \mathrm{~m}$ length structure cable-stayed bridge system (c) steel consumption is lower than in the case of the classical bridge (a), and it is lower than that of the intersecting cable-stayed bridge system (b). The analysis of the $84 \mathrm{~m}$ length bridge versions led to the following result: the steel mass of the (c) bridge version is smaller than that of the (a) type bridge and smaller than the mass of the (b) type bridge system. It is to be noted, that in this stage of research of the cost foundation is not taken into consideration

The dynamic behavior of a cable-string bridge is significantly different from the usual behavior of cable-stayed bridges. Preliminary dynamic calculations of such bridge's natural oscillation frequency showed a much lower frequency than a standard cable-stayed bridge. Future research is planned for a detailed dynamic analysis of this proposed bridge structure.

\section{CONCLUSIONS}

The developed of suggested cable-stayed steel bridge structure system, which mainly consists of tensioned flexible elements, helps reduce the steel consumption.

It is important to note that the structural solution of a cable-stayed steel bridge with intersecting cable stays and the conventional stiffening girder is also quite effective.

This hybrid cable-stayed bridge is deformable; however, under proper pre-stress conditions of its components (strings and intersecting cable stays) it is actually possible to effectively stabilize the initial form of this structural system under both symmetrical and asymmetrical loads.

It is recommended to use high-strength steel HSS (S690, S960) in case of relatively high/ large-scale levels of the load-bearing string and cable stay stresses. This allows to have a substantial reduction in the mass of these elements. 
The proposed hybrid cable-stayed steel bridge structure system can be used not only for pedestrian and bicycle bridges, but it can also be implemented as a part of a road system for lightweight new generation urban transport.

\section{REFERENCES}

Beivydas, E. (2019). A simplified calculation method for symmetrical loading of a single-span composite string steel structure. Engineering Structures and Technologies, 11(2), 70-73. 10.3846/est.2019.11323

Bleicher, A., Schlaich, M., Fujino, Y., \& Schauer, T. (2011). Model-based design and experimental validation of active vibration control for a stress ribbon bridge using pneumatic muscle actuators. Engineering Structures, 33(8), 2237-2247. https://doi.org/10.1016/j.engstruct.2011.02.035

Brownlie, K., Curran, P., \& Thompson, S. (2008, 2-4 July). Forthside Bridge, Stirling, Scotland (pp. 161) [Conference presentation]. Footbridge 2008 - Footbridges for Urban Renewal, Third International Conference on Footbridges. Porto, Portugal.

Cid, C., Baldomir, A., \& Hernández, S. (2018). Optimum crossing cable system in multi-span cable-stayed bridges. Engineering Structures, 160(2018), 342-355. 10.1016/j.engstruct.2018.01.019

Dokumentation 577. (2004). "Fußgängerbrücken aus Stahl"1. Auflage 2004 (40 p.). Stahl-InformationsZentrum. Düsseldorf.

Evans, G. J. (2009). A critical analysis of Wilkinson Eyre's sail bridge Swansea. In Proceedings of Bridge Engineering 2 Conference (p. 11). Bath, UK.

Ferreira, F., \& Simoes, L. (2019). Optimum design of a cable-stayed steel footbridge with three dimensional modelling and control devices. Engineering Structures, 180(2019), 510-523. https://doi.org/ 10.1016/j.engstruct.2018.11.038

Gimsing, N. J., \& Georgakis, C. T. (2012). Cable support bridges, concept and design (592 p.). John Wiley \& Sons Ltd. 10.1002/9781119978237

Goldack, A., Schlaich, M., \& Meiselbach, M. (2016). Stress ribbon bridges: mechanics of the stress ribbon on the saddle. ASCE Journal of Bridge Engineering, 21(5). https://doi.org/10.1061/(ASCE) BE.1943-5592.0000869

Juozapaitis, A., Vainiūnas, P., \& Kaklauskas, G. (2006). A new steel structural system of a suspension pedestrian bridge. Journal of Constructional Steel Research, 62(12), 1257-1263. https://doi.org/10.1016/ j.jcsr.2006.04.023

Juozapaitis, A., \& Norkus, A. (2007). Determination of rational parameters for the advanced structure of a pedestrian suspension steel bridge. The Baltic Journal of Road and Bridge Engineering, 2(4), 173-181.

Malinowski, M., Banas, A., Jeszka, M., \& Sitarski, A. (2018). Imaginative footbridge in Mikolajki, Poland. Stahlbau, 87(3), 248-255. https://doi.org/10.1002/stab.201810582

Reis, A. J., \& Oliveira Pedro, J. J. (2019). Bridge design: concepts and analysis (p. 531). John Wiley \& Sons, Ltd. https://doi.org/10.1002/9781118927595

Robin, C., Aubeeluck, G., De Kosmi, B., \& Datry, J.-B. (2014). The "Grand Large" footbridge: new masts in Dunkirk (pp. 264-265). Present \& Future.

Sandovic, G., Juozapaitis, A., \& Gribniak, V. (2017). Experimental and analytical investigation of deformations and stress distribution in steel bands of a two-span stress-ribbon pedestrian bridge. Mathematical Problems in Engineering, 2017, 1-11. https://doi.org/10.1155/2017/9324520

Schlaich, M. (2005). Guidelines for the footbridges (154 p.). Fib.

Schlaich, M., \& Bleicher, A. (2007). Spannbandbrücke mit Kohlenstofffaser-Lamellen. Bautechnik, 84 (5), 311-316 (in German). https://doi.org/10.1002/bate.200710028

Strasky J. (2005). Stress ribbon and cable-supported pedestrian bridges (232 p.). Thomas Telford Ltd.

Straupe, V., \& Paeglitis, V. (2012). Analysis of interaction between the elements in cable-stayed bridge. The Baltic Journal of Road and Bridge Engineering, 7(2), 84-91. https://doi.org/10.3846/bjrbe.2012.12

Svensson, H. (2012). Cable-stayed bridges: 40 years of experience worldwide (454 p.). Ernst \& Sohn. https://doi.org/10.1002/9783433601044

Unitsky, A. (2019). String transport systems: on earth and in space (25 p.). Minsk.

Walther, R., Houriet, B., \& Izler, W. (1999). Cable stayed bridges (227 p.). Thomas Telford Ltd.

Wells, M. (2002). 30 Bridges (pp. 112-116.) Laurence King. 


\title{
Fatigue design of tubular bracings in steel and composite bridges
}

\author{
L. Gölz \& U. Kuhlmann \\ Institute of Structural Design, University of Stuttgart, Stuttgart, Germany
}

\begin{abstract}
For sustainable and economical infrastructures such as steel and composite bridges a practice-oriented and fatigue-suitable design is crucial. Cross girder bracings or box girder diaphragms are often realised with tubular elements especially with circular hollow sections (CHS) including a welded connection between the slitted tubular element and the gusset plate. The gusset plate welding at the end of the slit of the tube is the critical fatigue spot. For the currently different design variants used in bridge construction with basically different notches there is no clear rule given regarding the detail category by the standards EN 1993-2 or EN 1993-1-9. This paper summarises the results of the AiF-DASt research project on three different fatigue design solutions for tubular bracings in steel and composite bridges. An insight on the practice-oriented design, the benefits for the execution and manufacturing as well as the results of the experimental fatigue tests are given.
\end{abstract}

\section{MOTIVATION}

In steel and composite bridge construction, for medium spans the superstructure is often designed as a box girder section due to the high torsional stiffness. In order to retain the shape constancy of the cross-section inside the box girder, a truss-framed solution is regularly realised, see Figure 1. For wider bridge cross-sections, the cantilevered slabs are typically supported by diagonal bracings outside of the box girder. For these two functions, tubular crosssections are mostly used since circular hollow sections are preferred for trussed beams due to the reduced risk of buckling in combination with isotropic stiffness.

This type of joint with slitted tubes at the gusset plates that is usually used in bridge crosssections inside or outside of box girders is under discussion due to critically assessed fatigue behaviour in some cases. In bridge construction, various design variants are currently used resulting from the unspecific requirements and rules in the standards EN 1993-2 (2005) or EN 1993-1-9 (2005). Those variants have fundamentally different notches and therefore projectspecific individual case studies are necessary to prove the fatigue strength for the current case. Mostly the fatigue behaviour has just been proven by numerical investigations, but not by fatigue experiments - except for the Rinsdorf Bridge in Germany. In those investigations some cases showed significantly worse fatigue strengths compared with the detail category 71 given in EN 1993-1-9 (2005) for the connection with holes at the end of the slit, see Figure 2. This detail category 71 has not been validated by fatigue experiments and the description in the standard is incomplete. Reducing however as a consequence the detail category in general on the safe side to 36 would lead to extremely unfavourable dimensioning and almost no longer feasible design thickness ratios. When looking at steel and composite bridges with box girder constructions that are currently under construction or have recently been completed, this topic proves to be of high importance. There is a fundamental need for research regarding the fatigue resistance of the different design variants of joints between circular hollow sections and plates. 

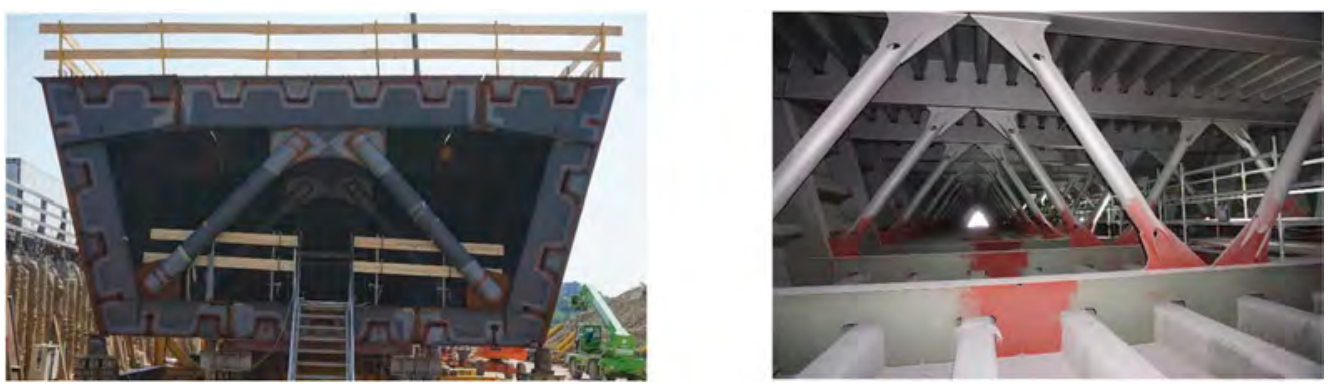

Figure 1. Design variants of tubular bracings inside of box girders of the German bridges Heidingsfeld (left) and Schierstein (right) (Kuhlmann \& Gölz 2021).

\begin{tabular}{|c|c|c|c|c|}
\hline 71 & $\alpha \leq 45^{\circ}$ & $\gamma$ & 2) Tube-plate joint, & 2) $\Delta \sigma$ computed in tube. \\
\hline 63 & $\alpha \geq 45^{\circ}$ & $x$ & welded to plate. & $\begin{array}{l}\text { weld should be verified } \\
\text { using Table } 8.5 \text {, detail } 8 \text { ). }\end{array}$ \\
\hline
\end{tabular}

Figure 2. Extract from EN 1993-1-9 (2005) - Table 8.6 Hollow sections $(\mathrm{t} \leq 12.5 \mathrm{~mm})$.

\section{STATE OF THE ART}

\section{$2.1 \quad$ Normative rules}

The current fatigue design of tubular bracings provided by EN 1993-2 (2005) and EN 19931-9 (2005) follows the nominal stress concept. For diagonals in bridges, the detail category 71 is given in EN 1993-1-9 (2005) with a restriction of the tube wall thickness ( $\mathrm{t} \leq 12.5 \mathrm{~mm})$, see Figure 2. A case differentiation is made depending on the angle of the chamfered hollow section, but no information is given on the effect of other geometric dimensions, such as the geometry of the cut-out, the shape of the gusset plate and the type of welding. Also, the location of the sealing plate (exterior or interior), that is usually required for corrosion protection inside or outside box girders, is not further specified. The location of the crack initiation also is questionable, since it is shown in Figure 2 in the gusset plate, but the stress range $\Delta \sigma$ has to be calculated for the hollow section.

A first basis for EN 1993-1-9 (2005) has been developed within the revision of the German steel design standard for the unpublished DIN 18800 - Part 6 (unpubl.) in connection with the S-N curves catalogue for hollow sections (Mang et al. 1987), which also contains international fatigue test results. In this context design recommendations for various notch details made of hollow sections have been prepared. Based on the design recommendations acc. to Mang et al. (1987), the detail categories were further classified in the Steel Construction Handbook (1993) by the type of welding.

Comparing the current valid standards and rules such as Eurocode (EN 1993-1-9 2005), IIW (Hobbacher 2014), British Standard (BS 7608 2014) and DNV (DNV GL-RP-C203 2016), obviously different requirements and approaches are used to determine the detail category. This underlines that there is a need for further research to identify the relevant parameters for the fatigue strength of joints between hollow sections and plates.

\subsection{Previous investigations on tubular bracings}

Due to the different approaches for the evaluation of detail categories in the standards (EN 1993-1-9 2005, Hobbacher 2014, British Standard 7608 2014, DNV GL-RP-C203 2016), the existing database of the fatigue tests of Zirn (1975), Baptista et al. (2017) and Hanswille \& 
a)

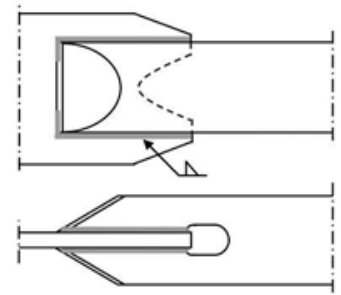

b)

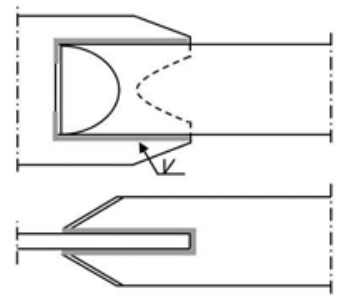

c)

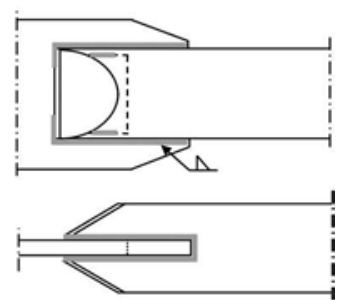

Figure 3. Recommendations from Baptista et al. (2017) for hollow-section-to-plate joints with detail category 56.

Schubart (2017) was statistically re-evaluated in the AiF-DASt-Project "Practice-oriented design of tubular bracings in steel and composite bridges" (Kuhlmann \& Gölz 2021). The aim is to evaluate the influences on the fatigue strength, e.g. chamfering of the hollow section, shape of gusset plate, type of welding, gusset plate thickness, material and the influence of cut-outs at the end of the slit in the hollow section.

Since extensive investigations on statistical evaluation methods were carried out in another AiF-DASt-FOSTA research project (Feldmann et al. 2020), the existing database was reevaluated in Kuhlmann \& Gölz (2021) acc. to Drebenstedt \& Euler (2018). This uniform statistical evaluation method according to EN 1990 (2002) and Background Document 9.01 (ECCS TC6 No.140 2018) by using the prediction interval (Holický 2005) allows the individual design details to be compared to each other.

The following results regarding the fatigue strength of tubular bracings have been derived from Zirn (1975): improvement by chamfering of the hollow section, improvement by semicircular shaped gusset plate, no influence of the material, full penetration welds have a higher fatigue strength than fillet welds - except for details with holes at the end of the slit.

As already mentioned in Baptista et al. (2017), the re-evaluation of the fatigue test results shows that only the type of welding has a large influence on the fatigue strength and all the other parameters have in fact a positive influence on the fatigue strength, but the effects are relatively small and may be even neglected. In Baptista et al. (2017) fatigue experiments and numerical investigations have been carried out. Based on this, recommendations are given for the investigated design details: a) single slit with elongated hole and fillet welds, b) single slit with full penetration welds and c) double slit with fillet welds, shown in Figure 3 with detail category 56.

In Kuhlmann \& Gölz (2021) design variants of Zirn (1975), Baptista et al. (2017) and Hanswille \& Schubart (2017) with slitted, chamfered hollow sections and full penetration welds were statistically re-evaluated and the fatigue strengths were compared. Although the test specimens differed in their geometric conditions like tube diameter, wall thickness, pool backing, gusset plate thickness and sealing plates and in their type of loading, the deviation in the evaluated characteristic fatigue strengths was not remarkable. As this design variant is similar to those in bridge practice, the classification of diagonal bracings in detail category 50 is much more realistic than the current detail category 71 acc. to EN 1993-1-9 (2005), which seems to be not conservative.

\section{EXPERIMENTAL INVESTIGATIONS ON TUBULAR BRACINGS}

\subsection{Introduction}

In the AiF-DASt research project (Kuhlmann \& Gölz 2021), for three design variants experimental and numerical investigations are carried out and notch effects are derived. The aim of the project is to achieve economically and technically improved constructional details, a wider range of application by normatively secured design solutions, practical dimensioning and 
design recommendations with optimised production as well as durable bridge construction to minimise cost-intensive maintenance and to avoid traffic closures. The analysis of existing test results, see section 2.2, showed that the weld around the gusset plate tip is the critical notch for details without cut-out at the end of the slit. The overall geometry of the three designed test specimens was adapted to real examples from bridge construction practice.

\subsection{Fatigue experiments}

The fatigue tests for the specimens shown in Figure 4 were carried out at the Material Testing Institute of the University of Stuttgart. Twenty-four specimens were tested with a specimen length of about $2 \mathrm{~m}$, eight tests per connection type at different stress levels from $50-225$ $\mathrm{MPa}$ with stress ratio $\mathrm{R}=0.1$ and frequencies of $1.2-9.5 \mathrm{~Hz}$. The diameter of the circular hollow section (CHS) tube was $168.3 \times 8 \mathrm{~mm}$, the thickness of the semi-circular shaped gusset plate was $t_{p}=20 \mathrm{~mm}$, the thickness of the sealing plates $t_{s}=10 \mathrm{~mm}$ and the thickness of the welds $\mathrm{a}_{\mathrm{w}}=8 \mathrm{~mm}$ with weld lengths $1_{\mathrm{w}}=265 \mathrm{~mm}$. The materials of the tube, gusset plate and sealing plate were $\mathrm{S} 355 \mathrm{~J} 2 \mathrm{H}$ and $\mathrm{S} 355 \mathrm{~J} 2+\mathrm{N}$.

Series 1 is adapted to the Schierstein Bridge, Germany regarding its dimensioning and choice of geometry. The geometry of the hole at the end of the slit is based on the numerical investigations of Baptista et al. (2017). The advantage of this design variant is that there is the possibility to compensate tolerances in the longitudinal direction of the tube without increasing the root gap. Also better conditions for welding and post-weld treatment are guaranteed compared to Series 2 and 3. When the crack is initiated at the edge of the hole, it is visible and can easily be detected. A disadvantage of this design variant is that it can only be used inside of the box girders or just for the lower joint of the diagonal outside box girders, as water can accumulate on the upper interior sealing plate. In this series, the type of welding is not the decisive parameter for the fatigue strength because the fatigue crack is not initiated from the weld, rather the geometry and surface quality of the cut-out is decisive.

For Series 2, a production-optimised and practical design was chosen with a straight sealing plate and a HY-weld with fillet weld. The exterior sealing plate ensures that the connection may also be used outside of the box girder. A disadvantage is that tolerance compensation in the longitudinal direction is not possible and that fatigue cracks at the gusset plate tip weld are difficult to detect. Compared to the HV-weld with pool backing in Series 3, the HY-weld provides a more practical design, as no ultrasonic testing is required, and the inside of the tube does not have to be accessible. This is also an alternative solution for tubes with small diameters, where pool backing is not possible. The tubes can already be delivered with sealing plates to the site, which is a great advantage for prefabrication. In Series 2, the tube and the gusset plate were formed with $45^{\circ}$ chamfers in the area of the critical weld at the gusset plate tip in order to produce a shape that is similar to the rounding in Series 3. The $45^{\circ}$ chamfers are an economical alternative for production purposes to complete rounding.

The third connection variant with an inclined sealing plate and a full penetration weld with pool backing, Series 3, is a notch-optimised, fatigue-resistant solution that involves higher production costs compared to Series 2. It was designed on the basis of the German RiZ-ING guideline drawings (BASt 2018) and the investigations carried out for the Rinsdorf Bridge

Series 1

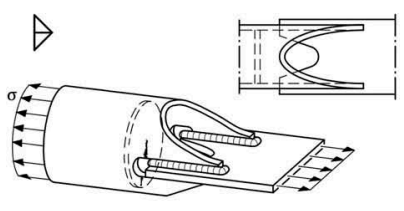

Series 2

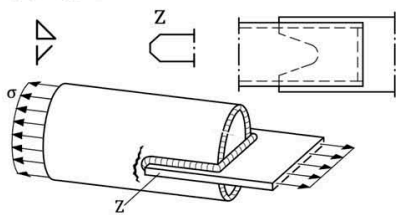

Series 3

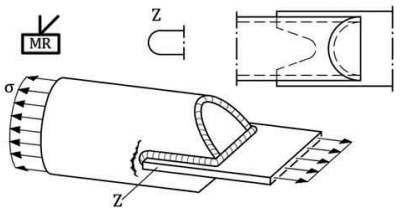

Figure 4. Overview of test specimens of the AiF-DASt research project (Kuhlmann \& Gölz 2021) acc. to prEN 1993-1-9 (2020). 
(Hanswille \& Schubart 2017). The disadvantages are analogous to Series 2. The advantage of the inclined sealing plate is that the inside of the tube is accessible. Due to this, the possibility is given to provide the necessary pool backing and to check the weld. The exterior sealing plate could only be welded to the tube after the joint between the hollow section and the plate due to inside quality assurance of the full penetration weld, which has a disadvantageous effect on prefabrication compared with Series 2. In the curved area of the gusset plate tip, no pool backing can be executed due to production possibilities. To achieve a notch-less and fatigue-resistant design, the gusset plate tip and the end of the slit in the tube have been rounded.

Based on the fatigue tests in Kuhlmann \& Gölz (2021), a comparison between the practical (Series 2) and the notch-optimised (Series 3) design is carried out.

\subsection{Results}

As already explained in section 2.2, the fatigue tests are evaluated with the prediction interval and a fixed slope of $m=3$. The failure criterion was defined as the complete fracture of the specimen. The nominal stresses are calculated in the tube gross section for Series 2 and 3, for Series 1 the net hollow section is used with $A_{\text {net }}=A-2 \cdot d_{H}$ where $d_{H}$ is the hole diameter at the end of the slit.

According to Figure 5, the characteristic fatigue resistances for fixed slopes with $\mathrm{m}=3$ are for Series 1: $\Delta \sigma_{C}=43.5 \mathrm{~N} / \mathrm{mm}^{2}$, for Series 2: $\Delta \sigma_{C}=50.8 \mathrm{~N} / \mathrm{mm}^{2}$ and for Series 3: $\Delta \sigma_{C}=56.9$ $\mathrm{N} / \mathrm{mm}^{2}$.

See Table 1 for typical crack patterns of the three different design variants. As expected, in Series 1 the crack was initiated at the cut-out. The interior sealing plate was not the decisive notch in this design variant and furthermore there were no other cracks located in the gusset plate near the longitudinal fillet weld. For Series 2 and 3, the welding at the gusset plate tip was the critical fatigue spot and the crack initiation was from the inside of the tube. There were also no other cracks visible in the gusset plate near the sealing plates or the longitudinal welds.

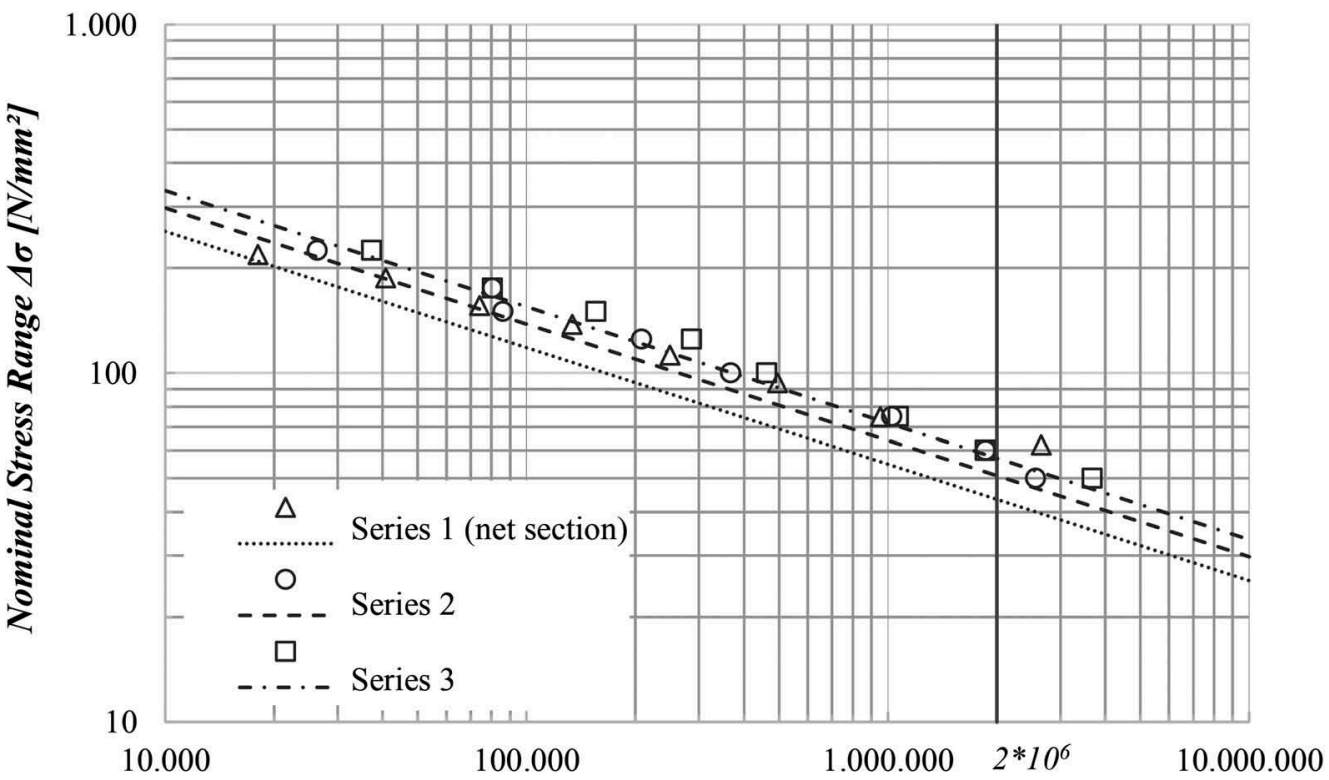

Number of Cycles $N$ [-]

Figure 5. Characteristic fatigue resistance curves of test results subject to nominal stress range evaluated with fixed slope $\mathrm{m}=3$ (Kuhlmann \& Gölz, 2021). 


Series 1

\section{CONCLUSIONS}

Based on the fatigue test results from Kuhlmann \& Gölz (2021) and the research about previous fatigue tests from Zirn (1975), Baptista et al. (2017) and Hanswille \& Schubart (2017) proposals and recommendations for the next generation of the Eurocode prEN1993-1-9 (2020) can be given. For design variants without cut-outs at the end of the slit, the type of welding is the decisive parameter for the fatigue resistance. For details with full penetration welds and pool backing, that therefore require a chamfered hollow section for quality assurance of the weld root, detail category 56 is recommended. For HY-welds with fillet welds and chamfered or straight hollow sections detail category 50 is recommended. For a design variant with a cut-out at the end of the slit and with a chamfered hollow section having the same length as the longitudinal double fillet weld, detail category 45 is recommended. For a similar design variant with cut-outs, Baptista et al. (2017) recommended detail category 56. The remarkable difference between these two variants from Kuhlmann \& Gölz (2021) and Baptista et al. (2017) is the ratio between the length of the chamfered hollow section and the longitudinal fillet weld. This and other geometric parameters need to be investigated in further research.

\section{ACKNOWLEDGMENTS}

The work presented has been carried out as part of a research project. This project 20452 (Kuhlmann \& Gölz 2021) of the research association DASt is financed by AiF, within the development programme for industrial community research and development IGF from the Federal Ministry of Economic Affairs and Energy BMWi based on a decision of the German Bundestag.

Special thanks go to "AG der Dillinger Hüttenwerke" and "Vallourec Deutschland GmbH" for provision of materials and to "Plauen Stahl Technologie GmbH", "Max Bögl Bauservice $\mathrm{GmbH} \& \mathrm{Co}$. KG" and "MCE GmbH" for the fabrication of the test specimens.

\section{REFERENCES}

Baptista, C., Kannuna, S., Pedro, J. O. \& Nussbaumer, A. 2017. Fatigue behaviour of CHS tubular bracings in steel bridges. International Journal of Fatigue 96, 126-141.

BASt - Bundesanstalt für Straßenwesen. 2018. Konstruktions- und Bemessungshinweise für Stahl- und Stahlverbundbrückenkonstruktionen - German RiZ-ING guideline drawings. draft.

BS 7608:2014+A1:2015 - Guide to fatigue design and assessment of steel products. BSI.

DNV GL-RP-C203: 2016. Fatigue design of offshore steel structures. Recommended Practice.

Drebenstedt, K. \& Euler, M. 2018. Statistical Analysis of Fatigue Test Data according to Eurocode 3. In: 9th International Conference on Bridge Maintenance, Safety and Management IABMAS, Melbourne.

ECCS TC6 No.140. 2018. Background Information on Fatigue Design Rules - Statistical Evaluation. 2nd edition. Technical Committee 6 Fatigue and Fracture. 
EN 1990:2002. Eurocode 0: Basis of structural design.

EN 1993-1-9:2005. Eurocode 3: Design of steel structures - Part 1-9: Fatigue.

EN 1993-2:2005. Eurocode 3: Design of steel structures - Part 2: Bridges.

Feldmann, M. et al. 2020. Neubewertung und Erweiterung des Kerbfallkataloges nach Eurocode 3 für eine zukunftsfähige Auslegung hochbeanspruchter Stahlkonstruktionen, AiF-DASt-FOSTA research project IGF-No. $19178 \mathrm{~N}$, final report.

Hanswille, G. \& Schubart, R. 2017. Entwurf der Talbrücke Rinsdorf. Stahlbau 86, Heft 8.

Hobbacher, A. 2014. Recommendations for fatigue design of welded joints and components, IIWDocument XIII-2151r4-07.

Holický, M. 2005. Basic statistical concepts and technique - Implementation of Eurocodes Handbook 2 Reliability Backgrounds. Leonardo da Vinci Pilot Project CZ/02/B/F/PP-134007.

Kuhlmann, U. \& Gölz, L. 2021. Praxisgerechte Gestaltung von Diagonalrohr-Anschlüssen im Stahl- und Verbundbrückenbau - Practice-oriented design of tubular bracings in steel and composite bridges. AiFDASt Final Report IGF-No. 20452N (in prep.).

Mang, F., Bucak, Ö. \& Klingler, J. 1987. Wöhlerlinienkatalog für Hohlprofilverbindungen. Versuchsanstalt für Stahl, Holz und Steine, Universität Karlsruhe, Studiengesellschaft für Anwendungstechnik von Eisen und Stahl, Düsseldorf.

prEN 1993-1-9. 2020. Eurocode 3: Design of steel structures - Part 1.9: Fatigue. Draft, European committee for standardization.

Sedlacek, G. 1984. Betriebsfestigkeitsnachweis für dynamisch beanspruchte Stahlkonstruktionen - DIN 18800 Teil 6. Research project No. 838000076. Institut für Bautechnik, Berlin.

Stahlbau Handbuch (Steel Construction Handbook). 1993. Für Studium und Praxis - Band 1 Teil A, Stahlbau-Verlagsgesellschaft mbH Köln.

Zirn, R. 1975. Schwingfestigkeitsverhalten geschweißter Rohrknotenpunkte und Rohrlaschenverbindungen. Dissertation. University of Stuttgart. 


\title{
Masonry infilled frames - contemporary structural concepts
}

\author{
I. Radić, T. Dokšanović, D. Markulak \& B. Pervan \\ Faculty of Civil Engineering and Architecture, Josip Juraj Strossmayer University of Osijek, Osijek, \\ Croatia
}

\begin{abstract}
Infilled frames were the focus of numerous experimental tests which have been executed to investigate the seismic behaviour of these systems, but the task remains challenging due to significantly pronounced nonlinear structural behaviour. The infill inevitably changes the "common" and well-known structural behaviour of bare steel and RC frames into a more complex interactive behaviour, strongly influenced by randomness introduced by heterogeneity of infill. While positive effects such as improved strength can be treated as redundant and consequently neglected in design to vertical forces, negative effects cannot be ignored in seismic areas. In the last decade, a few comprehensive research studies on RC and steel masonry infilled frames were carried out at the Faculty of Civil Engineering and Architecture Osijek. In this paper, the main conclusions from these studies are provided together with a review of contemporary structural solutions for steel and RC masonry infilled frames.
\end{abstract}

\section{INTRODUCTION}

Masonry products made of clay or lightweight concrete are commonly used as infill panels for reinforced concrete $(\mathrm{RC})$ and steel frames, primarily due to their favourable characteristics availability, acceptable cost, good physical properties, easy production and erection. The presence of such infill strongly affects the behaviour of the frame, but there are still no specific methods nor detailed design rules for the analysis of these structures. The structural behaviour of masonry-infilled frames is strongly nonlinear due to the influence of parameters such as material characteristics of its constituent parts, applied construction procedure, structural configuration, geometric properties, load characteristics etc. (Markulak et al., 2013). The main difficulty from a structural point of view is that the effects of masonry infill can be beneficial (increased stiffness and loading capacity) and detrimental (prying actions in connections caused by diagonal compression forces, limited displacement capacity, short column effect), depending on listed parameters.

The specific interest of past and ongoing research studies is the structural behaviour of masonry-infilled frames subjected to earthquake loading. Namely, while positive effects can be treated as redundant and consequently neglected, negative effects cannot be ignored in active seismic areas. The main reasons are higher seismic demand due to increased stiffness and possibly limited ductility due to earlier onset of plastic deformations. This type of structural behaviour of masonry-infilled RC and steel frames was investigated experimentally and numerically at the Faculty of Civil Engineering and Architecture Osijek (FCEA), within several research studies (Grubišić and Sigmund, 2014b, Grubišić and Sigmund, 2014a, Markulak et al., 2020, Markulak et al., 2013, Sigmund et al., 2014, Zovkic et al., 2013). These studies can be furthered by additional experimental and numerical studies, as well as evaluated from additional points of view. Therefore, the main objective of this paper is to offer a selection of comparisons between experimental data which will give insight into the behaviour of such 
systems. By outlaying obtained conclusions along with a discussion of typical contemporary structural solutions and design methods for steel and RC masonry infilled frames, it is possible to identify future research studies.

\section{CONTEMPORARY STRUCTURAL SOLUTIONS - STEEL VS. RC MASONRY INFILLED FRAMES}

Given the differences in structural properties of steel and RC frames, whether considered as standalone or in combination with masonry infill, there are generally different approaches to their design in regards to earthquake loading. The boundaries between these approaches have recently been less clear, but two distinct approaches can be identified. Namely, the typical design approach to RC frames is to incorporate the contribution of masonry infill into the overall response of the structure, which often results in proposals of various methods of additional infill strengthening. On the other hand, although there are examples of investigation of retrofitting and strengthening of steel infilled frames, inventing and establishing various forms of isolation of the masonry panel from the surrounding frame may be considered as a typical approach applied for steel frames. The differences in stiffness, strength and ductility of RC and steel frames combined with appropriate characteristics of masonry infill are key reasons for such opposite approaches.

The typical methods for infill strengthening in case of RC frames are the use of wire mesh reinforcement with cover mortar (Grubišić and Sigmund, 2014a), the connection of unreinforced infill wall to the surrounding frame by steel dowels (Grubišić and Sigmund, 2014a), use of more advanced materials for the cover of the infill wall like a designed highperformance fibre reinforced cementitious composite called ECC (Dehghani et al., 2015), glass fibre reinforced polymer (GFRP) (Abdel-Hafez et al., 2015), carbon fibre reinforced polymers (CFRP) (Altin et al., 2008), textile-reinforced mortar (TRM) with strengthening meshes based on BCRs (composite rod composed of external polyester protection of a reinforcing core composed of distinct types of fibres) (Martins et al., 2015), etc. In case of steel frames, there are typical approaches with forms of isolation of the masonry panel from the frame (mitigation of infill-frame interaction) or with the implementation of structural measures to modify the "natural" behaviour of an infill panel. Some of proposed solutions are partition of the infill panel into two or more zones in order to allow sliding (Preti et al., 2016), introducing so-called friction sliding fuses (Mohammadi and Akrami, 2010) or other types of seismic isolators (Tsantilis and Triantafillou, 2018) between the infill and frame, combining of various compression grades od masonry infill to achieve controlled cracking and separation (Markulak et al., 2020, Markulak et al., 2013), the invention of various interlock mechanisms for infill blocks instead of using mortar (Palios et al., 2017), etc.

Although the scientific community made a considerable effort to fully understand and improve the structural behaviour of masonry infilled frames, there is still no uniform and generally accepted methodology. This conclusion is substantiated by various solutions which are seemingly opposite to each other - e.g. in (Markulak et al., 2013) the main intention is to use masonry infill within steel frames up to a certain level of load and ensure the separation of infill for higher loads, whereas in (Tsantilis and Triantafillou, 2018) application of thin layers of cellular materials at the frame-infill contact area delays infill exploitation to higher load levels. There are examples of seemingly opposite solutions in infilled RC frames also.

\section{EXPERIMENTAL RESEARCH STUDIES AT FCEA OSIJEK}

This chapter presents the results of selected experimental work on frames with masonry infill loaded cyclicly, conducted at FCEA Osijek. These experimental investigations can be divided into three groups according to the frame material and objectives: testing of the steel frames with masonry infill (Markulak et al., 2020, Markulak et al., 2013, Radić, 2012), testing of reinforced concrete frames with masonry infill (Sigmund et al., 2014, Zovkić, 2013, Zovkic 
et al., 2013) which, after testing, were repaired and strengthened using various techniques and retested ((Grubišić, 2016, Grubišić and Sigmund, 2014b, Grubišić and Sigmund, 2014a). To be able to assess the impact of infill on the behaviour of the system, in addition to testing the frame with masonry infill, the behaviour of bare steel and RC frames was also experimentally determined.

\subsection{Test setup and procedure}

Analyzed frame configurations were tested in the steel reaction frame, shown in Figure 1, in a series of quasi-static gradually increasing load cycles until the failure of masonry infill or the frame. Hydraulic actuators, with the capacity of $335 \mathrm{kN}$ and a stroke of $150 \mathrm{~mm}$, were situated to the left and right of the specimen with $500 \mathrm{kN}$ capacity load cells monitoring the force. The displacement of frame beams, infill panels at bottom and top, and along the diagonals was monitored with LVDTs (range of $\pm 50 \mathrm{~mm}$ ). In case of significant damage of the masonry infill, the cyclic load pattern was interrupted and loading continued in a pushover manner (i.e. on one side).

\subsection{Steel frames with masonry infill}

The investigation of the behaviour of masonry infilled steel frames was executed in two phases. In the first phase commercially available masonry units were used for infill construction, while in the second phase the masonry infill consisted of specially developed masonry units made of recycled brick aggregate and ground expanded polystyrene (Markulak et al., 2018).

In the first phase of the research, rigid steel frames with three different types of masonry infill were built: "strong" infill made of hollow clay masonry units (SF-R-C), "weak" infill built of light autoclaved aerated concrete (AAC) units (SF-R-AAC) and combined infill made with a "weaker" AAC units (with drilled vertical holes) located beside the columns, while the "stronger" clay units occupied the rest of the infill (SF-R-CA). The combined masonry infill enabled a partial separation from the frame at by crushing the weaker AAC masonry units, thus minimizing negative effects of the infill at higher loads. The main goal was to take advantage of the beneficial effects of infill (increased stiffness and strength) up to a certain load level and to preserve ductile behaviour of the bare steel frame at higher load levels.

Compressive strength of hollow clay wall units and cement-lime mortar were 11.8 MPa and 5.0 MPa, respectively, while the compressive strengths of AAC elements and thin-layered adhesive mortar (glue) were 2.0 $\mathrm{MPa}$ and 9.1 MPa, respectively. Steel frames consisted of HEA 120 members with a nominal steel grade of S275.

The test results, shown in Table 1 and Figure 2, demonstrated that the highest load-bearing capacity was achieved on frames with AAC infill. The high strength of the mortar/glue
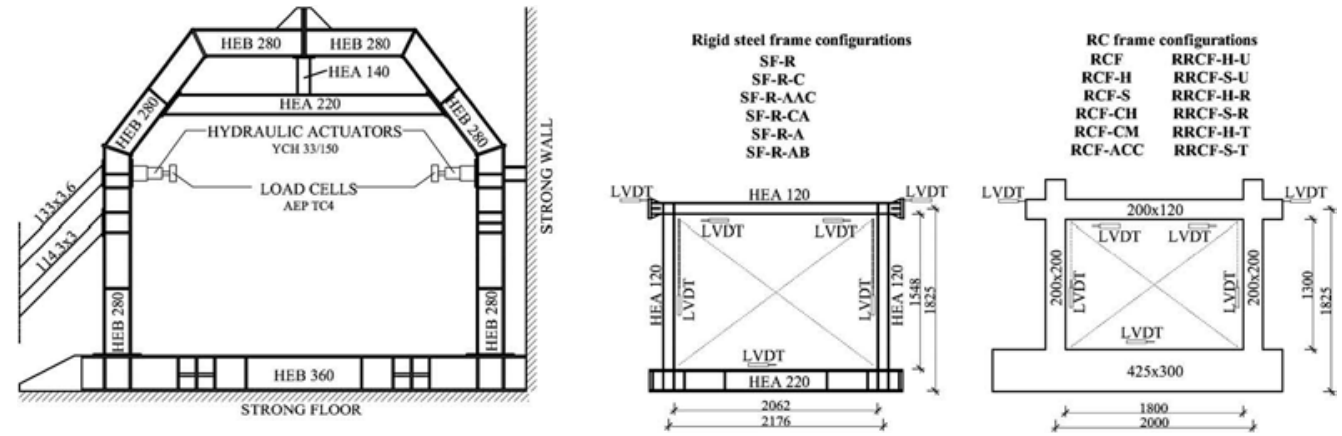

Figure 1. Steel reaction frame and tested steel/RC frame configurations. 


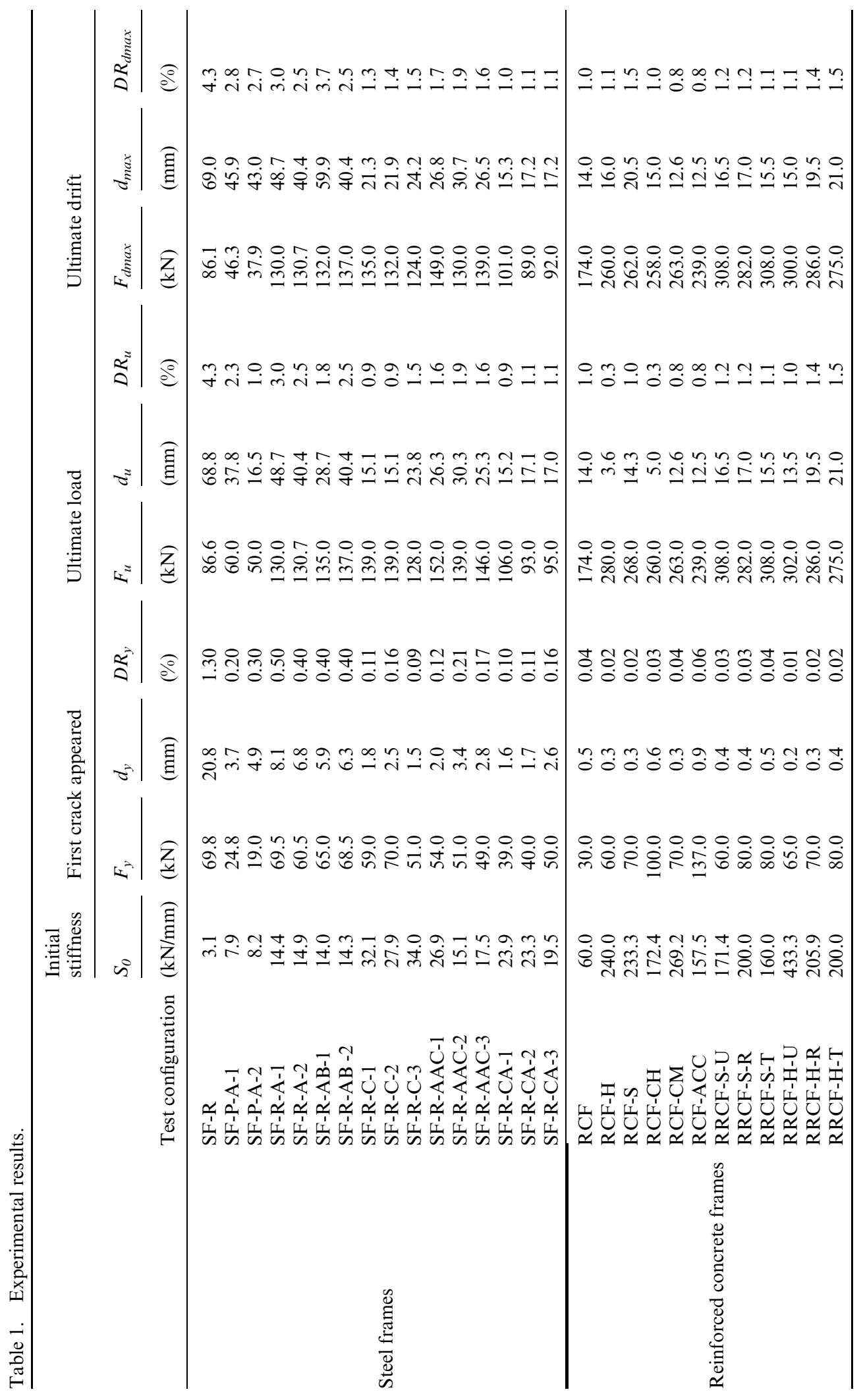


a)

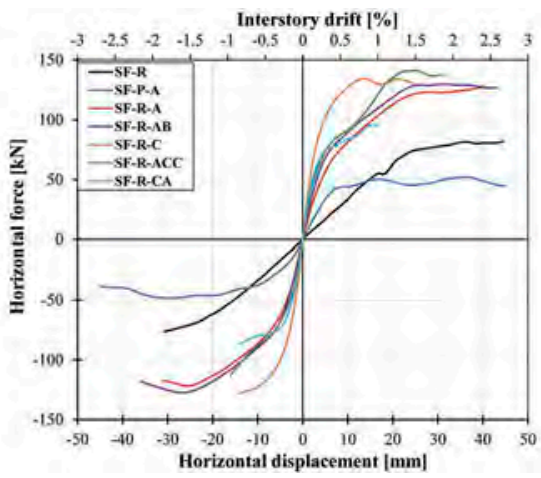

b)

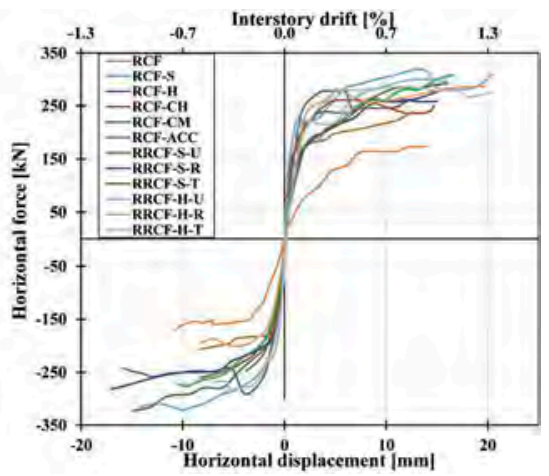

Figure 2. Hysteresis envelope curves of tested specimens. a) Infilled steel frames, b) Infilled RC frames.

enabled a more compact behaviour of the infill panel with a large number of minor cracks without extensive crushing and separation from the frame. Steel frames with clay units had the highest initial stiffness, followed by frames with combined masonry infill and frames with AAC infill. Experimental results proved the possibility of using a relatively simple solution to control the damage of masonry infill in laterally loaded steel frames - by partially separating the infill from the steel frame at certain levels of drift, it was possible to eliminate the main detrimental effects of the infill.

As a continuation of the previously described research, a special type of masonry units was developed at FCEA Osijek. The main idea was to create a masonry infill that has minimal detrimental effects on the steel frame while retaining positive characteristics of the masonry infill such as increased initial stiffness of the system. This achievement of this goal was attempted by developed masonry units with lower stiffness and strength, made of selfcompacting concrete with embedded crushed brick and ground polystyrene which makes them environmentally favourable compared to standard masonry units. In addition to a standard block shape (Type A), a special weakened unit was developed with one vertical wall removed along the sidewall (Type B). The tests included investigation of the behaviour of a rigid steel frame infilled with masonry units of Type A (SF-R-A), a rigid steel frame infilled with a combination of masonry units type $A$ and type $B$ which masonry units were located alongside the column-masonry contact patch (SF-R-AB), and a pinned steel frame infilled with type A masonry units (SF-P-A). In addition to testing the behaviour of frames with masonry infill, a rigid steel frame was tested (SF-R).

Normalized compressive strength of new masonry units was determined as 2.97 MPa, and mean compressive strength of mortar was $5.96 \mathrm{MPa}$. Pinned steel frames consisted of HEA 280 members and rigid frames of HEA 120 members, with the nominal steel grade being S235.

Experimental results show that infilled rigid steel frames (SF-R-A and SF-R-AB) have higher initial stiffness and ultimate load capacity compared to rigid steel frame without infill (SF-R) and pinned infill frames (SF-P-A). A comparison of the results between rigid steel frames with infill shows that the planned separation of the frame and the masonry infill was not achieved. The SF-R-A and SF-R-AB configurations show very similar fracture mechanisms dominated by a clear diagonal formation of concentrated strain, with minimal detrimental effects to the steel frame.

\subsection{Reinforced concrete frames with masonry infill}

The investigation of the influence of masonry infill on the behaviour of reinforced concrete (RC) frames included the construction and testing of a bare RC frame (RCF) and frames with three different types of masonry units: high strength perforated clay brick blocks (RCF-CH), medium strength perforated clay brick blocks (RCF-CM) and low strength lightweight aerated autoclaved 
concrete blocks (RCF-ACC). The dimensions of the RC frame, built of concrete $\mathrm{C} 30 / 37$ and reinforcement grade B500B, were $2.2 \mathrm{~m} \times 1.5 \mathrm{~m}$ with columns and beam cross-section $20 \times 20 \mathrm{~cm}$ and $12 \times 20 \mathrm{~cm}$. The experimentally determined mean compressive strengths of masonry units for the RCF-CH, RCF-CM, and RCF-ACC configurations were $13.21 \mathrm{MPa}, 3.87 \mathrm{MPa}$, and 13.89 $\mathrm{MPa}$, respectively. RCF-CH and RCF-CM configurations were built with cement-lime mortar whose compressive strengths were 5.11 MPa and 5.01 MPa, while for the RC-ACC configuration an adhesive mortar (glue) with a compressive strength of $13.89 \mathrm{MPa}$ was used.

Experimental results show an evident and expected contribution of the masonry infill to initial stiffness and an increase of ultimate load capacity of frames depending on the infill strength. The fracture mechanisms in RC frames with clay masonry units were similar - cracks spread horizontally along the masonry bed joints and create a sliding mechanism. A combined fracture mechanism was observed for the frame infilled with AAC masonry units - diagonal cracks at lower load levels followed by a small number of horizontal cracks formed at higher load levels.

$\mathrm{RC}$ frames damaged in previously described tests were repaired by replacing the spalled concrete with fast setting concrete mortar and infilled with two types of masonry units hollow and solid clay masonry units with a compressive strength of $4.01 \mathrm{MPa}$ and $8.30 \mathrm{MPa}$, respectively. The masonry infill was made by using cement-lime mortar with a nominal strength of $5 \mathrm{MPa}$. The masonry infill was added within the frame by three different techniques: unreinforced infill made of hollow and solid clay masonry units connected to RC frame by dowels (RRCF-H-U and RRCF-S-U), reinforced infill made of hollow and solid clay masonry units connected to RC frame by dowels (RRCF-H-R and RRCF-S-R) and unreinforced infill of hollow and solid clay masonry units strengthened with an additional vertical confining element (tie-column) and connected to RC frame by dowels (RRCF-H-T and RRCF-S-T). Two additional samples of an undamaged reinforced concrete frame with an infill of hollow (RCF-H) and solid clay (RCF-S) masonry units were built, to get an insight into the efficiency of each strengthening technique.

The test results showed that the addition of masonry infill directly affected the strength, stiffness and displacements of the structure under cyclic excitation and that the increase in the ultimate load capacity depended on the type of strengthening. All specimens had relatively small cracks in RC columns and beams as well as vertical and horizontal cracks in the joint mortar between clay solid/hollow units. In solid clay masonry infill cracks performed substantially later than then the hollow clay masonry infill, due to lower lateral stiffness. In almost all models, the first cracks appear due to slip of mortar, especially with solid clay infill.

\section{COMPARISON OF OBTAINED RESULTS AND DISCUSSION}

A summary of gathered experimental data from a wide range of test series on both steel and $\mathrm{RC}$ frames with various infill materials is given in Table 1 . The hysteresis envelope curves are shown in Figure 2, where test configuration designations correspond to previously used in headings 3.2 and 3.3 .

It is clear that structural differences between bare steel and $\mathrm{RC}$ frames also partially reflect on the behaviour of the corresponding infilled systems. Namely, initial stiffness of steel frame systems is generally lower, but drift capacity (ductility) is higher. The increase in initial stiffness and a decrease in ductility with the addition of infill can be applied for both RC and steel systems. A general rule of thumb is that use of infill has the effect of increased initial stiffness with lower ductility. AAC units stand out as being able to ensure a high level of ultimate load capacity, with lower initial stiffness and moderate levels of ductility, and this type of behaviour is additionally amplified when newly designed units in steel frames are used. The lateral system capacity is highly dependent on the frame strength (i.e. material), but relative comparisons between same frame types with different masonry units are possible. Consistency in behaviour can be achieved using solid units as they are compact and there is no side-wall delamination (the weakest link affects the behaviour of the panel). Figure 2 demonstrates that steel frames exhibit three-linear like behaviour whereas a bi-linear relation is more suitable for $\mathrm{RC}$ infilled frames. 
Based on presented research data and results, it can be concluded that the structural behaviour of infilled RC and steel frames do have some common ground. Namely, it seems that it is possible to predict to some extent the influence of the particular infill type on the behaviour of infilled steel and RC frames. Based on these findings certain patterns in behaviour observed in infilled steel frames can be extrapolated to be valid for RC infilled frames, and vice versa. Further work can be done in terms of reliability assessment and design models based on available results.

\section{REFERENCES}

Abdel-Hafez, L. M., Abouelezz, A. \& Elzefeary, F. F. (2015) Behavior of masonry strengthened infilled reinforced concrete frames under in-plane load. HBRC Journal, 11, 213-223.

Altin, S., Anil, Ö., Kara, M. E. \& Kaya, M. (2008) An experimental study on strengthening of masonry infilled RC frames using diagonal CFRP strips. Composites Part B: Engineering, 39, 680-693.

Dehghani, A., Nateghi-Alahi, F. \& Fischer, G. (2015) Engineered cementitious composites for strengthening masonry infilled reinforced concrete frames. Engineering Structures, 105, 197-208.

Grubišić, M. (2016) Modeli ocjene ojačanja armiranobetonskih okvira dodavanjem ispuna pri potresnom djelovanju. Josip Juraj Strossmayer University of Osijek. Faculty of Civil Engineering.

Grubišić, M. \& Sigmund, V. (2014a) Comparison of different strengthening techniques of damaged and weak reinforced-concrete frames. Second European Conference on Earthquake Engineering and Seismology, İstanbul

Grubišić, M. \& Sigmund, V. (2014b) Experimental studies of single bay RC frames with strengthened masonry infill. YOUNG SCIENTIST, 94-107.

Markulak, D., Dokšanović, T., Radić, I. \& Miličević, I. (2018) Structurally and environmentally favorable masonry units for infilled frames. Engineering Structures, 175, 753-764.

Markulak, D., Dokšanović, T., Radić, I. \& Zovkić, J. (2020) Behaviour of steel frames infilled with environmentally and structurally favourable masonry units. Engineering Structures, 204, 109909.

Markulak, D., Radić, I. \& Sigmund, V. (2013) Cyclic testing of single bay steel frames with various types of masonry infill. Engineering Structures, 51, 267-277.

Martins, A., Vasconcelos, G., Fangueiro, R. \& Cunha, F. (2015) Experimental assessment of an innovative strengthening material for brick masonry infills. Composites Part B: Engineering, 80, 328-342.

Mohammadi, M. \& Akrami, V. (2010) An engineered infilled frame: Behavior and calibration. Journal of Constructional Steel Research, 66, 842-849.

Palios, X., Fardis, M. N., Strepelias, E. \& Bousias, S. N. (2017) Unbonded brickwork for the protection of infills from seismic damage. Engineering Structures, 131, 614-624.

Preti, M., Bolis, V. \& Stavridis, A. (2016) Design of masonry infill walls with sliding joints for earthquake structural damage control. Proceedings of the 16th International Brick and Block Masonry Conference (IBMAC'16).

Radić, I. (2012) Ponašanje čeličnih okvirnih građevina sa zidanim ispunom pri djelovanju potresa. Faculty of Civil Engineering. Osijek, J. J. Strossmayer University of Osijek.

Sigmund, V., Zovkić, J. \& Guljaš, I. (2014) Behaviour of RC frame with strong masonry infill in response to cyclic horizontal loading. Tehnicki vjesnik/Technical Gazette, 21.

Tsantilis, A. V. \& Triantafillou, T. C. (2018) Innovative seismic isolation of masonry infills in steel frames using cellular materials at the frame-infill interface. Journal of Earthquake Engineering, 1-18.

Zovkic, J., Sigmund, V. \& Guljas, I. (2013) Cyclic testing of a single bay reinforced concrete frames with various types of masonry infill. Earthquake engineering \& structural dynamics, 42, 1131-1149.

Zovkić, J. (2013) Ponašanje armirano-betonskih okvira s ispunom pri djelovanju potresa. Josip Juraj Strossmayer University of Osijek. Faculty of Civil Engineering. 


\title{
Steel telecommunication towers subjected to fire - case studies
}

\author{
J. Szafran \\ Chair of Reliability of Structures, Department of Structural Mechanics, Faculty of Civil Engineering, \\ Architecture and Environmental Engineering, Łódź University of Technology, Łódź, Poland \\ K. Juszczyk-Andraszyk \\ Compact-Project Company, Lódź, Poland
}

\begin{abstract}
The paper deals with three independent cases of lattice telecommunication towers subjected to elevated temperatures caused by fire. Each fire incident had a different background: a fire in a hall adjacent to the tower structure (case no. 1), a fire started deliberately (case no. 2), and a fire in a neighboring site (case no. 3). This comparison is relevant in that it involves towers of the same series of types (their structural components were made of the same type of steel sections), the only difference being height or the distance between their legs. The paper addresses the causes of each fire, degradation of the towers' structural members due to high temperature, estimated fire temperatures, and, most importantly, actions that should follow to continue safe operation of the structures. The results and descriptions of the activities carried out as well as conclusions drawn can be useful when analyzing similar cases of actual damage in such structures.
\end{abstract}

\section{INTRODUCTION}

One of the issues which can occur during steel telecommunication tower usage is fire in the neighborhood or fire of the tower itself. Structure is subjected to elevated temperatures which can cause damages or changes in the internal structure of steel. The aim of this paper is to analyze structural members of towers subjected to elevated temperatures and proposing operations to be taken to enable further safe usage of these structures.

\section{STEEL TOWER STRUCTURES ADDRESSED IN THE PAPER}

The structures that are discussed in this paper and were subjected to high fire temperatures are of the same series of types. All the towers are lattice structures with a cross-section being an equilateral triangle, legs made of round solid bars, and diagonal braces made of hot-rolled equal- and unequal-leg angles. Tower no. 1 is $26.5 \mathrm{~m}$ in height, while the other two towers (no. 2 and no. 3 ) are $50.5 \mathrm{~m}$ high. Figure 1 shows diagrams of the structures including their basic dimensions.

\section{CAUSES OF FIRE}

\subsection{Tower no. 1}

Tower structure no. 1 was exposed to elevated temperature due to a fire in a neighboring warehouse (Figure 2). Photographic documents, videos available online, and descriptions of 

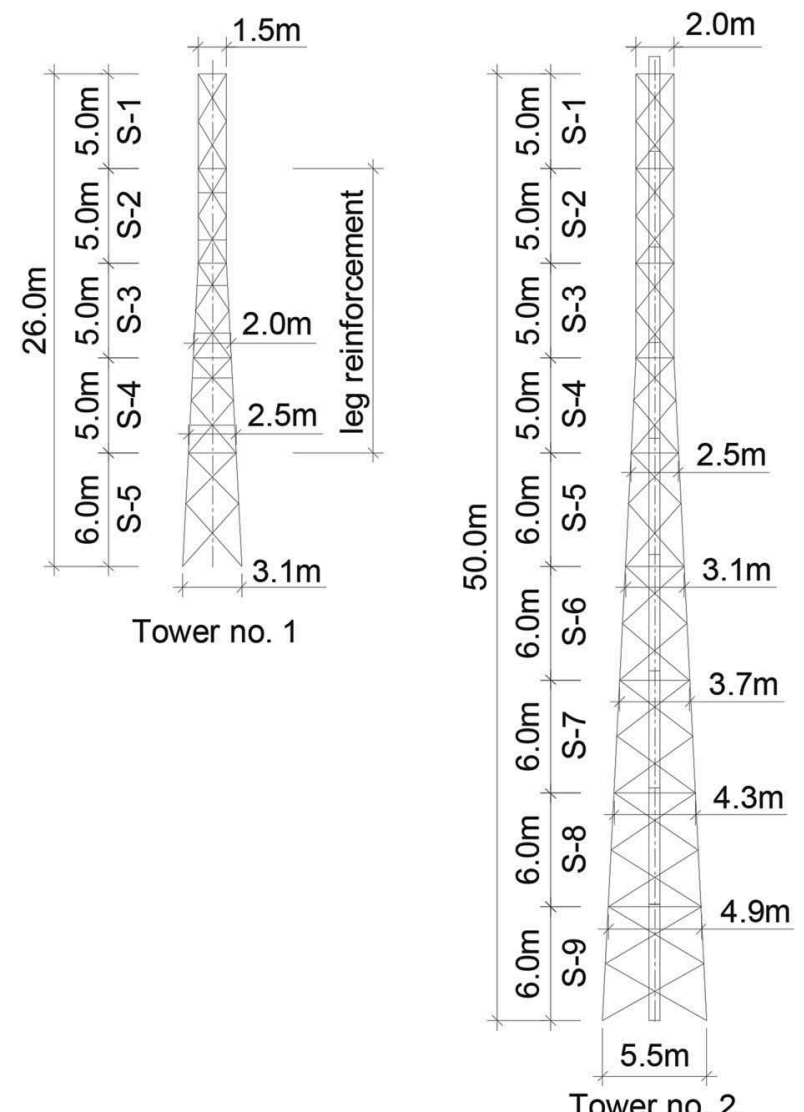

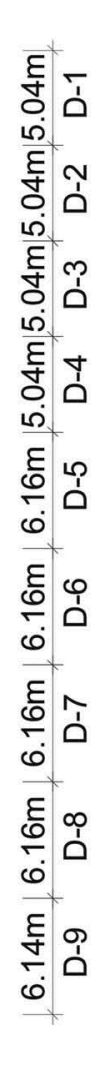

Tower no. 2

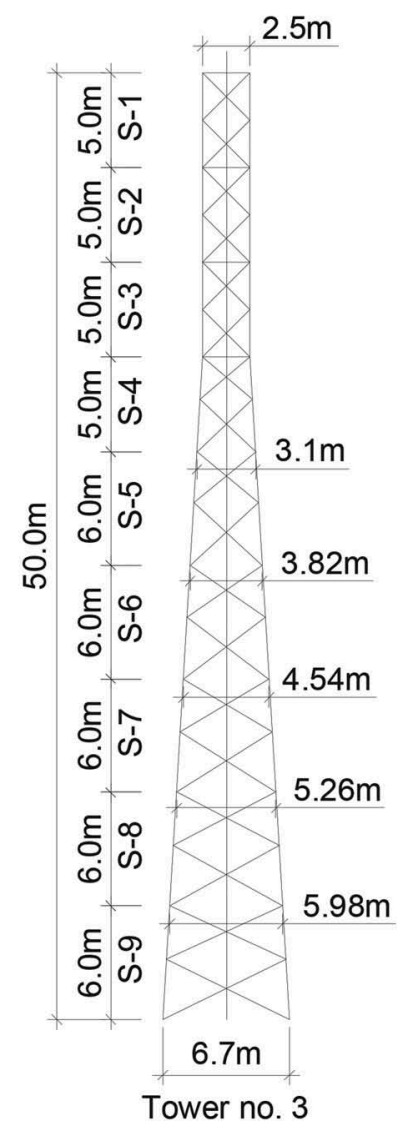

Figure 1. Diagrams of the telecommunication towers considered in the paper.
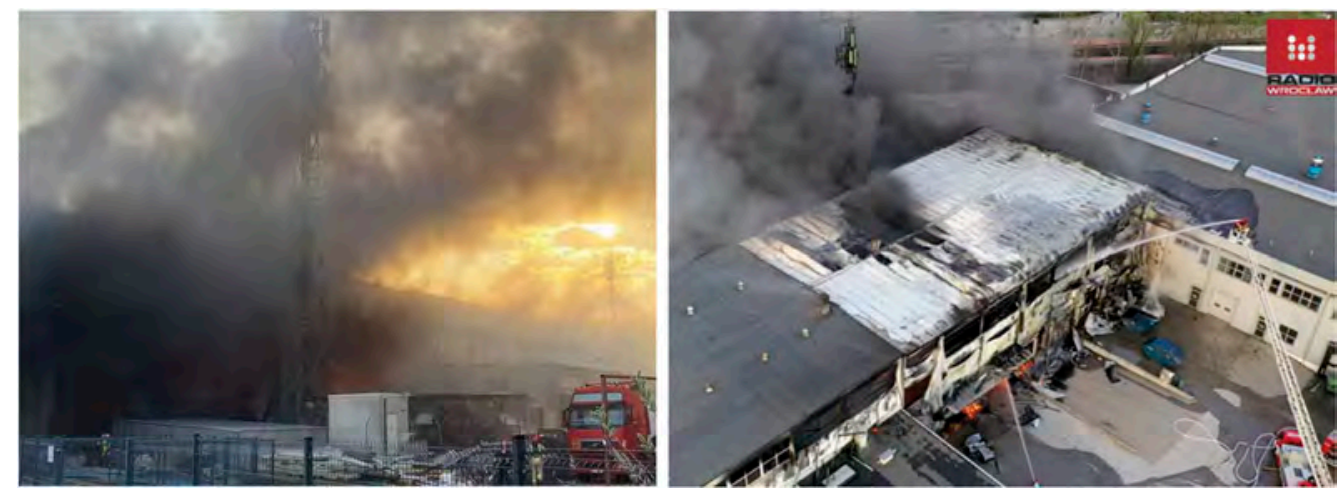

Figure 2. Fire in the warehouse adjacent to the tower (source: left - Gazeta Wrocławska; right - Radio Wrocław). 
a)

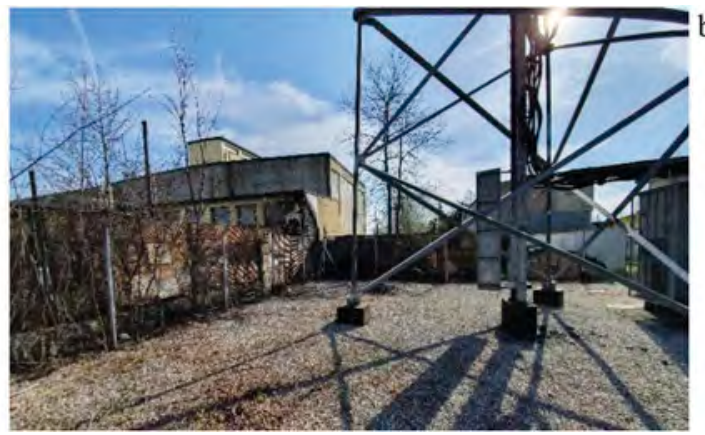

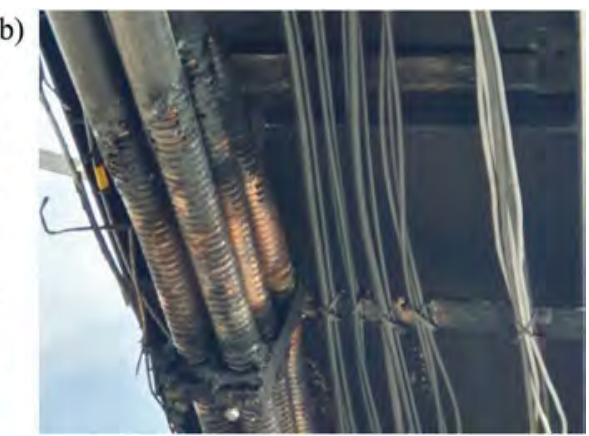

Figure 3. A) The area adjacent to the tower structure with visible distance between the area and the tower; b) Burnt polyethylene outer jacket of feeder cables.

the course of the incident indicate that the tower was subjected not directly to fire but to hot air (smoke) flowing in the tower's direction.

\subsection{Tower no. 2}

Tower structure no. 2 was exposed to high temperature when a neighboring warehouse and other facilities located in the adjacent industrial area were on fire (Figure 3) and also because cables started burning within a cable run between the tower structure and a telecom shelter.

Antenna cables seem to have been set on fire intentionally and independently of the fire in the nearby building. This opinion can be based on the following arguments: - the distance between the adjacent area where the fire occurred (Figure 3a) and the central part of the cable run is about $6.5 \mathrm{~m}$; - there is non-flammable breakstone on the ground of the base station area; - there are no other materials, including flammable ones, between the adjacent area and the tower structure, the cable run, and the cables; - the point where the antenna cables might have started burning is located directly under the crossing of bracing sections (Figure 3b); - damages and deformations of the cables were found from this point up to the right-hand side and then upwards.

\subsection{Tower no. 3}

Tower structure no. 3 was exposed to high temperature due to fire in a neighboring waste dump site (with household appliances and similar materials) and in a warehouse located in the same plot of land (Figure 4). As a consequence, a telecom shelter situated by the tower base was damaged (Figure 5). The fire might have been caused by spontaneous ignition of materials stored in the yard next to the base station area. Given the resulting damage and impact of the fire, this case was the most extreme one out of the three cases reported in the paper.

\section{ESTIMATED TEMPERATURES ACTING ON THE STRUCTURES}

When steel is exposed to elevated temperatures with access to fresh air, a colored layer forms on its surface. This layer contains iron oxides, and its color depends mainly on the temperature to which the steel component was exposed. The color of the layer is also affected by other factors, such as heating time, chemical composition of the steel, and thickness of the component, which is why assessment of temperature on the basis of the layer's color is approximate. At temperatures above $350{ }^{\circ} \mathrm{C}$ (the point when blue temper is formed), a characteristic, permanent blue color of steel is produced, but already at about $230-250{ }^{\circ} \mathrm{C}$ the layer turns yellowish. 


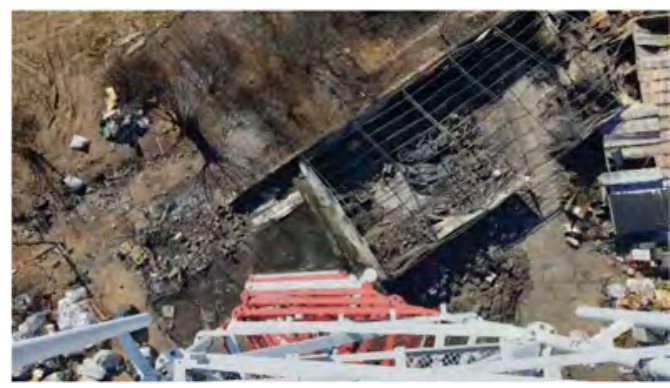

Figure 4. The adjacent area subjected to fire - the warehouse (top view).

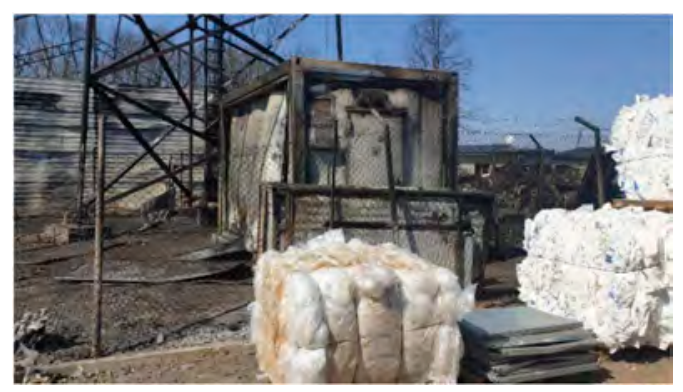

Figure 5. The telecom shelter destroyed during the incident.

The inference and arguments to estimate fire temperatures to which the structural members were exposed are provided below.

\subsection{Tower no. 1}

Since no plastic deformations of steel components of the structure and equipment were found, it can be concluded that the maximum temperature of the part of the tower that was exposed to the largest extent to this impact was $450{ }^{\circ} \mathrm{C}$. Considering that the layer was not found on the components of the structure, the temperature of air (smoke) can be assessed to have been lower. The outer jacket of the cable partly melted; the jacket was made of polyethylene whose melting point, depending on density of the material, is in the range between about 105 and $135^{\circ} \mathrm{C}$. Given the condition of cables (the outer jacket did not entirely melt; the corrugated copper layer underneath was not exposed), the temperature within S-3 segment was very likely within this range, while in other parts of the tower it was lower.

\subsection{Tower no. 2}

A yellow layer can be seen in Figure 6, which shows that the components were heated to less than $250^{\circ} \mathrm{C}$. This makes it possible to state that the fire temperature was relatively low (in the context of fire conditions). Ladder components deformed as a result of the combination of factors: elevated temperature, small thickness of the components' walls $(4 \mathrm{~mm})$, and strong constrainment both in the longitudinal axis (the lower part is fixed to the ladder foundation, while the upper one is rigidly connected to the next segment of the ladder) and perpendicularly through rungs and pieces designed to fasten cables). 

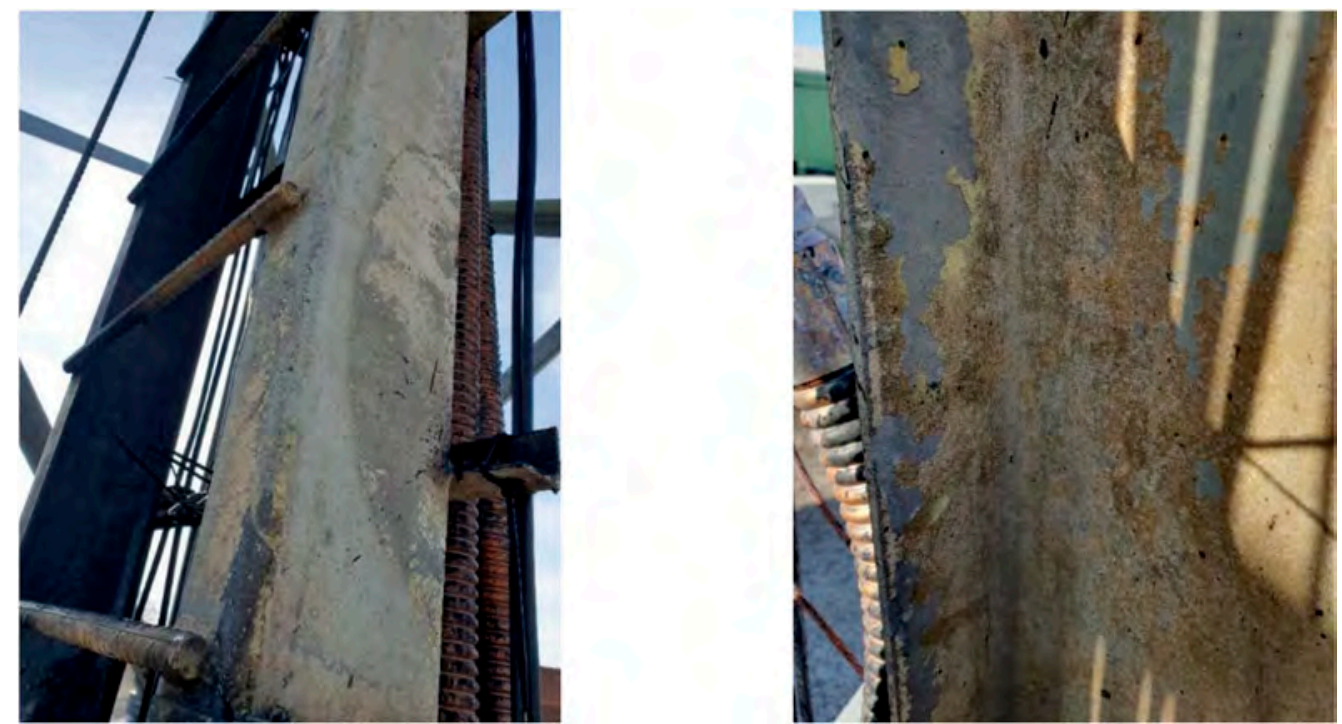

Figure 6. The effect of elevated temperature on components of the ladder rails (D-8 element).

The outer jacket of the cable melted; the jacket was made of polyethylene whose melting point, depending on density of the material, is in the range between about 105 and $135{ }^{\circ} \mathrm{C}$. Given the condition of cables (most of the outer jacket melted; the corrugated copper layer underneath was exposed - Figure 3b), the temperature within D-9 segment of the ladder was very likely between $105^{\circ} \mathrm{C}$ and $250{ }^{\circ} \mathrm{C}$; this description only relates to components used in lower segments of the access and cable ladder.

\subsection{Tower no. 3}

Since no plastic deformations of steel components of the structure and equipment were found, it can be concluded that the maximum temperature of the part of the tower that was exposed to the largest extent to this impact was $450{ }^{\circ} \mathrm{C}$. The blue temper was found on bracing sections of the bottom segment of the tower (Figure 7). Some deformation of the zinc coating on these sections can also be seen (zinc melting point is about $450{ }^{\circ} \mathrm{C}$ ). Diagonal braces depicted in Figure 7 were the closest to where waste was stored and then burnt in the waste dump site. Thus, a conclusion may be drawn that the components that were exposed to the fire temperature to the largest extent lost their formability and at the same time the brittleness of the material increased (particularly if during firefighting operations water was directly poured on the components and they quickly cooled down).

\section{STRENGTH PROPERTIES AND USABILITY OF STRUCTURES AFTER EXPOSURE TO FIRE}

Elevated temperatures decrease strength properties of steel and change its physical and mechanical properties. The relation shown in Figure 8 is recommended by Eurocode 3 to determine reduced values of quantities such as Young's modulus and the yield point.

According to (Tide, 1998), if hot-rolled steel is soaked for 3 hours at temperatures as high as $600{ }^{\circ} \mathrm{C}$ and then cooled down to the room temperature, its original mechanical properties are generally the same. The results of tests on samples taken from steel components that had been exposed to fire, provided in (Zhong, 2015), also show only a minor permanent reduction in the yield point. It should be noted, however, that the properties of structural steel after exposure to 

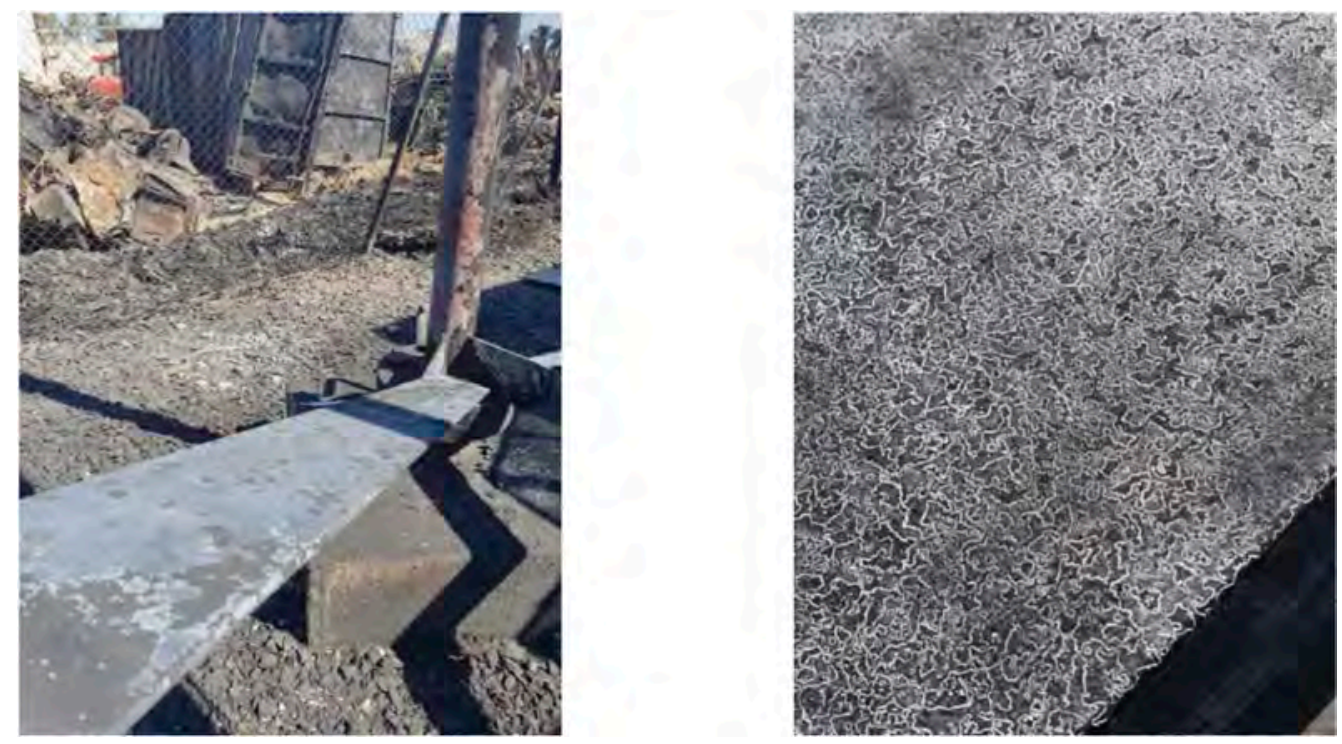

Figure 7. The blue temper on bracing sections in the bottom segment of the tower.

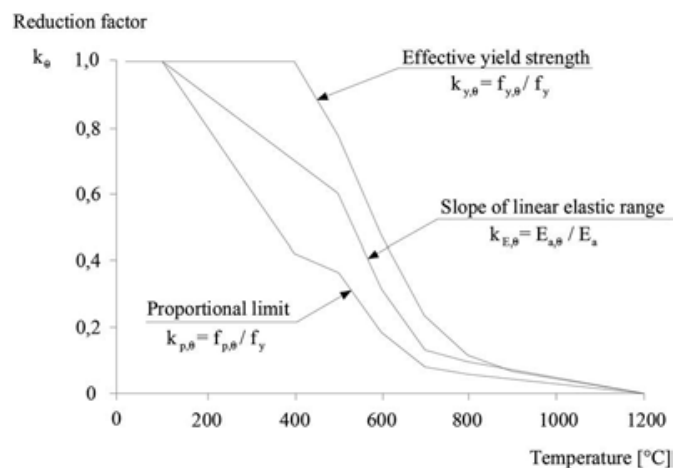

Figure 8. Reduction factors in the stress - strain relationship for carbon steel at elevated temperatures.

fire are also affected by structural changes which can occur in this material even when the threshold temperature related to recrystallization was not reached. Such changes generally lead to a significant increase in the material's susceptibility to brittle cracking (Maślak, 2012). Another type of impact caused by fire that should be taken into account is the potential of rheological effects, mainly the impact of steel creeping which intensifies at high temperatures, and stress decay that often accompanies the creeping behavior. What is also essential is how many times the components heated and partly cooled down during the fire incident, and how fast these processes occurred. When assessing the usability of components of a structure, one should consider the distribution of internal stresses that was generated thermally in these components and has an adverse effect in terms of future static operation, even if the components show no sign of major deformation or straining. What need to be emphasized is that various types of structural changes that are disadvantageous mainly due to reducing formability of materials freely occur in the material at temperatures much lower than $350{ }^{\circ} \mathrm{C}$. These changes are permanent and must not be ignored when the material, once cooled down, is assessed (Outinen \& Mäkeläinen, 2002). 


\section{CONCLUSIONS}

Based on the above information on the estimation of the temperature to which the structure is exposed during a fire, as well as visual inspection and analysis of structural elements, several conclusions can be drawn. The temperature to which the elements of tower no. 1 were exposed was in the range of $135-230^{\circ} \mathrm{C}$. In future analyses of the load-carrying capacity of the tower structure under variable load conditions (different number of antennas and cables mounted), Young modulus of steel within lower segments should be reduced by $10 \%$ (Maślak, 2020). In the case of tower no. 2 one can conclude that the temperature acting on ladder segments did not exceed $250^{\circ} \mathrm{C}$. The fire was local and the bearing elements were not exposed to elevated temperature. Young modulus of ladder members in lower sections should be reduced (by $15 \%-$ safe value), but taking into account their deformations during fire, the bottom segment of the ladder should be replaced. Tower no. 3 was subjected probably to the highest temperature - in the range of $350-450^{\circ} \mathrm{C}$. In this case not only Young modulus of steel should be reduced in future analyses of load-carrying capacity (by about 35\%), but also yield strength (reduction by $10 \%$ ). The safe solution that was used in this case is replacing bracing sections of the bottom segment (due to increased brittleness of steel) and adding crosswise supports of the legs.

\section{REFERENCES}

Maślak, M. 2012. Badania stali konstrukcyjnej po pożarze w kontekście oceny możliwości jej dalszego użytkowania w ustrojach nośnych elementów budowlanych. Przegląd Budowlany 6/2012, 48-51 (in Polish).

Maślak, M. 2020. Zachowanie się stali konstrukcyjnej w warunkach pożaru. Materialy, nowoczesne technologie, realizacje konstrukcji stalowych,173-230 (in Polish).

Outinen, J. \& Mäkeläinen, P. 2002. Mechanical properties of structural steel at elevated temperatures and after cooling down. Proceedings of the Second International Workshop "Structures in Fire", March 18 - 19, 2002, Christchurch, New Zealand, 273-289.

Tide, R.H.R. 1998. Integrity of Structural Steel After Exposure to Fire. Engineering Journal, first quarter.

Zhong, T. 2015. Mechanical properties of prestressing steel after fire exposure. Materials and Structures 48, 3037-3047. 
Joints and connections 


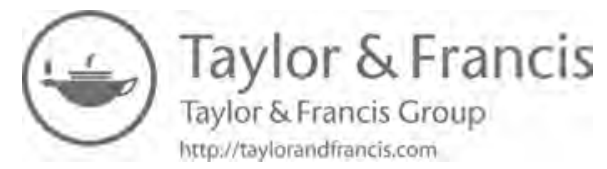




\title{
Failure modes of steel angles connected by one leg
}

\author{
E. Bernatowska \& L. Ślęczka \\ Rzeszów University of Technology, Rzeszów, Poland
}

\begin{abstract}
Paper presents a numerical model, developed to capture ultimate tensile resistance of steel angles connected by one leg using single row of bolts, based on plastic initiation and progression of fracture. The porous metal plasticity was implemented using GursonTvergaard-Needelman material model. Due to such approach, damage of the material microstructure was taken into account. Hierarchical validation of computational model was carried out on the base of own experimental tests. The paper describes the impact of individual geometrical parameters on the global behavior of the steel angle joints and their resistance. Eighty-eight numerical models and experimentally tested specimens gave insight into stress distribution, mechanism of failure and ultimate resistance. Based on these results three different failure modes were distinguished: block tearing, net section tearing and mixed mode.
\end{abstract}

\section{INTRODUCTION}

Steel angle members are very often used in engineering structures. Due to the easiness of manufacture and assembly, the most common form of their joining with construction is connecting only one leg, by single row of bolts. In the case of tension lap joints, category A, their tensile resistance is reached by one of the four forms of failure (EN 1993-1-8 2005): shear of bolts, bearing of bolts, block tearing of angle or failure of angle cross-section (reaching yield strength in gross cross-section, which is called plastic resistance or rupture of net crosssection, called ultimate resistance). The first two resistances are related to the fasteners; the others are related to the load capacity of the angle member.

If the elements in tension are connected only with a certain part of their cross-section, like angle members connected by only one leg, the possible eccentricities can influence the stress distribution in the vicinity of the connection and thus the resistance of the cross-section. The uneven distribution of stresses in the connection area (in the element that is nominally axially tensioned) is called shear lag effect. This phenomenon significantly reduces angle load capacity, Chesson \& Munse (1963), Kulak \& Wu (1997), and should be taken into account when determining the ultimate tensile resistance of sections fastened in this way. In most guidelines such influence is taken into account by means of certain reduction factor by which the net cross-sectional area is multiplied to form the effective cross-section. In this way, the time-consuming determination of additional bending effects is omitted and the entire section is treated as axially loaded.

The necessity to check the block tearing in the section was introduced at the end of the 20th century, Birkemoe \& Gilmor (1978). This form of failure occurs by simultaneous failure in shear at the row of bolts along the shear face of the holes group accompanied by tensile rupture along the line of bolt holes on the tension face of the bolt group.

Paper presents results of parametric analyzes conducted on the base of numerical simulations, carried out on tensile lap bolted connections with angles members. The aim of analyses was to obtain tensile resistances of connections and forms of angles failure. The study was aimed at observing block tearing and rupture of net cross-section of angles. 


\section{DESCRIPTION OF FINITE ELEMENT MODEL}

\subsection{Material model}

The material characteristics used in simulations were obtained from tensile tests of standard coupons cut from angles legs made of steel with nominal grade S275. Medium values of yield stress $f_{\mathrm{y}}$ was $288 \mathrm{MPa}$, and medium value of ultimate stress $f_{\mathrm{u}}$ was $425 \mathrm{MPa}$.

Block tearing and ultimate resistance of angle net cross-section are based on rupture of the material. To capture initiation, progression and final fracture of steel angles, it was decided to use Gurson-Tvergaard-Needleman (GTN) porous material model.

The GTN material model takes into account the influence of microstructural damage on the load capacity and material strength. Damage of the microstructure occurs in the form of voids, which are initiated on the inclusions present in the material. The destruction process takes place through the growth and merging of voids through localized plastic deformation, which is conducted in Kossakowski (2010), Kossakowski \& Wciślik (2018). Full description of conducted material model and its validation is described in Bernatowska \& Ślęczka (2019), Bernatowska (2020).

\subsection{Geometry and model assumptions}

All employed FE models were developed using the package ABAQUS. Finite element model of angle connection included four components: angle, gusset plate, bolt with nut and washers. Only half of the angle specimens were modelled (Figure 1). To model real boundary conditions some part of the gusset plate had blocked displacement in $x$ and $y$ direction. In $z$-direction the load in the form of displacement was applied to the gusset plate. Because of the connection symmetry the end of angle could not move in $z$-direction. Initially both washers and bolt were located concentrically with holes in angle and gusset plate.

Multilinear elastic-plastic material model based on coupon-test results was implemented for gusset plate and bolts (class 10.9). Because all analyzed connections were designed to cause angle failure, porous material characteristics (GTN) were applied only to angle member. Implementation of GTN material model required carrying Dynamic Explicit analysis. Finite elements mesh of angle, gusset plates and washers consisted of three-dimensional, hexahedral 8-node linear bricks with reduced integration (C3D8R). Bolts were built by using C3D8T and C3D6T elements, which are respectively 8-node thermally, coupled bricks with trilinear displacement and temperature and 6-node thermally coupled triangular prism used to complete the mesh. The type of finite elements on the bolt resulted from the temperature load on the bolt shank. The vertical thermal deformation method was utilized, Kim et al. (2007), to apply small clamping force starting from snug-tightened bolts. Shank was modelled as smooth cylinder without thread. Contact between surfaces was defined using general contact option. The frictional effects between surfaces were also included by incorporating the classical isotropic Coulomb friction model in the contact definition, with a friction coefficient $\mu$ equal to 0.1 .

a)

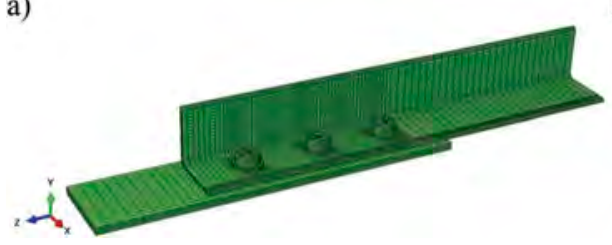

b)

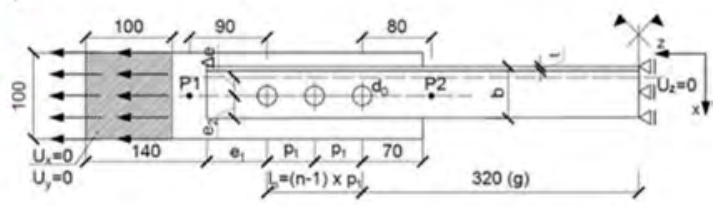

Figure 1. Example of angle member connected by one leg: a) FE model, b) geometry and boundary conditions. 


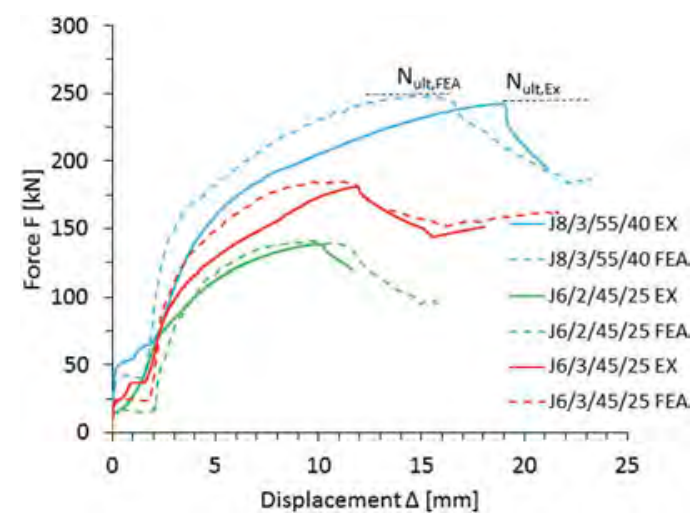

Figure 2. Comparison of force-displacement curves from FE analyses and from experimental research.

The pictures below (Figure 1) present the view on complete model with finite elements mesh and applied boundary conditions, which were used in parametric analyzes.

FE model was validated by comparing the computational results to own experimental data. More information about conducted model validation and verification process is described in publication Bernatowska (2020). Comparison of the computed $F-\Delta$ curves with these from experimental research is depicted in Figure 2 for few of the specimens. Very good accuracy of the failure load prediction was observed. Mean value of $N_{\text {ult,FEA }} / N_{\text {ult,Ex }}$ ratio is equal to 1.02.

\section{PARAMETRIC ANALYSES}

\subsection{Scope of analyses}

To check the influence of individual geometrical parameters on the global behavior of the joints their tensile resistance and forms of failure, parametric analyzes were carried out. Eighty-eight numerical models were built. They were divided into 8 groups, where following parameters were examined:

- the ratio of the width of the leg to its thickness $b / t$ (slenderness of the angle walls), in equal leg angles (A1),

- the spacing between centres of fasteners in a line in the direction of load transfer $p_{1}$ and the total length of the connection $l_{\mathrm{p}}(\mathrm{A} 2)$,

- the edge distance from the centre of a fastener hole to the adjacent edge of angle, measured at right angles to the direction of load transfer $e_{2}$ (A3),

- the end distance from the centre of a fastener hole to the adjacent end of angle, measured in the direction of load transfer $e_{1}$ (A4),

- profile arrangement in connection: joining with a wider or narrower leg in the case of unequal angles (A5),

- angle length (A6),

- profile doubling: single angles vs double angles (A7),

- differentiation of mechanical parameters of steel: elongation and proportion of $f_{\mathrm{u}} / f_{\mathrm{y}}(\mathrm{A} 8)$.

Marked points P1 and P2 were used to obtain longitudinal displacement of connection. Number of bolts vary from 1 to 5. Diameter of used bolts was M18 or M20 respectively for connection with one and more than one bolt. The sizes of angles used in simulations are produced in the steel mills, but several cross-sections were created only for the purpose of analysis, to obtain extreme geometrical proportions of both the cross-section and the connection. Thanks to this "model similarity" was achieved to the entire population of angle profiles of various sizes, connected with bolts with different diameters. 


\subsection{Failure modes obtained from analyses}

The results obtained from the analyzes include:

- force-displacement curves $F-\Delta$ (Figure 2), where $F$ is transmitted force, and $\Delta$ is difference in longitudinal displacements of points P1 and P2 (Figure 1),

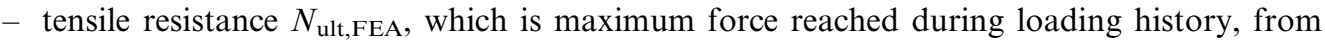
force-displacement $F$ - $\Delta$ curve (Figure 2),

- distribution of effective stresses $\sigma_{\text {eff }}$ (according to Huber-Mises-Hencky hypothesis) for the failure load $N_{\text {ult,FEA }}$ in the sections under block tearing along two paths. Their definitions are presented in Figure 3.

During analyses three failure modes were distinguish (Figure 4): block tearing (marked by symbol BT), net section tearing (symbol NT) and mixed failure mode (symbol M). The main premise for determining the failure mode was the effective stress distribution (for the failure load level $N_{\text {ult,FEA }}$ ) along the section subjected to block tearing (Figure 3). Elements where effective stresses $\sigma_{\text {eff }}$ along F-M or F'-J' achieved or exceeded value $f_{\mathrm{y}}$ were classified as block tearing failure mode (Figure 5a). If stresses along this path (between bolts holes) did not reach yield point, failure mode was net section tearing (Figure 5b). If none of these criteria was met (especially when effective stresses $\sigma_{\text {eff }}$ did not reach $f_{\mathrm{y}}$ in the region of end distance $e_{1}$ ), the element was classified into a mixed failure mode, Figure 5c. Force-displacement curves also confirm these types of failure. For angles, where net-section tearing appeared all $F-\Delta$ curves have des-

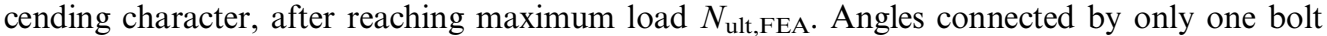
were treated as a separate case and the forms of failure were not distinguished as above.

The length of the connection turned out to have a substantial influence on the tension resistance of the angle. It also influenced the form of failure, i.e. in shorter joints or with a small spacing of bolts $p_{1}$, block tearing or a mixed form was observed, in longer joints (where the bolt spacing was significant) - net section tearing appeared.

a)

b)

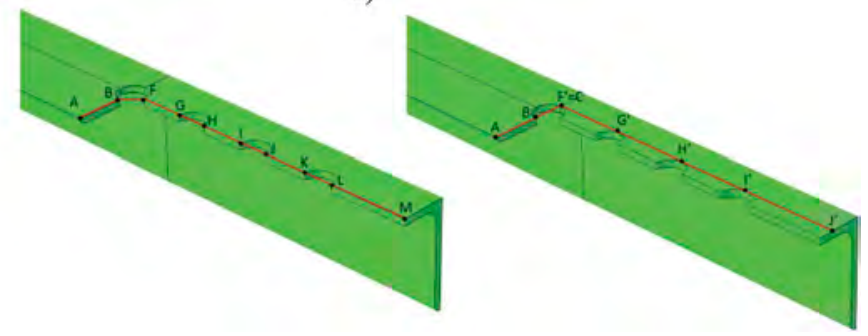

Figure 3. Paths definition for which stresses distribution were obtained: a) in net area subjected to shear, b) in gross area subjected to shear.

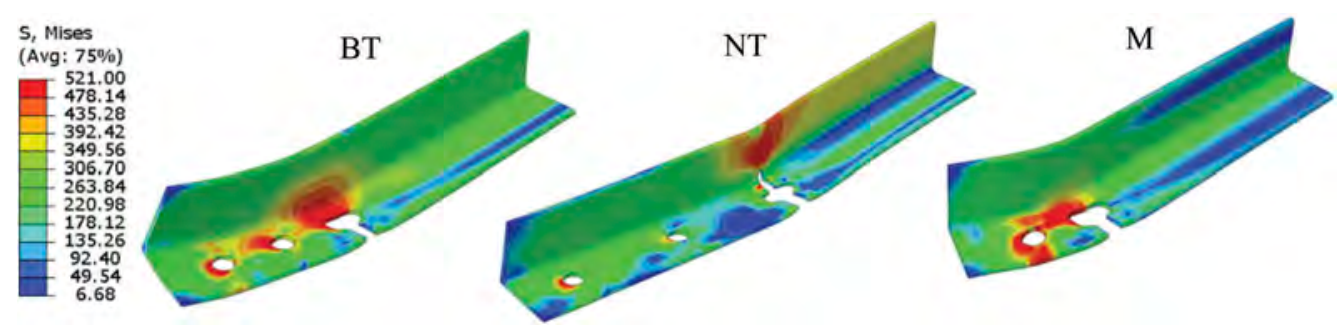

Figure 4. Effective stress distribution and fracture shape in angle members after reaching failure load $N_{\text {ult,FEA }}$ for three failure modes: block tearing (BT), net section tearing (NT) and mixed mode (M). 
a)
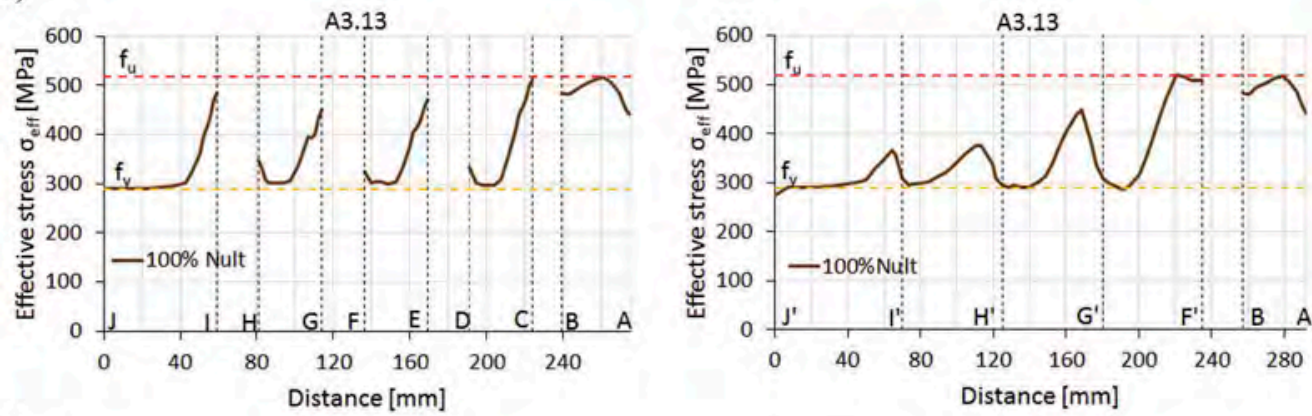

b)
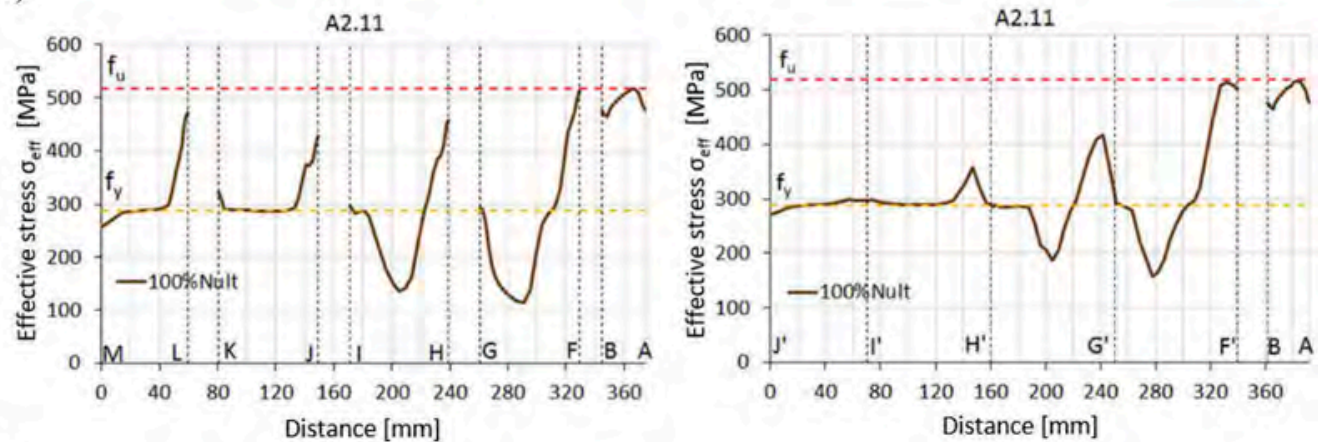

c)
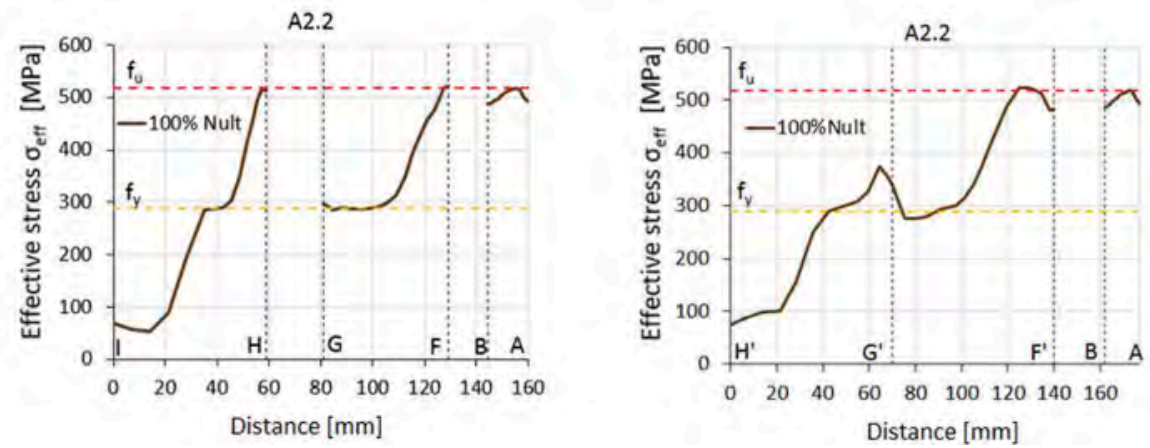

Figure 5. Distribution of effective stresses $\sigma_{\text {eff }}$ for the failure load $N_{\text {ult,FEA }}$ (left diagram shows distribution along net tension and net shear area; right one shows distribution along net tension and gross shear area); a) - c) description in the text.

The distance of the hole axis from the edge of the angle section in the direction perpendicular to the acting force $e_{2}$ (which also determine the eccentricity of the acting load $\Delta e$ ) also turned out to be important. The smaller the value of the eccentricity was, the higher load capacity angle achieved. Mixed failure mode appeared in specimens where $e_{2}<b / 2$ (except long connections with significant bolt spacing).

The analyzes indicated that the influence of unequal angles arrangement was more important for elements where block tearing appeared. For these cases greater tensile resistance can be achieved by connecting angle with a wider leg (a greater area of the tension face $A_{\mathrm{nt}}$ can be obtained). For the net section failure, the width of the connected leg has no influence, but the connection length and the load eccentricity $\Delta e$.

Elements with longer connections are sensitive to changes in the mechanical parameters of steel, which may cause a change in the form of failure: from block tearing (at S235) to net cross-section tearing (at S450). 


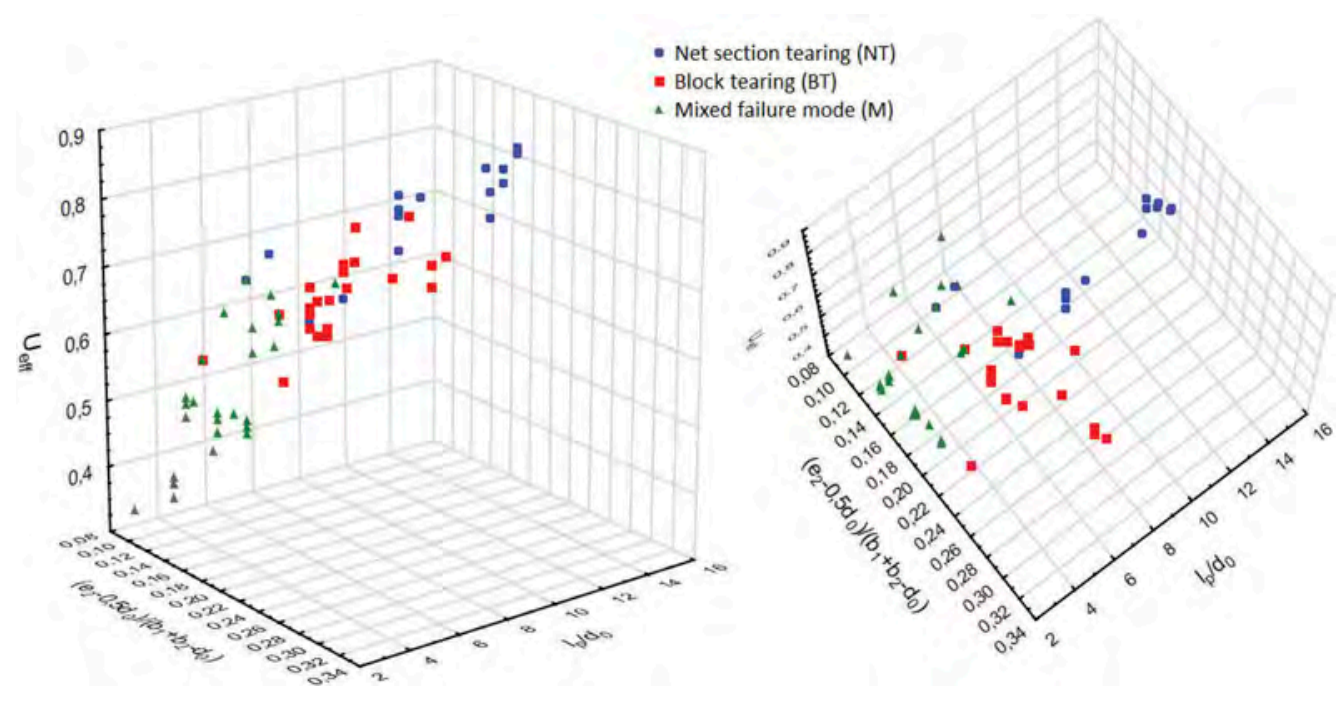

Figure 6. Relative tensile resistance of angles as a function of length of the joints and position of bolt hole measured at right angles to the direction of load transfer.

Comparison of obtained relative tensile resistance $U_{\text {eff }}=N_{\mathrm{ult}, \mathrm{FEA}} /\left(A_{\text {net }} \cdot f_{u}\right)$ for all specimens are shown in Figure $6\left(N_{\text {ult,FEA }}\right.$ is maximum force reached during loading history, $A_{n e t}$ is the net area of the angle, and $f_{u}$ is ultimate strength of the steel). Variable factors in Figure 6 are relative length of the joints $\left(l_{p} / d_{0}\right)$ and relative position of the bolt hole measured at right angles to the direction of load transfer $\left(e_{2}-0,5 d_{0}\right) /\left(b_{1}+b_{2}-d_{0}\right)$, where $l_{p}$ is the distance between the centres of the end fasteners in a joint, $d_{0}$ is diameter of bolt hole, $e_{2}$ is the edge distance from the centre of a fastener hole to the adjacent edge, measured at right angles to the direction of load transfer and $b_{1}$ and $b_{2}$ are widths of angle legs (see also Figure 1).

Slight differences in the obtained resistances in each groups (BT, NT and M) are visible. Specimens in which net section tearing (NT) was observed have net cross-sectional efficiency factor $U_{\text {eff }}$ in the range of $0.68-0.86$. In case of specimens with block tearing failure mode (BT) factor $U_{\text {eff }}$ is in the range 0.60-0.83, and for mixed form of failure $U_{\text {eff }}=0.30-0.70$. Angles with only one bolt, which are not included on diagram below, achieved $U_{\text {eff }}$ from 0.29 to 0.43 .

\section{SUMMARY AND CONCLUSIONS}

During the experimental research it is difficult to distinguish between the block tearing and net cross-section tearing in single angle in tension connected by one leg. In both cases initial form of failure is appearing as a crack forming in tension net cross-section area.

Validated and verified computational FE models based on microstructural damage material modelling give possibility to follow the failure process. Obtained results will be used to calibrate theoretical models for both forms of failure and to find borders between them.

\section{REFERENCES}

Bernatowska, E. \& Ślęczka, L. 2019. Net section fracture assessment of steel bolted joints with shear lag effect. Matec Web of Conferences 262 (09002).

Bernatowska, E. 2020. Numerical simulations of ductile fracture in steel angle tension members connected with bolts. Civil and Environmental Engineering Reports 2 (30): 32-54. 
Birkemoe, P. C. \& Gilmor, M. I. 1978. Behavior of Bearing Critical Double-Angle Beam Connections, Engineering Journal, AISC, Vol. 15: 109-115.

Chesson, E. \& Munse, W.H. 1963. Riveted and bolted joints. Journal of the Structural Division 89 (1): $67-126$.

EN 1993-1-8:2005: Eurocode 3 - Design of steel structures - part 1-8: Design of joints. CEN, Brussels.

Kim, J. \& Yoon, J. \& Kang, B. 2007. Finite element analysis and modeling of structure with bolted joints. Applied Mathematical Modelling 31: 895-911.

Kossakowski, P. 2010. An analysis of the load-carrying capacity of elements subjected to complex stress states with a focus on the microstructural failure. Archives of Civil and Mechanical Engineering 10 (2): $15-39$.

Kossakowski, P. \& Wciślik, W. 2018. Numerical simulation of material damage for structural steels S235JR and S355J2G3. Advances in Computational Design 3 (2): 133-146.

Kulak, G.L. \& Wu, E.Y. 1997. Shear lag in bolted angle tension members. Journal of Structural Engineering 123: 1144-1152. 


\title{
Effective resistance of demountable shear connectors
}

\author{
A. Kozma, J. Yang \& C. Odenbreit \\ ArcelorMittal Chair of Steel Construction, University of Luxembourg, Luxembourg
}

\begin{abstract}
Steel-concrete composite construction is structurally efficient but is impossible to dismount where the floor slab is permanently connected to the steel beams through traditional welded studs. This contradicts the reuse and reduce aspects of the circular economy concept which has recently been introduced to the construction industry. Within the RFCS REDUCE project, several solutions have been proposed. Demountability of the composite beams using the proposed new shear connectors has been successfully demonstrated by pushout tests and full-scale beam tests. Both experiments and numerical simulations showed that the composite beams can develop plasticity even the demountable shear connectors in solid concrete slabs failed in a brittle way. To extend the scope of Eurocode 4 and avoid uneconomic elastic design, effective shear resistance of the demountable shear connectors was defined by using a newly developed algorithm, for the calculation of the plastic moment capacity of composite sections with partial shear connection.
\end{abstract}

\section{INTRODUCTION}

\subsection{Motivation and background}

The concept of circular economy is based on three terms: reuse, reduce and recycle. Recently this concept is becoming increasingly important in the construction industry driven by the EU target of climate neutrality by 2050 .

Steel-concrete composite construction is structurally efficient and widely adopted. However, in current design it is not dismountable and the separation of materials is labor- and costintensive. This makes the recycling process complicated and decreases the reuse efficiency of materials. The EU RFCS funded project - REDUCE targeted this issue and explored design for deconstruction and reuse in commercial and residential buildings using steel-based hybrid structural systems. Specifically, novel types of demountable shear connectors used in composite beams have been developed and tested in the form of push tests, (long-span) beam tests. The use of normal bolts as shear connectors have been considered a few decades ago but only for retrofitting purposes. More recently, attention has been paid into deconstruction aspects and replacing welded studs by bolted connectors. Pavlović M. et al. (2013) provided respective analysis on bolted connectors against welded studs through push tests. Ataei A. et al. (2016) and Liu et al. (2017) investigated the high-strength friction-grip bolts used as shear connectors in beams with precast concrete slabs.

The scope of this paper is to present the development of effective shear resistance of the demountable shear connectors developed at the University of Luxembourg (UL) within REDUCE for the calculation of the plastic moment capacity of composite sections with partial shear connection. The push tests showed that the developed shear connection systems have six-millimeter deformation capacity, which is required by Eurocode 4 for a headed stud to be considered as ductile. However, the tests at UL showed that the general behavior of the 
demountable shear connections used in solid slabs is significantly different from the traditional solutions with welded studs. They did not show a ductile behavior at failure but failed in a brittle way. Consequently, Eurocode 4 does not enable the use of equidistant shear connector spacing and the design needs to be performed using fully elastic analysis which is uneconomic and hinders the practical application of demountable and reusable composite structures. As a result, an effective shear resistance was defined with the help of a newly developed algorithm, considering that composite beams can develop plasticity even if non-ductile shear connection is applied. It was shown that with the usage of the effective shear resistance, the Eurocode 4 rules for the calculation of the plastic moment capacity of composite sections with partial shear connection remain applicable; and therefore, the developed algorithm enables the extension of the code for demountable shear connections. In this way, the benefits of composite construction can be maintained while providing the possibility of reuse.

\subsection{Demountable shear connections}

In the frame of the conducted research, two types of shear connections (Figure 1) have been investigated at UL. They offer good level of reusability of the concrete slabs as the bolts connecting the slab and the steel beam are easily replaceable if thread damage occurs during service or dismantling/reassembling of the flooring system. Both types used prefabricated concrete deck elements, which were connected to a steel beam with the help of bolted shear connectors. The first type used two M20, Gr. 8.8 bolts coupled with the help of a mechanical coupler device of grade 10.9. One bolt and the coupler device were fully embedded in the deck element and the second bolt were placed through a predrilled hole in the flange of the steel beam. The second type was a through bolt connection that used pretensioned M20, Gr. 8.8 bolts placed inside an encased steel cylinder. The figure below shows the schematic drawing of the two types of connections. The detailed description of the connections can be found in the $\mathrm{PhD}$ thesis of Kozma, A. (2020).

\section{EXPERIMENTAL CAPAIGN AND NUMERICAL SIMULATIONS}

\subsection{Push-out tests}

Five series of push-out tests were carried out on different variants of the connectors based on Eurocode 4, Annex B. The deck elements were completely solid slabs in three series, while two series used profiled steel sheeting with a solid strip around the connectors (see Figure 1). No difference in the results could be observed between these two different types of deck. This way, it was possible to reduce the weight of the slab elements without compromising the load

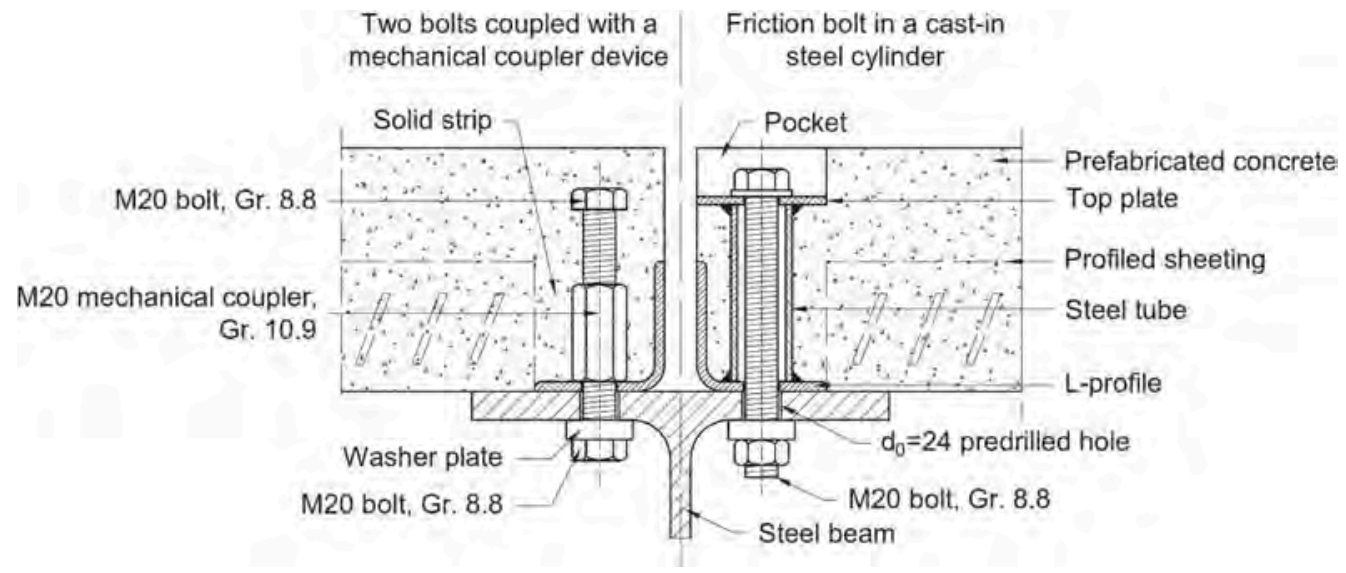

Figure 1. Left: coupled bolts (P15.1); right: friction bolt in a cast-in cylinder (P3.3). 
bearing capacity. Bolt shear failure occurred in each test after reaching the maximum shear capacity of the bolts. No plastic plateau, nor any significant descending branch was observed, all specimens failed in a brittle way. Nonetheless, all of the tested connections had a slip capacity that is greater than six millimeters, which is the slip capacity requirement for ductile shear studs given by EN 1994-1-1 (CEN 2004), Clause 6.6.1.1 (5). Figure 2 shows the load-slip measurements and the average load-slip curves of the two types of connections. As is shown, these load-slip curves differ from the load-slip curves of traditional headed studs that generally reach their ultimate capacity around $1 \mathrm{~mm}$ slip and can maintain that load until at least $6 \mathrm{~mm}$ (Kozma, A. et al. 2019).

\subsection{Beam tests}

Each type of shear connection was also investigated by full-scale beam tests. Two 6-meter-span demountable composite beams were fabricated. Each specimen comprised of an IPE 360 steel beam and two prefabricated concrete deck elements. The demountable shear connectors were placed in pairs equidistantly along the length with a longitudinal spacing of $600 \mathrm{~mm}$ and a transversal spacing of $100 \mathrm{~mm}$. The beams were subjected to 2-point loading. The loading regime included an incremental cyclic loading followed by loading up to failure. During the tests, the force and the displacement values were continuously recorded. Both beams behaved elastically before reaching a deflection level of $\mathrm{L} / 300$, which is a generally accepted criterion in the serviceability limit state. The beams reached their ultimate capacity at deflection levels greater than L/50. A certain plastic plateau could also be observed on the load-deflection curves. In other words, the beams behaved in a ductile way despite of the non-ductile nature of the applied shear connections.

\subsection{Modelling, validation and parametric studies}

The beam tests were reproduced numerically by 3D nonlinear simulations using ABAQUS 2017. The shear connectors (considering nonlinear load-slip behavior) were modelled as fasteners, which are point-based, mesh-independent connector elements. The shell element (S4R) was adopted and the global mesh density was $50 \mathrm{~mm}$. The concrete ribs and the profiled sheeting were neglected due to their insignificant contribution to the beam capacity. Tested material properties were used with concrete damaged plasticity model for concrete and a tri-linear model for steel considering a descending branch. Boundary and loading conditions of the experimental tests were replicated in the FE model. The numerical models were capable of capturing the load-deflection response, occurring slips and observed damages. A total of 112 simulations were performed for the parametric studies, considering the beam length, shear connection type, material grades, steel profiles and the distributions of connectors. The results were used for the evaluation of the developed calculation method, which will be presented in Section 3. Figure 3
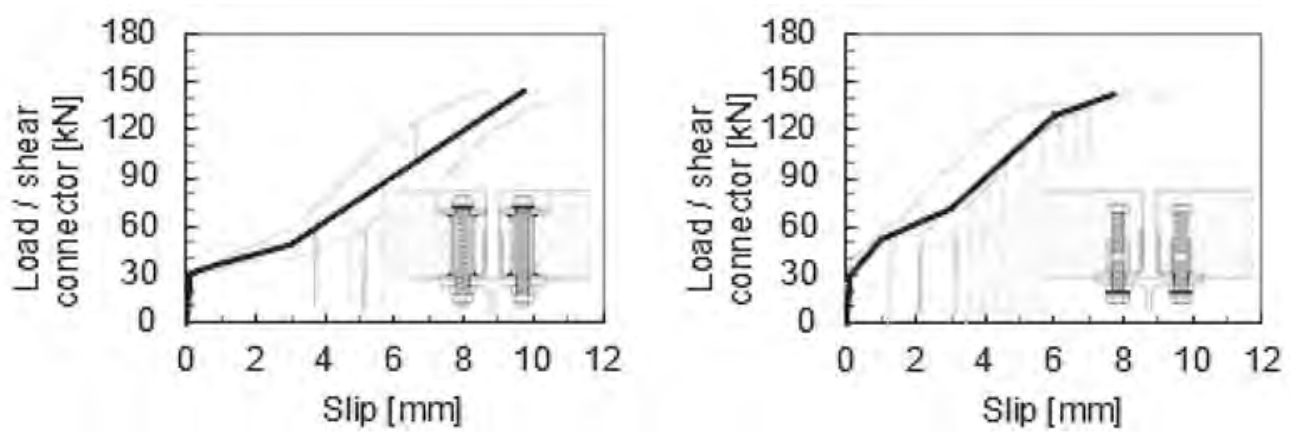

Figure 2. Load-slip relationships and the average load-slip curves of two types of connections. 


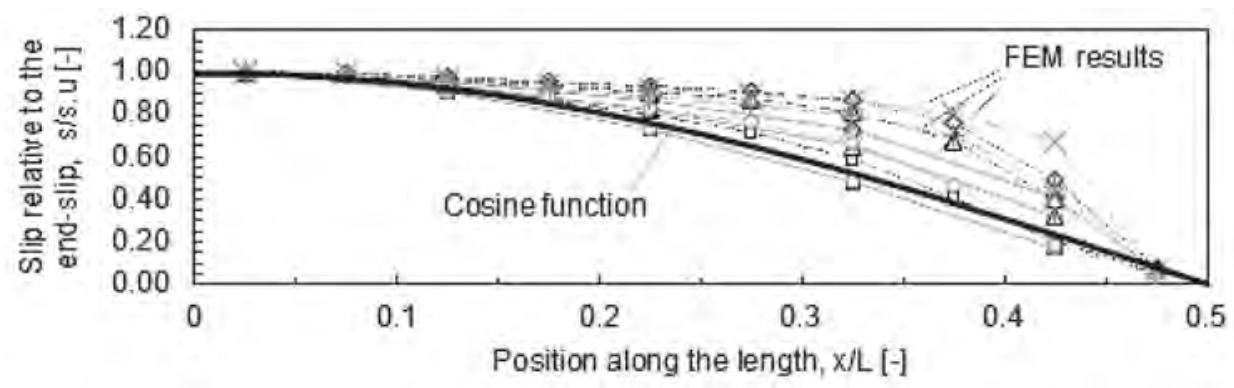

Figure 3. Slip distributions in comparison with a cosine function.

shows an extract of the results. It shows the slip distributions for twelve 6-meter-span beams using different amounts and types of shear connectors. The presented slip values correspond to the load level at which the plastic moment capacity is reached, and are shown relative to the end slip.

\section{EFFECTIVE SHEAR RESISTANCE}

From the previous section, it is obvious that the load-slip behavior of the demountable shear connectors is fundamentally different from the one of welded shear connectors. The slips could result in possible redistribution of the longitudinal shear depending on the flexibility and the deformation capacity of the connection. Therefore, the shear force that the flexible connectors can transfer needs to be evaluated for the moment capacity of a composite beam.

It is known that the occurring slip at each shear connector along the beam length should varies so as the shear force. Some researchers (Lawson R.M. et al. 2017, Hanswille, G. \& Schäfer, M. 2007) assume a cosine shaped slip distribution along the length for a simply supported beam with linear load-slip curve of the shear connectors. Theoretically, this would correspond to a sinusoidal moment diagram but it is also a reasonable approximation for uniformly loaded beams with a second order moment diagram. Beyond the elastic limit, further elastic deformations occur and plastic strains start to develop in the 'plastic zone'. The slip due to plastic deformation is constant in the elastic part of the beam (Bärtchi, R. 2005). The total slip can then be determined as the sum of the slips due to elastic and plastic deformations.

Nonetheless, the slip due to plastic deformation is difficult to quantify without the help of numerical simulations. Figure 3 demonstrated that the assumption of a cosine slip distribution is reasonable for the demountable shear connectors. And thus, the cosine function is adopted in this paper. It is important to point out that the more the bending moment diagram differs from a sinusoidal shape, the less accurate the procedures developed in this paper will become.

When the end slip $\bar{s}$ at the maximum load level of the composite beam (i.e. the beam reaches its plastic moment capacity) is set, the occurring slip at each shear connector along the beam span and then the corresponding shear force could be worked out based on the cosine function and the load-slip relationship of the shear connector. In EN 1994-1-1, Clause 6.6.1.1(5), a minimum $6 \mathrm{~mm}$ slip capacity is required for ductile shear connection. In consistent with this requirement, the end slip $\bar{s}$ is taken as $6 \mathrm{~mm}$ in this paper.

For a composite beam with concrete deck placed on the top flange of the beam, the compression force in concrete can be expressed as:

$$
N_{c}=n_{r} \sum_{i=1}^{n_{p}} P_{s c, i}
$$


where $n_{\mathrm{r}}$ is the number of shear connectors in a row, $n_{\mathrm{p}}$ is the number of shear connector rows placed within the critical length, $P_{\mathrm{sc}, \mathrm{i}}$ is the shear connector force at each shear connector. The determination of $P_{\mathrm{sc}, \mathrm{i}}$ relies on the assumed slip distribution function and the respective load-slip relationship of the chosen shear connector.

Noted that some conditions and assumptions applies as follows: 1) the beam is simply supported and subjected to a positive bending moment, 2) the steel beam section is Class 1 or 2 according to EN1993-1-1, 3) the section is symmetric to the vertical axis, 4) the shear connection is distributed equidistantly along the length, 5) the curvature of the composite beam under failure conditions is large enough to enable the assumption of a plastic stress distribution in the cross-section.

To simplify the calculations for $N_{\mathrm{c}}$, the average shear connector force, i.e. the effective shear resistance, $P_{\mathrm{R}, \mathrm{eff}}$, was proposed:

$$
P_{R, e f f}=\frac{\sum_{i=1}^{n_{p}} P_{s c, i}}{n_{p}}
$$

The compression force, $N_{\mathrm{c}}$, in the concrete can then be calculated by multiplying the number of shear connectors, $n$, between the support and the position of the maximum bending moment (critical length) by the effective shear resistance, $P_{\mathrm{R}, \text { eff }}$, of the connector:

$$
N_{c}=n \cdot P_{R, e f f} \leq N_{c, f}
$$

where $N_{\mathrm{c}, \mathrm{f}}$ is the maximum possible compression force in the concrete slab.

For easy calculation of the effective shear resistance, $P_{\mathrm{R} \text {,eff }}$, a parameter $k_{\mathrm{flex}}$ that represents the ratio of $P_{\mathrm{R}, \text { eff }}$ to the shear force in the last shear connector $\bar{P}$ was introduced:

$$
k_{f l e x}=\frac{P_{R, e f f}}{\bar{P}}
$$

The factor $k_{\text {flex }}$ depends on: 1) the load-slip curve of the shear connection, 2) the number of shear connector rows $n_{\mathrm{p}}$ on the critical length. The value of $k_{\text {flex }}$ can be calculated using the load-slip curves of the tested demountable shear connectors presented in Figure 2, with the following assumptions: i) the end slip is set as $6 \mathrm{~mm}$ when the plastic moment resistance is reached, ii) the slip distribution can be described by a cosine function, iii) the shear connectors are placed equidistantly. From Figure 4 , it is shown that the more shear connector rows $\left(n_{\mathrm{p}}\right)$, the lower the value of $k_{\text {flex }}$. However, the difference in the values of $k_{\text {flex }}$ between 4 rows and 30 rows is relatively small. For the tested shear connections, its value varies between 0.69 to 0.81 . As a simplification, it is proposed to use the number that corresponds to $n_{\mathrm{p}}=6$. This means, that when determining the average shear connector force $P_{\text {Reff }}$, we assume that only six pairs of shear connectors are placed on the critical length. The advantage of this simplification is that $k_{\text {flex }}$ now only depends on the load-slip curve, i.e. it became a shear connection specific parameter. For shear connection type P3.3 and P15.1, the value of $k_{\text {flex }}$ is 0.756 and 0.762 , respectively. The effective shear connector resistance can be determined as:

$$
P_{R, e f f}=k_{f l e x} \cdot P_{R, 6}
$$

where $P_{\mathrm{R}, 6}$ is the shear connector resistance at $6 \mathrm{~mm}$ slip.

After this point, the calculation procedure is analogous to the Eurocode 4 method for the determination of the plastic moment resistance of composite beam with partial shear connection. The plastic stress distribution and the location of the neutral axes can be determined from the equilibrium equations of compressive and tensile forces from the concrete and steel beam elements; and the moment resistance $M_{\mathrm{pl}, \eta}$ from the moment equation. The flowchart of 


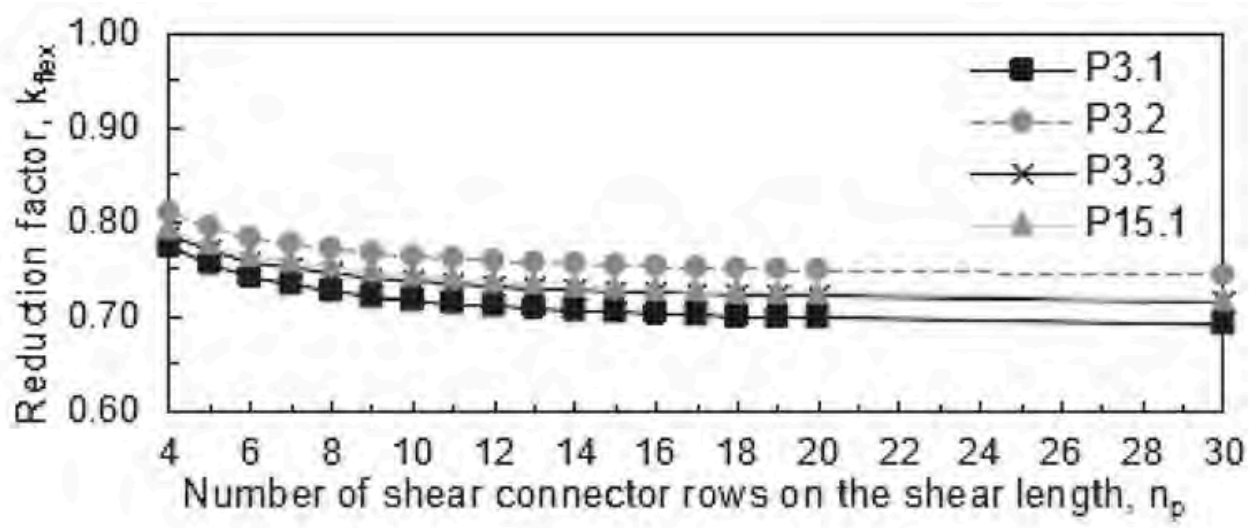

Figure 4. Reduction factor $k_{\text {flex }}$ depending on the number of shear connector rows.

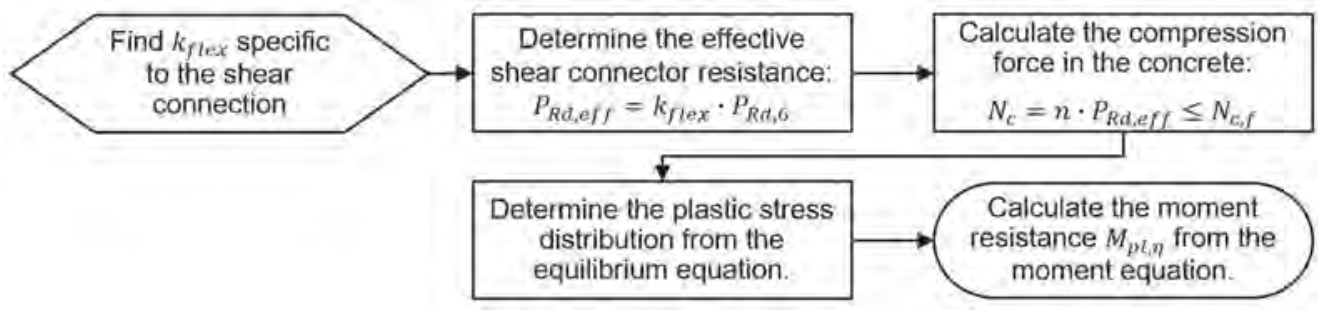

Figure 5. Simplified algorithm for the determination of the plastic moment resistance of composite beams with non-ductile shear connection.

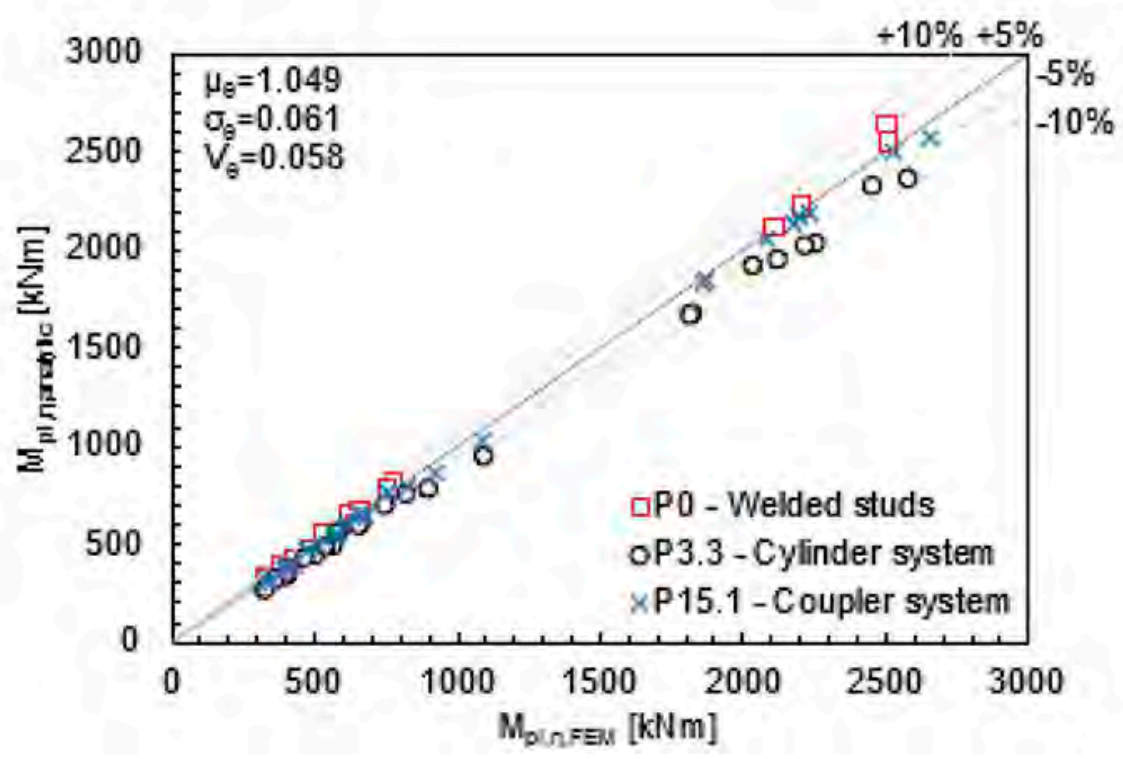

Figure 6. Comparison of the analytically and numerically obtained resistance values. 
the simplified calculation method is presented in Figure 5. The accuracy of the algorithm depends on the initially assumed end slip (6 $\mathrm{mm}$ in this paper) and slip distribution function (cosine function for simply supported beam with uniformly distributed load). The approximation of the occurring end slip is complicated at the ultimate limit state. However, conducted experimental and numerical investigations show that the aforementioned assumptions are reasonable. The calculated moment resistance values using the simplified algorithm were compared to the numerical simulation results. The mean value of the uncertainties, the standard deviation and the coefficient of variation is $\mu_{\theta}=1.049, \sigma_{\theta}=0.061$ and $V_{\theta}=0.058$, respectively. The comparison of the experimentally and numerically obtained resistance values is presented in Figure 6. Based on the comparison, it was concluded that the simplified algorithm is applicable for the determination of the plastic moment resistance of composite beams with the presented demountable shear connection.

\section{CONCLUSIONS}

The general behavior of the demountable shear connectors presented in this paper is fundamentally different than that of a welded stud. The shear connectors failed in a brittle way (classified as non-ductile shear connectors which does not exhibit an ideal plastic plateau) while allowed the development of plasticity of a composite beam. As a result, the basic assumptions for ductile studs in Eurocode 4 is not applicable. A simplified algorithm was therefore developed for the calculation of plastic bending resistance of a composite beam with the demountable shear connectors, which is analogous to the current Eurocode 4 design procedures. This algorithm adopted the proposed effective shear resistance and reduction factor for non-ductile shear connectors, with assumed end slip of $6 \mathrm{~mm}$ and a cosine function of the slip distribution of shear connectors along the beam span. From the comparison of analytical and numerically obtained results, it was shown that the simplified algorithm is able to produce plastic moment resistance $M_{\mathrm{pl}, \eta}$ values with acceptable accuracy.

\section{REFERENCES}

Ataei, A., Bradford, M.A. \& Liu, X. 2016. Experimental study of composite beams having a precast geopolymer concrete slab and deconstructable bolted shear connectors. Engineering Structures, 114, 1-13.

Bärtschi, R. 2005. Load-bearing behaviour of composite beams in low degrees of partial shear connection. PhD Thesis, Zürich: ETH Zürich Research Collection. https://doi.org/10.3929/ethz-a-004906133

CEN. 2004. EN1994-1-1. Eurocode 4: design of composite steel and concrete structures - part 1-1: general rules and rules for buildings. Brussels, Belgium.

Hanswille, G. \& Schäfer, M. 2007. Simplified method for the determination of the influence of flexibility of shear connection on deflections of composite beams and slim-floor systems (in German). Stahlbau, 76(11),845-854.

Kozma, A., Odenbreit, C., Braun, M.V., Veljkovic, M. \& Nijgh, M.P. 2019. Push-out tests on demountable shear connectors of steel-concrete composite structures. Structures, 21, 45-54.

Kozma, A. 2020. Demountable Composite Beams: Analytical Calculation Approaches for Shear Connections with Multilinear Load-Slip Behaviour. Doctoral Thesis, University of Luxembourg. http://hdl. handle.net/10993/44263

Lawson, R. M., Lam, D., Nellinger, S. \& Aggelopoulos, E.S. 2017. Serviceability performance of steel-concrete composite beams. Proceedings of the Institution of Civil Engineers - Structures and Buildings, 170(2): 98-114.

Liu, X., Bradford, M.A. \& Ataei A. 2017. Flexural performance of innovative sustainable composite steel-concrete beams. Engineering Structures, 130, 282-296.

Odenbreit, C. \& Kozma, A. 2019. Dismountable Flooring Systems for Multiple Use, BAMB, Brussels, Belgium.

Pavlović, M., Marković, Z., Veljković, M. \& Budevac, D. 2013. Bolted shear connectors vs. Headed studs behaviour in push-out tests, Journal of Constructional Steel Research, 88, 134-149. 


\title{
Analysis of steel bolted end-plate joints under accidental situation
}

\author{
D. Kukla \& A. Kozłowski \\ Rzeszow University of Technology, Rzeszów, Poland
}

\begin{abstract}
Shaping and performing building structures analysis based on avoiding the disproportionate damage to the initial cause during accidental situation is nowadays essential concern of designers. A several ways to protect the structures against progressive collapse are presented in current design standards. As a main strategy to mitigate a progressive collapse an alternative load path method is recommended. The ability of structure to overcome collapse is defining as structural robustness. The paper presents results of the part of research project aiming robustness behavior analysis of steel frames with bolted end-plate joints. First step was experimental test of selected, isolated flush and extended end plate joints, to obtain available rotation capacity of the joints tested in column loss scenario. Next, advanced FEM models were created, which after hierarchic validation, were used to simulate experimentally tested joints to compare results. FEM was also used to modeling behavior of subframe tested early experimentally. Last part will be FEM analysis of few plane frames configuration to obtain required rotation capacity of the joints.
\end{abstract}

\section{INTRODUCTION}

The subject of numerical simulation of the behavior and evaluation of the resistance of steel frame structures under accidental situation e.g. column loss scenario is a new and intensively developed issue.

The following methodology was applied in $\mathrm{PhD}$ dissertation of the first author, to analyze robustness behavior of steel frames subjected to accidental loading:

- Experimental tests of selected bolted joints, i.e. flush and extended end-plate joints. Joints were tested as isolated, in cruciform stand-up.

- Creation and hierarchical validation of FEM model of bolted connections.

- FEM modeling of experimentally tested joints,

- Parametric study on influence of another factors, not including in experimental tests,

- FEM analysis of substructure experimentally tested earlier,

- Analysis of few plane steel frames under column loss scenario.

- Comparison of available rotation capacity from own experimental tests with required rotation capacity obtained from frame analysis,

- Final conclusions about usefulness of bolted end-plate joint in frame structures to fulfill code requirements about structural integrity.

In this paper results of the part of research project described above has been presented. 


\section{ANALYSIS OF STEEL JOINTS}

As a first step to analysis the robustness of frame structures the experimental tests on steel joints were conducted. The six bolted end-plate joints with flush and extended end-plate were tested. The details of experimental test of double side end plate joints were presented in (Kozlowski \& Kukla 2019). Based on these tests the numerical analysis and validation of finite element models of this joints were done, which were presented in (Kukla \& Kozlowski \& Siwowski 2021). A close agreement of both technique at level of results and graphic comparison (Figure 1) were obtained. The experimental tests and numerical analysis gave a lot of information about behavior of steel end plate joints under accidental situation as column loss scenario.

The validated models of end plate joints were used to conduct the parametric numerical analysis under different factor influencing rotational and ultimate capacity. The three innovative conceptions of bolted end-plate joints to increase load and rotational capacity were also proposed. The results of this analysis were presented in (Kukla\& Kozlowski 2021).

\section{ANALYSIS OF FRAME SUBSTRUCTURE}

The next step to modeling steel frames was numerical analyzes of the frame subsystem (Figure 2) investigated as part of the research work (Kozlowski \&et al. 2011). The analysis was performed on two models. The first one concerned a substructure with flush end-plate joints with a $10 \mathrm{~mm}$ plate thickness. The second case involved the same subsystem but with extended end-plate $10 \mathrm{~mm}$ thick. Both systems were modeled in the same way.

For this purpose, the analysis of this system (Figure 2) was started in the Abaqus software (Abaqus). Explicit dynamic integration method to overcome convergence difficulties in static solver was used. To produce quasi-static response a time step control was applied. Mass scaling as a factor to reduce computational time of analysis was also used. The frame substructure
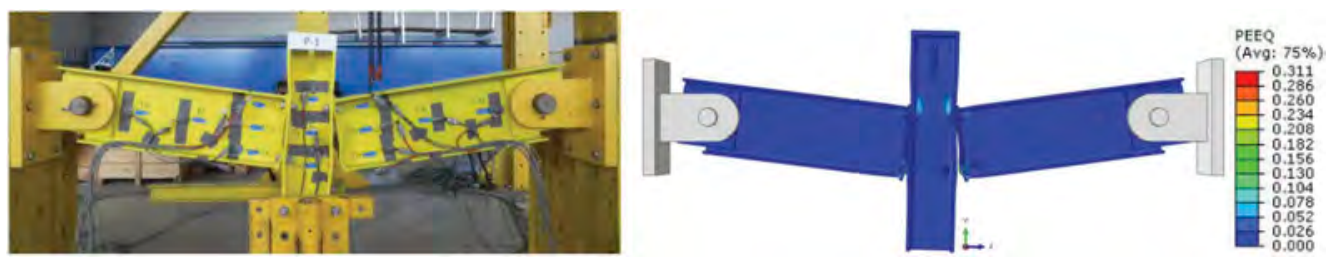

Figure 1. Comparison views of experimental and numerical test of joint with $10 \mathrm{~mm}$ flush end plate.

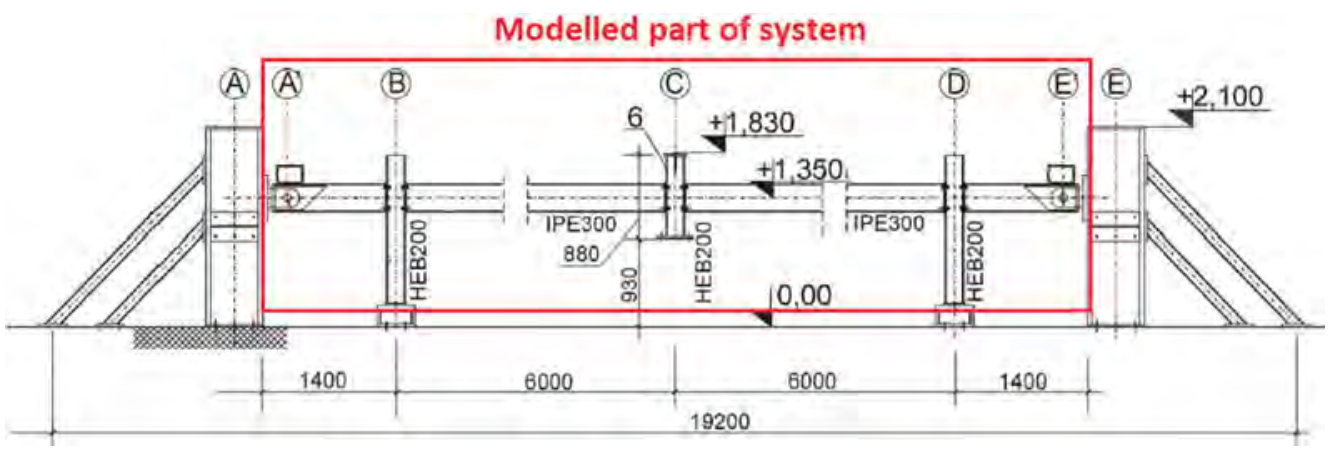

Figure 2. Planar view of frame substructure tested in (Kozlowski \& Gizejowski \& Sleczka \&..., 2011). 
a)

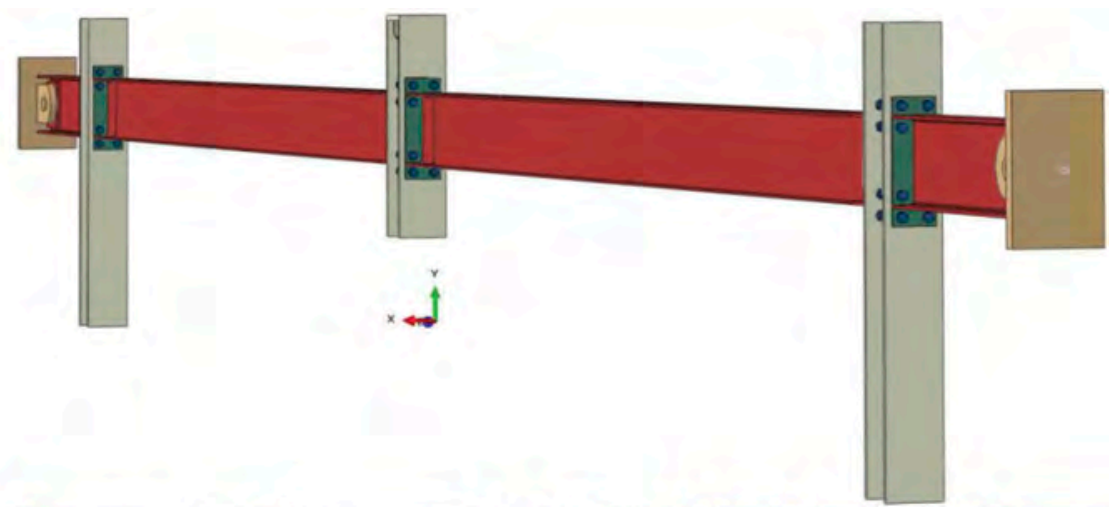

b)

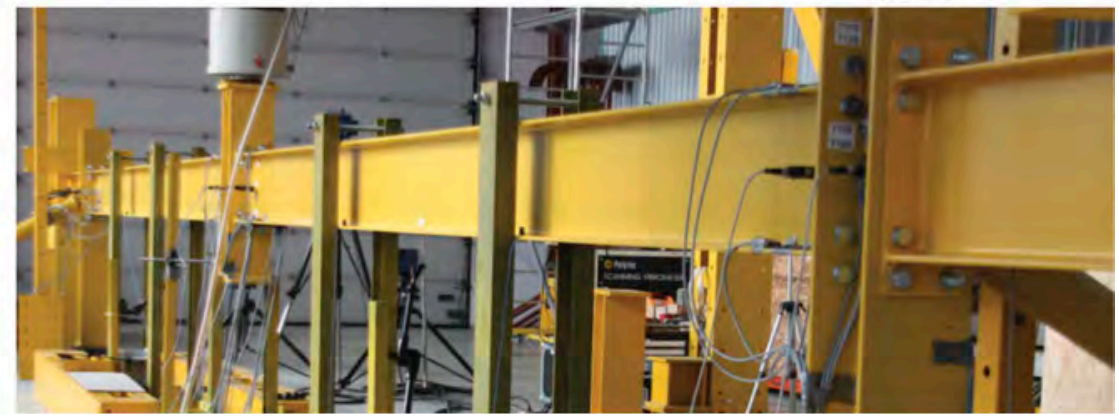

Figure 3. 3D view of substructure with extended end-plate joint: a) model, b) specimen under test.

(Figure 3a) composed of two elements types was modeled. A parts with the highest values of strains as end-plates, end parts of beams, columns, bolts connectors and pin connections at the end of system were modeled by solid elements C3D8R. The parts of beams between external and internal column (at part about $5 \mathrm{~m}$ ) were modeled by shell elements S4R. Application of shell element at long beam elements allows to significant reduction of element numbers and computational time of analysis. Both shell and solid elements allows to large displacements and strains at analysis time. To reproduce contact between elements a general contact interaction was developed. A hard contact to simulate the unilateral contact in normal direction of the interface between connected elements was used. An isotropic friction coefficient at value equal 0.3 to represent tangential behavior was applied.

Appropriate boundary conditions representing those in the experimental studies (Figure 3b) were applied. The "coupling" option has been used to connect a solid element to a shell element using a reference point.

Three steps of loading procedure were used to analysis. In the first step the axial compression force $10 \mathrm{kN}$ was applied into bolts to simulate initial contact between column flanges and end- plates. The gravity load of whole model as second step was applied to reduce dynamic effects and archiving model stability. In third step the vertical load on top of internal column was applied by carrying out a displacement controlled dynamic pushdown analysis. Smooth step option was applied to reduce dynamic effects.

As a columns cross-section HEB 200 was assumed. IPE 300 was used to modeling beams. The flush and extended end-plate with $10 \mathrm{~mm}$ thickness was applied as two types of end-plate. The welds at whole model were neglected. M20 bolts were used to connect the elements of the joints. A bolt, washer and nut were modeled as parts of connector. The detail of simulation of bolt connector was presented in (Kukla \& Kozlowski \& Siwowski 2021).

Corresponding material models were used for each of the model elements. The material properties of HEB200 and IPE 300 were taken from (Kozlowski \& et al. 2011). Due to lack of material models of end-plate and bolts, values obtained from own tests (Kozlowski \& Kukla 
2019) were assumed. The true stress-strain relationship was defined to simulate realistic behavior on material models. The material model used to analysis subframe as in (Kukla \& Kozlowski \& Siwowski 2021) were adopted.

For solid elements the hexagonal element shape in the mesh control was used. To obtain regular shapes of mesh in all solid elements of model the sweep technique with medial axis algorithm was applied. To fracture simulations the element deletion were employed. The columns, ends of beams and end-plate by $10 \mathrm{~mm}$ and $5 \mathrm{~mm}$ mesh size were meshed (Figure 4), respectively. The bolt connector was meshed singly. As a main density equal 3,5 $\mathrm{mm}$ for bolts and nut were assumed. Quad-dominated element shape with free technique in medial axis algorithm was developed for shell elements. As a size (Figure 4) of mesh $50 \mathrm{~mm}$ density was assumed.

Relevant results of the experimental tests of the frame subsystem with bolted joints with a $10 \mathrm{~mm}$ thick flush and extended end-plate with numerical analysis results based on the finite element method were compared. The basic behavior curve of the subsystem vertical load - vertical displacement was assessed for compliance of both methods. The force-displacement curve obtained from the experimental and numerical tests is shown in Figure 5a. It can be noticed that up to a specimen deflection of about $200 \mathrm{~mm}$ the compliance was almost perfect. After exceeding the displacement of $200 \mathrm{~mm}$, there was a slight increase in the difference of both results. Final displacement upon failure achieved good agreement in both cases. The presented results of the FEM analysis can therefore be considered as a good agreement with the results of experimental studies.

The response curves of the steel subsystem with extended end-plate joints are shown in Figure 5b. A very good convergence was obtained until the vertical displacement of the column was about $100 \mathrm{~mm}$. After exceeding the deflection of $100 \mathrm{~mm}$, the values began to
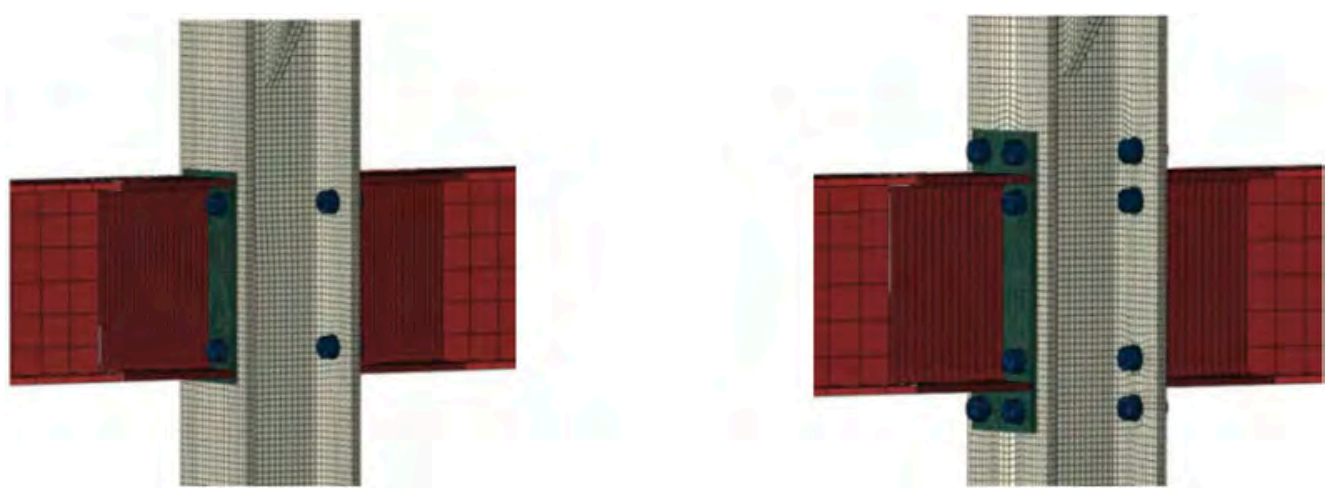

Figure 4. Detailed view of flush and extended end-plate joint with mesh.

a)

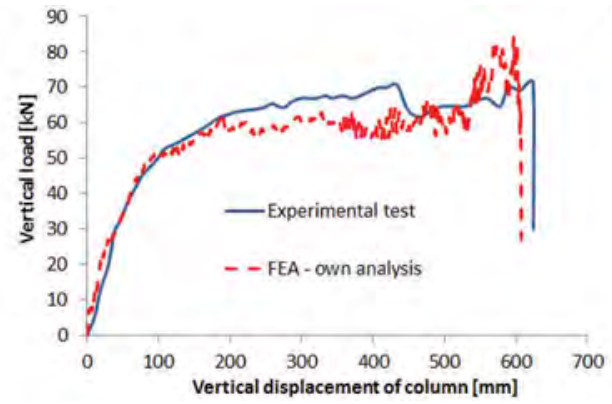

b)

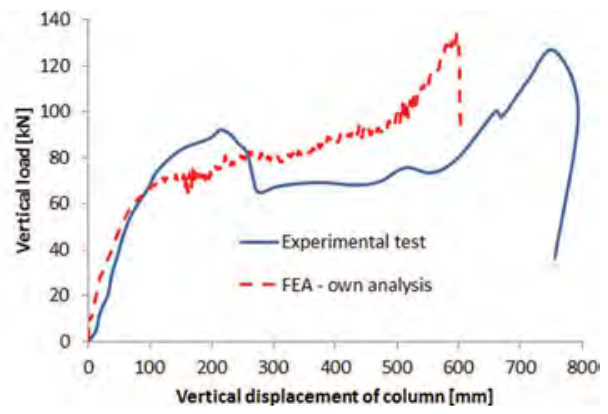

Figure 5. Curve load-vertical dispatement of specimen with: a) flush end-plate, b) extended end-plate. 
differ slightly. The difference in the final displacement on failure was about $150 \mathrm{~mm}$. The obtained values of the test results and the analysis can be considered acceptable.

Presented analysis confirms that created FEM model can be used in frame structures analysis mentioned in point 4.

The largest deformations of the system were located at the joints (Figure 6). The inner joint of the outermost column was significantly deformed. Large deformations (Figure 6a) can be seen especially in the end-plate. The bend of the column flange was also visible. The comparative image of the deformation of the extreme column shows their good agreement.

The deformation of the middle column joint is presented in the Figure 6b. The significant deformation of the joint (Figure 6b) was obtained in the numerical analysis. The comparison (Figure $6 \mathrm{~b}$ ) of the joint views after the tests confirms the good agreement. Both joints were destroyed by breaking the end plate at the level of the beam bottom flange. The comparison of whole view specimen and model after test was presented in Figure 7.

a)

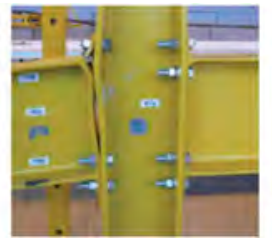

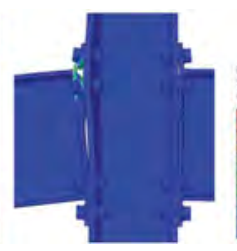

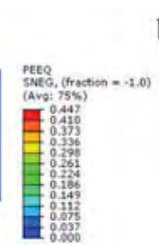

b)
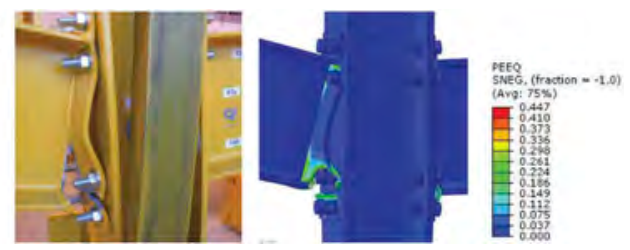

Figure 6. Failure mode of $10 \mathrm{~mm}$ exteneded end plate: a) external column joint, b) internal column joint.

a)

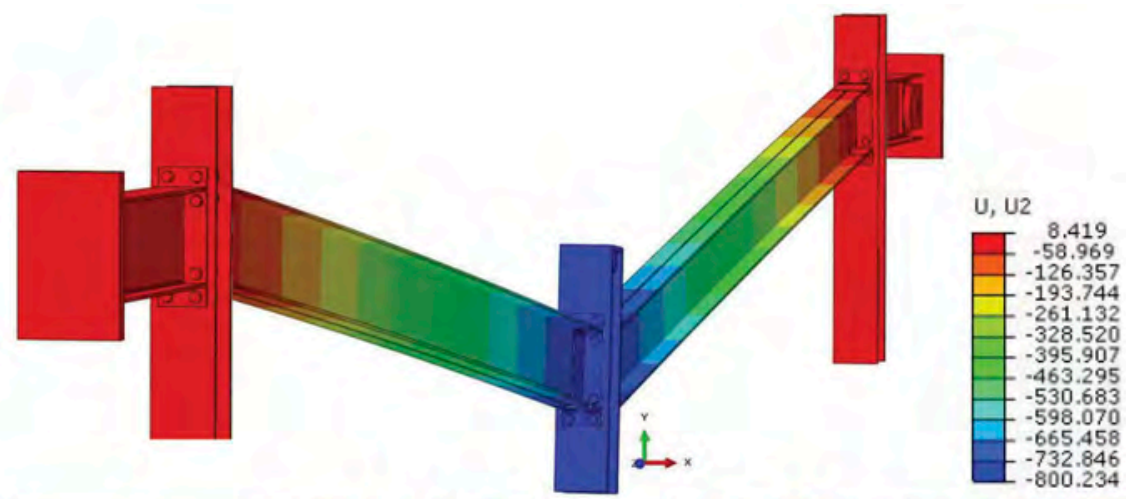

b)

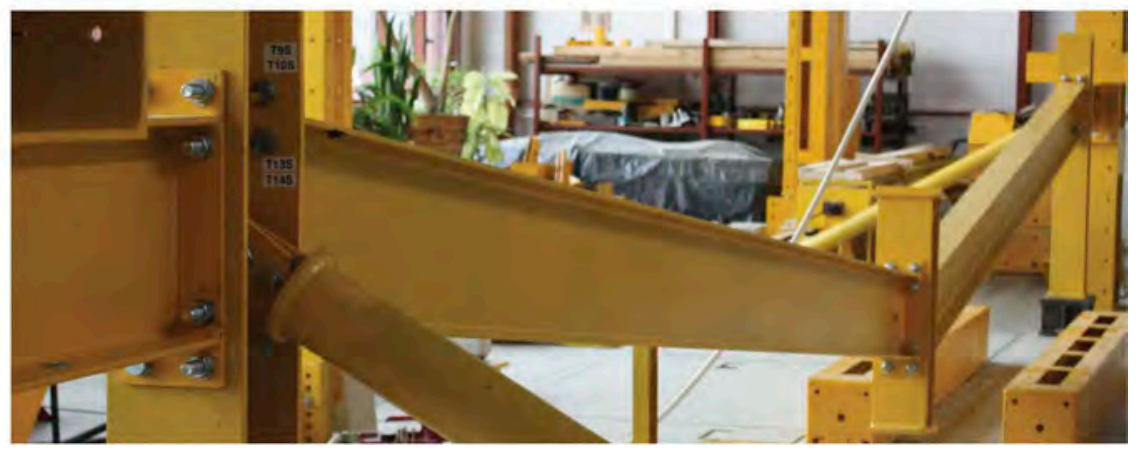

Figure 7. Failure mode of subframe: a) model, b) specimen. 
a)

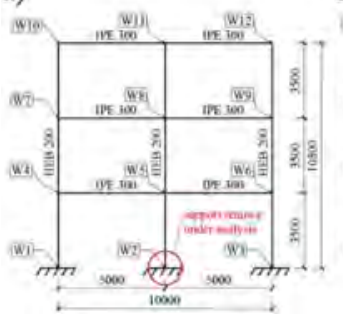

b)

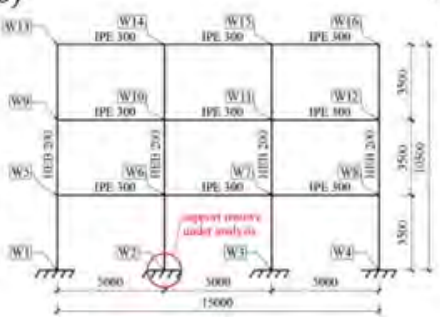

c)

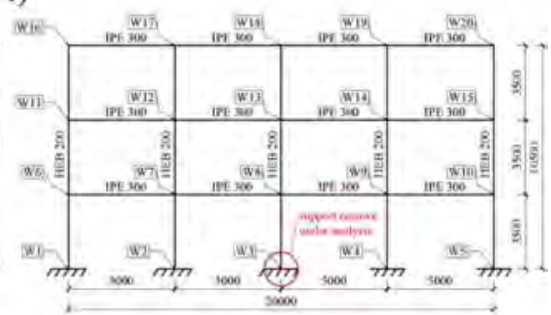

Figure 8. Static diagrams of analyzed frames: a) two span, b) three span, c) four span.

\section{FRAME STRUCTURE ANALYSIS}

The numerical dynamic study on progressive collapse of planar steel frames under sudden column loss were presented in (Znang \& Jiang \& Xu \& Wang 2018). Finite element models with refined shell elements were developed. The welded beam-to-column joints were analyzed. It was summarized that ascrucial load and robustness of frame structure in a strong beamweak column is larger than in a strong column-weak beam ones.

A joint model for assessing the rotational stiffness of semi-rigid connection were adopted in (Li \& Li \& Jiang \& Lu 2018) in the form of multi-spring component model (MSC). The effect of semi-rigid connection as crucial for the deformation and load-distribution were noticed. The results show that the side column loss leads to the largest maximum displacement at the top of the removed column.

The analysis of steel moment frame robustness under vehicle impact was presented in (Kang \& Kim 2014). A various speed of vehicle was adapted to assessing structural response. It was found out that effect of collision to the corner column was much greater than collision to the exterior column.

The study of progressive collapse of planar steel frames under column loss were presented in (Klakojour \& Sheidaii 2018). The influence of finite element modeling and analysis technique were analyzed. As a major influence on structural response a mesh size and removal time of column were obtained.

The next step of conducted research was to analyze behavior of steel frames presented in Figure 8 in column loss scenario. The models of frames were created at the same way as for subframe. The solid and shell elements were used. The sudden and gradual remove of column support were applied. The results of this analysis will be presented in the next papers.

\section{CONCLUSIONS}

Whole research project include multi steps process of experimental tests and numerical analyzes to assess the structural robustness under accidental situations of steel planar frame structures with bolted end-plate joints. In detail the project contain experimental tests of isolated bolted end-plate joints, numerical and parametrical analysis of joints, analysis of subframes structures and finally analysis of whole frame planar structures. In this paper results of the part of research project concerning finite element analysis used for a comparative analysis of the results of frame substructure has been presented. Based on obtained first results, the following remarks can be drawn:

- FEM models of experimentally tested bolted end-plate joints, tested in isolation and in subframe configuration, were positively checked by the presented comparative analysis of selected results. Presented modeling technique will be usedfor further numerical analysis of the whole frames, 
- the application of end plate joint in frame structure leads to obtain a significant load capacity, rotational capacity and large deformation of joint and whole models,

- the advanced FEM modeling with solid and shell elements allows to observe the behavior of all joint components under time analysis, state the weakest components and failure mode of joint and structure.

\section{ACKNOWLEDGEMENT}

This research was supported by a Polish Ministry of Science and Higher Education grant to maintain research potential.

\section{REFERENCES}

Dassault, Abaqus - User Analysis User's Manual. Dassault Systems Simulia Corp.

Kang, H. \& Kim, J. 2014. Progressive collapse of steel moment frames subjected to vehicle impact. American Society of Civil Engineers.

Klakojour, F. \& Sheidaii, M.R. 2018. Effects of finite modeling and analysis techniques on response of steel moment-resisting frame in dynamic column removal scenarios. Asian Journal of civil Engineering.

Kozlowski, A. \& Gizejowski, M. \& Sleczka, L. \& Pisarek, Z. \& Saleh, B. 2011.Experimental investigation of the joints behaviour-Robustness assessment of steel and steel concrete composite frames. Proceeding of the 6th European Conference on Steel and Composite Structures: 339-344. Budapest.

Kozlowski, A. \& Kukla, D. 2019. Experimental tests of steel unstiffened double side joints with flush and extended end plate. Archives of Civil Engineering. vol. LXV. ISSUE 4:127-154.

Kukla, D. \& Kozlowski, A. 2021.Parametric study of steel flush and extended end-plate joints under column loss scenario. Engineering Structures (Paper under review).

Kukla, D. \& Kozlowski, A. \& Siwowski, T. 2021. Numerical analysis of steel double side joints with flush and extended end plate under accidental situation. Eurosteel 2021 (Paper finally accepted).

Li, L-L. \& Li, G-Q. \& Jiang, B. \& Lu, Y. 2018. Analysis of robustness of steel frames against progressive collapse, Journal of Constructional Steel Research 143:264-278.

Znang, J. \& Jiang, J. \& Xu, S. \& Wang, Z. 2018.An investigation of the effect of semi-rigid connections on sudden column removal in steel frames. Structures 13:166-177. 


\title{
3D numerical models of steel joints with hollo-bolts - a comparison with experimental results
}

\author{
A.B. Mesquita, L. Simões da Silva \& S. Jordão \\ Institute for Sustainability and Innovation in Structural Engineering, Department of Civil Engineering, \\ University of Coimbra, Coimbra, Portugal
}

\begin{abstract}
The present paper focuses on the structural behaviour of beam-to-column connections between I and SHS sections using hollo-bolts on both external and corner joints. Several 3D numerical models were developed to compare numerical results with the experimental ones, previously obtained using full-scale prototypes under monotonic load. A numerical calibration was carried out with the real geometrical and mechanical properties of the different profiles. Both flush and extended endplates were used so that M16 and M20 hollo-bolts could be used to assemble the half T-stub to the tubular columns. All structures were modelled using 3D solid elements and static non-linear numerical analysis were performed. The principal conclusions concerning the moment-rotation curve and the main phenomena influencing the behaviour of the joints are discussed, regarding both plastic resistant moment and initial stiffness rotation. A comparative ratio between numerical and experimental results is presented for those structural properties.
\end{abstract}

\section{INTRODUCTION}

Steel frames with hollow section elements have been an attractive choice for several design solutions given their structural, technological, and constructive advantages that lead to aesthetic and optimized structures. The main drawback to its use is related with the joints, specifically in the case of bolted connections since there is no access to the inside of the section to tight the bolt's head. Lindapter's hollo-bolt is one of the fastening technologies included in the blind bolts systems and tries to minimize or even overcome that problem. However, these bolts are mainly indicated for design nominally pinned connections that only involve transfer of vertical shear, disregarding their use under tension originated by a bending moment.

Previous research carried out by several authors focused on evaluating the behaviour of blind bolts in either pure tension or shear loading (Yeomans (1998) and Wang et al. (2018)), on pull-out tests of EHB and standard hollo-bolts in concrete filled sections (Pitrakkos \& Tizani (2015)) and, for instance, on investigating the effect of bolt gauge on the face bending behaviour of concrete-filled SHS in connections using the hollo-bolt, Elamin et al. (2015).

This study introduces some new results about the hollo-bolts' resistant capacity under both tension and shear but also explores the behaviour of the SHS face when subjected to moments from a connection fastened using that blind bolt. For that purpose, an experimental campaign was carried out at the Department of Civil Engineering of the University of Coimbra, where 14 full scale prototypes were tested using IPE beams, SHS columns and HBM16/HBM20, considering both flush and extended endplates under monotonic loads. Results of this set of tests were presented and discussed in Mesquita et al. (2010) and Mesquita (2019), which are the basis for the geometrical and mechanical properties of the FEM models presented in this paper. 
Following the experimental work, this study presents a set of numerical models developed using the Ansys ${ }^{\circledR}$ software, which results are important to validate the behaviour of the structural response of the tested joints. In order to evaluate the accuracy of the finite element simulations, a comparison between the numerical results and the experimental ones is presented.

\section{FINITE ELEMENT MODELS}

\subsection{Node's configurations and joints' typologies}

The joints' typologies previously selected for the full-scale prototypes and used for the numerical models are presented in Figure 1a) (tests T01_1, T01_3, T02 and T04) and b) (test T03_2). Figure 1c) shows the hollo-bolts used in the correspondent tests. The nodes' configurations used on the FE models are indicated in Figure 1d). The nominal dimensions of the endplates are $370 \times 170 \times 20 \mathrm{~mm}$ for the flush's case (FEP) and 425x170x20 mm for the extended one (EEP), whereas the columns' dimensions are indicated in Figure 1e). Figure 1 also shows the models created on Autodesk Inventor ${ }^{\circledR}$ that were later exported to Ansys ${ }^{\circledR}$.

\subsection{Materials and mechanical properties}

The selected nominal steel grade for all profiles was S355, whereas the hollo-bolts are produced in class equivalent to ISO 8.8 (Lindapter ${ }^{\circledR}$ ). Table 1 shows the average values for the yield stress $\left(f_{y}\right)$, the ultimate stress $\left(f_{u}\right)$, the ultimate strain $\left(e_{u}\right)$ and the Young's modulus $(E)$ for the tested tubular profiles, beams, endplates (flush and extended) and bolts, obtained from uniaxial tensile tests according to Mesquita (2019). Table 1 also includes the values of the true stress $\left(f_{u}{ }^{*}\right)$ used in both multilinear and bilinear isotropic hardening definition and the tangent modulus $\left(E_{T}\right)$ for the bilinear one. These mechanical properties are essential to fully obtain the behaviour of each steel element, envisioning the plasticity of the joints' components.

\subsection{Numerical models}

Taking into account the ratio between the column's width and its thickness (21.5 and 13.17, respectively, for a width equal to $200 \mathrm{~mm}$ and a $t_{c}$ of either 8 or $12 \mathrm{~mm}$ ), the selected type of mesh for all components was the 3D solid hexahedric element (SOLID186) with uniform reduced integration and large deflection options applied. These options allow transversal deformation for each element, whereas also contemplating the propagation of stresses between the elements in contact. Additionally, that type of finite element suits well in irregular meshes, as in the bolts' case. An element size of $10 \mathrm{~mm}$ was selected for the central part of the column

a)

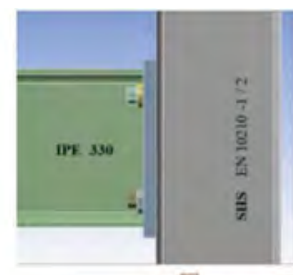

d)
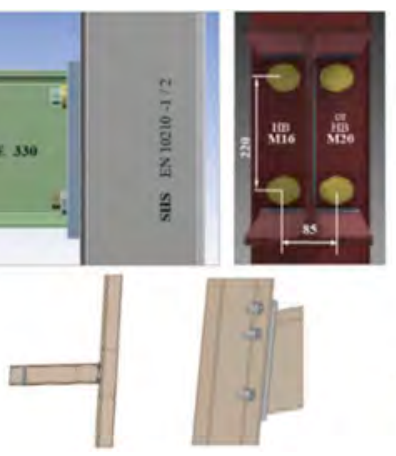

b)

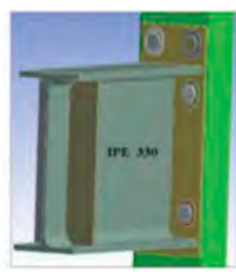

e)

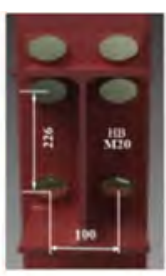

c)
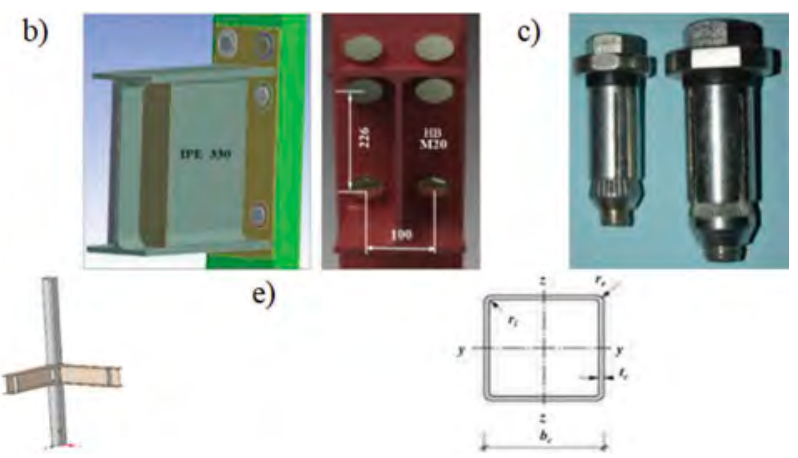

Figure 1. Caption of the joints' typologies and general dimensions of the external/corner nodes. a) Typology A, b) Typology B, c) Hollo-bolts, d) Nodes' configurations: external and corner, e) SHS dimensions: 200x8; $200 \times 12$. 
Table 1. Synthesis of the geometrical dimensions and element's mechanical properties.

\begin{tabular}{|c|c|c|c|c|c|c|c|c|}
\hline \multirow[b]{2}{*}{ Element(s) } & $f_{y}$ & $f_{u}$ & $\varepsilon_{u}$ & $\mathrm{E}$ & $\mathrm{v}$ & $f_{u}^{*}$ & $E_{T}$ & \multirow[b]{2}{*}{ Plastic/Strain* } \\
\hline & [MPa] & [MPa] & {$[\%]$} & [GPa] & & [MPa] & [MPa] & \\
\hline SHS 200x8 & 475.3 & 541.7 & 27.9 & 203.6 & 0.3 & 649.4 & - & M.I.H. \\
\hline SHS 200x12 & 503.3 & 568.3 & 25.1 & 205.5 & 0.3 & 610.3 & - & M.I.H. \\
\hline IPE 330 & 421.6 & 510.4 & 31.2 & 205.0 & 0.3 & 631.5 & - & M.I.H. \\
\hline FEP & 315.0 & 462.7 & 31.7 & 196.8 & 0.3 & 577.8 & 1151.4 & B.I.H. \\
\hline EEP & 315.0 & 462.7 & 31.7 & 196.8 & 0.3 & 577.8 & 1151.4 & B.I.H. \\
\hline Shank HBM16/20 & 640.0 & 800.0 & - & 190.0 & 0.3 & 880.0 & - & M.I.H. \\
\hline $\begin{array}{ll}\text { Sleeves } & \text { HBM16 } \\
& \text { HBM20 }\end{array}$ & $\begin{array}{l}427.6 \\
389.2\end{array}$ & $\begin{array}{l}527.0 \\
510.0\end{array}$ & - & 190.0 & 0.3 & - & 860.0 & B.I.H. \\
\hline
\end{tabular}

* Plastic/Strain relation introduced in Ansys: M.I.H. - Multilinear isotropic hardening; B.I.H. - Bilinear isotropic hardening;

a)
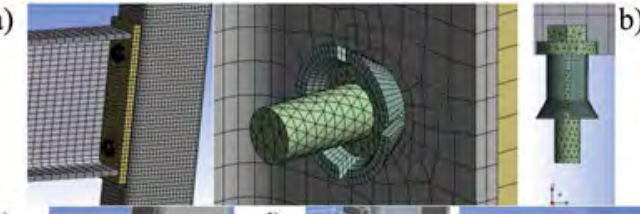

b)
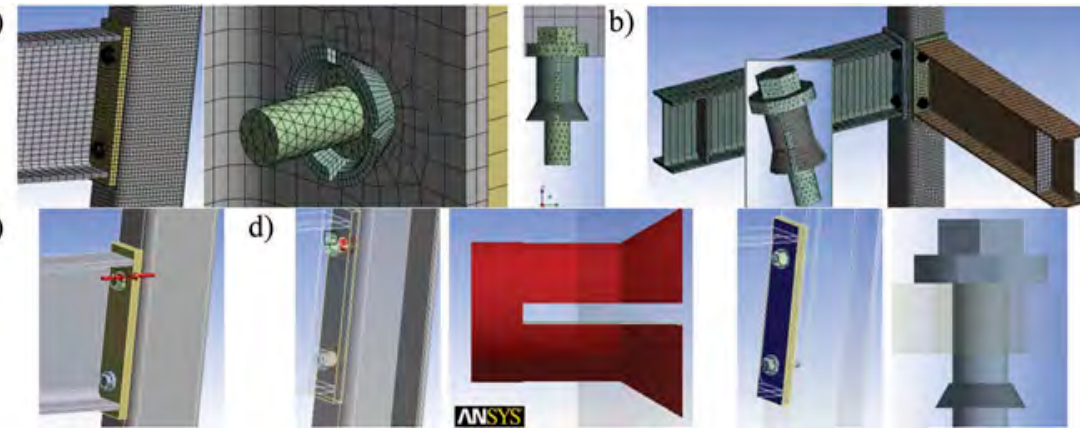

d)
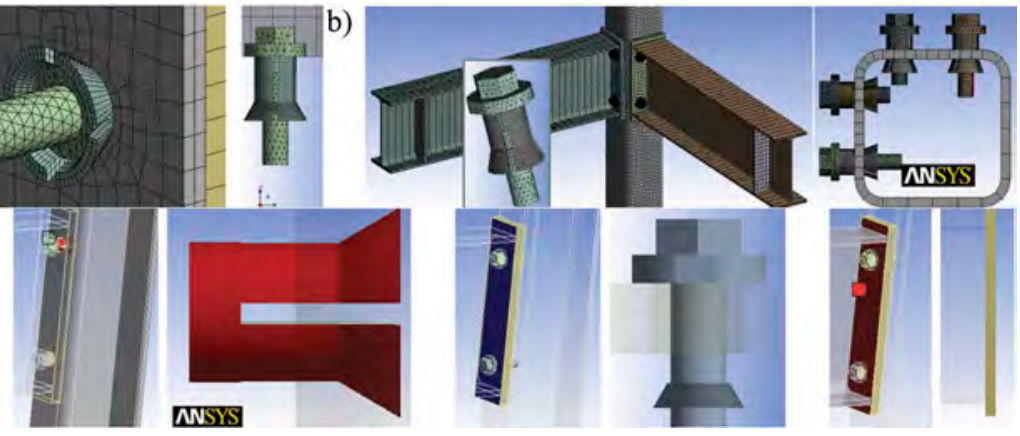

Figure 2. Caption of the models' mesh and contact elements' view. a) T01_1 mesh, b) T04 mesh (J1 and J2), c) Bolt pretension, d) Contact - target elements (sleeves-shank-collar-head-endplate-column-beam).

with 2 elements through its thickness, $25 \mathrm{~mm}$ for beams, $15 \mathrm{~mm}$ for endplates, $4 \mathrm{~mm}$ for bolts' shanks and $2 \mathrm{~mm}$ for sleeves.

The finite element model used for the analysis of the tests T01_1, T01_3 and T02 (external nodes using flush endplates) is shown in Figure 2a). Figure 2b) illustrates the model developed for the T04 joint (corner node). Also, the extended endplate joint (T03_2 test) used a mesh similar to T01_3 but with 3 bolts rows, as illustrated in Figure 9.

The contact elements have a critical influence on the success of the solution. These were defined as frictional (using Penalty formulation with a friction coefficient between 0.3 and 0.5 depending on the location), frictionless and bonded considering the location of the several components of the model. They were established to respect the contacts and targets with a symmetrical behaviour and an advanced specific formulation adapted to each case, Figure 2d). Following Mesquita et al. (2010) and Mesquita (2019), a bolt pretension was applied on both HBM16 and HBM20 using a tightening torque of $190 \mathrm{Nm}$ (first case) and $500 \mathrm{Nm}$ (second one), according to Figure 2c). In addition, symmetrical boundary conditions were taken in consideration where applicable.

\section{MAIN RESULTS OF THE NUMERICAL SIMULATIONS}

\subsection{General considerations}

Based on the information provided in Table 1, several static non-linear analyses were performed. A vertical displacement was imposed for each test (the final deformation obtained experimentally on each beam's free end), with the ultimate goal of obtaining the reaction 
forces for that test. The numerical results are presented and compared using forcedisplacement and moment-rotation diagrams, included in the next points. In order to obtain the rotation, it was followed the methodo-logy referred in Mesquita et al. (2010) and Mesquita (2019). The structural properties of the joints, such as the plastic moment $\left(M_{p l, n u m}\right)$ and the initial stiffness rotation $\left(S_{j, \text { ini,num }}\right)$, were calculated through graphical considerations based on Jaspart's method.

\subsection{T01_1 results: Column SHS 200x8, beam IPE 330 and 4 hollo-bolts HBM16}

Figure 3 shows the deformation obtained on the first test considered. The load-horizontal displacement (on the upper's bolts row) as well as the load-vertical displacement (on the beam's end) relations are shown in Figure 4, where is also included the moment-rotation diagram. For all cases, it is possible to observe a superposition between the numerical and experimental results on several parts of these diagrams, especially a well agreement $(M-\Phi)$ on the elastic range (with the slope of the experimental reload), but also on the plastic one.

\subsection{T01_3 results: Column SHS 200x8, Beam IPE 330 and 4 hollo-bolts HBM20}

Concerning the T01_3 test, the HBM20's deformation at the final stage of the plastic domain is illustrated in Figure 5, where is possible to see the sleeves plasticity responsible for the respective collapse of these bolts. This conclusion was observed on all tested joints, as referred in Mesquita et al. (2010) and Mesquita (2019), which indicates that this element is responsible for the integrity of the joint. Figure 5 presents also the evolution of the $M-\Phi$ numerical curve
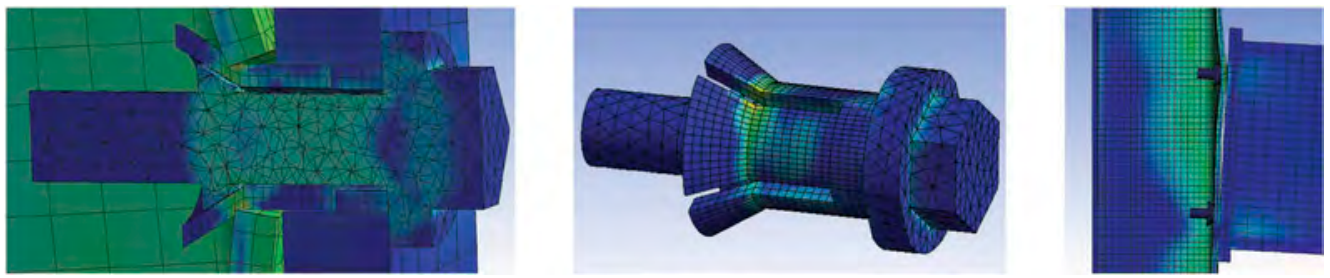

Figure 3. Caption of node and bolts' deformation - EN: T01_1 (FEP: typology A).
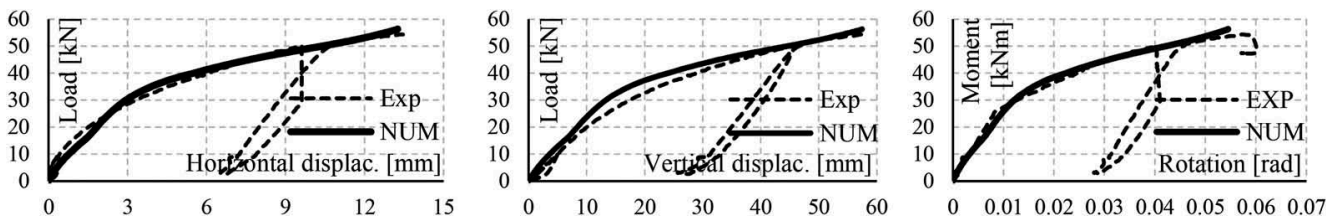

Figure 4. Caption of T01_1 F-d and $M-\Phi$ diagrams: experimental (Mesquita (2019)) versus numerical.
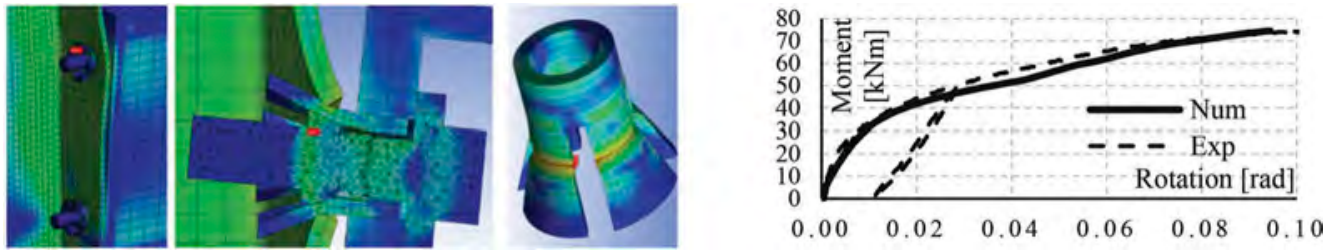

Figure 5. Caption of node and bolts' deformation - EN: T01_3 (FEP: typology A) and $M-\Phi$ diagrams: experimental (Mesquita (2019)) versus numerical. 
compared to the correspondent experimental one. The biggest values of displacements and rotations in this test, when compared to the previous ones indicated on test T01_1, are due to the largest diameter of the hollo-bolts used in this last case, which demonstrate superior resistance capacity.

\subsection{T02 results: Column SHS 200x12, Beam IPE 330 and 4 hollo-bolts HBM20}

This test introduces the column's thickness as a new variable in the study. The deformation of the column in T02 test (Figure 6) was smaller compared with the one of the test T01_3, once the respective column's thickness was equal to $12 \mathrm{~mm}$, which is $50 \%$ larger than the one from the SHS profile used in the previous tests $(8 \mathrm{~mm})$. Also, Figure 6 presents the evolution of the moment-rotation curves (experimental and numerical), showing a good agreement between these. The difference on the initial stiffness rotation is due to some contact penetration originated by a low normal stiffness value $(0.1)$ introduced in the contact definitions between the bolt's legs and the SHS. This value had to be lowered because convergence problems were detected on that contact area, as stated in Lee (2017).

\subsection{T04 results: Column SHS 200x12, 2 Beams IPE 330 and 4x2 hollo-bolts HBM20}

In addition, a corner node including two orthogonal joints using flush endplates was also simulated. Its results represent a typical situation of joints' asymmetry, Figure 7 . The differences between the experimental and numerical curves (Figure 8) are due not only to some experimental uncertainties caused by distinct load actuators (although they had the same increments) but also due to the column's bottom hinged support that allowed rotation in the plane of the left beam of Figure 7, restraining it in the perpendicular one, as illustrated in Mesquita et al. (2010). Moreover, the experimental values of load and displacement were only registered after the first $10 \mathrm{kN}$, which caused some differences concerning the graphical evolution (origin's ordinate) of the diagrams.
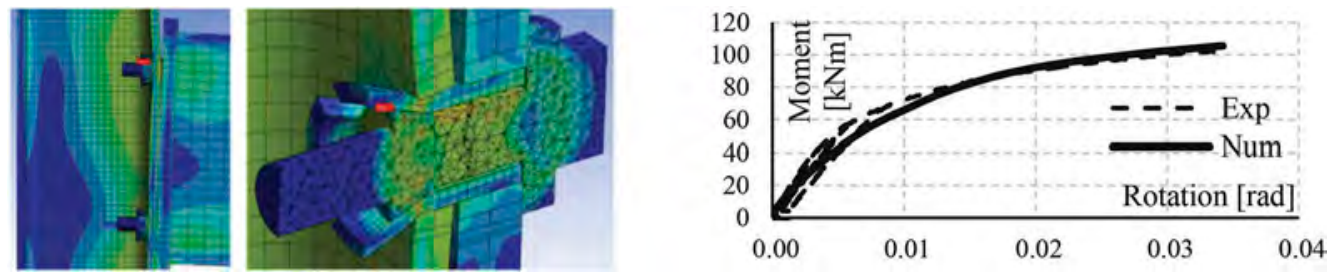

Figure 6. Caption of node and bolts' deformation for T02 (FEP: typology A) and $M-\Phi$ diagram: experimental (Mesquita (2019)) versus numerical.
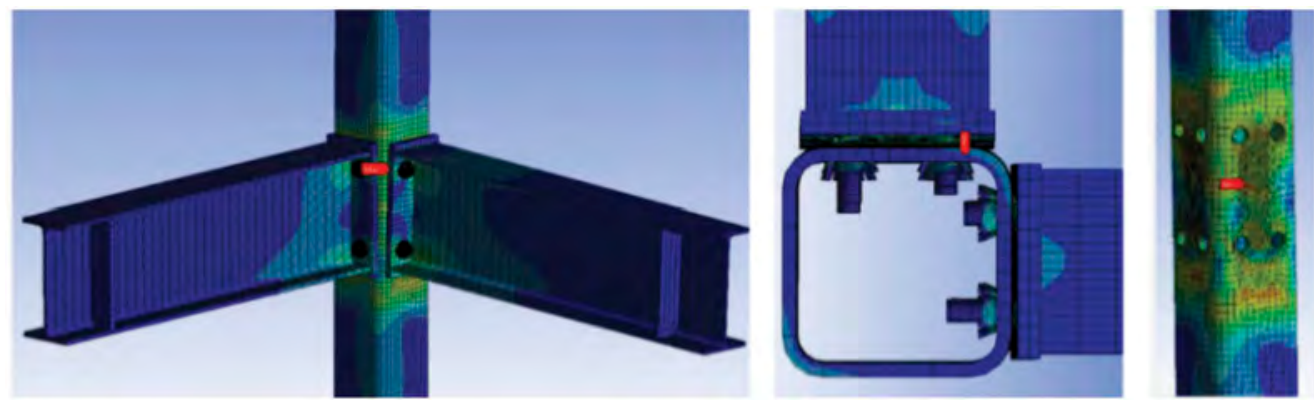

Figure 7. Caption of node, column and bolts' deformation - CN: T04 (FEP: typology A). 

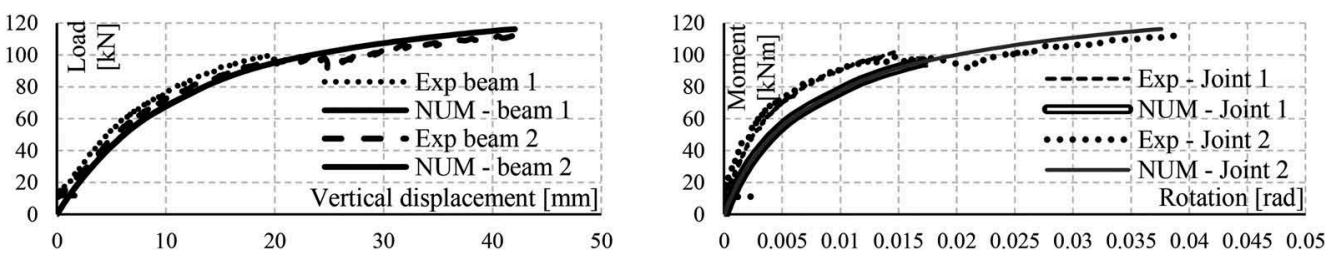

Figure 8. Caption of T04 $F-d$ and $M-\Phi$ diagrams: experimental (Mesquita (2019)) versus numerical.
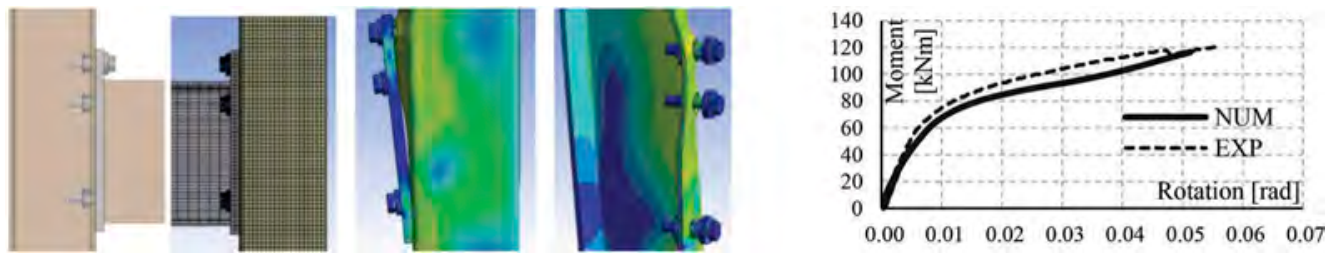

Figure 9. Caption of node and bolts' deformation - EN: T03_2 (EEP: typology B) and $M-\Phi$ diagrams: experimental (Mesquita (2019)) versus numerical.

\subsection{T03_2 results: Column SHS 200x8, 1 Beam IPE 330 and 6 hollo-bolts HBM20}

Figure 9 presents the results regarding T03_2 test that included an extended endplate where is possible to see the 3 bolts rows. The preliminary results regarding this analysis also show a relatively good approximation between both curves, in which the final numerical load was found to be $119 \mathrm{kN}$ against the experimental one $(120 \mathrm{kN})$. Anyway, the resistant capacity to bending evidenced by this joint was analogous to the results of the test T04.

\section{PLASTIC RESISTANT MOMENT AND INITIAL STIFFNESS ROTATION}

Table 2 presents the set of results obtained from the experimental analyses as well as from the numerical simulations concerning the plastic moment $\left(M_{p l}\right)$ and the initial stiffness rotation $\left(S_{i n i}\right)$. It is also presented a rattio between the numerical result over the experimental one in order to evaluate the relative proportion concerning those structural properties obtained for the simulated joints. In addition, it is crucial to mention that to calculate the $S_{j, \text { ini,exp }}$ the reload part of the elastic region in the experimental $M-\Phi$ diagrams was used, which didn't happen in the numerical ones so, some differences in this parameter might be due to this reason.

Table 2. Experimental and numerical results of $M_{p l}, S_{i n i}$ and its ratios.

\begin{tabular}{|c|c|c|c|c|c|c|}
\hline & $\mathrm{M}_{\mathrm{pl}, \exp }$ & $S_{j, \text { ini,exp }}$ & $\mathrm{M}_{\mathrm{pl}, \text { num }}$ & $\mathrm{S}_{\mathrm{j}, \text { ini,num }}$ & $M_{p l, \text { num }} / M_{p l, \exp }$ & $S_{j, \text { ini,num }} / S_{j, \text { ini, exp }}$ \\
\hline Test & {$[\mathrm{kNm}]$} & {$[\mathrm{kNm} / \mathrm{rad}]$} & {$[\mathrm{kNm}]$} & {$[\mathrm{kNm} / \mathrm{rad}]$} & {$[-]$} & {$[-]$} \\
\hline T01_1 & 36.1 & 3207.0 & 35.0 & 3010.2 & 0.97 & 0.94 \\
\hline T01_3 & 50.6 & 7380.7 & 40.3 & 5369.1 & 0.80 & 0.73 \\
\hline T02 & 70.7 & 21468.0 & 68.8 & 18435.0 & 0.97 & 0.86 \\
\hline $\mathrm{T} 04 \mathrm{~J}_{1}$ & 79.5 & 26307.0 & 76.5 & 18024.0 & 0.96 & 0.69 \\
\hline T04_J $\mathbf{J}_{2}$ & 81.0 & 26210.0 & 77.0 & 17670.0 & 0.95 & 0.67 \\
\hline \multirow[t]{2}{*}{ T03_2 } & 83.0 & 13534.0 & 76.4 & 13880.0 & 0.92 & 1.03 \\
\hline & & & & Average $=$ & 0.93 & 0.82 \\
\hline
\end{tabular}




\section{CONCLUSIONS}

The present work allows the evaluation of the level of confidence of the several finite element models developed in order to reproduce the full-scale joints previously tested between IPE and SHS sections using hollo-bolts subjected to both tension and shear. The average of the presented ratios concerning numerical and experimental results is about 0.93 for $M_{p l}$ and 0.82 for $S_{j, \text { ini }}$. Even though there is some lack of stiffness in the models T01_3 and T04, the presented set of results constitute a good basis for the analysis of all joints and nodes tested. Besides, the hollo-bolt's sleeves were the first component to enter in failure in all tests, which allows to conclude that they were responsible for the integrity of the joint. In future work, it will be possible to implement a parametric study in which the value of the bolt's tightening torque, the width and the thickness of the tubular profiles can be variable in the context of the design's process. To do that, it will be taken into account the collapse of the hollo-bolts' sleeves as well as the plasticity of the column's wall with a thickness of $8 \mathrm{~mm}$ around the bolts' holes. The plastic deformation of the column's loaded face in the SHS profiles $12 \mathrm{~mm}$ thick is not significant.

\section{REFERENCES}

Elamin, A., Tizani, W., Mahmood, M., 2015. Bolts Gauge Effect on the Face Bending Behaviour of Concrete-Filled Hollow Section for Hollo-Bolted Connections. Applied Mechanics and Materials 773$774,105-109$.

Lee, Huei H. 2017. Finite Element Simulations with ANSYS ${ }^{\circledR}$ Workbench 18 - Theory, Applications, Case Studies. SDC Publications.

Mesquita, A.C.B., Simões Da Silva, L.A.P., Jordão, S., 2010. Behaviour of I beam-SHS column steel joints with hollo-bolts: An experimental study, in: Tubular Structures XIII - Proceedings of the 13th International Symposium on Tubular Structures. pp. 17-25.

Mesquita, A.C.B. 2019. Three-Dimensional Behaviour of I Beam - SHS Column Joints with Hollo-bolts Subjected to Monotonic Loads. PhD Thesis in Steel and Mixed Construction presented to the Civil Engin. Depart. of the Faculty of Science and Technology of the University of Coimbra (in Portuguese).

Pitrakkos, T. \& Tizani, W. 2015. A component method model for blind-bolts with headed anchors in tension. Steel and Composite Structures, Vol. 18, No. 5. 1305-1330.

Wang, W., Li, L., Xu, T., 2018. Progressive collapse behaviour of extended endplate connection to square hollow column via blind Hollo-Bolts. Thin-Walled Structures 131, 681-694.

Yeomans, N. F. 1998. Rectangular hollow section column connections using the Lindapter Hollo-Bolt. Proceedings of Eighth International Symposium on Tubular Structures. Ed.: Choo, van der Vegte, Ro-terdam: Balkema. pp. 559-566. 


\title{
Effective weld lengths of RHS overlapped K connections with the transverse gusset plates
}

\author{
P. Milewski \& M. Broniewicz \\ Bialystok University of Technology, Biatystok, Poland
}

\begin{abstract}
European recommendations for rectangular hollow section (RHS) connection design requires that welds between truss bracing members and chords should have the same resistance as the yield capacity of the member. In the case of weld design based on the actual forces acting in the elements, the designer can use a smaller size of welds, meeting the requirements of the connection deformation and rotation capacity. For overlapped $\mathrm{K}$ and $\mathrm{N}$ connections, limited experimental research (Davies \& Packer (1982)), on 50\% overlaps connections have shown that entire overlapping bracing member contact perimeter can be considered as effective. However, no studies of overlapped joints have been carried out so far, with values of overlap from $25 \%$ to $50 \%$ and from $50 \%$ to $100 \%$ being used for overlapped $\mathrm{K}$ connections with transverse gusset plates. The finite element analysis (FEM) results presented in the article show that the stress distribution in the welds connecting the braces with the chord in $\mathrm{K}$ overlapped joints with the transverse gusset plate is varied and depends both on the value of the angle of the brace concerning the chord, the overlap ratio and the brace to chord width ratio. For inclination angles of braces to the chord of $54^{\circ}$ and $60^{\circ}$, the outer transverse welds are considered to be only partially effective, with the degree of effectiveness depending on the overlap ratio and the wall slenderness values.
\end{abstract}

\section{INTRODUCTION}

Hollow sections have strength, stability, operational and aesthetic advantages, and with a large gradation of the dimensions of sections and their thicknesses, they are suitable for economical design. The traditional shaping of joints, especially of circular hollow sections, leads to low-tech solutions requiring a lot of shop labour, making components too expensive to compete economically with hot-rolled, open sections. Construction difficulties and the relatively high price of hollow sections (particularly rectangular ones) made it necessary to develop modern design solutions.

Hollow sections can be reduced to a few basic shapes, suitable for both round and rectangular (or square) sections, convenient for semi-automatic control of production processes in a steel structure factory. These solutions are, typically, devoid of additional gusset plates or ribs and are cost-effective, in terms of labour consumption, but they require designers to consider the flexural stiffness of the connections between hollow sections. Due to the similarity of hollow section joints to letters, they are designated as K, N, KT, T, Y and X joints.

\section{DESIGN OF WELDS IN K-TYPE JOINTS}

The design procedure for K-type joints with mutually overlapping braces made of closed rectangular sections is included in EN 1993-1-8 (2006) and discussed in the publications Brodka \&

DOI: $10.1201 / 9781003132134-42$ 
Broniewicz (2001), Brodka \& Broniewicz (2004), Brodka \& Broniewicz (2016), Dutta (1999), and Packer et al. (2009). However, the accepted standards, such as those developed by the IIW (1999) or the ISO standard (prepared on their basis) BS ISO 14346 (2011), do not include recommendations regarding issues related to the design of welds between the joined elements. Also, the European standard (EN 1993-1-8 2006) for the design and calculation of structural steel joints, sets out very general recommendations for the assessment of the resistance of members' joints made of hollow sections. Design guidelines IIW (1999), also included in the ISO standard BS ISO 14346 (2011), present a method of checking the shear strength of fillet welds in the plane of contact of braces with the chord in K-type joints with partial or full overlaps using the formulas:

- when $\lambda_{o v, \lim }<\lambda_{o v}<100 \%$ then:

$$
N_{i} \cos \theta_{i}+N_{j} \cos \theta_{j} \leq 0,58 f_{u i} \frac{2 h_{i, r e d}+b_{i . e f f}}{\sin \theta_{i}} t_{i}+0,58 f_{u j} \frac{2 h_{j}+c_{s} b_{j . e f f}}{\sin \theta_{j}} t_{j}
$$

- when $\lambda_{o v, \lim }=100 \%$ then:

$$
N_{i} \cos \theta_{i}+N_{j} \cos \theta_{j} \leq 0,58 f_{u i} \frac{2 h_{i, r e d}+b_{j}}{\sin \theta_{i}} t_{i}
$$

where $N_{i}=$ design axial load in the overlapping brace; $N_{j}=$ design axial load in the overlapped brace; $\theta_{i}, \theta_{j}=$ respectively angles of overlapping and overlapped braces in relation to the chord; $f_{u i}, f_{u j}=$ tensile strength of overlapping and overlapped braces, respectively, provided that $f_{u i} \leq f_{u 0}$ and $f_{u j} \leq f_{u 0}$ ( $f_{u 0}$ is the yield strength of the steel used in the chord); $h_{i, \text { red }}=$ $\left(100-\lambda_{o v}\right) h_{i} / 100 ; b_{i}, h_{i}=$ the width and the height of a cross section of the overlapping brace, respectively; $t_{i}=$ wall thickness of the overlapping brace; $t_{j}=$ wall thickness of the overlapped brace; $t_{0}=$ wall thickness of the chord; $b_{0}=$ width of the chord section and $f_{y 0}, f_{y i}, f_{y j}=$ yield strength of the chord, overlapping and overlapped braces, respectively;

$$
\begin{array}{ll}
b_{i . e f f}=\frac{10}{b_{0} / t_{0}} \frac{t_{0} f_{y 0}}{t_{i} f_{y i}} b_{i} ; & b_{i . e f f} \leq b_{i} \\
b_{j . e f f}=\frac{10}{b_{0} / t_{0}} \frac{t_{0} f_{y 0}}{t_{j} f_{y j}} b_{j} ; & b_{j . e f f} \leq b_{j}
\end{array}
$$

The hidden seam of the brace with the chord can be welded or left without welding. This is expressed by the value $\lambda_{o v, \text { lim }}$ and coefficient $c_{s}$. It is assumed that:

- $c_{s}=1$ and $\lambda_{o v, \text { lim }}=60 \%$ if the hidden seam of overlapped brace is not welded, - $c_{s}=2$ and $\lambda_{o v, \lim }=80 \%$ if the hidden seam of overlapped brace is welded.

In the case of RHS joints, due to the variable stiffness of the thin-walled chord face, which de-creases from the wall edges towards the centre, the force transmitted by the transverse welds is not evenly distributed. The greatest load is transferred through the weld areas closest to the side walls, while the central region may not contribute to the load transmission at all. This can be taken into account in the design of welds using the method of determining their effective lengths. The effective length is the reduced length of the weld, reflecting the way it is strained. Failure to take into account the uneven distribution of stresses in the weld in the design may cause the weld in the area of the side walls to crack, starting at the ends.

Longitudinal welds parallel to the axis of a square or rectangular HSS can be assumed to be fully effective.

This effective length of transverse welds and transverse elements was introduced based on ex-perimental studies conducted by Rolloos (1969), Wardenier et al. (1981) and Davies \& Packer (1982). 


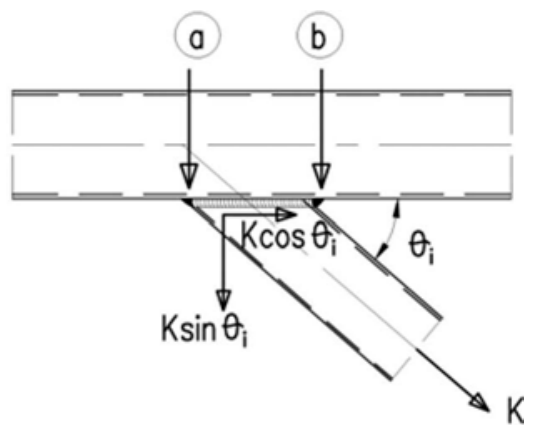

Figure 1. RHS Y-connection under branch axial tension.

From these tests, it was found that the outer transverse weld in a $\mathrm{K}$ gap connection (weld "b" in Figure 1) could only be considered effective in carrying the load when the angle between the brace and the chord $\theta_{i} \leq 50^{\circ}$. It follows that the effective lengths for RHS bracing member welds in gap $\mathrm{K}$ connections can be written using the equations:

$$
L_{i . e f f}=\left(\frac{2 h_{i}}{\sin \theta_{i}}\right)+2 b_{i} ; \quad \text { when } \quad \theta_{i} \leq 50^{\circ} ; \quad L_{i . e f f}=\left(\frac{2 h_{i}}{\sin \theta_{i}}\right)+b_{i} ; \quad \text { when } \quad \theta_{i} \geq 60^{\circ}
$$

For $50^{\circ}<\theta_{i}<60^{\circ}$ a linear interpolation is recommended.

\section{CALCULATION PROCEDURE OF EFFECTIVE WELD LENGTHS IN K-TYPE JOINTS WITH TRANSVERSE GUSSET PLATE}

A procedure for the approximate evaluation of resistance of welded $\mathrm{T}, \mathrm{Y}, \mathrm{X}, \mathrm{K}$ and $\mathrm{N}$ gap joints was developed in Brodka \& Broniewicz (2003) and in Brodka \& Broniewicz (2004). The procedure was extended to joints made of circular hollow sections.

In subsequent publications (Brodka \& Broniewicz 2013) these authors suggest an approximate assessment of the resistance of the welded connection in the overlapped $\mathrm{K}$ type joints, made of rectangular hollow sections (square).

The principles for designing truss joints made of rectangular hollow sections with a transverse gusset plate between the braces are not included in the provisions of ISO (2011) or IIW (1999). This is the result of an increase in required performance due to cutting and welding processes. Therefore, there is a lack of basic information about the resistance and the shaping of such joints in IIW (1999), AISC (2016) and AWS (2010) These joints are simple and necessary in some designs. Joints with a transverse gusset plate are useful when:

a) support joints are specifically designed to slightly overlap,

b) groove welds between brace members are omitted,

c) there is a small overlap of the brace members which is not recommended by EN 1993-1-8

(2006) and, despite their occurrence, requires strength assessment.

The basic shapes of the joints with the reinforcing gusset plates between the braces are shown in Figure 2, in the case of trusses made of square hollow sections. In relatively rare cases, rectangular hollow sections are also used, but the geometry of the joints remains the same. Mostly, the braces have the same width and height. Depending on the kind of truss used, the angles of inclination of the braces are different. Similarly, the joints made of circular hollow sections are shaped sometimes with minor changes. 
a)

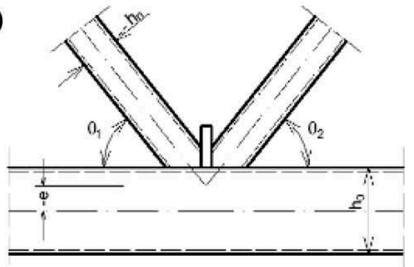

b)

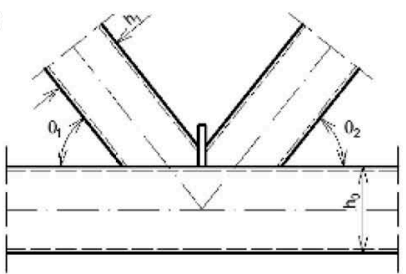

c)

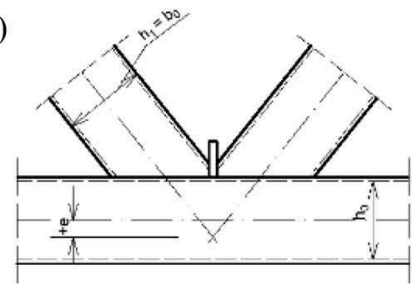

Figure 2. Intermediate joint made of rectangular hollow sections with a reinforcing plate: a) $-e<0,5 h_{0}$, b) $e=0$, c) $e \leq 0.25 h_{0}$.
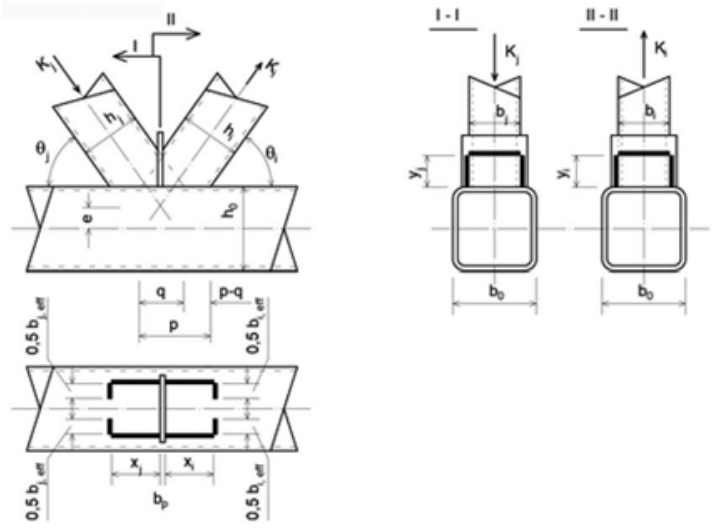

Figure 3. Weld layout in SHS overlap joint with transverse gusset plate.

The method of evaluation of the resistance of the welds in overlap joints with transverse gusset plates, using the formulas given in EN 1993-1-8, was presented by Brodka and Broniewicz (2015). To determine the resistance of the joints, the layout of the welds presented in Figure 3 are considered. In this figure, the dimensions of all of the welds in the spliced braces, with the chord and gusset plate, are indicated.

The lengths of these welds are determined as follows (Figure 4):

$$
\begin{gathered}
l_{1}=x_{j}-1,4 a_{w p}=\left(h_{j} / \sin \theta_{j}-0,5 q-0,5 t_{p}\right)-1,4 a_{w p} ; \quad l_{2}=b_{j . e f f} \\
l_{3}=y_{j}-1,4 a_{w p}=0,5\left(q+t_{p}\right) \tan \theta_{j}-1,4 a_{w p} ; \quad l_{4}=b_{j}
\end{gathered}
$$

\section{EVALUATION OF ANALYTICAL PROCEDURE AND FEM ANALYSIS ON RHS OVERLAP K JOINT WELDS WITH TRANSVERSE GUSSET PLATE}

\subsection{Stress distribution in welds based on the numerical FEM analysis}

FEM numerical tests were carried out for K-type joints with transverse plates made of SHS, at different angles of brace inclination $\theta_{i}$ and different degrees of overlap ratio $\lambda_{o v}$. To obtain different angles of brace inclination, a lattice girder with a span of $12.0 \mathrm{~m}$ was varied, in terms of height, i.e. $1.70 \mathrm{~m}, 1.40 \mathrm{~m}$ and $1.10 \mathrm{~m}$. Corresponding angles of brace inclination to the bottom chord were $60^{\circ}, 54^{\circ}$, and $48^{\circ}$. The truss was loaded with concentrated forces from the standard 


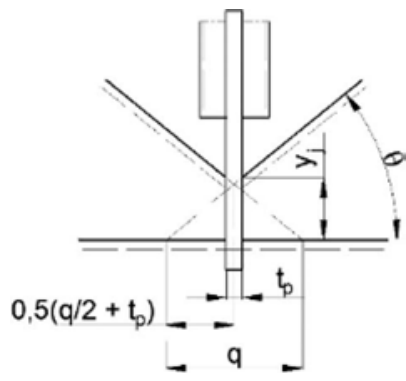

Figure 4. Height of the vertical weld of the plate.

loads (dead, snow, wind loads) in the joints of the top chord. Square hollow sections of SHS $(120 \times 4 \mathrm{~mm})$ were assumed for the sections of the top and bottom chord, while the braces were SHS of $60 \times 3 \mathrm{~mm}$. The ratio of overall brace width to chord width for SHS was constant and equal, $\beta=0,5$. The thickness of the transverse gusset plate was taken to be $5 \mathrm{~mm}$.

The values of stress in the welds decrease with increasing distance from the centre of the joint. This is due to greater stiffness of the joint between the braces $\left(b_{i} / b_{j}=1,0\right)$ than between the brace and the chord $\left(\beta=b_{i} / b_{0}=0,5\right)$ (Figure 5). As the overlap parameter increases, the stress reduction becomes less pronounced and is usually accompanied by an increase in the average stress in the welds.

The stresses in the internal transverse welds connecting the braces with the plate show a high value along the entire length of the weld. This is due to the high flexural stiffness of the joint area, re-sulting from the high value of the coefficient $\beta$. The stresses in the external transverse welds connecting the braces with the chord, decreased almost to zero, which is related to the high value of the chord wall flexibility $\left(\beta=0,5, \lambda=b_{0} / t_{0}=30\right)$. In the longitudinal welds, the stresses were relatively evenly distributed, with a slight decrease in the value away from the centre of the joint. of the joint $\lambda_{o v}=30 \%$.

The high value of stresses in the transverse weld between the braces and the gusset plate is mainly due to the stiffening of this joint zone by the transverse plate, which increases the stiffness connections and also the effective length of the weld.
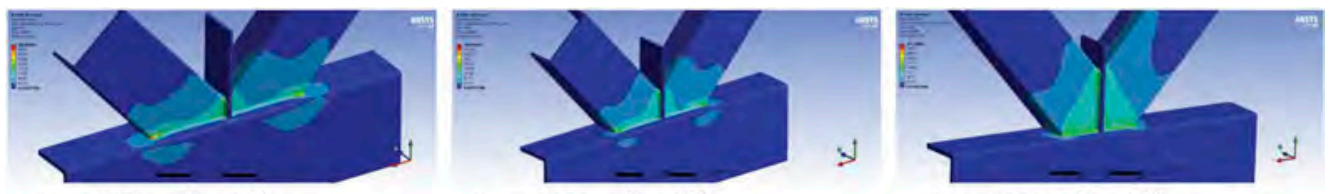

$\lambda_{o v}=30 \% \quad \theta_{1}=48^{\circ}$
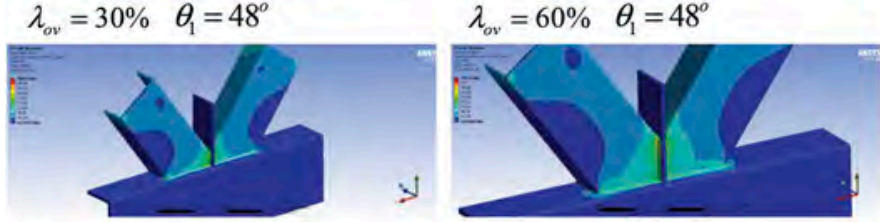

$$
\lambda_{o v}=90 \% \quad \theta_{1}=48^{\circ}
$$

$\lambda_{o v}=30 \% \quad \theta_{1}=54^{\circ}$
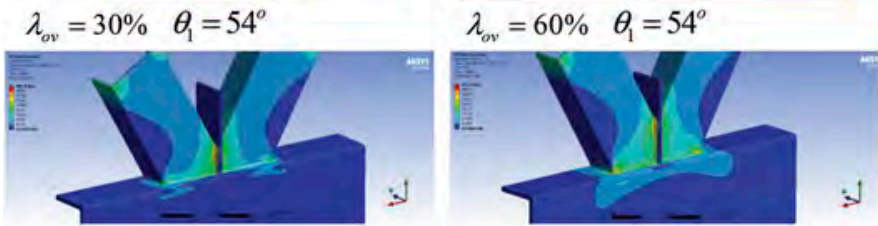

$\lambda_{o v}=30 \% \quad \theta_{1}=60^{\circ}$

$$
\lambda_{o v}=60 \% \quad \theta_{1}=60^{\circ}
$$

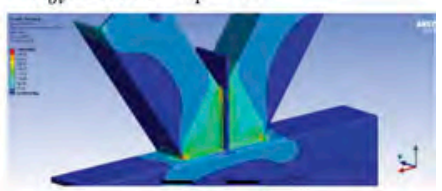

$$
\lambda_{o v}=90 \% \quad \theta_{1}=54^{\circ}
$$

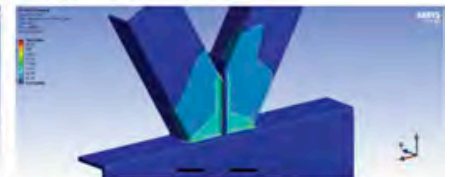

$\lambda_{o v}=90 \% \quad \theta_{1}=60^{\circ}$

Figure 5. Distribution of stresses around braces. 


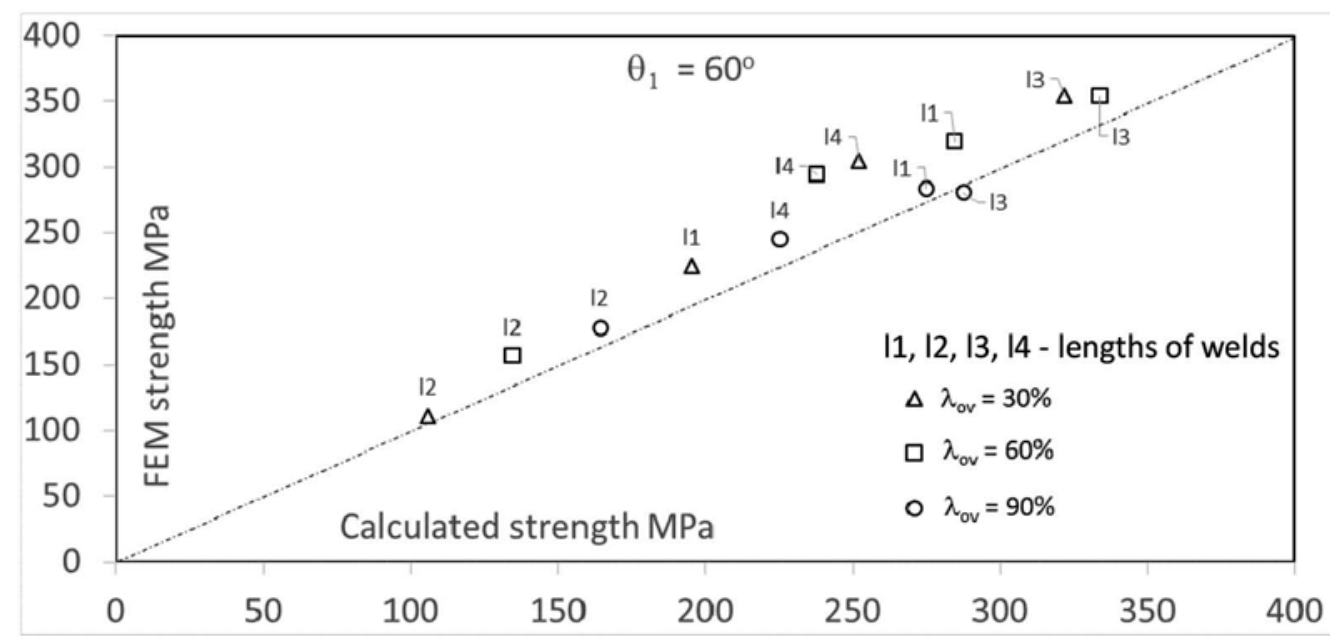

Figure 6. Correlation of FEM analysis with the analytical results for $\theta_{1}=60^{\circ}$.

The stress distribution in the welds around the joined elements shows that the longitudinal welds can be considered to be fully effective, with overlap coefficients $\lambda_{o v}=60 \%$ and $90 \%$. In the case of $\lambda_{o v}=30 \%$, the stress distribution in longitudinal welds is more non-uniform.

The outer transverse welds are only partially effective and become less effective as $\lambda_{o v}$ and $\beta$ decreases.

\subsection{Correlation of analytical results with the numerical FEM analysis}

The analytical procedure proposed by Brodka and Broniewicz (2015) was used to calculate the nominal strengths of the welded connections analysed. The calculated strength of each welded connection was determined by the summation of the individual weld element strengths along the four walls around the braces. The values were calculated analytically and compared with the values obtained from the FEM numerical analysis.

The correlation of FEM analysis with the analytical results is presented in Figure 6.

\section{CONCLUSIONS}

As part of this research, nine different RHS overlap K connections with transverse gusset plate joints were analysed, using the FEM computerised analysis method. Stress distribution, according to the finite element analysis for defined $\lambda_{o v}$ and $\theta$ parameters, is presented in Figure 5.

The analysis shows that all longitudinal welds are effective in stress transfer, with their distribution depending on the distance from the centre of the joint. The outer transverse welds, on the other hand, are not always effective in stress transmission. Their effectiveness depends on the degree of member overlap $\lambda_{o v}$ and the angle of the diagonals $\theta$. In the case of large angles of the braces to the chord $\left(60^{\circ}\right)$, their effectiveness in stress transfer increases. Also, their effec-tiveness decreases as the overlap parameter of lambda $\lambda_{o v}$ decreases. This is due to the greater rigidity of the central part of the joint.

The analytical method of calculating the weld resistance in RHS K-type joints with a transverse gusset plate, taking into account the effective weld lengths, allows for the rational design of welded joints made of hollow sections. It takes into account the actual forces that occur, which results in welds of smaller thicknesses, and this ensures the aesthetics and costeffectiveness of the structural solution. Comparison of the stress values occurring in individual welds obtained in an analytical way, with those using the FEM numerical method, indicates 
that the analytical method developed by Brodka and Broniewicz (2007) determines the actual weld stress level very well.

A further experimental study to determine the effective weld length in RHS K-type joints with a transverse gusset plate, is being carried out at the Bialystok University of Technology. Key pa-rameters, such as branch-to-chord angles $\theta=48^{\circ}, 54^{\circ}, 60^{\circ}$ and member overlap $\lambda_{o v}=$ $30 \%, 60 \%$ and $90 \%$, are being investigated. During the tests, the uneven stress distribution in the welds will be measured with the use of strain gauges, which will allow the determination of the actual stress distribution in the welds for different configurations of elements in the joints and will allow for safe design of K-type RHS joints with transverse gusset plates.

\section{ACKNOWLEDGEMENT}

This research was funded by grants numbers: WI/WB-IIL/B/2020); WZ/WBIIL/4/2020.

\section{REFERENCES}

ANSI/AISC 360. 2016. An American National Standard, AISC Specification for Structural Steel Buildings.

AWS D1.1/D1.1M:2010 Structural Welding Code—Steel. An American National Standard.

Brodka, J. \& Broniewicz, M. 2001. Steel structures made of hollow sections. Warsaw. Arkady. (in Polish)

Brodka, J. \& Broniewicz, M. 2003. Calculation of welded connections of truss joints from RHS. Warsaw: Steel structures. (in Polish)

Brodka, J. \& Broniewicz, M. 2004. Assessment of the load-bearing capacity of joints with welds laid at rounded corners of cold formed profiles. Warsaw: Steel structures. (in Polish)

Brodka, J. \& Broniewicz, M. 2013. Calculation of welding trusses overlap joints made of rectangular hollow sections. Warsaw: Archives of Civil Engineering.

Brodka, J. \& Broniewicz, M. 2015 Design Of Hollow Section Overlap Joints With The Reinforcing Rib Plate. Welded Connection Resistance. Warsaw: Archives of Civil Engineering.

Brodka, J. \& Broniewicz, M. 2016. Steel structures made of structural hollow sections. Part. 1. Warsaw: PWN. (in Polish)

BS ISO 14346, 2011. Welding - Static design procedure for hollow section joints.

Rolloos, A. (1969), "The Effective Weld Length of Beam to Column Connections without Stiffening Plates," Stevin Report 6-69-7-HL, Delft University of Technology, Delft, The Netherlands.

EN 1993-1-8:2006: Eurocode 3: Design of steel structures - Part 1-8: Design of joints.

Davies, G. and Packer, J.A. (1982), "Predicting the Strength of Branch Plate-RHS Connections for Punching Shear," Canadian Journal of Civil Engineering, Vol. 9, pp. 458-467.)

Dutta, D. 1999. Hohlprofil - Konstruktionen. Berlin: Ernst und Sohn. A Willey Company.

Packer, J.A. Wardenier, J. Zhao, X.L. van der Vegte, G.J. \& Kurobane Y. 2009. Design guide for rectangular hollow section (RHS) joints under predominantly static loading. LSS Verlag. CIDECT.

IIW 1999. Static design procedure for welded hollow section joints. Recommendations. 3rd Edition. International Institute of Welding. Commision XV. IIW Doc. XV-1329-09.

Wardenier, J., Davies, G. and Stolle, P. (1981), "The Effective Width of Branch Plate to RHS Chord Connections in Cross Joints," Stevin Report 6-81-6, Delft University of Technology, Delft, The Netherlands. 


\title{
The bearing capacity of hybrid bolted and riveted joints in steel bridge structures
}

\author{
K. Pawłowski \\ Wroctaw University of Environmental and Life Sciences, Wroctaw, Poland
}

\begin{abstract}
The aim of the research presented in this paper is to determine the influence of the way of conducting repair works of riveted joints in steel structures, where damaged or corroded rivets have to be replaced by bolts. The main research objective is to determine the bearing capacity of structures before and after reinforcement in order to create a basis for formulating the relevant conclusions concerning the safety of the structure in question.

The presented results define the influence of construction solutions that may be or are currently applied in practice, which, however, have not been confirmed yet by any model studies and computational analyses of the bearing capacity of hybrid, bolted and riveted joints. The tested elements were collected from railway bridge structures that were designated for demolition. The analysis of various arrangements of connectors in a joint was an important element of the conducted tests. According to current state of knowledge, the bearing capacity of a connector in an overlap joint, as far as bearing resistance is concerned, depends on its position in the joint. Due to that, the authors decided to test those joints, where marginal or intermediate rivets were replaced with bolts. The analysed topic is a valid issue and its scope is very wide, due to the fact that riveted steel structures that were manufactured on a mass scale more than a hundred years ago often require repairs in form of ongoing maintenance or modernisation of the structures. As riveted structures are common throughout the world, the problem applies to a multitude of objects. The conducted tests lead conclusions that partial replacement of the existing rivets with bolts has a real influence on the bearing capacity of joints in riveted structures. The degree of this influence depends on the position of the replaced connections with respect to the edge of the connected element. Nonprofessional repair works consisting in the replacement of existing, corroded rivets with new, unfitted bolts, may lead to excessive deflection of the structure. The aim of the conclusions of the paper is to provide guidelines concerning the possibility to apply hybrid, riveted and bolted joints in existing, often historic structures, where maintaining further safe operation often means preserving their cultural values, as these objects are an inseparable part of our cultural heritage.
\end{abstract}

\section{INTRODUCTION}

Steel structures have been designed and used for more than a century. As a result, many of them are approaching the end of their technical lifespan. However, due to their historic values, it is worth to maintain these structures in a proper technical condition, because they are part of our cultural heritage and proof of the technological development of our ancestors. As a result, it is necessary to renovate them. In most cases, even if a large element of the structure has to be replaced, due to various reasons, it will finally be necessary to connect the new element with existing ones. In our research we focused on the replacement of several connectors in a joint with new ones, different from those used in the original structure. This situation is even more complex, because in such event, the joint contains elements of varied bearing

DOI: $10.1201 / 9781003132134-43$ 
capacity and material characteristics. Such connection, that consists of the pre-existing rivets and newly installed bolts, may be considered a hybrid joint. The bearing capacity of a joint is a function of several factors, which makes the issue even more complex. One of these factors is the position of the connector in the joint. As the damaging mechanisms vary, for bearing resistance the position of the connector in relation to the edge of the element and to other connectors will influence the bearing capacity of the whole joint. Thus, it is important to determine the bearing capacity of the joint if a new bolt connector is added between already working connectors in form of rivets. In order to determine the influence of such works, laboratory tests were conducted on elements collected from railroad bridge structures.

\section{CHARACTERISTICS OF THE ANALYSED OBJECT}

As it has already been mentioned, the connections in historical steel structures were riveted. This resulted from technologies that were available at that time. As this was the era of dynamic development of railways, many riveted structures are the spans of railroad bridges. Obviously, other structures were also constructed in a similar way, including, e.g. steel tanks or lattice towers (including the Eiffel Tower). Tests were conducted on elements that had been cut out from the structure of the bridge span disassembled from the railway line No. 7 Warszawa Wschodnia - Dorohusk. When it was built, this line was called the Vistula Railroad. It was opened on the $19^{\text {th }}$ of August 1877 and led from Mlawa to Kowel. The bridge span from which the analysed elements were cut out was built in 1956, during the first renovation of the bridge. It was a double-girder plate girder span with the tracks down on the bridge plates. Open lattice, with crossbeams placed $2.57 \mathrm{~m}$ from each other and continuous longitudinal beams at $1.8 \mathrm{~m}$ distance. The main girders with a double-T cross-section had a total height of $2.0 \mathrm{~m}$. The structural height of the object was $1.16 \mathrm{~m}$ and the theoretical span $-18 \mathrm{~m}$. The view of the bridge is presented in Figure 1.

The tested elements were collected from bracings of longitudinal beams and main girders. These elements were selected due to the possibility to adapt them for bearing capacity tests in the universal testing machine. Additionally, the condition of riveted joints at this location was considered to be very good. Figure 2 shows the joint between the bracing and the longitudinal beams and cross-beams of the bridge span. The joint consisted of 3 rivets attached to the angle bracket being the bracing and to the node sheet metal. As the bridge span structure was relatively new (it was 63 years old at the moment of disassembly), it was in a good condition, which had a positive influence on the obtained results. No effects of corrosion or mechanical

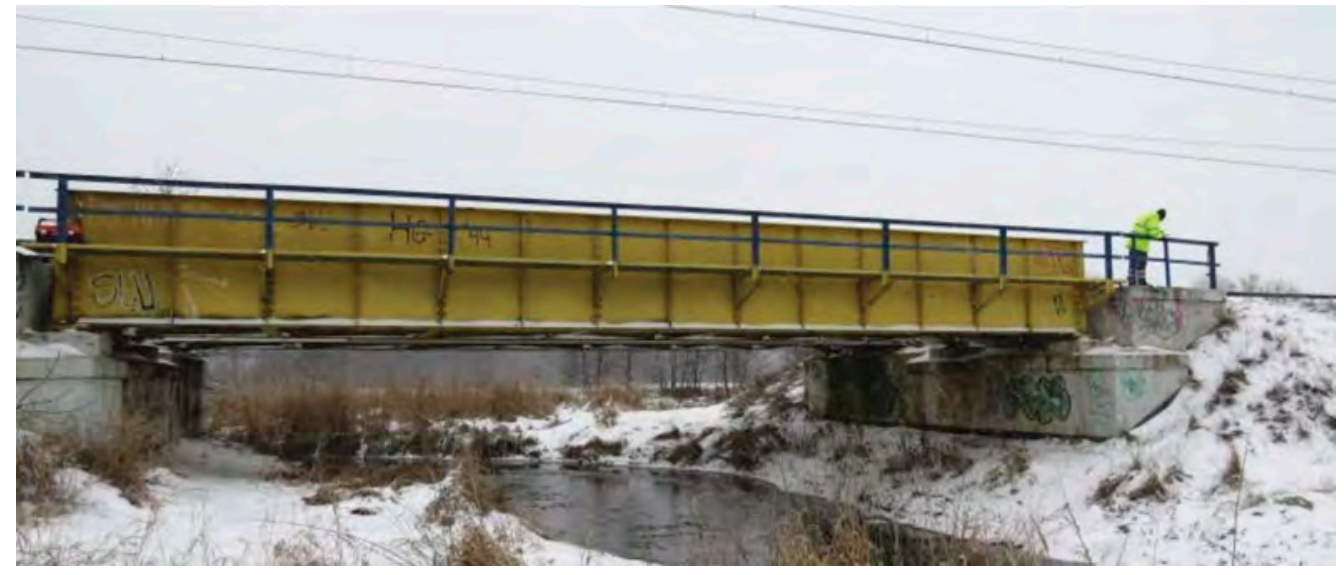

Figure 1. View of the span of the railroad bridge on $\mathrm{km} 207.887$ of the railway line No. 7 Warszawa Wschodnia - Dorohusk. 


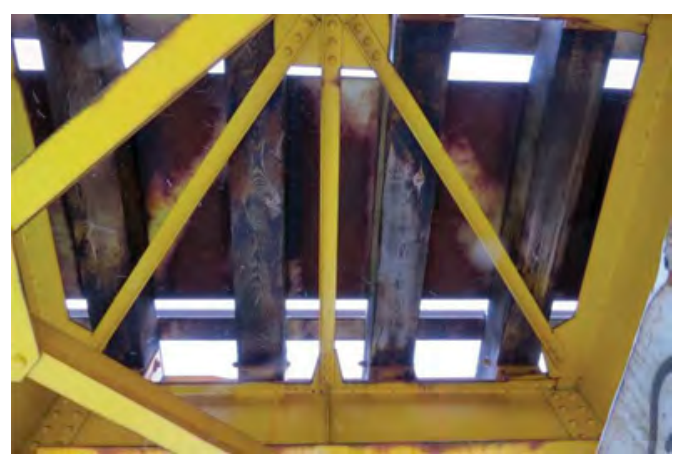

Figure 2. View of the bottom of the structure - elements, from which samples were collected.

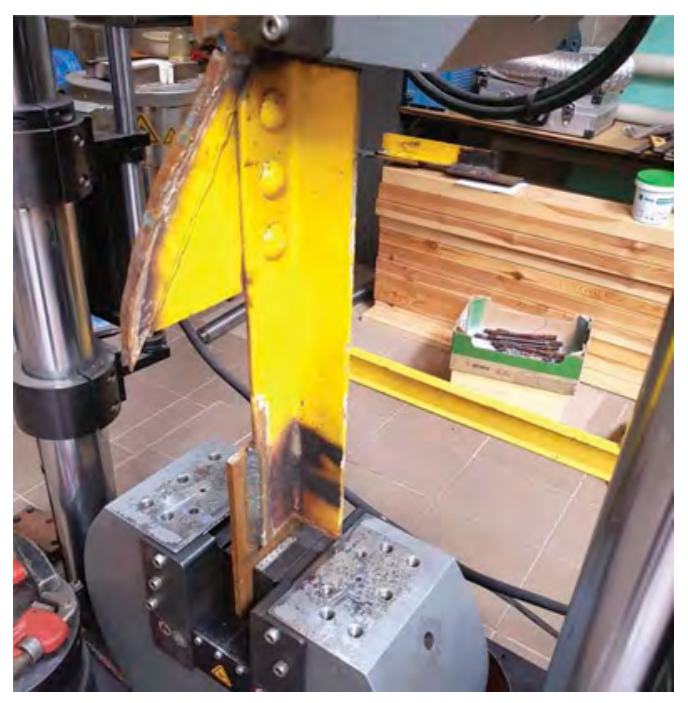

Figure 3. Element during bearing capacity tests of the riveted joint.

damages of the connecting elements were found. The replacement of the structure resulted from the modernisation of railway line No. 7 in order to adapt it to higher performance parameters.

Additionally, apart from the elements for joint testing, samples were also taken to conduct the resistance of steel. The samples were prepared in compliance with the guidelines provided in the PN-EN ISO 6892-1:2009 standard. Samples were collected from bracings of the main girders of the bridge span. Resistance tests were carried out in the Instron/SATEC KN 600 universal testing machine. Figure 3 shows the element tested for the bearing capacity of the joint, installed in the universal testing machine.

\section{RESULTS OF THE TESTS}

\subsection{Results of tensile strength tests}

The results of strength tests of steel samples are presented in Table 1. The characteristics of steel vary for different samples. The characteristics of steel from samples S.1 and S.4 are similar to those of high carbon steel, while the properties of other samples resembled those of low 
Table 1. Basic mechanical properties of steel determined in the tests of samples collected from the bridge.

\begin{tabular}{llllll}
\hline & $\mathrm{R}_{\mathrm{m}}$ & $\mathrm{R}_{\mathrm{eL}}$ & $\mathrm{R}_{\mathrm{eH}}$ & $\mathrm{R}_{\mathrm{z}}$ & $\varepsilon_{\mathrm{max}}$ \\
\cline { 2 - 6 } Sample No. & $\mathrm{MPa}$ & $\mathrm{MPa}$ & $\mathrm{MPa}$ & $\mathrm{MPa}$ & $\mathrm{mm} / \mathrm{mm}$ \\
\hline S.1 & 471 & - & - & 373 & 0.197 \\
S.2 & 446 & 286 & 301 & 361 & 0.288 \\
S.3 & 446 & 282 & 292 & 340 & 0.300 \\
S.4 & 477 & - & - & 370 & 0.220 \\
S.5 & 448 & 287 & 300 & 420 & 0.230 \\
S.6 & 446 & 270 & 287 & 333 & 0.300 \\
MIN & 446 & 270 & 287 & 333 & 0.197 \\
MAX & 477 & 287 & 301 & 420 & 0.300 \\
Average & 456 & 281 & 295 & 366 & 0.256 \\
Standard deviation & 15 & 8 & 7 & 31 & 0.045 \\
Coefficient of variation & 0.033 & 0.029 & 0.023 & 0.093 & 0.231 \\
Specific value & 428 & 266 & 282 & 302 & 0.144 \\
\hline
\end{tabular}

carbon steel. Thus, one may conclude that the steel used in historical structures was highly heterogeneous.

The characteristics used for the purposes of initial bearing capacity estimation were similar to those of S235 steel, although the average yield strength obtained in the tests was higher. However, as its mechanical properties were so heterogeneous, it was reasonable to maintain a safety margin when determining the bearing capacity of historical structures. Figure 4 shows that one of samples underwent lamellar tearing as a result of strength tests. This is additional proof of the above conclusion that the properties of construction steel used in structures from the beginning of the $20^{\text {th }}$ century are varied.

\subsection{Tests of joints}

Samples for the tests of hybrid, bolted and riveted joints were prepared in a way that ensured that they would work as lap joints. To this end, pieces of sheet metal were welded to the elements cut from the bridge structure to enable fixing them in the universal testing machine. Figure 4 shows a sample used in tests of bolted and riveted joints. Tests were conducted on 9 elements altogether. Three only riveted joints were tested as the reference group for the determination of the influence of replacing an existing rivet with a bolt. Three joints where the bolt was placed as a side connection and three joints with the bolt as an intermediate connection were tested. The hybrid joint used M16 bolts of the 5.8 class. The bolts were not fitted. The holes where rivets had been removed to be replaced by bolts had the diameter of approx. $17 \mathrm{~mm}$. The connection was not a prestressed joint.

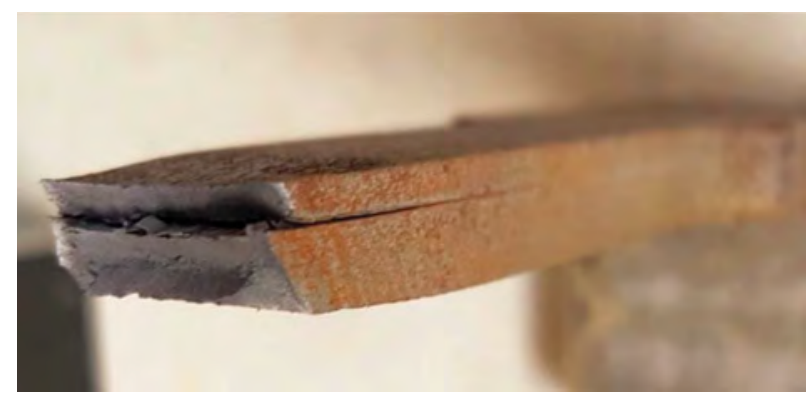

Figure 4. Steel sample that underwent lamellar tearing as a result of strength tests. 


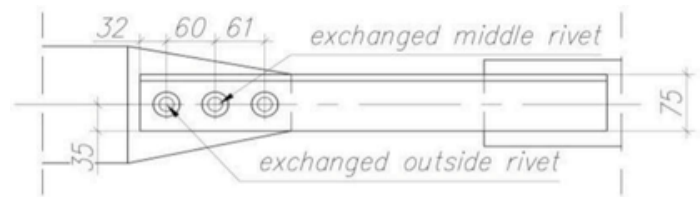

Figure 5. Drawing of the element used for bearing capacity tests of the hybrid joint.

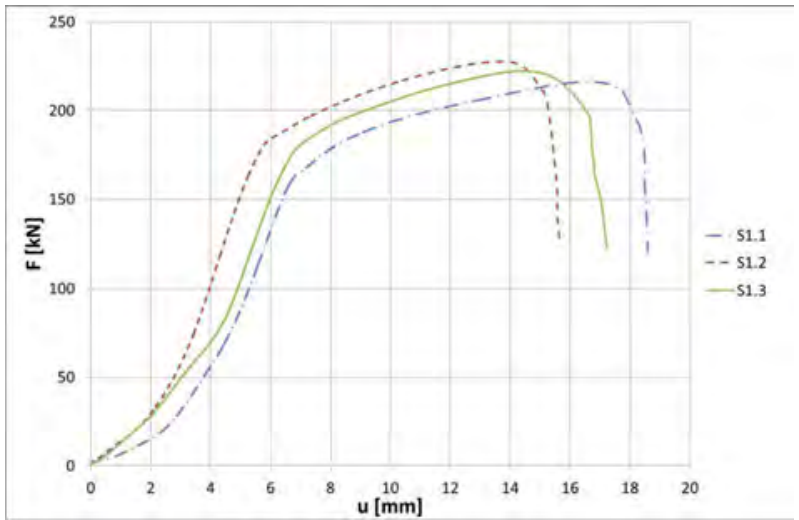

Figure 6. Diagram of the force-deformation relation for elements with 3 rivets.

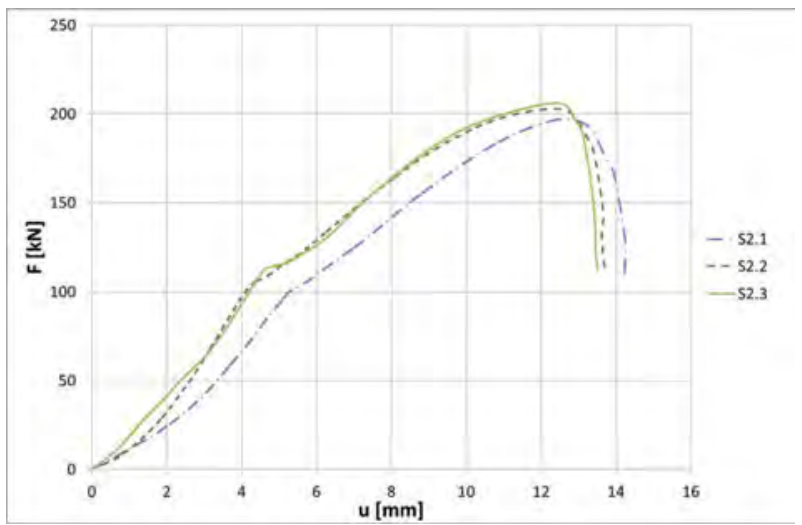

Figure 7. Diagram of the force-deformation relation for elements with 2 rivets and outside bolt.

The diagrams below show the relation between force and deformation for selected joints. The diagram in Figure 6 shows the curves for joints with 3 rivets. The subsequent two diagrams (Figures 7 and 8) show joints where, respectively, side and intermediate rivets were replaced.

The comparison of these diagrams reveals that the replacement of a rivet with a bolt in an existing structure leads to a lowered bearing capacity of the joint. However, there is a noticeable difference between joints where the outside and middle rivets were replaced. The bearing capacity of joints where outside rivets were replaced was significantly lower than that of the joints where middle rivets were replaced with bolts. The bearing capacity of the joint 


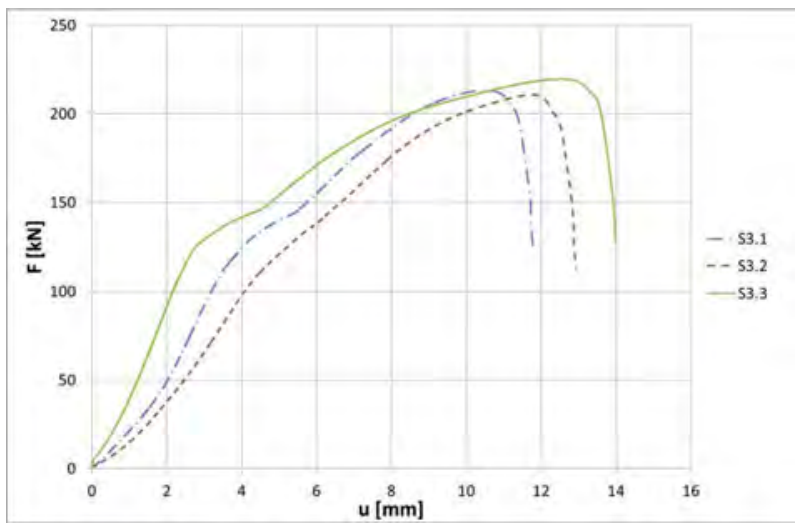

Figure 8. Diagram of the force-deformation relation for elements with 2 rivets and middle bolt.

where the middle rivet had been replaced with a bolt was $2.5 \%$ lower than that of the joint with 3 rivets. The comparison of the hybrid joint where the outside rivet had been replaced with the joint with 3 rivets revealed that the bearing capacity of the hybrid joint was $8.1 \%$ lower. Additionally, the course of the force-deformation relation was different. This results, to a great extent, from the fact that the applied bolts were not fitted. The connections were not prestressed, either. This is a result of the assumptions that were adopted for the joints discussed here. Tests on a wider group of joints are currently in progress. Further research will include joints with fitted bolts and bolts of different strength. The next stage will consist in introducing prestressed bolts, which, in the opinion of the author, should modify the characteristics of bearing capacity.

\section{CONCLUSIONS}

The conducted tests of hybrid bolt and riveted joints and the properties of the construction steel from which they were constructed lead to the following conclusions:

The tests of the construction steel of the bridge, built in 1956, demonstrated that the material was highly heterogeneous. This is important for the point of view of potential further operation of the structure. Such phenomena as lamellar tearing may be particularly dangerous when, due to the need to change the functions of the object or to reinforce it, elements are added that exert load perpendicularly to the rolling direction of sheet metal.

Partial replacement of the existing rivets with bolts has a real influence on the bearing capacity of joints in riveted structures. The degree of this influence depends on the position of the replaced connections with respect to the edge of the connected element. The presented tests revealed that the bearing capacity of a three-connection joint was approx. $2.5 \%$ lower when the middle connection was replaced. However, the bearing capacity of joints with replaced outside connection fell by over $8 \%$.

Performing repair works consisting in the replacement of existing, corroded rivets with new, unfitted bolts, may lead to excessive deflection of the structure when the nominal diameter of the selected hole ease is larger than the diameter of the bolt. In extreme cases, the rivets may be overloaded before the bolts start working, which may eventually lead to damage or failure of the whole structure.

The correlation between the bearing capacity of riveted and hybrid bolt and riveted joints taking into account the use of fitted connections, high strength connections, and prestressing of bolts is the subject of further research conducted by the author. 


\section{ACKNOWLEDGMENTS}

This work was supported by the Wrocław University of Environmental and Life Sciences (Poland) as the Ph.D. research program "Innowacyjny Naukowiec, no. NO60/0003/20"

\section{REFERENCES}

Biegus, A. 1997: Połączenia śrubowe, Warszawa-Wrocław, Wydawnictwo Naukowe PWN.

Design Manuals „Steel Building in Europe”, work carried out with a financial grant from the Research Fund for Coal and Steel of the European Community, 2013.

EN 1990, Eurocode - Basis of structural design.

EN 1993-1-1, Eurocode 3 Design of steel structures - Part 1-8: General rules and rules for buildings.

EN 1993-1-8, Eurocode 3 Design of steel structures - Part 1-8: Design of joints. 


\title{
Modelling of the ferritic stainless steel grade 430 bolted connections with damage implementation
}

\author{
K.P. Sobrinho, A.T. Silva, M.C. Rodrigues, P.C.G.S. Vellasco \& L.R.O. Lima \\ State University of Rio de Janeiro, Rio de Janeiro, Brazil \\ J. Henriques \\ Construction Engineering Research Group, Faculty of Engineering Technology, Hasselt University, Hasselt, \\ Belgium
}

\begin{abstract}
This paper presents the calibration of a numerical model to simulate bolted connections using a damage criterion for ductile materials. The motivation for this investigation is related to the difficulties in obtaining the ultimate load in connections with large deformations using a simple static analysis. The analyzed models consist of bolted connections made of the stainless steel grade 430 with a single bolt under double shear, where the weak part is located in the internal plate. A comparison of the results with the performed experimental tests made possible to check the efficiency of the developed model. The obtained results indicated a good correlation, both in terms of maximum load and associated failure modes, between the simulated and tested bolted connections.
\end{abstract}

\section{INTRODUCTION}

In recent years, a significant increase in the use of stainless steel in structures has been observed. This is directly related to the increase in research regarding its structural performance, including at the microstructural level. The analysis of the material's behavior by means of computational tools is one of the field of interests, as it makes possible to evaluate and exploit the material until its rupture, for example, the realization of collision simulations (Levanger, 2012). In certain situations, stainless steel was already widely used, since this material contains several properties that can provide advantages when compared to carbon steel. Some of these advantages may be pointed out such as: corrosion, high temperatures and impact resistances, recycled capacity and ductility (Baddoo, 2008). However, when a cost analysis is carried out without considering the life-cycle, due to the high initial cost of stainless steel, the material becomes uneconomical. For a correct comparison, it is necessary to consider the properties of the material and their impact in overall cost of construction beyond the intial cost (Gedge, 2008). Another important factor contributing to the cost reduction in the application is related to the structural design recommendations. The current codes and standards for design of stainless steel structures have equations analogous to carbon steel which are often conservative, as these do not consider the actual capacity of the material.

The modelling of structural members and connections with the finite element method is essential for research and requires a proper correlation of the numerical model with experiments. However, when the analyses involve mechanical problems with contact and subject to large deformations, as in stainless steel bolted connections, it is often not possible to calibrate the numerical model up to the ultimate load and associated deformation using traditional 
a)

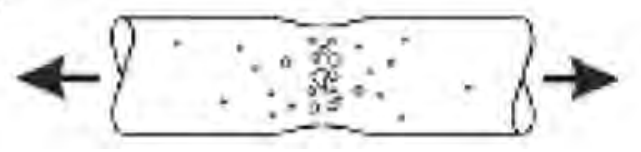

b)

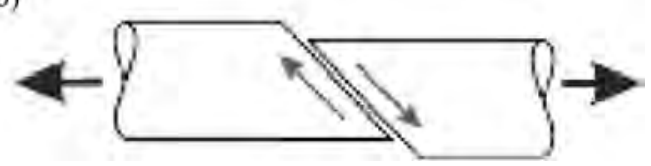

Figure 1. Ductile fracture of metals. a) void nucleation, coalescence and growth; b) shear band localization.

nonlinear analyses. The simulation of bolted connections subjected to large deformations often leads to convergence difficulties.

This paper is devoted to the modelling of stainless steel bolted connections, in the large deformation field, using a damage criteria. Experimental results of ferritic stainless steel 430 bolted connections subject to double shear were used to verify the assumptions adopted in the numerical modelling. This type of connection is of particular interest as it combines material, with high deformation capacity, with the complexity of bolted connections using thin-plate under high-stress concentrations near the bolt hole. A rupture criterion was required to be implemented in the finite element model despite the limitations on the available material mechanical properties, as it is often the case of material characterization consisting of only tensile tests (Dzugan, 2012). The use of a ductile material damage criterion allows the simulation of the behaviour of bolted connections and includes the determination of its structural capacity after the peak load (Lyu et al., 2019).

The Abaqus Finite Element Analysis (FEA) software has been used to simulate the material rupture. This granular material failure can be modelled by the ductile fracture of materials or by necking instability (Abaqus, 2005). The first strategy, used in this article, can occur through the nucleation of voids, where they coalesce and grow until they form the localized tightening (necking), or through the location of a cut band, as shown in Figure 1.

The numerical modelling will be presented, focusing on the implementation of the damage criterion for ductile materials applied to two stainless steel bolted connections. First, a simulation of the material characterization test is accompleshid to calibrate and validate the use of the referred criterion. Then, the results of the simulated connections are compared with experiments to further validate the developed numerical models. The performed experimental program used to calibrate the numerical simulations will be presented in the next section.

\section{EXPERIMENTAL PROGRAM}

\subsection{Coupon test}

The experimental study was made at the Civil Engineering Laboratory of the State University of Rio de Janeiro - Brazil. Two coupons were tested for characterizing the adopted ferritic steel grade 430 , with a measured density of $7.67 \mathrm{mg} / \mathrm{m}^{3}$. These tests were performed on an Instron 3382, which uses an embedded data acquisition system, Bluehill 3. As for redundancy, a clip gauge was used to measure the deformation up to $5 \%$. This test layout is shown in Figure 2 as well as the obtained stress-strain curves. The characterization tests followed the recommendations prescribed by Huang \& Young (2014).

\subsection{Bolted connection tests}

The bolted connection tests were performed on a $600 \mathrm{kN}$ Losenhausen testing system while the data was acquired with the HBM Quantum X-MX1615B system, Figure 3 (a). Two bolted connections tests were carried out made of three ferritic steel plates of the same thickness connected by a high strength carbon steel bolt to induce the failure of the inner plate. This configuration does not allow the curling effect to occur, a phenomenon 
a)

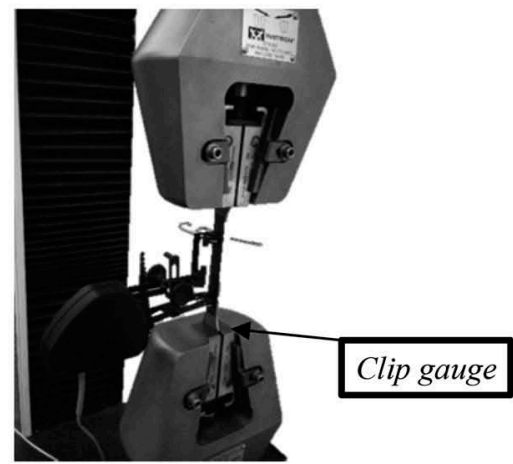

b)

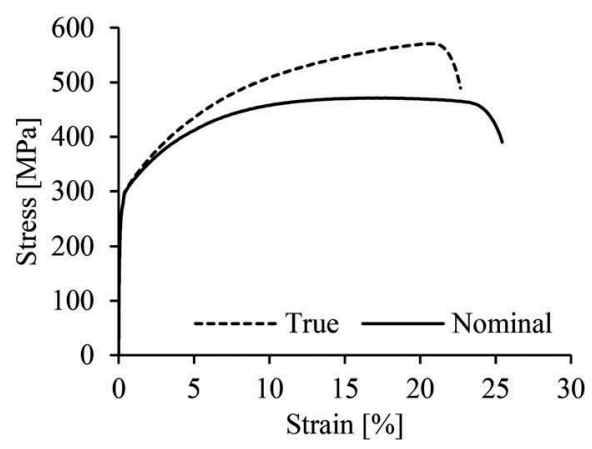

Figure 2. Coupon testing. a) Instron 3382 universal testing test machine. b) true and nominal stress-strain curves.

a)

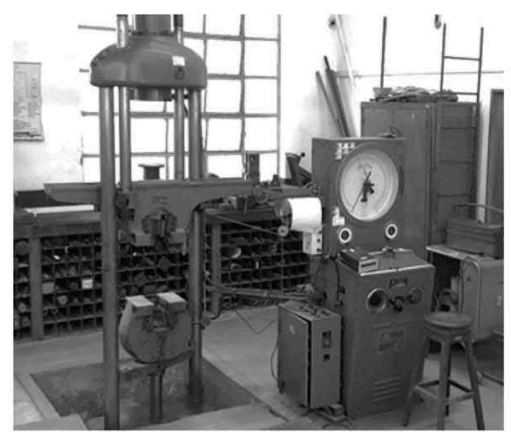

b)
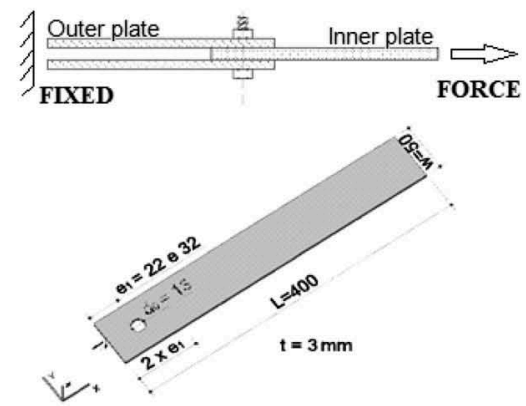

Figure 3. Experimental test setup a) universal tensile testing system. b) Specimens Geometry.

capable of influencing the behaviour of bolted connections, that could even reduce its ultimate capacity (Kim, 2011). Figure 3(b) shows a schematic configuration of the plate as well as the used geometric parameters. The nominal dimension was: $400 \mathrm{~mm} \times 50 \mathrm{~mm}$ x $3 \mathrm{~mm}$ while the adopted $\mathrm{e}_{1}$ values were $22 \mathrm{~mm}$ and $32 \mathrm{~mm}$, with the objective of inducing the bearing failure mode.

\section{NUMERICAL MODEL}

\subsection{Damage criteria}

The model analysis with damage criterion is characterized as an extremely nonlinear problem since the damage evolution is directly associated with large plastic deformations. Additionally, it is necessary to use advanced tools to enable the simulation of the material internal degradation.

The Finite Element Method (FEM) is an important mathematical tool for solving solid deformation problems. The great effectiveness of this method is related to the ability to satisfy equations that characterises the problem through interpolation functions from finite elements which in turn come from the discretization of a more complex integration space. Therefore, the FEM is characterised, basically, in three stages: i) integral formulation of the problem; ii) discretization of the problem and iii) solving the system of equations that result from the previous two steps (Reis, 2009). 
The Abaqus FEA software is a powerful finite element analysis tool where version 6.14 was used in this study. To simulate the behaviour of the analyzed connections, the dynamic explicit solver was used. In order to eliminate dynamics effects, an quasi-static analysis was performed. Since the modelling of a quasi-static problem in its natural time would require a long time to complete the analysis, it is essential to reduce the processing time of the analysis without compromising the accuracy of the solution. The model calibration in the explicit analysis was through Mass Scaling, which artificially increases the density of the material. This guarantees the use of an artificial time increase of the model, which results in a drastic reduction in processing time without compromising its accuracy.

The ductile damage with damage evolution criterion was used to assess the model rupture. This criterion requires the use of a curve that relates the deformation at the beginning of the fracture with the triaxial stress. The modelling of the material to the damage requires the definition of four parameters, which are presented below, whose points are outlined in Figure 4.

1. Material behaviour without the damage defined by points ABCD';

2. The damage initialization criterion, point $\mathrm{C}$;

3. The damage evolution curve defined by points C and D';

4. The element removal when its stiffness is compromised.

The variable $\mathrm{D}$ corresponds to the general damage value, $0 \leq \mathrm{D} \leq 1$, with the value zero being the virgin material, free from damage, and the value one when the volume element splits into two parts. Therefore, variable D characterises the level of material damage. After the damage starts, the tension tensor in the material is given by Equation 1:

$$
\sigma=(1-D) \bar{\sigma}
$$

where $\bar{\sigma}$ is the theoretical stress of the material in the absence of damage.

Point c, depicted in Figure 4, is obtained through the fracture strain versus stress triaxiality curve. These values were defined based on the studies carried out by Wierzbicki and Werner [1998], Bao [2004] and validated by Wang [2006].

The c-d curve shown in Figure 4, on the other hand, defines the damage evolution, which can be defined by a tabular softenig, damage variable versus displacement. When the damage variable is set to 1 , the corresponding element is removed. The values entered in the Abaqus program (2014), where the model calibration for a $3 \mathrm{~mm}$ finite element mesh are shown in Table 1. Further details regarding the model validation are presented in the next section.

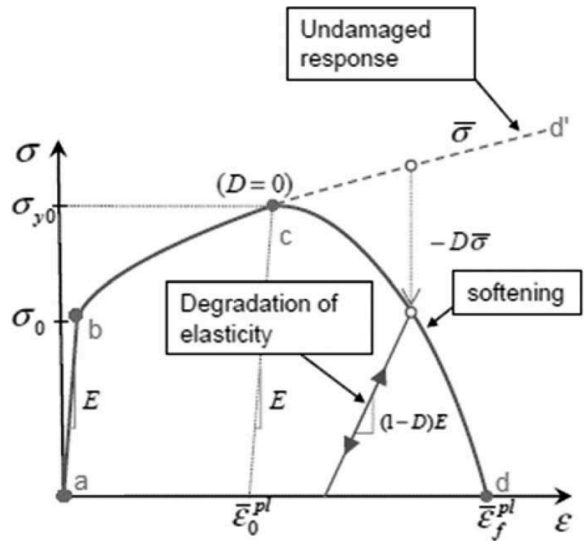

Figure 4. Schematic representation of elastic-plastic material with progressive damage. 
Table 1. Damage evolution.

\begin{tabular}{ll}
\hline Damage variable & Displacement \\
\hline 0.0 & 0.0 \\
0.8 & 0.5 \\
1.0 & 0.8 \\
\hline
\end{tabular}

a)

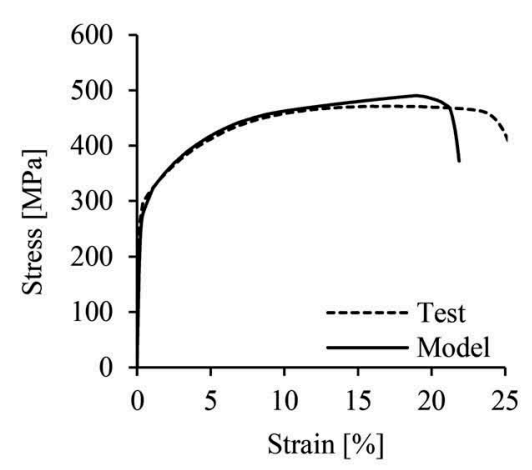

b)

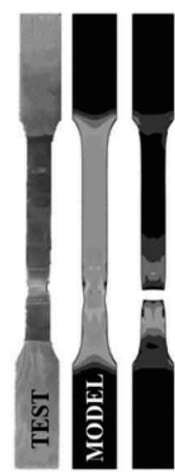

c)

$\begin{array}{ll}\begin{array}{l}\text { Yield Stress } \\ {[\mathrm{MPa}]}\end{array} & \begin{array}{l}\text { Plastic Strain } \\ {[\mathrm{mm} / \mathrm{mm}]}\end{array} \\ 28.70839 & 0.000000 \\ 109.2258 & 0.000272 \\ 203.4104 & 0.000813 \\ 326.9452 & 0.010616 \\ 402.4768 & 0.035280 \\ 502.4747 & 0.093999 \\ 546.4353 & 0.148300 \\ 567.7084 & 0.193507 \\ 570.7099 & 0.206057\end{array}$

Figure 5. Material characterization parameters: a) stress versus strain curve, b) deformation, c) true stress - true strain.

\subsection{Validation}

Initially, the model was calibrated for the tensile coupon tests where it was possible to define all parameters for configuring the adopted damage model. Figure 5 presents a comparison between the characterization curve obtained in the experiments with the numerical response. Therefore, the deformed specimen and the true stress versus true strain points used in the finite element model are also presented.

The coupon tension test model presented a good correlation with the experimental characterization tests. This allows proceeding to the next step to verify the calibration of the numerical model with the implementation of damage in the ferritic stainless steel bolted connections tests.

Figure 6 presents a comparison between the load versus displacement curves for connections with $\mathrm{e}_{1}$ values of $22 \mathrm{~mm}$ and $32 \mathrm{~mm}$, respectively. The deformed numerical models and experimental tests are illustrated in Figure 7. With these results, it can be concluded that the

a)

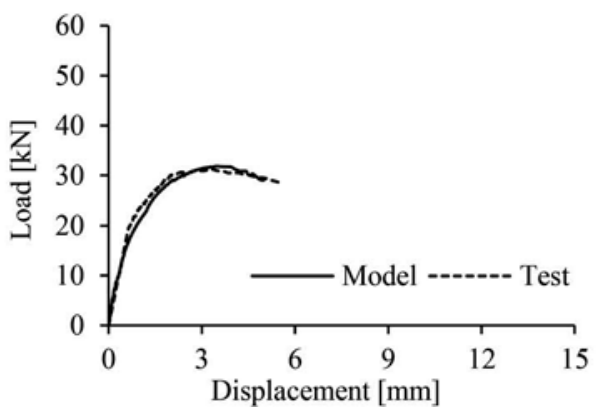

b)

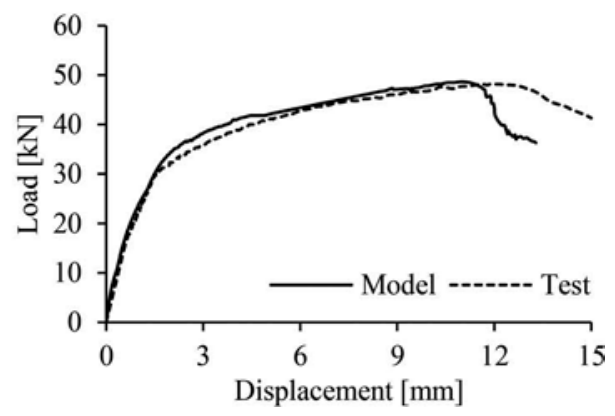

Figure 6. Load versus axial displacement curves. a) $\mathrm{e}_{1}=22 \mathrm{~mm}$; b) $\mathrm{e}_{1}=32 \mathrm{~mm}$. 
a)

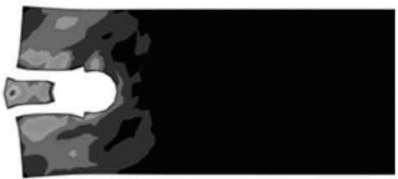

c)

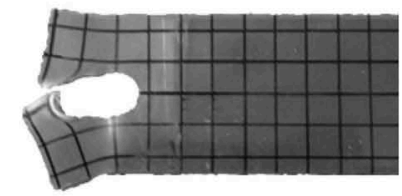

b)

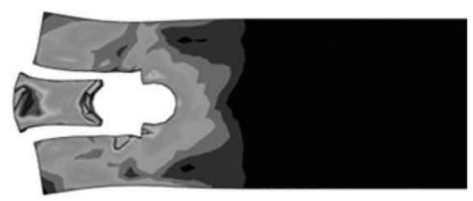

d)

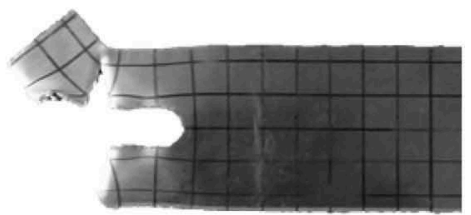

Figure 7. Deformed tested connections. a) $\mathrm{e}_{1}=22 \mathrm{~mm}$; b) $\mathrm{e}_{1}=32 \mathrm{~mm}$; c) $\mathrm{e}_{1}=22 \mathrm{~mm}$; d) $\mathrm{e}_{1}=32 \mathrm{~mm}$.

numerical modelling with the implementation of damage can be used to model the behaviour of bolted connections until their fracture. The model is also able to determine the connection failure mode. By simulating the failure of its connections, it is even possible to assess the overall behaviour of the structure (Gomes, 2017).

\section{CONCLUSIONS}

The work presented in this paper is part of an ongoing research on bolted connections using stainless steel conducted by the authors. It is recognized the high deformation of these connections due to material behavior, and depending of the stainless steel type (e.g. Austenitic), coupled with significant strain hardening. In order to improve current design methods for such connections, which are based on analogies with those for carbon steel, it is important the use of numerical models to complement the limitations of the experimental campaigns by means of parametric studies. Thus, this paper presents part of the validation process of a numerical model implementing the material damage able to reproduce the behavior of bolted connections using stainlesssteel and entering in the large deformation field. These are there-fore complex numerical simulations but necessary to adequately reproduce the mechanics of the referred connections.

Specifically, the objective of this paper was to characterise the bearing failure mode using a numerical model implementing the damage criterion for ductile materials. The behaviour of bolted connections of ferritic stainless steel 430 was evaluated for plates in double shear and $\mathrm{e}_{1}$ values of $22 \mathrm{~mm}$ and $32 \mathrm{~mm}$. The calibration of numerical models was performed by comparison with experiments. Initially, the material characterization model was performed, where it was possible to define all the damage parameters. This was followed by the connection evaluation through the load versus axial displacement curves, as well as their failure modes. Based on the results presented, it was possible to conclude that the numerical models were able to represent the bearing failure mode, a ratio between the ultimate numerical and experimental test load of 1.02 and 1.01 for connections with $\mathrm{e}_{1}$ values of $22 \mathrm{~mm}$ and $32 \mathrm{~mm}$, respectively, was obtained. On the other hand, the quality of the simulations to capture the ultimate deformation of the tested specimens decreases. Though, some improvement of the numerical model can still be envisaged, the simulation in the large deformation field is complex and highly dependent of the microscopic structure of the material.

\section{ACKNOWLEDGMENTS}

The authors would like to thank CAPES (Finance code 001), CNPq (306042/2013-4; 305026/ 2017-8), FAPERJ and CERG for the financial support to this research program. 


\section{REFERENCES}

Abaqus. 2005. Abaqus/Explicit. Advanced Topics. Lecture 9: Material Damage and Failure.

Abaqus/ CAE. 2014. Theory Reference. SIMULIA - Inc. [S.l.]. 6.14-5.

Baddoo, N. R. 2008. Stainless steel in construction: A review of research, applications, challenges and opportunities. Journal of Constructional Steel Research 64 (11): 1199-1206.

Bao, Y. Wierzbicki, T. 2004. A comparative study on various ductile crack formation criteria. Journal of Engineering Materials and Technology 126: 314-324.

Dzugan, J., Spaniel, M., Konopík, P., Ruzicka, J., Kuzelka, J. 2012. Identification of Ductile Damage Parameters for Austenitic Steel. World Academy of Science, Engineering and Technology. International Journal of Mechanical and Mechatronics Engineering6 (5): 6.

Gedge, G. 2008. Structural uses of stainless steel - buildings and civil engineering. Journal of Constructional Steel Research 64(11): 1194-1198.

Gomes, V. R. 2017. Análise da influência de ligações semirrígidas na robustez de pórticos metálicos. MSc Dissertation, PGECIV - Civil Engineering Graduate Program. Rio de Janeiro: State University of Rio de Janeiro, p. 141. (In Portuguese).

Huang, Y; Young, B. 2014. The Art of Coupon Tests. Journal of Constructional Steel Research 96: $159-175$.

Kim, T. S.; Kuwamura, H. 2011. Numerical investigation on strength design and curling effect of mechanically fastened joints in cold-formed austenitic stainless steel. Materials and Design 32: 3942-3956.

Levanger, H. 2012. Simulating ductile fracture in steel using the finite element method comparison of two models for describing local instability due to ductile fracture. MSc Dissertation, Norway: Faculty of Mathematics and Natural Sciences University of Oslo, p.135.

Lyu,Y.; Wang,Y.; Li, G.; Jiang,J. 2019. Numerical analysis on the ultimate bearing resistance of single-bolt connection with high strength steels. Journal of Constructional Steel Research 153: 118-129.

Reis, F. J. P. 2009. Fractura em metais dúcteis - modelação numérica do dano em metais dúcteis. $M S c$ Dissertation. Faculdade de Engenharia, Universidade do Porto.(In Portuguese).

Wang K. 2016. Calibration of the Johnson-Cook failure parameters as the chip separation criterion in the modelling of the orthogonal metal currint process. Master Thesis. Hamilton: McMaster University.

Wierzbicki, T. Werner, H. 1998. Cockroft and Latham Revisited. Impact \& Crashworthiness Laboratory Report:16. 


\title{
Research on AM non welded N RHS truss joints - resistance criteria
}

\author{
J.K. Szlendak \\ State School of Higher Professional Education in Suwalki, Suwatki, Poland
}

\author{
A. Szpyrka \\ Rzeszow University of Technology, Rzeszów, Poland
}

\begin{abstract}
This paper presents $\mathrm{N}$ type RHS plug \& play truss non-welded connections, made using AM technology. The Abaqus finite element three-dimensional models were created where the three-dimensional C3D8R, 8-node linear brick element with reduced integration were used. The mesh was densified in the area of maximum deformation and the boundary conditions correspond to realistic data from experiment set-up. A contact interaction between elements was assumed. Material properties were taken as the average values of the coupon tests. True stress-strain relationship were defined. Nine numerical models were created and validated by the experimental tests. Due to use of hierarchical validation in the performed simulations an appropriate level of accuracy was obtained. Failure mechanisms in FEM models and experimental tests seems to be similar. The criteria of joints load resistance are proposed such as permissible displacement of chord flange and Mann-Kendal (M-K) criterion. Finally, some conclusions are given.
\end{abstract}

\section{INTRODUCTION}

Fabrication and assembly of the typical steel connections requires considerable time and generation high costs. The use of modern techniques which belongs to AM as: $3 \mathrm{D}$ and $\mathrm{CNC}$ laser cutters or 3D printers made possibility to develop a new type of joints. These joints which are easy to make and install are the one of the possible answer for the strong need of manufactures to reduce the overall costs of steel structures. This knowledge related to demountable connections of steel trusses requires more extensive research. Such studies on plug \& play connections are shown, among others, in the works [Brekelmans, Bijlaard (2000), Bijlaard, Breckelmans (2007), Szlendak, Oponowicz (2011, 2013), Szlendak, Szpyrka (2018), Szlendak (2019)].

In Figure 1 the new concept of steel truss $\mathrm{N}$ type connection, which is studied herein, is presented. The socket in the flanges of RHS chord was made using Advanced Manufacturing (AM) technology (3D industrial laser cutting). In the slots of this socket the compressed RHS branch was inserted. The tension bracing contains of two elements. First of it contains two anchor blocks produced with the $3 \mathrm{D}$ printer and second is the round steel bar. Twisting nuts on the treaded ends eliminate clearances between the round bar of tension bracing and anchor blocks. This allows transmit stress to the top parts of anchor blocks and through they to the down parts up to the truss chord member. Concept of non-welded N RHS joints was presented in works of [Szlendak (2019) \& Szlendak, Szpyrka (2020)]. The joint eliminates welding as the typical technology [EN 1993-1-8 CEN (2005)] to connect the compressed and tension bracing with the RHS chord. Procedure for resistance verification of the N RHS joints was presented in [Szlendak, Szpyrka (2020)]. There the failure phenomena, the joint components and theoretical resistance of tested joints (WN3-WN9) were described. The test results show that the anchor blocks have 

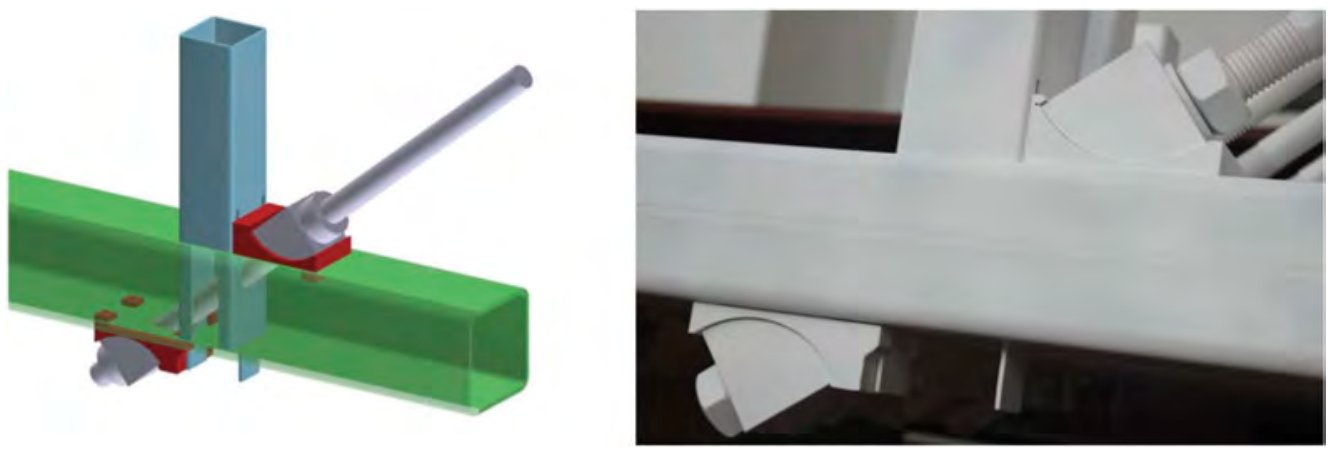

Figure 1. View of non-welded N type RHS truss joint using AM technology.

much higher resistance than other components. For the studied N type RHS connections it is possible to eliminate the welding and reach the resistance of joint not less than the welded ones.

\section{NUMERICAL MODEL}

\subsection{Material properties}

Material properties were taken as averaged values from the material coupon tests and defined on the basis of the actual stress-strain relationship. For the finite element analysis to simulate realistic behaviour, the material model has to be defined by true stress-strain relationship. The engineering data of material properties were converted to real values by applying equation (1) as follows:

$$
\sigma_{\text {true }}=\sigma_{\text {eng }}\left(1+\varepsilon_{\text {eng }}\right) ; \varepsilon_{\text {true }}=\ln \left(1+\varepsilon_{\text {eng }}\right)
$$

where $\sigma_{\text {eng }}$ - engineering stress; $\varepsilon_{\text {eng }}$ - engineering strain.

Ductile failure of an elastic-plastic material was defined. Beginning of destruction is assumed after achieving an equivalent plastic deformation. A technique with a centre axis algorithm was used to create a finite element mesh with regular shapes. In the area of maximum deformation, the mesh was compacted.

\subsection{Assumptions}

For estimation load resistance and deformation of the tested joints have been developed the numerical models. These models were created using Abaqus software [Abaqus CAE]. FEM analysis was also applied to the first generation of N type RHS non-welded joints [Szlendak, Oponowicz (2013)].

The FEM model of joint was built of solid elements and the finite element mesh was made using three-dimensional C3D8R eight-node elements with reduced integration, see Figure 2. The element type used in the model represents geometric and material nonlinearities, large deformations and crack simulations. Boundary conditions correspond to the real conditions carried out in experimental studies. In the numerical model, the 'general' contact was assumed between the surfaces, and the contact character was additionally defined as 'normal behaviour', see [Abaqus CAE]. Friction contact was assumed for the contact surface of the RHS chord face and the lower part of the anchor blocks and moreover for the lower part of the anchor block and the upper part of the anchor block. The friction coefficient was assumed to be equal to 0.15 . Nine numerical models of joints have been validated according to experimental tests. 


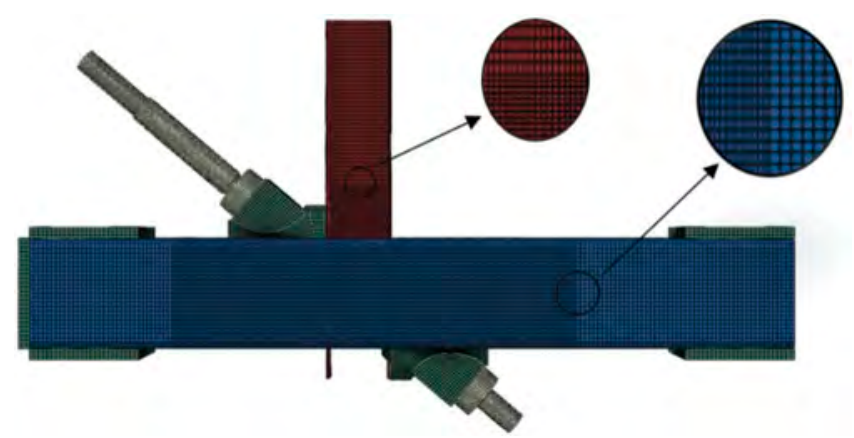

Figure 2. Numerical mesh used in FEM analysis for the N RHS truss joint.

\section{COMPARISON OF THE TEST RESULTS WITH FEA AND THEORETICAL ESTIMATIONS}

FEM models and results of natural scale experiments show the similar behaviour of joints. One of it could be seen in Figure 3. Concentrations of stresses in the 'teeth's' of anchor block in the place of 'teeth's' contact with the slots of chord are obtained, Figure 4. However, experiments confirmed the lack of failure of anchor blocks 'teeth's' and if it will be needed these anchor blocks can be used again.

\section{CRITERIA OF THE CONNECTION RESISTANCE}

The resistance of a connection for which FEM models exist can be estimated using different criteria. One of them is the permissible displacement of chord flange of studied joint. The second is the Mann-Kendall (M-K) criterion which detects the mutation of the characteristic parameter with load increase.

\subsection{Criterion of permissible displacement}

From numerical analyzes displacement maps for the joint chord was presented. Criterion of permissible displacement to be equal to the RHS chord flange thickness was proposed for RHS truss welded joints by Wardenier [Wardenier (1982)]. The similar assumption is suggested by the Authors for the non-welded N RHS truss joints. So, for specimens WN4, WN6
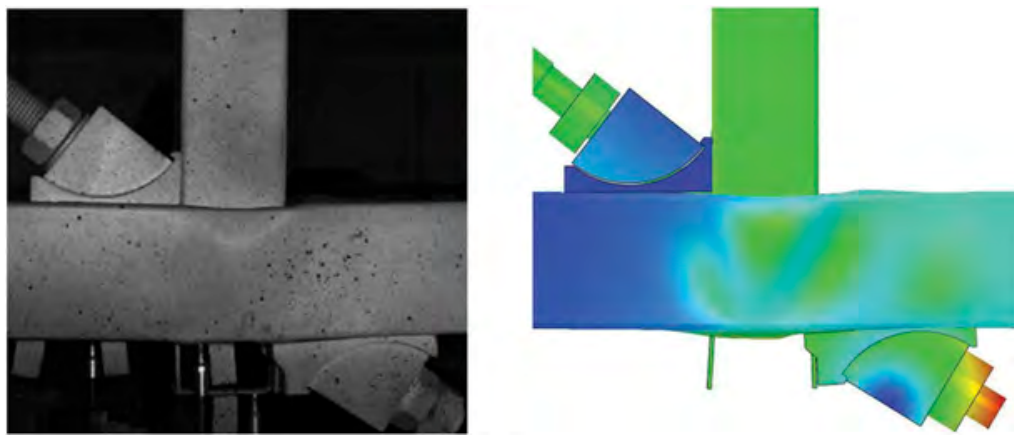

Figure 3. Destruction of the RHS webs for the joint WN8: during experiment (left), simulation by FEA (right). 

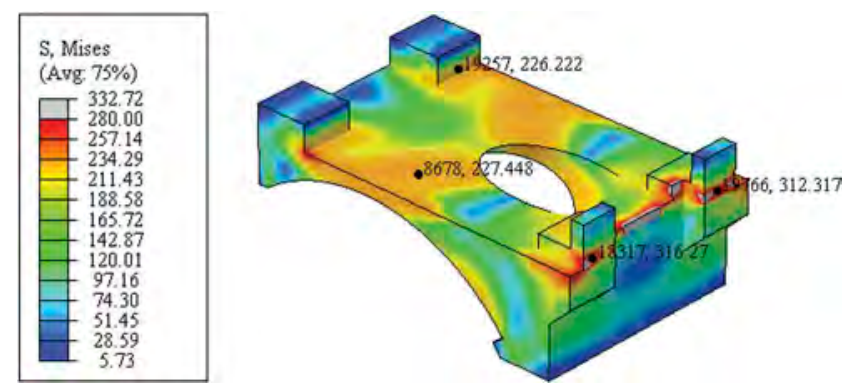

Figure 4. Stress concentration in anchor block - simulation by FEA.

and WN8 the permissible displacement is equal to $3 \mathrm{~mm}$; for WN5, WN7 and WN9 $4 \mathrm{~mm}$; for $\mathrm{WN} 1, \mathrm{WN} 2$ and WN3 $5 \mathrm{~mm}$. The deformation of the chord flange $3 \mathrm{~mm}$ thick (specimen WN4) is shown in Figure 5. For above limited deformations of joints the associated with them loads were registered and shown in Table 1.

Results of performed FEA show close agreement with the experimental data. The permissible displacement criterion can be also successfully applied, see Figure 6.

\subsection{The Mann-Kendal ( $M-K$ ) criterion}

This criterion was described in detail in the doctoral dissertation [Szpyrka, 2020]. The nonparametric Mann-Kendall test is commonly employed to detect monotonic trends in series of data. The null hypothesis, $H O$, is that the data come from a population with independent realizations and are identically distributed. The alternative hypothesis, $H A$, is that the data follow a monotonic trend.

A few years ago, the M-K criterion was used to evaluate HBBC connections [Chen, Zhao, Shao, Zhou (2020)]. Studied FEM connection model contain box-column, H-beam, seat angle, top angle and high strength bolts. The state-of-stress of the HBBC connection allows calculating the strain energy values which were received from the connection's FEA simulation. The Mann-Kendall criterion was used to detect the mutation point on the characteristic curves where statistic of test $\mathrm{M}-\mathrm{K}$ is a function of connection load. The connection failure criterion is defined by the mutation point $R$ on the characteristic curves shown in Figure 7.

The vector or matrix $S j$ can be used to form the structural stress $S j$ composed of the strain energy density values of some or all elements to the $\mathrm{j}$-th load value. The criterion is commonly used to detect trend analysis without a requirement for samples form a few abnormal number or to obey some certain distributions. Structural elements are far apart have little spatial relevance or mutual effect, according to Saint-Venant's. Also, the model and material properties have a significant independent content. In order to determine the $U F_{k}-F_{j}$ and $U B_{k}-F_{j}$, curves

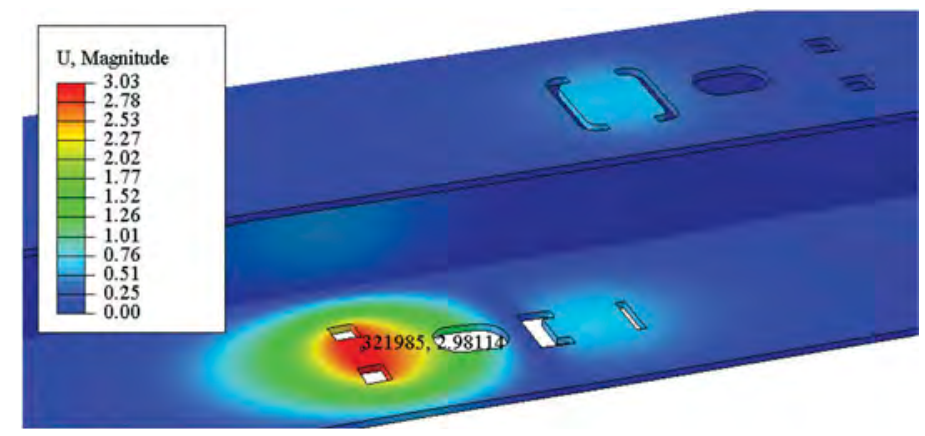

Figure 5. View of the displacement for the bottom chord of the joint WN4. 
Table 1. Resistance of connections - the criterion of permissible displacement and elastic resistance from experimental tests.

\begin{tabular}{llll}
\hline & $\begin{array}{l}\text { Resistance according to the criterion } \\
\text { of permissible displacement } N_{\text {el,pd }}\end{array}$ & $\begin{array}{l}\text { Elastic resistance from } \\
\text { experimental test } N_{\text {el,exp }} \\
- \text { criterion } C l[\mathrm{kN}]\end{array}$ & $N_{\text {el,pd }} / N_{\text {el,exp }}$ \\
\hline Specimen & $*$ & $* *$ & - \\
WN1 & $*$ & 129.99 & - \\
WN3 & $*$ & $* *$ & - \\
WN4 & 31.20 & 33.40 & 0.93 \\
WN5 & 49.17 & 47.60 & 1.03 \\
WN6 & 51.90 & 55.80 & 0.93 \\
WN7 & 104.60 & 93.00 & 1.12 \\
WN8 & 100.00 & 110.00 & 0.91 \\
WN9 & $*$ & 130.00 & - \\
\hline
\end{tabular}

* No results, the end of analysis before reaching resistance.

** No results, experiment interrupted before obtaining elastic resistance.
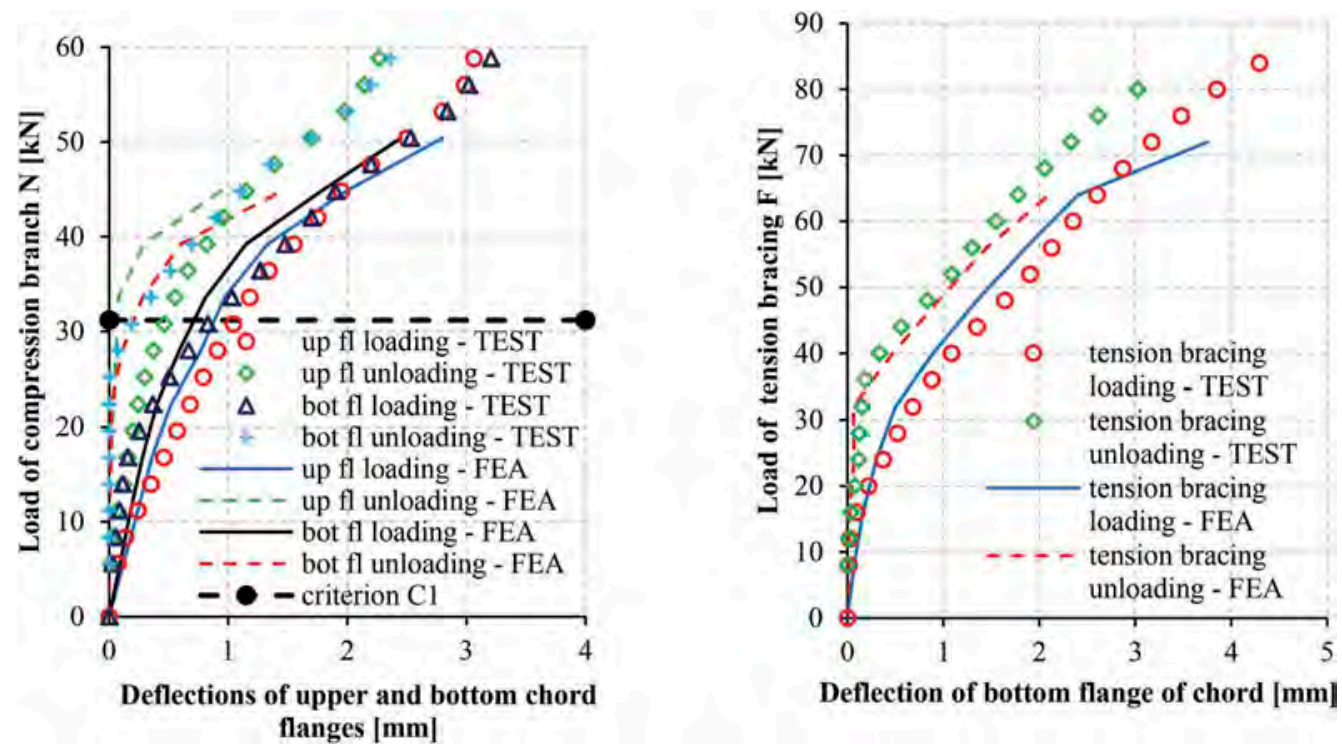

Deflection of bottom flange of chord [mm]

Figure 6. Load-defection diagram for joint WN4 $\left(\beta=0.4, \lambda_{0}=33.3\right)$.

shown in Figure 7, intersection of which marks the mutation point $R$, a statistical analysis should be performed, see [Chen, Zhao, Shao, Zhou (2020)]. The energy data $(E)$ obtained from the numerical analysis for the given time should be listed, that $E_{i}$ is greater than $E_{j}(1 \leq$ $\mathrm{j} \leq \mathrm{i})$ from the sequence $\left(E_{1}, E_{2}, \ldots, E_{n}\right)$. Determine the sign of all data, possible differences $E_{i}-E_{j}$, where i $>\mathrm{j}$. These differences are $E_{2}-E_{1}, E_{3}-E_{1}, \ldots, E_{n}-E_{1}, E_{3}-E_{2}, E_{4}-E_{2}, \ldots, E_{n}-E_{n-2}, E_{n}$ $-E_{n-1}$. Determine the sign of all differences $m_{i}$.

$$
m_{i}=\left\{\begin{array}{c}
+1, g d y E_{i}>E_{j}(1 \leq j \leq i) \\
0, \text { otherwise }
\end{array}\right.
$$

Then define statistical quantity $q_{\mathrm{k}}$ and mean value $E\left(q_{k}\right)$ and variance $v\left(q_{k}\right)$, calculated by the following equations: 


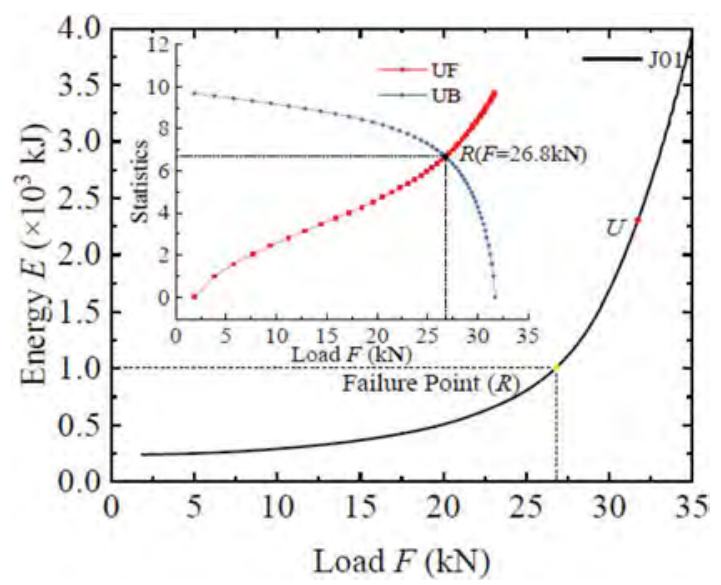

Figure 7. The E-F curve example [Chen, Zhao, Shao, Zhou (2020)].

$$
\begin{gathered}
\mathrm{q}_{\mathrm{k}}=\sum_{i=1}^{k} m_{i}(2 \leq \mathrm{k} \leq \mathrm{n}) \\
E\left(q_{k}\right)=\frac{k(k-1)}{4}(2 \leq k \leq n) \\
\nu\left(q_{k}\right)=\frac{k(k-1)(2 k+5)}{72}(2 \leq k \leq n)
\end{gathered}
$$

Obtain the gradient:

$$
U F_{k}=\left(q_{k}-E\left(q_{k}\right)\right) / \sqrt{\nu\left(q_{k}\right)}
$$

Then $U F_{k}-F_{j}$ curve can be obtained, where $F_{j}$ is the load value for which the energy is calculated. In order to obtain the gradient:

$$
U B_{k}=-\left(q_{k^{\prime}}-E\left(q_{k^{\prime}}\right)\right) / \sqrt{\nu\left(q_{k^{\prime}}\right)}
$$

Repeat previous steps for the sequence inverse $\left(E_{n}, \ldots, E_{2}, E_{l}\right)$. Normalize the new $q_{k}^{\prime}$ and then obtain $U B_{k}-F_{j}$ curve. The intersecting point $R$ of the $U F_{k}$ and $U B_{k}$ curves is the state-ofstress mutation point of the $E_{j}-F_{j}$ curve. It presents the starting of the failure process of connection or the ending point of the connection's normal working state. Using the described criterion, the resistance of the connections could be determined.

Criterion M-K can be also applied to the plug \& play connections studied herein. The results will be presented in subsequent publications.

\section{CONCLUSION}

The failure models obtained in simulations using FEM and from experimental tests are very similar.

Resistances obtained from the criterion of the permissible displacements were compared with the resistances from the experimental tests. Results vary by a maximum of $12 \%$, so the 
consistency of the results looks satisfactory. The permissible displacement criterion can be successfully applied for FEA of such connections to obtain their resistance.

The criterion M-K seems to be valuable to estimate of the resistance of studied connections modelled by FEM, where the mutation point is revealed as the beginning of the failure process.

\section{REFERENCES}

Abaqus CAE ver. 6.16, Dassault Systèmes.

Bijlaard F., Brekelmans J. 2007. Plug and play type joints in steel and steel-concrete composite constructions. Proceedings of the Fifth International Conference on Advances in Steel Structures, Singapore.

Brekelmans J., Bijlaard F. 2000. Design requirements for plug and play type joints in mixed and steel-concrete composite construction. Proceedings of the Fourth International Workshop on Connections in Steel Structures. Roanoke, VA, USA.

CEN, EN 1993-1-8.Eurocode 3: Design of Steel Structures: Part 1.8: Design of joints, 2005. Brussels.

Chen Z., Zhao Y., Shao Y., Zhou G. 2020. Essential state-of-stress features of HBBC connections revealed by modelling simulative strain energy. Engineering Structures, 1152.

Szlendak J.K., Oponowicz P.L. 2011. Behaviour of one and double side non-welded T RHS compression truss joints. Proceedings of the 7th International Conference on Steel \&Aluminium Structures. Kuching, Sarawak, Malaysia.

Szlendak J.K., Oponowicz P.L. 2013. Resistance of RHS truss N type joints made by laser as non-welded plug \& play connections. Lublin University of Technology Press.

Szlendak J.K., Szpyrka A. 2018. Resistance of tension brace in plug \& play N shape RHS truss connection. Journal of Civil Engineering, Environment and Architecture JCEFA, t. XXXIII, z. 65 (2/2018).

Szlendak J.K. 2019. Static resistance of laser-made, non-welded T RHS joint estimated using the component method. Journal of Constructional Steel Research. Vol. 159, No JCSR 5615, 574-583.

Szlendak J. K. 2019. Innovative steel structure connections. Polish Scientific Publishers PWN, Warsaw, pp.230 (in Polish).

Szlendak J.K., Szpyrka A. 2020. Resistance of plug \& play N type RHS truss connections. De Gruyter, Open Engineering. 10:563-570.

Szpyrka A. 2020. Resistance of non-welded type N joints of RHS steel trusses, PhD thesis, Rzeszow University of Technology, Faculty of Civil Engineering.

Wardenier J. 1982. Hollow Sections Joints. Delft: Delft University Press. 


\title{
Load capacity of anchors embedded into concrete and multi-layer façade slabs
}

\author{
J.K. Szlendak \\ State School of Higher Professional Education in Suwalki, Suwatki, Poland \\ D. Tomaszewicz \\ Faculty of Civil and Environmental Sciences, Bialystok University of Technology, Biatystok, Poland
}

\begin{abstract}
This paper presents the estimation of the load capacity of steel bonded anchors in concrete and multi-layer elements, in various arrangements and configurations, starting from single anchors perpendicular to the surface of the concrete element and ending with diagonal anchors bonded at 30,45 and 60 degrees. The estimates of load capacity used analytical models regarding, among others: individual anchors for pulling out taking into account the shear force of the texture layer and the anchor fixing factor (with or without lever arm); single concrete anchors for pulling out in full concrete elements and three-layer concrete elements as well as single diagonal anchors (without taking into account shear force). The first stage of experimental research included steel anchors bonded at an angle of 90 degrees in 22 three-layer samples and 10 samples with concreted anchors ( 7 solid samples and 3 three-layer samples) at different anchorage depths.at various anchoring depths. In the second stage, steel anchors concreted in concrete samples were tested. The third stage consisted of double-bolt anchor systems bonded at 30 and 45 degrees angles. The last, fourth stage was experimental study of three-bolt anchors. Experimental research was used to verify the theoretical load capacity of this type of connections in the external walls of large slab panel buildings. The results of experimental studies were compared with 56 numerical calculations made in ANSYS software and theoretical estimates according to the proposed analytical models.
\end{abstract}

\section{INTRODUCTION}

The theoretical estimation of the resistance of anchors has been the subject of many publications (Eligehausen et al. 2006, Ballarini et al. 1986). Usually, such estimates are preceded by experimental studies (Eligehausen et al. 2006, Eligehausen \& Appl J. 2006, Červenka et al. 1991), as well as numerical analysis using MES programs and environments (Eligehausen \& Appl J. 2006). In the work so far, only the anchors perpendicular to the surfaces of the concrete solid elements have been tested. This article also analyzes the anchors fixed at an angle (30, 45 and 60 degrees), extended with groups of anchors in two- and three-anchor systems, the load capacity of which was checked simultaneously.

\section{THEORETICAL ESTIMATION OF THE ANCHORS RESISTANCE- PROPOSED MODELS}

Load capacity of a single steel anchorglued in the concrete block has been developed by (Słowik \& Błazik-Borowa 2001) and their formula can be written as:

DOI: $10.1201 / 9781003132134-46$ 


$$
P=\pi \cdot d \int_{0}^{h e f} \tau_{p} \mathrm{dx} \rightarrow P=\pi \cdot d \cdot \tau_{p} \cdot h_{e f}[k N]
$$

where $d$-anchor diameter, [mm]; $\tau_{p}$ - adhesion stress, depending on the type of epoxy resin, $\left[\mathrm{N} / \mathrm{mm}^{2}\right] ; h_{e f}-$ lengths of effective anchors of individual anchors in samples, [mm].

In the experimental research, there were established the ultimate failureload of the joints anchored in the concrete blocks. Due to the nature of the impact of these loads in three-layer models, see Figure 1, the Authors extend formula (1) with the algebraic sum of the shear force of the top textured layer, the displacement of which is the resistance to the force pull-out the anchors. This model is described by the formula (2):

$$
P_{g r}=\pi \cdot d \int_{0}^{h e f} \tau_{p} d x=\pi \cdot d \cdot \tau_{p} \cdot h_{e f}+\frac{V}{\alpha_{M}}[k N]
$$

where $V$ - shear force of the top textured layer, [kN]; $\alpha_{M}$ - anchor fastening factor (shear loads with lever arm $\alpha_{M}=1.0$ or shear loads without lever arm $\alpha_{M}=2.0$ ) (ETAG 001 Annex C), [-].

When dealing with single anchors, the authors used the formula (1) and (2). However, in the case of anchors concreted in solid concrete elements, it was not necessary to take into account the effect of the shear force. For the group of anchors as it is shown in Figure 2. the theoretical resistance estimation is given using the formula (3):

$$
P_{g r}=\pi \cdot d \int_{0}^{h e f} f_{\text {ck.cube }} d x=\pi \cdot d \cdot f_{\text {ck.cube }} \cdot h_{e f}[k N]
$$

where $f_{\text {ck.cube }}$ - strength characteristic cube compressive, $\left[\mathrm{N} / \mathrm{mm}^{2}\right]$.

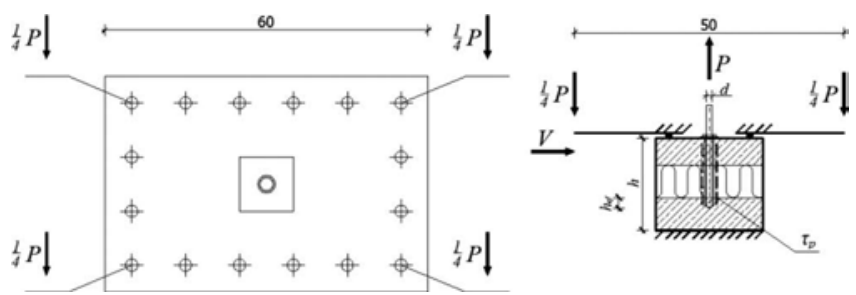

Figure 1. Scheme of three-layer sample load with anchor bonded perpendicularly.
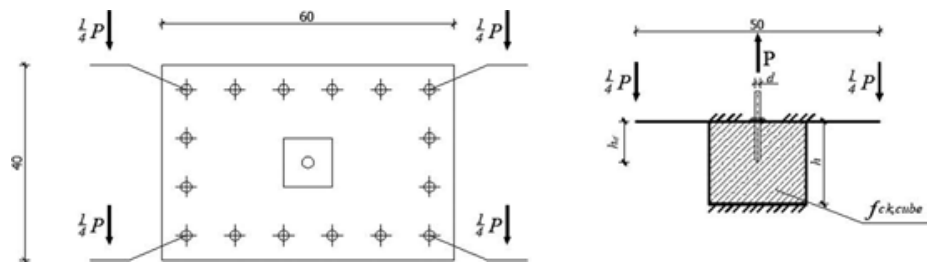

Figure 2. Scheme of single-layer sample load with anchor concreted perpendicularly. 
The value of the $\alpha_{M}$ coefficient, depending on the method of fastening and the nature of failure of the anchor, may be taken in accordance with the recommendations (ETAG 001).

Another theoretical model were discovered to describes the failure of diagonal bonded anchors at angles of $60^{\circ}, 45^{\circ}$ and $30^{\circ}$ (Figure 3). It does not take into account the effect of the shear force of the textured layer due to the lack of experimental verification. The failure load is estimated as:

$$
P_{g r}=\pi \cdot d \int_{0}^{h e f} f_{c k, c u b e} d x=\pi \cdot d \cdot f_{c k, c u b e} \cdot h_{e f}+\frac{V}{\alpha_{M}}[k N]
$$

where $\alpha$ - angle of inclination of diagonal anchors, $\left[^{\circ}\right]$.

Moreover, for two-anchor systems (Figure 4), the failure load was proposed equal to:

$$
P_{g r}=\frac{\pi \cdot d \int_{0}^{h_{e f 1} \cos \alpha_{1}}\left(\tau_{p} \cdot s\right) d s+\pi \cdot d \int_{0}^{h_{e f 2} \cos \alpha_{2}}\left(\tau_{p} \cdot s\right) d s}{2 c+2 l_{e f 1.2}}+\frac{V}{\alpha_{M}}[k N]
$$

where $h_{e f 1}, h_{e f 2}$ - effective anchor lengths of individual anchors, [mm]; s - distance between the anchors in the axes, [mm]; c - thickness of the epoxy resin covers between the anchor and the concrete substrate, $[\mathrm{mm}] ; l_{e f 1.2}-$ the length of total anchorage in the samples, $[\mathrm{mm}]$.

In the case of three-anchor systems, a theoretical resistance is equal to:
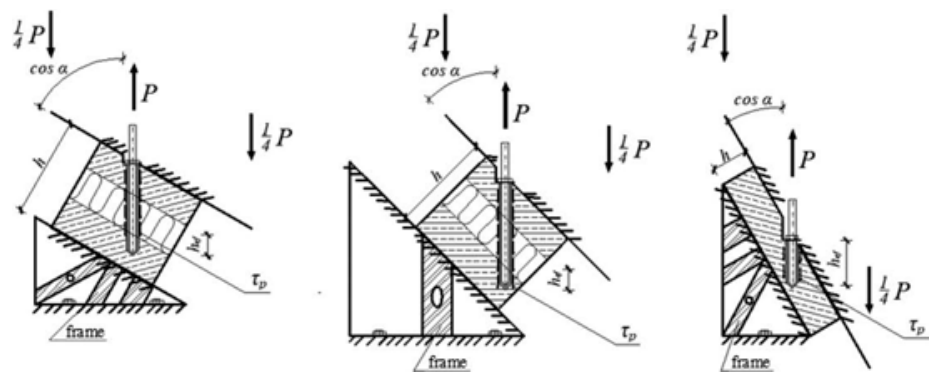

Figure 3. Sample load diagram with single diagonal anchors at $60^{\circ}, 45^{\circ}$ and $30^{\circ}$ respectively.

a)

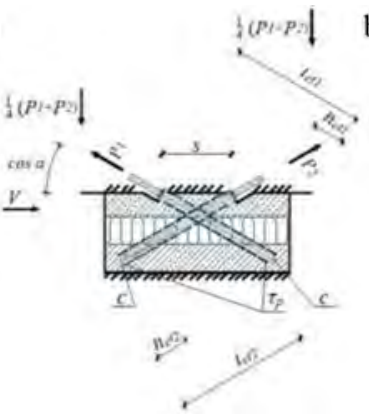

b)

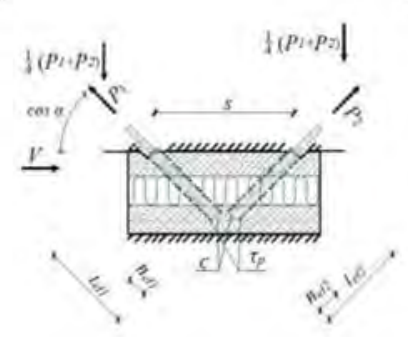

c)

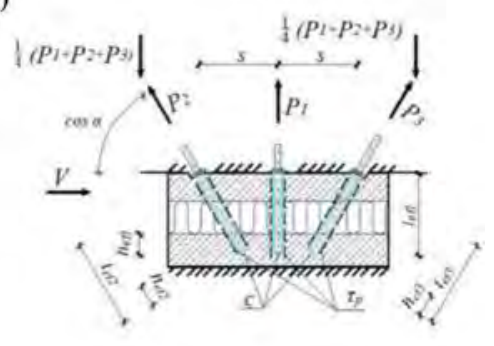

Figure 4. Diagram of a three-layer sample load in: a) a two-anchor system at an angle of $30^{\circ}$; b) a twoanchor system at an angle of $45^{\circ}$; c) a three-anchor system at an angle of $60^{\circ}$. 


$$
P_{g r}=\frac{\pi \cdot d \int_{0}^{h_{e f 1} \cos \alpha_{1}}\left(\tau_{p} \cdot s\right) d s+\pi \cdot d \int_{0}^{h_{e f 2}}\left(\tau_{p} \cdot s\right) d s+\pi \cdot d \int_{0}^{h_{e f 3} \cos \alpha_{3}}\left(\tau_{p} \cdot s\right) d s}{3 c+2 l_{e f 2,3}+l_{e f 1}}+\frac{V}{\alpha_{M}}[k N]
$$

and can be written as bellow:

$$
P_{g r}=\frac{\pi \cdot d \cdot \tau_{p} \cdot s \cdot h_{e f 2} \cdot \cos \alpha_{2}+\pi \cdot d \cdot \tau_{p} \cdot 2 s \cdot h_{e f 1}+\pi \cdot d \cdot \tau_{p} \cdot s \cdot h_{e f 3} \cdot \cos \alpha_{3}}{3 c+2 l_{e f 2,3}+l_{e f 1}}+\frac{V}{\alpha_{M}}[k N]
$$

where $h_{e f 2}=h_{e f 3}-$ effective lengths of diagonal anchorages, [mm]; $h_{e f 1}$ - effective length of the anchorage at an angle of 90 degrees, $[\mathrm{mm}] ; l_{\text {ef } 2.3}$ - the length of the total anchoring of diagonal anchors in the sample, [mm]; $l_{e f 1}$ - the length of the total anchoring of the anchor perpendicular to the sample surface, [mm].

Due to taking into account the parameters of the resin cover $c$ and the total anchorage length $\boldsymbol{l}_{\boldsymbol{e}}$, presented estimations achieve similar results with the numerical FEM simulation and experimental tests. A different approach to analytical calculations was proposed in (Szlendak et al., 2018).

\section{EXPERIMENTAL TESTS AND MES MODELS}

Experimental tests of steel anchor resistance were carried out in four stages. In the first stage, 32 specimens with 90-degree anchors were tested, in the second - 12 with single diagonal anchors, in the third -8 with two-anchor 30 and 45 degrees systems and in the fourth stage - 4in three-anchor systems with the two 60-degree anchors and one-90 degree. The increase the pull-out force in the anchors in the experimental tests and FEM analysis was $0,5 \mathrm{kN} / \mathrm{s}$. In addition (apart from individual diagonal anchors), a shear force was applied to the top texture layer equal to $1,4 \mathrm{kN}$. Tests of natural scale specimens were carried out at the Bialystok University of Technology, Department of Building Structures.

In the 90 degree bonded anchorages test, 22 tests of the interaction load capacity of bonded anchors were carried out, i.e. to obtain a relation of the bonding force of the bonded anchor and the shear force (Figure 5) of the upper concrete layer (textured layer).

The next stage of the tests is to check the resistance to stress of diagonal anchorages.

The tests of bonded diagonal anchorages at angles of 60 degrees, 45 degrees and 30 degrees were carried out in 4 tests for each anchorage angle. Figure 6 shows one of the failure models of the bonded anchorage at 60 degrees.
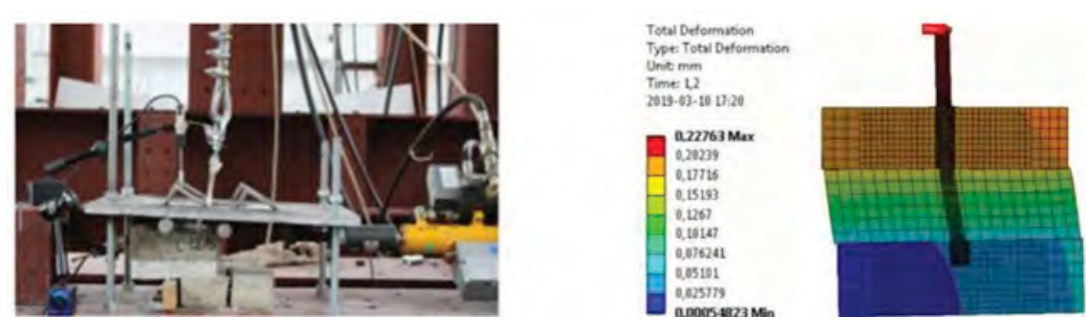

Figure 5. Failure models of 90 degree bonded anchorage: experimental test and FEM model. 

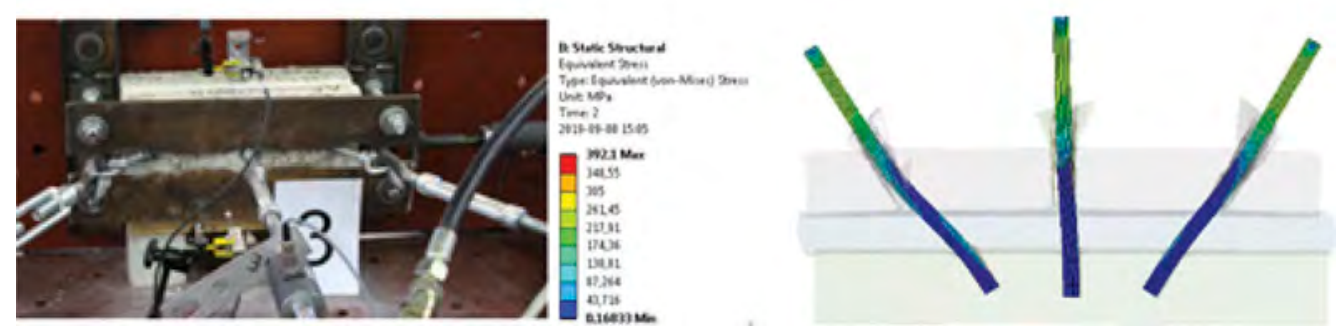

Figure 6. Failure models of three-anchor anchorages bonded at an angle of 60 degrees: experimental test and FEM model.

The model for anchoring made at an angle of 30 degrees was designed as a single-layer with a construction layer thickness of $6 \mathrm{~cm}$ due to the large inclination angle.

- Anchorages concreted at an angle of 90 degrees

In the solid concrete samples, depth of anchorages were used of $8.5 \mathrm{~cm} ; 11.5 \mathrm{~cm} ; 14.5 \mathrm{~cm}$; $15 \mathrm{~cm} ; 15.5 \mathrm{~cm} ; 16 \mathrm{~cm}$ and finally through the full cross-section, i.e. $17 \mathrm{~cm}$.

As for the three-layer models, the anchors were concreted at the depths of $2 \mathrm{~cm}, 4 \mathrm{~cm}$ and $6 \mathrm{~cm}$ of the cross-section of the construction layer.

- Two-anchor anchorages bonded under angle at 30 and 45 degrees

This stage of the tests consists of complex two-anchor systems at an angle of 30 degrees and 45 degrees.

- Three-anchor anchorages have been bonded under angle at 60 degrees. This is the last stage of the test in which the three-anchor systems consisted of two anchors at an angle of 60 degrees and anchors at an angle of 90 degrees between them (Figure 6).

\section{COMPARISON OF THEORETICAL ESTIMATIONS AND FEM MODELS WITH EXPERIMENTAL RESULTS}

\subsection{Comparison of the results for bonded anchors at an angle of 90, 60, 45 and 30 degrees}

Table 1 summarize the results for the anchor bonded. The results correspond to the most unfavourable anchorage $\left(h_{e f}=2 \mathrm{~cm}\right)$.

Table 1. Comparison of the results - steel anchors bonded at an angle of 90 degrees.

\begin{tabular}{|c|c|c|c|c|}
\hline \multirow[b]{3}{*}{ Description } & \multicolumn{2}{|c|}{ Theoretical estimate } & \multicolumn{2}{|c|}{ FEM calculations - ANSYS } \\
\hline & Force & displacement & Force & displacement \\
\hline & $\mathrm{kN}$ & $\mathrm{mm}$ & $\mathrm{kN}$ & $\mathrm{mm}$ \\
\hline The result of the experiment & 8.40 & 0.10 & 8.40 & 0.10 \\
\hline Calculation result & 8.43 & 0.14 & 10.00 & 0.14 \\
\hline Difference & 0.03 & 0.04 & 1.60 & 0.04 \\
\hline
\end{tabular}




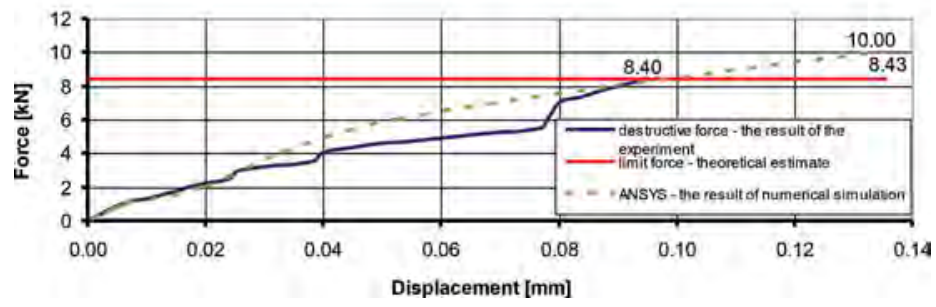

Figure 7. Comparison of theoretical estimation, experimental tests and numerical simulation for an anchor bonded at 90 degrees to the surface of the block model.

\subsection{Comparison of the results for anchors concreted at an angle of 90 degrees}

The anchorages in solid concrete and three-layer samples at a depth of only $2 \mathrm{~cm}$ were compared (Table 2).

\subsection{Comparison of the results of bonded two-anchors at an angle of 30 and 45 degrees}

In the case of the most unfavourable of the anchorages at an angle of 30 degrees, the difference between the experimental result and the FEM model was $1.20 \mathrm{kN}$ but in case of the theoretical estimatethis difference was $9.99 \mathrm{kN}$.

\subsection{Comparison of the results of bonded three-anchors at an angle of 60 degrees}

The three-anchors were two steel anchors bonded in at an angle of 60 degrees and one the anchors bonded in at an angle of 90 degrees. The results of a single model are presented in Table 3. The forces in individual anchors obtained in experiment are added, see Figure 8.

Table 2. Comparison of the results of models with steel anchors concreted at an angle of 90 degrees.

\begin{tabular}{|c|c|c|c|c|}
\hline \multirow[b]{3}{*}{ Description } & \multicolumn{2}{|c|}{ Theoretical estimate } & \multicolumn{2}{|c|}{ FEM calculations - ANSYS } \\
\hline & Force & displacement & Force & displacement \\
\hline & $\mathrm{kN}$ & $\mathrm{mm}$ & $\mathrm{kN}$ & $\mathrm{mm}$ \\
\hline The result of the experiment & 15.00 & 0.17 & 15.00 & 0.17 \\
\hline Calculation result & 12.70 & 0.12 & 16.00 & 0.09 \\
\hline Difference & 2.30 & 0.05 & 1.00 & 0.08 \\
\hline
\end{tabular}

Table 3. Comparison of the results of models with steel anchors bonded at an angle of 60 degrees.

\begin{tabular}{llllll}
\hline & \multicolumn{2}{l}{ Theoretical estimate } & & \multicolumn{2}{l}{ FEM calculations - ANSYS } \\
\cline { 2 - 3 } & Force & displacement & & Force & displacement \\
\cline { 2 - 3 } \cline { 5 - 6 } Description & $\mathrm{kN}$ & $\mathrm{mm}$ & & $\mathrm{kN}$ & $\mathrm{mm}$ \\
\hline 0.17 & 26.30 & 0.30 & & 26.30 & 0.30 \\
0.12 & 30.48 & 0.42 & & 25.00 & 0.42 \\
0.05 & 4.18 & 0.12 & & 1.30 & 0.12 \\
\hline
\end{tabular}




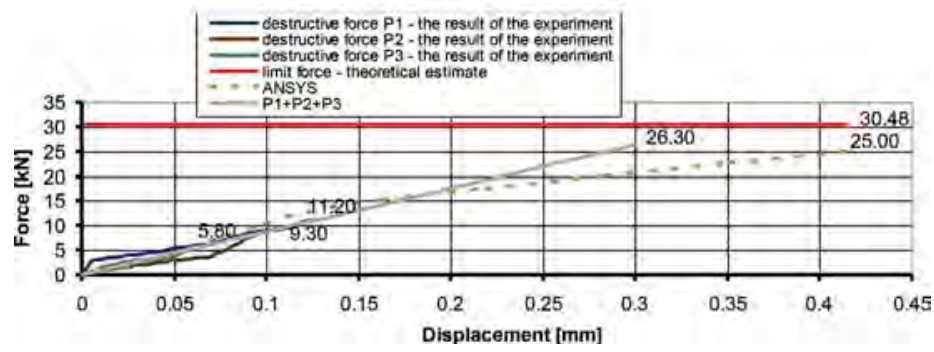

Figure 8. Comparison of theoretical estimate results, experimental tests and numerical simulation of athree-anchor bonded at 60 degrees to the surface of the block model.

A direct comparison of all group of anchors i.e. 90 degree bonded and also two and three anchors diagonal anchorages have been described in (Szlendak et al. 2018a and 2018b).

\section{CONCLUSIONS}

The experimental tests of anchors were carried out on two types of elements, made of C12/15 and C30/37 concrete with the use of epoxy resins: R-KER Bonded Anchors and Sika AnchorFix-1. At all stages of the tests, efforts were made to obtain the failure force which damage the anchorage. Theoretical estimations of these failure loads are given.

Most of the results showed high convergence. Larger discrepancies in the results occurred in the models with concrete anchors. This may be because the calculation models do not take into account the phenomenon of sample destruction caused to concrete fracture mechanics. This issue will be investigated in the future.

\section{REFERENCES}

Eligehausen R., Cook R. A., Appl J. 2006.Behaviour and design of adhesive bonded anchors. ACI Structural Journal, pp. 822-831.

Ballarini R., Shah S. P., Keer L. M. 1986. Failure characteristics of short anchor bolts embedded in a brittle material.The Royal Society London A 404, pp. 35-54.

Červenka V., Pukl R., Eligehausen R. 1991. Fracture analysis of concrete plane-stress pull-out tests. Institut für Werkstoffe im Bauwesen.

Eligehausen R., Appl J. 2006. Behavior and design of fastenings with bonded anchors: numerical analysis and experimental verification. Institute for Construction Materials, Univ. of Stuttgart, Germany.

Słowik M., Błazik-Borowa E. 2001. The influence of the choice of reinforcement's bars on stress distribuction in concrete element. EksploatacjaiNiezawodność $n r$ 5/2001, Polskie Naukowo-Techniczne Towarzystwo Eksploatacyjne, pp. 43-46 (in Polish).

ETAG 001. 2013. Guideline For European Technical Approval of Metal anchors for use in concrete. Part one: Anchors in general.

Szlendak J. K., Jablonska-Krysiewicz A., Tomaszewicz D. 2018a.Analytical modelling of a three layer wall system of strengthening for large-panel slab buildings by means of bonded anchors, MATEC Web Conf., Volume 174, pp. 859-868, ECCE 2018, Opole, Poland.

Szlendak J. K., Jablonska-Krysiewicz A. \& Tomaszewicz D. 2018b. Comparative Analysis of Oblique Bonded Anchors with Point Anchors Fixed in the Concrete Structural Layer of Buildings of Large Slab. $3^{\text {rd }}$ World Multidisciplinary Civil Engineering - Architecture - Urban Planning Symposium; WMCAUS 18-22 June 2018, At Prague, Czech Republic. 


\title{
Innovative bolted end-plate connections for high web I-beams
}

\author{
P. Tucki \& E. Hotała \\ Department of Civil Engineering, Wroctaw University of Science and Technology, Wroctaw, Poland
}

\begin{abstract}
Solid end-plate connections are commonly used in bolted joint of solid I-beam elements. But effective use is made only of the plate fragments lying adjacent to the webs and flanges of the I-beams. The paper presents the potential of using innovative bolted end-plate connections comprising independent T-stubs instead of traditional solid end-plates in relation to the example of steel I-beams with high webs. It has been shown that such innovative end-plate connections are justified economically, can be easily manufactured, and provide comparable load-bearing capacity and stiffness to traditional solid end-plate connections. The influence of T-stubs plate thickness on the load-bearing capacity and stiffness of these innovative connections has been demonstrated. Attention is drawn also to easier compliance with flatness standards of the independent T-stubs plates when compared to large solid end-plates.
\end{abstract}

\section{INTRODUCTION}

Bolted end-plate connections of I-beams with high webs requiring many rows of bolts pose considerable problems to designers and contractors. The calculation methods contained in (EN 1993-1-8) are insufficient for determining the load-bearing capacity of such connections, as the calculated standard load-bearing capacity is significantly overestimated, as has been demonstrated in several publications (Kawecki et al. 2016, Żółtowski et al. 2016). An acceptable differential in load-bearing capacity standards obtained from the calculations and from FEM analysis can be achieved by determining load-bearing capacity on the basis of a consideration of only two rows of bolts located directly adjacent to the tension zone and in the zone of the next row away from the tension zone, if there is one. Large end-plates in the connections are subject to large deformation during welding, which means that it is difficult to meet the flatness requirement of the EN-1090-2 standard.

Paper (Hotała et al. 2020) present end-plate connections as an innovative solution as they are not focused on a single end-plate on the front edge of the I-beam element, but on several independent small end-plates with the bolt holes, which are referred to as independent T-stubs. These T-stubs are not connected to one another. The small plates are welded onto the flanges, whereas others are welded on the I-beam web, which means that they constitute independent $\mathrm{T}$-stubs. The individual end-plates in these independent $\mathrm{T}$-stubs include bolt-holes and are welded onto the flanges of the I-beam or its web, with the proviso that each one of these end-plates is welded onto only one of the two flanges of the I-beam or to the web of the I-beam or else to one of the flanges and web. In this study, the results of a numerical analysis of T-stubs end-plate connection of an HEB400 beam are presented, showing that this kind of innovative connection can achieve comparable load-bearing capacity and stiffness to that of a single solid end-plate connection. Elimination of the cross T-stubs (consisting of solid endplates connected to flange and web) should ensure a high capability for rotating the joint, 
while bringing into play the bolts adjacent to web. In the paper was shown next analysis phase of an end-plate connection with T-stubs.

The authors of this paper are convinced that with a moment end-plate connection, the rows of bolts located away from the tension flange, adjacent to the web can contribute effectively to increasing the load-bearing capacity of the end-plate connection if that connection has a high rotational capability, as only then high tensile forces can occur in these bolt rows.

Designing moment end-plate connection of high beams with solid end-plates leads the problem of ensuring a sufficient rotational capability, while ensuring at the same time high loadbearing capacity of the connection. A problem arises from the limited capability of the bolts under tension to elongate, especially those which are high strength. When using thick endplates, the rotational capability depends on the ability of the bolts under tension to elongate. The rotational capability of the connection can be very beneficial for the design of systems, which require flexible joints, which provide for a planned distribution of bending moments.

This paper presents the results of comparative analysis of a traditional end-plate connection with solid end-plates and an innovative end-plate connection comprised of independent T-stubs used in a beam with high web $h_{w}=900 \mathrm{~mm}$. The influence of connection flexibility was analysed on the distribution of bending moments in the middle of the bending beam span.

\section{FEM ANALYSIS}

The end-plate connections of the I-beam shown in (Figure 1) provided the focus for a comparative numerical analysis. Connections with solid end-plates and independent T-stubs of a thickness of $\mathrm{t}=20,24,28 \mathrm{~mm}$ (solid and independent T-stubs) were analysed comparatively. The bolt arrangement in each case was identical. A numerical FEM model of the I-beams analysed was constructed, based on a simple-supported beam static schema of a $2 \mathrm{~m}$ span, and with boundary conditions imposed on the lower edge of the beam profile. A bending moment was applied using the pressure at the ends of the profiles. In all models longitudinal symmetry was used, which was ensured through using appropriate boundary conditions.

The modelling method for contact and the finite elements used are the same as those in (Hotała et al. 2020). The elastic-plastic model for S355 steel was used. Class 10.9 bolt material was also modelled as ideally elastic-plastic as $f_{u b}=720 \mathrm{MPa}, a f_{y b}=900 \mathrm{MPa}$. The boundary limit for deformation of bolt material under tension was adopted in accordance with EN ISO $898-1: 2013$ ), i.e. $\varepsilon_{\lim }=9 \%$. The load-bearing capacity of the I-beam profile analysed was $\mathrm{M}_{\mathrm{c}, \mathrm{Rd}}=2750 \mathrm{kNm}$. The authors are familiar with the models of materials used for FEM calculations of bolted connections, e.g. (Sumner 2003), but these were not used as the calculation parameters for the materials as these were taken from the EN 1993-1-8 standard.

As a result of the numerical analyses, determination was made of the static equilibrium paths and force distribution of the connections analysed at the ultimate limit state of their load-bearing for different thicknesses of end-plates. The static equilibrium paths are presented in (Figure 2).

The distribution of forces $F_{t}$ in bolts and the distribution of effective forces $F_{t, \text { eff }}$ in bolts are presented in (Figure 3), but only for plate thicknesses $t=28 \mathrm{~mm}$. The lower flanges of the beam are tensioned at the joint. In each case, the new connection type made with independent T-stubs had a rotation capability of $22 \%$ to $42 \%$ higher than in the solid plate connection. The greatest increase in rotational capability combined with only a small loss in load-bearing capacity was achieved for a $28 \mathrm{~mm}$ thick connection when compared to the solid end-plate. The values of bolt forces in both types of connection (solid end-plate, independent T-stubs) are presented in (Figure 3). The indication is that in connection with independent T-stubs, there are slightly higher effective forces in the bolts in the rows above the tension flange at the beam web than in the case of the solid plate. The exception is bolt $3 \mathrm{~A}$ in connection with solid endplate, as in this case the prying forces are concentrated on the level of bolt $4 \mathrm{~A}$, which means that the effective force in bolt $3 \mathrm{~A}$ cannot be unambiguously determined. The distribution of the prying effect of reactive forces is shown in (Figure 4). It should be noted that in both 


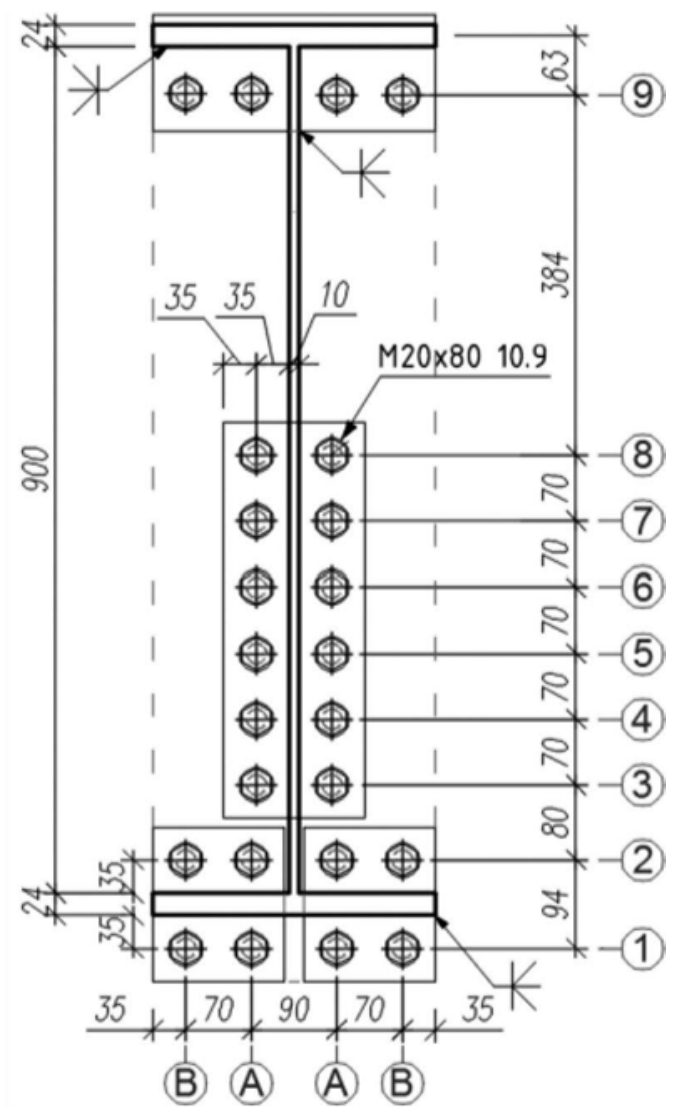

Figure 1. Geometry of the connection analysed with independent T-stubs and with a solid end-plate. The contour of the solid plate is indicated with a dashed line. Bolt row numbers: $1-9$.

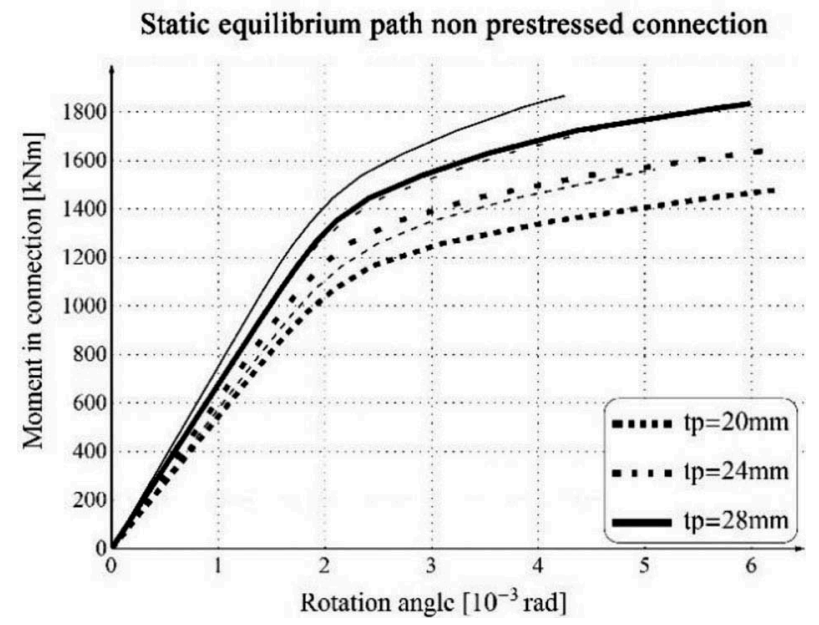

Figure 2. Static equilibrium paths for non prestressed connections. The thick lines mark the paths of connections with independent T-stubs. The thin lines indicate the paths of connections with a solid end-plate. 


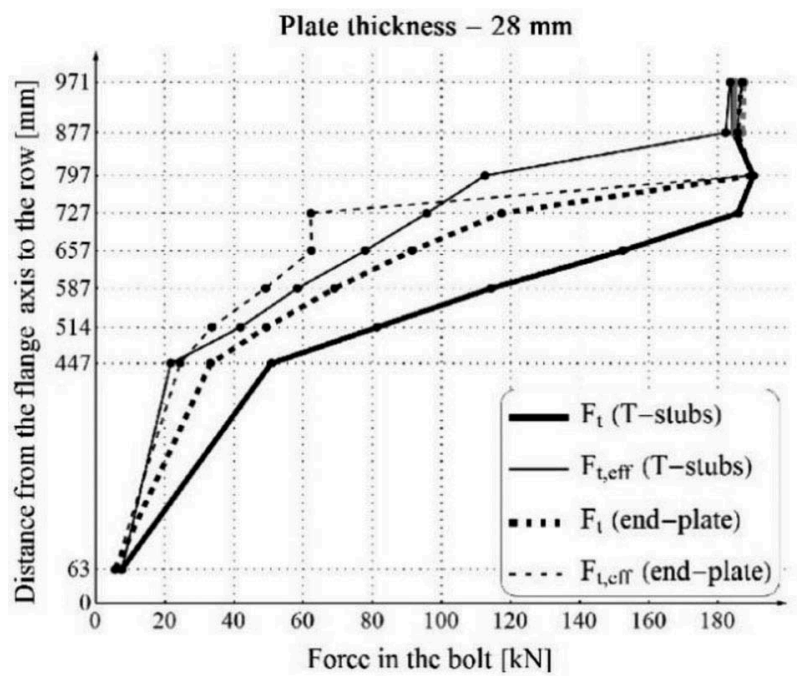

Figure 3. Values of bolt forces in combination with end plate $t=28 \mathrm{~mm}$. The bolts in vertical row A presented in (Figure 1), are marked in black and bolts in the vertical row B are marked in grey. Continuous lines refer to the independent $\mathrm{T}$-stubs and dashed lines are for the solid end-plates.

a)

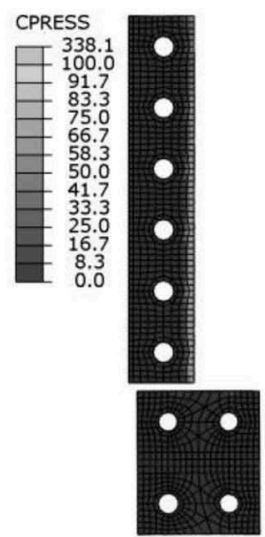

b)

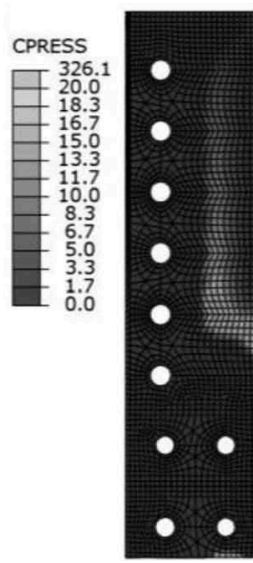

Figure 4. Distribution of pressure stress (light colouring) on end-plates resulting from the prying effect for: a) independent $\mathrm{T}$-stubs, b) solid end-plates.

models the effective forces in bolts (Figure 3) in the row 1 and 2 are to high. It can be result from the coarse mesh hence bolts fail according to model 3 in (EN 1993-1-8). Despite that connections with T-stubs have better rotational capacity. An analysis with thicker mesh should be performed. 


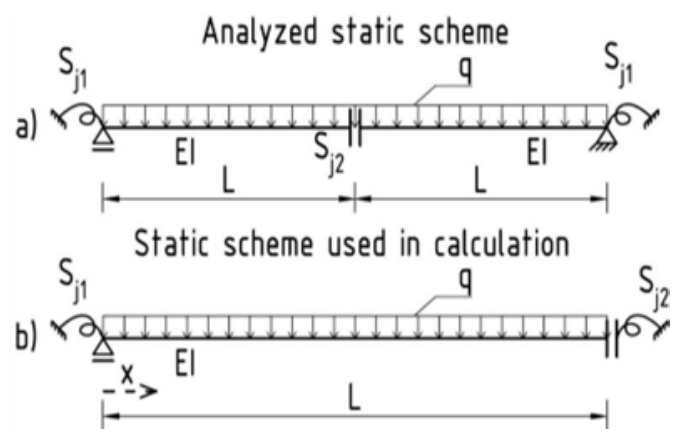

Figure 5. Symbols explanation used in in equation (3) and (Tabs 1,2).

\section{ANALYSIS OF A FLEXIBLY CONNECTED CONTINUOUS BEAM}

When designing bending beams with flexible support, the aim is to ensure bending moments above the supports and in the beam span are of comparable value. If a flexible joint is applied at the end of a beam, the desired bending moment distribution can be achieved.

Based on the graphs presented in (Figure 2), it can be concluded that the innovative type of connection made with independent $\mathrm{T}$-stubs can achieve a substantially greater rotational capability than the traditional type of connection with a solid end-plate, and is therefore much better suited to the type of situation described above. It was decided to investigate the influence of better rotational capability of a high end-plate connection on the ultimate load capacity of a $2 \mathrm{~L}$ span I-beam, taking into account the node flexibility (Figure 5a). The static scheme, which was taken into account in the calculations was shown in (Figure 5b). Using symmetry, scheme $5 \mathrm{a}$ can be transformed into scheme $5 \mathrm{~b}$. Thanks to this procedure, it is possible to take into account the connection flexibility in the middle of the beam span without dividing the beam into two for calculation purposes.

Applying the differential equation of the beam deflection line (1), formulas were introduced for deriving all variable values in relation to boundary conditions assumed (2). Solving the equation (1) provided the following function (3).

$$
\begin{gathered}
\frac{d^{2}}{d x^{2}}\left(E I \frac{d^{2} u(x)}{d x^{2}}\right)=-q(x) \\
u(0)=0, u^{\prime}(0)=u^{\prime \prime}(0) \cdot E I / S_{j 1}, u^{\prime}(L)=-u^{\prime \prime}(L) \cdot E I / S_{j 2}, u^{\prime \prime \prime}(L)=0 \\
M\left(x, L, E I, q, S_{j 1}, S_{j 2}\right)=\frac{1}{6 E I} \cdot q\left(-\frac{L^{2} S_{j 1}\left(3 E I+2 L S_{j 2}\right)}{L S_{j 1} S_{j 2}+E I\left(S_{j 1}+S_{j 2}\right)}+6 L x-3 x^{2}\right)
\end{gathered}
$$

In (Tab. 1) the results of the calculation are provided for a beam with a length of $2 \mathrm{~L}=$ $20 \mathrm{~m}$ flexibly connected on both sides ( $\mathrm{L}=10 \mathrm{~m}$ had to be entered into equation (3)). The secant stiffness $S_{j, \text { sec }}$ of the connection was applied, and (Tab. 1) presents the relative stiffness of the connection in relation to the stiffness of the cross-section. The designation $\mathrm{q} \Delta \mathrm{M}$ indicates the value of the load to be applied to the beam to bring about in the support a moment of value $M_{\text {max.. }}$ The results of the calculation analyses carried out are presented in (Tab. 2). These are equivalent to those presented in (Tab. 1), with the difference that in the middle of the beam of $2 \mathrm{~L}=20 \mathrm{~m}$ span (Figure $5 \mathrm{a}$ ) the connection was the same as that of the support. It was sufficient to use the initial stiffness of the connection at the middle of the beam span in both cases, as the span moments attained a value close to that, at which the joint starts to become plastic. 
Table 1. Flexibility connections in the ends of the beam, $\mathrm{t}_{\mathrm{p}}=28 \mathrm{~mm}\left(\mathrm{~S}_{\mathrm{j}, \mathrm{sec}}=\mathrm{M}_{\mathrm{j}, \mathrm{Rd}} / \Phi_{\mathrm{Cd}}\right)$.

\begin{tabular}{lllllllll}
\hline $\begin{array}{l}\text { Type } \\
{[-]}\end{array}$ & $\begin{array}{l}\mathrm{EI} \\
\mathrm{MNm}^{2}\end{array}$ & $\begin{array}{l}\mathrm{S}_{\mathrm{j}, \text { ini }} / \mathrm{EI} \\
1 /(\mathrm{m} \cdot \mathrm{rad})\end{array}$ & $\begin{array}{l}\mathrm{M}_{\mathrm{j}, \mathrm{Rd}} \\
\mathrm{kNm}\end{array}$ & $\begin{array}{l}\Phi_{\mathrm{Cd}} \\
10^{-3} \mathrm{rad}\end{array}$ & $\begin{array}{l}\mathrm{S}_{\mathrm{j}, \text { sed }} / \mathrm{EI} \\
1 /(\mathrm{m} \cdot \mathrm{rad})\end{array}$ & $\begin{array}{l}\mathrm{q} \Delta \mathrm{M} \\
\mathrm{kN} / \mathrm{m}\end{array}$ & $\begin{array}{l}\mathrm{M}_{\text {support }} \\
\mathrm{kNm}\end{array}$ & $\begin{array}{l}\mathrm{M}_{\text {span }} \\
\mathrm{kNm}\end{array}$ \\
\hline New & 773 & 0.86 & 1838 & 5.98 & 0.39 & 68.4 & 1838 & 1590 \\
Old & 773 & 0.94 & 1861 & 4.22 & 0.54 & 65.2 & 1861 & 1404 \\
\hline
\end{tabular}

Table 2. Flexibility connections in the ends and in the middle of the beam, $t_{\mathrm{p}}=28 \mathrm{~mm}\left(\mathrm{~S}_{\mathrm{j}, \mathrm{sec}}=\mathrm{M}_{\mathrm{j}, \mathrm{Rd}} / \Phi_{\mathrm{Cd}}\right)$

\begin{tabular}{lllllllll}
\hline $\begin{array}{l}\text { Type } \\
{[-]}\end{array}$ & $\mathrm{EI}_{\mathrm{HNm}}{ }^{2}$ & $\begin{array}{l}\mathrm{S}_{\mathrm{j}, \text { ini }} / \mathrm{EI} \\
1 /(\mathrm{m} \cdot \mathrm{rad})\end{array}$ & $\begin{array}{l}\mathrm{M}_{\mathrm{j}, \mathrm{Rd}} \\
\mathrm{kNm}\end{array}$ & $\begin{array}{l}\Phi_{\mathrm{Cd}} \\
10^{-3} \mathrm{rad}\end{array}$ & $\begin{array}{l}\mathrm{S}_{\mathrm{j}, \text { sec }} / \mathrm{EI} \\
1 /(\mathrm{m} \cdot \mathrm{rad})\end{array}$ & $\begin{array}{l}\mathrm{q} \Delta \mathrm{M} \\
\mathrm{kN} / \mathrm{m}\end{array}$ & $\begin{array}{l}\mathrm{M}_{\text {support }} \\
\mathrm{kNm}\end{array}$ & $\begin{array}{l}\mathrm{M}_{\text {span }} \\
\mathrm{kNm}\end{array}$ \\
\hline New & 773 & 0.86 & 1838 & 5.98 & 0.39 & 64.3 & 1838 & 1365 \\
Old & 773 & 0.94 & 1861 & 4.22 & 0.54 & 61.7 & 1861 & 1220 \\
\hline
\end{tabular}

The results of the analyses presented in (Tabs 1,2) indicate that for a beam that has a very rigid connection in the middle of its span or is continuous, the ultimate loading capacity is $4.9 \%(68.4 / 65.2=1.049)$ higher for the innovative connection as compared to the solid end-plate connection. If there is a joint in the middle of the span of the same characteristics as that of the support, the load-bearing capacity is $4.2 \%(64.3 / 61.7=1.042)$ higher for the innovative connection At the same time, taking into account the flexibility of the connection in the middle of the span reduces the ultimate load-bearing capacity by about $5 \%$ in both connection types.

\section{DISCUSSION}

When making a non-prestressed connection according to the EN 1090-2 standard, a separation up to $4 \mathrm{~mm}$ is allowed on the end-plate edges. The value of stiffness coefficients of the basic parts of the connection in line with the EN 1993-1-8 standard were introduced as a perfectly flat surface of the end-plate. As a thought experiment, consideration was given to a tensile connection which fails according to model no. 2 of this standard. Analysing behavior of a tensile connection with edge imperfections, indicates that, first of all, the end-plate starts to work as a cantilever and at a certain point it starts to become plastic, significantly impacting the stiffness of the connection. Only as a result of further plasticization will the end-plates come into contact with one another, and at this point the connection will have reached its ultimate loading capacity.

It is worth noting that the more flexible the connection in the middle of the beam span, the lower the load-bearing capacity of the whole system. (Basiński 2006) examined similar connections $\left(\mathrm{h}_{\mathrm{w}}=500 \mathrm{~mm}, \mathrm{t}_{\mathrm{p}}=30 \mathrm{~mm}, \mathrm{~d}=20 \mathrm{~mm}\right)$, and found that a four-fold difference in connection initial stiffness resulted from random prying effects.

Due to random prying effects appearing, an analysis was carried out to determine how much the support moment increases, if the connection stiffness in the middle of the beam span has decreased in an unpredictable way, e.g. due to imperfections introduced during construction and random prying effects. Based on (Tabs 1,2), the support stiffness is taken to be the secant stiffness of the connection, which is about 0.5 times the initial stiffness. In the denominator of expression $\mathrm{k}$ (Figure 6), the connection stiffness in the middle of the beam span is the same as the initial stiffness, because the moment in the beam span is not large and a connection of ideal geometry in most cases will not yet be turning plastic. Variable parameters were values of the connection initial stiffness in the middle of the beam span $S_{j 2 \text {,ini }}$ and value $\mathrm{x}$, which indicates what part of the stiffness remains in the connection as a result of 


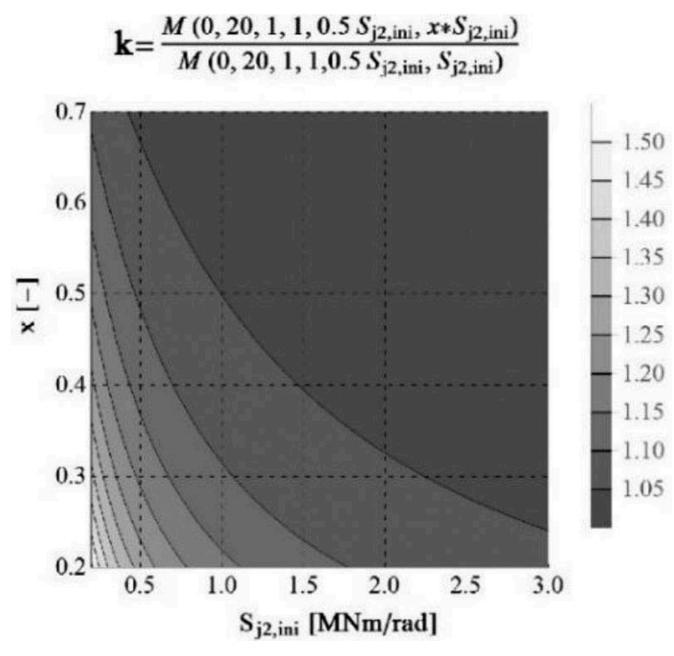

Figure 6. Increase of the beam support moment (Figure 5) as a result of a decrease of the joint stiffness in the middle of the beam span, caused by random effects of separation of end-plates.

random separation of the end-plates and their earlier plasticization, which due to separation acts as a cantilever in the initial work phase of the connection.

Based on the graphs presented in (Figure 6), it can be concluded that for beams with flexible connections, which have the same type of connection in the middle of their span as in the support, the decrease in stiffness is significant for the ultimate load bearing capacity of the whole beam.

\section{CONCLUSIONS}

In spite of up to $42 \%$ greater rotational capability (Figure 2 ) of the innovative type of connection using independent T-stubs as compared to connections with solid end-plates, it has not proven possible to make effective use of a much larger number of bolts arranged in tension series that are located adjacent to the web (Figure 3). Although the load-bearing capacity of the innovative connection is slightly lower than that of an equivalent connection comprising a solid end-plate, the analysis indicates that for certain thickness of end-plates, the ultimate load-bearing capacity of the beams with flexible end-plates (Figure 6) will be higher than for a traditional type of connection.

Given that bolted connections are not always compressed, it makes sense to determine the static equilibrium paths of imperfections of high connections, and then to check on the impact on ultimate load-bearing capacity of beams with flexible end connections in the middle of the beam span. This is an important issue as high web beam connections can be designed for high load-bearing capacity, even $\mathrm{M}_{\mathrm{j}, \mathrm{Rd}}=0.7 \mathrm{M}_{\mathrm{c}, \mathrm{Rd}}$, and for relatively low stiffness.

Only preliminary results were shown and an experimental verification is needed.

Calculations were carried thanks to resources provided by the Wroclaw Centre for Networking and Supercomputing (http://wcss.pl) under grant No. 81.

\section{REFERENCES}

Basiński W. 2006. Determination flexible end-plate connections rotational stiffness in metal structures on the basis of vibrations, Doctoral dissertation, Silesian University of Technology. (in polish)

EN 1090-2 - Execution of steel structures and aluminium structures - Part 2: Technical requirements for steel structures. 
EN 1993-1-8 Eurocode 3 - Design of Steel Structures Part 1-8 Design of Joints.

Hotała E. \& Tucki P. 2020. Innovative bolted end-plate connections for steel I-beams, Builder; 273 (4): 100-103. DOI: $10.5604 / 01.3001 .0013 .8798$

ISO 898-1:2013 - Mechanical properties of fasteners made of carbon steel and alloy steel - Part 1: Bolts, screws and studs with specified property classes - Coarse thread and fine pitch thread.

P. Kawecki \& J. Łaguna \& A. Kozłowski. 2016. FEM analysis of the extended end-plate splice of welded I-girders with multiple bolt rows and bolts per row, Proceedings of the XIII International Conference on Metal Structures (ICMS2016), Zielona Góra, Poland, 15-17 June 2016, Taylor \& Francis Group.

Sumner E. 2003. Unified Design of Extended End-Plate Moment Connections Subject to Cyclic loading. Dissertation submitted to the Faculty of the Virginia Polytechnic Institute.

Żółtowski K. \& Kalitowski P. 2016. Moment resistance of I-section end-plate roof girder splices; a case study, Archives of Civil Engineering, Vol. LXII, ISSUE 4, Part 1, s.187-200. 


\title{
Advanced analysis of members with gusset plate joints
}

\author{
M. Vild \\ Faculty of Civil Engineering, Brno University of Technology, Brno, Czech Republic \\ V. Chalupa \& L. Šabatka \\ IDEA StatiCa, Brno, Czech Republic \\ F. Wald \\ Faculty of Civil Engineering, Czech Technical University in Prague, Prague, Czech Republic
}

\begin{abstract}
The compressive resistance of truss members connected by gusset plates is estimated by taking the buckling length of the member equal to the member length. Usually, no check is provided for the gusset plate, although several design methods were proposed in the past. The paper presents an advanced member analysis, a design-oriented finite element method of a member including its joints. Geometrically and materially nonlinear analysis with imperfections is used to determine the load resistance of the joint-member-joint subsystem. Component-based Finite Element Method is used for joints; i.e. bolts and welds are modeled by nonlinear springs with properties based on design codes.

The advanced analysis is demonstrated on two cases. The buckling length of angles, vastly used for masts, may be assumed smaller than the theoretical length if the boundary conditions determined by bolted gusset plates provide sufficient stiffness. The experiments and detailed numerical analysis performed at the Graz University of Technology are used for validation of the advanced analysis.

The buckling resistance of gusset plates may govern the compressive resistance of the bracing. The experiments performed at the Czech Technical University in Prague (Vesecký), together with analytical design methods, are used for validation of buckling resistance of bolted eccentric gusset plate joints of circular hollow section braces.

The results depend on the chosen shape and amplitude of initial imperfections. Using recommended procedures, the proposed method provides results very close to the experiments.
\end{abstract}

\section{INTRODUCTION}

A novel design method using a model of a member together with its joints is presented. The advantage of this method is shown on two sets of examples - angles with gusset plate joints and eccentric gusset plate joints of braces. In both cases, the boundary conditions are unclear and traditional analytical models use significant simplifications. The experiments and research finite element models from literature are compared to the new method.

The design method uses component-based finite element method (CBFEM) where plates are modeled by shell finite elements and bolts and welds as special nonlinear elements based on design codes (Wald et al. 2020). The analysis model is generated automatically. The analysis has three stages: (i) materially nonlinear analysis, (ii) linear buckling analysis, (iii) geometrically and materially nonlinear analysis with imperfections. 


\subsection{Angles}

Steel angles are very commonly used in industrial structures or masts where they are typically eccentrically connected by gusset plates. The buckling length is simply assumed equal to system

length and any eccentricity is neglected. The boundary conditions are in fact difficult to determine. They depend on the thickness and length of the gusset plate, as well as the number of bolts or length of welds. Furthermore, the principal axes of angles do not coincide with axes of gusset plates. Utilizing the stiffness of joints may bring a lot of value to structures composed of steel angles.

\subsection{Eccentric joints of braces}

Flaws in design of eccentric gusset plate joints are responsible for several building collapses each year. No design guidelines are given in Eurocodes; just EN 1993-1-5 provides buckling curves for general plates. Several analytical design methods exist, e.g. Whitmore, Thornton, Modified Thornton, and Khoo, Perrera, Albermani, but none provides accurate results for all joint types. Whitmore (1952) proposed to use a dispersion angle to determine an effective section, for which steel yield resistance is calculated. Thornton (1984) modified Whitmore's method by widening the dispersion angle and to take into account buckling. Yam \& Cheng (2001) further modified the method to take into account plasticity. Khoo et al. (2009) proposed another method based on observed collapse mechanism of an experimental series. The first three methods give unconservative results for eccentric gusset plate joints by hundreds of percents. Only the method by Khoo et al. is close to reality (Vesecký, 2019a).

Component-based finite element method allows to assess the brace including its joints. Although the method is much more sophisticated, current computational power allows very fast calculation - in seconds, which is comparable with other analytical methods. The method removes most of the simplifications of analytical methods and leaves only the unknown of initial imperfections.

The experiments performed at Czech Technical University in Prague (Vesecký et al. 2019a) were used for CBFEM validation.

\section{METHODS}

\section{$2.1 \quad C B F E M$}

CBFEM for steel members allows to analyze buckling of a substructure system - member including its joints. The analyzed member as well as its joints are composed of shell finite elements. The components - welds and bolts - consist of multipoint constraints and nonlinear springs with properties (stiffness, resistance, deformation capacity) based on design codes, such as EN 1993-1-8. The related members starting at the joints are modeled by simple bar elements and ended by a support or loaded by a force or moment. The forces can be also directly applied to the plates of analyzed member. For an example of a CBFEM model; see Figure 1. IDEA StatiCa Member (IDEA StatiCa, 2020) application was used in this study.

Three types of analysis may be performed:

1. Materially nonlinear analysis (MNA),

2. Linear buckling analysis (LBA),

3. Geometrically and materially nonlinear analysis with imperfections (GMNIA).

GMNIA is the most sophisticated numerical analysis for static loading. Validated models are deemed trustworthy and are often used even for formulation of analytical formulas in codes. 


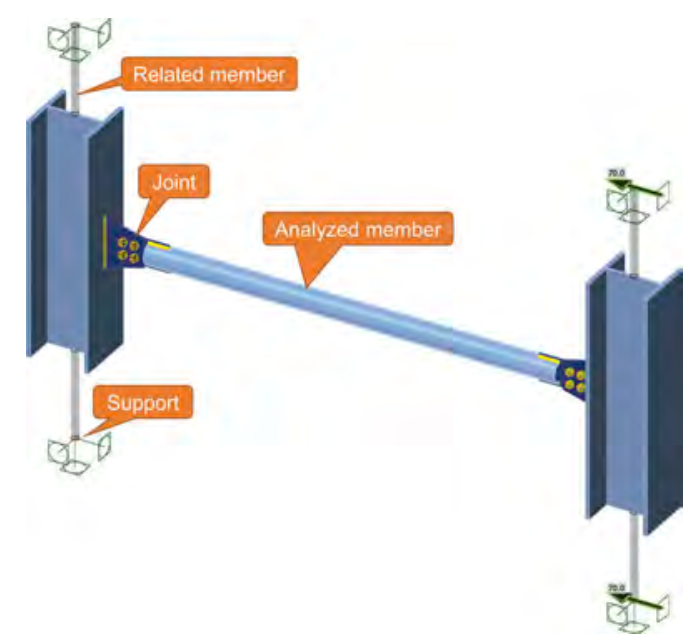

Figure 1. Model of specimen $\mathrm{C} 1$ - eccentric joint of a brace.

\subsection{Angles}

Experiments by Kettler et al. (2019) are used for validation of the model, and the recommendations given in Kettler et al. (2017) are used for modeling. A total of 9 selected cases are analyzed. The designation of individual specimens is maintained (A1-A3), (A4-A6), and (E1E3). Bolts M20 10.9 were used for specimens A1-A6 and bolts M27 10.9 for specimens E1E3. All bolts were preloaded. Their real cross-section dimensions are considered, as well as their real material properties. Two different sets of boundary conditions are investigated (BC1 - rigid, BC2 - uniaxially hinged; see Figure 2); there is also a variance in the column's relative slenderness.

The inputs of the calculation are summarized in Table 1 . The cross-section dimensions and material properties are presented, as well as the value of initial imperfection $e_{0}$ assumed as $L /$ 300 (Kettler et al. 2017) in the shape of the first buckling mode shape, which is decisive for the angle.

\subsection{Eccentric joints of braces}

The series comprises six specimens; three are connected perpendicularly (labeled C) and three at $45^{\circ}$ (labeled D). The connecting plate is welded into CHS of the brace, and two or four bolts are used to fasten the connecting plate to the gusset plate. The model of specimen $\mathrm{C} 1$ is shown in Figure 1.

a)

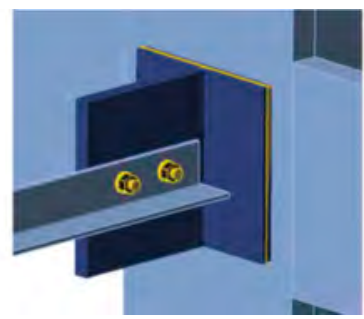

b)

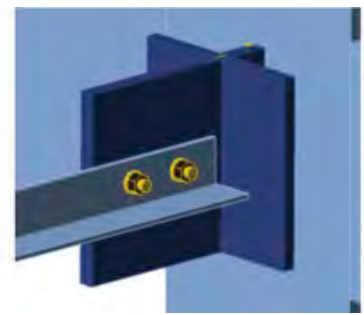

c)

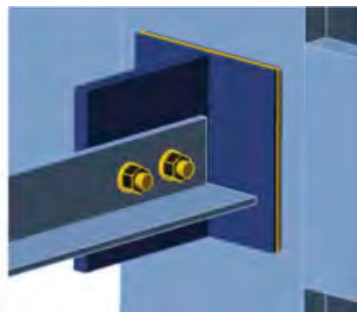

Figure 2. Boundary conditions of steel angles: a) A1-A3: rigid, b) A4-A6: uniaxially hinged, c) E1-E3: rigid. 
Table 1. Geometry, material properties, and used amplitude of equivalent imperfection.

\begin{tabular}{lllllll}
\hline Index & $L[\mathrm{~mm}]$ & Cross-section & Supports & $E[\mathrm{GPa}]$ & $f_{\mathrm{y}}[\mathrm{MPa}]$ & $e_{0}[\mathrm{~mm}]$ \\
\hline A1 & 1140 & L $80.4 \times 8.2$ & BC1 & 212 & 289.9 & 3.8 \\
A2 & 1820 & L $80.3 \times 8.1$ & BC1 & 212 & 289.9 & 6.1 \\
A3 & 2630 & L $80.4 \times 8.3$ & BC1 & 212 & 289.9 & 8.8 \\
A4 & 870 & L $80.3 \times 8.2$ & BC2 & 212 & 289.9 & 2.9 \\
A5 & 1550 & L $80.3 \times 8.2$ & BC2 & 212 & 289.9 & 5.2 \\
A6 & 2360 & L $80.3 \times 8.2$ & BC2 & 212 & 289.9 & 7.9 \\
E1 & 1850 & L $120.3 \times 12.0$ & BC1 & 192 & 299.3 & 6.2 \\
E2 & 3170 & L $120.1 \times 12.0$ & BC1 & 192 & 299.3 & 10.6 \\
E3 & 4200 & L $120.3 \times 12.0$ & BC1 & 192 & 299.3 & 14.0 \\
\hline
\end{tabular}

The imperfections have a significant impact on the results of GMNIA. The guidelines for imperfections specifically for gusset plates are not codified. The aim of this paper is not to select the most suitable amplitude and buckling mode shape for the buckling analysis of gusset plate joints. Unterweger \& Taras (2013) suggest that that the second buckling mode shape may be more dangerous for the gusset plate. Therefore, the first and second buckling mode shapes are investigated. The amplitude of initial imperfection is chosen as (1) $L / 200$, where $L$ is the system length of the CHS brace, and (2) $L_{\text {gusset }} / 50+L_{\text {member }} / 1250$, where $L_{\text {gusset }}$ is the length of the gusset plate and $L_{\text {member }}$ is the length of the CHS brace.

\section{RESULTS AND DISCUSSION}

\subsection{Angles}

Kettler et al. (2019) complemented the experimental study with the research-oriented finite element models (ROFEM). Their results were added to the comparison of CBFEM model and experiments. The comparison of LBA results of numerical models and GMNIA results to experiment is in Figure 3. The results of LBA verification are satisfactory, critical loads from both software solutions are very similar in all but one case (A4), where the difference in results
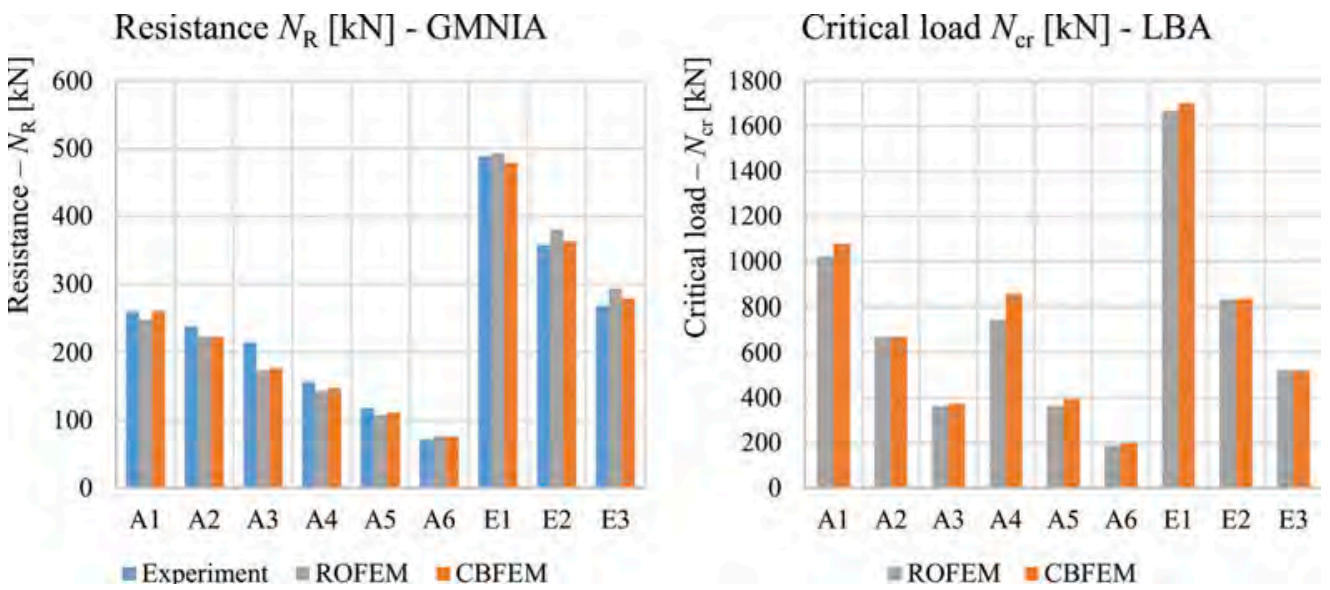

Figure 3. Comparison of CBFEM to experiments and research-oriented finite element models (Kettler et al. 2019). 
is $13 \%$. In all the other cases, the difference is under 5\%. The results of GMNIA validation show a good agreement with the experimental data. In fact, the CBFEM results are slightly closer to the experimental ones than the research-oriented finite element model created specifically for this experiment. There is also a good agreement when verifying the results of CBFEM to ROFEM, with the largest deviation under 5\%.

\subsection{Eccentric joints of braces}

The CBFEM results of author's models are compared to experimental results, analytical methods and research-oriented finite element models using imperfections measured by digital image correlation (ROFEM - DIC) and by EN 1993-1-5 (ROFEM - EN) (Vesecký, 2019b). It can be seen that analytical methods by Whitmore, Thornton, and Yam \& Cheng extremely overestimate the resistance of eccentric gusset plate joints. Method by Khoo et al. is closer to experimental resistances, but it underestimates the resistance of diagonal braces, predicting in average only half of their experimental resistances; see Figure 4.

In CBFEM, the first two buckling mode shapes from LBA were investigated; see Figure 5. Both critical buckling load factors are very close to each other.

In Figure 6, the effect of imperfections on the resulting load resistance determined by GMNIA in CBFEM is shown. The imperfections using the first buckling mode (1st - L/ 200) provide significantly higher resistance than the imperfections using the second buckling mode (2nd - L/200), confirming the theory of Unterweger \& Taras (2013). The second buckling mode is critical for the eccentric gusset plate joint. In both cases,

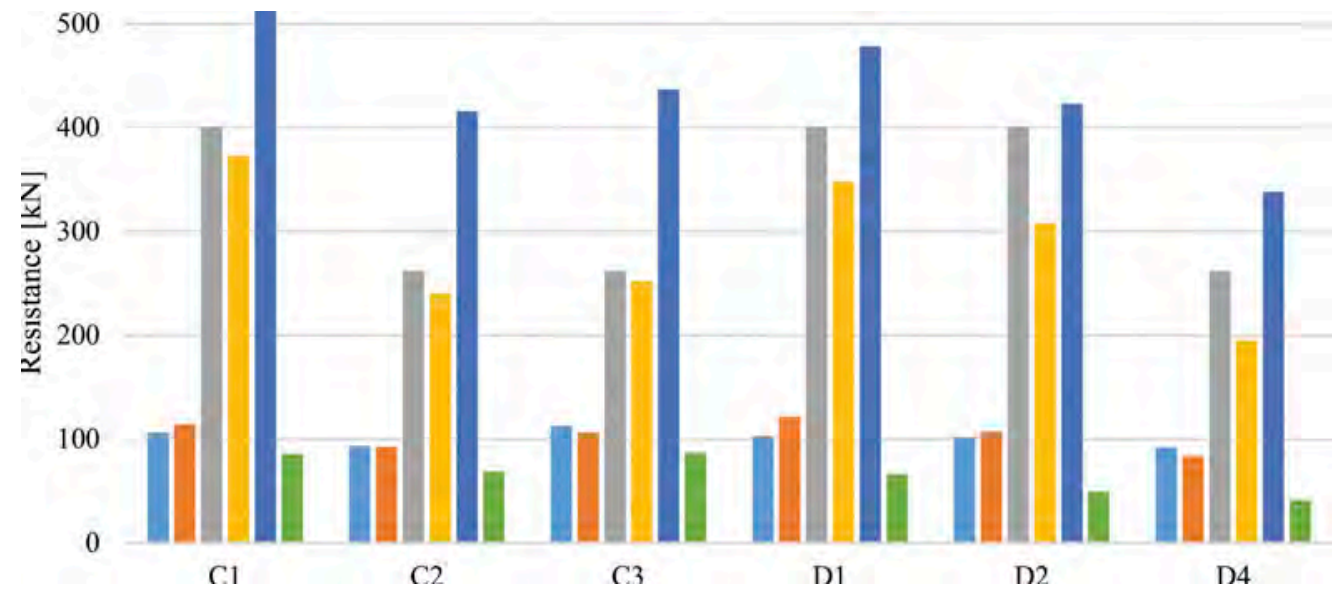

Figure 4. Comparison of CBFEM to experiments and analytical methods (Vesecký, 2019a).
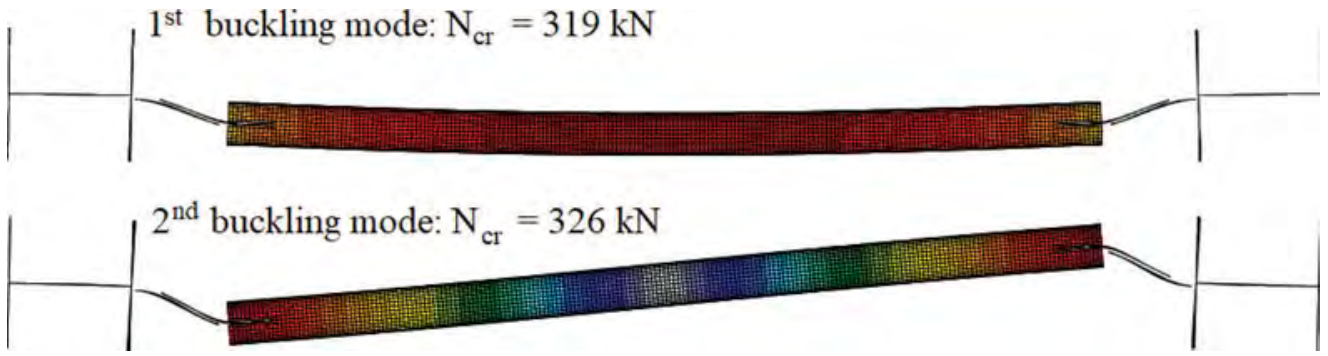

Figure 5. First two buckling mode shapes of braces with eccentric gusset plate joints. 
a)

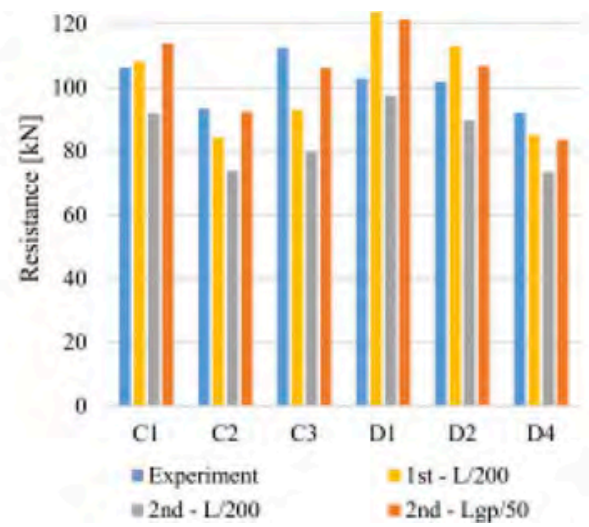

b)

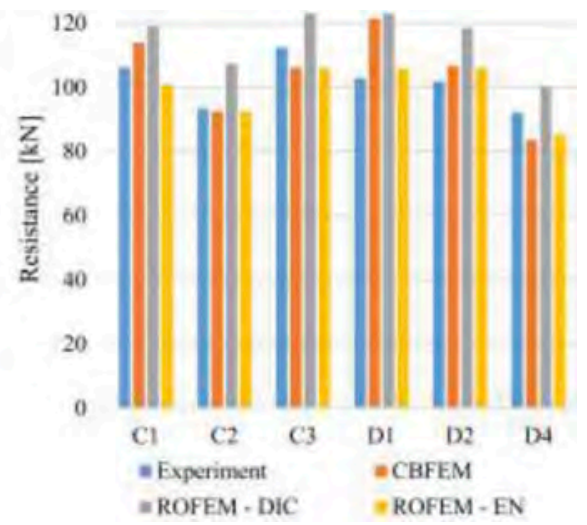

Figure 6. CBFEM GMNIA with different imperfections a) and comparison to experiments and ROFEMs b).

the amplitude of initial imperfections is taken as $L / 200$ where $L$ is the system length of the angle. The chosen amplitude of imperfections is too high for this set of experiments; the resistances are in all cases lower (in average at 83\%). Therefore, also the amplitudes of imperfection suggested by Vesecký are used with the second buckling mode shape: $L_{\text {gusset }} / 50+L_{\text {member }} / 1250$ where $L_{\text {gusset }}$ is the length of the gusset plate and $L_{\text {member }}$ is the length of the CHS brace (labeled $2 \mathrm{nd}-\mathrm{Lgp} / 50$ in Figure 6). The average is very close, at $102 \%$; however, the specimen D1 is quite unsafe at $118 \%$ of experimental resistance. It seems that the most suitable amplitude of imperfections should be higher. Nevertheless, these imperfections were chosen for further comparison with research-oriented numerical models published in Vesecký et al. (2019b).

Research-oriented numerical models with the same amplitude of initial imperfections according to EN 1993-1-5 made in ABAQUS (ROFEM - EN) provide slighly more accurate results. The research-oriented finite element models using DIC (ROFEM - DIC) should theoretically provide the most accurate prediction. However, it slightly overestimates the resistance in all cases, in average by $14 \%$. That can be explained by absence of residual stresses in the model. The equivalent imperfections should be used.

\section{CONCLUSION}

The CBFEM model in application IDEA StatiCa Member automatically creates an advanced numerical model. The model can be created and solved in minutes and allows design of members with their joints even if buckling is a governing failure mode. This is possible by geometrically and materially nonlinear analysis with imperfections.

The results show that CBFEM model can accurately predict the resistance of members with gusset plate joints. Two sets of experiments are presented; in both cases, the determination of boundary conditions as an input to codified procedures for buckling of members is questionable. The resistance of steel angles may be assumed much higher in the design process by taking real boundary conditions into account. The eccentric gusset plate joints simplify the assembly process, but are often a source of failure. The CBFEM model can reveal this failure mode and predict the load resistance of the joint much more accurately than any analytical methods.

The load resistance of models affected by buckling are susceptible to the selected buckling mode shapes and amplitudes of initial imperfections. The imperfections are codified for standard cases but care must be taken for novel cases. Higher amplitudes provide safer results but the first buckling mode shape may not include the governing failure mode. 


\section{ACKNOWLEDGMENT}

The work was prepared under the $\mathrm{R} \& \mathrm{D}$ project supported by Technology Agency of the Czech Republic, No FW01010392.

\section{REFERENCES}

EN 1993-1-5, Eurocode 3, Design of steel structures, Part 1-5: Plated structural elements, CEN, Brussels, 2006.

EN 1993-1-8, Eurocode 3, Design of steel structures, Part 1-8: Design of joints, CEN, Brussels, 2005.

IDEA StatiCa, Member: Theoretical background. 2020. Available at: https://www.ideastatica.com/sup portcenter/idea-statica-member-theoretical-background.

Kettler, M., Lichtl, G. \& Unterweger, H. Experimental tests on bolted steel angles in compression with varying end supports. Journal of Constructional Steel Research. 155 (2019). 301-315.

Kettler, M., Taras, A. \& Unterweger, H. Member capacity of bolted steel angles in compression: Influence of realistic end supports. Journal of Constructional Steel Research. 130 (2017). 22-35.

Khoo, X. E, Perera, M. \& Albermani, F. 2009. Design of eccentrically connected cleat plates in compression. Advanced Steel Construction. 6(2): 678-687.

Thornton, W. 1984. Bracing Connections for Heavy Construction. Engineering Journal. 21: 139-148.

Unterweger, H. \& Taras, A. Compression Members with Hollow Sections and Concentric Slotted Gusset Plates - Behavior and Recommended Design Model. In Proceedings of the Annual Stability Conference, Structural Stability Research Council, St. Louis, Missouri, April 16-20, 2013.

Vesecký, J., Cábová, K. \& Jandera, M. Tests of gusset plate connection under compression. In: Wald, F. $\&$ M. Jandera, eds. Proceedings of the International Colloquia on Stability and Ductility of Steel Structures (SDSS 2019). Stability and Ductility of Steel Structures 2019, Praha, 2019-09-11/2019-09-13. Leiden: CRC Press/ Balkema,2019. 1218-1226. ISBN 9780367335038.

Vesecký, J., Cábová, K. \& Jandera, M. Numerical modelling of gusset plate connections under eccentric compression. In: Wald, F. \& M. Jandera, eds. Proceedings of the International Colloquia on Stability and Ductility of Steel Structures (SDSS 2019). Stability and Ductility of Steel Structures 2019, Praha, 2019-09-11/2019-09-13. Leiden: CRC Press/ Balkema,2019. 1218-1226. ISBN 9780367335038.

Wald, F. et al. Component-based finite element design of steel connections. Czech Technical University Prague, 2020. ISBN 978-80-01-06702-4 print, ISBN 978-80-01-06703-1 online. 245.

Whitmore, R. E. 1952. Experimental Investigation of Stresses in Gusset Plates. Knoxville: Engineering Experimental Station, University of Tennessee.

Yam, M. C H \& Cheng, J. J. R. 2001. Behavior and design of gusset plate connections in compression. Journal of constructional steel research. 58: 1143-1159. 
Structural stability and integrity 


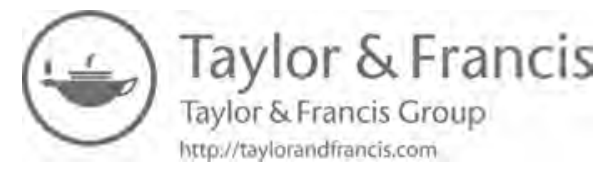




\title{
Effectiveness of butterfly-shaped links on structural behavior of slotted steel shear panels
}

\author{
H.M. Ahmadi \& G. De Matteis \\ Department of Architecture and Industrial Design, University of Campania Luigi Vanviteli, Aversa, Italy
}

\begin{abstract}
Steel Plate shear walls (SPSWs) utilize inelasticity properties of the web plate to reinforce and protect the main members of the structures from fatal fracture phenomena against lateral forces. In this study, slotted shear panels with various layouts of butterflyshaped links, which able to control out-of-plane deformations, by concentrating the majority of structural dam-age into the specific internal link elements, are investigated. To evaluate the structural behavior of proposed slotted shear panel, 54 computational models have been considered and analyzed according to previous calibration of the numerical model. The results prove that critical factors of butterfly-shaped links such as slenderness and number of links can improve the seismic performance of the proposed slotted shear panel subjected to shear loads.
\end{abstract}

\section{INTRODUCTION}

Steel Plate Shear Walls (SPSWs) are an efficient dissipative system to be used according to special features to protect high rise buildings against seismic forces (Brando and De Matteis, 2014). The SPSWs are composed by shear panels, boundary elements, plate-frame interactions and beam-to-column connections (Monsef Ahmad et al., 2020). Shear panels often absorb the seismic energy through the tension field mechanism (Monsef Ahmadi et al., 2020). The tension field mechanism is directly dependent on plate-frame interactions and column stiffness (Formisano et al., 2010). Therefore, the connections in the plate-frame interactions are intensively subjected to stress and fracture phenomena (De Matteis et al., 2005). To overcome these disadvantages several methods have been proposed (Formisano et al., 2016). The slotted shear panels represent one of the promising systems. They dissipate lateral forces through yielding mechanism of links between slits. Therefore, the geometry of links has a vital role for ensuring good seismic behavior of such shear panels (Ahmadi and De Matteis, 2020).

Recently, various slotted shear panels have been considered by researchers experimentally and numerically. Ma et al., 2010, investigated slotted shear plates with rectangular and butterfly-shaped links experimentally. The results proved that the number and the slenderness ratios of the links effect the hysteretic response of slotted shear plates. On the other hand, the butterfly-shaped links experienced much more fracture storage than the rectangular shaped links. Along the same line, the taper ratio (i.e., the ratio of end width over the middle width) equal to three had considerable influence on the structural behavior of slotted shear panels. Likewise, Farzampour and Eatherton, 2019, proposed equations to interpret the yielding mechanism of individual butterfly-shaped links through regression analysis. According to the study, the yielding mechanisms of butterfly-shaped links with web plate thickness equal to $(t)$ were highly dependent to taper ratio $(a / b)$, slenderness ratio $(h / t)$ and width ratio $(b / h)$. A geometry of butterfly-shaped link together with the meaning of the above symbols is shown in Figure 1.

DOI: $10.1201 / 9781003132134-49$ 


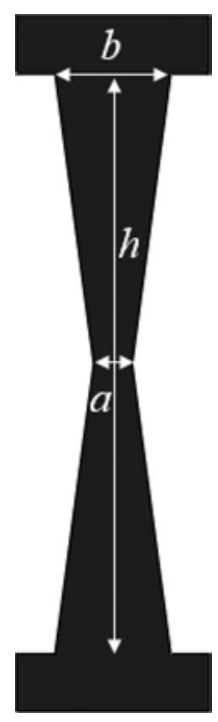

Figure 1. Butterfly-shaped link geometry with thickness $(t)$.

Monsef Ahmadi and De Matteis, 2020, evaluated two different categories of slotted shear panels with butterfly-shaped links by means of numerical analyzes. Each category of specimen was mainly different in relation to the number of butterfly-shaped links. Also, the first and the second categories had various the taper ratios namely three and two, respectively. Therefore, shear strength and initial stiffness of 30 specimens of each category which were different on the web plate and links slenderness ratio were assessed according to nonlinear static analyses (pushover). Furthermore, the hysteretic response of each specimen was estimated. The results illustrated that the shear strength and initial stiffness was decreased by increasing the number of links. On the other hand, the hysteretic response of the first category of specimens was stable especially when the link slenderness ratio was lower than 65 .

In this study, six different categories of slotted shear panels including butterfly-shaped links have been evaluated. Specimens were different in the web slenderness, number, and layout of slits. To gain the main goal of this investigation, a tested specimen was firstly modeled and the corresponding results validated through finite element method by ABAQUS software. Then, the shear strength, initial stiffness, and the effects of the slit pattern of slotted specimens on plate-frame interaction were calculated through nonlinear static analyses.

\section{THE PROPOSED FEM MODEL}

A solid tested specimen, approximately $1 \times 1 \mathrm{~m}^{2}$, with web plate thickness equal to $1.9 \mathrm{~mm}$, was tested under cyclic shear load according to the ATC-24 loading protocol by Egorova et al., 2014. To validate the test results, a finite element model was developed. It consists of shell and beam elements for web plate and boundary members, respectively. The yield strength and the modulus of elasticity of the web plate according to the material properties were $300 \mathrm{MPa}$ and $210 \mathrm{GPa}$, respectively. The narrow mesh size, approximately equal to $15 \mathrm{~mm}$, was calibrated over the web plate. As shown in Figure 2a, there is a good agreement between FE and experimental results in terms of cyclic and pushover analyses. In addition, the FE model has captured correctly the yielding of the web plate in the plate-frame interaction, as shown in Figure $2 b$ by gray color. 
a)

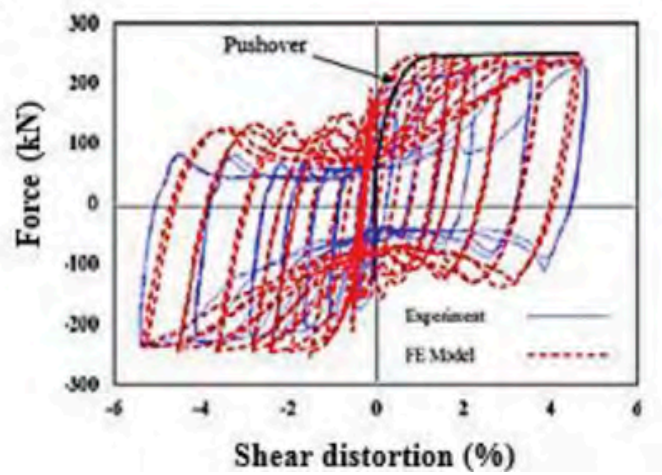

b)

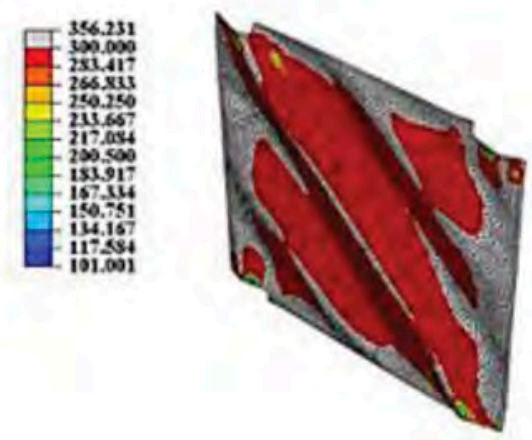

Figure 2. Verification of experimental specimen: a) hysteretic curve and b) von Mises stress (MPa) distribution.

\section{THE ANALYZED SPECIMENS}

To assess the influence of the layout of slits and the web plate slenderness on structural behavior of slotted shear panels, six categories of specimens have been designed as shown in Figure 3. It is worth noticing that the specimens were identical in the taper ratio of links, namely a $=$ $20 \mathrm{~mm}$ and $\mathrm{b}=60 \mathrm{~mm}$. In fact, the considered specimens, as well as the butterfly-shaped links, which varied in their number, (i.e., 18, 10 and 6), had various web plate thickness (i.e., 14, 7 and $3.5 \mathrm{~mm}$ ). Also, different values of $\omega$ (i.e., 80,60 and $40 \mathrm{~mm}$ ), $\alpha$ (i.e., 80 and $140 \mathrm{~mm}$ ) and $\beta$ (i.e., 120 and $180 \mathrm{~mm}$ ) have been considered. Therefore, the considered specimens are named as SP-CA-n-t- $\omega-\alpha-\beta$, in which, $C A$ is category types of slotted layout, $n$ the number of butterfly-shaped links, $t$ is the web plate thickness. The other symbols are considered as shown in Figure 3. For instance, a specimen with name of SP-D-10-14-60-80-120 refers to a specimen of $D$ type category, with ten butterfly-shaped links, web plate thickness equal to $14 \mathrm{~mm}$, having $\omega, \alpha$ and $\beta$ equal to 60,80 and $120 \mathrm{~mm}$, respectively.

a)

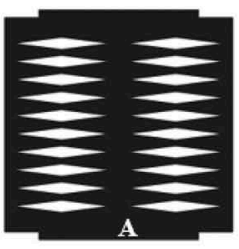

d)

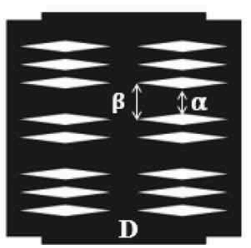

b)

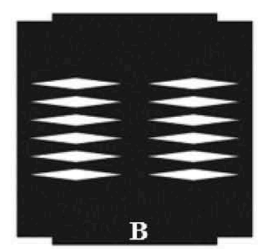

e)

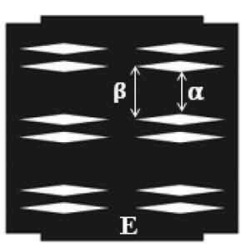

c)

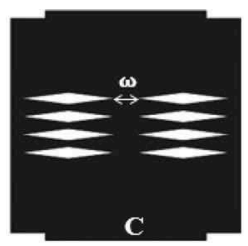

f)

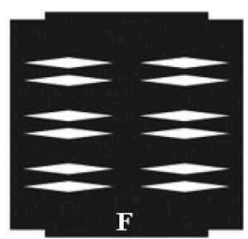

Figure 3. Geometry of considered specimens: a) A, b) B, c) C, d) D, e) E and f) F categories. 


\section{THE OBTAINED NUMERICAL RESULTS}

\subsection{General}

The selected specimens were analyzed according to nonlinear static analyses (pushover) up to $6 \%$ of drift. The bilinear curves were calibrated base on the ECCS method on pushover curves to calculate the yielding point. To this purpose, the shear strength and initial stiffness have been obtained from the numerical results. In addition, the von Misses stress currency of computational specimens at plate-frame interactions to obtain optimum slits layouts have been compared.

\subsection{Shear strength}

The maximum shear strength of computational specimens has been calculated. As shown in Figure $4 \mathrm{a}$, the shear strength of specimens increases when the number of butterfly-shaped links and the web plate slenderness ( $\lambda$ ) (i.e., 62, 123 and 247) decrease. However, the $\omega$ value has minor effect on the maximum shear strength. The shear strength of B and D categories are significantly different from each other. As a result, the layout of slits in the specimens $\mathrm{D}$ produces two butterfly-shaped link with middle and end length of $\alpha$ and $\beta$, respectively. Therefore, the high ratio of the web plate remains in the elastic range in this category of shear panels. Subsequently, this phenomenon occurs also for C, E and F categories. In fact, the specimens type E category experienced a lower shear strength than $\mathrm{F}$ and $\mathrm{C}$ types.

\subsection{Initial stiffness}

The initial stiffness of investigated slotted shear panels is compared in Figure 4b. It is evidenced that the initial stiffness increases when the number of butterfly-shaped links decreases. On the other hand, the $\omega$ has a slight effect on the initial stiffness. Likewise, the initial stiffness of specimens is not significantly affected by altering the slit layouts.

\subsection{Stress distribution}

To compare the effect of the number and layout of the butterfly-shaped links on distribution of stress at the plate-frame interactions, the von Mises stress related to specimens with web plate slenderness equal to 62 and 247 are shown in Figure 5. It appears that the slotted shear panel by web plate slenderness equal to 247 is prone to develop tension field mechanism due to small web plate thickness. Therefore, the degradation strength happened after $2 \%$ of drift in the specimens.

a)

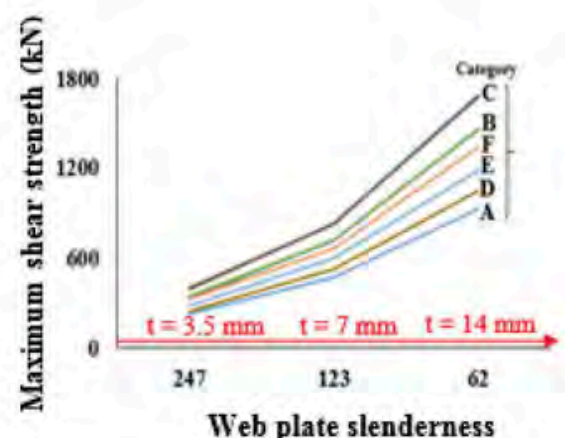

b)

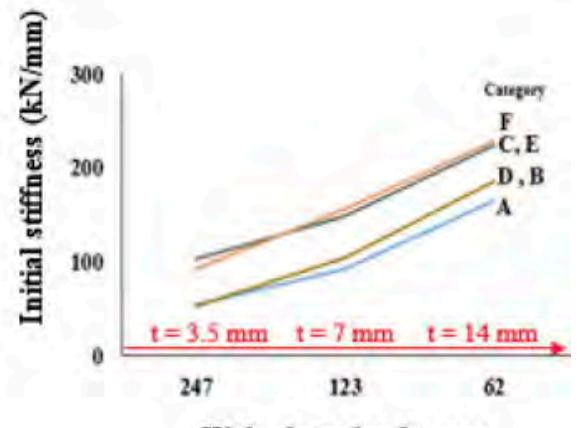

Web plate slenderness

Figure 4. Structural behavior of slotted shear panels versus web plate slenderness in terms of: a) maximum shear strength, and b) initial stiffness. 
a)

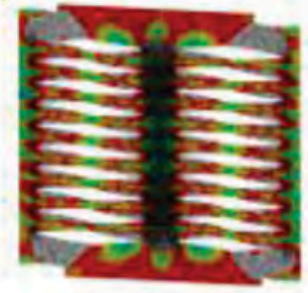

$\lambda=62$

d)

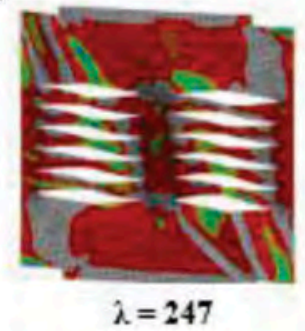

g)

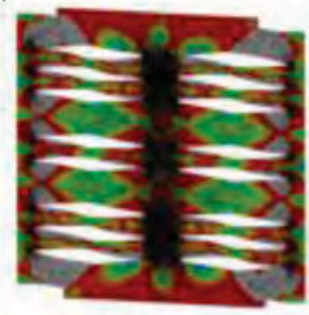

$\lambda=62$

j)

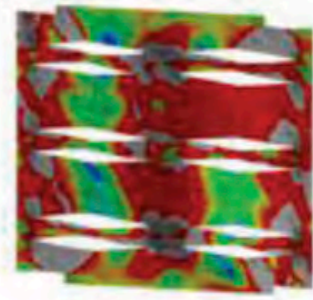

$$
\lambda=247
$$

b)

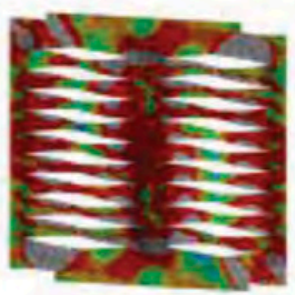

$\lambda=\mathbf{2 4 7}$

e)

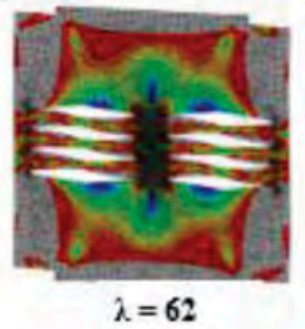

h)

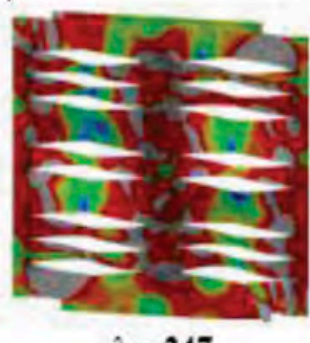

$$
\lambda=\mathbf{2 4 7}
$$

m)

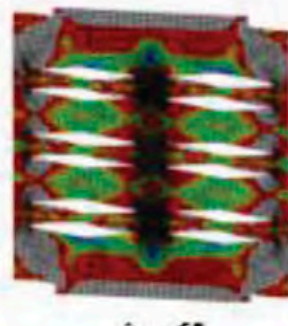

c)

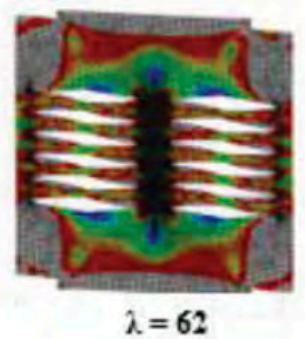

f)

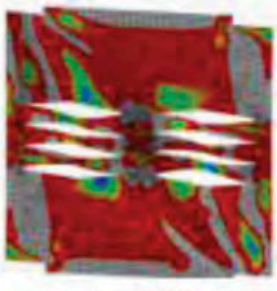

$\lambda=247$

i)

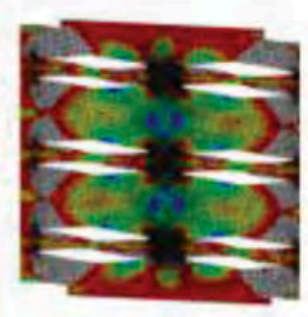

$\lambda=62$

n)

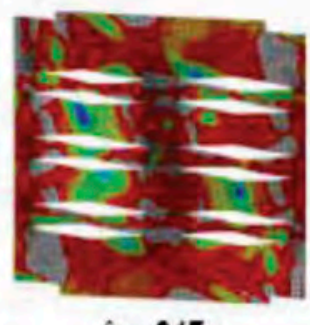

523.5

300.0

275.9

251.8 227.6 203.5

179.4

155.3

131.2

107,0

82.9

58.8

34.7

10.5

Figure 5. Von Mises stress (MPa) distribution for investigated slotted shear panels.

On the other hand, the stress accuracy of the specimens with web plate slenderness equal to 247 is lower than that of the web plate slenderness equal to 62 in the plate-frame interaction. In the shear panel with web plate slenderness equal to 62 , increasing the number of the butterfly-shaped links, and also the values of theoand $\beta$, has a significant effect to decrease the stress in the plate-frame interaction. This was expected because the shear strength of these types of slotted shear panels is significantly lower when compared to the other ones. Therefore, it is concluded that full slotted shear panels and also high values of $\alpha$ and $\beta$ improve the stress values in plate-frame interaction. 


\section{CONCLUSION}

In this study, the structural behavior of several slotted shear panels including butterfly-shaped links has been investigated numerically. To this purpose, a finite element model which has been calibrated against previous experimental results, has been obtained. Then, various slotted shear panels with different web plate slenderness, slits layout and number of slits have been investigated according to nonlinear static analyses. The results indicated that the maximum shear strength and initial stiffness of slotted shear panels are not dependent on horizontal gaps between links. In addition, it has been ascertained that the maximum shear strength and initial stiffness of slotted shear panels decay when increasing the number of butterfly-shaped links. On the other hand, when decreasing the web plate slenderness, the shear strength and initial stiffness of all types of slotted shear panels increases. The layout of slits has an effect on the distribution of stress in plate-frame interactions. Likewise, such stress decreases when the vertical gaps added between butterfly-shaped links increases. The cyclic behavior of these types of slotted shear panels will be evaluated in terms of maximum equivalent strain and energy-dissipating capacity by further investigations.

\section{ACKNOWLEDGEMENTS}

This research work has been developed as part of a $\mathrm{PhD}$ project, within the framework of the VALERE program (Vanvitelli per la Ricerca) of the University of Campania” Luigi Vanvitelli”.

\section{REFERENCES}

Ahmadi HM and De Matteis G (2020) Seismic performance of steel shear panels with butterfly- shaped links. International Journal of Earthquake engineering 37 (1)85-101.

Brando G and De Matteis G (2014) Design of low strength-high hardening metal multi-stiffened shear plates. Engineering Structures 60. Elsevier: 2-10.

De Matteis G, Formisano A, Mazzolani FM, et al. (2005) Design of low-yield metal shear panels for energy dissipation. In: Improvement of Buildings' Structural Quality by New Technologies. CRC Press, pp. $677-688$.

ECCS (1985) Recommended Testing Procedures for Assessing the Behaviour of Structural Elements under Cyclic Loads.

Egorova N, Eatherton MR and Maurya A (2014) Experimental study of ring-shaped steel plate shear walls. Journal of Constructional Steel Research 103. Elsevier: 179-189.

Farzampour A and Eatherton MR (2019) Yielding and lateral torsional buckling limit states for butterfly-shaped shear links. Engineering Structures 180. Elsevier: 442-451.

Ma X, Borchers E, Pena A, et al. (2010) Design and behavior of steel shear plates with openings as energy-dissipating fuses. John A. Blume Earthquake Engineering Center Technical Report, (173).

Formisano A, De Matteis G and Mazzolani FM (2010) Numerical and experimental behaviour of a full-scale RC structure upgraded with steel and aluminium shear panels. Computers \& structures 88 (23-24).Elsevier: 1348-1360.

Formisano A, Lombardi L and Mazzolani FM (2016) Perforated metal shear panels as bracing devices of seismic-resistant structures. Journal of Constructional Steel Research 126. Elsevier: 37-49.

Monsef Ahmad H, Sheidaii MR, Tariverdilo S, et al. (2020) Experimental and Numerical Study of Perforated Steel Plate Shear Panels. International Journal of Engineering 33 (4). Materials and Energy Research Center: 520-529.

Monsef Ahmadi H, Sheidaii MR, Boudaghi H, et al. (2020) Experimental and numerical study on largely perforated steel shear plates with rectangular tube-shaped links. Advances in Structural Engineering. SAGE Publications Sage UK: London, England: 1369433220937147.

Simulia DS, Fallis A and Techniques D (2018) Abaqus 6.14 Online Documentation.Abaqus Web. 


\title{
Full scale field testing of trapezoidal core sandwich panels subjected to adjacent and contact detonations
}

\author{
H. Al-Rifaie, R. Studziński, T. Gajewski, M. Malendowski, P. Peksa, W. Sumelka \& \\ P.W. Sielicki \\ Faculty of Civil Engineering and Transport, Poznań University of Technology, Poznań, Poland
}

\begin{abstract}
Corrugated-core sandwich panels are efficient protective structures that can absorb blast/impact energy through plastic deformation. A relatively non-expensive folding technique is used to manufacture the core to different topologies. Literature survey revealed that the dynamic response of metallic trapezoidal corrugated-core sandwich panels subjected to near-field/contact detonations has not yet been thoroughly investigated. Hence, the aim of this study is to examine, with field tests, if trapezoidal core sandwich panels can protect a precast concrete target from adjacent/contact detonations. The performance and damage behavior of two pre-cast RC slabs were assessed with and without aluminum sandwich panels. The two slabs were subjected to 4 detonations ranging from close to contact explosions. The study concludes that the implemented sandwich panel is not suitable for near-field or contact detonations and might be a protective solution for far-field explosion scenarios.
\end{abstract}

\section{INTRODUCTION}

The need for more robust systems of protection is of vital importance due to this increasing risk of explosive attacks (Al-Rifaie and Sumelka, 2017). Exposure of civilian facilities to explosion scenarios cannot be entirely avoided, but the effects of such accidents can be greatly mitigated by the use of protective systems, such as sandwich panels. To absorb the energy from blast/shock/impact, sandwich panels are used as sacrificial structures. They are usually made up of an inner-core sandwiched between two plates. The inner-core can be classified as either cellular or corrugated. The blast energy dissipation of such panels is based on the plastic deformation of the core.

Cellular cores can be metallic foams (Nowak et al., 2017), honeycomb structures (Li et al., 2014) or auxetic topologies (Al-Rifaie and Sumelka, 2019, Al-Rifaie and Sumelka, 2020) that are efficient but relatively expensive to produce (3D-printing). This may restrict their uses to particular fields, such as the aerospace field, biomedical engineering and military equipment. Corrugated core sandwich panels have been suggested as an alternative due to their high longitudinal stretching, shear strength and energy absorption properties (Zhang et al., 2015, Wiernicki et al., 1991). To manufacture the corrugated layers, a relatively non-expensive folding technique is used. The geometric topologies can be triangular, sinusoidal, rectangular or trapezoidal-shaped (Al-Rifaie et al., 2021). The later proved its performance compared to other topologies (Rong et al., 2018).

The performance of sandwich panels (with trapezoidal core) subjected to far-field explosions was generally perceived by researchers, either numerically or through real field testing. However, according to the authors' survey, the dynamic response of metallic trapezoidal corrugated-core sandwich panels subjected to near-field/contact detonations has not yet been thoroughly investigated. Hence, the aim of this study is to investigate, with field tests, if

DOI: $10.1201 / 9781003132134-50$ 
trapezoidal-core sandwich panels can protect a pre-cast concrete target from adjacent/contact detonations.

\section{CASE STUDY}

\subsection{Sandwich panel properties}

The panel used in this research is composed of 8 trapezoidal corrugated layers manufactured using cold-form press technique. The directions of the corrugated layers is cross-arranged $\left(0^{\circ} / 90^{\circ}\right)$, as better energy absorption can be achieved compared to the regular-arranged (AlRifaie et al., 2021). The 8 aluminum layers are neither welded, nor bolted together. They are hold by a C-shaped aluminum frame. The layer itself has a thickness of $1.5 \mathrm{~mm}$ while the frame has $2 \mathrm{~mm}$. Figure 1 shows the geometrical properties of the aluminum sandwich panel and its trapezoidal corrugated core. The sandwich panel has exterior dimensions of $1000 \times 1000 \times 163 \mathrm{~mm}$. Two sandwich panels of this type were used in this research. The aluminum material properties are listed in Table 1.

\subsection{The RC slab}

As mentioned earlier, the sandwich panels are supposed to protect a concrete target from contact or adjacent detonations. Two 3000x1500x145 mm pre-cast RC slabs were used. Each slab is simply supported on 2 concrete supports. The slab is reinforced with upper and lower layers of similar reinforcement. Each layer has longitudinal main reinforcement of $\emptyset 10 \mathrm{~mm} @ 150 \mathrm{~mm} c / c$

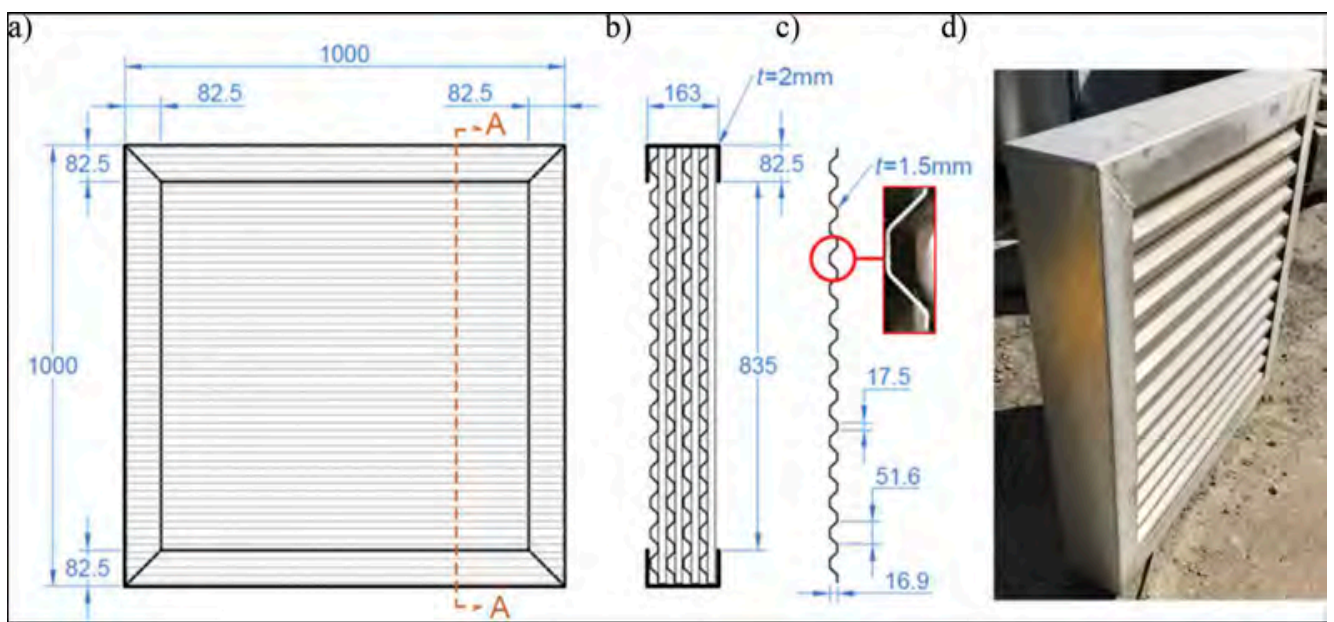

Figure 1. Geometrical properties of the aluminum sandwich panel and its trapezoidal corrugated core where: a) Top view, b) Section A-A, c) One layer and d) Produced panel.

Table 1. Material properties of the aluminum, reinforcing steel and concrete used in this study.

\begin{tabular}{|c|c|c|c|c|c|c|}
\hline \multirow[b]{2}{*}{ Material } & \multirow[b]{2}{*}{ Grade } & \multirow{2}{*}{$\frac{\text { Young's Modulus }}{\mathrm{GPa}}$} & \multirow{2}{*}{$\begin{array}{l}\text { Poisson's Ratio } \\
-\end{array}$} & \multicolumn{2}{|l|}{ Strength } & \multirow{2}{*}{$\frac{\text { Density } \rho}{\mathrm{kg} / \mathrm{m}^{3}}$} \\
\hline & & & & $\mathrm{MPa}$ & & \\
\hline Aluminum & 6063-T5 & 70 & 0.3 & $F_{y}=130$ & $F_{u}=175$ & 2700 \\
\hline Steel reinforcement & B500A & 200 & 0.3 & $\mathrm{~F}_{\mathrm{y}}=500$ & $F_{u}=650$ & 7850 \\
\hline Concrete & C35/45 & 34 & 0.17 & $\mathrm{~F}_{\mathrm{cu}}=35$ & $F_{t}=3.2$ & 2430 \\
\hline
\end{tabular}




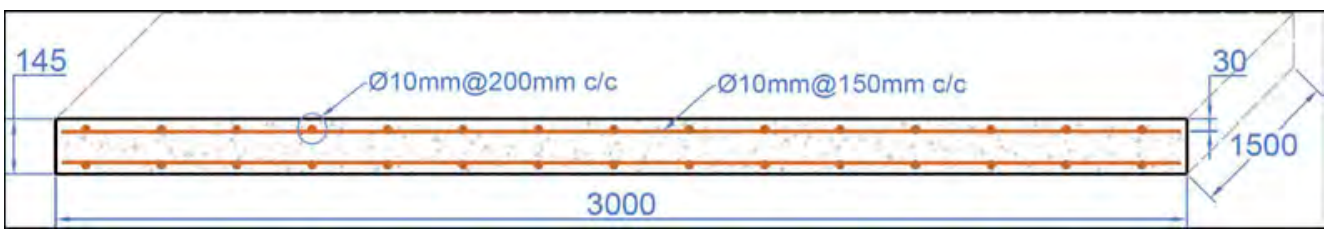

Figure 2. The reinforced concrete slab with its reinforcement details.

and transverse reinforcement of $\emptyset 10 \mathrm{~mm} @ 200 \mathrm{~mm} c / c$, as shown in Figure 2. The material properties for the concrete and the reinforcements are listed in Table 1. The test scheme and loadings are discussed in details in the flowing sections.

\subsection{Experimental setup}

The sandwich panels are supposed to protect the concrete slab from contact or adjacent detonations. To see the difference, two detonations $\left(1^{\text {st }}\right.$ and $\left.2^{\text {nd }}\right)$ were performed on a bare slab (Figures $3 \mathrm{a}$ and $3 \mathrm{~b})$. Then, two other similar detonations $\left(3^{\text {rd }}\right.$ and $\left.4^{\text {th }}\right)$ were conducted with the addition of the proposed sandwich panels (Figures $3 \mathrm{c}$ and $3 \mathrm{~d}$ ). The two pre-cast RC slabs were put on four concrete blocks/supports with $800 \times 800 \times 1600 \mathrm{~mm}$ each. The bearing area of the slab is $100 \times 1500 \mathrm{~mm}$ on each end, giving a clear slab span of $2800 \mathrm{~mm}$. The four detonations were done in sequence, one after the other with about an hour gap in between to analyze the performance and record the results. Each of the 4 detonations had mass of $1 \mathrm{~kg}$ of TNT and was positioned $750 \mathrm{~mm}$ far from adjacent slab edges. The stand-off distance for $1^{\text {st }}$ and $2^{\text {nd }}$ detonations (the distance between upper slab surface to the centroid of the explosive device) were $200 \mathrm{~mm}$ and $160 \mathrm{~mm}$, respectively (Figure $3 \mathrm{~b}$ ). The stand-off distance for the $3^{\text {rd }}$ and $4^{\text {th }}$ detonations were less, as sandwich panels were glued to the slab, leaving only $40 \mathrm{~mm}$ and $0 \mathrm{~mm}$, respectively. The $4^{\text {th }}$ detonation can be considered as a contact detonation attached directly to the sandwich panel's front layer.

The incident and peak reflected over-pressure generated from those 4 explosions, cannot be estimated using the well-known Kingery-Bulmash graphs/empirical equations. The reason is that they are close-range or contact blasts, where at this zone, more complex phenomena take

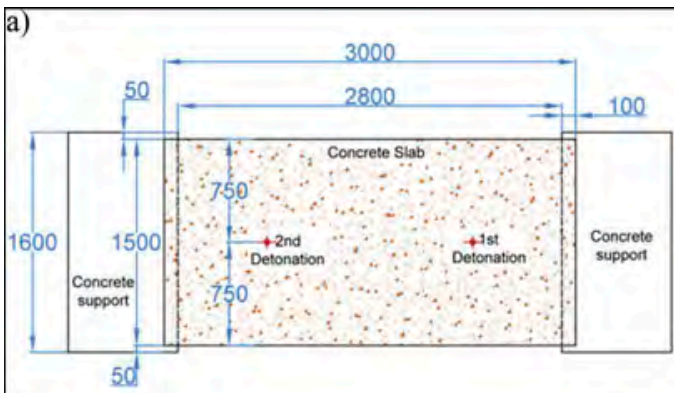

b)
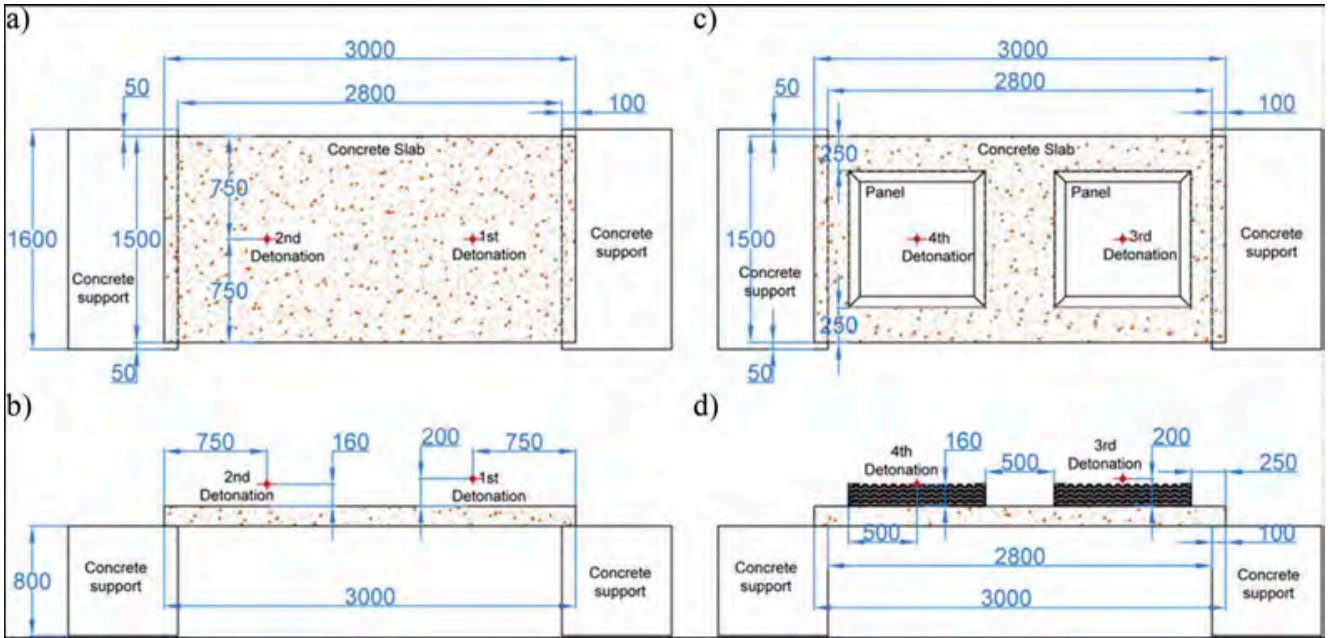

d)

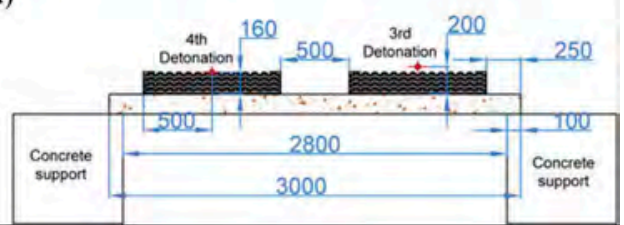

Figure 3. Field testing scheme with and without proposed sandwich panels. a) Top view-without panels, b) Side view-without panels, c) Top view-with panels and d) Side view-with panels. 
place due to afterburning and the violent outflow of the detonation gases (Novak et al., 2016). In other words, the pressure-time curve is not a single peak followed by exponential decay of Friedlander equation. There are limited test data available that might be used to validate the parameters for near regions (Baranowski et al., 2016, Bogosian and Heidenreich, 2012). Based on the mass of the TNT (W in $\mathrm{kg}$ ) and stand-off distance ( $\mathrm{R}$ in meters), the scaled distance $Z=(R) / \sqrt[3]{(W)}$ can be calculated as $0.2,0.16,0.04$ and $0 \mathrm{~m} / \mathrm{kg}^{1 / 3}$ for $1^{\text {st }}-4^{\text {th }}$ detonations, respectively. Those $Z$ values are less than the minimum scaled distance $0.4 \mathrm{~m} / \mathrm{kg}^{1 / 3}$ required to avoid close-range detonations (Rigby et al., 2015). Based on literature, the peak reflected over-pressure can roughly be estimated as $200,500,700$ and $900 \mathrm{MPa}$ for the $1^{\text {st }}-4^{\text {th }}$ detonation, respectively.

The $1 \mathrm{~kg}$ of TNT, refers to the situation when industrial infrastructural elements, such as gas cylinders, are located at a close distance from the structural elements. For example, in case of accidental explosion of $20 \mathrm{~L}$ of propane cylinder or $20 \mathrm{~L}$ of acetylene cylinder, they release blast energy equivalent to that of $0.82 \mathrm{~kg}$ and $0.86 \mathrm{~kg}$ of TNT, respectively (Studziński et al., 2021, Sielicki et al., 2017).

\section{RESULTS AND DISCUSSION}

\subsection{Behavior of RC slab without aluminum panels}

In general, the $\mathrm{RC}$ slab was able to resist the $1^{\text {st }}$ and $2^{\text {nd }}$ detonations without excessive damage. Figure 4 shows the behavior of the slab to the $1^{\text {st }}$ (Figures $4 \mathrm{a}$ and $4 \mathrm{~b}$ ) and $2^{\text {nd }}$ (Figures $4 \mathrm{c}$ and $4 d)$ detonations. The upper surface, maintained its integrity, with minor erosion to its surface directly under the centroids of the explosive devices (Figures $4 \mathrm{a}$ and $4 \mathrm{c}$ ). The sides of the slab showed no visible cracks, although micro-cracks may exist. The bottom surface revealed concrete

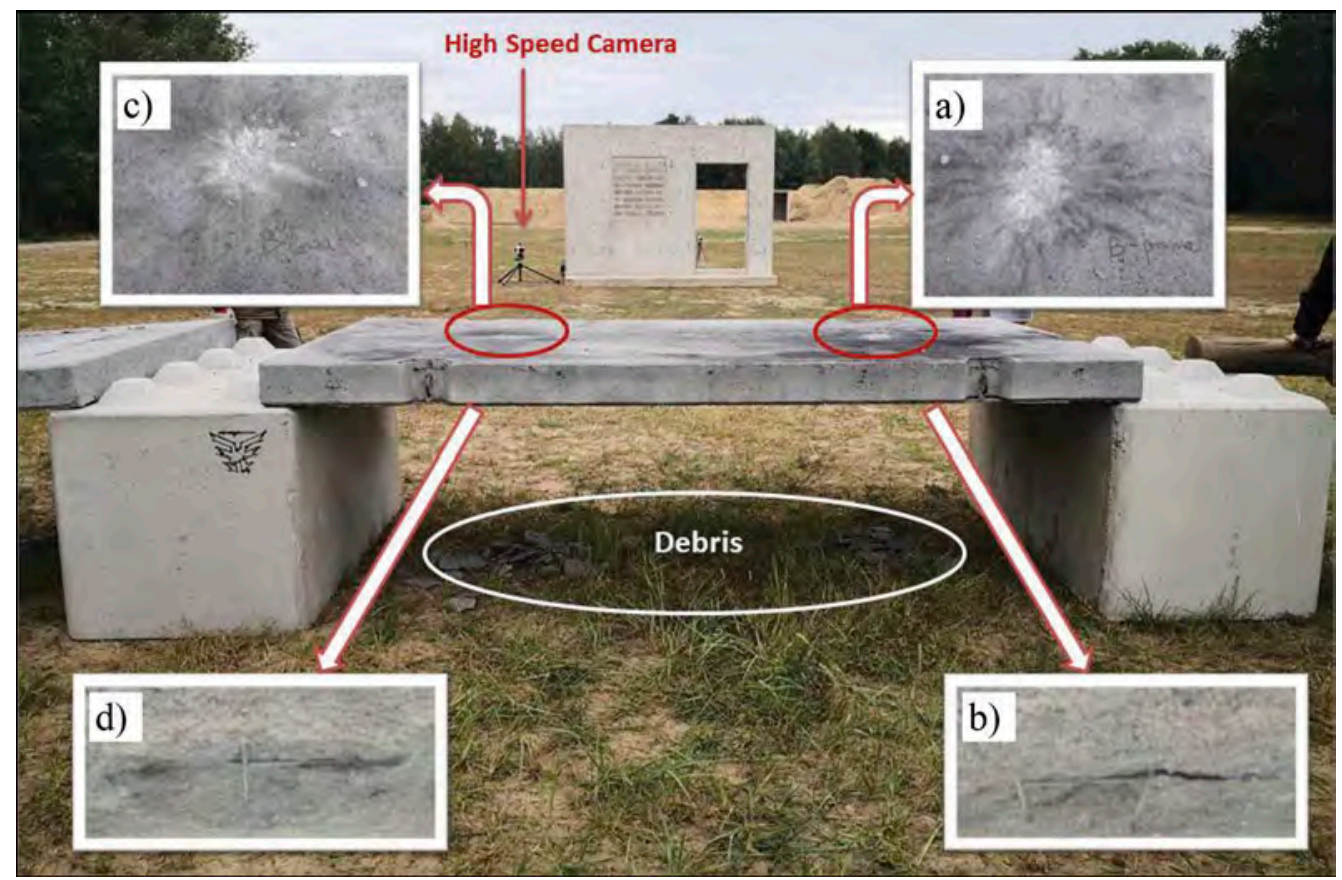

Figure 4. The failure mechanisms of the RC slab (without aluminum panels) subjected to 2 field detonations of $1 \mathrm{~kg}$ of TNT each, $1^{\text {st }}$ and $2^{\text {nd }}$, a) $1^{\text {st }}$ detonation, top concrete surface behavior, b) $1^{\text {st }}$ detonation, bottom concrete surface behavior, c) $2^{\text {nd }}$ detonation, top concrete surface behavior, d) $2^{\text {nd }}$ detonation, bottom concrete surface behavior. 
spalling and part of the reinforcement is visible (Figures $4 \mathrm{~b}$ and $4 \mathrm{~d}$ ). The mid-span deflection was recorded as $3 \mathrm{~mm}$. The aim of the addition of the sandwich panels in the next section is to see if the tension damage at the bottom surface of the slab would be reduced/prevented.

\subsection{Behavior of RC slab with the sacrificial aluminum panels}

Based on the testing scheme presented in Figures $3 \mathrm{c}$ and $3 \mathrm{~d}$, the two panels were glued to the top surface of the concrete (Figure 5a). When the $3^{\text {rd }}$ detonation was first performed, the panel (with mass of $45.2 \mathrm{~kg}$ ) was lifted and shifted $17.6 \mathrm{~m}$ away from the explosion location. The panel frame and the layers were also separated (Figure 5b). A circular local punching shear failure is the dominant behavior of the panel through all its 8 layers (Figures $5 \mathrm{c}-\mathrm{e}$ ). The adjacent panel, at this stage showed minor deformations due to the $3^{\text {rd }}$ detonation (Figure $5 b$ ). When the $4^{\text {th }}$ detonation was then performed, a similar panel behavior was observed, although the IED was in a complete contact with the frontal layer of the panel. These results agreed with (Kevin et al. (2013)) that contact detonations have extremely high pressures for just microseconds leading to local shear and punching failure.

The behavior of the concrete slab (with aluminum panels) is shown in Figure 6. The upper surface, under compression, was more deteriorated (Figures $6 \mathrm{a}$ and $6 \mathrm{c}$ ). The bottom surface (under tension) showed bigger areas of spalling with long visible longitudinal and transverse cracks (Figures $6 \mathrm{~b}$ and $6 \mathrm{~d}$ ). The sides of the RC slab were also cracked with visible damage (Figure 6e). The mid-span deflection was $73 \mathrm{~mm}$. It can be noticed that the addition of sandwich panels worsen the situation rather than protecting the slab. The cracks, damage and deflection were all more. The weight of the two panels $(\sim 90 \mathrm{~kg})$ and hence the kinetic energy from those panels might be the reason. Therefore, this study concludes that this type of sandwich panels may be protective in far-field explosion scenarios, but not for close or contact detonations.
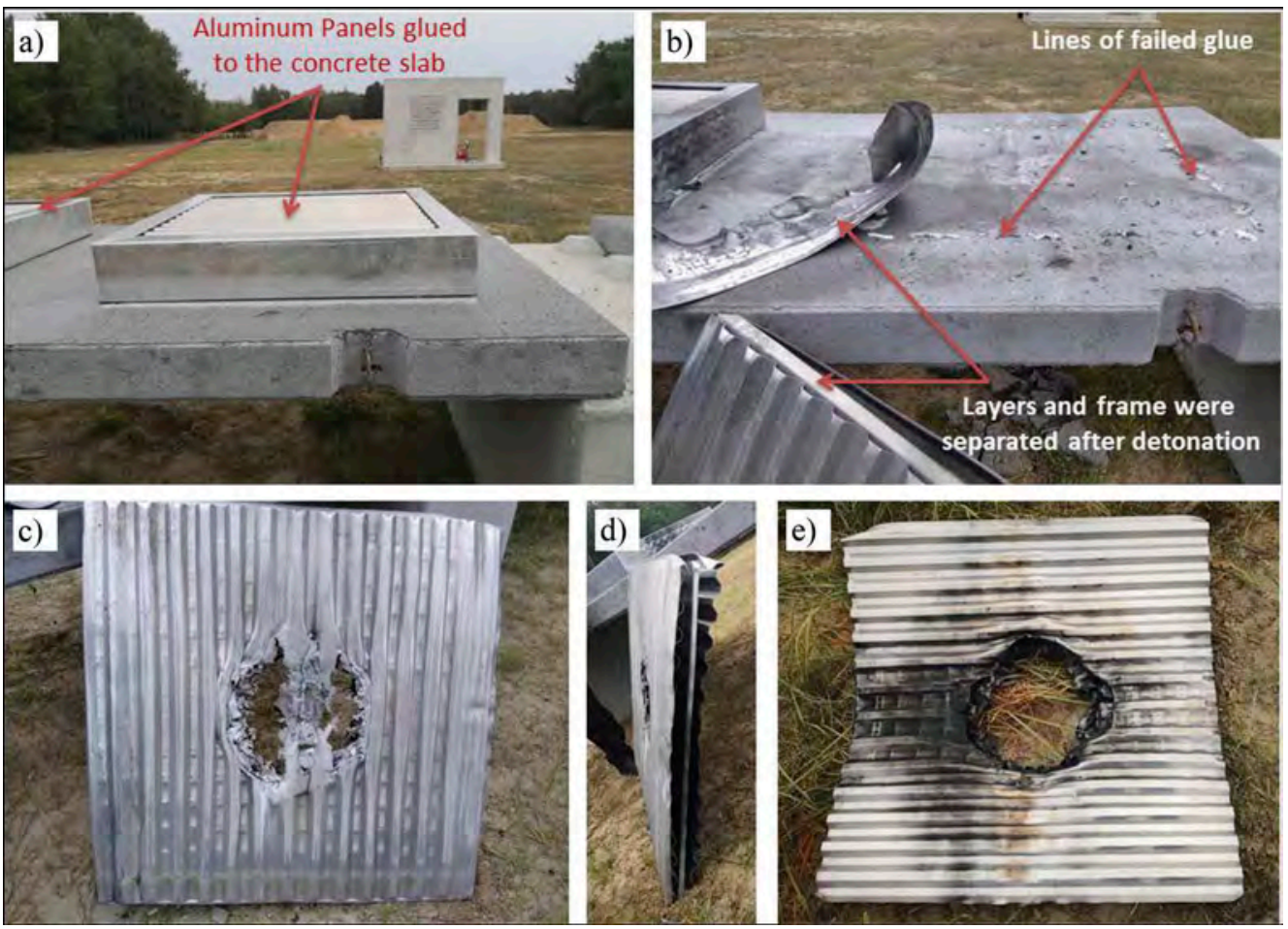

Figure 5. The failure modes of the aluminum panel after $3^{\text {rd }}$ detonation. 


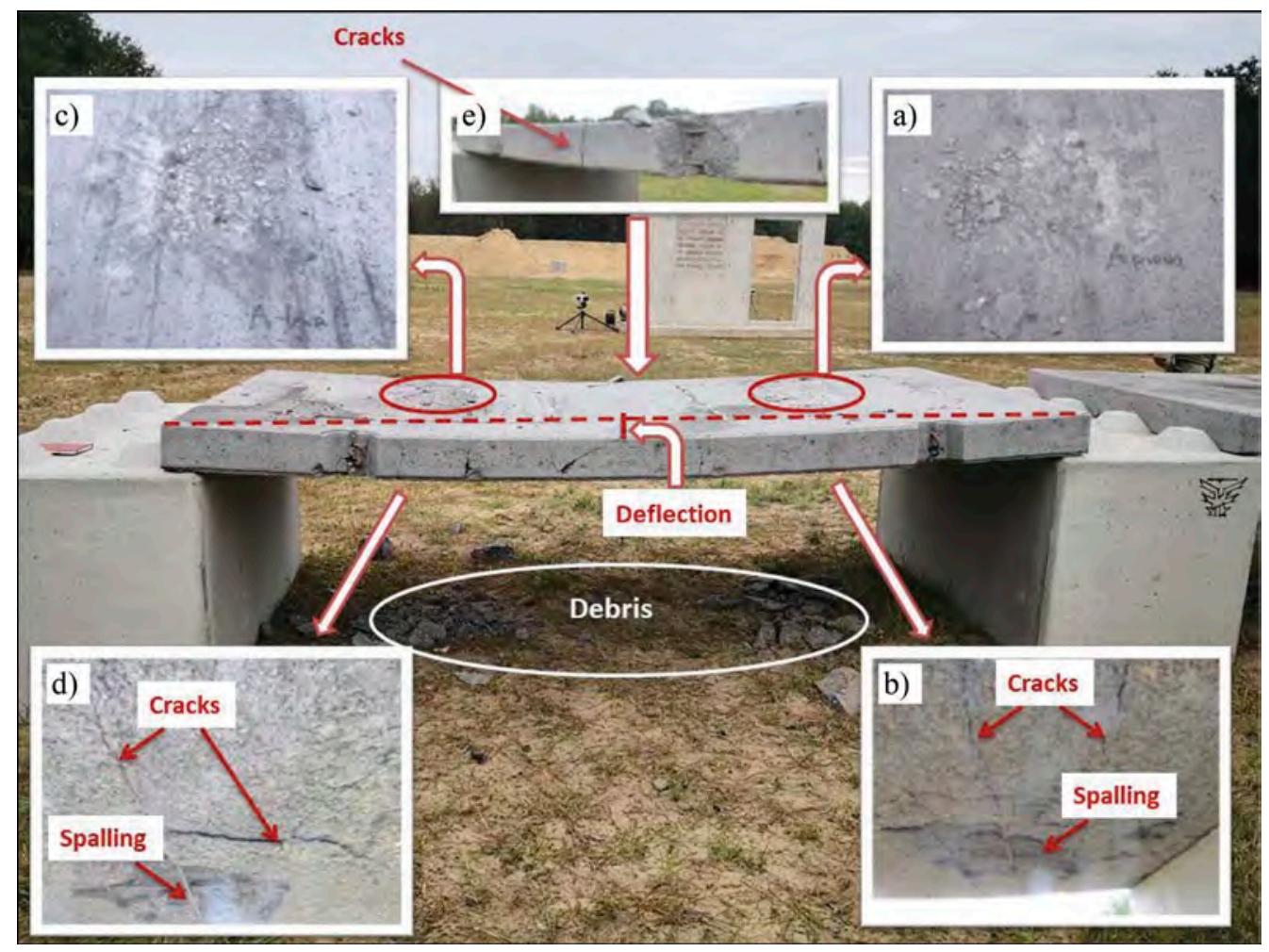

Figure 6. The failure mechanisms of the RC slab (with aluminum panel) subjected to 2 field detonations of $1 \mathrm{~kg}$ of TNT each. a) $3^{\text {rd }}$ detonation, top concrete surface behavior, b) $3^{\text {rd }}$ detonation, bottom concrete surface behavior, c) $4^{\text {th }}$ detonation, top concrete surface behavior, d) $4^{\text {th }}$ detonation, bottom concrete surface behavior, e) Side view of the concrete slab showing cracks and damage.

\section{CONCLUSIONS}

In this study, the performance and damage behavior of two pre-cast RC slabs were experimentally assesses with and without aluminum trapezoidal-core sandwich panels. The two slabs were subjected to 4 detonations ranging from close to contact explosions. Results showed that the behavior of the slabs was worse with the addition of those panels. More tension damage/ cracks were observed. The study concludes that this type of sandwich panels cannot resist close or contact detonations and might be a protective solution for far-field explosion incidents.

\section{ACKNOWLEDGEMENT}

This work was supported by the National Centre for Research and Development, Poland, grant DOB-BIO10/01/02/2019 within Defence and Security Programme.

\section{REFERENCES}

Al-Rifaie, H., Studziński, R., Gajewski, T., Malendowski, M., Sumelka, W. \& Sielicki, P. W. 2021. A New Blast Absorbing Sandwich Panel with Unconnected Corrugated Layers-Numerical Study. Energies, 14, 214.

Al-Rifaie, H. \& Sumelka, W. 2017. Numerical analysis of reaction forces in blast resistant gates. Structural Engineering and Mechanics, 63, 347-359. 
Al-Rifaie, H. \& Sumelka, W. 2019. The developement of a new shock absorbing Uniaxial Graded Auxetic Damper (UGAD). Materials, 12, 2573.

Al-Rifaie, H. \& Sumelka, W. 2020. Improving the Blast Resistance of Large Steel Gates-Numerical Study. Materials, 13, 2121.

Baranowski, P., Malachowski, J. \& Mazurkiewicz, L. 2016. Numerical and experimental testing of vehicle tyre under impulse loading conditions. International Journal of Mechanical Sciences, 106, 346-356.

Bogosian, D. \& Heidenreich, A. An evaluation of engineering methods for predicting close-in air blast. Structures congress, 2012. 90-101.

Kevin, C., Van Doormaal, A., Haberacker, C., Hüsken, G., Larcher, M., Saarenheimo, A., Solomos, G., Stolz, A., Thamie, L. \& Valsamos, G. 2013. Resistance of structures to explosion effects. Review report of testing methods, Ispra: European Commission-Joint Research Centre.

Li, X., Zhang, P., Wang, Z., Wu, G. \& Zhao, L. 2014. Dynamic behavior of aluminum honeycomb sandwich panels under air blast: Experiment and numerical analysis. Composite Structures, 108, 1001-1008.

Novak, N., Vesenjak, M. \& Ren, Z. 2016. Auxetic cellular materials-a review. Strojniški vestnik-Journal of Mechanical Engineering, 62, 485-493.

Nowak, Z., Nowak, M., Pecherski, R., Potoczek, M. \& Sliwa, R. 2017. Numerical simulations of mechanical properties of alumina foams based on computed tomography. Coupled Field Problems and Multiphase Materials, 107.

Rigby, S. E., Tyas, A., Clarke, S. D., Fay, S. D., Reay, J. J., Warren, J. A., Gant, M. \& Elgy, I. 2015. Observations from preliminary experiments on spatial and temporal pressure measurements from near-field free air explosions. International Journal of Protective Structures, 6, 175-190.

Rong, Y., Liu, J., Luo, W. \& He, W. 2018. Effects of geometric configurations of corrugated cores on the local impact and planar compression of sandwich panels. Composites Part B: Engineering, 152, 324-335.

Sielicki, P., ŁodygowskI, T., Al-Rifaie, H. \& Sumelka, W. 2017. Designing of Blast Resistant Lightweight Elevation System-Numerical Study. Procedia Engineering, 172, 991-998.

Studziński, R., Gajewski, T., Malendowski, M., Sumelka, W., Al-Rifaie, H., Peksa, P. \& Sielicki, P. W. 2021. Blast Test and Failure Mechanisms of Soft-Core Sandwich Panels for Storage Halls Applications. Materials, 14, 70.

Wiernicki, C. J., Liem, F., Woods, G. D. \& Furio, A. J. 1991. Structural analysis methods for lightweight metallic corrugated core sandwich panels subjected to blast loads. Naval Engineers Journal, 103, 192-202.

Zhang, P., Liu, J., Cheng, Y., Hou, H., Wang, C. \& Li, Y. 2015. Dynamic response of metallic trapezoidal corrugated-core sandwich panels subjected to air blast loading-An experimental study. Materials \& Design (1980-2015), 65, 221-230. 


\title{
Torsional, flexural and torsional-flexural buckling of angle section members - an analytical approach
}

\author{
A. Beyer \& A. Bureau \\ CTICM, Saint-Aubin, France \\ J-P. Jaspart \& J.F. Demonceau \\ Liège University, Liège, Belgium \\ M-Z. Bezas \\ Liège University, Liège, Belgium \\ NTUA, Athens, Greece
}

\begin{abstract}
In the framework of the ongoing revision of EN 1993-3-1, the RCFS funded research project ANGELHY is currently performing experimental, numerical and theoretical studies on angle sections and lattice towers. This paper presents a particular aspect of the ANGELHY project and focusses on a theoretical study concerning the behaviour of angle section members. First, the elastic second order equation of such members subjected to axial compression is established. Then, this differential equation is solved based on different assumptions concerning geometric imperfections to determine second order displacements, rotations and internal forces and moments. The analytical second order solution is validated through comparisons to a numerical elastic second order analysis. Based on the validated analytical solution, it is then shown, that even if torsional/torsional-flexural buckling of angle section members was relevant according to the elastic critical loads, the member rather fails by flexural buckling only. The reason for this unexpected conclusion may be directly derived from the second order internal forces and moments as shown in the last part of this paper.
\end{abstract}

\section{INTRODUCTION}

Owing to the need to optimise steel lattice towers, the research on angle section members has been very active in the last fifteen years. Interesting contributions on different questions are provided for example in references (Vayas et al. 2009), (Spiliopoulos et al. 2017), (Moze et al. 2014) and (Kettler \& Unterweger 2017). Nonetheless, there exists still a lack concerning the theoretical background on member buckling and more specifically concerning the torsionalflexural buckling mode. In fact, generally, it is considered that angle section members subjected to a compression force may fail due to instability by flexural buckling about their weak axis $v$ (see Figure 1) or by torsional-flexural buckling combining displacements and torsional twist. Usually, the sensitivity to one or the other failure mode is evaluated based on the critical axial forces $N_{\mathrm{cr}, \mathrm{v}}$ (minor axis flexural buckling) and $N_{\mathrm{cr}, \mathrm{TF}}$ (torsional-flexural buckling). The expressions for $N_{\mathrm{cr}, \mathrm{v}}$ and $N_{\mathrm{cr}, \mathrm{TF}}$ are given in Equations (1) and (2).

$$
N_{c r, v}=E I_{v}\left(\frac{\pi}{L}\right)^{2}
$$




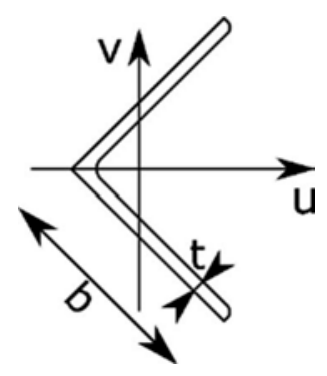

Figure 1. Definition of axes.

$$
N_{c r, T F}=\frac{i_{p}^{2}}{2\left(i_{p}^{2}-y_{s}^{2}\right)}\left(N_{c r, T}+N_{c r, u}-\sqrt{\left(N_{c r, T}-N_{c r, u}\right)^{2}+4 N_{c r, T} * N_{c r, u} \frac{y_{s}^{2}}{i_{p}^{2}}}\right)
$$

With:

$$
N_{c r, T}=\frac{1}{i_{p}^{2}} G I_{T}
$$

where: $E=$ Young's modulus; $I_{\mathrm{v}}=$ second moment of area about the minor axis; $L=$ member length; $i_{\mathrm{p}}=$ polar radius of inertia; $y_{\mathrm{s}}=$ distance between the shear centre and the centroid; $G=$ shear modulus, $I_{\mathrm{T}}=$ torsion constant.

Figure 1 shows the definition of axes. It should be noted that an axial compression force is considered as positive. Also, the major axis bending moment $M_{\mathrm{u}}$ is considered positive if it leads to compression of fibres with positive coordinate $\mathrm{v}$ and the minor axis bending moment $M_{\mathrm{v}}$ is considered positive if it leads to compression of fibres with positive coordinate $\mathrm{u}$.

In order to evaluate in which range torsional-flexural buckling may potentially be more critical than minor axis flexural buckling, it is interesting to compare the differences between $N_{\text {cr,TF }}$ and $N_{\text {cr,v }}$ for a given example. Figure 2 shows a comparison of the critical axial forces depending on the minor axis relative slenderness of a 150.150 .10 angle section member made of steel S355. This comparison suggests that torsional-flexural buckling may be a relevant failure mode up to a relative minor axis buckling slenderness of $1.0(L=2250 \mathrm{~mm})$. In particular, for legs of lattice towers, this value of the slenderness is in the practical range. Consequently, it is of importance to fill the lack of background on the torsional-flexural buckling of angle sections. Therefore, the following paragraphs will highlight, on a theoretical basis and analytical second order analyses, the behaviour of angle section members under compression.

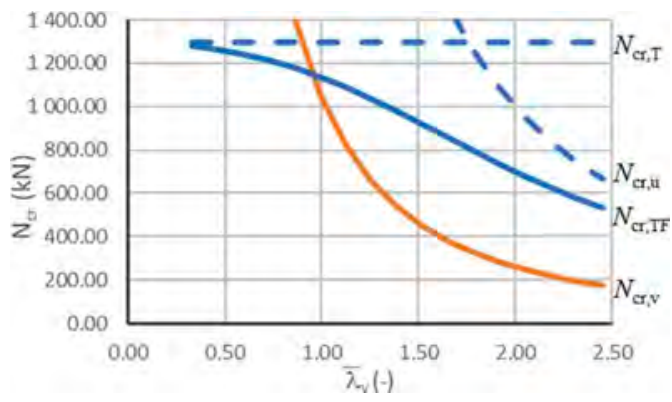

Figure 2. Critical axial forces for a given minor axis relative slenderness. 


\section{SECOND ORDER INTERNAL FORCES AND MOMENTS}

\subsection{Flexural buckling about the minor axis - Second order internal forces and moments}

First, it is recalled that the second order displacement $v$ and the second order bending moment $M_{\mathrm{v}}$ may be determined with equations (4) and (5). Both equations indicate that the second order quantities depend on the applied axial force $N$ and the amplitude of the chose imperfection $v_{0}$. In the framework of this study, an imperfection affine to a half sine wave has been chosen.

$$
\begin{gathered}
v=\frac{N v_{0}}{N_{c r, v}-N} \\
M_{v}=E l_{v} v^{I I}=-\frac{N v_{0}}{1-\frac{N}{N_{c r, v}}}
\end{gathered}
$$

Based on a realistic assumption of the amplitude of the equivalent imperfection $v_{0}$ (derived from physical tests and numerical simulations), the second order bending moment can be calculated and finally it is possible to apply a first yield criterion in order to obtain the member resistance:

$$
\sigma_{\max }=\frac{N}{A}+\frac{N v_{0}}{\left(1-\frac{N}{N_{c r, v}}\right) W_{e l, v}} \leq f_{y}
$$

where: $\sigma_{\max }=$ maximum stress in the cross-section; $W_{\mathrm{el}, \mathrm{v}}=$ elastic section modulus; $f_{\mathrm{y}}=$ yield stress.

Equation (6) can be used to derive the European buckling curves as has been done by (Rondal et al. 1979). This derivation is omitted here.

\subsection{Torsional-flexural buckling}

In this section, the second order internal forces and moments are derived for the case of torsional-flexural buckling. For this buckling mode, major axis flexural buckling is coupled with the torsional buckling. Consequently, the two coupled differential equations (7) and (8) have to be used to determine the second order quantities.

$$
\begin{aligned}
& E I_{u} w^{I I}-N y_{s} \varphi \varphi+N w w=-N w_{0}+N y_{s} \varphi_{0} \\
& -G I_{t} \varphi^{I}+N i_{p}^{2} \varphi^{I}-N y_{s} w^{I}=N y_{s} w_{0}^{I}-N i_{p}^{2} \varphi_{0}^{I}
\end{aligned}
$$

where: $\varphi=$ torsional twist, $w_{0}=$ the displacement component of the imperfection, $\varphi_{0}=$ the torsional twist component of the imperfection.

At this point, it should be highlighted that the equivalent imperfection is composed of two components here: $\varphi_{0}$ and $w_{0}$. It may be possible to choose values for both components independently. Nonetheless, if the imperfection is chosen affine to the eigen mode, a fixed ratio exists between the values of $w_{0}$ and $\varphi_{0}$ :

$$
w_{0}=\frac{y_{s}}{1-\frac{N_{c r, u}}{N_{c r, T F}}} \varphi_{0}=r_{w} \varphi_{0}
$$

Based on Equation (9), one may express the second order displacement components $w$ and $\varphi$ by: 


$$
\begin{gathered}
\varphi=-\frac{y_{s}^{2}\left(1-\frac{N_{c r, u}}{N} \frac{r_{w}}{y_{s}}\right)-i_{p}^{2}\left(1-\frac{N_{c r, u}}{N}\right)}{y_{s}^{2}-i_{p}^{2}\left(1-\frac{N_{c r, t}}{N}-\frac{N_{c r, u}}{N}+\frac{N_{c r, t N c r, y}}{N^{2}}\right)} \frac{w_{0}}{r_{w}} \\
w=\frac{N\left(\frac{y_{s}}{r_{w}}-1\right) w_{0}+N y_{s} \varphi}{N-N_{c r, u}}
\end{gathered}
$$

The second order internal forces and moments result from Equations (12) and (13):

$$
\begin{gathered}
M_{u}=E I_{u} w^{I I}=-\frac{N\left(\frac{y_{s}}{r_{w}}-1\right) w_{0}+N y_{s} \varphi}{1-\frac{N}{N_{c r, u}}} \\
M_{x}=M_{x, S t . V}=G I_{t} \varphi^{I}=\frac{\pi}{L} G I_{t} \frac{i_{p}^{2}\left(1-\frac{N_{c r, y}}{N}\right)-y_{s}^{2}\left(1-\frac{N_{c r, y}}{N} \frac{r_{w}}{y_{s}}\right)}{y_{s}^{2}-i_{p}^{2}\left(\frac{N_{c r, t}}{N}+\frac{N_{c r, y}}{N}-\frac{N_{c r, t N_{c r, y}}}{N^{2}}\right)} \frac{w_{0}}{r_{w}}
\end{gathered}
$$

It is important to note that the maximum second order major axis bending moment is located at mid span. Inversely, the Saint Venant's torsional moment is distributed according to a cosine half wave. Consequently, its maximum value, given in Equation (13), is located at the supports. Additionally, it should be recalled that the Saint Venant's torsional moment only generates shear stresses over the cross-section. Therefore, it is not possible to use a simple linear stress interaction as in Equation (6). Rather the maximum von Mises stress $\sigma_{v \text { Mises }}$ resulting from a combination of $N, M_{\mathrm{u}}$ and $M_{\mathrm{x}, \mathrm{St} . \mathrm{V}}$ should be checked along the member. The elastic resistance criterion consequently reads:

$$
\sigma_{v \text { Mises }}=\sqrt{\sigma_{x}^{2}\left(N, M_{u}\right)+3 \tau^{2}\left(M_{x, S t . V}\right)} \leq f_{y}
$$

where: $\sigma_{x}\left(N, M_{u}\right)=$ axial stress due to axial force and major axis bending; $\tau(M x,, S t . V)=$ shear stress due to Saint Venant's torsional moment.

In principle, it would be possible to derive a buckling curve for torsional-flexural buckling. However, even if this is not done here, it is clear from Equation (14) that this buckling curve cannot have the same format as the flexural buckling curves derived by (Rondal \& Maquoi 1979).

In the following section, the resistance criteria of Equations (6) and (14) will be applied to selected examples and compared to numerical simulations.

\section{COMPARISON TO NUMERICAL SIMULATIONS}

First, the second order results obtained in the previous paragraph will be validated by comparing the analytical solutions to elastic second order calculations. These elastic second order calculations are performed with the free software FE-STAB (Kindmann et al. 2013). This software allows the user to perform elastic $1^{\text {st }}$ and $2^{\text {nd }}$ order analyses including a geometric imperfection.

The second order results are compared based on an equivalent imperfection equal to L/250 corresponding to buckling curve $b$ according to EN 1993-1-1 (CEN 2005). The following calculations are performed for an angle section L150.150.10 and values of the relative slenderness $\lambda_{v}$ in the range of 0.5 to 1.25 . Table 1 presents the results. It should be noted that the geometric imperfection has been determined so that, for the torsional-flexural buckling mode, the combination of $w_{0}$ and $\varphi_{0}$ leads to a geometric imperfection of L/250 for one tip of the legs. 
Table 1. Second order displacements for the torsional-flexural buckling mode.

\begin{tabular}{|c|c|c|c|c|c|c|c|c|}
\hline \multirow{2}{*}{$\begin{array}{l}\text { Member } \\
\text { length } L\end{array}$} & \multirow[b]{3}{*}{$\lambda_{\mathrm{v}}$} & \multirow[b]{3}{*}{$N_{\mathrm{cr}, \mathrm{TF}} / N$} & \multicolumn{2}{|c|}{ Geometric imperfection } & \multicolumn{2}{|c|}{ Analytical solutions } & \multicolumn{2}{|c|}{ Numerical solutions } \\
\hline & & & $w_{0}$ & $\varphi_{0}$ & $w^{\mathrm{II}}$ & $\varphi^{\mathrm{II}}$ & $w^{\mathrm{II}}$ & $\varphi^{\mathrm{II}}$ \\
\hline$(\mathrm{mm})$ & & & $(\mathrm{mm})$ & $(\mathrm{rad})$ & $(\mathrm{mm})$ & $(\mathrm{rad})$ & $(\mathrm{mm})$ & $(\mathrm{rad})$ \\
\hline 570 & 0.25 & 3 & $1.55 \times 10^{-3}$ & $1.52 \times 10^{-3}$ & $\approx 0$ & 0.00076 & $\approx 0$ & 0.00076 \\
\hline 1150 & 0.50 & 3 & 0.0133 & 0.0306 & 0.0066 & 0.0153 & 0.0066 & 0.01531 \\
\hline 1700 & 0.75 & 3 & 0.0451 & 0.0451 & 0.0225 & 0.0225 & 0.0225 & 0.0225 \\
\hline 2250 & 1.00 & 3 & 0.1120 & 0.0591 & 0.0560 & 0.0295 & 0.0560 & 0.0295 \\
\hline $2850^{*}$ & 1.25 & 3 & 0.2460 & 0.0730 & 0.1230 & 0.0365 & 0.1230 & 0.0365 \\
\hline
\end{tabular}

* For $L=2850 \mathrm{~mm}: N_{\mathrm{cr}, \mathrm{u}}<N_{\mathrm{cr}, \mathrm{TF}}$

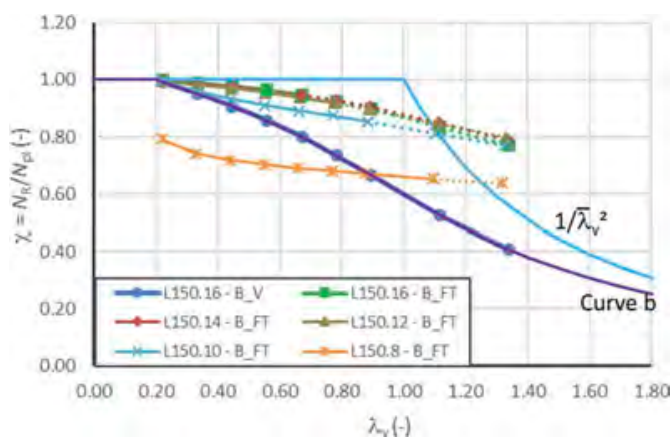

Figure 3. Analytical reduction curves for flexural and torsional-flexural buckling.

Table 1 provides the results for different member lengths. In order to obtain a significant second order amplification, the results are determined for a ratio $N_{\mathrm{cr}, \mathrm{TF}} / N$ equal to 3.0. Table 1 clearly indicates that the analytical solutions fit perfectly the numerically calculated displacement and torsional rotation.

Next, Figure 3 shows the obtained results for equal leg angle sections 150.16, 150.14, $150.12,150.10$ and 150.8 (b.t). The last angle section does not exist in classical cross-section catalogues but it is included here in order to enlarge the parameter field in terms of ratio b/t. It should be noted that the amplitude of the geometric imperfection applied in the analytical approach has been back calculated from buckling curve $b$, applicable for the buckling design of angle section members according to EN 1993-1-1 (CEN 2005). It is also recalled that the amplitude applied for the torsional-flexural buckling mode refers to the pre-deformation of the tip of one leg.

As the imperfection amplitude has been back calculated from the buckling curve, the analytically determined solution for minor axis flexural buckling (noted L150.16- B-V) perfectly overlaps European buckling curve $b$. As the minor axis buckling solutions are identical for all cross-sections, only the result for section L150.16 is represented. The analytical reduction curves determined for torsional-flexural buckling (based on Equation (14)), are divided into two parts:

- the continuous line indicates the slenderness range for which torsional-flexural buckling is relevant according to the critical axial forces $\left(N_{\mathrm{cr}, \mathrm{TF}}<N_{\mathrm{cr}, \mathrm{v}}\right)$;

- the dotted part of the curve indicates that minor axis flexural buckling is relevant $\left(N_{\mathrm{cr}, \mathrm{v}}<\right.$ $N_{\text {cr,TF. }}$ 
a)

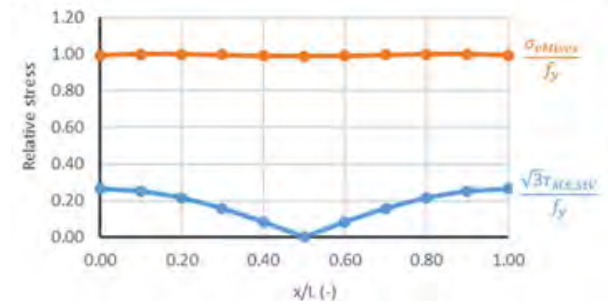

b)

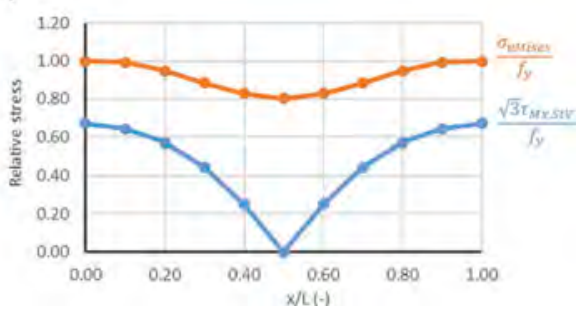

Figure 4. Evolution of shear stresses and von Mises stresses: a) section L150.10 with $L=750 \mathrm{~mm}$; b) section L150.8 with $L=750 \mathrm{~mm}$.

One may observe that, according to the analytical approach, only for section L150.8, the torsional-flexural buckling mode leads to a lower resistance than the minor axis flexural buckling mode. In fact, for the shortest members, the most loaded cross-section in case of torsional-flexural buckling is not the section at mid-span, but the section at the member ends. This section is subject to an interaction between shear stresses, resulting from Saint Venant's torsion, and axial stresses, resulting from the axial force. The major axis bending moment obviously vanishes at the member ends. When the member becomes longer, the section relevant for design in case of torsional-flexural buckling shifts from the member ends to midspan. For the longest members, the interaction between the axial force and the major axis bending moment becomes therefore relevant. Yet for these member lengths, minor axis flexural buckling is always much more critical. Observing Figure 3 again, one may remark the huge difference between section L150.8 and all other studied angle sections. The important strength reduction for this cross-section results from its low torsional constant $I_{\mathrm{t}}$. Two effects explain this observation: 1) the critical axial force for torsional-flexural buckling reduces highly and 2) the (elastic) resistance to Saint Venant's torsion also reduces highly. In order to represent this explanation, Figures 4 shows the evolution of the shear stresses and the von Mises stresses over the length of two members:

- Section L150.10 with a relative slenderness of $0.34(L=750 \mathrm{~mm})$;

- Section L150.8 with a relative slenderness of $0.34(L=750 \mathrm{~mm})$.

The stresses are represented as ratios with respect to the yield stress $f_{\mathrm{y}}$.

For section L150.10, Figure 4 a) shows that the shear stresses only represent approximatively $22 \%$ of the von Mises stresses. The main contribution to the von Mises stresses is resulting from the axial force. One may note that the maximum stress resulting from the second order major axis bending moment is only equal to $10 \mathrm{MPa}$ at mid-span.

In contrast, the shear stresses resulting from the Saint Venant's torsional moment highly contribute to the von Mises stresses in case of section L150.8. Owing to the high value of these shear stresses, the resistance, in terms of maximum axial force, of the section L150.8 with a length of $750 \mathrm{~mm}$ is much less than for section L150.10 with the same length.

\section{CONCLUSIONS}

This paper has presented an analytical approach to assess the torsional-flexural buckling behaviour of angle section members. It has been recalled that, based on the critical axial force, torsional-flexural buckling may be a relevant failure mode in the practical slenderness range of such members. However, the analytical derivation of a design criterion, conducted through rigorous second order theory has highlighted that the Eurocode 3 Part 1-1 design approach for torsional-flexural buckling is not suited for this failure mode. In fact, the Eurocode 3 buckling reduction curves have been determined based on the assumption that only axial stresses 
interact and lead to failure at mid height of a column. Yet, as angle sections possess only a negligible warping stiffness the second order torsional twist, developing in case of torsionalflexural buckling, does not lead to axial stresses but to shear stresses resulting from the Saint Venant's torsional moment. The maximum second order elastic stresses consequently result from an interaction between shear stresses and axial stresses near the member ends. This interaction appears to be much more favourable than the interaction between axial force and second order bending in case of flexural buckling. The Eurocode 3 provisions should therefore be amended. Nonetheless, it is recalled that the presented results possess certain limitations as they have been obtained following elastic second order theory based on certain assumptions. In particular:

- The amplitude of the equivalent geometric imperfection has been chosen equal for flexural buckling and torsional-flexural buckling.

- The resistance criterion for torsional-flexural buckling used here is purely elastic. A more refined plastic interaction could potentially lead to even higher resistance for torsionalflexural buckling.

- The effect of local buckling is not accounted for.

Finally, it is recalled that this research is part of the RFCS project ANGELHY. In the framework of this project, the mentioned limitations of this analytical approach are currently eliminated owing to an extensive laboratory testing campaign and numerical studies considering imperfections and material non linearity (GMNIA).

The present work has been realised in the framework of the research project ANGLEHY partially funded by the Research Fund for Coal and Steel (RFCS) under the grant agreement number 753993.

\section{REFERENCES}

CEN, 2005. EN 1993-1-1: Eurocode 3 - Design of steel structures Part 1-1: General rules and rules for buildings. Brussels.

CEN. 2007. EN 1993-3-1: Eurocode 3 - Design of steel structures Part 3-1: towers, masts and chimneys Towers and masts. Brussels.

Kettler, M. \& Unterweger, H. 2017. Tragfähigkeit von Winkelprofilen bei Druckbeanspruchungen und realen Lagerungsbedingungen. Stahlbau 86(3): 239-255.

Kindmann, R., Laumann, J., Vette, J. 2013. Program FE-STAB. https://www.stahlbau.ruhr-uni-bochum. de/sb/service/rubsteeltools.html.de.

Rondal, J. \& Maquoi, R. 1979. Formulations d'Ayrton-Perry pour le Flambement des Barres Métalliques. Revue Construction Métallique 1979(4): 41-53.

Moze, P., Cajot, L.-G., Sinur, F., Rejec, K., Beg, D. 2014. Residual stress distribution of large steel equal leg angles. Engineering Structures 71: 35-47.

Spiliopoulos, A., Dasiou, M.-E., Thanopoulos, P., Vayas, I. 2017. Experimental tests on members made from rolled angle sections. Steel Construction 11(3): 1-10.

Vayas, I., Charalampakis, A., Koumousis, V., 2009, "Inelastic resistance of angle sections subjected to biaxial bending and normal forces“, Steel Construction 2(2): 138-146. 


\title{
Resistance assessments of steel columns of variable cross sections
}

\author{
P. Błażejewski, S. Kołodziej, J. Marcinowski \& V. Sakharov \\ University of Zielona Góra, Zielona Góra, Poland
}

\begin{abstract}
Steel columns of hollow cross-sections and simply supported at their ends are considered in the paper. Columns of such shapes are recently frequently proposed by architects in public utility buildings of various types. In this work authors present the comparatively simple procedure which can be used by designers of steel columns of such shapes. The value of critical force required in the procedure was derived for columns of variable cross section by means of Mathematica ${ }^{\mathrm{TM}}$ system. The closed formulae were obtained for a rod with a certain, predefined geometry being the surface of revolution. Critical forces obtained by means of derived formulae were compared with numerical solutions. To assess the compression resistance of considered rods the general Ayrton-Perry approach was applied and bow imperfection with assumed amplitude was used in the analysis. Examples inserted in the paper confirm the correctness and the effectiveness of the proposed procedure.
\end{abstract}

\section{INTRODUCTION}

Tapered columns resembling a spindle shape and fabricated as a steel, hollow sections are more and more often encountered in engineering practice (Figure 1). Some of the main reasons for their increasing use are the material savings, a greater load capacity and aesthetic requirements (Thompson et al. 2007, Marcinowski 2015, Marcinowski \& Sadowski 2020). Provisions of EN 1993 (2005) do not deliver direct procedures which can be used in designing of such kind of columns. Existing design procedures based on general Ayrton \& Perry (1886) approach refers only to columns of constant sections. This general approach requires knowledge of the critical force value and it is the principal problem which should be solved.

There are a large number of papers in which the buckling problem of non-prismatic columns is considered (Li et al. 1995, Le 2001, Elishakoff \& Rollot 1999). Value of the critical forces is absolutely necessary to the assessment of load bearing capacity.

In the present paper the effective method of determination of the critical force has been presented. To this end the energetic criterion of stability proposed in Timoshenko \& Gere (1961) was used. The obtained analytical expression on the critical force has been verified positively by means of numerical solutions using commercial softwares based on finite element method.

To assess the compression resistance of the considered kind of columns the general AyrtonPerry approach is adopted. This approach dating from XIX century (Ayrton \& Perry 1886), after many modifications, was inserted into contemporary design provisions (EN 19931-1:2005) and used by many authors (Szalaj \& Papp 2010; Szalaj 2017; Giżejowski et al. 2019).

The stress criterion, in which the maximum stress was equated to the yield stress $f_{\mathrm{y}}$ in the most stressed section, was the condition from which the allowable compressive force was obtained. Similarly as in the Ayrton-Perry approach, the initial bow imperfection has been taken into account with the amplitude corresponding to the fabrication quality class. The effect of the eccentricity amplification, typical for slender compressed members, was taken into account as well. The stress condition has been checked in every section $\mathrm{x}$ along the 


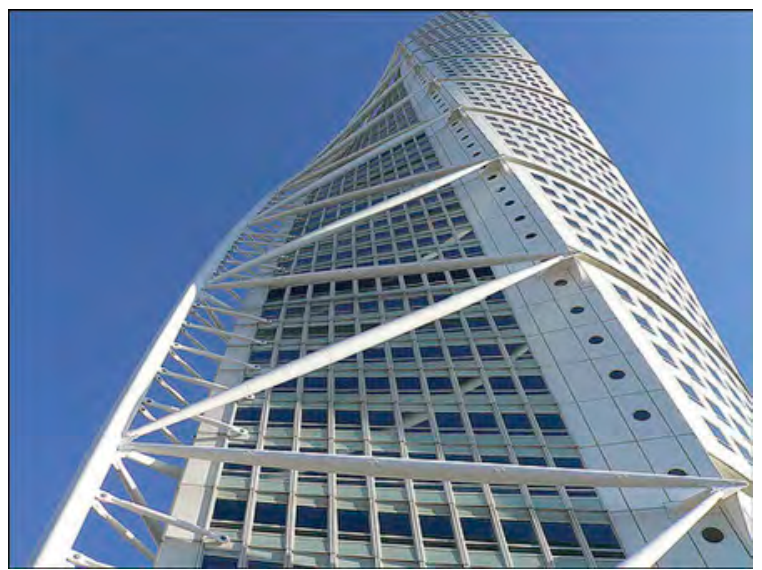

Figure 1. Santiago Calatrava's „Turning Torso” in Malmö.

column axis because, due to the column cross-section variability, it was not possible to predict in advance in which cross-section the stress condition will be decisive.

Only specific class of geometries of bulged column was considered in the paper. The effectiveness of the proposed designing procedure was illustrated on examples. They confirm the effectiveness of the proposed approach.

In authors' opinion the presented procedure can be used by engineers designing steel, bulged columns of the shape considered in the paper.

\section{DERIVATION OF FORMULAE FOR THE CRITICAL FORCE}

Due to the fact that columns of variable cross-sections are subject of interest in this work, the critical force can be established only in an approximate way using the energetic criterion of stability (Timoshenko \& Gere 1961). According to this criterion the critical force for pin ended column can be obtained from the formula:

$$
P_{k r}=E \cdot \int_{0}^{L} w^{\prime 2} d x / \int_{0}^{L} \frac{w^{2}}{J(x)} d x
$$

in which $w(\mathrm{x})$ is expected buckling form adopting here the shape of $1 / 2$ wave of sine function with the amplitude $A_{0}$ (Figure 2). In the equation (1) $J(\mathrm{x})$ is the moment of inertia of the cross section and $E$ is the Young's modulus. The moment of inertia $J(\mathrm{x})$ is defined in the following way (Figure 3):

$$
J(x)=\frac{\pi}{4}\left[r(x)^{4}-(r(x)-t)^{4}\right]
$$

in which $r(\mathrm{x})$ is the external radius of variable cross section defined as follows:

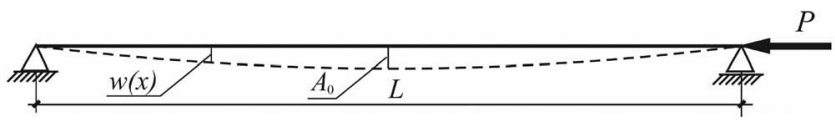

Figure 2. Buckling mode of the pin ended compressed bar. 
a)

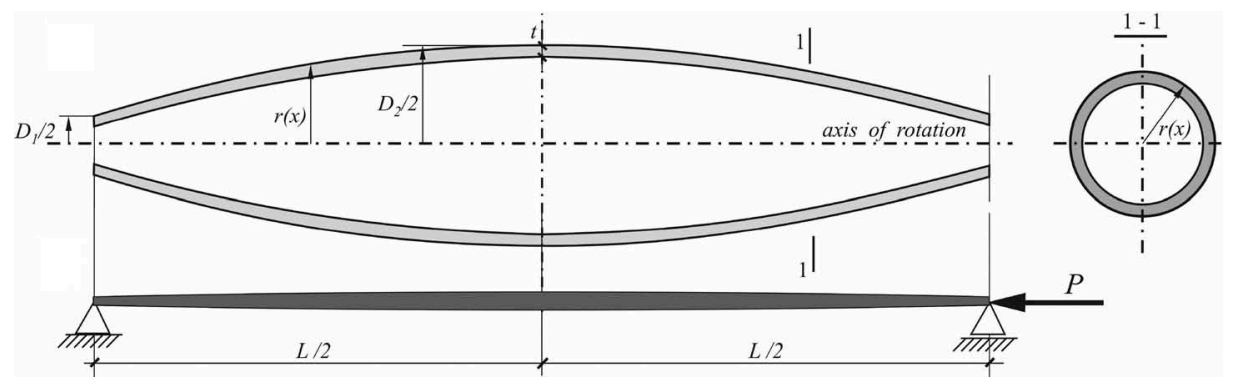

Figure 3. Sections of the rod a) (scale not preserved) and static scheme of the compressed bar b).

Table 1. Derived formulae on critical forces $P_{k r} /\left(E \cdot L^{2}\right)$.

\begin{tabular}{llll}
\hline $\mathrm{D}_{2} / \mathrm{L}$ & $\mathrm{t} / \mathrm{L}=1 / 1000$ & $\mathrm{t} / \mathrm{L}=2 / 1000$ & $\mathrm{t} / \mathrm{L}=3 / 1000$ \\
\hline $4 / 200$ & $5.20843 \cdot 10^{-7}$ & $3.10434 \cdot 10^{-7}$ & $2.46778 \cdot 10^{-7}$ \\
$5 / 200$ & $2.85456 \cdot 10^{-7}$ & $1.65675 \cdot 10^{-7}$ & $1.28347 \cdot 10^{-7}$ \\
$6 / 200$ & $1.75025 \cdot 10^{-7}$ & $9.97776 \cdot 10^{-6}$ & $7.59508 \cdot 10^{-6}$ \\
$7 / 200$ & $1.15857 \cdot 10^{-7}$ & $6.51976 \cdot 10^{-6}$ & $4.89997 \cdot 10^{-6}$ \\
$8 / 200$ & $8.10812 \cdot 10^{-6}$ & $4.51815 \cdot 10^{-6}$ & $3.36286 \cdot 10^{-6}$ \\
\hline
\end{tabular}

$$
r(x)=\frac{D_{1}}{2}+\left(\frac{D_{2}}{2}-\frac{D_{1}}{2}\right) \sin \frac{\pi x}{L} .
$$

Further considerations presented in this work were limited to some specific geometry defined uniquely by the column's length $L$. It was assumed that the external diameter of the terminal cross section is constant and equal $D_{1}=1 / 100 \mathrm{~L}$. External diameters of the middle cross sections of considered bars adopt the following values $D_{2} / \mathrm{L}=4 / 200,5 / 200$, $6 / 200,7 / 200,8 / 200$. The wall thickness $t$ is constant and adopts the following values: $t / L=1 / 1000,2 / 1000,3 / 1000$. These particular geometrical parameters were used in further considerations.

Formulae expressing the critical forces for particular geometries of columns are presented in Table 1. They were obtained from eqn. (1) by means of derivations carried out in Mathematica $^{\text {TM }}$ system (Wolfram 1988).

\section{NUMERICAL VERIFICATION OF DERIVED FORMULAE ON CRITICAL FORCES}

The correctness of derived formulae were verified numerically by means of commercial software based on finite element method. Three different programs were used and two different models were created. The beam model was prepared in Autodesk ${ }^{\circledR}$ Robot $^{\mathrm{TM}}$ Structural Analysis Professional system (RSA 2016), the shell model was created in COSMOS/M system (COSMOS/M 2002) while the 3D model was prepared in Simulia Abaqus system (Abaqus 2020).

In the performed comparative analysis the following data were adopted: $L=1000 \mathrm{~mm}, D_{1}=L /$ $100=10 \mathrm{~mm}, E=210000 \mathrm{MPa}$. Results are presented in Table 2.

Results presented in Table 2 confirm quite good correspondence between results obtained by means of derived formulae (labelled as Analytical) and results obtained numerically for the beam model (ROBOT), for the shell model (COSMOS/M) and for the 3D model (ABAQUS). 
Table 2. Critical forces in $[\mathrm{kN}]$ obtained for the column of length $L=1000 \mathrm{~mm}$.

\begin{tabular}{lllllll}
\hline $\mathrm{t}[\mathrm{mm}]$ & Calculation & $\mathrm{D}_{2}=20 \mathrm{~mm}$ & $\mathrm{D}_{2}=25 \mathrm{~mm}$ & $\mathrm{D}_{2}=30 \mathrm{~mm}$ & $\mathrm{D}_{2}=35 \mathrm{~mm}$ & $\mathrm{D}_{2}=40 \mathrm{~mm}$ \\
\hline 1 & Analytical & 4.032 & 7.357 & 11.998 & 18.126 & 25.900 \\
1 & ROBOT & 4.139 & 7.564 & 12.301 & 18.470 & 26.418 \\
1 & COSMOS & 4.096 & 7.561 & 12.300 & 18.469 & 26.162 \\
1 & ABAQUS & 4.158 & 7.561 & 12.373 & 18.584 & 26.364 \\
\hline 2 & Analytical & 6.765 & 12.675 & 21.047 & 32.210 & 46.479 \\
2 & ROBOT & 6.896 & 12.955 & 21.441 & 32.581 & 47.155 \\
2 & COSMOS & 6.822 & 12.946 & 21.438 & 32.581 & 46.549 \\
2 & ABAQUS & 6.946 & 13.032 & 21.678 & 32.931 & 47.095 \\
\hline 3 & Analytical & 8.510 & 16.362 & 27.649 & 42.857 & 62.447 \\
3 & ROBOT & 8.538 & 16.506 & 27.816 & 42.780 & 62.936 \\
3 & COSMOS & 8.438 & 16.488 & 27.808 & 42.780 & 61.639 \\
3 & ABAQUS & 8.748 & 16.819 & 28.424 & 43.647 & 62.897 \\
\hline
\end{tabular}

\section{RESISTANCE OF THE COMPRESSED COLUMN}

The resistance of the considered rod will be assessed on the basis of classical Ayrton-Perry's approach. Let us assume that the rod has an initial bow imperfection with amplitude $e_{0}$ (Figure 4) in a form of the one half-wave sine function defined as follows:

$$
e(x)=e_{0} \sin \frac{\pi x}{L}
$$

The total deflection $u_{c}(x)$ can be obtained from the formula (cf. Timoshenko \& Gere 1961):

$$
u_{c}(x)=f_{c} \sin \frac{\pi x}{L}, f_{c}=\frac{e_{0}}{1-\frac{P}{P_{k r}}}
$$

where $f_{c}$ - total eccentricity at middle section of the rod, $P_{k r}$ - critical buckling force.

The maximum longitudinal stresses at arbitrary cross section defined by $x$ can be calculated from the formula:

$$
\sigma_{\max }=\frac{P}{A(x)}+\frac{P f_{c}}{W(x)} \sin \frac{\pi x}{L} \leq f_{y}
$$

in which:

$$
A(x)=\pi\left[r(x)^{2}-(r(x)-t)^{2}\right]=\pi\left[2 r(x) t-t^{2}\right], W(x)=\frac{J(x)}{r(x)},
$$

are the cross sectional area and the elastic section modulus respectively, the $f_{\mathrm{y}}$ is the yield stress.

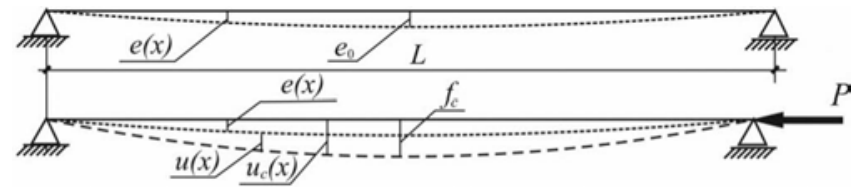

Figure. 4. Deflections of the initially curved rod. 
Using (5) and taking the equality in (6) we obtain:

$$
\frac{P}{A(x)}+\frac{P}{W(x)} e_{0} \frac{P_{k r}}{P_{k r}-P} \sin \frac{\pi x}{L}=f_{y}
$$

To convert the equation (8) to the form known from EN1993-1-1 (2005) let us introduce the notations:

$$
P(x)=\chi(x) \cdot A(x) \cdot f_{y}, \hat{\lambda}(x)=\sqrt{\frac{f_{y} A(x)}{P_{k r}}},
$$

where: $\chi(\mathrm{x})$ is the buckling reduction factor, $\hat{\lambda}(x)$ is the dimensionless measure of the slenderness, both dependent on $\mathrm{x}$ in this particular case.

Substituting (9) to eqn. (8) and introducing the quantity $\Phi(\mathrm{x})$ defined as follows:

$$
\Phi(x)=\frac{1}{2}\left[1+\frac{A(x)}{W(x)} e_{0} \sin \frac{\pi x}{L}+\hat{\lambda}^{2}(x)\right]
$$

one obtains the following equation:

$$
\chi^{2}(x) \cdot \hat{\lambda}^{2}(x)-\chi(x) \cdot 2 \Phi(x)+1=0
$$

from which the searched reduction factor $\chi(\mathrm{x})$ is obtained in the form:

$$
\chi(x)=\frac{\Phi(x)-\sqrt{\Phi^{2}(x)-\hat{\lambda}^{2}(x)}}{\hat{\lambda}^{2}(x)}=\frac{1}{\Phi(x)+\sqrt{\Phi^{2}(x)-\hat{\lambda}^{2}(x)}},
$$

which is consistent with the formula (6.49) from EN 1993-1-1 (2005) valid for columns of constant cross-section.

The column's resistance $P_{\text {ult }}$ is determined by the smallest value of the expression:

$$
P_{u l t}(x)=\chi(x) \cdot A(x) \cdot f_{y} .
$$

The value of ultimate force defined by formulae (13) could be too high in some circumstances. For save design procedures the additional partial coefficient $\gamma=1.2$ is proposed and the final formula for design value of column's resistance is as follows:

$$
P_{R d}(x)=\frac{1}{\gamma} \cdot \chi(x) \cdot A(x) \cdot f_{y}
$$

The whole procedure can be easily inserted in spreadsheet for the every $x$ from the interval $0<x<L / 2$, and in this way the smallest value of $P_{R d}$ can be found.

The initial bow amplitude $e_{0}$ required in this procedure can be adopted according to the code recommendations. Following provisions inserted in eurocodes specifying tolerances, dimensions and sectional properties of steel structural elements the $e_{0}$ can be adopted as $L / 750$ and this value guaranteeing the conservative assessment of columns resistance was adopted in examples presented in the next section. 


\section{EXAMPLES}

As the first example of the application of presented procedure let us consider the bulged, steel bar of length $L=1000 \mathrm{~mm}, D_{1}=L / 100=10 \mathrm{~mm}, D_{2}=2 L / 100=20 \mathrm{~mm}, t=L / 1000=1 \mathrm{~mm}$ and $e_{0}=L / 750=1.333 \mathrm{~mm}$. Material parameters: $E=210 \mathrm{GPa}$, the yield stress $f_{\mathrm{y}}=355 \mathrm{MPa}$.

The critical force is calculated by means of the formula (Table 1) is $P_{k r}=4.032 \mathrm{kN}$. Using the spreadsheet the sequence of $P_{\text {ult }}$ were calculated from the formula (13) for $x=0$ to 500 $(L / 2)$ with step $5 \mathrm{~mm}$. The smallest value of the compression force $P_{\text {ult,min }}=3.766 \mathrm{kN}$ and this value was obtained for $x=220 \mathrm{~mm}$. The column's design resistance calculated from the formula (14) is equal $P_{\mathrm{Rd}}=3.138 \mathrm{kN}$ and it is the searched measure of the bar's compression resistance.

The same example was solved numerically by means of Abaqus system. Two kind of modelling were adopted in numerical simulations which were carried out and namely the shell model (63126 DOF) and the 3D (solid) model (94695 DOF). Using these models for $1 / 4$ of the column (the column had two planes of symmetry) the geometrically and materially nonlinear analysis with imperfections (GMNIA) was performed. The uniformly distributed load was applied at the columns end. The bilinear material model for steel was adopted. Equilibrium paths obtained by two models were nearly identical (less than $2 \%$ ) which confirms the correctness of the simulation performed.

The $\sigma_{x}=355 \mathrm{MPa}$ appeared at section $x=237.5 \mathrm{~mm}$ (comp. Figure 5) when the load attained value $P=3.874 \mathrm{kN}$. It is the value $2.5 \%$ higher than the result obtained with the analytical method. The maximum load on the equilibrium path was equal $P_{\max }=3.883 \mathrm{kN}$. The design value of column's resistance was equal $3.874 / 1.2=3.23 \mathrm{kN}$ and this level was shown in Figure 5.

As the other example let us consider the column of following parameters: $D_{2}=4 \mathrm{~L} /$ $100=40 \mathrm{~mm}, t=3 L / 1000=3 \mathrm{~mm}$. Other geometrical and material parameters were the same.

The critical force is calculated by means of the formula (Table 1) is $P_{k r}=62.447 \mathrm{kN}$. In this case the $P_{u l t \text { min }}=23.421 \mathrm{kN}$ and this value was obtained for $x=0 \mathrm{~mm}$ (column's end). The column's design resistance calculated from the formula (14) is equal $P_{R d}$ $=19.52 \mathrm{kN}$. The counterpart of this value obtained numerically was equal $18.51 \mathrm{kN}$.

In both examples the column's design resistances obtained analytically were conservative.

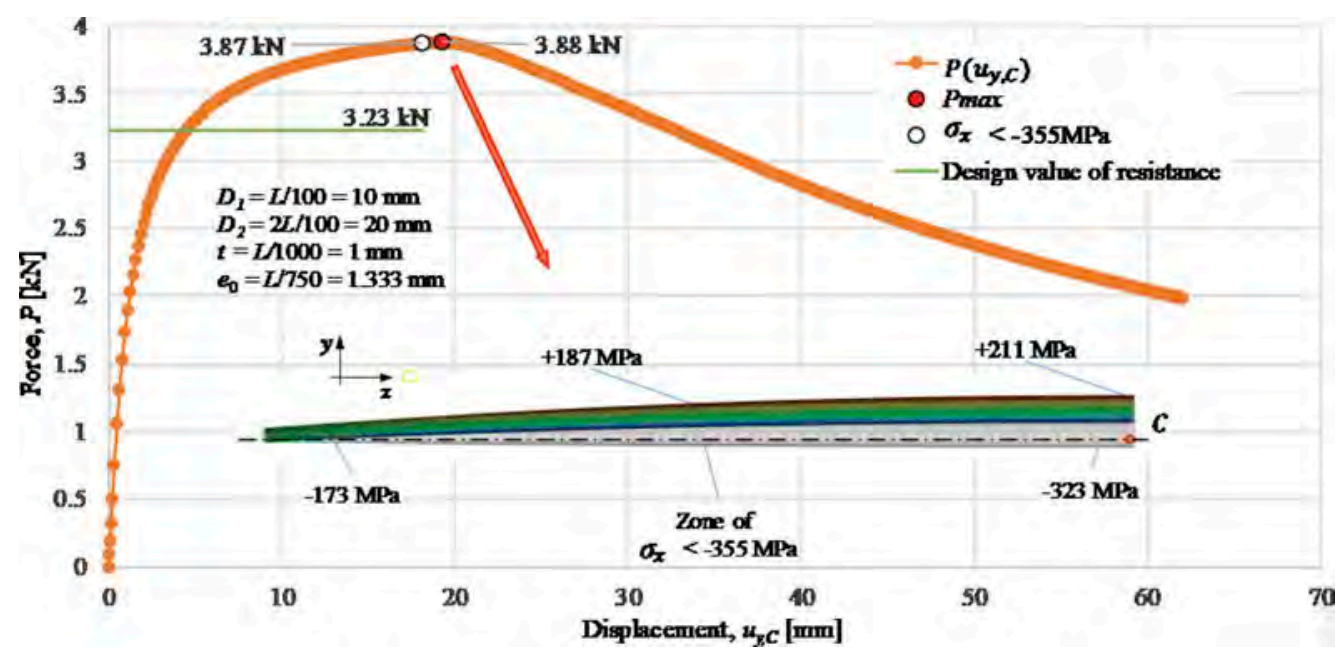

Figure 5. Nonlinear equilibrium path obtained in numerical simulation. 


\section{RECAPITULATION AND CONCLUSIONS}

Existing design regulations do not contain provisions for design of steel, compressed members of structures when they are non-prismatic. Authors have presented the procedure which allows determining the critical force for non-prismatic rods of specific geometry. Knowing the critical force one can assess the compression resistance of the rod under consideration using the other, based on Ayrton-Perry approach, procedure details of which were presented in the paper. Due to the fact that the cross section is variable, the stress criterion which follows from AyrtonPerry condition should be checked not only in middle section of the bar but also in all remaining cross-sections. This stage of the procedure can be accomplished easily by means of the spreadsheet in which formulae presented in this paper should be inserted for arbitrary value of the axial coordinate $x$ of the rod. The smallest value of compression force obtained as the result of the presented procedure is the measure of compression resistance of the considered rod.

Examples presented in the paper confirm that the proposed procedure is relatively easy, effective and correct what was proved in geometrically and materially nonlinear numerical simulations presented in the paper. This design procedure can be recommended for civil engineers designing steel, structural members of the particular shape considered by authors. The design value of compressive force obtained as a final result of the procedure can be treated as a compressive resistance of analysed columns. The presented proposal effectively fills the gap existing in the design recommendations.

\section{REFERENCES}

Abaqus Documentation. 2020 - Massachusetts Institute Of Technology. Available online: https://abaqusdocs.mit.edu/2017/English/SIMACAEMATRefMap/simaexc-c-docproc.htm (accessed on 3.03.2020)

Ayrton, W.E. \& Perry, J. 1886. On struts, The Engineer 62: 464 465.

COSMOS/M. 2002. Finite Element Analysis System, Version 2.9, Structural Research and Analysis Corporation, Electronic Manual, Los Angeles, California.

EN 1993-1-1:2005, Eurocode 3: Design of steel structures - Part 1-1: General rules and rules for buildings, CEN, Brussels 2005.

Elishakoff, I. \& Rollot, O. 1999. New closed-form solutions for buckling of a variable stiffness column by mathematica, Journal of Sound and Vibration 224 (1): 172-82.

Giżejowski, M. A. \& Stachura, Z. \& Szczerba, R. B. \& Gajewski M. D. 2019. Buckling resistance of steel H-section beam-columns: In-plane buckling resistance, Journal of Constructional Steel Research 157 (June): 347-358.

Li, Q.S. \& Cao, H. \& Li, G. 1995. Stability analysis of bars with varying cross-section, International Journal of Solids and Structures, 32 (21): 3217-3228.

Li, Q.S. 2001. Exact solutions for buckling of non-uniform columns under axial concentrated and distributed loading, European Journal of Mechanics - A/Solids 20 (3): 485-500.

Marcinowski, J. 2015. Maximum elastic buckling resistance of columns of constant volume. XIV Stability of structures XIV-th Symposium, 08-12 June 2015, Zakopane.

Marcinowski, J. \& Sadowski, M. Using the ERFI Function in the Problem of the Shape Optimization of the Compressed Rod, International Journal of Automotive and Mechanical Engineering 25 (2): 75-87. DOI: 10.2478/ijame-2020-0021.

Autodesk Robot Structural Analysis Professional 2016. User's manual.

Szalai, J. \& Papp, F. 2010. On the theoretical background of the generalization of Ayrton-Perry type resistance formulas, Journal of Constructional Steel Research 66 (5) May: 670-679.

Szalai, J. 2017. Complete generalization of the Ayrton-Perry formula for beam-column buckling problems, Engineering Structures 153 (15) December: 205-223.

Timoshenko, S. \& Gere, J. 1961. Theory of elastic stability. New York: McGraw-Hill.

Thompson, P. \& Papadopoulou, G. \& Vassiliou, E. 2007. The origins of entasis: illusion, aesthetics or engineering?, Spatial Vision 20 (6):531-543.

Wolfram, S. 1988. Mathematica ${ }^{\mathrm{TM}}$, A system for Doing Mathematics by Computer.: Addison-Wesley Publishing Company, Inc. 


\title{
The elastic local buckling behaviour and strength of the simply supported I-beam utilising the energy equilibrium method
}

\author{
S.M. Fujak, Y. Kimura \& A. Suzuki \\ Department of Architecture and Building Science, Tohoku University, Sendai, Miyagi, Japan
}

\begin{abstract}
One of the phenomena influencing the capacity of the structure, or the ultimate state, is local buckling of the frame's members. This article presents the analyses of the most common setup, the simply supported beam with an I-section, and proposes the equations to estimate the local buckling strength of such beam. The derivation of the solution is based upon the principles of the theory of elastic stability, the shell stability, and the equilibrium of the work done by external forces and the plate's strain energy. Solutions are proposed for the segments of the beam, depending on the geometrical properties of those, and are later connected into equations considering the coupled interactions between the web and flanges. Finally, the equation allowing for the precise estimation of the strength of the whole beam is proposed.
\end{abstract}

\section{INTRODUCTION}

\subsection{Previous research}

Local buckling is one of the common forms of the stability loss occurring within the section, without the lateral displacement or twist of the whole beam. Local buckling has a significant influence on the behaviour of the whole structure, drastically reducing the frame's capacity or leading to global loss of stability i.e. the collapse of the structure (Fujak \& Kimura 2019).

Full understanding of the local buckling phenomenon allows the engineer to correctly approximate the ultimate state of the structure, securing the linear behaviour in the elastic stage and nonlinear behaviour influenced only by the material properties in the plastic stage. Moreover, it allows for the correct classification of the section and determination if the members can stand the yielding load (sections class 1-3, see Eurocode 1993-1-1 (2005)), or are endangered by the local stability loss in the elastic work range (class 4). Additionally, the correct method of the analyses may be determined by the members elastic buckling strength. $\alpha_{c r}$ is the value of the elastic critical buckling load for the global instability mode based on initial elastic stiffness, $F_{c r}$, divided by the design loading on the structure, $F_{E d}$. Eurocode 1993-1-1 (2005) allows for the use of the first-order analysis only when $\alpha_{c r}$ is higher than 10 for the elastic analyses and 15 for plastic analyses. Therefore, understanding of the elastic buckling strength of the members is crucial to correctly calculate the capacities of the structure.

Previous research on local bucking capacity is based upon the Euler-Bernoulli beam theory and Kirchhoff-Love plate theory. Timoshenko \& Gere (1961) proposed the solutions for plates with simple boundary conditions and certain aspect ratios. With limited access to solving tools however, not all the solutions were given, and the effects of the flange-web interactions were not analysed. Roberts \& Jhita (1983) analysed the problem of the elastic buckling of the I-beam focusing mostly on the strength of the flange. Bradford \& Hancock (1984) described the method to consider the uneven stress distribution in wide-flange sections in the post-buckling stage.

Most of the recent research work is related to the problem of elastoplastic bucking. Ikarashi (2003) proposed the method of estimating the elastic buckling capacity of the whole beam

DOI: $10.1201 / 9781003132134-53$ 
based on the buckling capacity of the web. However, this research was conducted to explain the plastic behaviour of the beam, so the precision of results in the elastic stage is moderate. Later works (Ikarashi et al. 2011, Kimura et al. 2019) proposed the indexes for the beam classification with respect to both length of the beam and loading applied to the element. These researches, however, focus on the capacity of the elements in the plastic stage.

To overcome the previously mentioned limitations research on the elastic buckling capacity of the simply supported beams is necessary. The aim of this study is:

- To investigate the strength of the plates (web, flanges) - segments building up the simply supported beam depending on their aspect ratios, with the effects of interaction between the segments considered.

- To propose simplified equations allowing for the estimation of local buckling capacity of the simply-supported beam.

\subsection{Research proposal}

The research presented analyses the elastic buckling strength of simply supported I-beams. Two types of commonly used loading are used - point load (hereinafter PL) and uniformly distributed load (UDL). The beam is as presented in Figure 1. Figure 1a presents the beam loaded with PL and the resultant stresses in the segments of the beam - the web and the flange. In the same manner, Figure $1 \mathrm{~b}$ presents the loading and stress distribution in the beam loaded with UDL. Segments presented have simplified boundary conditions (BC) - either pinned or fixed. In reality, $\mathrm{BC}$ of the separate segments are semi-stiff, as the stiffness of the web influences the rotation of the flange and vice-versa. Note that the beams are ended with stiff diaphragm, which control node has certain degrees of freedom blocked $\left(\delta_{x}, \delta_{y}, \delta_{z}, \varphi_{x}, \varphi_{z}\right.$ in case of the left-hand side end and $\delta_{y}, \delta_{z}, \varphi_{x}, \varphi_{z}$ in case of the right-hand side end). The stresses and deformations of the beam/plates are symmetric about the vertical axis of the beam. $x, y, z$ are axes, $L$ stands for the half of the length of the beam/plate, $P_{i}$ for the PL in the $i$ direction, $q_{i}$ for the UDL in the $i$ direction, $M_{i}$ for the bending moment around the $i$ axis $\delta_{i}$ for the deflection in the $i$ direction, $\varphi_{i}$ for the rotation around the $i$ axis, $\sigma_{i}(j, k)$ for the axial

a)

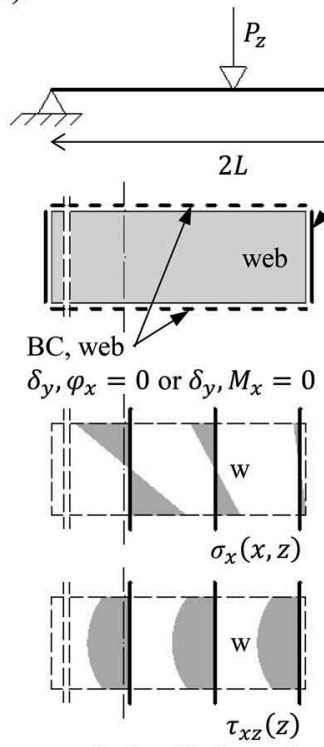

(web with flanges)
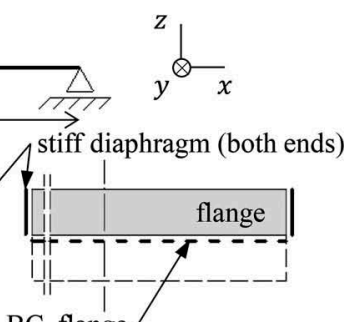

$\mathrm{BC}$, flange
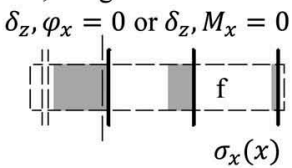

$\left(\tau_{x z} \cong 0\right)$

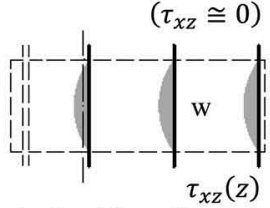

(web without flanges) b)

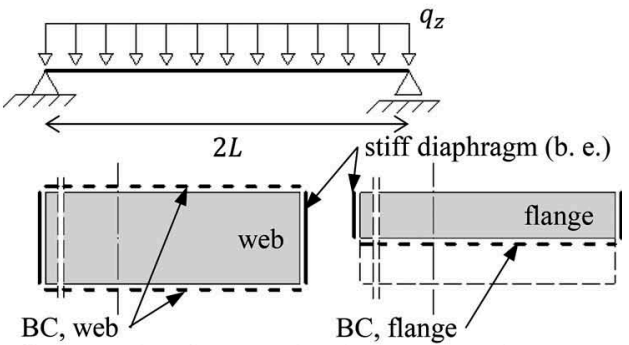

$\delta_{y}, \varphi_{x}=0$ or $\delta_{y}, M_{x}=0$

$\delta_{z}, \varphi_{x}=0$ or $\delta_{z}, M_{x}=0$
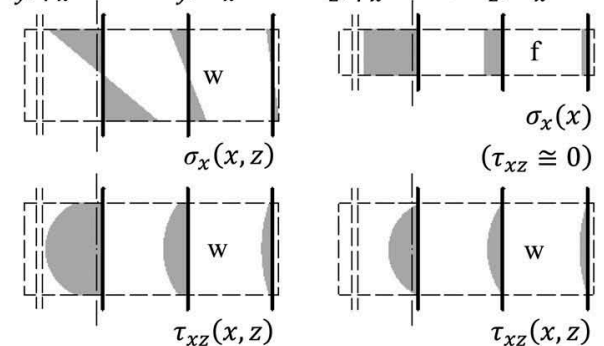

(web with flanges) $\left(\tau_{x z} \cong 0\right)$

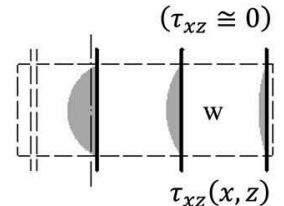

(web without flanges)

Figure 1. Simply supported beam - analysed BCs, loads and stresses. a) Simply supported beam loaded with PL, b) Simply supported beam loaded with UDL. 


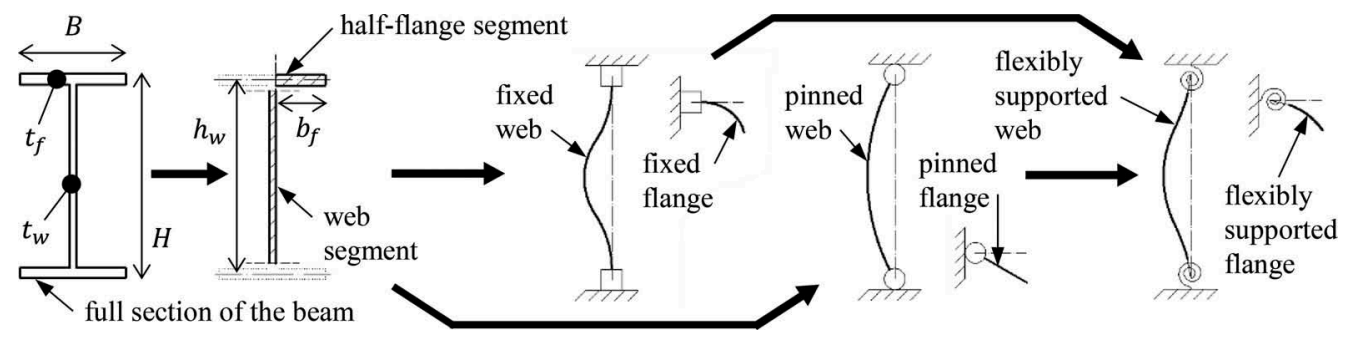

Figure 2. Beam's section and segments' BC.

stress in the $i$ direction as a function of $j$ and $k$ coordinates and $\tau_{i, j}(k, l)$ for the shear stress in the $i, j$ plane).

In order to analyse the section, it is crucial to understand the local behaviour of its segments. Therefore, the beam is first separated into segments, web and flanges, with simplified BC (Figure 2). The analyses of the detailed BC of web/flange influence is addressed in section 4.

As the flange is symmetrical about the vertical axis, it can be assumed to be built of two identical half-flanges. Note that $B$ stands for the beam width, $H$ for the height, $b_{f}$ for the halfflange width, $h_{w}$ for the web height, $t_{f}$ for the flange thickness and $t_{w}$ for the web thickness.

The proposed research is based on the energy equilibrium between the work done by external forces and the strain energy of the plate, see (1-4) (Timoshenko \& Gere 1961).

$$
\begin{gathered}
\Delta T=\Delta U \\
\Delta T=-\frac{1}{2} \iint\left[N_{x}\left(\frac{\partial w}{\partial x}\right)^{2}+N_{y}\left(\frac{\partial w}{\partial y}\right)^{2}+2 N_{x y} \frac{\partial w}{\partial x} \frac{\partial w}{\partial y}\right] d x d y \\
\Delta U=\frac{D}{2} \iint\left\{\left(\frac{\partial^{2} w}{\partial x^{2}}+\frac{\partial^{2} w}{\partial y^{2}}\right)^{2}-2(1-v)\left[\frac{\partial^{2} w}{\partial x^{2}} \frac{\partial^{2} w}{\partial y^{2}}-\left(\frac{\partial^{2} w}{\partial x \partial y}\right)^{2}\right]\right\} d x d y \\
D=E t^{3} /\left[12\left(1-\nu^{2}\right)\right]
\end{gathered}
$$

where $\Delta T$ stands for the work done by external forces, $\Delta U$ for the plate's strain energy, $N_{x}$ for the plate force in $x$ direction, $N_{y}$ for the plate force in $y$ direction, $N_{x y}$ for the shear force, $w(x, y)$ for the deformation of the plate in local $z$ direction, $\nu$ for the Poisson's ratio of the material, $E$ for the Young modulus of the material and $t$ for the thickness of the analysed plate.

\section{THE ELASTIC LOCAL BUCKLING OF SIMPLY SUPPORTED BEAM'S FLANGE}

The models of flange used were of the following parameters: $L$ of $600,1000,1500$ and $2000 \mathrm{~mm}, b_{f}$ of 25,50 and $100 \mathrm{~mm}, t_{f}$ of 2 and $7 \mathrm{~mm}$ for $b_{f}$ of 25 and $100 \mathrm{~mm}, t_{f}$ of 2, 2.5, 3, $3.5,4,5,6,7,8$ and $10 \mathrm{~mm}$ for $b_{f}$ of $50 \mathrm{~mm}$.

The solution for the fixed flange is based on the shape of buckling mode as given in (5), $\delta_{z}=\varphi_{x}=0$ along the long edge (Figure 1). The solution depends on values of the $m$ and $n$ parameters, related to the plate's aspect ratio $L / b_{f}$ and loading conditions - either PL or UDL. The shape of the eigenform is checked against the finite element analyses (hereinafter: FEA) output.

$$
w(x, y)=(x / L)^{m} \sin (n \pi x / L) \sin (\pi x / L)^{2}\left(y / b_{f}\right)^{2}
$$




$$
\begin{array}{ll}
\sigma_{c r, f f i x}=E t_{f}^{2}\left[\alpha_{1} L^{4}+\alpha_{2} L^{2} b_{f}{ }^{2}(1-1.5 \nu)+\alpha_{3} b_{f}^{4}\right] /\left[100000 L^{2} b_{f}^{4}\left(1-\nu^{2}\right)\right] \\
\alpha_{1, \mathrm{PL}}=50000\left(b_{f} / L\right)^{2} & \alpha_{1, \mathrm{UDL}}=30000\left(b_{f} / L\right)^{2} \\
\alpha_{2, \mathrm{PL}}=65000+500000\left(b_{f} / L\right) & \alpha_{2, \mathrm{UDL}}=65000+500000\left(b_{f} / L\right) \\
\alpha_{3, \mathrm{PL}}=600000+17500\left(L / b_{f}\right)^{2} & \alpha_{3, \mathrm{UDL}}=700000+25000\left(L / b_{f}\right)^{2}
\end{array}
$$

For all the solutions, despite of the plate's aspect ratio, the final solution takes form of (6), where $\sigma_{c r, f f i x}$ stands for the elastic buckling stress of the plate. The value of parameters $\alpha_{1}, \alpha_{2}$ and $\alpha_{3}$ depends on the parameters described above. The values received from closed form $(\mathrm{CF})$ solutions of (6) are presented in Figure 3 with markers. Plots of proposed (7-9) are given as well using dotted and dashed lines.

In (6), parameters $\alpha_{1}$ and $\alpha_{2}$ are used as the multipliers of the $L^{4}$ and $L^{2} b_{f}^{2}$, respectively. As the length of the plate is used, parameters are convergent to the certain value. In case of $\alpha_{1}$, the parameter can be treated as constant when $L / b_{f}$ is over 30 , in case of $\alpha_{2}$ (less dependent on $L$ ), the parameter stabilises with $L / b_{f}$ over 50 . This is not the case for $\alpha_{3}$, which is a multiplier for the $b_{f}{ }^{4}$. For the estimation of the equation the least squares method was used, with the additional restriction that $\alpha_{1}, \alpha_{2}$ and $\alpha_{3}$ must always be positive.

The identical procedure is implemented for the pinned flange model. Varying assumptions and results are given below in (10-13). Note that $\sigma_{c r, f, p i n}$ stands for the elastic buckling stress of the plate. Results from FEA models of plates can be replicate by proposed (12 and 13).

$$
\begin{gathered}
w(x, y)=(x / L)^{m} \sin (\pi x / L)^{2}\left(y / b_{f}\right) \\
\sigma_{c r, f, p i n}=E t_{f}^{2}\left[\alpha_{4} L^{2}(1-\nu)+\alpha_{5} b_{f}^{2}\right] /\left[100 L^{2} b_{f}^{2}\left(1-\nu^{2}\right)\right] \\
\alpha_{4, \mathrm{PL}}=110\left(b_{f} / L\right)^{0.2} \quad \alpha_{4, \mathrm{UDL}}=100\left(b_{f} / L\right)^{0.2} \\
\alpha_{5, P L}=6500\left(b_{f} / L\right)^{0.8} \quad \alpha_{5, U D L}=7500\left(b_{f} / L\right)^{0.8}
\end{gathered}
$$

a)

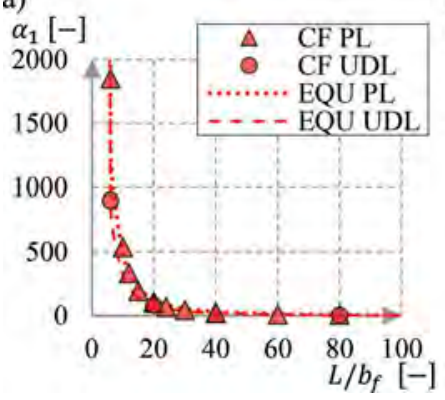

b)

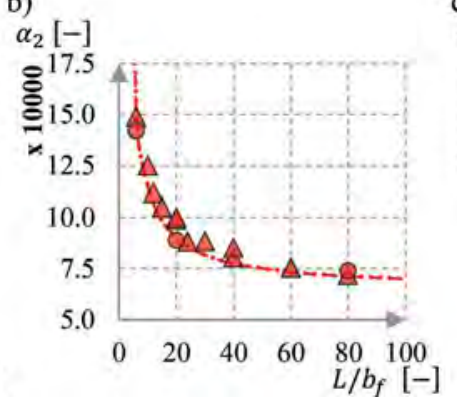

c)

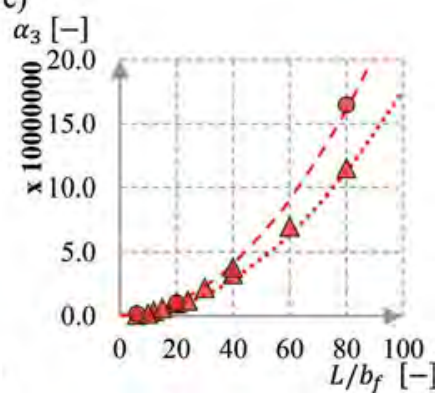

Figure 3. Equation parameters $\alpha_{1}, \alpha_{2}$, and $\alpha_{3}$ against $L / b_{f}$ ratio. a) $\alpha_{1}$ parameter, b) $\alpha_{2}$ parameter, c) $\alpha_{3}$ parameter. 


\section{THE ELASTIC LOCAL BUCKLING OF SIMPLY SUPPORTED BEAM'S WEB}

The models of web used were of the following parameters: $L$ of $600,1000,1500$ and $2000 \mathrm{~mm}$, $h_{w}$ of 100,200 and $400 \mathrm{~mm}, t_{w}$ of 2.2 and $5.2 \mathrm{~mm}$ for $h_{w}$ of 100 and $400 \mathrm{~mm}, t_{w}$ of 2.2, 2.7, 3.2, 3.7, 4.2, 4.7 and $5.2 \mathrm{~mm}$ for $h_{w}$ of $50 \mathrm{~mm}$. For all the models the $A_{f}$ was varying between 0 , $50,100,200,250,300,400,500,1000,2000,4000,5000,7500$ and $10000 \mathrm{~mm}^{2}$.

The influence of the flange onto the behaviour of the web is not limited to BC only. For the significant flange area $A_{f}$ the additional shear stress caused by tension/compression pair of forces in flanges influences the critical buckling strength of the web.

The method proposed is similar to the one presented in preceding section. The following solution does not consider the influence of additional stress caused by tension/compression in flanges. $\sigma_{c r, w, f i x, n s}$ stands for the elastic strength of the fixed web with shear flow disregarded.

$$
\begin{aligned}
& w(x, z)=(x / L)^{m} \sin (n \pi x / L) \sin (\pi x / L)^{2}\left(z^{2} / b_{f}\right) \sin \left(\pi z / b_{f}\right)^{2} \\
& \sigma_{c r, w, f i x, n s}=E t_{w}{ }^{2}\left(\beta_{1} L^{4}+\beta_{2} L^{2} h_{w}{ }^{2}+\beta_{3} h_{w}{ }^{4}\right) /\left[1000 L^{2} h_{w}{ }^{4}\left(1-\nu^{2}\right)\right] \\
& \beta_{1, \mathrm{PL}}=13500\left(h_{w} / L\right)^{2} \beta_{1, \mathrm{UDL}}=9500\left(h_{w} / L\right)^{2} \\
& \beta_{2, \mathrm{PL}}=10000+25000\left(h_{w} / L\right)^{2} \beta_{2, \mathrm{UDL}}=9000+22500\left(h_{w} / L\right)^{2} \\
& \beta_{3, \mathrm{PL}}=37500+9500\left(L / h_{w}\right)^{2} \beta_{3, \mathrm{UDL}}=23500+6000\left(L / h_{w}\right)^{2}
\end{aligned}
$$

The solution for the pinned web takes a similar form to the solution for the fixed web. Analyses of the elastic buckling strength of models with various BC and loading conditions lead to proposal of the reduction factor, $\chi$, which can be applied to the Equation (15) in order to obtain the elastic buckling strength of the pinned web. Equations (19-21) propose the $\chi$ factor and the resultant $\sigma_{c r, w, p i n, n s}$, critical elastic strength of the pinned web with shear flow disregarded.

$$
\begin{gathered}
\chi_{\mathrm{PL}}=1.55+0.08\left(L / h_{w}\right)^{0.3}-550\left(t_{w} / h_{w}\right)^{3} \\
\chi_{\mathrm{UDL}}=2.65-0.10\left(L / h_{w}\right)^{0.3}-1250\left(t_{w} / h_{w}\right)^{3} \\
\sigma_{c r, w, p i n, n s}=\sigma_{c r, w, f i x, n s} / \chi
\end{gathered}
$$

The consideration of the shear flow is based upon the assumption that the buckling mode can be either a bending buckling, coupled buckling or a shear buckling. In case of web with no shear flow the bending buckling takes place, changing to different forms as the $A_{f}$ rises. (22) shows the relation between the maximal bending and shear stress in the web with no shear flow, $\vartheta_{n s}$. Similarly, $\vartheta$ is a bending stress to shear stress relation with shear flow considered (23). The shear flow reduction factor $\psi$ is proposed based upon the limitation of bending stress (in the form of upper limitation of 1) and balance between shear stress and shear flow dictated by aspect ratio dependent parameters $\alpha_{\psi}$ and $\beta_{\psi}$, see (24-26). (27) shall be used for determination of the buckling strength of the web for both PL and UDL loading scenarios.

$$
\begin{array}{cc}
\vartheta_{n s, \mathrm{PL}}=h_{w} /(4 L) & \vartheta_{n s, \mathrm{UDL}}=h_{w} /(2 L) \\
\vartheta_{\mathrm{PL}}=\left(A_{f} / t_{w}+h_{w} / 4\right) / L & \vartheta_{\mathrm{UDL}}=\left(2 A_{f} / t_{w}+h_{w} / 2\right) / L \\
\psi=\min \left(1 ;\left[\alpha_{\psi}+\beta_{\psi}\left(\vartheta / \vartheta_{n s}\right)\right]\right)
\end{array}
$$




$$
\begin{gathered}
\psi_{\mathrm{PL}}=\min \left(1 ;\left\langle 0.7 \sqrt{h_{w} / L}+0.7\left(L / h_{w}\right)\left\{h_{w} /\left[4\left(A_{f} / t_{w}+h_{w} / 4\right)\right]\right\}\right\rangle\right) \\
\psi_{\mathrm{UDL}}=\min \left(1 ;\left\langle 0.7 \sqrt{h_{w} / L}+0.7\left(L / h_{w}\right)\left\{h_{w} /\left[2\left(A_{f} / t_{w}+h_{w} / 2\right)\right]\right\}\right\rangle\right) \\
\sigma_{c r, w, f i x}=\sigma_{c r, w, f i x, n s} * \psi \quad \sigma_{c r, w, p i n}=\sigma_{c r, w, p i n, n s} * \psi
\end{gathered}
$$

Results from FEA (markers) and proposed equations (lines) are shown in Figure 4 for the 1000/200/2.2 PL series.

\section{THE ELASTIC LOCAL BUCKLING CAPACITY OF SIMPLY SUPPORTED BEAM}

The procedure of strength approximation of semi-fixed plate (see Figure 2) is as given. The plate is assumed to be restrained along long edges with a rotational spring. Flange models are restrained with a spring of $K_{w}$ - stiffness corresponding to web stiffness per unit length whilst web models are restrained with $K_{f}(28)$. Based on the relation between the stiffnesses of plate and the restraint, the fixity factors for flange and web $\left(\gamma_{f}\right.$ and $\left.\gamma_{w}\right)$ are proposed (29 and 30). As $\gamma$ varies between 0.0 and 1.0, the buckling mode of the segment varies between the pinned and fixed eigenform. The segment's capacity is as in (31).

Final equation (32) estimates the buckling capacity of the whole beam. The results of (31) are compared and the lower-bound value is assumed as the buckling strength of the whole beam. Figure 5 presents the comparison of (31 and 32) against results of FEA. Models of the

a)

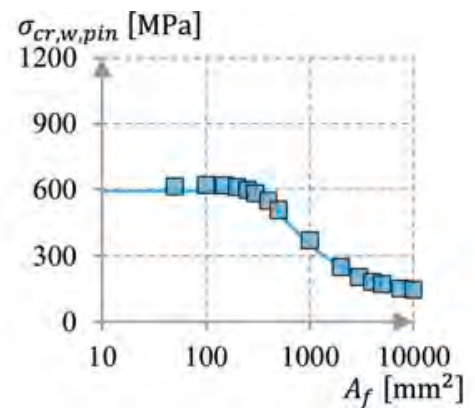

b)

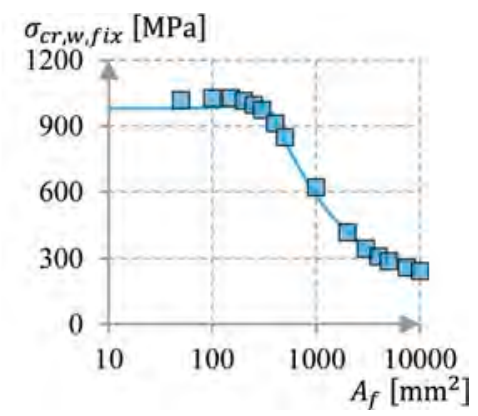

Figure 4. The strength reduction due to the shear flow effects. a) pinned web, b) fixed web.

a)

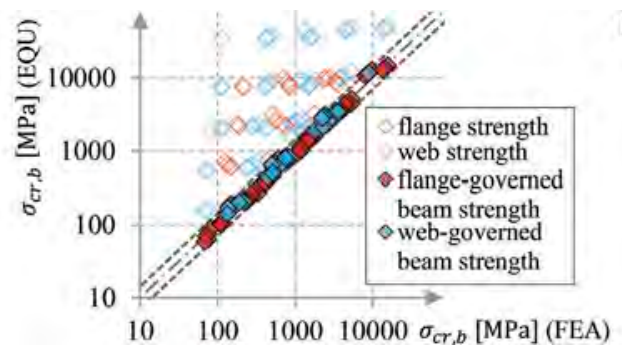

b)

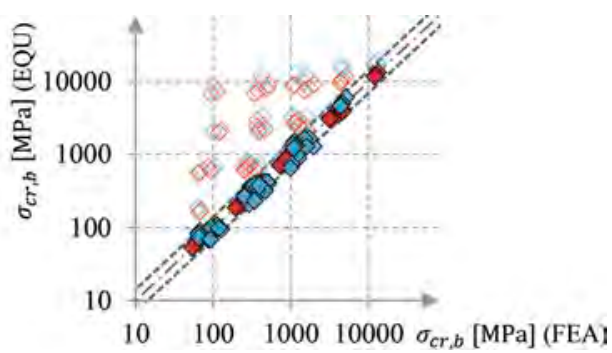

Figure 5. Comparison of results from proposed equations (EQU) and numerical analyses (FEA). a) PL: $\sigma_{c r}$ of the flange, web and beam (EQU) against $\sigma_{c r}$ of the beam (FEA), b) UDL: $\sigma_{c r}$ of the flange, web and beam (EQU) against $\sigma_{c r}$ of the beam (FEA). 
beams were built of segments having the same dimensions as in sections 2 and 3 . All models were consisting of S4R5 elements (12 for each flange, 22 for web, 180 length-wise) of certain thickness representing beam segments made of elastic material, with the $\mathrm{BC}$ and loads as shown in Figure 1. The FEA software used for the analyses was SOFiSTiK, with a crosscheck using Abaqus.

$$
\begin{gathered}
K_{w}=E t_{w}{ }^{3} /\left(2 h_{w}\right) K_{f}=E t_{f}{ }^{3} /\left(6 b_{f}\right) \\
\gamma_{f}=0<1.15 * \arctan \left\{1.75 *\left[-0.25-\log \left(K_{f} / K_{w}\right)\right]\right\} / \pi+0.5<1 \\
\gamma_{w}=0<1.15 * \arctan \left\{1.75 *\left[-0.25+\log \left(K_{f} / K_{w}\right)\right]\right\} / \pi+0.5<1 \\
\sigma_{c r, i}=\sigma_{c r, i, p i n}+\left(\sigma_{c r, i, f i x}-\sigma_{c r, i, p i n}\right) * \gamma_{i} \text { for } i \in(f ; w) \\
\sigma_{c r, b}=\min \left(\sigma_{c r, f} ; \sigma_{c r, w}\right)
\end{gathered}
$$

\section{SUMMARY}

This research is aimed to explain the elastic buckling behaviour of simply supported beam by fulfilling 2 targets: investigate the strength of the segments of the beam considering in-between interactions and to propose equation estimating the local buckling capacity of the whole beam.

It can be stated, that equations based upon the energy equilibrium are feasible for the estimation of the elastic bucking capacity of the simple plates building up the beam. It was proven that, by utilising equations for the estimation of the effects of the web-flange interactions, it is possible to approximate the elastic local buckling capacity of the beam with satisfying precision.

\section{ACKNOWLEDGMENTS}

This work was supported by the JST Program on Open Innovation Platform with Enterprises, Research Institute and Academia.

\section{REFERENCES}

Bradford, M.A., Hancock, G.J. 1984. Elastic Interactions of Local and Lateral Buckling in Beams, ThinWalled Structures, Applied Science Publishers Ltd, 2 (1983), pp. 1-25.

European Commission 2005. EN 1993-1-1 (2005) (English): Eurocode 3: Design of steel structures - Part 1-1: General rules and rules for buildings. European Committee for Standardization.

Fujak, S.M., Kimura, Y. 2019. A Comparison of The Capacity Evaluation Methods for Moment-Resistant Frames with Detailed Mid-Storey Pinned Connection as per Standards and Numerical Analyses with Respect to the Local Buckling of Members, 12th Pacific Structural Steel Conference, Tokyo, November 9-11, 2019.

Ikarashi, K. 2003. Buckling Strength of Simply Supported Web Plate Under the Action of Bending Shear Stress, Journal of Structural and Construction Engineering (Transactions of AIJ), Architectural Institute of Japan, 2003, Vol. 68, No. 565, pp. 135-141. (in Japanese)

Ikarashi, K., Suekuni, R., Shinohara, T., Wang, T. 2011. Evaluation of Plastic Deformation Capacity of H-shaped Steel Beams with Newly Proposed Limitation Value of Plate Slenderness, Journal of Structural and Construction Engineering (Transactions of AIJ), Architectural Institute of Japan, 2011, Vol. 76, No. 668, pp. 1865-1872. (in Japanese)

Kimura, Y., Suzuki, A., Kasai, K. 2019. Estimation of plastic deformation capacity for I-shaped beams with local buckling under compressive and tensile forces, Japan Architectural Review, 2019, 2:26-41.

Roberts, T.M., Jhita, P.S. 1983. Lateral, Local and Distortional Buckling of I-beams, Thin-Walled Structures, Applied Science Publishers Ltd, 1 (1983), pp. 289-308.

Timoshenko, S.P., Gere, J.M. 1961. Theory of Elastic Stability, Dover Publications Inc. 


\title{
Critical load of unbraced steel frames with classical and semi-rigid joints
}

\author{
P. Krystosik \\ Koszalin University of Technology, Koszalin, Poland
}

\begin{abstract}
The paper presents the stability issue of unbraced steel frames with special attention paid to the problem of determining the value of critical load in these frames.

The paper discusses ways of critical load determination in frames with the use of selected methods of stability analysis. The presented analysis procedures were used in calculations of certain steel frames.

The issue presented in the paper is important from the practical point of view, and therefore, it should be taken into account in the design process of such frames.
\end{abstract}

\section{INTRODUCTION}

Stability is one of the fundamental issues, which has to be taken into account in design of steel frames (Bródka et al. 2004, Chan et al. 1999, Chen et al. 1996, Pałkowski 2016). This issue is particularly important in the case of unbraced (sway) frames, especially in instance of unbraced frames with semi-rigid joints, which are known to be highly susceptible to stability loss.

During analyzing of unbraced frames stability, it is easy to see that the first (basic) buckling mode of the frame stands out first of all by horizontal displacements of the frame nodes. The sway-buckling mode is characteristic not only for the unbraced portal frames, but also in the case of multi-storey and multi-aisle frames, regardless of the location of the load acting on the individual frame nodes.

On the basis of performed analysis, the author of the work stated that the typical unbraced frame loses its stability under the influence of a certain, total load (a sum of loads acting on individual frame nodes), the value of which, approximately, is independent from the load distribution in nodes. This issue can be presented on a simple example of certain unbraced frame, which is loaded by the forces $P_{i}$ applied to the nodes (Figure 1).

The presented frame was subjected to the stability analysis (using the eigenvalues method of stiffness matrix), with taking into account 9 different load cases, which are listed in Table 1. Based on this analysis, the critical load multipliers $\lambda_{c r}$ and the total values of the critical nodal forces $P_{C R}$ were obtained for all cases (Table 1 ).

As it is easy to see, despite of the significant differences in the number and location of the forces $P_{i}$, the similar value of the total critical load $P_{C R}$ of the frame was obtained for each considered case. The largest disagreement appears between the case VII and IX and amounts to less than $10 \%$, while the differences in the results between other cases does not exceed $5 \%$.

The slight variations in the results between the presented load cases show that the resistance to the loss of stability of the frame largely depends on its lateral stiffness. This is evidenced by the way the analyzed frame loses its stability - for the all 9 cases, the bucking modes are characterized by horizontal displacements of the frame nodes. 


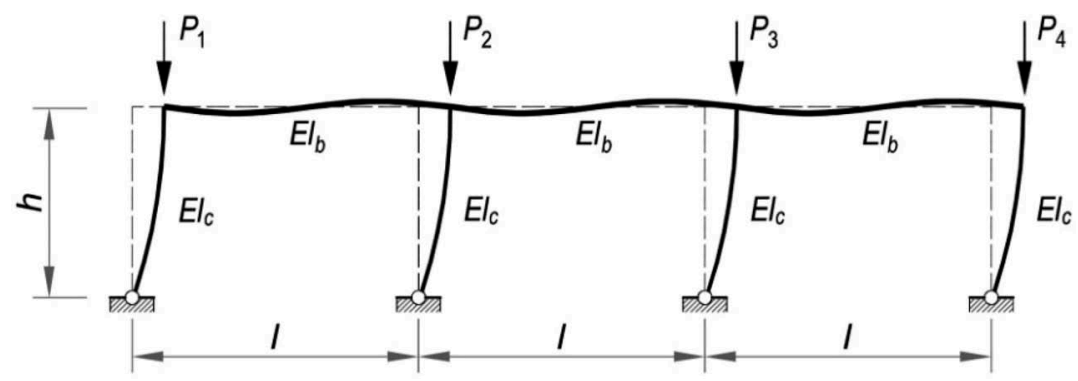

Figure 1. Analyzed frame.

Table 1. The list of load cases accepted for the analysis and the calculation results.

\begin{tabular}{|c|c|c|c|c|c|c|}
\hline & $\underline{P_{1}}$ & $P_{2}$ & $P_{3}$ & $P_{4}$ & $\underline{\lambda_{c r}}$ & $\underline{P_{C R}=\lambda_{c r} \Sigma P_{i}}$ \\
\hline Load case & {$[\mathrm{kN}]$} & {$[\mathrm{kN}]$} & {$[\mathrm{kN}]$} & {$[\mathrm{kN}]$} & & {$[\mathrm{kN}]$} \\
\hline II & 100 & 100 & 100 & 0 & 16.86 & 5058 \\
\hline III & 100 & 100 & 0 & 100 & 17.16 & 5147 \\
\hline IV & 100 & 100 & 0 & 0 & 25.25 & 5050 \\
\hline V & 0 & 100 & 100 & 0 & 24.59 & 4917 \\
\hline VI & 100 & 0 & 100 & 0 & 25.19 & 5037 \\
\hline VII & 100 & 0 & 0 & 100 & 25.92 & 5183 \\
\hline VIII & 100 & 0 & 0 & 0 & 49.36 & 4936 \\
\hline IX & 0 & 100 & 0 & 0 & 46.89 & 4689 \\
\hline
\end{tabular}

\section{THE APPROXIMATE METHOD OF DETERMINING THE CRITICAL LOAD OF UNBRACED FRAMES}

The frames property presented in the previous section, manifested by slight differences in the total $P_{C R}$ value of the frame for different load cases can be used in practical calculations of steel frames stability. For this purpose, the stability analysis, e.g., with the use of numerical methods, can be performed for the first (basic) load case, while calculations of the critical load multiplayer for the rest of load cases (or the load combinations) can be obtained according to the relation:

$$
\lambda_{c r}=\frac{\sum P_{c r i}}{\sum P_{i}}=\frac{P_{C R}}{\sum P_{i}}
$$

where: $P_{C R}$ is the total value of the critical load determined for the first load case (basic combination), while $\Sigma P_{i}$ is a sum of the loads assigned to the next considered load combination.

In the case, where the considered static scheme includes different types of loads (e.g., linear loads, surface loads, concentrated moments, etc.) the above condition can be replaced with the use of the equation:

$$
\lambda_{c r}=\frac{\sum N_{c r i}}{\sum N_{i}}=\frac{N_{C R}}{\sum N_{i}}
$$

where $\Sigma N_{c r . i}=N_{C R}$ refers to the combined value of the critical forces, which was determined for the basic load combination, whereas $\Sigma N_{i}$ determines the sum of the normal forces in columns, in currently considered combination. 
The critical load multiplier $\lambda_{c r}$ calculated in this way can be used for the approximate determination of a state of critical forces in loading cases or combinations, for which the results of static analysis are known.

\section{PARAMETRIC ANALYSIS}

In order to check the accuracy of the critical load determination with the use of the presented in section 2 the way, the parametric analysis of a four-aisle, four-storey frame presented in Figure 2 was performed, with taking into account 10 different load cases.

Data: $E I_{c}=15000 \mathrm{kNm}^{2}, E I_{b}=30000 \mathrm{kNm}^{2}, l=6 \mathrm{~m}, h=4 \mathrm{~m}, P_{i}=100 \mathrm{kN}$

First, the numerical analysis was performed in the SOFISTIK program (Sofistik, 2018) according to the eigenvalue method for all the load cases. Then, the critical load multipliers were determined according to the proposed in section 2 algorithm for 9 load cases (from II to $\mathrm{X}$ ), assuming the result of numerical calculations for the first case as the base value, with the use of which calculations according to formula (1) were performed. The results of the calculations are presented in Table 2.

On the basis of buckling analysis of the presented frame, it can be seen that the largest differences between the $P_{C R}$ values of the considered load cases do not exceed $10 \%$. These differences are not significant, if one takes into account the load distribution of the static scheme in the individual cases, both in terms of the forces number and the locations of their application.

Moreover, presented in Table 2 the results indicate that the simplified calculating method of the critical load multiplier proposed in the paper allows to estimate its value with accuracy of $10 \%$.

It is worth noting that the analyzed example does not present the load model with the permanent load occurring in the real structure (in the analyzed example of the frame, such load would occur in each node). Adoption of the permanent load in the analysis causes that the differences in the values of the total critical load $P_{C R}$ between the individual cases are much smaller. The results of such calculations of the frame for the two selected load cases are presented in Table 3.

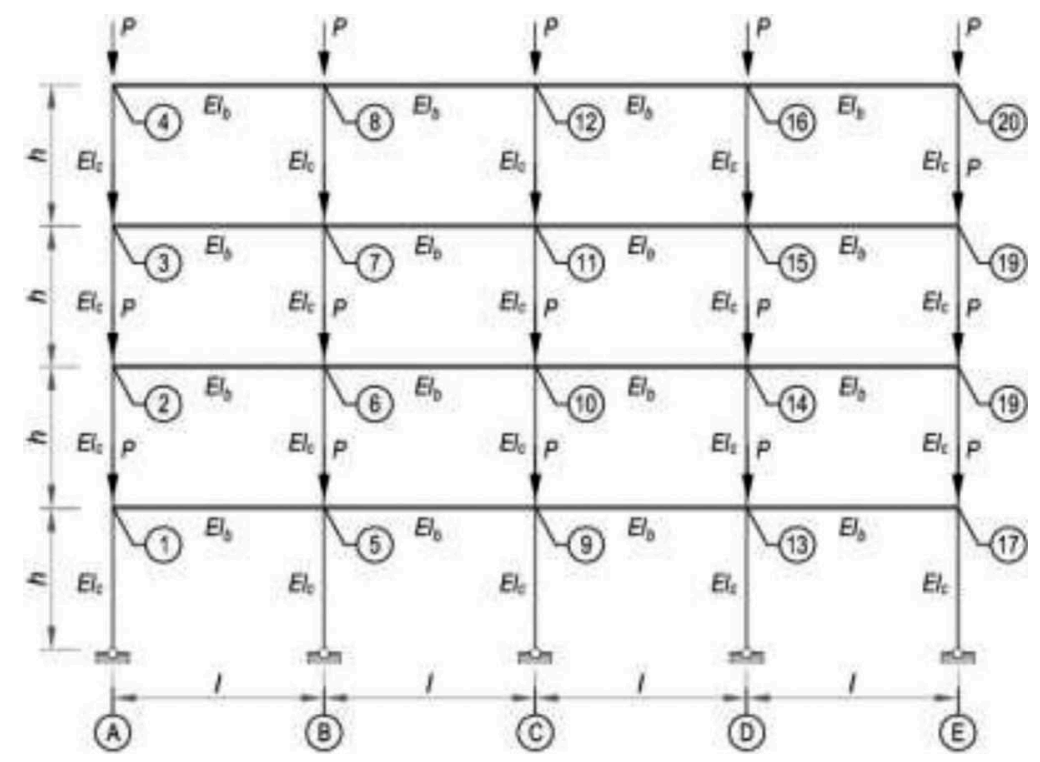

Figure 2. Analyzed four-aisle, four-storey frame. 
Table 2. The list of load cases accepted for the analysis and the calculation results.

\begin{tabular}{|c|c|c|c|c|c|c|c|c|}
\hline \multirow[b]{3}{*}{ Load case } & \multicolumn{5}{|c|}{ Scheme of nodal forces } & \multirow{3}{*}{$\begin{array}{l}\frac{\lambda_{c r} / P_{C R}}{/ P} \\
\text { num. calc. }\end{array}$} & \multirow{3}{*}{$\begin{array}{l}\lambda_{c r} \\
\text { eq. (1) }\end{array}$} & \multirow{3}{*}{$\begin{array}{l}\text { Difference } \\
\%\end{array}$} \\
\hline & \multicolumn{5}{|c|}{ node number),$P=100 \mathrm{kN}$} & & & \\
\hline & axis $\mathrm{A}$ & axis $\mathrm{B}$ & axis $\mathrm{C}$ & axis D & axis $\mathrm{E}$ & & & \\
\hline \multirow[t]{4}{*}{ I (basic) } & 4) $\mathrm{P}$ & ${ }^{8)} \mathrm{P}$ & 12) $\mathrm{P}$ & 16) $\mathrm{P}$ & ${ }^{20)} \mathrm{P}$ & \multirow[t]{4}{*}{$10.34 / 206.86$} & \multirow[t]{4}{*}{-} & \multirow[t]{4}{*}{-} \\
\hline & 3) $\mathrm{P}$ & 7) $\mathrm{P}$ & 11) $\mathrm{P}$ & 15) $\mathrm{P}$ & 19) $\mathrm{P}$ & & & \\
\hline & 2) $\mathrm{P}$ & 6) $\mathrm{P}$ & ${ }^{10)} \mathrm{P}$ & 14) $\mathrm{P}$ & 18) $\mathrm{P}$ & & & \\
\hline & 1) $\mathrm{P}$ & 5) $\mathrm{P}$ & 9) $\mathrm{P}$ & 13) $\mathrm{P}$ & 17) $\mathrm{P}$ & & & \\
\hline II & 4) $\mathrm{P}$ & ${ }^{8)} \mathrm{P}$ & ${ }^{12)} \mathrm{P}$ & 16) $\mathrm{P}$ & ${ }^{20)} \mathrm{P}$ & $41.22 / 206.10$ & 41.37 & 0.4 \\
\hline III & 2) $\mathrm{P}$ & ${ }^{6)} \mathrm{P}$ & ${ }^{10)} \mathrm{P}$ & 14) $\mathrm{P}$ & ${ }^{18)} \mathrm{P}$ & $41.23 / 206.15$ & 41.37 & 0.3 \\
\hline IV & ${ }^{1)} \mathrm{P}$ & ${ }^{5)} \mathrm{P}$ & ${ }^{9)} \mathrm{P}$ & ${ }^{13)} \mathrm{P}$ & ${ }^{17)} \mathrm{P}$ & $41.71 / 208.57$ & 41.37 & -0.8 \\
\hline \multirow[t]{4}{*}{ V } & 4) $\mathrm{P}$ & 8) - & ${ }^{12)} \mathrm{P}$ & 16) & ${ }^{20)} \mathrm{P}$ & \multirow[t]{4}{*}{$17.26 / 207.14$} & \multirow[t]{4}{*}{17.24} & \multirow[t]{4}{*}{0.1} \\
\hline & 3) $\mathrm{P}$ & 7) & 11) $\mathrm{P}$ & 15) & 19) $\mathrm{P}$ & & & \\
\hline & 2) $\mathrm{P}$ & 6) & 10) $\mathrm{P}$ & 14) & 18) $\mathrm{P}$ & & & \\
\hline & 1) $\mathrm{P}$ & 5) - & 9) $\mathrm{P}$ & 13) & 17) $\mathrm{P}$ & & & \\
\hline \multirow{4}{*}{ VI } & 4) _ & ${ }^{8)} \mathrm{P}$ & 12) & 16) $\mathrm{P}$ & 20) & \multirow{4}{*}{$25.00 / 200.00$} & \multirow{4}{*}{25.86} & \multirow{4}{*}{3.4} \\
\hline & 3) - & 7) $\mathrm{P}$ & 11) - & 15) $\mathrm{P}$ & 19) - & & & \\
\hline & 2) & 6) $\mathrm{P}$ & 10) & 14) $\mathrm{P}$ & 18) & & & \\
\hline & 1) & 5) $\mathrm{P}$ & 9) & 13) $\mathrm{P}$ & 17) & & & \\
\hline \multirow{4}{*}{ VII } & 4) $\mathrm{P}$ & 8) & 12) - & 16) & 20) - & \multirow{4}{*}{$47.84 / 191.36$} & \multirow{4}{*}{51.72} & \multirow[t]{4}{*}{8.1} \\
\hline & 3) $\mathrm{P}$ & 7) & 11) & 15) & 19) & & & \\
\hline & 2) $\mathrm{P}$ & 6) & 10) & 14) & 18) & & & \\
\hline & 1) $\mathrm{P}$ & 5) - & 9) & 13) - & 17) & & & \\
\hline \multirow{4}{*}{ VIII } & 4) - & ${ }^{8)} \mathrm{P}$ & 12) - & 16) & 20) & \multirow{4}{*}{$47.17 / 188.66$} & \multirow{4}{*}{51.72} & \multirow{4}{*}{9.6} \\
\hline & 3) & 7) $\mathrm{P}$ & 11) & 15) & 19) - & & & \\
\hline & 2) & 6) $\mathrm{P}$ & 10) & 14) & 18) & & & \\
\hline & 1) & 5) $\mathrm{P}$ & 9) & 13) & 17) & & & \\
\hline IX & 4) $\mathrm{P}$ & 8) & 12) - & 16) - & 20) - & $191.42 / 191.42$ & 206.86 & 8.1 \\
\hline $\mathrm{X}$ & 1) - & 5) & 9) - & 13) & ${ }^{17)} \mathrm{P}$ & $191.35 / 191.35$ & 206.86 & 8.1 \\
\hline
\end{tabular}

Table 3. The list of load cases accepted for the analysis and the calculation results.

\begin{tabular}{|c|c|c|c|c|c|c|c|c|}
\hline \multirow[t]{3}{*}{ Load case } & \multicolumn{5}{|c|}{ Scheme of nodal forces } & \multirow{3}{*}{$\begin{array}{l}\frac{\lambda_{c r} / P_{C R}}{I P} \\
\text { num. calc. }\end{array}$} & \multirow{3}{*}{$\begin{array}{l}\lambda_{c r} \\
\\
\text { eq. (1) }\end{array}$} & \multirow{3}{*}{$\begin{array}{l}\text { Difference } \\
\%\end{array}$} \\
\hline & \multicolumn{5}{|c|}{ node number),$P=100 \mathrm{kN}$} & & & \\
\hline & axis $\mathrm{A}$ & axis B & axis $\mathrm{C}$ & axis D & axis $\mathrm{E}$ & & & \\
\hline \multirow{4}{*}{ XI } & 4) $G$ & 8) $G+P$ & 12) $G$ & 16) $G$ & 20) $G$ & \multirow{4}{*}{$8.58 / 205.92-$} & \multirow{4}{*}{8.61} & \multirow{4}{*}{0.3} \\
\hline & 3) $G$ & 7) $G+P$ & 11) $G$ & 15) $G$ & 19) $G$ & & & \\
\hline & 2) $G$ & 6) $G+P$ & 10) $G$ & 14) $G$ & 18) $G$ & & & \\
\hline & 1) $G$ & 5) $G+P$ & 9) $G$ & ${ }^{13)} G$ & 17) $G$ & & & \\
\hline \multirow[t]{4}{*}{ XII } & 4) $G$ & 8) $G$ & ${ }^{12)} G$ & 16) $G$ & 20) $G$ & \multirow[t]{4}{*}{$9.86 / 207.14$} & \multirow[t]{4}{*}{9.85} & \multirow[t]{4}{*}{0.1} \\
\hline & 3) $G$ & 7) $G$ & 11) $G$ & 15) $G$ & 19) $G$ & & & \\
\hline & 2) $G$ & 6) $G$ & 10) $G$ & 14) $G$ & 18) $G$ & & & \\
\hline & 1) $G$ & 5) $G$ & 9) $G$ & 13) $G$ & 17) $G+P$ & & & \\
\hline
\end{tabular}

Comparing the load case I (Table 2) and the cases XI and XII (Table 3), it can be clearly seen that the differences in the $P_{C R}$ values are very small. Also, the estimation of the parameter $\lambda_{c r}$ using formula (1) is very accurate.

On the basis of the performed analysis, it can be assumed that for the sway frames, even with significantly different load cases, the total value of the critical load will be approximately constant in value, but characteristic for a given frame. 


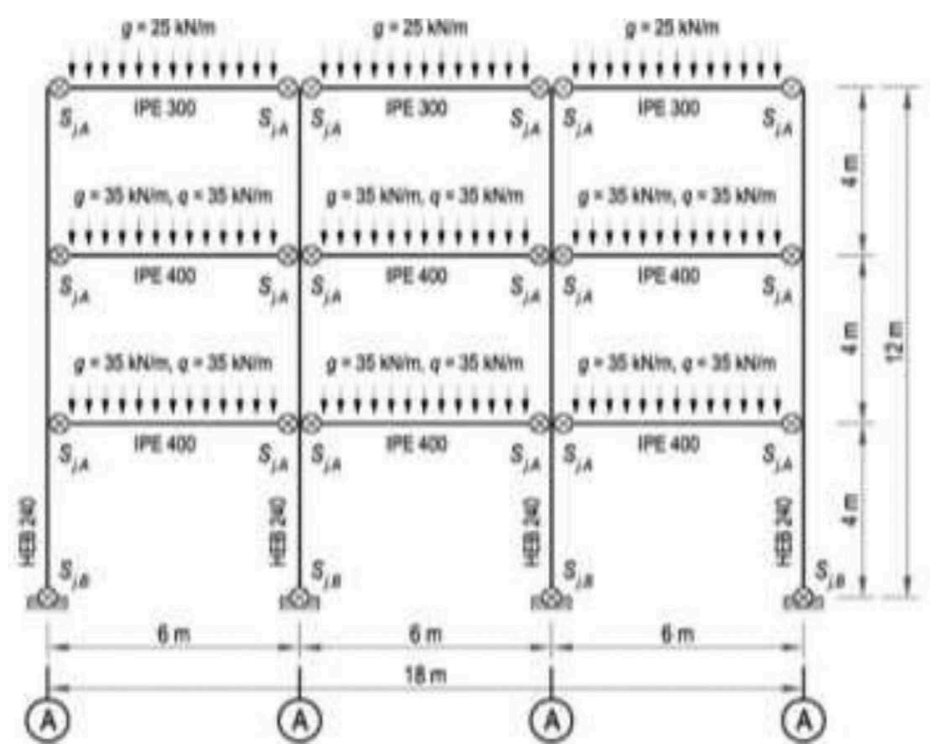

Figure 3. Analyzed frame with semi-rigid joints.

\section{NUMERICAL EXAMPLE OF A FRAME WITH SEMI-RIGID JOINTS}

The validity of the presented regularity in frames with semi-rigid joints was checked on an example of three-aisle, three-storey steel frame, shown in Figure 3.

The calculations were performed in the Sofistik program, according to the eigenvalues method for 10 load cases. Determination of the critical load multipliers was also performed according to the proposed in section 2 algorithm for 8 load cases (from II to IX), accepting the result of the numerical calculations for the I case as a basic value. The results of the preformed calculation were listed in Table 4.

Data: steel grade S355, steel modulus of elasticity $E=210 \mathrm{GPa}$.

It was assumed that two types of loads act on the load-bearing structure: $g$ - permanent load with the value of $25 \mathrm{kN} / \mathrm{m}$ and $35 \mathrm{kN} / \mathrm{m}$, and $q$ - variable load with the value of $35 \mathrm{kN} / \mathrm{m}$ (Figure 3).

On the basis of the static analysis and strength calculations of that frame, the elements cross-sections were selected. Then, based on recommendations of the standard (EN 1993$1-8,2005)$, the frame joints were designed in the form of single- and double-side end-plate bolted joints. The column bases in the form of anchored horizontal plates were also calculated.

Finally, in order to carry out the buckling analysis, the average stiffnesses of the internal joints (beam-to-column joints) equal $S_{j . A}=60 \times 10^{3} \mathrm{kNm} / \mathrm{rad}$, as well as the stiffnesses of the external joints (column bases) equal $S_{j . B}=15 \times 10^{3} \mathrm{kNm} / \mathrm{rad}$ was adopted in the model. Appropriate stability calculations were performed, as of the parametric analysis, in the SOFISTIK program (Sofistik, 2018), and also according to the algorithm presented in section 2 . The calculation results are presented in Table 4.

The obtained results clearly demonstrate that the total values of the critical loads $P_{C R}$, which were determined for the presented load cases reach very similar values. The largest differences between obtained values do not exceed $2 \%$.

Furthermore, the presented calculation results show very good agreement of the parameters $\lambda_{c r}$, which were calculated on the basis of numerical method and according to proposed in section 2 , simplified way of determining the critical load. 
Table 4. The list of load cases accepted for the analysis and the calculation results.

\begin{tabular}{|c|c|c|c|c|c|c|c|c|}
\hline \multirow[t]{3}{*}{ Load case } & \multicolumn{4}{|c|}{ Load $g=35, g=25, q=35$} & \multirow{2}{*}{$\frac{\lambda_{\mathrm{cr}}}{\mathrm{kN}}$} & $P_{C R}=\lambda_{c r} \Sigma\left(g_{i}+q_{i}\right) l_{i}$ & \multirow{3}{*}{$\begin{array}{l}\lambda_{\mathrm{cr}} \\
\text { eq. (1) }\end{array}$} & \multirow[t]{2}{*}{ Difference } \\
\hline & \multicolumn{4}{|l|}{$\mathrm{kN} / \mathrm{m}$} & & & & \\
\hline & storey & aisle I & aisle II & aisle III & numer & analysis & & $\%$ \\
\hline \multirow[t]{3}{*}{ I (basic) } & 3 & $g$ & $g$ & $g$ & 14.56 & $24.9 \times 10^{3} \mathrm{kN}$ & - & - \\
\hline & 2 & $g$ & $g$ & $g$ & & & & \\
\hline & 1 & $g$ & $g$ & $g$ & & & & \\
\hline \multirow[t]{3}{*}{ II } & 3 & $g$ & $g$ & $g$ & 10.82 & $25.3 \times 10^{3} \mathrm{kN}$ & 10.64 & -1.7 \\
\hline & 2 & $g$ & $g$ & $g$ & & & & \\
\hline & 1 & $g+q$ & $g+q$ & $g+q$ & & & & \\
\hline \multirow[t]{3}{*}{ III } & 3 & $g$ & $g$ & $g$ & 10.52 & $24.6 \times 10^{3} \mathrm{kN}$ & 10.64 & 1.1 \\
\hline & 2 & $g+q$ & $g+q$ & $g+q$ & & & & \\
\hline & 1 & $g$ & $g$ & $g$ & & & & \\
\hline \multirow[t]{3}{*}{ IV } & 3 & $g$ & $g$ & $g$ & 8.44 & $25.1 \times 10^{3} \mathrm{kN}$ & 8.38 & -0.7 \\
\hline & 2 & $g+q$ & $g+q$ & $g+q$ & & & & \\
\hline & 1 & $g+q$ & $g+q$ & $g+q$ & & & & \\
\hline \multirow[t]{3}{*}{ V } & 3 & $g$ & $g$ & $g$ & 11.70 & $24.9 \times 10^{3} \mathrm{kN}$ & 11.69 & -0.1 \\
\hline & 2 & $g$ & $g+q$ & $g$ & & & & \\
\hline & 1 & $g$ & $g+q$ & $g$ & & & & \\
\hline \multirow[t]{3}{*}{ VI } & 3 & $g$ & $g$ & $g$ & 11.73 & $25.0 \times 10^{3} \mathrm{kN}$ & 11.69 & -0.3 \\
\hline & 2 & $g+q$ & $g$ & $g$ & & & & \\
\hline & 1 & $g+q$ & $g$ & $g$ & & & & \\
\hline \multirow[t]{3}{*}{ VII } & 3 & $g$ & $g$ & $g$ & 9.80 & $25.0 \times 10^{3} \mathrm{kN}$ & 9.77 & -0.3 \\
\hline & 2 & $g+q$ & $g+q$ & $g$ & & & & \\
\hline & 1 & $g+q$ & $g+q$ & $g$ & & & & \\
\hline
\end{tabular}

\section{SUMMARY AND FINAL REMARKS}

The paper presents the issue of critical load determination of the unbraced steel frames. On the basis of the stability analysis, it was noticed that structures of this type generally loses their stability under the influence of certain, total value of load, which essentially is independent from the assumed load scheme. The occurrence of this regularity was confirmed on the example of the single-storey, multi-aisle frame.

On the basis of the noticed property of unbraced frames, in the section 2 of the work, the algorithm of approximate determination of the critical load value was proposed. The practical way of calculating and the accuracy of the results obtained according to this algorithm is shown on the example of the four-aisle, four-storey frame.

A detailed stability analysis on the example of the real steel frame with the internal and external semi-rigid joints was also performed.

The results comparisons of the presented in the paper examples, which were obtained with the use of the software and the equation (1) prove, that the proposed in the paper algorithm of the critical load determination is very useful in practical calculations of unbraced frames.

Although the above-presented conclusions refer directly to the examples presented in the paper, it should be assumed that they are more of general nature and relate mostly to the unbraced frames used in practice.

\section{REFERENCES}

Bródka J., Barszcz A., Giżejowski M., \& Kozłowski A. 2004. Stiffness and strength of sway frames with semi-rigid joints” (in Polish), Rzeszów: Publishing House of Rzeszów University of Technology. 
Chan S. L., \& Chui P. P. 1999. Non-linear static and cyclic analisys of steel frames with semi-rigid connections. Amsterdam: Elsevier, 1999.

Chen W. F., Goto Y., \& Liew J. Y. 1996. Stability design of semi-rigid frames”, New York: John Wiley and Sons.

EN 1993-1-8 Eurocode 3: Design of steel structures - Part 1-8: Design of joints, 2005.

Pałkowski Sz. 2016. Stability basis of steel member structures" (in Polish), Koszalin: Publishing House of Koszalin University of Technology.

Sofistik. 2018. Finite Element Software. http://www.sofistik.com. 


\title{
Lateral torsional buckling of tapered steel I-beams with stiffener ribs
}

\author{
J. Kuś \& T. Maleska \\ Faculty of Construction and Architecture, Opole University of Technology, Opole, Poland
}

\begin{abstract}
A procedure for calculating the critical buckling moment of a web-tapered I-beam with stiffener ribs is proposed, using potential energy calculations using the RayleighRitz method. The solution identifies the critical moments where lateral buckling begins in simply supported, web-tapered steel I-beams with ribs. In particular, lateral-torsional buckling is considered in beams with tapered web, and with various numbers of stiffener ribs. Detailed, numerical, parametric analyses are carried out. Uniformly distributed design loads are considered across three cases: applied to the top flange, to the shear center, and to the bottom flange. A parametric analysis, of a tapered beam with ribs, demonstrates that tapering of both the web and stiffener ribs influences the critical moments more than tapering only the web.
\end{abstract}

\section{INTRODUCTION}

Tapered steel beams, with varying web heights or flange widths, are widely used in the construction of industrial halls. Varying the cross-section can gives significant economic benefits by optimizing materials use to match the uneven distribution of internal forces. Most often, the bending moments reach their maxima only locally along the length of the element; therefore, the cross-section can be reduced in places with lower bending moments. Such optimization reduces steel consumption, and hence reduces the overall costs.

Protection against the torsional buckling of elements with changing cross-sections has a significant impact on their load-bearing capacity. If a bar is insufficiently protected against lateral-torsional buckling, the general instability may reduce its load capacity.

Determining the critical load that initiates overall stability loss in beams with linearly varying web or flange sections is a current concern, due to the increasing use of these elements. Analytical solutions for the critical moments of tapered beams can be found in Andrade et al. (2007), Asgarian et al. (2012), Benyamina et al. (2013), (Kuś 2015), Hakan Ozbasaran, Tolga Yilmaz (2018). Recently, experimental results for lateral-torsional buckling of steel members were presented by Tankova et al. (2018).

The above-cited work is limited to the analysis of unbraced beams. Adding vertical stiffening ribs to beams with slender webs, however, greatly influences both the ultimate loadbearing capacity and the resistance to torsional buckling. This issue for prismatic beams was presented in Lindener (1996), where the influence of endplates at beam ends was analyzed for several load cases. The effect of box-type ribs on the critical LTB load when a single-beam is loaded by the end moments are presented in Chambers et al. (1977). Gosowski $(2003,2007)$ made a broad assessment of how both the ribs and box ribs affect on the critical loading of free-supported beams with bi and monosymmetric cross-sections, loaded with pure bending and concentrated forces.

This article provides a solution for the elastic critical torsional buckling of an unbraced beam with a tapered web, supported by a fork, with a continuous, evenly distributed load 
a)

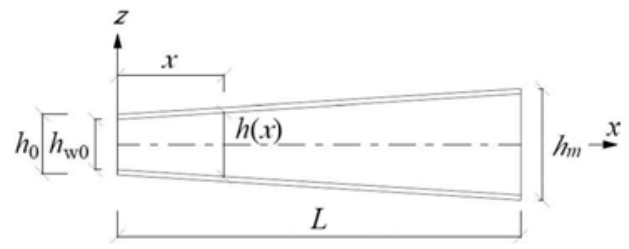

b)

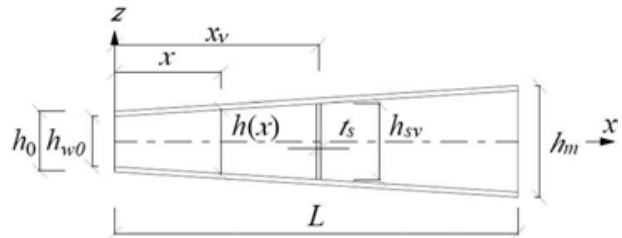

Figure 1. Tapered cross-section.

applied to the upper or lower flange, as well as to the shear center. Additionally, critical forces were calculated for a beam with the same geometric parameters, but with vertical ribs added for stiffening. The stiffening ribs were located along the length of the beam in different configurations. The Rayleigh-Ritz method was used to determine critical loads. In addition, a numerical example is given to illustrate the method, characterizing how the beam's crosssectional tapering affects the critical moments, as well as how the vertical stiffening ribs affect the critical load.

\subsection{Geometric characteristics of the cross-section of the beam with tapered cross-section}

The geometrical features of a beam with a linearly varying cross-section depend on the toe parameters determining their shape along the beam length. The taper parameter $\alpha_{T P}$, defined in equation (1) below, describes the change in web height, and also the change in the height of ribs along the beam length. For the tapered beam shown in Figure 1, the key geometrical characteristics can all be expressed as functions of the taper parameter:

$$
\alpha_{T P}=\frac{h_{m}-h_{0}}{h_{0}}
$$

Where $x$ and $z$ are beam coordinates, $h_{0}$ is height at the beginning of the beam, $h_{m}$ is height at the end of the beam, $t_{s}$ is the width of stiffening rib, $h_{s v}$ is the height of stiffening rib. Detailed geometrical features of the tapered cross-section can be found in paper (Kuś 2013).

\section{POTENTIAL ENERGY OF THE TAPERED CROSS-SECTION BEAM}

The potential energy for an I-beam with linearly variable cross-section (Figure 2), loaded with transverse forces on its length, is presented (Kuś 2013, 2015):

In Figure 2 and in the discussion below, $u, v, w$ are the displacement components of the shear center in the $x, y$ and $z$ directions, and $\theta$ is the twist angle.

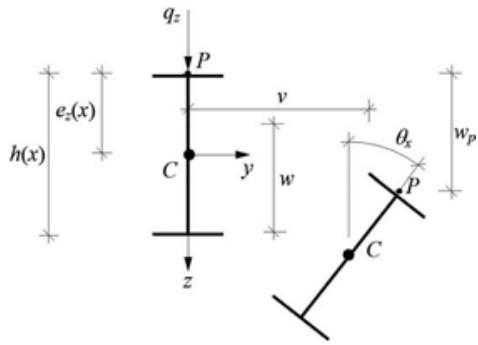

Figure 2. I-Section under lateral-torsional buckling. 


$$
\begin{aligned}
& \Pi_{L T B}= \\
& \frac{1}{2} \int_{0}^{L}\left(E I_{Z}(x)\left(\frac{d^{2} v}{d x^{2}}\right)+G I_{T}(x)\left(\frac{d \theta}{d x}\right)^{2}+E I_{\omega}(x)\left(\frac{d^{2} \theta}{d x^{2}}\right)\right) d x+ \\
& \frac{1}{2} \int_{0}^{L}\left(E I_{Z}(x)\left(\frac{d h(x)}{d x}\right)^{2}\left(\frac{d \theta}{d x}\right)^{2}+h(x)\left(\frac{d h(x)}{d x}\right)\left(\frac{d \theta}{d x}\right)\left(\frac{d^{2} \theta}{d x^{2}}\right)\right) d x+\int_{0}^{L} M_{y} \theta\left(\frac{d^{2} v}{d x^{2}}\right) d x+ \\
& \frac{1}{2} \int_{0}^{L}\left(q_{z} e_{z}(x) \theta^{2}\right) d x
\end{aligned}
$$

Where:

- $E I_{z}(x), G_{I T}(x), E I_{\omega}(x)$ are stiffnesses-respectively bent, torsional, and warped,

$-v$ and $\theta_{\mathrm{x}}$ are the lateral displacement and torsion angle,

- $M_{\mathrm{y}}$ is the moment of external forces,

$-q_{z}$ is the lateral load from distributed forces

- $e_{z}(x)$ is the distance from the shear center to the load application point, and

$-h(x)$ is the height of the cross-section.

The effectiveness of the ribs restraining the section depends on the constant $R_{\omega v}$ (see below), and also on the $I_{T S}$ torsional moment. The influence of ribs, located along the beam's length, on critical load values can be determined using the Rayleigh-Ritz method. The potential energy function (2) should be extended with an additional element (3), which takes into account the geometric and strength parameters of stiffening ribs. Due to the linearly changing web height along the beam length, the height of the stiffening ribs will also vary. Therefore, the elastic resistance coefficient depends on $\alpha_{T P}$.

$$
\Pi_{\omega}=\frac{1}{2} \sum_{\nu=1}^{n} R_{\omega \nu} \frac{\partial \theta_{x}^{2}}{\partial x}\left(x_{\nu}\right)^{2}
$$

where:

$-R_{\omega \nu}$ is the coefficient of elastic resistance:

$$
\begin{aligned}
& R_{\omega v}=G_{s} \times I_{T S} \times h_{s v} \\
& h_{s v}=h_{s 0}\left(1+\alpha_{T P} \frac{x_{v}}{L}\right)
\end{aligned}
$$

- $G_{S}$ is the lateral modulus of elasticity,

$-I_{T S}$ is the moment of inertia for twisting the stiffening rib,

$-h_{s v}$ is the rib height,

$-x_{n}$ is the location of rib $n$ along the beam, and

$-n_{v}$ is the number of stiffening ribs.

\section{SOLUTION FOR CRITICAL BUCKLING LOADS OF TAPERED I-BEAMS WITH STIFFENER RIBS}

The Rayleigh-Ritz method was used to determine the critical load which initiates torsional buckling of a beam with a coinciding web, and with vertical stiffening ribs. The discussion here provides only basic information on the application of the Rayleigh-Ritz method, insofar 
as is needed to obtain a solution for a bisymmetrical beam loaded with a uniformly distributed, continuous load. To obtain an approximate solution, the Ritz functions, describing displacements arising from bending and fulfilling boundary conditions, were expressed as sums of trigonometric functions:

$$
\begin{gathered}
v=\sum_{i=1}^{n} v_{i} \sin \left(i \pi \frac{x}{L}\right) \\
\theta_{x}=\sum_{i=1}^{n} \theta_{i} \sin \left(i \pi \frac{x}{L}\right)
\end{gathered}
$$

Using a finite number of terms $(6,7)$ replaces the continuous model with a discrete one. For practical engineering calculations for single-span, free-supported steel beams, the first-order approximation $(n=1)$ suffices.

To determine the critical moments of lateral-torsional buckling, we introduce a bending moment gradient function to describe how bending moments vary along the bar:

$$
m(x)=\frac{M_{e, E d(x)}}{M}, m(x)=\frac{4\left(\frac{x}{L}-\frac{x^{2}}{L^{2}}\right)}{M}
$$

Substituting the resistance coefficient (3) and boundary conditions into (2) yields the potential energy in a beam of the convergent cross-section. In matrix form, this is:

$$
\left[\begin{array}{cc}
k_{b b} & k_{b c} \\
s y m & k_{c c}
\end{array}\right]\left(\begin{array}{c}
v_{1} \\
\theta_{1}
\end{array}\right)=\left(\begin{array}{l}
0 \\
0
\end{array}\right)
$$

where:

$$
\begin{gathered}
k_{b b}=\frac{1}{2} \int_{0}^{L}\left(E I_{z}(x) \frac{\pi^{4} \sin ^{2}\left(\frac{\pi x}{L}\right)}{L^{4}}\right) \mathrm{d} x \\
k_{c c}=\frac{1}{2} \int_{0}^{L}\left(G I_{T}(x) \frac{\pi^{2} \cos ^{2}\left(\frac{\pi x}{L}\right)}{L^{2}}+E I_{\omega}(x) \frac{\pi^{4} \sin ^{2}\left(\frac{\pi x}{L}\right)}{L^{4}}\right) d x+ \\
\frac{1}{2} \int_{0}^{L}\left(E I_{Z}(x)\left(\left(\frac{\partial h(x)}{\partial x}\right)^{2} \frac{\pi^{2} \cos ^{2}\left(\frac{\pi x}{L}\right)}{L^{2}}\right)\right) d x+ \\
\frac{1}{2} \int_{0}^{L}\left(E I_{Z}(x)\left(h(x)\left(\frac{\partial h(x)}{\partial x}\right) \frac{\pi^{3} \sin ^{2}\left(\frac{2 \pi x}{L}\right)}{L^{3}}\right)\right) d x+\frac{1}{2} \sum_{v=1}^{n} R_{\omega v} \frac{\partial \theta x^{2}}{\partial x}\left(x_{v}\right)^{2} \\
k_{b c}=\bar{M} \int_{0}^{L}\left(\left(\frac{x}{L}-\frac{x^{2}}{L^{2}}\right) \frac{\pi^{2} \sin ^{2}\left(\frac{\pi x}{L}\right)}{L^{2}}\right) \mathrm{d} x
\end{gathered}
$$

The elements of the coefficient matrix (13) were obtained by determining the expressions, taking into account the taper parameter of the beam (1) and the geometric characteristics (Kuś, 2013). Finally, an approximate solution for critical moments initiating loss of ribbed, simply supported beam, loaded with uniformly distributed continuous load was obtained by setting the determinant to zero: 


$$
\operatorname{det}\left[\begin{array}{cc}
k_{b b} & k_{b c} \\
s y m & k_{c c}
\end{array}\right]=0
$$

Solving the matrix (13) due to $M$, gave critical moments that initiate loss of the stability of beam with linearly varying web height and vertical stiffening ribs distributed along the beam length. The presented solution was used in numerical examples.

\section{APPLICATION}

\subsection{Solution and checking calculations for prismatic beams with ribs}

In order to verify the correctness of the analysis above, critical load values were calculated as described, for a beam with taper parameter $\alpha_{\mathrm{tp}}=0$, and compared with solutions available in the literature. Three cases were considered: a prismatic beam without ribs $\left(n_{v}=0\right)$, one with stiffening ribs on supports $\left(n_{v}=2\right)$, and one with support ribs plus either two or four intermediate ribs $\left(n_{v}=4,6\right)$.

The beam was bisymmetric, with a span $L=6 \mathrm{~m}$, and initial cross-sectional parameters $h_{0}=$ $400 \mathrm{~mm}, b_{f o}=155 \mathrm{~mm}, t_{f}=22 \mathrm{~mm}, t_{w}=14.4 \mathrm{~mm}$ (I400). A continuous load was distributed evenly across the beam, applied to the upper flange $(g=-0.25 \mathrm{~m})$.

The calculations confirm the derived calculation formulae for critical buckling moments of torsional buckling for beams with web convergence parameter $\alpha_{\mathrm{TP}}=0$ (prismatic beam). The results do not differ by more than $1 \%$.

\subsection{Application to web-tapered I-beam with ribs}

The following example determines the critical buckling moments for a simply supported steel I-beam with a tapered web. The beam span is set variously to $6 \mathrm{~m}, 9 \mathrm{~m}$ and $12 \mathrm{~m}$. Its cross-sectional parameters are $h_{0}=300 \mathrm{~mm}, b_{f 0}=150 \mathrm{~mm}, t_{f}=10.7 \mathrm{~mm}$, $t_{w}=7.1 \mathrm{~mm}$.

Next, the ribbed beams with various numbers of ribs and linearly varying web height are analyzed. The load was applied to each of the upper flange, shear center, and lower flange. The web toe parameter was changed from $\alpha_{T P}=0$ (prismatic beam) to $\alpha_{T P}=1$ (web height at the right-hand end is twice as high as at the left-hand end). The same height change was used for the vertical stiffening ribs. The rib distributions for each case are shown in Figure 3.

The critical moment values are shown in Tables $2-4$. From the results of this parametric analysis, it can be concluded that the web tapering significantly increases the critical lateral-torsional buckling moments. Also, stiffening ribs elevate the critical buckling moments.

Table 1. Critical buckling load for prismatic I400 beam with and without ribs.

\begin{tabular}{lcccc}
\hline Critical point load [kN] & $n_{v}=0$ & $n_{v}=2$ & $n_{v}=4$ & $n_{v}=6$ \\
\hline Critical load by (Gosowski 2003) & 66.367 & 67.924 & 68.421 & 69.284 \\
Critical load by (Żmuda 2004) & 66.000 & 67.700 & 68.100 & 68.900 \\
Critical load by (Author) & 66.422 & 68.467 & 68.970 & 69.971 \\
Difference (Gosowski 2003 - & $0.08 \%$ & $0.79 \%$ & $0.81 \%$ & $0.99 \%$ \\
Author) & & & & \\
\hline
\end{tabular}



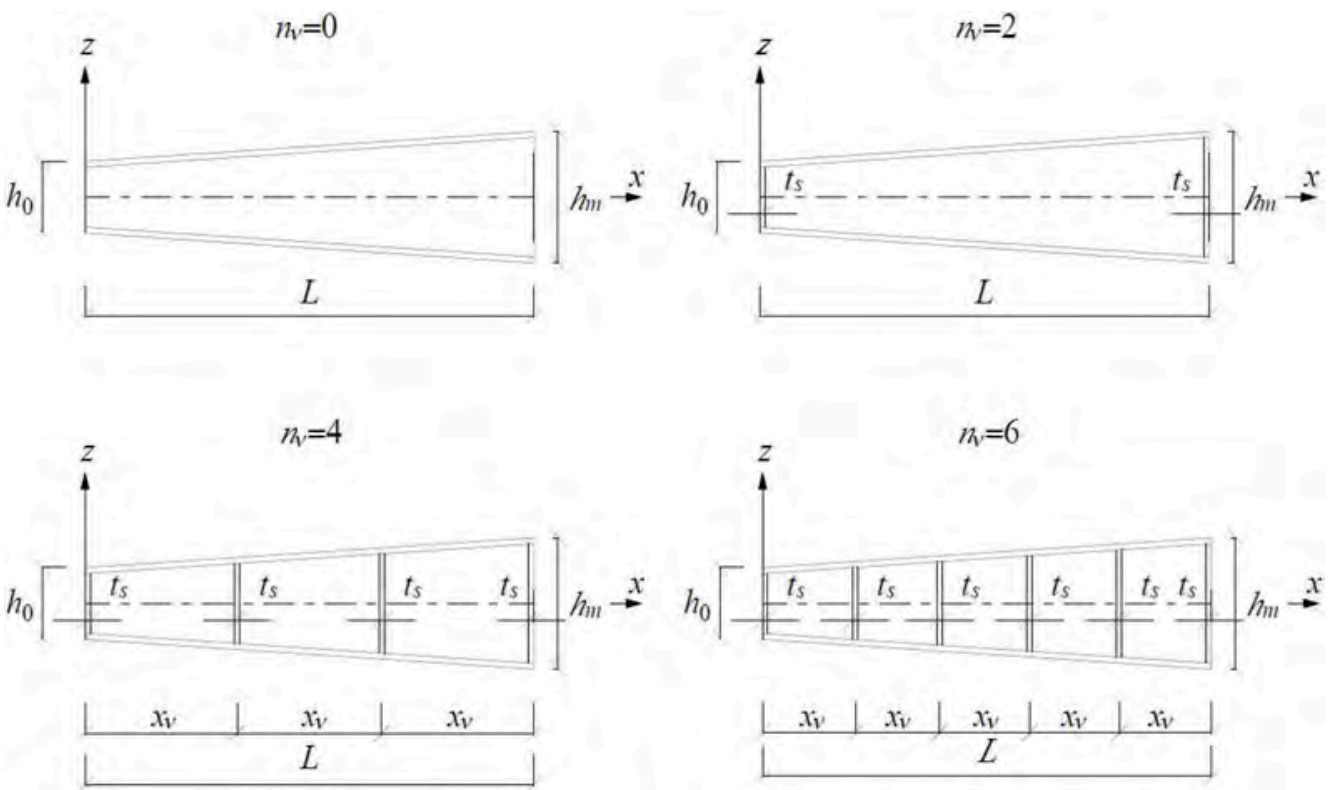

Figure 3. Tapered I-beam with stiffener ribs.

Table 2. Critical buckling moments for tapered I-beam with and without ribs; load on shear center.

\begin{tabular}{|c|c|c|c|c|c|c|}
\hline Load scheme & \multirow[t]{2}{*}{ Number of ribs } & \multicolumn{5}{|c|}{ Critical buckling moment $[\mathrm{kNm}]$} \\
\hline$q_{z}$ & & $\alpha_{T P}=0$ & $\alpha_{T P}=0.4$ & $\alpha_{T P}=0.6$ & $\alpha_{T P}=0.8$ & $\alpha_{T P}=1.0$ \\
\hline & $n v=0$ & 86.630 & 94.320 & 98.781 & 103.583 & 108.681 \\
\hline & $n v=2$ & 99.866 & 108.897 & 113.872 & 119.102 & 124.439 \\
\hline & $n v=4$ & 102.91 & 112.245 & 117.341 & 122.676 & 128.219 \\
\hline & $n v=6$ & 108.74 & 118.659 & 123.990 & 129.527 & 135.246 \\
\hline
\end{tabular}

Table 3. Critical buckling moments for tapered I-beam with and without ribs; load on top flange.

\begin{tabular}{|c|c|c|c|c|c|c|c|}
\hline \multicolumn{2}{|c|}{ Load scheme } & \multirow[t]{2}{*}{ Number of ribs } & \multicolumn{5}{|c|}{ Critical buckling moment $[\mathrm{kNm}]$} \\
\hline \multirow{5}{*}{$e_{z}(x)$} & $q_{z}$ & & $\alpha_{T P}=0$ & $\alpha_{T P}=0.4$ & $\alpha_{T P}=0.6$ & $\alpha_{T P}=0.8$ & $\alpha_{T P}=1.0$ \\
\hline & 1 & $n v=0$ & 64.374 & 68.299 & 70.825 & 73.760 & 76.940 \\
\hline & & $n v=2$ & 77.119 & 82.242 & 85.261 & 88.532 & 92.023 \\
\hline & & $n v=4$ & 80.067 & 85.466 & 88.594 & 91.958 & 95.528 \\
\hline & & $n v=6$ & 85.728 & 91.662 & 95.002 & 98.549 & 102.277 \\
\hline
\end{tabular}

Consider, for example, the results for the beam with its bottom flange loaded (Table 4). For the tapering parameters $\alpha_{\mathrm{TP}}=1$ and number of ribs $n_{\mathrm{v}}=6$, the critical moments, with respect to the beam without ribs, increase by approximately $14 \%$. 
Table 4. Critical buckling moments for tapered I-beam with and without ribs; load on bottom flange.

\begin{tabular}{|c|c|c|c|c|c|c|}
\hline Load scheme & \multirow[t]{2}{*}{ Number of ribs } & \multicolumn{5}{|c|}{ Critical buckling moment $[\mathrm{kNm}]$} \\
\hline & & $\alpha_{T P}=0$ & $\alpha_{T P}=0.4$ & $\alpha_{T P}=0.6$ & $\alpha_{T P}=0.8$ & $\alpha_{T P}=1.0$ \\
\hline \multirow{4}{*}{$e_{z}(x)$} & $n v=0$ & 116.474 & 130.176 & 137.55 & 145.308 & 153.349 \\
\hline & $n v=2$ & 129.219 & 144.065 & 151.946 & 160.080 & 168.433 \\
\hline & $n v=4$ & 132.166 & 147.290 & 155.280 & 163.506 & 171.938 \\
\hline & $n v=6$ & 137.828 & 153.485 & 161.688 & 170.097 & 178.686 \\
\hline
\end{tabular}

\section{CONCLUSIONS}

The solution proposed here provides a way to determine the critical moments that initiate torsional buckling of ribbed beams with tapered cross-sections, for different taper angles. Calculations show that changing the taper parameters significantly affects the critical moments. The increase in the critical moments of a beam with a tapered web $\left(\alpha_{T P}=1\right)$ compared to a prismatic beam $\left(\alpha_{T P}=0\right)$ was about $20 \%$. As expected, beams with slender webs are more sensitive to loss of stability. However, the use of stiffening ribs increased the critical moments compared to beams without it.

\section{REFERENCES}

Andrade A., Camotim D., Borges Dinis P. 2007. Lateral-torsional buckling of singly symmetric web-tapered thin-walled I-beams: 1D model vs. Shell FEA, Computers and Structures. vol. $85,1343-1359$.

Abdelrahmane Bekaddour Benyamina, Sid Ahmed Meftah, Foudil Mohri, El Mostafa Daya. 2013. Analytical solutions attempt for lateral-torsional buckling of double symmetric web-tapered I-beams, Engineering Structures. vol. 56, 1207-1219.

Asgarian B., Soltani M., Mohri F. 2001. Lateral-torsional buckling of tapered thin-walled beams with arbitrary cross-sections, Thin-walled structures. vol. 62, 96-108.

Gosowski B. 2003. Spatial stability of braced thin-walled members of steel structures, Journal of Constructional Steel Research, vol. 59, 839-865.

Gosowski B. 2007. Non-uniform torsion of stiffened open thin-walled members of steel structures, Journal of Constructional Steel Research, vol. 63, 849-865.

Kuś J. 2013. Analysis of stability of beams with converging cross-sections, PhD thesis, Faculty of Construction, Technical University of Opole. 1-92, Opole.

Kuś J. 2015. Lateral-torsional buckling steel beams with simultaneously tapered flanges and web, Steel Composite Structures An International Journal, vol.19, 897-916.

Lindener J. 1996. Influence of constructional details on the load carrying of beams, Engineering Structures, vol. 11, 752-758.

Trahair N. S. 1993. Flexural-Torsional Buckling of Structures, E and F. N. Spon, London.

Trahair N. S. 2014. Bending and buckling of tapered steel beam structures, vol. 59, 229-237.

Żmuda J. 2004. Problems of instability in designing steel girders, Studies and Monographs, no.156, Opole University of Technology Publishing Office, Opole (in Polish). 


\title{
Experimental testing of the critical loading for flexural-torsional buckling of steel two-chord columns laced in a single plane
}

\author{
P. Lorkowski \& B. Gosowski \\ Wroctaw University of Science and Technology, Wroctaw, Poland
}

\begin{abstract}
This paper presents the results of experimental research on the critical loading of two-chord steel columns laced in a single plane. Eight semi-technical scale physical models were constructed for the purposes of experimental testing, modelled on railway traction columns. Loading was focused at the level of the head and applied to an eccentric in the lacing plane. The goal of experimental testing was to determine the pathways to static equilibrium between the longitudinal force on the eccentric, and the bending angle of the cross-section at half the column height and its head displacement. The models were tested to structural failure. The forms of structural failure were observed in relation to flexural-torsional buckling of the column, as well as local buckling of the lacings. Critical forces of flexural-torsional buckling were determined using the Southwell method. The physical models were also analyzed numerically with the ABAQUS program using solid finite elements. Practice-oriented conclusions are presented.
\end{abstract}

\section{INTRODUCTION}

Steel columns with two-chord shafts and laced in a single plane are widely used as railway traction gate columns (Gosowski 2001). Such columns usually have branches consisting of structural channels, which are connected to form a single plane by means of flat or angled bars. A similar construction has been proposed for columns in industrial halls (Biegus 2009, Kucharczuk \& Labocha 2012, Guide of Design... 2003). In the case of halls with moving overhead cranes, the moving overhead part is usually constructed as an I-beam, whereas the bottom part is constructed from structural channels, I-beams or hollow profiles, laced at a $45^{\circ}$ angle.

Previous studies (Hasheela 2013, Lorkowski \& Gosowski 2018, Lorkowski \& Gosowski 2020) have shown the sensitivity of this type of structure to torsion, as well as spatial forms of stability loss. An additional contribution to the research on physical models referred to above and discussed in (Lorkowski \& Gosowski 2018) is the experimental testing presented in what follows, which is concerned with determining the critical loading for flexural-torsional buckling of steel columns laced in a single plane under eccentric compression conditions.

\section{DESCRIPTION OF ELEMENTS TESTED}

Two types of rods were tested for flexural-torsional buckling. They differed in terms of assembly method of the lacing. All the element types had branches (chords) made of rolled C 80 channels with axial spacing of $221 \mathrm{~mm}$ (see Figures 1, 2).

The lacing was made of square tubes RQ $40 \times 3 \mathrm{~mm}$ or FB $40 \times 5 \mathrm{~mm}$ flat bars and laid at an angle of $45^{\circ}$ in relation to the chords. The length of the chords was $4800 \mathrm{~mm}$, whereas with the nodal plates, the design height was $4937 \mathrm{~mm}$. The chords were made of S355 steel, whereas the plates and the lacing were made from S235 steel.

DOI: $10.1201 / 9781003132134-56$ 

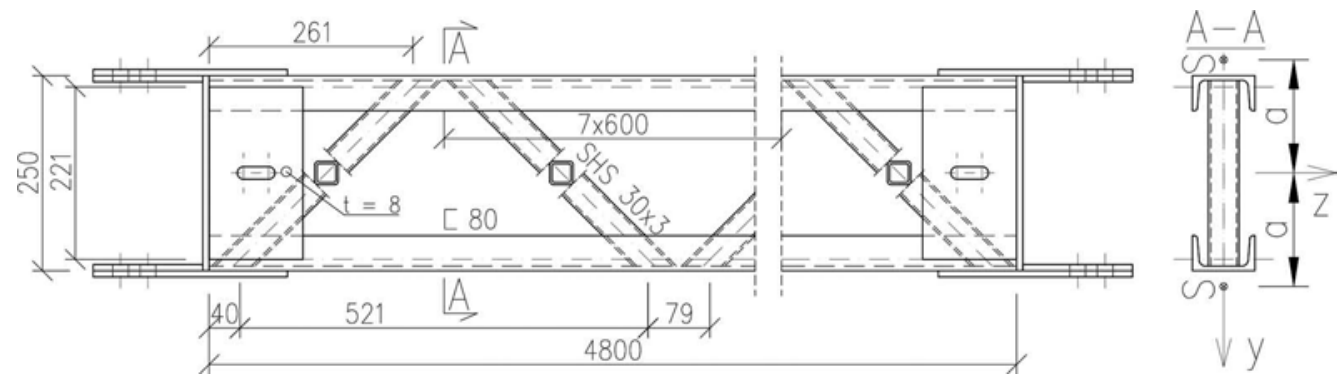

Figure 1. S-1 model with dimensions.

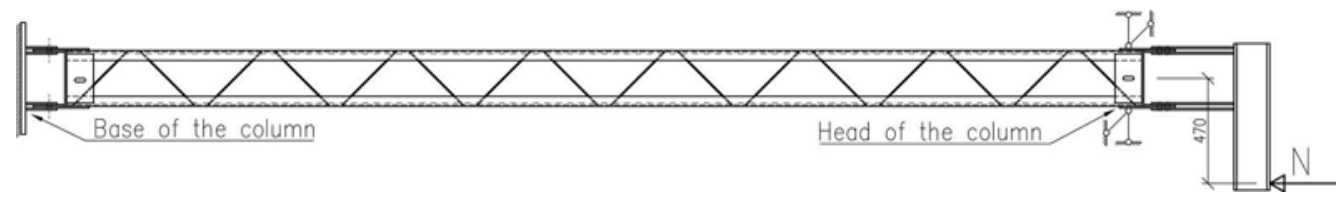

Figure 2. Schematic of column subjected to eccentric compression.

Figure 1 presents the S-1 physical model with a lacing structure made from square tubes, whereas in the S-2 physical model, the lacing was made with flat bars.

\section{PHYSICAL MODEL TESTING STATION}

The model of the column (cf. Figure 2) in the testing station was set up vertically. The base of the column provided a means for translational holding in all directions, as well as twisting around the longitudinal axis and rotation in the lacing plane. The rotation from the lacing plane was released. Displacement of the head of the column was blocked in both lateral directions, as well as the rotation around the longitudinal axis. The head allowed for displacement along the axis of the bar, as well as rotation in and out of the lacing plane. Deplaning at both ends of the column was blocked by nodal plates, diaphragm and lacings.

Loading was applied by means of a manual hydraulic cylinder with a load capacity of 200 $\mathrm{kN}$. The $N$ force was transferred to the model by means of a lever screwed to the model with 6 pre-stressing screws. The lever was used to apply the longitudinal force $\mathrm{N}$ on the eccentric. The eccentric force $\mathrm{N}$ was $e_{y}=470 \mathrm{~mm}$. The main parameter measured during the testing was the section torsion angle at half the column height. The measurement was carried out using four inductive displacement sensors with a range of $100 \mathrm{~mm}$ located in pairs in two perpendicular directions. Additionally, in order to control for stiffness of the support, the side displacements of the chords were measured in the head with two inductive sensors with a $10 \mathrm{~mm}$ range. They were negligibly small. The values of displacement and $N$ force were recorded by computer every 0.25 seconds. More detail concerning the testing station will be presented during the conference.

\section{EXPERIMENTAL TESTING OF THE PHYSICAL MODELS}

All models were inventoried prior to experimental testing. The dimensions of the rolled sections and dimensions (transverse and longitudinal) of the composite bar were checked, also for geometrical imperfections. As the deviations in the dimensions of rolled sections were found to be within acceptable tolerance limits, and the deviations of dimensions and 
imperfections were also within deviations specified in standards (PN-EN 1090-1, PN-EN 1090-2), the design dimensions of elements and nominal sections were adopted for further experimental testing (ArcelorMittal 2008, Bogucki \& Żyburtowicz 2006).

The models were subjected to eccentric compression in two or one loading cycles. The first of the models tested, i.e. S-1.1, S-2.1 and S-2.2 was subjected to a two-loading cycle, whereas the next one was subjected to a single loading cycle. The model S-2.1 was tested first, serving as a benchmark for subsequent experimental testing. This test had to be terminated and the results were rejected as unreliable due to an insufficient torsional hold on the head. Another model, S-1.1, was loaded with a preload of $20.02 \mathrm{kN}$ and then relieved. The permanent deformation was recorded in the form of a twisted shank amounting to $2 \times 10^{-4} \mathrm{rad}$. In the second cycle, the model was loaded with a force of $60.16 \mathrm{kN}$, which represented about $50 \%$ of the theoretical critical loading force. Further increase of the loading was interrupted due to the risk of the actuator slipping off the lever. Following modification of the actuator attachment, tests were carried out on the S-2.2 model. The loading regime was applied in two cycles, first the load was loaded to a value of about $20 \mathrm{kN}$, then relieved and reloaded until structural failure occurred. In the remaining models, loading was applied in a single cycle until structural failure occurred.

In models S-2.2 and S-2.3, the load capacity was exceeded with the loss of stability of the cross-braces. In the last model of the S-2 series, the cross-braces on the flat bar were reinforced by welding overlaps onto the cross-braces in order to determine when loading capacity was exceeded due to loss of overall stability of the column. The overlays were the same thickness as the flat bars of the lacing $(5 \mathrm{~mm})$ and $230 \mathrm{~mm}$ long. The caps were fixed with point-back welds. The testing of the pipe models was carried out yielding no surprises.

Measurements were obtained from the displacement sensors, which had been set in pairs 1-2 and 3-4, and placed in the middle of column height. Static equilibrium paths $\varphi-N$ were prepared for each post where $\varphi$ is the angle of twisting of the section. Critical forces of flexural-torsional buckling were determined using the Southwell method, with simple regression relationships (1) determined using the smallest squares method.

$$
\varphi=N_{c r, T F} \frac{\varphi}{N}+\varphi_{0}
$$

Figure 3 shows examples of the static equilibrium pathways of the S-1.2 column and the corresponding Southwell correlation graphs are shown in Figure 4.

Table 1 summarises the results of the model testing. Southwell relationships were used to calculate the value of the critical force for flexural-torsional buckling $N_{c r, T F}$, which was determined separately from the torsion angle on the basis of measurements from a pair of sensors 1-2 and $3-4$, which were used to calculate the arithmetic mean value $N_{c r, T F}$. The table also presents the load capacity limits $N_{g r}$ for the individual models.

Comparing the values obtained for the critical force of flexural-torsional buckling, it can be stated that displacement is greater in the case of elements with a piping lacing, than in the case of
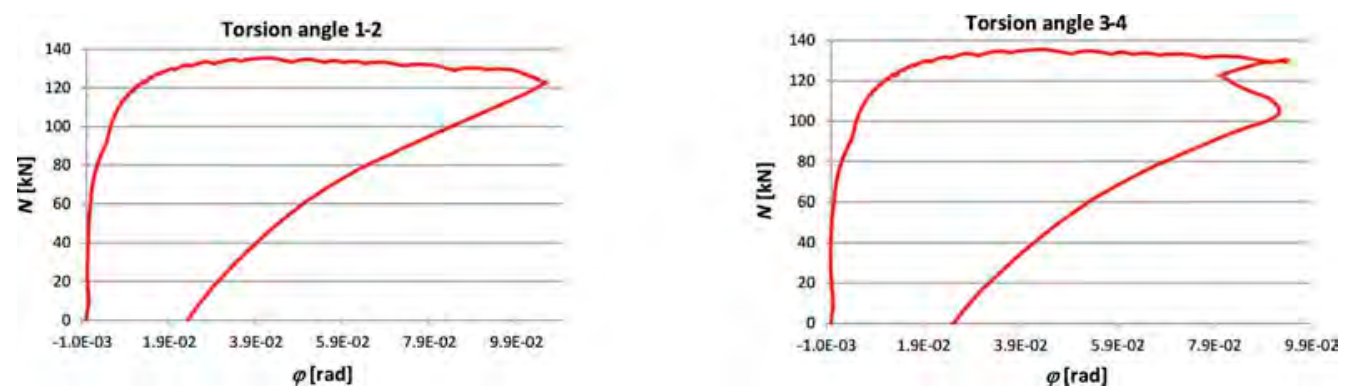

Figure 3. Static equilibrium paths $\varphi-N$ obtained during eccentric compression tests of model S-1.2. 

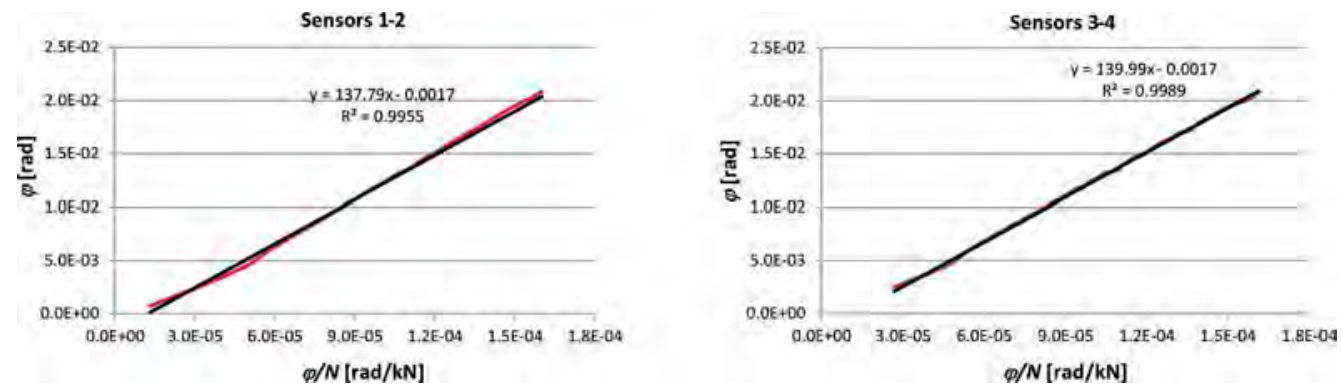

Figure 4. Graphs showing Southwell relationships determined for model S-1.2.

Table 1. Models S-1 and S-2 - presentation of results.

\begin{tabular}{|c|c|c|c|c|c|c|c|}
\hline \multirow[t]{4}{*}{ Model } & \multicolumn{4}{|c|}{ Sensor identification } & \multirow{3}{*}{$\begin{array}{l}\text { Average } \\
N_{c r, T F} \\
\end{array}$} & \multirow[t]{3}{*}{$N_{g r}$} & \multirow{3}{*}{$\frac{\text { Model }}{\text { Failure }}$} \\
\hline & \multicolumn{2}{|c|}{$1-2$} & \multicolumn{2}{|l|}{$3-4$} & & & \\
\hline & $N_{c r, T F}$ & $R^{2}$ & $N_{c r, T F}$ & $R^{2}$ & & & \\
\hline & $\mathrm{kN}$ & - & $\mathrm{kN}$ & - & $\mathrm{kN}$ & $\mathrm{kN}$ & - \\
\hline S-1.1 & 150.17 & 0.9732 & 147.76 & 0.9558 & 148.97 & - & (1) \\
\hline $\mathrm{S}-1.2$ & 137.79 & 0.9955 & 139.99 & 0.9989 & 138.89 & 135.59 & (2) \\
\hline S-1.3 & 134.03 & 0.9985 & 133.70 & 0.9996 & 133.87 & 129.67 & (2) \\
\hline S-1.4 & 150.84 & 0.9997 & 145.67 & 0.9997 & 148.26 & 141.19 & (2) \\
\hline S-2.1 & no results & & & & & & \\
\hline $\mathrm{S}-2.2$ & 139.14 & 0.9722 & 134.79 & 0.9657 & 136.97 & 133.23 & (3) \\
\hline $\mathrm{S}-2.3$ & 148.33 & 0.9962 & 145.01 & 0.9958 & 146.67 & 124.61 & (3) \\
\hline S- 2.4 & 133.62 & 0.9987 & 128.68 & 0.9950 & 131.15 & 124.46 & (2) \\
\hline
\end{tabular}

(1) - did not result in structural failure, (2) - flexural-torsional buckling of column, (3) - flexural buckling of lacings.

columns with a flat bar lacing. It is important to note also that exceeding load-bearing capacity of the columns with flat bars led to a sudden structural failure with no prior indications evident.

\section{ANALYSIS OF RESULTS OF PHYSICAL MODEL TESTING}

The system of differential equations of flexural-torsional buckling of a bi-symmetric bar compressed by longitudinal force $N$ and bent in a plane of higher stiffness at a constant moment $M_{z}$ can be expressed in the following form (Gosowski 1999), (Weiss \& Giżejowski 1991):

$$
\begin{gathered}
E I_{y} \frac{\mathrm{d}^{4} w}{\mathrm{~d} x^{4}}+N \frac{\mathrm{d}^{2} w}{\mathrm{~d} x^{2}}+M_{z} \frac{\mathrm{d}^{2} \varphi}{\mathrm{d} x^{2}}=0 \\
E I_{\omega} \frac{\mathrm{d}^{4} \varphi}{\mathrm{d} x^{4}}+\left(N i_{o}{ }^{2}-G I_{T}\right) \frac{\mathrm{d}^{2} \varphi}{\mathrm{d} x^{2}}+M_{z} \frac{\mathrm{d}^{2} w}{\mathrm{~d} x^{2}}=0 .
\end{gathered}
$$

Assuming that the bending moment results from the longitudinal force applied on the eccentric $\left(M_{z}=-N \cdot e_{y}\right)$, the critical force of flexural-torsional buckling can be determined from the following formula (Gosowski 1999): 
Table 2. Values of coefficients $\mu_{y}, \mu_{T}$ and $c$ (Gosowski 1999).

\begin{tabular}{lllll}
\hline Support in the plane & & \multicolumn{2}{l}{ Length coefficient buckling } & Coefficient $c$ \\
\hline$x z$ & $y z$ & $\mu_{y}$ & $\mu_{T}$ & \\
\hline f-f & f-h & 0.5 & 0.7 & 0.78 \\
f-h & f-f & 0.7 & 0.5 & 0.78 \\
h-h & f-f & 1 & 0.5 & 0.77 \\
h-h & f-h & 1 & 0.7 & 0.83 \\
f-r & f-e & 1 & 0.2 & 0.83 \\
f-e & f-r & 2 & 1 & 0.79 \\
\hline
\end{tabular}

$\mathrm{h}$ - hinged, $\mathrm{f}$ - fixed, $\mathrm{e}$ - free end, $\mathrm{r}$ - restrained against rotation or warping but free translation or twist, respectively.

Table 3. Values $I_{\bar{T}}$ for models S-1 i S-2 and from earlier research.

\begin{tabular}{|c|c|c|c|c|c|c|}
\hline \multirow[t]{2}{*}{ Model } & \multicolumn{4}{|c|}{ Eccentric compression } & \multirow{2}{*}{$\begin{array}{l}\begin{array}{l}\text { Torsion } \\
\text { (L\&G 2018) }\end{array} \\
I_{\bar{T}, s^{\prime} r}\end{array}$} & \multirow{2}{*}{$\begin{array}{l}\text { Bending } \\
\text { (L\&G 2020) } \\
I_{\bar{T}, s^{\prime} r} \\
\end{array}$} \\
\hline & $N_{c r, T F}$ & $I_{\bar{T}}$ & $N_{c r, T F, s r}$ & $I_{\bar{T}, s^{\prime} r}$ & & \\
\hline & $\mathrm{kN}$ & $\mathrm{cm}^{3}$ & $\mathrm{kN}$ & $\mathrm{cm}^{3}$ & $\mathrm{~cm}^{3}$ & $\mathrm{~cm}^{3}$ \\
\hline S-1.1 & 148.97 & 32.811 & 142.50 & 26.25 & 19.04 & 20.80 \\
\hline S-1.2 & 138.89 & 22.299 & & & & \\
\hline S-1.3 & 133.87 & 17.902 & & & & \\
\hline S-1.4 & 148.26 & 31.985 & & & & \\
\hline S-2.1 & - & - & 138.26 & 22.16 & 16.60 & 17.26 \\
\hline S-2.2 & 136.97 & 20.555 & & & & \\
\hline S-2.3 & 146.67 & 30.191 & & & & \\
\hline S-2.4 & 131.15 & 15.724 & & & & \\
\hline
\end{tabular}

$$
N_{c r, T F}=\frac{i_{o}{ }^{2}\left(N_{y}+N_{T}\right) \pm \sqrt{i_{o}{ }^{4}\left(N_{y}+N_{T}\right)^{2}+4 \cdot e_{y}{ }^{2} \cdot i_{o}{ }^{2} \cdot N_{y} \cdot N_{T}}}{2\left(i_{o}{ }^{2}-c \cdot e_{y}{ }^{2}\right)}
$$

where: $N_{y}, N_{T}$ - critical buckling force: flexural and torsional respectively, $i_{o}$ - polar radius of inertia with respect to the centre of gravity, $e_{y}$ - eccentricity of the force; $c$ - coefficient depending on support conditions, which is equal to 1 at $\mu_{y}=\mu_{T}$, and at $\mu_{y} \neq \mu_{T}$ takes on the values presented in Table 2 .

On the basis of the critical force of flexural-torsional buckling determined in the experimental tests, transforming the formula (4) accordingly, makes it possible to determine the equivalent pure torsional moment of inertia $I_{\bar{T}}$. Material constants $E=205 \mathrm{GPa}, v=0.3$ and relevant coefficients with the following values were adopted: $c=0.77, \mu_{y}=1, \mu_{T}=0.5$. The notional sectorial moment of inertia was determined from the relationships presented by Lorkowski \& Gosowski (2018)

$$
I_{\bar{\omega}}=2\left(I_{\omega p}+a^{2} \cdot I_{y p}\right)
$$

where: $I_{y p}, I_{\omega p}-$ the moment of inertia about $y$-axis and the sectorial moment of inertia of a single chord respectively, $a$ - the distance from the shearing source of the chords (cf. Figure 1).

The values obtained for $I_{\bar{T}}$. are presented in Table 3, in which the two final columns provide for comparative purposes, the results from testing of the similar models for torsion and bending. 
Table 4. Summary of results for eccentric compression, torsional and bending models.

\begin{tabular}{|c|c|c|c|c|}
\hline \multirow[t]{2}{*}{ Model } & \multicolumn{2}{|c|}{ Eccentric compression } & \multirow{2}{*}{$\begin{array}{l}\text { Torsion (L\&G 2018) } \\
I_{\bar{T}}\end{array}$} & \multirow{2}{*}{$\begin{array}{l}\text { Bending (L\&G 2020) } \\
I_{\bar{T}},\end{array}$} \\
\hline & $N_{c r, T F}$ & $I_{\bar{T}}$ & & \\
\hline & $\mathrm{kN}$ & $\mathrm{cm}^{3}$ & $\mathrm{~cm}^{3}$ & $\mathrm{~cm}^{3}$ \\
\hline S-1 & 138.14 & 21.61 & 16.69 & 15.67 \\
\hline S-2 & 135.55 & 19.32 & 14.09 & 13.31 \\
\hline
\end{tabular}

\section{TESTING WITH NUMERICAL MODELS}

Numerical model testing was carried out using the ABAQUS program for calculations (ABAQUS 2012). The program is based on the Finite Element Method (FEA).

Calculations using the ABAQUS program were performed with resources made available by the Wrocław Supercomputer Network (http://wcss.pl), under the calculation grant No. 306.

The models were generated in the CAE module, whereas calculations were made using the STANDARD module. The models were divided into solid, 8-node finite elements, with reduced integration (C3D8R), and in places where the geometry of the model did not allow for it - 6-node solid elements (C3D6). Solid elements, in contrast to coated elements, take into account the deformation of the cross-section throughout its thickness, so they are better suited for testing the types of structures with which we are concerned here (Gosowski \& Niżniowski 2008). The size of finite elements was selected so as to ensure the maximum length did not exceed $8 \mathrm{~mm}$. The number of finite elements, depending on the model type was in the range of $65 \div 98$ thousand.

Material constants were adopted as for the physical models. As the focus of concern was not the analysis in the extra-elastic range, a linear-elastic material model was assumed.

The calculation procedure assumed three steps. The initiating step, in which the support conditions were defined, the first step - overall static analysis and the second step - stability analysis. The stability analysis was carried out using the buckle procedure, which belongs to the group of linear instabilities

In the case of the S-1 model, the programme generated 15 eigenvalues, which fell within the force range defined (between 130 and $160 \mathrm{kN}$ ), with only one of them taking on a form of overall stability loss, which was interpreted as the critical force for flexural-torsional buckling.

In the case of the S-2 model, 24 eigenvalues were found to lie in the force range between 110 and $150 \mathrm{kN}$. The value that had the lowest positive value and a generalisable form was interpreted as the critical force for flexural-torsional buckling.

Table 4 shows the calculation results for the eccentric compressive models S-1 and S-2. The first column presents the first eigenvalue relating to the loss of overall stability, which is also the critical force of flexural-torsional buckling. On the basis of this value, $I_{\bar{T}}$. was calculated. The formula (4) was used for this purpose, and the solution was obtained using an iterative method. In the last two columns the values $I_{\bar{T}}$, are presented for purposes of comparison. These value were obtained from torsional and bending numerical analysis.

The comparison of the two models from the point of view of the critical force for flexuraltorsional buckling leads to the conclusion that there is little benefit from using pipes over flat bars for the lacing. However, a comparison of results of loading capacity limit results indicates a clear advantage of using piping for the lacing.

\section{SUMMARY AND CONCLUSIONS}

The tests carried out on the elements of concern for eccentric compression confirm their sensitivity to spatial loss of stability, when compared to quasi-closed lacing elements. In addition, 
both FEM testing and physical model testing confirm that bars with pipe lacing exhibit more favourable behaviour in relation to localized stability. In the case of elements subjected to compression, this is important as the stability loss pathway of cross-braces with flat bars takes place suddenly without prior indication.

When the load-bearing capacity is exceeded, more than half of the compressed bars with flat bars buckled. In contrast to elements subjected to bending, a different failure mechanism appears. In elements subjected to bending, the cause of stability loss is related to localised loading of cross-braces in response to changes in the support structure. In the case of eccentric compression, the loading on the cross-braces comes mainly from the transverse force of the column body. Stability loss of one of the cross-braces results in it being excluded from loading transfer and, in consequence, demands that forces are transferred through the remaining cross-braces. It is this that results in a rapid, cascading loss of stability of the remaining crossbraces. This phenomenon is especially dangerous in relation to important load-bearing structures. Incorrect diagnosis of this phenomenon may result in structural failure.

\section{REFERENCES}

ABAQUS 6.12. 2012 Online Documentation. Dassault Systèmes.

Biegus, A. 2009. Stalowe budynki halowe. Warszawa: Arkady.

Gosowski, B. 1999. Spatial buckling of thin-walled steel-construction beam-columns with discrete bracings. Journal of Constructional Steel Research 52: 293-317.

Gosowski, B. 2001. Problems of durability of steel in railway overhead structures. Ochrona przed Korozja. 2: 40-44 (in Polish).

Gosowski, B. \& Niżniowski, P. 2008. Verification of FEM program solutions of stability and torsion problems for I shape steel members. Archives of Civil Engineering 54(1): 129-145.

Guide for the Design and Construction of mill buildings AISE. 2003. Technical Report No. 13, Pittsburgh, Pennsylvania

Hasheela P.F. 2013. Behaviour of single laced columns versus double laced columns. Johannesburg. MSc Thesis.

Kucharczuk, W. \& Labocha, L. 2012. Hale o konstrukcji stalowej. Poradnik projektanta. Rzeszów: Polskie Wydawnictwo Techniczne.

Lorkowski, P. \& Gosowski B. 2018. Experimental and numerical research of the torsion problem of built-up steel columns laced in a single plane. Engineering Structures, 160, 566-580.

Lorkowski P. \& Gosowski B. 2020 Investigations for lateral buckling of two chords steel members laced in a single plane. Inżynieria i Budownictwo 1: 50-55 (in Polish).

Weiss S. \& Giżejowski M. 1991. Stateczność konstrukcji metalowych. Układy prętowe, Arkady, Warszawa. 


\title{
Axial capacity of steel built-up battened columns
}

\author{
P. Pieczka \& P. Iwicki \\ Department of Metal Structures, Faculty of Civil and Environmental Engineering, Gdańsk University of \\ Technology, Gdańsk, Poland
}

\begin{abstract}
This paper deals with the numerical investigation aimed to study the axial capacity of pin-ended steel built-up columns. Three methods of calculating forces in chords and batten, taking into account the material and geometric imperfections specified in the Eurocode 3 are considered. The aim of this study was to compare different methods allowing the calculation of the column load capacity and determine a simpler and faster method than the present Eurocode 3 procedure related to design of built up members. In the paper, the method according to Eurocode 3 for uniform built-up compression member and the method according to PN-B-03200:1990 are compared with the code method for the structure modeled as separate members for column chords and battens. Calculations were carried out for the column modeled by 1D-beam elements and for a whole shell model of the column. Finite element (FE) models were established and verified against the built-up columns with similar configurations that were tested experimentally in the studies presented in the literature, and then compared with the calculations specified in Eurocode 3.
\end{abstract}

\section{INTRODUCTION}

Thanks to the spacing of the chords, built-up columns make it possible to obtain high moments of inertia at low cross-sectional area, and thus low steel expenditure. This is especially important for columns with long buckling length. The chords can be made of hot-rolled or cold-formed sections, connections between them can be made with lacings or battens.

The most common in engineering practice method of calculation of built-up columns with battens is the procedure according to Eurocode 3 (2005) (EC3) where the model of a uniform built-up compression member is applied. The assumption described in EC3 allows to calculate regular structures with battens smeared along the column. The problem is that this method is precisely defined only for columns with parallel chords of constant cross-section, modular battens distribution and pinned supports.

\section{STATIC ANALYSIS}

The load capacity of the entire built-up member can be calculated knowing the values of internal forces in its individual elements, and then checking the code limit load for each element separately. The EC3 standard recommends assuming an initial bow imperfection $e_{0}=L /$ 500 , where $L$ is the column length. The calculation of internal forces with initial imperfection can be performed in several ways, three of them are presented below.

For the calculation of internal forces, the data of an example column were adopted. Steel S235 (yield stress $f_{y}=235 \mathrm{MPa}$, elastic modulus $E=210 \mathrm{GPa}$ ) was used, and the column was loaded with a concentrated force of $1500 \mathrm{kN}$. Figure 1 shows the diagram and dimensions of the built-up member. 

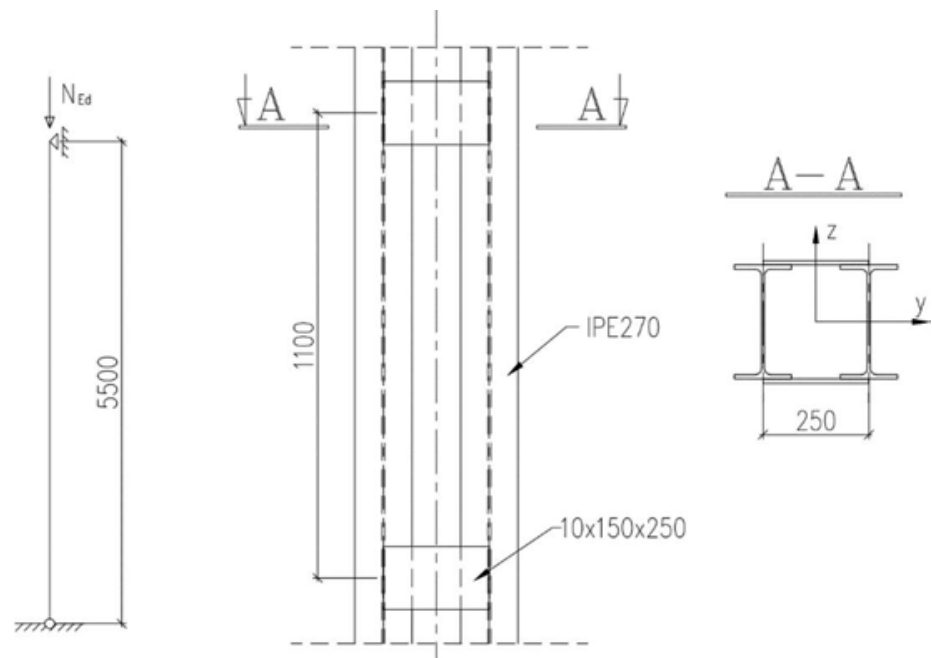

Figure 1. Diagram and dimensions of the built-up member of the example.

\section{$2.1 \quad$ Procedure according to Eurocode 3 (EC3)}

PN-EN 1993-1-1, point 6.4 describes the method of calculating internal forces in the chords and battens of built-up members with parallel and constant chords along the entire length of the column, and the battens fixed in the modular arrangement (not less than 4 battens). The supports of the column must be pinned. For columns with a different boundary condition or variable cross-section, EC3 recommends performing appropriate modifications, but it has not been specified how to implement them.

The distribution of internal forces in the end panel proposed in EC3 is shown in Figure 2. Simultaneity occurrence of the maximum chord forces $N_{c h ; E d}$ and the maximum shear force $V_{E d}$ is assumed.

\subsection{Numerical model with equivalent horizontal load}

In the literature, it was proposed to implement imperfections to the beam model using the horizontal equivalent force, as for example by Falborski et al. (2019). The uniform linear load to one chord along its entire length is applied. The force is calculated so that the bending moment in the center of the column is equal to the moment that would occur in the column with the initial imperfection $e_{0}=L / 500$.

The value of the equivalent horizontal forces can be obtained from the condition of the equilibrium moments:

$$
q=8 \frac{N_{E d} e_{0}}{L^{2}}
$$

The beam model with an additional element redistributing the force from the support to the column was made in the ARSA program. Each pair of battens was modeled as a single beam with a thickness equal to twice the thickness of the batten. All member connections are fixed. The calculations as a nonlinear static analysis were performed.

\subsection{Numerical model with geometric imperfection directly implemented in form of initial bow}

The ARSA program enables implementing the initial imperfection to the model by importing the buckling mode with a specified maximum displacement. A linear buckling analysis was carried out with the beam model from the previous point, and then, using the buckling 


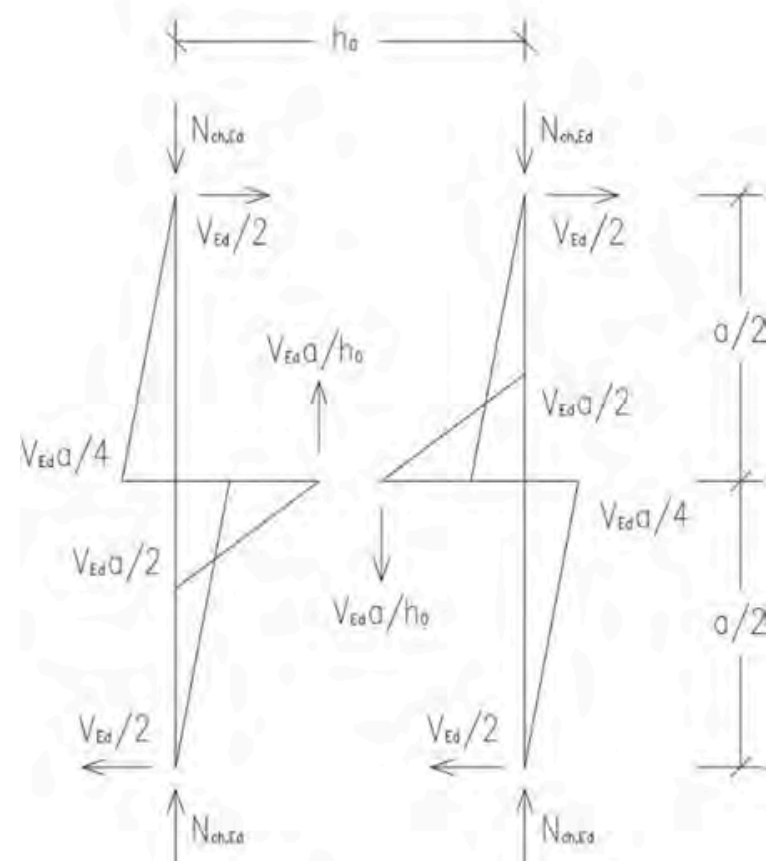

Figure 2. Moments and forces in an end panel of a battened built-up member (EN 1993-1-1 1992).

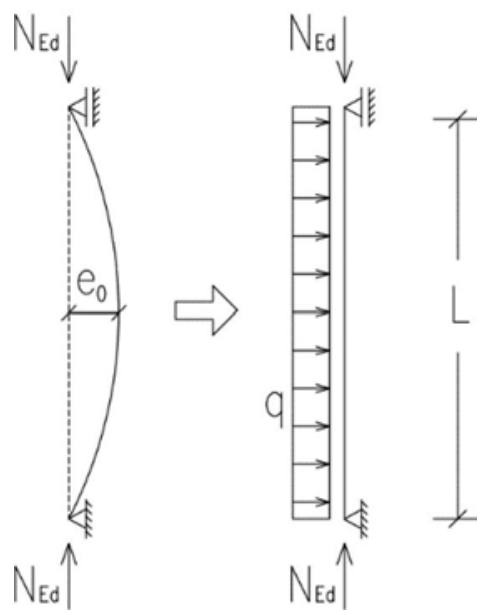

Figure 3. Replacement of initial imperfections by equivalent horizontal forces (EN 1993-1-1 1992).

deformation option, the initial deformation from the first buckling mode was assigned to the model (global buckling of the entire column with a buckling length equal to the column length).

\subsection{Comparison of internal forces}

The comparison of internal forces obtained by different methods is shown in Table 1. Comparing the obtained forces, it can be seen that the normal force in the chord $N_{c h \text {; Ed }}$ is almost 
Table 1. Comparison of internal forces obtained by different methods.

\begin{tabular}{|c|c|c|c|c|}
\hline & $N_{c h, E D}$ & $M_{c h, E D}$ & $V_{b, E d}$ & $M_{b, E D}$ \\
\hline Internal force & {$[\mathrm{kN}]$} & {$[\mathrm{kNm}]$} & {$[\mathrm{kN}]$} & {$[\mathrm{kNm}]$} \\
\hline EC3 procedure & 834.1 & 3.50 & 56.0 & 7.00 \\
\hline Horizontal equivalent load & 832.2 & 3.61 & 38.8 & 4.85 \\
\hline Imperfection in form of initial bow & 831.2 & 3.16 & 39.1 & 4.89 \\
\hline
\end{tabular}

identical regardless of the calculation method used. The results obtained from both numerical methods are very similar. The greater bending moment in the chord $M_{c h \text {; Ed }}$, occurring in the method using the equivalent load, is due to the way the load is applied, which directly increases the bending moment in the chord.

Code calculations assume that the moments on both sides of the chord connected to the batten are equal, therefore the moment in the batten is twice the maximum moment in the chord. However, the maximum moment in the chord occurs only at its end, where it is transferred to the last batten without doubling. The moment on both sides of the chord is summed up on the penultimate batten, at this point the moment in the chord is less than the maximum.

\section{CALCULATION OF THE LOAD CAPACITY}

By knowing the internal forces in the individual elements, it is possible to calculate the load bearing capacity of the entire column using the procedure according to EC3. The PNB-03200:1990 (PN) standard also presents a method of calculating the buckling resistance of built-up columns. The calculation procedure is based on reduction factors.

\subsection{Method of calculating the bearing capacity based on the linear buckling analysis (LBA)}

Method of calculating the bearing capacity based on the buckling resistance procedure of a homogeneous member according to EC3 is proposed. The elastic critical force of the entire column was calculated by the linear buckling analysis in the ARSA program. The buckling curve c was assumed. Similar considerations are described in the article Uziak \& Gizejowski (2010).

\subsection{Comparison with experimental results known from the literature}

For the purpose of comparison of the above-mentioned methods of calculating the resistance of built-up pin-ended columns with battens, the experimental studies carried out by Mitsui \& Sato (2017) were used. The article describes the experimental research, numerical calculations and code calculations according to Design Standard for Steel Structure (AIJ 2005).

In the article the calculations were carried out for columns composed of two cold-formed chords and battens made of flat bars. The connection between them was made by pretension bolts, for the purposes of subsequent calculations, it was assumed that these connections are fixed. Parameters selected to determine the configuration of the specimens were the separation between connectors $a$, the distance between the centroids of chords $h$, and the length of the member $L$. An example of the column cross-section used in the article is shown in Figure 4. In this article, six types of columns each with a height of $L=3700 \mathrm{~mm}$ were used for calculations.

The comparison of load capacities obtained by different methods is shown in Table 2. In most cases, the calculated load capacity is less than that known from the experiments. For built-up members with a small number of battens (a1200h50, a1200h70) the load capacity is significantly underestimated by EC3 and PN code procedures. The load capacities obtained using the LBA method are in most cases more similar to the experimental ones than those 

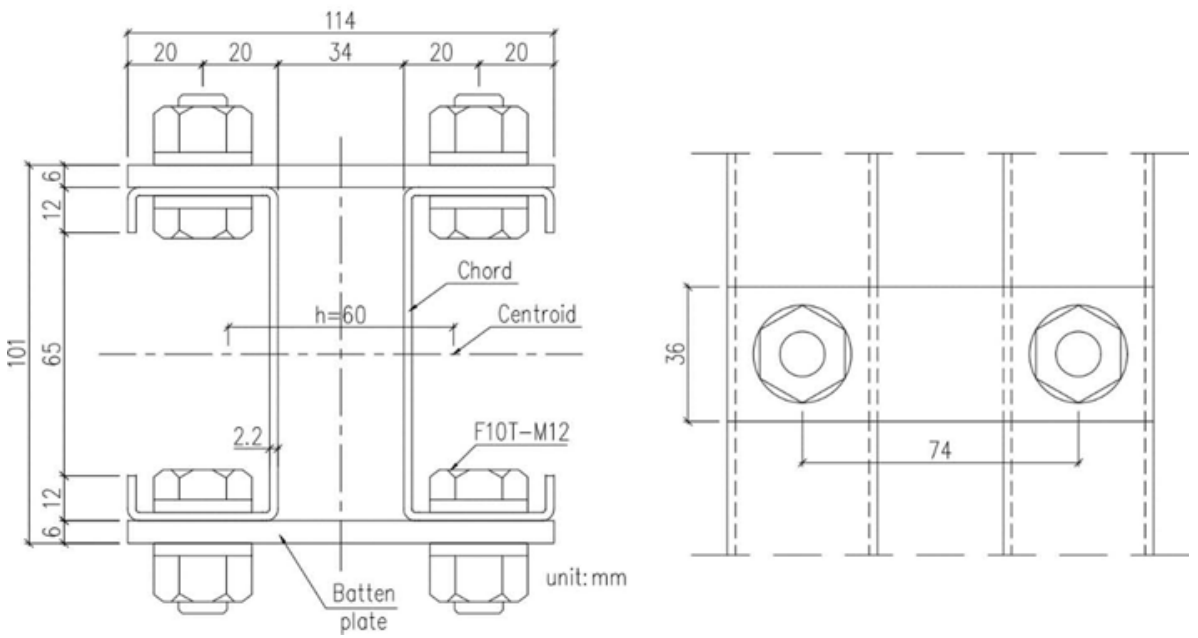

Figure 4. The cross-section of the exemplary column based on Mitsui \& Sato (2017).

Table 2. Load capacities of the tested columns obtained by various methods.

\begin{tabular}{|c|c|c|c|c|c|c|}
\hline & a $400 \mathrm{~h} 60$ & a720h50 & a720h60 & a1200h50 & a1200h60 & a1200h70 \\
\hline Method & {$[\mathrm{kN}]$} & {$[\mathrm{kN}]$} & {$[\mathrm{kN}]$} & {$[\mathrm{kN}]$} & {$[\mathrm{kN}]$} & {$[\mathrm{kN}]$} \\
\hline Strength tests (average) & 99.5 & 66.1 & 77.7 & 53.7 & 71.2 & 88.3 \\
\hline EC3 procedure & 92.2 & 60.3 & 79.2 & 46.9 & 57.7 & 65.8 \\
\hline $\mathrm{PN}$ procedure & 81.5 & 59.6 & 73.4 & 49.0 & 58.2 & 66.8 \\
\hline LBA method & 83.8 & 64.4 & 77.7 & 56.9 & 66.5 & 74.7 \\
\hline
\end{tabular}

calculated using the EC3 and PN code procedures. This may indicate that the LBA method describes the resistance of built-up members with battens whose failure model is global buckling, sufficiently well.

\section{CALCULATIONS ON THE SHELL MODEL}

\subsection{Numerical analysis model}

In order to verify the correctness of the critical force calculation on the beam model in ARSA program and to perform geometrically and materially non-linear static analysis, a shell model of the entire column was created in the ABAQUS program. The model was made of a720h60 column, for which the load capacity tested experimentally was $77.7 \mathrm{kN}$. Chords and battens were modeled as shells, the connections between them are fixed. The steel properties were assumed as elasto-plastic according to the data given in the article: yield stress $f_{y}=306 \mathrm{MPa}$, ultimate tensile strength $f_{u}=450 \mathrm{MPa}$, elastic modulus $E=205 \mathrm{GPa}$ and Poisson's ratio $v=0.3$. The column was loaded with a concentrated force at one end.

\subsection{Linear buckling analysis}

In order to obtain critical loads and buckling modes, the linear buckling analysis of the column was performed. The obtained critical force was similar to that obtained from calculations on the beam model. This confirms the validity of using the beam model for the calculations presented earlier. 


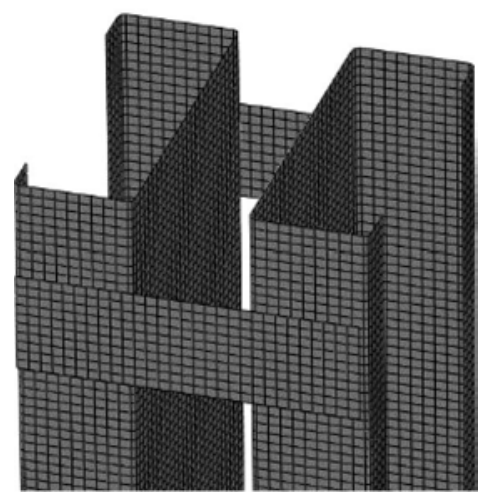

Figure 5. The shell model in the ABAQUS program.

\subsection{Geometrically and materially non-linear static analysis}

Geometrically and materially non-linear static analyses were performed on the presented shell model. The initial imperfection in form of the first buckling mode (similar to bow) of the entire column was assigned to the model, according to the EC3: $e_{0}=L / 500$. Imperfections were assigned by importing nodal displacements from the linear buckling analysis with a set maximum displacement. In the case of the global imperfection assigned only (recommended for built-up members), the obtained load capacity is significantly overestimated and amounts to $86.8 \mathrm{kN}$.

To obtain a result more similar to the strength tests, an additional imperfection related to the buckling of the chord in its central part (buckling between battens) should be added. The bow imperfection (with distortion of the cross-section) with a value of $a / 200$ was introduced. The load capacity obtained in this case was $78.6 \mathrm{kN}$.

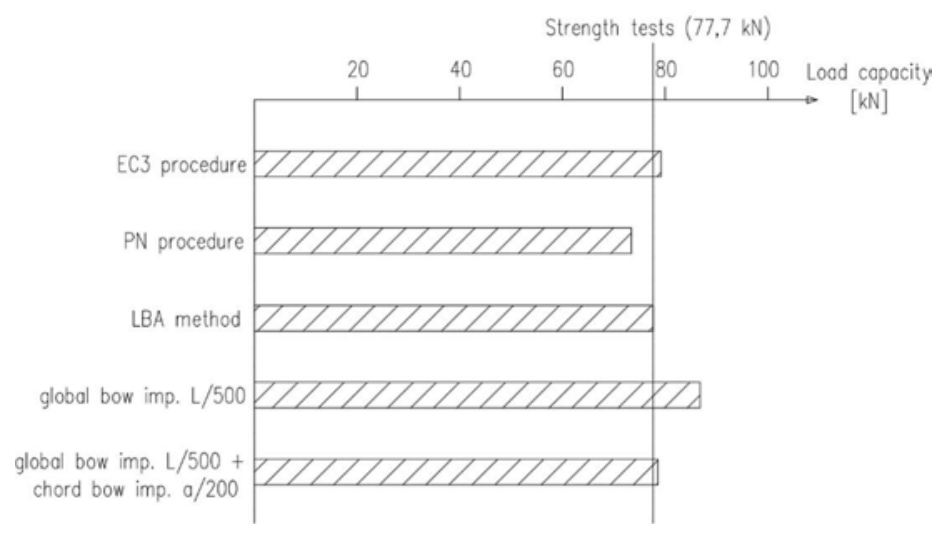

Figure 6. Load capacities of the a $720 \mathrm{~h} 60$ column obtained by various methods.

\section{CONCLUSIONS}

- The code procedure for single homogeneous axially compressed members (LBA) can be used to calculate the global buckling resistance of a built-up column. The buckling curve that best describes the buckling resistance of a built-up member: $\mathrm{c}$. 
- Currently, computer programs allow to perform non-linear static analyses of the entire column model (beam or shell), and the code regulations should specify exactly the imperfections that should be assumed in the model.

\section{ACKNOWLEDGEMENTS}

The numerical calculations were performed using the computing resources of CI TASK at Gdańsk University of Technology.

\section{REFERENCES}

Abaqus, Theory Manual. 2008. Version 6.8. Hibbit, Karlsson \& Sorensen Inc.

Autodesk Robot Structural Analysis Professional - Verification Manual for EU Codes. 2014.

EN 1993-1-1. 2005. Eurocode 3: Design of Steel Structures. Part 1.1: General rules and rules for buildings. Brussels: CEN.

Falborski, T. Knabe, W. Perliński, A. \& Urbańska-Galewska, E. 2019. Wybrane zagadnienia projektowania stalowych konstrukcji prętowych z wykorzystaniem programu Autodesk Robot Structural Analysis. Gdańsk: Wydawnictwo Politechniki Gdańskiej.

Giżejowski, M. Król, P. \& Ślęczka, L. 2008. Projektowanie elementów rozciaganych i ściskanych osiowo wedhug PN-EN 1993-1-1i PN-EN 1993-1-5. Inżynieria i Budownictwo 3/2008: 126-134.

Goczek, J. Supeł, Ł. \& Gajdzicki, M. 2010. Przykłady obliczeń konstrukcji stalowych, Łódź: Wydawnictwo Politechniki Łódzkiej.

Matysiak, A. \& Grochowska, E. 2014. Konstrukcje stalowe ze stupami dwugatęziowymi z przewiązkami projektowane wg norm PN i EN. Przegląd budowlany 9/2014: 41-45.

Mitsui, K. \& Sato, A. 2017. Flexural Elastic Buckling Stress of Batten Type Light Gauge Built-Up Member. Civil and Environmental Engineering Reports No. 25(2): 161-172.

PN-B-03200:1990 Konstrukcje stalowe. Obliczenia statyczne i projektowanie.

Uziak, J. \& Gizejowski, M. 2010. Coupled buckling design of steel laced columns. Botswana Journal of Technology. 18. 10.4314/bjt.v18i2.52261. 


\title{
Major axis in-plane buckling resistance of I-section beam-columns under moment gradient
}

\author{
Z. Stachura \& M.A. Giżejowski \\ Department of Concrete and Metal Structures, Warsaw University of Technology, Warsaw, Poland \\ R.B. Szczerba \\ Faculty of Civil Engineering, Warsaw University of Technology, Warsaw, Poland \\ M.D. Gajewski \\ Department of Strength of Materials and Theory of Elasticity and Plasticity, Warsaw University of \\ Technology, Warsaw, Poland
}

\begin{abstract}
The inelastic second-order resistance of I-section beam-columns under arbitrary loading cases of one-directional bending is mainly dependent upon two factors, namely the direction of bending and the contribution of the web and flanges to the section moment of inertia in the plane of bending. Based on the concept of an approximate method of the evaluation of inelastic second-order resistance of beam-columns presented by the authors elsewhere, the objective of the present study is to develop the model parameters representing functions for accounting an approximate inclusion of distributed plasticity effects of plastic zones (stress redistribution along the member length) and within the member most stressed section (stress redistribution across the most stressed section depth). The model parameters for major axis bending are assessed for narrow flange I-section beam-columns (symbol I is used for the narrow flange section identification) on the basis of results obtained from a number of FEM simulations based on an accurate shell modelling technique and using Abaqus software. The concept of equivalent geometric imperfections is applied in compliance with the so-called Eurocode's general method in order to include globally the effect of geometric and material imperfections. The resulting model parameters evaluated for I-section steelwork elements being laterally and torsionally restrained are compared with those developed elsewhere for hot-rolled wide flange HEB section members subjected to both compression and bending about the major principal axis. Additionally, results are compared with those obtained in previous studies and those of Eurocodes interaction criteria based on Methods 1 and 2. Concluding remarks with regard to the in-plane buckling resistance of double-tee section beam-columns are presented.
\end{abstract}

\section{INTRODUCTION}

When the laterally and torsionally restrained I-section beam-column, simply supported in the plane of bending is uniformly compressed and arbitrary bent about the major principal axis, its in-plane dimensionless buckling resistance curve evaluated in the plane $n_{E d}-m_{y, E d}$ is strongly dependent upon the moment gradient (where $n_{E d}=N_{E d} / N_{p l, R k}$ and $m_{y, E d}=M_{E d} / M_{y, p l . R k}$ and the other symbols sre used according to the Eurocode 3 notations, see Simoes da Silva et al. 2016). Since the axial force produces an additional moment component resulting from the $P-\delta_{z}$ effect, the member buckling resistance prediction requires a less or more precise evaluation of 
the most stressed section location along the member length. This in turn is an easy task only for the uniform bending for which the most stressed section is that at mid-length of the member. All other cases of the moment gradient need to either an estimation of the location of the most stressed section along the member length or making a rough assumption for engineering practice that the nonuniform moment case is replaced by the case of a substitute uniform moment in which the equivalent moment takes the form $M_{y, e q}=C_{m y} M_{y, \max }$ where $C_{m y}$ is the conversion factor (lower index $E d$ is dropped off in the following for the convenience of presentation).

For the reference perfect member of a linear first-order moment gradient produced by unequal support moments, the value of $M_{y, \max }$ has widely been approximated by the following relationship (see Trahair et al. 2008):

$$
\frac{M_{y, \max }}{M_{y}}=\frac{C_{m y}}{1 \frac{N}{N_{y}}} \geq 1
$$

where $N_{y}=$ lowest bifurcation (critical) force for buckling about $y-y$ axis; $\psi_{m y}=M_{y d \text {,min }}$ $I M_{y d, \text { max }}$ is the ratio of applied support moments; $C_{m y}=0.6+0.4 \psi_{m y}$ is the moment conversion factor.

Gizejowski \& Stachura (2020) postulate that for any moment gradient the maximum moment coincides with the member end section of the maximum moment, and it can be treated as a combination of symmetric and antisymmetric components, so that Equation (1) might be replaced by the following:

$$
\frac{M_{y, \max }}{M_{y}}=\frac{0.5\left(1+\psi_{m y}\right)}{1-\frac{N}{N_{y}}}+\frac{0.5\left(1-\psi_{m y}\right)}{1-\frac{N}{N_{y a}}} \geq 1
$$

where $N_{y a}=$ second-lowest bifurcation force for buckling about $y$ - $y$ axis, so that the conversion factor in Equation (1) may be approximated by:

$$
C_{m y}=0.5\left[\left(1+\psi_{m y}\right)+\left(1-\psi_{m y}\right) \frac{1-\frac{N}{N_{y}}}{1-\frac{N}{N_{y a}}}\right] \geq 1
$$

In reality, the location of the maximum moment is not at the support for any moment gradient situations but changes from the mid-section in case of the equal support moments in opposite directions to the end-section in case of the equal support moments in the same direction. For more accurate predictions, Gizejowski \& Stachura (2020) propose the deflected profile to be represented by a combination of two eigenmodes corresponding to two lowest eigenvalues detected from the bifurcation LEA analysis of a perfect column. Then, the maximum moment closed-form relationship for the section most stressed in bending is developed, more accurate than those given by Equations (1) and (2). The buckling resistance utilization ratio $B R U R$ of a straight and residual free beam-column may therefore be represented as a sum of the section resistance utilization ratio in the axial compression and the most stressed section resistance ratio in the second-order bending:

$$
B R U R=\frac{N}{N_{c, R}}+\frac{M_{y}}{M_{c y, R}} \frac{M_{y, \max }}{M_{y}} \quad 1
$$

where $N_{c, R}=$ class dependent section axial resistance; $M_{c y, R}=$ class dependent section bending resistance about $y$ - $y$ axis.

Current design codes are based on the buckling resistance models of imperfect members. Eurocode 3 (2005) introduces the Ayrton-Perry first yield column buckling model so that Equation (4) is no longer valid. It has been proposed that the resultant beam-column 
resistance utilization ratio $R U R$ can be approximated by using the maximum value of those corresponding to the class-dependent section resistance under compression and bending $C R U R$ and the class-dependent buckling resistance under compression and bending BRUR that is a simple extension of Equation (4) with $C_{m y}$ according to Equation (1) being not less than 0.4 (see Trahair et al. 2008):

$$
B R U R=\frac{N}{N_{b y, R}}+\frac{C_{m y}}{1-\frac{N}{N_{y}}} \frac{M_{y}}{M_{c y, R}} \leq 1
$$

where $N_{b y, R}=$ class-dependent buckling resistance of an imperfect column, replacing that of a perfect member $\min \left(N_{y} ; N_{c, R}\right) ; C_{m y} \geq 0.4=$ moment conversion factor according to Equation (1).

Trahair et al. (2008) suggest that the in-plane buckling resistance of beam-columns bent about $y-y$ axis may be suitably interpolated between the linear and parabolic approximations valid accordingly for single curvature bending $\left(\psi_{m y}=1\right)$ and double curvature bending $\left(\psi_{m y}=-1\right)$ :

$$
B R U R=\frac{M_{y}}{M_{c y, N, R}} \leq 1
$$

where

$$
M_{c y, N, R}=M_{c y, R}\left\{\left[1-\left(\frac{1-\psi_{m y}}{2}\right)^{3}\right]\left(1-\frac{N}{N_{b y, R}}\right)+1.18\left(\frac{1-\psi_{m y}}{2}\right)^{3} \sqrt{1-\frac{N}{N_{y}}}\right\} \leq M_{c y, R}
$$

Eurocode 3 (2005) introduces the interpolation equations being distinctively different from those of Equations (5) and (6). Moreover, they include the fact that different double-tee sections have different technological imperfections affecting the buckling response. The buckling resistance of rolled double-tee section columns is dependent upon the ratio of the section depth and flange width as well as upon the flange thickness while the buckling resistance of their welded counterparts is dependent mainly upon the flange thickness.

Many recent investigations refer to interpolation equations adopted in current design codes in order to propose alternative analytical-numerical formulations that allow for even more reliable reproduction of in-plane and out-of-plane buckling resistances of real (imperfect) beam-columns. Kucukler et al. (2015) developed a direct design method, the so-called stiffness reduction method, that takes into account the detrimental influence of imperfections and effect of distributed plasticity on the buckling resistance of beam-columns. Authors of this paper refined the so-called General Method of Eurocode 3 (2005) in their study of Gizejowski et al. (2019b). The study was referred to wide flange double-tee beam-columns of the size ratio $h / b \leq 1.2$ (symbol $\mathrm{H}$ was used for such section identification). For the buckling resistance of $\mathrm{H}$-section beam-columns, the degrading effect of imperfections, as well as the effect of inelastic stress redistributions across the sections and the member length were suitably included in the proposed formulation. For evaluating the in-plane buckling resistance of $\mathrm{H}$-section beamcolumns, the amplified second-order formulation developed introduced the model parameters which were calibrated (Gizejowski et al. 2019a). Since the developed approach would rather be considered as general but model parameters were calibrated for $\mathrm{H}$-section beam-columns, it needs to be verified when postulated to be used in the buckling resistance prediction of I-section beam-columns for which $h / b>1.2$. This study is entirely devoted to this issue.

Firstly, a brief description of the proposed model is presented. Next, the model parameters are calibrated for I-section beam-columns subjected to unequal end moments. The verification exercise is carried out by using FEM results from a numerical shell model built up within the framework of ABAQUS software. Resultant calibrated model parameters for I-section beam-columns are compared with those developed earlier for $\mathrm{H}$-section beam-columns. Finally, the results from the 
proposed model and calibrated model parameters were compared with those obtained with the use of interpolation formulas adopted in Eurocode 3 (2005) in which the interaction factors were evaluated according to Methods 1 and 2 according to respectively Annexes A and B of that code. Conclusions with regard to engineering practice are formulated.

\section{ANALYTICAL MODEL FOR IN-PLANE BUCKLING RESISTANCE}

\subsection{Brief description of proposed model}

The base model was studied and its details were presented and discussed in the authors original paper of Gizejowski et al. (2019a). In the following, the proposed model based on a linear combination of elementary resistance utilisation ratios is called the refined analytical formulation (RAF).

\subsection{Finite element simulations and calibration of I-section beam-column model parameters}

A representative narrow flange section of IPE 180 made of steel grade S235 is used. Beamcolumns of the comparative slenderness ratio being the same as those used for $\mathrm{H}$-section members of HEB 300 in Gizejowski et al. (2019a) are used, namely 0.5, 1.0, 1.5. The method of equivalent geometric imperfection is used for numerical simulations. The imperfection amplitude was calculated according to Eurocode 3 (2005) using the plastic properties of the section. For the I-section used in simulations, the Eurocode's buckling curve " $a$ " is relevant, therefore the imperfection factor of $\alpha_{y}=0.21$ has to be used. The results of the finite element method simulations (FEM) were obtained using ABAQUS software with shell modelling techniques. The constitutive steel model was piece-wise-linear elastic-plastic with isotropic hardening. More details can be found in Gizejowski et al. (2019a).

\subsection{Comparison of model parameters for I- and H-section beam-column}

In Table 1, the values of calibrated model parameters are summarized for I- and H-section beam-columns (for H-section members, see Gizejowski et al. 2019a).

Figure 1 shows the comparison, in dimensionless coordinates, of the in-plane resistance curves of I-section and $\mathrm{H}$-section beam-columns under unequal end moments and two extreme cases of moment gradient ratios, namely $\psi_{m y}=1$ and -1 and three slenderness ratios.

From the comparison of results presented in Figure 1 one can observe that zones of the stable behaviour of $\mathrm{I}$ - and $\mathrm{H}$-section beam-columns are not identical. The zone bounded by the ultimate strength curves for I-section beam-columns is greater than that for $\mathrm{H}$-section of corresponding slenderness ratios. It is visible good consistency between RAF and FEM results for members of IPE 180 cross-section, as well. Comparison of the in-plane resistance results of RAF and FEM for members of HEB 300 were presented in Gizejowski et al. (2019a).

Table 1. Comparison of model parameters for I- and H-section beam-columns.

\begin{tabular}{llllll}
\hline & \multicolumn{2}{l}{ Section depth } & & \multicolumn{2}{l}{ Member length } \\
\cline { 2 - 3 } \cline { 6 - 7 } Redistribution & $c_{c y}$ & & & $c_{b y}$ & $\gamma$ \\
\hline H-section & 3.75 & 2.0 & & 3.75 & 2.0 \\
I-section & 3.75 & 3.0 & & 11.25 & 3.0 \\
\hline
\end{tabular}


a)

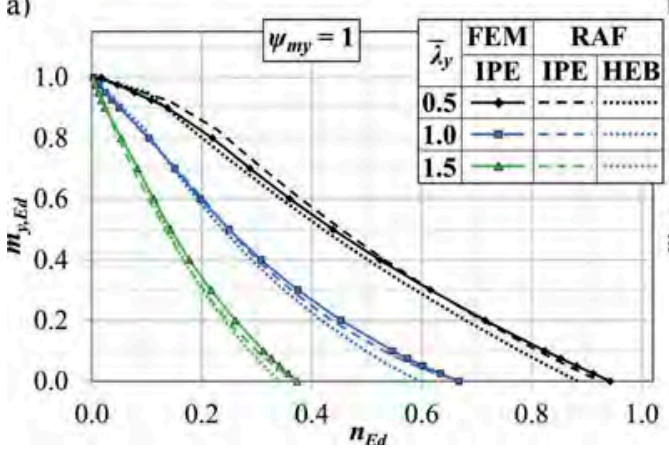

b)

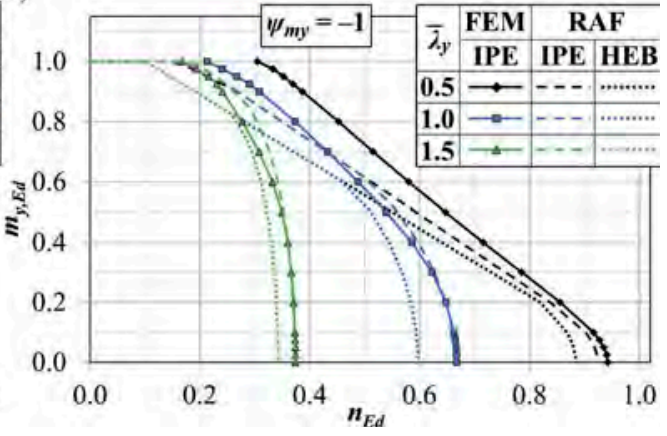

Figure 1. Comparison of ultimate strength curves for I- and H-section beam-columns: a) $\psi_{m y}=1$; b) $\psi_{m y}=-1$.

\section{COMPARISON USING EUROCODE'S INTERPOLATION RELATIONSHIP}

\subsection{Brief description of Eurocode 3 interpolation relationship approach}

Eurocode 3 (2005) provides a set of resistance interpolation functions for the section resistance and the member buckling resistance as well as the interaction factors of the latter are obtained with the use of Method 1 (Annex A, background given by Boissonnade et al. 2004) or Method 2 (Annex B, background given by Greiner \& Lindner 2006).

\subsection{Presentation of results}

Figure 2 shows the comparison, in dimensionless coordinates, of the in-plane resistance curves of I-section beam-columns under unequal end moments and two moment gradient ratios, namely $\psi_{m y}=1$ (symmetrical bending) and -1 (antisymmetrical bending) and three slenderness ratios. Results from the authors' analytical model with the model parameters of the present study (marked as RAF) are compared with those from the Eurocode's interpolation relationships and interaction factors according to Method 1 (marked as EN-M1).

From the comparison of results presented in Figure 2 one can observe that curves of present study, verified positively with the use of FEM simulations (see Figure 1), are generally placed above those based on the Eurocode 3 (2005) and member interpolation equations with the use of interaction factors according to Method 1 . In case of the uniform bending moment $\left(\psi_{m y}=1\right)$

a)

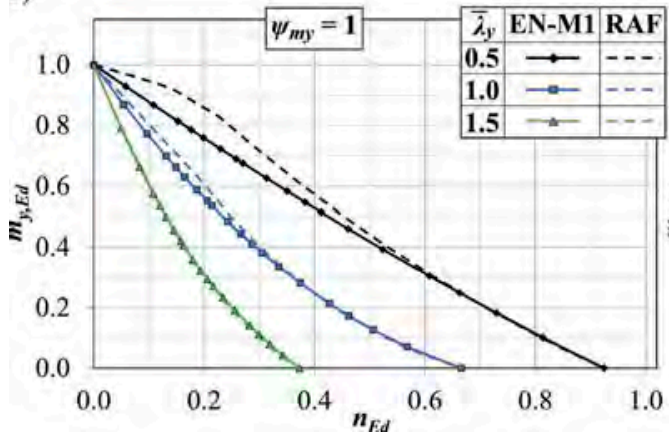

b)

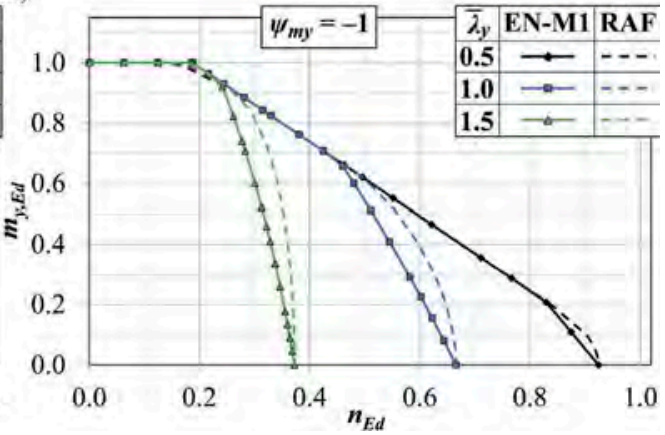

Figure 2. Comparison of ultimate strength curves of present study and Method 1 Eurocode's interpolation relationships: a) $\psi_{m y}=1$; b) $\psi_{m y}=-1$. 
a)

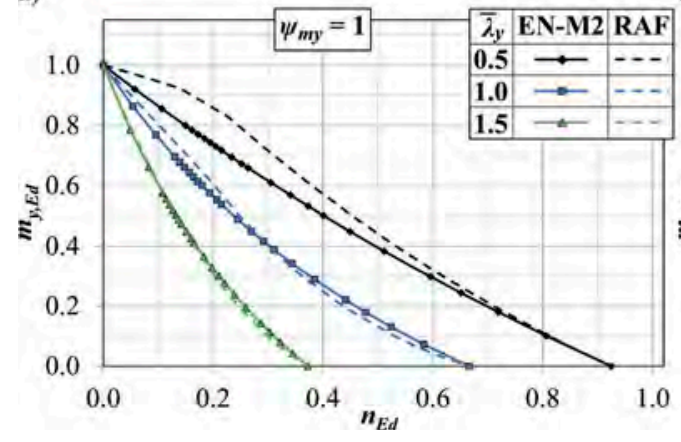

b)

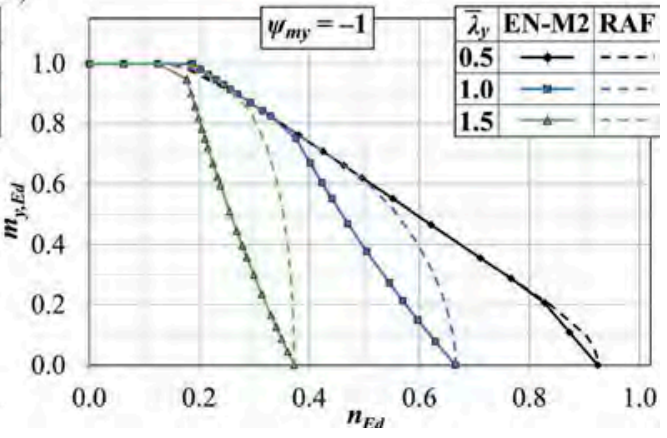

Figure 3. Comparison of ultimate strength curves of present study and Method 2 Eurocode's interpolation relationships: a) $\psi_{m y}=1$; b) $\psi_{m y}=-1$.

and the member slenderness ratio equals to 1.0 and 1.5 both analytical formulations are close to each other. Good consistency between considered methods is for the antisymmetric moment diagram $\left(\psi_{m y}=-1\right)$ and the member slenderness ratio 0.5 , as well. The difference is increasing with decreasing value of the moment gradient ratio $\psi_{m y}$ where an antisymmetric loading component is more important.

Figure 3 shows the comparison of the RAF developed herein for I-section beam-columns and the results of the Eurocode's interpolation relationships and interaction factors according to Method 2 (marked as EN-M2). Results are presented for the same moment gradient ratios $\psi_{m y}$ and slenderness ratios as in Figure 2. Observing the results of the conducted comparison, one can conclude that curves of the present study are practically above those calculated from Eurocode's interaction equations and interaction factors according to Method 2, especially for antisymmetrical bending moment. In case of the uniform bending moment $\left(\psi_{m y}=1\right)$ and the member slenderness ratio equals to 1.0 and 1.5 both analytical formulations are close to each other. The same observation is for the antisymmetric moment diagram $\left(\psi_{m y}=-1\right)$ and the member slenderness ratio 0.5 . The highest differences between all methods presented in Figures 2 and 3 are for $\psi_{m y}=-1$ and the member slenderness ratio 1.0 and 1.5 .

\section{CONCLUDING REMARKS}

In this paper, based on the concept of an approximate method of the evaluation of inelastic second-order resistance of beam-columns presented by Gizejowski et al. (2019a), the model parameters for narrow flange I-section beam-columns were developed. Investigations concerned the functions for accounting an approximate inclusion of distributed plasticity effects of plastic zones (stress redistribution along the member length) and within the member most stressed section (stress redistribution across the most stressed section depth).

The results presented in Figures 2 and 3 indicate that the analytical model developed in Gizejowski et al. (2019a) for the in-plane buckling resistance is considerably less conservative than that of Eurocode's Method 1 and Method 2. The comparison of results in Figures 2 and 3 clearly supports the conclusion that the concept of the so-called equivalent uniform moment factor used in Eurocode 3 (2005) results in significantly more conservative results, specifically for the antisymmetrical loading component $\left(\psi_{m y}=-1\right)$ and when Eurocode's Method 2 is used. The advantage of the proposed formulation is that there is no need for the introduction of any equivalent moment factor. The developed model has a simple physical interpretation and is based on a linear combination of elementary resistance utilisation ratios. In addition, the proposed analytical model has only one design condition instead of 
two required by Eurocode 3 (2005), where the cross-section capacity and the overall stability must be checked separately.

The verification of the results presented in subsection 2.3 and Gizejowski et al. (2019a) indicates that the proposed analytical model of the in-plane buckling resistance represents the behaviour of imperfect I- and H-section beam-columns with sufficient accuracy for practical applications for any value of the moment gradient ratio or member slenderness ratio.

\section{REFERENCES}

Boissonnade, N., Jaspart, J.-P., Muzeau, J.-P. \& Villette, M. 2004. New interaction formulae for beam-columns in Eurocode 3: The French-Belgian approach. Journal of Constructional Steel Research 60: 421-431.

Eurocode 3 2005. Design of steel structures, Part 1-1: General rules and rules for buildings. Brussels: European Committee for Standrization.

Gizejowski, M.A., Stachura, Z., Szczerba, R.B. \& Gajewski, M.D. 2019a. Buckling resistance of steel I-section beam-columns: in-plane buckling resistance. Journal of Constructional Steel Research 157: $347-358$.

Gizejowski, M.A., Stachura, Z., Szczerba, R.B. \& Gajewski, M.D. 2019b. Out-of-plane buckling resistance of rolled stel H-section beam-columns under unequal end moments. Journal of Constructional Steel Research 160: 153-168.

Gizejowski, M.A. \& Stachura, Z. 2020. On evaluation of maximum second order elastic moment of steel elements under compression and bending being produced by moment applied at supports. Inżynieria $i$ Budownictwo 76(4-5): 228-231 [in Polish].

Greiner, R. \& Lindner, J. 2006. Interaction formulae for members subjected to bending and axial compression in Eurocode 3: The Method 2 approach. Journal of Constructional Steel Research 62: 757-770.

Kucukler, M., Gardner, L. \& Macorini, L. 2015. Flexural-torsional buckling assessment of steel beam-columns through a stiffness reduction method. Engineering Structures 101: 662-676.

Simoes da Silva, L., Simoes, R. \& Gervasio, H. 2016. Design of steel structures. Eurocode 3: Design of steel structures, part 1-1 - General rules and rules for buildings (Second edition). ECCS Eurocode Design Manuals. Berlin: Wilhelm Ernst \& Son.

Trahair, N.S., Bradford, M.A., Nethercot, D.A. \& Gardner, L. 2008. The behaviour and design of steel structures to EC3 (Fourth edition). Abington: Taylor \& Francis. 


\title{
Robust optimisation of a single-layer lattice dome
}

\author{
P. Zabojszcza \& U. Radoń \\ Faculty of Civil Engineering and Architecture, Kielce University of Technology, Kielce, Poland \\ P. Tauzowski \\ Department of Information and Computational Science, Institute of Fundamental Technological Research \\ Polish Academy of Sciences, Warsaw, Poland
}

\begin{abstract}
The formulation of deterministic optimization in no way takes into account the randomness of the design variables [Chybiński, M., Garstecki, A. (2017), Czubacki, R., Lewiński T. (2020)]. Optimum structures are particularly sensitive to parameter imperfections. Optimal solutions located on the border of the acceptable area may relatively easily turn out to be completely useless if the parameter values differ from the assumed nominal values. It seems natural to extend the formulation of deterministic optimization, which takes into account the uncertainty of parameter values. Robust optimization proposed in the paper offers such possibilities. In the paper, robust optimisation is discussed on the example of a single-layer lattice covering. After dimensioning the individual groups of bars, the safety level of the structure was assessed by determining the reliability index and failure probability. The structure under analysis is susceptible to stability failure resulting from the condition of the node snap-through. On this basis, a displacement limit function was adopted, which refers to the maximum displacement value at the instant of the node snap-through. Next, two methods of structure optimisation (deterministic and robust), based on analogous constraints and objective function, were compared. The comparison of both methods ends with a reassessment of the safety level of the structure. As a result of robust optimization, a structure with a slightly larger mass was obtained. The difference in the weight of the structure in the case of deterministic and immunity optimization did not exceed $2 \%$. However, the reliability index, which measures the safety of the structure, has increased significantly. At the expense of a slight increase in weight, we obtained a structure that is more reliable and resistant to the dispersion of parameters characterizing the structure's operation.
\end{abstract}

\section{INTRODUCTION}

The notion 'robust design' covers broadly understood methodology of designing structures, devices and also manufacturing processes, which aims to find a solution showing the highest resistance to changes in parameters. At the same time, high functionality of the systems designed is to be maintained. Reduction in the variance of quantities that characterize the structure performance can be achieved by either limiting, or eliminating the scatter of the values of input parameters. In practice, such an approach generates too high costs, making it unviable. A far better method involves a choice of selected design variables made in such a way that a design resistant to parameter variances is obtained, but variances in the structure random parameters do not change. Robust optimisation falls into the methodology category specified above. 


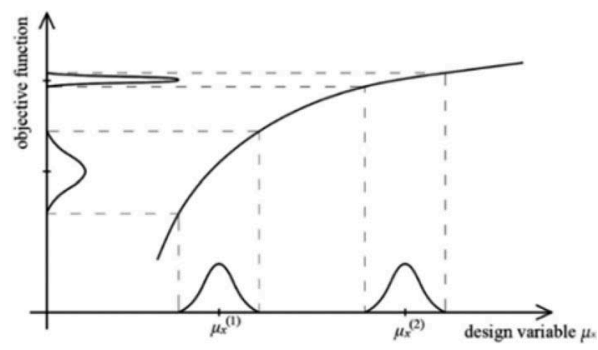

Figure 1. The concept of robust optimisation for a single design variable.

The concept of robust optimisation, shown in Figure 1, is explained on the example of a problem with one design variable $\mathrm{X}$. When a constant variance of the $\mathrm{X}$ random variable is assumed, it can be observed that for the solution $\mu_{\mathrm{X}}{ }^{(2)}$, the objective function variance is decidedly lower than for solution $\mu_{\mathrm{X}}{ }^{(1)}$. In the latter case, the reduction in the average value of the objective function is accompanied by a significant increase in variance.

Robust optimisation represents non-deterministic optimisation formulations. That is due to the fact this approach takes into account the impact of the random nature of the structure parameters on the scatter of the structure response, which usually leads to an increase in the structure reliability. A typical objective function in robust optimisation problem usually includes terms of the mean value, and of variance of the structure response function. Constraints can be deterministic, or can be expressed by the first two statistical moments of response. Contrary to other optimisation types (e.g. reliability optimisation), imprecise determination of types of probability distributions is not of primary importance. The values of the first statistical moments of the structure responses depend primarily on the first moments of random variables. When relevant data are not available, a uniform or normal distribution of variables is often assumed [Błachowski et al. (2020), Tauzowski et al. (2019)]. Interesting modern optimization methods using e.g. genetic algorithms are presented in the paper [Miller, Ziemiański (2020)]. The paper [Rozvany et al (2014)] deals with so-called "optimal plastic design" of trusses with multiple loads, which is based on ultimate load limit principles and requires only statical admissibility of the solution.

\section{PROBLEM FORMULATION}

The aim of robust optimisation is a simultaneous minimization of both the average value and random variation of the objective function. The standard deviation is most often used to describe the scatter. In the formulation below, a two-element vector of the optimisation criteria is found, namely: mean value $\mathbf{E}[\mathrm{f}(\mathbf{d}, \mathbf{X}, \mathbf{P})]$, and standard deviation $\sigma[\mathrm{f}(\mathbf{d}, \mathbf{X}, \mathbf{P})]$, which accounts for multi-criteria optimisation problem formulation. The task of robust optimisation can be formulated as follows:

Find values of variables:

$$
\text { d, } \mu_{\mathbf{x}}
$$

that minimize:

$$
\{\mathbf{E}[\mathrm{f}(\mathbf{d}, \mathbf{X}, \mathbf{P})], \sigma[\mathrm{f}(\mathbf{d}, \mathbf{X}, \mathbf{P})]\}
$$

with the constraints:

$$
\mathbf{E}\left[\mathrm{g}_{\mathrm{i}}(\mathbf{d}, \mathbf{X}, \mathbf{P})\right]-\widetilde{\beta_{\mathrm{i}}} \sigma\left[\mathrm{g}_{\mathrm{i}}(\mathbf{d}, \mathbf{X}, \mathbf{P})\right] \geq 0, \quad \mathrm{i}=1, \ldots, \mathrm{k}_{\mathrm{g}}
$$




$$
\begin{array}{ll}
\sigma\left[\mathrm{c}_{\mathrm{k}}(\mathbf{d}, \mathbf{X}, \mathbf{P})\right] \leq \sigma_{k}^{u}, & \mathrm{k}=1, \ldots, \mathrm{k}_{\mathrm{c}}, \\
\mathrm{d}_{\mathrm{j}}^{l} \leq \mathrm{d}_{\mathrm{j}} \leq \mathrm{d}_{\mathrm{j}}^{u}, & \mathrm{j}=1, \ldots, \mathrm{n}_{\mathrm{d}}, \\
\boldsymbol{\mu}_{\mathrm{x} r}^{l} \leq \boldsymbol{\mu}_{\mathrm{x} r} \leq \boldsymbol{\mu}_{\mathrm{x} r}^{u}, & \mathrm{r}=1, \ldots, \mathrm{n}_{x} .
\end{array}
$$

where: $\mathbf{d}$ - deterministic design variables, $\mathbf{X}, \mathbf{P}$ - vectors of random variables with expected values of $\boldsymbol{\mu}_{\mathrm{x}}, \boldsymbol{\mu}_{\mathrm{p}}, \mathrm{f}-$ objective function, $\mathrm{g}_{\mathrm{i}}$ - functions of constraints $\mathrm{c}_{\mathrm{k}}-$ functions, the standard deviations of which must not exceed the allowable values $\sigma_{\mathrm{k}}^{u}, \beta_{\mathrm{i}}>0$ - coefficients corresponding to the constraints $\mathrm{g}_{\mathrm{i}} \geq 0$ which represent the safety margin with which these constraints must be met.

The concept of constraints is shown in Figure 2. While solving the problem of robust optimisation, it is sought that, at the optimum point, the mean values of the constraint functions $\mathrm{g}_{\mathrm{i}}$, $\mathrm{i}=1, \ldots, \mathrm{k}_{\mathrm{g}}$, should be shifted away from zero by at least $\widetilde{\beta_{\mathrm{i}}}$ standard deviations. A very popular way to solve multi-criteria optimisation tasks is to employ the problem scalarization method. In the method, a linear combination of criteria is used as an objective function. Consequently, the problem (7) - (12) can be modified to obtain the following scalar optimisation problem:

Find values of variables:

$$
\text { d, } \mu_{\mathbf{x}}
$$

that minimize:

$$
\widetilde{\mathrm{f}}=\frac{1-\alpha}{\boldsymbol{\mu}^{*}} \mathbf{E}[\mathbf{f}(\mathbf{d}, \mathbf{X}, \mathbf{P})]+\frac{\alpha}{\sigma^{*}} \sigma[\mathrm{f}(\mathbf{d}, \mathbf{X}, \mathbf{P})]
$$

with the constraints:

$$
\begin{array}{lr}
\mathbf{E}\left[\mathrm{g}_{\mathrm{i}}(\mathbf{d}, \mathbf{X}, \mathbf{P})\right]-\widetilde{\beta_{\mathrm{i}}} \sigma\left[\mathrm{g}_{\mathrm{i}}(\mathbf{d}, \mathbf{X}, \mathbf{P})\right] \geq 0, & \mathrm{i}=1, \ldots, \mathrm{k}_{\mathrm{g}}, \\
\sigma\left[\mathrm{c}_{\mathrm{k}}(\mathbf{d}, \mathbf{X}, \mathbf{P})\right] \leq \sigma_{\mathrm{k}}^{u}, & \mathrm{k}=1, \ldots, \mathrm{k}_{\mathrm{c}}, \\
\mathrm{d}_{\mathrm{j}}^{l} \leq \mathrm{d}_{\mathrm{j}} \leq \mathrm{d}_{\mathrm{j}}^{u}, & \mathrm{j}=1, \ldots, \mathrm{n}_{\mathrm{d}}, \\
\mu_{\mathrm{x} r}^{l} \leq \mu_{\mathrm{x} r} \leq \mu_{\mathrm{x} r}^{u}, & \mathrm{r}=1, \ldots, \mathrm{n}_{x} .
\end{array}
$$

The weight coefficient $\alpha \in[0,1]$, found in formula (8), specifies the relevance of each of the criteria, whereas $\mu^{*}$ and $\sigma^{*}$ are normalizing constants. Assuming $\alpha=0$, the optimisation problem is converted into a typical task of minimising the mean value. For $\alpha=1$, however,

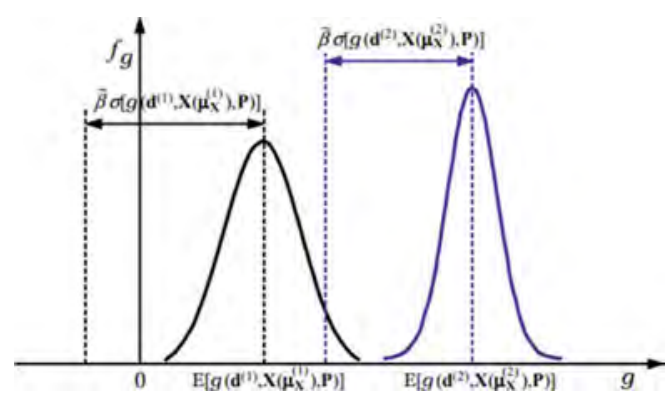

Figure 2. The concept of constraints in the robust optimisation. 
optimisation becomes the problem of minimising the objective function variance. A key element of the algorithm employed to perform the robust optimisation task involves an effective method of estimating mean values and standard deviations of the objective function and the constraint function [Stocki et al. (2012)].

\section{EXAMPLE}

In the study, a steel single-layer lattice dome loaded with force $\mathrm{P}=3.665 \mathrm{kN}$ at each node was analysed. The members of the dome were designed to be made of S235 steel, with yield strength $\mathrm{f}_{\mathrm{y}}=235 \mathrm{MPa}$, Young's modulus $\mathrm{E}=210 \mathrm{GPa}$ and Poisson index $\mathrm{v}=0.3$. The geometry of the dome of concern is shown in Figure 3 and Table 1. The weight of the structure modelled is Mass $=813.5139 \mathrm{~kg}$.

In the structure, three groups of bars were specified as shown in Table 2.

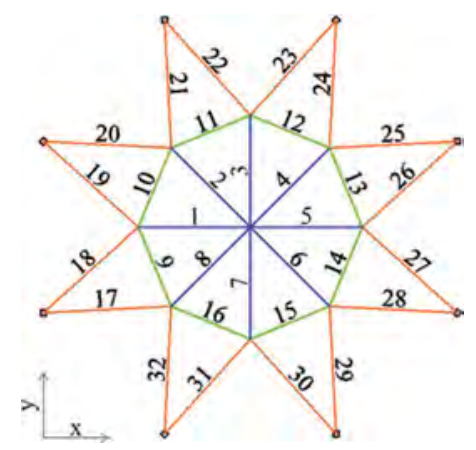

Figure 3. The lattice dome geometry.

Table 1. The lattice dome geometry.

\begin{tabular}{|c|c|c|c|c|c|c|c|}
\hline \multirow{2}{*}{$\begin{array}{l}\text { Node } \\
\text { number }\end{array}$} & $X$ & $\mathrm{Y}$ & Z & \multirow{2}{*}{$\begin{array}{l}\text { Node } \\
\text { number }\end{array}$} & $X$ & $\mathrm{Y}$ & $\mathrm{Z}$ \\
\hline & {$[\mathrm{cm}]$} & {$[\mathrm{cm}]$} & {$[\mathrm{cm}]$} & & {$[\mathrm{cm}]$} & {$[\mathrm{cm}]$} & {$[\mathrm{cm}]$} \\
\hline 1 & 646.716 & 646.716 & 46.000 & 10 & 378.837 & 1293.431 & 0.0 \\
\hline 2 & 646.716 & 996.716 & 34.000 & 11 & 914.594 & 1293.431 & 0.0 \\
\hline 3 & 894.203 & 894.203 & 34.000 & 12 & 1293.431 & 914.594 & 0.0 \\
\hline 4 & 996.716 & 646.716 & 34.000 & 13 & 1293.431 & 378.837 & 0.0 \\
\hline 5 & 894.203 & 399.228 & 34.000 & 14 & 914.594 & 0.0 & 0.0 \\
\hline 6 & 646.716 & 296.716 & 34.000 & 15 & 378.837 & 0.0 & 0.0 \\
\hline 7 & 399.228 & 399.228 & 34.000 & 16 & 0.0 & 378.837 & 0.0 \\
\hline 8 & 296.716 & 646.716 & 34.000 & 17 & 0.0 & 914.594 & 0.0 \\
\hline 9 & 399.228 & 894.203 & 34.000 & & & & \\
\hline
\end{tabular}

Table 2. Cross-sections adopted for individual groups of bars.

\begin{tabular}{lll}
\hline Group name & Bar numbers & Profile \\
\hline Meridian_1 (Blue) & 1 to 8 & RO54 $\times 3.6$ \\
Meridian_2 (Orange) & 17 to 32 & RO60.3 6.3 \\
Ring (Green) & 9 to 16 & RO51x6.3 \\
\hline
\end{tabular}


Table 3. Values of axial forces and load capacity for the most stressed members of the structure and values of the maximum vertical and horizontal displacements for nodes 2-9.

\begin{tabular}{llll}
\hline Internal force/Load capacity & $\begin{array}{l}\text { Meridian_1 } \\
\text { Bar no. } 7\end{array}$ & $\begin{array}{l}\text { Meridian_2 } \\
\text { Bar no. 30 }\end{array}$ & $\begin{array}{l}\text { Ring Bar } \\
\text { no. 15 }\end{array}$ \\
\hline Ned [kN] - axial force & 12.664 & 25.093 & 31.976 \\
Strength utilisation [\%] & 46 & 55 & 56 \\
Maximum vertical displacement [mm] & 1.071 & & \\
Allowable vertical displacement [mm]-D/300 & 4.667 & & \\
Maximum horizontal displacement [mm] & 0.06 & & \\
Allowable horizontal displacement [mm] - H/150 & 0.307 & & \\
\hline
\end{tabular}

Table 3 collates the values of internal forces and load capacity for the most stressed elements of individual bar groups and limit values of displacements of nodes 2 to 9 .

\subsection{Reliability analysis}

The first stage involved structure reliability analysis in which the Monte Carlo method was used. Geometric characteristics of cross-sections ( $A_{\mathrm{i}}$ - area of successive bar groups) and heights of individual structure nodes $(Z i)$ were assumed as random variables. The description of random variables is shown in Table 4 . The variables are not correlated.

The structure under analysis is susceptible to stability failure resulting from the condition of the node snap-through. On this basis, a displacement limit function was adopted, which refers to the maximum displacement value at the instant of the node snap-through:

$$
\mathrm{f}_{\mathrm{s}}=1-\frac{w(\mathbf{x})}{\mathrm{W}_{\max }}=1-\frac{w(\mathbf{x})}{1.841}
$$

where: $w(\mathbf{x})$ - node 2 displacement, $\mathrm{w}_{\max }$ - node 2 displacement at the instant of the snapthrough.

The value of the reliability index, at the instant the structure was loaded with force $\mathrm{P}=$ $3.665 \mathrm{kN}$, was $\beta=2.138$, whereas the failure probability was $\mathrm{p}_{\mathrm{f}}=0.016$.

\subsection{Deterministic optimisation}

The second stage involved the deterministic optimisation. The design variables were crosssectional areas of the individual bar groups. The following notation was adopted for the variables: Meridian_1: A1, Meridian_2: A2, and Ring: A3. The objective function was the structure weight:

Table 4. Description of random variables.

\begin{tabular}{|c|c|c|c|c|c|c|c|}
\hline \multirow{2}{*}{$\begin{array}{l}\text { Random } \\
\text { variables } X_{\mathrm{i}}\end{array}$} & $\begin{array}{l}\text { Mean } \\
\text { values }\end{array}$ & $\begin{array}{l}\text { Standard } \\
\text { deviation }\end{array}$ & $\begin{array}{l}\text { Variation } \\
\text { coefficient }\end{array}$ & \multirow{2}{*}{$\begin{array}{l}\text { Random } \\
\text { variables } X_{\mathrm{i}}\end{array}$} & $\begin{array}{l}\text { Mean } \\
\text { values }\end{array}$ & $\begin{array}{l}\text { Standard } \\
\text { deviation }\end{array}$ & $\begin{array}{l}\text { Variation } \\
\text { coefficient }\end{array}$ \\
\hline & {$[\mathrm{cm}]$} & {$[\mathrm{cm}]$} & {$[\%]$} & & {$[\mathrm{cm}]$} & {$[\mathrm{cm}]$} & {$[\%]$} \\
\hline$A_{1}$ & 5.7 & 0.285 & 5 & $Z 4$ & 34 & 0.34 & 1 \\
\hline$A_{2}$ & 10.7 & 0.535 & 5 & $Z 5$ & 34 & 0.34 & 1 \\
\hline$A_{3}$ & 8.85 & 0.443 & 5 & Z6 & 34 & 0.34 & 1 \\
\hline$Z 1$ & 46 & 0.46 & 1 & $Z 7$ & 34 & 0.34 & 1 \\
\hline$Z 2$ & 34 & 0.34 & 1 & $Z 8$ & 34 & 0.34 & 1 \\
\hline$Z 3$ & 34 & 0.34 & 1 & $Z 9$ & 34 & 0.34 & 1 \\
\hline
\end{tabular}




$$
\mathrm{f}_{\mathrm{C}}=\operatorname{minimum}(\text { Mass })
$$

Simple constraints are shown in Table 5. They constitute the upper and lower boundary of the design variables being sought.

The inequality constraint was formulated as a condition of non-exceedance of the allowable node vertical displacement:

$$
\mathrm{g}(\mathbf{x})=w-\mathrm{w}_{\max }=\mathrm{w}-1.841<0
$$

The deterministic optimisation was carried out using the Nelder Mead simplex method at the maximum number of iterations $\mathrm{N}=1000$, and the convergence parameter $\epsilon=1.0 \mathrm{E}-08$.

The dimensions of cross-sections obtained for individual bar groups are summarised in Table 6. The value of the objective function was $f_{C}=772.924 \mathrm{~kg}$. The failure probability and the reliability index, which in this case amounted to: $\mathrm{p}_{\mathrm{f}}=0.034, \beta=1.824$, respectively, were also verified.

\subsection{Robust optimisation}

As regards robust optimisation, random variables, design variables, the objective function and constraints were defined. The value of the variation coefficient was set at $5 \%$. For the case of concern, the robust optimisation task takes on the following form:

1. Find the values of variables: $A 1, A 2, A 3$

2. That minimise: $\mathrm{f}_{\mathrm{C}}=\frac{1-\alpha}{\eta *} \mathbf{E}[$ Mass $]+\frac{\alpha}{\sigma *} \boldsymbol{\sigma}[$ Mass $]$

3. With the constraints:

$$
\begin{aligned}
& \mathbf{E}[w-1.841]-\beta \cdot \boldsymbol{\sigma}[w-1.841] \geq 0 \\
& 5.415 \leq R 1 \leq 5.985 \\
& 10.165 \leq R 2 \leq 11.235 \\
& 8.408 \leq R 3 \leq 9.293
\end{aligned}
$$

where: $\alpha \in[0,1]$ - specifies the relevance of each of the criteria, $\eta *, \sigma *$ - normalizing constants, $w$-1.841 - constraint on the allowable vertical displacement.

The dual response area method and the strategy of statistical approximation were employed. The parameters adopted were: $\alpha=0.5, \beta=2.0$. Dual response areas were

Table 5. Description of simple constraints.

\begin{tabular}{lll}
\hline Design variable & Lower boundary $[\mathrm{cm}]$ & Upper boundary $[\mathrm{cm}]$ \\
\hline$A 1$ & 5.415 & 5.985 \\
$A 2$ & 10.165 & 11.235 \\
$A 3$ & 8.408 & 9.293 \\
\hline
\end{tabular}

Table 6. Values of the design variables produced with deterministic optimization.

\begin{tabular}{ll}
\hline Random variable & Optimum value $[\mathrm{cm}]$ \\
\hline A1 & 5.415 \\
A2 & 10.167 \\
A3 & 8.408 \\
\hline
\end{tabular}


Table 7. Values of design variables obtained in the robust optimisation.

\begin{tabular}{ll}
\hline Random design variable & Optimum mean value $[\mathrm{cm}]$ \\
\hline A1 & 5.426 \\
A2 & 10.216 \\
A3 & 8.793 \\
\hline
\end{tabular}

constructed using the the Kriging method, while the experiments were designed in accordance with optimum Latin hyper-cube sampling. To solve the optimisation problem of concern, i.e. to minimise the $\mathrm{f}_{\mathrm{C}}$ function, the Nelder Mead simplex algorithm was applied.

The robust optimisation yielded the following values of the design variables shown in Table 7. In this case, the structure weight was $\mathrm{f}_{\mathrm{C}}=782.076 \mathrm{~kg}$. The robust optimisation type produced the structure weight that was slightly higher compared with that obtained with the deterministic optimisation. The reliability index increased and the failure probability decreased compared with the deterministic optimisation, for which the values were $\beta=1.951$ and $\mathrm{p}_{\mathrm{f}}=0.026$.

\section{SUMMARY}

In the example above, two methods of structure optimisation, based on analogous constraints and objective function, were compared. At the initial stage of the design, the cross-section dimensions adopted were $\mathrm{A} 1=5.7 \mathrm{~cm}^{2}, \mathrm{~A} 2=10.7 \mathrm{~cm}^{2}, \mathrm{~A} 3=8.85 \mathrm{~cm}^{2}$. The reliability index for this design situation was $\beta=2.138$. In the deterministic optimisation carried out with the Nelder-Mead simplex method, new dimensions of cross-sections were determined. A decrease in the structure weight by approx. $5 \%$ was observed. Modification of the areas led to a decrease in the reliability index to the value of $\beta=1.824$.

As a result of robust optimization, a structure with a slightly larger mass was obtained. The difference in the weight of the structure in the case of deterministic and immunity optimization did not exceed $2 \%$. However, the reliability index, which measures the safety of the structure, has increased significantly. At the expense of a slight increase in weight, we obtained a structure that is more reliable and resistant to the dispersion of parameters characterizing the structure's operation.

\section{REFERENCES}

Błachowski, B., Tauzowski, P., Logo, J., 2020, Yield limited optimal topology design of elastoplastic structures, Structural and Multidisciplinary Optimization, Vol. 61, p. 1953-1976.

Chybiński, M., Garstecki, A., 2017, Optimal rib configuration in steel welded beams and its robustness, CMM - 22nd Computer Methods in Mechanics September 13th-16th 2017, Lublin, Poland.

Czubacki, R., Lewiński, T., 2020, Optimal archgrids: a variational setting. Struct Multidisc Optim 62, 1371-1393, DOI:10.1007/s00158-020-02562-y.

Miller, B., Ziemiański, L., 2020, Optimization of dynamic behavior of thin-walled laminated cylindrical shells by genetic algorithms and deep neural networks supported by modal shape identification, Advances in Engineering Software, Volume 147, DOI: 10.1016/j.advengsoft.2020.102830, ISSN 09659978.

Rozvany, G.,I.,N., Sokół, T., Pomezanski, V., 2014, Fundamentals of exact multi-load topology optimization - stress-based least-volume trusses (generalized Michell structures) - Part I: Plastic design., Struct Multidisc Optim 50, 1051-1078, DOI: 10.1007/s00158-014-1118-7.

Stocki, R., Szolc, T., Tauzowski, P., Knabel, J., 2012, Robust design optimization of the vibrating rotor-shaft system subjected to selected dynamic constraints, Mechanical Systems and Signal Processing, Vol. 29, p. $34-44$.

Tauzowski P., Błachowski B., Logo J., 2019, Functor-oriented topology optimization of elasto-plastic structures, Advances in Engineering Software, Vol. 135. 
Structural steel, metallurgy, durability and behaviour in fire 


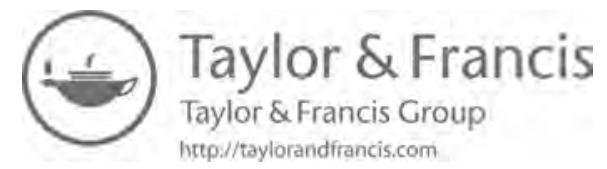




\title{
Numerical investigation on cyclic behavior of steel shear panels endowed with innovative perforation patterns
}

\author{
H.M. Ahmadi \& G. De Matteis \\ Department of Architecture and Industrial Design, University of Campania Luigi Vanviteli, Aversa, Italy
}

\begin{abstract}
Steel Plate Shear walls (SPSWs) due to their high seismic performance such as ductility and valuable energy dissipation capacity, have been deemed as an effective seismic device in buildings for protecting constructions from fatal fractures. The present study investigates the structural behavior of SPSWs with an innovative elliptical perforation pattern. The elliptical perforation pattern is consisted of ellipse-shaped holes which are located in the perimeter of the web plate same as a peripheral perforation layout. Therefore, the effectiveness of geometric properties of links between both ellipse-shaped holes and opening array on hysteretic behavior are studied numerically. To this aim, two experimental laboratory cyclic tests were initially verified through finite element models and the corresponding deformation shapes according to the Von-Mises stresses were perfectly captured. Subsequently, sixteen perforated specimens with various geometric properties of links which are different in the length and the slenderness ratios are investigated. The results show that the specimens with narrow links improve the pinching force significantly allowing for large energy dissipation capacity.
\end{abstract}

\section{INTRODUCTION}

Since 1970, Steel Plate Shear Walls (SPSWs) are deemed as one of the most effective dissipating seismic energy system, which are commonly used in high raise buildings against lateral loads (Formisano et al., 2018a). Shear panels, boundary elements, plate-frame interactions and beam-to-column connections are the main components of the SPSWs. To eliminate the fatal fracture phenomenon of the main members of SPSWs, shear panels should be designed to satisfy the inelasticity demands of structures (Formisano, et al., 2018b). Therefore, the weak shear panels and strong frame is a design approach of SPSWs to provide the inelasticity capacity of shear panels (De Matteis et al., 2009). Based on this design approach, the boundary elements of SPSWs should remain in the elastic range up to the shear panel is completely yielded before destabilizing of frame members (Monsef Ahmadi and De Matteis, 2020).

Recently, several types of shear panels have been proposed i.e., with and without perforation, with and without stiffeners, slender and compact (De Matteis et al., 2007). The perforated SPSWs, based on the opening area that are the main subject of this study, intend to decrease the shear strength and initial stiffness of shear panels to reach in earlier the plastic capacity. For this reason, these types of shear panels are an alternative of shear panels with low yield stress material which are difficult to be found in the market (De Matteis et al., 2003). However, the hysteresis response of perforated shear panels suffers pinching effect owing to the buckling phenomenon at early stage of drift (De Matteis et al., 2008). Decreasing the web plate slenderness ratio, which is the ratio of length of sheet over the thickness of web plate, is an effective option to improve the pinching behavior in the hysteresis curves of perforated shear panels (Monsef Ahmadi et al., 2020).

DOI: $10.1201 / 9781003132134-60$ 
Formisano et al. (2016) investigated several geometries of perforated shear panels under cyclic shear load. The numerical results illustrated that increasing the opening area greatly reduces the structural behavior such as shear strength, initial stiffness and energy-dissipation capacity, and also increases the ductility ratio. Similarly, a study by De Matteis et al. (2016) evaluated the effect of hourglass-shaped links that gap between circular holes, experimentally and numerically. The shear strength and initial stiffness of perforated shear panel with narrow links were decreased and reduction of the shear yielding of links by bending mode was found. Subsequently, the structural behavior of perforated shear panels in terms of pinching load was improved when the web plate slenderness decreased. For this reason, the hysteretic response of these types of perforated shear panels was plumper and the energy-dissipating capacity was increased.

Monsef Ahmadi et al. (2020) tested two perforated shear panels under cyclic shear load according to the SAC loading protocol. The perforated shear panels were constant in the opening area and web plate slenderness. The perforated specimens were cut-outed according to the code requirements and author's suggestion. The perforation pattern of author's suggestion was consisted of hourglass-shaped links that were located in the perimeter of shear panel. The experimental results proved that the second type of perforated shear panel had good structural behavior in terms of energy-dissipation capacity up to $3 \%$ of drift. Subsequently, the shear strength and initial stiffness of this type of shear panels were able to control by geometry properties of hourglass-shaped links. Likewise, the web plate slenderness had significantly influence on the hysteresis behavior according to the numerical analyses.

In this paper, the structural behavior of sixteen perforated shear panels including elliptical holes are numerically investigated. To reach the main objectives of this study, two experimented perforated shear panels are simulated and validated by finite element (FE) models through ABAQUS software. Likewise, the considered specimens which are various in length of links and area of perforation are numerically evaluated. The obtained results shown that the specimens with narrow links are able to achieve dissipative mechanisms based on bending deformation of links.

\section{CALIBRATION OF THE FEM MODEL}

\subsection{Reference tested specimens}

Two different, approximately $1 \times 1 \mathrm{~m}^{2}$, perforated shear panels with web plate thickness equal to $0.7 \mathrm{~mm}$, as shown in Figure 1 have been investigated. They were tested under cyclic shear load according to the SAC loading protocol by Monsef Ahmadi et al. (2020). The diameter of circular holes was constant and equal to $92 \mathrm{~mm}$. To obtain the pure shear behavior of perforated shear panels the beam-to-column connections were designed as a hinged connection. The hinged frame was connected to the reaction frame from right side, and also, to the hydraulic

a)

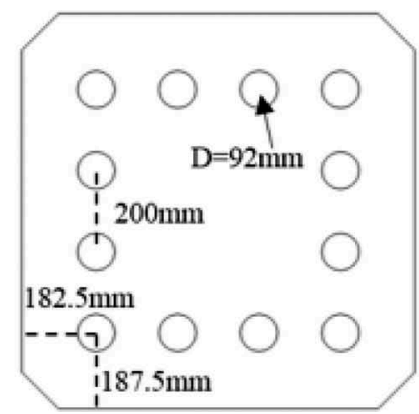

b)

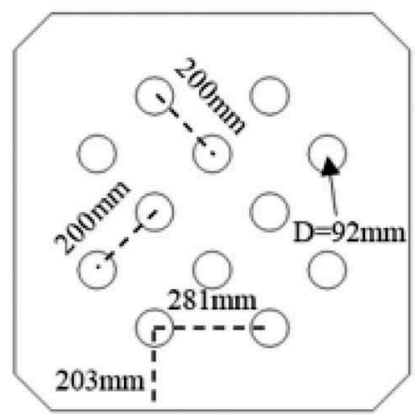

Figure 1. Tested specimens details: a) SP1 and b) SP2. 
a)

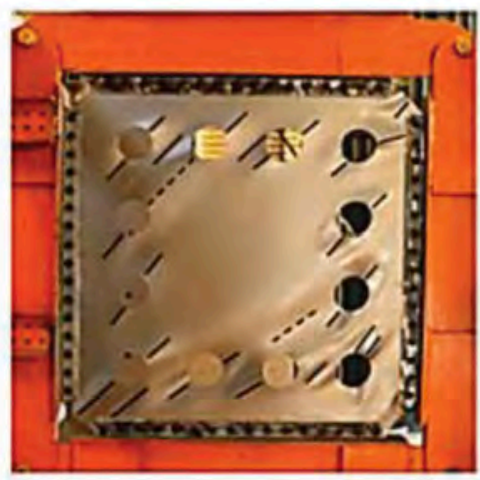

b)

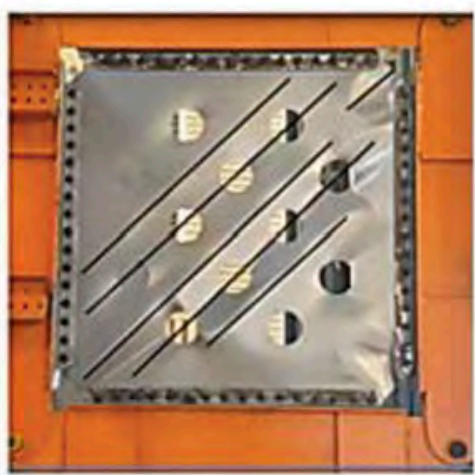

Figure 2. Failure modes: a) SP1 and b) SP2.

jack from left side. The beam element was used to transfer the cyclic load from actuator to the hinged frame. More details can be found in the reference study.

The failure modes of both tested specimens are shown in Figure 2. As experimental results, the fracture phenomenon of the SP1 and SP2 occurred around the corner holes and plate-frame interactions, respectively. Different failure modes of specimens were found. The SP1, owing to the perforation pattern, did not allow the tension field mechanism transfers into the center of the web plate. Therefore, the stress was concentrated between the holes and fracture was developed. For this reason, the shear strength of this type of perforated shear panel and ductility ratio was lower than the SP2. On the other hand, due to the shear behavior of links between circular holes in the SP1 specimen the energy dissipation capacity was larger than the SP2 up to 3\% of drift.

\subsection{Finite element ( $F E$ ) models and comparison of results}

To validate the experimental results, a FE model has been developed by ABAQUS software. The boundary elements and web plate were modeled by beam and shell elements, respectively. The TIE and HING connector types were considered in the plate-to-frame interaction and beam-to-column connections. The yield stress, modulus of elasticity and the Poisson ratio of the web plate were calibrated $180 \mathrm{MPa}, 176 \mathrm{GPa}$ and 0.3 , respectively. As the boundary elements essentially remained in the elastic range during the cyclic load condition, only the elastic properties of steel were considered. The cyclic load was attached to the beam element. The hysteretic curves are compared in Figure 3, where it is evidenced that there is a good agreement between experimental and numerical analyses.

\section{INVESTIGATED SPECIMENS}

According to the features of the SP1 type perforated shear panel, sixteen of perforated numerical models $1 \times 1 \mathrm{~m}^{2}$ including elliptical holes (SP-E), as shown in Figure 4, have been considered and analyzed. Except of length of links $(L)$ and web plate thickness $(t)$, the SP-E specimens are constant in the middle-length $(a=30 \mathrm{~mm})$ and end-length $(b=90 \mathrm{~mm})$ of links. It is worth noticing that the material properties and the load condition are like as the one considered in the reference study. Additional details of the investigated specimens are shown in Table 1.

\section{THE OBTAINED RESULTS}

The structural behavior of numerical specimens is examined in terms of maximum shear strength, initial stiffness and cumulative energy dissipation capacity up to $6 \%$ of drift. The maximum shear strength and initial stiffness are evaluated according to ECCS bilinear method. 
a)

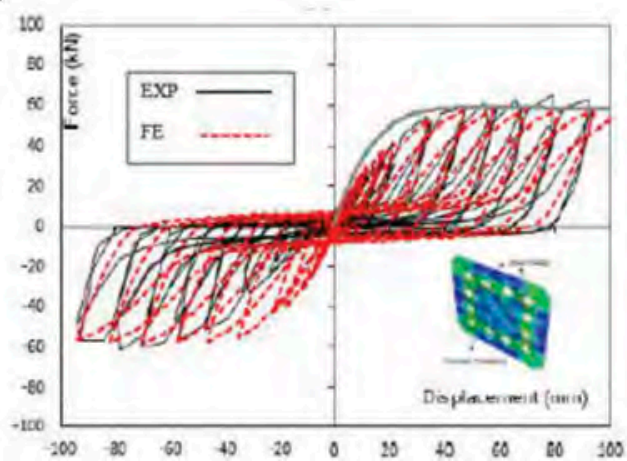

b)

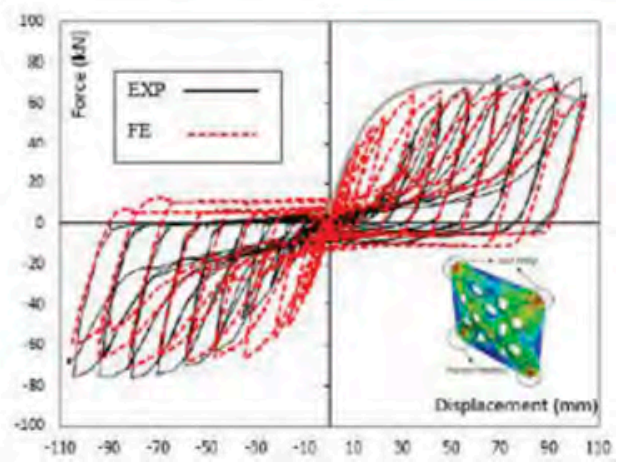

Figure 3. Comparison between experimental and numerical results: a) SP1 and b) SP2.

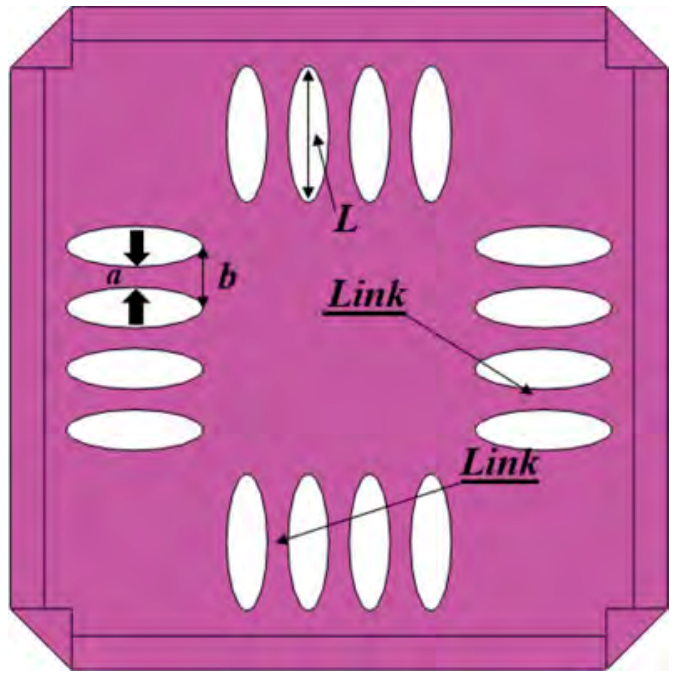

Figure 4. Schematic shapes of SP-E models.

The cumulative energy dissipation capacity was obtained by summing of the area of cyclic loops. The results of hysteresis responses of SP-E-:100-3, 150-3, 200-3, 250-3 and SP-E-:100-12, 150-12, 200-12,250-12, as an example among the tested specimens, are shown in Figure 5. As shown in Figure 5, the hysteretic responses are stable and affected by pinching phenomenon. According to the results, the shear strength, initial stiffness and energy dissipation capacity of specimens increase when the web plate slenderness decreases. On the other hand, this process repeats by increasing the slenderness of links. However, the pinching effect of specimens has been significantly improved by decreasing the web plate slenderness, and also increasing slenderness ratio of links. This is a worth achievement of this study. This is because narrow links allow concentrating the stress along the links instead of the plate-frame interaction, thus dissipating the seismic energy through a bending deformation of links. Therefore, the links under shear deformation activate a tension field mechanism over the panel surface. Likewise, the boundary elements and plate-frame interactions are prone to fracture phenomenon. The shear strength, initial stiffness, cumulative energy dissipation capacity and ratio of maximum shear strength over yield strength are compared in Figure 6. It is apparent that the structural behavior of the considered specimens improves as the web plate slenderness decreases. 
Table 1. Main parameters of the considered specimens.

\begin{tabular}{|c|c|c|c|c|}
\hline \multirow[b]{2}{*}{ Specimens } & \multicolumn{2}{|c|}{ Dimensions } & \multicolumn{2}{|c|}{ Slenderness } \\
\hline & $t(\mathrm{~mm})$ & $L(\mathrm{~mm})$ & Plate & Link \\
\hline SP-E-100-3 & 3 & 100 & 322 & 33 \\
\hline SP-E-100-6 & 6 & 100 & 161 & 17 \\
\hline SP-E-100-9 & 9 & 100 & 107 & 11 \\
\hline SP-E-100-12 & 12 & 100 & 80 & 8 \\
\hline SP-E-150-3 & 3 & 150 & 322 & 50 \\
\hline SP-E-150-6 & 6 & 150 & 161 & 25 \\
\hline SP-E-150-9 & 9 & 150 & 107 & 17 \\
\hline SP-E-150-12 & 12 & 150 & 80 & 12.5 \\
\hline SP-E-200-3 & 3 & 200 & 322 & 67 \\
\hline SP-E-200-6 & 6 & 200 & 161 & 33 \\
\hline SP-E-200-9 & 9 & 200 & 107 & 22 \\
\hline SP-E-200-12 & 12 & 200 & 80 & 17 \\
\hline SP-E-250-3 & 3 & 250 & 322 & 83 \\
\hline SP-E-250-6 & 6 & 250 & 161 & 42 \\
\hline SP-E-250-9 & 9 & 250 & 107 & 28 \\
\hline SP-E-250-12 & 12 & 250 & 80 & 21 \\
\hline
\end{tabular}

a)

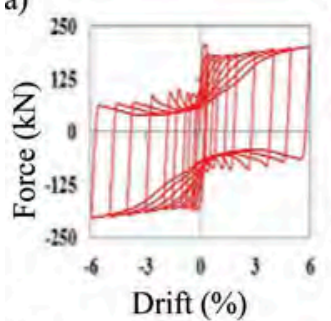

e)

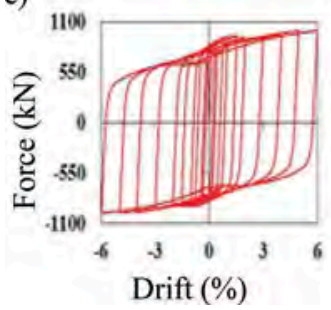

b)

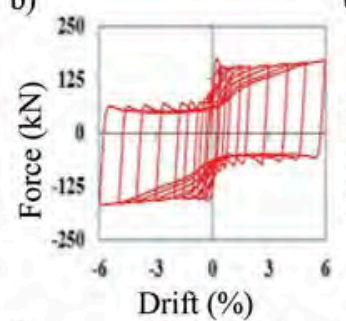

f)

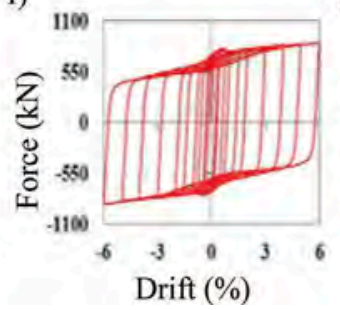

c)

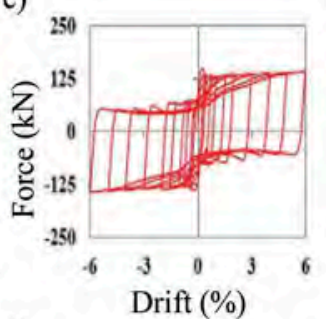

g)

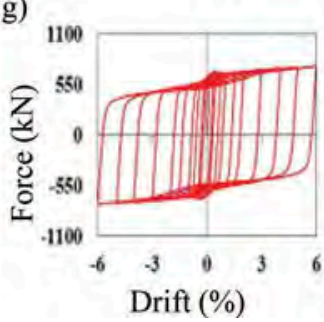

d)

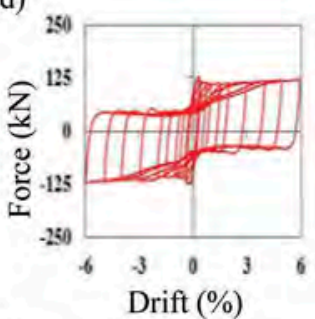

h)

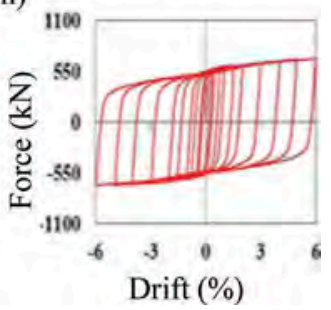

Figure 5. Hysteretic curves for considered specimens: a) SP-E-100-3, b) SP-E-150-3, c) SP-E-200-3, d) SP-E-250-12, e) SP-E-100-12, f) SP-E-150-12, g) SP-E-200-12, and h) SP-E-250-12.

\section{CONCLUSION}

In this paper, sixteen specimens of perforated shear panels have been modeled and analyzed through finite element (FE) method by ABAQUS software. The computational models considered elliptical holes which were constant in the middle-length and endlength of the links between two elliptical-shaped holes. The effectiveness of slenderness ratios of the web plate and links on structural behavior of FE models have been deeply evaluated. 

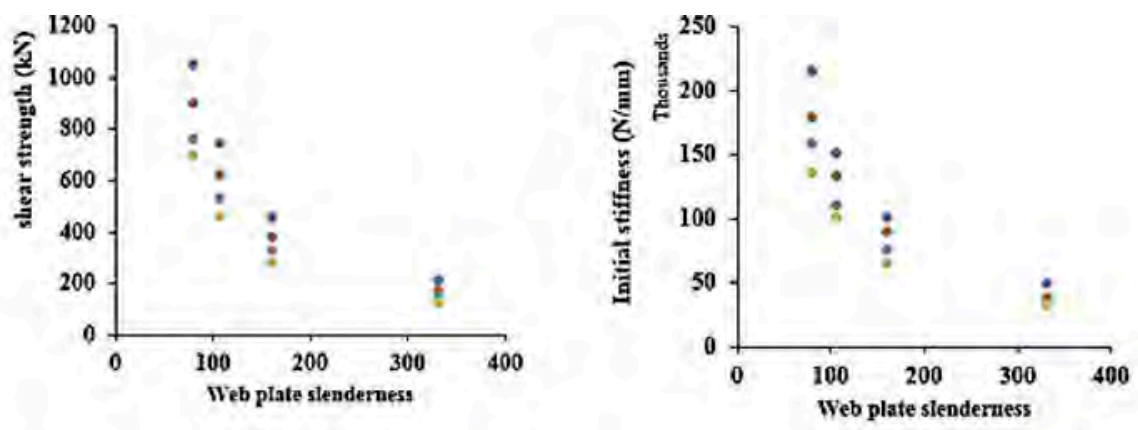

$-\mathrm{L}=100 \mathrm{~mm}$
$\cdot \mathrm{L}=150 \mathrm{~mm}$
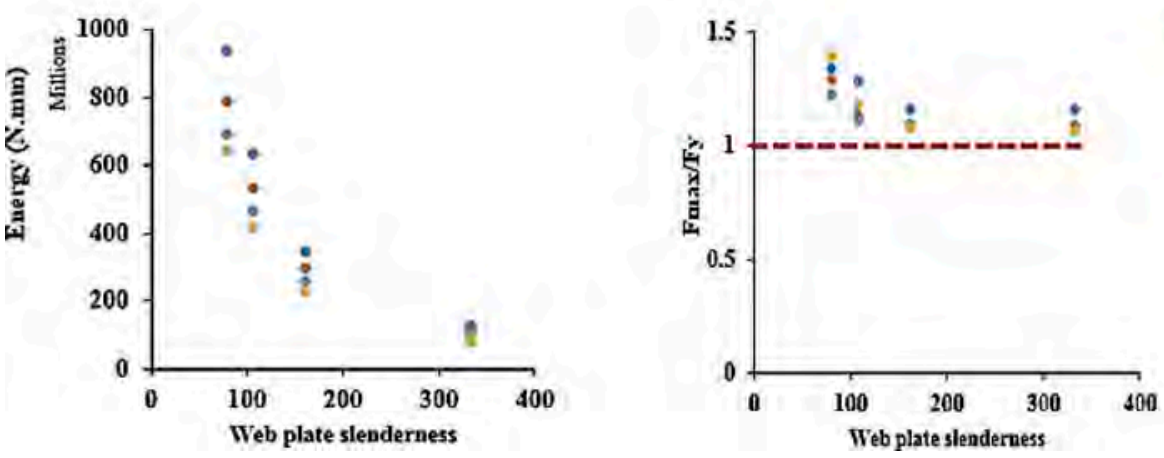

Figure 6. Structural behavior of elliptical perforated shear panels.

The results indicated that the structural behavior of elliptical perforated shear panels could be controlled by geometric properties of the links. As a result, the shear panels with higher slenderness ratios of the links and lower ratios of the web plate slenderness significantly improve the pinching effects on the cyclic response due to the high ratios of the maximum shear strength over the yield strength.

\section{ACKNOWLEDGEMENTS}

This research work has been developed as part of a $\mathrm{PhD}$ project, within the framework of the VALERE program (Vanvitelli per la Ricerca) of the University of Campania" Luigi Vanvitelli".

\section{REFERENCES}

Ahmadi HM and De Matteis G (2020) Seismic performance of steel shear panels with butterfly-shaped links. International Journal of Earthquake engineering 37 (1)85-101.

De Matteis G, Landolfo R and Mazzolani FM (2003) Seismic response of MR steel frames with low-yield steel shear panels. Engineering Structures 25 (2).Elsevier: 155-168.

De Matteis G, Mazzolani FM and Panico S (2007) Pure aluminium shear panels as dissipative devices in moment-resisting steel frames. Earthquake engineering \& structural dynamics 36 (7). Wiley Online Library: 841-859.

De Matteis G, Mazzolani FM and Panico S (2008) Experimental tests on pure aluminium shear panels with welded stiffeners. Engineering Structures 30 (6).Elsevier: 1734-1744.

De Matteis G, Brando G, Panico S, et al. (2009) Bracing type pure aluminium stiffened shear panels: an experimental study. Adv Steel Constr 5(2): 106-119.

De Matteis G, Sarracco G and Brando G (2016) Experimental tests and optimization rules for steel perforated shear panels. Journal of Constructional Steel Research 123. Elsevier: 41-52. 
ECCS (1985) Recommended Testing Procedures for Assessing the Behaviour of Structural Elements under Cyclic Loads.

Formisano A, Lombardi L and Mazzolani FM (2016) Perforated metal shear panels as bracing devices of seismic-resistant structures. Journal of Constructional Steel Research 126. Elsevier: 37-49.

Formisano A, Ahmadi HM and Mazzolani FM (2018a) Ductility and Behaviour Factor of RC FramePerforated SPSW Dual Systems. In: Key Engineering Materials, 2018, pp. 835-845. Trans Tech Publ.

Formisano A, Sheidaii MR, Ahmadi HM, et al. (2018b) Numerical calibration of experimental tests on perforated Steel Plate Shear Walls: influence of the tightening torque in the plate-frame members bolted connections. In: AIP Conference Proceedings, 2018, p. 450005. AIP Publishing LLC.

Monsef Ahmad H, Sheidaii MR, Tariverdilo S, et al. (2020) Experimental and Numerical Study of Perforated Steel Plate Shear Panels. International Journal of Engineering 33 (4). Materials and Energy Research Center: 520-529.

Monsef Ahmadi H, Sheidaii MR, Boudaghi H, et al. (2020) Experimental and numerical study on largely perforated steel shear plates with rectangular tube-shaped links. Advances in Structural Engineering. SAGE Publications Sage UK: London, England: 1369433220937147.

Simulia DS, Fallis A and Techniques D (2018) Abaqus 6.14 Online Documentation.Abaqus Web. 


\title{
Fatigue life estimation of treated welded attachments via High Frequency Mechanical Impact treatment (HFMI-treatment)
}

\author{
H. Al-Karawi, M. Al-Emrani \& R. Haghani \\ Chalmers University of Technology, Gothenburg, Sweden
}

\begin{abstract}
High Frequency Mechanical Impact (HFMI) is one of the newest post weld treatment methods that can be used to repair cracks in welded structures. The main effect of this method is to extend the fatigue life by putting the cracks under compression. Linear Elastic Fracture Mechanics (LEFM) is to be used as an analysis tool accompanied by Paris law. Crack growth curves are presented in this work. The effects of the induced residual stress, the initial crack size, the clamping stress, and the stress range are all incorporated in the analysis. Subsequently, the analysis results are compared to experimental results obtained from fatigue testing on transverse non load-carrying welded attachment. The scatter in fatigue test results is found to be mainly attributed to the scatter in both the induced residual stresses and the variation in the existing crack sizes before treatment. Moreover, the analysis could successfully expect at what conditions the crack would not propagate through incorporating the concept of threshold stress intensity factor.
\end{abstract}

\section{INTRODUCTION}

Fatigue of welds gains increasing attention in the last decades. Therefore, several post weld treatment methods have been developed to increase the fatigue strength of welded structures. High Frequency Mechanical Impact (HFMI-treatment) is one of these methods which aims at inducing compressive residual stress at the weld toe vicinity. This method can be used for treating either new manufactured or cracked structures. In the latter case, HFMI-treatment puts the existing cracks under compression and reduces the crack propagation rate. In addition to this effect, it also removes the singularity existing at the weld toe. Moreover, it causes material hardening because of the cold working effect.

Linear elastic fracture mechanics (LEFM) is used as a practical tool for fatigue life assessments of metallic structures. Branco et al. investigated the life extension of T-joints by HFMItreatment using Paris law. The results were not satisfactory because the residual stress effect was not incorporated (Branco, Infante, \& Baptista 2004). Fracture mechanics led Fueki et al. to evaluate the crack size rendered harmlessly by HFMI indentor. Herein, the stress intensity factor of the applied stress range was compared to the threshold stress intensity factor $K_{t h}$ (Fueki, Takahashi, \& Houjou 2015). Besides, Leitner et al. incorporated both residual stress effect and threshold stress intensity factor concept, and satisfactory results were obtained (Leitner, Barsoum, \& Schäfers 2016).

The effects of both the induced residual stress $\left(\sigma_{R S}\right)$ and the existing crack sizes $\left(a_{i}\right)$ on fatigue life extension of repaired welded structures is rarely studied in the literature and requires further elaboration. This paper contributes to the crack propagation calculations using fracture mechanics. Fracture mechanics calculations are used to explore the effect of various aspects induced by HMFI-treatment, including the residual stress on fatigue life 
extension of welds. Moreover, the effects of existing crack size and the applied load level are also studied to figure out the "safe crack" which can be tolerated before HFMI-treatment.

\section{EXPERIMENTAL INVESTIGATIONS}

\section{$2.1 \quad$ Fatigue testing}

Axial fatigue testing is conducted on transverse welded attachments made of S355 structural steel under a stress ratio $R=0.29$. An axial testing rig is used to generate the loading. In addition to the membrane stresses due to axial load, unintentional bending stresses are generated at the weld toe because of the specimen's straightening to get rid of the angular distortions. The specimens are divided into two groups. In group A, the specimens are tested in as-welded conditions (denoted by AW), while seven specimens are fatigue tested until a crack of specific size appeared and detected at the weld toe in group B. Afterwards, their toes are treated by single HFMI-indentor (denoted by HFMI). Finally, they are tested to failure. The dimensions of the specimens and the fatigue testing rig are shown in Figure 1, and the fatigue test results are shown in Figure 2. The treated specimens exhibited significant fatigue strength, and six of them did not fail when tested under stress range $\Delta \sigma=150 \mathrm{MPa}$ after 10 million cycles as indicated in Figure 2.

\subsection{Crack detection and repair}

The specimens in group B are instrumented with five strain gauges at each side of the attachment to determine the crack size as shown in Figure 1. A previous study showed that a $25 \%$

a)

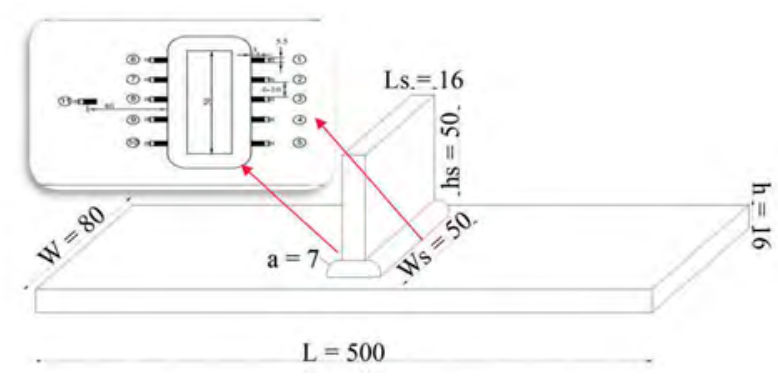

b)

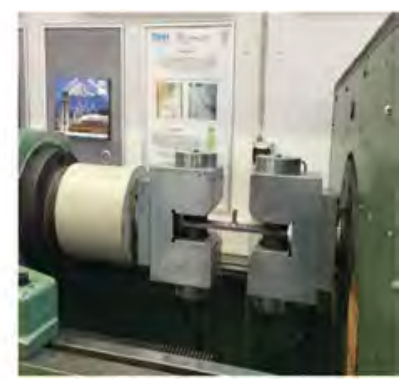

Figure 1. a) Specimen's geometry with attached strain gauges (dimensions in mm); b) Fatigue testing rig.

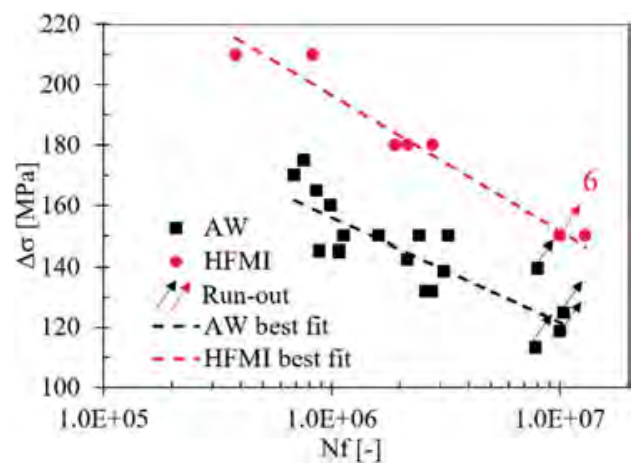

Figure 2. Fatigue test results of the tested specimens. 
drop in strain in any of the attached gauges corresponded to 0.6-1.2 mm crack (Al-Karawi, von Bock und Polach, \& Al-Emrani 2020). Afterwards, a HiFIT indentor with a $3 \mathrm{~mm}$ diameter is used for treatment. The treatment is performed in accordance with the International Institute of Welding IIW recommendations (Gary Marquis 2016). Moreover, beach marks are created on one the surface by reducing the stress range to its half without changing the maximum stress for 5000 cycles.

\subsection{Stress concentration evaluation}

Stress concentration factor gives the ratio between the local stress to the nominal stress. In order to find out the local stresses at the weld toe, the toe radii of the specimens in as-welded state and after HFMI-treatment are investigated using a 3D laser scanner. The geometry scanning shows a remarkable increase in the weld toe radii after HFMI-treatment (The average value increases from $0.67 \mathrm{~mm}$ to $2.1 \mathrm{~mm}$ ). Therefore, the obtained average radii are used as inputs for 2D elastic finite element analysis conducted using ABAQUS/CAE to evaluate the stress concertation factors due to membrane loading. Local mesh size is selected in accordance with the effective notch approach, which is followed to get around the singularity at the weld toe (Hobbacher et al. 2009). The model for evaluating the stress concentration factors is shown in Figure 3. More information about the model can be found in (Al-Karawi, von Bock und Polach, \& Al-Emrani 2020).

\subsection{Residual stress and distortions}

The residual stresses at the weld toe are investigated by means of the hole drilling method. Several holes are created at the weld toes of some specimens from both groups (i.e. AW \& HFMI). Compressive residual stress is found in as-welded conditions, while higher compression is induced after HFMI-treatment. The depth of compression is obtained from a previous paper based on literature reviews (Al-Karawi, von Bock und Polach, \& Al-Emrani 2020). The distributions are plotted in Figure 4. Four curves are plotted for the HFMI induced residual stresses containing the maximum and the minimum surface residual stresses with two depth of compression $(z=1.5$ or $2 \mathrm{~mm})$.

In order to quantify the tensile bending stresses generated by straightening the distorted specimens, the angular distortions are measured, and the clamping stresses are investigated using elastic finite element analysis to simulate the clamping process. The mesh size and the toe radii

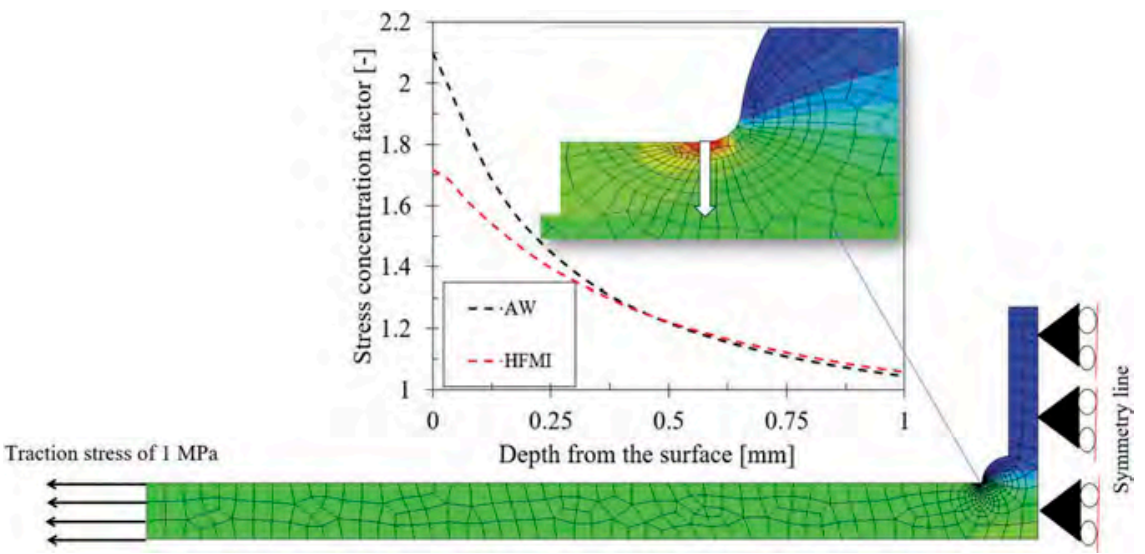

Figure 3. The model used for evaluating the stress concentration factors. 


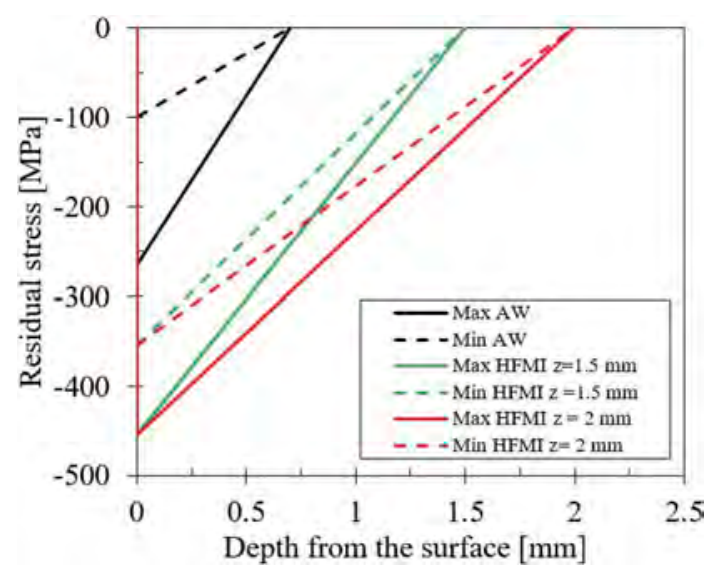

Figure 4. The proposed residual stress distributions according to (Al-Karawi, von Bock und Polach, \& Al-Emrani 2020).

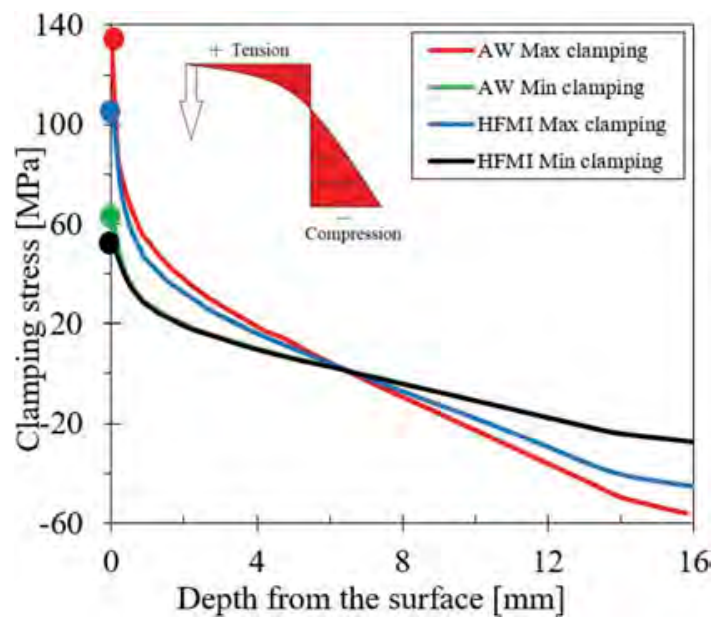

Figure 5. The clamping stress distributions.

are selected according to IIW recommendations for effective notch approach (Hobbacher et al. 2009). The clamping jaws are modelled as undeformed bodies, and hard contact is defined between them and the specimen's surfaces. The local stresses below the weld toe are extracted when the specimens get fully straightened. The results are validated against the clamping stresses obtained from the attached strain gauges. The results of the obtained maximum and minimum clamping stresses are shown in Figure 5.

\section{FRACTURE MECHANICS MODEL}

Linear elastic fracture mechanics analysis is carried out to estimate the specimen's fatigue lives in both as-welded state and after HFMI-treatment. Weight function approach is employed to quantify the stress intensity factors. The stress intensity factors are calculated by integrating the product of the weight function $m(x, a)$ obtained from (Al-Mukhtar 2013) times the stress profile along the prospective crack path for the un-cracked specimens $\sigma(x)$ as indicated in equation 1 . 


$$
K=\int_{0}^{a} m(x, a) \cdot \sigma(x) \cdot d x
$$

The local stresses (obtained from the nominal stresses multiplied by the stress concentration factors shown in Figure 3) are used to compute $\sigma(x)$. Moreover, the distributions of the residual stresses $(R S)$ and the clamping stresses $(C S)$ shown in Figures 4 and 5 are used to incorporate the effect of mean stresses in the analysis, as given in the definition of the effective stress ratio $\left(R_{e f f}\right)$ in equation 2 . Then, Paris law is used to calculate the extension in crack size after $d N$ load cycles, see equation 3. Paris law parameters $C, m$ are selected to be $1.65 .10^{-13}$ and 3 respectively. The threshold stress intensity factor is incorporated to explain the obtained 6 runouts obtained in fatigue testing as shown in Figure 2. The value of $C, m$ and $K_{t h}$ are selected in accordance with the IIW recommendations (Hobbacher et al. 2009).

$$
\begin{gathered}
R_{e f f}=\frac{K_{\text {min }}+K_{R S}+K_{c s}}{K_{\text {min }}+K_{R S}+K_{c s}} \\
d a= \begin{cases}\frac{C\left(K_{\max }-K_{\min }\right)}{\left(1.5-R_{\text {eff }}\right)^{m}} d N, & K_{\text {max }}-K_{\text {min }}>K_{t h} \\
0, & \text { Otherwise }\end{cases}
\end{gathered}
$$

The initial crack size used to commence the crack propagation in the as-welded condition is selected to be 0.5 or $0.15 \mathrm{~mm}$. The former is the maximum allowable undercut height according to the British standard (BS7910 2005), while the latter is the recommended initial crack size according to the IIW recommendations. On the other hand, the existing crack sizes in the specimens in group B of 0.6-1.2 $\mathrm{mm}$ are used in the crack propagation analysis of the HFMItreated specimens. The results of the fracture mechanics analysis for as-welded and HFMItreated specimens tested under different stress ranges are shown in Figure 6. Different combinations of residual and clamping stresses are presented. Furthermore, fatigue lives, prefatigue lives and beach mark results are marked by black crosses in the figures.

a)

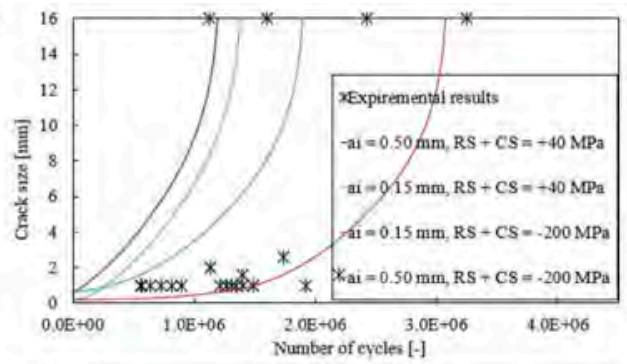

c)

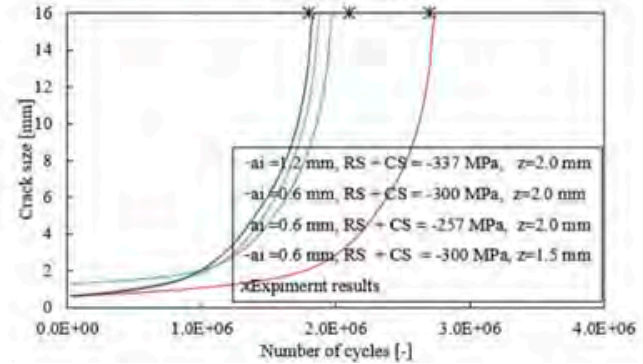

b)

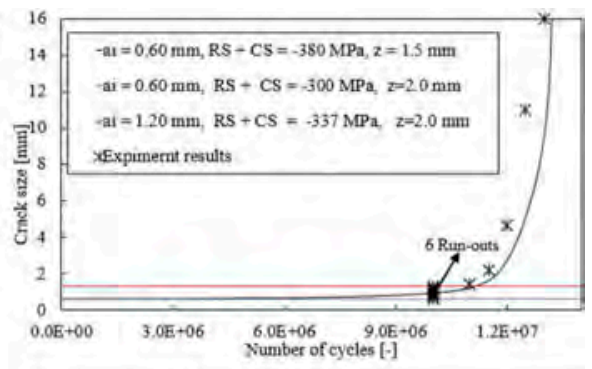

d)

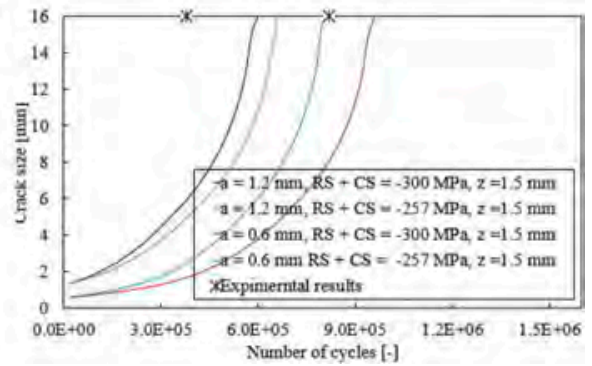

Figure 6. Crack propagation curves for: a) As-welded specimens tested under nominal stress range $\Delta \sigma=$ $150 \mathrm{MPa}$; a), c), d) HFMI-treated specimens tested under nominal stress of 150, 180 and $210 \mathrm{MPa}$ respectively. 

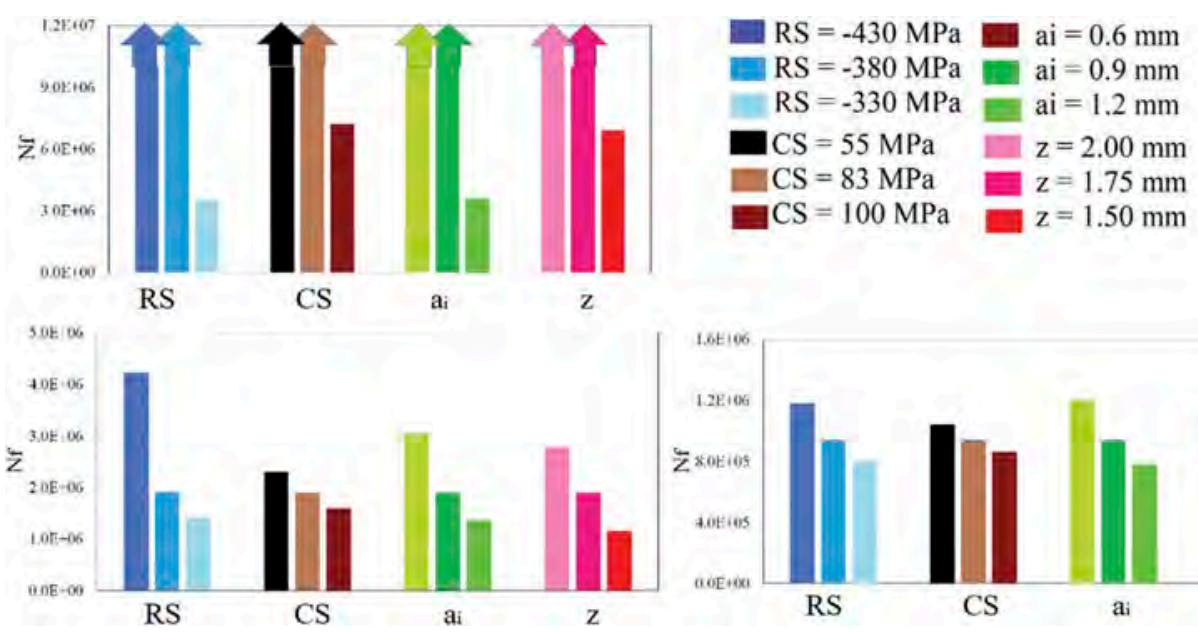

Figure 7. The effect of different parameters on fatigue lives of HFMI-treated specimens tested under applied stress range $\Delta \sigma=150,180$ and $210 \mathrm{MPa}$ respectively.

Most of the experimental results are found in the band of the generated curves in as-welded conditions. Moreover, the analysis could predict the 6 run-outs when the HFMI-treated specimens are tested under a stress range $\Delta \sigma=150 \mathrm{MPa}$ as the obtained $\Delta K$ is less than $K_{t h}$ (see Figure 6b). Remarkably, the specimens become significantly stronger after HFMI-treatment although they contain cracks of $0.6-1.2 \mathrm{~mm}$. Moreover, the analysis results are in line with the beach marking results, as shown in the same figure. In addition, the fatigue lives of 4 out of 5 specimens tested under stress range $\Delta \sigma=180$ or $210 \mathrm{MPa}$ are also well predicted by the analysis as shown in Figure 6c, d.

Fatigue test results are highly scattered in both as-welded and HFMI-treated conditions. The analysis gives an insight into the reason behind the scatter, which is traced back to the differences in four parameters: residual stress $(R S)$, depth of compression $(z)$, clamping stress $(C S)$, and existing crack size $(a i)$. The effect of these parameters on fatigue life extension are studied under different stress levels (see Figure 7). In the analysis, when one parameter is under study, the other parameters are fixed to the average values $(R S=-380 \mathrm{MPa}, C S=83$ $\mathrm{MPa}, a i=0.9 \mathrm{~mm}$ and $z=1.75 \mathrm{~mm}$ ). The effects of residual stress and initial crack size is found to be the most influential on fatigue life extension. On the other hand, the clamping stress effect is found to be less significant. Moreover, the analysis shows that eight out of the ten studied cases 'run-out' after 10 million cycles when the stress range is $150 \mathrm{MPa}$ which is in line with the test results where six out of total seven specimens run-out.

\section{SUMMARY AND CONCLUSIONS}

Within the current study, linear elastic fracture mechanics analysis is conducted to predict the fatigue lives of transverse attachment specimens made of S355 structural steel. Moreover, several experimental and numerical investigations are conducted to evaluate the stress concentration factors, the residual stresses and the clamping stresses. Relatively long fatigue lives are obtained even in as-welded conditions which is caused by the presence of compressive residual stress at the weld toe. HFMI-treatment causes reduction in the angular distortion which reduces the clamping stress. The average weld toe radius is doubled after HFMI-treatment, which causes a significant reduction in the stress concentration factor. The performed fracture mechanics analysis incorporates the effects of stress range, residual stress, clamping stress, initial crack size and threshold stress intensity factor. The analysis results match the experiments in most of the cases. Moreover, the variability of residual stress and the initial crack size are found to be the most influential factors behind fatigue life scattering of the HFMI-treated specimens. 


\section{REFERENCES}

Al-Karawi, H., R.U.F. von Bock und Polach, \& M. Al-Emrani (2020). Fatigue life extension of welded structures via high frequency mechanical impact treatment. Engineering structures (Submitted).

Al-Mukhtar, A. (2013). Consideration of the residual stress distributions in fatigue crack growth calculations for assessing welded steel joints. Fatigue \& Fracture of Engineering Materials \& Structures 36 (12), 1352-1361.

Branco, C., V. Infante, \& R. Baptista (2004). Fatigue behavior of welded joints with cracks, repaired by hammer peening. Fatigue \& Fracture of Engineering Materials \& Structures 27(9), 785-798.

BS7910, B. S. (2005). Guide on methods for assessing the acceptability of flaws in metallic structures, BS7910. British Standards Institute.

Fueki, R., K. Takahashi, \& K. Houjou (2015). Fatigue limit prediction and estimation for the crack size rendered harmless by peening for welded joint containing a surface crack. Materials Sciences and Applications 6(06), 500.

Gary Marquis, Z.B. (2016). IIW recommendations for the HFMI treatment for improving the fatigue strength of welded joints. Springer.

Hobbacher, A. et al. (2009). Recommendations for fatigue design of welded joints and components. Springer.

Leitner, M., Z. Barsoum, \& F. Scha"fers (2016). Crack propagation analysis and rehabilitation by HFMI of pre-fatigued welded structures. Welding in the World 60 (3), 581-592. 


\title{
Fire design proposal for cold-formed steel lipped channel beam-columns
}

\author{
F. Arrais, N. Lopes \& P. Vila Real \\ RISCO, Department of Civil Engineering, University of Aveiro, Aveiro, Portugal
}

\begin{abstract}
Steel structural elements composed of cold-formed thin-walled sections are commonly applied in buildings due to their efficiency in terms of stiffness and strength. However, under fire conditions the thin walls of these profiles, along with the steel high thermal conductivity, induce fast increase on the steel temperature and corresponded significant loss of those referred stiffness and strength. This paper presents a numerical study on the members behaviour with cold-formed lipped channel sections at high temperatures, when subjected to bending plus compression. Comparisons between the finite element results and the analytical methodologies from EN1993-1-2 are presented, using its Annex E as well as its French National Annex, where different reduction factors for the steel constitutive law and different design formulae are recommended for cold-formed profiles. Both methodologies revealed to be safe but sometimes too conservative, which motivated the development of a new design proposal.
\end{abstract}

\section{INTRODUCTION}

Cold-formed steel profiles application on structures has been gaining popularity in construction industry due to their lightness, high strength-weight ratio, faster manufacturing process, easy prefabrication and mass production, contributing positively to the sustainability of buildings. These elements are typically used in steel structures as joists, tracks, studs or girts, subjected to different loading conditions (Schafer, 2011, Dubina et al., 2012).

Open cold-formed steel members have high susceptibility to the occurrence of different instability phenomena, such as local, global and also distortional buckling. The influence of these instability phenomena on the ultimate bearing capacity of beam-columns, composed of those cold-formed sections, at normal temperature have been widely studied (Torabian et al., 2015, Li et al., 2016). However, and although it is known that elevated temperatures impose significant loss of strength and stiffness on cold formed members (Kankanamge \& Mahendran, 2011, Ranawaka \& Mahendran, 2009), the behaviour under fire situation of these structural elements, subjected to bending plus compression, is still less known.

Hence, this paper presents a numerical parametric study on the behaviour of laterally restrained double hinged members with cold-formed lipped channel sections in case of fire, subjected to bending plus compression, considering different member and section slendernesses, bending moment diagrams, steel grades and elevated temperatures.

The members ultimate bearing capacity is obtained through numerical modelling, considering geometrically and materially nonlinear analyses including imperfections (GMNIA), using the Finite Element software SAFIR (Gernay \& Franssen, 2017). The different instability modes (local, distortional and global buckling), needed for the definition of initial geometric imperfections, are obtained using the software CAST3M (CAST3M, 2012) and applying RUBY interface (Couto et al., 2013).

DOI: $10.1201 / 9781003132134-62$ 
Comparisons between the finite element results and the analytical methodologies from EN1993-1-2 (CEN, 2005) rules are here presented, using its Annex E for Class 4 crosssections and its French National Annex (CEN, 2007), where different reduction factors for the steel constitutive law and different design formulae are recommended for coldformed profiles. Following the obtained observations, a new proposal for the safety evaluation of these cold-formed beam-columns at elevated temperatures is presented and analysed here.

\section{FIRE DESIGN RULES}

The EN1993-1-2 recommends the use of the 0,2\% proof strength at temperature $\theta$ instead of the strength at $2 \%$ total strain at temperature $\theta$, applied to non-slender sections (Class 1,2 or 3 ), for members with Class 4 cross-sections (common on cold-formed steel profiles).

The expression for laterally restrained steel beam-columns subjected to bending about the major axis in fire situation considered here is:

$$
\frac{N_{f i, E d}}{\chi_{y, f i} A_{e f f} k_{y, \theta} \frac{f_{y}}{\gamma_{M, f i}}}+k_{y} \frac{M_{y, f i, E d}}{W_{e f f, y} k_{y, \theta} \frac{f_{y}}{\gamma_{M, f i}}}+k_{z} \frac{\Delta M_{z, f i, E d}}{W_{e f f, z} k_{y, \theta} \frac{f_{y}}{\gamma_{M, f i}}} \leq 1.0
$$

with $A_{\text {eff }}$ (effective area) and $W_{\text {eff }, y}$ (effective section modulus) the cross-section effective properties, $\Delta M_{z, f i, E d}$ the additional bending moment due to the shift of the centroidal axis, and where the reduction factor $\chi_{f i}$ value is obtained according to equation (2):

$$
\chi_{f i}=\frac{1}{\phi_{\theta}+\sqrt{\left[\phi_{\theta}\right]^{2}-\left[\bar{\lambda}_{\theta}\right]^{2}}} \leq 1.0
$$

with:

$$
\phi_{\theta}=\frac{1}{2}\left[1+\alpha \bar{\lambda}_{\theta}+\left(\bar{\lambda}_{\theta}\right)^{2}\right]
$$

and $\alpha$ an imperfection factor determined by:

$$
\alpha=0.65 \sqrt{\frac{235}{f_{y}}}
$$

The recommended interaction factor, for Class 4 cross-sections, is obtained from:

$$
k_{i}=1-\frac{\mu_{i} N_{f i, E d}}{\chi_{i, f i} A_{e f f} k_{0.2 p, \theta} f_{y} / \gamma_{M, f i}} \leq 3 \text { with } i=y \text { or } z
$$

being $\mu$ (for the strong axis) given by:

$$
\begin{gathered}
\mu_{y}=\left(2 \beta_{M, y}-5\right) \bar{\lambda}_{y, \theta}+0.44 \beta_{M, y}+0.29 \leq 0.8 \text { with } \bar{\lambda}_{y, 20{ }^{\circ} \mathrm{C}} \leq 1.1 \\
\mu_{z}=\left(1.2 \beta_{M, z}-3\right) \bar{\lambda}_{z, \theta}+0.71 \beta_{M, z}-0.29 \leq 0.8
\end{gathered}
$$

and $\beta_{M, i}$, which is in function of the bending diagram shape, equal to: 


$$
\beta_{M, i}=1.8-0.7 \psi
$$

where $\psi$ is the ratio between the end moments ( $\left.\begin{array}{lll}1 & \psi & 1\end{array}\right)$.

The French National Annex (FN Annex) of EN1993-1-2 proposes a similar calculation methodology, considering for cold-formed steel profiles $k_{i}=1$ and lower reduction factors for steel yield strength and young modulus at high temperatures, when compared to Annex E of EN1993-1-2 (Zhao et al., 2005). Moreover, for flexural buckling the following equation should be used:

$$
\phi_{\theta}=\frac{1}{2}\left[1+\alpha\left(\bar{\lambda}_{\theta}-0.2\right)+\left(\bar{\lambda}_{\theta}\right)^{2}\right]
$$

considering the imperfection factor $\alpha$ obtained from EN1993-1-3 (CEN, 2006a), where curve $\mathrm{b}(\alpha=0.34)$ is proposed for lipped channel sections, and $\bar{\lambda}_{\theta}$ the relative slenderness for flexural buckling at the steel temperature $\theta$. A new proposal is presented here based in an adaptation methodology for flexural buckling on cold-formed steel lipped channel cross-section elements, proposed in previous studies (Arrais, 2018), where the equations considered in this new proposal remain the same from EN1993-1-2 considering the use of interaction equation (1) with the flexural buckling curve of FN Annex (equation 9) and a new limit for equation (6) of $\mu_{y} \quad 1.1$.

\section{CASE STUDY AND NUMERICAL MODELS}

The cold-formed lipped channel sections (C) presented on Table 1 were chosen from different references for the numerical analysis of beam-columns without lateral torsional buckling (LTB). Parameters such as the steel grade (S280, S320, S355 and S460), member slenderness $(0.5 \mathrm{~m}, 1.5 \mathrm{~m}, 3.0 \mathrm{~m}, 4.0 \mathrm{~m}, 5.0 \mathrm{~m}$ and $10.0 \mathrm{~m})$ and bending diagrams (uniform bending, $\psi=1$, and non-uniform bending $\psi=0$ and $\psi=-1$ ) are studied here. The temperatures of $350{ }^{\circ} \mathrm{C}$, $500{ }^{\circ} \mathrm{C}$ and $600{ }^{\circ} \mathrm{C}$ were applied and considered uniform throughout the cross section.

In the finite element model (Figure 1), rectangular shell finite elements with four nodes, with six degrees of freedom (three translations and three rotations), of $10 \mathrm{~mm}$ length over the member cross-section at flat plates, are used. The mesh was refined at the corners in order to better reproduce the rounded shape. In the longitudinal direction, the mesh size varies between $10 \mathrm{~mm}$ (for small lengths) and $25 \mathrm{~mm}$ (for the longest member). For imposing end moments, loads in the parallel direction to the beam-column axis were applied on the nodes at the element ends, according to the linear stresses distribution resulting from simple bending around the strong axis. Restrictions are applied to reproduce simple supports on beam-column ends.

This study did not take into account the corner enhancement, resulting from the manufacturing process, since this increase is not considered in EC3 (CEN, 2006a) in the occurrence of instability phenomena and because its influence is reduced at high temperatures (Arrais et al. 2019). Residual stresses were considered according to Schafer \& Peköz (1998).

\begin{tabular}{|c|c|c|c|c|}
\hline & Web & Flange & Lip & Thickness \\
\hline Designation & $\mathrm{mm}$ & $\mathrm{mm}$ & $\mathrm{mm}$ & $\mathrm{mm}$ \\
\hline C_229x64x $20 \times(1.5)^{*}$ & 229 & 64 & 20 & 1.5 \\
\hline C_ $154 \times 35 \times 11 \times(1.5)^{* *}$ & 154 & 35 & 11 & 1.5 \\
\hline C_150x43x $20 \times(2.0)^{* * *}$ & 150 & 43 & 20 & 2.0 \\
\hline
\end{tabular}

Table 1. Lipped channel sections analysed and respective dimensions. 


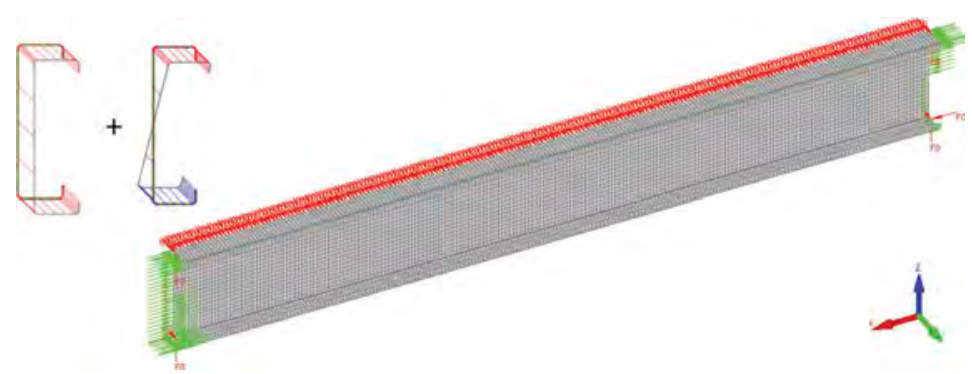

Figure 1. Numerical model adopted for analysed beam-columns.

Table 2. Geometric imperfections' magnitudes considered.

\begin{tabular}{lll}
\hline Local & Distortional & Global \\
\hline $0.80 \frac{b}{100}$ & $0.80 \frac{b}{100}$ & $0.80 \frac{L}{750}$ \\
\hline
\end{tabular}

The shapes obtained from local, distortion and global buckling modes, applying CAST3M program together with the RUBY interface, were used to define the initial geometric imperfections. According to Annex C of EN 1993-1-5 (CEN, 2006b), the geometric imperfections' magnitudes were obtained from $80 \%$ of the geometric manufacturing tolerances prescribed in EN 1090-4 (CEN, 2018). Table 2 shows the maximum amplitude of these imperfections where $b$ is the length of the web or flange, depending on the highest deformation value, and $L$ is the member length.

A geometric imperfection's combination is introduced in the numerical model. EN 19931-5 states that a leading imperfection should be chosen, and the accompanying imperfections may have their value reduced to $70 \%$. In this work, the leading imperfection was chosen according to the achieved lower resistances from each individual imperfection obtained resistance.

The applied steel material laws follow EN 1993-1-2 steel constitutive law model. However, and as aforementioned, FN Annex proposes for cold-formed profiles the use of lower values for the reduction factors of the yield strength and elasticity modulus at elevated temperatures. The comparison between the EN 1993-1-2 and FN Annex constitutive laws is presented in Figure 2.

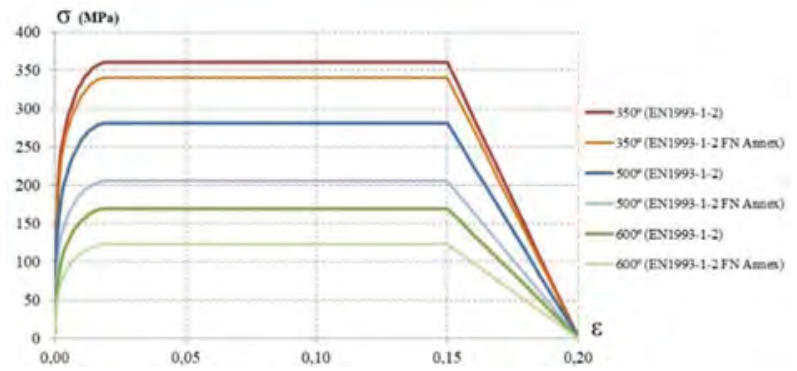

Figure 2. Constitutive law for elevated temperatures according to EN1993-1-2 and respective FN Annex. 


\section{COMPARISON BETWEEN NUMERICAL RESULTS AND FIRE DESIGN RULES}

The numerically obtained ultimate bearing load capacities are here compared with the calculation rules of EN 1993-1-2. Since the analysed profile is composed of a monosymmetric section, the change of the centre of gravity, due to the consideration of the effective area $A_{\text {eff }}$, results in an eccentricity of the applied axial force, which induces an additional, $\Delta M_{\mathrm{z}, \mathrm{fi} \text {.Ed }}$, acting bending moment about the weak axis. For illustrating the referred comparisons for a $\mathrm{C} 229 \times 64 \times 20$ with $1.5 \mathrm{~m}$ length at $500{ }^{\circ} \mathrm{C}$ with different load levels, this additional moment was added to the axial force buckling resistant capacity on the vertical axis of the charts in Figures 3 (uniform bending) and 4 (triangular bending diagram). Figure 5 illustrates the failure mode of tested beam-columns.
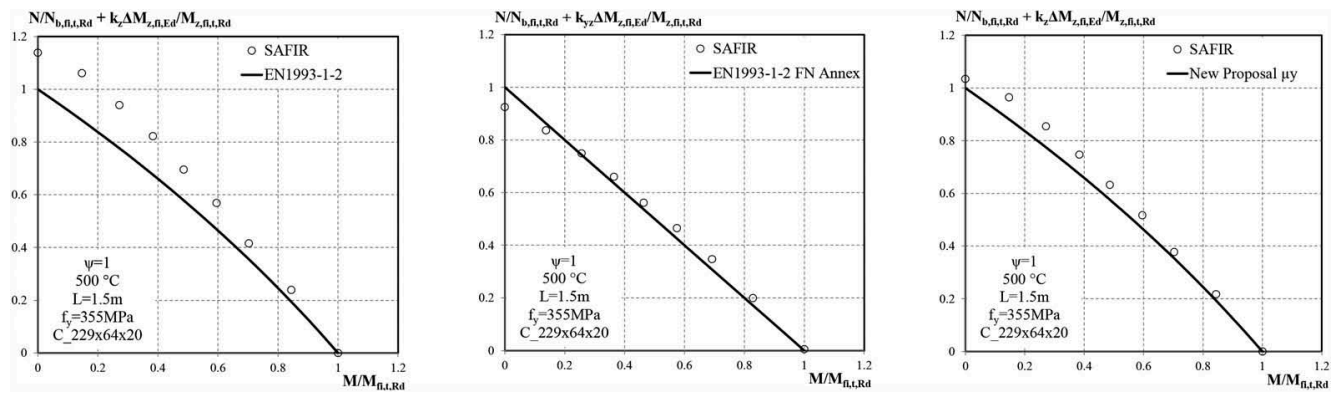

Figure 3. Comparison between the numerical results and the design rules of the EN1993-1-2 Annex E, the French National Annex (FNA) and the New Proposal, for uniform bending $(\psi=1)$, at $500^{\circ} \mathrm{C}$.
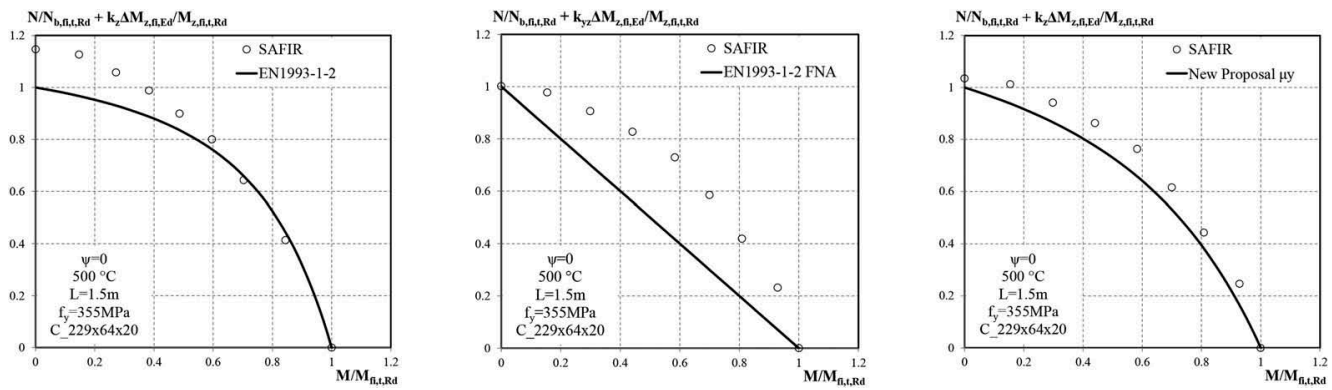

Figure 4. Comparison between the numerical results and the design rules of the EN1993-1-2 Annex E, the French National Annex (FNA) and the New Proposal, for non-uniform bending $(\psi=0)$, at $500{ }^{\circ} \mathrm{C}$.

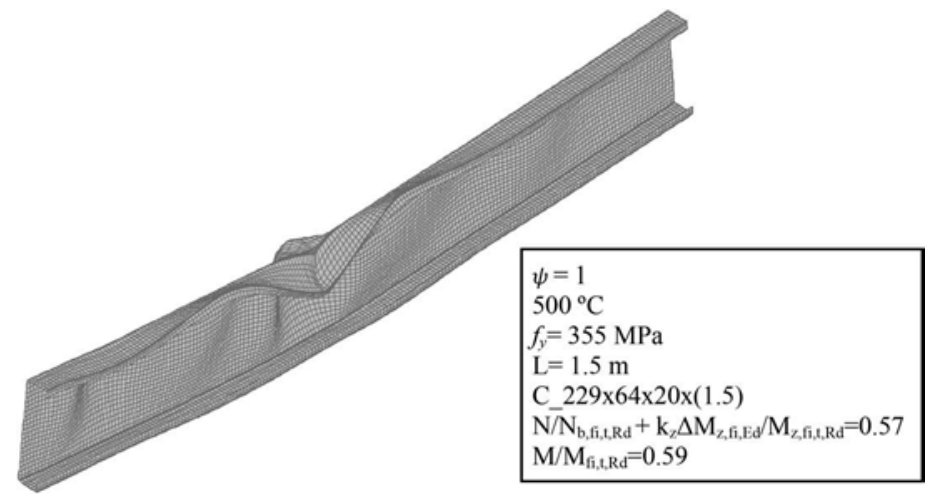

Figure 5. Collapse mode of a C_229x64x20 section beam-column model. 
Table 3. Statistical evaluation considering uniform bending diagram on a total of 1176 results.

\begin{tabular}{llllc}
\hline Design rule & Average value $(\mu)$ & Standard deviation $(s)$ & Máx. unsafe & $\%$ unsafe \\
\hline $\begin{array}{l}\text { EN1993-1-2 } \\
\text { (EN1993-1-2 Constitutive Law) }\end{array}$ & 0.93 & 0.10 & - & 0.00 \\
$\begin{array}{l}\text { EN1993-1-2 FNA } \\
\text { (FN Annex Constitutive Law) }\end{array}$ & 1.09 & 0.16 & 1.05 & 18.23 \\
$\begin{array}{l}\text { New Proposal } \\
\text { (FN Annex Constitutive Law) }\end{array}$ & 0.97 & 0.03 & 1.02 & 6.74 \\
\hline
\end{tabular}

Table 4. Statistical evaluation considering non-uniform bending diagram results on a total of 1512 results.

\begin{tabular}{llllc}
\hline Design rule & Average value $(\mu)$ & Standard deviation $(s)$ & Máx. unsafe & $\%$ unsafe \\
\hline $\begin{array}{l}\text { EN1993-1-2 } \\
\text { (EN1993-1-2 Constitutive Law) }\end{array}$ & 0.67 & 0.30 & - & 0.00 \\
$\begin{array}{l}\text { EN1993-1-2 FNA } \\
\text { (FN Annex Constitutive Law) }\end{array}$ & 1.31 & 0.33 & 1.07 & 12.37 \\
$\begin{array}{l}\text { New Proposal } \\
\text { (FN Annex Constitutive Law) }\end{array}$ & 0.81 & 0.28 & 1.01 & 6.51 \\
\hline
\end{tabular}

Following the criteria of the validation proposed by Kruppa (1999), Table 3 presents the statistical evaluation for uniform bending moments based on a total of 1176 results (considering both constitutive laws) and Table 4 for non-uniform bending moments based on a total of 1512 results.

From the presented comparisons, it can be concluded that both approaches are mostly on the safety side, being however too conservative. Considering FN Annex, the values are closer to the EC3 curve for $\psi=-1$, whereas in the case of non-uniform moments, the curve remains very conservative, as in this methodology the interaction factor $\boldsymbol{k}_{\boldsymbol{y}}$ and $\boldsymbol{k}_{z}$ are always one. The proposed adjustments are more accurate and safe when compared to the numerical results.

\section{CONCLUSIONS}

In the present work, a parametric study of the fire behaviour of cold-formed beam-columns with lipped channel (C) sections, without lateral torsional buckling, was presented, considering the EN1993-1-2 as well as its French National Annex constitutive laws.

A comparison was made between the ultimate load capacities obtained numerically and the requirements of EC3, concluding that these last calculation rules are on the safety side in most cases, being too conservative. The comparison with the FN Annex demonstrated that the values are closer to the FNA curve, whereas in the case of non-uniform moments, the curve remains very conservative. The results were obtained considering the variation of several parameters such as different steel grades, bending moment diagrams and slendernesses.

Thus, a new design proposal was developed with some adjustments in relation to the current calculation rules. It was possible to observe that the new proposal presents a better approximation to the numerical results when compared to EC3.

\section{ACKNOWLEDGEMENTS}

This research was partially funded by the Portuguese Government through the FCT (Foundation for Science and Technology) under the PhD grant SFRH/BD/90455/2012 (POPH/FSE 
funding) awarded to the first author and was performed within the framework of the project "StaSteFi - Fire design of stainless steel members", PTDC/ECI-EGC/30655/2017, supported by the Portuguese Operational Programme "Competitividade e Internacionalização", in its FEDER/FNR component, and the Portuguese FCT, in its State Budget component (OE).

\section{REFERENCES}

Arrais, F., Behaviour of cold-formed steel members in case of fire, $\mathrm{PhD}$ thesis, University of Aveiro, Portugal, 2018.

Arrais, F., Lopes, N., Vila Real, P., Jandera, M., Numerical modelling of cold-formed steel members at elevated temperatures, proceedings of SDSS 2019, Prague, Czech Republic, 2019.

CAST3M, sponsored by French Atomic Energy Commission; 2012. http://www-cast3m.cea.fr/

CEN - EN 1993-1-2, Eurocode 3: Design of Steel Structures - Part 1-2: General rules - Structural fire design, Belgium, 2005.

CEN - EN 1993-1-3, Eurocode 3: Design of Steel Structures - Part 1-3: Rules for cold-formed members and sheeting, Belgium, 2006a.

CEN - EN 1993-1-5, Eurocode 3: Design of Steel Structures - Part 1-5: Plated structural elements, Belgium, 2006b.

CEN - EN 1090-4, Execution of steel structures and aluminium structures - Part 4: Technical requirements for cold-formed structural steel elements and cold-formed structures for roof, ceiling, floor and wall applications, Belgium, 2018.

CEN - NF EN 1993-1-2, Eurocode 3: Calcul des structures en acier - Annexe Nationale à la NF EN 1993-1-2: Calcul du comportment au feu, Belgium, 2007.

Couto, C., Vila Real, P., Lopes, N., RUBY - an interface software for running a buckling analysis of SAFIR models using Cast3M, University of Aveiro, 2013.

Dubina, D., Ungureanu, V., Landolfo, R., Design of cold-formed steel structures, ECCS - European Convention for Constructional Steelwork, Ernst \& Sohn, 2012.

Gernay, T., Franssen, J.M. (2017), "Modeling structures in fire with SAFIR ®: Theoretical background and capabilities", Journal of Structural Fire Engineering, Vol. 8, issue 3, pp. 300-323.

Kankanamge, N. D., Mahendran, M., Mechanical properties of cold-formed steels at elevated temperatures, Thin-Walled Structures, Vol. 49, Iss 1, 2011, 26-44.

Kruppa, J. Eurocodes - fire parts, proposal for a methodology to check the accuracy of assessment methods, CEN TC 250, Horizontal Group Fire, Document n 99/130, 1999.

Li, Y.-L., Li, Y.-Q., Song, Y.-Y., Shen, Z.-Y, In-plane behavior of cold-formed thin-walled beam-columns with lipped channel section, Thin-Walled Structures, Vol. 105, pp. 1-15, 2016.

PERFISA - Steel Profiles Factory, S.A., Catalogue: Profiles for Light Steel Framing, Portugal, 2014.

Ranawaka, T., Mahendran, M., Experimental study of the mechanical properties of light gauge cold-formed steels at elevated temperatures, Fire Safety Journal, Vol. 44, Iss 2, 2009, 219-229.

Schafer, B., Cold-formed steel structures around the world. Steel Construct., 4, 2011, 141-149.

Schafer, B., Peköz, T., Computational modeling of cold-formed steel: characterizing geometric imperfections and residual stresses, J. of Constructional Steel Research, 47, 3, 1998, 193-210.

Torabian, S., Zheng, B., Schafer, B. W. "Experimental response of cold-formed steel lipped channel beam-columns", Thin-Walled Structures, Vol. 89, pp. 152-168, 2015.

Zhao B., Kruppa J., Renaud C., O'Connor M., Mecozzi E., Apiazu W., Demarco T., Karlstrom P., Jumppanen U., Kaitila O., Oksanen T., Salmi P., Calculation rules of lightweight steel sections in fire situations, European Commission, Luxembourg, 2005. 


\title{
Fire resistance of stainless steel slender cross-sections under bending and axial compression
}

\author{
F. Arrais, N. Lopes \& P. Vila Real \\ RISCO, Department of Civil Engineering, University of Aveiro, Aveiro, Portugal
}

\begin{abstract}
Stainless steel has different advantages when compared to conventional carbon steel. The corrosion resistance and aesthetic appearance are the most known, but its higher fire resistance can also be decisive. With its increased use, the validation of existing design rules, for structural elements made of this material, becomes urgent. In order to have a comprehensive understanding of the overall thin-walled members' fire resistance, it is important to first analyse the cross-section resistance at elevated temperatures, which is directly affected by local instabilities occurrence on the composed thin plates. This work presents a numerical study on the behaviour of stainless steel slender cross-sections under bending and under axial compression at elevated temperatures, with the purpose of evaluating the accuracy of Eurocode 3 design formulations for the effective section calculation. The obtained numerical results are compared with the Eurocode prescriptions and with a recently proposed method, concluding that the design methodologies should be improved for rectangular hollow profiles.
\end{abstract}

\section{INTRODUCTION}

The application of stainless steel as a structural material has been increasing, due to a number of desirable qualities such as its durability, resistance to corrosion and aesthetic appearance (Gardner, L., 2005 \& Euro Inox, 2006). Despite having a high initial cost, stainless steel can be a competitive material if life cycle cost analysis is considered, due to its low maintenance needs. Moreover, it has a higher fire resistance when compared to carbon steel (CEN, 2005b) allowing in some cases the absence of thermal protection.

The austenitic stainless steels are generally the most used groups for structural applications but some interest has been recently shown for increasing the use of ferritic and austeniticferritic (Duplex) steels for structural purposes due to specific advantages. Some of those advantages are the very good resistance to wear and stress corrosion cracking of the duplex grade and the lower percentage of Nickel of the ferritic grade, which reduces its price.

Regarding structural design, Eurocode 3 (EC3) (CEN, 2006a) considers that the walls slenderness determine the cross-section classification (Class 1 - stocky sections to Class 4 - slender sections).

Although the subject of local buckling at elevated temperatures has been studied by different authors (Couto et al., 2014, Couto et al., 2015, FIDESC4, 2014, Knobloch \& Fontana, 2006, Maraveas et at., 2017, Quiel \& Garlock, 2010), they have only addressed elements in carbon steel, and research of the local buckling effect on stainless steel sections at elevated temperatures has just started to be developed (Xing et al., 2020), focused on I-sections.

According to EN 1993-1-2 (CEN, 2005b), stainless steel stress-strain relationships at high temperatures are characterized by having a non-linear behaviour with an extensive hardening phase, when compared with carbon steel constitutive law. As existing fire design rules for stainless steel, such as in EN 1993-1-2 (CEN, 2005b), are based on the formulations developed for carbon steel 
members (CEN, 2005a, CEN, 2006b) in spite of the different material behaviour, it is still necessary to develop knowledge on stainless steel structural behaviour at high temperatures.

This work presents a numerical study on the behaviour of stainless steel slender crosssections under bending and under axial compression at elevated temperatures. I-sections and Rectangular Hollow Sections (RHS) are analysed with the purpose of evaluating the accuracy of EC3 design formulations (CEN, 2005b) for the reduction of the widths of each crosssection element (internal elements in hollow sections, or internal and outstand elements in I-sections), according to the effective width method. Although EC3 uses the concept of simply supported plates for the effective width method, not differentiating between I-sections and RHS. The disposition of the different elements on these two cross-section types provides different restriction degrees (restrictions to rotation) to the corresponded plates, which might influence the cross-section resistance.

A parametric study considering different stainless steel grades (such as Austenitic, Ferritic and Duplex, which have different constitutive laws), cross-section slenderness, uniform elevated temperatures (from $350{ }^{\circ} \mathrm{C}$ to $700{ }^{\circ} \mathrm{C}$ ) and loading conditions (compression and bending) is presented. The study was conducted applying geometrically and materially nonlinear analyses including imperfections (GMNIA), using the SAFIR ${ }^{\circledR}$ finite element program (Gernay \& Franssen, 2017).

Comparisons between the numerically obtained ultimate bearing capacities of the tested cross-sections, the EC3 design methods and the application of a recent proposal for slender stainless steel plates (Xing et al., 2020), are made.

\section{FIRE DESIGN RULES}

According to EN 1993-1-2 (CEN, 2005), the section resistance of a stainless steel member in case of fire is calculated in the same way as for carbon steel, changing only the mechanical properties of the material. Regarding the cross-section classification, equation (1) is used to determine $\varepsilon_{f i}$, a parameter necessary for the determination of the EC3 classification limits (Franssen \& Vila Real, 2015):

$$
\varepsilon_{f i}=0.85\left[\frac{235}{f_{y}} \frac{E}{210000}\right]^{0.5}
$$

The cross-section resistance value of axially compressed members of Class 1, 2 or 3 crosssections with a uniform temperature, should be determined from equation (2):

$$
N_{f i, \theta, R d}=A f_{y, \theta} / \gamma_{M, f i}
$$

For Class 4 cross-sections, according to Annex E of EN 1993-1-2, the effective area $\left(A_{\text {eff }}\right)$ should be considered instead of the gross cross-section area, determined with the effective section properties obtained from EN 1993-1-5 at normal temperature. In fire situation, higher strains are acceptable when compared to normal temperature design. Therefore, instead of $0.2 \%$ proof strength usually considered at normal temperature, for cross-sections of Class 1,2 and 3 at elevated temperatures the stress corresponding to $2 \%$ total strain should be adopted as the yield strength, equation (3):

$$
f_{y, \theta}=f_{2, \theta}=k_{2, \theta} f_{y}
$$

Being the $0.2 \%$ proof strength used for Class 4 cross-sections:

$$
f_{y, \theta}=f_{p 0.2, \theta}=k_{p 0.2, \theta} f_{y}
$$


Table 1. Reduction factor for stainless steel sections elements.

\begin{tabular}{llll}
\hline Cross-section elements & \multicolumn{2}{l}{ Reduction factor } \\
\hline Welded outstand elements & $\rho=\frac{1}{\bar{\lambda}_{\mathrm{p}}}$ & $\frac{0.242}{\bar{\lambda}_{\mathrm{p}}^{2}}$ & 1 \\
Welded internal elements & $\rho=\frac{0.772}{\bar{\lambda}_{\mathrm{p}}}$ & $\frac{0.125}{\overline{\bar{\lambda}}_{\mathrm{p}}^{2}}$ & 1 \\
\hline
\end{tabular}

The respective yield strength reduction factors are presented in Annex C of EN 1993-1-2.

In beams, the design value of the bending moment resistance of a cross-section with a uniform temperature shall be determined from:

$$
M_{f i, \theta, R d}=W_{y} f_{y, \theta} / \gamma_{M, f i}
$$

Being $W_{y}$ for Classes 1 and 2 the plastic section modulus, $W_{p l, y}$, for Class 3 the elastic section modulus, $W_{e l, y}$, and for Class 4 sections the effective section modulus, $W_{e f f, y}$, at normal temperature, determined with the effective section properties obtained from EN 1993-1-5. The effective area and effective section modulus are determined through the application of the effective width method, considering the reduction of resistance due to local buckling effects (CEN, 2006b). In this regard, EN 1993-1-4 (CEN, 2006a) provides specific equations for the determination of the plate reduction factors to the width of elements composing the stainless steel sections (Table 1).

The plate slenderness $-\bar{\lambda}_{\mathrm{p}}-$ value is determined with equation (6):

$$
\bar{\lambda}_{\mathrm{p}}=\sqrt{\frac{f_{y}}{\sigma_{c r}}}=\frac{\bar{b} / t}{28.4 \varepsilon \sqrt{k_{\sigma}}}
$$

Xing et al. (2020) considers the use of the stress corresponding to $2 \%$ of total strain for the stainless steel yield strength of Class 4 cross-sections at elevated temperatures, as it is done for the remaining sections, providing the plate reduction factors to be calculated as presented in Table 2.

\begin{tabular}{|c|c|c|}
\hline Cross-section elements & Stainless steel grade & Reduction factor \\
\hline \multirow[t]{3}{*}{ Outstand elements } & Austenitic & $\rho=1.0$ for $\bar{\lambda}_{\mathrm{p}, \theta} \leq \bar{\lambda}_{\mathrm{p} 0, \theta}$ \\
\hline & & $\begin{array}{l}\rho=\frac{0.6}{\left(\bar{\lambda}_{\mathrm{p}, \theta} / \sqrt{\xi_{\theta}}\right)}-\frac{0.075}{\left(\bar{\lambda}_{\mathrm{p}, \theta} / \sqrt{\xi_{\theta}}\right)} \text { for } \bar{\lambda}_{\mathrm{p}, \theta}>\bar{\lambda}_{\mathrm{p} 0, \theta} \\
\bar{\lambda}_{\mathrm{p} 0, \theta}=0.237 \sqrt{\xi_{\theta}}\end{array}$ \\
\hline & Ferritic and Duplex & $\begin{array}{l}\rho=1.0 \text { for } \bar{\lambda}_{\mathrm{p}, \theta} \leq \bar{\lambda}_{\mathrm{p} 0, \theta} \\
\rho=\frac{0.67}{\left(\overline{\mathrm{p}}_{\mathrm{p}, \theta} / \sqrt{\xi_{\theta}}\right)^{0.6}}-\frac{0.075}{\left(\bar{\lambda}_{\mathrm{p}, \theta} / \sqrt{\xi_{\theta}}\right)} \text { for } \bar{\lambda}_{\mathrm{p}, \theta}>\bar{\lambda}_{\mathrm{p} 0, \theta} \\
\bar{\lambda}_{\mathrm{p} 0, \theta}=0.344 \sqrt{\xi_{\theta}}\end{array}$ \\
\hline \multirow[t]{2}{*}{ Internal elements } & Austenitic & $\begin{array}{l}\rho=1.0 \text { for } \bar{\lambda}_{\mathrm{p}, \theta} \leq \bar{\lambda}_{\mathrm{p} 0, \theta} \\
\rho=\frac{0.54}{\left(\bar{\lambda}_{\mathrm{p}, \theta} / \sqrt{\xi_{\theta}}\right)^{0.75}}-\frac{0.015(3+\psi)}{\left(\bar{\lambda}_{\mathrm{p}, \theta} / \sqrt{\xi_{\theta}}\right)^{1.5}} \text { for } \bar{\lambda}_{\mathrm{p}, \theta}>\bar{\lambda}_{\mathrm{p} 0, \theta} \\
\bar{\lambda}_{\mathrm{p} 0, \theta}=(0.27+\sqrt{0.0279-0.015 \psi})^{1.33} \sqrt{\xi_{\theta}}\end{array}$ \\
\hline & Ferritic and Duplex & $\begin{array}{l}\rho=1.0 \text { for } \bar{\lambda}_{\mathrm{p}, \theta} \leq \bar{\lambda}_{\mathrm{p} 0, \theta} \\
\rho=\frac{0.6}{\left(\bar{\lambda}_{\mathrm{p}, \theta} / \sqrt{\xi_{\theta}}\right)^{0.75}}-\frac{0.015(3+\psi)}{\left(\bar{\lambda}_{\mathrm{p}, \theta} / \sqrt{\xi_{\theta}}\right)^{1.5}} \text { for } \bar{\lambda}_{\mathrm{p}, \theta}>\bar{\lambda}_{\mathrm{p} 0, \theta} \\
\bar{\lambda}_{\mathrm{p} 0, \theta}=(0.3+\sqrt{0.045-0.015 \psi})^{1.33} \sqrt{\xi_{\theta}}\end{array}$ \\
\hline
\end{tabular}

Table 2. Reduction factor for stainless steel slender sections elements proposed by Xing et al. (2020). 
The relative elevated temperature slenderness $\bar{\lambda}_{\mathrm{p}, \theta}$ is determined as $\bar{\lambda}_{\mathrm{p}, \theta}=\xi_{\theta} \bar{\lambda}_{\mathrm{p}}$ with the elevated temperature factor $\xi_{\theta}=\sqrt{k_{2, \theta} / k_{E, \theta}}$ (with $\psi$ the ratio between the end moments $(-1 \leq \psi \leq 1)$.

\section{CASE STUDY AND NUMERICAL MODELLING}

A parametric study was developed based on finite element analysis to determine and compare the ultimate bearing capacity of I-section and RHS subjected to compression or bending. The results determined with EC3 formulae and with the new proposal for stainless steel sections in fire (Xing et al., 2020) are compared to the numerical ultimate cross-sectional bearing capacity.

The I-sections and RHS considered in this study have equivalent webs that are always Class 4 (slender), being the flanges of Class 1 . The I-sections had $150 \mathrm{~mm}$ height and $140 \mathrm{~mm}$ width, varying the thicknesses for both cross-section types and the RHS were analysed as welded box sections with $150 \mathrm{~mm}$ height and $100 \mathrm{~mm}$ width. These restrained members had $1 \mathrm{~m}$ length. The stainless steel grades austenitic (1.4301), ferritic (1.4003) and duplex (1.4462) were considered in the study at the temperatures of $350{ }^{\circ} \mathrm{C}, 500{ }^{\circ} \mathrm{C}, 600{ }^{\circ} \mathrm{C}$ and $700^{\circ} \mathrm{C}$.

In the finite element models (Figure 1), rectangular shell finite elements with four nodes, with six degrees of freedom (three translations and three rotations), of $10 \mathrm{~mm}$ length over the member cross-section at flat plates, are used. During all the analysis the end-plates were at normal temperature and had 10 times the thickness of the thickest element's wall. In the longitudinal direction, the mesh size is $10 \mathrm{~mm}$. Loads in the parallel direction to the members axis were applied on the nodes of the members ends, according to the linear stresses distribution resulting from simple bending around the strong axis or axial compression. Restrictions are applied to reproduce hinged supports and to restrain the out-of-plane buckling. This study did not consider the residual stresses as they exhibit low influence at elevated temperatures.

The shapes obtained from local buckling modes, applying CAST3M program (CEA, 2012) together with the RUBY interface (Couto et al., 2013), were used to define the initial geometric imperfections. According to Annex C of EN 1993-1-5 (CEN, 2006b), the geometric imperfections' magnitudes were obtained from $80 \%$ of the prescribed geometric manufacturing tolerances: $0.8 b / 200$ (for $b / t \leq 80$ ) or $0.8 b^{2} /(16000 t$ ) (for $80<b / t \leq 200$ ) or $0.8 b / 80$ (for $b / t>200$ ) (being always higher than the thickness) as local imperfection for I-sections, according to EN 1090-2 (CEN, 2018); and 0.8b/100 as local imperfection for RHS obtained from EN 10219-2 (CEN, 2019), where $b$ is the length of the web or flange, depending on the highest deformation value.

a)

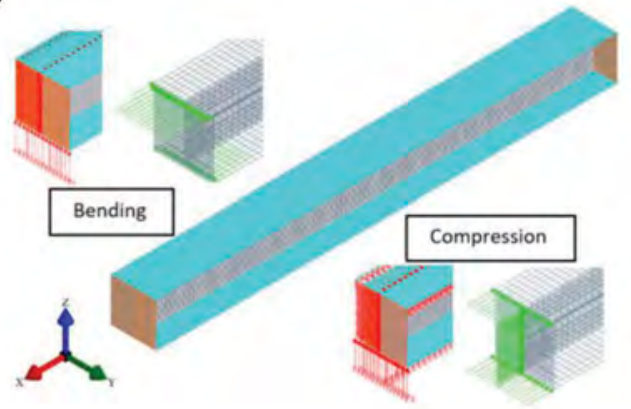

b)

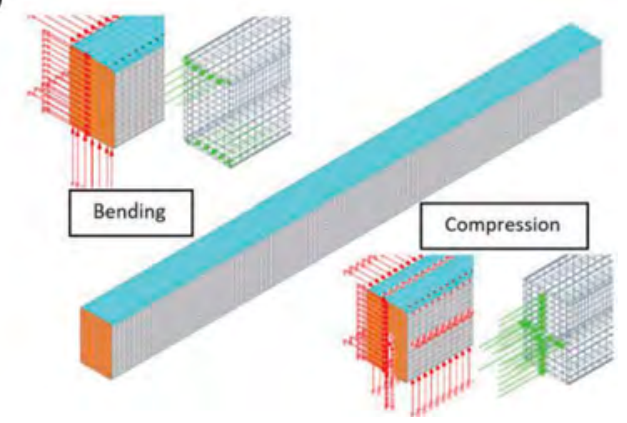

Figure 1. Numerical models adopted and respective loads and restrictions. a) I-section model, b) RHS model. 


\section{COMPARISON BETWEEN NUMERICAL RESULTS AND FIRE DESIGN RULES}

This section presents the parametric study results. The numerically obtained ultimate bearing load capacities were compared with the calculation rules of EN 1993-1-2 (Figure 2) and Xing et al. (2020) proposal (Figure 3). Figure 4 presents collapse modes examples obtained from the numerical analysis for I-section and RHS members under axial compression.

With the validation criteria proposed by Kruppa (1999), Table 3 presents the statistical evaluation for bending based on a total of 240 numerical results and Table 4 for axial compression based on a total of 336 numerical results, both tables considering all stainless steel grades results.

a)

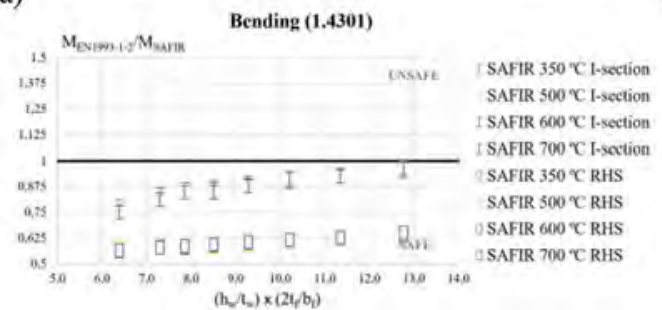

b)

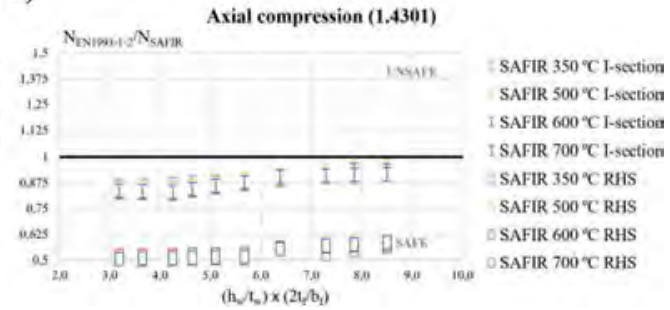

Figure 2. Comparison between the EN1993-1-2 and the numerical results, at elevated temperatures, for austenitic stainless steel cross-sections under a) bending and b) axial compression.

a)

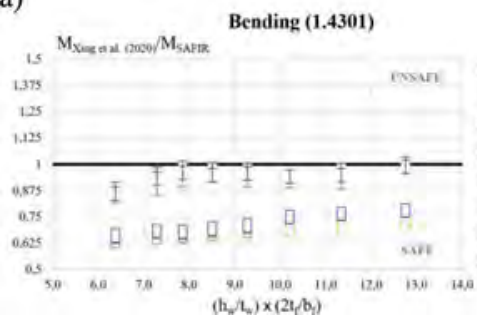

b)

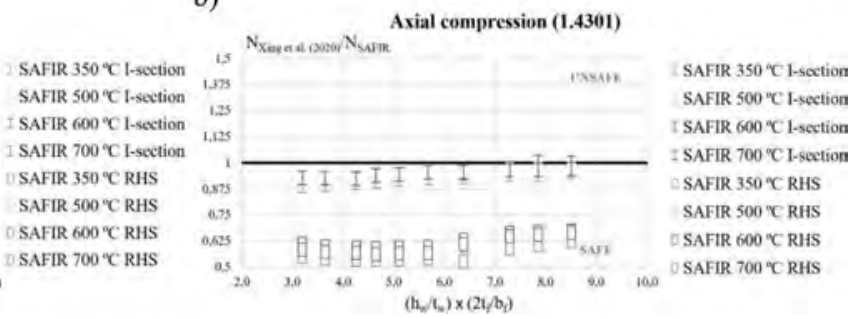

Figure 3. Comparison between the new proposal of Xing et al. (2020) and the numerical results, at elevated temperatures, for austenitic stainless steel cross-sections under a) bending and b) axial compression.

a)

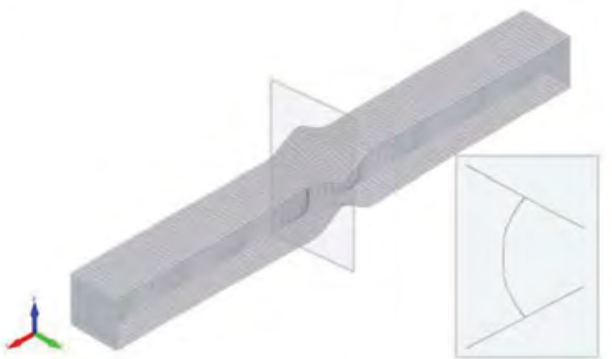

b)

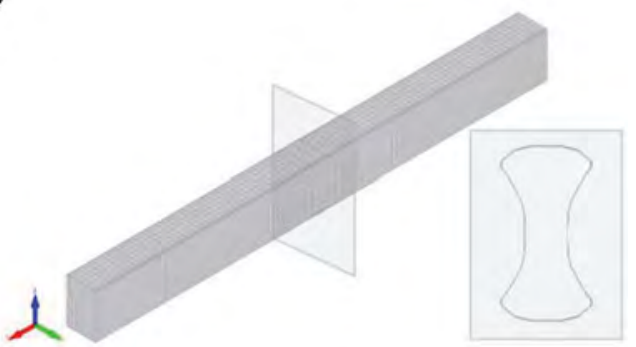

Figure 4. Example of numerical collapse mode obtained for a) I-section and for b) RHS under axial compression at elevated temperatures. 
Table 3. Statistical evaluation with bending results considering the different stainless steel grades.

\begin{tabular}{|c|c|c|c|c|c|c|c|c|c|c|c|c|}
\hline \multirow[b]{2}{*}{ Bending } & \multicolumn{4}{|c|}{ Austenitic } & \multicolumn{4}{|c|}{ Ferritic } & \multicolumn{4}{|c|}{ Duplex } \\
\hline & $\mu$ & $s$ & Max. & $\begin{array}{l}\% \\
\text { Uns. }\end{array}$ & $\mu$ & $s$ & Max. & $\begin{array}{l}\% \\
\text { Uns. }\end{array}$ & $\mu$ & $s$ & Max. & $\begin{array}{l}\% \\
\text { Uns. }\end{array}$ \\
\hline EN1993-1-2 (I) & 0.876 & 0.060 & 0.970 & 0.0 & 0.702 & 0.022 & 0.723 & 0.0 & 0.850 & 0.046 & 0.901 & 0.0 \\
\hline Xing et al. (I) & 0.951 & 0.044 & 1.009 & 7.7 & 0.759 & 0.029 & 0.813 & 0.0 & 0.859 & 0.034 & 0.927 & 0.0 \\
\hline $\begin{array}{l}\text { EN1993-1-2 } \\
\text { (RHS) }\end{array}$ & 0.602 & 0.026 & 0.656 & 0.0 & 0.543 & 0.048 & 0.644 & 0.0 & 0.564 & 0.050 & 0.630 & 0.0 \\
\hline $\begin{array}{l}\text { Xing et al. } \\
\text { (RHS) }\end{array}$ & 0.701 & 0.039 & 0.781 & 0.0 & 0.674 & 0.064 & 0.788 & 0.0 & 0.694 & 0.054 & 0.796 & 0.0 \\
\hline
\end{tabular}

Table 4. Statistical evaluation with axial compression results considering the different stainless steel grades.

\begin{tabular}{|c|c|c|c|c|c|c|c|c|c|c|c|c|}
\hline \multirow[b]{2}{*}{ Compression } & \multicolumn{4}{|c|}{ Austenitic } & \multicolumn{4}{|c|}{ Ferritic } & \multicolumn{4}{|c|}{ Duplex } \\
\hline & $\mu$ & $s$ & Max. & $\begin{array}{l}\% \\
\text { Uns. }\end{array}$ & $\mu$ & $s$ & Max. & $\begin{array}{l}\% \\
\text { Uns. }\end{array}$ & $\mu$ & $s$ & Max. & $\begin{array}{l}\% \\
\text { Uns. }\end{array}$ \\
\hline EN1993-1-2 (I) & 0.880 & 0.037 & 0.960 & 0.0 & 0.780 & 0.040 & 0.859 & 0.0 & 0.845 & 0.039 & 0.965 & 0.0 \\
\hline Xing et al. (I) & 0.944 & 0.028 & 1.003 & 7.5 & 0.820 & 0.044 & 0.916 & 0.0 & 0.889 & 0.959 & 1.000 & 2.3 \\
\hline $\begin{array}{l}\text { EN1993-1-2 } \\
\text { (RHS) }\end{array}$ & 0.534 & 0.029 & 0.593 & 0.0 & 0.616 & 0.030 & 0.658 & 0.0 & 0.604 & 0.031 & 0.657 & 0.0 \\
\hline $\begin{array}{l}\text { Xing et al. } \\
\text { (RHS) }\end{array}$ & 0.595 & 0.045 & 0.674 & 0.0 & 0.729 & 0.038 & 0.768 & 0.0 & 0.695 & 0.044 & 0.757 & 0.0 \\
\hline
\end{tabular}

From these comparisons, it can be concluded that both approaches are mostly on the safety side for I-sections and the results are relatively well adapted for Xing et al., 2020 proposal highlighting the results of the austenitic stainless steel (as also demonstrated in Figures 3 and 4). For RHS the methodologies are also safe, however over conservative specially compared to EN 1993-1-2 design rules, due to the stiffness provided by the flanges, that are in RHS internal elements, to the slender webs.

\section{CONCLUSIONS}

This research presented a parametric study on the cross-sectional resistance of stainless steel slender I-sections and Rectangular Hollow Sections (RHS) at elevated temperatures of members under bending and under axial.

A comparison was made between the ultimate load bearing capacities obtained numerically and the requirements of EC3 and Xing et al. (2020) proposal, leading to the conclusion that both design methodologies are too conservative for RHS. It was also possible to observe that Xing et al. (2020) proposal presents a better approximation to the I-section numerical results when compared to EC3. Further studies will help to develop more precise design formulae for RHS, following the format of the proposed approaches.

\section{ACKNOWLEDGEMENTS}

This research was performed within the framework of the project "StaSteFi - Fire design of stainless steel members", PTDC/ECI-EGC/30655/2017, supported by the Portuguese Operational Programme "Competitividade e Internacionalização", in its FEDER/FNR component, and the Portuguese FCT, in its State Budget component (OE). 


\section{REFERENCES}

CAST3M, sponsored by French Atomic Energy Commission; 2012. http://www-cast3m.cea.fr/

CEN - EN 1993-1-1, Eurocode 3: Design of steel Structures - Part 1-1: General rules and rules for buildings, Belgium, 2005a.

CEN - EN 1993-1-2, Eurocode 3: Design of Steel Structures - Part 1-2: General rules - Structural fire design, Belgium, 2005b.

CEN - EN 1993-1-4, Eurocode 3: Design of steel Structures - Part 1-4: General rules - Supplementary Rules for Stainless steels, Belgium, 2006a.

CEN - EN 1993-1-5, Eurocode 3: Design of Steel Structures - Part 1-5: Plated structural elements, Belgium, 2006b.

CEN - EN 1090-2, Execution of steel structures and aluminium structures - Part 2: Technical requirements for the execution of steel structures, Belgium, 2018.

CEN - EN 10219-2, Cold Formed Welded Steel Structural Hollow Sections - Part 2: Tolerances, Dimensions and Sectional Properties, Belgium, 2019

Couto, C., Vila Real, P., Lopes, N., RUBY - an interface software for running a buckling analysis of SAFIR models using Cast3M, University of Aveiro, 2013.

Couto, C., Vila Real, P., Lopes, N. \& Zhao, B., Effective width method to account for the local buckling of steel thin plates at elevated temperatures. Thin-Walled Structures, 84, 2014, 134-149.

Couto, C., Fire design of steel members with class 4 cross-section, $\mathrm{PhD}$ thesis, University of Aveiro, Portugal, 2015.

Euro Inox, SCI, Design Manual for Structural Stainless Steel, 3rd edition, 2006.

FIDESC4, Fire Design of Steel Members with Welded or Hot-Rolled Class 4 Cross-Section, RFCS-CT -2011-2014, Technical Report No. 5, 2014.

Franssen, J-M. \& Vila Real, P., Fire Design of Steel Structures, ECCS, Ernst \& Sohn, a Wiley Company, 2nd edition, 2015.

Gardner, L. 2005. The use of stainless steel in structures. Progress in Structural Engineering and Materials, vol 7, pp 45-55.

Gernay, T., Franssen, J.M., Modelling structures in fire with SAFIR®: Theoretical background and capabilities, Journal of Structural Fire Engineering, Vol. 8, issue 3, 2017, pp. 300-323.

Knobloch, M., \& Fontana, M., Strain-based approach to local buckling of steel sections subjected to fire, Journal of Constructional Steel Research, 62(1-2), 2006, 44-67.

Kruppa, J. Eurocodes - fire parts, proposal for a methodology to check the accuracy of assessment methods, CEN TC 250, Horizontal Group Fire, Document n 99/130, 1999.

Maraveas, C., Gernay, T. \& Franssen, J-M., Amplitude of local imperfections for the analysis of thin-walled steel members at elevated temperatures, ASFE'17, Manchester, UK, 2017.

Quiel, S. E., Garlock, M. E. M., Calculating the buckling strength of steel plates exposed to fire, ThinWalled Structures, 48(9), 2010, 684-695.

Xing, Z., Kucukler, M., Gardner, L., Local buckling of stainless steel plates in fire, Thin-Walled Structures, $148,2020,106570$. 


\title{
Lifetime estimation for hollow-section joints under variable amplitude loading
}

\author{
A. Dürr \& J. Roth \\ University of Applied Sciences Munich, Munich, Germany
}

\begin{abstract}
Bridges, crane constructions and automotive vehicles are subjected to variable loads and are often realised as truss constructions made of hollow sections. For Designing against fatigue failure normally entails the use of damage accumulation procedures according to the Palmgren-Miner-Rule, which is the industry-standard stipulated proceeding given in various design guides and recommendations. In these guidelines, damage sums between $D=0.5$ and $D=1.0$ are given. Different test results reveal that these damage sums partly are too conservative and can lead to uneconomic structures. To investigate the influence of variable amplitude loadings according to the damage sums and overload effects, a large number of tests was performed at the University of Applied Sciences Munich. For the tests, specimens were loaded with different load spectra with blocked and random load sequences. Within this paper the test series and the test results are presented.
\end{abstract}

\section{INTRODUCTION}

Truss structures made of hollow sections are commonly used for bridge and crane constructions as well as in the energy sector and commercial vehicle constructions industry due to their slender appearance and the high loading capacity. Common to all of these hollow section types of construction is the fact that they are subjected to variable amplitude loadings and they have to be designed against fatigue failure. For this design purpose, there are many of different design guidelines and recommendations for hollow sections, such as those from the International Institute of Welding (IIW) (Hobbacher, 2008), the CIDECT design guide (Zhao et al., 2001) and the Eurocode 3 (DIN EN 1993-1-9, 2010). In terms of variable amplitude loadings, these guidelines use the approach of linear damage accumulation by Palmgren-Miner, albeit each demonstrating different damage sum thresholds. Research results have shown that a damage sum of $D=0.5$ or $D=1.0$ can, in some cases, lead to very conservative results and thus to uneconomic constructions which are economically unviable, especially for constructions made of hollow sections (Bucak, 1990). To receive detailed knowledge about the influence of the load sequence and the impact of single overloads for the lifetime estimation of constructions made of hollow sections, a large number of tests was performed at the University of Applied Sciences Munich in the research project FOSTA P1195 (Dürr et al., 2021). Therefore, X-joints made of square hollow sections (SHS) and circular hollow sections (CHS) were tested with different load spectra. Within this paper the test results are compared with test results from literature and a conclusion of the test results is drawn. 
Table 1. Differences between guidelines and recommendations according to damage accumulation for hollow section joints.

\begin{tabular}{llllll}
\hline Guideline & slope $m_{1}$ & slope $m_{2}$ & Knee point & Cut-off point & D \\
\hline EC3 & 5 & 5 & $5 \cdot 10^{6}$ & $10^{7}$ & 1.0 \\
prEN1993-1-9 & 5 & 9 & $5 \cdot 10^{6}$ & $10^{8}$ & 1.0 \\
IIW & 5 & $2 m_{1}-1$ & $10^{7}$ & $10^{9}$ & $0.5 \cdots 1.0$ \\
CIDECT & 5 & 5 & $5 \cdot 10^{6}$ & $10^{8}$ & 1.0 \\
\hline
\end{tabular}

\section{STATE OF THE ART}

\subsection{Damage accumulation in design rules and recommendations}

The damage accumulation based on the Palgrem-Miner-Rule is the standard approach for fatigue design under variable amplitude loadings (VAL). Therefore, the applied load cycles $n_{i}$ on a certain stress range are compared with the allowed load cycles $N_{i}$ based on the $\mathrm{S}-\mathrm{N}$-curve. The damage sum $D$ summarises all incurred stress ranges, see equation (1).

$$
D=\sum \frac{n_{i}}{N_{i}}
$$

This approach can be found in all common design recommendations for fatigue design under VAL. The main difference between the recommendations and design guidelines using the nominal stress approach are the used knee point and the cut-off point of the S-N-curve as well as the slope of the S-N-curve $\left(m_{2}\right)$ below the knee-point and the allowed damage sum. These values are shown in Table 1. For stress ranges, which account for only a small impact on the damage sum, the most guidelines recommend to view these small stress ranges as negligible (DIN EN 1993-1-9, 2010).

\section{EXPERIMENTAL TEST SERIES}

\subsection{Specimens}

In accordance with the aforementioned regarding hollow sections the $\tau, \beta$ and $\gamma$ values, see Table 2, as well as the kind of hollow sections used (SHS or CHS) play a decisive role in the fatigue behaviour. Two different test series with circular and rectangular hollow sections of different dimension ratios were used in order to counter the influence of the profile type used in the research project P1195 (Dürr et al., 2021), see Table 2. The tested joints were X-joints under tension loads and the stress ratio was $R=0.1$.

\subsection{Used load spectra and test series}

Tests with VAL are generally conducted with load spectra based on measurements at a certain construction detail in service or with standardised load spectra. In the research project P1195 (Dürr et al., 2021), one load spectrum was chosen, which is taken from the long established, but not valid anymore, German guideline DIN EN 15018 (DIN EN 15018, 1984) pertaining to cranes. This load spectrum according the long established German crane guideline is called $\mathrm{p}(1 / 3)$-load spectrum. This spectrum has a convex distribution with a small number of high stress ranges, which is typical for crane and bridge constructions. The second load spectrum, which was chosen in the research project P1195 (Dürr et al., 2021), is based on measurements at different tower cranes on various sites over one year in the framework of the research project FOSTA P778 (Ummenhofer et al., 2012). This loading spectrum is called q-loading spectrum because of the relatively long number of loading cycles with a high stress range. The exact distribution and the sequence length for both load spectra can be taken from Figure 1. 


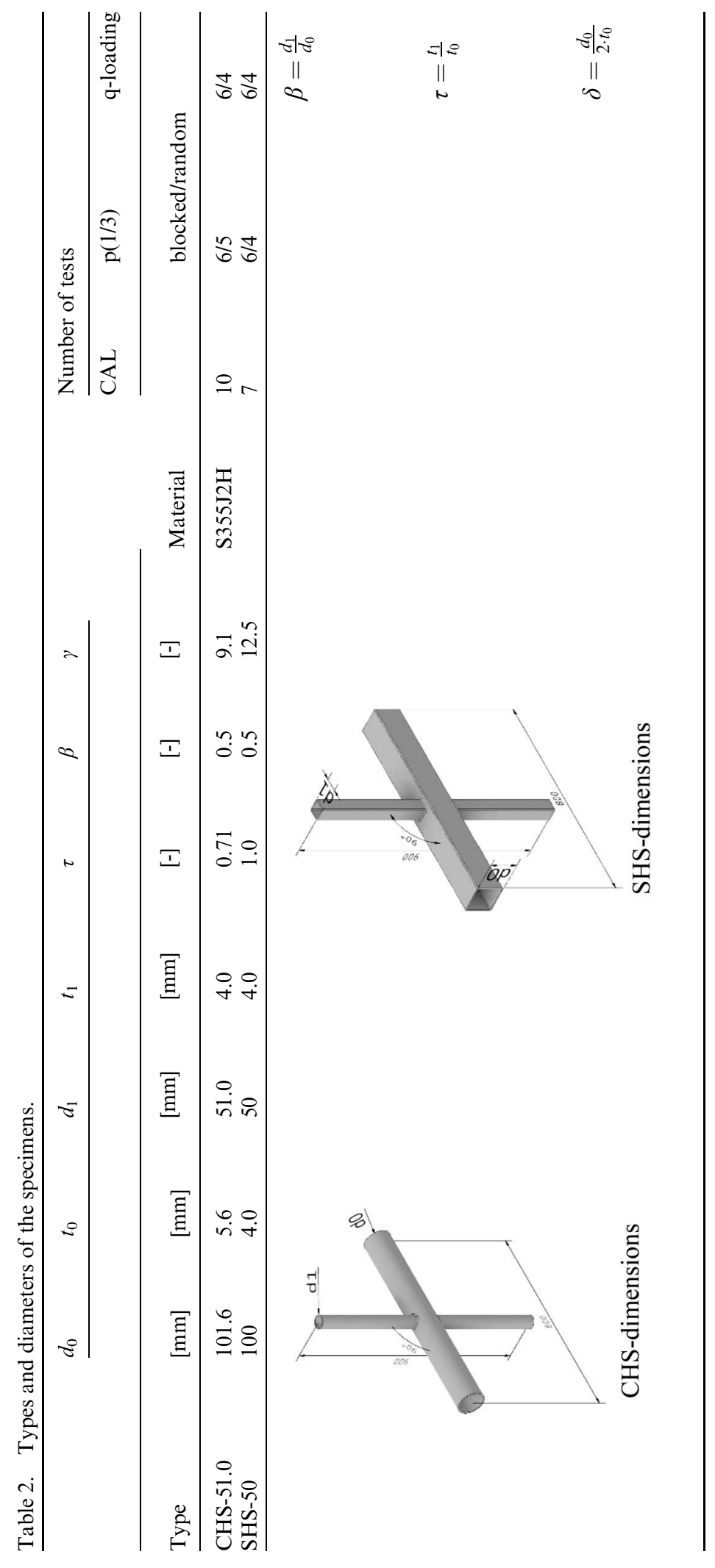


a)

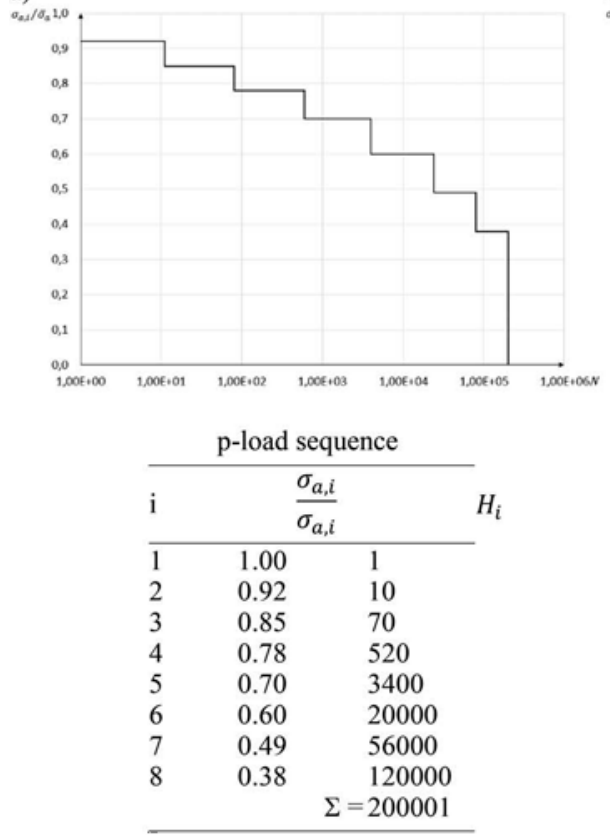

b)

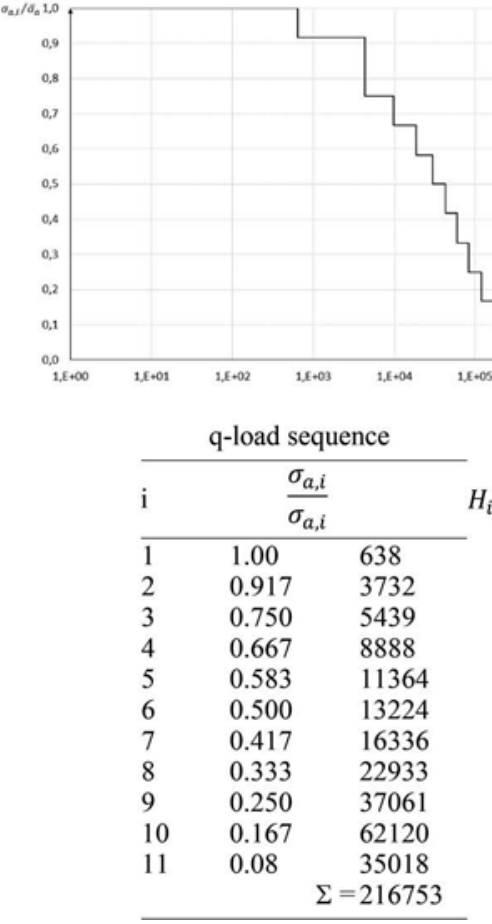

Figure 1. Load spectra used for the experimental tests. a) p(1/3) load spectrum according (DIN EN 15018, 1984), b) Tower crane load spectrum according (Ummenhofer et al., 2012).

In a preliminary step for each specimen type constant amplitude loading (CAL) tests were performed in order to attain a reference S-N-curve. The CAL test results were used for the further assessment of the VAL tests. In a second step, the block and random load test series were been carried out for the p-load sequence and the q-load sequence. The blocked load spectra were conducted with the up and down test sequence according to Gassner and with Markov transition (Haibach, 2006). Each test started with a middle block of each load spectra. For the random load sequence the standardised load spectra with an irregularity factor of $\mathrm{I}=0.99$ (Haibach, 2006) were generated. For the assessment of the test results the rainflow counting method was applied. To compare the VAL-test results directly with the CAL-test results, a conversion to an equivalent number of load cycles $N_{e q, i}$ based on the maximum stress range $\Delta \sigma_{\max }$ of the load sequence according to the equation (2) was applied. The exact number of tests of each series can be taken from Table 2 .

$$
N_{e q, i}=N_{i} \cdot\left(\frac{\Delta \sigma_{i}}{\Delta \sigma_{\max }}\right)^{m}
$$

\subsection{Test rigs}

To reduce the runtime of the tests, different test rigs were used for the blocked loadings and for the random loadings. For the tests with blocked load sequences an universal spindle machine was used for the higher stress ranges with a smaller number of load cycles and in this testing machine the tests were conducted at a frequency of $0.5 \mathrm{~Hz}$. For the load blocks with a large number of load cycles a resonance pulsator was used with a frequency of around 38 
a)

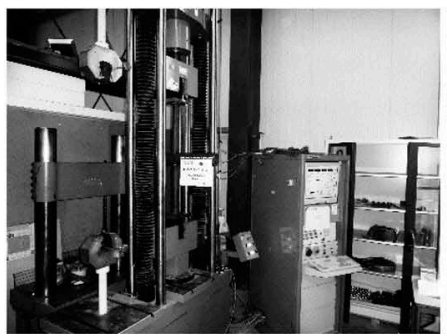

b)

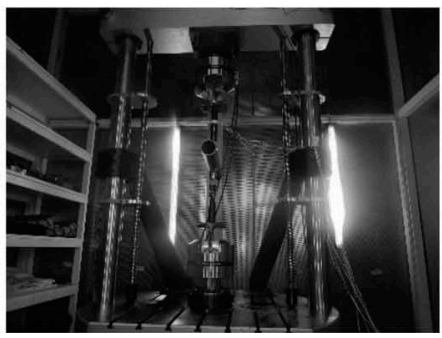

c)

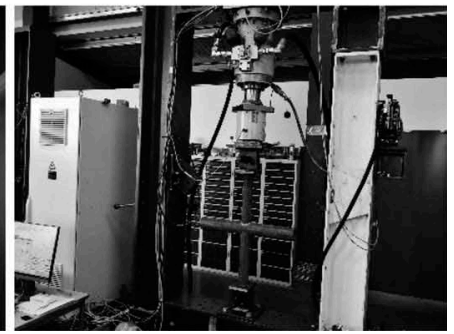

Figure 2. Test rigs for blocked load tests and random load tests. a) Universal spindle machine, b) Resonance pulsator, c) Servohydraulic cylinder.

Hz. Tests were deemed completed upon cracks appearing that penetrated the wall. For the test series with a random load sequence a servohydraulic cylinder was used. This kind of test rigs have the advantage that the exact peak value in an arbitrary order can be reached by the cylinder. The tests were conducted by a force controlled actuator and the tests were concluded upon an increase in deformation of $1 \mathrm{~mm}$. In order for results to be comparable, the abort criterion for all tests was uniform i.e. the occurrence of a crack that penetrated the wall.

\section{RESULTS}

\subsection{Square hollow section}

The results of the tests with the specimen type SHS-50 can be seen in Figure 3. In the left diagram the results of the different test series in comparison to the CAL-results are shown, as well as the existing test results from the literature (Bucak, 1990). In the right diagram the results are shown where the transmission to the equivalent number of cycles according to the highest stress range of the test was applied. It can be observed that the blocked test procedure for both loading sequences led to better results than the test results with a random test procedure. It appears that the blocked test results may lead to the lifetime of constructions being overestimated where VAL occurs. For nearly all test results the damage sums lie between $1.0 \leq$ $D \leq 3.0$ for the tower crane load spectrum and $1.0 \leq D \leq 9.0$ for the $\mathrm{p}(1 / 3)$ load spectrum.

a)

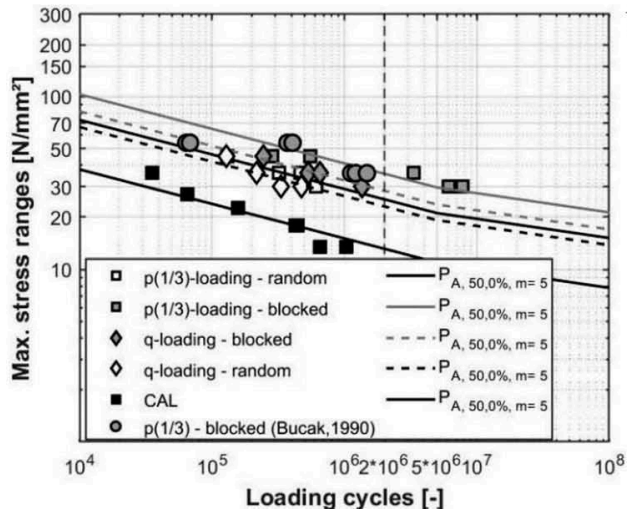

)

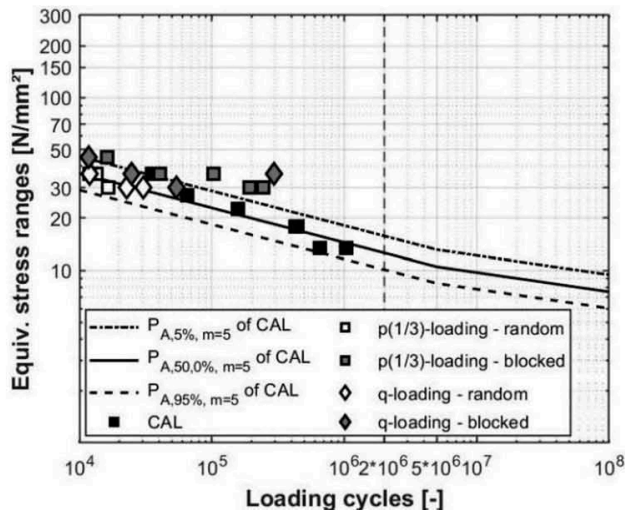

Figure 3. Test results of square hollow sections. a) Test results for SHS-50 series, b) Comparison of test results with equivalent stress ranges. 
a)

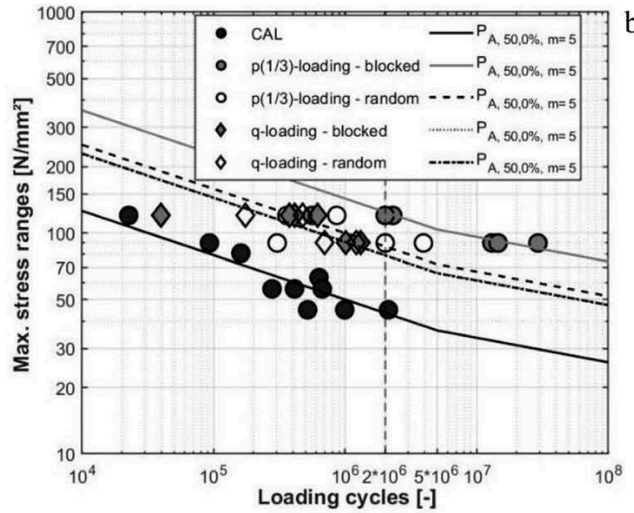

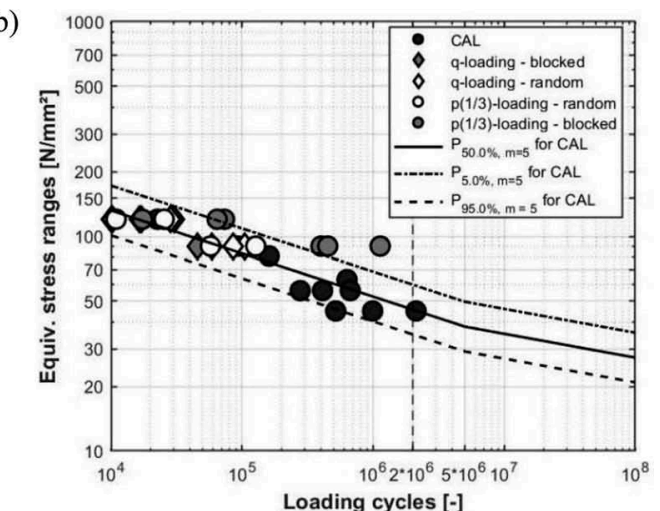

Figure 4. Test results of circular hollow sections. a) Test results for CHS-51.0 series, b) Comparison of test results with equivalent stress ranges.

However, after transmission to the equivalent number of cycles according to equation (2), it can be seen in Figure $3 b$ ) that almost all test results are within the scatter band of the CAL test results. The damage sum of $D=1.0$ according to EN 1993-1-9 (DIN EN 1993-1-9, 2010) and CIDECT (Zhao et al., 2001) appears to be on the conservative side when considering application for these hollow section joints.

\subsection{Circular hollow section}

The results of testing with the specimen type CHS-51.0 can be taken from Figure 4 . In the left diagram it can be observed that the $\mathrm{p}(1 / 3)$-loading test results lead to better results than the test results conducted with the q-loading spectrum. This effect can be explained by the shape of the load spectrum, which is described in (Haibach, 2006). For the tests with $\mathrm{p}(1 / 3)$-loading, the blocked test results are slightly more favourable than the test results with a random load sequence.

For the test results conducted with the q-loading sequence no difference between blocked and random loading sequence can be observed. However, after transmission to the equivalent number of cycles according to equation (2), it can be seen in Figure $4 \mathrm{~b}$ that almost all test results are within the scatter band of the CAL test results, with the same range of damage sums $D$ as like the SHS results.

\section{CONCLUSIONS}

To concluded, the following effects became evident from the test results:

- It appears that blocked test results lead to an overestimation in the lifetime of construction details compared to random tests.

- The tests with q-loading sequences lead to a shorter lifetime in comparison to the p-loading sequence. This fact concerns the shape of the loading sequence.

- The test results with damage equal stress ranges fit within the scatterband of the constant amplitude test results.

- The damage sum $D$ for all tests carried out so far were predominantly above $D=1.0$. On the basis of these test results, a reduction of the damage sum for hollow section joints seems not recommendable according to the current state of the research project P1195 (Dürr et al., 2021). 
Further tests on and investigations into the effect of loading sequences will be performed within the framework of the research project FOSTA P1195 (Dürr et al., 2021). This shall have as its aim the validation of current tests and the development of a correction factor based on the loading sequence shape for calculating the damage sum.

\section{ACKNOWLEDGEMENT}

The authors would like to take this opportunity to express their profound gratitude to all supporters of their research in the project FOSTA P1195. Special thanks is extended to the German Federal Ministry for Economic Affairs and Energy, Forschungsvereinigung Stahlanwendung (FOSTA) e.V., as well as Vallourec Deutschland and Tata Steel for the material donations. Moreover, the authors would like to thank all project partners for their supportive and fruitful cooperation.

\section{REFERENCES}

Bucak, Ö., 1990. Ermüdung von Hohlprofilknoten, PhD-Thesis, Universität Fridericiana zu Karlsruhe.

DIN EN 1993-1-9, 2010. Eurocode 3: Design of steel structures - Part 1-9: Fatigue, German version, Berlin: Beuth Verlag.

DIN EN 15018, 1984. Krane: Grundsätze für Stahltragwerke; Berrechnung von Fahrzeugkranen, Berlin: Beuth Verlag.

Dürr et al., 2021. Berücksichtigung von Reihenfolgeeffekten bei der Lebensdauerabschätzung von Hohlprofilkonstruktionen, FOSTA P1195/IGF-Nr. $19410 \mathrm{~N}$, (in progress).

Haibach, E., 2006. Betriebsfestigkeit - Verfahren und Daten zur Bauteilberechnung, Berlin: SpringerVerlag.

Hobbacher, A., 2008. Recommendations for fatigue design of welded joints and components, International Institute of Welding, IIW-1823-07 ex XIII-2151r4-07/XV-1254R4-07, 2008.

PrEN 1993-1-9, 2020. Design of steel structures - Part 1: Fatigue.

Ummenhofer et al., 2012. Bemessung von ermüdungsbeanspruchten Bauteilen aus hoch- und ultrahochfesten Feinkornbaustählen im Kran- und Analgenbau.

Zhao et al., 2001. Design Guide - For Circular and rectangular hollow section welded joints under fatigue loading, Comité International pour le Développement et l'Etude de la Construction Tubulaire (CIDECT), TÜV-Verlag. 


\title{
A new approach for the design of plates with trapezoidal longitudinal stiffeners
}

\author{
M.Z. Haffar \& S. Ádány \\ Department of Structural Mechanics, Budapest University of Technology, Budapest, Hungary \\ B. Kövesdi \\ Department of Structural Engineering, Budapest University of Technology, Budapest, Hungary
}

\begin{abstract}
The design approach for longitudinally stiffened plates in the relevant Eurocode interprets the stiffener buckling as a combination of so-called plate-like behavior and column-like behavior. In this paper an alternative design approach is presented for the problem of compressed plates with longitudinal trapezoidal stiffeners. One single Winter-type buckling curve is proposed for the calculation of the reduction factor for stiffener buckling. The proposed buckling curve is described by one single formula, but with some geometrydependent parameters. The parameters are determined and the results are evaluated by large number of advanced finite element analyses.
\end{abstract}

\section{INTRODUCTION}

The current European design approach for the resistance calculation of longitudinally stiffened plates can be found in CEN (2006). It assumes that, depending on the geometry, the behavior can be column-like, plate-like, or in between the plate-like and column-like behavior modes, i.e. interactive. To calculate the resistance, a reduction factor is to be determined, separately for the column-like and plate-like behaviors. For the reduction factor for the column-like behavior an Ayrton-Perry formula is used, as usual in the European practice for column design. For the reduction factor for the plate-like behavior a Winter formula is used, as usual in the European practice for plate design. In a general case the final reduction factor is interpolated from the two separate reduction factors. Once the final $\rho_{c}$ reduction factor is known, the compression resistance of the stiffened plate is calculated by Equation (1).

$$
N_{R d}=\frac{f_{y}\left(\rho_{c} \cdot A_{c, e f f, l o c}+A_{e d g e, e f f}\right)}{\gamma_{M 0}}
$$

where $A_{c, \text { eff, loc }}$ is the effective area of the entire internal part of the stiffened plate, $A_{\text {edge,eff }}$ is the total effective area of the edge plate elements, see Figure 1, while $\gamma_{M 0}$ is a partial factor and $f_{y}$ is the yield strength.

The precision of the above design approach has recently been questioned, and proposals for various improvements in the design process have also been published, see e.g. Sinur (2011), Martin et al. (2017), or Kövesdi (2019). In this paper we propose a new approach, which is based on slightly different principles compared to the earlier proposals. 


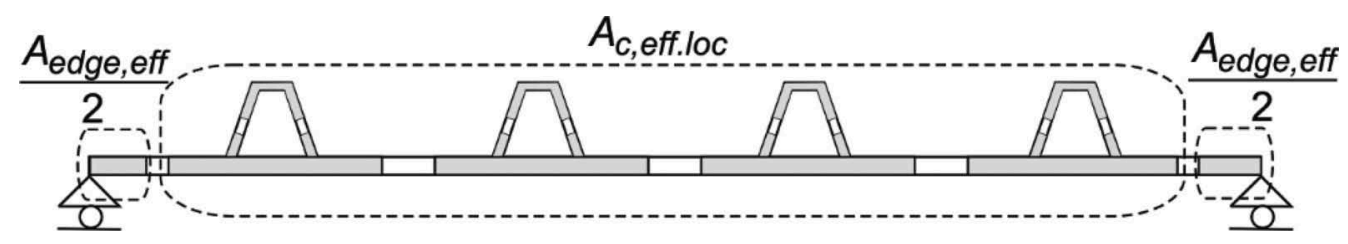

Figure 1. Separation of the compressed plate into middle and edge parts.

\section{PROPOSED NEW DESIGN METHOD}

The new design approach is originated from the observation that in cold-formed steel structural members the buckling of longitudinal stiffeners is usually described as distortional buckling, and in the various relevant cold-formed steel design codes the distortional buckling is covered by one single reduction factor, calculated by one single formula. The goal here, therefore, is to find a single formula for the reduction factor (instead of calculating it by interpolating from the reduction factors to plate-like and column-like behavior).

The proposed new design approach adopts Equation (1), as well as utilizes some formulae from the current design process. The main novelty is in the calculation of the reduction factor. The proposed design process can be completed through the following steps:

1. $\sigma_{c r, p}$ is the critical buckling stress must be calculated; it is recommended to perform shell finite element calculation (linear buckling analysis).

2. The non-dimensional slenderness $\bar{\lambda}_{p}$ is given by:

$$
\bar{\lambda}_{p}=\sqrt{\frac{f_{y}}{\sigma_{c r, p}}}
$$

3. The $\sigma_{c r, c}$ critical stress for a single stiffener is calculated as follows:

$$
\sigma_{c r, c}=\frac{\pi^{2} E I_{s l}}{a^{2} A_{s l}}
$$

where $I_{s l}$ is the second moment of area of the gross cross section of the stiffener and the adjacent parts of the plate, relative to the out-of-plane bending of the plate; $A_{s l}$ is the gross cross-sectional area of the stiffener and the adjacent parts of the plate, and $a$ is the buckling length (i.e. distance between the cross girders).

4. The $\xi$ stress ratio parameter, similarly as in CEN (2006), is given by:

$$
\xi=\frac{\sigma_{c r, p}}{\sigma_{c r, c}}-1
$$

5. The $\rho_{c}$ reduction factor is calculated by a new formula, as presented in Section 4 . 6. The $N_{R d}$ compression resistance of the stiffened plate is calculated by Equation (1).

It is to observe that the above procedure requires the calculation of the critical stress to the buckling where the whole stiffened panel buckles. Though this critical stress could be estimated by some analytical formula, but the numerical experience is that the available analytical formulae are not precise enough, see e.g. Haffar et al. (2019). That is why we propose to use shell finite element linear buckling analysis. 


\section{ADVANCED NUMERICAL ANALYSIS}

In order to find the new formula for the reduction factor (as in Step \#4 above), we would need to know the real resistance of various stiffened plates. The real resistance could ideally be obtained from real experiments, however, can be predicted by carefully completed advanced numerical analysis with considering geometric and material nonlinearity and imperfections (i.e. GMNI analyses). This latter approach is followed here. For the GMNIA the ANSYS 17.2 general purpose finite element software has been used, which has been used to calculate both the buckling resistance and the critical stress of the investigated panels. The model is described in detail and the results are reported in Haffar et al. (2019). Here only a brief summary is given.

The numerical model is a full shell model using four node thin shell elements (Shell 181 in Ansys terminology). All the sub-plates are divided into 6-10 elements in the transverse direction; the longitudinal discretization is adjusted to the transverse one in order to have nearly square elements. The model includes three panels, see Figure 2. The ends are supported by applying rigid constraints (see the left part of the figure). The longitudinal edges and the lines of the cross-girders are simply supported (see the right part of the figure). This model is a realistic representation of a typical application of stiffened plates such as flange element of a box-girder bridge.

The considered material is steel. A multi-linear elastic-plastic material model is applied. Global and local equivalent geometric imperfections have been used in the GMNI analyses with an amplitudes of $\min (a / 400, b / 400)$ for the global and $b_{i} / 200$ for the local imperfections according to the recommendations of CEN (2006), where $a$ is the length, $b$ is the width of the stiffened plate, while $b_{i}$ is the width of the plate part between two adjacent stiffeners, see Figure 2.

The variable parameters are as follows: the length of the panel $(a)$, the number of longitudinal stiffeners $(n)$, the distance between the longitudinal stiffeners $(w)$, the width and thickness of the analysed plate $\left(b, t_{p}\right)$ and the cross-section of the longitudinal stiffeners $\left(h_{s l}, t_{s l}\right.$, $\left.b_{s l, 1}, b_{s l, 2}\right)$, as shown in Figure 3. Altogether 394 different configurations are considered. In each case the ultimate resistance was aimed to calculate. Due to the applied model, the failure always occurred in the middle panel.

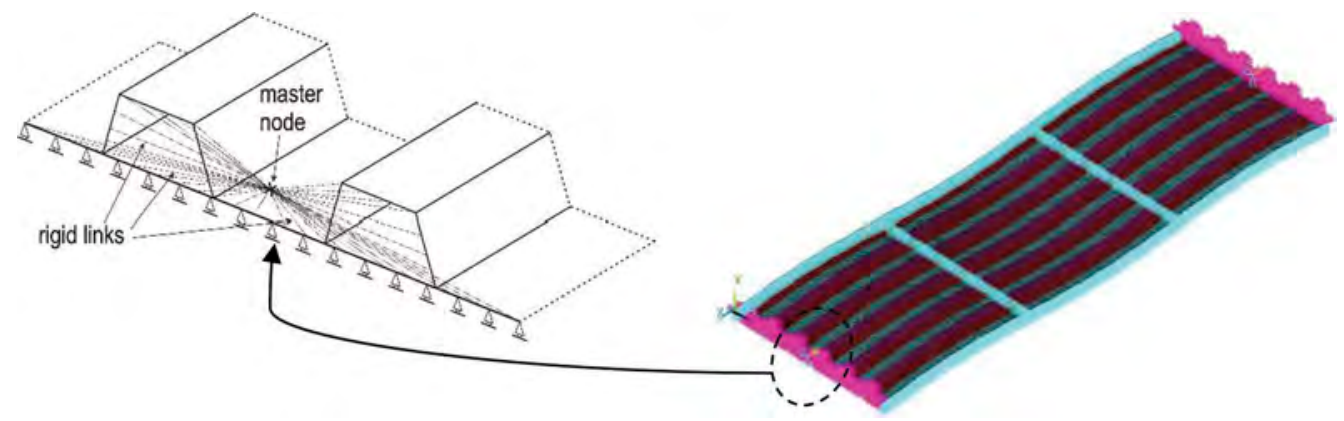

Figure 2. Applied shell model with the imperfections, and with the end supports highlighted.

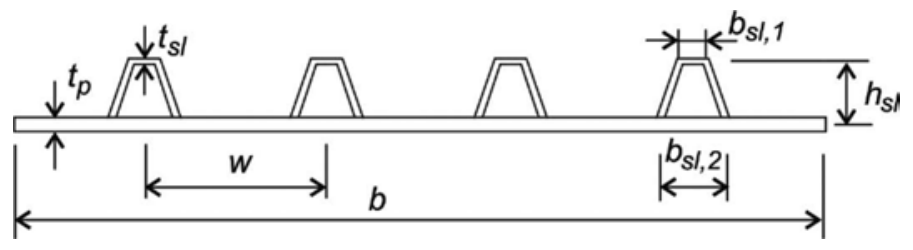

Figure 3. Geometric parameters in the parametric studies. 
Once the $N_{u l t}$ compression resistance of the stiffened plate is determined from the GMNIA, the reduction factor $\rho_{c, G M N I}$ can be back-calculated by rearranging Equation (1) to Equation (5).

$$
\rho_{c, G M N I}=\frac{N_{u l t} / f_{y}-A_{\text {edge }, e f f}}{A_{c, e f f, l o c}}
$$

It is to note that the geometric parameters were selected so that all the cross-sections would (at least approximately) be fully effective, thus, in the calculation of the relative slenderness parameter no adjustment for the effective cross-section is necessary in Step \#2 in Section 2. In case of not fully effective cross-sections Equation (2) could be modified.

\section{AUXILIARY MODIFIED WINTER CURVES}

The new design approach is based on the idea that the buckling of the stiffeners can be described as distortional buckling, and in the case of distortional buckling the reduction factor is calculated by Winter-type buckling curves in several design codes. Accordingly, some Winter-type buckling curves have been considered in our investigations, and finally a simple formula was found to be the most promising, as follows:

$$
\rho_{c}=\frac{\bar{\lambda}_{p}-\bar{\lambda}_{p 0}+1}{\left(\bar{\lambda}_{p}-\bar{\lambda}_{p 0}+1\right)^{e}} \text { if } \bar{\lambda}_{p}>\bar{\lambda}_{p 0}, \text { otherwise } \rho_{c}=1
$$

where $\bar{\lambda}_{p 0}$ and $e$ are two parameters that need to be determined. (It is to notice that $\bar{\lambda}_{p 0}$ has a physical meaning: it is the length of the plateau of the buckling curve.) The observation was that these two parameters are dependent on the $\xi$ stress ratio value. Therefore, the results from the 394 GMNI analyses were ordered into groups based on the stress ratio, and then the parameter values have been determined to each group. This was done by an optimization procedure, in which the difference between the $\rho_{\mathrm{c}, G M N I}$ reduction factor from GMNI analysis and the $\rho_{\mathrm{c}}$ reduction factor from Equation (6) was minimized. This minimization is completed range by range, leading to quasi-optimal $\bar{\lambda}_{p 0}$ and $e$ values for each $\xi$ range. The calculated parameters values are summarized in Table 1. In Figure 4 the found new curves are plotted for some selected ranges, together with the back-calculated reduction factors.

\section{THE FINAL REDUCTION FACTOR}

As it is clear from Table $1, \bar{\lambda}_{p 0}$ and $e$ are dependent on the $\xi$ value, which is visible also from Figure 5, where the quasi-optimal parameters are plotted in the function of the stress ratio. Figure 5 suggests that the parameters are continuous functions of the logarithm of is $\xi$. This means that instead of taking the $\bar{\lambda}_{p 0}$ and $e$ from Table 1 for the various ranges, it is simpler

Table 1. Parameters $\bar{\lambda}_{p 0}$ and $e$ for various $\xi$ ranges.

\begin{tabular}{lllllllll}
\hline$\xi$ from & $\xi$ to & $\bar{\lambda}_{p 0}$ & $e$ & & $\xi$ from & $\xi$ to & $\bar{\lambda}_{p 0}$ & $e$ \\
\hline 0 & 0.2 & 0.509 & 2.994 & & 1.6 & 2.0 & 0.597 & 2.138 \\
0.2 & 0.4 & 0.526 & 2.824 & & 2.0 & 2.5 & 0.550 & 2.099 \\
0.4 & 0.6 & 0.512 & 2.604 & & 2.5 & 3.0 & 0.562 & 2.052 \\
0.6 & 0.8 & 0.514 & 2.537 & & 3.0 & 4.0 & 0.591 & 2.116 \\
0.8 & 1.0 & 0.505 & 2.421 & & 4.0 & 5.0 & 0.667 & 2.229 \\
1.0 & 1.2 & 0.495 & 2.355 & & 5.0 & 10 & 0.728 & 2.385 \\
1.2 & 1.4 & 0.531 & 2.272 & & 10 & 25 & 0.937 & 2.664 \\
1.4 & 1.6 & 0.521 & 2.144 & & & & \\
\hline
\end{tabular}



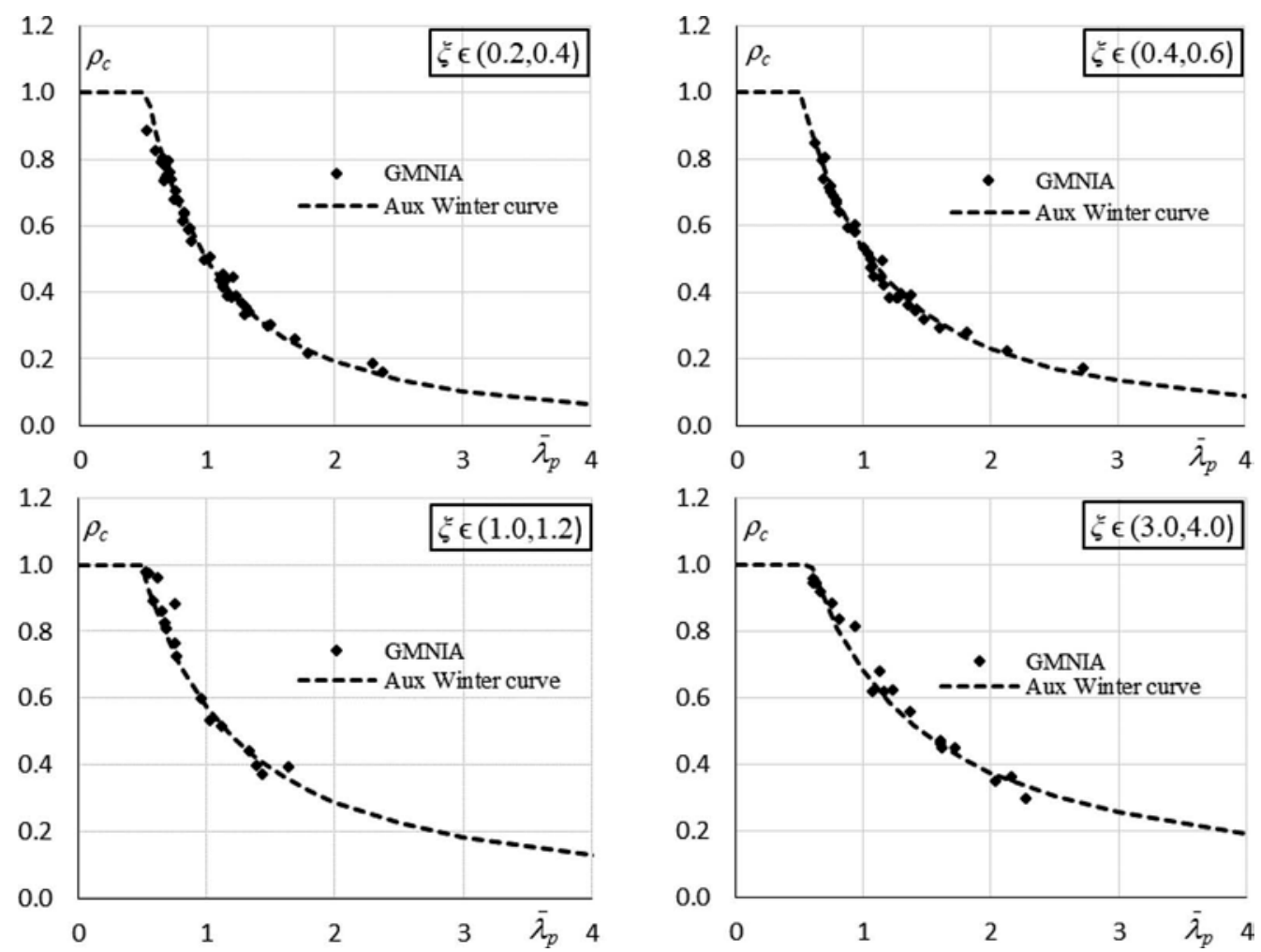

Figure 4. Auxiliary modified Winter curves and GMNIA reduction factors for 4 ranges of $\xi$.
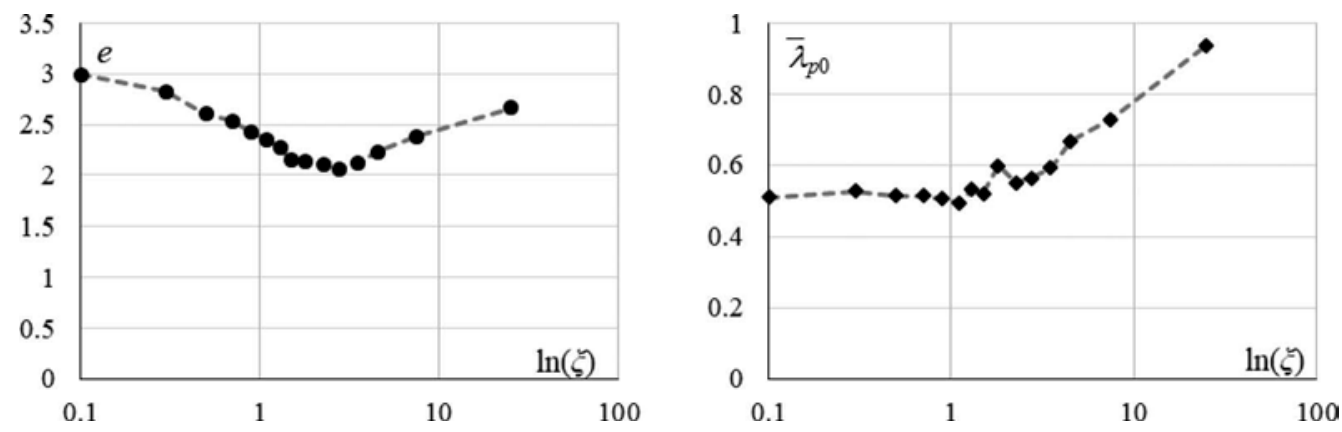

Figure 5. $\bar{\lambda}_{p 0}$ and $e$ values in the function of the $\xi$ stress ratio.

and potentially more precise to express them by analytical functions. Based on Figure 5, we assume here that both parameters can be approximated by two straight lines (in the semilogarithmic diagram), hence, we use the following formulae:

$$
\begin{gathered}
e=\max \left(A_{1} \ln (\xi)+B_{1} ; A_{2} \ln (\xi)+B_{2}\right), \\
\bar{\lambda}_{p 0}=\max \left(C_{1} \ln (\xi)+D_{1} ; D_{2}\right)
\end{gathered}
$$

The altogether 7 pieces of $A, B, C$ or $D$ constants have been determined by optimization in which the sum of the absolute differences between the $\rho_{c, G M N I}$ reduction factors from GMNI 


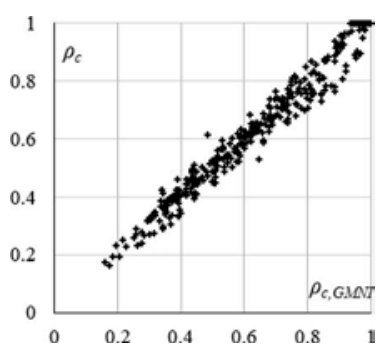

Figure 6. Comparison of the reduction factor values: GMNIA vs. Equations (6-8).

analysis and the $\rho_{c}$ reduction factors from Equations (6-8) is minimized. The final equations are as follows:

$$
\begin{aligned}
& e=\max \left\{\begin{array}{c}
-0.177 \ln (\xi)+2.411 \\
0.147 \ln (\xi)+1.862
\end{array}\right\}, \\
& \bar{\lambda}_{p 0}=\max \left\{\begin{array}{c}
0.488 \\
0.098 \ln (\xi)+0.526
\end{array}\right\} .
\end{aligned}
$$

\section{EVALUATION OF THE RESULTS}

All the cases (considered in the GMNI analyses) were re-calculated by using Equations (6-8), and the reduction factor values are compared to the GMNIA predictions. Figure 6 shows the comparison of the reduction factor values, while Figure 7 shows the $\left(\rho_{c, G M N I}-\rho_{c}\right) / \rho_{c, G M N I}$ relative differences in the function of the slenderness parameter. The most important statistical characteristics of the results are as follows:

- The average of the absolute values of the $\left(\rho_{c, G M N I}-\rho_{c}\right)$ differences is 0.030 .

- The mean value of the $\left(\rho_{c, G M N I}-\rho_{c}\right) / \rho_{c, G M N I}$ relative differences is $-0.2 \%$.

- The standard deviation of the $\left(\rho_{c, G M N I}-\rho_{c}\right) / \rho_{c, G M N I}$ relative differences is $6.8 \%$.

\section{CONCLUSION}

In this paper a new approach was proposed for the calculation of the resistance of longitudinally stiffened plates with trapezoidal stiffeners. The proposed approach adopts certain formulae from the current Eurocode procedure, still, it is theoretically different from the current

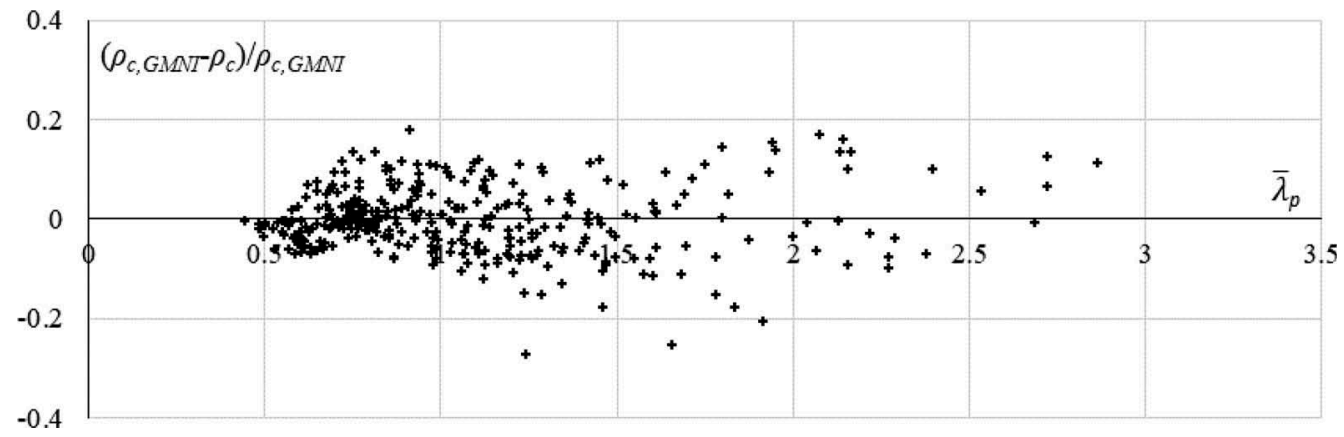

Figure 7. $\left(\rho_{c, G M N I}-\rho_{c}\right) / \rho_{c, G M N I}$ relative differences in the function of the slenderness parameter. 
Eurocode approach, since this latter one interprets the stiffener buckling as a combination of plate-like and column-like behavior, while in the new proposal no such interpretation is included. Accordingly, in the new design approach one single formula is applied to calculate one single reduction factor (which should be applied to reduce the cross-section resistance). The proposed formula is a modified Winter-formula.

The parameters of the proposed new formulae were determined by using the results of large number of resistance predictions by advanced finite element analyses. The results of the newly proposed design process were compared to those from the advanced numerical analyses, and they were evaluated statistically. Based on the statistical evaluation the new proposal was found to be reasonably precise.

It is to note that the reported research is still in progress. Other possible curves (including Ayrton-Perry type curves) are under consideration. Moreover, further geometries (including different types of longitudinal stiffeners) are intended to study in order to further enlarge the resistance database. The further results of the research are expected to be reported in the near future.

\section{ACKNOWLEDGEMENTS}

The presented research program was supported by the UNNKP-18-4 New National Excellence Program of the Ministry of Human Capacities, by the János Bolyai Research Scholarship of the Hungarian Academy of Sciences and by the K119440 project of the Hungarian National Research, Development and Innovation Office. The financial supports are gratefully acknowledged.

\section{REFERENCES}

CEN 2006. EN 1993-1-5:2005, Eurocode 3: Design of steel structures, Part 1-5: Plated Structural elements.

Sinur F. 2011. Behavior of longitudinally stiffened girders under combination of high bending and shear loading, PhD thesis, University of Ljubljana, Faculty of Civil and Geodetical Engineering.

Martin P.O., Nguyen T.M., \& Davaine L. 2017. Effect the torsional stiffness of closed section stiffeners on plate buckling in Eurocode 3 Part 1-5, Research report, ECCS-TWG8.3, 2017.

Kövesdi B. 2019. Buckling resistance of orthotropic plates subjected by compression interpolation between plate and column-like behavior, Journal of Constructional Steel Research, Vol. 160, pp. 67-76.

Haffar M.Z., Kövesdi B. \& Ádány S. 2019. Buckling of longitudinally stiffened plates Part 2: Eurocode-based design for plate-like behavior of plates with closed-section stiffeners, Thin-Walled Structures, Vol. 145. 


\title{
Fire resistance evaluation of simple steel hall carried out by using various computational models
}

\author{
M. Maślak, M. Pazdanowski, M. Suchodoła \& P. Woźniczka \\ Cracow University of Technology, Cracow, Poland
}

\begin{abstract}
It has been shown, how the selection of static scheme for a single transverse frame in a typical steel hall determines the sought fire resistance of that hall. For comparative purposes several computational models differing in complexity have been considered for the same fire development scenario and the same frame. Loss of the capacity to safely resist the applied static loads, identified on the equilibrium path, has been considered as the representative measure of resistance against increasing in fire temperature of structural steel components. Juxtaposition and comparison of the obtained results leads to the unequivocal conclusion, that the higher the level of simplification in the applied computational model, the more overestimated the resultant fire resistance determined based on that model.
\end{abstract}

\section{INTRODUCTION}

In order to obtain a reliable fire resistance estimate for a steel hall, one should perform the analysis referring to the 3D bearing structure treated as a whole, or, if the available computer resources exclude this option, determine this resistance approximately, after detailed analysis of a single transverse frame formally isolated from structural system. The time during which such a frame will be able to safely resist the loads applied to it under the same fire development scenario accompanied by progressing material weakening will differ depending on the model selected to represent the considered structure. In general the fire resistance forecast for a steel frame is determined numerically, based on a bar model of all structural components, subject to the assumption that the temperature of these components is evened out not only in the respective cross sections but also along their whole lengths. In this analysis we intend to show how the selection of a particular static scheme affects the sought fire resistance. In order to do that a selected typical one-aisle and one-storey high steel hall is subjected to a simulated fire action by using various computational models. The calculations have been executed using SAFIR computer code (Franssen \& Gernay, 2017). In each considered case the final fire resistance, specified for the same frame, but modelled in a different way, has been identified on the static equilibrium path corresponding to that model.

\section{DESCRIPTION OF THE ANALYZED FRAME AND CHARACTERISTICS OF THE CONSIDERED COMPUTATIONAL MODELS}

A single transverse frame of a typical steel hall having the geometry, dimensions, rafter and column cross sections depicted in Figure la has been selected as the basis for comparative analysis. All the structural components of the frame have been made of S235 steel. It is assumed, that fully developed fire has been initiated inside the hall, such that during every moment of the fire action the temperature of combustion plume has been evened out in the

DOI: $10.1201 / 9781003132134-66$ 
a)

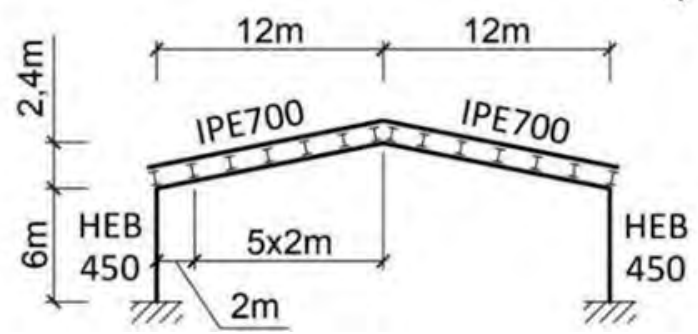

b)

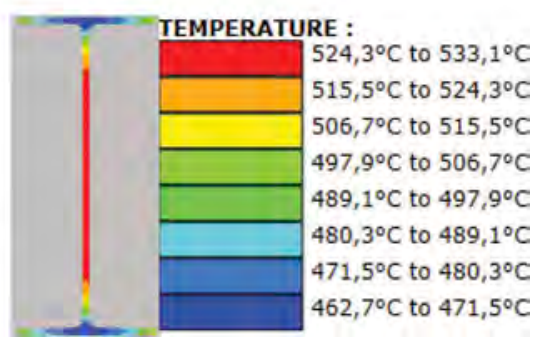

Figure 1. The reference frame: a) geometry and a static scheme, b) steel temperature distribution in the rafter identified after 660 seconds of fire exposure.

whole fire compartment and increased in time following the classical scenario of the standard fire. Due to the different ratios of heated periphery to the surface area of a cross-section, specified for the thermally uninsulated frame components, those components have been heated with different speeds. The scheme of uniform fire exposure of such the components along the entire perimeter of their cross-section has been selected for the analysis (i.e. their heating from four sides). In the authors' opinion, considering the case of heating these elements from only three sides, which could be selected as an alternative analysis, in the case of a hall with a light housing would not lead to a more precise and more accurate description of the reality. As a result of such the findings the uneven distribution of steel temperature field in the cross section of columns and rafter in each moment of fire has been accounted for, though under assumption, that this distribution does not change along their lengths. The characteristics of particular thermal actions related to selected moments of fire are shown in the Table 1. This table is accompanied by a sample map of temperature distribution in a rafter, obtained after 660 seconds of fire exposure (Figure 1b). It is assumed, that both left and right end plate beam to column joints remain fully rigid during the whole time of fire.

The transverse frame described above subjected to numerically simulated fire exposure of intensity increasing in time in the following analysis is modelled with application of several computational models differing in complexity. These models are listed in turn below:

- models A1 and A2 - understood as fully 2D models. Only deformations occurring in the frame plane are accounted for in these models. Flexural in plane buckling of rafter or column, i.e. the global instability of an element about the "stronger" axis of its cross section, usually determines the bearing capacity here. Model A1 pertains to the frame with fully rigid supports, while model A2 pertains to the analogous frame with pinned supports.

- Model B1 - frame with rigid supports. An out of frame plane deformation, including classical flexural out of plane buckling as well as lateral torsional buckling of column or rafter, is accounted for. Thus the bearing capacity may be determined by the global instability of an element about the "weaker" axis of its cross section. Such a scheme of transverse braces in the hall roof has been assumed, as to assure that every other purlin would constitute a support stabilizing the rafter in the frame plane at its point of support (Figure 2).

Table 1. Steel temperature in the rafter and columns of the considered frame after various fire exposure times (its minimum and maximum values identified at the cross-section heights).

\begin{tabular}{llll}
\hline \multirow{2}{*}{ Fire duration $[\mathrm{s}]$} & \multicolumn{2}{l}{ Temperature $\min / \max \left[{ }^{\circ} \mathrm{C}\right]$} \\
\cline { 2 - 4 } & Fire plume $\Theta_{g}$ & Rafter $\left(\right.$ IPE700) $\Theta_{a}^{\text {beam }}$ & Columns $\left(\right.$ HEB450) $\Theta_{a}^{\text {column }}$ \\
\hline 180 & 502 & $104 / 135$ & $77 / 128$ \\
360 & 603 & $240 / 300$ & $179 / 286$ \\
540 & 663 & $380 / 452$ & $292 / 434$ \\
720 & 705 & $499 / 567$ & $402 / 516$ \\
900 & 738 & $591 / 647$ & $498 / 633$ \\
\hline
\end{tabular}



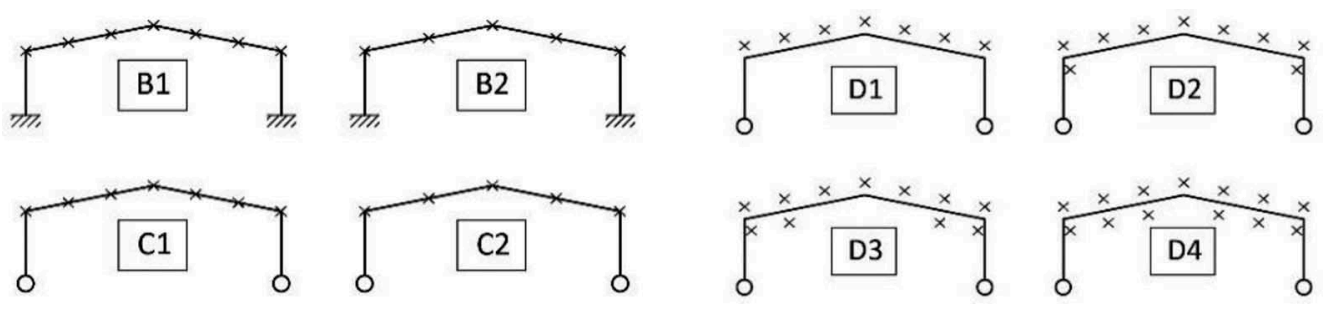

Figure 2. Computational models considered in this paper.

- Model B2 - analogous to the model B1, but in this case, due to the different distribution of braces in the roof plane only every third purlin stabilizes the rafter (Figure 2). Frame with rigid supports.

- Model C1 - analogous to the model B1, but prepared for the frame with pinned supports.

- Model C2 - analogous to the model B2, but prepared for the frame with pinned supports.

- Model C3 - analogous to the model C1, but prepared for the frame with columns and rafter made of S355 steel.

- Model D1 - analogous to the model C1, but additionally taking into account the offset of the axis of purlins bracing the rafter, identified in relation to the axis of such a rafter (Figure 2). The magnitude of this offset has been approximately assumed at $35 \mathrm{~cm}$, i.e. half of the rafter height.

- Models D2, D3 and D4 - analogous to the model D1, but taking into account an additional offset introduced by application of additional anti-twist braces in the selected cross sections of the frame. The magnitude of this offset is assumed to be equal to $35 \mathrm{~cm}$ at both sides.

In each of the considered models a nonlinear relationship between stresses and strains of the structural steel exposed to the fire action is taken into account, as well as an appropriate reduction of the steel yield limit induced by the ambient temperature increasing during fire.

\section{COMPARATIVE ANALYSIS OF THE OBTAINED RESULTS}

In each of the considered cases during the initial phase of fire exposure, due to the thermal expansion of steel, the expanding columns raised the roof ridge, and at the same time the expanding rafter pushed the columns outwards. With the progress of time the rafter, increasingly weakened by the increasing ambient temperature, exhibited increasing deflection. This deflection effectively negated the initial push up of the roof ridge. As a result the columns initially pushed in the outwards direction now became pulled inwards due to the ever increasing rafter sagging induced by the increasing fire intensity. This change in the sense of displacements in general occurs abruptly. This allows for unequivocal indication of fire exposure related to the fire resistance of the considered frame.

Detailed analysis of the equilibrium paths depicted in Figures $3 \mathrm{a}$ and $3 \mathrm{~b}$ leads to the following estimates of the fire resistance $\tau_{f i, R}[\mathrm{~s}]$ sought: for model A1 $-\tau_{f i, R}=1088 \mathrm{~s}$, for model B1 $\tau_{f i, R}=997 \mathrm{~s}$, for model B2 $-\tau_{f i, R}=899 \mathrm{~s}$. However small in absolute terms, the quantitative differences identified in this juxtaposition seem to be significant when expressed in relative terms. It has to be emphasized, that in the model A1 the frame is destroyed by the flexural in plane buckling of column or rafter, while in the models B1 and B2 the destruction occurs usually due to flexural out of plane or more probably by lateral torsional buckling. The much lower fire resistance of the frame B2 with respect to the analogous result obtained for the same frame modeled as B1 may be attributed to the larger distance between supports stabilizing the rafter in frame plane.

In Figure 4a the results analogous to those shown in Figure 3a are depicted, but obtained for the frame with pinned supports (models $\mathrm{C} 1$ and $\mathrm{C} 2$ ). This figure is juxtaposed with Figure $4 \mathrm{~b}$, to show the differences in the estimated fire resistance in the case of the same frame, but 
a)

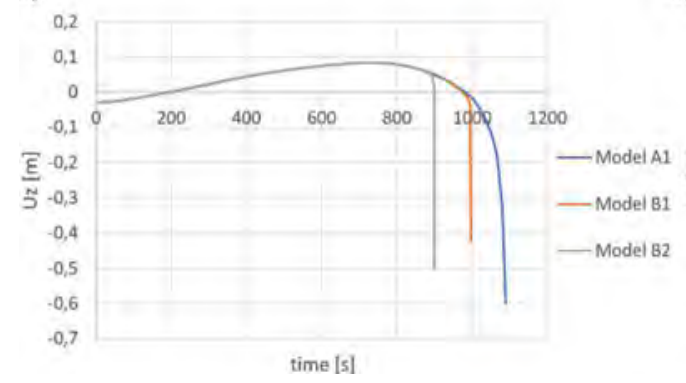

b)

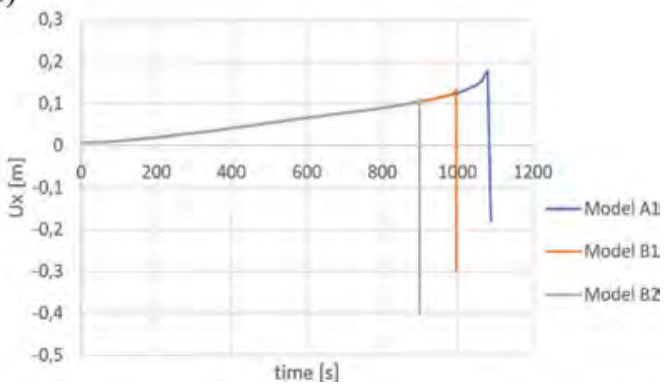

Figure 3. Static equilibrium paths obtained for the frame with fully rigid supports, for: a) roof ridge (vertical displacements, b) eaves (horizontal displacements).

a)

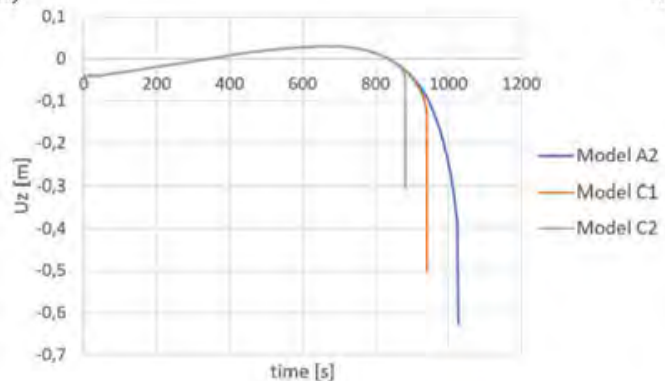

b)

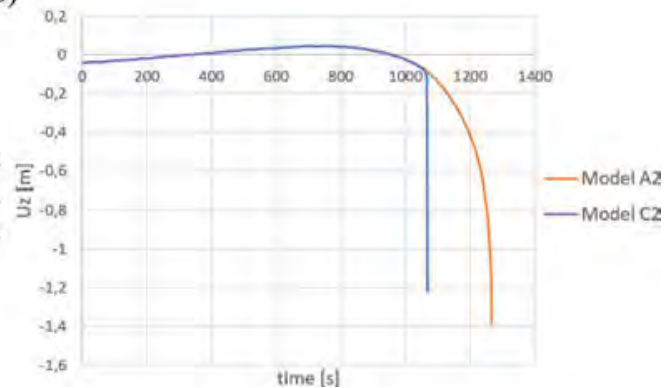

Figure 4. Static equilibrium paths related to vertical displacements for the roof ridge of a frame with pinned supports, rafter and columns made of: a) S235 steel, b) S355 steel.

this time with rafter and columns made of S355 steel, exhibiting much higher strength. The fire resistance obtained for this frame is obviously much higher.

The subsequent group of analyzed frames relates to the structure having pinned supports and modelled offsets of various origins (models D1, D2, D3 and D4). The model D1 accounts for the offset of purlin with respect to the rafter, while models D2, D3 and D4 additionally account for application of anti-twist braces in the several cross sections of the frame (Figure 2). The static equilibrium paths obtained numerically under such boundary conditions are juxtaposed in Figure 5. The fire resistance obtained after application of the D1 model proved to be much lower than the one obtained previously after application of the model $\mathrm{C} 1$. This is an adverse result of the additional moment twisting the rafter. Application of appropriate anti-twist braces efficiently eliminates this influence. In the model D1 this occurs to the relatively low degree, as the braces have been applied only in the line of columns. The stiffening effect, observed on the models D3 and D4 with much higher number of braces, is much more pronounced and therefore in those cases the fire resistance substantially exceeds the one determined previously on the model C1.

\section{CREDIBILITY OF THE MODEL WITH SINGLE TRANSVERSE FRAME}

The analysis presented above seems to indicate unequivocally, that appropriate modelling of the boundary conditions has, in the case of application of simple computational model with single transverse frame, a direct and significant influence on the obtained value of fire resistance sought. The general rule seems to be, that the higher the degree of model simplification the more overestimated the final fire resistance is with respect to the real value. Thus the 


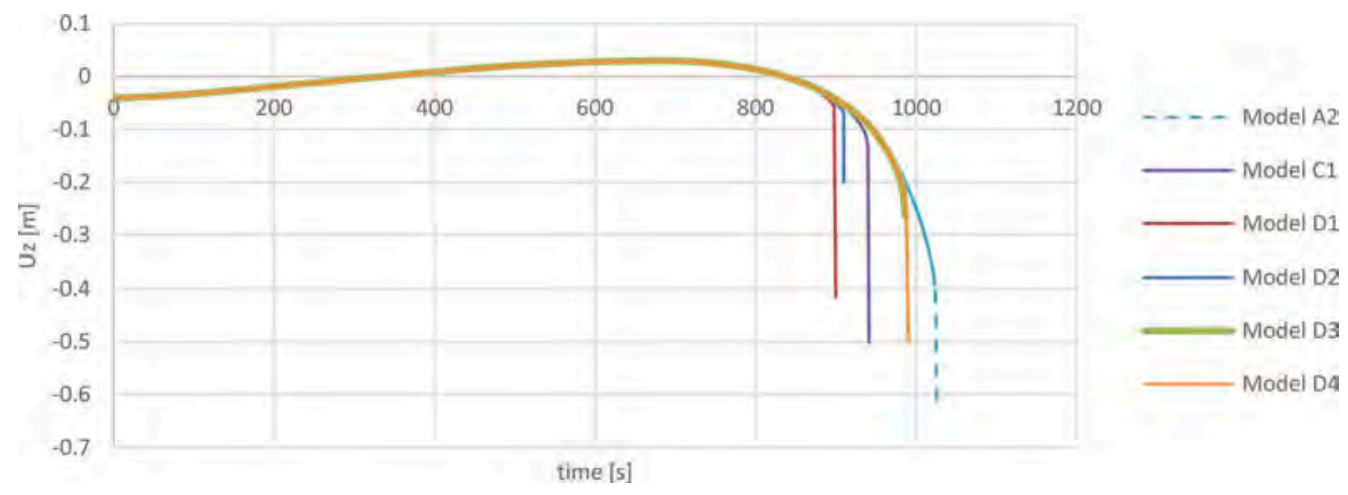

Figure 5. Static equilibrium paths related to vertical displacements obtained for the roof ridge of a frame with pinned supports, when taking into account offsets of various types (models D1, D2, D3 and D4 of Figure 2).

desire to simplify the calculations in this situation seems to be burdened by high risk, as the result obtained by the simulation may impart a completely unjustified sense of false security upon the hall user. However, the basic question remains, how credible the result of even the most accurate estimate may be to the user, if this result is supported only by a simple modelling with application of a single transverse frame. The response, to be authoritative, requires at least a comparison of static equilibrium paths obtained for the same hall and determined with application of a full 3D model taking into account the spatial interactions between structural components and a reduced 2D model consisting of a single transverse frame formally isolated from the whole structure and with relatively carefully applied boundary conditions. The results of such comparison are depicted in Figures 6a, 6b and 6c (Wozniczka, 2020). A single frame with truss rafter depicted in Figure $6 \mathrm{a}$ is in this case denoted as model E. The action of purlins and wall girts is in this model accounted for by application of appropriate supports. This simple model has been subsequently correlated with a full $3 \mathrm{D}$ model depicted in Figure $6 \mathrm{~b}$ and denoted as model $\mathrm{F}$. The static equilibrium paths obtained for both models are juxtaposed in Figure 6c. It is clearly visible, that the equilibrium path obtained in this juxtaposition for a complex model $\mathrm{F}$ is in general identical to the path obtained independently after analysis of a simple model E. There is a catch, however. The fire resistance obtained after application of the model E proved to be significantly higher, than the one obtained after application of the model F, this in turn means that such result should be treated as an undoubtedly overestimated value with respect to the real value of fire resistance, overestimating the safety level actually warranted to the user.

\section{CONCLUDING REMARKS}

The considerations presented here fit within the wider scope of research conducted by the authors and pertaining to the credibility of various computational models, differing in complexity, applied to estimate the fire resistance of steel hall bearing structures (Maslak et al, 2017, Wozniczka, 2019). In the juxtapositions presented here we intend to show, that application to that purpose of simple models based on the single transverse frame with appropriately modelled boundary conditions usually leads to overly optimistic estimates, more or less overestmating the level of safety warranted to the user. Of course, sufficiently careful modelling of support conditions and taking into account spatial nature of the potential deformations occurring in a frame exposed to fire action results in the fire resistance estimated on a model converging to the real value. The final result of the analysis is highly affected by the formal inclusion in the model of offsets induced by the way the purlins are supported on the rafter - this fact in 
a)

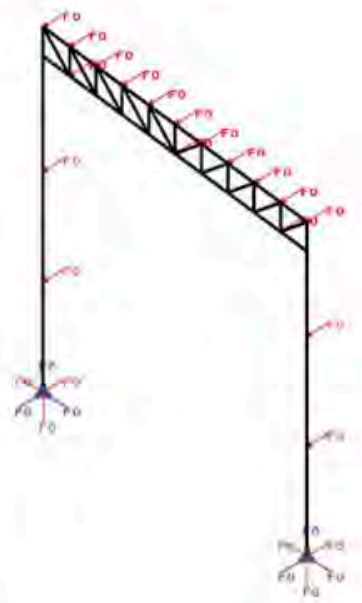

b)

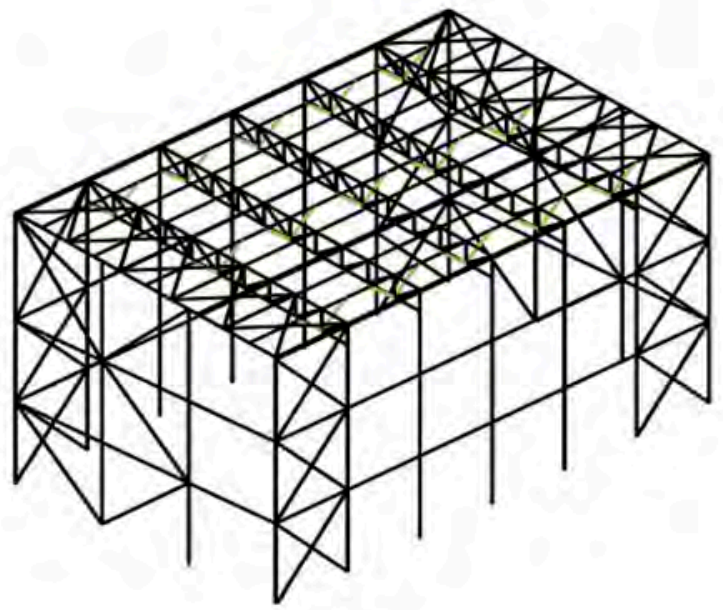

c)

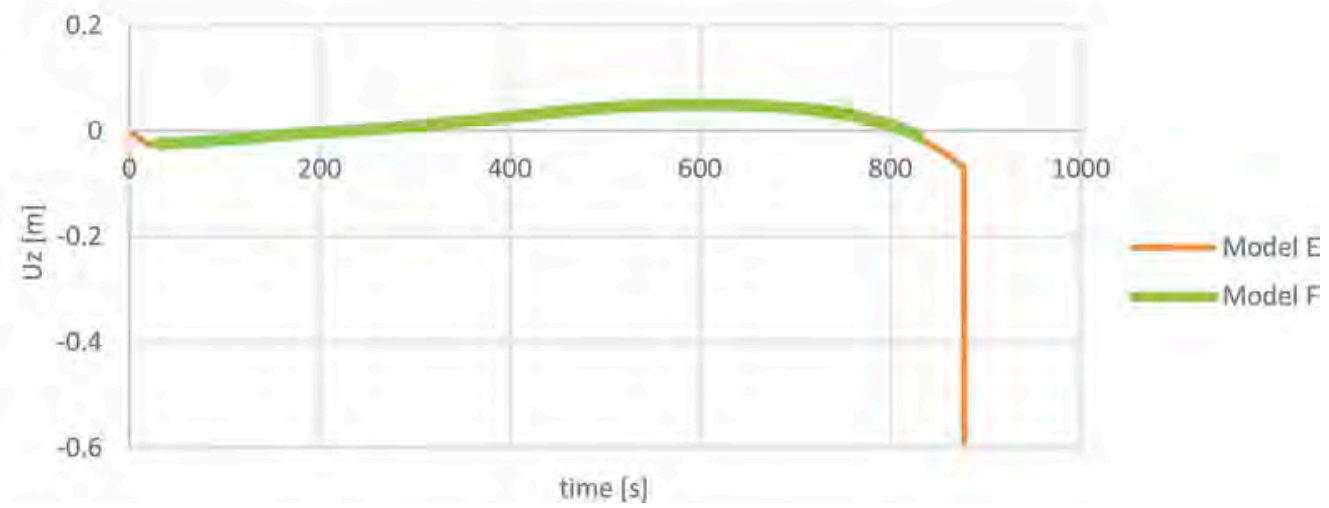

Figure 6. Verification of the credibility of results obtained after application of simple computational models, including: a) model of a single transverse frame (model E), b) 3D model taking into account the spatial interactions between structural components of the hall (model F), c) juxtaposition of the corresponding static equilibrium paths related to vertical displacements.

general is neglected in the analyses. The purlins induce an additional torsion in the rafter, and this in turn in the case of rafter rigidity decreased by the thermal action of fire may substantially accelerate its loss of stability.

In the computational models analyzed above the influence of potential substitute geometrical imperfections has been disregarded. The authors' research seems to indicate, that formal inclusion of these imperfections does not significantly affect the final estimate of fire resistance. Additional inclusion of wall girts in the analysis proved to be similarly insignificant. The destruction mode is the determining factor, and this is obviously determined by the support conditions defined in the model.

The question of selecting the optimum computational model for the analysis of fire resistance of a bar bearing structure in a steel hall, and especially sufficiently precise modelling of support conditions seems to be especially important if the complex 3D models, taking into account the 3D interactions between structural components, are selected for analysis (Jiang et al, 2018). One has to remember, that the rigidity of the structural components decreases with the increasing ambient temperature. This is accompanied by the increasing pliability of 
the joints, even those between columns and rafters. The joints, modelled as nominally rigid, under fire conditions with passing time become partially flexible, and this should be accounted for in the developed model. Research conducted so far seems to indicate as well, that the final fire resistance of a steel frame is highly affected by the behaviour of purlins stiffening the rafter (Obiala et al, 2010; Vassart et al. 2007). Those purlins, due to smaller cross section get heated much faster, than the rafter or columns of the transverse frame. Thus relatively early, at monotonous increase of temperature stop supporting the rafter and thus its increasing deflections, often determining the bearing capacity of the analyzed frame is no longer restrained in any way. Sufficiently precise modelling of the whole bracing system in the hall seems to be similarly important, as its influence changes during fire action.

\section{REFERENCES}

Franssen J.M. \& Gernay T. 2017. Modelling structures in fire with SAFIR: Theoretical background and capabilities. Journal of Structural Fire Engineering 8(3): 300-323.

Jiang J., Wang C., Lou G. \& Li G. 2018. Quantitative evaluation of progressive collapse process of steel portal frames in fire, Journal of Constructional Steel Research. 150: 277-287.

Maslak M., Tkaczyk A. \& Wozniczka P. 2017. The usability of a computational model of a single transverse frame in the fire resistance assessment of an entire steel hall. Safety \& Fire Technology. 45(1): 52-67.

Obiala R., Vassart O., Zhao B., Sakj M.S., de la Quintana J., Morente F., Fransen J.M. \& Lansival J.B. 2010. Fire safety of industrial halls. A valorization project. EUR 24222 EN Final Report. Luxembourg.

Vassart O., Brasseur M., Cajot L.G., Obiala R., Griffin A., Spasov Y., Renaud C., Zhao B., Arce C. \& de la Quintana J. 2007. Fire safety of industrial halls and low-rise buildings: realistic fire design, active safety measures, post-local failure simulation and performance based requirements. EUR $22568 \mathrm{EN}$ Final Report. Luxembourg.

Wozniczka P. 2019. Performance-based analysis of older-type large-space hall in fire. Archives of Civil Engineering. 65(1): 17-29.

Wozniczka P. 2020. Application of advanced fire resistance assessment method for industrial structures. Builder. 04 (273): 58-60 (in Polish). 


\title{
Investigations of the relationship between the Brinell hardness and strength parameters of structural steels S235 and S355
}

\author{
P. Organek, B. Gosowski \& M. Redecki \\ Wroctaw University of Science and Technology, Wroctaw, Poland
}

\begin{abstract}
The paper discusses the results of experimental studies that determine the relationships between the Brinell hardness and strength parameters (yield point and tensile strength) of the currently produced S235 and S355 unalloyed structural steels. The conducted research allowed the relationship between the Brinell hardness and strength of modern structural steels to be determined, as well as empirical equations that enable the estimation of the strength parameters of the analysed steels to be derived.
\end{abstract}

\section{INTRODUCTION}

Determining strength indirectly on the basis of hardness (Gosowski et al. 2014) may sometimes be the only way to estimate the yield point and tensile strength of the steel elements of a building structure, for which it is not possible to take a sufficient number of samples for static tensile testing. Many standards, such as DIN EN ISO 18265:2004-02, PN-H-04357:1993, ISO/ TR 10108: 1989, ASTM E140-86, and ISO 4964: 1984, allow strength to be estimated on the basis of Brinell hardness.

However, in the current European standards concerning the measurement of steel hardness, there is the following notification, which generally applies to structural steels manufactured according to European standards: "It is not possible to accurately convert hardness into other hardness or tensile strength. It is therefore advisable to avoid such recalculations, unless they are based on conducted comparative measurements." Relevant studies on this issue were carried out, among others, within a doctoral dissertation (Organek 2018). A fragment of this research is discussed in this paper.

The results of tests of the selected grades of structural steels, which are currently used in the construction industry and produced (since about 2005 (Ślęczka 2010)) using modern technologies according to European metallurgical standards, are presented below. Direct transition from the steel grades that were previously produced according to national metallurgical standards (Dudkiewicz \& Gosowski 2004, 2006) into modern steel grades is not possible. This is due to the fact that currently produced steel grades are qualitatively better, which is achieved mainly thanks to such technological procedures as secondary metallurgy (argon blowing, greater chemical purity - especially with regards to sulphur and phosphorus, and better forms of plasticity of a given grade), continuous casting (greater homogeneity in terms of structure and chemical composition), and controlled rolling with optional controlled cooling (a finer crystalline grain and greater strength and ductility) (Rykaluk 2007). In addition, due to the changes in metallurgical standards, rimming steels are now completely out of use.

The classification of steel grades is based on their chemical composition and mechanical properties. The most important, with regards to designing steel structures, are mechanical properties (yield point, tensile strength, impact strength). In turn, the chemical composition is taken into account during the production of welded structures. This is due to the fact that it

DOI: $10.1201 / 9781003132134-67$ 
determines one of the main parameters of metallurgical weldability - the CEV carbon equivalent.

Currently, the steel elements of building structures are made of structural steel grades, which are described in the relevant PN-EN 10025 standards. The basic properties of these steels are described in more detail in technical literature, e.g. in (Blicharski 2014), (Ślęczka 2010).

\section{EXPERIMENTAL STUDIES}

\subsection{Research program}

The above-mentioned relationships were verified on three sets of samples of steels that are currently produced. The prepared samples were subjected to tests, which included: measurements of Brinell hardness $H B W$, and the static tensile test.

On their basis, the relationship between Brinell hardness $H B W$ and the strength parameters $R_{e}$ and $R_{m}$ was determined, as well as the conversion factors $a_{e}$ and $a_{m}$.

\subsection{Samples for testing}

The material for testing was taken from fragments of steel sections that are currently used in building structures.

The first set consisted of 10 flat samples (marked as $\mathrm{S} 2.1 \div \mathrm{S} 2.10$ ), which were made of S235JR+AR steel. Specimens S2.1 and S2.2, with dimensions of $\sim 4.5 \times 60 \times$ $490 \mathrm{~mm}$, were made of the web of a U-channel 100 with parallel flanges (UPE100). In turn, S2.3 and S2.4, with dimensions of $\sim 8 \times 65 \times 500 \mathrm{~mm}$, were made from the web of a C-channel 180 (C180). Samples S2.5 $\div$ S2.10 were made of an I-beam 220 with parallel flanges (IPE220), of which samples S2.5 and S2.6, with dimensions of $\sim 6 \times 60 \times$ $500 \mathrm{~mm}$, were taken from the web, and samples S2.7 $\div \mathrm{S} 2.10$, with dimensions of $\sim 11 \times$ $60 \times 500 \mathrm{~mm}$, were taken from the flanges.

The second set consisted of 6 flat samples (marked as S2.11 $\div \mathrm{S} 2.16$ ) made of S235JR+M steel. Samples S2.11 and S2.12, with dimensions of $\sim 7 \times 65 \times 500 \mathrm{~mm}$, were made from the web of a C-channel 120 (C120). In turn, samples S2.13 $\div$ S2.16 were made of a U-channel 200 with parallel flanges (UPE200), of which samples S2.13 and S2.14, with the dimensions of $\sim 6$ $\times 65 \times 500 \mathrm{~mm}$, were taken from the web, and samples S2.15 and S2.16 were taken from the flanges.

The third set consisted of 8 flat samples (marked as S3.1 $\div \mathrm{S} 3.8$ ) made of S355J2+N steel. Samples with dimensions of $\sim 10.5 \times 60 \times 450 \mathrm{~mm}$ were taken from the flanges of various I-beams 300 with parallel flanges (IPE300).

After carrying out Brinell hardness measurements, all the samples were prepared for destructive tensile tests in accordance with PN-EN ISO 6892-1:2016.

\subsection{Test stand}

The test stand for the stationary Brinell hardness measurements consisted of a B3Cs type stationary Brinell hardness tester from KABiD-PRESS Company, and an Edge AM7515MZTL type electronic measuring microscope from Dino-Lite Company with a computer that records images and enables the diameter of the imprint obtained during the hardness test on the surface of the sample to read.

In order to measure Brinell hardness, while taking into account the different levels of longitudinal load of the samples, a test stand was prepared, which consisted of: a UFP400 testing machine with a digital control system from Zwick Company, and also a table on which the Zwick portable Brinell PZ3 hardness tester and an Edge AM7515MZTL type electronic microscope from Dino-Lite Company with an image recording computer were placed. The table was able to move vertically on a trapezoidal screw and rotate around its axis. This 
solution made it possible to efficiently place the hardness tester and measure hardness in the right places on the sample.

The static tensile test was carried out on a test stand consisting of a UFP400 testing machine with a digital control system from Zwick Company, and also a macroXtens II extensometer from Zwick Company.

\subsection{The course of research}

Brinell hardness measurements were carried out in accordance with PN-EN ISO 6506-1:2014. Cemented carbide balls with a diameter of 5 and $10 \mathrm{~mm}$, and a load factor of $K=30$ (the load was respectively: $F=7355 \mathrm{~N}$ and $F=29430 \mathrm{~N}$ ) were used.

During the tests of the influence of normal stresses, the load levels of the samples were selected so that the elastic limit of the steel, which is defined as the tensile stress value and which causes a permanent elongation equal to $0.05 \%$ of the original measured length of the sample, was not exceeded. Additionally, during compression, the values of stresses that did not exceed $70 \%$ of the Eulerian value of the critical stresses of the samples were allowed.

\section{RESULTS OF EXPERIMENTAL TESTS}

\subsection{Brinell hardness measurements}

The results of stationary measurements of Brinell hardness, as well as those that took into account longitudinal loading, constitute the basis of statistical analyses. Table 1 shows the average values of the results of Brinell hardness measurements HBW 5/750 and HBW 10/3000 (marked as $\mathrm{HBW}_{5}$ and $\mathrm{HBW}_{10}$ ) for the individual sets, as well as the basic descriptive statistics.

By analyzing the results, it is possible to observe the relationship between the hardness and the steel grade, i.e. the higher the strength parameters required by a given steel grade, the higher the Brinell hardness. The results of the sets are characterized by low coefficients of variation that do not exceed $5 \%$.

\subsection{Static tensile test}

The average results of the static tensile test for individual sets, and also the basic descriptive statistics, are presented in Table 2. The strength parameters of the individual samples (i.e. yield strength $R_{e}$ and tensile strength $R_{m}$ ) were correlated with the results of hardness measurements, and then the relationships between them were determined.

The tested steels meet the requirements regarding the mechanical properties specified in the relevant standards of products.

\section{STATISTICAL EVALUATION OF TEST RESULTS}

The results of Brinell hardness measurements and the static tensile test of all the samples were used as a database for statistical studies.

Table 1. Average HBW 5/750 and HBW 10/3000 hardness for individual sets of steel.

\begin{tabular}{|c|c|c|c|c|c|c|c|}
\hline \multirow[b]{3}{*}{ Samples } & \multicolumn{3}{|c|}{ HBW 5/750 } & \multicolumn{3}{|c|}{ HBW 10/3000 } & \multirow[b]{2}{*}{$\Delta=\frac{\overline{H B W}_{5} \overline{H B W}_{10}}{\overline{H B}_{5}}$} \\
\hline & $\overline{H B W}_{5}$ & $s_{H B W}$ & $\nu_{H B W}$ & $\overline{H B W}_{10}$ & $s_{H B W}$ & $\nu_{H B W}$ & \\
\hline & {$[-]$} & {$[-]$} & {$[\%]$} & {$[-]$} & {$[-]$} & {$[\%]$} & {$[\%]$} \\
\hline 1. $\mathrm{S} 235 \mathrm{JR}+\mathrm{AR}$ & 146 & 5.9 & 4.0 & 140 & 3.5 & 2.5 & 3.7 \\
\hline 2. $\mathrm{S} 235 \mathrm{JR}+\mathrm{M}$ & 142 & 6.0 & 4.2 & 137 & 6.9 & 5.0 & 3.4 \\
\hline 3. S355J2+N & 171 & 3.3 & 1.9 & 166 & 1.7 & 1.0 & 2.9 \\
\hline
\end{tabular}


Table 2. Average values of mechanical properties for individual sets of steel.

\begin{tabular}{llcllcllllll}
\hline & $R_{e H}$ & $s_{R e H}$ & $\nu_{R e H}$ & $R_{m}$ & $s_{R m}$ & $\nu_{R m}$ & $R_{e H} / R_{m}$ & $A$ & $s_{A}$ & $E$ & $\mathrm{~s}_{\mathrm{E}}$ \\
\hline Set & {$[\mathrm{MPa}]$} & {$[\mathrm{MPa}]$} & {$[\%]$} & {$[\mathrm{MPa}]$} & {$[\mathrm{MPa}]$} & {$[\%]$} & {$[-]$} & {$[\%]$} & {$[\%]$} & {$[\mathrm{GPa}]$} & {$[\mathrm{GPa}]$} \\
\hline 1 & 321 & 10.8 & 3.4 & 486 & 7.5 & 1.5 & 0.66 & 28.4 & 3.1 & 208 & 11.1 \\
2 & 303 & 8.3 & 2.7 & 467 & 26.6 & 5.7 & 0.65 & 29.5 & 2.1 & 204 & 13.5 \\
3 & 383 & 10.4 & 2.7 & 565 & 8.9 & 1.6 & 0.68 & 28.9 & 1.3 & 209 & 11.7 \\
\hline
\end{tabular}

Designations:

$R_{e H}$ - average value of the upper yield point,

$R_{m}$ - average value of tensile strength,

$A$ - percentage elongation after rupture,

$E$ - modulus of longitudinal elasticity,

$s_{i}, \nu_{\mathrm{i}}$-standard deviation and the coefficient of variation of the average value for $i=R_{e H}, R_{m}, A$ and $E$.

The analyses aimed to quantitatively determine the relationship between Brinell hardness and steel strength parameters, as well as between Brinell hardness and the effort of the samples due to longitudinal load (normal stresses) during the measurements.

The above-mentioned relationships were sought using simple linear regression models (one explanatory variable - hardness, and one explained variable - strength parameter $R_{e}$ or $R_{m}$ ), with the assumed significance level of $\alpha=0.05$. This level corresponds to the confidence level of 0.95 .

\subsection{Brinell hardness and steel strength}

The results of the analyses are presented in Table 3 . The values of the $t$ statistics for the coefficients $a_{e}$ and $a_{m}$ are located in the critical area $\left(t_{k r(0,05 ; 22)}= \pm 2.07\right)$, and therefore there are statistical grounds for assuming a hypothesis that there is a linear relationship between variables $R_{i}$ and $H B W_{5}$ (this is also confirmed by $p=0$ ). In turn, for coefficients $b_{e}$ and $b_{m}$, the value of the statistics $t$ is outside the critical area, which proves that the absolute term is statistically irrelevant (this is also confirmed by the value $p>0.05$ ).

The conducted analysis of simple linear regression (with the absolute term) allows for the statement that the simple linear regression model, which takes into account explanatory variable $H B W_{5}$, enables approx. $90 \%$ of the variance of the dependent variable $R_{e}\left(R^{2}=0.88\right)$ and $R_{m}\left(R^{2}=0.92\right)$ to be explained. Moreover, relatively small standard errors in the estimation of

Table 3. Results of simple linear regression analysis $R_{e}=f\left(H B W_{5}\right)$ and $R_{m}=f\left(H B W_{5}\right)$.

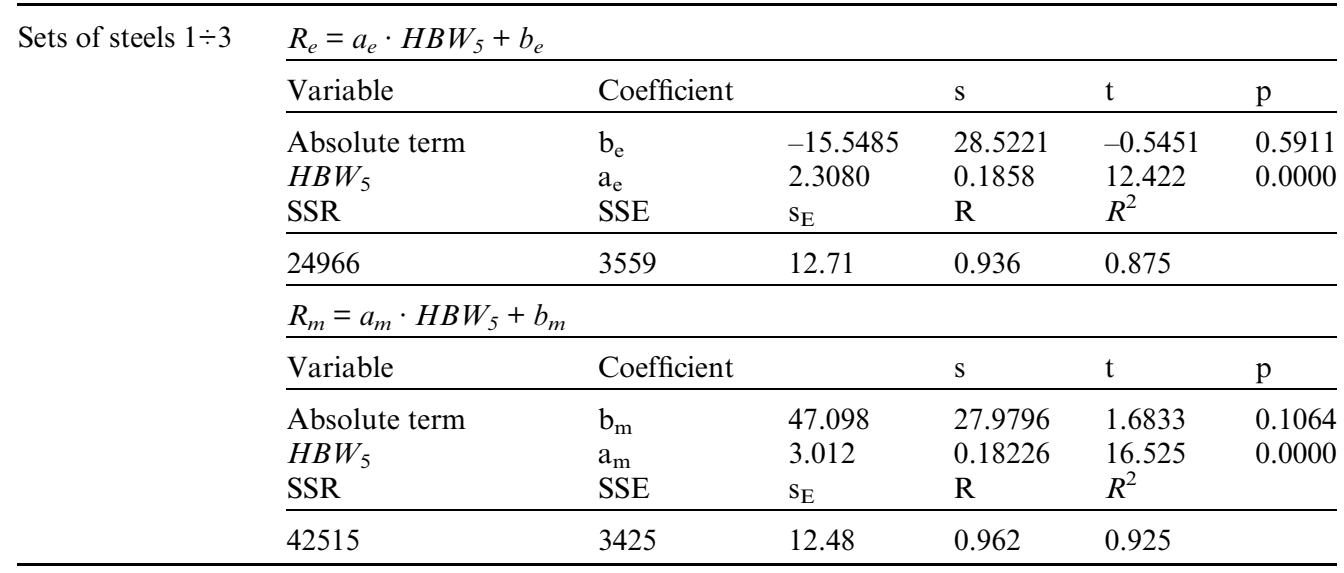


the mean values of the dependent variables $s_{E}$, which amounted to approx. $12.5 \mathrm{MPa}$ (which constitutes approx. $4 \%$ of the mean value of $R_{e}$ and approx. $3 \%$ of the mean value of $R_{m}$ ), were obtained.

Moreover, the results of the simple linear regression of the dependent variables $R_{e}$ and $R_{m}$ without the absolute term were analyzed. The values of the calculated statistics $t$ are in the critical region $\left(t_{k r(0,05 ; 23)}= \pm 2.07\right)$ in the case of coefficients $a_{e}$ and $a_{m}$. What is more, the value of the $p$-factor is close to 0 , which confirms the statistical significance of the adopted linear model without the absolute term. The appropriate coefficients then take the following values: $a_{e}=2.21, a_{m}=3.32$.

In the case of the regression for variables $R_{e}$ and $R_{m}$, the sum of squared residuals $S S E$ slightly increased. The standard deviation of the estimation of the mean yield point $s_{E}$ remained practically unchanged, as did the correlation coefficient $R$ and the coefficient of determination $R^{2}$.

A graphic illustration of statistical models with and without the absolute term is presented in Figure 1. It can be seen that for $R_{e}$ and $R_{m}$, the regression lines of both models (with and without the absolute term) practically coincide with each other and almost give the same results.

The conducted analyses allow for the statement that for modern steels there is a linear relationship between their strength parameters and their Brinell hardness. However, the derived equations of simple linear regressions have their limitations. They are appropriate for unalloyed structural steels that have Brinell hardness within the range of $110 \div 180$.

\subsection{Brinell hardness of steels tested under the influence of load}

Figure 2 Shows the selected results of the tests of hardness of elements that were loaded axially. There is a tendency that with an increase in compressive stresses, Brinell hardness increases in relation to $H B W_{0}$, and with an increase in tensile stresses, a decrease in hardness occurs. The change in hardness is approximately $1 \%$ for every $100 \mathrm{MPa}$ in relation to $H B W_{0}$, $H B W_{5}$, and $H B W_{10}$.

a)

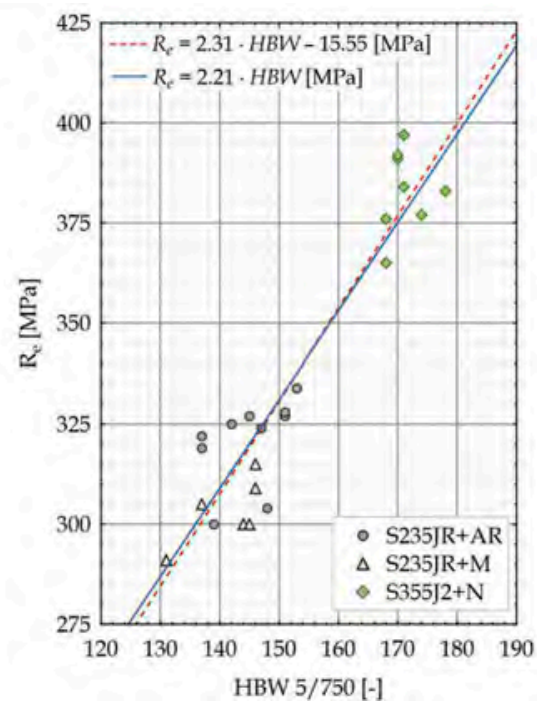

b)

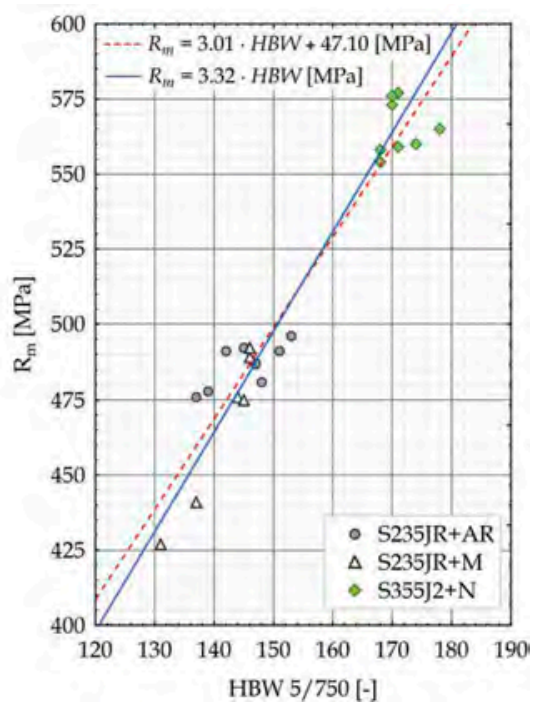

Figure 1. Diagrams of the dispersion for a set of $1 \div 3$ modern steels: a) $R_{e}$ with regards to $\mathrm{HBW}_{5}, \mathrm{~b}$ ) $R_{m}$ with regards to $\mathrm{HBW}_{5}$ with linear adjustment (simple regression). Diagram: red dashed - model with the absolute term, blue continues - model without the absolute term. 
a)

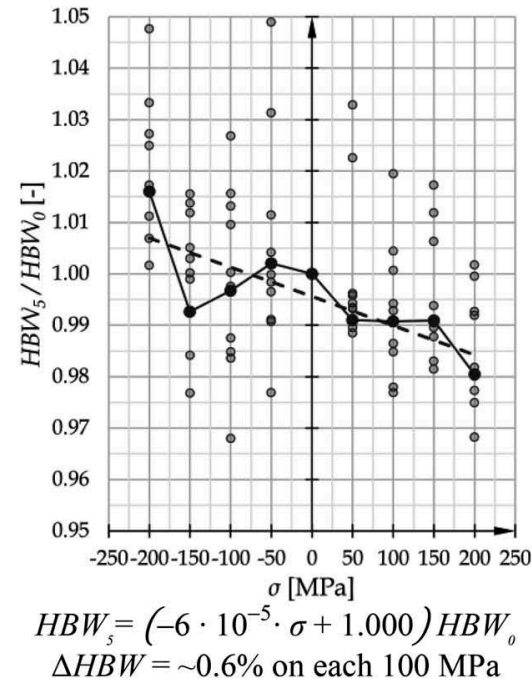

b)

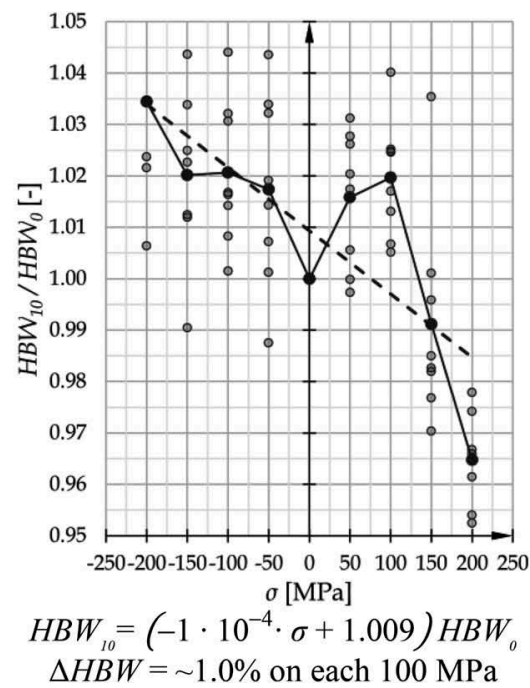

Figure 2. Diagrams of the dispersion for $\mathrm{HBW} / \mathrm{HBW}_{0}$ in relation to $\sigma$, and also the average values (solid line) and linear adjustment (dashed line) of steel set 1. a) S235JR+AR (D=5 mm), b) S235JR+AR $(\mathrm{D}=10 \mathrm{~mm})$.

It is noticeable (especially in the case of $H B W_{10}$ ) that there is a greater influence of tensile stresses than compressive stresses on hardness. As a result, a better approximation of the studied relationship than the applied linear function could be e.g. a parabolic function. However, due to the small changes in Brinell hardness (i.e. of about $1 \%$ of $H B W_{0}$ for every $100 \mathrm{MPa}$ of compressive or tensile stresses), it was considered unreasonable to use more complex functions.

\section{GENERAL REMARKS AND CONCLUSIONS}

Modern steels are characterized by a greater homogeneity and a much greater range of strength, and thus also a greater range of Brinell hardness. There is a linear relationship between the strength and the Brinell hardness of the tested structural steels. Due to this, it is possible to estimate the strength within the range of Brinell hardness from 110 to 180 using the determined dependence and the simple linear regression method (the classic least squares method). The real strength parameters may be $9 \%$ lower and $4 \%$ higher than the estimated average yield point value, and 3\% lower and 7\% higher than the estimated average tensile strength.

It can also be concluded that the effort of the material has an influence on the Brinell hardness measurements. The obtained results are qualitatively consistent with the results of studies available in literature (Dudkiewicz \& Gosowski 2004, 2006), but this influence was significantly reduced. Moreover, it should be noted that the observed changes in hardness, due to changes in normal stresses, are smaller than the uncertainty of the hardness measurement results. Therefore, the obtained quantitative results are not reliable. From a practical point of view, a slight change in hardness due to the influence of normal stresses seems to be negligible.

When estimating the strength of steel on the basis of hardness and with the use of the formulas given in Figure 1, it is advisable to also conduct tests of the chemical composition of the steel and its microstructure.

\section{REFERENCES}

Blicharski M. 2014. Inżynieria materiałowa. Stal. Wydanie II zmienione i rozszerzone. Warsaw: WNT.

Ślęczka L. 2010. Steel and steel products. In Giżejowski M. \& Ziółko J. (eds), Budownictwo ogólne, tom 5. Warsaw: Arkady: pp.87-142 (In Polish). 
Rykaluk K. 2007. Structural steels according to PN-EN-1993-1-1, Inżynieria i Budownictwo No. 3 : pp.124-133 (in Polish).

Dudkiewicz J. \& Gosowski B. 2004. Generalizations of relations between strength and hardness of steel in structural elements under longitudinal load. Archives of Civil Engineering (50)1: pp. 45-67.

Dudkiewicz J. \& Gosowski B. 2006. The use of non-destructive hardness tests to assess the strength of steel in building structures. Inżynieria i Budownictwo no 1: pp. 48-52 (in Polish).

Gosowski B., Organek P. \& Redecki M. 2014. Direct and indirect determination of the computational strength of steel in building structures. Materialy Budowlane No. 3: pp. 56-59 (in Polish).

Organek P. 2018. Verification of the relationship between the Brinell hardness and the strength of old and modern structural steels. Report of the Faculty of Civil Engineering of Wrockaw University of Science and Technology, Series PRE No.13/2018 (PhD dissertation, in Polish). 


\title{
Yield strength of structural steel
}

\author{
P.J. Wolert \\ COWI NA, Seattle, USA
}

\author{
A.S. Nowak \\ Auburn University, Auburn, USA
}

\begin{abstract}
Material properties are important in calibration of new generation design codes. The statistical parameters of strength of material often govern in establishing the acceptable safety margin. This paper provides a summary of the available statistical parameters for structural steel produced in the United States including ASTM A709 and ASTM A992, with nominal yield strength $50 \mathrm{ksi}(345 \mathrm{MPa})$ and $70 \mathrm{ksi}(483 \mathrm{MPa})$. The review of cumulative distribution functions (CDF) confirms that the bias factor (ration of mean to nominal) is larger than 1.10 and coefficient of variation for the lower tail of the CDF is less than 0.05.
\end{abstract}

\section{INTRODUCTION}

In the new generation of design codes, safety margin is provided by load and resistance factors. Factored loads are conservatively specified as exceeding the maximum expected value and factored resistance is specified below the low expected value. Values of load and resistance are determined in the reliability-based calibration procedure and acceptability criterion is closeness to the target reliability index (Nowak and Collins 2013). Load and resistance are treated as random variables that are defined by non-dimensional statistical parameters such as bias factor, $\lambda$, and coefficient of variation, $V$. Bias factor is the ratio of mean-to-nominal, and coefficient of variation is the ratio of standard deviation-to-mean value. Structural resistance or load carrying capacity can be considered as a product of three factors that represent the uncertainty in: (1) material properties, (2) dimensions and (3) analytical model. Objective of this paper is to present a summary of statistical analysis of the major property of structural steel, i.e. yield strength.

Material test data was provided by several mills in the United States. The statistical parameters including bias factor and coefficient of variation were determined for two most common steel grades: ASTM A709 steel with nominal yield strength of $50 \mathrm{ksi}(345 \mathrm{MPa})$ and $70 \mathrm{ksi}$ (483 MPa), ASTM A992 with the nominal strength and $50 \mathrm{ksi}(345 \mathrm{MPa})$. ASTM A992 is the most common steel used construction of building frames and bridges. At present, $93 \%$ of steel includes recycled material (AISC 2021). The need for steel with resistance to environmental corrosion drove the development of weathering steel in 1940s such as ASTM A242, A588, and A709. ASTM A709 is the Standard Specification for Structural Steel for Bridges and encompasses carbon, high-strength low-alloy, and quenched and tempered alloy steels used as structural plates in the construction of bridges.

For an easier interpretation of the results, cumulative distribution functions (CDF) of yield strength are plotted on the normal probability paper. Horizontal axis represents the yield strength and vertical axis is the probability of being below the corresponding value of yield. Important characteristic of the normal probability paper is that CDF of any normal random

DOI: $10.1201 / 9781003132134-68$ 
variable is a straight line. The construction and use of the probability paper is presented in textbook (e.g. Nowak and Collins 2013).

\section{STEEL TEST DATA}

\subsection{A992 steel}

The A992 steel test data comes from Bartlett et al. (2001), with a total of 207 flange and web steel coupon specimens. They were obtained from different rolled I-shaped beams provided by three producers, and tested at the University of Western Ontario (UWO) and the University of Minnesota (UM). The resulting CDF's are plotted in Figure 1. In practice, only the lower tail of CDF determines the reliability. For flanges, $\lambda=1.10$ and $V=0.035$ and for webs, $\lambda=$ 1.15 and $V=0.05$.

\subsection{A709-50 steel}

Results of tensile strength tests for A709-50 steel plates were provided by two steel producers. The tests were carried out between 2011 and 2017, about 19,000 samples came from producer A and 2800 from B. The datasets contain yield strength, tensile strength, and elongation but only yield strength data was considered. The test results in the database are for various plates with thicknesses increments of $1 / 16$ inch $(1.6 \mathrm{~mm})$ up to 1 inch $(25 \mathrm{~mm})$, and $1 / 4$ inch $(6 \mathrm{~mm})$ increments above. The resulting CDF's are shown in Figure 2 (Wolert, 2019).

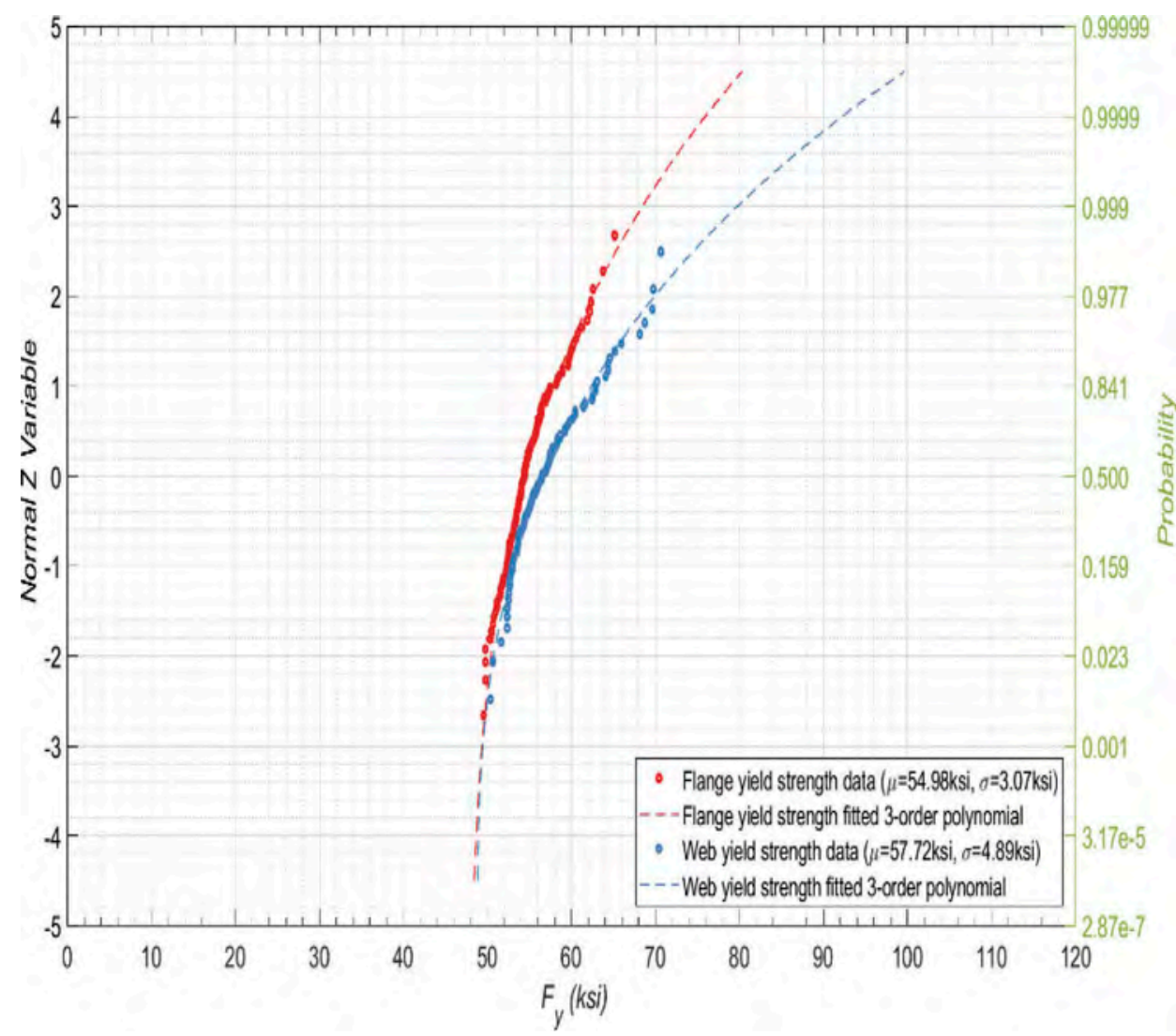

Figure 1. CDFs for the data and fitted polynomials of A992-50 yield strength (345 MPa). 


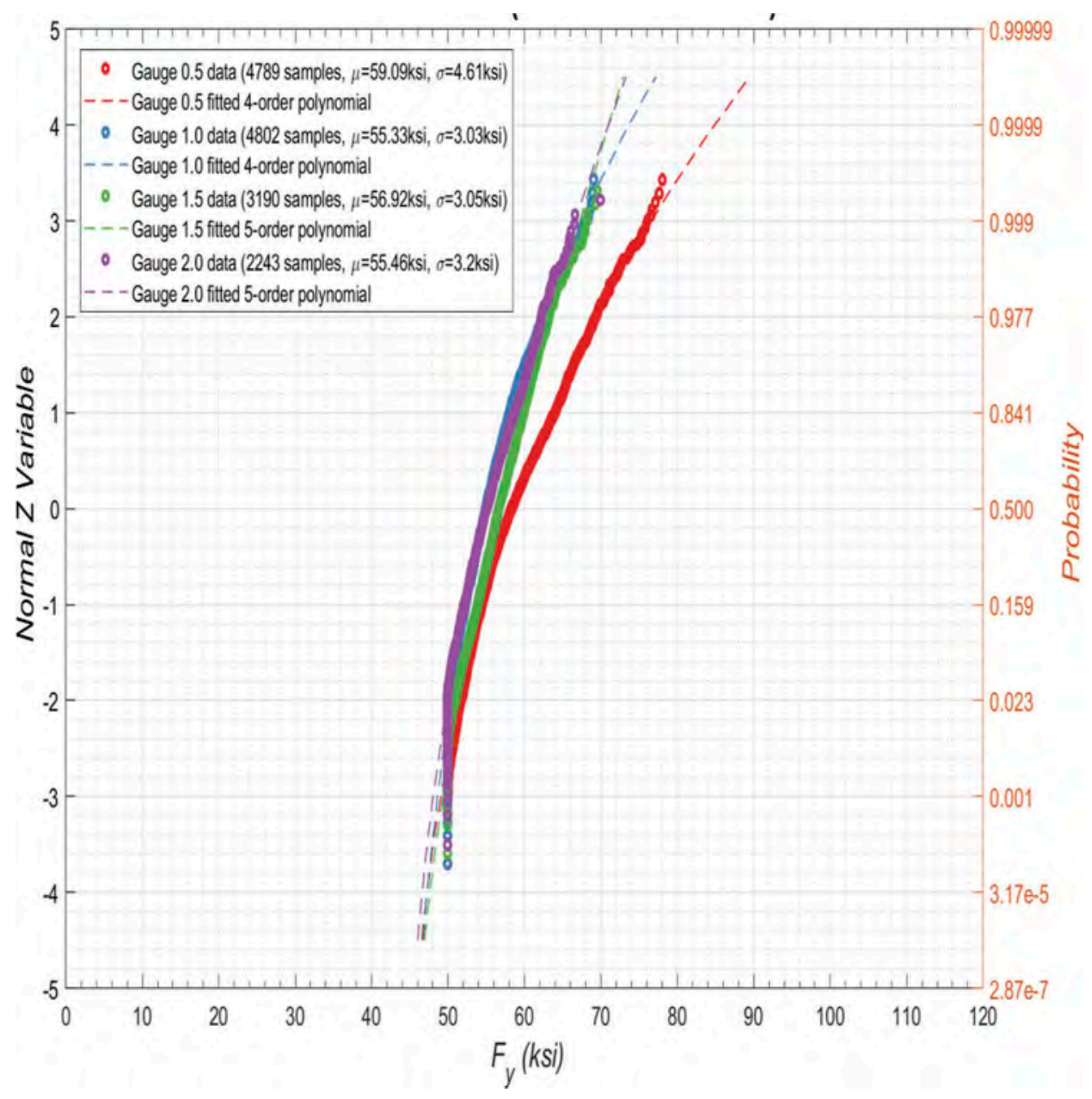

Figure 2. CDFs for the data and fitted polynomials of A709-50 steel from source A (345 MPa). Gauges $0.5-2.0$ inch.

\subsection{A709-50W steel}

Results of tensile strength tests for A709-50W steel plates were provided by two steel producers. The tests were carried out between 2011 and 2017, about 520 samples came from producer A and 3200 from B. The datasets contain yield strength, tensile strength, and elongation but only yield strength data was considered. The test results in the database are for various plates with thicknesses increments of $1 / 16$ inch $(1.6 \mathrm{~mm})$ up to 1 inch $(25 \mathrm{~mm})$, and $1 / 4$ inch $(6 \mathrm{~mm})$ increments above. The resulting CDF's are shown in Figure 3 (Wolert, 2019).

\subsection{A709-HPS50W steel}

Results of tensile strength tests for A709-HPS50W steel plates were provided by two steel producers. The tests were carried out between 2011 and 2017, about 230 samples came from producer A and 160 from B. The datasets contain yield strength, tensile strength, and elongation but only yield strength data was considered. The test results in the database are for various plates with thicknesses increments of $1 / 16$ inch $(1.6 \mathrm{~mm})$ up to 1 inch $(25 \mathrm{~mm})$, and $1 / 4$ inch $(6 \mathrm{~mm})$ increments above. The resulting CDF's are shown in Figure 4 (Wolert, 2019). 


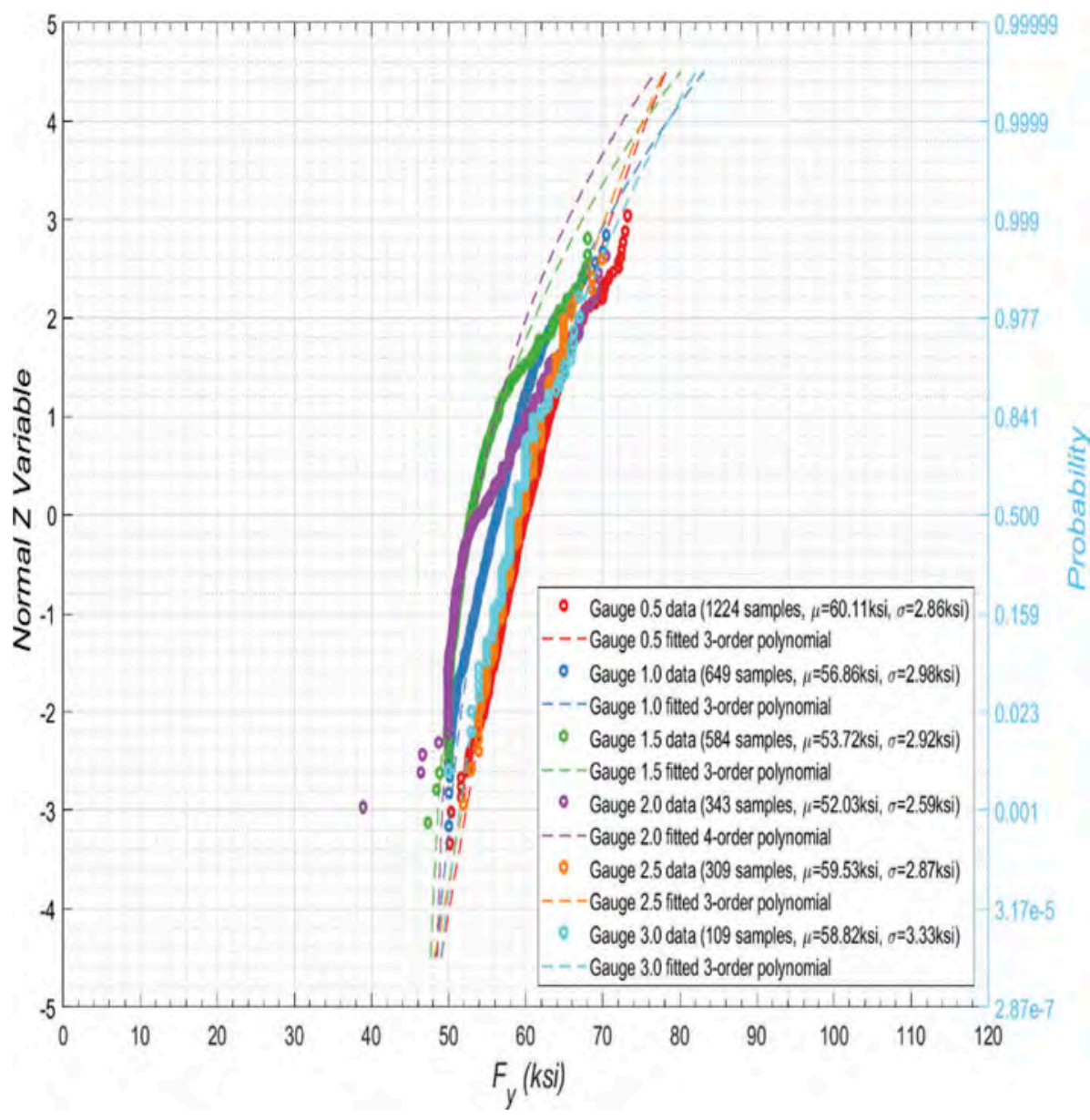

Figure 3. CDFs for the data and fitted polynomials of A709-50W steel from source B (345 MPa). All gauges.

\subsection{A709-HPS70W steel}

Results of tensile strength tests for A709-HPS70W steel plates were provided by two steel producers. The tests were carried out between 2011 and 2017, about 2600 samples came from producer A and 980 from B. The datasets contain yield strength, tensile strength, and elongation but only yield strength data was considered. The test results in the database are for various plates with thicknesses increments of $1 / 16$ inch $(1.6 \mathrm{~mm})$ up to 1 inch $(25 \mathrm{~mm})$, and $1 / 4$ inch $(6 \mathrm{~mm})$ increments above. The resulting CDF's are shown in Figure 5 (Wolert, 2019).

\section{SUMMARY OF STATISTICAL PARAMETERS}

The statistical parameters of yield strength for grade 50 are $\lambda=1.06-1.10$ and $V=0.02-0.03$, grade 50W $\lambda=1.04-1.19$ and $V=0.01-0.03$, grade HPS 50W $\lambda=1.06-1.11$ and $V=0.01-0.03$, grade HPS 70W $\lambda=1.54-1.76$ and $V=0.02-0.06$. The coefficients of variation are for the lower tail of the CDF. 


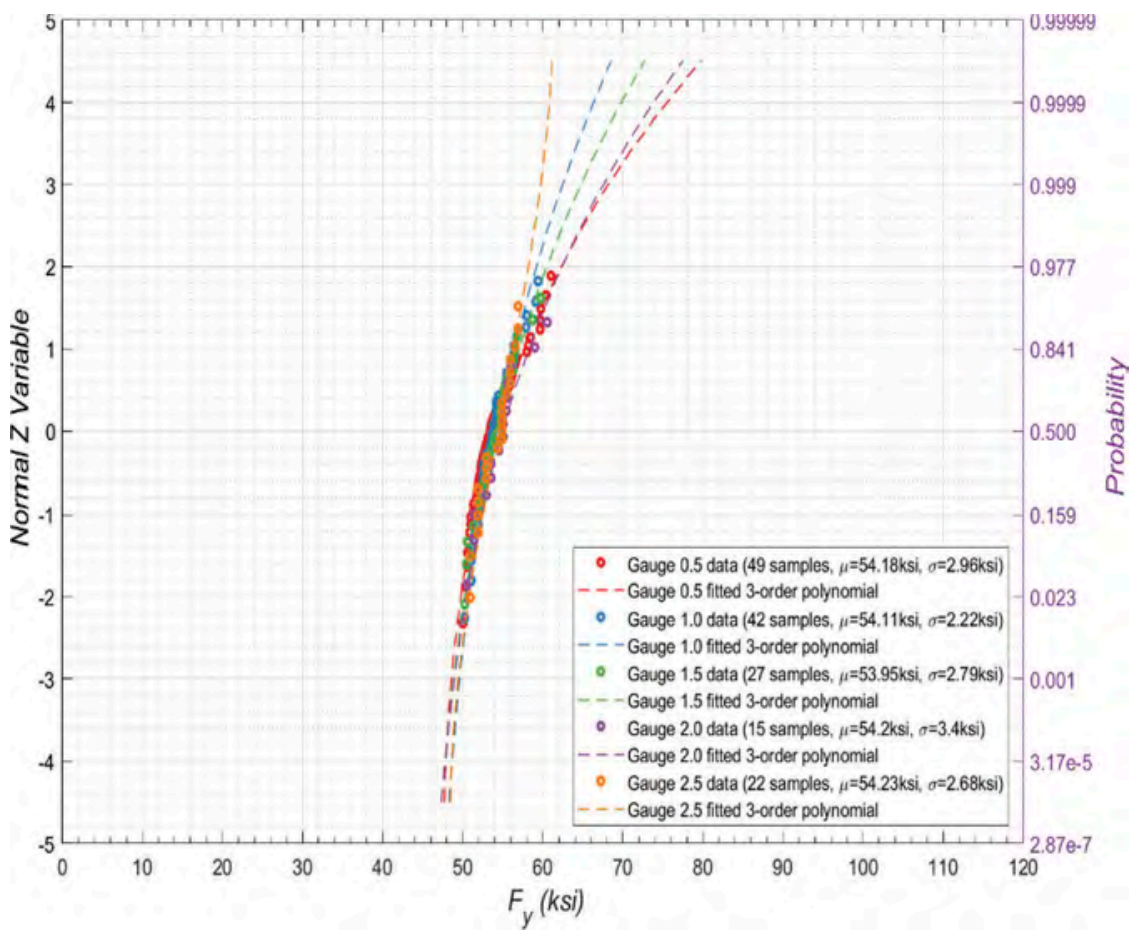

Figure 4. CDFs for the data and fitted polynomials of A709-HPS50W steel from source B (345 MPa). All gauges.

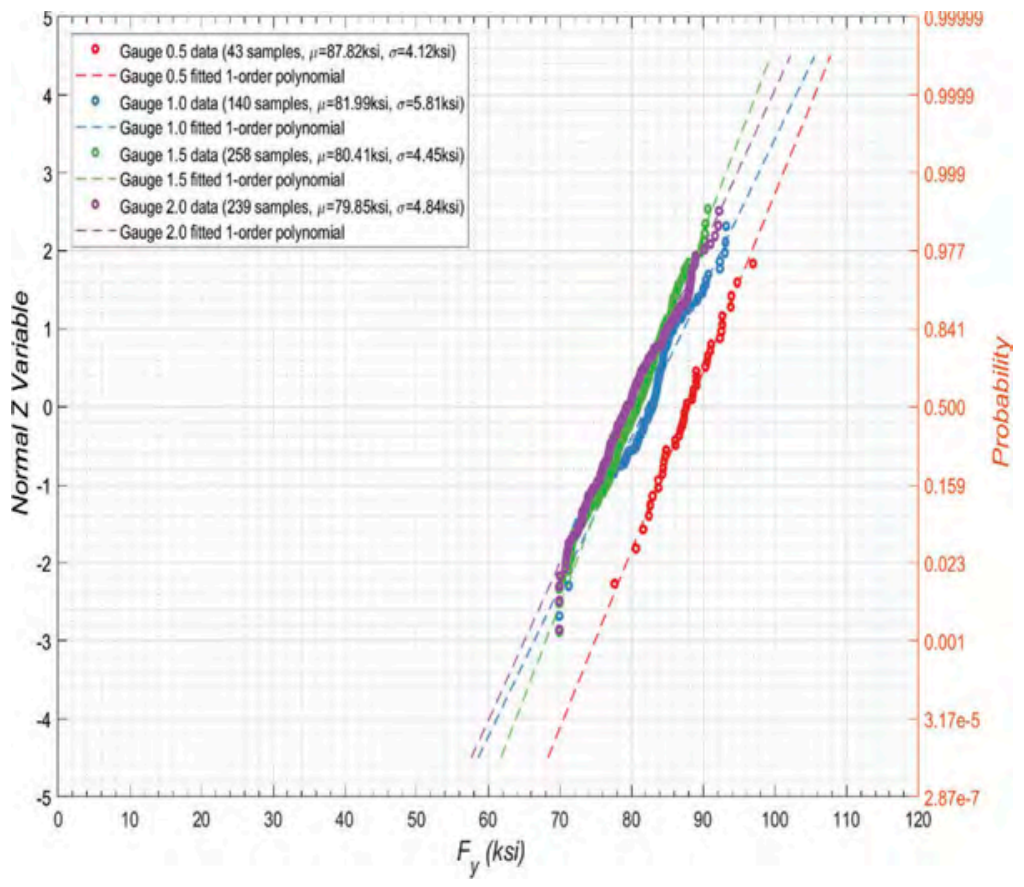

Figure 5. CDFs for the data and fitted polynomials of A709-HPS70W steel from source A (483 MPa). Gauges $0.5-2.0$ inch. 


\section{ACKNOWLEDGEMENTS}

The A709 steel test data was provided by the American Institute for Steel Construction which is gratefully acknowledged.

\section{REFERENCES}

American Institute of Steel Construction, www.aisc.org, accessed on 23 Feb 2021.

Bartlett M. F., Dexter R. J., Graeser M. D., Jelinek J. J., Schmidt B. J. \& Galambos T. V. 2001. Updating Standard Shape Material Properties Database for Design and Reliability. American Institute of Steel Construction.

Nowak, A.S. and Collins, K.R., 2013, Reliability of Structures, CRC Press, New York.

Wolert, P., 2019. Reliability-Based Calibration of the Code for Steel Girder Bridges. PhD Dissertation, Auburn University. 


\title{
Design of experiments approach for ultimate strength assessment of corroded stiffened plates
}

\author{
K. Wołoszyk \\ Faculty of Mechanical Engineering and Ship Technology, Gdansk University of Technology, Gdańsk, Poland \\ Y. Garbatov \\ Centre for Marine Technology and Ocean Engineering (CENTEC), Instituto Superior Técnico, Universi- \\ dade de Lisboa, Lisboa, Portugal
}

\begin{abstract}
The impact of corrosion degradation on the ultimate strength of stiffened plates subjected to compressive loading is investigated. The DoE technique is used considering different plate and column slenderness ratios and corrosion severity. The FE method, considering geometrical and material nonlinearities, is employed. A two-stage corrosion degradation model is adopted. Firstly, a uniform thickness loss is adopted to reflect the mean loss of the volume of material. Secondly, mechanical properties are reduced, to reflect the local non-uniformity of the corroded surface, leading to a local strain reduction when compared to a smooth surface plate. As an analysis outcome, the most important governing factors and interactions between them are obtained. The post-collapse shapes are presented and discussed. The resulting structural response surface allows for fast estimation of the ultimate strength of corroded stiffened plate, revealing to be a swift and practical tool to be adopted in the engineering practice.
\end{abstract}

\section{INTRODUCTION}

Ships and offshore structures are operating in the marine environment, which is known as highly corrosive. Corrosion degradation can significantly affect structural members' strength, mainly due to reducing the initial cross-sectional area. One can identify to most common types of corrosion, pitting, and general one (Wang et al. 2014). These two types of corrosion need to be treated separately in terms of modelling and analysis. The focus of the current work is to investigate the impact of general corrosion.

General corrosion (Panayotova et al. 2010) causes metal degradation in two levels. In the first one, a uniform loss of the thickness can be considered. In the second level, the local irregularities of the corroded surface are observed. The uniform degradation model considers only the first level; thus, it is easily applied to different numerical methods and closed-form formulations. The non-uniform corrosion model is suitable only for sophisticated FE analyses. However, it was found that the non-uniformity of the corroded surface can be recorded when evaluating the mechanical properties of small-scale coupons subjected to tensile loading.

Intensive studies related to the mechanical properties of steel elements subjected to corrosion have been performed recently. (Garbatov et al. 2014) tested corroded specimens with different severity of corrosion degradation. The observed reduction of mechanical properties was significant, including yield stress, Young modulus, and total elongation. Other studies related to the mechanical properties of corroded flat specimens can be found in (Wang et al. 2017, Nie et al. 2019), and the conclusions were similar. The mechanical properties reduction was observed in severely corroded specimens and the initially 
corroded ones. However, it needs to be pointed out that if the corrosion degradation is perfectly uniform, its effect on the mean stress-strain response of the specimen will be due to the general corrosion degradation of the thickness. In this respect, (Wang et al. 2017) concluded that the reduction of mechanical properties originates from the nonuniformity of the corroded surface.

Studies related to other structural elements were also carried out. The effects of random non-linear and non-uniform time-dependent corrosion on the ultimate compressive strength of unstiffened rectangular steel plates have been analyzed by (Silva et al. 2013), where a series of 3575 corroded plate surfaces or different degree of corrosion and ages were generated, and non-linear finite element analyses were carried out. Based on a regression analysis, empirical formulae to predict strength reduction because of corrosion degradation have been derived, demonstrating good accuracy.

The ultimate strength of corroded stiffened plates was investigated experimentally by (Garbatov et al. 2017), taking into account different corrosion levels. The observed capacity reduction was significant. These experimental results have been used to validate the numerical model developed by (Woloszyk et al. 2018), where the effect of the thickness loss and subsequent mechanical properties reduction has been incorporated in the FE model. The agreement between experimental and numerical results was very good.

Series of experiments considering corroded box girders subjected to the vertical bending moment can be found in (Saad-Eldeen et al. 2011, 2014). The non-uniform corrosion loss caused significant strength reduction, but the asymmetrical structural behaviour has been observed too. The analyzed box girders aimed to model the behaviour of ship hull girders subjected to vertical bending.

In the present study, corrosion degradation on the ultimate strength of flat-bar stiffened plates is studied. Different plate and column slenderness ratios are investigated, taking into account different levels of corrosion severity. A two-stage corrosion model is adopted, including uniform thickness loss and change of mechanical properties of steel. As a function of the degree of degradation, the constitutive model of the mechanical properties is based on smallscale coupon specimens' experimental testing. As a result, the governing factors that influence the ultimate capacity of stiffened plates are identified. A polynomial formulation for assessing the residual capacity of corroded stiffened plates is established.

\section{CORROSION MODELLING}

The corrosion model used in the current study is used as presented in (Woloszyk et al. 2018), where the uniform thickness loss and mechanical properties reduction are considered coupled. The mechanical properties of mild steel change with the corrosion development in terms of the mean stress-strain response. Herein, the experimental results, as presented in (Garbatov et al. 2014), are used here. Nevertheless, only changes in yield stress and Young modulus are considered. A study presented in (Woloszyk and Garbatov 2019) showed that the total elongation and ultimate tensile stress have a marginal influence on ultimate strength and for the present study are taken equal to $400 \mathrm{MPa}$ and 0.28 , respectively. The properties are presented as a function of the Degree of Degradation (DoD), which is the percentage loss of the initial specimen volume.

However, the referred corrosion model was non-precise in the region of degradation level between $0 \%$ up to $25 \%$, which is not in line with similar studies (Wang et al. 2017, Nie et al. 2019). In the initial study presented in (Garbatov et al. 2014), the yield stress of non-corroded steel has been assumed, due to lack of intact specimens, whereas typically, this value is higher than the normative one. The model has been adjusted in (Woloszyk and Garbatov 2020a), where the initial yield stress value was based on the extrapolation from the corroded specimens. In case of Young modulus, adjustment was not needed. The relationships for Young modulus and yield stress are as follows: 


$$
\begin{gathered}
E=-1.0349 \cdot D o D+196[G P a] \\
R e=-1.7029 \cdot D o D+284.4[M P a]
\end{gathered}
$$

\section{FE MODEL}

The analyzed flat-bar stiffened plates consist of a $1.06 \mathrm{~m}$ length and $0.4 \mathrm{~m}$ wide plate and stiffeners of different heights. The structural behaviour is analyzed using the FE method employing commercial software (ANSYS 2019). SHELL181 finite elements are used, and the nonlinearities related to geometry and material are considered. The material model is defined as bilinear with hardening, as indicated in Section 2. The tangent modulus of linear hardening was considered as $E / 500$. The Newton - Raphson iterative procedure is employed to reflect the non-linear behaviour of the compressed stiffened plate. The mesh convergence studies were performed to find the optimum element size, leading to a $0.02 \mathrm{~m}$ element size (Woloszyk et al. 2018). The assumed boundary conditions are presented in Figure 1a, where the loaded edges are clamped, and unloaded edges are left free. The loading was generated as an incremental compressive load, leading to shortening of the edges, where coupled $u_{y}$ displacement was subjected.

The welding-induced initial imperfections are modelled as described in (Garbatov et al. 2016). The superposition of the global column imperfection, $c_{0}$, and local plate imperfection, $\delta_{0}$ is incorporated in the model, as presented in Figure $1 \mathrm{~b}$. The local plate distortion is a function of plate slenderness ratio $\beta$, defined as:

$$
\beta=\frac{w}{t} \sqrt{\frac{R e}{E}}
$$

where $w$ is the plate width, and $t$ is the plate thickness.

The average level of the local plate imperfections is considered as $0.1 \beta t^{2}$. In the case, the global imperfections are taken as $0.0015 l$, where $l$ is the length of the stiffened plate. The initial imperfections level is assumed to be constant for specific plate slenderness apart from the corrosion degradation level since it is strictly related to welding-induced distortion. The welding-induced distortions are applied by changing the z-coordinate on each node location of the finite element.

\section{DESIGN OF EXPERIMENT PLAN}

The ultimate strength of stiffened plates is mainly governed by two factors, i.e., the plate slenderness ratio and column slenderness ratio (Zhang and Khan 2009). The plate slenderness ratio has already been introduced in Equation 3. The column slenderness ratio is defined as:

a)

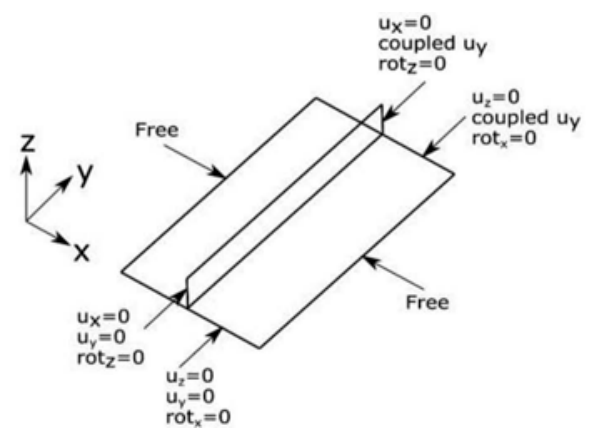

b)

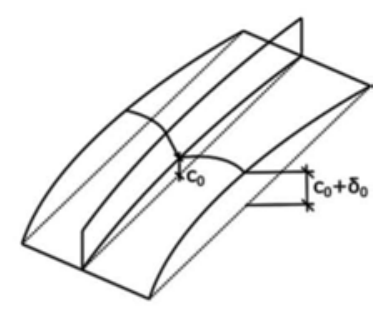

Figure 1. A) Boundary conditions and b) initial imperfections. 


$$
\lambda=\frac{l}{\pi \sqrt{I / A}} \sqrt{\frac{R e}{E}}
$$

where $I$ is the moment of inertia of the stiffened plate cross-section, $A$ is the cross-section area, and $l$ is the stiffened plate length. Based on the analysis presented in (Zhang 2015), the typical plate and column slenderness ratios are between 1.4 and 2.5 and between 0.15 and 0.8 , respectively.

Due to the non-linear relationship between ultimate strength and plate thickness, the Central Composite Design (CCD) experimental plan (Montgomery 2006) is used to investigate the dependency between the ultimate strength of corroded stiffened plates and governing factors. In that plan, the selected factors are considered taking into account their maximum $(+1)$, mean (0), and minimum (-1) values. Apart from both plate (factor A) and column (factor B) slenderness ratio, the level of corrosion degradation (factor $\mathrm{C}$ ) is considered as a third factor. The total number of 15 cases has been analyzed, considering factors values, as presented in Table 1. It needs to be noted that based on the plate and column slenderness ratios, the plate thickness $\left(t_{p}\right)$ together with stiffener dimension (height $h_{s}$ and thickness $t_{s}$ ) has been obtained. The estimated normalized ultimate strength (the ultimate force divided by the initial crosssection of the stiffener plate and yield stress value) are presented in Table 1. It could be noticed that for all studied cases, the plate thickness is equal or lower than the stiffener one. The plate dimensions and stiffener height are assumed, thus, for particular slenderness ratios, the thicknesses are resulting values.

\section{RESULTS AND DISCUSSION}

Analyzing the results presented in Table 1, one can first obtain the model's response factors' influence. More detailed information about the factorial analysis can be found in (Woloszyk and Garbatov 2020b). One of the most efficient methods is to use the half-normal probability plots (Daniel 1959). If the factor is lying on the left-hand side of the dashed line, it is nonrelevant. The three primary factors $(\mathrm{A}, \mathrm{B}, \mathrm{C})$ and interactions between them are considered $(\mathrm{A}: \mathrm{B}, \mathrm{A}: \mathrm{C}, \mathrm{B}: \mathrm{C}, \mathrm{A}: \mathrm{B}: \mathrm{C})$. Additionally, the primary factors' squares are considered too $\left(\mathrm{A}^{2}\right.$, $\left.\mathrm{B}^{2}, \mathrm{C}^{2}\right)$ to investigate the response surface's possible nonlinearity. The half-normal probability plot of the considered study is presented in Figure 2.

Table 1. Ultimate strength of stiffened plates for the DoE cases.

\begin{tabular}{rrrrrllllll}
\hline & \multicolumn{2}{l}{ Factor } & & \multicolumn{1}{l}{$t_{p}$} & $h_{s}$ & \multicolumn{1}{l}{$t_{s}$} & $\beta$ & $\lambda$ & DoD & Normalized ultimate strength \\
\cline { 2 - 9 } Case & $\mathrm{A}$ & $\mathrm{B}$ & $\mathrm{C}$ & $\mathrm{mm}$ & $\mathrm{m}$ & $\mathrm{mm}$ & - & - & $\%$ & - \\
\hline 1 & -1 & -1 & -1 & 11 & 0.25 & 13 & 1.39 & 0.15 & 0 & 0.915 \\
2 & -1 & -1 & 1 & 11 & 0.25 & 13 & 1.39 & 0.15 & 25 & 0.449 \\
3 & -1 & 1 & -1 & 11 & 0.07 & 10 & 1.39 & 0.8 & 0 & 0.846 \\
4 & -1 & 1 & 1 & 11 & 0.07 & 10 & 1.39 & 0.8 & 25 & 0.481 \\
5 & 1 & -1 & -1 & 6 & 0.25 & 8 & 2.54 & 0.15 & 0 & 0.602 \\
6 & 1 & -1 & 1 & 6 & 0.25 & 8 & 2.54 & 0.15 & 25 & 0.335 \\
7 & 1 & 1 & -1 & 6 & 0.07 & 6 & 2.54 & 0.8 & 0 & 0.64 \\
8 & 1 & 1 & 1 & 6 & 0.07 & 6 & 2.54 & 0.8 & 25 & 0.366 \\
9 & 0 & 0 & 0 & 8 & 0.1 & 9 & 1.91 & 0.47 & 12.5 & 0.566 \\
10 & -1 & 0 & 0 & 11 & 0.1 & 11.5 & 1.39 & 0.47 & 12.5 & 0.744 \\
11 & 1 & 0 & 0 & 6 & 0.1 & 7 & 2.54 & 0.47 & 12.5 & 0.507 \\
12 & 0 & -1 & 0 & 8 & 0.25 & 10 & 1.91 & 0.15 & 12.5 & 0.519 \\
13 & 0 & 1 & 0 & 8 & 0.07 & 7.5 & 1.91 & 0.8 & 12.5 & 0.55 \\
14 & 0 & 0 & -1 & 8 & 0.1 & 9 & 1.91 & 0.47 & 0 & 0.766 \\
15 & 0 & 0 & 1 & 8 & 0.1 & 9 & 1.91 & 0.47 & 25 & 0.421 \\
\hline
\end{tabular}




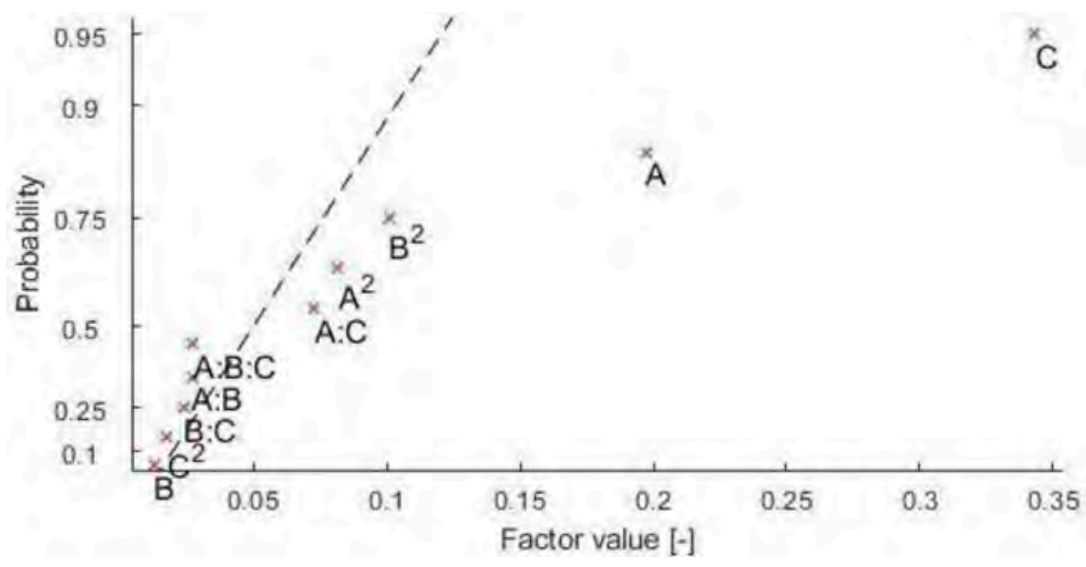

Figure 2. Half-normal probability plot.

As can be noticed, the factors that can be taken as important ones are (in the order of importance): $\mathrm{C}, \mathrm{A}, \mathrm{B}^{2}, \mathrm{~A}^{2}, \mathrm{~A}: \mathrm{C}$. The most important factor revealed to be the corrosion degradation level. Further, the plate slenderness and square of this variable significantly impact the resulting stiffened plate capacity. This indicates that the relation between that factor and the ultimate strength is non-linear. An interesting observation can be made about the column slenderness, which does not impact ultimate strength when considering only the maximum and minimum value. However, the square of this factor was revealed to be an influential one. The only interaction factor captured as necessary is between the corrosion level and plate slenderness ratio. When plate slenderness ratio is low, the decrease of the ultimate strength with corrosion development is less significant than the slenderer plates.

The different cases presented in Table 1 have different normalized ultimate strength, and the post-collapse shapes vary. In most cases, the plate induced failure lead to the collapse (e.g., case 9 - see Figure 3a). However, when the plate slenderness is significantly higher than the column one, the overall column buckling caused stiffened plate collapse (e.g., case 3 - see Figure 3b).

Based on the factors obtained from the DoE analysis, the response surface to estimate the ultimate strength of corroded stiffened plates can be established. Considering only the most essential factors, a polynomial equation may be defined as:

$$
\frac{\sigma_{U}}{R e}=0.581-0.099 \cdot x_{1}+0.041 \cdot x_{1}^{2}-0.05 \cdot x_{2}^{2}-0.172 \cdot x_{3}+0.036 \cdot x_{1} \cdot x_{3}
$$

where:

$$
x_{1}=\frac{\beta-1.965}{0.575} ; x_{2}=\frac{\lambda-0.475}{0.325} ; x_{3}=\frac{D o D-12.5}{12.5}
$$

a)

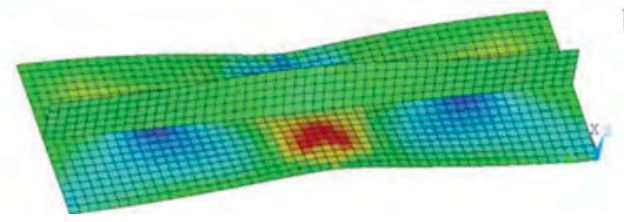

b)

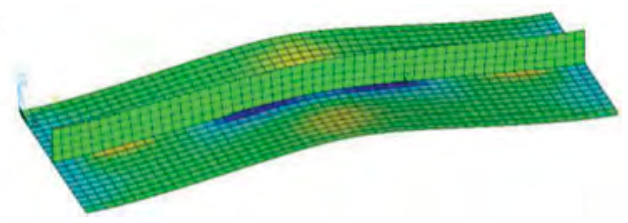

Figure 3. Post-collapse shape: a) case 9 and b) case 3 . 


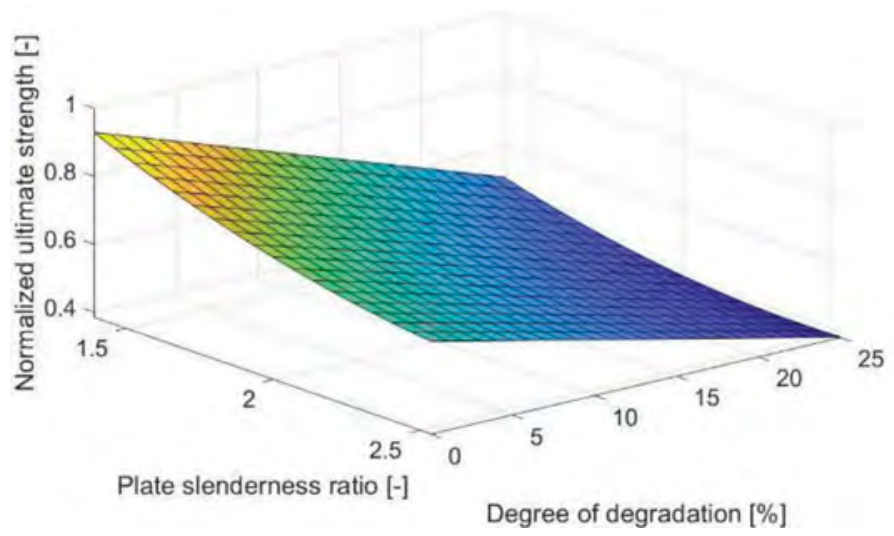

Figure 4. Response surface as a function of DoD and plate slenderness.

The response surface considering the mean value of the column slenderness ratio is presented in Figure 4. It can be noticed that the ultimate strength decreases with the increase of both plate slenderness ratio as well as corrosion degradation level.

\section{CONCLUSIONS}

The presented work investigated the influence of different governing factors on corroded stiffened plates' ultimate strength employing the DoE technique. The corrosion degradation level and plate slenderness ratio are the primary factors that govern the load-carrying capacity. The observed reduction of the ultimate strength in a severely corroded stiffened plate $(D o D=25 \%)$ reaches the level of $50 \%$ from the initial value, and it was slightly higher for slender plates. However, the column slenderness ratio was also an essential factor, considering this parameter's square. It was found that apart ultimate strength, the post-collapse shape will also vary depending on the governing factors. In the majority of the studied cases, the plate-induced failure was identified as a collapse mode. However, for the high plate slenderness ratio and low column one, the global column buckling occurred. As an analysis outcome, the response surface for fast estimation of the ultimate strength of corroded stiffened plates has been established, which may be used in the engineering practice, especially in the initial stages of the structural design process.

\section{ACKNOWLEDGEMENTS}

This work has been supported by the National Science Centre, Poland (grant No. 2018/31/N/ ST8/02380). The ANSYS software used in presented simulations in this paper was available as a part of the partnership cooperation agreement between ANSYS Inc., MESco sp. z o.o., and the Gdansk University of Technology.

\section{REFERENCES}

ANSYS, 2019. Online Manuals, Release 19.

Daniel, C., 1959. Use of Half-Normal Plots in Interpreting Factorial Two-Level Experiments. Technometrics, 1 (4), 311-341.

Garbatov, Y., Guedes Soares, C., and Masubuchi, K., 2016. Residual Stresses and Distortion in Welds. In: Reference Module in Materials Science and Materials Engineering. Elsevier.

Garbatov, Y., Guedes Soares, C., Parunov, J., and Kodvanj, J., 2014. Tensile strength assessment of corroded small scale specimens. Corrosion Science, 85, 296-303. 
Garbatov, Y., Tekgoz, M., and Guedes Soares, C., 2017. Experimental and numerical strength assessment of stiffened plates subjected to severe non-uniform corrosion degradation and compressive load. Ships and Offshore Structures, 12 (4), 461-473.

Montgomery, D.C., 2006. Design and Analysis of Experiments. John Wiley \& Sons Ltd, USA.

Nie, B., Xu, S., Yu, J., and Zhang, H., 2019. Experimental investigation of mechanical properties of corroded cold-formed steels. Journal of Constructional Steel Research, 162, 105706.

Panayotova, M. and Garbatov, Y., 2010. Corrosion of steels in marine environment, monitoring and standards. In: Safety and Reliability of Industrial Products, Systems and Structures. CRC Press, $369-413$.

Saad-Eldeen, S., Garbatov, Y., and Guedes Soares, C., 2011. Experimental assessment of the ultimate strength of a box girder subjected to severe corrosion. Marine Structures, 24 (4), 338-357.

Saad-Eldeen, S., Garbatov, Y., and Guedes Soares, C., 2014. Strength assessment of a severely corroded box girder subjected to bending moment. Journal of Constructional Steel Research.

Silva, J.E., Garbatov, Y., and Guedes Soares, C., 2013. Ultimate strength assessment of rectangular steel plates subjected to a random localised corrosion degradation. Engineering Structures, 52, 295-305.

Wang, Y., Wharton, J.A., and Shenoi, R.A., 2014. Ultimate strength analysis of aged steel-plated structures exposed to marine corrosion damage: A review. Corrosion Science, 86, 42-60.

Wang, Y., Xu, S., Wang, H., and Li, A., 2017. Predicting the residual strength and deformability of corroded steel plate based on the corrosion morphology. Construction and Building Materials, 152, $777-793$.

Woloszyk, K. and Garbatov, Y., 2019. Uncertainty assessment of ultimate strength of corroded stiffened plates subjected to maintenance. In: P. Georgiev and C. Guedes Soares, eds. Sustainable Development and Innovations in Marine Technologies. CRC Press, 429-436.

Woloszyk, K. and Garbatov, Y., 2020a. Ultimate compressive strength assessment of cleaned corroded plates with locked crack.

Woloszyk, K. and Garbatov, Y., 2020b. Analysis of Ultimate Compressive Strength of Cracked Plates with the Use of DoE Techniques. Polish Maritime Research, 27 (3), 109-120.

Woloszyk, K., Kahsin, M., and Garbatov, Y., 2018. Numerical assessment of ultimate strength of severe corroded stiffened plates. Engineering Structures, 168, 346-354.

Zhang, S., 2015. A review and study on ultimate strength of steel plates and stiffened panels in axial compression. Ships and Offshore Structures, 1-11.

Zhang, S. and Khan, I., 2009. Buckling and ultimate capability of plates and stiffened panels in axial compression. Marine Structures, 22 (4), 791-808. 


\title{
MAG welding process for S700MC steel
}

\author{
B. Szczucka-Lasota, T. Węgrzyn \& B. Łazarz \\ Silesian University of Technology, Gliwice, Poland
}

T. Szymczak

Motor Transport Institute, Warsaw, Poland

A. Jurek

Novar Sp. z o.o., Gliwice, Poland

K.I. Wilczyński

COBRABID Sp. z o.o, Warsaw, Poland

P. Cybulko

MEDGAL Sp. z o.o., Księżyno, Poland

\begin{abstract}
High-strength steel steels (for instance S700MC) are relatively not very well weldable due to the dominant martensitic microstructure. The utmost difficulty in welding these steels is their tendency to crack after welding. Joint strength tensile and NDT (nondestructive tests) tests were mainly carried out as the main investigation. Also bending tests and metallographic microstructure analyses were carried out. The welds were created using MAG welding with various parameters. Paper aims to verify tensile strength of the thinwalled S700MC steel microstructure after welding with base material.
\end{abstract}

\section{INTRODUCTION}

Definition of Smart City was first used by prof. Boyd Cohen from University Del Desarrollo in Santiago de Chile. A smart city is an urban area that uses different types of electronic methods and sensors to collect data (Lai et al. 2020). This includes also data about transportation systems and communication technology, new materials and innovate technology (interestingengineering.com 2018, McLaren \& Agyeman 2015). Prof. Cohen puts especial attention to necessity of using various modern technologies (including welding) to create a Smart City model. In This research area (also called PBO4), high-strength martensitic steels become increasingly used. The weld metal of S700MC (representative of that grade of steels) deposit contains mainly martensite and coarse ferrite while the base material contains mainly martensite, bainite and much more fragmented ferrite. The differences in microstructure affect the mechanical properties of the base material and the joint (Celin \& Burja 2018, Hobbacher 2016, Muszyński \& Mikielewicz, 2017, Hadryś et al. 2016). In the paper it was decided to make joints with different parameters and compare their properties with base material. From an engineering point of view application of various types of steel depends on their mechanical parameters, which follows material behavior in elastic and elastic-plastic states. It is very well known that the proportional limit is related to Hooke's law and is very requested parameter by a lot of engineering groups on designing and modelling different types of components of various branches of industry (Hadryś 2015, Węgrzyn et al. 2019, www.worldautosteel.org, 
Szymczak et al. 2019). Therefore, this parameter has to obviously be determined by material manufacturers. Nevertheless, a lot of material certificates usually report yield point, ultimate tensile strength as well as elongation, indicating a lack of value considered. This parameter is especially important for high-strength steels because of stress range between proportional limit and yield stress is wider than in the case of typical steels, creating a region for initiation of the first permanent deformation. It can be also connected with cracks occurring earlier than the calculations and manufactures indicates (Szymczak et al, 2019). It also plays an important role in the case of welded joints at which weld and HAZ (Heat Affected Zone) are the potential regions for crack occurring. With respect to fatigue durability and engineering efforts determination of a relationship between stress corresponding with mechanical parameters and number of cycles to fracture plays an important role. Therefore, capturing all mechanical parameters associated with tensile characteristic and fatigue test at the values taken is still important and should not be ignored.

\section{MATERIALS AND METHODS}

A butt-welded joints of S700MC (Table 1) steel with a thickness of $3 \mathrm{~mm}$ was made.

The high content of titanium and niobium translates into high strength of the joint. In lowalloy steels, titanium is at the maximum level of $0.003 \%$. Mechanical properties of S700MC steel are presented in Table 2.

The MAG (Metal Active Gas) welding process in the low position (PA) was applied according to the requirements of EN 15614-1 standards. It was decided to produce welds with the use of MAG process testing two various gas mixtures: $\mathrm{Ar}+2 \% \mathrm{O}_{2}$ and $\mathrm{Ar}+18 \% \mathrm{CO}_{2}$. All of the samples were welded with electrode wire UNION X96 (EN ISO 16834-A G 895 M21 $\mathrm{Mn} 4 \mathrm{Ni2}, 5 \mathrm{CrMo}$ ). Chemical composition of the wire is presented in Table 3.

The input energy during the welding of thicker sheets $(3 \mathrm{~mm})$ was below recommended value $4 \mathrm{~kJ} / \mathrm{cm}$. All welding tests were carried out without preheating. Tables 1 and 2 show the chemical composition and respectively mechanical properties used in the S700MC steel tests. The gap between sheets was varied in range $0-3 \mathrm{~mm}$. The correct results were obtained for gap = $1.5 \mathrm{~mm}$ mainly. That case was taken to further tests (Table 4).

A butt-welded joint made of S700MC steel with a thickness of $3 \mathrm{~mm}$ was made. The MAG welding method (135) was used in the flat position (PA) in accordance with the requirements

Table 1. Chemical composition of S700MC steel (SSAB, 2017).

\begin{tabular}{lllllllll}
\hline $\mathrm{C}[\%]$ & $\mathrm{Si}[\%]$ & $\mathrm{Mn}[\%]$ & $\mathrm{P}[\%]$ & $\mathrm{S}[\%]$ & $\mathrm{Al}[\%]$ & $\mathrm{Nb}[\%]$ & $\mathrm{V}[\%]$ & $\mathrm{Ti}[\%]$ \\
\hline 0.12 & 0.10 & 2.10 & 0.025 & 0.010 & 0.015 & 0.09 & $0.20 *$ & 0.15 \\
\hline
\end{tabular}

Table 2. Mechanical properties of S700MC steel, yield stress, ultimate tensile strength (SSAB, 2017).

\begin{tabular}{llll}
\hline $\begin{array}{l}\text { Yield stress [MPa] } \\
\text { min }\end{array}$ & $\begin{array}{l}\text { Ultimate tensile strength }[\mathrm{MPa}] \\
\min \div \max \end{array}$ & $\begin{array}{l}<3[\mathrm{~mm}] \mathrm{A}_{80 \%} \\
\min \end{array}$ & $\begin{array}{l}\geq 3[\mathrm{~mm}] \mathrm{A}_{5 \%} \\
\min \end{array}$ \\
\hline $500-700$ & $750-950$ & 10 & 12 \\
\hline
\end{tabular}

Table 3. Wire UNION X96 - chemical composition (Böhler Welding, 2004).

\begin{tabular}{llllllll}
\hline $\mathrm{C}[\%]$ & $\mathrm{Si}[\%]$ & $\mathrm{Mn}[\%]$ & $\mathrm{P}[\%]$ & $\mathrm{Cr}[\%]$ & $\mathrm{Mo}[\%]$ & $\mathrm{Ni}[\%]$ & $\mathrm{Ti}[\%]$ \\
\hline 0.1 & 0.8 & 1.8 & 0.010 & 0.45 & 0.65 & 2.45 & 0.007 \\
\hline
\end{tabular}


Table 4. Welding parameters of S700MC steel.

\begin{tabular}{llllllll}
\hline $\begin{array}{l}\text { Layers } \\
\text { order }\end{array}$ & $\begin{array}{l}\text { Welding } \\
\text { method }\end{array}$ & $\begin{array}{l}\text { Diameter of the } \\
\text { electrode }[\mathrm{mm}]\end{array}$ & $\begin{array}{l}\text { Current } \\
\text { intensity } \\
{[\mathrm{A}]}\end{array}$ & $\begin{array}{l}\text { Voltage } \\
{[\mathrm{V}]}\end{array}$ & $\begin{array}{l}\text { Welding } \\
\text { speed }[\mathrm{mm} /\end{array}$ & $\begin{array}{l}\text { Input } \\
\text { energy }[\mathrm{kJ} / \\
\mathrm{cm}]\end{array}$ \\
\hline 1 & 135 & 1.0 & 105 & 19 & DC , $+"$ & $300-400$ & below 4 \\
\hline
\end{tabular}

of EN 15614-1. The preparation of material for a single-bead welding. The detailed data of the welding process parameters is given in Table 4.

Once all of the test were performed the following quality control checks were applied: nondestructive and destructive tests. Non-destructive tests included (NDT): Visual testing (VT) and Magnetic-particle testing (MT). The destructive tests included: bending, examination of microstructure digested with Adler reagent using light microscopy (LM) and tensile and fatigue tests.

Determination of mechanical properties of the parent material, as well as its weld, was carried out using 8874 INSTRON servo-hydraulic testing machine, 2620-602 INSTRON extensometer with measuring range of $12.5 \mathrm{~mm}$ and flat mini-specimens having the nominal dimensions in the measuring region as of: $3 \times 4 \mathrm{~mm}$. All specimens were mounted directly in the gripping systems employing upper and lower grips. The quality of the S700MC was determined based on three tensile tests conducted at three different velocity of control signals i.e. displacement, strain and force (stress), using the following values: $1 \mathrm{~mm} / \mathrm{min}, 0.08 \mathrm{~mm} / \mathrm{mm}$, $1400 \mathrm{~N} / \mathrm{min}(178 \mathrm{MPa} / \mathrm{min})$. It was performed taking the fundamental mechanical parameters such as proportional limit, elastic limit, yield stress and ultimate tensile strength. In the general analysis of the weld behaviour the data from the test under the stress signal was taken into account. It was used with respect to determining the mechanical behavior and the weld under signal directly related to the specimen stiffness, which corresponds to its geometry and material type examined.

Assessment of the weld quality was also examined in fatigue tests taking stress values close to ultimate tensile strength (UTS), yield point (YP), elastic limits (EL) and proportional limit (PL). The experiments under cyclic loading were performed at stress ratio $\mathrm{R}=\sigma_{\min } / \sigma_{\max }=0.1$ up to material fracture at a frequency of $10 \mathrm{~Hz}$ using sinusoidal function, where $\sigma_{\min }$ and $\sigma_{\max }$ mean minimum and maximum stress, respectively. This kind of experiment aimed to assess the value of stress at the number of cycles, which connects fatigue limit and comparing the fatigue data with mechanical parameters of the weld from tensile test.

The specimens were selected by means of laser technique using the commercial device named MAZAK STX mark III having the power of $2.5 \mathrm{~kW}$.

\section{RESULTS}

\subsection{The results of non-destructive tests}

Visual inspection of welds was made using standard auxiliary measures, i.e. $\times 3$ loupe, luxmeter with white light $520 \mathrm{Lx}$. It was found that only some of tested joints were made correctly and met the quality requirements, they were characterized by the limit of acceptability " $\mathrm{B}$ " according to PN-EN ISO 5817. Magnetic-particle test of welds was made using the wet method with the following conditions: field strength $3 \mathrm{kA} / \mathrm{m}$, white light $515 \mathrm{Lx}$, temperature $20{ }^{\circ} \mathrm{C}$, MR-76 detection means, MR-72 contrast. Non-destructive test results are presented in Table 5.

\subsection{The data from bending tests}

Then, a bending test was performed only for those samples that passed the NDT test (W3 and W4). Thus, the experiment was carried out only for samples without cracks (with $\mathrm{B}$ acceptability). 
Table 5. Assessment of non-destructive testing of the movable platform joint.

\begin{tabular}{llllll}
\hline $\begin{array}{l}\text { Sample } \\
\text { designation }\end{array}$ & $\begin{array}{l}\mathrm{Gap} \\
{[\mathrm{mm}]}\end{array}$ & $\begin{array}{l}\text { Gas mixture of } \\
\text { argon }\end{array}$ & $\begin{array}{l}\text { Welding } \\
\text { speed } \\
{[\mathrm{mm} / \mathrm{min}]}\end{array}$ & Observation & Acceptability \\
\hline W1 & 2 & $18 \% \mathrm{CO}_{2}$ & 300 & Cracks in the weld & - \\
W2 & 2 & $2 \% \mathrm{O}_{2}$ & 300 & Cracks in the weld & - \\
W3 & 1.5 & $18 \% \mathrm{CO}_{2}$ & 350 & No cracks & B \\
W6 & 1.5 & $2 \% \mathrm{O}_{2}$ & 350 & No cracks & B \\
W5 & 1.5 & $18 \% \mathrm{CO}_{2}$ & 400 & Cracks in the weld & - \\
W6 & 1.5 & $2 \% \mathrm{O}_{2}$ & 400 & Cracks in the weld & - \\
W7 & 2 & $18 \% \mathrm{CO}_{2}$ & 300 & Cracks in the weld & - \\
W8 & 2 & $2 \% \mathrm{O}_{2}$ & 300 & Cracks in the weld & - \\
\hline
\end{tabular}

Table 6. Bending tests results.

\begin{tabular}{lllll}
\hline Sample designation & Deformed side & $\mathrm{a}_{\mathrm{o}} \times \mathrm{b}_{\mathrm{o}}[\mathrm{mm}]$ & Bending angle $\left[^{\circ}\right]$ & Notes \\
\hline W3 & root of weld & $3.0 \times 20.0$ & 180 & no cracks \\
W3 & face of weld & $3.0 \times 20.0$ & 180 & no cracks \\
W4 & root of weld & $3.0 \times 20.0$ & 180 & cracks in the weld \\
W4 & face of weld & $3.0 \times 20.0$ & 180 & cracks in the weld \\
\hline
\end{tabular}

The tests used: sample with a thickness of $a=3 \mathrm{~mm}$, width of the sample $b=20 \mathrm{~mm}$, mandrel $\mathrm{d}=22 \mathrm{~mm}$, spacing of supports $\mathrm{d}+3 \mathrm{a}=31 \mathrm{~mm}$ and the required angle of bending 180 . Five bending test measurements were carried out for each tested joint thickness on the root side and on the face side. The test results are summarized in Table 6. From the analysis of the results presented in Table 6, it follows that gas mixture $\mathrm{Ar}-18 \% \mathrm{CO}_{2}$ is it is more suitable for this welding process.

\subsection{The results from microscopic observation}

Observations of the samples digested in Adler's reagent were carried out on the Reichert Light Microscope (RLM). The examined joints are dominated by a martensitic and ferritic microstructure - Figure 1a shows the microstructure of W3 sample.

\subsection{Responses in tensile test}

Differences between the strength parameters were followed as a key stage for determining variations in the steel behaviour with respect to the material quality, Table 7. As it can be noticed the value of $30 \mathrm{MPa}$ expressed the maximum difference between the values collected at the type of the mechanical parameter. This confirmed the high quality of the material tested as well as its insensitivity to the control signal types.

Beneficial mechanical parameters of the S700MC welded using the Union X96 wire have been confirmed in the tensile test (Figure 2). This was visible by the values of proportional limit (PL), elastic limit (EL), yield stress (YS) and ultimate tensile strength (UTS). They were very close to the same type points of the tensile curve for the parent material. the significant difference was noticed for elongation, which has obtained close to $86 \%$ lower value than in the case of the parent material, Table 8. It can be explained based on the microstructure ingredient i.e. martensite as the dominant element of the welded joint. In addition to martensite with small amount of coarse-grained ferrite was observed. Only in the base metal more fragmented ferrite apart from martensite microstructure is visible (shown in Figure 1b). 
a)

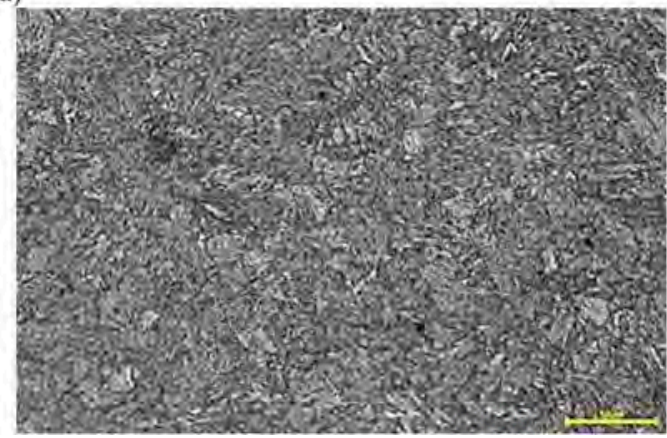

b)

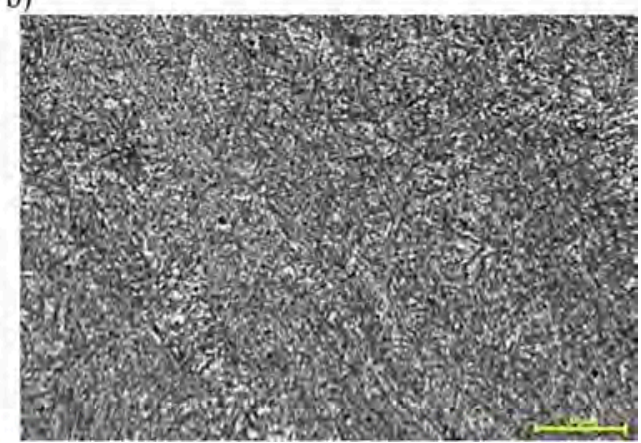

Figure 1. a) Microstructure of the joint (W90). Visible martensite and course ferrite (LM - Light Microscopy), b) Microstructure of the base material. Visible martensite, bainite and fine-grained ferrite (LM).

a)

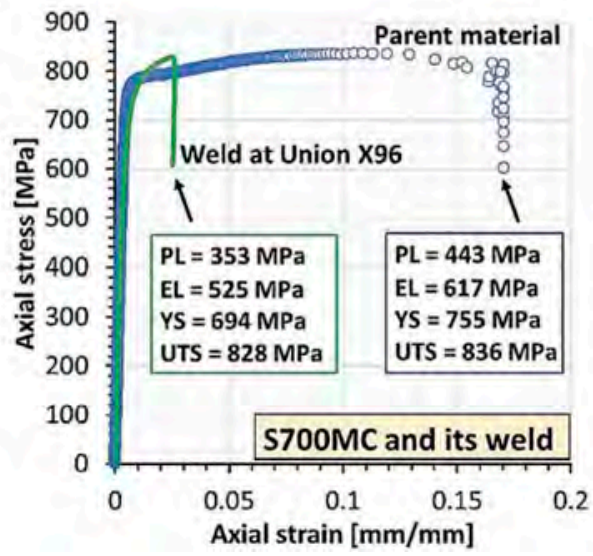

b)

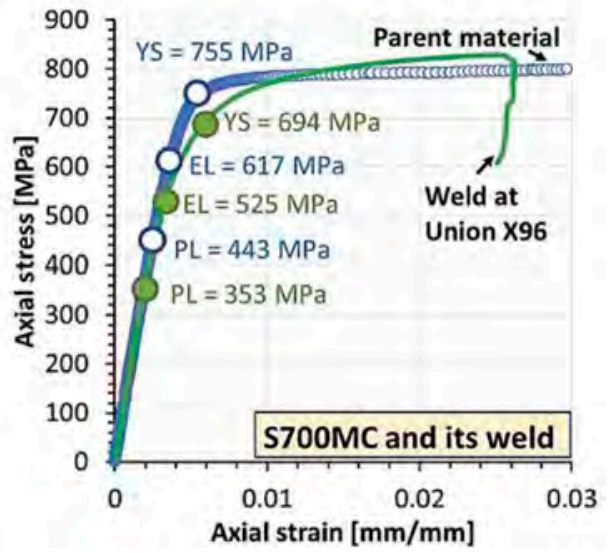

Figure 2. Tensile characteristic of the S700MC as parent material and its welded joint manufactured using the welding wire of Union X96: a) general view with mechanical parameters, b) at magnification on elastic and elastic-plastic sections with selected mechanical parameters.

Table 7. Mechanical parameters of S700MC steel at different control signals: displacement, strain and stress.

\begin{tabular}{lllll}
\hline Velocity & $\begin{array}{l}\text { Proportional } \\
\text { limit[MPa] }\end{array}$ & $\begin{array}{l}\text { Elastic limit } \\
{[\mathrm{MPa}]}\end{array}$ & $\begin{array}{l}\text { Yield stress } \\
{[\mathrm{MPa}]}\end{array}$ & $\begin{array}{l}\text { Ultimate tensile strength } \\
{[\mathrm{MPa}]}\end{array}$ \\
\hline $1 \mathrm{~mm} / \mathrm{min}$ & 463 & 648 & 735 & 850 \\
$0.08 \mathrm{~mm} / \mathrm{mm}$ & 462 & 634 & 765 & 820 \\
$178 \mathrm{MPa} / \mathrm{min}$ & 456 & 628 & 757 & 836 \\
Maximal & 7 & 20 & 30 & 30 \\
difference & & 635 & 755 & 831 \\
Average value & 460 & & &
\end{tabular}

The weld behavior under fatigue at the value of maximum stress close to selected strength parameters enabled to indicate the number of cycles, showing stress value connected directly 
Table 8. Comparison of mechanical parameters of the S700MC and its weld using percentage values.

Percentage differences between mechanical parameters of the parent material and its weld collected in the tensile test

\begin{tabular}{lllll}
\hline $\begin{array}{l}\text { Proportional limit } \\
{[\%]}\end{array}$ & $\begin{array}{l}\text { Elastic limit } \\
{[\%]}\end{array}$ & $\begin{array}{l}\text { Yield stress } \\
{[\%]}\end{array}$ & $\begin{array}{l}\text { Ultimate tensile strength } \\
{[\%]}\end{array}$ & $\begin{array}{l}\text { Elongation } \\
{[\%]}\end{array}$ \\
\hline 20.3 & 14.9 & 8.1 & 1.0 & 85.6 \\
\hline
\end{tabular}

Table 9. Results from fatigue tests conducted at maximum stress close to UTS (828 MPa), YS (694 MPa), EL (525 MPa) and PL (353 MPa).

\begin{tabular}{llll}
\hline$\sigma_{\max }=800 \mathrm{MPa}$ & $\sigma_{\max }=700 \mathrm{MPa}$ & $\sigma_{\max }=500 \mathrm{MPa}$ & $\sigma_{\max }=400 \mathrm{MPa}$ \\
\hline 23090 & 32163 & 349177 & $2 \times 10^{6}$ \\
\hline
\end{tabular}

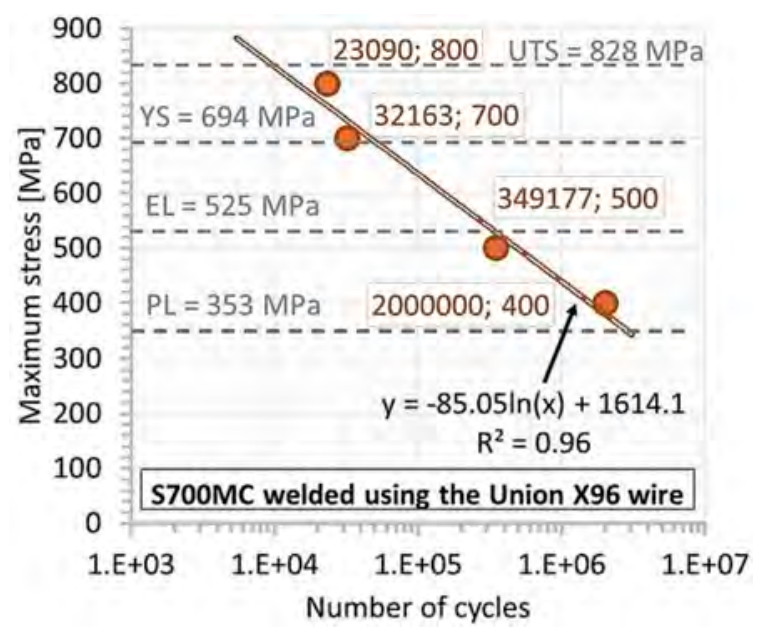

Figure 3. The fatigue test results at the background of the mechanical parameters of the weld.

with fatigue limit, Table 9, Figure 3. Taking these data prediction of fatigue durability of the component made of the S700MC steel welded at the Union X96 wire, especially at stress close to the values of the mechanical parameters selected, is possible to be followed. Nevertheless, for better understanding, the welded joint behavior under fatigue more experiments are needed, capturing Wöhler curve at a greater number of stress level.

\section{SUMMARY}

The weldability of S700MC steel was tested with a large number of different parameters. The result of non-destructive testing limited the possibility of correct welding with all the parameters initially proposed. The bending test result also allowed to reject incorrect welding parameters of S700MC steel. The most appropriate welding parameters depend on a properly selected shielding mixture, the gap between the sheets to be welded and the welding speed. The most 
appropriate parameters (sample W3) correspond to an argon gas mixture containing $18 \% \mathrm{CO}_{2}$ and a welding speed of $350 \mathrm{~mm} / \mathrm{min}$. Strength parameters of the S700MC were almost insensitive on the welding process at the Union X96 wire. This sentence, confirmed by the obtained results, has enabled to indicate this method as an effective joining technique for welding of the S700MC sheet at a thickness up to $5 \mathrm{~mm}$. Fatigue tests have enabled to present the wide range of stress values, which can be directly used in designing and predicting the durability of S700MC welded components, i.e. between proportional limit $353 \mathrm{MPa}$ and ultimate tensile strength $828 \mathrm{MPa}$. The significant feature of the weld of S700MC was also represented by the fatigue limit $400 \mathrm{MPa}$, which supports the engineering point of view because it informs no damages in the weld up to stress value at the mechanical parameter mentioned. Comparing the value of fatigue limit and ultimate tensile strength the following proportion of 0.48 can be proposed for engineers who predict the fatigue limit of welds made of the Strenx MC steel grade capturing results in a form of a tensile curve as well as microstructure similar to data presented.

\section{ACKNOWLEDGMENTS}

The paper is part of the COST project, CA 18223.

\section{REFERENCES}

Lai, C. S., Jia, Y., Dong, Z., Wang, D., Tao, Y., Lai, Q. H., Wong, R. T. K., Zobaa, A. F., Wu, R. \& Lai, L. L. 2020. A Review of Technical Standards for Smart Cities. Clean Technologies, 2, 3, pp. 290-310. (doi:10.3390/cleantechnol2030019).

Connected Vehicles in Smart Cities: The Future of Transportation. Published by interestingengineering. com on 16 November 2018, retrieved on 4 April 2019.

McLaren, D. \& Agyeman, J. 2015. Sharing Cities: A Case for Truly Smart and Sustainable Cities. MIT Press. (ISBN 9780262029728).

Celin, R. \& Burja, J. 2018. Effect of cooling rates on the weld heat affected zone coarse grain microstructure. Metallurgical and Materials Engineering, 24, 1, pp. 37-44. (DOI: https://doi.org/ $10.30544 / 342$ ).

Hobbacher, A. 2016. Recommendations for fatigue design of welded joints and components. International Institute of Welding Collection, Cham, Switzerland: Springer, 27.

Muszyński, T. \& Mikielewicz, D. 2017. Structural optimization of microjet array cooling system. Applied Thermal Engineering, 123, pp. 103-110. (DOI: https://doi.org/10.1016/j.applthermaleng.2017.05.082).

Hadryś D. 2015. Impact load of welds after micro-jet cooling, Archives of Metallurgy and Materials, 60, 4, pp. 2525-2528. (https://doi.org/10.1515/amm-2015-0409).

Węgrzyn, T., Szczucka-Lasota, B., Uściłowska, A., Stanik, Z. \& Piwnik, J. 2019. Validation of parameters selection of welding with micro-jet cooling by using method of fundamental solutions. Engineering Analysis with Boundary Elements, 98, pp. 17-26 (DOI: https://doi.org/10.1016/j.enganabound.2018.09.012).

https://www.worldautosteel.org/steel-basics/automotive-steel-definitions/

Szymczak, T., Brodecki, A., Makowska, K. \& Kowalewski, Z.L. 2019. Tow truck frame made of high strength steel under cyclic loading. Materials Today: Proceedings, 12, 2, pp. 207-212 (DOI: https://doi. org/10.1016/j.matpr.2019.03.115).

SSAB, General Product Description, Data sheet 2008 Strenx 700MC 2017-04-20, 2 pages.

Böhler Welding, Union X 96, Solid wire, low-alloyed, 12.2004, 1 page. 


\section{Author Index}

Ádány, S. 500

Ahmadi, H.M. 387, 465

Al-Emrani, M. 472

Al-Karawi, H. 472

Al-Rifaie, H. 393

Arrais, F. 479, 486

Azizi, E. 265

Baldassino, N. 157

Barcewicz, W. 85

Barszcz, A.M. 92, 171

Bedon, C. 3

Bernardi, M. 157

Bernatowska, E. 307

Beyer, A. 400

Bezas, M-Z. 400

Błażejewski, P. 407

Bogdan, T. 201

Bogdaniuk, M. 148

Bredow, R. 272

Broniewicz, M. 335

Bureau, A. 400

Chalupa, V. 378

Chrzanowski, M.P. 201

Chybiński, M. 249

Ciesielczyk, K. 208

Cybulko, P. 534

Czyż, R. 85

Dabrila, P. 278

De Matteis, G. 387, 465

Degée, H. 201

Demonceau, J.F. 14, 400

Dokšanović, T. 291

Dürr, A. 493

El Boueiz, P. 134

Enders, A. 164
Falborski, T. 99

Fujak, S.M. 414

Gajewski, M.D. 449

Gajewski, T. 120, 185, 393

Garbatov, Y. 527

Garbowski, T. 120, 185

Gardner, L. 25

Giżejowski, M.A. 85, 92, 171, 449

Glorieux, A. 134

Gölz, L. 284

Górski, M. 215

Gosowski, B. 435, 514

Grimm, S. 222

Guminiak, M.J. 178

Haffar, M.Z. 500

Haghani, R. 472

Harada, Y. 53

Henriques, J. 235, 349

Hotała, E. 370

Iwicki, P. 442

Jankowski, R. 99

Jaroszewski, T. 99

Jaspart, J-P. 400

Jordão, S. 328

Jurek, A. 534

Juozapaitis, A. 278

Juszczyk-Andraszyk, K. 298

Kamiński, M. 272

Kanishchev, R. 256

Kawecki, P. 36

Kimura, Y. 414

Kołodziej, S. 407

Kövesdi, B. 500
Kozłowski, A. 321

Kozlowski, A. 36

Kozma, A. 314

Krystosik, P. 421

Kuhlmann, U. 164, 284

Kukla, D. 36, 321

Kuś, J. 428

Kvočák, V. 256

Labocha, S. 85

Lange, J. 222

Łazarz, B. 534

Lima, L.R.O. 349

Lopes, N. 479, 486

Lorkowski, P. 435

Machelski, Cz. 106

Malendowski, M. 393

Maleska, T. 428

Marcinowski, J. 407

Markulak, D. 291

Martins, J. 134

Maślak, M. 507

Mesquita, A.B. 328

Milewski, P. 335

Mochocki, W. 113

Mońka, M. 106

Mrówczyński, D. 120

Nowak, A.S. 521

Obara, P. 113, 127

Obiala, R. 201

Odenbreit, C. 201, 228, 314

Organek, P. 514

Ostrowski, K. 36

Pawłowski, K. 342

Pazdanowski, M. 507 
Peksa, P. 393

Pervan, B. 291

Pieczka, P. 442

Polus, Ł. 249

Radić, I. 291

Radoń, U. 456

Redecki, M. 514

Rodrigues, M.C. 235, 349

Roth, J. 493

Różyło, P. 178

Rzeszut, K. 66, 178

Šabatka, L. 378

Sakharov, V. 407

Sielicki, P.W. 393

Silva, A.T. 235, 349

Simões da Silva, L. 53, 328

Ślęczka, L. 307

Sobrinho, K.P. 349

Sokół, L. 66

Souza, K.L.B. 235

Stachura, Z. 92, 449
Staszak, N. 185

Stranghöner, N. 265

Studziński, R. 208, 393

Suchodoła, M. 507

Sumelka, W. 393

Suzuki, A. 414

Szafran, J. 298

Szczerba, R.B. 449

Szczucka-Lasota, B. 534

Szewczak, I. 178

Szewczyk, P. 242

Szlendak, J.K. 356, 363

Szpyrka, A. 356

Szumigała, M. 141, 242, 249

Szumigała, T. 192

Szymczak, T. 534

Tauzowski, P. 456

Tomala, P. 106

Tomasik, J. 127

Tomaszewicz, D. 363

Tucki, P. 370
Uziak, J. 171

Vande Voorde, J. 134

Vaňová, P. 256

Vellasco, P.C.G.S. 235, 349

Vigneri, V. 228

Vila Real, P. 479, 486

Vild, M. 378

Wald, F. 378

Walport, F. 25

Węgrzyn, T. 534

Wierzbicki, K. 141

Wierzbicki, S. 85

Wilczyński, K.I. 534

Wolert, P.J. 521

Wołoszyk, K. 148, 527

Woźniczka, P. 507

Yang, J. 314

Zabojszcza, P. 456

Zandonini, R. 157 